DOE/ER-0313/15

Distribution

Categories

UC-423, -424

\title{
FUSION REACTOR MATERIALS SEMIANNUAL PROGRESS REPORT FOR THE PERIOD ENDING \\ SEPTEMBER 30, 1993
}

Prepared for

DOE Office of Fusion Energy

(AT $150203 \mathrm{~A})$

DATE PUBLISHED: February 1994

Prepared for

OAK RIDGE NATIONAL LABORATORY

Oak Ridge, Tennessee 37831

Managed by

MARTIN MARIETTA ENERGY SYSTEMS, INC.

for the

U.S. DEPARTMENT OF ENERGY

under Contract DE-AC05-84-OR21400 
FOREWORD

This is the fifteenth in a series of semiannual technical progress reports on fusion reactor materials. This report combines research and development activities which were previously reported separately in the following progress reports:

- Alloy Development for Irradiation Performance

- Damage Analysis and Fundamental Studies

- Special Purpose Materials

These activities are concerned principally with the effects of the neutronic and chemical environment on the properties and performance of reactor materials; together they form one element of the overall materials prc grams being conducted in support of the Magnetic Fusion Energy Program of the U.S. Department of Energy. The other major elemc.at of the program is concerned with the interactions between reactor materials and the plasma and is reported separately.

The Fusion Reactor Materials Program is a national effort involving several national laboratories, universities, and industries. The purpose of this series of reports is to provide a working technical record for the use of the program participants, and to provide a means of communicating the efforts of materials scientists to the rest of the fusion community, both nationally and worldwide.

This report has been compiled and edited under the guidance of A. F. Rowcliffe, G. L. Burn, S. S Knee', and C. L. Dowker, Oak Ridge National Laboratory. Their efforts, and the efforts of the many persons who made technical contributions, are gratefully acknowledged.

F. W. Wiffen

Division of Advanced Physics and Technology 
Reports previously listed in this series are as follows:

DOE/ER-0313/1

DOE/ER-0313/2

DOE/ER-0313/3

DOE/ER-0313/4

DOE/ER-0313/5

DOE/ER-0313/6

DOE/ER-0313/7

DOE/ER-0313/8

DOE/ER-0313/9

DOE/ER-0313/10

DOE/ER-0313/11

DOE/ER-0313/12

DOE/ER-0313/13

DOE/ER-0313/14

DOE/ER-0313/15
Period ending September 30, 1986

Period ending March 31, 1987

Period ending September 30, 1987

Period ending March 31, 1988

Period ending September 30, 1988

Period ending March 31, 1989

Period ending September 30, 1989

Period ending March 31, 1990

Period ending September 30, 1990

Period ending March 31, 1991

Period ending September 30, 1991

Period ending March 31, 1992

Period ending September 30, 1992

Period ending March 31, 1993

Period ending September 30, 1993 
CONTENTS

1.0 IRRADIATION FACILITIES, TEST MATRICES, AND EXPERIMENTAL

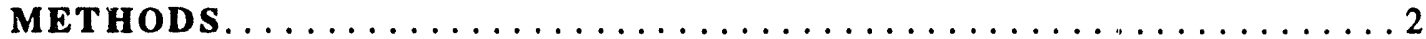

1.1 STATUS OF U.S./JAPAN COLLABORATIVE PROGRAM PHASE II HFIR TARGET AND RB* CAPSULES--J. E. Pawel, A. W. Longest, R. L. Senn (Oak Ridge National Laboratory), K. Shiba (Japan Atomic Energy Research Institute), D. W. Heatherly

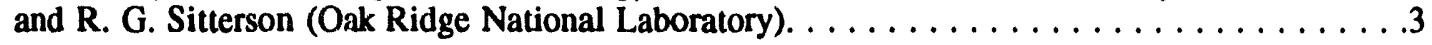

Capsules HFIR-MFE-JP9 through 16 were installed in the High Flux Isotope Reactor (HFIR) target July 20, 1990 for irradiation beginning with HFIR fuel cycle 289. Of these eight target capsules, JP10, 11,13,16 completed their scheduled number of cycles (11) and were removed from the reactor in September 1991. In addition, JP14 was removed from the reactor at the end of cycle 310 (September 18, 1992) after 21 cycles. Capsules JP9, 12, and 15 have completed 32 of 37 cycles.

Target capsules JP17, 18 and 19 contained fracture toughness specimens and were irradiated to approximately $3 \mathrm{dpa}$. All three capsules have been disassembled and testing is in progress.

Three new target capsules, JP20, 21, and 22, have been assembled and are scheduled to begin irradiation at the start of Cycle 322 . These capsules will operate at $300-600^{\circ} \mathrm{C}$ and will achieve doses of 8,18 and 35 dpa, respectively. Many isotopically tailored specimens are included in the matrix.

The $\mathrm{RB}^{*}$ experiments are the continuation of the ORR spectrally tailored experiment. In this stage, a hafnium liner is used to modify the spectrum to simulate fusion helium to displacements per atom (He/dpa) ratio in the austenitic steel specimens. Of the four capsules in this set, two (60J-1 and 330 -1 ) are ready to be disassembled, having achieved a total fluence of $18 \mathrm{dpa}$, and two (200J-1 and $400 \mathrm{~J}-1)$ are in the reactor.

1.2 FABRICATION AND OPERATION OF HFIR-MFE RB* SPECTRALLY TAILORED IRRADIATION CAPSULES--A. W. Longesh, J. E. Pawel, D. W. Heatherly, R. G. Sitterson,

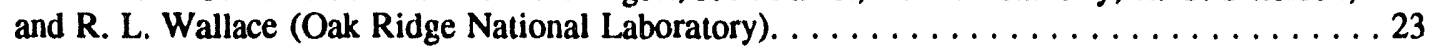

Fabrication and operation of four HFIR-MFE RB* capsules $\left(60,200,330\right.$, and $\left.400^{\circ} \mathrm{C}\right)$ to accommodate MFE specimens previously irradiated in spectrally tailored experiments in the ORR are proceeding satisfactorily. With the exception of the $60^{\circ} \mathrm{C}$ capsule, where the test specimens were in direct contact with the reactor cooling water, specimen temperatures (monitored by 21 thermocouples) are controlled by varying the thermal conductance of a thin gas gap region between the specimen holder outer sleeve and containment tube.

Irradiation of the 60 and $330^{\circ} \mathrm{C}$ capsules, which started on July 17, 1990, was completed on November 14, 1992, after 24 cycles of irradiation to an incremental damage level of approximately 10.9 displacements per atom (dpa). Assembly of the follow-up 200 and $400^{\circ} \mathrm{C}$ capsules was completed in November, 1992, and their planned 20-cycle irradiation to approximately 9.1 incremental dpa was started on November 21, 1992. As of September 4, 1993, the 200 and $400^{\circ} \mathrm{C}$ capsules had successfully completed nine cycles of irradiation to approximately 4.1 incremental dpa. 
2.0 DOSIMETRY, DAMAGE PARAMETERS, AND ACTIVATION

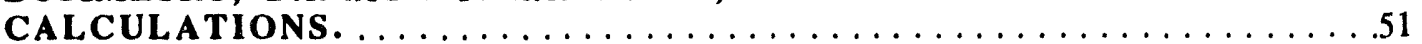

2.1 REANAL YSIS OF NEUTRON DOSIMETRY FOR THE MOTA-1E EXPERIMENT IN

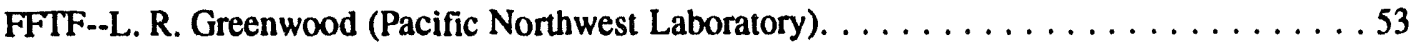

Revised neutron fluence and spectral measurements and radiation damage calculations are reported for the Materials Open Test Assembly (MOTA)-1E experiment in the Fast Flux Test Facility (FFTF). The irradiation was conducted from September 10, 1986, to October 10,1987 , for a total exposure of $341.8 \mathrm{EFPD}$ at $291 \mathrm{MW}$. The maximum fluence was 14.4 $\times 10^{22} \mathrm{n} / \mathrm{cm}^{2}, 10.1 \times 10^{22}$ above $0.1 \mathrm{MeV}$, producing $41.8 \mathrm{dpa}$ in iron. Neutron fluence and radiation damage maps are presented for the entire MOTA assembly based on the analysis of six neutron spectral measurements and five additional flux gradient measurements.

2.2 TRANSMUTATION OF Mo, Re, W, Hf, AND V IN VARIOUS IRRADIATION TEST FACILITIES AND STARFIRE--L. R. Greenwood and F. A. Garner (Pacific Northwest

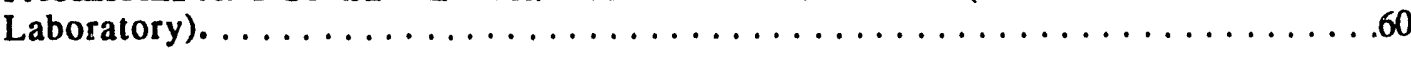

With the exception of $\mathrm{V}$ and $\mathrm{Cu}$ alloys, the formation of solid transmutants has not been thought to play a large role in the response of metals to irradiation. For a number of refractory elements, however, it appears that very large levels of solid transmutation can occur both in fission and fusion spectra. The phase stability and other properties of alloys can be strong functions of the changing composition. The spectral sensitivity of transmutation also poses some difficulty in correlating data from various neutron spectra. Transmutation of Mo, Re, W, Hf and V have been calculated for the Fast Flux Test Facility (FFTF), the High Flux Isotope Reactor (HFIR), and the STARFIRE fusion reactor. Results show that $\mathrm{Re}$ and $\mathrm{W}$ undergo sizable transmutation in these spectra, and may limit the use of these elements in fusion reactor materials. Vanadium and hafnium have high transmutation rates in HFIR and may require spectral tailoring.

3.0 MATERIALS ENGINEERING AND DESIGN REQUIREMENTS.

No contributions.

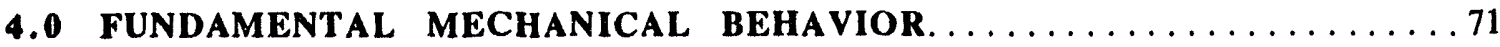

No contributions.

5.0 RADIATION EFFECTS, MECHANISTIC STUDIES, THEORY, AND

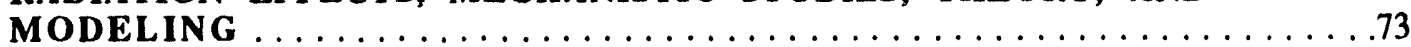

5.1 MOLECULAR DYNAMICS CALCULATIONS OF DEFECT ENERGETICS IN $\beta$-SiC*.Hanchen Huang and Nasr Ghoniem (Mechanical, Aerospace and Nuclear Engineering Department,University of California, Los Angeles). . . . . . . . . . . . . . . . 75

The Molecular Dynamics (MD) method is used to calculate defect energetics in $\beta$-silicon carbide. Many body interaction effects in this covalent material are accounted for by using a hybrid of two body and three-body potentials. Pearson's potential is modified to accurately fit sublimation energy of $\beta$-SiC. Inter-atomic potentials among silicon, carbon, and helium 
atoms are also constructed based on available data and reasoning. A micro-crystal is constructed to represent the computational cell and external forces are applied to the microcrystal so that it behaves as a part of an infinite medium. Potential energy for the unperturbed computational cell is first calculated. The cell is then set at a defect configuration and relaxed, and the potential energy of the relaxed cell is calculated. The difference between the potential energy of the unperturbed cell and that of the defectcontaining cell is used to calculate formation energies of point defects, defect clusters and helium-filled vacancy clusters in SiC. Binding energies, and migration energies of the point defects are then deduced. Pre-exponential factors of point defect diffusion coefficients are calculated from potential profile obtained. Calculated activation energies and pre-exponential factors of thermal diffusion through vacancy mechanism are compared to experimental data. Good agreement backups our construction of potential functions and MD calculations.

5.2 MODELING DEFECT PRODUCTION IN HIGH ENERGY COLLISION CASCADES-H. L. Heinisch (Pacific Northwest Laboratory), B. N. Singh (Risø National Laboratory) and T. Diaz de la Rubia (Lawrence Livermore National Laboratory). . . . . . . . . . . . . . . . . 87

A multi-model approach (MMA) to simulating defect production processes at the atomic scale is described that incorporates molecular dynamics (MD), binary collision approximation (BCA) calculations and stochastic annealing simulations. The central hypothesis of the MMA is that the simple, fast computer codes capable of simulating large numbers of high energy cascades (e.g., BCA codes) can be made to yield the correct defect configurations when their parameters are calibrated using the results of the more physically realistic MD simulations. The calibration procedure is investigated using results of MD simulations of $25 \mathrm{keV}$ cascades in copper. The configurations of point defects are extracted from the MD cascade simulations at the end of the collisional phase, similar to the information obtained with a binary collision model. The MD collisional phase defect configurations are used as input to the ALSOME annealing simulation code, and values of the ALSOME quenching parameters are determined that yield the best fit to the postquenching defect configurations of the MD simulations.

5.3 INFLUENCE OF HELIUM GENERATION RATE AND TEMPERATURE HISTORY ON MECHANICAL PROPERTIES OF MODEL Fe-Cr-Ni ALLOYS IRRADIATED IN FFTF AT RELATIVEL Y LOW DISPLACEMENT RATES--M. L. Hamilton, F. A. Garner and D. J. Edwards (Pacific Northwest Laboratory). . . . . . . . . . . . . . . . . . 94

In agreement with earlier studies conducted at higher displacement rates, the evolution of mechanical properties of model $\mathrm{Fe}-\mathrm{Cr}$-Ni alloys irradiated at lower displacement rates in the ${ }^{59} \mathrm{Ni}$ isotopic doping experiment does not appear to be strongly affected by large differences in helium generation rate. This insensitivity to helium/dpa ratio is exhibited during both isothermal and non-isothermal irradiation. The overall behavior of the model alloys used in this study is dominated by the tendency to converge to a saturation strength level that is independent of thermomechanical starting state and helium/dpa ratio, but which is dependent on irradiation temperature and alloy composition.

5.4 MICROSTRUCTURAL EVOLUTION OF NEUTRON-IRRADIATED Fe-Cr-Ni TERNARY ALLOYS AT HIGH HELIUM GENERATION RATES--N. Sekimura (University of Tokyo)

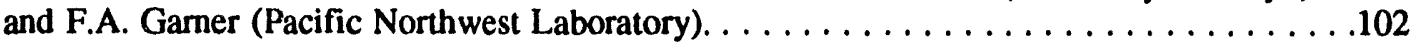

A series of Fe-Cr-Ni ternary alloys were irradiated to 12-14 dpa in the Oak Ridge Research Reactor (ORR). In this experiment, most of helium atoms were produced by the ${ }^{58} \mathrm{Ni}(\mathrm{n}, \gamma)^{59} \mathrm{Ni}(\mathrm{n}, \alpha)^{56} \mathrm{Fe}$ sequential reaction, and therefore, the helium generation rate was almost proportional to the nickel content, ranging from 27 to $58 \mathrm{appm} \mathrm{He} / \mathrm{dpa}$ in 20 to 
viii

$45 \mathrm{wt} . \% \mathrm{Ni}$ alloys. Irradiation temperatures were $330,400,500$ and $600^{\circ} \mathrm{C}$, and the specimen variables were the nickel level, the chromium level and cold working. The high levels of helium, combined with details of the temperature history, were found to have dominated to microstructural development, sometimes overwhelming and even reversing the action of a given material variable. Microscopy examination showed that there was an unprecedented refinement of cavity microstructure at all temperatures, which accounts for the substantial alterations in both swelling and mechanical properties observed in earlier studies.

5.5 MICROSTRUCTURAL DEVELOPMENT IN IRRADIATED VANADIUM ALLOYS-D S Gelles (Pacific Northwest Laboratory), and J. F. Stubbins (University of Illinois). . . . . .11

Three simple vanadium alloys, V-5Al, V-1Ni, and $\mathrm{V}-2 \mathrm{Ti}-1 \mathrm{Ni}$ have been examined to determine the effects of fast neutron irradiation in microstructural evolution. Specimens were irradiated in EBR Il at temperatures in the range 425 to $600^{\circ} \mathrm{C}$ to doses of 15 and 31 dpa. Each alloy responded very differently to irradiation. All V-5Al specimens were generally void-free and contained high densities of coherent precipitates, and moderate densities of network dislocations. Swelling was much higher in $\mathrm{v}-1 \mathrm{Ni}$. Voids were uniformly distributed, but with widely varying shape and size. Precipitation of two types also developed. The response in V-2Ti-1Ni was intermediate to that of the other two alloys. Irradiation produced extensive precipitation of thin rods and a moderate density of large voids often associated with much larger precipitate particles. The dislocation structure strongly interacted with the rod precipitate particles.

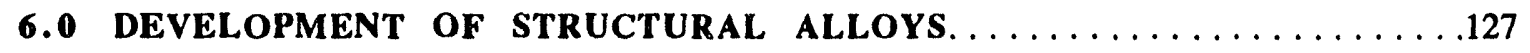

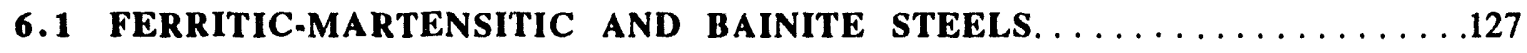

\subsubsection{REPORT ON IEA COLLABORATION ON FERRITIC/MARTENSITIC STEELS --}

R. L. Klueh (Oak Ridge National Laboratory). . . . . . . . . . . . . . . . . . . . . . 129

A collaborative program is underway under the auspices of the IEA (International Energy Agency) to develop a reduced-activation ferritic steel for a demonstration fusion power plant. A task has been initiated for which Japan will produce a $5000-10000 \mathrm{~kg}$ heat of reducedactivation 8Cr-2WVTa steel. Once the steel is produced, the Japanese, EC, and US fusion programs will conduct detailed cooperative test programs on the steel. Two meetings have been held to plan the collaboration, and the results from those meetings are reviewed.

\subsubsection{EFFECT OF LOADING MODE ON THE FRACTURE TOUGHNESS OF A FERRITIC/} MARTENSITIC STAINLESS STEEL--Huaxin Li (Associated Western Universities--Northwest Division), R. H. Jones (Pacific Northwest Laboratories), J. P. Hirth (Washington State University--Pullman) and D. S. Gelles (Pacific Northwest Laboratories).

The critical $\mathrm{J}$ integrals of mode I $\left(\mathrm{J}_{\mathrm{IC}}\right)$, mixed-mode I/III $\left(\mathrm{J}_{\mathrm{MC}}\right)$, and mode III $\left(\mathrm{J}_{\mathrm{mc}}\right)$ were examined for a ferritic stainless steel (F-82H) at ambient temperature. A determination of $\mathrm{J}_{\mathrm{MC}}$ was made using modified compact-tension specimens. Different ratios of tension/shear stress were achieved by varying the principal axis of the crack plane between 0 and 55 degrees from the load line. $\mathrm{J}_{\mathrm{mc}}$ was determined using triple-pantleg like specimens. The results showed that $\mathrm{F}-82 \mathrm{H}$ steel is a very tough steel. Both $\mathrm{J}_{\mathrm{IC}}$ and $\mathrm{J}_{\mathrm{mc}}$ are about $500 \mathrm{~kJ} / \mathrm{m}^{2}$, and mode I tearing modula $\left(\mathrm{T}_{\mathrm{I}}\right)$ is about $\left(360 \mathrm{~kJ} / \mathrm{m}^{2}\right) / \mathrm{mm}$. However, $\mathrm{J}_{\mathrm{MC}}$ and mixed-mode tearing modula $\left(\mathrm{T}_{M}\right)$ values varied with the crack angles and were lower than 
their mode I and mode III counterparts. Both the minimum $\mathrm{J}_{\mathrm{MC}}$ and $\mathrm{T}_{\mathrm{M}}$ values occurred at a crack angle between 40 and 50 degrees, where the load ratio of $\sigma \mathrm{i} / \sigma$ iii was 1.2 to 0.84 . The $\mathrm{J}_{\mathrm{min}}$ was $240 \mathrm{~kJ} / \mathrm{m}^{2}$, and ratios of $\mathrm{J}_{\mathrm{IC}} / \mathrm{J}_{\min }$ and $\mathrm{J}_{\mathrm{mc}} / \mathrm{J}_{\mathrm{min}}$ were 2.1 and 1.9 , respectively. The morphology of fracture surfaces was consistent with the change of $\mathrm{J}_{\mathrm{MC}}$ and $\mathrm{T}_{M}$ values. While the upper shelf-fracture toughness of $\mathrm{F}-82 \mathrm{H}$ depends on loading mode the $\mathrm{J}_{\min }$ remains very high. Other important considerations include the effect of mixedmode loading on the DBT temperature, and effects of hydrogen and irradiation on $\mathrm{J}_{\min }$.

\subsubsection{IMPACT TOUGHNESS OF IRRADIATED REDUCED-ACTIVATION FERRITIC} STEELS -- R. L. Klueh and D. J. Alexander (Oak Ridge National Laboratory) . . . . . . . . . 148

Eight chromium-tungsten steels ranging from 2.25 to $12 \mathrm{wt} \% \mathrm{Cr}$ were irradiated at $365^{\circ} \mathrm{C}$ to 13-14 dpa in the Fast Flux Test Facility. Post irradiation Charpy impact tests showed a loss of toughness for all steels, as measured by an increase in the ductile-brittle transition temperature (DBTT) and a decrease in the upper-shelf energy. The most irradiation-resistant steels were two $9 \% \mathrm{Cr}$ steels: the DBTT of a $9 \mathrm{Cr}-2 \mathrm{~W}-0.25 \mathrm{~V}-0.1 \mathrm{C}$ stcel increased $29^{\circ} \mathrm{C}$, and for the same composition with an addition of $0.07 \%$ Ta the DBTT increased only $15^{\circ} \mathrm{C}$. This is the smallest shift ever observed for such a steel irradiated to these levels. The other steels developed shifts in DBTT of 100 to $300^{\circ} \mathrm{C}$. A $2.25 \% \mathrm{Cr}$ steel with $2 \% \mathrm{~W}, 0.25 \% \mathrm{~V}$, and $0.1 \% \mathrm{C}$ was less severely affected by irradiation than $2.25 \% \mathrm{Cr}$ steels with $0.25 \% \mathrm{~V}$ and no tungsten, $2 \% \mathrm{~W}$ and no vanadium, and with $1 \% \mathrm{~W}$ and $0.25 \% \mathrm{~V}$. Irradiation resistance appears to be associated with microstructure, and microstructural manipulation may lead to improved properties.

\subsubsection{MICROSTRUCTURAL DEVELOPMENT IN REDUCED ACTIVATION FERRITIC} ALLOYS ?RADIATED TO 200 DPA AT $420^{\circ}$ C--D. S. Gelles (Pacific Northwest Labora

Density change and microstructural development are reported for nine reduced activation ferritic steels covering the range 2.3 to $12 \mathrm{Cr}$ with varying additious of $\mathrm{V}$ and/or $\mathrm{W}$ for hardening and up to $6.5 \mathrm{Mn}$ for austenite stability. Specimens were examined following irradiation in FFTF/MOTA at $420^{\circ} \mathrm{C}$ to a dose exceeding 200 dpa. Void swelling was found, but the swelling remained at $5 \%$ or below, with the worst case in an alloy of $9 \mathrm{Cr}$ 2Mn-1WV. The carbide structure pinning Martensite lath boundaries remains in place.

\subsubsection{IRRADIATION CREEP AND SWELLING OF THE U.S. FUSION HEATS OF HT9 AND} $9 \mathrm{Cr}-1 \mathrm{Mo}$ TO 208 DPA AT $400^{\circ} \mathrm{C}-\mathrm{M}$. B. Toloczko (University of California at Santa Barbara), F. A. Garner (Pacific Northwest Laboratory) ${ }^{a}$, and C. R. Eiholzer (Westinghouse Hanford Company). . . . . . . . . . . . . . . . . . . . . . . . . . . . . . 164

The irradiation creep and swelling behaviors of the fusion heats of HT9 and $9 \mathrm{Cr}-1 \mathrm{Mo}$ at $-400^{\circ} \mathrm{C}$ have been measured to exposures as large as $208 \mathrm{dpa}$, using both diametral and density measurements of helium-pressurized creep tubes. Void swelling was found in both alloys at $208 \mathrm{dpa}$ to occur at rates of $0.012 \%$ /dpa or less, with the swelling of HT9 exhibiting a larger degree of stress enhancement than 9Cr-1Mo. The creep rate of HT9 is rather nonlinear in its response to keep stress level in the range $0-200 \mathrm{MPa}$, but $9 \mathrm{Cr}-1 \mathrm{Mo}$ exhibits only slightly greater than linear behavior with stress level. The creep-swelling coupling coefficients for $9 \mathrm{Cr}$ - $1 \mathrm{Mo}$ are consistent with values obtained for other steels. 


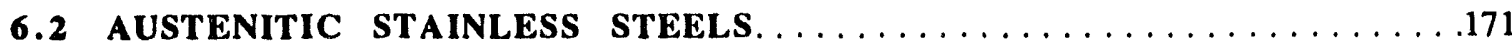

\subsubsection{FRACTURE TOUGHNESS OF CANDIDATE MATERIALS FOR ITER FIRST WALL,} BLANKET, AND SHIELD STRUCTURES--J. E. Pawel, D. J. Alexander, M. L. Grossbeck, A. W. Longest, A. F. Rowcliffe (Oak Ridge National Laboratory), G. E. Lucas (University of California, Santa Barbara), S. Jitsukawa, A. Hishinuma, and K. Shiba (Japan Atomic Energy

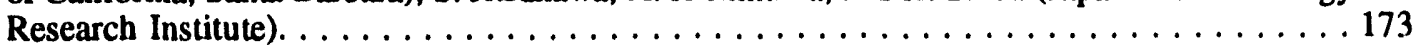

Although the design of the International Thermonuclear Experimental Reactor is still in an evolutionary phase, the most probable choice for a structural material is a 300 series austenitic stainless steel. An experiment was carried out in the High Flux Isotope Reactor to quantify the effects of neutron irradiation on the fracture toughness properties of a range of austenitic stainless steels. The alloys investigated were provided by programs in the European Community, United States, and Japan; they included 316, 316L, and titaniumstabilized steels in cold-worked, annealed, and welded conditions. Subsize disk compact tension specimens were irradiated to a dose of about $3 \mathrm{dpa}$ and $50 \mathrm{appm}$ helium (the expected fusion value) at temperatures of either 60 to $125^{\circ} \mathrm{C}$ or 250 to $300^{\circ} \mathrm{C}$. With the exception of a cold-worked air-melted heat of 316 , all materials retained excellent fracture toughness, with $\mathrm{K}$, values varying from 150 to $400 \mathrm{MPa} \sqrt{\mathrm{m}}$ over the test temperature range from 90 to $250^{\circ} \mathrm{C}$.

\subsubsection{TENSILE PROPERTIES OF BASE AND WELD METAL SPECIMENS OF AUSTENITIC} STAINLESS STEELS IRRADIATED IN THE HIGH FLUX ISOTOPE REACTOR--

K. Shiba and S. Jitsukawa (Japan Atomic Energy Research Institute) and J. E. Pawel and

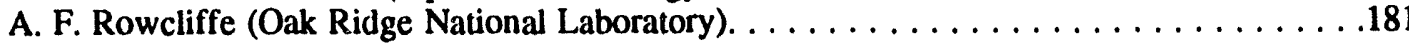

Tensile properties of Japanese Primary Candidate Alloy (JPCA) base metal and welded specimens irradiated in HFIR target positions were investigated. Electron beam (EB) and tungsten inert gas (TIG) welding techniques were used to make welded specimens. Welded specimens included weld metai and weld joint specimens. These specimens were irradiated up to $18 \mathrm{dpa}$ at $300,400,500$ and $600^{\circ} \mathrm{C}$. JPCA solution annealed base metal had maximum irradiation hardening at $300^{\circ} \mathrm{C}$, and it showed minimum elongation at that temperature. EB welded specimens exhibited almost the same tensile properties as the base metal, with the strength of the EB weld metal and weld joint specimens being only slightly lower than that of the base metal. EB welded specimens retained uniform elongations in the range of 2 to $7 \%$ after irradiation. TIG welded specimens had less ductility than the EB welded specimens, however the other tensile properties of the TIG welded specimens were almost same as for the EB welded specimens.

\subsubsection{A PRELIMINARY ANALYSIS OF CRACK GROWTH IN TYPE 316L STAINLESS} STEEL IN AIR AND WATER UNDER CYCLIC LOADING CONDITIONS FOR ITER FIRST-WALL DESIGN--M. R. Fox, W. K. Soppet, W. E. Ruther, and T. F. Kassner (Argonne National Laboratory). . . . . . . . . . . . . . . . . . . . .

Initial results on stress corrosion cracking (SCC) susceptibility and crack growth rate (CGR) of Type 316L SS in oxygenated water were used with fracture-mechanics relations to compare the fatigue life (cycles to failure) in air and water at $200^{\circ} \mathrm{C}$ of a coolant tube within the ITER first-wall structure for burn and pulse times of 480 and $1000 \mathrm{~s}$, respectively. Fatigue life was evaluated as a function of maximum stress intensity, initial flaw depth in the 3.2-mm wall of the tube, water purity, and threshold stress intensity for SCC. 


\subsubsection{DENSITY MEASUREMENTS PERFORMED ON ISPRA SECOND GENERATION AMCR} ALLOYS IRRADIATED IN MOTA-2A AND MOTA-2B.-F. A. Garner (Pacific Northwest Laboratory), P. Schiller (Ispra Establishment), and H. Takahashi (Hokkaido University). . . . . .198

Density change measurements have been completed on the Ispra second generation AMCR alloys irradiated in MOTA-2A and MOTA-2B. The various compositional modifications induce a wide variation of swelling behavior in the range $423-600^{\circ} \mathrm{C}$ at $32-61 \mathrm{dpa}$.

\subsubsection{DENSITY CHANGES INDUCED BY NEUTRON IRRADIATION IN DYNAMICALLY COMPACTED TUNGSTEN AND PCA IN MOTA's 2A and 2B--F. A. Garner (Pacific} Northwest Laboratory) and J. Megusar (Massachusetts Institute of Technology).

Dynamically compacted tungsten with a starting density of $95.3 \%$ of the theoretical value densified 2 to $3 \%$ when irradiated in FFTF/MOTAs 2A and 2B at three temperatures between 423 and $600^{\circ} \mathrm{C}$ and displacement levels corresponding to 32 to $36 \mathrm{dpa}$ in stainless steel during the first irradiation segment and 54.2 to 60.8 dpa during the second segment. Rapidly solidified and dynamically compacted PCA with high levels of titanium and carbon were also irradiated at these conditions. The density changes were variable between nominally identical specimens but were small enough to determine that significant swelling had not occurred. Microscopy is necessary to determine whether any void growth occurred in addition to precipitate-related strains.

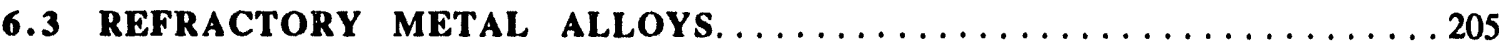

\subsubsection{EFFECTS OF FABRICATION VARIABLES ON IMPACT PROPERTIES AND} MICROSTRUCTURE OF V-CR-TI ALLOYS--H. M. Chung, J. Gazda, L. J. Nowicki, J. E. Sanecki, and D. L. Smith (Argonne National Laboratory). . . . . . . . . . . . . . . . . 207

In spite of the small differences in composition of alloying elements, $\mathrm{V}-4 \mathrm{Cr}-4 \mathrm{Ti}, \mathrm{V}-5 \mathrm{Cr}$ 5Ti, and V-5Cr--5Ti alloys exhibited surprisingly large variations in ductile-britte transition temperatures (DBTTs) $\left(<-190,-60\right.$, and $-85^{\circ} \mathrm{C}$, respectively) in previous investigations. To provide a better understanding of the origin of the variation, effects of fabrication parameters (extrusion, forging, annealing temperature, and quality of $\mathrm{Ti}$ raw material) on the microstructure and impact properties were investigated in this work. Fracture surfaces of $\mathrm{V}$ 5CR-5Ti and V-5Cr-3Ti alloys, which exhibited DBTTs $\approx 110^{\circ} \mathrm{C}$ higher than that of V-4Cr$4 \mathrm{Ti}$, were characterized by relatively large precipitates $(2,000-17,000 \mathrm{~nm})$ which appear to be complex vanadium compounds containing different compositions of $\mathrm{C}, \mathrm{S}, \mathrm{O}, \mathrm{Cl}, \mathrm{Ca}, \mathrm{Na}$, $\mathrm{K}, \mathrm{Cr}$, and $\mathrm{Cu}$. The two alloys also contained high-density precipitates $30-70 \mathrm{~nm}$ in size that seem to be vanadium compounds rich in $\mathrm{O}, \mathrm{C}, \mathrm{S}$, and $\mathrm{Ca}$. This unusual precipitation of vanadium compounds in the V-5Cr-5Ti and V-5CR-3Ti alloys seems to be associated in part with $\mathrm{Ti}$ sponge (relatively rich in $\mathrm{Cl}, \mathrm{Na}$, and $\mathrm{K}$ ) that was used to prepare the alloy ingots. Based on thermodynamic consideration, formation of some of the complex precipitates (e.g., vanadium oxycarbochloride) is preferred to titanium oxycarbonitirides in alloys containing a high level of $\mathrm{Cl}$. Vanadium-based precipitates were absent in $\mathrm{V}-4 \mathrm{Cr}$ 4Ti, which was fabricated using vacuum-arc-melted Ti plates low in $\mathrm{Cl}, \mathrm{Na}$, and $\mathrm{K}$. V-5Cr$3 \mathrm{Ti}$, which was forged at $=650^{\circ} \mathrm{C}$ rather than extruded at the usual temperature of $1150^{\circ} \mathrm{C}$, also contained unusually small titanium oxycarbonitrides in high-density. Cleavage was the predominant process in brittle fracture of V-5Cr-5Ti. However, evidence of intergranular separation, apparently associated with grain-boundary segregation of $\mathrm{Ti}, \mathrm{S}$, and $\mathrm{P}$, was also observed in the material. The origin of the higher than-expected DBTTs of the V-5Cr-5Ti and $\mathrm{V}-5 \mathrm{Cr}-3 \mathrm{Ti}$ alloys seems to be issociated with the unusual precipitation of vanadium compounds and intergranular separation. Effect of post-fabrication annealing on ductilebrittle-transition behavior was secondary, although annealing at $\approx 1050^{\circ} \mathrm{C}$ produced the most favorable impact properties. In contrast to $\mathrm{V}-5 \mathrm{Cr}-5 \mathrm{Ti}$ and $\mathrm{V}-5 \mathrm{Cr}-3 \mathrm{Ti}, \mathrm{V}-4 \mathrm{Cr}-4 \mathrm{Ti}$ remained ductile for impact temperatures higher than $-196^{\circ} \mathrm{C}$ regardless of annealing at 1050 or $1125^{\circ} \mathrm{C}$. 


\subsubsection{EFFECT OF NEUTRON IRRADIATION ON TENSILE PROPERTIES OF V-Cr-Ti} Alloys--B. A. Loomis, L. J. Nowicki, and D. L. Smith (Argonne National Laboratory). . . . . 219

Vanadium-base alloys with $\mathrm{Cr}$ and $\mathrm{Ti}$ as the principal alloying additions have a number of attractive physical and mechanical properties for application as structural material in the International Thermonuclear Experimental Reactor (ITER) and in fusion reactors that may be constructed in the future. These alloys offer an excellent combination of low, long-term radioactivation, high-temperature capability, and resistance to irradiation damage. At the present time, the $\mathrm{V}-4 \mathrm{Cr}-4 \mathrm{Ti}$ alloy is recommended for the near-optimal combination of desirable physical and mechanical properties for a vanadium alloy structural material. In this paper, we present the tensile properties of the V-4C4-4Ti alloy and, in addition, tensile properties of V-14Cr-5Ti, V-9Cr-5Ti, V-3Ti-1Si, V-5Ti, and V-18Ti alloys after neutron irradiation to $28-46$ atom displacements per atom (dpa) at 420,520 , and $600^{\circ} \mathrm{C}$.

\subsubsection{IRRADIATION-INDUCED DENSITY CHANGE AND MICROSTRUCTURAL EVOLUTION} OF VANADIUM-BASE ALLOYS--H. M. Chung, B. A. Loomis, L. Nowicki, J. Gazda, and D. L. Smith (Argonne National Laboratory) . . . . . . . . . . . . . . . . . . . . . . . . .223

Irradiation-induced density change (swelling) and microstructural evolution of $\mathrm{V}-\mathrm{Ti}, \mathrm{V}-\mathrm{Cr}-\mathrm{Ti}$, and V-Ti-Si alloys were investigated after irradiation in a fast reactor at 420 to $600^{\circ} \mathrm{C}$ up to $114 \mathrm{dpa}$. The allicys exhibited swelling maxima in the damage range of 30 to 70 dpa and swelling decreased on irradiation to higher dpa. The swelling resistance of the alloys was associated with high-density precipitation of ultrafine $\mathrm{Ti}_{5} \mathrm{Si}_{3}$, and it was concluded that $\mathrm{Ti}>4$ wt.\% and 400 to 1000 wppm Si are desirable to effectively suppress swelling. Swelling resistance of $\mathrm{V}-4 \mathrm{Cr}-4 \mathrm{Ti}$ was excellent, and this alloy is virtually immune to irradiation embrittlement. The excellent swelling resistance was associated with ultrafine $\mathrm{Ti}_{5} \mathrm{Si}_{3}$ for irradiation at 520 to $600^{\circ} \mathrm{C}$ and dense formation of dislocation loops for irradiation at $<420^{\circ} \mathrm{C}$.

\subsubsection{RELATIONSHIP OF MICROSTRUCTURE AND MECHANICAL PROPERTIES--}

J. Gazda, B A. Loomis, and L. J. Nowicki (Argonne National Laboratory), and

S. Danyluk (University of Illinois at Chicago) $\ldots \ldots \ldots \ldots \ldots \ldots \ldots$

The relationship of composition, number density, and diameter of precipitates in the microstructures of unalloyed $\mathrm{V}$ and $\mathrm{V}-\mathrm{Cr}-\mathrm{Ti}$ alloys to the yield strength, hardness, creep stress, and ductile-brittle transition temperature (DBTT) of these materials was determined from electron microscopy analyses of precipitates in these materials and from mechanical property data. Unalloyed V and V-Cr-Ti alloys with $\leq 3 \mathrm{wt}$.\% Ti contained VC and Ti(CNO) nrecipitates, which were coherent with the matrix. The most common precipitates in the alloys were $\mathrm{Ti}\left(\mathrm{C}_{1-x-y} \mathrm{~N}_{\mathrm{x}} \mathrm{O}_{\mathrm{y}}\right)$ that were noncoherent with the matrix. The number density of noncoherent precipitates was maximal in $\mathrm{V}-3 \mathrm{Ti}$ and and $\mathrm{V}-5 \mathrm{Cr}-3 \mathrm{Ti}$ alloys, and the average diameter of noncoherent precipitates was minimal in V-(1-3) Ti and V-5Cr-3Ti alloys. The increase of yield strength and hardness of $\mathrm{V}$ on alloying with $\mathrm{Ti}$ and $\mathrm{Cr}$ was shown to be primarily due to coherent precipitates, solute-atom misfit, and shca-modulus difference effects. The creep stress for rupture in $1000 \mathrm{~h}$ was related to the number of precipitates, whereas the DBTT was related to the volume fraction of precipitates.

6.3.5 MICROSTRUCTURAL STABILITY OF V-4Cr-4Ti DURING NEUTRON IRRADIATION-H. Matsui and M. Tanno (Tohoku University) and J. Gazda and H. M. Chung (Argonne National Laboratory) . . . . . . . . . . . . . . . . . . . . . . . . . . . . . . .240

Microstructural evolution of $\mathrm{V}-4 \mathrm{Cr}-4 \mathrm{Ti}$, an alloy recently shown to exhibit excellent tensile and creep properties, virtual immunity to irradiation embrittlement, and good resistance to swelling, was characterized after irradiation in a lithium environment in the Fast Flux Text Facility (FFTF) (a sodium-cooled fast reactor located in Richland, Washington) at 420, 520, and $600^{\circ} \mathrm{C}$ to $24-34 \mathrm{dpa}$. The primary feature of microstructural evolution during irradiation 
at 520 and $600^{\circ} \mathrm{C}$ was high-density formation of ultrafine $\mathrm{Ti}_{5} \mathrm{Si}_{3}$ precipitates and short dislocations. For irradiation at $420^{\circ} \mathrm{C}$, precipitation of $\mathrm{Ti}_{5} \mathrm{Si}_{3}$ was negligible, and "blackdot" defects and dislocations were observed in significantly higher densities. In spite of their extremely high densities, neither the "black-dot" defects nor $\mathrm{Ti}_{5} \mathrm{Si}_{3}$ precipitates are overly detrimental to ductility and toughness of the alloy, yet they very effectively suppress irradiation-induced swelling. Therefore, these features, normally observed in V-base alloys containing $\mathrm{Ti}$ and $\mathrm{Si}$, are considered stable. Unstable microstructural modifications that are likely to degrade mechanical properties significantly were not observed, e.g., irradiationinduced formation of fine oxides, carbides, nitrides, or $\mathrm{Cr}$-rich clusters.

6.3.6 STATUS OF THE DYNAMIC HELIUM CHARGING EXPERIMENT (DHCE)--H. Tsai, H. M. Chung, B. A. Loomis, and D. L. Smith (Argonne National Laboratory). . . . . . . . . 247

Irradiation of the seven DHCE capsules was completed in MOTA-2B at the end of FFTF Cycle 12B. The accrued exposure was 203.3 effective full power days (EFPDs) and the peak damage in the samples was $\approx 23 \mathrm{dpa}$. All seven capsules have been discharged from the FFTF and shipped to ANL-East. Procedures have been developed to disassemble the tritiumcontaining capsules to retrieve the specimens for examination and testing.

\subsubsection{EFFECTS OF NEUTRON IRRADIATION AND HYDROGEN ON DUCTILE-BRITTLE} TRANSITION TEMPERATURES OF V-Cr-Ti ALLOYS--B. A. Loomis, H. M. Chung, L. J. Nowicki, and D. L. Smith (Argonne National Laboratory) . . . . . . . . . . . . .253

The effects of neutron irradiation and hydrogen on the ductile-brittle transition temperatures (DBTTs) of unalloyed vanadium and V-Cr-Ti alloys were determined from Charpy-impact tests on 1/3 ASTM-standard-size specimens and from impact tests on 3-mm diameter disks. The tests were conducted on specimens containing $<30$ appm hydrogen and 600-1200 appm hydrogen and on specimens after neutron irradiation to 28-46 atom displacements per atom at 420,520 , and $600^{\circ} \mathrm{C}$. The DBTTs were minimum $\left(<-220^{\circ} \mathrm{C}\right)$ for V-(1-5)Ti alloys and for V$4 \mathrm{Cr}-4 \mathrm{Ti}$ alloy with $<30 \mathrm{appm}$ hydrogen. The effect of 600-1200 appm hydrogen in the specimens was to raise the DBTTs by $60-100^{\circ} \mathrm{C}$. The DBTTs were minimum $\left(<-200^{\circ} \mathrm{C}\right)$ for $\mathrm{V}$-(3-5)Ti and $\mathrm{V}-4 \mathrm{Cr}-4 \mathrm{Ti}$ alloys after neutron irradiation.

6.3.8 WELDING OF VANADIUM ALLOYS--D. R. Diercks, C. F. Konicek, and R. H. Lee

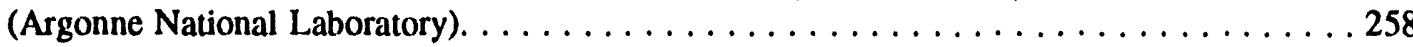

An exploratory activity has been initiated to investigate potential welding processes and the effects of these processes on the properties of candidate vanadium-base alloys has been initiated. Weldments of $\mathrm{V}-5 \mathrm{Cr}-5 \mathrm{Ti}$ and $\mathrm{V}-15 \mathrm{Ti}-7.5 \mathrm{Cr}$ have been prepared by the tungsten/inert-gas process without the use of filler metal. The weldments were examined metallographically and found to be free of significant defects. Chemical analyses of the weldments indicate only slight oxygen pickup during welding, and microhardness profiles indicate no unusual effects.

\subsubsection{DEVELOPMENT OF MINIATURE-SPECIMEN TECHNOLOGY TO DETERMINE} DUCTILE-BRITTLE TRANSITION BEHAVIOR OF IRRADIATED VANADIUM ALLOYS--H. M. Chung, L. J. Nowicki, J. Gazda, D. E. Busch, and D. L. Smith

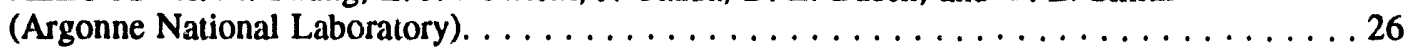

Simple uninstrumented impact tests were conducted on unirradiated and irradiated transmission electron microscopy (TEM) disks of vanadium alloys between -196 and $300^{\circ} \mathrm{C}$. The results were combined with quantitative fractography of the fractures specimens in a scanning electron microscope (SEM) to determine the effect of impact temperature on fracture behavior. Based on the fractographic information, ductile-brittle transition behavior of several alloys was determined before and after irradiation. The ductile-brittle transition 
xiv

temperature (DBTT) obtained from this tcannique was then compared with the DBTT from Charpy impact testing of the same material. A correlation curve was then obtained for use in estimating DBTTs of irradiated vanadium-base alloys based on ductile-brittle transition behavior of standard-size TEM disks. The method seems to be adequate to estimate the ductile brittle transition behavior of a material whose Charpy-impact DBTT is higher than approximately $-70^{\circ} \mathrm{C}$. For a material whose Charpy DBTT is $<-70^{\circ} \mathrm{C}$, the method can provide an estimation of upper limit of the DBTT. Conpared to a similar; method based on slow-strain-rate small-punch testing, the present method seems to be significantly more advantageous in evaluating ductile-brittle transition behavior.

\subsubsection{ASSESSMENT OF NIOBIUM-BASE ALLOYS FOR STRUCTURAL APPLICATIONS} IN THE ITER DIVERTOR--I. M. Purdy (Argonne National Laboratory). . . . . . . . . . 268

The corrosion and embrittlement of pure $\mathrm{Nb}, \mathrm{Nb}-1 \mathrm{Zr}, \mathrm{Nb}-5 \mathrm{Mo}-1 \mathrm{Zr}$, and $\mathrm{Nb}-5 \mathrm{~V}-1.25 \mathrm{Zr}$ (alloy elements in wt.\%) were evaluated in high-purity (HP) deoxygenated water at $300^{\circ} \mathrm{C}$ for up to 120 days. One heat of the Nb-5V-1.25Zr alloy ("O" lot) exhibited both a modest corrosion rate and good resistance to embrittlement relative to other Nb-base alloys. At present, $\mathrm{Nb}-5 \mathrm{~V}-1.25 \mathrm{Zr}$ is the most promising $\mathrm{Nb}$-base alloy with respect to both corrosion and embrittlement characteristics in $\mathrm{HP}$ deoxygenated water at $300^{\circ} \mathrm{C}$.

\subsubsection{THE INFLUENCE OF STARTING STATE ON NEUTRON INDUCED DENSITY} CHANGES OBSERVED IN Nb-Zr AND Mo-41Re AT HIGH EXPOSURES--

F. A. Garner, L. R. Greenwood, and D. J. Edwards (Pacific Northwest Laboratory). . . . . . . 274

Both $\mathrm{Nb}-1 \mathrm{Zr}$ and Mo-41Re were irradiated in FFTF at five temperatures between 420 and $730^{\circ} \mathrm{C}$, reaching maximum exposure levels of 58 to $111 \mathrm{dpa}$, depending on the irradiation temperature. Each alloy was irradiated in two starting conditions, cold-worked and aged or annealed and aged. The neutron-induced swelling behavior in response to starting condition was quite different for the two alloys and appeared to reflect a strong role of precipitation in each. While transmutation does not play a major role in the response of $\mathrm{Nb}-1 \mathrm{Zr}$, it plays a significant role in the behavior of Mo-4lRe, which becomes a heavily-precipitated Mo-ReOs-Tc-Ru alloy. This strong response may preclude the use of Mo-Re alloys for fusion application.

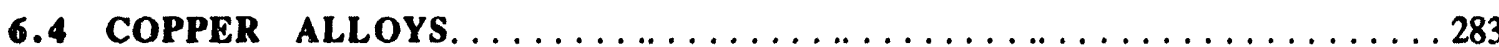

\subsubsection{NEUTRON-INDUCED MICROSTRUCTURAL ALTERATION OF GLIDCOPTM} ALLOYS AT $415^{\circ} \mathrm{C}$ AND HIGH NEUTRON EXPOSURE-D. J. Edwards, F. A. Garner (Pacific Northwest Laboratory) ${ }^{2}$, J. W. Newkirk (University of Missouri) and A. Nadharni

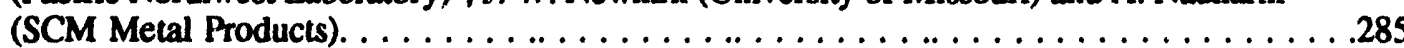

GlidCop ${ }^{\mathrm{TM}}$ internally oxidized copper alloys remain the leading candidates for high heat flux applications in fusion reactors. This paper presents the microstructural changes incurred in three GlidCop ${ }^{\mathrm{TM}}$ alloys exposed to long term, high temperature neutron irradiation.

Irradiation at high temperature produced a microstructure containing a much lower dislocation density than the unirradiated specimens. Although $1-50 \mathrm{~nm}$ size triangular oxide particles were observed in areas with a very low number density of particles, spherical oxide particles on the order of 5-7 nm in diameter, thought to be $\mathrm{CuAl}_{2} \mathrm{O}_{4}$, were the predominant morphology. The changes in grain size distribution, dislocation density, and precipitate type and distribution saturate in the range of 34 to $50 \mathrm{dpa}$, as reflected in the saturation of mechanical properties. 


\subsubsection{DISTRIBUTION OF TRANSMUTANT NICKEL FORMED IN FAST NEUTRON} IRRADIATED COPPER--T. Muroga (Kyushu University) and F. A. Garner (Pacific

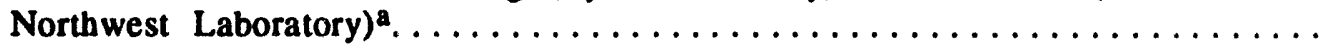

Nickel formed by transmutation of pure copper after irradiation to 95.4 dpa in FFTF was measured using the EDS technique. The nickel measurements agree rather well with the predicted level, although the foil-averaged value is higher than the bulk-averaged value due to the large amount of void intersections that occur in this specimen, which swelled $\sim 45 \%$. Nickel was shown to segregate strongly at void surfaces.

\subsection{ENVIRONMENTAL EFFECTS IN STRUCTURAL MATERIALS. . . . . . . . 299}

\subsubsection{CONSIDERATION OF TRITIUM AND HYDROGEN DISTRIBUTIONS IN LAYERED} STRUCTURES FOR ITER--E. P. Simonen, J. L. Brimhall and R. H. Jones (Pacific

Northwest Laboratory) $\ldots \ldots \ldots \ldots \ldots \ldots \ldots \ldots \ldots \ldots \ldots \ldots \ldots \ldots$

The distributions of tritium from the plasma and hydrogen from the coolant in candidate ITER structures depends on the selection of base alloys as well as layered materials that are applied to improve compatibility with the plasma or the coolant. Two hydrogen sources are considered in the present calculations using the DIFFUSE 83 code, namely, implantationdriven permeation of tritium from the plasma and gas-driven permeation of hydrogen from the coolant. A stainless steel layer in contact with the coolant can achieve significant tritium and hydrogen concentrations depending on choice of base material, temperature, ion implantation flux and coolant pressure of hydrogen. Hydrogen ingress through a stainless steel layer to V structures may be significant but ingress through layers to $\mathrm{Cu}$-based alloys is not expected to be significant.

\subsubsection{MEASUREMENT OF ELECTRICAL. RESISTIVITY OF THERMALLY GROWN} TITANIUM NITRIDE THIN FILMS IN LIQUID LITHIUM--J.-H. Park and T. Domenico

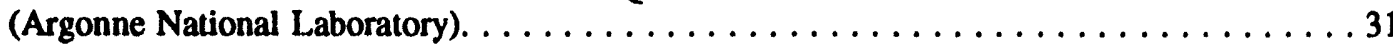

A sample of pure $\mathrm{Ti}$ and a pair of Ti electrodes were placed in small capsules containing liquid $\mathrm{Li}$ and $\mathrm{Li}_{3} \mathrm{~N}$ for seven days at $710^{\circ} \mathrm{C}$ to investigate the formation of titanium nitride (TiN). An attempt was made to enhance the resistivity of in-situ-formed TiN films by adding to the $\mathrm{Li}$ small amounts of $\mathrm{Al}, \mathrm{Si}$, and $\mathrm{Mg}$, which might be incorporated into the

films. One sample and set of electrodes was nitrided in $\mathrm{Li}$ containing $\mathrm{Li}_{3} \mathrm{~N}$ and another was immersed in pure $\mathrm{Li}$. The electrical resistance of the films was $\approx 1.0$ to $1.5 \Omega$ and the values increased slightly with temperature, which is indicative of metallic conduction. Energydispersive-spectroscopy (EDS) analyses of the films by scanning electron microscopy (SEM) showed that none of the dopants was incorporated into the TiN lattice.

6.5.3 DEVELOPMENT OF ELECTRICAL-INSULATOR COATINGS: IN-SITU ELECTRICAL RESISTANCE MEASUREMENTS ON V-5\%Cr-5\%Ti IN LIQUID LITHIUM--J.-H. Park

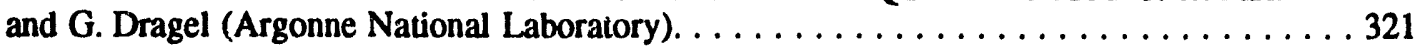

The electrical resistance of insulator coatings produced on V-5\%Cr-5\% Ti by exposure of the alloy to liquid $\mathrm{Li}$ that contained 5 at.\% $\mathrm{N}$, with and without 5 at.\% dissolved $\mathrm{Al}$, was measured as a function of time at temperatures between 250 and $500^{\circ} \mathrm{C}$. The solute elements ( $\mathrm{N}$ and $\mathrm{Al}$ ) reacted in liquid $\mathrm{Li}$ with the alloy substrate at $415^{\circ} \mathrm{C}$ to produce thin adherent coatings. The resistance of the coating layer was $\approx 1.5$ and $1.0 \Omega$ at 415 and $500^{\circ} \mathrm{C}$, respectively. Thermal cycling between 250 and $415^{\circ} \mathrm{C}$ did not change the resistance of the coating layers. These results and those reported previously suggest that homogeneous coatings can be produced on variously shaped surfaces by controlling the exposure time, 
temperature, and composition of the liquid metal. The integrity of the coatings does not appear to be sensitive to defects (e.g., open pores, fissures, or microcracks) present in the alloy substrate in liquid $\mathrm{Li}$.

\subsubsection{INVESTIGATION OF A MAGNETIC TRAP USED IN A LITHIUM/STAINLESS STEEL} TEST LOOP-- P. R. Luebbers and O. K. Chopra (Argonne National Laboratory) . . . . . . . . 326

The magnetic trap from a plugged cold-trap purification loop of a forced-circulation lithium system was examined to study mass transfer/deposition behavior in liquid lithium systems. Two types of particles, large faceted crystals and globules, were observed in the residue collected from the magnetic trap. These particles are similar to the $(\mathrm{Mn}, \mathrm{Fe}) \mathrm{Ni}$ and $(\mathrm{Mn}, \mathrm{FE})$ $\mathrm{Ni}_{3}$ compounds that had been identified earlier in the particulate collected from plugged sections of a cold-trap loop. The ternary nitride $\mathrm{Li}_{9} \mathrm{CrN}_{5}$ was also identified in the residue. Results indicate that a magnetic trap is effective for capturing magnetic particles within a liquid lithium loop.

6.5.5 COMPATIBILITY OF OXIDIZED TYPE 316 SS WITH STATIC GALLIUM--P R. Luebbers, W. F. Michaud, and O. K. Chopra (Argonne National Laboratory). . . . . . . . . . 333

Scoping tests were conducted on compatibility of gallium with Type 316 SS in three conditions: as-received, oxidized in water at $290^{\circ} \mathrm{C}$ for $100 \mathrm{~h}$, and oxidized in air at $350^{\circ} \mathrm{C}$ for $100 \mathrm{~h}$. Corrosion tests were conducted at $400^{\circ} \mathrm{C}$ for times up to $3000 \mathrm{~h}$. The results indicate that at $400^{\circ} \mathrm{C}$, an iron[II] chromite coating does not provide protection against

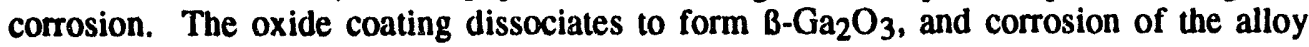
proceeds by dissolution accompanied by formation of $\mathrm{FeGa}_{3}$ and other gallium/intermetallic compounds. However, oxidized specimens have a lower corrosion rate than nonoxidized Type 316 SS. Corrosion rates are 4.0, 2.2, and $2.7 \mathrm{~mm} / \mathrm{y}$ for Type $316 \mathrm{SS}$ as-received, oxidized in water, and oxidized in air, respectively.

7.0 SOLID BREEDING MATERIALS AND BERYLLIUM $\ldots \ldots \ldots \ldots \ldots \ldots . \ldots \ldots 1$

\subsection{RADIATION EFFECTS IN BERYLLIUM USED FOR PLASMA PROTECTION--}

D. S. Gelles (Pacific Northwest Laboratory), M. Dalle Donne (Kernforschungszentrum Karlsruhe, Germany), G. A. Semyaev (SF NIKIET, Russia Federation) and H. Kawamura (Blanket Irradiation \& Analysis Laboratory, JAERI, Japan). . . . . . . . . . . . 343

This paper reviews the literature on beryllium, emphasizing the effects of irradiation on essential properties. Swelling and embrittlement experiments as a function of irradiation temperature and dose, and as a function of neutron spectrum are described, and the results are quantified, where possible. Effects of impurity content are also reported, from which optimum composition specifications can be defined. Microstructural information has also been obtained to elucidate the processes controlling the property changes.

The available information indicates that beryllium divertors can be expected to embrittle quickly and many need frequent replacement.

7.2 POSTIRRADIATION EXAMINATION OF BEATRIX-II, PHASE I--O. D. Slagle, F. D. Hobbs, D. L. Baldwin (Pacific Northwest Laboratory), T. Takahashi, K. Noda (Japan Atomic Energy Research Institute) R. A. Verrall (AECL Research). . . . . . . . . 358

BEATRIX-II is an in situ tritium recovery experiment that was designed to characterize the behavior of lithium ceramics irradiated to high burnup in a fast neutron flux. Postirradiation 
examination was carried out on the Phase I vented canisters: one containing a $\mathrm{Li}_{2} \mathrm{O}$ ring capable of temperature changes and the other a $\mathrm{Li}_{2} \mathrm{O}$ solid specimen with a center temperature of $1000^{\circ} \mathrm{C}$.

The tritium inventory of the ring specimen at $650^{\circ} \mathrm{C}$ was determined to be in the range from 0.2-0.6 wppm while for the solid specimen the inventory varied from $1.4 \mathrm{wppm}$ at the surface to 0.06 wppm at the inner surface. Downstream transport of the $\mathrm{Li}_{2} \mathrm{O}$ by the sweep gas was determined to be insignificant from analyses of acid rinses of selected canister surfaces. Densification and restructuring of the solid specimen during irradiation resulted in the development of a central annulus. Ceramography was used to characterize the columnar grain structure and the mechanisms involved in its evolution.

\subsection{TRITIUM RELEASE FROM LITHIUM TITANATE, A LOW ACTIVATION TRITIUM} BREEDING MATERIAL -- J. P. Kopasz and C. E. Johnson (Argonne National Laboratory) and J. M. Miller (AECL Research, Canada). . . . . . . . . . . . . . . . . . . . . . . . . 366

The goals for fusion power are to produce energy in as safe, economical, and environmentally benign a manner as possible. To ensure environmentally sound operation low activation materials should be used where feasible. The ARIES Tokamak Reactor Study has based reactor designs on the concept of using low activation materials throughout the fusion reactor. For the tritium breeding blanket, the choices for low activation tritium breeding materials are limited. Lithium titanate is an alternative low activation ceramic material for use in the tritium breeding blanket. To date, very little work has been done on characterizing the tritium release for lithium titanate. We have thus performed laboratory studies of tritium release from irradiated lithium titanate. The results indicate that tritium is easily removed from lithium titanate at temperatures as low as $600 \mathrm{~K}$. The method of titanate preparation was found to affect the tritium release, and the addition of $0.1 \% \mathrm{H}_{2}$ to the helium purge gas did not improve tritium recovery.

\subsection{TRITIUM RELEASE FROM BERYLLIUM DISCS AND LITHIUM CERAMICS} IRRADIATED IN THE SIBELIUS EXPERIMENT -- C. E. Johnson and J. P. Kopasz (Argonne National Laboratory) and D. L. Baldwin (Pacific Northwest Laboratory). . . . . . . . 373

The SIBELIUS experiment was designed to obtain information on the compatibility between beryllium and ceramics, as well as beryllium and steel, in a neutron environment. Four capsules were used to examine beryllium/ceramic $\left(\mathrm{Li}_{2} \mathrm{O}, \mathrm{LiAlO}_{2}, \mathrm{Li}_{4} \mathrm{SiO}_{4}\right.$, and $\left.\mathrm{Li}_{2} \mathrm{ZrO}_{3}\right)$ and beryllium/steel (Types 316 and 1.4914) compacts. Isothermal anneal experiments have been run on representative beryllium and ceramic disks from each of the four capsules at $550^{\circ} \mathrm{C}$ to $850^{\circ} \mathrm{C}$ in steps of $100^{\circ} \mathrm{C}$. The results indicate that tritium release from the beryllium did not exhibit burst release behavior, as previously reported, but rather a progressive release with increasing temperature. Generally $\sim 99$ percent of the tritium was released by $850^{\circ} \mathrm{C}$. Tritium release from the ceramic discs was quite similar to the behavior shown in other dynamic tritium release experiments on lithium ceramics. The tritium content in beryllium discs adjacent to a steel sample was found to be significantly lower than that found in a beryllium disc adjacent to a ceramic sample. Recoil of tritium from the ceramic into the beryllium appears to be the source of tritium entering the beryllium, probably residing in the beryllium oxide layer. 
xviii

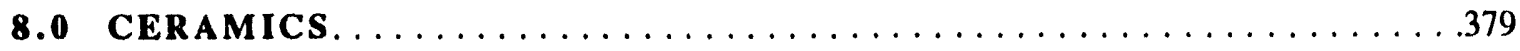

8.1 TOUGHENING OF CERAMIC COMPOSITES WITH SLOW CRACK GROWTH-C. R. Jones, C. H. Heneger, Jr., and R. H. Jones (Pacific Northwest Laboratory) . . . . . . . 381

Ceramic matrix composites show the uncommon and promising property of increasing their toughness and maintaining their load carrying capacity with increasing crack lengths under conditions of subcritical crack growth (SCG). As the crack grows, a more extensive bridging zone is formed allowing it to withstand far greater stress intensities than would be expected from fracture tests. It is also possible that crack bifurcation contributes to this effect, but is not likely to be the primary cause. It has not been determined whether or not an equilibrium crack-wake bridging zone will occur in these samples. Further testing may show that it occurs at greater crack lengths than those obtained in these tests or that it can't occur at all in these samples. Either way, the results of these tests are encouraging and expand the possible uses of these types of materials in applications that require long-term stability under stress.

8.2 POST-IRRADIATION ANAL'YSIS OF FIBER DEBONDING AND PULL-OUT IN SiC-SiC COMPOSITES--A.E-Azab and N. M. Ghoniem (University of California,

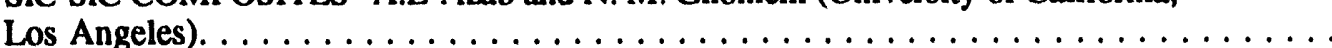

The toughness of SiC-SiC composites is contributed by crack bridging, matrix crack deflection, fiber debonding and pull-out and other minor effects. Fiber pull-out toughening relies on the debonding and frictional characteristics of the fiber-matrix interface. The interface friction depends on the interface pressure (i.e., on misfit strains) and interface roughness. An earlier study by the present authors [1] has shown that misfit strain in SiC$\mathrm{SiC}$ composites undergo complex changes under neutron irradiation due to irradiation-induced creep and swelling. The present work complements the study presented in Ref. [1] by developing a calculational model for post-irradiation fiber debonding and pull-out toughness in SiC-SiC composites. It is shown that fiber debonding and pull-out toughness in SiC$\mathrm{SiC}$ composites vary significantly with neutron fluence and irradiation temperature, which is a direct consequence of the dependence of the misfit strain on these irradiation variables.

8.3 RADIATION EFFECTS ON NICALON POLYMER PRECURSOR FIBERS --

L. L. Snead, M. C. Osborne and K. L. More (Oak Ridge National Laboratory). . . . . . . . . 396

This paper presents a summary of the radiation effects in the Nicalon polymer precursor fiber. It is shown that the serious degradation previously seen in this fiber (and fiber composite) is primarily due to the presence of a silicon oxycarbide phase. Results supporting this interpretation include microstructural analysis as well as post irradiation mechanical property measurements. Preliminary results on the effects of radiation on low oxygen Nicalon fibers are presented. The reduced oxygen fibers have shown radiation induced density, strength, Weibull's and Young's moduli changes typical for ceramic materials. This contrasts sharply with the poor irradiation behavior of the standard Nicalon fiber and suggests that improved radiation resistance can be expected in $\mathrm{SiC} / \mathrm{SiC}$ composites fabricated with low oxygen Nicalon.

8.4 FATIGUE CRACK GROWTH RATE (FCGR) BEHAVIOR OF SiC/SiC

COMPOSITES -- N. Miriyala, P. K. Liaw and C. J. McHargue (University of Tennessee,

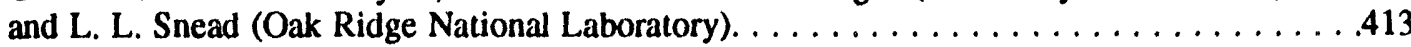

Two different techniques, viz. compliance and FRACTOMAT methods, have been evaluated to precisely determine the crack length during fatigue crack propagation testing. A software program has been developed to compute $\mathrm{da} / \mathrm{dN}$ and $\Delta \mathrm{K}$ values. Facilities are being augmented to conduct the tests at temperatures as high as $2000^{\circ} \mathrm{C}$. Machining of $\mathrm{SiC} / \mathrm{SiC}$ 
composites has been successfully accomplished using the facilities at the University of Tennessee. Work has been initiated on the theoretical modeling of the various crack shielding mechanisms that can profoundly influence the crack propagation rates.

\subsection{SUMMARY OF IEA WORKSHOP ON RADIATION EFFECTS IN CERAMIC}

INSULATORS--S. J. Zinkle (Oak Ridge National Laboratory, G. P. Pells (Harwell

National Laboratory, England) and F. W. Clinard, Jr, (Las Alamos National Laboratory). . . . . .417

A workshop on radiation effects in ceramics was held during the 6th International Conference on Fusion Reactor Materials in Stresa, Italy. Recent work on radiation effects in ceramics was reviewed by participants from Europe, Japan, and the United States. Most of the ensuing discussion centered on the phenomenon of radiation induced electrical degradation (RIED). A round robin RIED experiment on the IEA reference ceramic (Wesgo AL995) was formulated.

8.6 RADIATION-INDUCED ELECTRICAL DEGRADATION OF CERAMIC MATERIALS: AN ARTIFACT? -- W. Kesternich and F. Scheuermann (Institut für Festkörperforschung, Germany), and S. J. Zinkle (Oak Ridge National Laboratory). . . . . . . . . . . . . . 422

Recent electrical conductivity measurements made on aluminum oxide during irradiation with $28 \mathrm{MeV} \mathrm{He}+$ ions near $550^{\circ} \mathrm{C}$ indicate that radiation induced electrical degradation (RIED) does not occur for damage levels up to $\sim 0.2 \mathrm{dpa}$. Increases in electrical cunent that resemble the RIED effect have been observed in some cases, but were found to be due to an incrcase in the surface leakage current and are attributed to a buildup of surface contamination during irradiation.

8.7 SEARCH FOR RADIATION-INDUCED ELECTRICAL DEGRADATION IN AL.UMINA DURING SPALLATION-NEUTRON IRRADIATION -- E. H. Farnum, F. W. Clinard, Jr. W. F. Sommer, J. C. Kennedy III (Los Alamos National Laboratory) and Tatsuo Shikama (Tohoku University). . . . . . . . . . . . . . . . . . . . . . . . . . . . . . . . . . . . .427

No summary submitted.

8.8 TRANSIENT EFFECTS OF IONIZING AND DISPLACIVE RADIATION ON THE DIELECTRIC PROPERTIES OF CERAMICS -- R. H. Goulding, S. J. Zinkle, R. E. Stoller, and D. A. Rasmussen (Oak Ridge National Laboratory) . . . . . . . . . . . .434

A resonant cavity technique was used to measure the dielectric constant and loss tangent of ceramic insulators at a frequency near $100 \mathrm{MHz}$ during gamma ray and pulsed fission reactor irradiation near room temperature. Tests were performed on single crystal and several different grades of polycrystalline $\mathrm{Al}_{2} \mathrm{O}_{3}, \mathrm{MgAl}_{2} \mathrm{O}_{4}, \mathrm{~A} 1 \mathrm{~N}$ and $\mathrm{Si}_{3} \mathrm{~N}_{4}$. Lead shielding experiments were performed for some of the pulsed fission reactor irradiations in order to examine the importance of gamma ray versus neutron irradiation effects. With the exception of $\mathrm{A} 1 \mathrm{~N}$, the dielectric constant of all of the ceramics decreased slightly during the pulsed fission reactor irradiation. Significant transient increases in the loss tangent to values as high as $6 \times 10^{-3}$ occurred during pulsed reactor irradiation with peak ionizing and displacements per atom (dpa) radiation fields of $4.2 \times 10^{4} \mathrm{Gh} / \mathrm{s}$ and $2.4 \times 0-6 \mathrm{dpa} / \mathrm{s}$, respectively. The loss tangent measured during irradiation for the different ceramics did not show any correlation with the preirradiation or postirradiation values. Analysis of the results indicates that the transient increases in loss tangent are due to radiation induced increases in the electrical conductivity. The loss tangent increases were proportional to the ionizing dose rate. 
8.9 IN-CORE MEASUREMENT OF DC ELECTRICAL CONDUCTIVITY OF CERAMICS -L. L. Snead, D. P. White, S. J. Zinkle (Oak Ridge National Laboratory), J. Oconor, G. Hartsough and J. Errante (Brookhaven National Laboratory). . . . . . . . . . . . . 457

An in-situ DC conductivity capsule has been constructed and tested at the High Flux Beam Reactor (HFBR) at Brookhaven National Laboratory. The prototype capsule contained two alumina and one silicon nitride polycrystalline samples. In-situ measurement of the DC conductivity was made utilizing custom-made mineral insulated triaxial cables with a guard ring configuration for the samples and the sample holders. Sample and capsule temperatures were also measured in-situ. This prototype capsule was designed to operate at ITER relevant temperatures of $80^{\circ} \mathrm{C}$ (alumina) and $300^{\circ} \mathrm{C}$ (alumina and silicon nitride) with an applied electric field of $133 \mathrm{~V} / \mathrm{mm}$. It is significant that a large prompt increase in conductivity occurred but that no pe:manent radiation induced electrical degradation was observed in alumina after irradiation at $80^{\circ} \mathrm{C}$ to a neutron dose of $>0.1 \mathrm{dpa}$.

\subsection{THE EFFECT OF IONIZING AND DISPLACIVE RADIATION ON THE THERMAL} CONDUCTIVITY OF ALUMINA AT LOW TEMPERATURE--D. P. White (Oak Ridge National Laboratory). . . . . . . . . . . . . . . . . . . . . . . .

Microwave heating of plasmas in fusion reactors requires the development of windows through which the microwaves can pass without great losses. The degradation of the thermal conductivity of alumina in a radiation environment is an important consideration in reliability studies of these microwave windows. Several recent publications have calculated the radiation induced degradation at high temperature and at low temperature. The current paper extends the low temperature calculations in order to determine the effect of phonon scattering by radiation produced vacancies and by conduction band electrons due to RIC on the thermal conductivity at $77 \mathrm{~K}$. These low temperature calculations are of interest because the successful application of high power $(>1 \mathrm{MW})$ windows for electron cyclotron heating systems in fusion reactors will most likely require cryogenic cooling to take advantage of the low loss tangent and higher thermal conductivity of candidate window materials at these temperatures.

It is found that vacancy scattering can significantly reduce the thermal conductivity; for example, a vacancy concentration of 0.01 per atom leads to a fractional change in thermal conductivity of about $90 \%$. It is also concluded that the scattering of phonons by electrons in the conduction band due to RIC does not lead to a large reduction in the thermal conductivity.

\subsection{MICROSTRUCTURE OF ION IRRADIATED CERAMIC INSULATORS -- S. J. Zinkle}

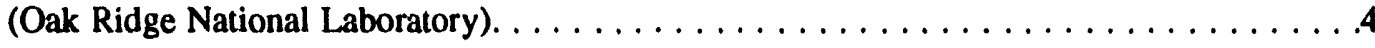

Cross-section transmission electron microscopy was utilized to examine the radiationinduced microstructural changes in $\mathrm{Al}_{2} \mathrm{O}_{3}, \mathrm{MgO}, \mathrm{Si}_{3} \mathrm{~N}_{4}$ and $\mathrm{MgAl}_{2} \mathrm{O}_{4}$ after irradiation with a wide variety of energetic ion beams. The relative influence of ionizing and displacive radiation was studied by systematically varying the mass and energy of the bombarding ions between $1 \mathrm{MeV} \mathrm{H}^{+}$and $4 \mathrm{MeV} \mathrm{Zr}^{+}$ions. The measured ion ranges were between 1 and $15 \%$ greater than the ranges calculated by the TRIM code, with the largest discrepancies occurring for intermediate mass ions. The implanted ions exerted a strong influence on the overall microstructural evolution of the irradiated ceramics. Numerous microstructural features (e.g., amorphization, colloids) were produced in the implanted ion regions which could not be produced in irradiated regions that were well separated from the implanted ions. The microstructural evolution in regions well separated from the implanted ions was found to depend strongly on the mass and energy of the bombarding ion. Light ion irradiation produced a significant enhancement in point defect diffusion (evidenced by defect-free zones at 
the surface and adjacent to internal defect sinks) compared to heavy ion irradiation at the same damage rate. Similarly, irradiation with a given ion at a higher flux generally produced an increased amount of observable diffusion. In some cases such as $1 \mathrm{MeV}$ proton irradiation, observable defect clusters did not form. This suppression in defect cluster formation is attributed to the high amount of point defect recombination associated with ionization enhanced diffusion that occurs during energetic light ion irradiation.

\subsection{ISSUES RELATED TO MECHANICAL PROPERTIES OF NEUTRON-IRRADIATED} CERAMICS -- F. W. Clinard, Jr. (Los Alamos National Laboratory), W. Dienst (KfK Karlsruhe), and E. H. Farnum (Los Alamos National Laboratory).

Ceramics will be used for a number of applications in fusion devices, where their dielectric properties, high strength, refractoriness, or low activation characteristics are required. In all cases starting mechanical properties must be adequate to preserve structural integrity, and the material must tolerate irradiation damage without undue degradation. A review of the irradiation response of four prototypical candidate ceramics shows that significant deterioration of mechanical properties can be expected for most applications in ITER. Future studies are identified that will establish the basis for specifying developing ceramics that can meet the needs of ITER and subsequent fusion reactor concepts.

\subsection{DIMENSIONAL STABILITY, OPTICAL AND ELASTIC PROPERTIES OF $\mathrm{MgAl}_{2} \mathrm{O}_{4}$} SPINEL IRRADIATED IN FFTF TO VERY HIGH EXPOSURES--F. A. Garner,

\section{G. W. Hollenberg and J. L. Ryan (Pacific Northwest Laboratory), Z. Li (Argonne National} Laboratory), C. A. Black and R. C. Bradt (University of Nevada-Reno). . . . . . . . . . . . 502

Stoichiometric $\mathrm{MgAl}_{2} \mathrm{O}_{4}$ spinel specimens irradiated in FFTF-MOTA at temperatures between 385 and $750^{\circ} \mathrm{C}$ to fluences ranging from 2.2 to $24.9 \times 10^{22} \mathrm{n} \mathrm{cm}^{-2}$ (E>0.1 MeV) darken significantly, but do not develop any significant loss in weight or change in dimensions. Similar behavior was observed in both single crystal and fully dense polycrystalline specimens. Measurements of elastic constants by an ultrasonic technique show that no measurable changes occur as a result of the irradiation. These and other results confirm the stability of this material for fusion application as an electrical insulator.

8.14 INFLUENCE OF HIGH DOSE NEUTRON IRRADIATION AT 385 AND $750^{\circ} \mathrm{C}$ ON THE MICROHARDNESS OF $\mathrm{MgAl}_{2} \mathrm{O}_{4}$ SPINEL--C. A. Black (University of Nevada-Reno), F. A. Garner (Pacific Northwest Laboratory, R. C. Bradt (University of Nevada-Reno). . . . . .508

High-purity specimens of stoichiometric $\mathrm{MgAl}_{2} \mathrm{O}_{4}$ single crystal spinel and a hot-pressed polycrystalline ceramic spinel were irradiated to exposures as large as $24.9 \times 10^{22} \mathrm{~cm}^{-2}$ $\left(\mathrm{E}>0.1 \mathrm{MeV}\right.$ ) in FFTF at $385^{\circ} \mathrm{C}$ and $750^{\circ} \mathrm{C}$. The specimens did not develop any brittleness or fragility, and maintained their physical integrity. Microhardness measurements revealed that initially all specimens hardened a small amount and then recovered slightly. At the lower irradiation temperature, the dependence of microhardness on orientation observed prior to irradiation tended to disappear. There was also some evidence that a secondary slip system was being activated. Following $750^{\circ} \mathrm{C}$ irradiation, the orientation dependence was not lost, and the evidence for activation of a secondary slip system was stronger. 
1.0 IRRADIATION FACILITIES, TEST MATRICES, AND EXPERIMENTAL METHODS 
STATUS OF U.S./JAPAN COLLABORATIVE PROGRAM PHASE II HFIR TARGET AND RB* CAPSULES - J. E. Pawel, A. W. Longest, R. L. Senn (Oak Ridge National Laboratory), K. Shiba (Japan Atomic Energy Research Institute), D. W. Heatherly, and R. G. Sitterson (Oak Ridge National Laboratory)

\section{OBJECTIVE}

The objective of the HFIR irradiations is to determine the response of the various U.S. and Japanese austenitic and ferritic steels with different pretreatments and alloy compositions to the combined effects of displacement damage and helium generation. Specimen temperatures during irradiation range from 60 to $600^{\circ} \mathrm{C}$ and fluences range up to $70 \mathrm{dpa}$. The $\mathrm{RB}^{*}$ experiments are a continuation of the ORR spectrally tailored experiments in which the spectrum is modified with a hafnium shield to simulate the expected fusion helium to damage (He/dpa) ratio. In the HFIR target capsules, many specimens have been isotopically tailored in order to achieve fusion helium generation rates.

\section{SUMMARY}

Capsules HFIR-MFE-JP9 through 16 were installed in the High Flux Isotope Reactor (HFIR) target July 20, 1990 for irradiation beginning with HFIR fuel cycle 289. Of these eight target capsules, JP10, $11,13,16$ completed their scheduled number of cycles (11) and were removed from the reactor in September 1991. In addition, JP14 was removed from the reactor at the end of cycle 310 (September 18, 1992) after 21 cycles. Capsules JP9, 12, and 15 have completed 32 of 37 cycles.

Target capsules JP17, 18 and 19 contained fracture toughness specimens and were irradiated to approximately $3 \mathrm{dpa}$. All three capsules have been disassembled and testing is in progress.

Three new target capsules, JP20, 21, and 22, have been assembled and are scheduled to begin irradiation at the start of Cycle 322 . These capsules will operate at $300-600^{\circ} \mathrm{C}$ and will achieve doses of 8,18 and $35 \mathrm{dpa}$, respectively. Many isotopically tailored specimens are included in the matrix.

The RB* experiments are the continuation of the ORR spectrally tailored experiment. In this stage, a hafnium liner is used to modify the spectrum to simulate fusion helium to displacements per atom (He/dpa) ratio in the austenitic steel specimens. Of the four capsules in this set, two $(60 \mathrm{~J}-1$ and $330 \mathrm{~J}-1$ ) are ready to be disassembled, having achieved a total fluence of $18 \mathrm{dpa}$, and two (200J-1 and $400 \mathrm{~J}-1)$ are in the reactor.

\section{PROGRESS AND STATUS}

\section{Target Capsules JP9 through JP16}

Capsules HFIR-MFE-JP9 through 16 were installed in the High Flux Isotope Reactor (HFIR) target July 20, 1990 for irradiation beginning with HFIR fuel cycle 289. A complete description and details of the design, construction, and installation of capsules JP9 through JP16 have been previously reported [1,2,3]. The as-built specimen matrix can be found in a previous report [3]. These capsules contain primarily transmission electron microscopy disks (TEM) and SS-3 flat tensile specimens. A wide variety of alloys and thermomechanical conditions are included. Many of the TEM disks were made from isotopically tailored alloys to produce a range of $\mathrm{He} / \mathrm{dpa}$ ratios $(<0.1,10$, 20,70 appm/dpa). Details of the irradiation history of these capsules are shown in Table 1. Capsules JP10, 11, 13, and 16 were removed at the end of Cycle 300 (September 1991) after achieving a total of 18 dpa. Capsule JP14 was removed at the end of Cycle 310 (September 1992), after accumulating 
Table 1. Irradiation history of U. S. Japan Program Capsules.

\begin{tabular}{|c|c|c|c|c|c|c|c|}
\hline \multicolumn{4}{|c|}{ HFIR OPERATION } & \multicolumn{2}{|c|}{ JP-9,-12,-15 2 } & \multicolumn{2}{|c|}{$200 \mathrm{~J}-1,400 \mathrm{~J}-1$} \\
\hline \multirow{2}{*}{$\begin{array}{c}\text { CYCLE } \\
\text { NO. }\end{array}$} & \multirow{2}{*}{$\begin{array}{l}\text { START } \\
\text { DATE }\end{array}$} & \multirow{2}{*}{$\begin{array}{l}\text { END } \\
\text { DATE }\end{array}$} & \multirow{2}{*}{$\begin{array}{l}\text { MWdI } \\
\text { Cycle }\end{array}$} & \multicolumn{2}{|c|}{ IRR.TO 70 DPA } & \multicolumn{2}{|c|}{ INCREMENTAL } \\
\hline & & & & MWd & dpa $[1]$ & MWd & dpa $[1]$ \\
\hline 289 & $07 \cdot 20-90$ & $09-07-90$ & 1879 & 1879 & 1.64 & & \\
\hline 290 & $09 \cdot 19-90$ & $10-11-90$ & 1852 & 3731 & 3.26 & & \\
\hline 291 & $10-17-90$ & $11-13-90$ & 1838 & 5569 & 4.86 & & \\
\hline 292 & 11.25 .90 & $12 \cdot 10-90$ & 1847 & 7416 & 6.47 & & \\
\hline 293 & $12 \cdot 27-90$ & $01-23-91$ & 1965 & \multicolumn{2}{|c|}{ OUT OF REACTOR } & & \\
\hline 294 & $02-01-91$ & $02 \cdot 25-91$ & 1906 & \multirow{2}{*}{9322} & \multirow{2}{*}{$\begin{array}{l}8.14 \\
9.80\end{array}$} & & \\
\hline 295 & $03.01-91$ & $03-24-91$ & 1908 & & & & \\
\hline 296 & $04-06-91$ & $04-28-91$ & 1874 & 13104 & 11.44 & & \\
\hline 297 & $05-19-91$ & $06-15-91$ & 1845 & 14949 & 13.05 & & \\
\hline 298 & $06-20-91$ & $07-11-91$ & 1747 & 16696 & 14.58 & & \\
\hline 299 & $07-25-91$ & $08-15-91$ & 1741 & 18437 & 16.10 & & \\
\hline 300 & $08-28-91$ & $09-17-91$ & 1724 & 20161 & 17.60 & & \\
\hline 301 & $09-27-91$ & $10-19.91$ & 1851 & 22012 & 19.22 & & \\
\hline 302 & $10-27-91$ & 11.21 .91 & 1829 & 23841 & 20.81 & & \\
\hline 303 & $12-01-91$ & $12 \cdot 22-91$ & 1821 & 25662 & 22.40 & & \\
\hline 304 & $12-31-91$ & $01 \cdot 24-92$ & 1826 & 27488 & 24.00 & & \\
\hline 305 & $01-30-92$ & $02-27-92$ & 1876 & 29364 & 25.63 & & \\
\hline 306 & $03-31.92$ & $04-27-92$ & 1845 & 31209 & 27.25 & & \\
\hline 307 & $05-01-92$ & $05-28-92$ & 1842 & 33051 & 28.85 & & \\
\hline 308 & $06-02-92$ & $06-30-92$ & 1938 & 34989 & 30.55 & & \\
\hline 309 & $07-03-92$ & $08-01-92$ & 1949 & 36938 & 32.25 & & \\
\hline 310 & $08-27-92$ & $09-18-92$ & 1848 & 38786 & 33.86 & & \\
\hline 311 & $09-25-92$ & $10-12.92$ & 1856 & 40642 & 35.48 & & \\
\hline 312 & $10-22-92$ & $11-14.92$ & 1834 & 42476 & 37.08 & BEOIN & CLE 313 \\
\hline 313 & $11-21-92$ & $12 \cdot 15-92$ & 1858 & 44334 & 38.10 & 1858 & 0.46 \\
\hline 314 & $12-20-92$ & $01.12-93$ & 1867 & 46201 & 40.33 & 3725 & 0.91 \\
\hline 315 & $01-19-93$ & 02.11 .93 & 1861 & 48062 & 41.96 & 5586 & 1.37 \\
\hline 316 & $02-17.93$ & $04-03-93$ & 1807 & 49869 & 43.54 & 7393 & 1.81 \\
\hline 317 & $04-23-93$ & $05-14-93$ & 1841 & 51710 & 45.14 & 9234 & 2.26 \\
\hline 318 & $05-20-93$ & $06-13-93$ & 1878 & 53588 & 46.78 & 11112 & 2.72 \\
\hline 319 & $06-18-93$ & 07.10 .93 & 1863 & 55451 & 48.41 & 12975 & 3.18 \\
\hline 320 & $07.15-93$ & 08.07 .93 & 1934 & 57385 & 50.10 & 14909 & 3.65 \\
\hline 321 & 08.12 .93 & $09.04-93$ & 1884 & 59269 & 51.74 & 16793 & 4.11 \\
\hline 322 & & & & & & & \\
\hline 323 & & & & & & & \\
\hline 324 & & & & & & & \\
\hline 325 & & & & & & & \\
\hline 326 & & & & & & & \\
\hline 327 & & & & & & & \\
\hline 328 & & & & & & & \\
\hline
\end{tabular}

11 DPA levels based on achieving $0.000873 \mathrm{dpa} / \mathrm{MWd}$ in the JP capsules and $.000245 \mathrm{dpa} / \mathrm{MWd}$ in the MFE-RB $200 \mathrm{~J}-1$ and $400 \mathrm{~J}-1$ capsules.

[2] JP-10,-11,-13,-16 removed at EOC 300 . JP-14 removed at EOC 310. 
$34 \mathrm{dpa}$, and was disassembled during this reporting period. Capsules JP9, 12, and 15 have completed 32 of the scheduled 37 cycles, and have accumulated 52 dpa.

Many of the specimens from the JP10,11,13, and 16 capsules have been tested in the Irradiated Materials Examination and Testing Facility hot cells. The initial set of tensile tests of JPCA and 316F stainless steels in solution annealed, cold worked, and welded conditions have been completed. Analyses include reduction-of-area measurements and fracture stress calculations. Details of the testing of JPCA are presented elsewhere [4]. Density measurements have been taken on specimens removed from the JP10 Position 6, JP11 Position 6, JP13 Position 6, and JP16 Position 6 TEM tubes using the ORNL precision densitometer. These four tubes contain isotopically tailored alloys from both the ORNL and JAERI programs as well as other candidate fusion alloys. The JP10 Position 4 TEM tube also has been opened and the specimens have been sorted and cleaned.

\section{Target Capsules JP17, 18, and 19}

Capsules HFIR-MFE-JP17, 18 and 19 contained fracture toughness specimens and were irradiated to approximately $3 \mathrm{dpa}$. The crack region temperatures of the specimens in JP17 were $250-300^{\circ} \mathrm{C}$ and those of the specimens in JP18 and 19 were $60-125^{\circ} \mathrm{C}$. Experimental details and loading lists can be found in references 5, 6, and 7. All three capsules have been disassembled and testing is in progress. Preliminary test results are reported elsewhere $[8,9]$.

\section{Target Capsules JP20 through 22}

Three new capsules, HFIR-MFE-JP20, 21, and 22, have been designed to complete the original experiment matrix of the JP9 through JP16 series capsules [10]. Component fabrication and capsule assembly were completed during this reporting period for all three capsules. It is planned to irradiate the capsules in inner target positions for 5, 11, and 22 cycles, respectively, to achieve peak doses of approximately 8, 18, and 35 dpa. Specimen temperatures in each capsule will be $300,400,500$, or $600^{\circ} \mathrm{C}$. Irradiation is scheduled to begin with the start of reactor Cycle 322.

Many isotopically tailored specimens are included in the test matrix. The specimen loading lists for these capsules are given in Tables 2 and 3 . The specimen identification codes are shown in Tables 4 and 5. Alloy compositions are given in Tables 6-10.

RB* Capsules HFIR-MFE-60J-1, 200J-1, 330J-1 and 400J-1

The RB* capsules are irradiated in the removable beryllium positions of the HFIR. These experiments are a continuation of the ORR spectrally tailored experiment. At this stage in the experiment, a hafnium liner surrounds the capsules in order to harden the spectrum and achieve the expected fusion helium generation rate in the austenitic steel specimens. Capsule design, assembly and details of specimen loading have been previously described in references 11, 12,13, and 14. Capsules 60J-1 and 330J-1 were removed from the reactor in November 1992 after accumulating approximately $11 \mathrm{dpa}$ in the HFIR. Most of the specimens had also been irradiated to approximately $7 \mathrm{dpa}$ in the ORR. These capsules are scheduled for disassembly in November 1993. Capsules $200 \mathrm{~J}-1$ and $400 \mathrm{~J}-1$ have completed nine of the scheduled 20 irradiation cycles, as shown in Table 1. The capsules are performing as designed, with the temperatures holding within the expected ranges. Details of the capsule performance are described elsewhere in this report [15]. 
Table 2. Capsule loading lists.

HFIR-MFE-JP20 (10 dpa)

\begin{tabular}{|c|c|c|}
\hline Position & Specimen Holder & Specimen I. D. \\
\hline 1 & $S S-3, T(2), 400^{\circ} \mathrm{C}$ & $A 101, A 201$ \\
\hline 2 & SS-3, $T(2), 600^{\circ} \mathrm{C}$ & $\mathrm{C} 102, \mathrm{Cl01}$ \\
\hline 3 & $\mathrm{SS}-3, \mathrm{~T}(2), 500^{\circ} \mathrm{C}$ & E101, F108 \\
\hline 4 & SS-3, T(4), 300 & $\begin{array}{l}\text { BLA7, BLA7, } \\
\text { BLA7W, BLA7W }\end{array}$ \\
\hline 5 & TEM, $300^{\circ} \mathrm{C}$ & see TEM lists \\
\hline 6 & TEM, $300^{\circ} \mathrm{C}$ & see TEM lists \\
\hline 7 & TEM, $500^{\circ} \mathrm{C}$ & see TEM lists \\
\hline 8 & TEM, $600^{\circ} \mathrm{C}$ & see TEM lists \\
\hline 9 & $\mathrm{TEM}, 400^{\circ} \mathrm{C}$ & see TEM lists \\
\hline 10 & $S S-3, T(4), 300^{\circ} \mathrm{C}$ & $\begin{array}{l}\text { A301, C103, } \\
\text { C104, A302 }\end{array}$ \\
\hline 11 & $S \mathrm{~S}-3, \mathrm{~T}(4), 300^{\circ} \mathrm{C}$ & $\begin{array}{l}\text { A103, A203, } \\
\text { A102, A202 }\end{array}$ \\
\hline 12 & SS-3, T(2), $500^{\circ} \mathrm{C}$ & $\mathrm{C} 105, \mathrm{~K} 405$ \\
\hline 13 & SS-3, T(2), $600^{\circ} \mathrm{C}$ & $K 203, \mathrm{~K} 401$ \\
\hline 14 & $\mathrm{SS}-3, \mathrm{~T}(2), 400^{\circ} \mathrm{C}$ & A303, A304 \\
\hline
\end{tabular}

HFIR-MFE-JP21 (20 dpa)

\begin{tabular}{|c|c|c|}
\hline Position & Specimen Holder & Specimen I. D. \\
\hline 1 & SS-3, T(2), $400^{\circ} \mathrm{C}$ & F104, E103 \\
\hline 2 & SS-3, T(2), $600^{\circ} \mathrm{C}$ & $\mathrm{K} 408, \mathrm{~K} 206$ \\
\hline 3 & $\mathrm{SS}-3, \mathrm{~T}(2), 500^{\circ} \mathrm{C}$ & E105, F107 \\
\hline 4 & SS-3, T(4), $300^{\circ} \mathrm{C}$ & $\begin{array}{l}\text { T133, SB41, } \\
\text { TL11, SD42 }\end{array}$ \\
\hline 5 & TEM, $300^{\circ} \mathrm{C}$ & see TEM lists \\
\hline 6 & TEM, $300^{\circ} \mathrm{C}$ & see TEM lists \\
\hline 7 & TEM, $500^{\circ} \mathrm{C}$ & see TEM lists \\
\hline 8 & TEM, $600^{\circ} \mathrm{C}$ & see TEM lists \\
\hline 9 & TEM, $400^{\circ} \mathrm{C}$ & see TEM lists \\
\hline 10 & SS-3, $T(4), 300^{\circ} \mathrm{C}$ & $\begin{array}{l}\text { A105, A204, } \\
\text { A205, A104 }\end{array}$ \\
\hline 11 & $S S-3, T(4), 300^{\circ} \mathrm{C}$ & $\begin{array}{l}\text { A306, A305, } \\
\text { C106, C107 }\end{array}$ \\
\hline 12 & $S S-3, \mathrm{~T}(2), 500^{\circ} \mathrm{C}$ & $\mathrm{K} 410, \mathrm{ClOS}$ \\
\hline 13 & $\mathrm{SS}-3, \mathrm{~T}(2), 600^{\circ} \mathrm{C}$ & $\mathrm{K} 409, \mathrm{~K} 302$ \\
\hline 14 & $S S-3, T(2), 400^{\circ} \mathrm{C}$ & $\mathrm{C110}, \mathrm{C109}$ \\
\hline
\end{tabular}

HFIR-MFE-JP22 (40 dpa)

\begin{tabular}{|c|c|c|}
\hline Position & Specimen Holder & Specimen I. D. \\
\hline 1 & ss-3, T(2), $400^{\circ} \mathrm{C}$ & E102, F103 \\
\hline 2 & ss-3, $\mathrm{T}(2), 600^{\circ} \mathrm{C}$ & K406, K304 \\
\hline 3 & SS-3, T(2), $500^{\circ} \mathrm{C}$ & F102, E106 \\
\hline 4 & $5 s-3, \mathrm{~T}(4), 300^{\circ} \mathrm{C}$ & $\begin{array}{l}\text { TI34, SB42 } \\
\text { TL12, SD41 }\end{array}$ \\
\hline 5 & TEM, $300^{\circ} \mathrm{C}$ & see TEM lists \\
\hline 6 & TEM, $300^{\circ} \mathrm{C}$ & see TEM lists \\
\hline 7 & $\mathrm{TEM}, 500^{\circ} \mathrm{C}$ & see TEM lists \\
\hline 8 & $T E M, 600^{\circ} \mathrm{C}$ & see TEM lists \\
\hline 9 & TEM, $400^{\circ} \mathrm{C}$ & see TEM lists \\
\hline 10 & SS-3, T(4), $500^{\circ} \mathrm{C}$ & $\begin{array}{l}\text { C112, C111, } \\
\text { D101, D102 }\end{array}$ \\
\hline 11 & $\mathrm{SS}-3, \mathrm{~T}(4), 300^{\circ} \mathrm{C}$ & $\begin{array}{l}\text { E107, F105, } \\
\text { C113, D104 }\end{array}$ \\
\hline 12 & $S S-3, T(2), 500^{\circ} \mathrm{C}$ & $\mathrm{K} 407, \mathrm{~K} 204$ \\
\hline 13 & $S S-3, T(2), 600^{\circ} \mathrm{C}$ & $\mathrm{K} 403, \mathrm{~K} 205$ \\
\hline 14 & $S S-3, T(2), 400^{\circ} \mathrm{C}$ & D103, C114 \\
\hline
\end{tabular}


Table 3. TEM tube holders loading lists.

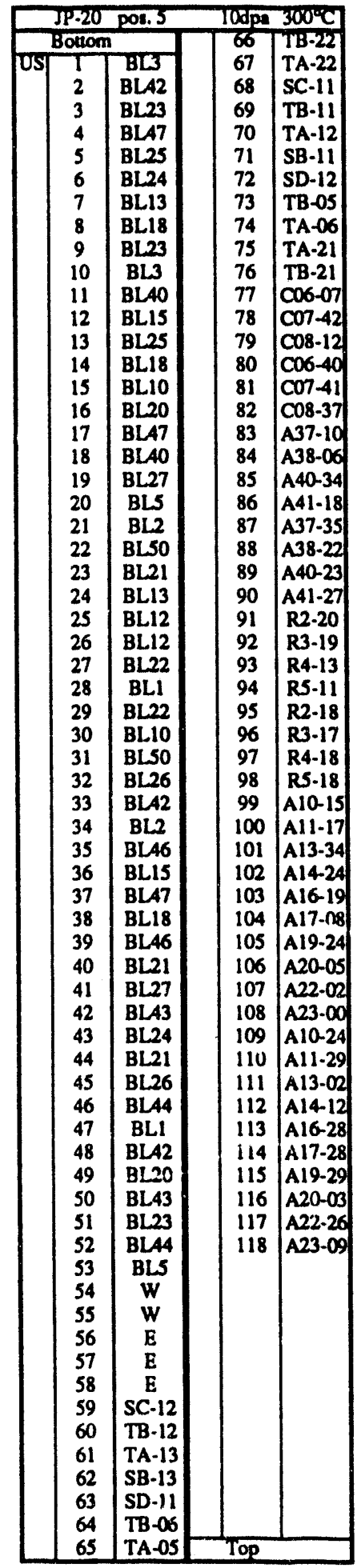

\begin{tabular}{|c|c|c|c|c|c|}
\hline & $J P=20$ & pos. 6 & & 10dpe & $300^{\circ} \mathrm{C}$ \\
\hline & Botlar & & & 66 & $\mathrm{CO}_{4-34}$ \\
\hline $\mathrm{J}$ & $T$ & Hा. 02 & & 67 & C25.27 \\
\hline & 2 & $\mathrm{H} 2-03$ & & 68 & C26-24 \\
\hline & & H3-03 & & & C27.38 \\
\hline & 4 & H4-03 & & 70 & $\mathrm{CO}-0 \mathrm{O}$ \\
\hline & 8 & $\begin{array}{l}\mathrm{K} 1-02 \\
\mathrm{~K} 2-01\end{array}$ & & 71 & $\begin{array}{ll}C 02-31 \\
C\end{array}$ \\
\hline & 7 & $\mathrm{~K} 3-02$ & & 73 & CO4-09 \\
\hline & 8 & K4-01 & & 74 & C25-38 \\
\hline & 9 & $\mathrm{HI}-03$ & & 75 & $\mid C_{26-25}$ \\
\hline & 10 & $\mathrm{H} 2-02$ & & 76 & C.27.22 \\
\hline & 11 & H3-01 & & 77 & C43-24 \\
\hline & 12 & $\begin{array}{l}\mathrm{H} 4-01 \\
\mathrm{~K} 1 \mathrm{O}\end{array}$ & & $\begin{array}{l}78 \\
70\end{array}$ & $\begin{array}{l}C 44-00 \\
445-0\end{array}$ \\
\hline & 14 & K2-03 & & 80 & A46-24 \\
\hline & 15 & $\mathrm{~K} 3-01$ & & 81 & A43-02 \\
\hline & 16 & K4-02 & & 82 & A44-17 \\
\hline & 17 & $\mathrm{H} 1-01$ & & 83 & A45-23 \\
\hline & 18 & H2-01 & & 84 & A46-09 \\
\hline & 19 & H3.-02 & & 85 & A43-09 \\
\hline & 20 & H4-02 & & 86 & A44-13 \\
\hline & 21 & KI-01 & & 87 & A45-07] \\
\hline & 22 & K2-02 & & 88 & A46-00 \\
\hline & 23 & K3-03 & J & 89 & BT-01 \\
\hline & 24 & K4-03 & & 90 & B2-02 \\
\hline & $\begin{array}{l}25 \\
26\end{array}$ & $\begin{array}{l}A 01-02 \\
A 02-34\end{array}$ & & $\begin{array}{l}91 \\
92\end{array}$ & $\begin{array}{l}83-01 \\
\text { FI-03 }\end{array}$ \\
\hline & 27 & A03-01 & & 93 & Ci-02 \\
\hline & 28 & A04-46 & & 94 & $C 2-02$ \\
\hline & 29 & A25.16 & & 95 & C3-O2 \\
\hline & $\begin{array}{l}30 \\
31\end{array}$ & $\begin{array}{l}\text { A26-01 } \\
\text { A27-01 }\end{array}$ & & $\begin{array}{l}96 \\
97\end{array}$ & $\begin{array}{l}C_{4-02} \\
C_{5-02}\end{array}$ \\
\hline & 32 & A29-25 & & 98 & C6-01 \\
\hline & 33 & A30-37 & & 99 & $\mathrm{~J} 1.03$ \\
\hline & 34 & $A 31-25$ & & 100 & $\mathrm{~J} 2.02$ \\
\hline & 35 & A32-20 & & 101 & J3-03 \\
\hline & 36 & $\mathbb{R}$ & & 102 & B1-02 \\
\hline & 37 & $7 U$ & & 103 & B2-01 \\
\hline & 38 & A43-08 & & 104 & B3-02 \\
\hline & 39 & A44-05 & & 105 & $\mathrm{Fl}-02$ \\
\hline & 40 & A45-03 & & 106 & $\mathrm{Cl}-01$ \\
\hline & 41 & A46-05 & & 107 & C2-01 \\
\hline & 42 & $7 \mathrm{~V}$ & & 108 & C3-01 \\
\hline & 43 & $7 X$ & & 109 & C4-01 \\
\hline & 44 & A01-22 & & 110 & C5-01 \\
\hline & 45 & A02-38 & & 111 & C6-02 \\
\hline & 46 & A03.03 & & 112 & J1-01 \\
\hline & 47 & $A 04-40$ & & 113 & $\mathrm{~J} 2.03$ \\
\hline & 48 & A25-28 & & 114 & $\mathrm{~J} 3-02$ \\
\hline & 49 & $A 26-22$ & & 115 & F1-01 \\
\hline & 50 & A27-28 & & 116 & $\mathrm{~J} 1-02$ \\
\hline & 51 & A29-14 & & 117 & J2-01 \\
\hline & 52 & A30-31 & & 118 & J3-01 \\
\hline & 53 & $A 31-20$ & & 119 & F1-05 \\
\hline & 54 & A32-38 & & 120 & F1-04 \\
\hline & 55 & 5K7P & US & 121 & A06-19 \\
\hline & 56 & 5HTT & & 122 & A07-29 \\
\hline & 57 & C43.1] & & 123 & A08-02 \\
\hline & 58 & A44-04 & & 124 & A06-12 \\
\hline & 59 & A45-02 & & 125 & A07-06 \\
\hline & 60 & C46-11 & & 126 & A08-29 \\
\hline & 61 & $7 \mathrm{~V}$ & & 127 & $\mid c 06-14$ \\
\hline & 62 & $7 x$ & & 128 & C07.37 \\
\hline & 63 & $C 01.30$ & & 129 & C08-43 \\
\hline & 64 & CO2-14 & & & \\
\hline & 65 & Cos.39 & & Top & \\
\hline
\end{tabular}

\begin{tabular}{|c|c|c|c|c|}
\hline & $J P=20$ & pos. 7 & lodpa & $300^{\circ} \mathrm{C}$ \\
\hline & Botion & & 66 & 70 \\
\hline J & 1 & FIन-3 & 67 & A43-06 \\
\hline & $\begin{array}{l}2 \\
3\end{array}$ & $\begin{array}{l}\text { C1-09 } \\
\text { C2-10 }\end{array}$ & $\begin{array}{l}68 \\
69\end{array}$ & $\begin{array}{l}\text { A44-00 } \\
\text { A45-06 }\end{array}$ \\
\hline & 4 & C3-09 & 70 & $\begin{array}{l}A 43-00 \\
A 46-03\end{array}$ \\
\hline & 5 & C4-10 & 71 & $5 \mathrm{KTV}$ \\
\hline & 6 & C. $5-09$ & 72 & 5H7X \\
\hline & 7 & $\begin{array}{r}06-09 \\
H 1-16\end{array}$ & $\begin{array}{l}73 \\
74\end{array}$ & $\mid \begin{array}{c}A 01-13 \\
-10323\end{array}$ \\
\hline & 9 & H2-17 & 75 & $\mathrm{AOS}-19$ \\
\hline & 10 & H3-16 & 76 & AO4-41 \\
\hline & 11 & H4-16 & 77 & A06-06 \\
\hline & 12 & $\mathrm{J1} 1-13$ & 78 & A07.16 \\
\hline & 13 & J2-13 & 79 & A08-18 \\
\hline & 14 & J3-15 & 80 & A10-10 \\
\hline & 15 & K1-10 & 81 & A11-30 \\
\hline & 16 & K2-11 & 82 & $A 13-00$ \\
\hline & 17 & K3-18 & 83 & A14-14 \\
\hline & 18 & K4-18 & 84 & A16-29 \\
\hline & 19 & F1-32 & 85 & A17-12 \\
\hline & 20 & C1-10 & 86 & A19-13 \\
\hline & 21 & $\begin{array}{l}C 2-09 \\
C 3.10\end{array}$ & 87 & A20-33 \\
\hline & $\begin{array}{l}22 \\
23\end{array}$ & C4-09 & $\begin{array}{l}88 \\
89\end{array}$ & $\begin{array}{l}A 22-32 \\
A 23-16\end{array}$ \\
\hline & 24 & C5-10 & 90 & A25-33 \\
\hline & 25 & C6.10 & 91 & $A 26-05$ \\
\hline & 26 & $\mathrm{HI}-17$ & 92 & $|A 27.31|$ \\
\hline & 27 , & H2-16 & 93 & A29-31 \\
\hline & 28 & H3-17 & 94 & $A 30-02$ \\
\hline & 29 & H4-17 & 95 & A31-21 \\
\hline & 30 & $\mathrm{J1}-14$ & 96 & A32-02 \\
\hline & $\begin{array}{l}31 \\
32\end{array}$ & $\begin{array}{l}J 2-14 \\
33-14\end{array}$ & $\begin{array}{l}97 \\
98\end{array}$ & $\mid \begin{array}{l}\mathrm{A}, 1-10 \\
\mathrm{A3S}-35\end{array}$ \\
\hline & 33 & $\mathrm{~K} 1-11$ & 99 & A40-18 \\
\hline & 34 & $K_{2}-10$ & 100 & A41-21 \\
\hline & 35 & K3-20 & 101 & in \\
\hline & 36 & K4-19 & 102 & $\pi$ \\
\hline US & & AOI-24 & 103 & A43-05 \\
\hline & 38 & A02-09 & 104 & A44-02 \\
\hline & 39 & $\mathrm{~A} 03-33$ & 105 & A45-05 \\
\hline & $\begin{array}{l}40 \\
41\end{array}$ & $\begin{array}{l}A 04-07 \\
A 06-07\end{array}$ & $\begin{array}{l}100 \\
107\end{array}$ & $\begin{array}{c}A 40-04 \\
7 V\end{array}$ \\
\hline & 42 & A07-02 & 108 & $T \mathbf{X}$ \\
\hline & 43 & A08-26 & 109 & Col-35 \\
\hline & 44 & A10-19 & 110 & $\cos .29$ \\
\hline & 45 & Al1-24 & III & $\mathrm{CO} 1-42$ \\
\hline & 46 & $A 13-28$ & 112 & C03.37 \\
\hline & 47 & A14-25 & 113 & $\cos -40$ \\
\hline & 48 & A16-16 & 114 & $\cos -19$ \\
\hline & 49 & A17-16 & 115 & $\cos -19$ \\
\hline & 50 & A19-15 & 116 & cos-34 \\
\hline & 51 & A20-14 & 117 & A43-15 \\
\hline & 52 & $\begin{array}{l}\text { A22-24 } \\
A 23-28\end{array}$ & $\begin{array}{l}118 \\
110\end{array}$ & A44-10 \\
\hline & $\begin{array}{l}53 \\
54\end{array}$ & $\begin{array}{l}\text { A23-28 } \\
\text { A25-13 }\end{array}$ & 120 & $\begin{array}{l}\text { A45-37 } \\
\text { A46-34 }\end{array}$ \\
\hline & 55 & A26-19 & 121 & A43-29 \\
\hline & 56 & A27-18 & 122 & A44-25 \\
\hline & 57 & A29-39 & 123 & A45.25 \\
\hline & 58 & A30-26 & 124 & A46-21 \\
\hline & 59 & A31-41 & 125 & C04-25 \\
\hline & 60 & A32-24 & 126 & C08-29 \\
\hline & 61 & A37.34 & 127 & $\mathrm{CO}_{4}-33$ \\
\hline & 62 & A38-34 & 128 & C08-31 \\
\hline & 63 & $A 40-05$ & 129 & $\mathrm{CO} 2-03$ \\
\hline & 64 & A41 & 130 & $1002-4$ \\
\hline & 65 & $n$ & top & \\
\hline
\end{tabular}


Table 3. Continued.

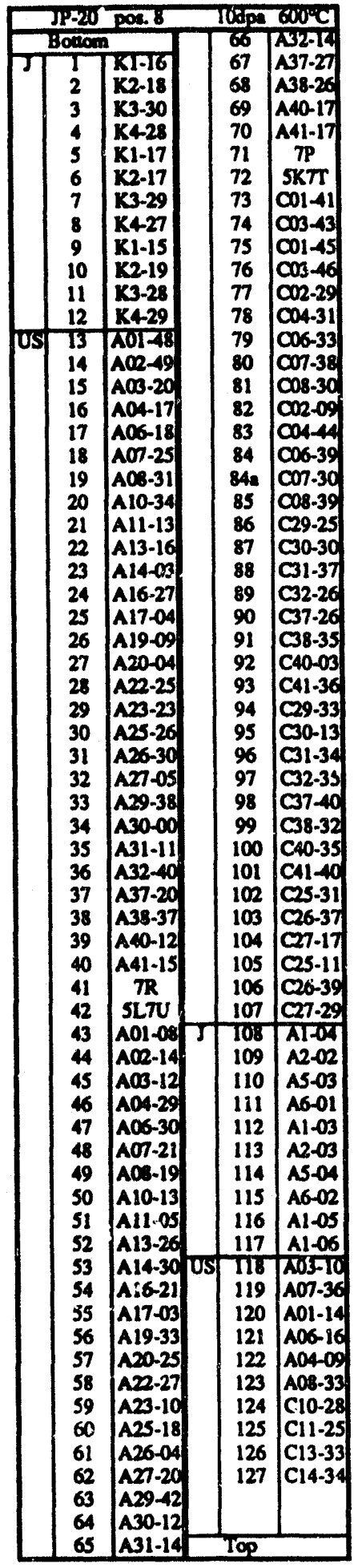

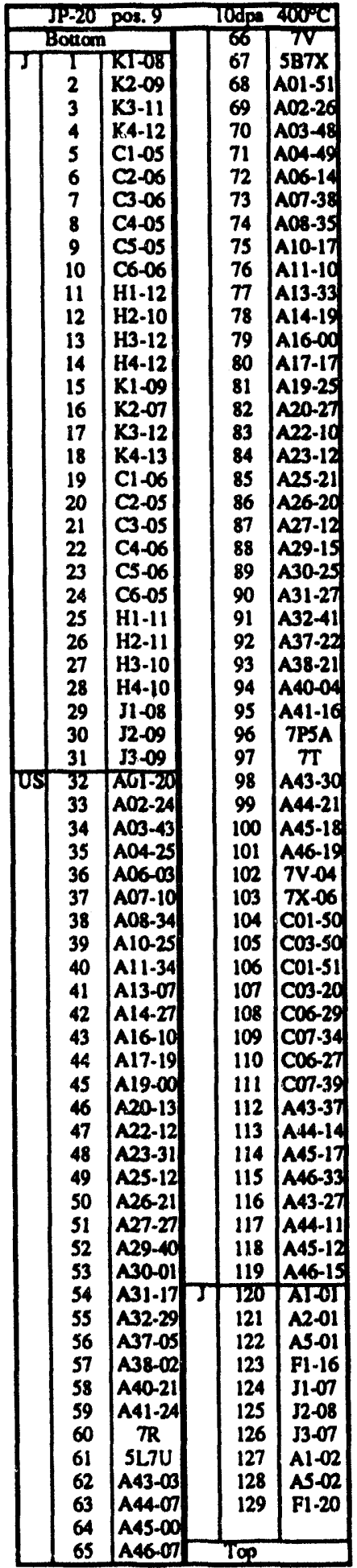

\begin{tabular}{|c|c|c|c|}
\hline$J P=21$ & pos. & 20402 & $300^{\circ} \mathrm{C}$ \\
\hline Bota & & 66 & \\
\hline y 1 & $\mathrm{SB}=02$ & 67 & A16-13 \\
\hline $\begin{array}{l}2 \\
3\end{array}$ & $\begin{array}{l}\mathrm{TB}-02 \\
\mathrm{SC}-02\end{array}$ & $\begin{array}{l}68 \\
69\end{array}$ & \begin{tabular}{|l|} 
A17-0s \\
A19-17
\end{tabular} \\
\hline 4 & SD-02 & 70 & $A 20-20$ \\
\hline 5 & TA-DQ & 71 & A22-08 \\
\hline $\begin{array}{l}6 \\
7\end{array}$ & $\begin{array}{l}\text { SB-18 } \\
\text { SD-18 }\end{array}$ & $\begin{array}{l}72 \\
73\end{array}$ & $\mid \begin{array}{l}A 23-18 \\
A 37-11\end{array}$ \\
\hline 8 & SC-17 & 74 & A38-20 \\
\hline 9 & TB-18 & 75 & $A 40-03$ \\
\hline 10 & TA-18 & $\begin{array}{l}76 \\
77\end{array}$ & $\begin{array}{l}141-35 \\
180-21\end{array}$ \\
\hline 12 & SB-09 & 78 & A11-27 \\
\hline 13 & TA-10 & 79 & A13-32 \\
\hline 14 & TB-10 & 80 & $A 14-17$ \\
\hline 16 & $S B-01$ & 82 & $\begin{array}{l}\text { Alo-us } \\
\text { A17-23 }\end{array}$ \\
\hline 17 & SC-01 & 83 & A19-21 \\
\hline 18 & SD-01 & 84 & $A 20-22$ \\
\hline 19 & TA-01 & 85 & A22-11 \\
\hline 20 & TB-01 & 86 & A23-32 \\
\hline 22 & SB-17 & 88 & $\left|\begin{array}{l}A 37-08 \\
A 38-33\end{array}\right|$ \\
\hline 23 & TB-17 & 89 & A $40-29$ \\
\hline 24 & SC-18 & 90 & A41-12 \\
\hline 25 & TA-17 & 91 & C10-30 \\
\hline $\begin{array}{l}26 \\
27\end{array}$ & SD-09 & 92 & C11 -04 \\
\hline $\begin{array}{l}27 \\
28\end{array}$ & $\begin{array}{l}\text { IA-9 } \\
\text { SB-10 }\end{array}$ & $\begin{array}{l}93 \\
94\end{array}$ & $\begin{array}{l}\mathrm{Cl}-38 \\
\mathrm{Cl}-3 \mathrm{8}\end{array}$ \\
\hline 29 & sc-os & 95 & C16-34 \\
\hline 30 & TB-09 & 96 & C17-32 \\
\hline $\begin{array}{l}31 \\
32\end{array}$ & $\begin{array}{l}\text { A43-32 } \\
\text { A44-36 }\end{array}$ & $\begin{array}{l}97 \\
98\end{array}$ & $\begin{array}{l}\text { C19-29 } \\
\text { Co-20-27 }\end{array}$ \\
\hline 33 & A45-29 & 99 & C22-21 \\
\hline 34 & A46-14 & 100 & C23-26 \\
\hline 35 & A43-16 & 101 & C.7.12 \\
\hline $\begin{array}{l}36 \\
37\end{array}$ & A44-28 & 102 & C38-23 \\
\hline $\begin{array}{l}37 \\
38\end{array}$ & $\begin{array}{l}\text { A A5-32 } \\
\text { A46-25 }\end{array}$ & $\begin{array}{l}103 \\
104\end{array}$ & $\begin{array}{l}\mathrm{C} 40-40 \\
\mathrm{C} 41-27\end{array}$ \\
\hline 39 & $6 A-26$ & 105 & C10-33 \\
\hline 40 & 71.26 & 106 & C11-02 \\
\hline $\begin{array}{l}41 \\
42\end{array}$ & $\begin{array}{l}73-22 \\
74-28\end{array}$ & 107 & C13-25 \\
\hline $\begin{array}{l}42 \\
43\end{array}$ & $\begin{array}{l}74-28 \\
6 A-27\end{array}$ & $\begin{array}{l}108 \\
109\end{array}$ & $\begin{array}{l}\mathrm{C} 14-37 \\
\mathrm{Cl} 16-24\end{array}$ \\
\hline 44 & $71-27$ & 110 & C17-39 \\
\hline 45 & $73-23$ & 111 & C19-32 \\
\hline 46 & $74-30$ & 112 & C20-33 \\
\hline $\begin{array}{l}47 \\
48\end{array}$ & 6A-28 & 113 & C22.38 \\
\hline $\begin{array}{l}48 \\
49\end{array}$ & $\begin{array}{l}71-28 \\
73-24\end{array}$ & $\begin{array}{l}114 \\
115\end{array}$ & $\begin{array}{l}\text { C23.00 } \\
\text { C37.01 }\end{array}$ \\
\hline 50 & $74-09$ & 116 & C38-31 \\
\hline 51 & $6 A-11$ & 117 & C40-27 \\
\hline 52 & $71-29$ & 118 & C41-25 \\
\hline 53 & $73-15$ & 119 & $1003-14$ \\
\hline 54 & $74-29$ & 120 & AO4-18 \\
\hline 55 & R2-14 & 121 & AOI-03 \\
\hline $\begin{array}{l}56 \\
57\end{array}$ & R3-20 & 122 & $\cos -51$ \\
\hline $\begin{array}{l}57 \\
58\end{array}$ & $\begin{array}{l}\text { R4-12 } \\
\text { RS-12 }\end{array}$ & $\begin{array}{l}123 \\
124\end{array}$ & Col-30 \\
\hline 59 & R2-16 & 125 & AOB-18 \\
\hline 60 & R3-11 & 126 & Cos-31 \\
\hline 61 & R4-16 & & \\
\hline $\begin{array}{l}62 \\
63\end{array}$ & RS-14 & & \\
\hline $\begin{array}{l}63 \\
64\end{array}$ & $\begin{array}{l}\text { A10-16 } \\
\text { A11-32 }\end{array}$ & & \\
\hline & A13-15 & 109 & \\
\hline
\end{tabular}


Table 3. Continued.

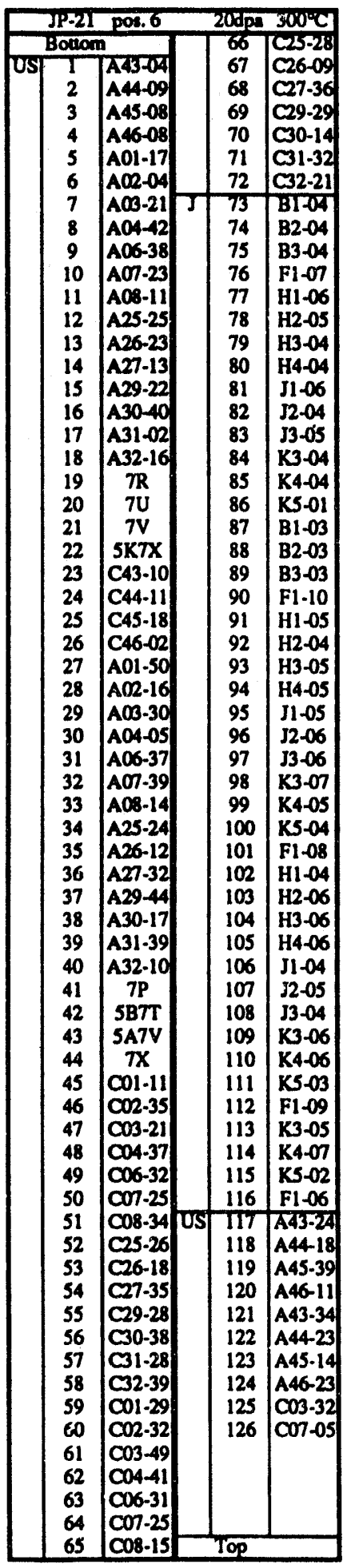

\begin{tabular}{|c|c|c|c|c|}
\hline & JP-2I & pos. 7 & $200 \mathrm{pe}$ & $500^{\circ} \mathrm{C}$ \\
\hline & Bonar & & 66 & |AI3-05 \\
\hline I & 7 & F[-35] & 67 & A14-00 \\
\hline & 2 & E1-01 & 68 & A16-11 \\
\hline & 3 & $\mathrm{Cl} \cdot 12$ & 69 & $\mathrm{COL}-31$ \\
\hline & 5 & C.12 & 71 & $\begin{array}{l}C 02-20 \\
C 03-27\end{array}$ \\
\hline & 6 & $C_{4}-12$ & 72 & CO4-15 \\
\hline & 7 & C5.12 & 73 & $(C 06-11$ \\
\hline & 8 & C6-12 & 74 & Cot-26 \\
\hline & 9 & H1-20 & 75 & CO8-40 \\
\hline & 10 & H2-2O & 76 & C01-38 \\
\hline & 11 & H3-19 & 77 & $C 02-40$ \\
\hline & 12 & H4-2O & 78 & C03-22 \\
\hline & 13 & K3-2! & 79 & C04-39 \\
\hline & 14 & K4-21 & 80 & C06-04 \\
\hline & 15 & K5-09 & 81 & CO7-33 \\
\hline & 16 & F1-33 & 82 & C08-35 \\
\hline & 17 & E1-03 & 83 & C43-08 \\
\hline & 18 & C1-11 & 84 & C44-01 \\
\hline & 19 & C2-11 & 85 & C45-00 \\
\hline & $\begin{array}{l}20 \\
21\end{array}$ & $\begin{array}{l}C 3-11 \\
c 4-11\end{array}$ & $\begin{array}{l}86 \\
87\end{array}$ & $\begin{array}{l}C 46-14 \\
C 43-04\end{array}$ \\
\hline & 22 & C5-11 & 88 & C44-05 \\
\hline & 23 & C6-11 & 89 & C45-02 \\
\hline & 24 & HI-19 & 90 & C46-23 \\
\hline & 25 & $\mathrm{H} 2-18$ & 91 & A43-31 \\
\hline & 26 & H3-18 & 92 & A44-29 \\
\hline & 27 & H4-19 & 93 & A45-11 \\
\hline & 28 & K3-22 & 94 & A46-17 \\
\hline & 29 & K4-22 & 95 & $7 V-03$ \\
\hline & 30 & KS-14 & 96 & $7 X-5 K$ \\
\hline & 31 & F1.37 & 97 & A43-17 \\
\hline & 32 & E1-02 & 98 & A44-38 \\
\hline & 33 & H1-18 & 99 & \\
\hline & 34 & H2-19 & 100 & A46-18 \\
\hline & 35 & H3-20 & 101 & \\
\hline & 36 & H4-18 & 102 & $7 X-04$ \\
\hline & 37 & K3-24 & 103 & 6A-05 \\
\hline & 38 & K4-20 & 104 & $71-05$ \\
\hline & 39 & K5-11 & 105 & 73.05 \\
\hline & 40 & F1-36 & 106 & $74-17$ \\
\hline & 41 & K3-23 & 107 & 6A-06 \\
\hline & 42 & K4-23 & 108 & $71-06$ \\
\hline & 43 & K5-12 & 109 & 73.06 \\
\hline & 44 & F1.34 & 110 & $74-13$ \\
\hline US & 45 & A01-41 & 111 & $6 \mathrm{~A}-07$ \\
\hline & 46 & A02-32 & 112 & $71-07$ \\
\hline & 47 & A03-22 & 113 & $73-07$ \\
\hline & 48 & A04-03 & 114 & $74-18$ \\
\hline & 49 & A06-34 & 115 & A43-38 \\
\hline & 50 & A07.33 & 116 & A44-17 \\
\hline & 51 & A08-37 & 117 & A45.26 \\
\hline & 52 & Al0.22 & 118 & A46-10 \\
\hline & 53 & Al1-09 & 119 & A25.07 \\
\hline & 54 & A13-10 & 120 & A26-08 \\
\hline & 55 & A14-06 & 121 & A27-23 \\
\hline & 56 & A16-26 & 122 & A29-45 \\
\hline & 57 & $A 01-27$ & 123 & A $30-22$ \\
\hline & 58 & $A 02-21$ & 124 & A31.3! \\
\hline & 59 & A03-26 & 125 & A32-25 \\
\hline & 60 & A04-19 & 126 & A03-1 \\
\hline & 61 & A06-24 & 127 & A07-14 \\
\hline & 62 & A07.30 & 128 & A04-32 \\
\hline & 63 & A08-16 & 129 & A08-30 \\
\hline & 64 & A $10-20$ & & \\
\hline & & & & \\
\hline
\end{tabular}

\begin{tabular}{|c|c|c|c|c|}
\hline$\frac{A P-2}{B \times 10}$ & poo. 8 & & $20 \mathrm{dpa}$ & cortsest \\
\hline Bowo & 1 & & 66 & Cot/228 \\
\hline 1 & A0I-11 & & 67 & C10-21 \\
\hline 2 & A02-17 & & 68 & C11-33 \\
\hline $\begin{array}{l}3 \\
4\end{array}$ & $\mathrm{~A} 03-27$ & & 69 & $\begin{array}{l}\mathrm{C} 13-04 \\
\mathrm{C} 14-32\end{array}$ \\
\hline 5 & A06-28 & & 71 & Ci6-14 \\
\hline 6 & A07-19 & & 72 & C17.16 \\
\hline 7 & A08-01 & & 73 & C19-25 \\
\hline $\begin{array}{l}8 \\
9\end{array}$ & Allove & & $\begin{array}{l}74 \\
75\end{array}$ & $\begin{array}{l}C 20-13 \\
C 22-30\end{array}$ \\
\hline 10 & A13-25 & & 76 & C23-27 \\
\hline 11 & Al4-23 & & 77 & C25-0s \\
\hline 12 & Al6-03 & & 78 & C26-07 \\
\hline 13 & A17-26 & & 79 & C27-28 \\
\hline $\begin{array}{l}14 \\
15\end{array}$ & $\begin{array}{l}A 19-31 \\
A 20-16\end{array}$ & & $\begin{array}{l}80 \\
81\end{array}$ & $\begin{array}{l}\text { C29-38 } \\
\text { Co-04 }\end{array}$ \\
\hline 16 & A22-18 & & 82 & C31-08 \\
\hline 17 & 123.04 & & 83 & C32-29 \\
\hline 18 & A25-15 & & 84 & C37-38 \\
\hline 19 & A26-11 & & 85 & C38-39 \\
\hline 20 & A27-03 & & 86 & C40-31 \\
\hline 21 & A29-03 & & 87 & C41-33 \\
\hline $\begin{array}{l}22 \\
23\end{array}$ & $\left|\begin{array}{l}A 30-11 \\
A 31-12\end{array}\right|$ & & $\begin{array}{l}88 \\
89\end{array}$ & $\begin{array}{l}C 08-36 \\
C 01-33\end{array}$ \\
\hline 24 & A $32-30$ & & 90 & $002-27$ \\
\hline 25 & $A 37.18$ & & 91 & $\cos -45$ \\
\hline $\begin{array}{l}26 \\
27\end{array}$ & $\begin{array}{l}\text { A } 38-24 \\
\text { A } 40-27\end{array}$ & & $\begin{array}{l}92 \\
93\end{array}$ & $\begin{array}{l}C_{04}-08 \\
C 06-21\end{array}$ \\
\hline 28 & A41-03 & & 94 & Co7.08 \\
\hline 29 & $5 L 7 R$ & & 95 & \\
\hline 30 & $7 \mathrm{U}$ & & 96 & C10-29 \\
\hline $\begin{array}{l}31 \\
32\end{array}$ & $\begin{array}{l}A 01-31 \\
A 02-20\end{array}$ & & $\begin{array}{l}97 \\
98\end{array}$ & $\begin{array}{l}\text { C11-34 } \\
\text { C13-36 }\end{array}$ \\
\hline 33 & $\mathrm{~A} 03-40$ & & 99 & C14-29 \\
\hline 34 & A04-03 & & 100 & Cl6-17 \\
\hline 35 & A06-33 & & 101 & C17-28 \\
\hline 36 & A07-15 & & 102 & C19-26 \\
\hline 37 & A08-24 & & 103 & C20-29 \\
\hline 38 & A10-09 & & 104 & C22-11 \\
\hline 39 & A11-12 & & 105 & C23-07 \\
\hline 40 & A13-13 & & 106 & C25-30 \\
\hline 41 & Al 4-32 & & 107 & C26-17 \\
\hline 42 & A16-34 & & 108 & C27-30 \\
\hline 43 & A17-07 & & 109 & C29-11 \\
\hline 44 & A19-23 & & 110 & c30-39 \\
\hline 45 & A20-18 & & 111 & \\
\hline 46 & A22-13 & & 112 & C32-25 \\
\hline 47 & A23-19 & & 113 & C37.29 \\
\hline 48 & A25-27 & & 114 & \\
\hline 49 & $A 26-14 \mid$ & & 115 & \\
\hline 50 & A27-14 & & 116 & $C_{41-22}$ \\
\hline 51 & A29-21 & $J$ & IIT & \\
\hline 52 & A30-43 & & 118 & K4- \\
\hline 53 & A31-06 & & 119 & K5-18 \\
\hline 54 & A $32-26$ & & 120 & K3-31 \\
\hline 55 & A $37-30$ & & 121 & K4-31 \\
\hline 56 & A 38 -32 & & 122 & \\
\hline 57 & $A 40-37$ & US & 123 & A103-25 \\
\hline 58 & A41-31 & & 124 & \\
\hline 59 & $7 \mathbf{P}$ & J & 125 & K3-34 \\
\hline 60 & SATT & & 126 & K4-30 \\
\hline 61 & $\mathrm{CO}-49$ & & 127 & K5-15 \\
\hline 62 & CO2-30 & & 128 & K3-3 \\
\hline 05 & CO3-26 & & 129 & K4- \\
\hline 64 & $\mathrm{CO} 4$ & & & \\
\hline 65 & $\mid 006-28$ & & & \\
\hline
\end{tabular}


Table 3. Continued.

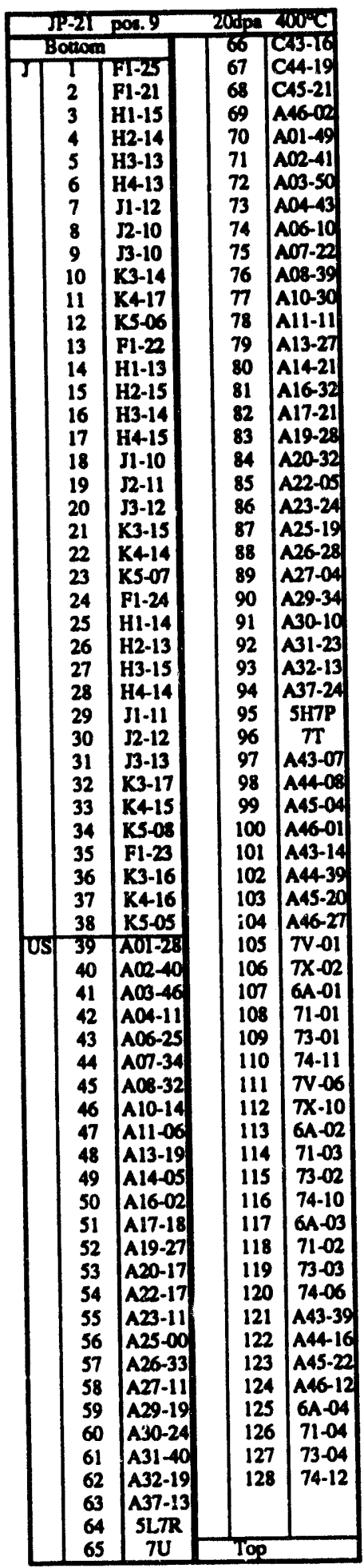

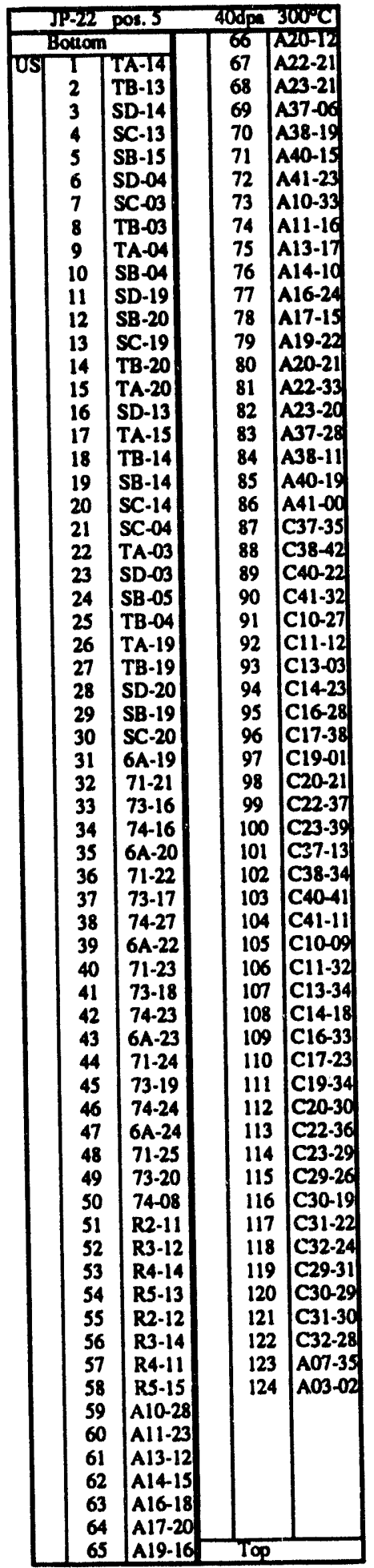

\begin{tabular}{|c|c|c|c|c|}
\hline & $J P=22$ & pas. 6 & $40 d \mathrm{~d}$ & sure \\
\hline E & Bolom & & 66 & $7 v$ \\
\hline J & T & $\begin{array}{l}1-06 \\
82-06\end{array}$ & 67 & $\begin{array}{c}5 \mathrm{HTX} \\
\mathrm{A} 01-25\end{array}$ \\
\hline & 3 & B3-06 & 69 & AOl-25 \\
\hline & 4 & F1-11 & 70 & $A O B-4$ \\
\hline & 5 & C1-03 & 71 & $104-02$ \\
\hline & $\begin{array}{l}6 \\
7\end{array}$ & $\begin{array}{l}C_{2}-03 \\
C_{3}-03\end{array}$ & $\begin{array}{l}72 \\
73\end{array}$ & $\begin{array}{l}A 06-26 \\
A 07-9\end{array}$ \\
\hline & 8 & C4-04 & 74 & A0s-36 \\
\hline & 9 & $\begin{array}{l}C 5-04 \\
C 6-03\end{array}$ & 75 & A25-22 \\
\hline & $\begin{array}{l}10 \\
11\end{array}$ & $\begin{array}{l}\cos -03 \\
H 1-09\end{array}$ & 77 & $\begin{array}{l}26-15 \\
427-17\end{array}$ \\
\hline & 12 & H2-08 & 78 & 129-35 \\
\hline & 13 & H3-07 & 79 & A $30-23$ \\
\hline & 14 & $\begin{array}{l}\text { H4-08 } \\
\mathrm{K} 1-06\end{array}$ & 80 & (131-13 \\
\hline & $\begin{array}{l}15 \\
16\end{array}$ & $\begin{array}{l}K 1-06 \\
\text { K2-06 }\end{array}$ & $\begin{array}{l}81 \\
82\end{array}$ & $\begin{array}{lll}132-4 & 4\end{array}$ \\
\hline & 17 & K3-09 & 83 & A44-30 \\
\hline & 18 & K4-10 & 84 & A45-35 \\
\hline & 19 & B1-05 & 85 & $A 46-30$ \\
\hline & $\begin{array}{l}20 \\
21\end{array}$ & $\begin{array}{l}\text { B2-05 } \\
\text { B3-05 }\end{array}$ & $\begin{array}{l}86 \\
87\end{array}$ & $\underset{7 \mathrm{H}}{5 \mathrm{HTV}}$ \\
\hline & 22 & Fl-14 & 88 & $|001-37|$ \\
\hline & 23 & $\mathrm{Cl}-04$ & 89 & $|c 02-11|$ \\
\hline & 24 & $\begin{array}{c}C 2-04 \\
C 3-04\end{array}$ & 90 & $\cos -40$ \\
\hline & $\begin{array}{l}20 \\
26\end{array}$ & C4-03 & 92 & $\left|\begin{array}{l}C 04-03 \\
C 06-10\end{array}\right|$ \\
\hline & 27 & C5-03 & 93 & $007-35$ \\
\hline & $\begin{array}{l}28 \\
29\end{array}$ & $\begin{array}{l}C 6-04 \\
\text { H1-07 }\end{array}$ & $\begin{array}{l}94 \\
95\end{array}$ & $\mid \begin{array}{c}008-06 \\
C 25-18\end{array}$ \\
\hline & 30 & $\mathrm{H} 2-09$ & 96 & C26-28 \\
\hline & $\begin{array}{l}31 \\
32\end{array}$ & $\begin{array}{l}H 3-08 \\
H 4-09\end{array}$ & 97 & C27-06 \\
\hline & 33 & $\mathrm{~K} 1-05$ & 99 & $\left|\begin{array}{l}C 01-34 \\
C_{2}-37\end{array}\right|$ \\
\hline & 34 & $K 2-05$ & 100 & cos-35 \\
\hline & 35 & K3-08 & 101 & c04-36 \\
\hline & 36 & $\begin{array}{l}\text { K4-08 } \\
\text { F1-15 }\end{array}$ & 102 & C06-12 \\
\hline & 37 & $\begin{array}{l}\text { F1-15 } \\
\text { H1-08 }\end{array}$ & 103 & Con-36 \\
\hline & $\begin{array}{l}38 \\
39\end{array}$ & $\mathrm{H}_{2}-07$ & $\begin{array}{l}104 \\
105\end{array}$ & $\mid \begin{array}{l}C 08-25 \\
\text { C25-25 }\end{array}$ \\
\hline & 40 & H3-09 & 106 & C26-15 \\
\hline & 41 & H4-07 & 107 & C27.2 \\
\hline & 42 & KI-04 & 108 & A43-1 \\
\hline & 43 & $\begin{array}{l}\text { K2-04 } \\
\text { K3-10 }\end{array}$ & 109 & $4-2$ \\
\hline & $\begin{array}{l}44 \\
45\end{array}$ & $\begin{array}{l}k 3-10 \\
K 4-09\end{array}$ & 110 & A \\
\hline & $\begin{array}{l}45 \\
46\end{array}$ & F1-12 & 112 & $\mid \begin{array}{l}A 40-3 C \\
A 43-2\end{array}$ \\
\hline & 47 & F1-13 & 113 & A44-1 \\
\hline US & 48 & AOनIS & 114 & A45-1 \\
\hline & 49 & AO2-11] & 115 & \\
\hline & 50 & $\begin{array}{lll}A 03 & -04\end{array}$ & 116 & A43-2 \\
\hline & $\begin{array}{l}51 \\
52\end{array}$ & $\begin{array}{l}A 04-14 \\
A 06-21\end{array}$ & $\begin{array}{l}117 \\
118\end{array}$ & $\begin{array}{l}\text { A44-33 } \\
\text { A45-38 }\end{array}$ \\
\hline & 53 & A07-31 & 119 & $A 46-2$ \\
\hline & 54 & A08-10 & 120 & C29-3 \\
\hline & 55 & $\begin{array}{l}\text { A25-11 } \\
\text { A26-20 }\end{array}$ & 121 & C30-27 \\
\hline & $\begin{array}{l}56 \\
57\end{array}$ & $\mid \begin{array}{l}A 26-29 \\
\text { A27-10 }\end{array}$ & $\begin{array}{l}122 \\
123\end{array}$ & $\begin{array}{l}C 31-25 \\
032-31\end{array}$ \\
\hline & 58 & A29-05 & 124 & C10-2 \\
\hline & 59 & A $30-16$ & 125 & Cil-2 \\
\hline & 60 & $\begin{array}{l}\text { A31-18 } \\
\text { A32-34 }\end{array}$ & $\begin{array}{l}126 \\
127\end{array}$ & A38-1 \\
\hline & $\begin{array}{l}61 \\
62\end{array}$ & $\begin{array}{l}\text { A32-34 } \\
\text { A43-26 }\end{array}$ & & \\
\hline & 63 & A44-32 & & \\
\hline & $\begin{array}{l}64 \\
65\end{array}$ & & & \\
\hline & & $|A 46-28|$ & Top & \\
\hline
\end{tabular}


Table 3. Continued.

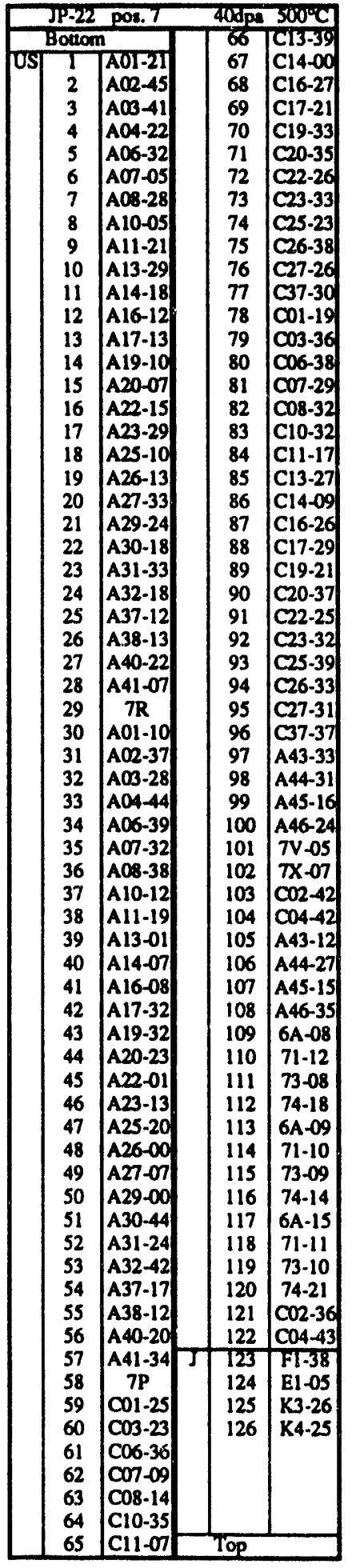

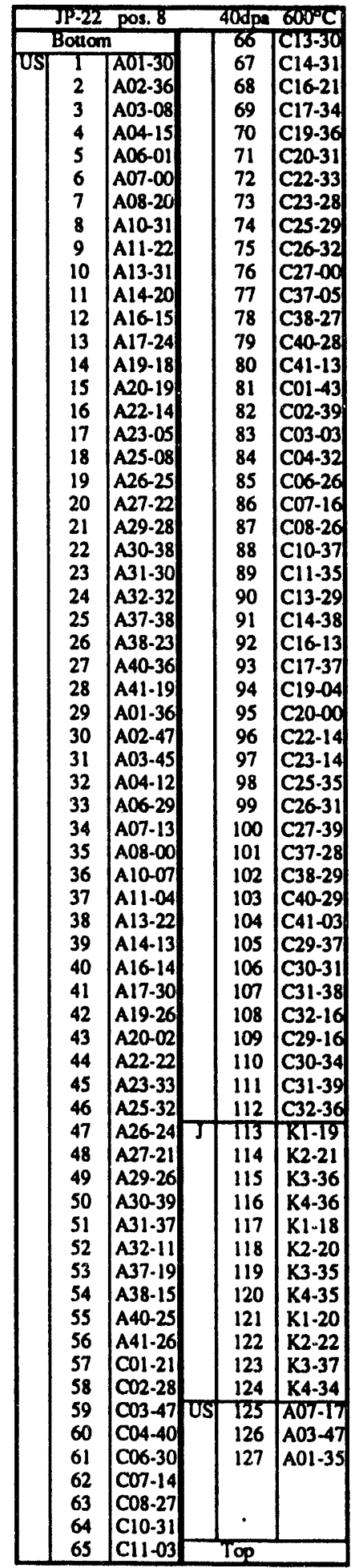

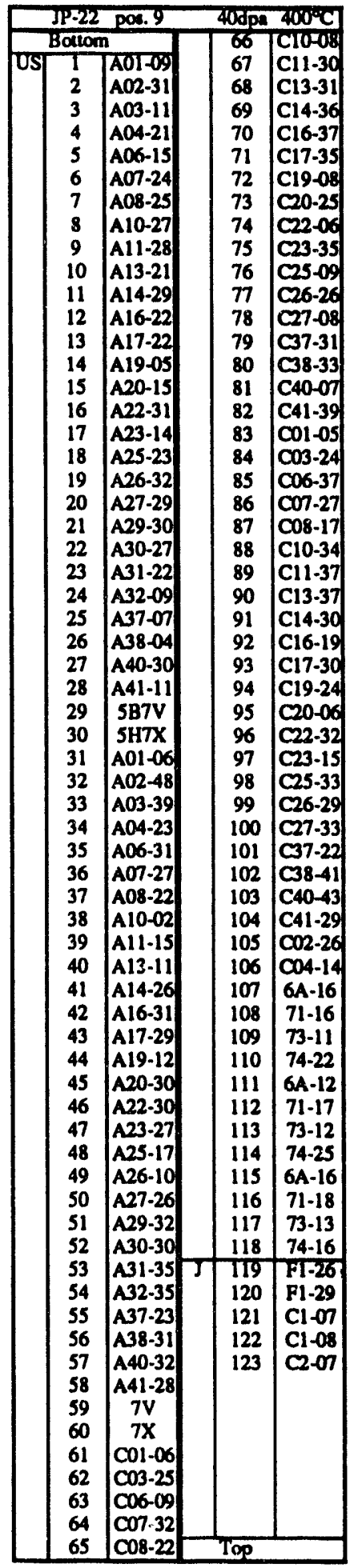


Table 4. Specimen identifications for JAERI program alloys.

\begin{tabular}{|c|l|l|}
\hline ID code & Material set & \multicolumn{1}{|c|}{ Material } \\
\hline A1 & JPCA & JPCA SA \\
A2 & & JPCA CW \\
A3 & & JPCA SA EB weld-joint \\
A5 & & JPCA SA \\
A6 & & JPCA CW \\
\hline B1 & SAR & $316(3)-00$ \\
B2 & & $316(3)-01$ \\
B33 & & $36(3)-12$ \\
E1 & & F3ESAR \\
F1 & & F5ESAR \\
\hline C1 & Isotope tailored & F82H \\
C2 & ferritic steels & F82H + 10B (T23) \\
C3 & & F82H + natural B (T20) \\
C4 & & F82H + 58 Ni (Lot 35) \\
C5 & & F82H +60Ni (Lot 34) \\
C6 & & F82H + 54Fe \\
D1 & & F82H + natural B \\
& & (360 appmB) \\
\hline H1 & Duplex & AF2 \\
H2 & & AF3 \\
H3 & & AF4 \\
H4 & & AF7 \\
\hline J1 & Shape memory & SM13 \\
J2 & alloys & SM15 \\
J3 & & C8 \\
\hline K1 & Ti-Al alloys & Ti-Al-1 \\
K2 & & Ti-Al-2 \\
K3 & & Ti-Al-3 \\
K4 & & Ti-Al-4 \\
K5 & & Ti-Al-5 \\
\hline & & \\
\hline
\end{tabular}


Table 5. Specimen identification for U. S. program alloys.

\begin{tabular}{|c|c|c|c|c|c|}
\hline Alloy & Condition & ID Code & Alloy & Condition & ID Code \\
\hline $316-1$ & $\mathrm{SA} 1050^{\circ} \mathrm{C} / 1 \mathrm{~h}$ & A01 & RSP1-1 & $\mathrm{SA} 1100^{\circ} \mathrm{C} / 1 \mathrm{~h}$ & A37 \\
\hline $316-1$ & CW 25\% & $\mathrm{C} 01$ & RSP1-1 & CW 25\% & C37 \\
\hline $316-4$ & SA $1050^{\circ} \mathrm{C} / 1 \mathrm{~h}$ & A02 & RSP1-12 & $\mathrm{SA} 1100^{\circ} \mathrm{C} / 1 \mathrm{~h}$ & A.38 \\
\hline $316-4$ & CW 25\% & $\mathrm{CO2}$ & RSP1-12 & CW 25\% & C38 \\
\hline $316-12$ & SA $1050^{\circ} \mathrm{C} / 1 \mathrm{~h}$ & A03 & RSP2-1 & $\mathrm{SA} 1100^{\circ} \mathrm{C} / 1 \mathrm{~h}$ & $\mathbf{A 4 0}$ \\
\hline $316-12$ & CW 25\% & $\mathrm{CO3}$ & RSP2-1 & CW 25\% & $\mathrm{C40}$ \\
\hline $316-70$ & SA $1050^{\circ} \mathrm{C} / 1 \mathrm{~h}$ & A04 & RSP2-12 & $\mathrm{SA} 1100^{\circ} \mathrm{C} / 1 \mathrm{~h}$ & A41 \\
\hline $316-70$ & CW 25\% & $\mathrm{CO4}$ & RSP2-12 & CW 25\% & $\mathrm{C} 41$ \\
\hline PCA-1 & $\mathrm{SA} 1175^{\circ} \mathrm{C} / 1 \mathrm{~h}$ & A06 & $316-12 \mathrm{NS}$ & $\mathrm{SA} 1050^{\circ} \mathrm{C} / 1 \mathrm{~h}$ & $7 \mathrm{R} / 7 \mathrm{P}^{*}$ \\
\hline PCA-1 & CW 25\% & $\mathrm{CO6}$ & $316-12 \mathrm{NS}$ & CW $20 \%$ & $7 \mathbf{P}$ \\
\hline PCA-12 & $\mathrm{SA} 1175^{\circ} \mathrm{C} / 1 \mathrm{~h}$ & A07 & $316-12 \mathrm{NSC}$ & $\mathrm{SA} 1050^{\circ} \mathrm{C} / 1 \mathrm{~h}$ & $7 \mathrm{U} / 7 \mathrm{~T}^{\circ}$ \\
\hline PCA-12 & CW 25\% & $\mathrm{CO7}$ & $316-12 \mathrm{NSC}$ & CW 20\% & $7 \mathrm{~T}$ \\
\hline PCA-70 & $\mathrm{SA} 1175^{\circ} \mathrm{C} / 1 \mathrm{~h}$ & A08 & & & \\
\hline PCA-70 & CW 25\% & $\mathrm{COB}$ & HT9-3 & $\begin{array}{l}1050^{\circ} \mathrm{C} / .5 \mathrm{~h} \\
+780^{\circ} \mathrm{C} / 2.5 \mathrm{~h}\end{array}$ & A43/C43 \\
\hline $14-16 C P 1-1$ & $\mathrm{SA} 1175^{\circ} \mathrm{C} / 1 \mathrm{~h}$ & A10 & HT9.12 & $1050^{\circ} \mathrm{C} / .5 \mathrm{~h}$ & A44/C44 \\
\hline 14-16CP1-1 & CW 25\% & $\mathrm{ClO}$ & & $+780^{\circ} \mathrm{C} / 2.5 \mathrm{~h}$ & \\
\hline 14-16CP1-12 & SA $1175^{\circ} \mathrm{C} / 1 \mathrm{~h}$ & A11 & HT9.C3 & $1050^{\circ} \mathrm{C} / .5 \mathrm{~h}$ & A45/C45 \\
\hline 14-16CP1-12 & CW $25 \%$ & $\mathrm{C11}$ & & $+780^{\circ} \mathrm{C} / 2.5 \mathrm{~h}$ & \\
\hline 14-16CP2-1 & $\mathrm{SA} 1175^{\circ} \mathrm{C} / 1 \mathrm{~h}$ & A13 & HT9-C12 & $1050^{\circ} \mathrm{C} / .5 \mathrm{~h}$ & A46/C46 \\
\hline 14-16CP2-1 & CW $25 \%$ & $\mathrm{C13}$ & & $+780^{\circ} \mathrm{C} / 2.5 \mathrm{~h}$ & \\
\hline $14-16 \mathrm{CP} 2-12$ & SA $1175^{\circ} \mathrm{C} / 1 \mathrm{~h}$ & A14 & HT9-NS & $1050^{\circ} \mathrm{C} / .5 \mathrm{~h}$ & $7 \mathrm{~V}$ \\
\hline 14-16CP2-12 & CW 25\% & $\mathrm{C} 14$ & & $+760^{\circ} \mathrm{C} / 5 \mathrm{~h}$ & \\
\hline 14-16CP3-1 & $\mathrm{SA} 1175^{\circ} \mathrm{C} / 1 \mathrm{~h}$ & A16 & HT9-CNS & $1050^{\circ} \mathrm{C} / .5 \mathrm{~h}$ & $7 X$ \\
\hline 14-16CP3-1 & CW $25 \%$ & $\mathrm{C} 16$ & & $+760^{\circ} \mathrm{C} / 5 \mathrm{~h}$ & \\
\hline $14-16 C P 3-12$ & $\mathrm{SA} 1175^{\circ} \mathrm{C} / 1 \mathrm{~h}$ & A17 & & & \\
\hline $14-16 C P 3-12$ & CW $25 \%$ & $\mathrm{C17}$ & E62R & $1040^{\circ} \mathrm{C} / 1 \mathrm{~h}$ & $6 \mathrm{~A}$ \\
\hline 14-16CP4-1 & $\mathrm{SA} 1175^{\circ} \mathrm{C} / 1 \mathrm{~h}$ & A19 & & $+760^{\circ} \mathrm{C} / 1 \mathrm{~h}$ & \\
\hline $14-16 \mathrm{CP} 4-1$ & CW 25\% & $\mathrm{C} 19$ & R168 & $1040^{\circ} \mathrm{C} / 1 \mathrm{~h}$ & 71 \\
\hline 14-16CP4-12 & SA $1175^{\circ} \mathrm{C} / 1 \mathrm{~h}$ & A20 & & $+760^{\circ} \mathrm{C} / 1 \mathrm{~h}$ & \\
\hline 14-16CP4-12 & CW $25 \%$ & $\mathrm{C} 20$ & $\mathrm{R} 169$ & $1040^{\circ} \mathrm{C} / 1 \mathrm{~h}$ & 73 \\
\hline 14-16CP5-1 & SA $1175^{\circ} \mathrm{C} / 1 \mathrm{~h}$ & A22 & & $+760^{\circ} \mathrm{C} / 1 \mathrm{~h}$ & \\
\hline 14-16CP5-1 & CW $25 \%$ & $\mathrm{C} 22$ & R170 & $1040^{\circ} \mathrm{C} / 1 \mathrm{~h}$ & 74 \\
\hline $14-16 C P 5-12$ & $\mathrm{SA} 1175^{\circ} \mathrm{C} / 1 \mathrm{~h}$ & A23 & & $+760^{\circ} \mathrm{C} / 1 \mathrm{~h}$ & \\
\hline \multirow[t]{2}{*}{ 14-16CP5-12 } & CW $25 \%$ & $\mathrm{C} 23$ & & & \\
\hline & & & PRC316L & $1050^{\circ} \mathrm{C} / 1 \mathrm{~h}$ & R2 \\
\hline 14-15B12-1 & SA $1100^{\circ} \mathrm{C} / 1 \mathrm{~h}$ & A25 & PRC316L & CW $20 \%$ & R3 \\
\hline 14-15B12-1 & CW 25\% & $\mathrm{C} 25$ & PRC316Ti & $1050^{\circ} \mathrm{C} / 1 \mathrm{~h}$ & R4 \\
\hline $14-15 B 12-12$ & $\mathrm{SA} 1100^{\circ} \mathrm{C} / 1 \mathrm{~h}$ & A26 & PRC316Ti & CW $20 \%$ & R5 \\
\hline 14-15B12-12 & CW 25\% & $\mathrm{C} 26$ & & & \\
\hline 14-15B12-70 & SA $1100^{\circ} \mathrm{C} / 1 \mathrm{~h}$ & A27 & HT9 & $1050^{\circ} \mathrm{C} / 0.5 \mathrm{~h}$ & SB \\
\hline \multirow[t]{2}{*}{$14-15 B 12-70$} & CW 25\% & $\mathrm{C} 27$ & & $+700^{\circ} \mathrm{C} / 5 \mathrm{~h}$ & \\
\hline & & & $\mathrm{HT}^{\mathrm{T}}+1 \% \mathrm{Ni}$ & $1050^{\circ} \mathrm{C} / 0.5 \mathrm{~h}$ & SC \\
\hline FE-15-35-1 & $\mathrm{SA} 1100^{\circ} \mathrm{C} / 1 \mathrm{~h}$ & A29 & & $+700^{\circ} \mathrm{C} / 5 \mathrm{~h}$ & \\
\hline FE-15-35-1 & $\mathrm{CW} 25 \%$ & C29 & $\mathrm{HT} 9+2 \% \mathrm{Ni}$ & $1050^{\circ} \mathrm{C} / 0.5 \mathrm{~h}$ & SD \\
\hline FE-15-35-4 & SA $1100^{\circ} \mathrm{C} / 1 \mathrm{~h}$ & A30 & & $+700^{\circ} \mathrm{C} / 5 \mathrm{~h}$ & \\
\hline FE-15-35-4 & CW $25 \%$ & C30 & T9 MOD & $1050^{\circ} \mathrm{C} / 0.5 \mathrm{~h}$ & TA, TL \\
\hline FE-15-35-12 & SA $1100^{\circ} \mathrm{C} / 1 \mathrm{~h}$ & A31 & & $+700^{\circ} \mathrm{C} / 5 \mathrm{~h}$ & \\
\hline FE-15-35-12 & CW $25 \%$ & C31 & $\mathrm{T} 9 \mathrm{MOD}+2 \% \mathrm{Ni}$ & $1050^{\circ} \mathrm{C} / 0.5 \mathrm{~h}$ & $\mathrm{~TB}, \mathrm{TI}$ \\
\hline FE-15-35-130 & SA $1100^{\circ} \mathrm{C} / 1 \mathrm{~h}$ & A32 & & $+700^{\circ} \mathrm{C} / 5 \mathrm{~h}$ & \\
\hline FE-15-35-130 & $\mathrm{CW} 25 \%$ & $\mathrm{C} 32$ & & & \\
\hline
\end{tabular}


Table 6a. Alloy compositions (weight percent) for JAERI program alloys.

\begin{tabular}{|c|c|c|c|c|c|c|c|c|c|c|c|c|c|}
\hline & \multirow{2}{*}{ JPCA } & \multicolumn{4}{|c|}{ Duplex } & \multicolumn{3}{|c|}{ Shape Memory Alloys } & \multicolumn{5}{|c|}{ SAR } \\
\hline & & AF2 & AP3 & AP4 & AP7 & SM13 & SMis & C8 & FSE & F3E & $\begin{array}{l}316 \\
-00\end{array}$ & $\begin{array}{l}316 \\
.01\end{array}$ & $\begin{array}{l}316 \\
-12\end{array}$ \\
\hline Fe & bal. & bal. & bel. & bal. & bal. & bal. & bal. & bal. & bal. & bal. & bal. & bal. & bat. \\
\hline C & .064 & .02 & .02 & .02 & .02 & .017 & .016 & .006 & .0016 & .0012 & .0042 & .0042 & .0042 \\
\hline $\mathbf{s}$ & .54 & .48 & .49 & .50 & .47 & 4.51 & 4.47 & 5.84 & .038 & .08 & .61 & .61 & .61 \\
\hline Mn & 1.63 & 1.01 & 1.01 & 1.05 & 1.06 & 1.01 & 1.01 & 14.19 & .016 & .02 & 1.91 & 1.91 & 1.91 \\
\hline $\mathbf{P}$ & .027 & .02 & .02 & .02 & .02 & .017 & .017 & $<.003$ & .002 & .002 & .004 & .004 & .004 \\
\hline $\mathbf{s}$ & .0045 & .003 & .003 & .003 & .002 & .002 & .002 & .002 & .0008 & .0025 & .009 & .009 & .009 \\
\hline $\mathrm{Cr}$ & 14.27 & 25.2 & 21.3 & 19.3 & 20.9 & 18.2 & 181 & 5.1 & 17.7 & 16.8 & 19.96 & 19.96 & 19.96 \\
\hline $\mathrm{Ni}^{\mathrm{N}^{*}}$ & 15.95 & 5.8 & 9.0 & 11.0 & 8.9 & 14.8 & 14.9 & 89 & 35.1 & 25.1 & 13.78 & .05 & 2.12 \\
\hline $60_{\mathrm{Ni}}$ & - & - & . & . & - & . & - & . & . & - & . & 13.71 & 11.64 \\
\hline Mo & 2.35 & 2.5 & 25 & 25 & 25 & - & . & - & 2.26 & 219 & 267 & 267 & 267 \\
\hline$\pi$ & .21 & * & $\cdot$ & $\cdot$ & .22 & $\cdot$ & - & - & .27 & .25 & $<.01$ & $<.01$ & $<, 01$ \\
\hline B & .0041 & $\cdot$ & $\cdot$ & $\cdot$ & - & $\cdot$ & $\dot{ }$ & . & .003 & .003 & $<.001$ & $<.001$ & $<.001$ \\
\hline Co & .015 & .004 & .004 & .004 & - & .01 & .01 & $<.01$ & .004 & $<.01$ & $<.01$ & $<.01$ & $<, 01$ \\
\hline $\mathbf{N}$ & .003 & .02 & .01 & .02 & .01 & .010 & .009 & .002 & .0022 & .0066 & .0016 & .0016 & .0016 \\
\hline No & - & - & . & . & . & tr & .20 & . & - & . & $<.01$ & $<.01$ & $<.01$ \\
\hline Al & - & $\cdot$ & - & . & - & . & - & - & . & . & .005 & .005 & .005 \\
\hline$v$ & . & . & $\cdot$ & $\cdot$ & $\dot{-}$ & . & $\dot{ }$ & . & . & . & $<.01$ & $<.01$ & $<.01$ \\
\hline $\mathrm{Cu}$ & - & - & . & . & . & . & - & . & . & - & .01 & .01 & .01 \\
\hline $\mathbf{w}$ & $\cdot$ & - & - & . & . & . & $\dot{-}$ & . & . & - & . & - & - \\
\hline$T_{\mathbf{a}}$ & - & • & $\cdot$ & . & • & . & - & . & . & - & - & . & - \\
\hline
\end{tabular}

* $\mathrm{Ni}^{\mathrm{N}}$ : natural nickel 
Table 6b. Alloy compositions (weight percent) for JAERI program alloys.

\begin{tabular}{|c|c|c|c|c|c|c|c|c|c|c|c|c|c|c|c|}
\hline & $\mathrm{Fe}$ & C & $\mathrm{Si}$ & $\mathbf{M n}$ & $\mathbf{P}$ & $\mathbf{S}$ & $\mathrm{Cr}$ & $\mathbf{W}$ & V & $\mathrm{Ta}$ & B & ${ }^{10} \bar{B}$ & $\mathrm{Al}$ & $\mathbf{N}$ & $\mathrm{Ni}$ \\
\hline $\begin{array}{l}\mathrm{F} 82 \mathrm{H} \\
\mathrm{F} 82 \mathrm{H}+{ }^{\mathrm{N}} \mathrm{B} \\
\mathrm{F} 82 \mathrm{H}+1{ }^{10 \mathrm{~B}}\end{array}$ & & 09 & 0.09 & $\begin{array}{l}0.49 \\
0.50 \\
0.50\end{array}$ & $\begin{array}{l}0.005 \\
0.001 \\
0.001\end{array}$ & $\begin{array}{l}0.001 \\
0.001 \\
0.001\end{array}$ & $\begin{array}{l}7.65 \\
7.49 \\
7.23 \\
\end{array}$ & $\begin{array}{l}1.98 \\
2.1 \\
2.1 \\
\end{array}$ & $\begin{array}{l}0.17 \\
0.20 \\
0.22\end{array}$ & $\begin{array}{l}0.04 \\
0.04\end{array}$ & & 0.000 & $\begin{array}{l}0.01 \\
0.021 \\
0.021 \\
\end{array}$ & $\begin{array}{c}0.0019 \\
0.001 \\
0.002 \\
\end{array}$ & $\begin{array}{c}0.01 \\
-\end{array}$ \\
\hline
\end{tabular}

Table 6c. Alloy compositions (weight percent) for JAERI program alloys.

\begin{tabular}{|l|l|l|c|l|}
\hline ID code & Alloy & \multicolumn{1}{|c|}{ Structure } & $\begin{array}{c}\text { Composition } \\
(\mathrm{Ti}-\mathrm{Al} \text {, at\%) }\end{array}$ & Method 1$)$ \\
\hline K1 & Ti-Al-1 & Ti3 1 Al & $70-30$ & MA \\
K2 & Ti-Al-2 & Ti3Al + TiAl3) & $55-45$ & MA \\
K3 & Ti-Al-3 & TiAl & $50-50$ & MA \\
K4 & Ti-Al-4 & Ti3 3 Al + TiAl 3$)$ & $53-472)$ & PREP \\
K5 & Ti-Al-5 & TiAl & $53-472)$ & Casting \\
\hline
\end{tabular}

1) MA : Mechanical Alloying, PREP : Plasma Rotating Electrode Process

2) 0.27 and 0.05 wt\% oxygen are included as impurity in $\mathrm{K} 4$ and $\mathrm{K} 5$ respectively.

3) The amount of $\mathrm{Ti}_{3} \mathrm{Al}$ in $\mathrm{Ti}_{3} \mathrm{Al}+\mathrm{TiAl}$ mixed structure is less than $1 / 10$ in both alloys. 


\begin{tabular}{|c|c|c|c|c|c|c|c|c|c|c|c|c|c|c|c|c|c|}
\hline$\infty$ & ' & & • & & & & & 8 & \&. & 8 & \&. & 8 & 8 & 8 & 8 & 8 & 8 \\
\hline a. & & & & & $\overline{0}$ & 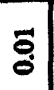 & 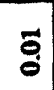 & ఏे & ఏ. & : & 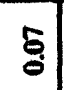 & s. & s. & క. & 5 & 总 & ठ \\
\hline$\frac{9}{2}$ & $\Xi$ & $\Xi$ & $\mp$ & $I$ & $\stackrel{\infty}{-}$ & 9 & $\stackrel{\infty}{q}$ & i & i) & ลิ & i) & సి & ㄱ. & 구 & i & 이 & สి \\
\hline$\frac{1}{\Sigma}$ & $\lambda$ & $\lambda$ & $\eta$ & त & $\eta$ & $\lambda$ & $\eta$ & $\lambda$ & $y$ & $\eta$ & $y$ & $y$ & $\lambda$ & $\lambda$ & 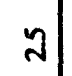 & ฟ & $y$ \\
\hline$>$ & & & . & ' & & & . & ฉి & ํํㅇ & ถุ & 号 & 웅 & : & â & ถి & के & ஜ̆ \\
\hline$\hat{z}$ & & ' &. & . & & & . & $:$ & 잉 & 웅 & 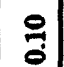 & 영 & 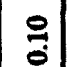 & $\stackrel{0}{\circ}$ & 웅 & $\stackrel{0}{0}$ & $\stackrel{\circ}{0}$ \\
\hline in & $\hat{\tilde{z}}$ & ڤิ & ถิ & 3 & fo & \& & ơ & : & d & ชั & : & : & : & : & : & : & $\dot{0}$ \\
\hline$z$ & & , & . & . & $\dot{0}$ & ठ̊. & ö & \&్ & : & $\tilde{\delta}$ & క్ & : & : & : & s. & $\tilde{~}$ & : \\
\hline 0 & $\stackrel{0}{\circ}$ & $\stackrel{\circ}{\circ}$ & $\check{0}$ & \% & : & 气。 & $\stackrel{0}{0}$ & $\stackrel{8}{\circ}$ & 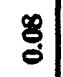 & $\stackrel{8}{0}$ & $\stackrel{8}{8}$ & 8 & $\stackrel{8}{0}$ & $\frac{0}{0}$ & : & $\stackrel{8}{0}$ & 8 \\
\hline$E$ & & & . & ' & มุ & ปู & มุ & \% & 2 & mo & \%̆ & m & : & \%) & m & o & \% \\
\hline 宓 & & & ' & . & . & & . & . & ? & . & . & & & & & & \\
\hline $\bar{\xi}$ & $\hat{m}$ & $\stackrel{\circ}{\ddot{m}}$ & $\stackrel{8}{=}$ & . & 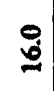 & d్ & ' & 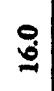 & $\stackrel{q}{\alpha}$ & : & $\tilde{్}$ & $\stackrel{8}{\circ}$ & $\stackrel{g}{a}$ & 递 & ฐ్ & 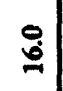 & $\tilde{\omega}$ \\
\hline$\dot{i}$ & & ¿̊ & ت & $\underline{g}$ & . & 8 & : & & $\stackrel{8}{*}$ & . & $\stackrel{8}{*}$ & & $\stackrel{8}{*}$ & & $\stackrel{8}{\text { s. }}$ & & $\stackrel{8}{8}$ \\
\hline o & $\underline{n}$ & 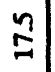 & $\cong$ & $\Xi$ & $\stackrel{q}{\dot{I}}$ & $\dot{I}$ & $\stackrel{8}{\dot{*}}$ & $\stackrel{P}{\dot{I}}$ & $\stackrel{0}{\dot{I}}$ & $\stackrel{0}{ \pm}$ & $\stackrel{0}{+}$ & 8 & $\stackrel{0}{i}$ & 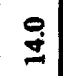 & 足 & $\stackrel{f}{i}$ & $\stackrel{i}{ \pm}$ \\
\hline L & $\overrightarrow{8}$ & $\overline{\mathbf{g}}$ & İ & $\overline{8}$ & g & छे & छ & $\overrightarrow{\mathbf{g}}$ & 8 & $\overrightarrow{8}$ & बे & $\overrightarrow{8}$ & $\vec{\Phi}$ & $\overline{8}$ & $\overrightarrow{\mathrm{s}}$ & $\vec{\Phi}$ & $\bar{g}$ \\
\hline है & 总 & 总 & $\frac{\vec{n}}{\mathrm{~m}}$ & 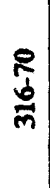 & $\underset{d}{d}$ & త্ & 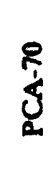 & 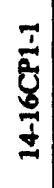 & 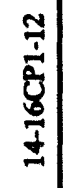 & 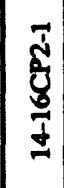 & 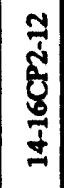 & 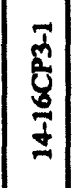 & 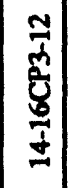 & 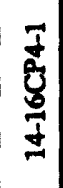 & 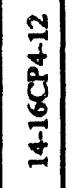 & 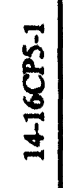 & \\
\hline
\end{tabular}




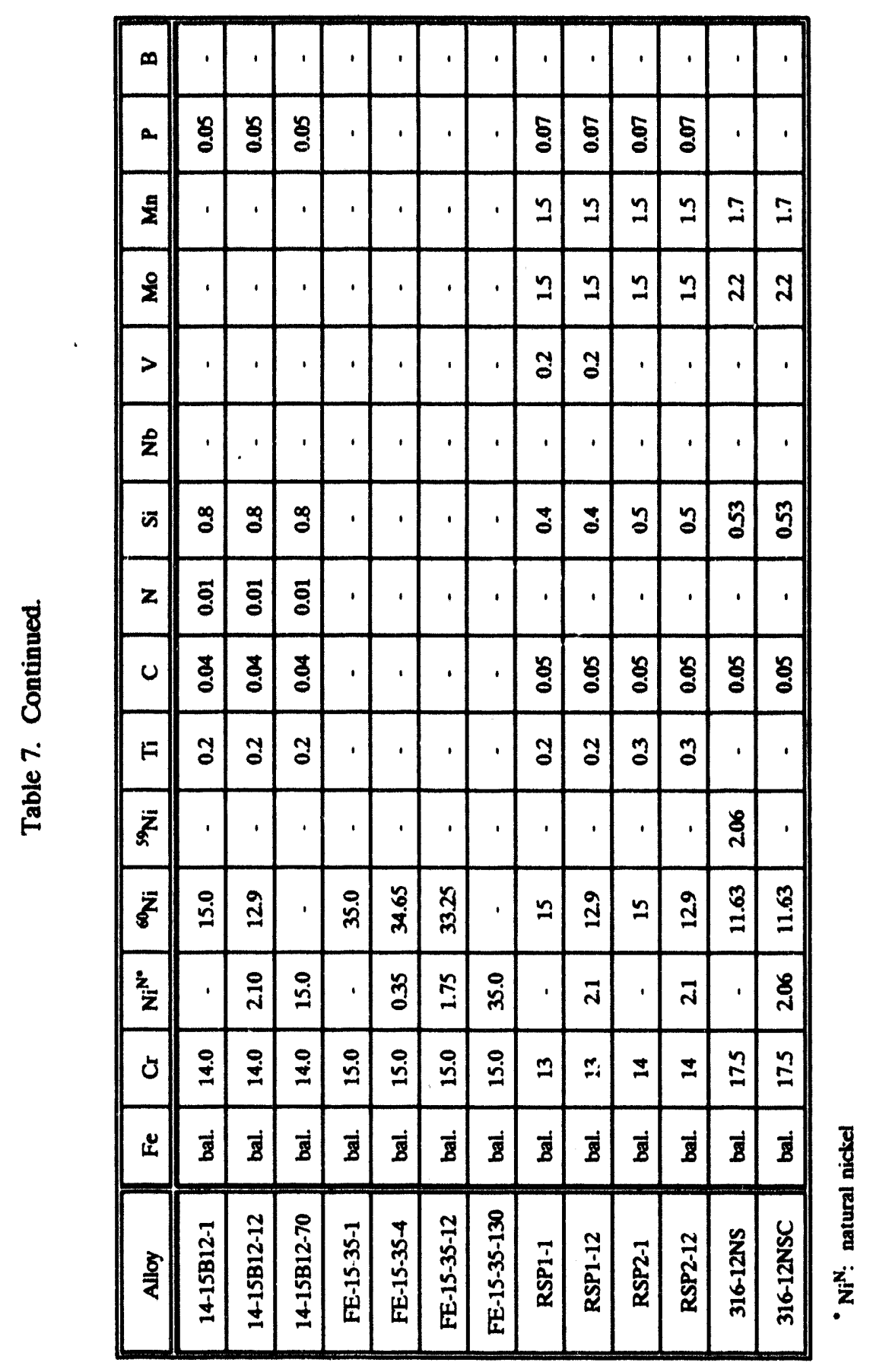


Table 8. Alloy compositions (weight percent) for U. S. program isotopically tailored ferritic alloys.

\begin{tabular}{|c|c|c|c|c|c|c|c|c|c|c|c|c|c|c|c|c|c|}
\hline Alloy & Fe & $\mathrm{Cr}$ & $\mathrm{Ni}^{\mathrm{N}^{*}}$ & $60 \mathrm{Ni}$ & s9Ni & ${ }^{S} \mathbf{N i}_{\mathrm{N}}$ & c & $\mathbf{N}$ & $\mathbf{S i}$ & $\mathbf{N b}$ & $\mathbf{v}$ & Mo & $\mathbf{M n}$ & $\mathbf{o}$ & $\mathbf{w}$ & $\mathbf{S}$ & $\stackrel{P}{\mathbf{P}}$ \\
\hline HT9-3 & bal. & 120 & 0.5 & - & - & - & 0.20 & 0.02 & 0.18 & 0.01 & 0.3 & 1.0 & 0.5 & .007 & 0.5 & .004 & 0.01 \\
\hline HT9-12 & bal. & 120 & - & - & - & 1.4 & 0.20 & 0.02 & 0.18 & 0.01 & 0.3 & 1.0 & 0.5 & .007 & 0.5 & .004 & 0.01 \\
\hline HT9-C3 & bal. & 120 & - & 0.5 & - & - & 0.20 & 0.02 & 0.18 & 0.01 & 0.3 & 1.0 & 0.5 & .007 & 0.5 & .004 & 0.01 \\
\hline HTY-C12 & bal. & 12.0 & - & 1.4 & - & - & 0.20 & 0.02 & 0.18 & 0.01 & 0.3 & 1.0 & 0.5 & .007 & 0.5 & .004 & 0.01 \\
\hline HT9-NS & bal. & 12.0 & - & - & 20 & - & 0.20 & 0.02 & 0.18 & 0.01 & 0.3 & 1.0 & 0.5 & .007 & 0.5 & .004 & 0.01 \\
\hline HTY-CNS & bal. & 12.0 & 20 & - & - & - & 0.20 & 0.02 & 0.18 & 0.01 & 0.3 & 1.0 & 0.5 & .007 & 0.5 & .004 & 0.01 \\
\hline
\end{tabular}

${ }^{-} \mathrm{Ni}^{\mathrm{N}}$ : natural nicked 


\begin{tabular}{|c|c|c|c|c|c|c|c|c|c|c|c|}
\hline 2 & ' & : & ' & $:$ & อิ & g & $\overline{\tilde{z}}$ & 웅 & $\bar{a}$ & \& & \& \\
\hline is & . & . & . & $\cdot$ & 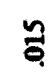 & ఫ్రి & క్ర & t్ర & ఫ్తి & ఫ్ర & ఫ్ర \\
\hline 8 & & a & ' & ธ. & ' & 8 & ta & $\frac{n}{a}$ & $\bar{\delta}$ & $\stackrel{m}{a}$ & $\frac{n}{a}$ \\
\hline 3 & & $\ddot{0}$ & ' & $\dot{b}$ & . & . & $\bar{n}$ & $\tilde{n}$ & $\vec{n}$ & $\bar{a}$ & t) \\
\hline 0 & & . & & ' & & & है & ซิ & है & ६ै. & ళ̧ \\
\hline$\frac{9}{2}$ & & : & & : & $\mp$ & $\stackrel{9}{9}$ & \& & f. & \% & \%ి & in \\
\hline 욜 & & $\vec{i}$ & & $i_{i}$ & ה & : & 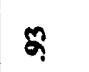 & $\underset{-}{t}$ & $\underset{\sim}{s}$ & $\$$ & 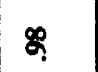 \\
\hline$>$ & & : & & $\bar{\vdots}$ & & . & is & $\vec{m}$ & $\bar{\eta}$ & ఫ్శీ & สุ \\
\hline $\mathbf{z}$ & & 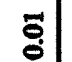 & & 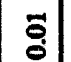 & . & . & $\stackrel{\infty}{a}$ & $\frac{n}{a}$ & $\tilde{a}$ & \% & 8 \\
\hline is & & క్ & & : & శ్రి & $\&$ & $\stackrel{\infty}{\longrightarrow}$ & $\dddot{m}$ & \pm & 8 & 8 \\
\hline$z$ & . &. & & . & ' & ฐి & કุ & ఝ̆ & ؛े & 웅 & n̊a \\
\hline u & . & है? & & ఫ్రి & $\nexists$ & $\tilde{a}$ & $\vec{\pi}$ & శి & જุ & 8 & ఫ్ \\
\hline$F$ & . & $\vec{i}$ & & $\dot{b}_{i}$ & . & $\stackrel{\circ}{m}$ & \% & \% & $\tilde{8}$ & $\tilde{\S}$ & ชิ \\
\hline $\bar{z}$ & , & & $n$ & . & ' & . & . & . & . & . & . \\
\hline $\bar{z}$ & & జี & & $\cdot$ & . & . & . & . & . & & . \\
\hline$\dot{z}_{\mathbf{z}}$ & . & & & $\stackrel{\vec{n}}{3}$ & 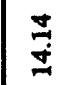 & 悥 & $\%$ & $\stackrel{ \pm}{\Xi}$ & Aิ & $=$ & $\hat{N}$ \\
\hline c) & స్తి & $\Xi$ & స్ & $\cong$ & శ્ & 2 & 8 & 5 & 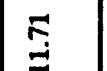 & $\underset{\infty}{\widetilde{\infty}}$ & 5 \\
\hline L & $\dot{\Phi}$ & $\overrightarrow{\mathrm{g}}$ & $\overrightarrow{\mathrm{g}}$ & $\dot{\Phi} \mid$ & I & $\dot{\Phi}$ & $\dot{8}$ & छే & $\overrightarrow{\mathbf{g}}$ & छ & छ \\
\hline$\frac{\delta}{2}$ & 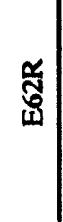 & $\frac{\mathscr{z}}{\widetilde{\alpha}}$ & $\frac{\hat{\theta}}{\alpha}$ & $\mid \begin{array}{l}\Omega \\
\bar{\alpha}\end{array}$ & $\begin{array}{l}\text { ठ․ } \\
\text { हु } \\
\frac{\alpha}{2}\end{array}$ & $\begin{array}{l}E \\
0 \\
0 \\
\frac{\alpha}{2}\end{array}$ & 鸽 & 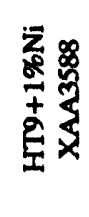 & 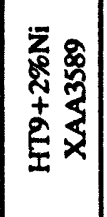 & 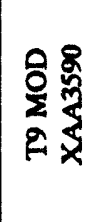 & 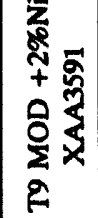 \\
\hline
\end{tabular}


Table 10. Alloy compositions (weight percent) for U. S. Program vanadium alloys.

\begin{tabular}{|c|c|c|c|c|c|c|c|c|c|c|}
\hline ID: & coves. & $\mathbf{v}$ & Cr & TI & OTHER & c & $\mathbf{H}$ & $N$ & 0 & si \\
\hline$B L-1$ & $v-4$ Yyo & B & $\leq 100$ & $<50$ & $4.028 \mathrm{MO}$ & 90 & 8 & 73 & 230 & 110 \\
\hline$B L-2$ & $v-10 w$ & B & $<100$ & $<50$ & $8.6 \% \mathrm{~W}$ & 120 & 11 & 150 & 300 & 59 \\
\hline$B L-3$ & $v-10 N 1$ & B & $\leq 100$ & $\leq 50$ & $22.38 N_{1}$ & 500 & 8 & 280 & 490 & 405 \\
\hline$B L-5$ & $\mathrm{~V}-15 \mathrm{Cr}$ & B & 14.18 & $<50$ & - & 200 & 14 & 69 & 330 & $<50$ \\
\hline$B L-10$ & $v-7.5 C r-15 x i$ & B & 7.28 & 14.5 & & 400 & $<5$ & 250 & 1110 & 400 \\
\hline$B L-12$ & $v-10 T 1$ & B & $<100$ & 9.778 & $0.63 \% \mathrm{Fe}$ & 450 & 9 & 390 & 1670 & 245 \\
\hline$B L-13$ & $V-15 T 1$ & $\mathbf{B}$ & $<100$ & 14.48 & $0.63 * \mathrm{Fe}$ & 440 & 12 & 370 & 1580 & 205 \\
\hline$B L-15$ & $v-2011$ & B & 150 & 17.78 & - & 380 & $<5$ & 160 & 830 & 480 \\
\hline$B Z-18$ & $v-20 T i$ & B & & $20 t$ & & 305 & 5 & 243 & 580 & \\
\hline$B L-20$ & $\mathbf{v}$ & B & $<100$ & $<50$ & & 120 & & 110 & 570 & 325 \\
\hline$B L-21$ & $v-15 C r-5 T i$ & B & 13.78 & 4.88 & & 180 & $<5$ & 510 & 340 & 1150 \\
\hline$B L-22$ & $V-15 \mathrm{Cr}-5 \mathrm{~T} 1$ & $\mathbf{B}$ & 13.48 & 5.18 & & 150 & $<5$ & 52 & 300 & 56 \\
\hline$B L-23$ & $v-15 C r-5 T i$ & B & 12.98 & 5.98 & & 280 & $<9$ & 490 & 400 & 1230 \\
\hline$B L-24$ & $V-15 C r-5 T i$ & B & 13.58 & 5.28 & & 500 & $<5$ & 360 & 1190 & 390 \\
\hline$B L-25$ & $V-15 \mathrm{Cr}-0.3 \mathrm{TI}$ & B & 14.48 & 0.317 & & 120 & 9 & 64 & 390 & $<50$ \\
\hline$B L-26$ & $\mathrm{~V}-15 \mathrm{Cr}-1 \mathrm{Ti}$ & $\mathbf{B}$ & 14.17 & 0.978 & & 140 & 9 & 80 & 560 & $<50$ \\
\hline BL-27 & $V-3 T i-0.25 S i$ & $\mathbf{B}$ & $<50$ & 3.17 & & 310 & 8 & 310 & 210 & 0.251 \\
\hline$B L-40$ & $V-12 C r-5 T i$ & B & 10.98 & 5.08 & & 90 & $<5$ & 80 & 470 & 270 \\
\hline$B L-42$ & $v-3 T i-0.5 s i$ & $\mathbf{B}$ & $<50$ & $3.1 t$ & & 140 & $<5$ & 190 & 580 & 0.548 \\
\hline$B L-43$ & $v-10 \mathrm{Cr}-5 \mathrm{TI}$ & B & 9.28 & 4.98 & & 100 & $<5$ & 31 & 230 & 340 \\
\hline$B L-44$ & $\mathrm{~V}-10 \mathrm{Cr}-10 \mathrm{Ti}$ & $\mathbf{B}$ & 9.98 & 9.28 & & 150 & $<5$ & 87 & 300 & 270 \\
\hline$B L-46$ & $V-5 T i$ & $\mathbf{B}$ & $<100$ & 4.68 & & 100 & $<5$ & 52 & 270 & 150 \\
\hline $\mathrm{BL}-47$ & $v-5 \mathrm{Cr}-5 \mathrm{Ti}$ & $\mathbf{B}$ & 4.18 & 4.38 & & 200 & & 220 & 350 & 870 \\
\hline$B L-50$ & $V-1 T i$ & B & $<100$ & 1.038 & & 235 & & 130 & 230 & 1050 \\
\hline
\end{tabular}

"W" -. BL-47W: specimens from TIG weld zone in V-5Cr-5Ti.

"E" -- BL-47HA: specimens from heat-affected zone adjacent to weld zone in V-5Cr-5Ti. 


\section{REFERENCES}

1. R. L. Senn, "Status of U.S./Japan Collaborative Program Phase II HFIR Target Capsules," Fusion Reactor Materials Semiannual Progress Report for the Period Ending September 30 1987, DOE/ER-0313/3, U.S. DOE Office of Fusion Energy, 1988, p. 8.

2. R. L. Senn, "Status of U.S./Japan Collaborative Program Phase II HFIR Target Capsules," Fusion Reactor Materials Semiannual Progress Report for the Period Ending March 31, 1988, DOE/ER-0313/4, U.S. DOE Office of Fusion Energy, 1988, p. 7.

3. R. L. Senn, "Status of U.S./Japan Collaborative Program Phase II HFIR Target Capsules," Fusion Reactor Materials Semiannual Progress Report for the Period Ending Sept. 30, 1988, DOE/ER-0313/5, U. S. DOE Office of Fusion Energy, 1989, p. 6.

4. K. Shiba, S. Jitsukawa, J. E. Pawel and A. F. Rowcliffe, "Tensile Properties of Base and Weld Metal Specimens of Austenitic Stainless Steels Irradiated in the High Flux Isotope Reactor," this report.

5. A. W. Longest, D. W. Heatherly, K. R. Thoms, and J. E. Corum, "Design and Fabrication of HFIR-MFE-JP Target Irradiation Capsules," Fusion Reactor Materials Semiannual Progress Report for Period Ending March 31, 1991, DOE/ER-0313/10, U.S. DOE Office of Fusion Energy, 1991, p. 3.

6. A. W. Longest, D. W. Heatherly, J. E. Wolfe, K. R. Thoms, and J. E. Corum, "Fabrication and Irradiation of HFIR-MFE-JP-17, -18, and -19 Target Irradiation Capsules," Fusion Reactor Materials Semiannual Progress Report for Period Ending September 30, 1991, DOE/ER-0313/11, U.S. DOE Office of Fusion Energy, 1992, p. 30.

7. A. W. Longest, D. W. Heatherly, K. R. Thoms, and J. E. Corum, "Fabrication and Irradiation of HFIR-MFE-JP-17, -18, and -19 Target Irradiation Capsules," Fusion Reactor Materials Semiannual Progress Report for Period Ending March 31, 1992, DOE/ER-0313/12, U.S. DOE Office of Fusion Energy, 1992, p. 24.

8. D. J. Alexander, J. E. Pawel, M. L. Grossbeck, and A. F. Rowcliffe, "Fracture Toughness of Irradiated Candidate Materials for ITER First Wall/Blanket Structures: Preliminary Results," Fusion Reactor Materials Semiannual Progress Report for Period Ending March 31, 1993, DOE/ER-0313/14, U.S. DOE Office of Fusion Energy, 1993, p. 277.

9. J. E. Pawel, D. J. Alexander, M. L. Grossbeck, A. W. Longest, A. F. Rowcliffe, G. E. Lucas, S. Jitsukawa, A. Hishinuma, and K. Shiba, "Fracture Toughness of Candidate Materials for ITER First Wall, Blanket, and Shield Structures," this report.

10. J. E. Pawel and R. L. Senn, "Status of U.S./Japan Collaborative Program Phase II HFIR Target Capsules," Fusion Reactor Materials Semiannual Progress Report for Period Ending March 31, 1992, DOE/ER-0313/12, U.S. DOE Office of Fusion Energy, 1992, p. 15.

11. A. W. Longest, J. E. Corum, D. W. Heatherly, and K. R. Thoms, "Design and Fabrication of HFIR-MFE RB* Spectrally Tailored Irradiation Capsules," Fusion Reactor Materials Semiannual Progress Report for Period Ending September 30, 1987, DOE/ER-0313/3, U.S. DOE Office of Fusion Energy, 1988, p. 2. 
12. A. W. Longest, J. E. Corum, and D. W. Heatherly, "Design and Fabrication of HFIR-MFE RB* Spectrally Tailored Irradiation Capsules," Fusion Reactor Materials Semiannual Progress Report for Period Ending March 31, 1988, DOE/ER-0313/4, U.S. DOE Office of Fusion Energy, 1988, p. 2.

13. A. W. Longest, J. E. Corum, and D. W. Heatherly, "Design and Fabrication of HFIR-MFE RB* Spectrally Tailored Irradiation Capsules," Fusion Reactor Materials Semiannual Progress Report for Period Ending September 30, 1:88, DOE/ER-0313/5, U.S. DOE Office of Fusion Energy, 1989, p. 2.

14. A. W. Longest, J. E. Pawel, D. W. Heatherly, R. G. Sitterson, and R. L. Wallace, "Fabrication and Operation of HFIR-MFE RB* Spectrally Tailored Irradiation Capsules," Fusion Reactor Materials Semiannual Progress Report for Period Ending March 31, 1993, DOE/ER-0313/14, U.S. DOE Office of Fusion Energy, 1993, p. 14.

15. A. W. Longest, J. E. Pawel, D. W. Heatherly, R. G. Sitterson, and R. L. Wallace, "Fabrication and Operation of HFIR-MFE RB* Spectrally Tailored Irradiation Capsules," this report. 
FABRICATION AND OPERATION OF HFIR-MFE RB* SPECTRALLY TAILORED IRRADIATION CAPSULES - A. W. Longest, J. E. Pawel, D. W. Heatherly, R. G. Sitterson, and R. L. Wallace (Oak Ridge National Laboratory)

\section{OBJECTTVE}

The objective of this work is to fabricate and operate irradiation capsules for irradiating magnetic fusion energy (MFE) candidate first-wall materials in the High Flux Isotope Reactor (HFIR) removable beryllium ( $\mathrm{RB}^{*}$ ) positions. Japanese and U.S. MFE specimens were transferred to $\mathrm{RB}^{*}$ positions following irradiation to approximately $7 \mathrm{dpa}$ at temperatures of $60,200,330$, and $400^{\circ} \mathrm{C}$ in Oak Ridge Research Reactor (ORR) experiments ORR-MFE-6J and -7J.

\section{SUMMARY}

Fabrication and operation of four HFIR-MFE RB* capsules $\left(60,200,330\right.$, and $\left.400^{\circ} \mathrm{C}\right)$ to accommodate MFE specimens previously irradiated in spectrally tailored experiments in the ORR are proceeding satisfactorily. With the exception of the $60^{\circ} \mathrm{C}$ capsule, where the test specimens were in direct contact with the reactor cooling water, specimen temperatures (monitored by 21 thermocouples) are controlled by varying the thermal conductance of a thin gas gap region between the specimen holder outer sleeve and containment tube.

Irradiation of the 60 and $330^{\circ} \mathrm{C}$ capsules, which started on July 17, 1990, was completed on November 14, 1992, after 24 cycles of irradiation to an incremental damage level of approximately 10.9 displacements per atom (dpa). Assembly of the follow-up 200 and $400^{\circ} \mathrm{C}$ capsules was completed in November, 1992, and their planned 20-cycle irradiation to approximately 9.1 incremental dpa was started on November 21, 1992. As of September 4, 1993, the 200 and $400^{\circ} \mathrm{C}$ capsules had successfully completed nine cycles of irradiation to approximately 4.1 incremental dpa.

\section{PROGRESS AND STATUS}

\section{Introduction}

A series of spectrally tailored irradiation capsules are being fabricated and operated as part of the U.S./Japan collaborative program for testing MFE candidate first-wall materials in mixed-spectrum fission reactors. The test specimens are being irradiated in the $\mathrm{RB}^{*}$ facility ${ }^{1}$ of the HFIR.

Four HFIR-MFE RB* capsules were designed to accommodate Japanese and U.S. MFE specimens previously irradiated to approximately $7 \mathrm{dpa}$ at temperatures of $60,200,330$, and $400^{\circ} \mathrm{C}$ in the ORR in spectrally tailored experiments ORR-MFE-6J and -7J. Details of these ORR experiments, including descriptions of the test matrix, mechanical property specimens, and techniques of spectral tailoring, have been reported elsewhere. ${ }^{23}$ Hafnium liners are being used in the HFIRMFE RB* experiments to tailor the neutron spectrum to closely match the helium production-to-atom displacement ratio (14 appm/dpa) expected in a fusion reactor first wall.

The HFIR-MFE RB* capsules are being irradiated in pairs (first the 60 and $330^{\circ} \mathrm{C}$ capsules, then the 200 and $400^{\circ} \mathrm{C}$ capsules) to total damage levels on the reencapsulated specimens of approximately 18 (24 HFIR cycles) and $16 \mathrm{dpa}$ (20 HFIR cycles), respectively. Previously, ${ }^{4}$ the target exposure level was approximately 17 total dpa on the reencapsulated specimens (22 HFIR cycles) for 
all four capsules; however, the 60 and $330^{\circ} \mathrm{C}$ irradiations were extended for two additional cycles until the 200 and $400^{\circ} \mathrm{C}$ capsules were ready to replace them.

\section{$60^{\circ} \mathrm{C}$ Capsule}

The $60^{\circ} \mathrm{C}$ capsule, designated HFIR-MFE-60J-1, was an uninstrumented capsule with the test specimens in contact with the reactor cooling water. Capsule design, assembly, and details of the specimen loading were described previously.

As reported previously, irradiation of this capsule was started on July 17, 1990, and was completed on November 14, 1992, after 24 cycles of irradiation to a total damage level on the reencapsulated specimens of approximately $18 \mathrm{dpa}$. Specimen operating temperatures in this capsule were predicted to be within $10^{\circ} \mathrm{C}$ of $60^{\circ} \mathrm{C}$.

\section{$330^{\circ} \mathrm{C}$ Capsule}

The $330^{\circ} \mathrm{C}$ capsule, designated HFIR-MFE-330J-1, was an instrumented and singly contained capsule where the specimen temperatures were monitored by 21 thermocouples and controlled by adjusting the thermal conductance of a thin gas gap region between the specimen holder outer sleeve and containment tube. This capsule was cooled with $49^{\circ} \mathrm{C}$ reactor cooling water flowing downward over the containment tube surface. Capsule design, assembly, and details of the specimen loading were described previously. ${ }^{7.8}$

As reported previously, irradiation of this capsule was started on July 17, 1990, and was completed on November 14, 1992, after 24 cycles of irradiation to a total damage level on the reencapsulated specimens of approximately $18 \mathrm{dpa}$. Typical thermal operating data for the $330 \mathrm{~J}-1$ experiment were presented in detail previously.?

\section{0 and $400^{\circ} \mathrm{C}$ Capsules}

The 200 and $400^{\circ} \mathrm{C}$ capsule designs are basically the same as that of the $330^{\circ} \mathrm{C}$ capsule. The main differences in the three capsule designs are associated with (1) the number and spacing of the specimen holder slots and holes to accommodate differences in the number of specimens of the various types, (2) the width of the temperature control gas gap region between the specimen holder outer sleeve and containment tube to obtain the desired specimen operating temperatures, and (3) the instrumented test piece included in the aluminum plug and holder above the test specimen holder to obtain extra information. Capsule assembly and details of the specimen loadings in the 200 and $400^{\circ} \mathrm{C}$ capsules were described previously. ${ }^{6.10}$

Irradiation of the 200 and $400^{\circ} \mathrm{C}$ capsules began on November 21,1992 , at the start of HFIR cycle 313. As of September 4,1993, these capsules had successfully completed nine cycles (4.11 dpa) of their planned 20 -cycle $(9.1 \mathrm{dpa})$ irradiation to a total damage level of approximately $16 \mathrm{dpa}$ on the reencapsulated specimens. A cycle-by-cycle summary of their irradiation history through HFIR cycle 321 is given in Table 1. paragraphs.

Thermal operating information for the 200 and $400^{\circ} \mathrm{C}$ capsules is presented in the following

Vertical and horizontal sections through the $200^{\circ} \mathrm{C}$ capsule, designated HFIR-MFE-200J-1, are shown in Figs. 1 and 2, respectively. These figures show the general arrangement of test specimens and thermocouple assemblies in the aluminum alloy specimen holder. Thermocouple junction locations are given in Table 2. Typical thermal operating data for the 200J-1 capsule are shown in Figs. 3 through 9 for HFIR Cycle No. 317 and in Figs. 10 through 16 for HFIR Cycle No. 318. Two 
cycles are required to show pertinent thermal patterns because the capsule is rotated $180^{\circ}$ at the end of each cycle to provide near-uniform neutron exposure to specimens at any given elevation.

Vertical and horizontal sections through the $400^{\circ} \mathrm{C}$ capsule, designated HFIR-MFE-400J-1, are shown in Figs. 17 and 18, respectively. Thermocouple junction locations are given in Table 3. Typical thermal operating data for the 400J-1 capsule are shown in Figs. 19 through 25 for HFIR Cycle No. 319 and in Figs. 26 through 32 for HFIR Cycle No. 320.

As indicated in Figures 2 and 18, there are seven thermocouple assemblies in the aluminum alloy specimen holder of each capsule, each containing three thermocouple elements. These threejunction assemblies were formed by swaging a stainless steel tube containing three individual Type K stainless-steel-sheathed thermocouples to a final diameter of $1.04 \mathrm{~mm}$. In addition, there are three single-junction thermocouples (TE-22, TE-23, and TE-24) in the aluminum plug and holder above the specimen holder to measure temperature rise data for the simulated packet of transmission electron microscopy (TEM) specimens in the 200J-1 capsule and the simulated hourglass fatigue specimen in the $400 \mathrm{~J}-1$ capsule.

Design calculations for these capsules were updated with heat generation rates determined from 330J-1 operating data, and values for the temperature increase from the adjacent instrumented specimen holder to the specimen mid-length peak temperature were calculated. These calculated temperature rise values are $16^{\circ} \mathrm{C}$ for the TEM specimens $\left(12^{\circ} \mathrm{C}\right.$ of which is the temperature increase across $0.0025-\mathrm{cm}$ helium gaps on either side of the tube containing the TEM disks), $12^{\circ} \mathrm{C}$ for the simulated packet of TEM specimens under helium, $46^{\circ} \mathrm{C}$ for the relatively large hourglass fatigue specimens $\left(39^{\circ} \mathrm{C}\right.$ of which is the temperature increase across $0.0076-\mathrm{cm}$ helium gaps on either side of the aluminum alloy assembly holding the hourglass fatigue specimen), $42^{\circ} \mathrm{C}$ for the simulated hourglass fatigue specimen under helium, $12^{\circ} \mathrm{C}$ maximum for the pressurized tube specimens (i.e., before tube deformation, if any, takes place), and $4^{\circ} \mathrm{C}$ for the flat tensile, crack growth, and grodzinski fatigue specimens (based on a $0.0013-\mathrm{cm}$ helium gap between the flat specimens and holder). The calculated temperature rise for the $0.104-\mathrm{cm}$-diameter thermocouple assemblies in the specimen holder is $3^{\circ} \mathrm{C}$ (based on a uniform $0.0064-\mathrm{cm}$ helium gap between the thermocouple assemblies and the holder).

The data acquisition systems being used with the $200 \mathrm{~J}-1$ and $400 \mathrm{~J}-1$ capsules are of the same design as the one used with the 330J-1 capsule. The system for each capsule scans all the sensor signals approximately every six seconds and determines the maximum, minimum, and average temperature indicated by the thermocouples in the specimen holder. The average temperature is used for capsule temperature control and is maintained within about $5^{\circ} \mathrm{C}$ of the control value by manual adjustment of the composition, and hence thermal conductance, of the flowing helium-neon mixture in the control gas gap between the specimen holder outer sleeve and containment tube.

The average temperature is recorded approximately every six seconds; a sample of all other operating data is recorded every minute. These raw data are further reduced to produce plots such as those shown in Figs. 3 through 16 and 19 through 32. The data reduction program reduces each selected parameter to 200 data points for the period being processed. Several modes of data processing are available. These are SAMPLE which gives the last sample in each interval, AVERAGE which gives the average of all samples within the interval, HIGH which gives the highest sample within the interval, and LOW which gives the lowest sample within the interval. In preparation of Figs. 3 through 16 and 19 through 32, the HIGH mode was used for maximum temperature, the LOW mode was used for minimum temperature, and the AVERAGE mode was used for all other parameters. 
Thermal operating data from the 200J-1 capsule are in good agreement with design predictions. The temperature criterion for this experiment was to operate at specimen temperatures within $25^{\circ} \mathrm{C}$ of $200^{\circ} \mathrm{C}$. Based on the temperature measurements shown in Figs. 5 through 8 for HFIR Cycle 317 and in Figs. 12 through 15 for HFIR Cycle 318 (ranging from 167 to $207^{\circ} \mathrm{C}$ ) and the design calculations relating measured temperatures to specimen temperatures, the operating temperature range of all the specimens are close to the temperature criterion range of $175^{\circ} \mathrm{C}$ to $225^{\circ} \mathrm{C}$.

Thermal operating data from the $400 \mathrm{~J}-1$ capsule are close to expectations. The temperature criterion for this experiment was to operate at specimen temperatures within $25^{\circ} \mathrm{C}$ of $400^{\circ} \mathrm{C}$. Based on the temperature measurements to date and the design calculations relating measured temperatures to specimen temperatures, the operating temperature range of the specimens are within the temperature criterion range of $375^{\circ} \mathrm{C}$ to $425^{\circ} \mathrm{C}$ except as noted below for the hourglass fatigue specimens at the lower end of the holder and some of the specimens near the top of the holder. From Figs. 23 and 30, TE-13 and TE-19 at the mid-length elevation of the hourglass fatigue specimens typically operate between 365 and $395^{\circ} \mathrm{C}$ for an average temperature of approximately $380^{\circ} \mathrm{C}$. When the calculated temperature rise of $46^{\circ} \mathrm{C}$ from the holder to the centerline of the hourglass fatigue specimen is added to these measured holder temperatures, there are times during the latter part of a HFIR fuel cycle when the estimated hourglass specimen temperatures may be as high as $450^{\circ} \mathrm{C}$, which is $25^{\circ} \mathrm{C}$ above the criterion range. Also from Figs. 23 and 30, TE-15 and TE-21 near the top of the specimen holder typically operate between 353 and $388^{\circ} \mathrm{C}$; therefore, temperatures of some of the specimens near the top of the holder may be as low as $350^{\circ} \mathrm{C}$ during the early part of a cycle, which is $25^{\circ} \mathrm{C}$ below the criterion range.

No thermocouple failures have occurred in the $200 \mathrm{~J}-1$ and $400 \mathrm{~J}-1$ capsules.

\section{FUTURE WORK}

Design, preparation of fabrication drawings, procurement of parts, and assembly of a capsule for reencapsulating specimens from the above capsules into a dual-temperature capsule (probably $200 / 400^{\circ} \mathrm{C}$ or $60 / 330^{\circ} \mathrm{C}$ ) is scheduled to start in late FY 1994 and be completed in FY 1995.

\section{REFERENCES}

1. K. R. Thoms et al., "HFIR Irradiation Facilities Improvements - Completion of the HIFI Project," J. Nucl. Mater., 155-157 (1988) 1340-45.

2. J. L. Scott et al., pp. 12-20 in ADIP Semiann. Prog. Rep., March 31, 1985, DOE/ER-0045/14, U.S. DOE, Office of Fusion Energy.

3. J. L. Scott et al., Second Annual Prog. Rep. on United States-Japan Collaborative Testing in the High Flux Isotope Reactor and the Oak Ridge Research Reactor, Sept. 30, 1985, ORNL/TM-10102.

4. A. W. Longest et al., "Fabrication and Operation of HFIR-MFE RB* Spectrally Tailored Iradiation Capsules," in Fusion Reactor Materials Semiann. Prog. Rep., March 31, 1992, DOE/ER-0313/12, U.S. DOE, Office of Fusion Energy. 
5. A. W. Longest et al., "Design and Fabrication of HFIR-MFE RB* Spectrally Tailored Irradiation Capsules," in Fusion Reactor Materials Semiann. Prog. Rep., March 31, 1988, DOE/ER-0313/4, U.S. DOE, Office of Fusion Energy.

6. A. W. Longest et al., "Fabrication and Operation of HFIR-MFE RB* Spectrally Tailored Irradiation Capsules, "in Fusion Reactor Materials Semiann. Prog. Rep., March 31, 1993, DOE/ER-0313/14, U.S. DOE, Office of Fusion Energy.

7. A. W. Longest et al., "Design and Fabrication of HFIR-MFE RB* Spectrally Tailored Irradiation Capsules," in Fusion Reactor Materials Semiann. Prog. Rep., Sept. 30, 1987, DOE/ER-0313/3, U.S. DOE, Office of Fusion Energy.

8. A. W. Longest et al., "Design and Fabrication of HFIR-MFE RB* Spectrally Tailored Irradiation Capsules, "in Fusion Reactor Materials Semiann. Prog. Rep., Sept. 30, 1988, DOE/ER-0313/5, U.S. DOE, Office of Fusion Energy.

9. A. W. Longest et al., "Fabrication and Operation of HFIR-MFE RB* Spectrally Tailored Irradiation Capsules,"in Fusion Reactor Materials Semiann. Prog. Rep., Sept. 30, 1991, DOE/ER-0313/11, U.S. DOE, Office of Fusion Energy.

10. A. W. Longest et al., "Fabrication and Operation of HFIR-MFE RB* Spectrally Tailored Irradiation Capsules, "in Fusion Reactor Materials Semiann. Prog. Rep., Sept. 30, 1992, DOE/ER-0313/13, U.S. DOE, Office of Fusion Energy. 
Table 1. IRRADIATION HISTORY OF US/JAPAN SPECTRAL TAILORED CAPSULES HFIR-MFE-60J-1, -330J-1,- 200J-1, AND -400J-1

\begin{tabular}{|c|c|c|c|c|c|c|c|}
\hline \multicolumn{4}{|c|}{ HFIR OPERATION } & \multicolumn{2}{|c|}{$60 \mathrm{~J}-1,330 \mathrm{~J}-1$} & \multicolumn{2}{|c|}{$200 \mathrm{~J}-1,400 \mathrm{~J}-1$} \\
\hline \multirow{2}{*}{$\begin{array}{l}\text { CYCLE } \\
\text { NO. }\end{array}$} & \multirow{2}{*}{$\begin{array}{l}\text { START } \\
\text { DATE }\end{array}$} & \multirow{2}{*}{$\begin{array}{l}\text { END } \\
\text { DATE }\end{array}$} & \multirow{2}{*}{$\begin{array}{l}\text { MWdI } \\
\text { Cycle }\end{array}$} & \multicolumn{2}{|c|}{ INCREMENTAL } & \multicolumn{2}{|c|}{ INCREMENTAL } \\
\hline & & & & MWd & dpa* & MWd & dpa" \\
\hline 289 & $07-17.90$ & $09-07-90$ & 1879 & 1879 & 0.46 & & \\
\hline 290 & $09.19-90$ & $10-11-90$ & 1852 & 3731 & 0.91 & & \\
\hline 291 & $10-17.90$ & $11-13-90$ & 1838 & 5569 & 1.36 & & \\
\hline 292 & $11-25-90$ & $12-10-90$ & 1847 & 7416 & 1.82 & & \\
\hline 293 & $12 \cdot 27.90$ & $01-23-91$ & 1965 & 9381 & 2.30 & & \\
\hline 294 & 02.01 .91 & $02-25-91$ & 1906 & 11287 & 2.77 & & \\
\hline 295 & 03.01 .91 & $03-24-91$ & 1908 & 13195 & 3.23 & & \\
\hline 296 & $04-06-91$ & $04-28-91$ & 1874 & 15069 & 3.69 & & \\
\hline 297 & $05-19-91$ & $06-15-91$ & 1845 & 16914 & 4.14 & & \\
\hline 298 & $06-20-91$ & 07.11 .91 & 1747 & 18661 & 4.57 & & \\
\hline 299 & $07-25-91$ & $08-15-91$ & 1741 & 20402 & 5.00 & & \\
\hline 300 & $08-28-91$ & $09-17-91$ & 1724 & 22126 & 5.42 & & \\
\hline 301 & $09-27.91$ & $10-19-91$ & 1851 & 23977 & 5.87 & & \\
\hline 302 & $10-27-91$ & $11-21-91$ & 1829 & 25806 & 6.32 & & \\
\hline 303 & 12.01 .91 & $12-22-91$ & 1821 & 27627 & 6.77 & & \\
\hline 304 & $12 \cdot 31-91$ & $01-24-92$ & 1826 & 29453 & 7.22 & & 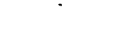 \\
\hline 305 & $01-30-92$ & $02-27.92$ & 1876 & 31329 & 7.68 & & \\
\hline 306 & $03-31-92$ & $04-27-92$ & 1845 & 33174 & 8.13 & & \\
\hline 307 & $05-01-92$ & $05-28-92$ & 1842 & 35016 & 8.58 & & \\
\hline 308 & $06-02-92$ & $06-30-92$ & 1938 & 36954 & 9.05 & & \\
\hline 309 & $07-03-92$ & $08-01-92$ & 1949 & 38903 & 9.53 & & \\
\hline 310 & $08.27-92$ & $09-18-92$ & 1849 & 40752 & 9.98 & & \\
\hline 311 & $09-25-92$ & $10-12-92$ & 1856 & 42608 & 10.44 & & \\
\hline 312 & $10-22-92$ & $11-14-92$ & 1842 & 44450 & 10.89 & BEOIN & E 313 \\
\hline 313 & $11-21-92$ & $12 \cdot 15-92$ & 1850 & REMOVED & 312 & 1850 & 0.45 \\
\hline 314 & $12-20-92$ & $01-12-93$ & 1866 & & & 3716 & 0.91 \\
\hline 315 & $01-19-93$ & $02-11-93$ & 1861 & & & 5577 & 1.37 \\
\hline 316 & $02-17-93$ & $04-03-93$ & $\overline{1807}$ & & & 7384 & 1.81 \\
\hline 317 & $04-23-93$ & $05-14-93$ & 1841 & & & 9225 & 2.26 \\
\hline 318 & $05-20-93$ & $06 \cdot 13.93$ & 1878 & & & 11103 & 2.72 \\
\hline 319 & $06-18-93$ & $07-10-93$ & 1863 & & & 12966 & 3.18 \\
\hline 320 & $07-15-93$ & $08-07-93$ & 1934 & & & 14900 & 3.65 \\
\hline $\begin{array}{l}321 \\
322 \\
\end{array}$ & $08-12-93$ & 09.04 .93 & 1884 & & & 16784 & 4.11 \\
\hline
\end{tabular}

- DPA levels based on achieving $0.0002 \wedge 5 \mathrm{dpa} / \mathrm{MWd}$. 
Table 2. Thermocouple junction locations in the HFIR-MFE-200J-1 Irradiation Capsule

\begin{tabular}{|c|c|c|c|}
\hline \multirow[b]{2}{*}{ Thermocouple number } & \multicolumn{3}{|c|}{ Junction location } \\
\hline & $\begin{array}{l}\text { Axial distance above } \\
\text { reactor core midplane } \\
(\mathrm{cm})\end{array}$ & $\begin{array}{l}\text { Radial distance from } \\
\text { capsule centerline } \\
\text { (cm) }\end{array}$ & $\begin{array}{l}\text { Odd-numbered-cycle } \\
\text { orientation (degrees } \\
\text { clockwise from } \\
\text { direction of reactor } \\
\text { core vertical centerline) }\end{array}$ \\
\hline TE-01 & -10.7 & 0.394 & 349 \\
\hline TE-02 & -0.01 & 0.394 & 349 \\
\hline TE-03 & 10.6 & 0.394 & 349 \\
\hline TE-04 & -10.6 & 0.394 & 169 \\
\hline TE-05 & -0.15 & 0.394 & 169 \\
\hline TE-06 & 10.6 & 0.394 & 169 \\
\hline TE-10 & -6.62 & 1.27 & 259 \\
\hline TE-11 & 2.58 & 1.27 & 259 \\
\hline TE-12 & 6.86 & 1.27 & 259 \\
\hline TE-16 & -6.54 & 1.27 & 79 \\
\hline TE-17 & -2.55 & 1.27 & 79 \\
\hline TE-18 & 6.41 & 1.27 & 79 \\
\hline TE-13 & -14.2 & 1.27 & 349 \\
\hline TE-14 & 0.06 & 1.27 & 349 \\
\hline TE-15 & 14.3 & 1.27 & 349 \\
\hline TE-19 & -14.1 & 1.27 & 169 \\
\hline TE-:0 & -0.08 & 1.27 & 169 \\
\hline TE-2 & 14.2 & 1.27 & 169 \\
\hline TE-07 & -2.53 & 0.795 & 287 \\
\hline TE-08 & -0.03 & 0.795 & 287 \\
\hline TE-09 & 2.51 & 0.795 & 287 \\
\hline TE-22 & 20.3 & $\mathbf{0}$ & Not applicable \\
\hline TE-23 & 20.4 & 0.394 & 45 \\
\hline TE.24 & 20.5 & 0.394 & 225 \\
\hline
\end{tabular}

- Capsule is rotated $180^{\circ}$ at the end of each HFIR fuel cyclc. For odd-numbercd cycles, the experiment identification tab points toward the reactor centerline. For even-numbered cycles, the experiment identification tab points $180^{\circ}$ away from the reactor centerline. 
Table 3. Thermocouple junction locations in the HFIR-MFE-400J-1 Irradiation Capsule

\begin{tabular}{|c|c|c|c|}
\hline \multirow[b]{2}{*}{ Thermocouple number } & \multicolumn{3}{|c|}{ Junction location } \\
\hline & $\begin{array}{l}\text { Axial distance above } \\
\text { reactor core midplane } \\
\text { (cm) }\end{array}$ & $\begin{array}{l}\text { Radial distance from } \\
\text { capsule centerline } \\
\text { (cm) }\end{array}$ & $\begin{array}{l}\text { Odd-numbered-cycle } \\
\text { orientation (degrees } \\
\text { clockwise from } \\
\text { direction of reactor } \\
\text { core vertical centerline) }\end{array}$ \\
\hline TE-01 & -10.6 & 0.302 & $\mathbf{0}$ \\
\hline TE.02 & -0.08 & 0.302 & $\mathbf{0}$ \\
\hline TE-03 & 10.6 & 0.302 & $\mathbf{0}$ \\
\hline TE-04 & -10.7 & 0.302 & 180 \\
\hline TE-05 & -0.14 & 0.302 & 180 \\
\hline TE-06 & 10.5 & 0.302 & 180 \\
\hline TE.10 & -6.54 & 1.27 & 284 \\
\hline TE-11 & 2.45 & 1.27 & 284 \\
\hline TE-12 & 6.54 & 1.27 & 284 \\
\hline TE-16 & -6.57 & 1.27 & 104 \\
\hline TE-17 & -2.50 & 1.27 & 104 \\
\hline TE-18 & 6.61 & 1.27 & 104 \\
\hline TE-13 & -12.9 & 1.27 & 352 \\
\hline TE-14 & 0.08 & 1.27 & 352 \\
\hline TE-15 & 14.3 & 1.27 & 352 \\
\hline TE-19 & -13.2 & 1.27 & 189 \\
\hline TE-20 & -0.21 & 1.27 & 189 \\
\hline TE-21 & 14.1 & 1.27 & 189 \\
\hline TE-07 & -2.17 & 1.07 & 258 \\
\hline TE.08 & -0.37 & 1.07 & 258 \\
\hline TE-09 & 2.81 & 1.07 & 258 \\
\hline TE-22 & 20.9 & 0.523 & 270 \\
\hline TE-23 & 20.9 & 0.831 & 321 \\
\hline TE-24 & 21.0 & 0.831 & 219 \\
\hline
\end{tabular}

- Capsule is rotated $180^{\circ}$ at the end of each HFIR fuel cycle. For-odd numbered cycles, the experiment identification tab points toward the reactor centerline. For even-numbered cycles, the cxperiment identification tab points $180^{\circ}$ away from the reactor centerline. 


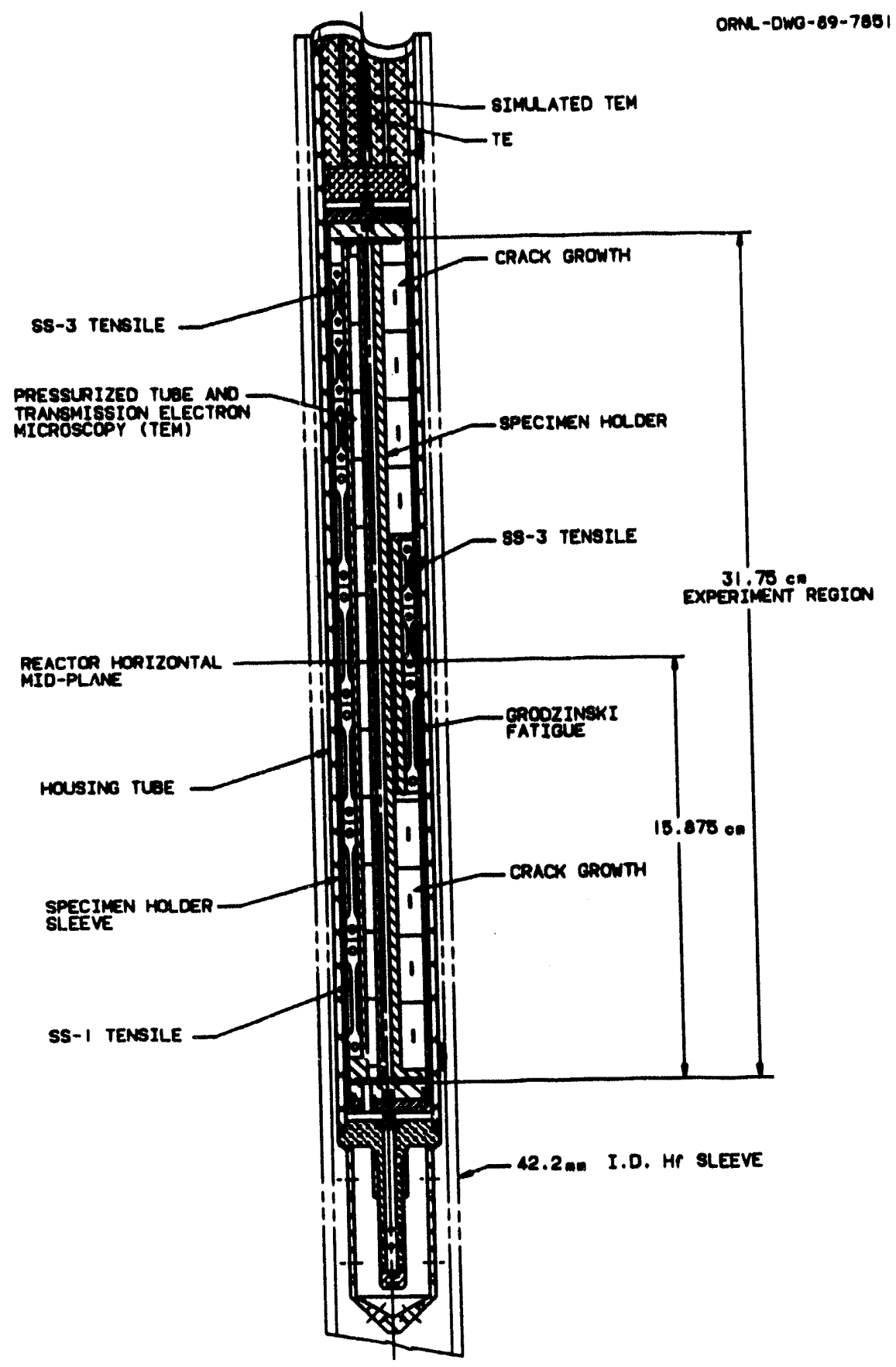

Fig. 1. Vertical section through the HFIR-MFE-200J-1 capsule. 
ORNL-DWG 93-15796
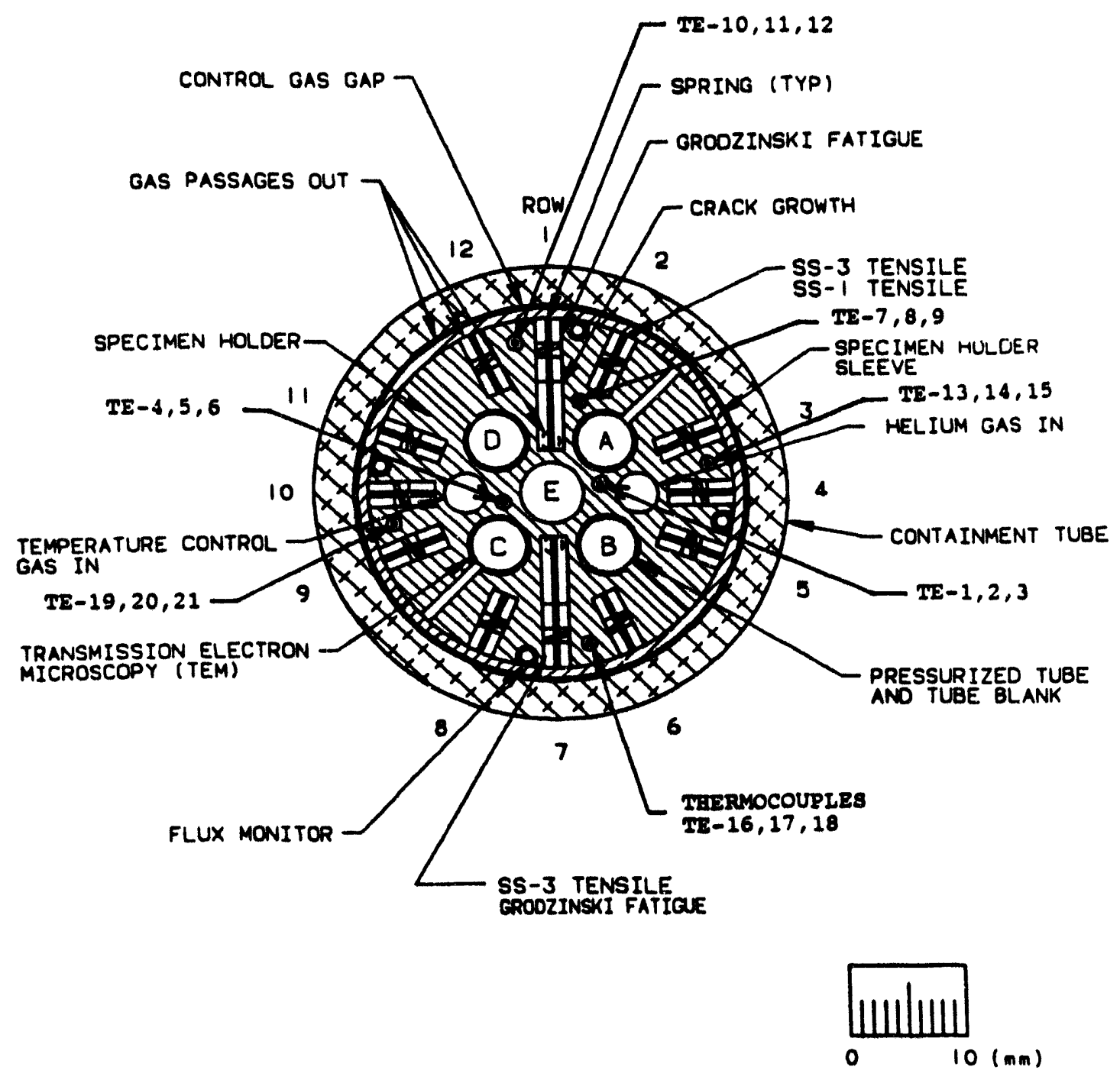

Fig. 2. Horizontal section through the HFIR-MFE-200J-1 capsule. 


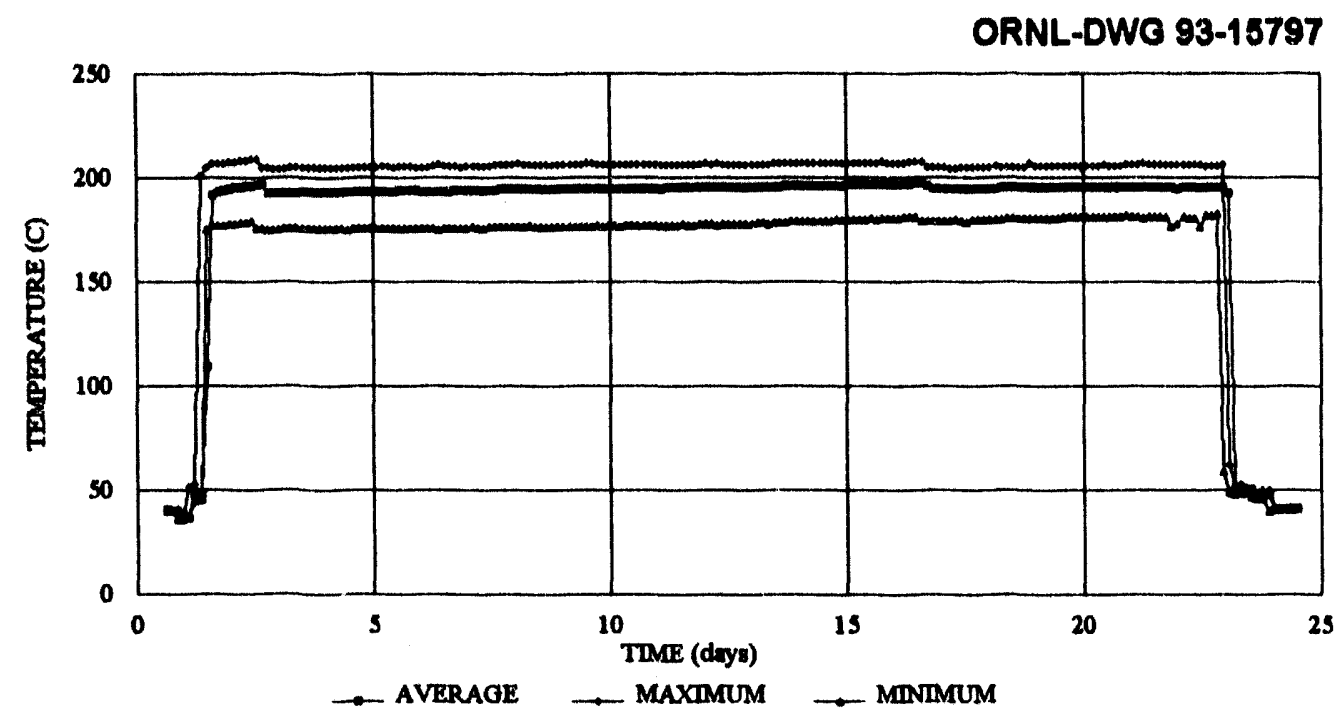

Fig. 3. Specimen holder temperatures in the HFIR-MFE-200J-1 capsule during HFIR Cycle 317. (TIME $0=0000$ hours on April 21, 1993).

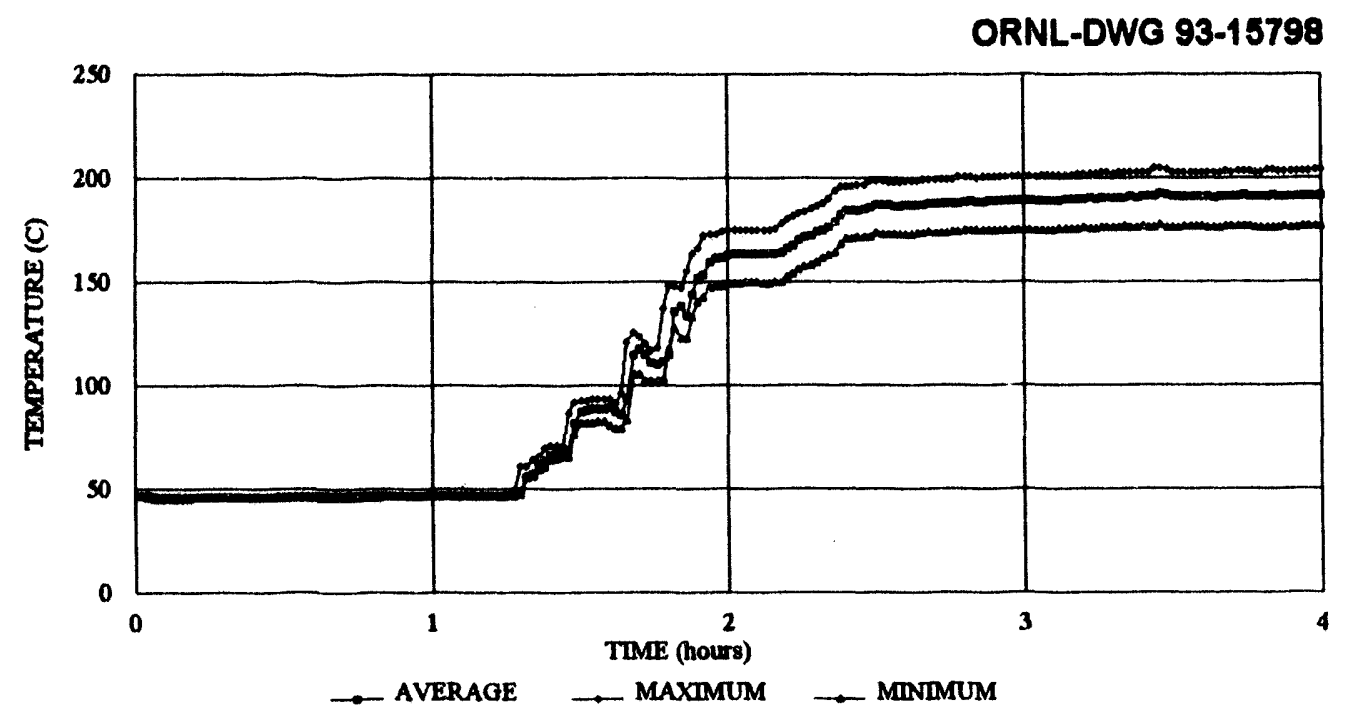

Fig. 4. Specimen holder temperatures in the HFIR-MFE-200J-1 capsule during HFIR Cycle 317 start-up on April 22, 1993. (TIME $0=0800$ hours on April 22, 1993). 


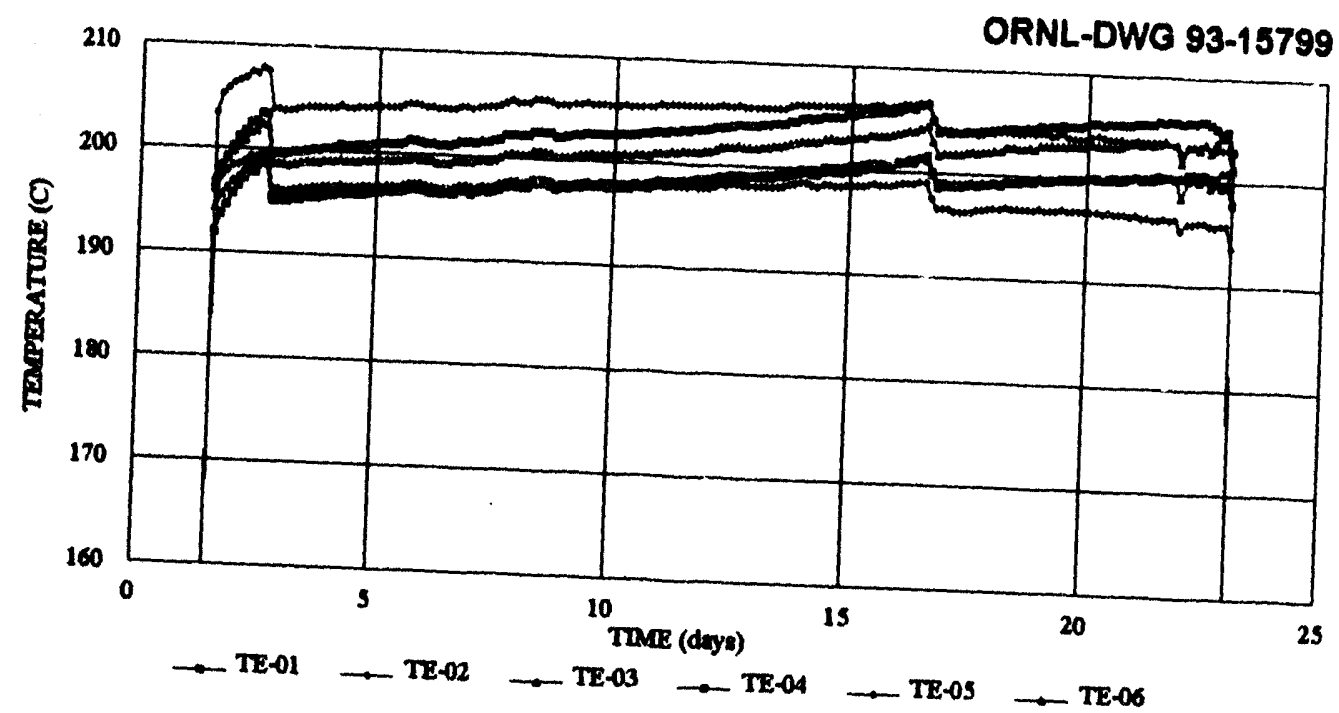
Fig. 5. Individual thermocouple readings in the HFIR-MFE-200J-1 capsule during
HFIR Cycle 317. (TIME $0=0000$ hours on April 21, 1993).

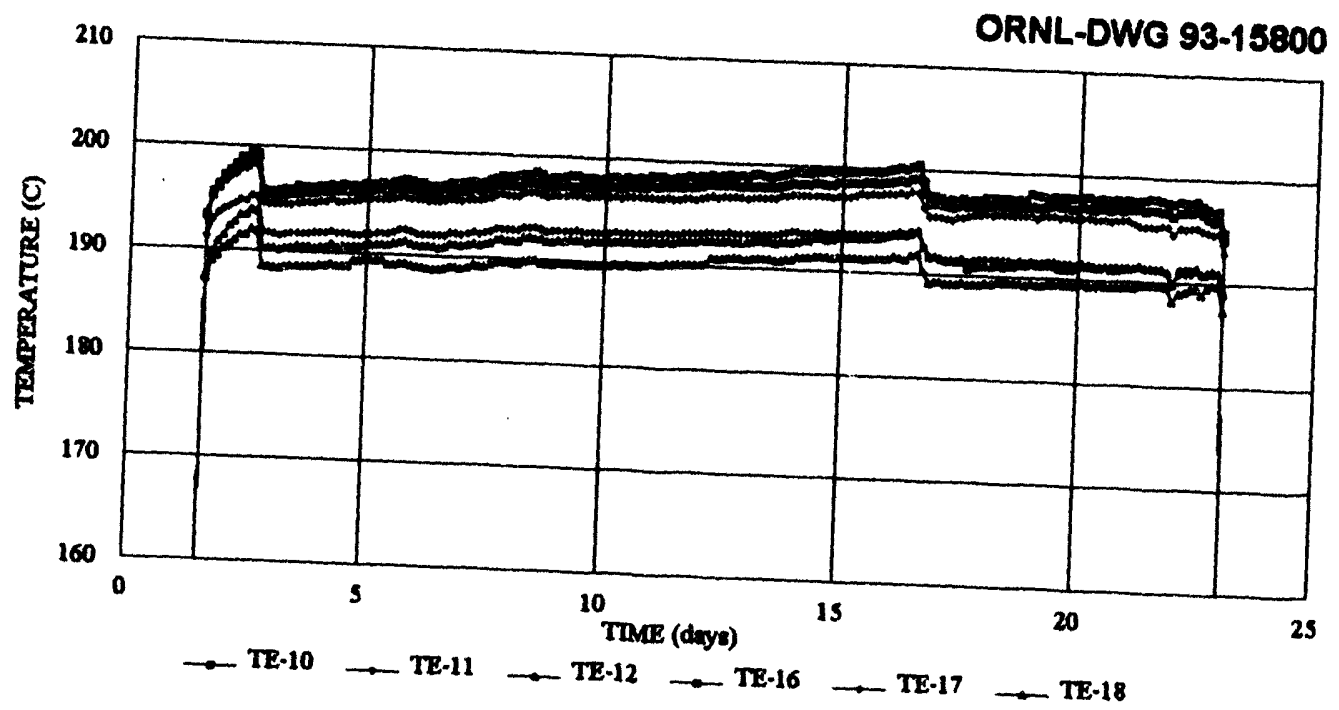
Fig. 6. Individual thermocouple readings in the HFIR-MFE-200J-1 capsule during
HFIR Cycle 317. (TIME $0=0000$ hours on April 21, 1993). 


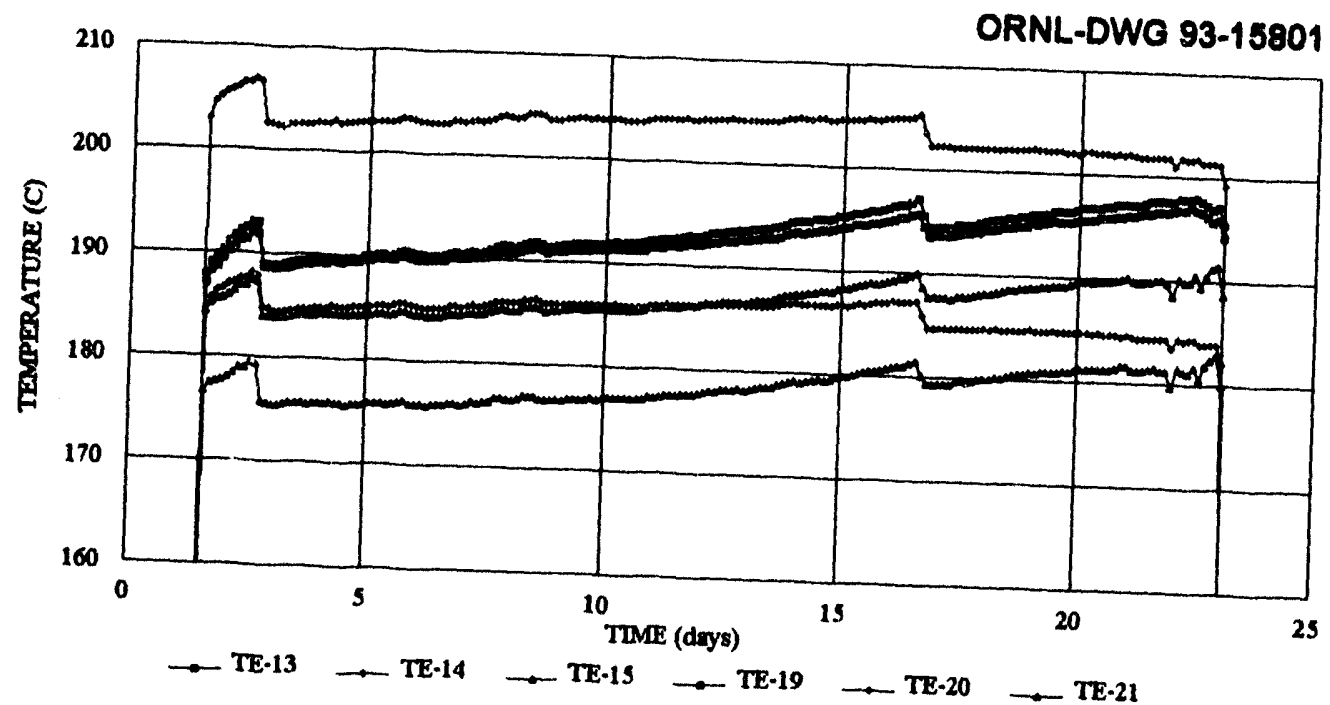

Fig. 7. Individual thermocouple readings in the HFIR-MFE-200J-1 capsule during HFIR Cycle 317. (TIME $0=0000$ hours on April 21, 1993).

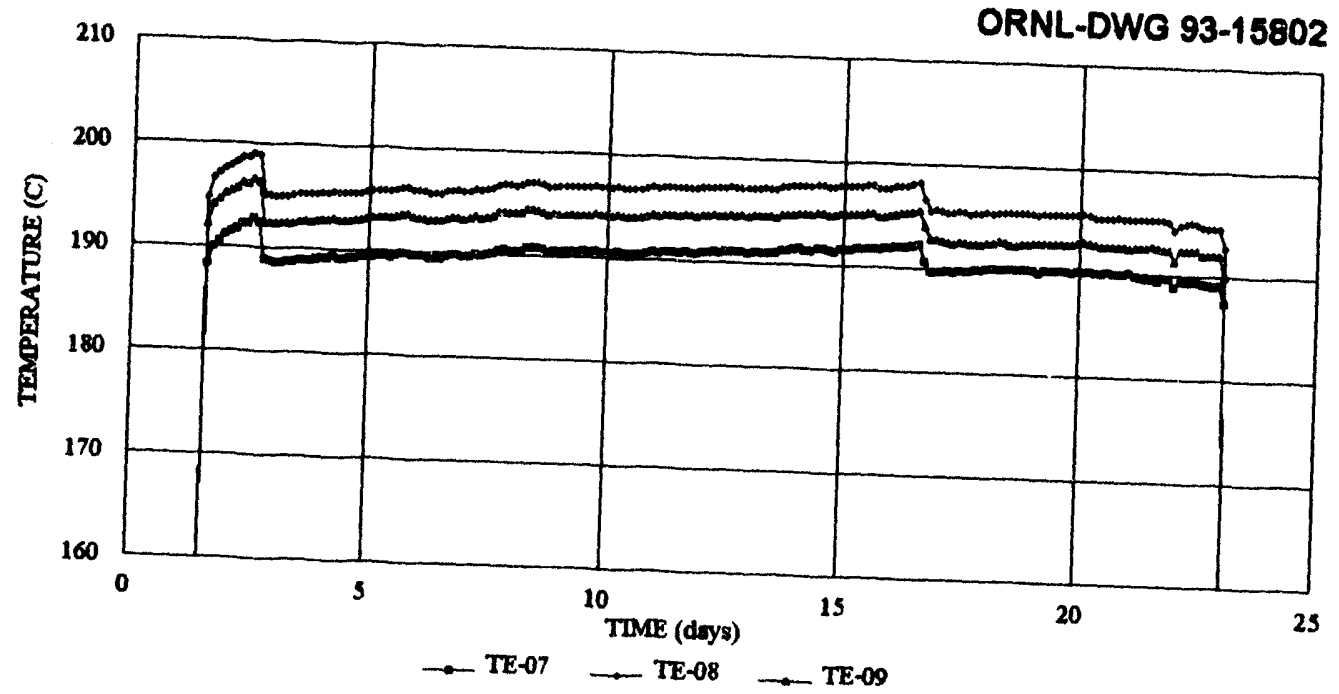

Fig. 8. Individual thermocouple readings in the HFIR-MFE-200J-1 capsule during
HFIR Cycle 317. (TIME $0=0000$. HFIR Cycle 317. (TIME $0=0000$ hours on April 21, 1993). 
ORNL-DWG 93-15803

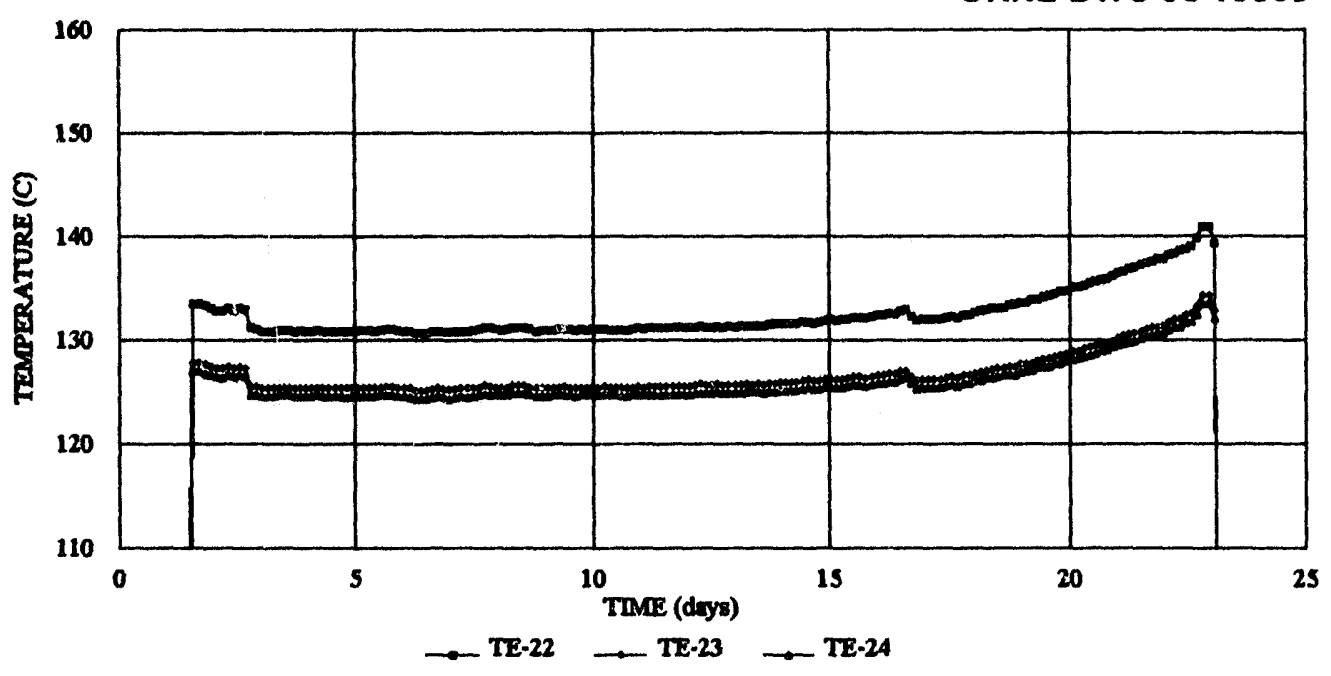

Fig. 9. Individual thermocouple readings in the HFIR-MFE-200J-1 capsule during HFIR Cycle 317. (TIME $0=0000$ hours on April 24, 1993). 


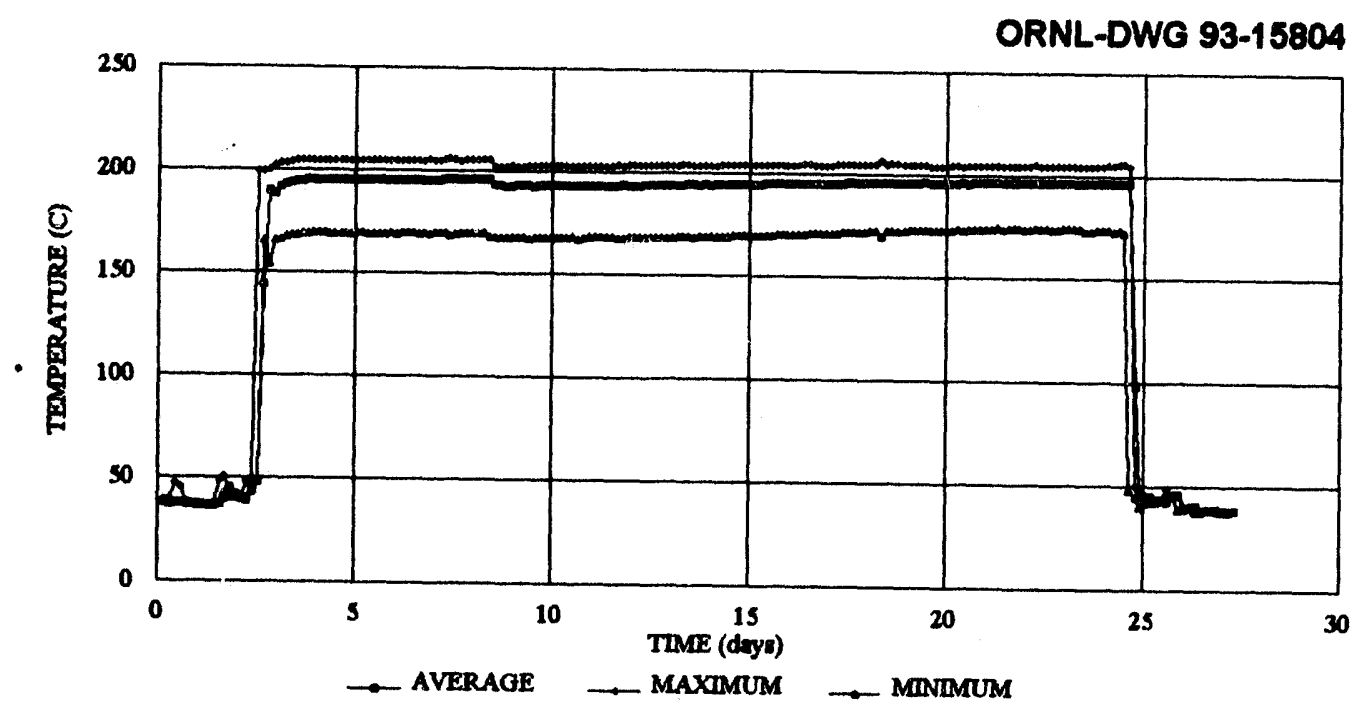

Fig. 10. Specimen holder temperatures in the HFIR-MFE-200J-1 capsule during HFIR Cycle 318. (TIME $0=0000$ hours on May 20, 1993).

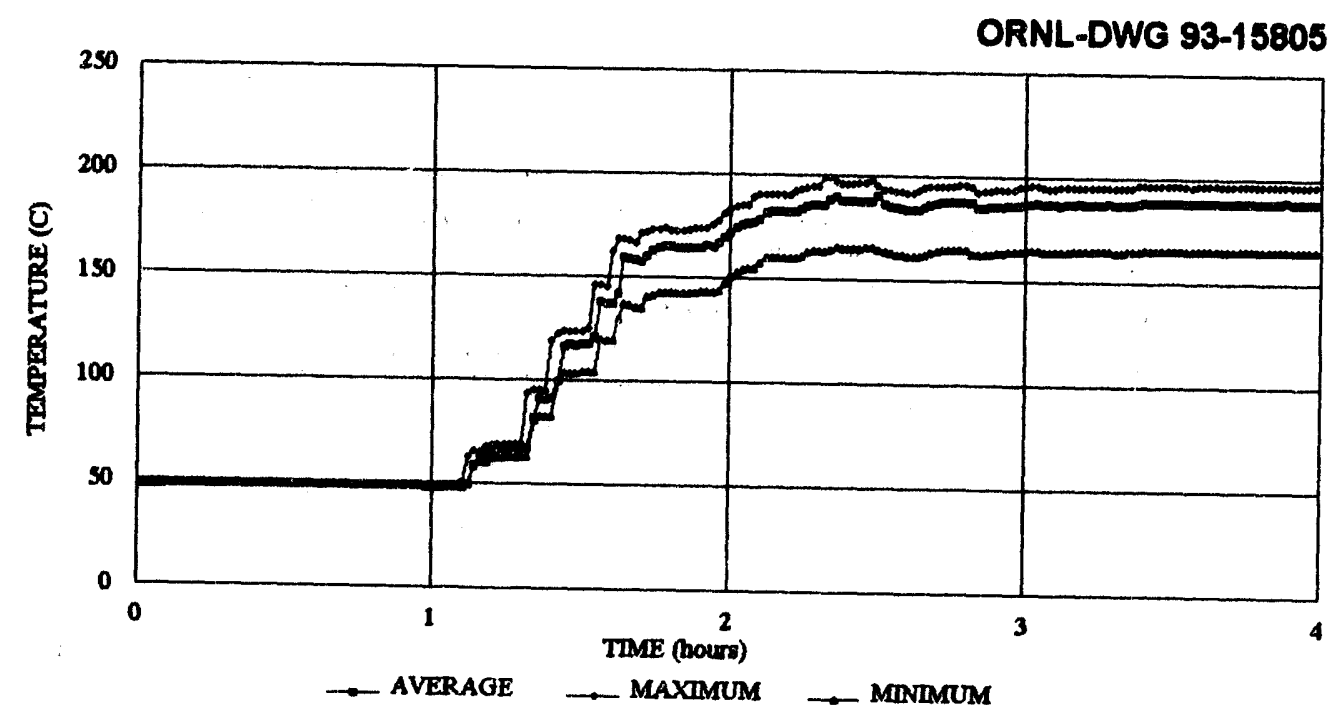

Fig. 11. Specimen holder temperatures in the HFIR-MFE-200J-1 capsule during HFIR Cycle 318 start-up on May 22, 1993. (TIME $0=1200$ hours on May 22, 1993). 


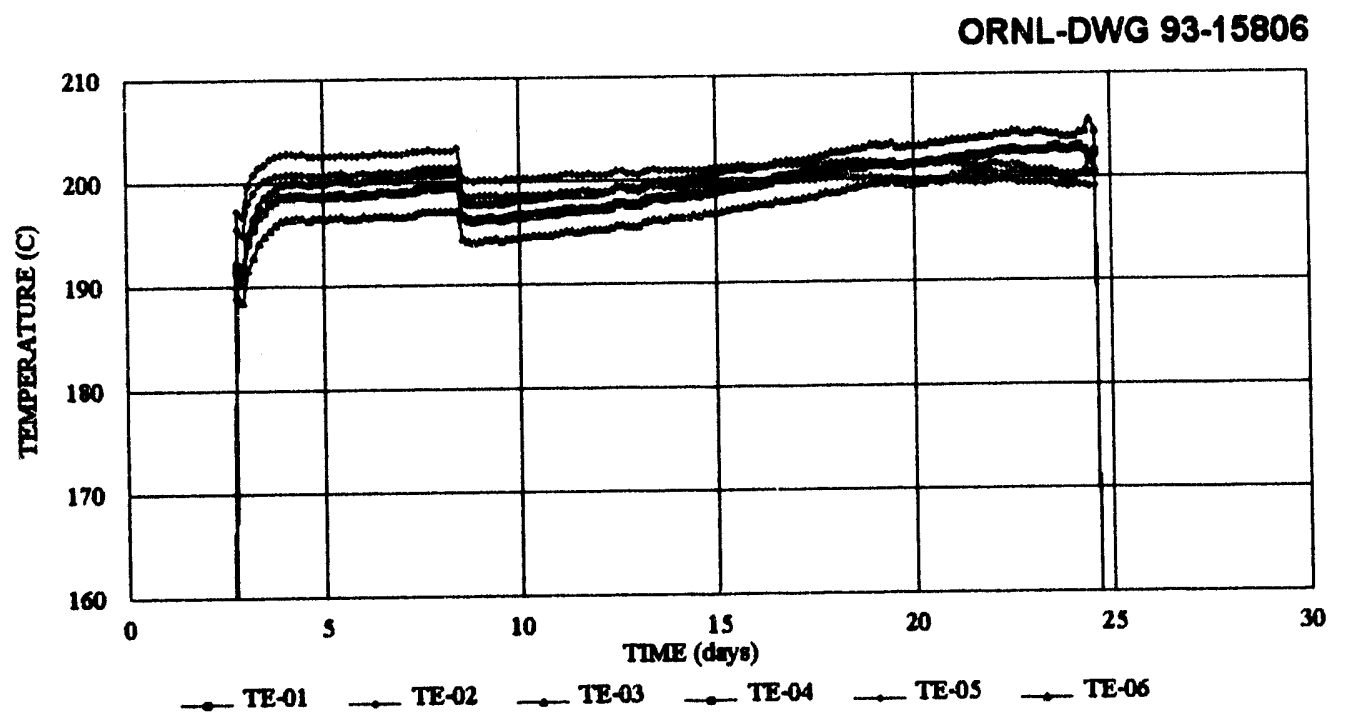

Fig. 12. Individual thermocouple readings in the HFIR-MFE-200J-1 capsule during HFIR Cycle 318. (TIME $0=0000$ hours on May 20, 1993).

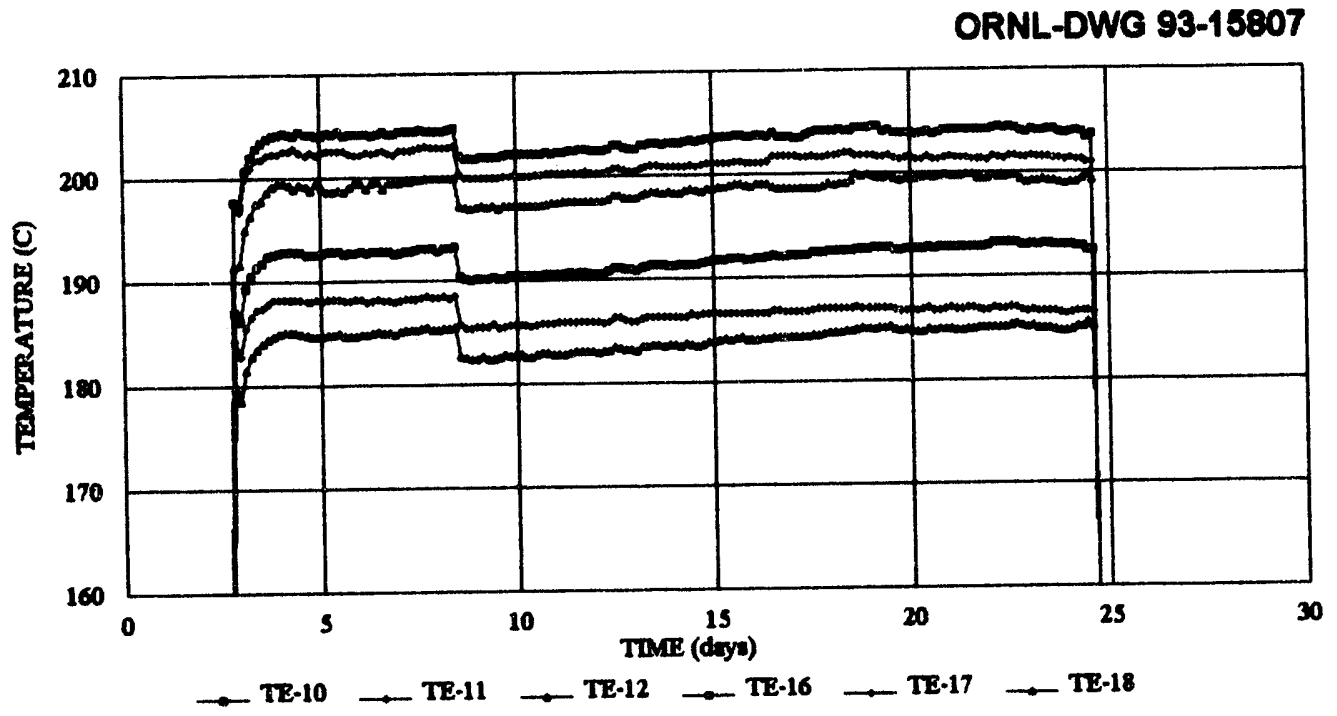

Fig. 13. Individual thermocouple readings in the HFIR-MFE-200J-1 capsule during HFIR Cycle 318. (TIME $0=0000$ hours on May 20, 1993). 


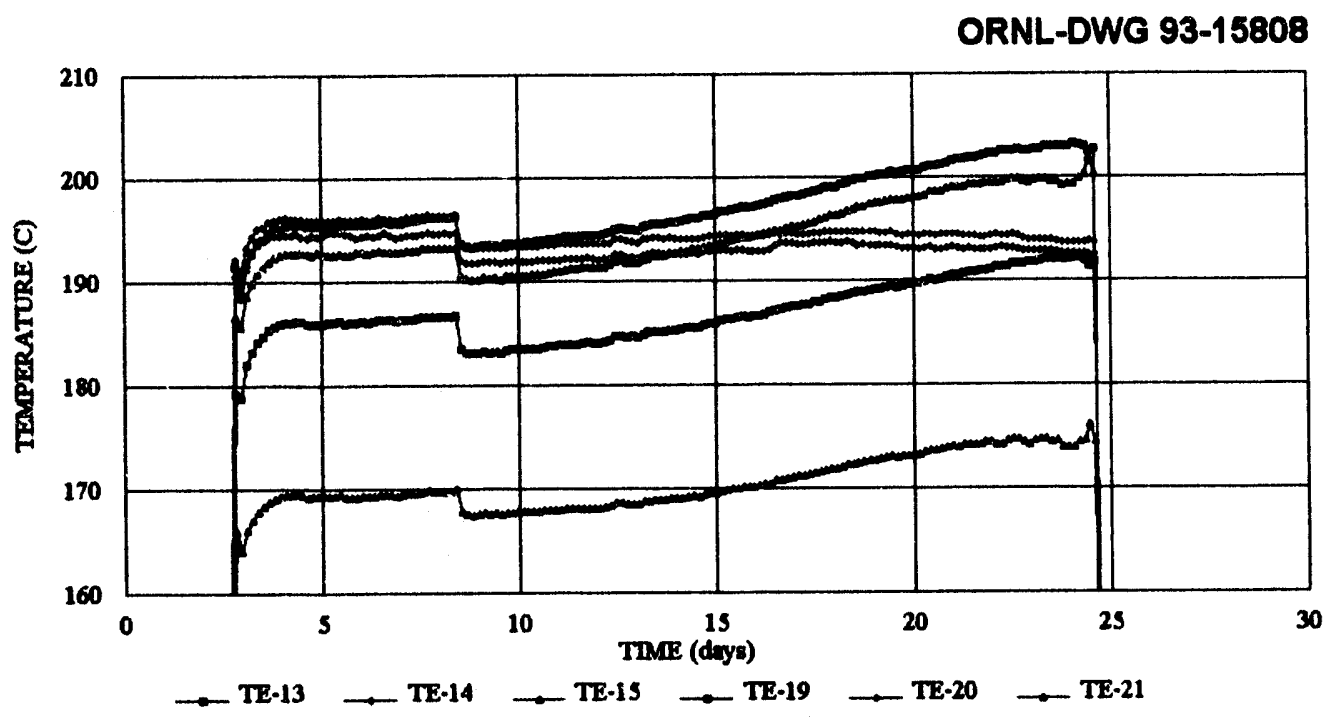

Fig. 14. Individual thermocouple readings in the HFIR-MFE-200J-1 capsule during HFIR Cycle 318. (TIME $0=0000$ hours on May 20, 1993).

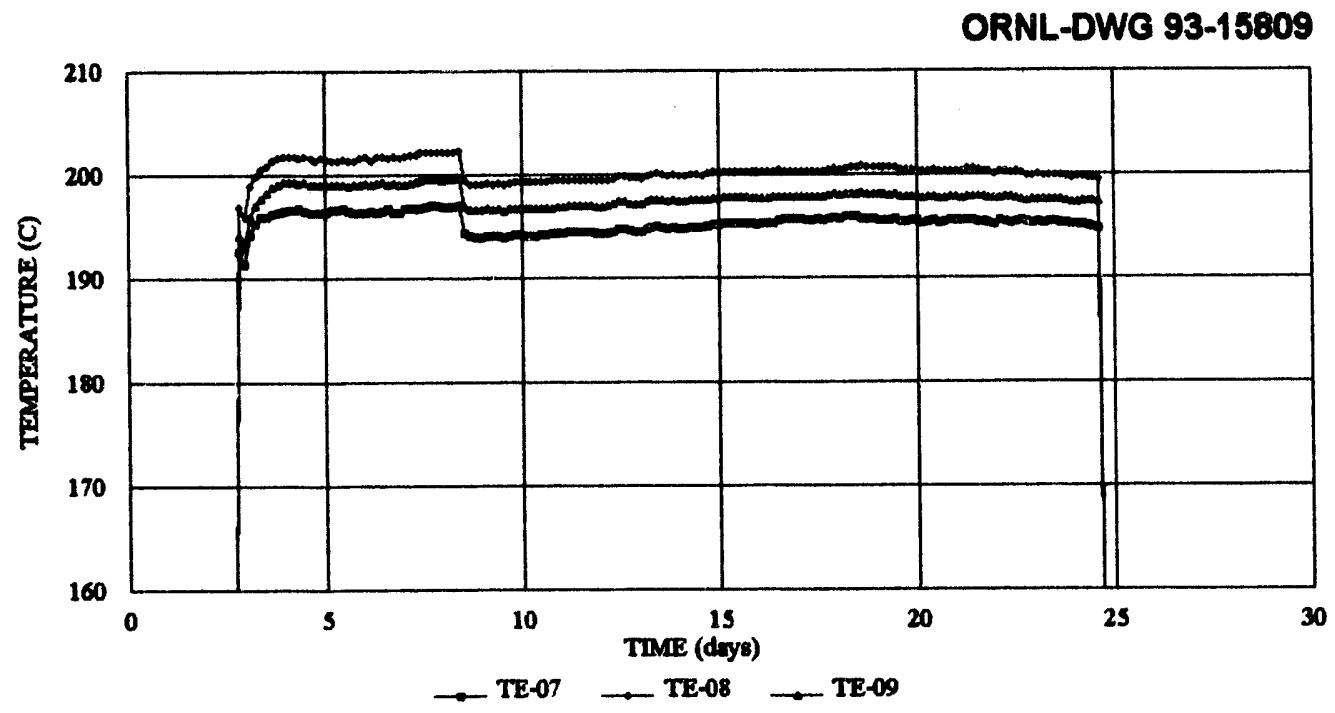

Fig. 15. Individual thermocouple readings in the HFIR-MFE-200J-1 capsule during HFIR Cycle 318. (TIME $0=0000$ hours on May 20, 1993). 
ORNL-DWG 93-15810

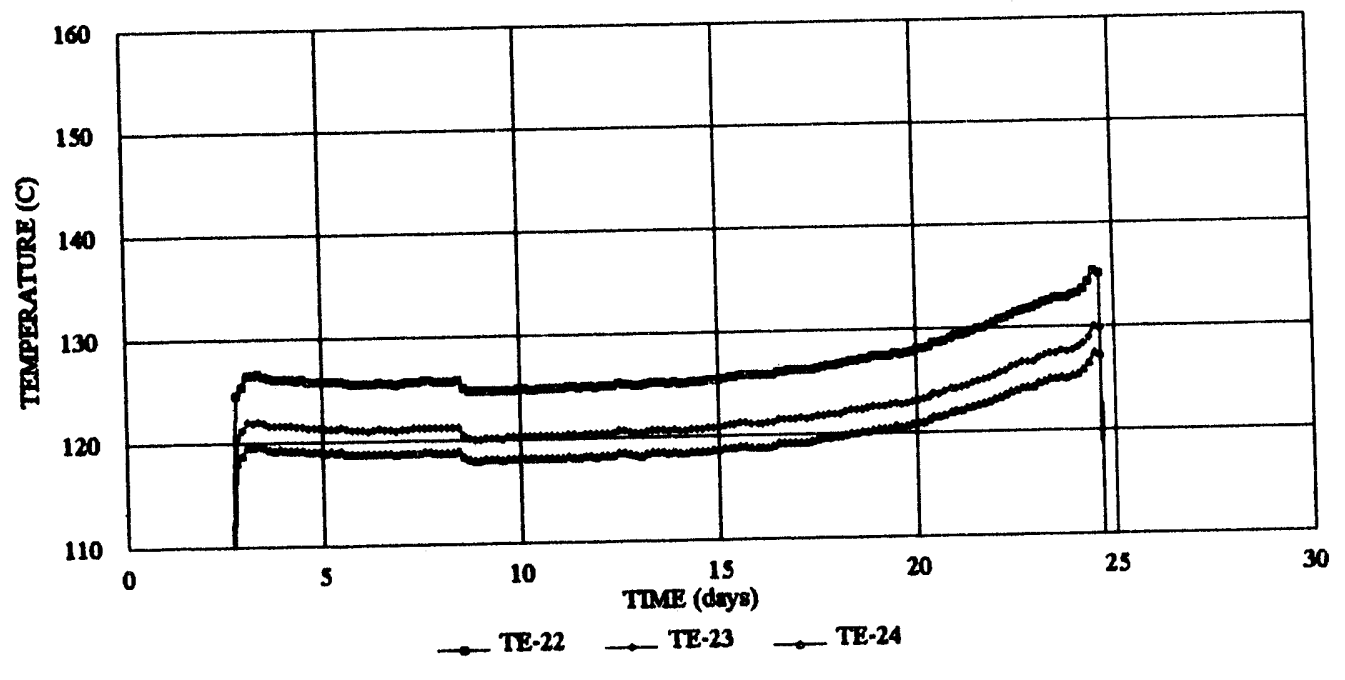

Fig. 16. Individual thermocouple readings in the HFIR-MFE-200J-1 capsule during HFIR Cycle 318. (TIME $0=0000$ hours on May 20, 1993). 


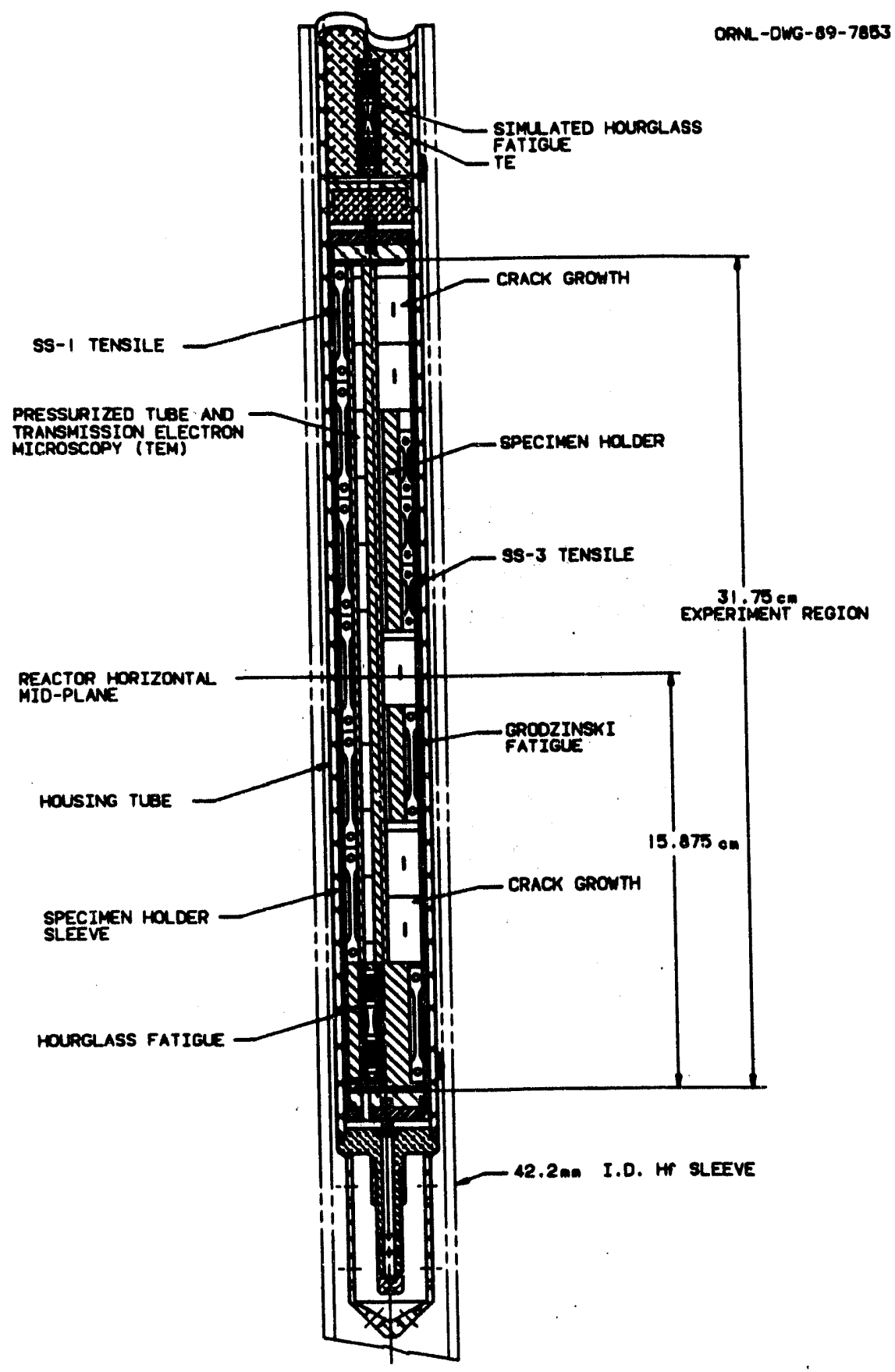

Fig. 17. Vertical section through the HFIR-MFE-400J-1 capsule. 
ORNL-DWG 93-15811

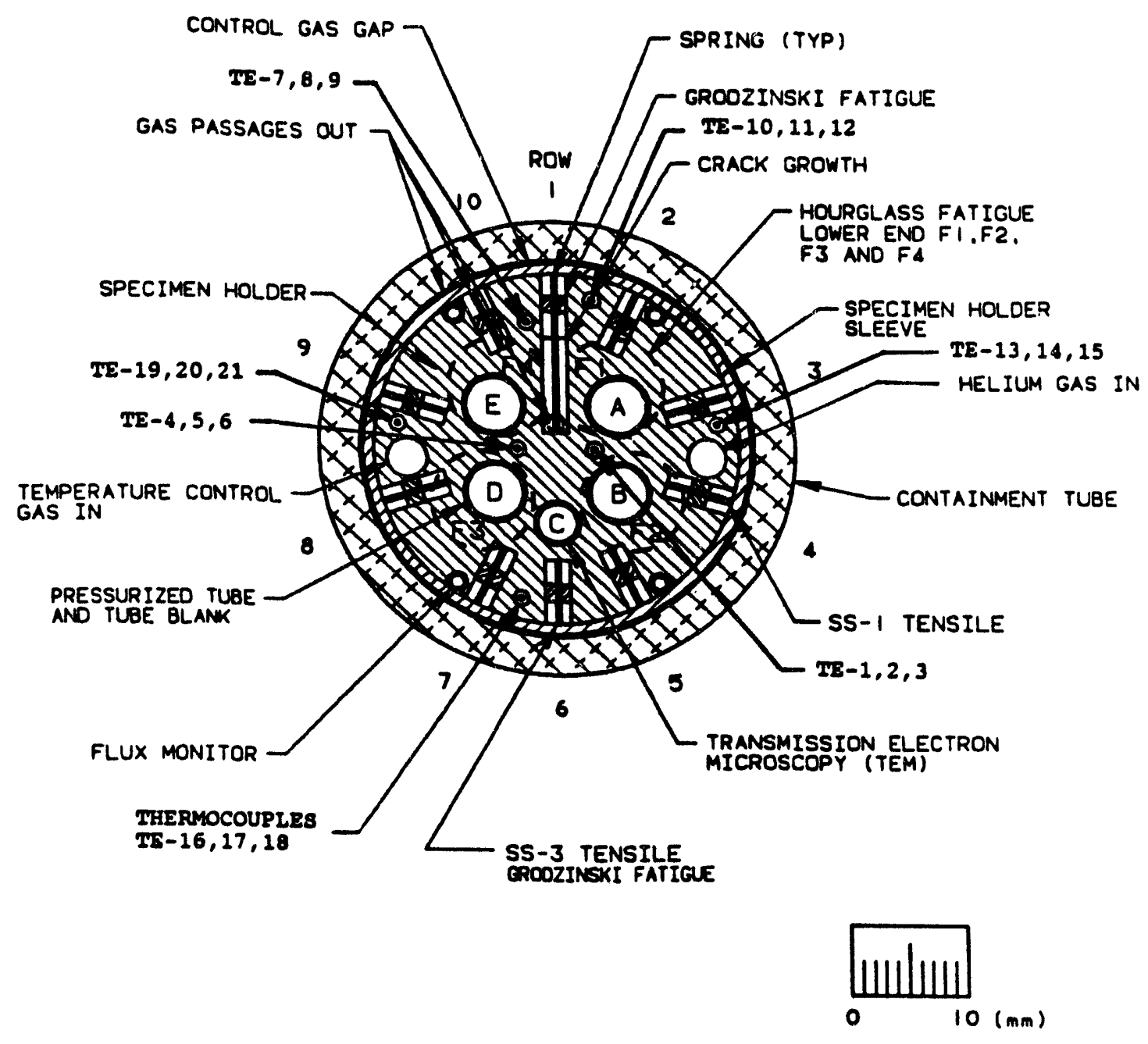

Fig. 18. Horizontal section through the HFIR-MFE-400J-1 capsule. 
ORNL-DWG 93-15812

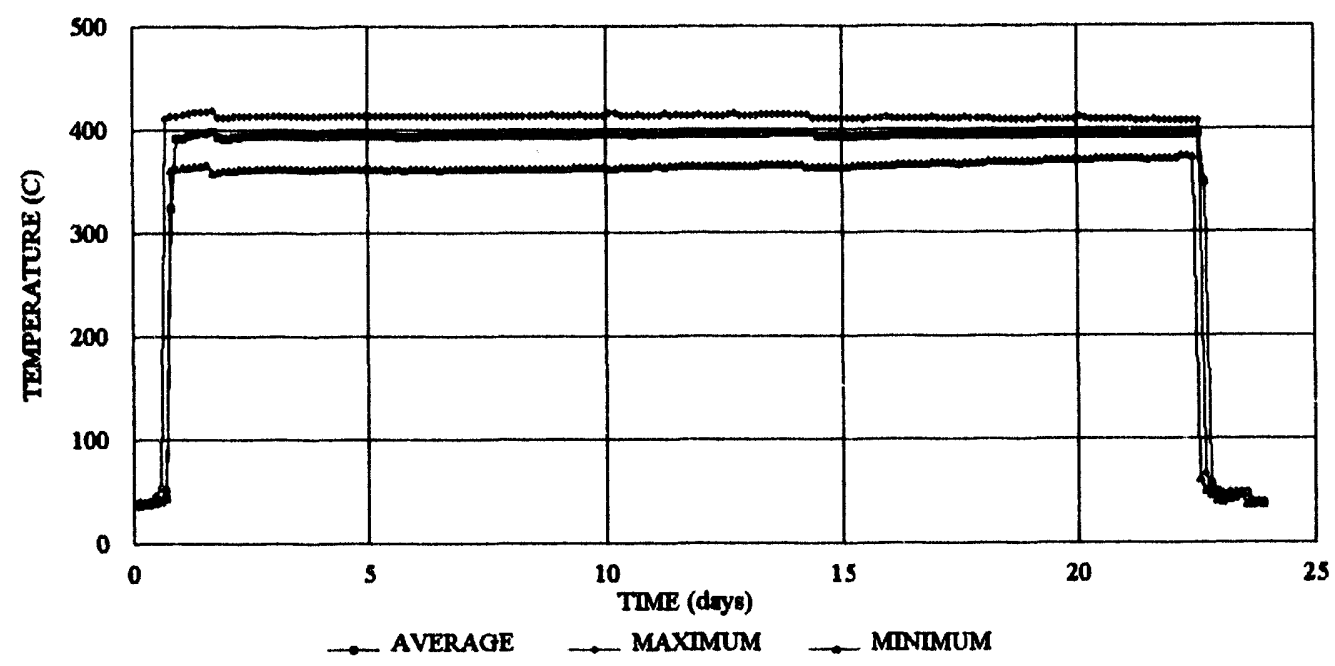

Fig. 19. Specimen holder temperatures in the HFIR-MFE-400J-1 capsule during HFIR Cycle 319. (TIME $0=0000$ hours on June 18, 1993).

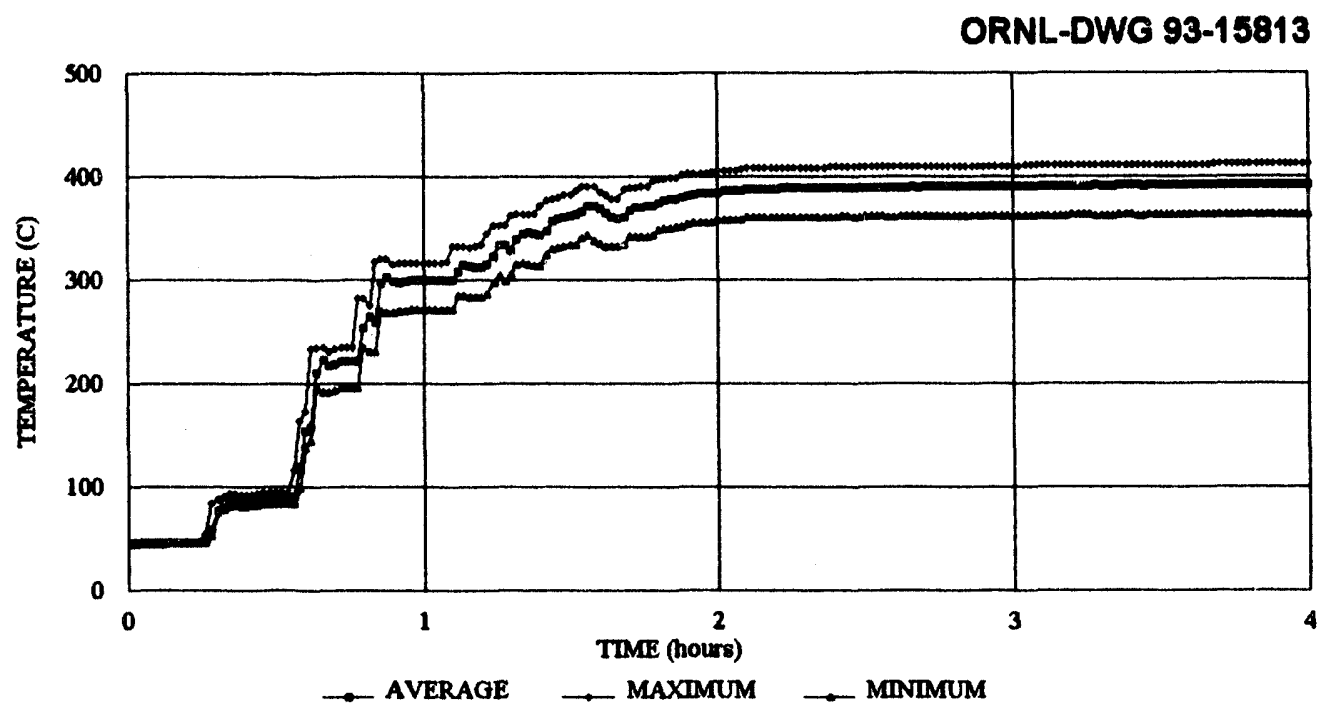

Fig. 20. Specimen holder temperatures in the HFIR-MFE-400J-1 capsule during HFIR Cycle 319 start-up on June 18, 1993. (TIME $0=1700$ hours on June 18, 1993). 


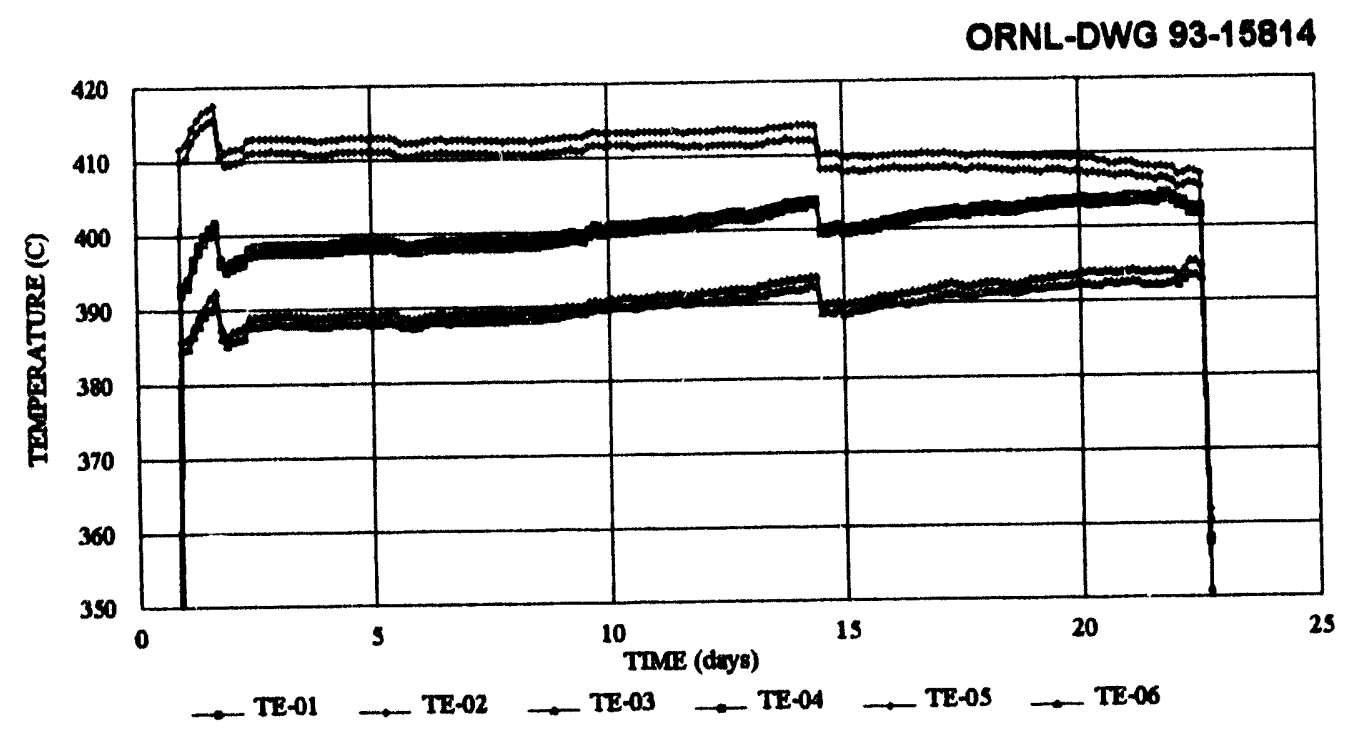

Fig. 21. Individual thermocouple readings in the HFIR-MFE-400J-1 capsule during HFIR Cycle 319. (TIME $0=0000$ hours on June 18, 1993).

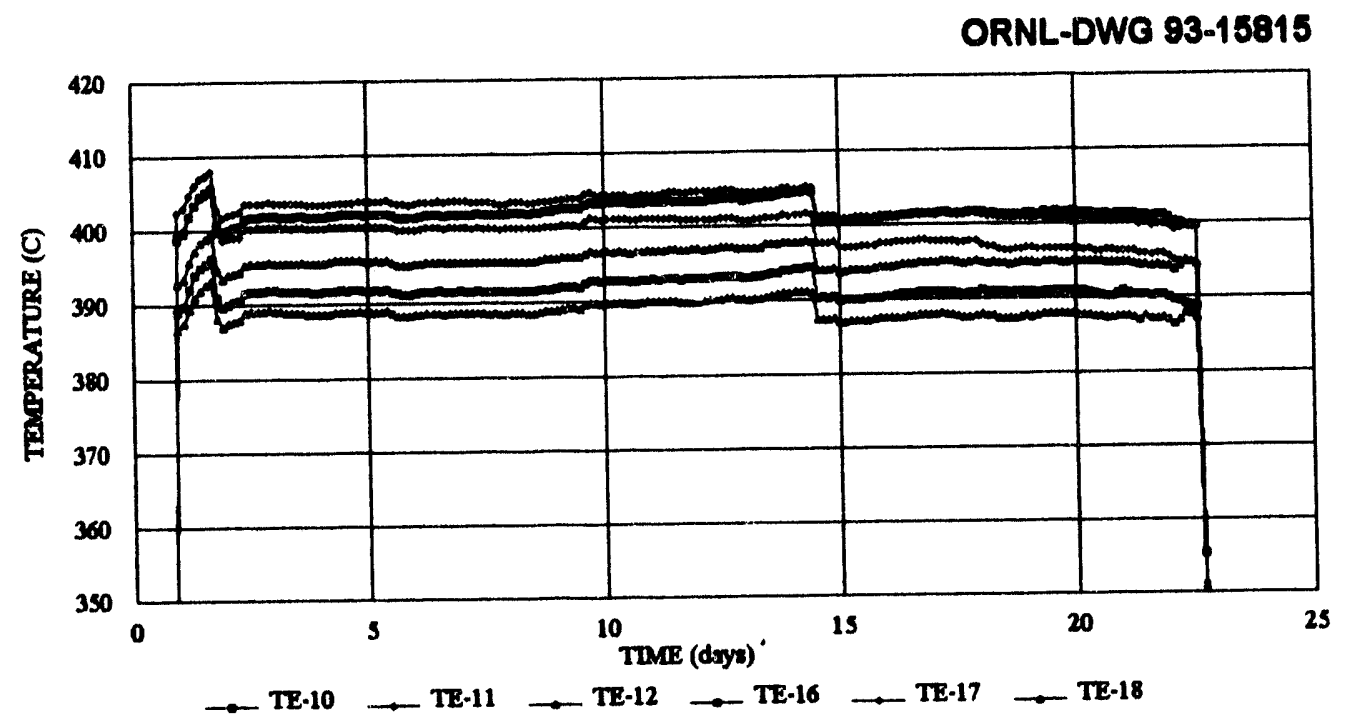

Fig. 22. Individual thermocouple readings in the HFIR-MFE-400J-1 capsule during HFIR Cycle 319. (TIME $0=0000$ hours on June 18, 1993). 


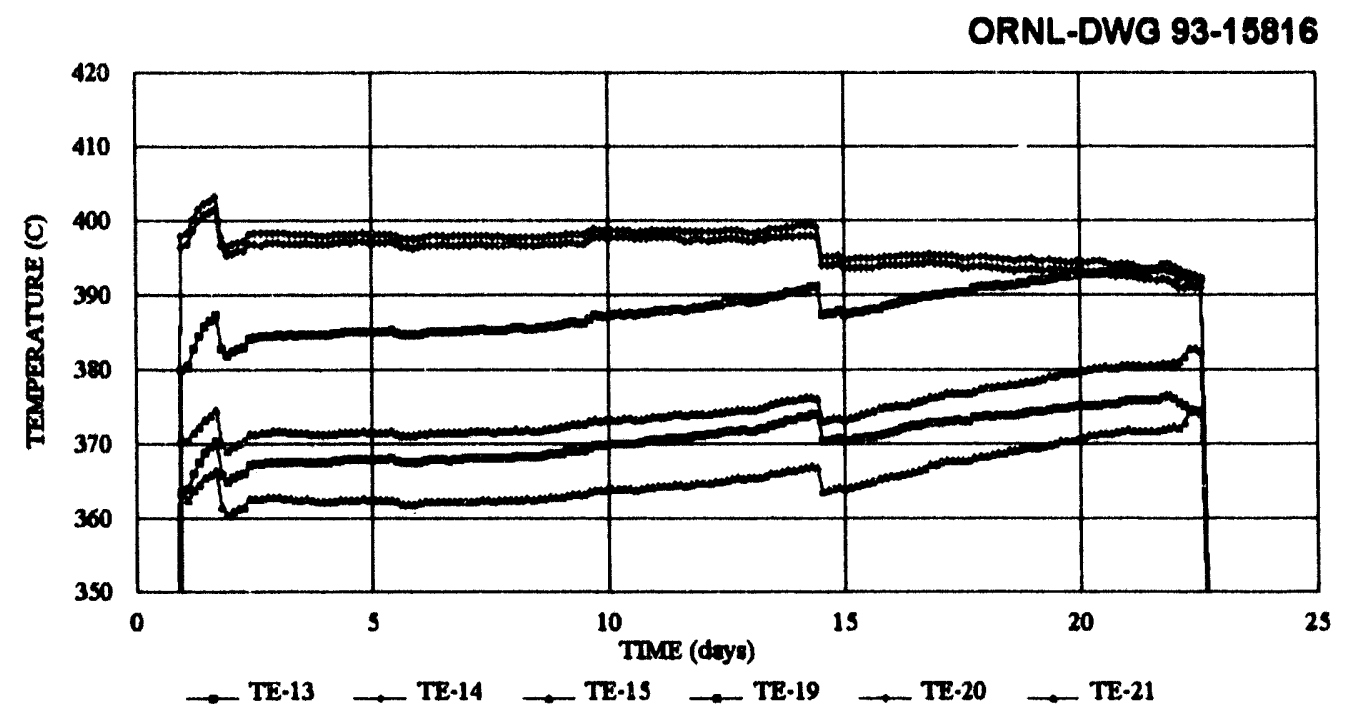

Fig. 23. Individual thermocouple readings in the HFIR-MFE-400J-1 capsule during HFIR Cycle 319. (TIME $0=0000$ hours on June 18, 1993).

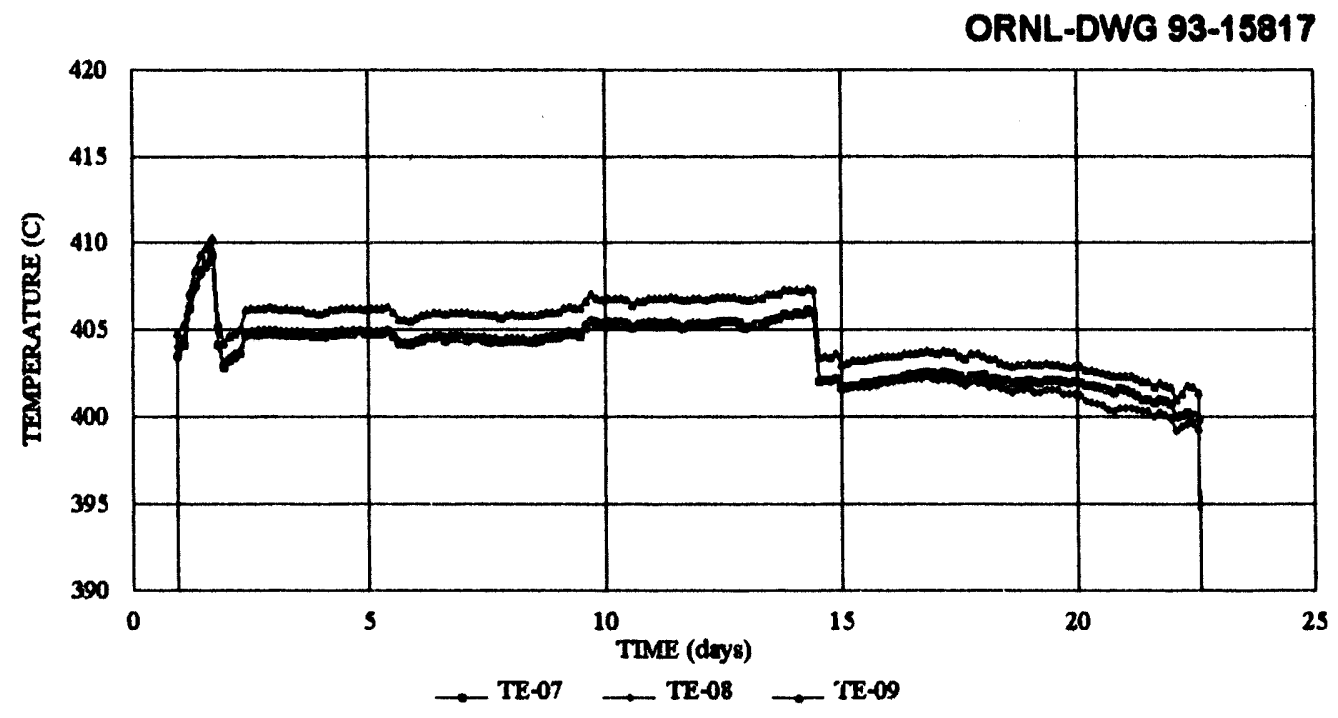

Fig. 24. Individual thermocouple readings in the HFIR-MFE-400J-1 capsule during HFIR Cycle 319. (TIME $0=0000$ hours on June 18, 1993). 
ORNL-DWG 93-15818

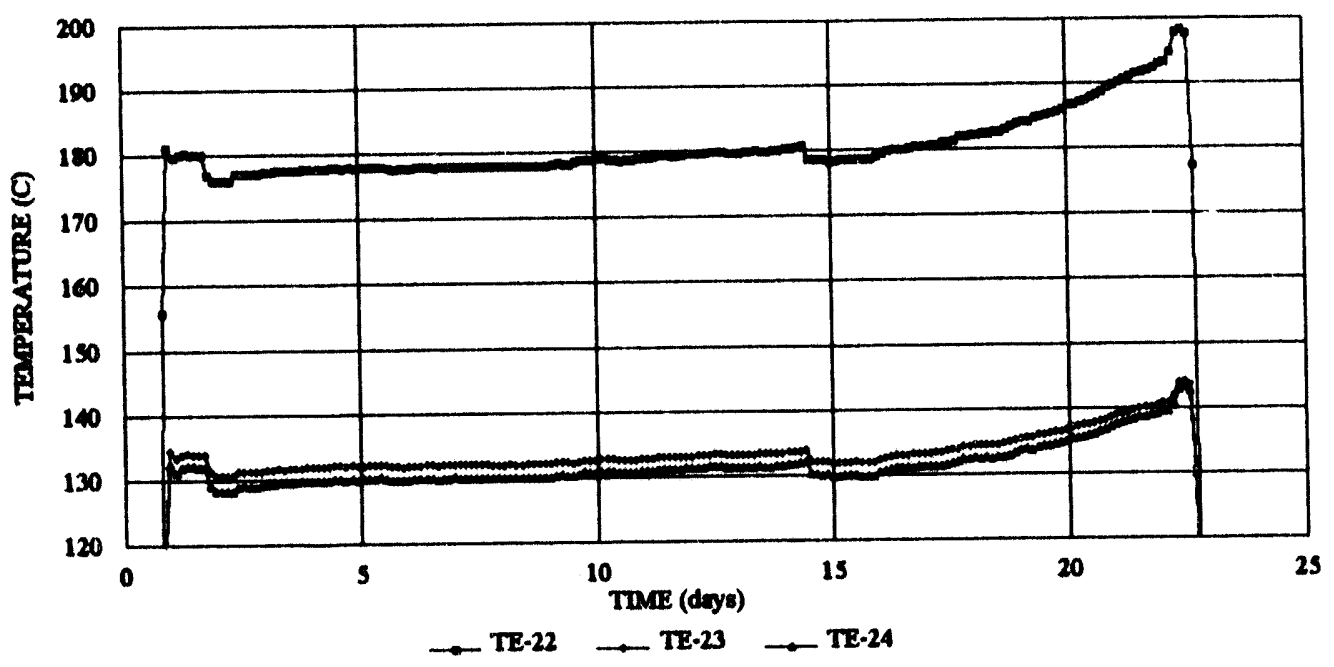

Fig. 25. Individual thermocouple readings in the HFIR-MFE-400J-1 capsule during HFIR Cycle 319. (TIME $0=0000$ hours on June 18, 1993). 


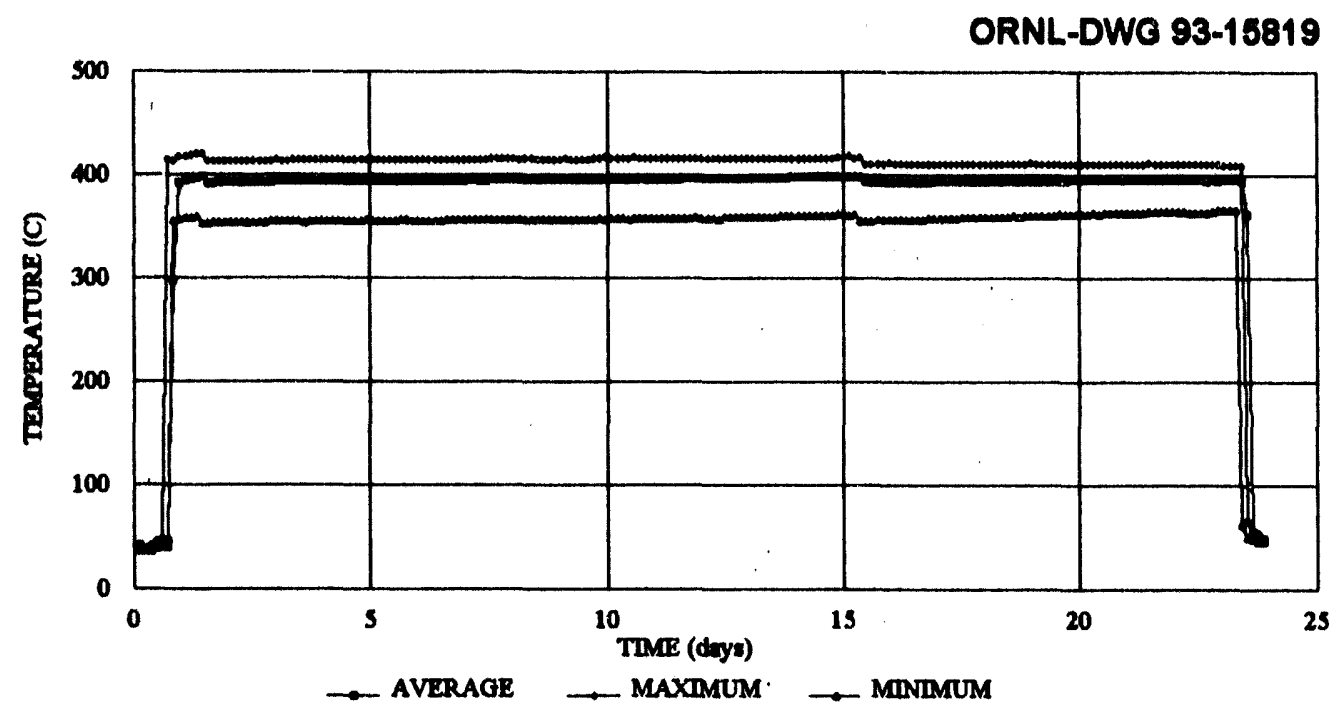

Fig. 26. Specimen holder temperatures in the HFIR-MFE-400J-1 capsule during HFIR Cycle 320. (TIME $0=0000$ hours on July 15, 1993).

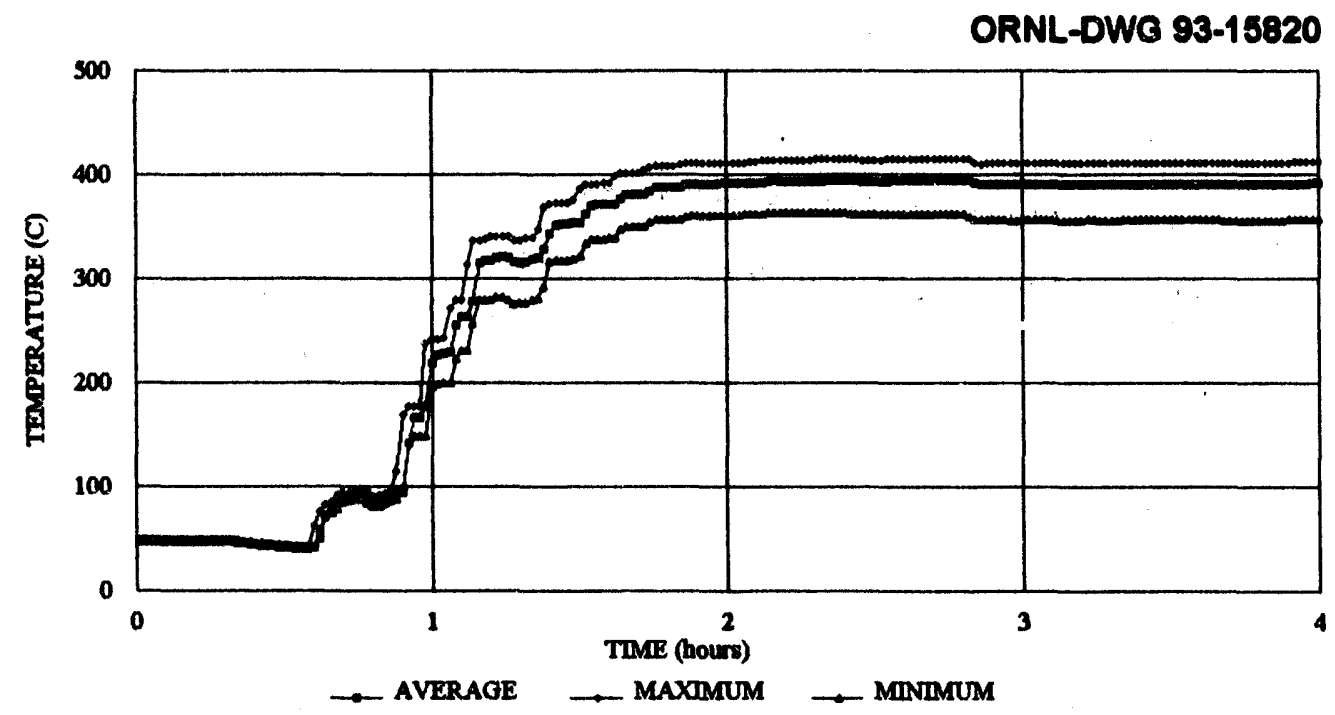

Fig. 27. Specimen holder temperatures in the HFIR-MFE-400J-1 capsule during HFIR Cycle 320 start-up on July 15, 1993. (TIME $0=1700$ hours on July 15, 1993). 
ORNL-DWG 93-15821

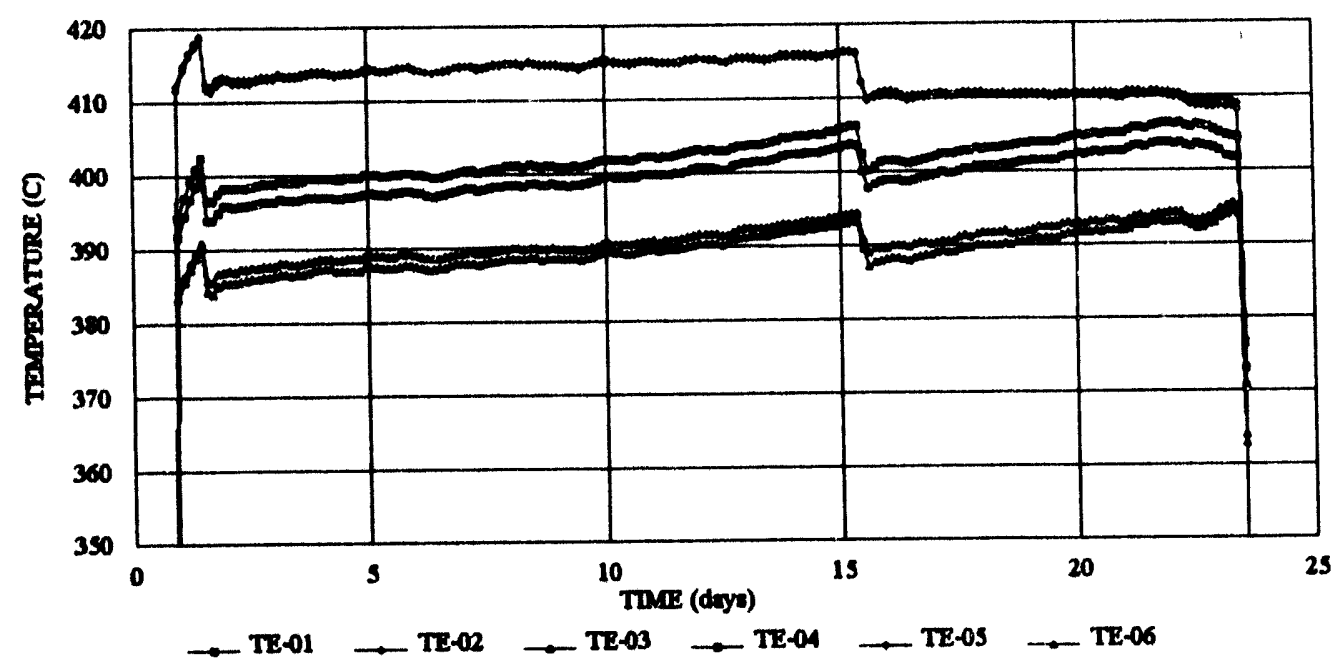

Fig. 28. Individual thermocouple readings in the HFIR-MFE-400J-1 capsule during HFIR Cycle 320. (TIME $0=0000$ hours on July 15, 1993).

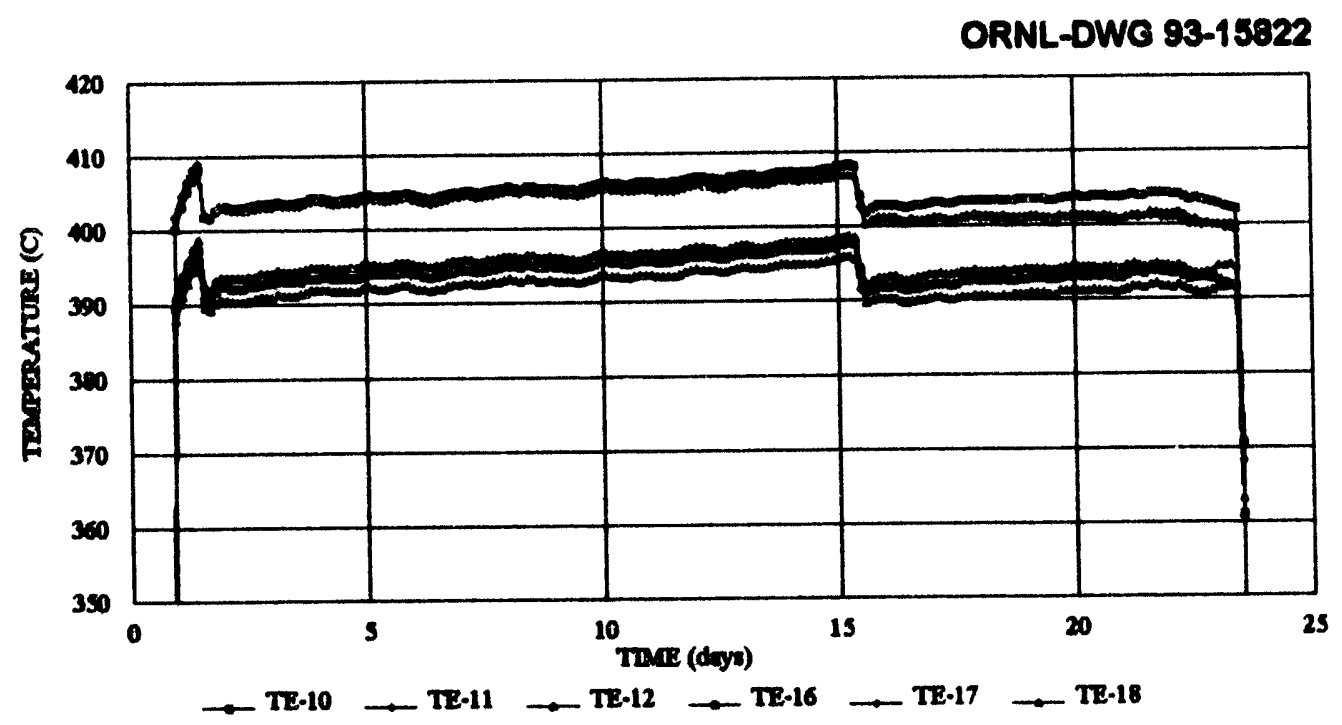

Fig. 29. Individual thermocouple readings in the HFIR-MFE-400J-1 capsule during HFIR Cycle 320. (TIME $0=0000$ hours on July 15, 1983). 


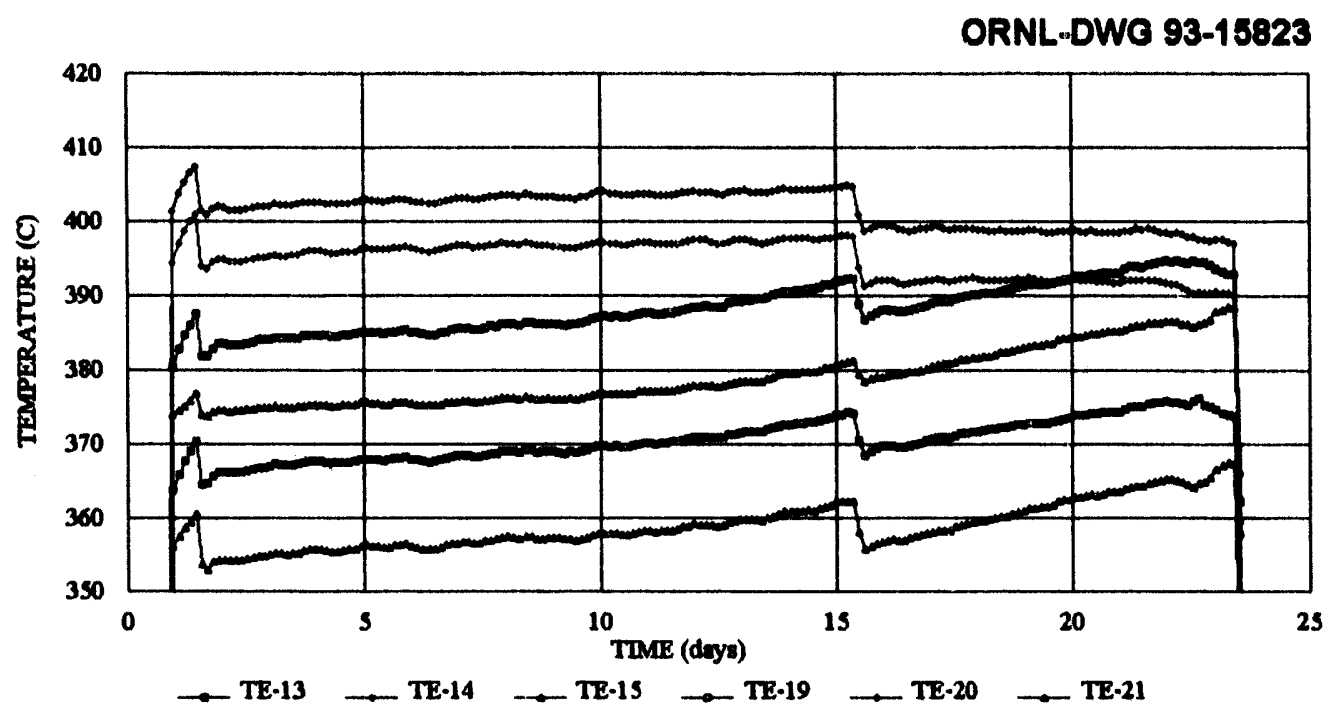

Fig. 30. Individual thermocouple readings in the HFIR-MFE-400J-1 capsule during HFIR Cycle 320. (TIME $0=0000$ hours on July 15, 1993).

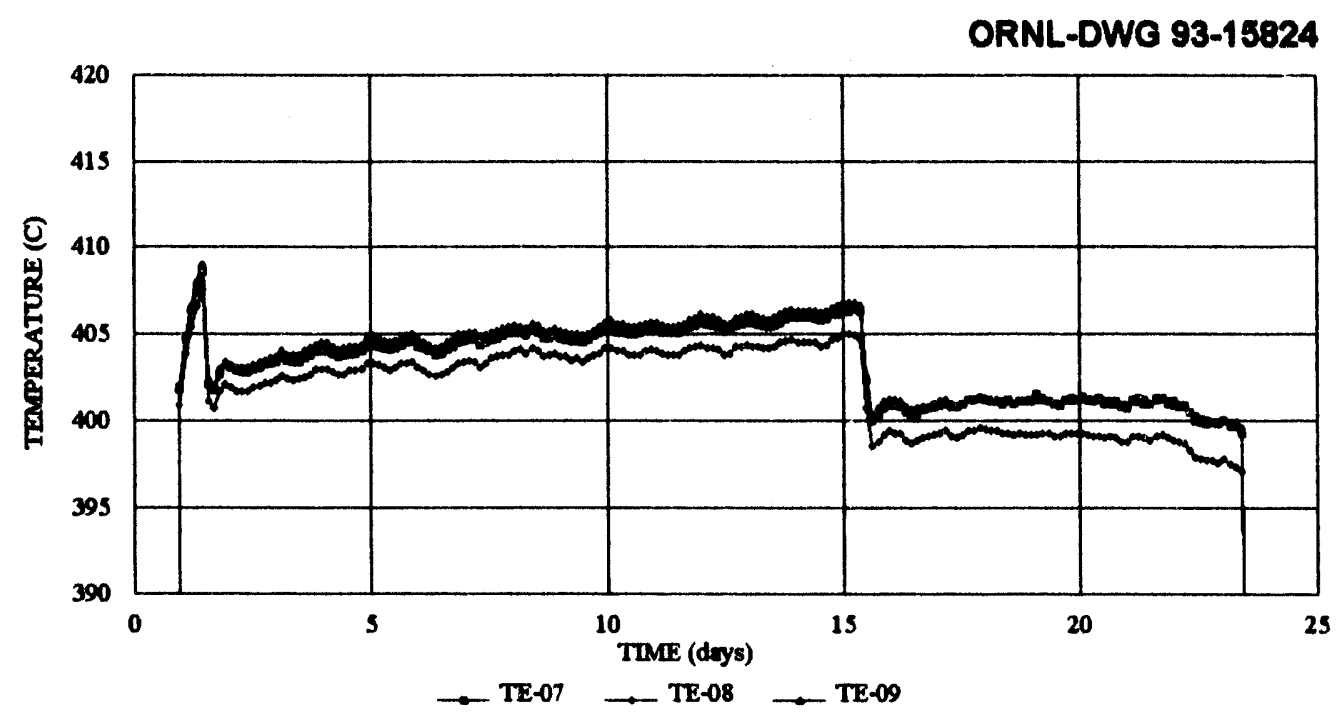

Fig. 31. Individual thermocouple readings in the HFIR-MFE-400 J-1 capsule during HFIR Cycle 320. (TIME $0=0000$ hours on July 15, 1993). 


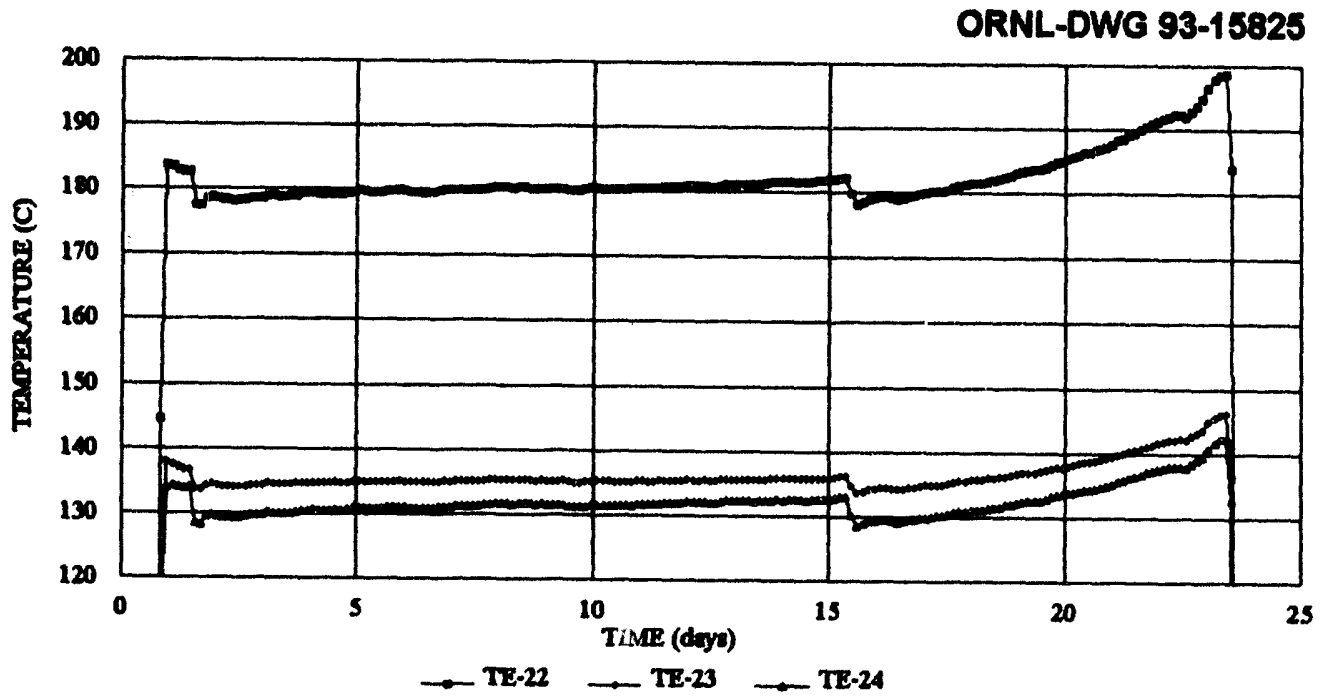

Fig. 32. Individual thermocouple readings in the HFIR-MFE-400J-1 capsule during HFIR Cycle 320. (TIME $0=0000$ hours on July 15, 1993). 
2.0 DOSIMETRY, DAMAGE PARAMETERS, AND ACTIVATION CALCULATIONS 
REANALYSIS OF NEUTRON DOSIMETRY FOR THE MOTA-1E EXPERIMENT IN FFTF L. R. Greenwood, (Pacific Northwest Laboratory)

\section{OBJECTIVE}

To provide dosimetry and damage analysis for fusion materials irradiation experiments.

\section{SUMMARY}

Revised neutron fluence and spectral measurements and radiation damage calculations are reported for the Materials Open Test Assembly (MOTA)-1E experiment in the Fast Flux Test Facility (FFTF). The irradiation was conducted from September 10, 1986, to October 10, 1987, for a total exposure of 341.8 EFPD at $291 \mathrm{MW}$. The maximum fluence was $14.4 \times 10^{22} \mathrm{n} / \mathrm{cm}^{2}, 10.1 \times 10^{22}$ above $0.1 \mathrm{MeV}$, producing $41.8 \mathrm{dpa}$ in iron. Neutron fluence and radiation damage maps are presented for the entire MOTA assembly based on the analysis of six neutron spectral measurements and five additional flux gradient measurements.

\section{PROGRESS AND STATUS}

Neutron dosimetry for the Materials Open Test Assembly (MOTA)-1E experiment in the Fast Flux Test Facility (FFTF) at Hanford was reported previously in a letter report (L. S. Kellogg, W. M. McElroy, and W. Y. Matsumoto, PNL-NDC Letter Report 5, 1989); however, the results have not been published. More recent dosimetry results have been published for the FFTF/MOTA for the $1 F, 1 G$, and $2 \mathrm{~A}$ irradiations. ${ }^{1-3}$ These results included burnup corrections of about $20 \%$ for the fissile monitors, which results in a significant increase in the fast neutron fluences. It was thus decided to reanalyze the MOTA-1E data, including these burnup corrections.

The MOTA-1E neutron dosimetry provided measurements over the entire assembly with a total of eleven capsules positioned at different axial locations in the assembly, spanning a distance from -67 to $+123 \mathrm{~cm}$. Each stainless steel dosimetry capsule contained dosimetry wires for either spectral or gradient measurements. The six spectral capsules contained small wires of $\mathrm{Fe}, \mathrm{Ti}, \mathrm{Ni}, \mathrm{Cu}, 0.1 \% \mathrm{Co}-\mathrm{Al}$ alloy, $\mathrm{Sc}-$ oxide, $0.825 \%{ }^{235} \mathrm{U}$ in $\mathrm{V}, 0.936 \%{ }^{239} \mathrm{Pu}$ in $\mathrm{MgO}$, and $0.42 \%{ }^{237} \mathrm{~Np}$ in $\mathrm{MgO}$, whereas the five gradient capsules contained $\mathrm{Fe}$ and $0.1 \% \mathrm{Co}-\mathrm{Al}$ alloy wires.

Following irradiation, each dosimetry capsule was opened in a hot cell, and each individual monitor was identified and mounted for gamma analysis. The measured activities were then converted to saturated activities by correcting for the sample weight, atomic weight, isotopic abundance, gamma absorption, reactor power history, and fission yield, as needed. Neutron self-shielding effects were not significant since the $\mathrm{Co}, \mathrm{U}$, and Pu were dilute alloys and the FFTF neutron spectrum has few neutrons at lower neutron energies. For the $\mathrm{U}, \mathrm{Pu}$, and $\mathrm{Np}$ fission monitors, the gamma measurements detected five fission products, namely, ${ }^{95} \mathrm{Zr},{ }^{103} \mathrm{Ru},{ }^{106} \mathrm{Ru},{ }^{137} \mathrm{Cs}$, and ${ }^{144} \mathrm{Ce}$. The standard deviation from the mean fission rate was generally less than $5 \%$ except for the ${ }^{237} \mathrm{~Np}$ reactions at out-of-core locations, as discussed below.

'Pacific Northwest Laboratory is operated for the U.S. Department of Energy by Battelle Memorial Institute under Contract DE-AC06-76RLO 1830. 
One of the main motivations for this reanalysis of the MOTA-1E data was to include burnup corrections. The only significant burnup corrections are for the Co and fission monitors. In the case of Co, the ${ }^{59} \mathrm{Co}(\mathrm{n}, \gamma){ }^{60} \mathrm{Co}$ reaction is responsible for the loss of ${ }^{59} \mathrm{Co}$. If we assume that the reaction rate for the burnup of ${ }^{60} \mathrm{Co}$ is proportional to that for ${ }^{59} \mathrm{Co}$, in the ratio of the known resonance integrals, then a simple iterative procedure can be used to determine the proper correction, as follows. Starting with the measured reaction rate, a correction is determined. This corrected rate is then used to determine a second-order correction, and so on. This process quickly converges, and Co burnup corrections varied from $0.6 \%$ at midplane to about $3 \%$ at the below core position.

In principal, we can use the same method to determine burnup corrections for the fission monitors. However, in these cases, the $(n, \gamma)$ reactions must be included along with the fission reactions to determine the total burnup cross sections. Furthermore, reaction rates for some of the radioactive product isotopes are also not so well-known. In all cases, burnup corrections were determined by starting with the measured fission rates and calculating ratios of $(n, \gamma)$ reactions for the fission monitors and the radioactive fission products. These cross-section ratio calculations were performed using calculations of the neutron flux spectra. Burnup corrections were applied separately to each fission product, and the results were then averaged to determine a new fission rate. Second-order corrections were then determined assuming that the ratios to the $(n, \gamma)$ reactions remained the same. This process was then repeated for several iterations until the corrections converged. Although several assumptions and uncertainties are involved in this process, especially for ${ }^{237} \mathrm{~Np}$ where the burnup reactions are not so strongly related to the threshold fission reactions, averaging over several fission products tends to increase our confidence in the final results. In most cases, burnup of the fission products is negligible, and the principal effect is from burnup of the fissionable material. Burnup corrections averaged about $20 \%$ for all three fission monitors.

Burnup of ${ }^{237} \mathrm{~Np}$ breeds various $\mathrm{Pu}$ isotopes that tend to have higher fission reaction rates than does $\mathrm{Np}$. However, this effect is minimal except at the below-core position. Due to the high scatter in the measured fission product yields, this reaction was not included in subsequent neutron spectral determinations at the below-core position.

The corrected reaction rates are listed in Tables 1-3. All values are normalized to $282.48 \mathrm{MW}$ operation, and the values have an estimated absolute uncertainty of about $5 \%$, although the fission reactions have an additional uncertainty of about $5 \%$ due to problems in determining the burnup corrections. These rates appear to be in reasonable agreement with previous measurements. ${ }^{1-3}$

The measured activities were used as input to the STAY'SL computer code ${ }^{4}$ to adjust the calculated neutron spectra determined for cycle 9 A, which were provided by R. L. Simons, Westinghouse Hanford Company. The STAY'SL code performs a generalized least-squares adjustment of all measured and calculated values, including the measured activities, calculated spectra, and neutron cross sections. Neutron cross sections and their uncertainties were generally taken from ENDF/B-V, although new data were available from ENDF/B-VI for the ${ }^{46} \mathrm{Ti}(\mathrm{n}, \mathrm{p})$ and ${ }^{63} \mathrm{Cu}(\mathrm{n}, \mathrm{a})$ reactions. The adjusted neutron fluence values are listed in Table 4. The neutron spectral adjustments for the six spectral positions are illustrated in Figure 1, which shows neutron spectra results at midplane, the edge of the core, and the below-core basket. The agreement is reasonable ( 20 to $30 \%$ ) when comparing the in-core positions with calculated spectra. However, at out-of-core positions, the disagreement becomes progressively worse, as seen in earlier experiments. ${ }^{1.3}$ 
Table 1 - Activation Measurements in MOTA-1E (atoms/atom-s)

(Values normalized to $282.48 \mathrm{MW}$; burnup corrections included for $\mathrm{Co}$ )

\begin{tabular}{||c|c|c|c|c||}
\hline $\begin{array}{c}\text { Sample/ } \\
\text { Level-Pin }\end{array}$ & Ht, cm & $\begin{array}{c}{ }^{54} \mathrm{Fe}(\mathrm{n}, \mathrm{p}){ }^{54} \mathrm{Mn} \\
(\mathrm{xE}-11)\end{array}$ & $\begin{array}{c}{ }^{58} \mathrm{Fe}(\mathrm{n}, \gamma){ }^{59} \mathrm{Fe} \\
(\mathrm{xE}-11)\end{array}$ & $\begin{array}{c}{ }^{59} \mathrm{Co}(\mathrm{n}, \gamma)^{60} \mathrm{Co}^{*} \\
(\mathrm{xE}-10)\end{array}$ \\
\hline M63 8-D1 & 122.7 & 0.00134 & 0.323 & 1.89 \\
M57 6-E1 & 75.2 & 0.0418 & 0.914 & 3.71 \\
M56 5-E2 & 41.7 & 1.03 & 2.63 & 2.51 \\
M62 5-E2 & 41.9 & 1.02 & 2.64 & 3.22 \\
M54 4-A3 & 20.0 & 2.66 & 3.89 & 2.42 \\
M53 3-A3 & -2.2 & 3.12 & 4.60 & 2.80 \\
M60 3-E3 & -0.8 & 2.90 & 4.34 & 2.68 \\
M52 1-A1 & -42.1 & 1.79 & 3.60 & 6.12 \\
M59 1-D2 & -42.1 & 0.459 & 0.852 & 5.52 \\
M51 BC-A4 & -67.1 & 0.141 & 3.39 & 18.0 \\
\hline
\end{tabular}

Table 2 - Activation Measurements in MOTA-1E (atoms/atom-s)

(Values normalized to $282.48 \mathrm{MW}$ )

\begin{tabular}{||c|c|c|c|c|c||}
\hline $\begin{array}{c}\text { Sample/ } \\
\text { Level-Pin }\end{array}$ & Ht, cm & $\begin{array}{c}{ }^{46} \mathrm{Sc}(\mathrm{n}, \gamma){ }^{46} \mathrm{Sc} \\
(\mathrm{xE}-10)\end{array}$ & $\begin{array}{c}{ }^{46} \mathrm{Ti}(\mathrm{n}, \mathrm{p}){ }^{46} \mathrm{Sc} \\
(\mathrm{xE}-12)\end{array}$ & $\begin{array}{c}{ }^{58} \mathrm{Ni}(\mathrm{n}, \mathrm{p}){ }^{58} \mathrm{Co} \\
(\mathrm{xE}-11)\end{array}$ & $\begin{array}{c}{ }^{63} \mathrm{Cu}(\mathrm{n}, \alpha)^{60} \mathrm{Co} \\
(\mathrm{xE}-13)\end{array}$ \\
\hline M57 6-E1 & 75.2 & 0.259 & 0.048 & 0.0632 & - \\
M56 5-E2 & 41.7 & 0.718 & 1.65 & 1.94 & 0.800 \\
M54 4-A3 & 20.0 & 1.05 & 3.03 & 3.86 & 1.62 \\
M53 3-A3 & -2.2 & 1.37 & 4.09 & 4.60 & 1.97 \\
M52 1-A1 & -42.1 & 1.09 & 2.27 & 2.45 & 1.05 \\
M51 BC-A4 & -67.1 & 1.06 & 0.161 & 0.197 & 0.0742 \\
\hline
\end{tabular}

Table 3 - Fission Reaction Measurements in MOTA-1E (fission/atom-s)

(Values normalized to $282.48 \mathrm{MW}$; burnup corrections included)

\begin{tabular}{|c|c|c|c|c|}
\hline $\begin{array}{c}\text { Sample/ } \\
\text { Level-Pin }\end{array}$ & Ht, cm & $\begin{array}{c}{ }^{237} \mathrm{~Np}(\mathrm{n}, \mathrm{f}) \\
(\mathrm{xE}-9)\end{array}$ & $\begin{array}{c}{ }^{235} \mathrm{U}(\mathrm{n}, \mathrm{f}) \\
(\mathrm{xE}-9)\end{array}$ & $\begin{array}{c}{ }^{239} \mathrm{Pu}(\mathrm{n}, \mathrm{f}) \\
(\mathrm{xE}-9)\end{array}$ \\
\hline M57 6-E1 & 75.2 & 0.0674 & 1.64 & 1.47 \\
M56 5-E2 & 41.7 & 0.795 & 4.85 & 4.41 \\
M54 4-A3 & 20.0 & 1.70 & 7.87 & 7.85 \\
M53 3-A3 & -2.2 & 1.99 & 9.44 & 9.30 \\
M52 1-A1 & -42.1 & 1.12 & 6.66 & 6.20 \\
M51 BC-A4 & -67.1 & - & 6.05 & 6.01 \\
\hline
\end{tabular}

Damage calculations were performed at all spectral positions using the SPECTER computer code. ${ }^{5}$ Dpa rates for iron are shown in Table 4 as well as the ratio of dpa per $10^{22} \mathrm{n} / \mathrm{cm}^{2}$ fast flux above 0.1 MeV. Damage parameters for $\mathbf{4 0}$ other elements and several compounds have been calculated and will be made available on request. 
Table 4 - Neutron Fluence and Displacement Damage for MOTA-1E

\begin{tabular}{|c|c|c|c|c|c|c|}
\hline $\begin{array}{l}\text { Capsule/ } \\
\text { Position }\end{array}$ & $\mathrm{Ht}, \mathrm{cm}$ & $\begin{array}{l}\text { Total Fluence } \\
x E+22 \mathrm{n} / \mathrm{cm}^{2}\end{array}$ & $\begin{array}{c}\text { Fast Fluence } \\
(>.1 \mathrm{MeV}) \\
\times \mathrm{E}+22 \mathrm{n} / \mathrm{cm}^{2}\end{array}$ & Iron dpa & $\begin{array}{c}\text { Ratio dpa } \\
\text { Fluence }(>0.1)\end{array}$ & SS* dpa \\
\hline M63 8-D1 & 122.7 & 0.19 & 0.045 & 0.17 & 3.7 & 0.18 \\
\hline M57 6-E1 & 75.2 & 1.15 & 0.52 & 1.9 & 3.7 & 2.0 \\
\hline M56 5-E2 & 41.7 & 6.38 & 4.12 & 16.8 & 4.1 & 17.4 \\
\hline M54 4-A3 & 20.0 & 11.8 & 8.56 & 35.1 & 4.1 & 36.3 \\
\hline M53 3-A3 & -2.2 & 14.4 & 10.23 & 41.8 & 4.1 & 43.3 \\
\hline M60 3-E3 & -0.8 & 13.6 & 9.51 & 39.0 & 4.1 & 40.4 \\
\hline M52 1-A1 & -42.1 & 8.64 & 5.50 & 22.9 & 4.2 & 23.7 \\
\hline M51 BC-A4 & -67.1 & 3.79 & 1.81 & 6.3 & 3.5 & 6.6 \\
\hline
\end{tabular}

*Stainless steel - Fe-18Cr-8Ni

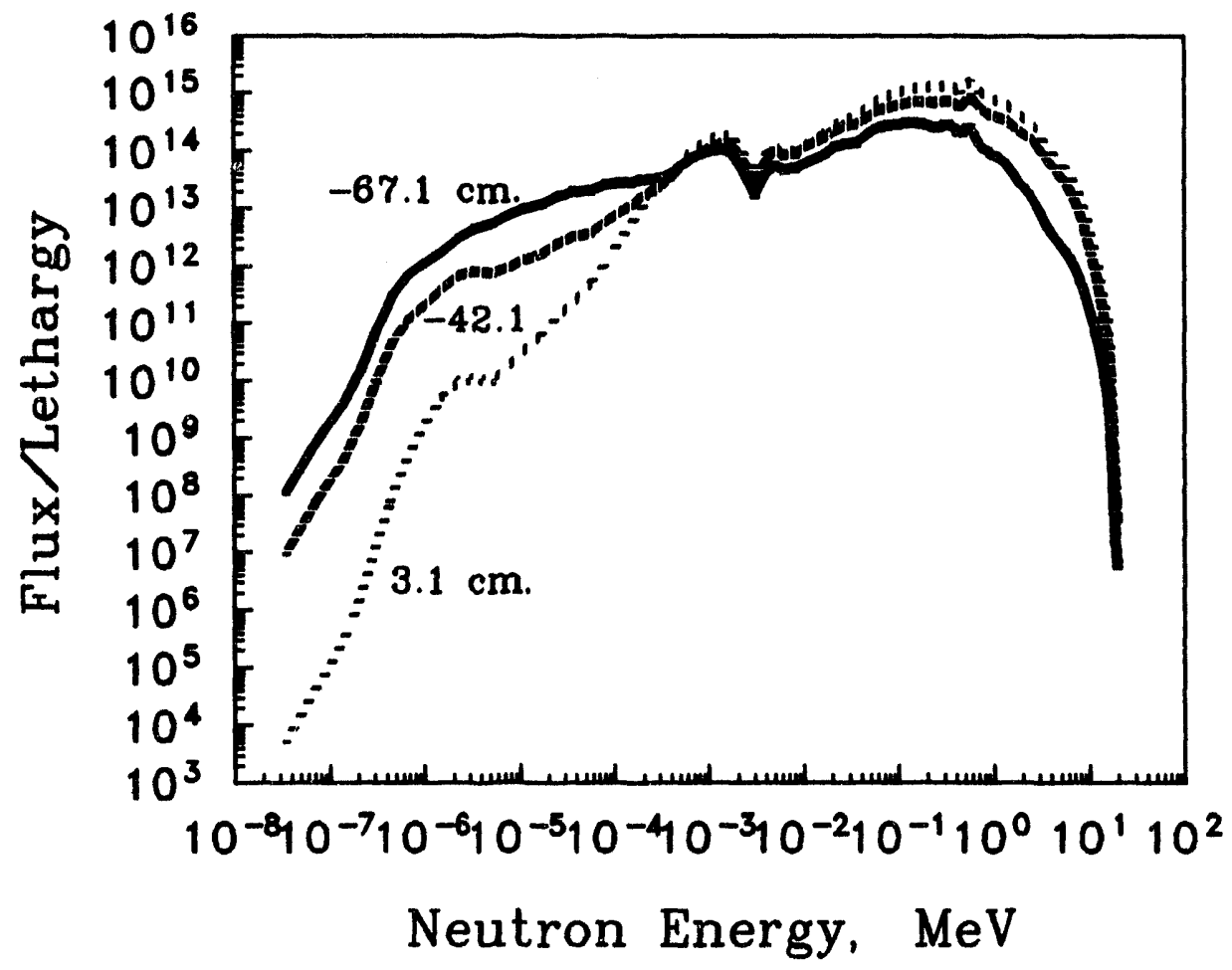

Fig. 1. Adjusted neutron flux spectra are shown at axial positions of $3.1 \mathrm{~cm}$ (dotted line), $-42.1 \mathrm{~cm}$ (dashed line), and $-67.1 \mathrm{~cm}$ (solid line). Note the drop in fast flux and increase in low-energy flux at out-of-core locations. 


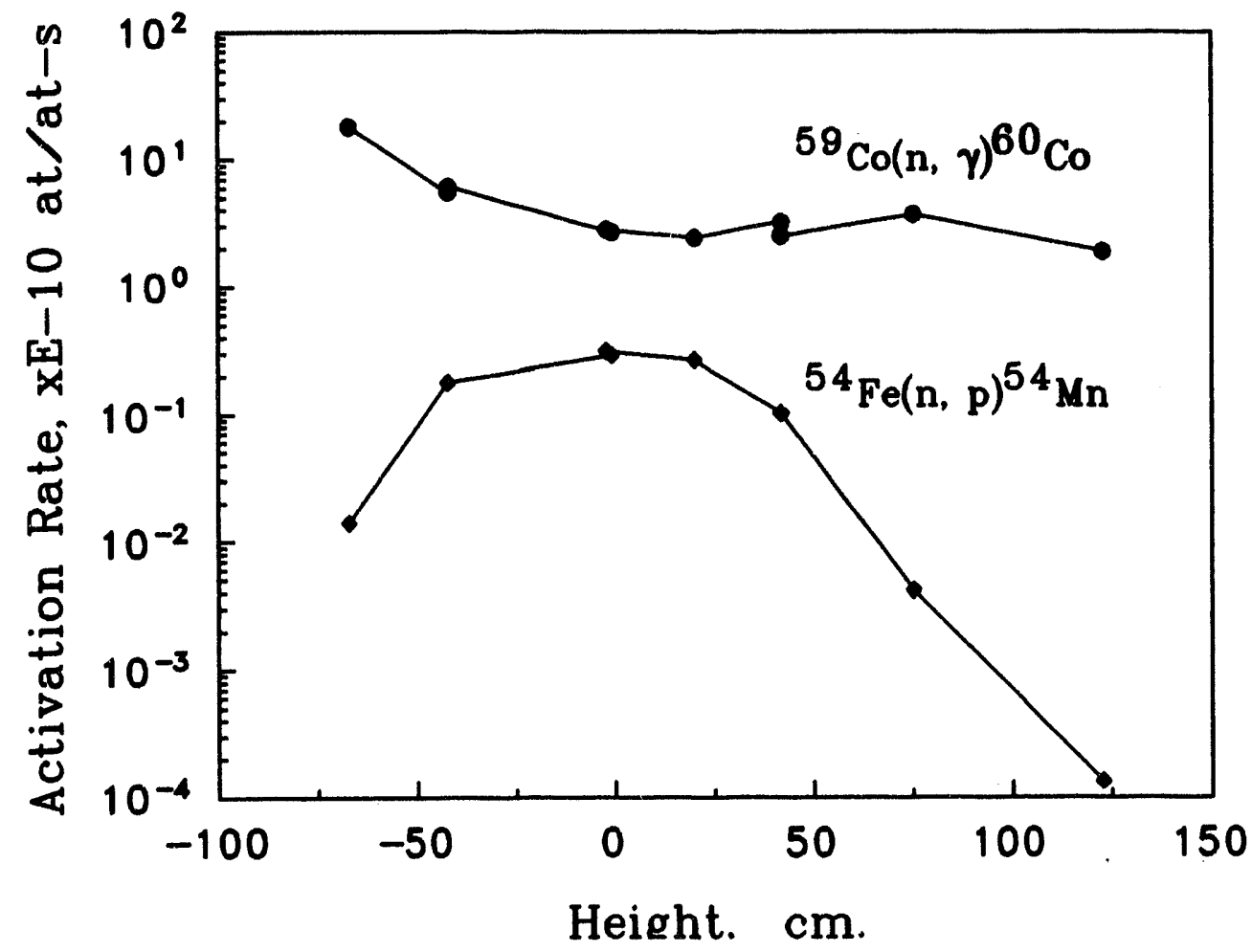

Fig. 2. Activity rates are shown for the ${ }^{54} \mathrm{Fe}(\mathrm{n}, \gamma){ }^{54} \mathrm{Mn}$ and ${ }^{59} \mathrm{Co}(\mathrm{n}, \gamma){ }^{60} \mathrm{Co}$ reactions as a function of axial location in the MOTA-1E assembly.

The flux and damage gradients at other positions can be found from the activity gradient data in Table 1 which are shown in Figure 2. Note that the ${ }^{59} \mathrm{Co}(\mathrm{n}, \gamma)$ reaction rate peaks outside of the core since it is sensitive to the lower-energy neutrons. The unusual behavior of the Co reaction is due to cross section resonance effects. Fast fluence and dpa gradients from Table 4 are plotted in Figure 3. The apparent scatter in the data is caused by the radial flux gradients, as discussed below.

Close examination of the activity data indicates the presence of radial flux and spectral gradients. The letters $\mathrm{A}$ to $\mathrm{F}$ under the position column in Tables 1-4 indicate the radial position at the height indicated. The MOTA basket has six radial positions ( $A$ to $F$ ); hence, for example, $A$ and $D$ are the furthest apart while $\mathrm{A}$ and $\mathrm{B}$ or $\mathrm{F}$ are adjacent. The maximum radial flux differences are on the order of $10 \%$; however, we also see clear indications of spectral differences in the ratio of the fast flux to the ${ }^{54} \mathrm{Fe}(\mathrm{n}, \mathrm{p})$ activity rate.

\section{FUTURE WORK}

Reanalysis of the MOTA-1A, 1B, 1C, and 1D irradiations is in progress. Comparisons will then be made for all MOTA irradiations to date. Analysis of the MOTA-2B experiment is in progress. Dosimetry work is also in progress for a variety of US/Japanese experiments in the High Flux Isotopes Reactor at Oak Ridge National Laboratory. 


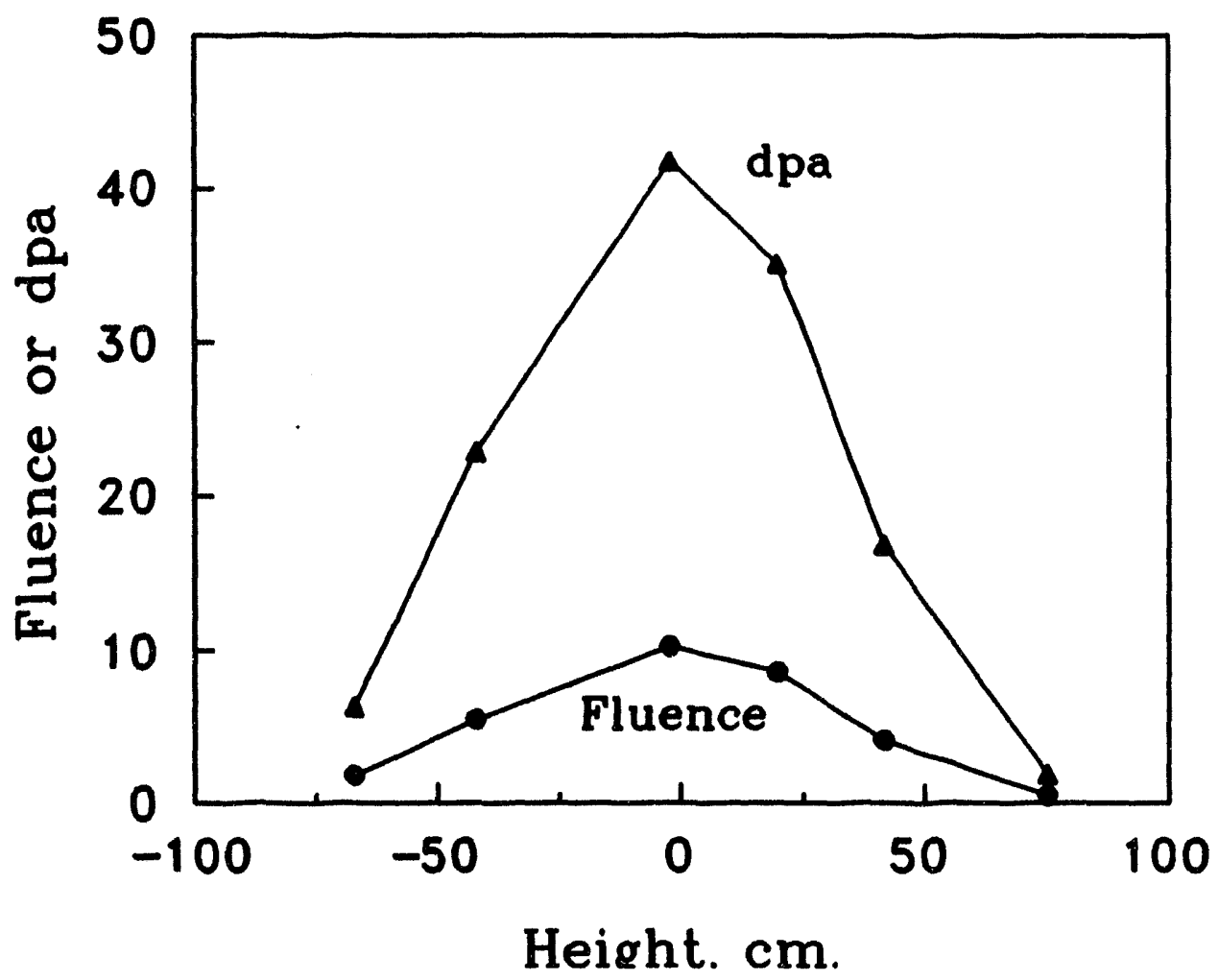

Fig. 3. Fast fluence $\left(\times 10^{22} \mathrm{n} / \mathrm{cm}^{2},>0.1 \mathrm{MeV}\right)$ and dpa values in iron are shown as a function of height in the MOTA-1E assembly.

\section{REFERENCES}

1. L. R. Greenwood and L. S. Kellogg, Neutron Dosimetry for the MOTA-2A Experiment in FFTF, Fusion Reactor Materials Semiannual Progress Report, DOE/ER-0313/12, pp.49-53, March 1992.

2. L. R. Greenwood and L. S. Kellogg, Neutron Dosimetry for the MOTA-1F Experiment in FFTF, Fusion Reactor Materials Semiannual Progness Report, DOE/ER-0313/9, pp. 31-36 (1990).

3. L. R. Greenwood and L. S. Kellogg, Neutron Dosimetry for the MOTA-1G Experiment in FFTF, Fusion Reactor Materials Semiannual Progress Report, DOE/ER-0313/14, in press.

4. F. G. Perey, Least Squares Dosimetry Unfolding: The Program STAY'SL, ORNL/TM-6062 (1977).

5. L. R. Greenwood and R. K. Smither, SPECTER: Neutron Damage Calculations for Materials Irradiations, ANL/FPP-TM-197, January 1985. 


\section{PUBLICATIONS}

1. L. R. Greenwood, F. A. Garner, and D. J. Edwards, Calculation of Transmutation in Copper and Comparison with Measured Electrical Properties, Presented at the Eighth ASTM-EURATOM Symposium on Reactor Dosimetry, Vail, CO, August 29-September 3, 1993, submitted for publication in ASTM-STP 1228.

2. L. R. Greenwood and F. A. Garner, Transmutation of Mo, Re, W, Hf, and V in Various Irradiation Test Facilities and STARFIRE, presented at the International Conference on Fusion Reactor Materials 6, Stresa, Italy, September 27-October 1, 1993, submitted for publication in the Journal of Nuclear Materials.

3. L. R. Greenwood, F. A. Garner, and B. M. Oliver, An Assessment of the ${ }^{59}$ Ni lsotopic Tailoring Technique to Study the Influence of Helium/dpa Ratio, ibid. 
Transmutation of Mo, Re, W, Hf, and V in Various Irradiation Test Facilities and STARFIRE L. R. Greenwood and F. A. Garner, (Pacific Northwest Laboratory)"

\section{OBJECTIVE}

The objective of this effort is to determine the impact of transumtation on fission-fusion correlations.

\section{SUMMARY}

With the exception of $\mathrm{V}$ and $\mathrm{Cu}$ alloys, the formation of solid transmutants has not been thought to play a large role in the response of metals to irradiation. For a number of refractory elements, however, it appears that very large levels of solid transmutation can occur both in fission and fusion spectra. The phase stability and other properties of alloys can be strong functions of the changing composition. The spectral sensitivity of transmutation also poses some difficulty in correlating data from various neutron spectra. Transmutation of Mo, Re, W, Hf and V have been calculated for the Fast Flux Test Facility (FFTF), the High Flux Isotope Reactor (HFIR), and the STARFIRE fusion reactor. Results show that Re and $\mathrm{W}$ undergo sizeable transmutation in these spectra, and may limit the use of these elements in fusion reactor materials. Vanadium and hafnium have high transmutation rates in HFIR and may require spectral tailoring.

\section{PROGRESS AND STATUS}

\section{Introduction}

Various refractory elements have been proposed for fusion reactor applications, either as major refractory alloy components, as substitute elements in austenitic alloys to achieve low-activation goals, or as additions to other composite materials. Various Mo-base alloys, such as Mo-Re, have been suggested for structural and high heat flux applications. ${ }^{1 \cdot 2}$ Tungsten is currently being used as a substitute solute for Mo in ferritic steels, ${ }^{3-5} \mathrm{~W}$ or W-Re alloys have been suggested as armor materials for plasma-facing components, ${ }^{6,7}$ and Cu-W composites have been irradiated in the Fast Flux Test Facility (FFTF) and High Flux Isotope Reactor (HFIR). ${ }^{9}$ Hafnium oxide is currently being used to strengthen $\mathrm{Cu}$ alloys. Vanadium has been proposed as a low-activation strengthener for ferritic alloys ${ }^{3-5}$ and V-base alloys are serious contenders for structural applications. ${ }^{10,11}$ It is now apparent that the formation of solid transmutation products will play a role as large or larger than gaseous transmutants in the performance of these materials.

\section{Transmutation Calculations}

The transmutation calculations required several steps, including the determination of the principal nuclear reactions and subsequent decays, extraction of nuclear cross sections from ENDF/B-V or VI, ${ }^{12}$ spectral averaging of each cross section, and numerical calculations for lengthy irradiations. In most cases, the accuracy is estimated at 10 to $20 \%$, due both to uncertainties in the adjusted neutron spectra and in the evaluated neutron activation cross sections. Second-order transmutation of the primary reaction products into secondary or tertiary products was often neglected. This is generally a good assumption unless either

"Pacific Northwest Laboratory is operated for the U.S. Department of Energy by Battelle Memorial Institute under Contract DE-AC06-76RLO 1830. 
the primary transmutation is quite high (above 1 at\%), and/or the product isotope has a very high transmutation rate.

In cases where reaction data were not available from ENDF/B-V or VI, reaction rates were estimated from similar better-known reactions. Calculations were performed for FFTF at the midplane and the middle of the MOTA-1G below-core canister $(-66 \mathrm{~cm})$ at a reactor power of $291 \mathrm{MW} .^{13}$ The High Flux Isotope Reactor (HFIR) calculations are mainly for the Peripheral Target Position at midplane with the reactor operating at $85 \mathrm{MW} .^{14}$ For V, HFIR calculations were also performed for the removable beryllium (RB) positions, with and without a hafnium liner to suppress thermal neutrons. ${ }^{15}$ The STARFIRE calculations are for the first wall position at a wall loading of $3.8 \mathrm{MW} / \mathrm{m}^{2}{ }^{26}$ Neutron fluences and dpa values are listed in Table 1. All dpa values are quoted for iron to simplify comparison of different elements in the same spectra. Table 2 lists dpa conversion factors for some of these elements in all spectra; however, dpa calculations are not available for $\mathrm{Re}$ or Hf. For calculations of dpa for alloys with significantly different masses or displacement threshold values, it may not be sufficient to use a linear combination of the elemental dpa values.

Table 1. Transmutation in FFTF, HFIR, and STARFIRE

(Values are listed in at\%, unless noted as appm)

\begin{tabular}{|c|c|c|c|c|c|c|}
\hline Full Power Days: & \multicolumn{2}{|c|}{$\begin{array}{c}\text { FFTF Midplane } \\
244 \quad 833\end{array}$} & \multicolumn{2}{|c|}{$\begin{array}{l}\text { FFTF Blow Core } \\
244833\end{array}$} & $\begin{array}{c}\text { HFIR } \\
\text { Midplane }\end{array}$ & $\begin{array}{l}\text { STARFIRE } \\
365 \text { FPD }\end{array}$ \\
\hline $\begin{array}{l}\text { Fluence, } \times 10^{23} \\
\text { dpa, } \mathrm{Fe}\end{array}$ & $\begin{array}{l}1.0 \\
30\end{array}$ & $\begin{array}{l}3.4 \\
100\end{array}$ & $\begin{array}{l}0.30 \\
4.4\end{array}$ & $\begin{array}{l}1.02 \\
14.5\end{array}$ & $\begin{array}{l}1.4 \\
27 .\end{array}$ & $\begin{array}{l}0.58 \\
42 .\end{array}$ \\
\hline $\begin{array}{l}\text { Molybdenum: } \\
{ }^{99} \mathrm{Tc}\end{array}$ & 0.24 & 0.76 & 0.17 & 0.62 & 0.49 & 0.35 \\
\hline $\mathbf{R u}$ & 0.07 & 0.24 & 0.05 & 0.17 & 0.64 & 0.14 \\
\hline${ }^{94} \mathrm{Nb}$, appm: & 0.02 & 0.07 & 0.00 & 0.00 & 0.11 & 1900. \\
\hline $\mathrm{Zr}$, appm: & 2.0 & 6.8 & & & 9.1 & 29. \\
\hline${ }^{89} \mathrm{Y}$, appm: & - & - & & & - & 9. \\
\hline $\begin{array}{l}\text { Vanadium: } \\
\mathrm{Cr}\end{array}$ & 0.15 & 0.51 & 0.11 & 0.39 & 19.3 & 0.66 \\
\hline Ti, appm & - & - & - & - & 71. & 190. \\
\hline Mn, appm & - & - & - & - & 260. & - \\
\hline Fe, appm & - & - & - & - & 31. & - \\
\hline
\end{tabular}


Table 2. Comparison of Normalized dpa Rates for Various Spectra

\begin{tabular}{|c|c|c|c|c|}
\hline Element & $\begin{array}{c}\text { FFTF } \\
\text { (Midplane) }\end{array}$ & $\begin{array}{c}\text { FFTF } \\
\text { (Below Core) }\end{array}$ & $\begin{array}{c}\text { HFIR } \\
\text { (Midplane) }\end{array}$ & STARFIRE \\
\hline Fe & 1 & 1 & 1 & 1 \\
V & 1.34 & 1.56 & 1.28 & 1.08 \\
Mo & 0.88 & 1.04 & 0.72 & 0.68 \\
W & 0.28 & 0.25 & 0.27 & 0.29 \\
\hline
\end{tabular}

Some of the highest transmutation rates can be significantly moderated by neutron self-shielding, especially in thick structures. In HFIR, the rates are so large that this is a moot point; however, many of the Re and $\mathrm{W}$ isotopes will eventually burn up anyway, thus having the same net long-term effect in changing the composition. In FFTF, neutron self-shielding is not so important; however, some of the resonance region reactions will be moderated and this should be explored in more detail. The nearby presence of other experiments containing strong neutron moderators (e.g., Cd, Gd, B, Li, etc.) would also reduce the transmutation rates of these isotopes due to flux depression effects.

The results for Re, W, and $\mathrm{Hf}$ are shown in Figures 1-3. Results for Mo and V are listed in Table 1. Detailed notes follow for each of the elements.

\section{Molybdenum}

The principal transmutation reactions in HFIR and FFTF for Mo are the $(n, \gamma)$ capture reactions on ${ }^{98} \mathrm{Mo}$ to ${ }^{99} \mathrm{Mo}$ (2.7 days), which decays to ${ }^{99} \mathrm{Tc}\left(200,000\right.$ years), and on ${ }^{100} \mathrm{Mo}$ to ${ }^{101} \mathrm{Mo}$ (15 minutes), which decays to ${ }^{101} \mathrm{Ru}$. Capture reactions on the other Mo isotopes lead to other stable Mo isotopes. Weaker reactions considered include $(n, p)$ and $(n, \alpha)$. Many of the $(n, p)$ reactions produce short-lived products that decay back to other Mo isotopes. However, ${ }^{94} \mathrm{Mo}(\mathrm{n}, \mathrm{p})^{94} \mathrm{Nb}\left(20,000\right.$ years) and ${ }^{92} \mathrm{Mo}(\mathrm{n}, \mathrm{p})^{92} \mathrm{Nb}$ (10 days), which decays to ${ }^{92} \mathrm{Zr}$, must also be considered. The $(n, \alpha)$ reactions to $\mathrm{Zr}$ were included for all of the Mo isotopes except that ${ }^{92} \mathrm{Mo}$ produces ${ }^{89} \mathrm{Zr}$ (3.3 days), which decays to ${ }^{89} \mathrm{Y}$ and ${ }^{98} \mathrm{Mo}$ and ${ }^{100} \mathrm{Mo}$ have products which decay back to other Mo isotopes. For Mo, the only significant second-order transmutation is that ${ }^{99} \mathrm{Tc}$ will partially transmute to ${ }^{100} \mathrm{Ru}$ in HFIR. In STARFIRE, the $14-\mathrm{MeV}$ neutron flux produces transmutation via $(\mathrm{n}, 2 \mathrm{n})$ reactions. The most important reactions lead to ${ }^{99} \mathrm{Tc}$ and ${ }^{91} \mathrm{Nb}$ with some further neutron capture to $\mathrm{Ru}$.

\section{Rhenium}

Both ${ }^{185} \operatorname{Re}$ and ${ }^{187} \operatorname{Re}$ have large $(n, \gamma)$ reaction rates leading to significant transmutation in all three facilities. Both reactions lead to Os where further capture reactions only lead to other stable Os isotopes. All of the $(n, p)$ reactions lead to short-lived tungsten isotopes that decay back to Re. The $(n, \alpha)$ reactions produce small amounts of ${ }^{182} \mathrm{~W}$ and ${ }^{184} \mathrm{~W}$. in STARFIRE, the $(n, 2 \mathrm{n})$ reactions lead to ${ }^{186} \mathrm{Os}$ and ${ }^{184} \mathrm{~W}$.

\section{Tungsten}

Tungsten has three isotopes that produce significant transmutation via $(n, \gamma)$ reactions. The isotopes ${ }^{184} \mathrm{~W}$ and ${ }^{186} \mathrm{~W}$ have large reactions rates leading to Re. Much of the Re produced will, in turn, transmute to Os, especially in HFIR. The isotope ${ }^{180} \mathrm{~W}$ produces ${ }^{131} \mathrm{~W}$ (121 days) which decays to ${ }^{181} \mathrm{Ta}$. During a long 

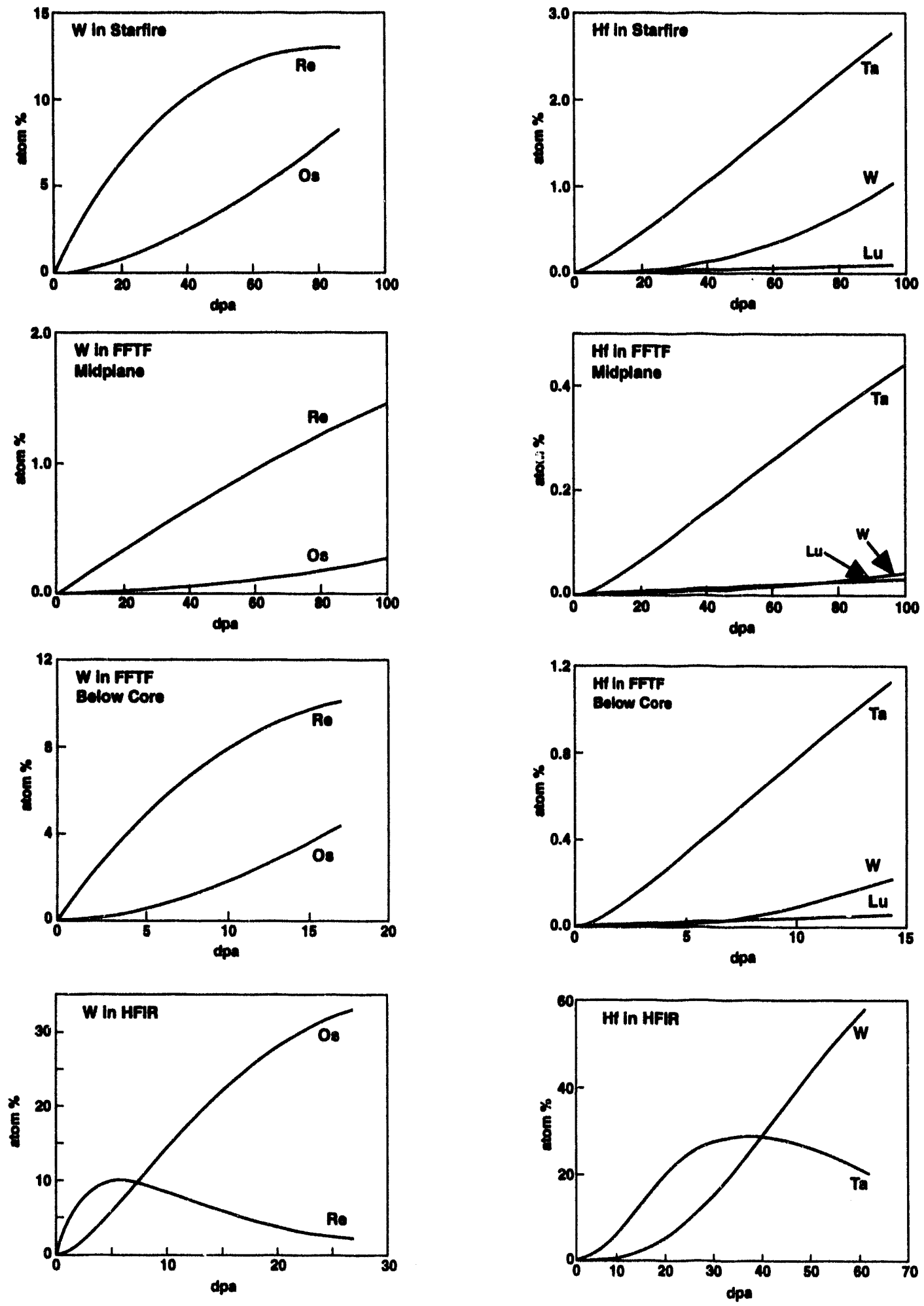

Fig. 1. Transmutation of tungsten to rhenium and osmium in various irradiation facilities.

Fig. 2. Transmutation of hafnium to tantalum,tungsten, and lutetium in various irradiation facilities. 


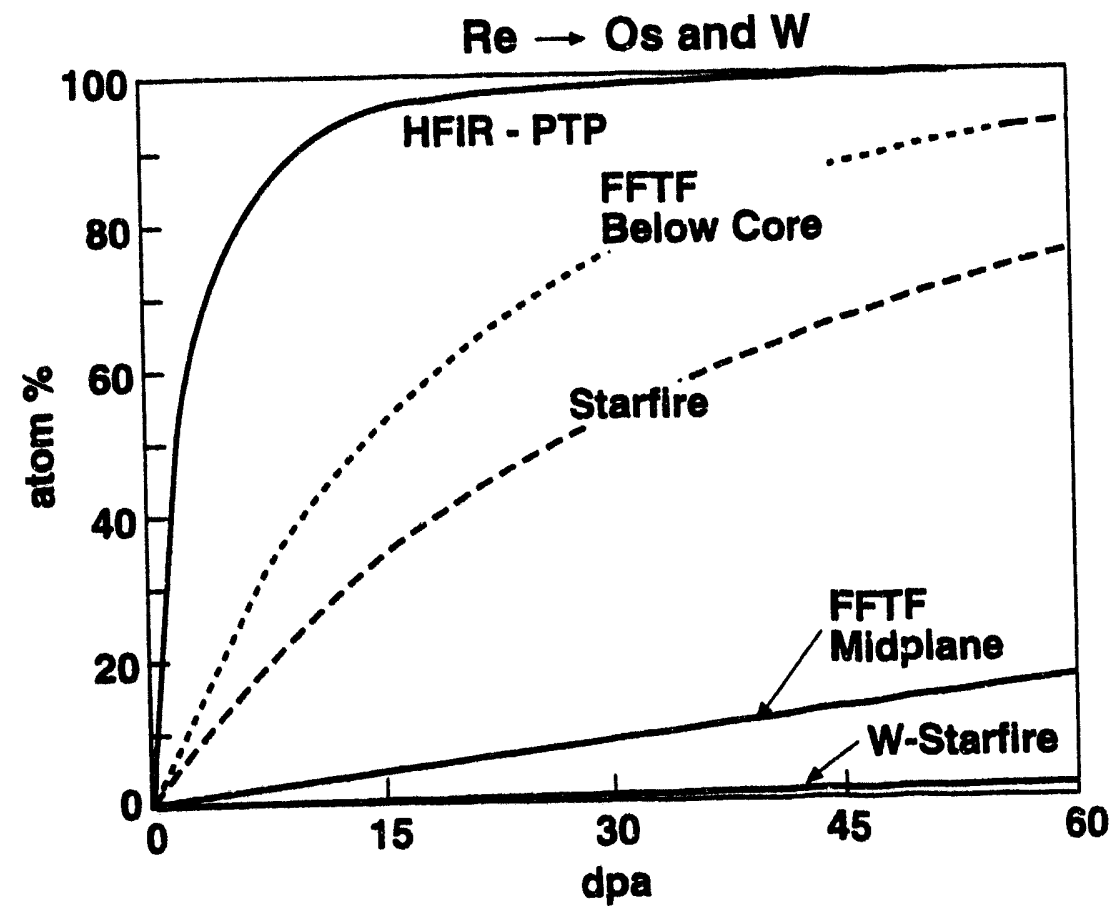

Fig. 3. Transmutation of rhenium to osmium in various irradiation facilities. Production of tungsten is also shown for STARFIRE; however, tungsten production is negligible in HFIR and FFTF.

irradiation, ${ }^{181} \mathrm{Ta}$ will transmute to ${ }^{182} \mathrm{Ta}$ (114 days) which decays to ${ }^{182} \mathrm{~W}$. The isotope ${ }^{181} \mathrm{~W}$ may also transmute directly to ${ }^{182} \mathrm{~W}$. The abundance of ${ }^{180} \mathrm{~W}$ is only $0.12 \%$, so this reaction is not very important. The net effect thus depends on the details of the irradiation. Burnup is also severe for ${ }^{182} \mathrm{~W}$ and ${ }^{183} \mathrm{~W}$. In these cases, ${ }^{182} \mathrm{~W}$ captures to ${ }^{183} \mathrm{~W}$, which in turn captures to ${ }^{184} \mathrm{~W}$, thus increasing the fraction of ${ }^{184} \mathrm{~W}$, which in turn transmutes to ${ }^{185} \mathrm{Re}$ and so on. It is also necessary to include the radioactive decay of three isotopes, namely, ${ }^{181} \mathrm{~W}$ (121 days to $\left.{ }^{181} \mathrm{Ta}\right) ;{ }^{182} \mathrm{Ta}\left(114\right.$ days to $\left.{ }^{182} \mathrm{~W}\right)$; and ${ }^{185} \mathrm{~W}$ (75 days to $\left.{ }^{185} \mathrm{Re}\right)$. All of these will continue to decay after the irradiation, leading to significant changes in composition after reactor shutdown. The $(n, p)$ reactions on $W$ all lead to products that eventually decay back to $W$, as do many of the $(n, \alpha)$ reaction channels. Small amounts $(<1 \mathrm{appm})$ of Ta and Hf will be produced; however, these reactions are not well-known and have thus been neglected. For $W$ in STARFIRE, the $(n, 2 n)$ reactions mostly lead to other stabie $\mathrm{W}$ isotopes, except ${ }^{10}{ }^{180} \mathrm{~W}$ that leads to ${ }^{179} \mathrm{Ta}$ (1.8 years) which decays to ${ }^{179} \mathrm{Hf}$. The abundance of ${ }^{180} \mathrm{~W}$ is so low that this effect is negligible.

\section{Hafnium}

The principal transmutation reactions are $(\mathrm{n}, \gamma)$ capture reactions on the major hafnium isotopes to $\mathrm{Ta}, \mathrm{W}$, and $\mathrm{Lu}$. Hafnium has rather substantial thermal and epithermal neutron cross sections, and this material has been used as a neutron absorber in the HFIR spectral tailoring experiments. Some of the highest cross sections are for isotopes like ${ }^{177} \mathrm{Hf}$; however, this transmutes to ${ }^{178} \mathrm{Hf}$, which is also stable. However, eventually, most of the isotopes burn up to ${ }^{180} \mathrm{Hf}$ (originally $35.1 \%$ abundant), which then transmutes to radioactive ${ }^{181} \mathrm{Hf}$ ( 42.4 days). This decays to ${ }^{181} \mathrm{Ta}$, which rapidly thansmutes to ${ }^{182} \mathrm{Ta}$ (114 days) which in turn decays to ${ }^{182} \mathrm{~W}$. At low fluences, the main end product is ${ }^{181} \mathrm{Ta}$. However, in HFIR the burnup is so rapid that after about 1.5 years, ${ }^{182} \mathrm{~W}$ is the main product, and at 2 years most of the Hf has been totally consumed! The figures show the $\mathrm{W}$ and $\mathrm{Ta}$ transmutants at the end of a continuous irradiation. About half of the $\mathrm{W}$ will eventually decay to $\mathrm{Ta}$. ${ }^{182} \mathrm{Ta}$ is the source of many high energy gammas and will contribute the majority of the residual activity in Hf-doped samples. Other transmutants are Lu, 
formed from the decay of ${ }^{175} \mathrm{Hf}$ (70 days), and $\mathrm{Yb}$, produced at the appm level by both (n,p) and (n, $\left.\alpha\right)$ reactions. In about a year after the end of irradiation, ${ }^{175} \mathrm{Hf}$ decays to ${ }^{175} \mathrm{Lu}$. For STARFIRE, the only important additional reaction is ${ }^{176} \mathrm{Hf}(\mathrm{n}, 2 \mathrm{n}){ }^{175} \mathrm{Hf}(70$ days $){ }^{175} \mathrm{Lu}$. Due to the low abundance of ${ }^{176} \mathrm{Hf}(5.2 \%)$, this is not the major effect, and Lu production is weaker than $\mathrm{W}$ and $\mathrm{Ta}$.

\section{Vanadium}

Vanadium results are listed in Table 1 and shown in Figure 4. The principal transmutation reaction for vanadium is ${ }^{51} \mathrm{~V}(\mathrm{n}, \gamma)^{52} \mathrm{~V}$, which promptly decays to ${ }^{52} \mathrm{Cr}$. In HFIR, further captures on $\mathrm{Cr}$ isotopes eventually lead to ${ }^{55} \mathrm{Mn}$ and ${ }^{56} \mathrm{Fe}$. In STARFIRE, the $(\mathrm{n}, 2 \mathrm{n})$ reaction leads to ${ }^{99} \mathrm{~V}$ (337 days) which eventually decays to ${ }^{49} \mathrm{Ti}$, and the $(n, \alpha)$ reaction produces ${ }^{48} \mathrm{Sc}$ which rapidly decays to ${ }^{48} \mathrm{Ti}$. It is important to note that in $\mathrm{V}-\mathrm{Cr}$ alloys $\mathrm{Cr}$ burns back to $\mathrm{V}$, thereby reducing the overall loss of $\mathrm{V}$.

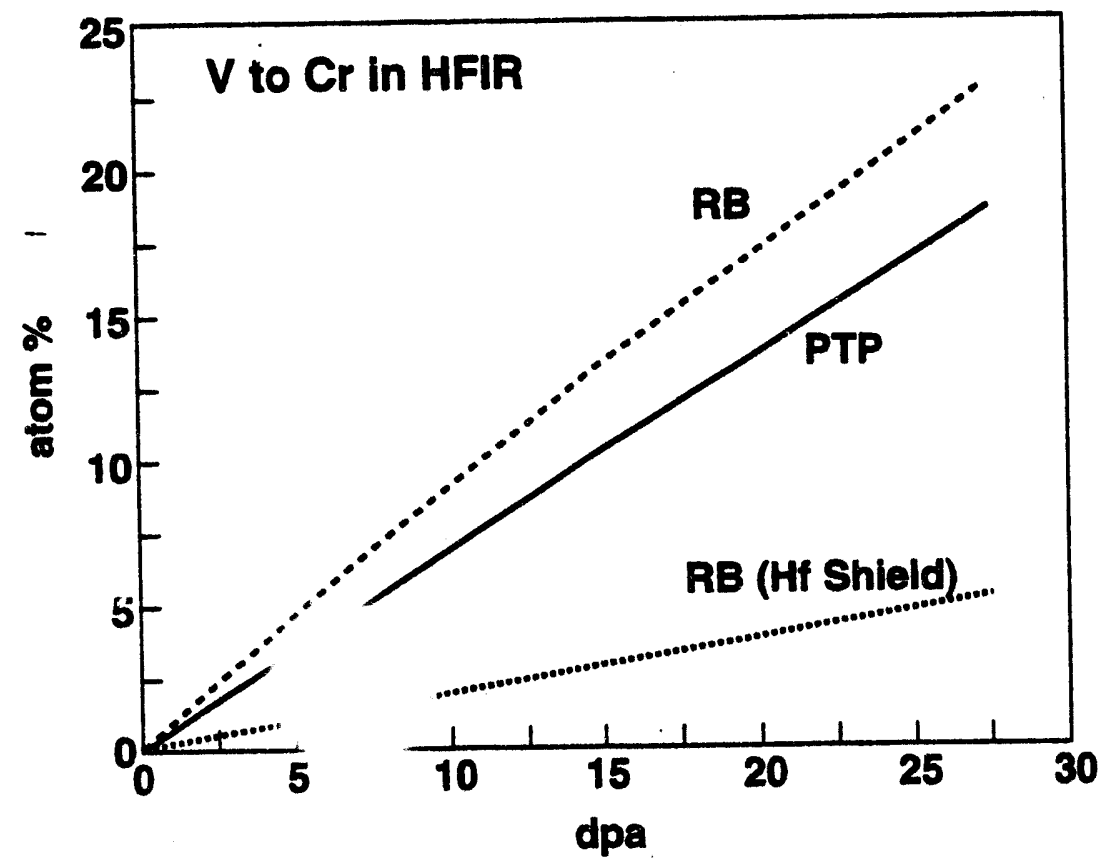

Fig. 4. Transmutation of vanadium to chromium in HFIR. The rates are shown for the PTP, RB, and RB with Hf thermal neutron shield positions.

Materials irradiations in HFIR are currently being performed in the RB positions outside of the core, both with and without a hafnium shield to suppress thermal neutrons. The neutron spectral effects of the RB versus the PTP position are illustrated for the transmutation of $V$ in figure 4. Without the Hf shield, transmutation per dpa is higher than in the central target region of HFIR. The Hf shield reduces $V$ transmutation about a factor of four; however, the production of $\mathrm{Cr}$ is still significant.

\section{$\underline{\text { Results and Discussion }}$}

The transmutation calculations show high transmutation rates for $\mathrm{Re}$ to $\mathrm{Os}$ and for $\mathrm{W}$ to $\mathrm{Re}$ and $\mathrm{Os.}$ In a mixed spectrum reactor like HFIR, some of the isotopes are totally consumed in only a few months of irradiation. For example, ${ }^{185} \mathrm{Re}$ is consumed in HFIR at the rate of $3.3 \%$ per day! The isotopes of ${ }^{100} \mathrm{~W}$, ${ }^{186} \mathrm{~W}$ and ${ }^{187} \mathrm{~W}$ are consumed at a rate of more than $1 \%$ per day. Vanadium and $\mathrm{Hf}$ also have significant transmutation rates in HFIR and STARFIRE. 
Garner et al. ${ }^{17}$ and Abe et al. ${ }^{18}$ have recently ascribed the severe degradation of irradiated Mo-Re alloys to the combined effects of irradiation-induced precipitation and substantial alloying of these materials with solid transmutation products, which were shown in these papers not only to form at high rates, but also to be very spectrally sensitive. This makes it difficult to compile and compare data from different reactor spectra. A similar problem exists for $W$ alloys or for alloys containing $W$ as a substituie for Mo to achieve low-activation goals. Comparable irradiations of such alloys in HFIR and FFTF for instance, may not lead to an unambiguous comparison. While solid transmutation is strong in Re and W in most spectra, the largest transmutation rates are in general found in HFIR, necessitating the use of spectral tailoring to conduct successful experiments.

Transmutation calculations for $\mathrm{W}$ and $\mathrm{W}-\mathrm{Re}$ alloys by Forty, et al. ${ }^{19}$ are in good agreement with our results. This work further explores the effects of neutron self-shielding, which would substantially reduce the transmutation rates, especially in HFIR and STARFIRE. Such effects are difficult to calculate since they are highly dependent on sample geometry, alloy composition, irradiation history, and the presence of adjacent materials and hence are beyond the scope of this work.

\section{REFERENCES}

1. I. V. Gorynin, V. A. Ignatov, V. V. Rybin, S. A. Fabritsiev, V. A. Kazakov, V. P. Chakin, V. A. Tsykanov, V. R. Barabash, and Y. G. Prokofyev, J. Nucl. Mater. 191-194 (1992) 421-425.

2. S. A. Fabritsiev, V. A. Gosudarenkova, V. A. Potapova, V. V. Rybin, L. S. Kosachev, V. P. Chakin, A. S. Pokrovsky, and V. R. Barabash, J. Nucl. Mater. 191-194 (1992) 426-429.

3. D. S. Gelles, Reduced Activation Materials for Fusion Reactors, ASTM-STP 1047 (1990) $113-$ 129.

4. F. Abe, T. Noda, H. Araki, and M. Okada, ibid. p. 130-139.

5. R. Kleuh and P. J. Maziasz, ibid. p. 140-158.

6. A. Tobin, J. Nucl. Mater. $85-86$ (1979) 197-201.

7. D. Murphy, S. Warren, and G. J. Butterworth, Fusion Engineering and Design 22 (1993) 379392.

8. F. A. Garner, M. L. Hamilton, D. J. Edwards, B. N. Singh, J. F. Stubbins, T. Shikama, S. J. Zinkle, and P. Samal, Fusion Reactor Materials Semiannual Progress Report DOF/ER-0313/10 (1991) 186-191.

9. I. Smid, K. Satoh, M. Akiba, M. Araki, M. Dairaku, E. Kny, K. Nakamura, S. Suzuki, and K. Yokoyama, proceedings of ICFRM-6, in press.

10. B. A. Loomis and D. L. Smith, J. Nucl. Mater. 191-194 (1992) 84-91.

11. D. R. Harries, ibid. pp. 92-99.

12. Evaluated Nuclear Data File, National Nuclear Data Center, Brookhaven National Laboratory. 
13. L. R. Greenwood and L. S. Kellogg, Fusion Reactor Materials Semiannual Progress Report, DOE/ER-0313/14 (1993) in press.

14. L. R. Greenwood, Alloy Development for Irradiation Performance Semiannual Progress Report, DOE/ER-0045/11 (1983) 30-37.

15. L. R. Greenwood, ibid., DOE/ER-0045/16 (1986) 17-24.

16. STARFIRE: Commercial Tokamak Fusion Power Plant Study, ANL/FPP-80-1 (1980).

17. F. A. Garner, L. R. Greenwood, and D. J. Edwards, in this semiannual report.

18. K. Abe, M. Satou, and F. A. Garner, Annual Progress Report for Fusion Year 1992, FFTF/MOTA Japan U.S. Collaboration, in press.

19. C. B. A. Forty, G. J. Butterworth, and J-Ch. Sublet, proceedings of ICFRM-6, in press. 
3.0 MATERIALS ENGINEERING AND DESIGN REQUIREMENTS

No contributions. 


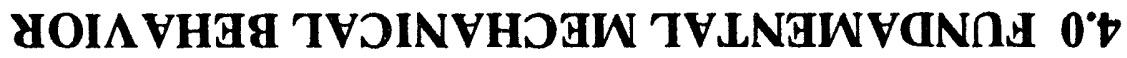


5.0 RADIATION EFFECTS, MECHANISTIC STUDIES, THEORY AND MODELING 


\section{MOLECULAR DYNAMICS CALCULATIONS OF DEFECT ENERGETICS IN $\beta$-SiC ${ }^{*}$-. Hanchen Huang and Nasr Ghoniem (Mechanical, Aerospace and Nuclear Engineering Department, University of California, Los Angeles, CA 90024-1597, USA)}

\section{OBJECTIVE}

The objective of this study is to establish data base of defect energetics in beta silicon carbide, which is of critical importance for defect evolution and in turn determines the material's response to radiation damage.

\section{SUMMARY}

The Molecular Dynamics (MD) method is used to calculate defect energetics in $\beta$ silicon carbide. Many body interaction effects in this covalent material are accounted for by using a hybrid of two body and three-body potentials. Pearson's potential is modified to accurately fit sublimation energy of $\boldsymbol{\beta}$-SiC. Inter-atomic potentials among silicon, carbon, and helium atoms are also constructed based on available data and reasoning. A microcrystal is constructed to represent the computational cell and external forces are applied to the micro-crystal so that it behaves as a part of an infinite medium. Potential energy for the unperturbed computational cell is first calculated. The cell is then set at a defect configuration and relaxed, and the potential energy of the relaxed cell is calculated. The difference between the potential energy of the unperturbed cell and that of the defectcontaining cell is used to calculate formation energies of point defects, defect clusters and helium-filled vacancy clusters in SiC. Binding energies, and migration energies of the point defects are then deduced. Pre-exponential factors of point defect diffusion coefficients are calculated from potential profile obtained. Calculated activation energies and preexponential factors of thermal diffusion through vacancy mechanism are compared to experimental data. Good agreement backups our construction of potential functions and MD calculations.

\footnotetext{
* Work supported by the Office of Fusion Energy, US DOE under grant DE-FE03-91ER54115
} 


\section{PROGRESS AND STATUS}

\section{Introduction:}

Defect energetics in covalent materials have not yet been studied by the Molecular Dynamics (MD) simulation technique. Several approximate calculations were performed for vacancy formation energies[1-6] in germanium, diamond, silicon, and siliconcarbide. These studies can be classified into two categories. The first one[1,2,3] employed a Morse-type potential and made several approximations about the relaxation of atoms neighboring a vacancy. Shortcomings of this approach are: (1) it does not fully relax the defected lattice, and (2) it does not consider surface distortion associated with forming a vacancy. The second approach $[4,5,6]$, however, considered the electronic structure of a defected lattice and omitted lattice relaxation. Since a defected lattice does relax, this approach shouldn't be able to give reasonable results. Surprisingly, results of both approaches are in good agreement with experimental data.

In the present numerical simulations, an empirically calibrated potential function given by Pearson et al[8] is modified to accurately fit experimental sublimation energy of $\beta$-SiC. Many-body effects are taken into account by employing a phenomenological three-body potential. Inter-atomic potential functions among silicon, carbon, and helium atoms are also developed. Using the constructed potential functions, we study defect energetics in $\beta$-SiC by the Molecular Dynamics simulation technique. When an atom is put on a crystal's surface, some bonds will be formed. Meanwhile, there will also be surface distortion. This effect is included in the present computation.

Nuclear reactor components are affected by neutron irradiation. Changes of their macroscopic properties are determined not only by point defect production rate but also by defect evolution processes. In order to understand the defect evolution processes, defect energetics have to be studied first. Generally, there are several possible defect cluster configurations. One factor that determines the defect configuration is its formation energy. Study of defect binding energies can also help us to determine importance of backward reactions with respect to forward reactions. These results are critical to defect clustering processes to be studied later. 


\section{Simulation}

The Molecular Dynamics simulation method is well established. Calibrating interatomic potential functions and constructing a representative computational cell are generally the two most important considerations when the MD simulation technique is applied to a variety of problems.

\section{Inter-atomic Potentials in Silicon Carbide}

Two-body potentials have been widely used for metals (e.g., ref 9 ). When one considers a covalent material (e.g., SiC), directional dependent interactions become important. A many-body potential appropriate for this purpose has been developed by Born and Oppenheimer[7], and is given in the form:

$$
\begin{aligned}
\Phi_{i}\left(\underline{r}_{1}, \underline{r}_{2}, \ldots \ldots, \underline{r}_{n}\right)= & \frac{1}{2 !} \sum_{j \neq i} V^{(2)}\left(\underline{r}_{i j}\right)+\frac{1}{3 !} \sum_{k \neq *} \sum_{j \neq i} V^{(3)}\left(\underline{r}_{i j}, \underline{r}_{i k}, \underline{r}_{j k}\right) \\
& +\ldots \ldots+\frac{1}{n !} \sum_{q *} \ldots \sum_{m \neq} \ldots \sum_{j \neq i} V^{(n)}\left(\underline{r}_{i j}, \ldots, \underline{r}_{i q}, \ldots, \underline{r}_{m q}\right)
\end{aligned}
$$

To make this many-body potential usable in practice, Pearson et al[8] truncated the expansion up to the three-body level. For SiC, they combined the Lunnard-Jones two-body potential[9] and Axilrod-Teller three-body potential[10] in the form:

$$
\begin{aligned}
& V^{(2)}\left(\underline{r}_{i j}\right)=\frac{\varepsilon}{m-n}\left[n\left(\frac{R_{0}}{r_{i j}}\right)^{m}-m\left(\frac{R_{0}}{r_{i j}}\right)^{n}\right] \\
& V^{(3)}\left(\underline{r}_{i j}, \underline{r}_{i k}, \underline{r}_{j k}\right)=Z\left[\frac{1+3 \cos \theta_{i j} \cos \theta_{i k} \cos \theta_{j k}}{\left(r_{i j} r_{i k} r_{j k}\right)^{3}}\right]
\end{aligned}
$$

where the energy parameters $(\varepsilon, Z)$ and the two-body structure parameters $\left(m, n, R_{0}\right)$ were adjusted to fit experimental data for bulk solid and atomic clusters (sublimation energies and bond length). A set of potential parameters is given by Pearson et al[8]. Unfortunately, the calculated Si-C sublimation energy $(15.409 \mathrm{eV})$ with their parameters is at discrepancy with corresponding experimental data $(12.865 \mathrm{eV})$ for $\boldsymbol{\beta}-\mathrm{SiC}$. Since defect formation energies are generally on the order of several $\mathrm{eV}$, higher accuracy of the potential function is required. To improve this fit and keep other constants unchanged, 
we modify the $\mathrm{Z}$ parameter for the Si-C-C system. The Si-Si-C and Si-C-C systems are symmetrical with respect to silicon and carbon atoms. Assuming that contribution of a carbon atom to three-body interaction is underestimated, we multiply $\mathrm{Z}_{\mathrm{Si}-\mathrm{C}-\mathrm{C}}$ by a factor $f$ and $Z_{S i-S i-C}$ by $\frac{f}{2}$. The factor $f$ is adjusted to fit the experimental sublimation energy of $\beta$-SiC. With this simple procedure, we derive the following potential function parameters:

$(\mathrm{m}, \mathrm{n})$ value: $(12,6)$

$\varepsilon$ value $(\mathrm{eV}): \quad(\mathrm{Si}-\mathrm{Si})=2.817, \quad(\mathrm{Si}-\mathrm{C})=3.895, \quad(\mathrm{C}-\mathrm{C})=5.437$

$\mathrm{R}_{\mathrm{o}} \operatorname{value}(\AA): \quad(\mathrm{Si}-\mathrm{Si})=2.2951, \quad(\mathrm{Si}-\mathrm{C})=1.7400,(\mathrm{C}-\mathrm{C})=1.4806$

$\mathrm{Z}$ value $\left(\mathrm{eV} \AA^{9}\right):(\mathrm{Si}-\mathrm{Si}-\mathrm{Si})=3484.0,(\mathrm{Si}-\mathrm{Si}-\mathrm{C})=796.8,(\mathrm{Si}-\mathrm{C}-\mathrm{C})=597.5,(\mathrm{C}-\mathrm{C}-\mathrm{C})=167.3$

\section{Inter-atomic Potentials among $\mathrm{He}, \mathrm{C}$, and Si Atoms}

The interaction between closed shell atoms is dominated by a Van der Waals mechanism. Using a perturbation method, Slater et al[11] calculated inter-atomic potential function between two helium atoms $\left(\mathrm{V}_{\mathrm{He}-\mathrm{He}}\right)$. Their calculated result of polarizability is close to that measured experimentally, and their potential function can be written as: $\mathrm{V}_{\mathrm{He}-\mathrm{He}}=-\frac{0.91}{\mathrm{r}^{6}} \mathrm{eV}$

The Van der Waals potential is proportional to the polarizability of participating atoms[21]. Polarizability data for silicon or carbon atom is not available while that for noble gas atoms is available. Since a carbon atom has fewer electrons than a neon atom, it should have a smaller polarizability. On the other hand, a carbon atom has an open electronic structure while a neon atom has a closed shell configuration. A carbon atom should therefore have larger polarizability than a neon atom. As a first order approximation, the polarizability of a carbon atom $\left(\alpha_{C}\right)$ is taken as equal to that of a neon atom $\left(\alpha_{\mathrm{No}_{\mathrm{o}}}\right)$. Likewise, the polarizability of a silicon atom $\left(\alpha_{\mathrm{Si}}\right)$ is taken as equal to that of an argon atom $\left(\alpha_{A_{x}}\right)$.

According to Slater et al[11], the polarizability of a helium atom $\left(\alpha_{\mathrm{He}_{\mathrm{H}}}\right)$, a neon atom $\left(\alpha_{\mathrm{Ne}_{\mathrm{e}}}\right)$, and an argon atom $\left(\alpha_{A_{\mathrm{s}}}\right)$ are $0.205 \times 10^{-24} \mathrm{~cm}^{3}, 0.39 \times 10^{-24} \mathrm{~cm}^{3}$, and $1.65 \times 10^{-24} \mathrm{~cm}^{3}$, respectively. The Van der Waals potential between helium and carbon 
atoms $\left(\mathrm{V}_{\mathrm{He}-\mathrm{C}}\right)$ can then be derived from the helium-helium Van der Waals potential and is written as:

$\mathrm{V}_{\mathrm{Hb}-\mathrm{C}}=\left(\frac{\boldsymbol{\alpha}_{\mathrm{C}}}{\boldsymbol{\alpha}_{\mathrm{He}}}\right) \mathrm{V}_{\mathrm{Ho}-\mathrm{He}_{\mathrm{e}}}$

Similar expression holds for the helium-silicon Van der Waals potential $\left(\mathrm{V}_{\mathrm{He}-\mathrm{Si}_{\mathrm{i}}}\right)$. The two-body potential for Si-He or C-He system can be written in the same form as for $\mathrm{Si}-\mathrm{C}$ system. The equilibrium distance is approximated as the sum of the atomic radii of interacting atoms. When bonds are formed, the atomic radii of helium, carbon, and silicon atoms are $0.93 \AA, 0.77 \AA$, and $1.11 \AA$, respectively[12].

Since the three-body Van der Waals potential is also proportional to the polarizability of each participating atom[22], the potential function parameter for $\mathrm{Si}-\mathrm{Si}-\mathrm{He}$ system can be derived from that of silicon and carbon systems, and is written as:

$\mathrm{Z}_{\mathrm{Si}-\mathrm{Si}-\mathrm{He}}=\sqrt{\frac{\alpha_{\mathrm{He}}}{\alpha_{\mathrm{Si}}} \mathrm{Z}_{\mathrm{Si}-\mathrm{Si}-\mathrm{Si}} \frac{\alpha_{\mathrm{He}}}{\alpha_{\mathrm{c}}} \mathrm{Z}_{\mathrm{Si}-\mathrm{Si}-\mathrm{C}}}$

Similar expressions hold for $\mathrm{Z}_{\mathrm{C}-\mathrm{C}-\mathrm{He}}$ and $\mathrm{Z}_{\mathrm{Si}-\mathrm{C}-\mathrm{He}}$. In these expressions, differences in covalent and Van der Waals interactions are not included. A three-body system containing a helium atom is less directionally dependent than that containing silicon and carbon atoms alone. In other words, participation of helium atoms reduces the covalent nature of the three-body system. We found that a reduction of energy by a factor of two will give reasonable results (i.e., helium stabilizes a silicon vacancy and has positive interstitial formation energy). The two-body and three-body potential parameters involving a helium atom are summarized as:

$(m, n)$ value: $(12,6)$

$\varepsilon$ value(eV): $\quad(\mathrm{Si}-\mathrm{He})=0.0677, \quad(\mathrm{C}-\mathrm{He})=0.2193$

$\mathrm{R}_{\mathrm{O}} \operatorname{value}(\AA): \quad(\mathrm{Si}-\mathrm{He})=2.04$, $(\mathrm{C}-\mathrm{He})=1.70$

$\mathrm{Z}$ value $\left(\mathrm{eVA}{ }^{9}\right):(\mathrm{Si}-\mathrm{Si}-\mathrm{He})=78.3$, (Si-C-He) $=32.4,(\mathrm{C}-\mathrm{C}-\mathrm{He})=14.9$

\section{Construction of a Computational Cell}

A computational cell consists of inner atoms and boundary atoms. The thickness of boundary layer atoms is larger than the effective range of interactions in the crystal. The boundary consists of a hybrid of fixed and flexible atoms. Due to the cutoff of interatomic interactions, a net force on an atom in a perfect crystal is not zero. External forces 
are applied to lattice atoms to balance these net forces. A vacancy is created by moving an inner lattice atom to the crystal's surface. A vacancy cluster is created by moving several neighboring atoms to the crystal's surfaces. These atoms are located far away from each other on the surfaces, so that mutual interactions do not take place. An antisite defect is formed by replacing a silicon (or carbon) atom by a carbon (or silicon) atom. A cavity consisting of a vacancy and a helium atom is formed by: (1) creating a vacancy, and (2) filling the vacancy by a helium atom. When an extra atom is added to the lattice, an interstitial is formed. Two tetrahedral interstitial configurations are the most favorable, one is that surrounded by four carbon lattice atoms (TC) and the other is that surrounded by four silicon lattice atoms (TSi).

A computer code for solving these coupled equations was developed at UCLA[13]. The standard Leap-frog numerical method was used in solving the set of coupled differential equations. In the simulation process, a velocity component is quenched to zero whenever it is in the opposite direction to the corresponding acceleration component.

\section{Defect Energetics}

Potential energy of the computational cell is calculated before any defect is introduced. The computational cell is then set at a defect configuration and the increased potential energy is calculated. Relaxation of the defected lattice results in an energy decrease. Net increase of the potential energy from a perfect configuration to a relaxed defected configuration is formation energy of the defect. Clustering of two defects usually results in decrease of their total potential energy. This decrease is binding energy of the two defects. The relaxation of lattice atoms surrounding a silicon single vacancy is shown in figure (1), where it is clearly shown that the four nearest neighbors of the vacancy undergo the largest displacement from their equilibrium positions. The magnitude of this relaxation decreases rapidly with distance away from the vacancy. Relaxation of nearest neighbors to a silicon vacancy and that of those to a carbon vacancy are compared in figure (2). It is observed that the four nearest neighbors of a vacancy tend to form bonds. When a silicon vacancy is created, the four nearest neighbors relax significantly. On the other hand, the nearest neighbors of a carbon vacancy don't relax as much, because of the geometrical asymmetry of silicon and carbon atoms. 


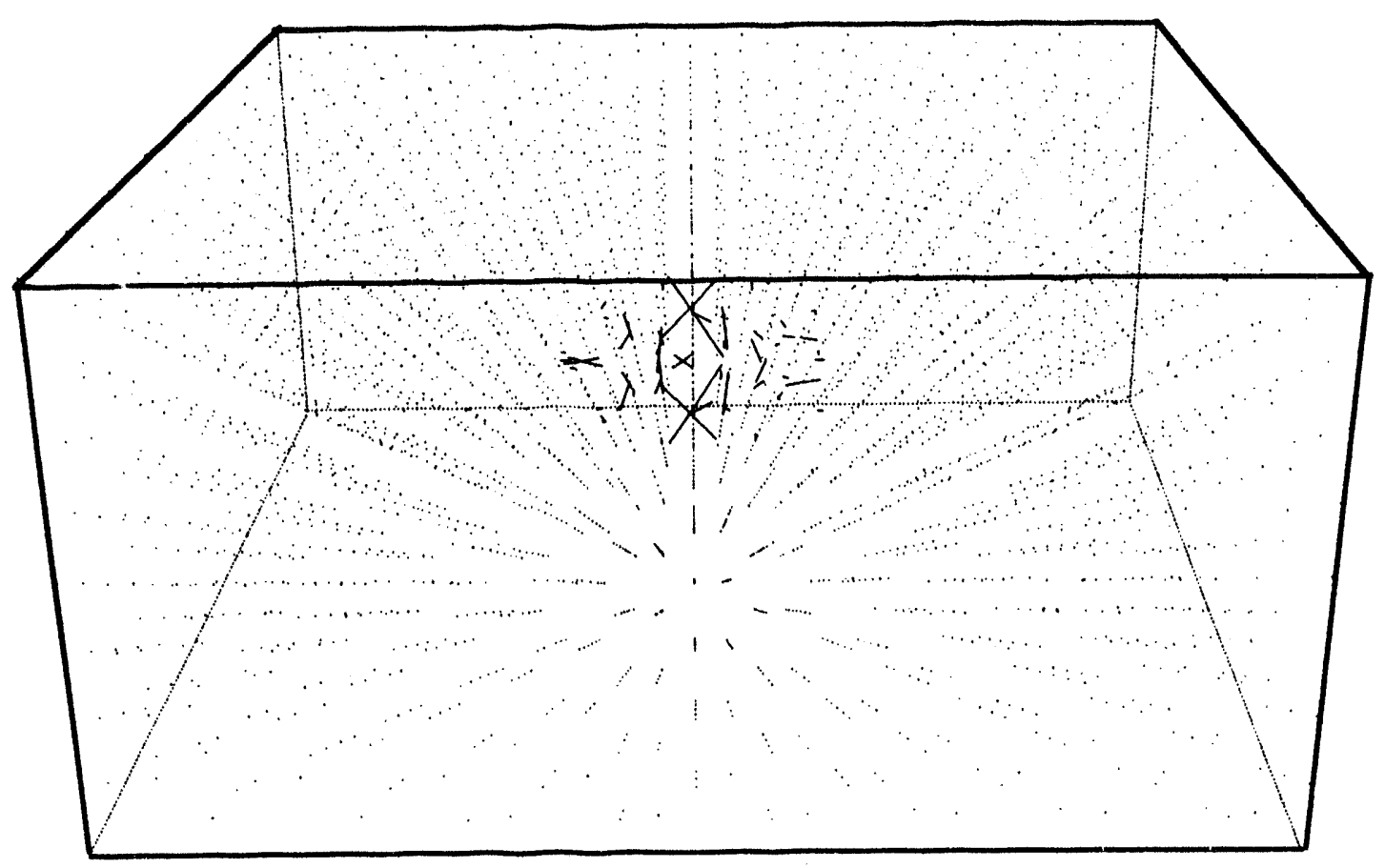

Fig 1. Relaxation field of lattice around a silicon vacancy. The length of the lines corresponds to the manitude of displacement.

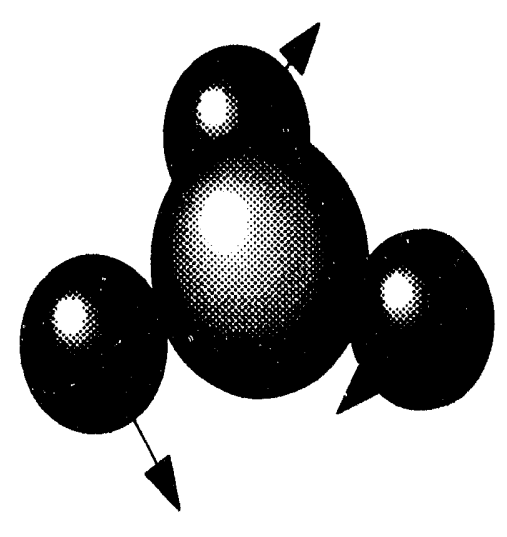

(a)

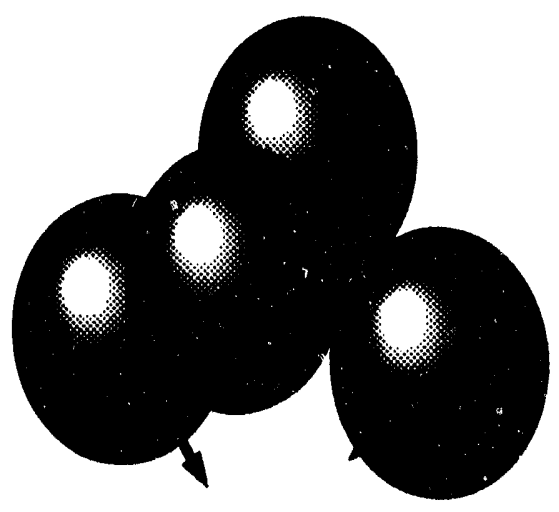

(b)

Fig 2. Relaxation of the nearest neighbors around: (a) a silicon vacancy, and (b) a carbon vacancy 
When a defect migrates, it must cross a potential barrier. Formation energies of the defect at an equilibrium position $\left(E^{\text {oq }}\right)$ and a saddle point position $\left(E^{\text {add }}\right)$ can be calculated in the same way as for defect formation energies. The migration energy of a defect can then be deduced as the difference of $E^{\text {udd }}$ and $E^{\text {eq }}$.

It is found that $\mathrm{TC}$ is energetically the most favorable interstitial position. The most favorable path of interstitial migration is $T_{C} \Rightarrow T_{S i} \Rightarrow$ (another $T_{C}$ ). The most favorable path for a silicon vacancy $\left(V_{S i}\right)$ is $V_{S i} \Rightarrow T S i \Rightarrow$ (nearest silicon lattice). Similarly, a carbon vacancy migrates through a $\mathrm{T}_{\mathrm{C}}$. If we assume that the potential profile along the migration path, $\mathrm{E}(\mathrm{x})$, can be approximated by a parabola, the Debye frequency $(v)$ and diffusion coefficient (D) of the defect can be calculated as[23]:

$v=\frac{1}{2 \pi}\left[\frac{1}{m}\left(\frac{d^{2} E}{d x^{2}}\right)_{x=x_{m}}\right]^{1 / 2}$

$\mathrm{D}=\frac{1}{6} \lambda^{2} \delta v \mathrm{e}^{-\mathrm{B}-\mathrm{m} / \mathrm{kT} \mathrm{T}}$

where $\lambda=\frac{\sqrt{2}}{2} a_{0}$ is jump distance and $\delta=12$ is number of the nearest identical neighbors for the jumping atom or defect. a0 is the lattice constant.

For SiC, thermal diffusion data has been documented by Ghoshtagore et al[14], Hong et al[15,16] and Hon et al[17,18]. A vacancy diffusion mechanism is strongly suggested by the experimental data[14-18]. It is found that acceptor dopants always occupy Si-sites[19,20]. Hong et al[15,16] found that $n$-doping increases Si diffusivity and decreases $\mathrm{C}$ diffusivity. These results imply that $\mathrm{Si}$ atom diffuses through $\mathrm{Si}$ vacancies while $C$ atom diffuses through $C$ vacancies. Based on these experimental evidences, we can take the measured activation energy as the sum of vacancy formation energy and vacancy migration energy. The pre-exponential factors for self-diffusion will therefore correspond to those of vacancy diffusion coefficients.

\section{RESULTS AND CONCLUSHONS}

The calculated defect energetics data for point defects are summarized in table 1 and those for extended defects are summarized in table 2. From the calculated results, several salient conclusions can be made: 
(1) The surface distortion energy is found to have an important contribution to defect energetics calculation.

(2) A silicon atom can be spontaneously replaced by a carbon atom from the energy point of view. This means that more carbon atoms may be present in nonstoichiometric cases.

(3) Atoms surrounding a silicon vacancy undergo substantial relaxation while those surrounding a carbon vacancy do not relax as much. This is due to the size asymmetry of silicon and carbon atoms

(4) The sum of calculated formation energy and migration energy of a vacancy agrees quite well with the corresponding experimental data on self-diffusion in SiC, indicating the validity of the modified Pearson potential.

\section{TABLE 1: Energetics of Point Defects in SiC}

\begin{tabular}{|c|c|c|c|c|c|}
\hline & \multicolumn{3}{|c|}{ Calculated } & \multicolumn{2}{|c|}{ Experimental } \\
\hline & $\begin{array}{c}\begin{array}{c}\text { formation } \\
\mathrm{E}^{\mathrm{f}}(\mathrm{eV})\end{array} \\
\end{array}$ & $\begin{array}{c}\begin{array}{c}\text { migration } \\
\mathrm{E}^{\mathrm{m}}(\mathrm{eV})\end{array} \\
\end{array}$ & $\begin{array}{l}\text { diffusion } \\
\mathrm{D}_{0}\left(\mathrm{~cm}^{2} / \mathrm{s}\right)\end{array}$ & $\begin{array}{c}\mathrm{E}^{\mathrm{f}}+\mathrm{E}^{\mathrm{m}} \\
(\mathrm{eV})\end{array}$ & $\begin{array}{l}\text { diffusion } \\
\mathrm{D}_{0}\left(\mathrm{~cm}^{2} / \mathrm{s}\right.\end{array}$ \\
\hline $\begin{array}{l}\text { Si interstitial } \\
\left(\mathrm{T}_{\mathrm{C}}\right)\end{array}$ & 2.49 & 7.32 & $1.09 \times 10^{-2}$ & N/A & N/A \\
\hline $\begin{array}{c}\text { Si interstitial } \\
\left(\mathrm{T}_{\mathrm{Si}}\right)\end{array}$ & 9.81 & N/A & N/A & N/A & N/A \\
\hline $\begin{array}{c}\text { Cinterstitial } \\
\left(\mathrm{T}_{\mathrm{C}}\right)\end{array}$ & 3.31 & 1.47 & $1.31 \times 10^{-2}$ & N/A & N/A \\
\hline $\begin{array}{c}\text { Cinterstitial } \\
\left(\mathrm{T}_{\mathrm{Si}}\right)\end{array}$ & 3.74 & N/A & N/A & N/A & N/A \\
\hline $\begin{array}{l}\text { He interstitial } \\
\left(\mathrm{T}_{\mathrm{C}}\right)\end{array}$ & 0.70 & 0.68 & $1.38 \times 10^{-2}$ & N/A & N/A \\
\hline $\begin{array}{l}\text { He interstitial } \\
\left(\mathrm{T}_{\mathrm{Si}}\right)\end{array}$ & 1.07 & N/A & N/A & N/A & N/A \\
\hline Si vacancy & 3.62 & 7.39 & $1.10 \times 10^{-2}$ & 9.5 & $8.4 \times 10^{7}$ \\
\hline C vacancy & 2.66 & 6.10 & $1.51 \times 10^{-2}$ & 8.7 & $2.6 \times 10^{8}$ \\
\hline $\begin{array}{c}\text { Antisite } \\
\text { Si replaces C }\end{array}$ & 3.66 & N/A & N/A & N/A & N/A \\
\hline $\begin{array}{c}\text { Antisite } \\
\text { C replaces Si }\end{array}$ & -3.33 & N/A & N/A & N/A & N/A \\
\hline
\end{tabular}


TABLE 2: Energetics of Extended Defects in SiC

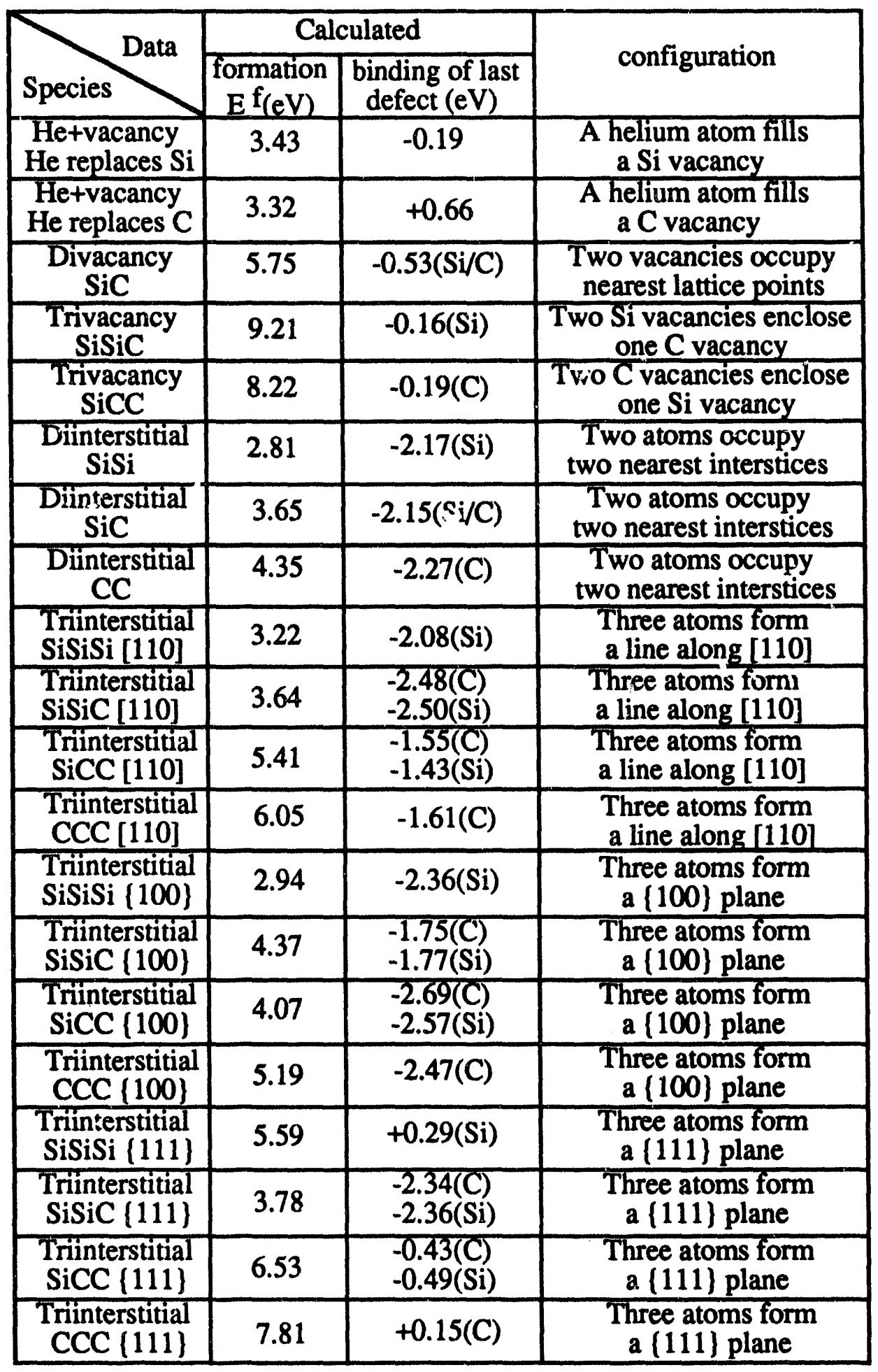


(5) Helium-filled silicon vacancies are more stable as compared to unoccupied ones. The effect of helium in stabilizing vacancies is therefore important.

(6) Defects tend to cluster. A divacancy is always composed of one silicon vacancy and one carbon vacancy because the nearest neighbors are always of different types.

(7) The calculated pre-exponential factors of vacancies are not in good agreement with experimental data. This may be accounted for by the complexity of experimental conditions. In reality, many diffusion mechanisms may operate at the same time.

\section{FUTURE WORK}

The results of defect energetics will be examined by checking their dependences on inter-atomic potentials. We will study defect energetics using different inter-atomic potentials. Experimental data and ab initio calculations will be used to calibrate our calculations.

Once equiped with reliable defect energetics, we will study defect evolution in silicon carbide and correlate the microscopic evolution to its macroscopic responses to radiation damage.

\section{ACKNOWLEDGMENT}

Special thanks are directed to Mr. A. El-Azab for passing on the MD subroutines to us, and to Mr. Ed Aguilar for his assistance in typing the manuscript. Support of the Office of Fusion Energy, through the DOE-grant DE-FG03-91ER54115 with UCLA, is greatly acknowledged.

\section{REFERENCES}

1 R. Swalin, J. Phys. Chem. Solids 18(1960)290

2 A. Scholz, Phys. Status Solidi 3(1063)43

3 A. Scholz and A. Seeger, Phys. Status Solidi 3(1963)1480

4 C. Hwang and L. Watt, Phys. Rev. 171(1965)958

$5 \quad$ K. Bennemann, Phys. Rev. 137A(1965)1497 
6 J. Bernholc, S. Kajhara, C. Wang, and A. Antonelli, Mater. Sci. Engr. B11(1992)265

7 J. Lennard-Jones, Interatomic Forces, Special Publication No. VIII, Indian Association for the Cultivation of Science,Calcutta, India, 1939

8 E. Pearson, T. Takai, T. Halicioglu and W. Tiller, J. Crystal growth 7C(1984)33

9 G. Maitland et al, Intermolecular Forces, Oxford, 1981, Appendix 1.

10 B. Axilrod and E. Teller, J. Chem. Phys. 54(1971)2129

11 J. Slater and J. Kirwood, Phys. Rev. 37(1931)690

12 Table of Periodic Properties of the Elements, Sargent-Welch Scientific Company, USA, 1992

13 P. Chou and N. Ghoniem, Phys. Rev. B43(1991)2490

14 R. Ghoshtagore and R. Coble, Phys. Rev. 143(1966)623

15 J. Hong and R. Davis, J. Am. Ceram. Soc. 63(1980)546

16 J. Hong, R. Davis and D. Newbury, J. Mater. Sci. 16(1981)2485

17 M. Hon and R. Davis, J. Mater. Sci. 14(1979)2411

18 M. Hon and R. Davis, J. Mater. Sci. 15(1980)2073

19 W. Choyke and L. Patrick, Phys. Rev. B2(1970)4959

20 Y. Vodakov and E. Mokhov, Silicon Carbide-1973, ed by R. Marshall, J. Faust Jr, and C. Ryan, University of Southern California Press, 1974, p508

21 D. Adams, Inorganic Solids/An Introduction to Concepts in Solid-state Structural Chemistry, John Wiley \& Sons, London, 1974

22 B. Axilrod and E. Teller, J. Chem. Phys. 11(1943)299 
MODELING DEFECT PRODUCTION IN HIGH ENERGY COLLISION CASCADES - H. L. Heinisch (Pacific Northwest Laboratory"), B. N. Singh (Ris $ø$ National Laboratory) and T. Diaz de la Rubia (Lawrence Livermore National Laboratory)

\section{OBJECTIVE}

The objective of this work is to determine the energy and temperature dependence of defect production and microstructure evolution for the development of fission-fusion correlations.

\section{SUMMARY}

A multi-model approach (MMA) to simulating defect production processes at the atomic scale is described that incorporates molecular dynamics (MD), binary collision approximation (BCA) calculations and stochastic annealing simulations. The central hypothesis of the MMA is that the simple, fast computer codes capable of simulating large numbers of high energy cascades (e.g., BCA codes) can be made to yield the correct defect configurations when their parameters are calibrated using the results of the more physically realistic MD simulations. The calibration procedure is investigated using results of MD simulations of $25 \mathrm{keV}$ cascades in copper. The configurations of point defects are extracted from the MD cascade simulations at the end of the collisional phase, similar to the information obtained with a binary collision model. The MD collisional phase defect configurations are used as input to the ALSOME annealing simulation code, and values of the ALSOME quenching pararneters are determined that yield the best fit to the post-quenching defect configurations of the MD simulations.

\section{PROGRESS AND STATUS}

\section{$\underline{\text { Introduction }}$}

The processes of radiation damage, from the initial production of defects to the evolution of the microstructure, occur over a wide range of time and size scales. The initial displacement-producing collisions take place in the first few tenths of a picosecond, producing nanometer-scale damage regions. The thermal spike develops and dissipates within ten picoseconds, and defect interactions continue in the cascade region for tens of nanoseconds. Beyond this "primary damage state," long range migration of the mobile defects causes microstructure evolution on a scale well beyond the atomic level. A single theoretical model does not exist that can encompass all elements in this range and lead to a quantitative understanding of the damage process. A good description of the primary damage state at the atomic scale can be obtained, in principle, using molecular dynamics (MD) techniques. However, the present computational limits of MD effectively prevent it from being used for simulating large numbers of high energy cascades or for following the motion of defects by thermally activated diffusion. However, an atomic-level description of the primary damage state, through the short-term annealing stage, can be obtained using the proposed multi-model approach (MMA).

The central hypothesis of the MMA is that simple, fast computer codes capable of simulating large numbers of high energy cascades and containing the essence of the physical aspects being modeled, such as binary collision approximation (BCA) calculations and stochastic annealing simulations (SAS), can be

\footnotetext{
- Pacific Northwest Laboratory is operated for the U.S. Department of Energy by Battelle Memorial Institute under Contract DE-AC06-76RLO 1830
} 
structured and calibrated to yield the correct defect configurations using the results of the computationally intense but more physically realistic MD simulations. The BCA code MARLOWE' simulates the collisional stage only, and it has been used to investigate the morphology of large numbers of high energy cascades. ${ }^{2}$ The SAS code ALSOME simulates the diffusion and interaction of defects, treating the defects as interacting entities and ignoring the interactions of individual atoms. In earlier work, summarized in Ref. 3, the collisional stages of cascades were simulated with MARLOWE, and the defect distributions were followed through the short-term annealing stage with ALSOME. The considerable effects of the thermal spike were accounted for by using "quenching" values for the ALSOME parameters, determined empirically by requiring total and freely migrating defect yields to be similar to "measured" defect yields. Of course, defect production from individual cascades cannot be ineasured directly. Experimental defect yields, which are averages over time and volume, are inferred from measurements of diffusion-driven phenomena. These inferences are drawn on the basis of assumptions regarding defect production which may not necessarily be appropriate. ${ }^{4}$ Although the freely migrating defect yields from individual cascades obtained in the early work compare favorably with recent $\mathrm{MD}$ simulations, ${ }^{5}$ the $\mathrm{MMA}$ will be more useful if it is based on a realistic description of the behavior of defects in individual cascades.

In the present work, MARLOWE and ALSOME are employed as in the earlier work, except that the quenching parameters are determined by comparison with $\mathrm{MD}$ results. The calibration is performed using results of MD simulations for cascades in copper of $25 \mathrm{keV}$, which is near the threshold energy for subcascade formation. The configurations of point defects are extracted from output of the MOLDYCASK $^{6}$ MD cascade simulations at the end of the collisional stage, obtaining distributions of vacancies and displaced atoms similar to those obtained with the BCA code MARLOWE. The MD collisional stage defect configurations are used as input to ALSOME, and values of the ALSOME quenching parameters are determined that yield the best fit to the post-quenching defect configurations of the MD simulations. Thus, both the initial collisional stage configuration and the final configuration of the quenching stage come from the same MD cascade. These quenching parameter values are then used in ALSOME when applied to high energy MARLOWE BCA cascades.

\section{Calculations}

Defect Distributions in the Collisional Phase. For the quenching scheme to be useful, it is crucial that the collisional stage information extracted from $\mathrm{MD}$ output have vacancy-interstitial pair separations similar to those obtained in the BCA cascades. Collisional phase information was extracted from the output of the MOLDYCASK code for the two $25 \mathrm{kev}$ cascades generated in copper at $10 \mathrm{~K}^{7}$. As in MARLOWE, the atoms in MOLDYCASK receiving kinetic energy greater than a selected threshold energy ECUT $(4.8 \mathrm{eV})$ are identified and followed over many time steps until their energies fall below a cut-off value. Their initial lattice sites are considered to be vacant sites, and the positions of the atoms where their energies fall below the cut-off are taken as the locations of the displaced atoms. In MARLOWE the cut-off energy has the same value as the threshold energy ECUT, and each displaced atom is located at the turning point of its last collision. In the MOLDYCASK output, each displaced atom identified is located at the position occupied during the last recorded time step in which it had energy greater than the cut-off energy. To maintain the same average vacancy-displaced atom pair separation distributions as MARLOWE, it was necessary to follow displaced atoms in the MOLDYCASK cascades until their kinetic energy dropped well below ECUT $(2 \mathrm{eV})$. It should be noted that the collisional stage configurations from MOLDYCASK have somewhat fewer defect pairs, somewhat smaller volumes, and somewhat higher vacancy densities than the average values for 100 MARLOWE cascades, but the MOLDYCASK values are within one standard deviation of the MARLOWE distributions.

Calibrating ALSOME. ALSOME is based on a simple model of defect diffusion and interaction. Point defects and defect clusters are considered to be spherical and centered on lattice sites, with radii related to their cluster size. Mobile defects, including clusters of any size if desired, move one lattice site at a 
time in randomly chosen directions. The order in which the defects are chosen to move is determined by random selection, depending on the number of mobile defects and their assigned relative jump probabilities. Two defects interact when their separation falls within the assigned critical reaction distance for that interaction. The interaction product is placed at the target defect's lattice site. The adjustable parameters are the defect species (type and size) that are considered mobile (e.g., mono-, di- and trivacancies; mono-, di-, tri- and tetra-interstitials for normal annealing in this work), the relative jump probabilities for each of the mobile species, and the critical reaction distances. The annealing is modeled as a sequence of events rather than as a function of elapsed real time, and it continues until no mobile defects remain in the volume being annealed, unless some other criterion is imposed. When simulating the short-term annealing in a single cascade region, the cascade is placed at the center of a volume that is somewhat larger than the cascade in all directions. During annealing, defects escaping this volume are no longer followed, and they are considered to be migrating defects.

ALSOME was designed to simulate normal, thermally activated diffusion, and it is most physically correct when applied to relatively dilute concentrations of defects. It is the aim of this work to determine if ALSOME can be effectively applied to the quenching stage of high energy cascades. To be sure, the actions of defects within a thermal spike (if they could be defined during the short-lived, extremely nonequilibrium excursion above the melting temperature) cannot be simulated using the assumptions of ALSOME. However, it may be possible to simulate the results of those actions, i.e., the distribution of remaining defects, by choosing ALSOME parameter values for the quenching stage that result in the required amount of clustering and annihilation in the cascade region. The anticipated success of this simple approach derives from the strong influence of the collisional stage defect configuration on the configuration after quenching.

The MD simulations show that during the quenching of a thermal spike, the vacancy distribution becomes concentrated toward the center of the cascade, and interstitial atoms are largely eliminated from the spike region. This is illustrated in Table 1, where the size of a defect distribution is represented by the root

TABLE 1

Average Radius of Defect Distributions in $25 \mathrm{keV}$ Cascades in Cu (values in Angstrom units)

\begin{tabular}{|c|c|c|}
\hline & VACANCY & INTERSTITIAL \\
\hline COLLISIONAL STAGE & & \\
CASCADE A & 29 & 32 \\
CASCADE B & 28 & 31 \\
\hline AFTER QUENCHING* $^{*}$ & & \\
MOLDYCASK $^{\text {MMA }}$ & 19 & 40 \\
AFTER SHORT-TERM ANNEALING $^{*}$ & 33 & 38 \\
MOLDYCASK $^{\text {MMA }}$ & & 32 \\
\hline
\end{tabular}

* Average of Cascades A and B 


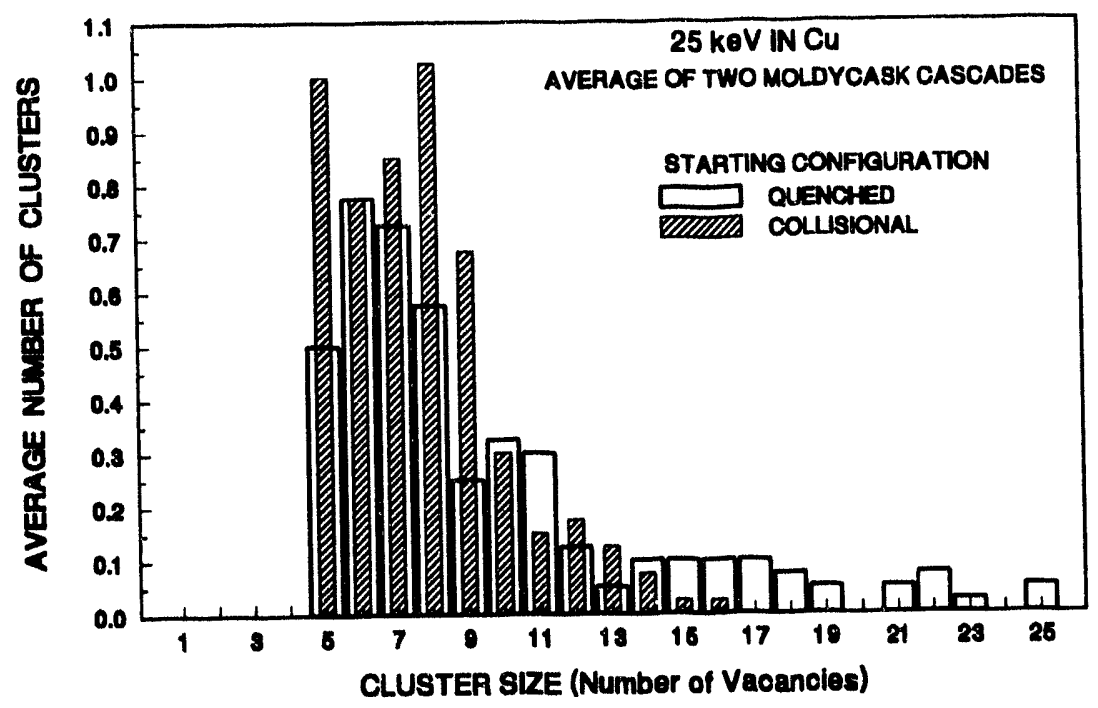

Figure 1. Vacancy cluster size distributions at the end of the thermal spike quenching stage for $25 \mathrm{keV}$ cascades in copper. The open bars are for the quenched configuration directly from MOLDYCASK and the striped bars are for the quenched configuration as simulated with ALSOME, starting from the collisional stage in MOLDYCASK.

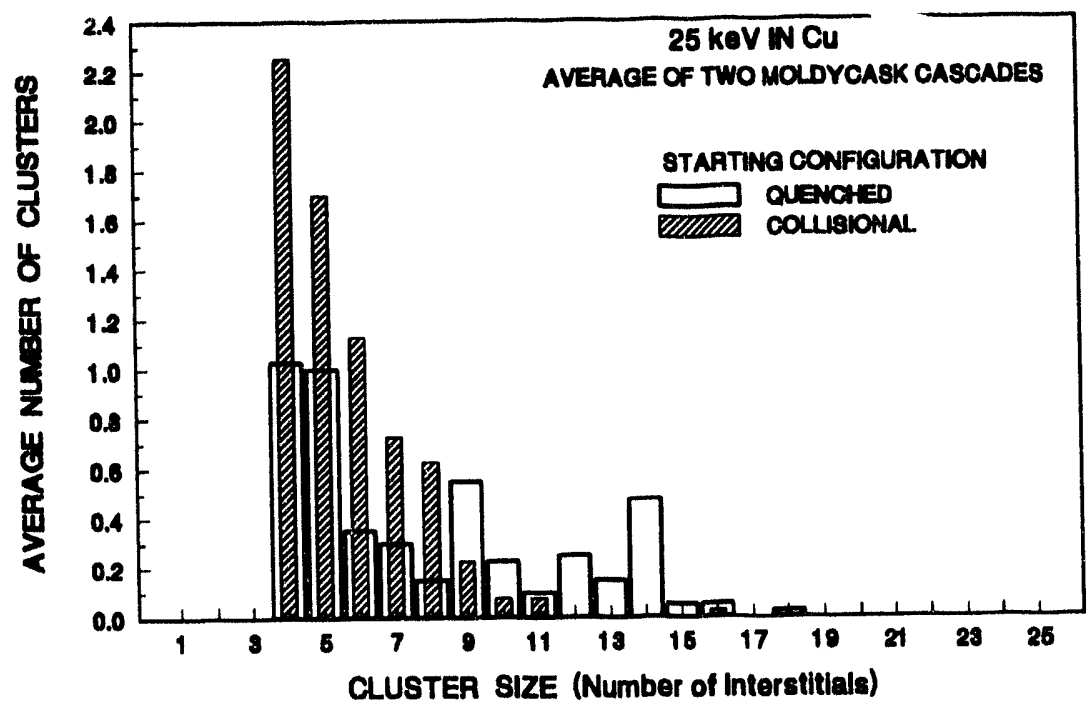

Figure 2. Interstitial cluster size distributions after short-term annealing for a time and temperature at which single vacancies diffuse from the cascade region, for $25 \mathrm{keV}$ cascades in copper. The open bars are for the configuration when starting from the quenched cascades from MOLDYCASK and the striped bars are for the configuration as simulated with ALSOME, starting from the collisional stage in MOLDYCASK. 
mean square distance of defects from the centroid. The sizes of the vacancy and displaced atom distributions for the two $25 \mathrm{keV}$ MOLDYCASK cascades are about the same after the collisional stage. After the quenching stage, the displaced atom distributions are about the same size as before, but the vacancy distributions are about half their previous size.

The collisional phase was extracted from the MOLDYCASK cascades in the form of a distribution of vacant sites and displaced atoms. There was no attempt to define stable defects or clusters of defects, since the cascade energy still resides in the significant kinetic energies of a relatively small number of atoms at that point. Following development and quenching of the thermal spike (at 11-12 ps, when the MOLDYCASK runs were terminated), point defects were identified as vacancies or self-interstitial atoms (SIAs) in terms of the occupation of Wigner-Seitz cells. As the list of point defects is read into ALSOME, defect clusters are immediately identified according to the clustering criteria represented by the critical reaction distances. Figure 1 shows the distribution of vacancy clusters at $12 \mathrm{ps,} \mathrm{after} \mathrm{the}$ quenching stage (open bins). Both large clusters and single point defects are present after the quench. This is true in the SIA distribution as well.

The ALSOME quench was performed on the extracted collisional stage configurations in Monte Carlo fashion, running many times over different sets of random numbers with each set of trial parameter values. The criteria for a successful simulation of the quenching stage of the MOLDYCASK cascades are that 1) the correct number (about 60 ) of total point defect pairs should remain after the quench, 2) the vacancy distribution should collapse to about half its collisional stage size, and 3) the cluster size distributions should be similar to those of the quenched configuration, especially in having large clusters as well as individual point defects.

Unfortunately, no set of parameter values was found that could simultaneously satisfy all three criteria. In particular, it was not possible to reduce the size of the vacancy distribution without eliminating the population of mobile vacancies through clustering. Subsequently, a revised set of criteria were adopted that involved comparing the results of short term annealing on the quenched cascades remaining at the end of the MOLDYCASK runs to the results after quenching and short term annealing of the collisional stage configurations extracted from MOLDYCASK. The criteria for selecting parameter values in this case are simply that the total number of remaining defect pairs should be the same, and the numbers of vacancies and SIAs escaping the cascade should be the same, respectively. The short-term annealing is carried out at an effective temperature and time such that no mobile defects remain in the cascade region.

In Table 1 the sizes of the vacancy and SIA distributions after quenching and short term annealing with ALSOME are listed. Compared with the MD standard, the interstitial distributions are slightly smaller, while the vacancy distributions are almost twice the size of the standard. The vacancy cluster size distribution after quenching is in Fig. 1, and the SIA cluster distribution after short term annealing, starting from both the quenched standard and the collisional stage, are shown in Fig. 2. After short term annealing the small mobile clusters are gone, either clustering, annihilating or escaping. The large SIA clusters obtained from annealing the MD standard were not produced when starting from the collisional stage. This is also true for vacancy clusters.

A set of 100 cascades of $25 \mathrm{keV}$ in copper was produced with MARLOWE and run through the ALSOME quenching and short term annealing. The average defect production from those cascades is listed in Table 2. The total number of defects at each stage agrees well with the MOLDYCASK cascades, but there are twice as many freely migrating vacancies and $50 \%$ more freely migrating SIAs on average resulting from the MARLOWE cascades. As described above, the collisional stage configurations of the two MOLDYCASK cascades are smaller and more compact than the average $25 \mathrm{keV}$ MARLOWE cascade. The closer proximity of the defects in the compact MOLDYCASK cascades evidently results in the greater clustering observed. 
TABLE 2

Defect Production in $25 \mathrm{keV}$ Cascades in $\mathrm{Cu}$

\begin{tabular}{|l|l|c|c|c||}
\hline \hline $\begin{array}{l}\text { STARTING } \\
\text { CONFIGURATION }\end{array}$ & \multicolumn{2}{|c|}{ TOTAL DEFECT PAIRS } & \multicolumn{2}{c|}{ FREELY MIGRATING } \\
QUENCHED & ANNEALED & \multicolumn{2}{|c|}{ VACANCIES SIAS } \\
\hline \hline QUENCHING STAGE & 60 & $49 \pm 4$ & $8 \pm 4$ & $9 \pm 3$ \\
\hline COLLISIONAL STAGE & $61 \pm 10$ & $48 \pm 7$ & $8 \pm 3$ & $9 \pm 4$ \\
\hline MARLOWE, 100 CASCADES & $65 \pm 15$ & $45 \pm 11$ & $16 \pm 6$ & $15 \pm 5$ \\
\hline \hline
\end{tabular}

\section{Discussion}

The ALSOME annealing code was unable to simulate all the features of the quenched MOLDYCASK cascade defect distributions using only the simple adjustment of its defect jumping and interaction parameters. It was, however, quite successful in simulating the proper yields of total and freely migrating defects after short term annealing.

ALSOME, as used, did not produce the compaction of the vacancy distribution during quenching that is observed in the MD results. This is understandable, since, after the collisional stage, a highly disordered (molten) region develops in which the actions of point defects cannot be recognized. This thermal spike then rapidly quenches to the crystal temperature. To model that behavior in terms of only interacting defects is probably impossible. On the other hand, the quenched configuration exists only for a short time. Defect interactions continue to take place in the cascade region long after the spike has cooled.

The large clusters produced during the quenching stage in the MOLDYCASK cascades, and which continue to exist even after short term annealing, were not produced as frequently in quenching and short term annealing with ALSOME. This may be due primarily to the simplicity of the model used in ALSOME, in which all defect migration is by uncorrelated jumps. A region of high local defect density that collapses to a large cluster may form two or more smaller clusters under ALSOME, depending on the statistical variation of the uncorrelated random jumps, which would tend to favor the production of multiple clusters in such a case. With respect to defect production, this may not be a serious limitation. The same total number of defects is tied up in clusters, and two closely spaced medium-sized clusters may have about the same effect on subsequent defect disposition as a single large cluster.

An important cascade feature that ALSOME is presently incapable of simulating is the direct formation of both vacancy and interstitial loops in cascades. The $25 \mathrm{keV}$ cascades used in this work contain a loop of 14 vacancies in a single (111) plane and a loop of 17 SIAs, also on a single (111) plane.

\section{Conclusions}

The MMA, utilizing MOLDYCASK, MARLOWE and ALSOME, provides a feasible approach to modeling the production of defects in high energy cascades. Quenching parameter values were determined for ALSOME by calibration to results from $25 \mathrm{keV}$ MD cascades in copper produced with MOLDYCASK. Cascades at the collisional stage produced using MARLOWE, then quenched and short term annealed using ALSOME, give defect yields consistent with cascades generated in MOLDYCASK MD simulations. 
The ALSOME simulation in its simplest form cannot duplicate the compactness of the vacancy distribution or the large clusters or loops formed in the MD simulations. This limitation may be important when cascade and subcascade interactions or vacancy cluster dissociation are involved. However, present computing capabilities now allow the rules governing migration and interaction of defects in ALSOME to be much more complex. Continuing work will develop those rules from the actions of defects observed in detail in MD simulations.

\section{ACKNOWLEDGEMENTS}

This research was supported in part by the U.S. Department of Energy under Contract DE-AC06-76RLO 1830 and in part by the European Fusion Technology Programme.

\section{REFERENCES}

1. M. T. Robinson and I. M. Torrens, Phys. Rev. B 9, 5008 (1974).

2. H. L. Heinisch and B. N. Singh, Phil. Mag. A 67, 407 (1993).

3. H. L. Heinisch, Rad. Eff. and Def. in Solids 113, 53 (1990).

4. S. J. Zinkle and B. N. Singh, J. Nucl. Mater. in press.

5. H. L. Heinisch and B. N. Singh, J. Nucl. Mater. 191-4, 1083 (1992).

6. T. Diaz de la Rubia and M. W. Guinan, J. Nucl. Mater. 174, 125 (1990).

7. T. Diaz de la Rubia and M. W. Guinan, Phys. Rev. Lett. 66, 2766 (1991). 


\section{INFLUENCE OF HELIUM GENERATION RATE AND TEMPERATURE HISTORY ON MECHANICAL PROPERTIES OF MODEL Fe-Cr-Ni ALLOYS IRRADIATED IN FFTF AT RELATIVELY LOW DISPLACEMENT RATES - M.L. Hamilton, F $\$$. Garner and D.J.}

Edwards (Pacific Northwest Laboratory) ${ }^{\text {a }}$

\section{OBJECTIVE}

The objective of this effort is to determine the influence of high helium generation rates on evolution of mechanical properties of simple model fcc alloys.

\section{SUMMARY}

In agreement with earlier studies conducted at higher displacement rates, the evclution of mechanical properties of model $\mathrm{Fe}-\mathrm{Cr}-\mathrm{Ni}$ alloys irradiated at lower displacement rates in the ${ }^{59} \mathrm{Ni}$ isotopic doping experiment does not appear to be strongly affected by large differences in helium generation rate. This insensitivity to helium/dpa ratio is exhibited during both isothermal and non-isothermal irradiation. The overall behavior of the model alloys used in this study is dominated by the tendency to converge to a saturation strength level that is independent of thermomechanical starting state and helium/dpa ratio, but which is dependent on irradiation temperature and alloy composition.

\section{PROGRESS AND STATUS}

\section{Introduction}

Until recently, it has been almost impossible to conduct experiments in which spectrum-related parameters such as helium/dpa ratio were varied without also accepting variations in other important parameters such as displacement rate or temperature history. A technique currently being used, however, allows the study cf the influence of helium alone on density change, microstructural evolution and mechanical properties. This technique utilizes isotopic tailoring to vary the helium production rate without introducing changes in specimen composition, neutron spectrum or displacement rate $(1,2)$. This generates substantial variations in $\mathrm{He} / \mathrm{dpa}$ ratio without varying any other important parameter by using alloys whose only difference is the presence or absence of ${ }^{59} \mathrm{Ni}$, an isotope that does not occur naturally (3), and irradiating doped and undoped specimens side-by-side in the appropriate reactor spectrum (1).

The extensive ${ }^{59} \mathrm{Ni}$ isotopic tailoring experiment conducted in the FFTF reactor since 1985 to study the effects of helium generation rate on mechanical properties is now approaching completion. Whereas previous papers $(3,4)$ have concentrated on the irradiation sequences conducted at higher displacement rates, this report focuses on the tests conducted at lower displacement rates, reaching cumulative displacement levels ranging from 0.2 to $13.9 \mathrm{dpa}$. These two groups explored both LMR relevant helium/dpa ratios and more fusion-relevant ratios of 4.4 and 20 , as well as a higher-thanfusion rate of $62 \mathrm{appm} / \mathrm{dpa}$. The alloys studied were $\mathrm{Fe}-15 \mathrm{Cr}-25 \mathrm{Ni}$ (both with and without $0.04 \mathrm{P}$ ) and $\mathrm{Fe}-15 \mathrm{Cr}-45 \mathrm{Ni}$, all in weight percent. Two of the three irradiation series reported here involved

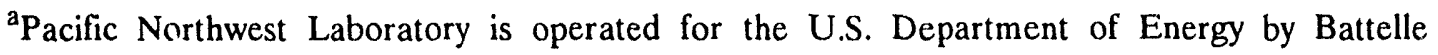
Memorical Institute under Contract DE-AC06-76RLO 1830.
} 
comparison of isothermal and non-isothermal irradiations, since the details of temperature history are now known to have dominated many earlier experiments directed toward the influence of helium (5).

\section{Experimental Details}

The alloys employed in this study were irradiated in both the cold worked and annealed conditions. The acquisition of the ${ }^{59} \mathrm{Ni}$, and the production of the ${ }^{59} \mathrm{Ni}$-doped miniature tensile specimens and microscopy disks, as well as their irradiation conditions, are described by Simons and coworkers (1). The miniature tensile specimens measured $5.1,1.0$, and $0.25 \mathrm{~mm}$ in gauge length, width and thickness, respectively. They were tested at room temperature at a strain rate of $4.7 \times 10^{-4} \mathrm{~s}^{-1}$ in a horizontal test frame described in ref. 6 . Yield strengths were determined at $0.2 \%$ offset. The majority of test conditions involved single specimens, but two specimens were tested for most alloy conditions in the $600^{\circ} \mathrm{C}$ series.

Figure 1 shows the discharges from the final three irradiation sequences of the ${ }^{59} \mathrm{Ni}$ experiment, each defined by its target irradiation temperature and its location in the Materials Open Test Assembly (MOTA) in the FFTF reactor. The experiment was initiated in the MOTA 1D irradiation segment, but one-third of the way through the irradiation segment there was a pronounced temperature excursion of relatively short duration $(\sim 1 \mathrm{hr})$, referred to as an over-temperature event. This event compromised the integrity of many of the experiments in the MOTA and a programmatic decision was therefore made to run the MOTA in the helium-purged mode for the remainder of FFTF cycles 7 and 8 while a series of reactivity feedback tests were conducted. The majority of the MOTA canisters therefore operated at variable but lower than target temperatures until the end of the MOTA ID. Isothermal irradiation at the original target temperatures then proceeded in MOTA segments $1 \mathrm{E}, 1 \mathrm{~F}$ and $1 G$.

Specimens in the out-of-core irradiation sequence conducted at $465^{\circ} \mathrm{C}$ were thought to have been affected very little by the temperature history event and their irradiation was continued, with discharges

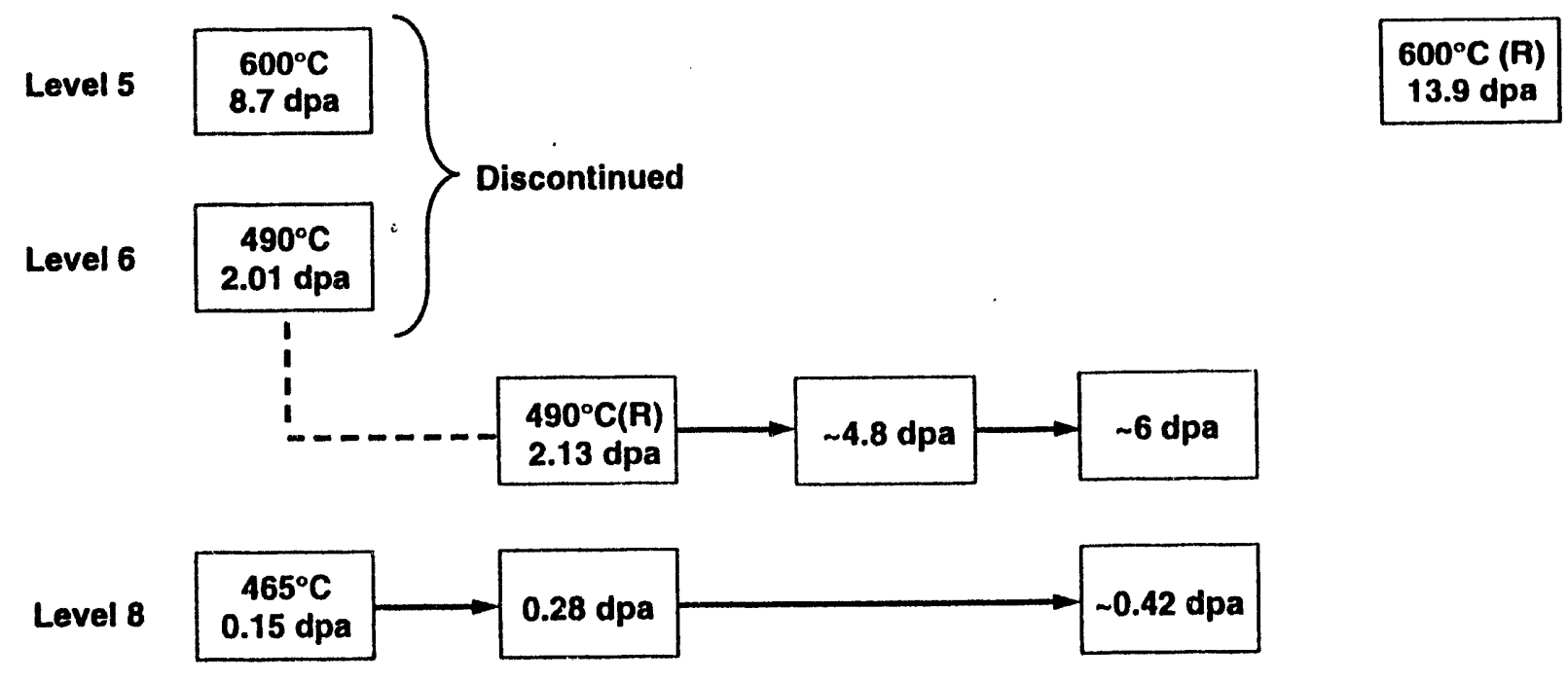

Fig 1. Schematic representation of the low displacement rate irradiations sequences for the ${ }^{59} \mathrm{Ni}$ isotopic tailoring experiment. " $600^{\circ} \mathrm{C}(\mathrm{R})$ " and " $490^{\circ} \mathrm{C}(\mathrm{R})$ " refer to the replacement sequences substituted for the original compromised sequences at 600 and $490^{\circ} \mathrm{C}$. Damage levels shown represent cumulative totals. 
occurring at $0.14,0.26$ and $0.40 \mathrm{dpa}$. The specimens in the original in-core sequence at $490^{\circ} \mathrm{C}$ were not returned to the reactor after reaching $2.0 \mathrm{dpa}$, but were replaced with a repeat sequence in MOTAs 1E through $1 G$ with discharges at $2.1,4.2$ and 6.7 dpa. The specimens in the in-core sequence at $600^{\circ} \mathrm{C}$ were very strongly impacted by the temperature history, both in the overtemperature and under-temperature portions, and irradiation was discontinued after $8.7 \mathrm{dpa}$. A decision was made later, however, to repeat this sequence for two irradiation segments in MOTA $2 B$ and 2C. Unfortunately, both groups of specimens at $600^{\circ} \mathrm{C}$ had to be retrieved when FFTF was shut down before MOTA $2 \mathrm{C}$ was initiated. Only $13.9 \mathrm{dpa}$ was attained in this repeat sequence.

The successful conduct and interpretation of these experiments is contingent on measurement of the helium levels attained. The details of the helium measurements are presented in refs. 7-9. The displacement levels were calculated from dosimetry measurements using the standard NRT model for dpa.

\section{Results and Discussion}

The yield strength and total elongation data for the full series of irradiations at $490,465^{\circ} \mathrm{C}$ and $600^{\circ} \mathrm{C}$ are shown in Figures 2-4. At $490^{\circ} \mathrm{C}$ the yield strengths of the cold worked and annealed specimens appear to be converging in each of the three alloys studied. The elongation data exhibit a similar convergence. This behavior is in agreement with a similar tendency toward convergence observed in many other irradiation experiments (10). While the yield strengths of both the annealed and cold worked alloys exhibit essentially no dependence on helium/dpa level, there is possibly a small effect of helium on the total elongation, but only for the annealed $\mathrm{Fe}-15 \mathrm{Cr}-25 \mathrm{Ni}-0.04 \mathrm{P}$ alloy. However, the maximum difference between doped and undoped specimens is comparable to the range of variation observed in the unirradiated specimens. The cold worked alloys clearly do not exhibit an influence of helium on elongation. The impact of the non-isothermal temperature history appears to be significant only for the $\mathrm{Fe}-15 \mathrm{Cr}-25 \mathrm{Ni}$ alloy in both starting conditions.

Convergence in tensile properties also appears to be occurring in the high-helium, low-dose sequence at $465^{\circ} \mathrm{C}$, with very little or no consistent influence of helium on the yield strength. Approximately 25 appm have accumulated in the doped specimens at an exposure of $0.4 \mathrm{dpa}$ in this low dose rate experiment. There may be some small and possibly increasing influence of helium, however, on the elongation of the cold worked $\mathrm{Fe}-15 \mathrm{Cr}-25 \mathrm{Ni}-0.04 \mathrm{P}$ alloy with increasing dpa level.

At $600^{\circ} \mathrm{C}$ convergence in the tensile properties also occurs in the isothermal sequence, but very little change is occurring in the annealed condition. The impact of the over-temperature/under-temperature history is very pronounced, but with one possible exception (total elongation, annealed $45 \% \mathrm{Ni}$ alloy), there appears to be no significant effect of the differences in helium generation rate. Convergence in the non-isothermal sequence is approached by both the cold worked and annealed specimens, reflecting the lower average temeprature over the last two-thirds of the sequence. Once again, however, the helium generation rate does not appear to be a significant factor.

The microstructural origins of the non-isothermal response at $600^{\circ} \mathrm{C}$ and $8.7 \mathrm{dpa}$ have been presented previously (11), but microscopy has not yet been performed for the isothermal repeat sequence. Assuming that the response differs only in the details of the microstructure, it is expected that changes in tensile properties can be successfully related to the densities and sizes of cavities, dislocation loops, and dislocation segments, as well as phosphide precipitates in the case of the $\mathrm{Fe}-15 \mathrm{Cr}-25 \mathrm{Ni}-0.04 \mathrm{P}$ alloy. Mitchell has shown, however, that the superposition rules employed to estimate the combined influence of various microstructural components must be modified when needle-like phosphides exhibit large aspect ratios, and also when the phosphides are directly associated with cavities (12). 


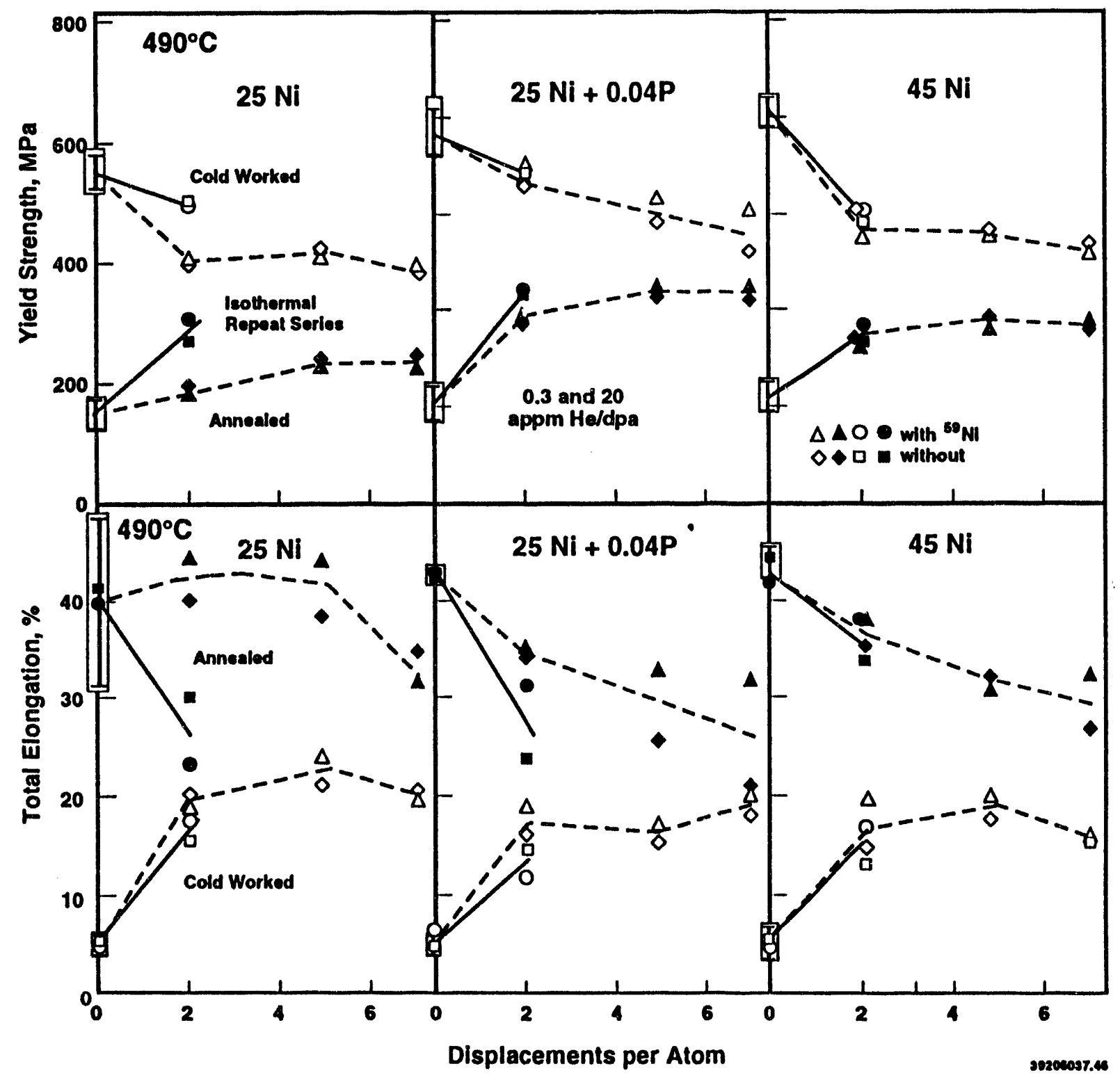

Fig. 2. Influence of thermomechanical starting state, isotopic doping and temperature history on yield strength and elongation following irradiation just above the top of the FFTF core at $490^{\circ} \mathrm{C}$. The dotted lines correspond to the isothermal repeat sequence. The boxes on the y-axis show the range of values obtained for the unirradiated specimens. 


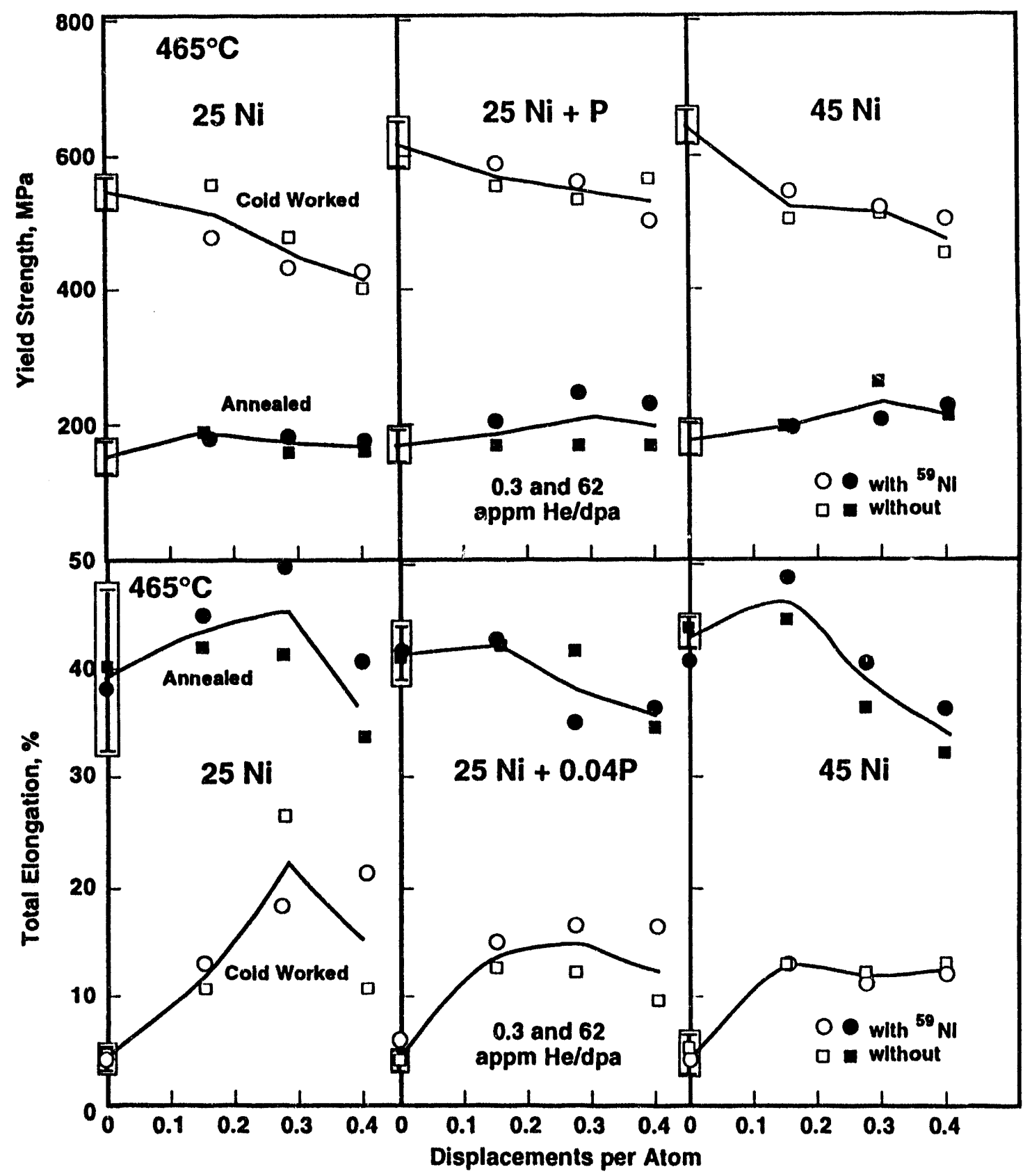

Fig. 3. Influence of thermomechanical starting state and isotopic doping on yield strength and elongation following irradiation high above the FFTF core at $465^{\circ} \mathrm{C}$.

Whereas success has been attained in describing the microstructural origins of strength changes at high displacement rates in terms of relatively large microstructural components (11-14), the annealed Fe$15 \mathrm{Cr}-25 \mathrm{Ni}$ alloy in the low exposure sequence at $465^{\circ} \mathrm{C}$ was found not to develop cavities or dislocations, but to be dominated by the formation of many small point defect clusters (15). In this case, high levels of helium were observed to decrease the density of such clusters, with a concurrent 


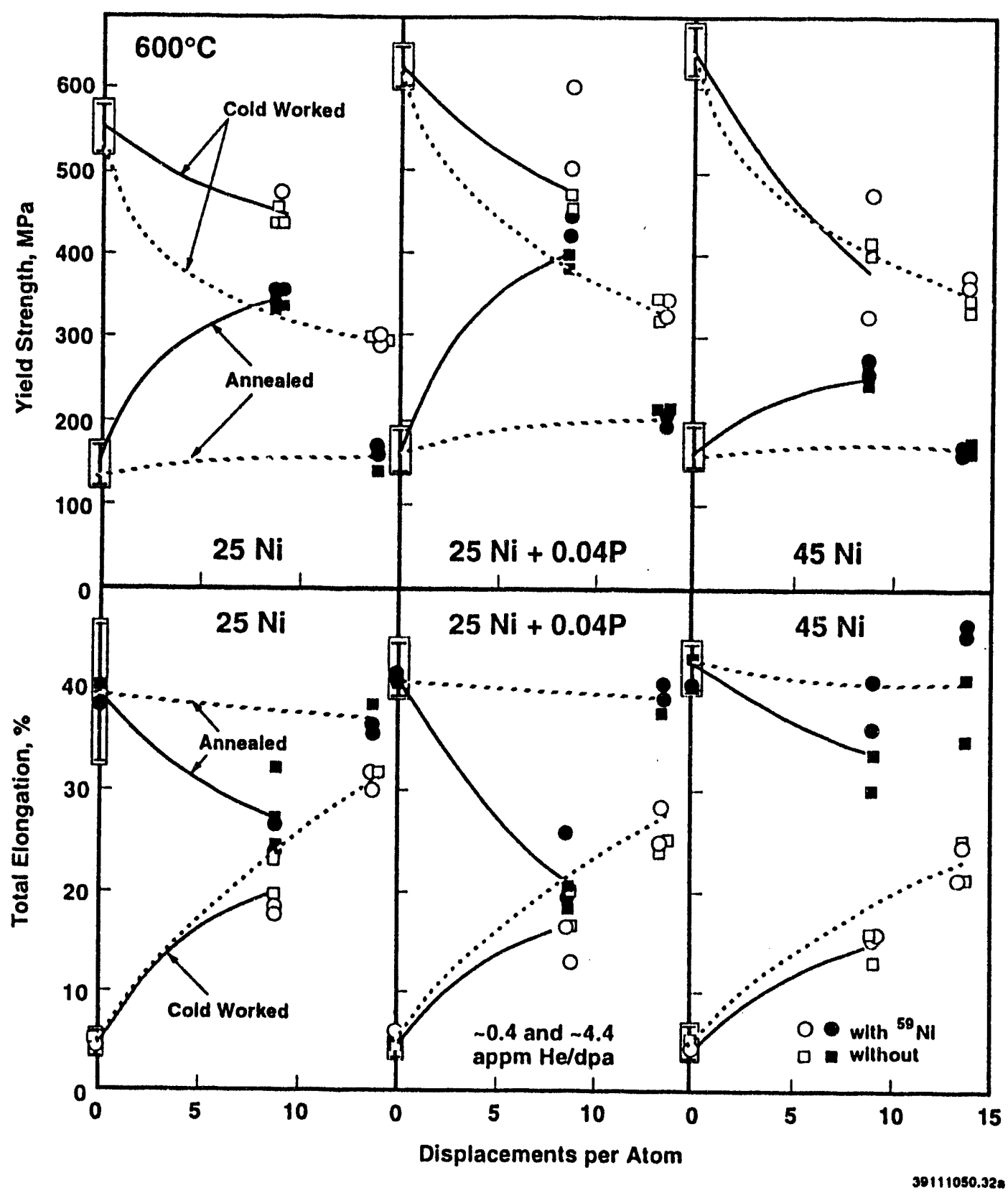

Fig. 4. Influence of themomcchanical starting state, isotopic doping and temperature history on yield strength and total elongation following irradiation at the top of the core at $600^{\circ} \mathrm{C}$. The dotted lines corrospond to the isothermal repeat sequences.

increase in their mean size. This helium-induced difference led, in turn, to a small but measurable change in alloy hardness (15) that may account for the difference observed in the total elongation of the annealed $\mathrm{Fe}-15 \mathrm{Cr}-25 \mathrm{Ni}$ alloy. 


\section{CONCLUSIONS}

In agreement with other studies $(3,4,10)$ these results demonstrate the strong tendency of austenitic alloys to converge during irradiation to a yield strength that is independent of the thermomechanical starting state.

When the results of this and the previous study at higher displacement rates (4) are compared, it appears that the influence of helium/dpa ratio on the evolution of mechanical properties in three model $\mathrm{Fe}-\mathrm{Cr}-\mathrm{Ni}$ alloys is small or insignificant when compared to the scatter exhibited by the unirradiated material, or when compared to the action of compositional variations, temperature or cold work level. The impact of temperature history on tensile properties is often quite strong, but is somewhat dependent on alloy composition. The role of helium/dpa ratio in these alloys is small even during non-isothermal irradiation, however.

\section{FUTURE WORK}

This work will continue, using the TEM specimens irradiated at $600^{\circ} \mathrm{C}$ to conduct shear punch tests for small specimens development.

\section{ACKNOWLEDGEMENTS}

This work was supported by the U.S. Department of Energy under contract DE-AC06-76 RLO 1830 with Pacific Northwest Laboratory, and contract DE-FG06-89ER-75522 with Associated Western Universities. The assistance of Jill Walters and Diane Forsyth in preparing the manuscript is gratefully acknowledged.

\section{REFERENCES}

1. R. L. Simons, H. R. Brager and W. Y. Matsumoto, J. Nucl. Mater. 141-143 (1986) 1057.

2. G. R. Odette, J. Nucl. Mater. 141-143 (1986) 1011.

3. F. A. Garner, M. L. Hamilton, R. L. Simons, and M. K. Maxon, J. Nucl. Mater. 179-181 (1991) 554.

4. M. L. Hamilton and F. A. Garner, J. Nucl. Mater. 191-194 (1992) 1239.

5. F. A. Garner, N. Sekimura, M. L. Grossbeck, A. M. Ermi, J. W. Newkirk, H. Watanabe, M. Kiritani, J. Nucl. Mater., in press.

6. N. F. Panayotou, S. D. Atkin, R. J. Puigh, and B. A. Chin, in: The Use of Small-Scale Specimens for Testing Irradiated Material, eds., W. R. Corwin and G. E. Lucas, ASTM STP 888 (Am. Soc. for Testing and Materials, Philadelphia, 1986) p. 201.

7. L. R. Greenwood, F. A. Garner, and B. M. Oliver, J. Nucl. Mater. 191-194 (1992) 1051. 
8. F. A. Garner, M. L. Hamilton, L. R. Greenwood, J. F. Stubbins, B. M. Oliver, in: Proc. of 16th Inter. Symp. of Effects of Radiation on Materials, STP 1175, Philadelphia: American Society for Testing Materials (in press).

9. F. A. Garner, B. M. Oliver, Fusion Reactor Materials Semiannual Progress Report DOE/ER$0313 / 14$, in press.

10. F. A. Garner, Proc. Conf. on Evolution of Microstructure in Metals During Irradiation, Sept 29-Oct 2, 1992, J. Nucl. Mater. in press.

11. H. Kawanishi, F. A. Garner and R. L. Simons, J. Nucl. Mater 179-181 (1991) 511.

12. M. A. Mitchell, "A Microstructural Evaluation of Fast Flux Irradiated $\mathrm{Fe}-15 \mathrm{Cr}$-XNi-YP Alloys at $490^{\circ} \mathrm{C}$ to $6.7 \mathrm{dpa}$," Master's Thesis, University of Illinois at Champaign-Urbana, 1993.

13. J. F. Stubbins and F. A. Garner, J. Nucl. Mater. 179-181 (1991) 523.

14. J. F. Stubbins and F. A. Garner, J. Nucl. Mater. 191-194 (1992) 1300.

15. H. Kawanishi and F. A. Garner, to be published in J. Nucl. Mater., proceedings of ICFRM- 6 , 1994. 
MICROSTRUCTURAL EVOLUTION OF NEUTRON-IRRADIATED Fe-Cr-Ni TERNARY ALLOYS AT HIGH HELIUM GENERATION RATES - N. Sekimura (University of Tokyo) and F. A. Garner (Pacific Northwest Laboratory)"

\section{OBJECTIVE}

The objective of this effort is to determine the influence of helium and other important variables on the radiation-induced evolution of metals and alloys.

\section{SUMMARY}

A series of $\mathrm{Fe}-\mathrm{Cr}-\mathrm{Ni}$ ternary alloys were irradiated to 12-14 dpa in the Oak Ridge Research Reactor (ORR). In this experiment, most of helium atoms were produced by the ${ }^{58} \mathrm{Ni}(\mathrm{n}, \gamma)^{59} \mathrm{Ni}(\mathrm{n}, \alpha)^{56} \mathrm{Fe}$ sequential reaction, and, therefore, the helium generation rate was almost proportional to the nickel content, ranging from 27 to $58 \mathrm{appm} \mathrm{He/dpa} \mathrm{in} 20$ to $45 \mathrm{wt} . \% \mathrm{Ni}$ alloys. Irradiation temperatures were 330, 400, 500 and $600^{\circ} \mathrm{C}$, and the specimen variables were the nickel level, the chromium level and cold working. The high levels of helium, combined with details of the temperature history, were found to have dominated to microstructural development, sometimes overwhelming and even reversing the action of a given material variable. Microscopy examination showed that there was an unprecedented refinement of cavity microstructure at all temperatures, which accounts for the substantial alterations in both swelling and mechanical properties observed in earlier studies.

\section{PROGRESS \& STATUS}

The influence of helium generation rate on microstructural evolution in austenitic stainless steels during neutron irradiation has been the focus of many experimental studies over the past two decades. Recently, the focus of some studies has shifted toward experiments in which variations in the helium generation rate were put in competition with variations in other important material or environmental variables. This allows for the relative importance of helium and other variables to be assessed. Three major approaches have been used. These are isotopic tailoring $(1,2)$, spectral tailoring (3), and comparative irradiations in two reactors with significantly different neutron spectra, and, therefore, different helium generation rates $(4,5)$.

The latter approach has been used in a recent series of studies conducted in both EBR-II and ORR on

"Pacific Northwest Laboratory is operated for the U.S. Department of Energy by Battelle Memorial Institute under Contract DE-AC06-76RLO 1830. 
simple ternary austenitic alloys. The principle difference in the two reactor environments was originally anticipated to be the magnitude of the helium/dpa ratio, although it was recognized that the ORR irradiation proceeded at a displacement rate roughly an order of magnitude lower than that in EBR-II. It was later discovered, however, that the ORR experiment was subjected to frequent and numerous $(600)$ intermittent reductions in temperature, while the EBR-II irradiation proceeded in a much more isothermal manner $(5,6)$.

These reductions in temperature caused periodic and profuse production of small dislocation loops, known to be efficient nucleation sites for small helium bubbles. Once formed, these bubbles are sessile and remain after the loop disappears when the target temperature is re-established. This leads to an extensive and unprecedented refinement of the cavity microstructure that is very atypical of isothermal irradiation. This, in turn, leads to much larger increases in yield strength compared to that developed during isothermal irradiation (4).

The comparative irradiation experiments in ORR and EBR-II were designed to examine the relative influence of helium/dpa ratio, alloy composition, irradiation temperature and cold-work level. Some portions of the influence of nickel content on microstructural development in competition with helium generation rate were reported earlier for annealed specimens (5). This paper presents the influence of chromium content and cold-working at 500 and $600^{\circ} \mathrm{C}$, and then compares these results with those arising from variations in nickel content and helium/dpa ratio.

\section{Experimental Details}

The specimens used in the ORR experiment were in the form of standard $3 \mathrm{~mm}$ diameter microscopy disks with nominal composition Fe-15Cr-xNi $(x=20,25,30,35,45 w t \%)$ and Fe-yCr-35Ni $(y=7.5,15,22 w t \%)$. Table I presents the actual compositions. While most specimens were prepared in the annealed condition, $\mathrm{Fe}-15 \mathrm{Ni}-25 \mathrm{Cr}$ and $\mathrm{Fe}-15 \mathrm{Cr}-35 \mathrm{Ni}$ were also prepared in the $30 \%$ cold-worked condition.

The various alloys were irradiated side-by-side in sealed helium-filled subcapsules in ORR at 330,400 , 500 and $600^{\circ} \mathrm{C}$. The large thermal component of the neutron spectrum in ORR caused a high generation rate of helium to occur via the two step ${ }^{58} \mathrm{Ni}(\mathrm{n}, \gamma)^{59}(\mathrm{~N}, \propto)^{56} \mathrm{Fe}$ sequential reaction. Spectral tailoring was employed during the latter portion of the experiment to produce a nearly constant generation rate of helium.(3,4) Thus, the generation rate was roughly proportional to the nickel content of the alloys, with measured values varying from 27 to 58 appm/dpa (5).

As shown in Table 2, the dpa levels also varied as a function of nickel content and local neutron spectrum (12.2 to $14.3 \mathrm{dpa}$ ). This difference in dose level arises from the large recoil energy of ${ }^{56} \mathrm{Fe}$ and, therefore, varies with nickel level and neutron spectrum (7). Thus, the experiment does not allow for a complete separation of the relative influence of nickel level and helium/dpa ratio. 
Table 1 Alloys used in the EBR-II and ORR experiments)

\begin{tabular}{|c|c|c|c|}
\hline \multirow{2}{*}{$\begin{array}{l}\text { Composition } \\
\text { (wt \%) }\end{array}$} & \multicolumn{2}{|l|}{ EBR-II } & ORR \\
\hline & Tensile & TEM Disk & Tensile \\
\hline $\mathrm{Fe}-19.7 \mathrm{Ni}-14.7 \mathrm{Cr}$ & -- & SA & - \\
\hline $\mathrm{Fe}-24.4 \mathrm{Ni}-14.9 \mathrm{Cr}$ & SA & $\mathrm{SA}, \mathrm{CW}$ & SA \\
\hline $\mathrm{Fe}-30.1 \mathrm{Ni}-15.1 \mathrm{Cr}$ & -- & SA & -- \\
\hline $\mathrm{Fe}-34.5 \mathrm{Ni}-15.1 \mathrm{Cr}$ & SA & $\mathrm{SA}, \mathrm{CW}$ & SA \\
\hline $\mathrm{Fe}-45.3 \mathrm{Ni}-15.0 \mathrm{Cr}$ & SA & SA & SA \\
\hline $\mathrm{Fe}-35.5 \mathrm{Ni}-7.5 \mathrm{Cr}$ & SA & SA & -- \\
\hline $\mathrm{Fe}-34.1 \mathrm{Ni}-21.7 \mathrm{Cr}$ & SA & SA & SA \\
\hline
\end{tabular}

a) $\mathrm{SA}=$ solution annealed $\left(954^{\circ} \mathrm{C} / 15 \mathrm{~m} / \mathrm{AC}\right)$,

$\mathrm{CW}=30 \%$ cold worked.

Table 2 Displacement and helium levels in the MFE-4 experiment*)

\begin{tabular}{llllr}
$\begin{array}{l}\text { Composition } \\
\text { (wt\%) }\end{array}$ & \multicolumn{2}{c}{330 and $400^{\circ} \mathrm{C}$} & \multicolumn{2}{c}{500 and $600^{\circ} \mathrm{C}$} \\
\cline { 2 - 5 } & dpa & appm He & dpa & appm He \\
& & & & \\
Fe-19.7Ni-14.7Cr & 13.4 & 371 & 12.2 & 332 \\
Fe-24.4Ni-14.9Cr & 13.6 & 463 & 12.4 & 414 \\
Fe-30.1Ni-15.1Cr & 13.8 & 555 & 12.6 & 495 \\
Fe-34.5Ni-15.1Cr & 14.0 & 647 & 12.7 & 573 \\
Fe-45.3Ni-15.0Cr & 14.3 & 832 & 13.1 & 740 \\
& & & & \\
\hline
\end{tabular}

a) These values were calculated using dosimetry calculations and measurements provided in ref. [13] for individual elements irradiated in the ORR equipment. Selected measurements on four of the ORR microscopy specimens later confirmed that these calculations were correct within $4-8 \%$ (14). 
Density measurements were conducted on the disk specimens using a immersion technique established to be accurate to $\pm 0.16 \%$ swelling for typical disks. The specimens were then electropolished using standard techniques and examined in an electron microscope operating at $200 \mathrm{KeV}$. Examination focused primarily on cavity microstructure.

\section{$\underline{\text { Results }}$}

Figure 1 and Table 3 show the bulk swelling of $\mathrm{Fe}-15 \mathrm{Cr}-\mathrm{xNi}$ alloys for both the ORR and EBR-II experiments. Significant swelling occurred in $\mathrm{ORR}$ only at $500^{\circ} \mathrm{C}$ and was dependent on nickel content.

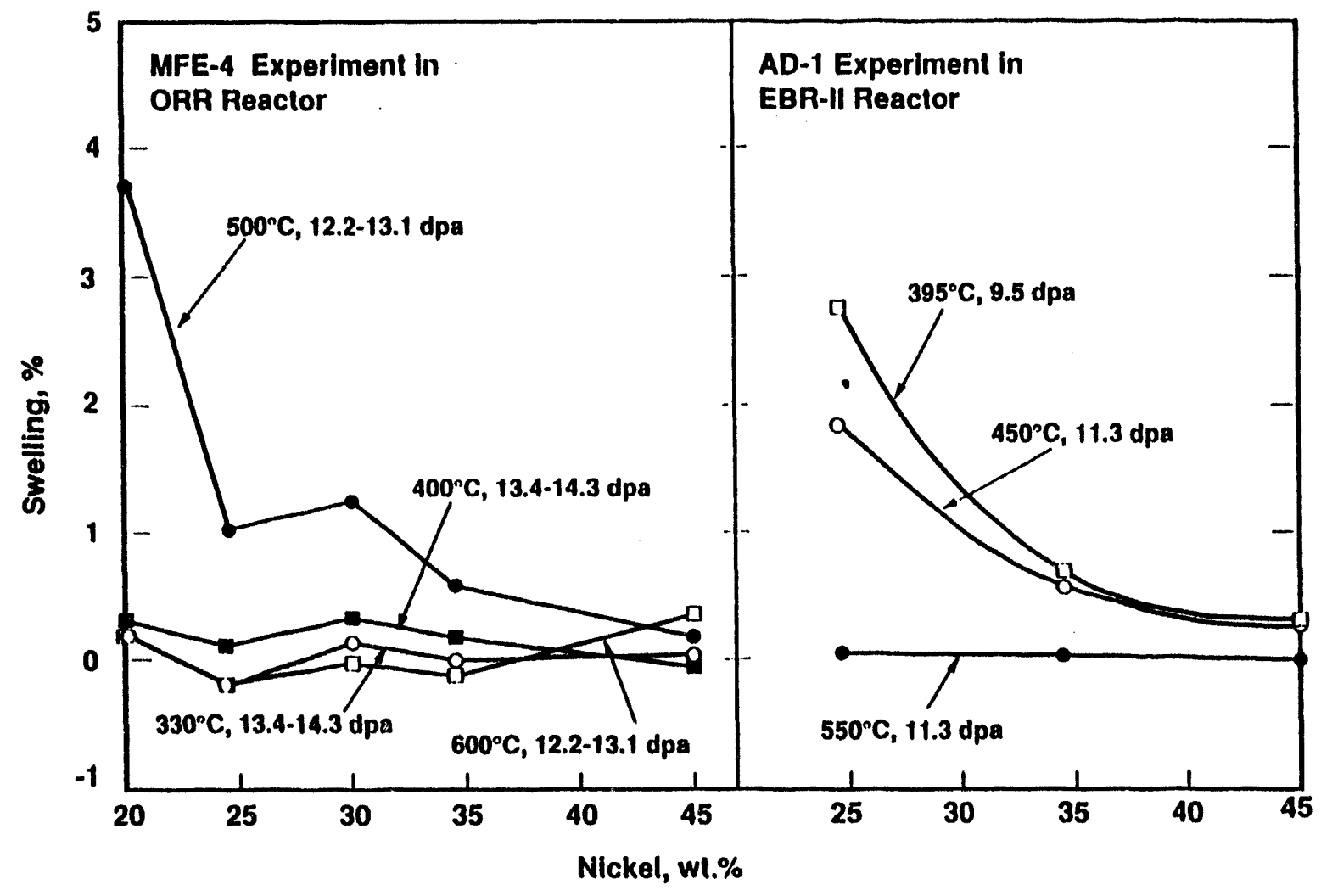

Fig. 1. Comparison of swelling determined by an immersion density technique for $\mathrm{Fe}-15 \mathrm{Cr}-\mathrm{xNi}$ alloys irradiated in the ORR and EBR-II reactors.

For all nickul levels, the cavity densities of these alloys at $330^{\circ} \mathrm{C}$ were so high $\left(210^{24} \mathrm{~m}^{-3}\right)$ that they could not be measured accurately, although it was possible to measure the average sizes. As shown in Figure 2a, the cavity density is a strong function of irradiation temperature, a relatively weak function of nickel content and is essentially insensitive to cold-working. Figure $2 b$ shows that the average cavity size was not a strong function of nickel content except at $500^{\circ} \mathrm{C}$, where it declined strongly with nickel content. Cold-working had no significant effect at this temperature. At $600^{\circ} \mathrm{C}$, 
Table 3 Density data on the effect of cold-work

$$
\text { Swelling }(\%)
$$

\begin{tabular}{lllll} 
& \multicolumn{2}{c}{ Fe-25Ni-15Cr } & \multicolumn{2}{c}{ Fe-35Ni-15Cr } \\
\cline { 2 - 5 } Temperature $\left({ }^{\circ} \mathrm{C}\right)$ & $\mathrm{SA}$ & $\mathrm{CW}$ & $\mathrm{SA}$ & $\mathrm{CW}$ \\
\hline 330 & 0.21 & 0.15 & -0.05 & -0.10 \\
400 & 0.04 & 0.04 & 0.14 & -0.06 \\
500 & 1.04 & 0.29 & 0.55 & -0.11 \\
600 & -0.21 & 0.16 & -0.14 & -0.07 \\
\hline
\end{tabular}

- Negative density changes, particularly for $\mathrm{Fe}-15 \mathrm{Cr}-35 \mathrm{Ni}$, can result from radiation-induced spinodal-like decomposition (15).
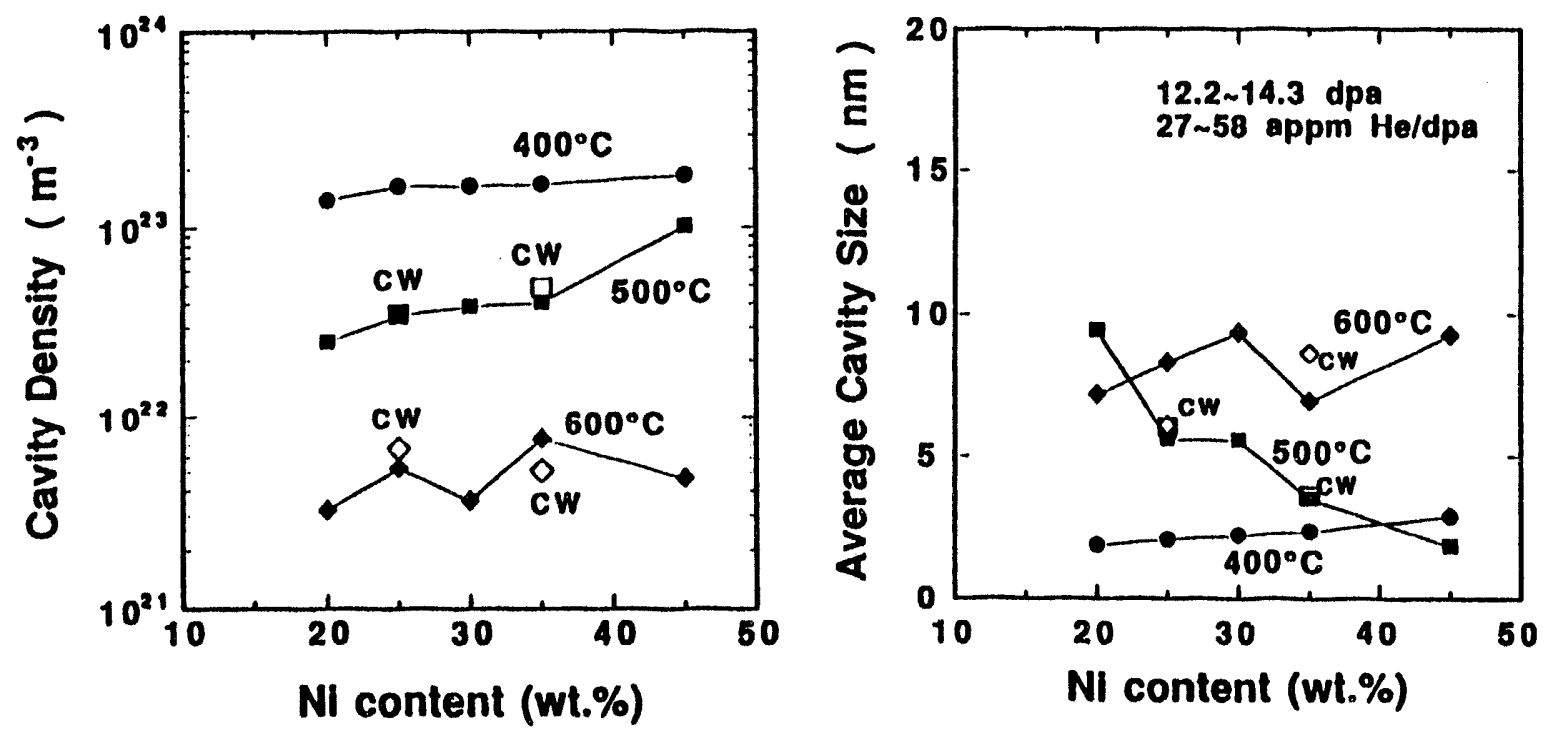

Fig. 2. Influence of irradiation temperature, nickel content and cold-work on cavity characteristics; a) cavity density and b) average cavity diameter. 

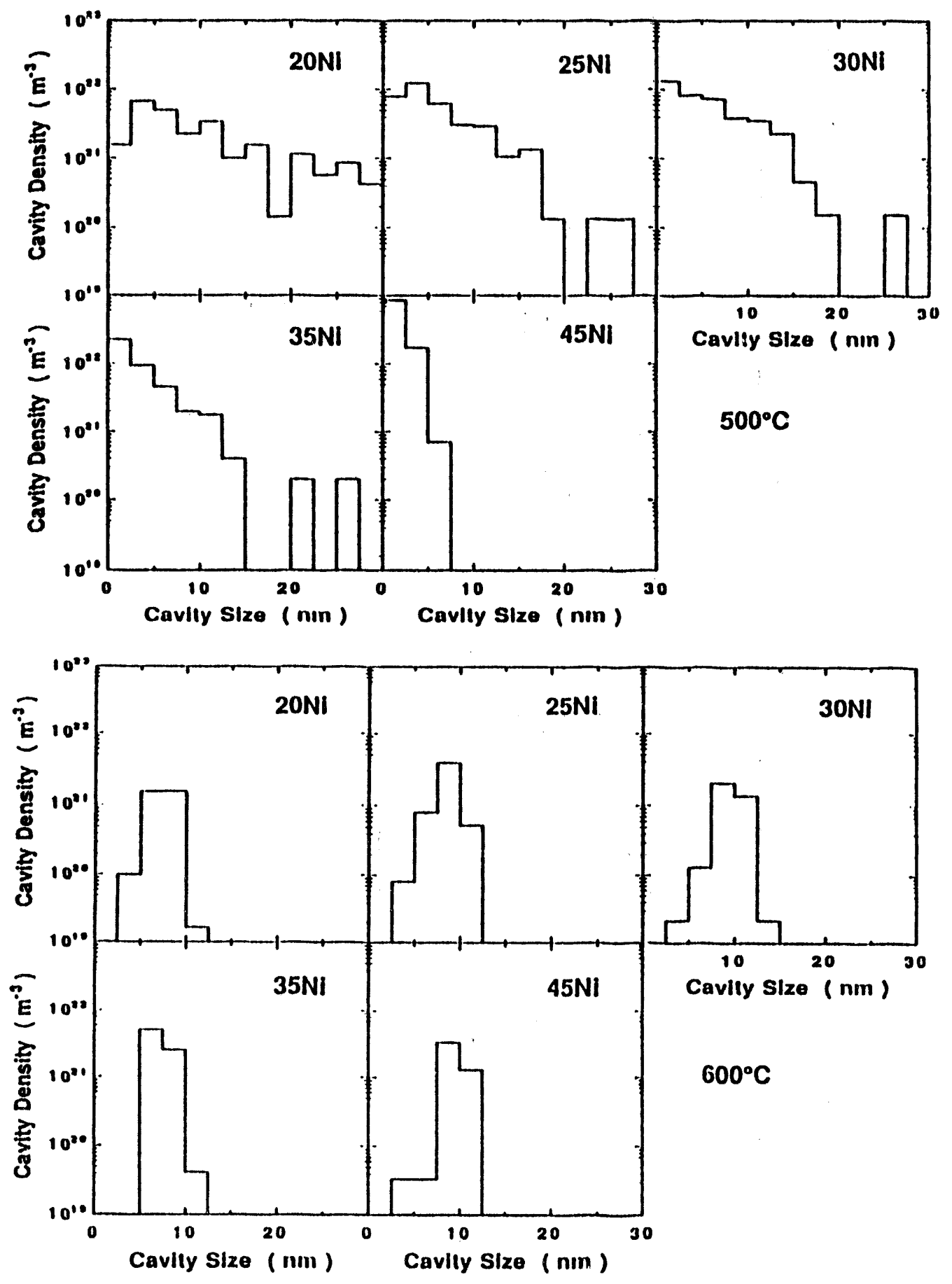

Fig. 3. Cavity size distributions observed in $\mathrm{Fe}-15 \mathrm{Cr}-\mathrm{xNi}$ alloys irradiated at a) $500^{\circ} \mathrm{C}$ and b) $600^{\circ} \mathrm{C}$ in ORR. 

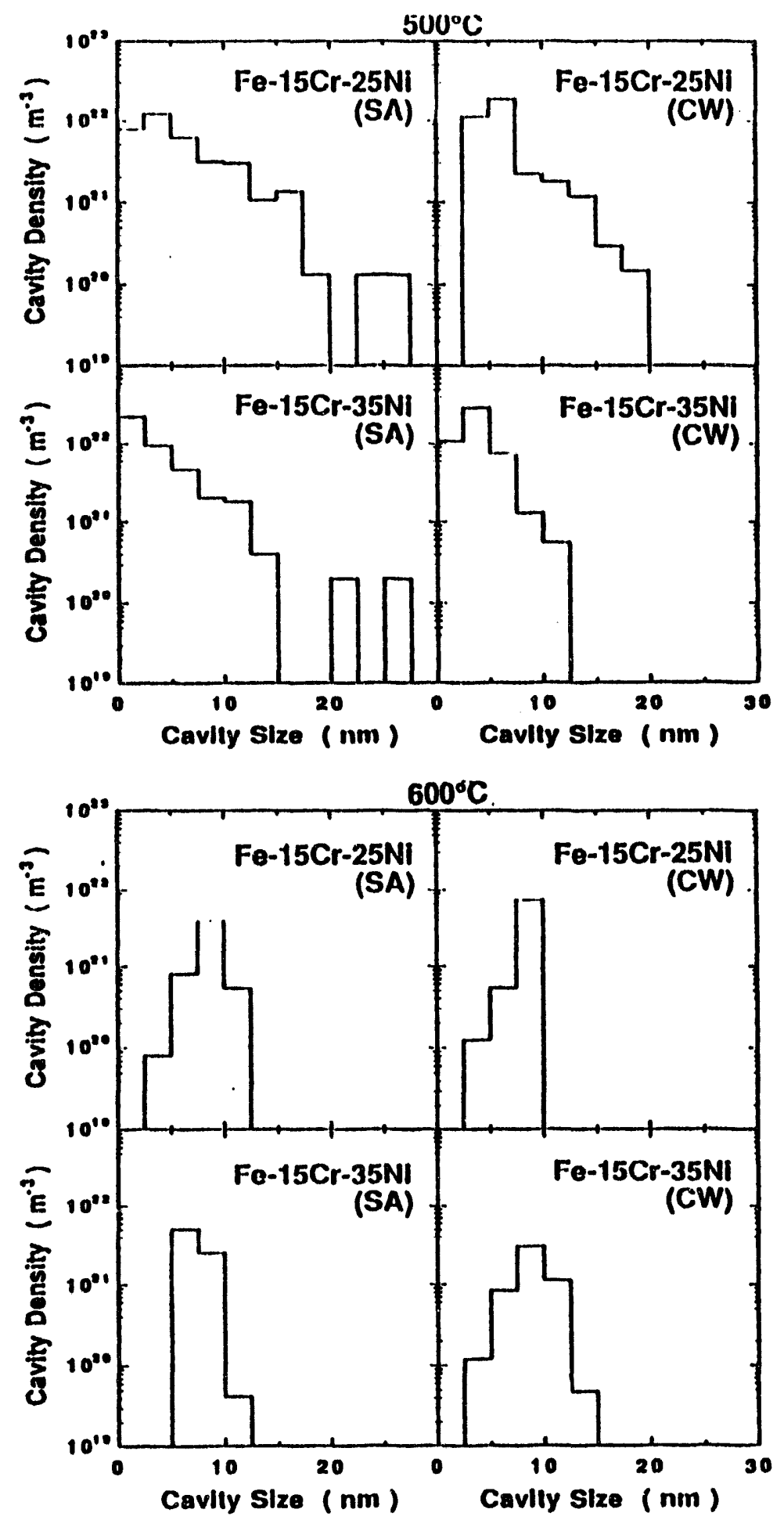

Fig. 4. Comparison of cavity distributions in annealed and cold-worked alloys irradiated at 500 and $600^{\circ} \mathrm{C}$ in ORR. 


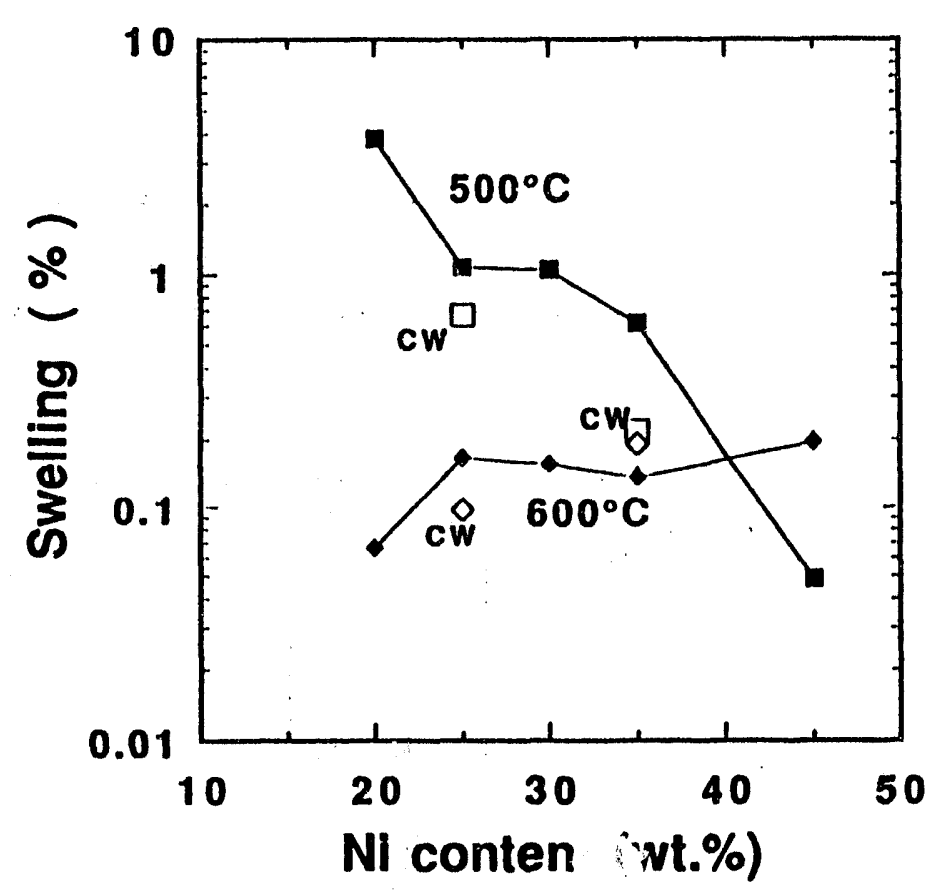

Fig. 5. Swelling determined by microscopy for $\mathrm{Fe}-15 \mathrm{Cr}-\mathrm{xNi}$ alloys irradiated in $\mathrm{ORR}$ at 500 and $600^{\circ} \mathrm{C}$.

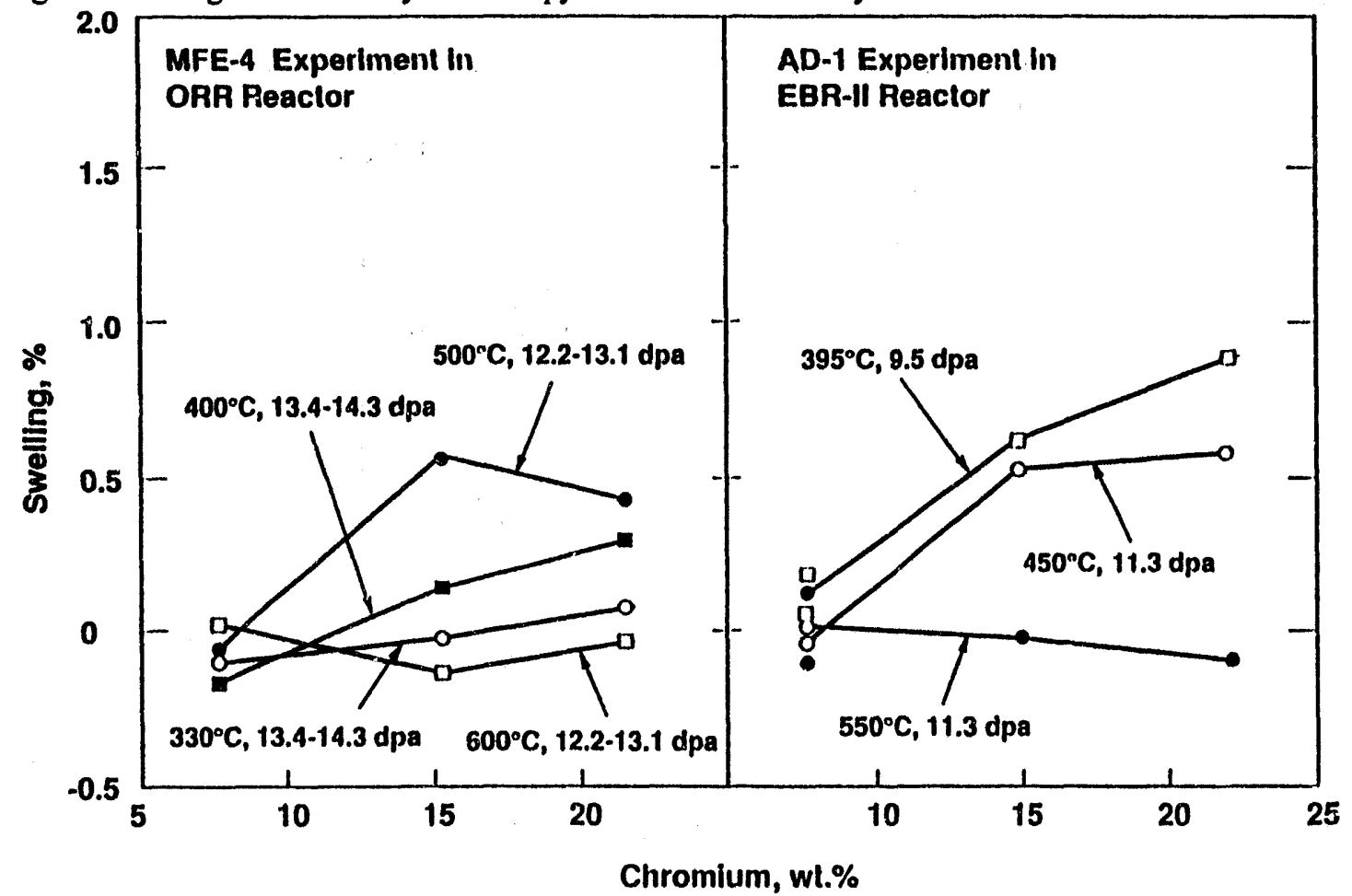

Fig. 6. Comparison of swelling determined by an immersion density technique for $\mathrm{Fe}-35 \mathrm{Ni}-\mathrm{Cr}$ alloys irradiated in the ORR and EBR-II reactors. 
'צ्षO ய!

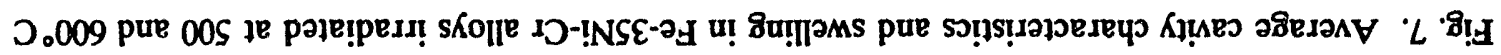

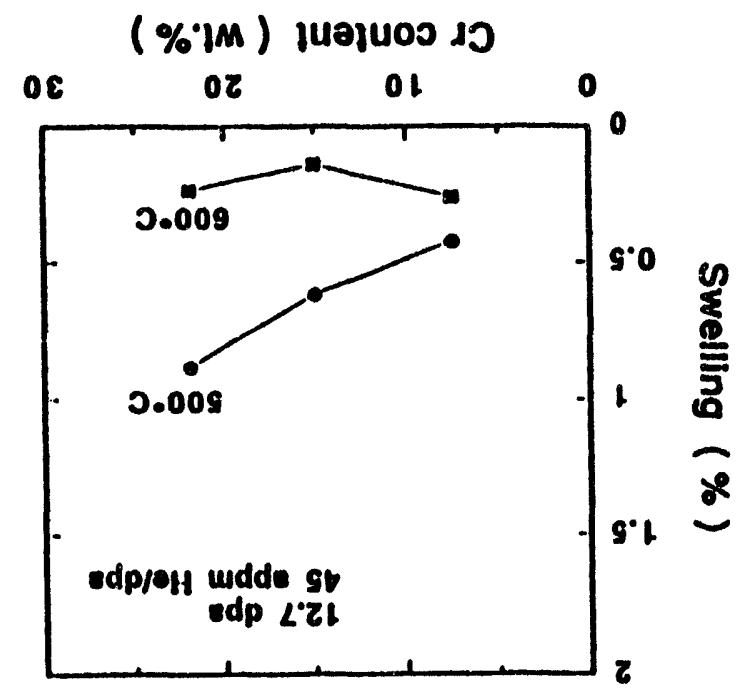

(\%०1m ) Jualuos do

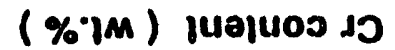
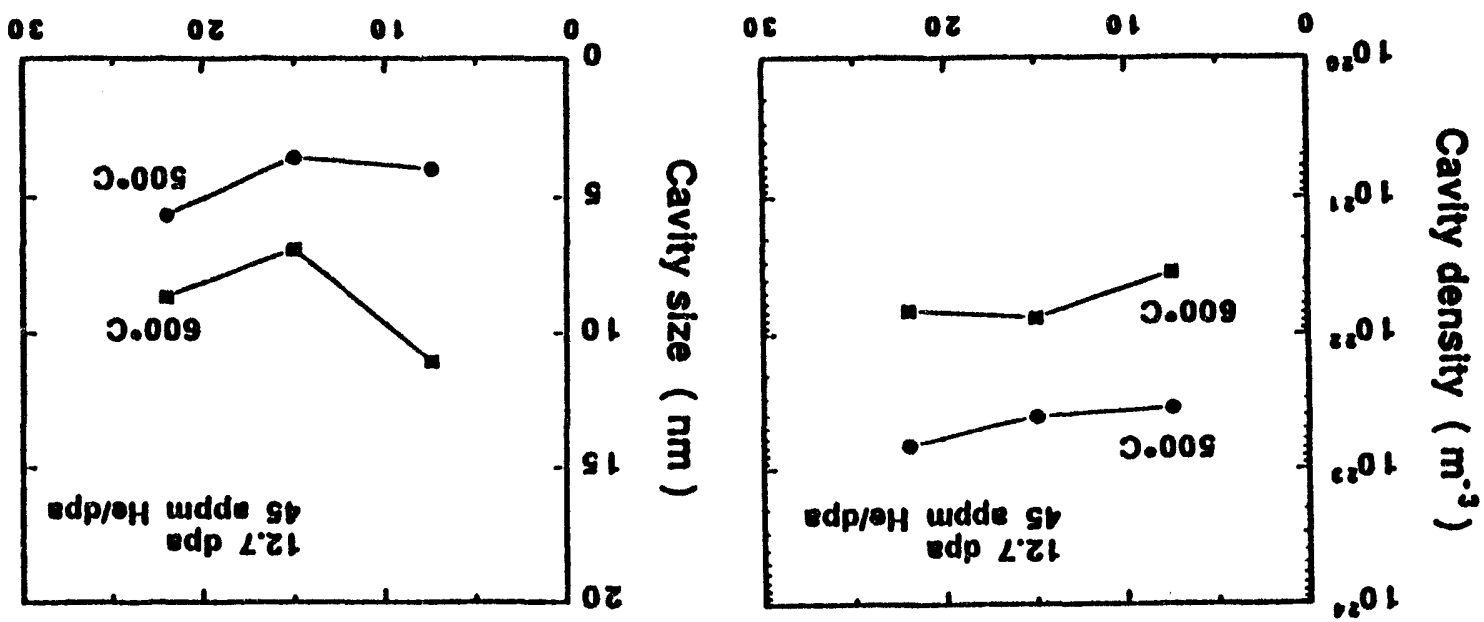

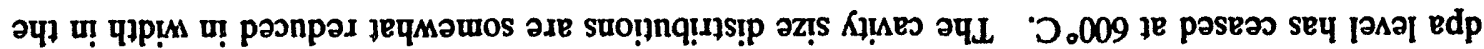

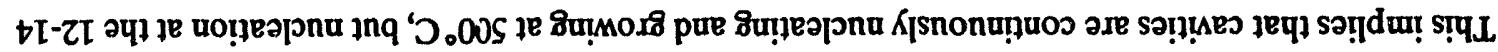

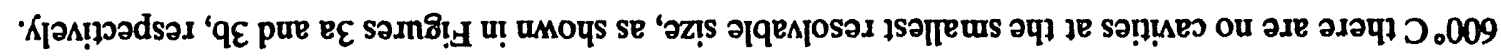

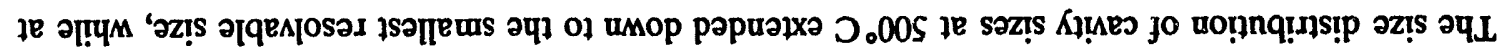

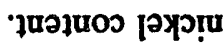

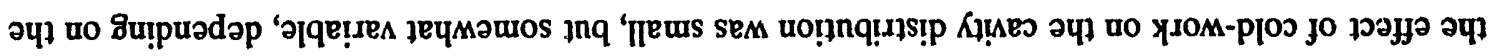


cold-worked alloys at $500^{\circ} \mathrm{C}$ (Figure 4), suggesting that some small delay in cavity nucleation may have occurred, probably in the early stages of the irradiation. The effect of cold work is not as large as usually observed in irradiations conducted at lower helium generation rates, however.

The cavity swelling measured by microscopy ( $\mathrm{Fe}-15 \mathrm{Cr}$-xNi alloys) is shown in Figure 5 and agrees well with that determined by immersion density. While cold-working reduced swelling at $500^{\circ} \mathrm{C}$, the effect at $600^{\circ} \mathrm{C}$ varies with nickel content, but was not large at any nickel level.

Swelling of Fe-35Ni-Cr alloys measured by immersion density is shown in Figure 6, increasing a small amount with increasing chromium content except at $600^{\circ} \mathrm{C}$, where swelling is very low. These trends are confirmed by microscopy, as shown in Figures 7 and 8 . The effect of chromium on swelling is sinaller than that observed at lower helium generation rates (9).
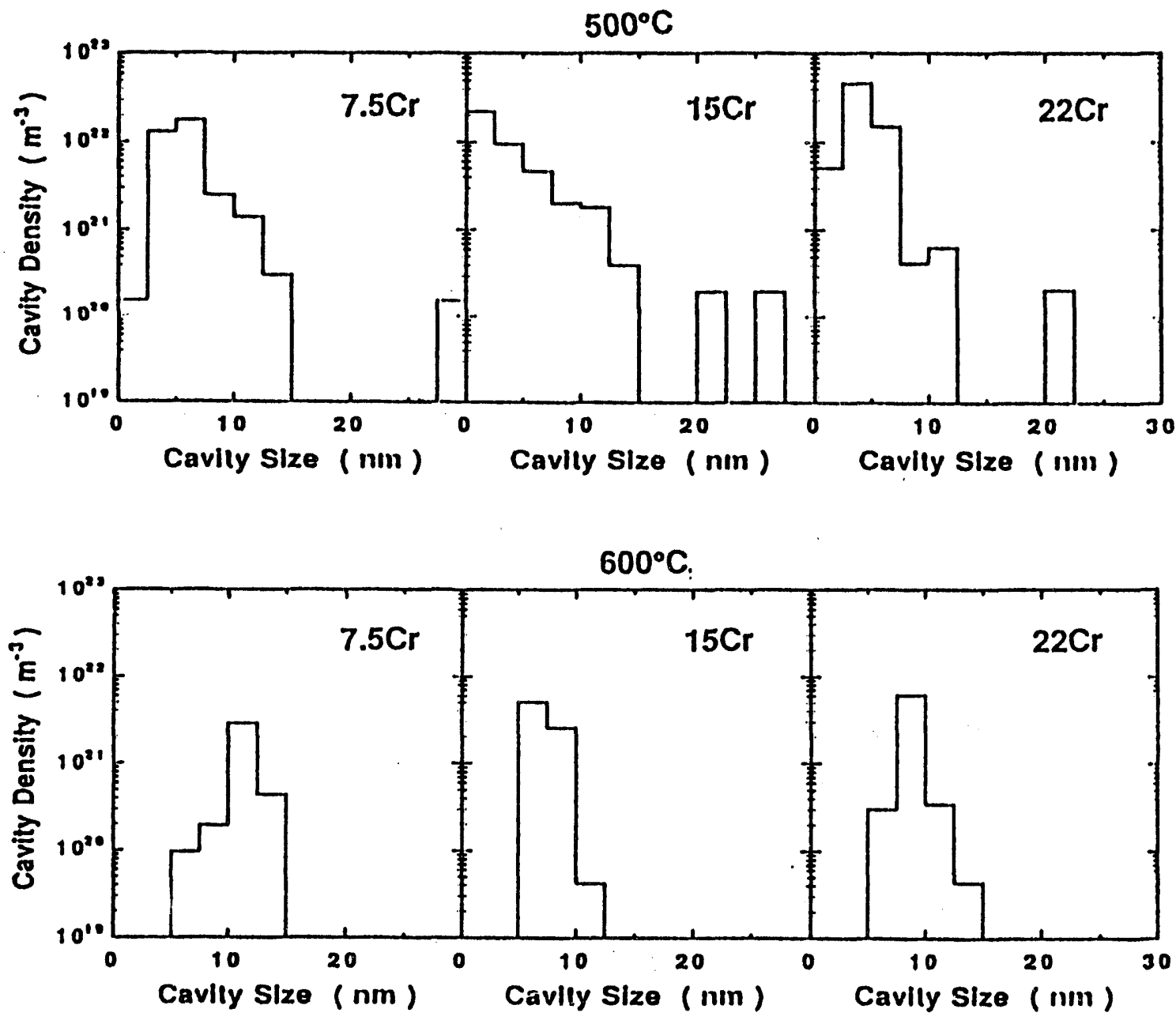

Fig. 8. Cavity size distributions observed in $\mathrm{Fe}-35 \mathrm{Ni}-\mathrm{Cr}$ alloys irradiated at 500 and $600^{\circ} \mathrm{C}$ in $\mathrm{ORR}$. 


\section{Discussions and Conclusions}

It is well known that swelling in fast reactors with low helium generation rates decreases with increasing nickel content in the range $20-45 \% \mathrm{Ni}$ and increases with increasing chromium level $(8,9)$. Similar but less pronounced behavior appears to occur in this study at significantly higher helium generation rates, as showl in Figure 9. The cavity distribution as a function of nickel content behaves very differently in ORR, however, compared to that in EBR-II. Not only are the cavity densities much higher in ORR, but their dependence on nickel content in general exhibits the opposite sign, reflecting the coupling between nickel content and helium generation rate.

The significantly higher density of cavities in ORR is not only a result of the higher helium generation rates (27 to $58 \mathrm{appm} / \mathrm{dpa}$ compared to 0.66 to $1.2 \mathrm{appm} / \mathrm{dpa}$ in EBR-II), but is thought to arise as a consequence of the frequent set-backs in temperature experienced in ORR. These set-backs induce dense populations of small dislocation loops that are instrumental in nucleating helium bubbles (6). Independent confirmation of such history-dependent loop nucleation was provided by Sekimura and Ishino in another similar experiment conducted in FFTF (11).



Fig. 9. Comparison of cavity densities observed in irradiations conducted in ORR and EBR-II. Data at $510^{\circ} \mathrm{C}$ taken from ref. 10. 
Another consequence of the higher cavity density is that the mean cavity size at lower irradiation temperatures $\left(330,400^{\circ} \mathrm{C}\right)$ is pushed below the critical cavity size for bubble-to-void conversion, thus suppressing the onset of void growth as shown in Figure 1. The cavity size distributions at 330 and $400^{\circ} \mathrm{C}$ suggest that, at all nickel levels, most cavities are probably helium bubbles. At $500^{\circ} \mathrm{C}$ the cavity size distribution shifts from void-like to bubble-like character as the nickel level increases. At $45 \% \mathrm{Ni}$ and $500^{\circ} \mathrm{C}$, the cavity distribution is clearly typical of bubbles. It is important to note that the critical cavity size is also predicted to be a function of nickel content, decreasing at higher nickel levels due to nickel's influence on vacancy diffusivity (12). Thus, the normal tendency toward suppression of swelling and void nucleation with increasing nickel content is amplified by nickel's indirect effect on helium levels and thereby on bubble nucleation.

It appears, therefore, that the combined influence of helium and temperature history dominates the microstructural evolution of $\mathrm{Fe}-\mathrm{Cr}$ - Ni alloys irradiated in ORR and thereby reduces or even reverses the trends observed with cold-work, nickel content, and chromium content at lower helium generation rates.

\section{Acknowledgement}

This work was sponsored by the Japan/US collaboration in FFTF/MOTA established between the U. S. Department of Energy (Contract DE-AC06-76RLO 1830) and Monbusho, the Japanese Ministry for Education, Science and Culture. The assistance of Jill Walters in preparing the manuscript is gratefully acknowledged.

\section{References}

1. G.R. Odette, J. Nucl. Mater. 141-143 (1986) 1011.

2. F.A. Garner, M.L. Hamilton, L.R. Greenwood, J.F. Stubbins, and B.M. Oliver in: 16th International Symposium on Effects of Radiation on Materials, ASTM STP 1175, A.S. Kumar, D.S. Gelles, R.K. Nanstad, and E.A. Little, Eds., (American Society for Testing and Materials, Philadelphia, 1993) in press.

3. A.F. Rowcliffe, A. Hishinuma, M.L. Grossbeck, and S. Jitsukawa, J. Nucl. Mater. 179-181 (1991) 125.

4. M.L. Hamilton, A. Okada, and F.A. Garner, J. Nucl. Mater. 179-181 (1991) 558.

5. N. Sekimura, F.A. Garner, and R.D. Griffin, J. Nucl. Mater. 191-194 (1992) 1234.

6. F.A. Garner, IN. Sekimura, M.L. Grossbeck, A.M. Ermi, J.W. Newkirk, H. Watanabe, and M. Kiritani, to be published in J. Nucl. Mater.

7. L.R. Greenwood, J. Nucl. Mater. 115 (1983) 137.

8. F.A. Garner and H.R. Brager, in: Effects of Radiation on Materials: 12th International Symposium, ASTM STP 870, F.A. Garner and J.S. Perrin, Eds. (American Society for Testing and Materials, Philadelphia, 1985) pp. 187-201. 
9. F.A. Garner and A.S. Kumar, in: Radiation-Induced Changes in Microstructure: 13th International Symposium (Part I), ASTM STP 955, F.A. Garner, N.H. Packan, and A.S. Kumar, Eds. (American Society for Testing and Materials, Philadelphia, 1987) pp. 289-314.

10. T. Muroga, F.A. Garner, and S. Ohnuki, J. Nucl. Mater. 179-181 (1991) 546.

11. N. Sekimura and S. Ishino, J. Nucl. Mater. 179-181 (1991) 542.

12. W.A. Coghlan and F.A. Garner, in: Radiation-Induced Changes in Microstructure: 13th International Symposium (Part I), ASTM STP 955, F.A. Garner, N.H. Packan, and A.S. Kumar, Eds. (American Society for Testing and Materials, Philadelphia, 1987) pp. 315-329.

13. L.R. Greenwood, in: Fusion Reactor Materials Semiannual Progress Report DOE/ER-0313/6 (1989) pp. 29-35.

14. F.A. Garner and B.M. Oliver, in: Fusion Reactor Materials Semiannual Progress Report DOE/ER-0313/9 (1992) pp. 58-60.

15. F.A. Garner and J.M. McCarthy, in: Proceedings of Symposium on Physical Metallurgy of Controlled Expansion Invar-Type Alloys, K.C. Russell and D.F. Smith, Eds. (The TMS Ferrous Metallurgy Committee, Warrendale, 1987) pp. 187-206. 
MICROSTRUCTURAL DEVELOPMENT IN IRRADIATED VANADIUM ALLOYS - D.S. Gelles, (Pacific Northwest Laboratory)", and J. F. Stubbins (University of Illinois)

\section{OBJECTIVE}

The objective of this work is to provide further understanding of swelling response in vanadium alloys.

\section{SUMMARY}

Three simple vanadium alloys, $\mathrm{V}-5 \mathrm{Al}, \mathrm{V}-1 \mathrm{Ni}$, and $\mathrm{V}-2 \mathrm{Ti}-1 \mathrm{Ni}$ have been examined to determine the effects of fast neutron irradiation on microstructural evolution. Specimens were irradiated in EBR II at temperatures in the range 425 to $600^{\circ} \mathrm{C}$ to doses of 15 and $31 \mathrm{dpa}$. Each alloy responded very differently to irradiation. All V-5Al specimens were generally void-free and contained high densities of coherent precipitates, and moderate densities of network dislocations. Swelling was much higher in V-1Ni. Voids were uniformly distributed, but with widely varying shape and size. Precipitation of two types also developed. The response in V-2Ti-1Ni was intermediate to that of the other two alloys. Irradiation produced extensive precipitation of thin rods and a moderate density of large voids often associated with much larger precipitate particles. The dislocation structure strongly interacted with the rod precipitate particles.

\section{PROGRESS AND STATUS}

\section{Introduction}

Vanadium alloys are being seriously considered as candidate fusion reactor first wall materials based on inherent radiation damage resistance, low activation and high temperature refractory properties. ${ }^{1,2}$ However, recent results have demonstrated that vanadium alloys such as V-5Fe can lose radiation damage resistance. $^{2-6}$ Swelling as high as $100 \%$ was observed in V-5Fe specimens following irradiation at 520 and $600^{\circ} \mathrm{C}$ to $52 \mathrm{dpa}^{3}$ and more recently $93.2 \%$ swelling was observed following irradiation at $600^{\circ} \mathrm{C}$ to $34.2 \mathrm{dpa}^{6} \mathrm{~V}-\mathrm{Cr}$ alloys in the 10 to $15 \% \mathrm{Cr}$ range with minor $\mathrm{Al}$ additions developed $40 \%$ swelling after irradiation at $600^{\circ} \mathrm{C}$ to approximately $80 \mathrm{dpa},{ }^{4} \mathrm{~V}-5 \mathrm{Cr}$ developed $24.6 \%$ swelling after irradiation at $600^{\circ} \mathrm{C}$ to $34.2 \mathrm{dpa},{ }^{6}$ and $27 \%$ swelling after irradiation at $600^{\circ} \mathrm{C}$ to $45 \mathrm{dpa}^{5}$ and $\mathrm{V}-2 \mathrm{Si}$ developed $35 \%$ swelling after irradiation at both 425 and $520^{\circ} \mathrm{C}$ to $45 \mathrm{dpa},{ }^{5}$ and $\mathrm{V}-1 \mathrm{Si}$ developed $18.7 \%$ swelling following irradiation at $600^{\circ} \mathrm{C}$ to $34.2 \mathrm{dpa}^{6}{ }^{6}$ Finally, V-12Ni developed $15 \%$ swelling following irradiation at $600^{\circ} \mathrm{C}$ to about $80 \mathrm{dpa}^{2}$ The swelling rates that can be estimated from these results are summarized in Table 1. This high swelling response is in contrast to much lower swelling rates found in all other body centered cubic metal alloys. For example, a rate of $0.06 \% / \mathrm{dpa}$ is the highest found in simple ferritic alloys. $^{7}$

The effort described here is intended to study the effects of fast neutron irradiation on the microstructures of three simple vanadium alloys: V-5Al, V-1Ni, and V-2Ti-1Ni. Specimens were irradiated in the Experimental Breeder Reactor (EBR) II at temperatures in the range 425 to $600^{\circ} \mathrm{C}$ to doses of 15 and 31 $\mathrm{dpa}$ in order to expand our understanding of microstructural evolution in vanadium alloys not previously studied.

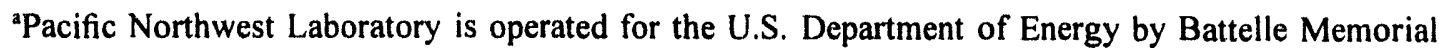
Institute under Contract DE-AC06-76RLO 1830. 
Table 1. Summary of high swelling rate response in vanadium alloys.

\begin{tabular}{|c|c|c|c|c|c||}
\hline Alloy & $\begin{array}{c}\text { Irradiation } \\
\text { Temperature } \\
\left({ }^{\circ} \mathrm{C}\right)\end{array}$ & $\begin{array}{c}\text { Dose } \\
(\mathrm{dpa})\end{array}$ & Swelling (\%) & $\begin{array}{c}\text { Swelling Rate } \\
(\% / \mathrm{dpa})\end{array}$ & Reference \\
\hline $\mathrm{V}-5 \mathrm{Fe}$ & 520 & 52 & 100 & 2.0 & 3 \\
& 600 & 34.2 & 93.2 & 2.7 & 6 \\
\hline $\mathrm{V}-\mathrm{Cr}$ & 600 & 80 & 210 & 0.5 & 4 \\
\hline $\mathrm{V}-5 \mathrm{Cr}$ & 600 & 34.2 & 24.6 & 0.7 & 6 \\
& 600 & 45 & 27 & 0.6 & 5 \\
\hline $\mathrm{V}-2 \mathrm{Si}$ & 425 & 45 & 35 & 0.8 & 5 \\
& 520 & 45 & 35 & 0.8 & 5 \\
\hline $\mathrm{V}-1 \mathrm{Si}$ & 600 & 34.2 & 18.7 & 0.5 & 6 \\
\hline $\mathrm{V}-12 \mathrm{Ni}$ & 600 & 80 & 15 & 0.2 & 2 \\
\hline
\end{tabular}

\section{Experimental Procedures}

Specimens for transmission electron microscopy (TEM) ( $3 \mathrm{~mm}$ diameter $\times 0.25 \mathrm{~mm}$ thick) in the fully heat treated condition were obtained from P. Okamoto of Argonne National Laboratory (ANL) and were included in an early fusion reactor materials irradiation experiment, designated AA XIV. The alloys had been arc melted at ANL, then levitation melted and cast in a chill copper mold, cold rolled $92 \%$ to 0.25 $\mathrm{mm}$ sheet, and heat treated at $1250^{\circ} \mathrm{C}$ for one hour and furnace cooled. A single specimen of each alloy condition was included in each of six helium filled stainless steel packets along with various other alloy specimens. Two packets were irradiated at each of three temperatures, 425,500 and $600^{\circ} \mathrm{C}$ in gas gapped canisters of B7a design in EBR-II in Idaho Falls, ID. One packet irradiated at each temperature was removed after $15 \mathrm{dpa}$ (doses are given based on displacement rates for stainless steel) and the second packet completed irradiation to $31 \mathrm{dpa}$. The irradiation temperature, dose and swelling (where measured by immersion density) for those specimens examined by TEM are summarized in Table 2.

These specimens were not examined until the recent results on V-SFe were obtained, and it became apparent that further understanding of the high swelling in vanadium alloys was required. Specimens from the 15 dpa irradiations were first examined by TEM, and following those examinations, specimens irradiated to $31 \mathrm{dpa}$ were measured for density change and then examined by TEM. TEM specimens were prepared following routine jet electropolishing procedures using a solution of $20 \%$ sulfuric acid in methanol at 10 to $15^{\circ} \mathrm{C}$ and about $60 \mathrm{~V}$ at high pump speed. Examinations were performed on a JEOL $1200 \mathrm{EX}$ operating at $120 \mathrm{KeV}$. Compositional overchecks using analytical electron microscopy confirmed that the respective alloying additions of $\mathrm{Al}, \mathrm{Ni}$ and $\mathrm{Ni}$ plus $\mathrm{Ti}$ were present in the irradiated specimens. 
Table 2. Compositions and irradiation conditions for vanadium alloy specimens in this study.

\begin{tabular}{|c|c|c|c|c|c|}
\hline $\begin{array}{c}\text { Alloy Composition } \\
\text { (Heat \#) }\end{array}$ & $\begin{array}{c}\text { Heat } \\
\text { Treatment }\end{array}$ & $\begin{array}{c}\text { Specimen } \\
\text { ID }\end{array}$ & $\begin{array}{c}\text { Irradiation } \\
\text { Temperature } \\
\left({ }^{\circ} \mathrm{C}\right)\end{array}$ & $\begin{array}{c}\text { Dose } \\
(\mathrm{dpa})\end{array}$ & $\begin{array}{c}\text { Swelling } \\
(\%)\end{array}$ \\
\hline V-5Al (RAC 153) & $1250^{\circ} \mathrm{C} / \mathrm{lh}$ & $5 \mathrm{AJ} 1$ & 425 & 15 & NA \\
\hline$"$ & & $5 \mathrm{AJ} 2$ & 500 & 15 & NA \\
\hline$"$ & & $5 \mathrm{AJ} 3$ & 600 & 15 & NA \\
\hline$"$ & & $5 \mathrm{~A} 92$ & 500 & 31 & 0.13 \\
\hline V-1Ni (RAC 156) & $1250^{\circ} \mathrm{C} / \mathrm{lh}$ & $5 \mathrm{BJ} 2$ & 500 & 15 & NA \\
\hline$"$ & & $5 \mathrm{~B} 03$ & 600 & 15 & NA \\
\hline$"$ & & $5 \mathrm{~B} 92$ & 500 & 31 & 3.37 \\
\hline $\mathrm{V}-2 \mathrm{Ti}-1 \mathrm{Ni}(\mathrm{RAC} 157)$ & $1250^{\circ} \mathrm{C} / \mathrm{lh}$ & $5 \mathrm{EJ} 1$ & 425 & 15 & NA \\
\hline$"$ & & $5 \mathrm{EJ} 2$ & 500 & 15 & NA \\
\hline$"$ & & $5 \mathrm{E} 92$ & 500 & 31 & 0.72 \\
\hline
\end{tabular}

$\overline{\mathrm{NA}}-\mathrm{not}$ available, never measured for density.

Results

V-5Al

Specimens of V-5Al were examined following irradiation at 425,500 and $600^{\circ} \mathrm{C}$ to $15 \mathrm{dpa}$ and at $500^{\circ} \mathrm{C}$ to $31 \mathrm{dpa}$. The samples were remarkably free of voids. Only the specimen irradiated at $600^{\circ} \mathrm{C}$ was found to contain any voids, and those were nonuniformly distributed in regions near grain boundaries and associated with large precipitate particles. The dislocation structure formed a network in all conditions with highest dislocation densities occurring at the lowest irradiation temperatures and doses. Comparison of $\vec{g}=200$ and 110 images of the san e area following irradiation at $600^{\circ} \mathrm{C}$ indicated that the primary Burgers vector is $\frac{a}{2}<111>$. Associated with the fislocation structure was a high density of precipitate particles. In general, precipitates were smaller and at higher density for the lower irradiation temperatures.

Microstructures of $\mathrm{V}-5 \mathrm{Al}$ are presented in Figure 1. Figures 1 a) through c) show dislocation and precipitate structures in $\mathrm{V}-5 \mathrm{Al}$ irradiated to $15 \mathrm{dpa}$ as a function of increasing temperature. The precipitates in $1 \mathrm{c}$ ) appear largest. Figure $1 \mathrm{~d}$ ) provides a precipitate dark field image using $\vec{g}=\frac{3}{4}(200)$ of the region in $1 \mathrm{~b}$ ); comparison of the two images indicates a close to one-to-one correspondence of particles. Figure 1 e) gives examples of voids associated with large precipitate particles near grain boundaries shown at a lower magnification following irradiation at $500^{\circ} \mathrm{C}$. Figures $1 \mathrm{f}$ ) through $\mathrm{h}$ ) provide examples of $\mathrm{V}-5 \mathrm{Al}$ following irradiation at $500^{\circ} \mathrm{C}$ to $31 \mathrm{dpa}$. Figure $1 \mathrm{f}$ ) shows the dislocation structure, and Figures $\mathrm{g}$ ) and $\mathrm{h}$ ) provide comparison of precipitate structures under bright and dark field $\left(\vec{g}=\frac{3}{4}(200)\right)$ imaging conditions. Therefore, Figures 1 b) and d) can be compared to $\left.1 \mathrm{f}\right)$ and $h$ ) to demonstrate dislocation evolution and precipitate growth with increasing dose at $500^{\circ} \mathrm{C}$. 


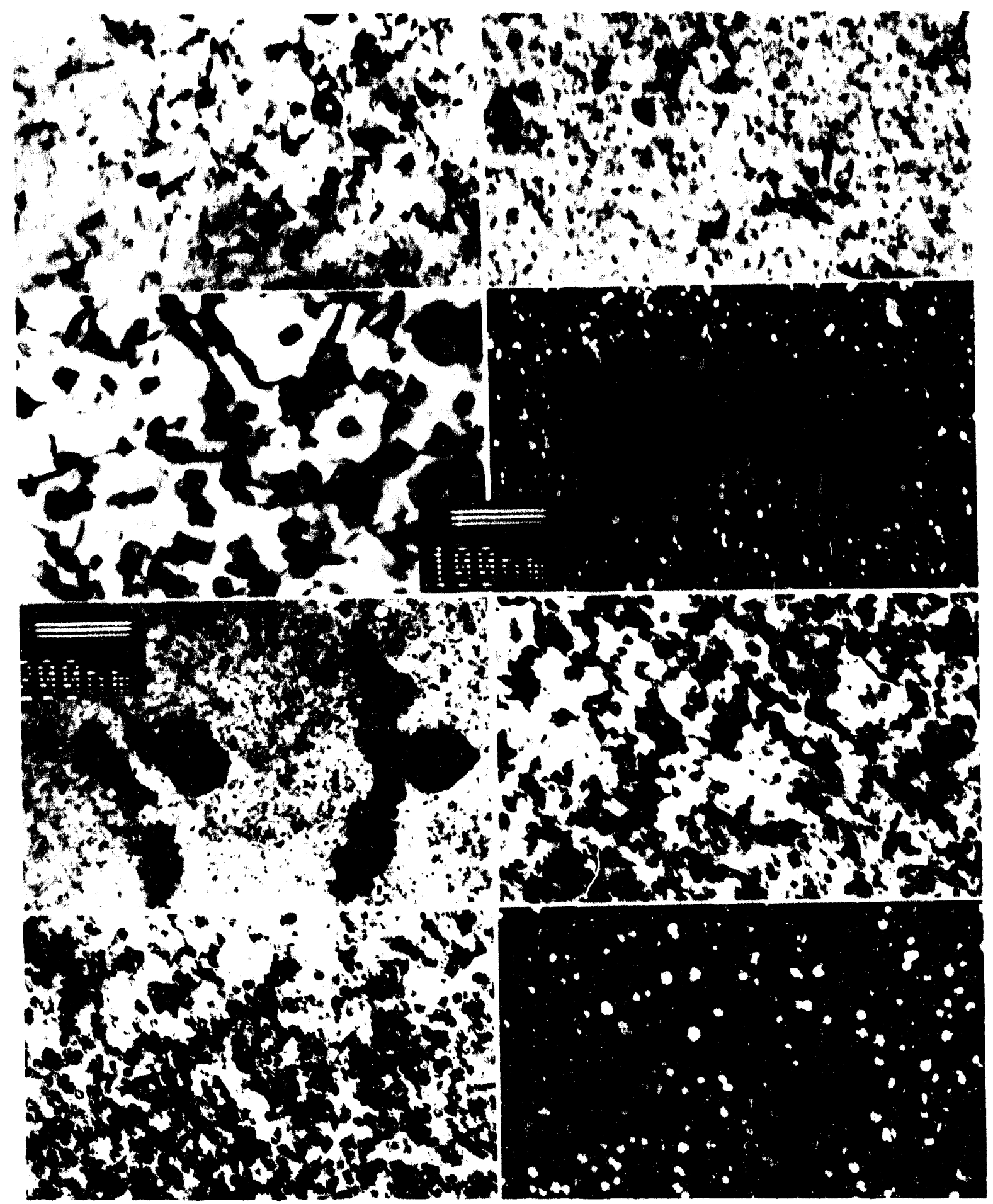

Figure 1. Microstructures in V-5Al following irradiation to $15 \mathrm{dpa}$ at 425 in a), at $500^{\circ} \mathrm{C}$ in b), and at $600^{\circ} \mathrm{C}$ in c) with d) showing precipitates at $500^{\circ} \mathrm{C}$ in dark field contrast, at lower magnification for the $600^{\circ} \mathrm{C}$ condition in e) and following irradiation to $31 \mathrm{dpa}$ at $500^{\circ} \mathrm{C}$ in dislocation contrast in $\mathrm{f}$ ) and in bright and dark fisld precipitate contrast in $g$ ) and $h$ ). 
$\mathrm{V}-\mathrm{INi}$

Specimens of $\mathrm{V}-1 \mathrm{Ni}$ were successfully examined following irradiation at 500 and $600^{\circ} \mathrm{C}$ to $15 \mathrm{dpa}$ and at $500^{\circ} \mathrm{C}$ to $31 \mathrm{dpa}$. All specimens contained extensive void swelling and precipitation. The lower irradiation temperature produced voids and precipitates on a finer scale, as expected. Voids produced at $500^{\circ} \mathrm{C}$ were often of unusual shape due to association with precipitates, but voids produced at $600^{\circ} \mathrm{C}$ were generally cuboidal. The dislocation structure produced at $500^{\circ} \mathrm{C}$ consisted of an unfaulted network and faulted regions on (100) planes believed to be associated with precipitate structure, whereas following irradiation at $600^{\circ} \mathrm{C}$, a dislocation network was created with few connections to precipitates and voids. Comparison of $\vec{g}=200$ and 110 images of the same area following irradiation at $60^{\circ} \mathrm{C}$ indicated that the primary Burgers vector is ${ }^{\circ}<111>$. However, irradiation to higher dose at $500^{\circ} \mathrm{C}$ resulted in disappearance of the faulted structure and a very unusual dislocation contrast indicative of helical coiling of the dislocations.

The microstructures of $\mathrm{V}-1 \mathrm{Ni}$ following irradiation are provided in Figure 2. Figures 2 a) and b) show dislocation, void, and precipitate structures in $\mathrm{V}-1 \mathrm{Ni}$ irradiated at 500 and $600^{\circ} \mathrm{C}$, respectively, to $15 \mathrm{dpa}$ using $\overrightarrow{\mathbf{g}}=110$. Two precipitate types can be identified in Figure 2 a): dark, blocky, equiaxed particles uniformly distributed and occasionally associated with voids; and plate-like features apparently on (100) planes and often containing stacking fault features. Figure $2 \mathrm{~b}$ ) indicates voids and blocky precipitates are much larger following irradiation at the higher temperature. Note that the specimen irradiated at $600^{\circ} \mathrm{C}$ contains a surface contaminant that formed bubbles under the electron beam; those circular bubble features should be ignored.

Figure $2 \mathrm{c}$ ) shows the microstructural features following irradiation at $500^{\circ} \mathrm{C}$ to $31 \mathrm{dpa}$ using the same imaging condition as in Figure 2 a). Comparison of Figures 2 a) and c) reveals that irradiation to higher dose creates a major change in the dislocation structure, so that dislocations evolve into helical arrays and display unusual contrast, indicative of solute segregation effects. Figures $2 \mathrm{~d}$ ), e), and f) show the same area as in $2 \mathrm{c}$ ) using precipitate dark field contrast to show the blocky precipitate in various orientations. At least three different orientations can be identified. Figures $2 \mathrm{~g}$ ) and $\mathrm{h}$ ) provide low magnification examples of grain boundary migration following irradiation at $500^{\circ} \mathrm{C}$ to $15 \mathrm{dpa}$. The grain boundary moved vertically in Figure $2 \mathrm{~g}$ ) and toward the lower right in $2 \mathrm{~h}$ ). Note enhanced void nucleation in the latter case.

Figure 3 was prepared to provide understanding of the dislocation structures in irradiated $\mathrm{V}-1 \mathrm{Ni}$. Figures 3 a) and b) show $\mathrm{V}-1 \mathrm{Ni}$ irradiated at $500^{\circ} \mathrm{C}$ to $31 \mathrm{dpa}$ using $\overrightarrow{\mathrm{g}}=110$ and 002 near a (110) orientation. The horizontal dislocations at the upper left and lower center in both images indicate a Burgers vector of type $\frac{1}{2}<11>$. The helical diagonal images also appear in both images, but these images are not typical of dislocations. Therefore, strain in $\langle 111\rangle$ directions is again indicated, but precipitation due to solute segregation at dislocations is thought to be the cause. Note that similar diagonal images are developing in association with the horizontal dislocations, suggesting that those

$2<111>$ dislocations are beginning to climb into helical configuration.

Also of interest is the wide variation in void shape in this micrograph series. Based on the geometries displayed, these voids are cuboidal with (110) or dodecahedral truncation, but the degree of truncation on the specific truncation planes varies widely from void to void. Wide variations in truncation are often due to associated precipitation or solute segregation. Figures $3 \mathrm{c}$ ) and d) show $\mathrm{V}-1 \mathrm{Ni}$ irradiated at $600^{\circ} \mathrm{C}$ to 15 dpa using $\overrightarrow{\mathrm{g}}=110$ and 200 near an (001) orientation. Because all dislocation images in 110 contrast also appear in 200 contrast, $2<111>$ Burgers vectors are again indicated. However, the tendency for solute segregation appears to be reduced at the higher irradiation temperature. 

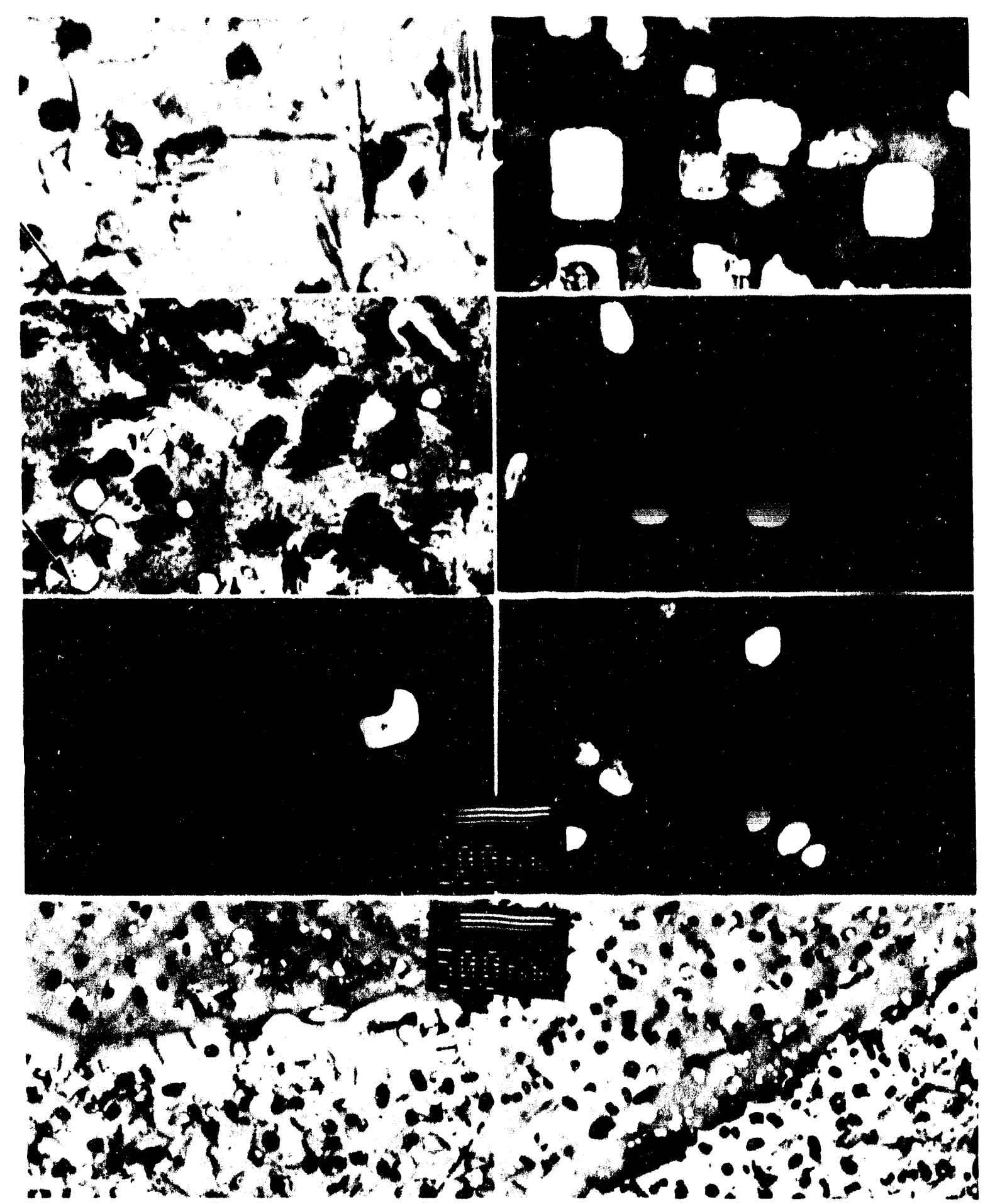

Figure 2. Microstructures in $\mathrm{V}-1 \mathrm{Ni}$ following irradiation to $15 \mathrm{dpa}$ at $500^{\circ} \mathrm{C}$ in dislocation contrast in a), and at $600^{\circ} \mathrm{C}$ in dislocation contrast in b), to $31 \mathrm{dpa}$ at 500 in dislocation contrast in c) and in precipitate dark field contrast in d), e) and f), and to $15 \mathrm{dpa}$ at $500^{\circ} \mathrm{C}$ showing grain boundary migration in $\mathrm{g}$ ) and h). 


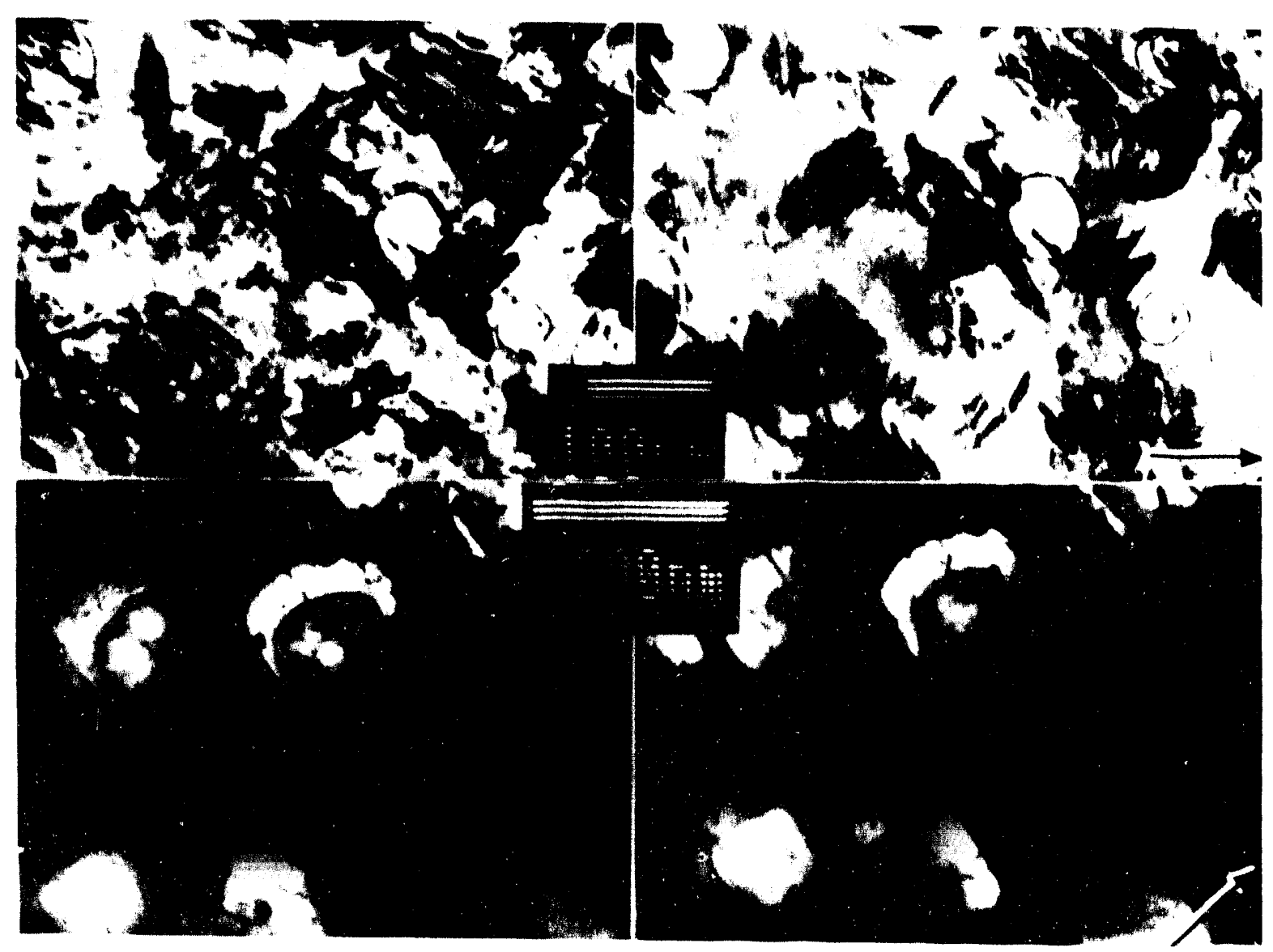

Figure 3. Examples of dislocation contrast in $\mathrm{V}-1 \mathrm{Ni}$ following irradiation at $500^{\circ} \mathrm{C}$ to $31 \mathrm{dpa}$ in a), and b), and at $600^{\circ} \mathrm{C}$ to $15 \mathrm{dpa}$ in c) and d).

\section{V-2Ti-1Ni}

Specimens of V-2Ti-1Ni were examined following irradiation at 425 and $500^{\circ} \mathrm{C}$ to $15 \mathrm{dpa}$ and at $500^{\circ} \mathrm{C}$ to $31 \mathrm{dpa}$. All specimens contained extensive precipitation, but precipitate morphologies were very different at the two irradiation temperatures. Moderate swelling was found following irradiation at $425^{\circ} \mathrm{C}$, but following irradiation at $500^{\circ} \mathrm{C}$, voids were only found in association with grain boundary structure and only at the higher dose. Therefore, additions of titanium completely altered the microstructural evolution when $1 \%$ nickel was present.

Examples of V-2Ti-1Ni microstructures are provided in Figure 4. Figures 4 a) and b) show void and precipitate structures in V-2Ti-1Ni that was irradiated to $15 \mathrm{dpa}$ at 425 and $500^{\circ} \mathrm{C}$. Precipitates are highly elongated in $<100>$ directions following irradiation at $425^{\circ} \mathrm{C}$, whereas after irradiation at $500^{\circ} \mathrm{C}$, they are smaller and more equiaxed. Voids formed at $425^{\circ} \mathrm{C}$ are cuboidal with (100) faces, whereas no voids were observed following irradiation to $15 \mathrm{dpa}$ at $500^{\circ} \mathrm{C}$. Figures $4 \mathrm{c}$ ) and d) provide higher magnification examples of the structure formed following irradiation at $425^{\circ} \mathrm{C}$. Figure $4 \mathrm{c}$ ) shows an area in absorption contrast to reveal precipitates and voids, and Figure $4 \mathrm{~d}$ ) shows the same area in $\vec{g}=200$ contrast to show the dislocation structure. The dislocation structure in Figure $4 \mathrm{~d}$ is difficult to interpret, consisting of short line segments connected to precipitate particles. 


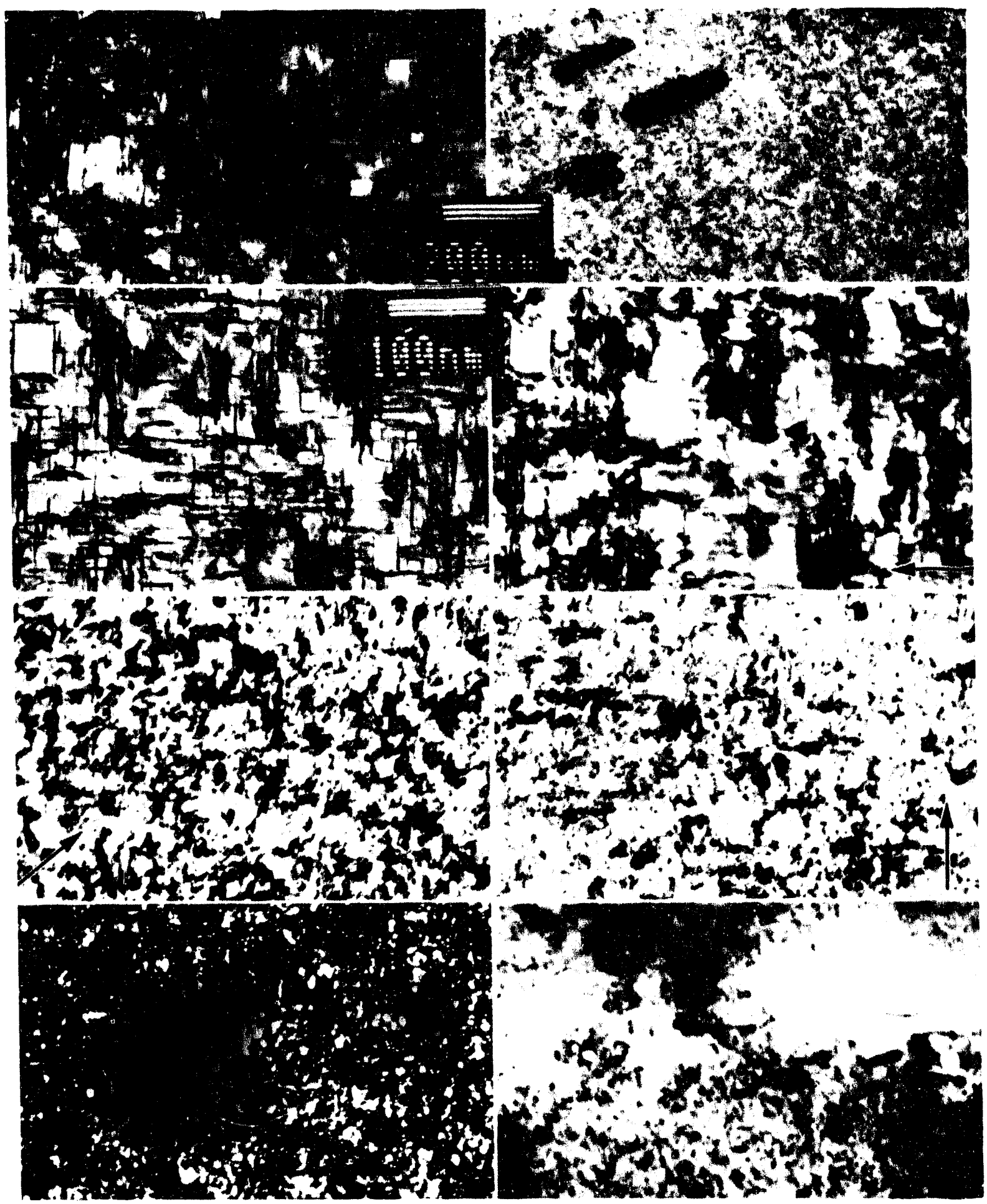

Figure 4. Microstructures in V-2Ti-Ni following irradiation to 15 dpa at 425 in a), and at $500^{\circ} \mathrm{C}$ in b), at higher magnification to $15 \mathrm{dpa}$ at $425^{\circ} \mathrm{C}$ in c) and in dislocation contrast in d) and at $500^{\circ} \mathrm{C}$ to $31 \mathrm{dpa}$ in dislocation contrast in e) and f) and in precipitate contrast in $\mathrm{g}$ ), and showing voids at grain boundaries in $h$ ). 
Figures $4 \mathrm{e}$ ) through $4 \mathrm{~h}$ ) give examples of the microstructure in V-2Ti-1 Ni following irradiation at $500^{\circ} \mathrm{C}$ to 31 dpa. Figures $4 \mathrm{e}$ ), f), and g) show the same area under different contrast conditions. Figure $4 \mathrm{e}$ ) uses $\overrightarrow{\mathrm{g}}=110$ and $\mathrm{f}$ ) uses $\mathbf{2 0 0}$ for a foil near (001). However, the dislocation images in these figures are very difficult to compare due to precipitate images that also appear. Figure $4 \mathrm{~g}$ ) shows the precipitate particles in $\frac{5}{8}(200)$ dark field contrast, although other precipitate reflections showed similar images. From this figure, it is apparent that particle sizes vary from 3 to $6 \mathrm{~nm}$, with some as large as $10 \mathrm{~nm}$. Figure $4 \mathrm{~h}$ ) shows one of several examples where a few voids are found in the vicinity of grain boundaries. The voids vary considerably in shape and size. Precipitate particles are also present (based on the mottled background contrast), so precipitate denuding due to grain boundary migration does not explain the presence of the voids.

\section{Discussion}

It has been proposed that the high swelling of vanadium alloys can be interpreted in terms of the atomic size effect of the alloying elements. ${ }^{6}$ Solute atoms that are smaller in size will diffuse by an interstitial mechanism and be preferentially segregated to point defect sinks such as dislocations and voids, and there, may significantly alter the sink.bias for point defects. ${ }^{6}$ Based on a relative atomic size measurement from extrapolation of the lattice constant data for the alloy, it was shown that additions of $\mathrm{Fe}$, with a relative atomic size of 0.86 , developed higher swelling than did addition of $\mathrm{Si}(0.88)$ and $\mathrm{Cr}(0.93)$, which in turn developed higher swelling than pure $\mathrm{V}(1.00)$ and pure Mo (1.04). The present results suggest that $\mathrm{Ni}$ additions may produce swelling intermediate between $\mathrm{Cr}$ and $\mathrm{V}$, and that $\mathrm{Al}$ and $\mathrm{Ti}$ additions produce response similar to Mo. However, if one uses the metallic radii estimates by Asaroff, ${ }^{8}$ the order of atomic size (in $\AA$ ) is Si:1.17, Fe:1.24, Ni:1.24, Cr:1.25, V:1.31, Mo:1.36, Al:1.43, and Ti:1.44. Therefore, a different measure of the tendency for solute segregation is created that predicts the strongest effect with $\mathrm{Si}$ additions; next in potency would be $\mathrm{Fe}, \mathrm{Ni}$, and $\mathrm{Cr}$ and then pure $\mathrm{V}, \mathrm{Mo}, \mathrm{Al}$, and $\mathrm{Ti}$.

A large number of simple vanadium alloys have now been examined following neutron irradiation, and the present study adds to that list. Microstructural examinations have previously been reported for pure $\mathrm{V}^{6,9,90} \mathrm{~V}-5 \mathrm{Fe}^{2,6} \mathrm{~V}-1 \mathrm{Si},{ }^{6} \mathrm{~V}-10$ to $15 \mathrm{Cr}(-.2 \mathrm{Al}){ }^{6,9} \mathrm{~V}-5$ to $22 \mathrm{Ti},{ }^{9-11,12} \mathrm{~V}-5$ to $15 \mathrm{Cr}-5$ to $25 \mathrm{Ti},{ }^{13.15} \mathrm{~V}-4$ to $5 \mathrm{Mo},{ }^{6,9}$ and V-8.6W.9 Those studies have shown that $\mathrm{V}-5 \mathrm{Fe}$ swells rapidly because of rapid void growth and rapid dislocation evolution. ${ }^{3,6}$ It was assumed that the cavities also developed an iron-rich surface layer. Rapid void growth can also occur with $\mathrm{Si}$ additions at low irradiation temperatures $\left(410^{\circ} \mathrm{C}\right)$ and with $\mathrm{Cr}$ additions at $600^{\circ} \mathrm{C}$ (although only to half the level obtained with $\mathrm{Fe}$ ). ${ }^{6}$ The present results for void growth in $\mathrm{V}-1 \mathrm{Ni}$ at $600^{\circ} \mathrm{C}$ are similar to those for $\mathrm{V}-5 \mathrm{Cr}$. A value of about $150 \mathrm{~nm}$ was found following irradiation at $600^{\circ} \mathrm{C}$ in EBR-II to $31 \mathrm{dpa}$, whereas Nakajima and coworkers found a mean cavity size of $200 \mathrm{~nm}$ following irradiation at $600^{\circ} \mathrm{C}$ in the Fast Flux Test Facility to $34 \mathrm{dpa}^{6}$

Additions of Ti, Mo, and $\mathrm{W}$ have previously been shown to reduce swelling. ${ }^{6.9}$ The present studies have shown that $\mathrm{Al}$, and $\mathrm{Ti}$ additions to $\mathrm{V}-1 \mathrm{Ni}$ have a similar effect. However, the mechanism that controls the reduction of swelling that can be identified from the present work is fine scale precipitation, similar to the mechanism proposed for $\mathrm{V}-15 \mathrm{Cr}-5 \mathrm{Ti}^{13}$ and ascribed to $\mathrm{Ti}_{5} \mathrm{Si}_{3},{ }^{14}$ and similar to the previous observations on V-10Ti. ${ }^{9}$ The present work has indicated that dislocation movement would be inhibited by the precipitation in these systems. Therefore, a means for prevention of swelling in vanadium alloys may be precipitation rather than a high relative atomic size of solute additions. 


\section{CONCLUSIONS}

The effects of solute additions of $\mathrm{Ni}, \mathrm{Al}$ and $\mathrm{Ti} / \mathrm{Ni}$ to vanadium have been studied based on microstructural examination of alloys V-5Al, V-1Ni, and V-2Ti-1Ni following irradiation in EBR-II in the temperature range 425 to $600^{\circ} \mathrm{C}$. Based on these examinations, Ni additions promote swelling and precipitation on a coarse scale similar to but not as effectively as $\mathrm{Cr}$ additions, whereas additions of $\mathrm{Al}$ and $\mathrm{Ti} / \mathrm{Ni}$ inhibit swelling and promote precipitation on a fine scale.

Therefore, solute additions of a small relative size are confirmed to promote swelling in vanadium alloys, and solute additions of a large relative size inhibit swelling.

\section{FUTURE WORK}

This work will be continued when suitable specimens become available.

\section{ACKNOWLEDGEMENT}

The authors acknowledge the assistance of F. A. Garner, Pacific Northwest Laboratory, for his assistance in the planning for this work.

\section{REFERENCES}

1. International Thermonuclear Experimental Reactor Task Proposal BL-RD-6, "Assessment, Characterization and Development of Vanadium Structural Materials," issued by the ITER design team, May 1993.

2. B. A. Loomis and D. L. Smith, J. Nucl. Mater, $191-4$ (1992) 84.

3. H. Matsui, D. S. Gelles and Y. Kohno, in Effects of Raaiation on Materials: 15th International Symposium, ASTM STP 1125, R. E. Stoller, A. S. Kumar and D.S. Gelles, Eds. (ASTM, Philadelphia, PA, 1992) 928.

4. B. A. Loomis, D. L. Smith and F. A. Garner, J. Nucl. Mater, 179-81 (1991) 771.

5. F. A. Garner, D. S. Gelles, H. Takahashi, S. Ohnuki, H. Kinoshita and B. A. Loomis, in Fusion Reactor Materials Semiannual Progress Report for the Period Ending September 30, 1991, DOE/ER-0313/11 (1992) 233.

6. N. Nakajima, S. Yoshida, Y. Kohno and H. Matsui, J. Nucl. Mater, 191-4 (1992) 952.

7. D. S. Gelles, in Effects of Radiation on Materials: 14th International Symposium, Volume 1, ASTM STP 1046, N. H. Packan, R. E. Stoller and A. S. Kumar, Eds. (ASTM, Philadelphia, PA, 1990) 73.

8. L. V. Azaroff, Introduction to Solids, (McGraw-Hill, N.Y., 1960) Appendix 3, Table 4, 441.

9. S. Ohnuki, D. S. Gelles, B. A. Loomis, F. A. Garner and H. Takahashi, J. Nucl. Mater, 179-80 (1991) 775. 
10. H. Kawanishi, Y. Arai and S. Ishino, J. Nucl. Mater, 191-4 (1992) 933.

11. L. I. Ivanov, V. V. Ivanov, V. M. Lazorenko, Yu. M. Platovand V. I. Tovtin, J. Nucl. Mater, 1914 (1992) 928.

12. H. M. Chung and D. L. Smith, J. Nucl. Mater, 191-4 (1992) 942.

13. D. S. Gelles, S. Ohnuki, B. A. Loomis, H. Takahashi, and F. A. Garner, J. Nucl. Mater, 186 (1991) 77.

14. M. Satou and H. M. Chung, in Fusion Reactor Materials Semiannual Progress Report for the Period Ending September 30, 1992, DOE/ER-0313/13 (1992) 227.

15. M. Satou, K. Abe and H. Matsui, J. Nuçl. Mater, 191-4 (1992) 938. 


\subsection{DEVELOPMENT OF STRUCTURAL ALLOYS}

\subsection{Ferritic Stainless Steels}


REPORT ON IEA COLLABORATION ON FERRITIC/MARTENSITIC STEELS -- R. L. Klueh (Oak Ridge National Laboratory)

\section{OBJECTIVE}

An international collaboration is being planned with the objective of developing an optimized reduced-activation ferritic steel for fusion.

\section{SUMMARY}

A collaborative program is underway under the auspices of the IEA (International Energy Agency) to develop a reduced-activation ferritic steel for a demonstration fusion power plant. A task has been initiated for which Japan will produce a $5000-10000 \mathrm{~kg}$ heat of reduced-activation $8 \mathrm{Cr}$ 2 WVTa steel. Once the steel is produced, the Japanese, EC, and US fusion programs will conduct detailed cooperative test programs on the steel. Two meetings have been held to plan the collaboration, and the results from those meetings are reviewed.

\section{PROGRESS AND STATUS}

\section{Introduction}

The proposal for an IEA collaborative program originated at the workshop on ferritic/martensitic steels for fusion held under the auspices of the IEA Fusion Materials Working Group Task Annex II at Tokyo, October 26-28, 1992. At the workshop, the Japanese delegation offered to produce two large heats of candidate reduced-activation ferritic steels for use in a collaborative effort to determine the feasibility of using such a steel and then optimize the composition, for the structural material for a demonstration fusion power plant. According to the proposal, these steels would be tested in Japan, Europe, and the United States in a series of agreedupon tasks. The cost of the production was to be borne by the Japanese program. Since the Japanese offer was made near the end of the Tokyo workshop, there was no time to act on the proposal at that meeting.

\section{Working Group Meeting, Oak Ridge}

An IEA Working Group meeting on ferritic/martensitic steels was held in Oak Ridge on May 21, 1993 to follow up on the Japanese proposal to further clarify their proposal and determine how it might be implemented. The Working Group consisted of three members from Japan (Drs. A. Hishinuma, A. Kohyama, and M. Tamura), three from the United States (Drs. D. S. Gelles, R. L. Klueh, and G. R. Odette), and one from the European Community (Dr. D. R. Harries).

\section{Selection of Composition}

The general consensus at the Tokyo Workshop was that reduced-activation steels with 7$10 \% \mathrm{Cr}, 2 \% \mathrm{~W}, 0.25 \% \mathrm{~V}$ (all compositions are in wt \%), and small amounts of tantalum show the most promise for successful fusion applications. It was acknowledged, however, that only a limited amount of irradiation data was available for these steels. 
At the Oak Ridge meeting, the Working Group reviewed data for the most promising of the 8-10Cr-2WVTa steels. This review demonstrated that steels from each national program show promise, and confirmed that the most promising are the high-chromium steels, for which the most irradiated data are available. It was recognized that the ferritic/martensitic reduced-activation compositions investigated to date have not been optimized and that further improvement in properties by the suitable choice of composition may be possible.

In Oak Ridge, the Japanese delegation restated their offer to purchase one or two large heats of reduced-activation steel that would then be investigated in Japan, Europe, and the United States in a series of agreed-upon tasks. Alternate possibilities for procuring material were proposed by the Japanese delegation as follows: (1) Two large heats (F82H and JLF-1), (2) One large heat and a small heat, (3) One large commercial-type heat and two small heats.

Different possibilities for producing the steels were still being explored in Japan at the time of the meeting.

After discussing the merits of producing one or two large heats, the Working Group concluded the best approach would be to produce one large $(5000-10000 \mathrm{~kg})$ heat and several smaller heats. The discussion to arrive at a composition for the large IEA heat resulted in a proposal for a 8Cr-2WVTa steel (a modified F82H). The composition is given in Table I. The 8Cr (rather than $9 \mathrm{Cr}$ ) composition was selected because of the past experience NKK Corporation developed from producing a large heat ( 5 tons) of $\mathrm{F82H}$, which has the $8 \mathrm{Cr}$ composition. That experience will be utilized, because it is expected that NKK will produce the heat.

Table I Proposed specification of large IEA heat of reduced-activation martensitic steel

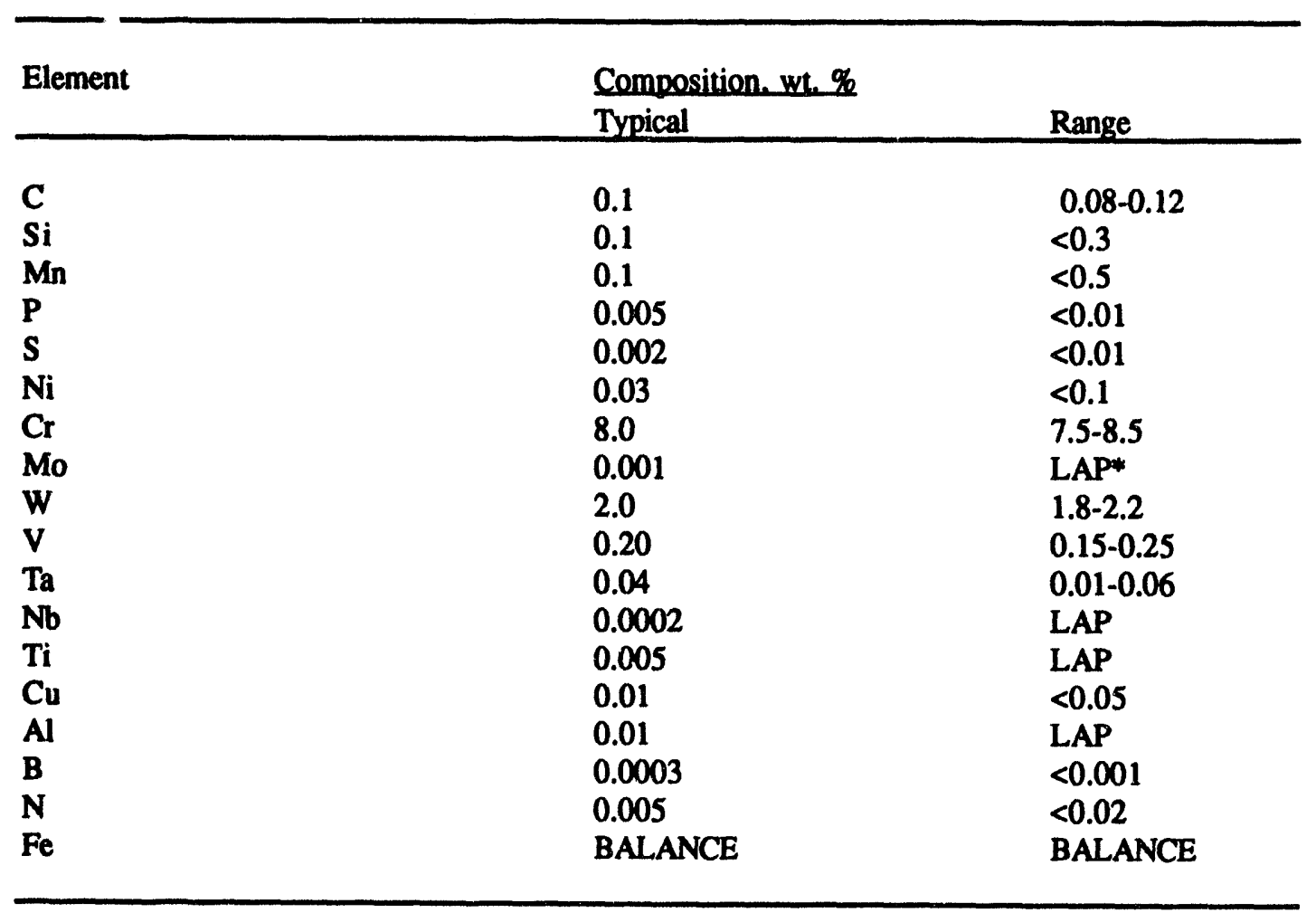

\footnotetext{
* Low as possible
} 
Once the reduced-activation steel ingot is obtained, it was proposed that it be worked into plate and tube. Plates $3 \mathrm{~m} \times 1 \mathrm{~m} \times 15 \mathrm{~mm}$ and $3 \mathrm{~m} \times 1 \mathrm{~m} \times 25 \mathrm{~mm}$ would be obtained. Tube dimensions were unspecified at the Oak Ridge meeting.

Rather than seek to purchase two large heats, the Working Group decided to supplement the work on the large heat with work on four smaller (approximately $50 \mathrm{~kg}$ ) heats. The following compositions were selected to investigate the effects of variations in some of the major alloying element concentrations:

(1) $7 \% \mathrm{Cr}$ with other elemental compositions similar to the large heat.

(2) $9 \% \mathrm{Cr}$ with other elemental compositions similar to the large heat.

(3) $1 \% \mathrm{~W}$ with other elemental compositions similar to the large heat.

(4) $1 \% \mathrm{Mn}$ with other elemental compositions similar to the large heat.

Results from tests on these steels will be used to optimize compositions for the 7-9Cr-WVTa steels.

Although the production arrangements were not yet finalized at the time of the Oak Ridge meeting, the smaller heats were expected to be produced by the Nippon Steel Company as part of the Japanese universities (MONBUSHO) program. Drs. Hishinuma and Kohyama assumed the task of seeking formal approval in Japan to proceed with the procurement of the steels. They agreed to distribute a detailed plan for the production and fabrication of the heats and recommend the tasks to be undertaken on the steel plate, welds, and possibly, some prototypic fusion reactor components.

It was estimated that the steels could be made and the products distributed to the parties participating in the tests by January 1995.

\section{International Test Program}

The Working Group discussed the types of tests to be performed on the large heat. Table II lists the tests envisaged for the large heat of steel. Tests will be required on irradiated and unirradiated material. Not all of the tests in Table II are of equal importance. Fracture toughness of irradiated material is crucial. These and other tests of irradiated material, especially over the temperature range $200-350^{\circ} \mathrm{C}$, will be of highest priority. On the other hand, tests, such as those for physical property measurements, may not have as high priority, since these properties will not change much from those determined on conventional ferritic/martensitic steels and those determined previously on smaller heats of reduced-activation steels. A detailed coordinated test program will have to be determined at a future IEA meeting.

Because of the importance of tests at $200-350^{\circ} \mathrm{C}$ and the fact that results from irradiation tests for the new heats will not be completed before 1997, the Working Group concluded that it is imperative that efforts continue to acquire such data with the experimental heats of reducedactivation steels now available. As part of such an effort, the planned cooperative irradiation experiment instigated at the Tokyo Workshop was cited. The experiment is planned for HFR in Petten, The Netherlands, in 1994/95. Conventional and reduced-activation martensitic steels will be irradiated to $3 \mathrm{dpa}$ (maximum) in the range $250-450^{\circ} \mathrm{C}$; steels to be included are the EC steels MANET I and II, and OPTIFER, the US s.els 7.5Cr-2W and 9Cr-2WVTa steels, and the Japanese F82H steel. Sub-size Charpy V-notcii specimens form the bulk of the loading, but some tensile samples are included. 
Table II Proposed tests for large heat of reduced-activation steel

\begin{tabular}{lll}
\hline $\begin{array}{l}\text { Metallurgical } \\
\text { Characterization }\end{array}$ & $\begin{array}{c}\text { Out-of-Reactor } \\
\text { Effects }\end{array}$ & $\begin{array}{c}\text { Irradiation } \\
\text { Effects }\end{array}$ \\
\hline Processing & Tensile & Tensile \\
Heat Treatment Optimization & Fracture Toughness & Swelling \& Microstructure \\
Tensile & Fatigue & Fatigue \\
Charpy Impact Toughness & Thermal Creep & Fracture Toughness \\
Creep rupture & Charpy Impact & Charpy Impact \\
Physical Properties & Thermal Aging & Irradiation Creep \\
Weldability & Microstructure & Creep-Fatigue \\
& Creep-Fatigue & Stress-Relaxation \\
& Corrosion/Compatibility & \\
& Stress-Relaxation & \\
& Fatigue Crack Growth & \\
& Thermal Fatigue & \\
& Multiaxial Fatigue & \\
& Hydrogen Effects &
\end{tabular}

\section{Working Group Meeting. Stresa. Italy}

The IEA Working Group reconvened in Stresa, Italy, September 29, 1993, to update the schedules for the production of the large and small IEA heats of reduced-activation ferritic steel discussed at Oak Ridge.

Dr. Hishinuma reported that the large IEA had been ordered and should be available by February 1994, to be distributed to the participating parties by April 1994. It was decided that plates $300 \mathrm{~mm}$ by $500 \mathrm{~mm}$ with thicknesses of 25,15 , and $7 \mathrm{~mm}$ will be produced. Some TIG and EB welds will also be provided.

Professor Kohyama stated that of the four $50 \mathrm{~kg}$ heats discussed at Oak Ridge, no $7 \mathrm{Cr}$ heat would be made, and the $9 \mathrm{Cr}$ heat will be a one-ton heat. These three heats are scheduled for the next Japanese fiscal year (beginning April 1994) and should be available in the summer of 1994. 
Lists of the proposed tasks on the large heat and the amounts of steel required by the U.S. and the European Community are to be submitted to Dr. Hishinuma by November 1, 1993. The U.S. and EC will be informed by the Japanese concerning the tasks they will take on. A Working Group meeting will be convened in Sun Valley, Idaho in June 1994 to develop a coordinated program and task sharing plan. 
EFFECT OF LOADING MODE ON THE FRACTURE TOUGHNESS OF A FERRITIC/MARTENSITIC STAINLESS STEEL - Huaxin Li (Associated Western Universities--Northwest Division), R. H. Jones (Pacific Northwest Laboratories)" J. P. Hirth (Washington State University--Pullman) and D. S. Gelles (Pacific Northwest Laboratories)"

\section{OBJECTIVE}

The purpose of this research is to investigate the effect of hydrogen and loading mode on the fracture toughness of a reduced activation ferritic stainless steel (F-82H).

\section{SUMMARY}

The critical $\mathrm{J}$ integrals of mode I $\left(\mathrm{J}_{\mathrm{IC}}\right)$, mixed-mode $\mathrm{IIII}\left(\mathrm{J}_{\mathrm{MC}}\right)$, and mode III $\left(\mathrm{J}_{\mathrm{mC}}\right)$ were examined for a ferritic stainless steel $(\mathrm{F}-82 \mathrm{H})$ at ambient temperature. A determination of $\mathrm{J}_{\mathrm{MC}}$ was made using modified compact-tension specimens. Different ratios of tension/shear stress were achieved by varying the principal axis of the crack plane between 0 and 55 degrees from the load line. $J_{m c}$ was determined using triplepantleg like specimens. The results showed that $\mathrm{F}-82 \mathrm{H}$ steel is a very tough steel. Both $\mathrm{J}_{I C}$ and $\mathrm{J}_{\mathrm{mc}}$ are abnut $500 \mathrm{~kJ} / \mathrm{m}^{2}$, and mode I tearing modula $\left(T_{1}\right)$ is about $\left(360 \mathrm{~kJ} / \mathrm{m}^{2}\right) / \mathrm{mm}$. However, $J_{M c}$ and mixedmode tearing modula $\left(T_{M}\right)$ values varied with the crack angles and were lower than their mode $I$ and mode III counterparts. Both the minimum $J_{M C}$ and $T_{M}$ values occurred at a crack angle between 40 and 50 degrees, where the load ratio of $\sigma_{1} / \sigma_{\mathrm{iit}}$ was 1.2 to 0.84 . The $J_{\min }$ was $240 \mathrm{~kJ} / \mathrm{m}^{2}$, and ratios of $\mathrm{J}_{\mathrm{IC}} / \mathrm{J}_{\min }$ and $\mathrm{J}_{\mathrm{mc}} / \mathrm{J}_{\min }$ were 2.1 and 1.9 , respectively. The morphology of fracture surfaces was consistent with the change of $J_{M C}$ and $T_{M}$ values. While the upper shelf-fracture toughness of F-82H depends on loading mode, the $\mathrm{J}_{\min }$ remains very high. Other important considerations include the effect of mixed-mode loading on the DBT temperature, and effects of hydrogen and irradiation on $\mathrm{J}_{\min }$.

\section{PROGRESS AND STATUS}

Introduction

Traditionally, mode I fracture has been used to study elastic-plastic fracture mechanics. However, in recent years, mixed-mode fracture has become a focus of many studies because many observed failures included shear components [1-9]. Fracture characteristics have been found to differ from one another when subjected to mixed-mode I/III loading, depending on the microstructure, strength, and toughness level of materials. In low-toughness high-strength alloys, such as $0.29 \mathrm{C}-0.83 \mathrm{Cu}$ steel, and $1.25 \mathrm{C}$ bainitic steel [7-10], mode III contributions to mode I loading had little or no effect on the overall value of $\mathrm{J}_{\mathrm{iC}}$, the mode $I$ component of the $J$ integral for mixed-mode crack initiation, and tended to increase $J_{M C}$, the total $\mathrm{J}$ integral for mixed-mode crack initiation. In tougher materials (such as $3.5 \mathrm{NiCrMoV}$ steel, A710A, and a high-purity rotor steel (HPRS) [1-9], which failed primarily by a microvoid nucleation and growth mechanism) mode III contributions lowered the $\mathrm{J}_{M C}$ values considerably from their mode I values. The $\mathrm{J}_{M C}$ values passed through a minimum at a position between mode $\mathrm{I}$ and mode III on a plot of $\mathrm{J}_{M C}$ vs crack inclination angle.

"Pacific Northwest Laboratory is operated for the U.S. Department of Energy by Battelle Memorial Institute under Contract DE-AC06-76RLO 1830. 
A steel with $0.1 \mathrm{C}-8 \mathrm{Cr}-2 \mathrm{~W}-0.2 \mathrm{~V}-0.04 \mathrm{Ta}$ (designated as $\mathrm{F}-82 \mathrm{H}$ ) has been developed as a reduced activation ferritic/martensitic steel and considered as one of the candidates for the first-wall material of a fusion reactor. Preliminary J integral data [11] obtained from three point bending specimens showed that $\mathrm{F}-82 \mathrm{H}$ is a very tough steel. It is possible that introducing mode III components to mode 1 loading would also lower the total $J$ integral of $F-82 \mathrm{H}$ as in the case of HPRS. Hence, investigation of the effect of mixedmode loading on fracture toughness of $\mathrm{F}-82 \mathrm{H}$ is critical if the steel is to be used as first-wall material.

\section{Material and Experimental Methods}

\section{Material}

The F-82H plate used in this study was supplied by Nippon Kokan Steel Company (NKK) in Japan. The chemical composition of the plate (as provided by NKK) is (by wt\%): $0.096 \mathrm{C}-7.71 \mathrm{Cr}-2.1 \mathrm{~W}-0.18 \mathrm{~V}-0.04 \mathrm{Ta}$ $0.003 \mathrm{P}-0.003 \mathrm{~S}$. Specimens used in this study were cut in the orientation of T-L as specified in ASTM E399-90 and were heat-treated using $1000^{\circ} \mathrm{C} / 20 \mathrm{~h} /$ air cooling $(\mathrm{AC}), 1100^{\circ} \mathrm{C} / 7 \mathrm{~min} / \mathrm{AC}$, and $700^{\circ} \mathrm{C} / 2 \mathrm{~h} / \mathrm{AC}$. The microstructure was tempered martensite. The average intersection distance grain size was $25 \mu \mathrm{m}$ (ASTM \#7.5). The heat-treatment resulted in a yield strength $\left(\sigma_{y}\right)$ of $648 \mathrm{MPa}$, ultimate tensile strength $\left(\sigma_{u t s}\right)$ of $735 \mathrm{MPa}$, elongation of $16.7 \%$, and reduction of area of $70 \%$.

\section{Experimental Methods}

The details of experimental methods were reported in Ref. 12. In order to make a complete and independent report, and also for the sake of reader's convenience, the important portions of experimental methods are summarized here.

The geometry of modified compact-tension (MCT) specimens used for mixed-mode $1 / 11$ testing is schematically shown in Fig. 1. The magnitude of mode III components can be varied by changing the crack slant angle $\Phi$. An angle of 0 degree represents mode I loading and the geometry of a 0 -degree specimen becomes the standard compact-tension (CT) specimen as specified in ASTM standard E813-89. As $\Phi$ increases, the contribution of mode III components increases. The crack-inclination angles used in this study were $0,10,20,30,40,45,50$, and 55 degrees. Side grooves of $20 \%$ reduction of total thickness were incorporated in all specimens. These side grooves can increase the triaxiality at the edges of a growing crack and constrain the advancing crack in the original crack plane. Calculating the $\mathbf{J}$ integrals in mixed-mode $\mathrm{I} / \mathrm{III}$ requires measuring both vertical displacement $\left(\delta_{v}\right)$ and horizontal displacement $\left(\delta_{h}\right)$ of load points. A pair of knife edges was secured to the front face of a specimen. A standard clip crack opening distance (COD) gage was positioned on the knife edges. The load-line $\delta_{v} s$ were calculated from the front face $\delta_{\mathrm{y}} \mathrm{s}$ with the method proposed by Saxena and Hudak, Jr. [13]. It was found that the $\delta_{h}$ increased with $\delta_{v}$ in a linear mode $[1,3]$. Hence $\delta_{h} s$ were calculated approximately using a relation of $\delta_{\mathrm{h}}=\alpha \times \delta_{\mathrm{v}}$, where $\alpha=\delta_{\mathrm{hmax}} / \delta_{\mathrm{vmax}}$.

An electric discharge machine (EDM) was used to make thin cuts with a smaall radius (radius $=0.051$

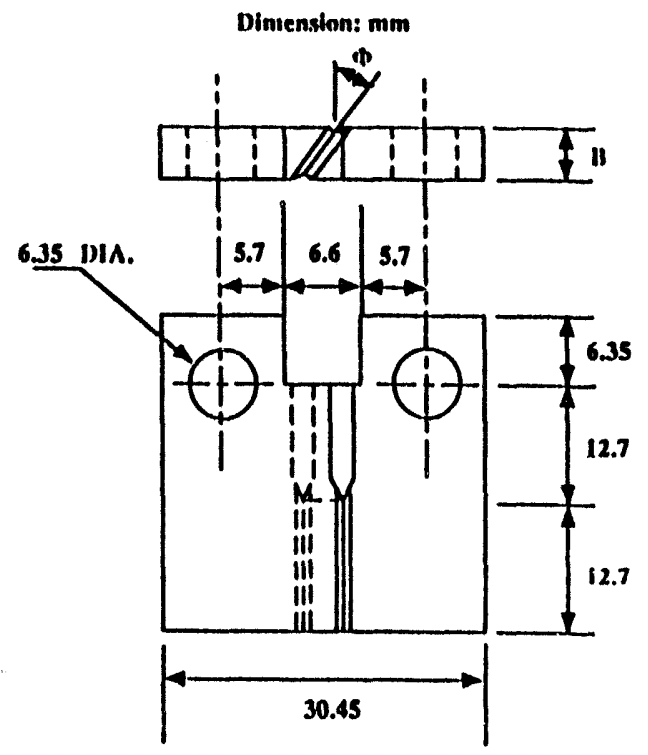

Fig. 1. The geometry of a modified compact tension specimen. 
$\mathrm{mm}$ ) and approximately $1.3 \mathrm{~mm}$ long. The cuts were used as a substitute for a pre-fatigued-crack (PFC) because a PFC tends to grow out of the original crack plane in mixed-mode specimens. The fine EDM cut was found to give identical values of $\mathrm{J}_{\mathrm{IC}}$ as for a PFC [4]. The EDM cuts were made after final heattreatment, and specimens with cuts were heated at about $100^{\circ} \mathrm{C}$ for $24 \mathrm{~h}$ in a vacuum oven $\left(10^{-3} \mathrm{~Pa}\right)$ to outgas possible hydrogen introduced by EDM cutting [14]. The single-specimen technique was used in this study, which allows a J-R curve (J vs crack extension $\Delta a$ ) to be generated with one specimen. During testing, the specimen was frequently and partially unloaded, and the partial unloading compliances were used to calculate the corresponding crack lengths following the procedure described in E813-89 and Ref. 13. Values of $J$ matching those crack lengths were also calculated by means of Eq. (1) in the next section. At least 12 pairs of J- $\Delta$ a data were used to construct a J-R curve.

The triple-pantleg like specimens (Fig. 2) [3$5,12]$ were used to determine $\mathrm{J}_{\mathrm{mc}}$. The specimens had two cracks that led to a symmetric loading and minimized an out-of-plane bending [4]. Two 1.3-mm EDM cuts were also made as substitutes for PFCs. Indirect crack-leng t h mon it oring techniques, such as the electrical potential drop method or unloading compliance, are affected by the contact of the asperities on the two specimen surfaces during mode III ( $\mathrm{sh}$ e a $\mathrm{r}$ i g $\mathrm{g}$ ) deformation. Hence, a multiple-specimen (five specimens) technique was adopted, and the crack lengths were measured after breaking open the

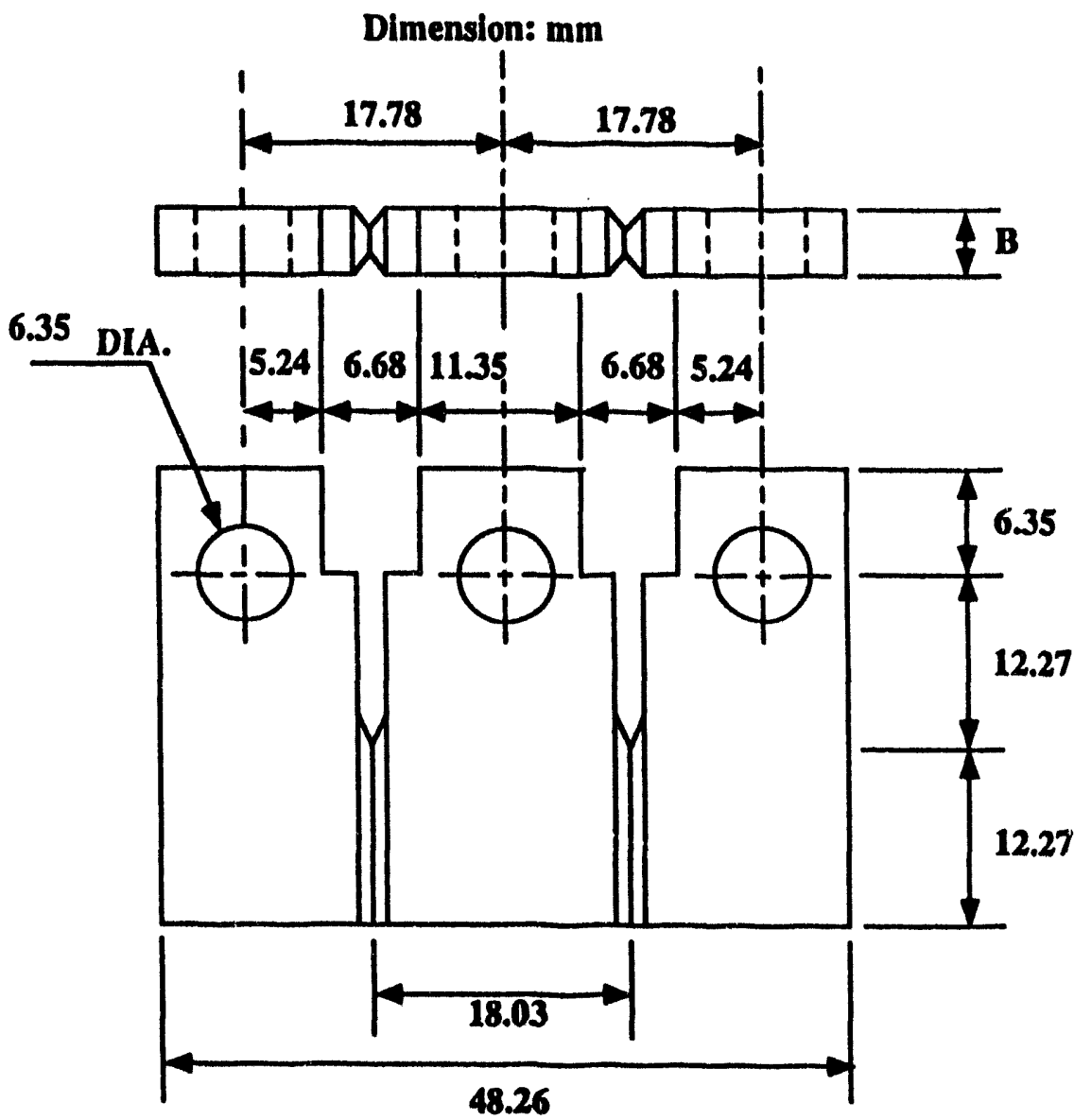

Fig. 2. The geometry of a specimen used for a mode III fracture toughness specimens.

\section{Data Analysis}

The mode $I$ integral $\mathrm{J}_{\mathrm{I}}$ and mixed mode $\mathrm{V} / \mathrm{III}$ integral $\mathrm{J}_{\mathrm{M}}$ were calculated from the area under the load vs load-line-displacement curve by means of Eq. (1) [15]: 


$$
J=\frac{2}{B_{n e t} b_{0}} \int_{0}^{\delta_{v}} P d V
$$

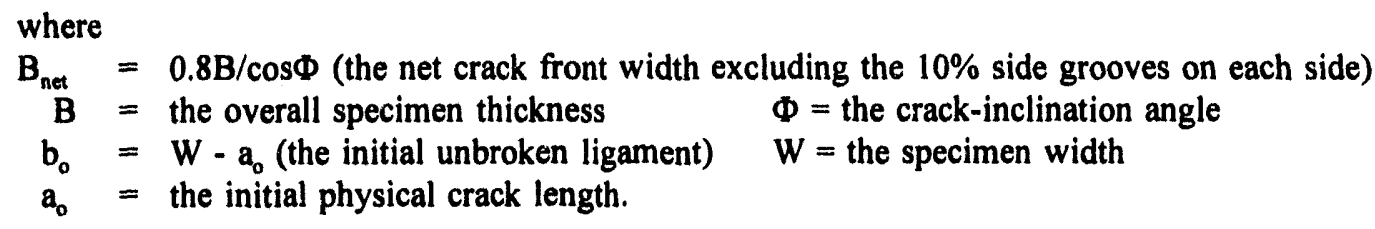

To construct J-R curves and determine critical $\mathrm{J}$ values $\left(\mathrm{J}_{\mathrm{IC}}\right.$ and $\left.\mathrm{J}_{M C}\right)$, ASTM E813-89 was used. The slope of the blunting line for mixed mode I/III was calculated using Eq. (2):

$$
m_{i / i i i}=\frac{m_{i} \cos \Phi+m_{i i i} \sin \Phi}{\sin \Phi+\cos \Phi}
$$

where $m_{i}=\left(\sigma_{y}+\sigma_{u s t}\right)$ and $m_{i i i}=\left(\sigma_{y}+\sigma_{u t s}\right) / 2$, which are blunting line slopes of pure mode $I$ and mode III, respectively. When $\Phi$ equals 0 and $90, m_{i j i i l}$ is equal to $m_{i}$ and $m_{i i j}$, respectively. A best straight line was also made using the J- $\Delta \mathrm{a}$ data between the upper and lower exclusion lines, and the slope of the straight line was taken as the unnormalized tearing moduli $\left(T_{1}\right.$ or $\left.T_{M}\right)$ for each specimen. The critical mode $\mathrm{I}$ and mode III $\mathrm{J}$ components $\left(\mathrm{J}_{\mathrm{ic}}\right.$ and $\mathrm{J}_{\mathrm{iii}}$ ) in mixed-mode specimens could also be calculated in terms of the corresponding resolved loads and displacements. The calculations of resolved mode I and mode III load and displacement and the determinations of $\mathrm{J}_{\mathrm{ic}}$ and $\mathrm{J}_{\mathrm{iic}}$ have been reported in detail in Ref. 6,7 , and 12 .

Due to the presence of two cracks in the "triple-pantleg" specimen, Eq. (1) needs to be divided by a factor of 2 . Due to the $20 \%$ side grooves on each side, $B_{\text {net }}=0.60 \mathrm{~B}$. The slope of the blunting line is $J_{\mathrm{III}} / \Delta \mathrm{a}$ $=2 \tau_{f}$, where $\tau_{f}=\left(\sigma_{y}+\sigma_{\text {uts }}\right) / 4$. The values of $J_{\text {IIIC }}$ and $T_{\text {III }}$ were determined in the same way as that used in mode I and mixed mode I/III tests.

\section{Results}

\section{The Critical J Values}

The effect of crack angle, i.e. the ratio of tension to shear stress, on $\mathrm{J}_{\mathrm{MC}}$ (the total critical $\mathrm{J}$ values) was demonstrated by Fig. 3. In the limits of $\Phi=0$ and 90 degrees, $J_{M C}$ is equal to $J_{I C}$ and $J_{\text {IIIC }}$, respectively, while for $0<\Phi<90$ degrees $J_{M C}$ represents the total critical $\mathrm{J}$ values under mixed-mode loading. A solid circle was used for $\mathrm{J}_{\mathrm{IIC}}$ in Fig. 3 because a different specimen geometry and different technique, compared to the CT and MCT specimens, were used to determine $J_{\text {IIIC }}$. The $J_{\text {IIIC }}$ reported here is not accurate because the energy stored as strain energy in a specimen after finishing testing was not deducted from the total energy used to determine the $\mathbf{J}_{\text {mIc }}$. Accordingly, as it will be discussed later, $\mathrm{J}_{\mathrm{mic}}$ was overvalued about $15 \%$. While the $J_{M C}$ data have some scatter, the trend is clear. As the crack inclination angle $\Phi$ increases, i.e. the mode III component increases, and $\mathrm{J}_{\mathrm{MC}}$ decreases to a minimum at an angle between $\mathbf{4 0}$ and 50 degrees. Curve fitting showed that the change of $J_{M C}$ with $\Phi$ could be represented by a polynomial function of order 2, as shown in Fig. 3. Calculations from the best fit curve indicated that $\mathrm{J}_{\mathrm{IC}}$ and $\mathrm{J}_{\mathrm{IIC}}$ were 511 and $490 \mathrm{~kJ} / \mathrm{m}^{2}$, respectively. The minimum $J$ value $\left(J_{\min }\right)$ was about $240 \mathrm{~kJ} / \mathrm{m}^{2}$ and occurred at a crack angle between 40 and 50 degrees. The magnitude of $\mathrm{J}_{\min }$ was only $48 \%$ of $\mathrm{J}_{\mathrm{IC}}$ and $50 \%$ of $\mathrm{J}_{\mathrm{IIC}}$, respectively. The variation of $\mathrm{J}_{\mathrm{MC}}$ with crack angle in F-82H was similar to other tough steels [5-7], 


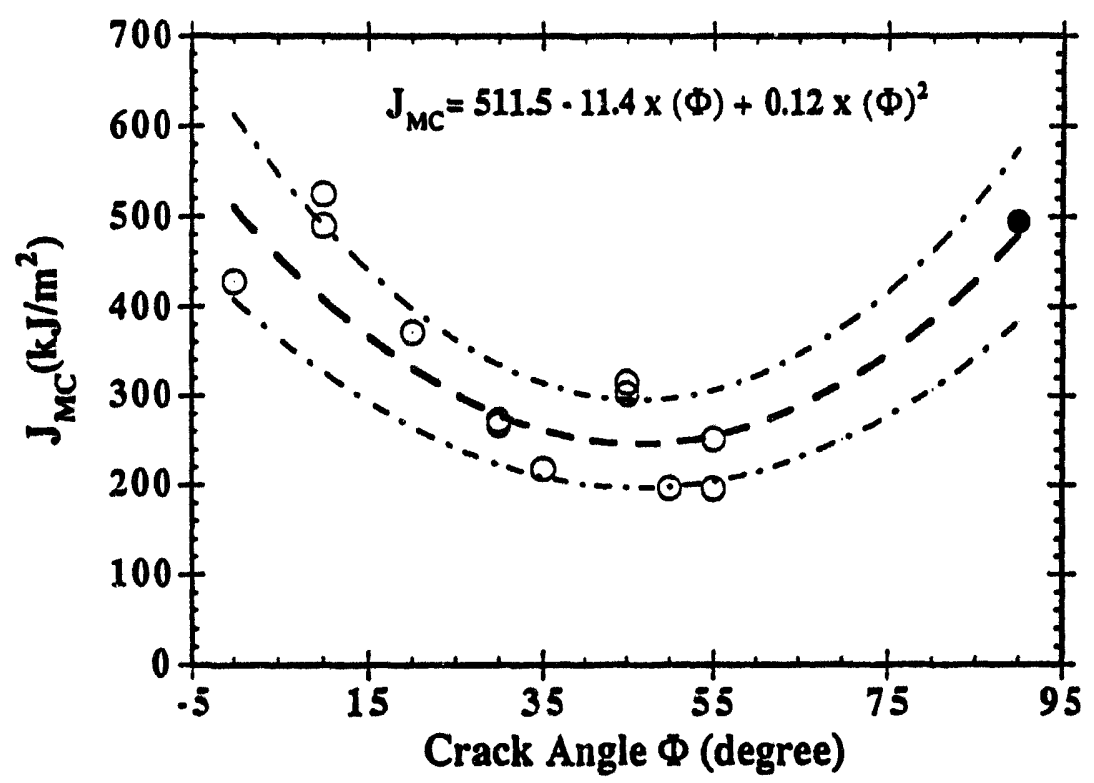

Fig. 3. The dependence of the critical total $J$ integrals of $F-82 \mathrm{H}$ on the crack inclination angles. The dash-dot lines represent a $\pm 20 \%$ error band from the best fitted line (dash line). The solid circle represents $\mathrm{J}_{\mathrm{mC}}$, which was determined with a multiple-specimen technique (five specimens). The $\mathrm{J}_{\mathrm{MC}}$ vs $\Phi$ equation was generated by a least-squares curve fit.

where adding a mode III load component to mode I loading caused a dramatic drop in the critical J values in tough steels. However, F-82H steel was more sensitive to combined stress loading, and accordingly the reduction of $\mathrm{J}_{\mathrm{MC}}$ values was more pronounced than that in the Ni-Cr-Mo-V rotor steel (HPRS) [5]. For example, $\mathrm{J}_{\mathrm{MC}}$ at $\Phi=15$ degrees was $83 \%$ of $\mathrm{J}_{\mathrm{IC}}$ for HPRS, but only $68 \%$ of $\mathrm{J}_{\mathrm{IC}}$ for $\mathrm{F}-82 \mathrm{H}$ steel. The $J_{\min }$ of HPRS was $54 \%$ of $J_{I C}$ and $85 \%$ of $J_{m c}$, respectively.

The effect of crack angle on critical $J$ values of component $I\left(\mathrm{~J}_{\mathrm{ic}}\right)$ and component III $\left(\mathrm{J}_{\text {iic }}\right)$ are shown in Fig. 4 and 5 . It can be seen that as $\Phi$ increases, i.e. increasing mode III loading, $J_{i c}$ drops dramatically until $\Phi$ reaches 35 degrees, then decreases moderately. On the other hand, $J_{\text {iitc }}$ increases linearly ith $\Phi$ increase. The same trends of $\mathrm{J}_{\mathrm{ic}}$ and $\mathrm{J}_{\mathrm{itic}}$ were also found in the case of HPRS [5]. It is worthy of noting that $J_{\text {mic }}$ in Fig. 5 is well above the best fit line. Because $J_{M C}=J_{i C}+J_{\text {iic }}$, the large drop in $J_{M C}$ between $\Phi=0$ and 35 degrees is primarily due to the dramatical decrease of $\mathrm{J}_{\mathrm{ic}}$.

The critical $\mathrm{J}$ values of $1.5 \mathrm{~mm}$ exclusion line $\left(\mathrm{J}_{\text {MExc }}\right.$ ) are plotted vs $\Phi$ in Fig. 6. One can see that $\mathrm{J}_{\text {MExc }}$ has less scatter than $J_{M C}$ (Fig. 3). However, the trend is similar. As $\Phi$ increases, $J_{M E x c}$ decreases and reaches a minimum at about 50 degrees.

\section{The Tearing Moduli $\left(T_{M}\right)$}

Combined mode V/III loading decreased not only the energy for crack initiation $\left(\mathrm{J}_{\mathrm{WCC}}\right)$, but also the resistance to stable crack growth, which can be evaluated by the mixed-mode tearing moduli $\left(T_{M}\right)$. The unnormalized tearing moduli corresponding to crack angles are shown in Fig. 7. The variation of $T_{M}$ with $\Phi$ was also found to obey a polynomial function of order 2 (see Fig. 7). Furthermore, the $T_{M}-\Phi$ data had much less scatter than those of $J_{M c}-\Phi$. From Fig. 7, it is apparent that $360 \mathrm{~kJ} / \mathrm{m}^{2}$ is needed for a mode I crack to grow $1 \mathrm{~mm}$ and $295 \mathrm{~kJ} / \mathrm{m}^{2}$ for a mode III crack, but only $110 \mathrm{~kJ} / \mathrm{m}^{2}$ for a mixed mode $\mathrm{I} / \mathrm{III}$ specimen with a crack angle of 40 degrees. 


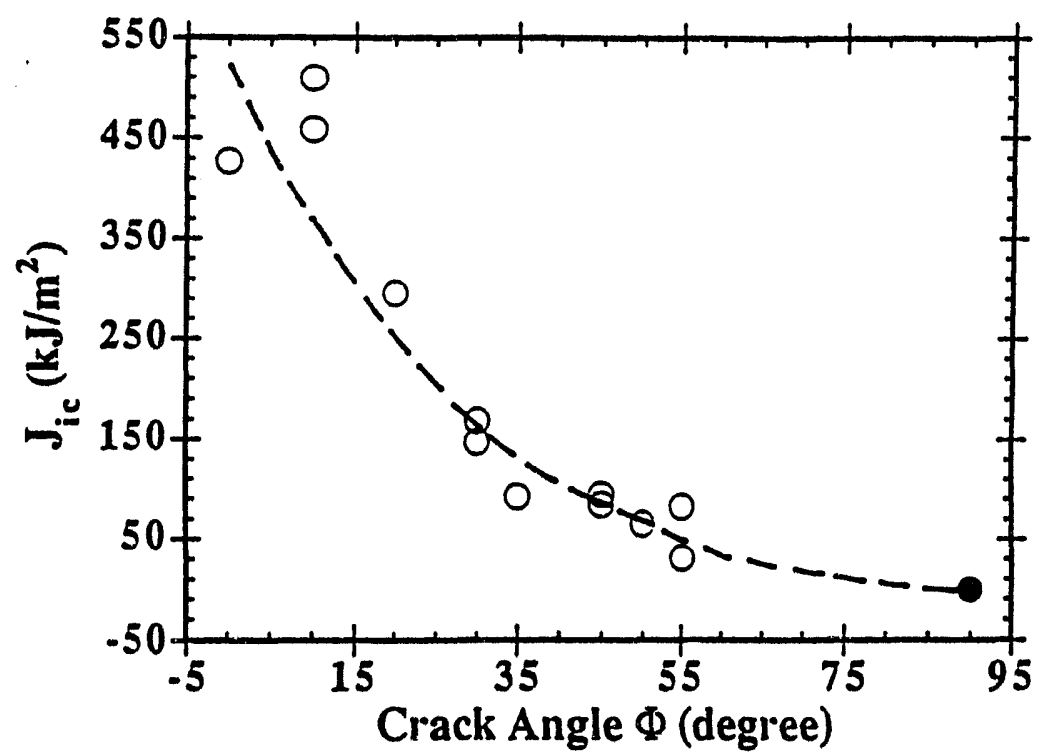

Fig. 4. A plot of $\mathrm{J}_{\mathrm{ic}}$ vs crack angle showing $\mathrm{J}_{\mathrm{ic}}$ nonlinearly decreasing with $\Phi$.

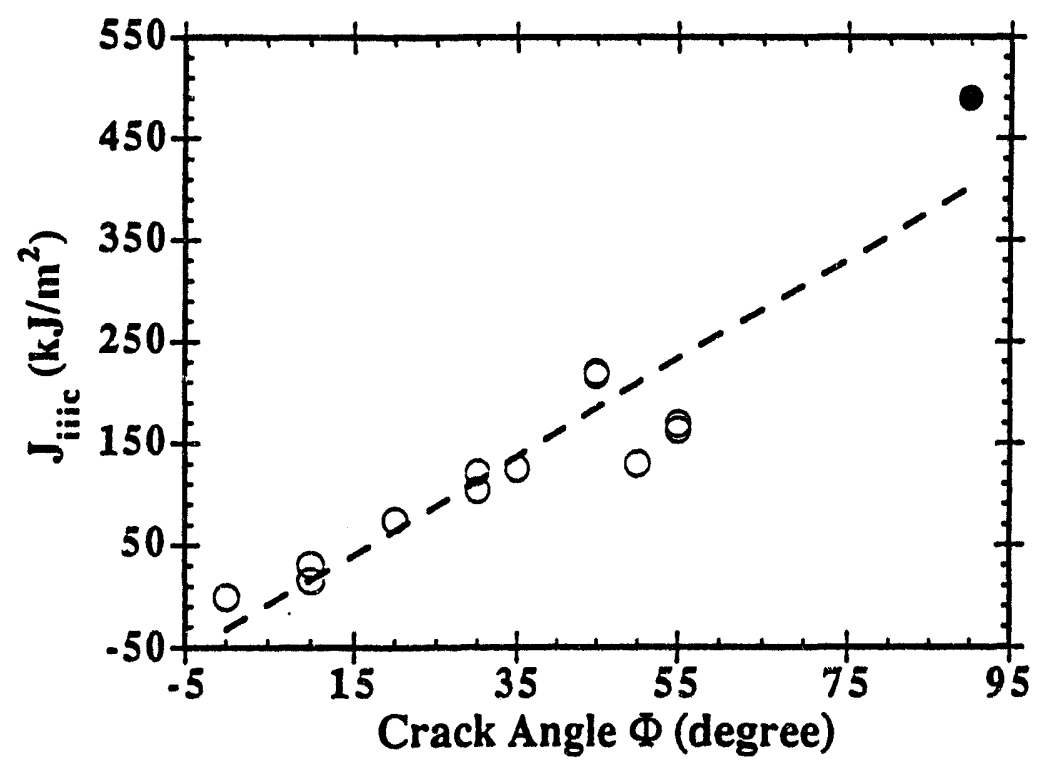

Fig. 5. A plot of $\mathrm{J}_{\text {iiic }}$ vs crack angle showing $\mathrm{J}_{\text {iiic }}$ linearly increasing with $\Phi$.

\section{Fractography}

The crack fronts of all specimens remained in their initial orientation during $J$ testing. All specimens exhibited a microvoid-coalescence type of fracture. Most voids initiated at sulfides and a few of the big voids initiated at $\mathrm{Al}_{2} \mathrm{O}_{3}$ particles, as shown in Fig. $8 \mathrm{a}$, b. The average size of sulfide particles is $0.3 \mu \mathrm{m}$, and that of $\mathrm{Al}_{2} \mathrm{O}_{3}$ particles is $3 \mu \mathrm{m}$. There is only a small amount of $\mathrm{Al}_{2} \mathrm{O}_{3}$ particles (Fig. 9 a). Sulfide particles are distributed uniformly, but two or three $\mathrm{Al}_{2} \mathrm{O}_{3}$ particles tend to group together. While adding a mode III loading component to mode I loading did not change the nature of fracture, the roughness of the fracture surfaces and the size as well as uniformity of the voids varied significantly with $\Phi$. 


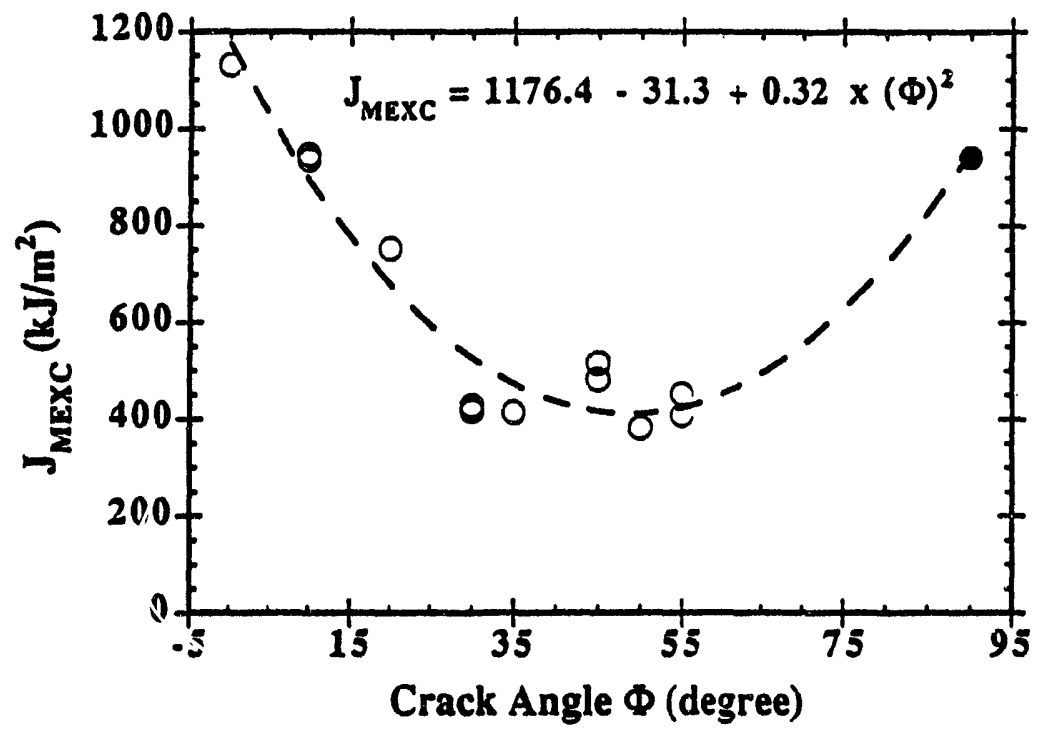

Fig. 6. The dependence of critical $\mathrm{J}$ values for the $1.5 \mathrm{~mm}$ exclusion line $\left(\mathrm{J}_{\mathrm{MExC}}\right)$ on the crack inclination angles .

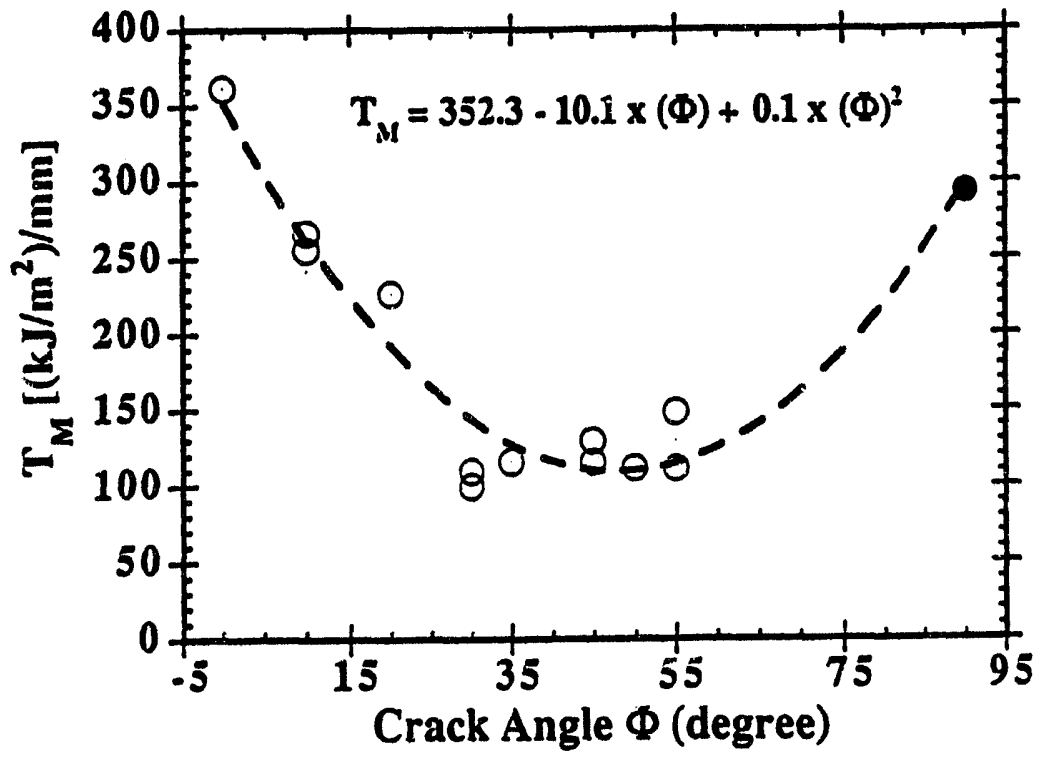

Fig. 7. The dependence of the total tearing moduli on the crack inclination angles .

Generally, as the mode III component increased, the fracture surfaces became smooth, and the size of the voids became more uniform and smaller. The most dramatic change in the fracture surfaces occurred between $\Phi=10$ and 30 degrees, where large drops in $\mathrm{J}_{M C}, \mathrm{~J}_{\mathrm{ic}}$, and $\mathrm{T}_{\mathrm{M}}$ occurred. The fracture surfaces of the specimens with $\Phi=10$ and 55 degrees are shown in Fig. 9. The fracture surface of the 10-degree specimen (Fig. 9 a) consisted of very small voids along the tearing ridges where final rupture occurred and larger voids where nucleation and substantial growth of voids occurred before the final rupture. On the other hand, the voids of the 55-degree specimen (Fig. 9 b) were small and relatively uniform. The small dimples are associated with low-energy dissipation and low $\mathrm{J}_{M C}$ and $\mathrm{T}_{\mathrm{M}}$. Shear-stress components also distorted the shape of the voids and produced voids elongated in the shear direction (see Fig. $9 \mathrm{~b}$ ). A fracture surface of a mode III specimen is shown in Fig. $10 \mathrm{a}$ and $\mathrm{b}$. It can be seen that the surface 


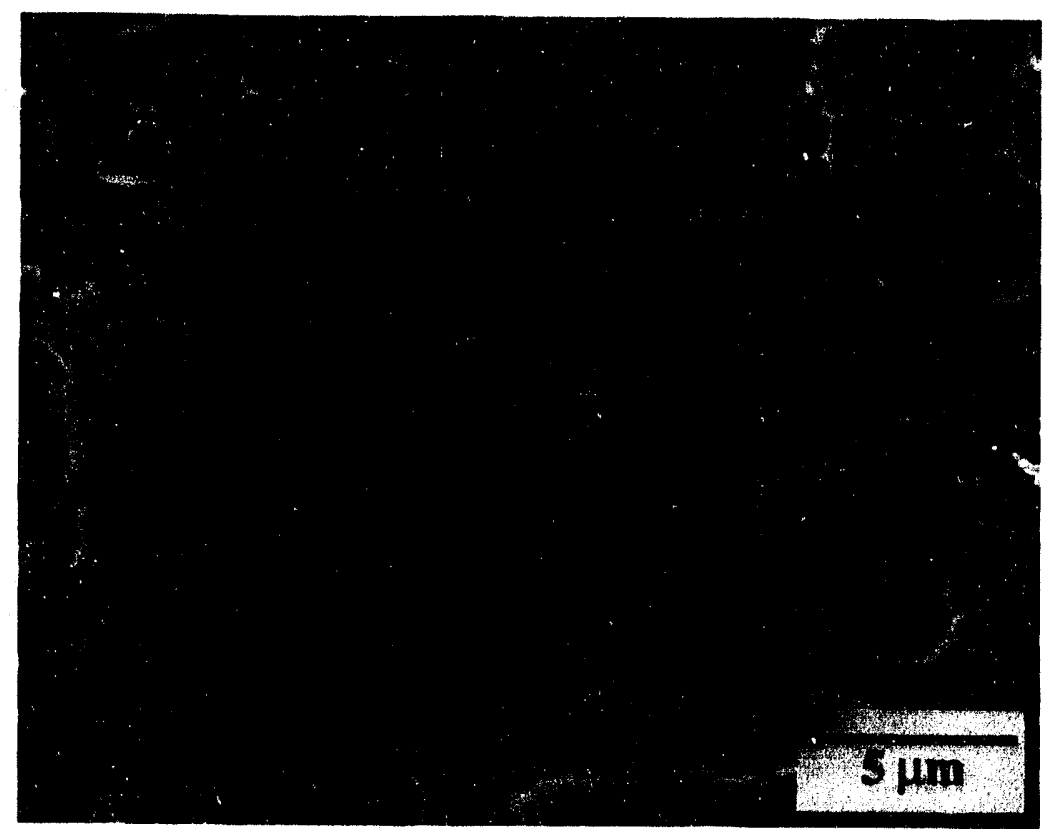

(a)

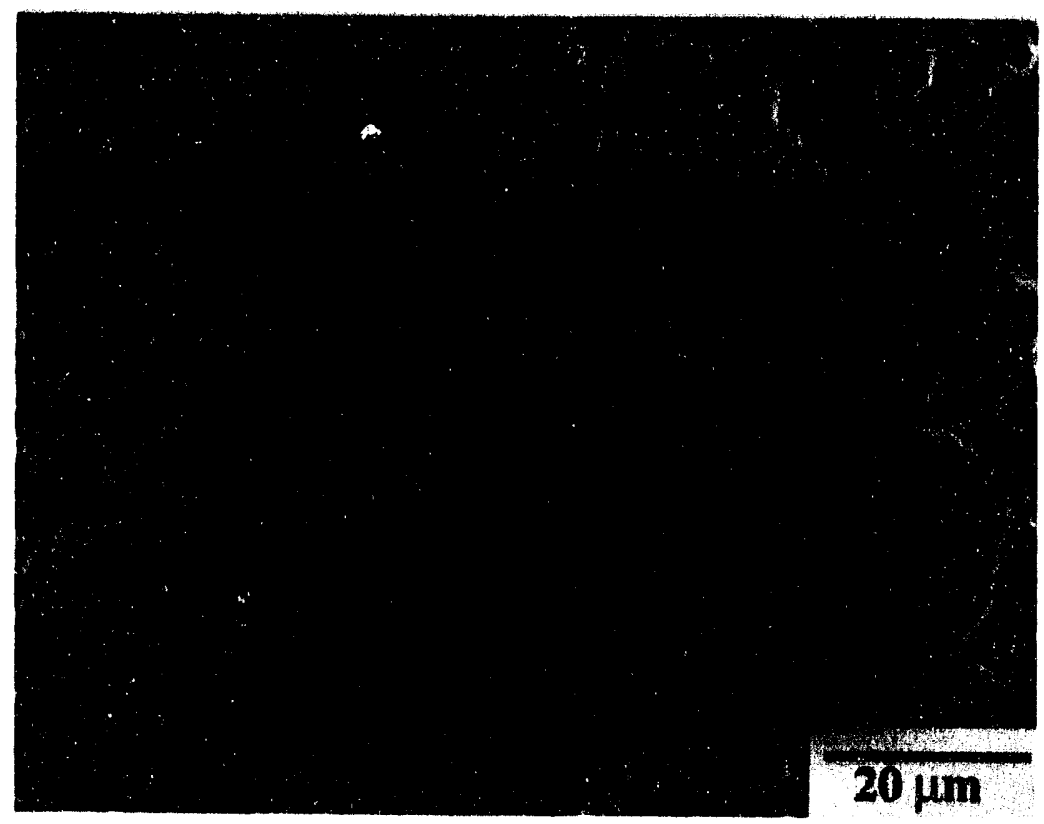

(b)

Fig. 8. SEM fractographs showing the microvoids initiated at sulfide particles (a) and aluminum-oxide particles (b). 


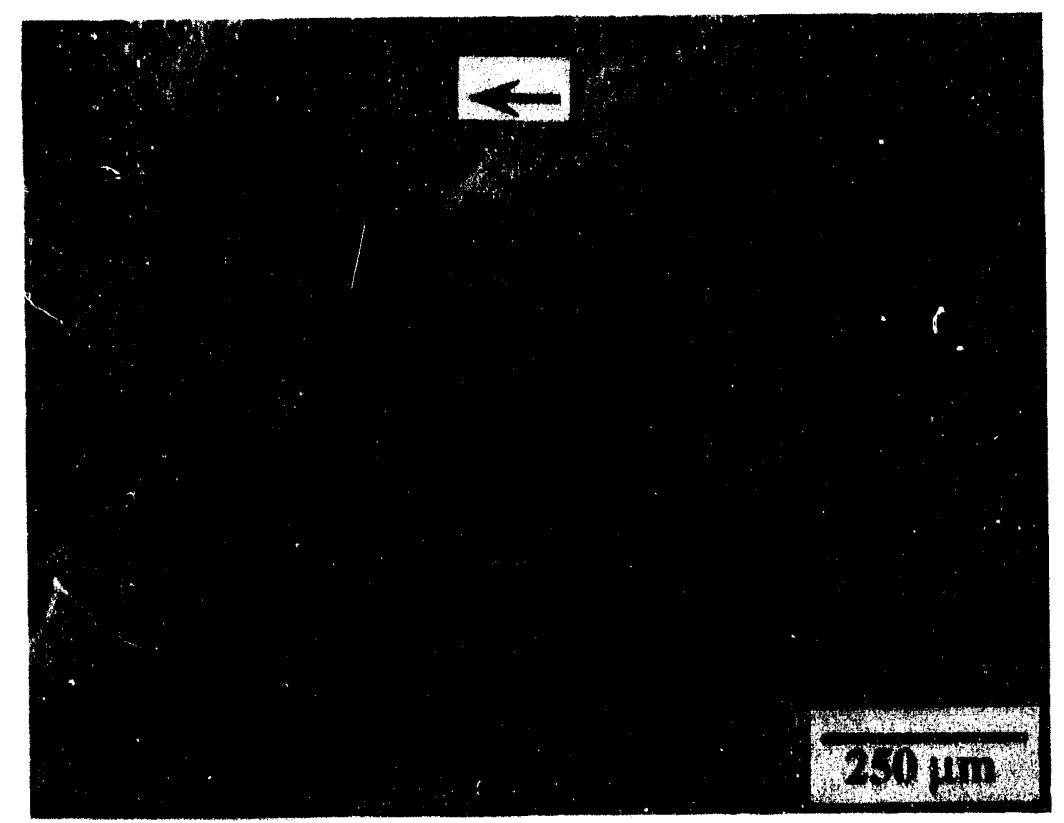

(a)

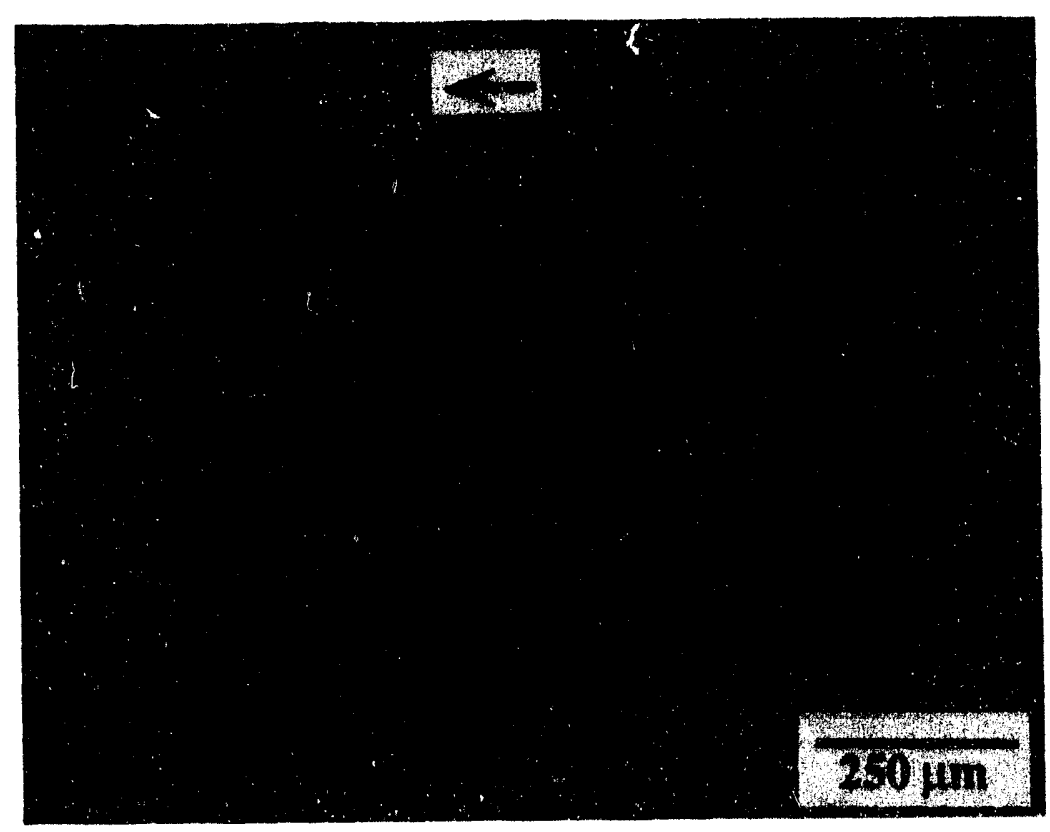

(b)

Fig. 9. SEM fractographs showing the effect of crack angles on the morphology of the fracture surfaces of $\mathrm{F}-82 \mathrm{H}$. The photos were taken at the areas immediately close to pre-existing cracks. The arrows indicate the shear directions. (a). 10 degree specimen; (b). 55 degree specimen. 


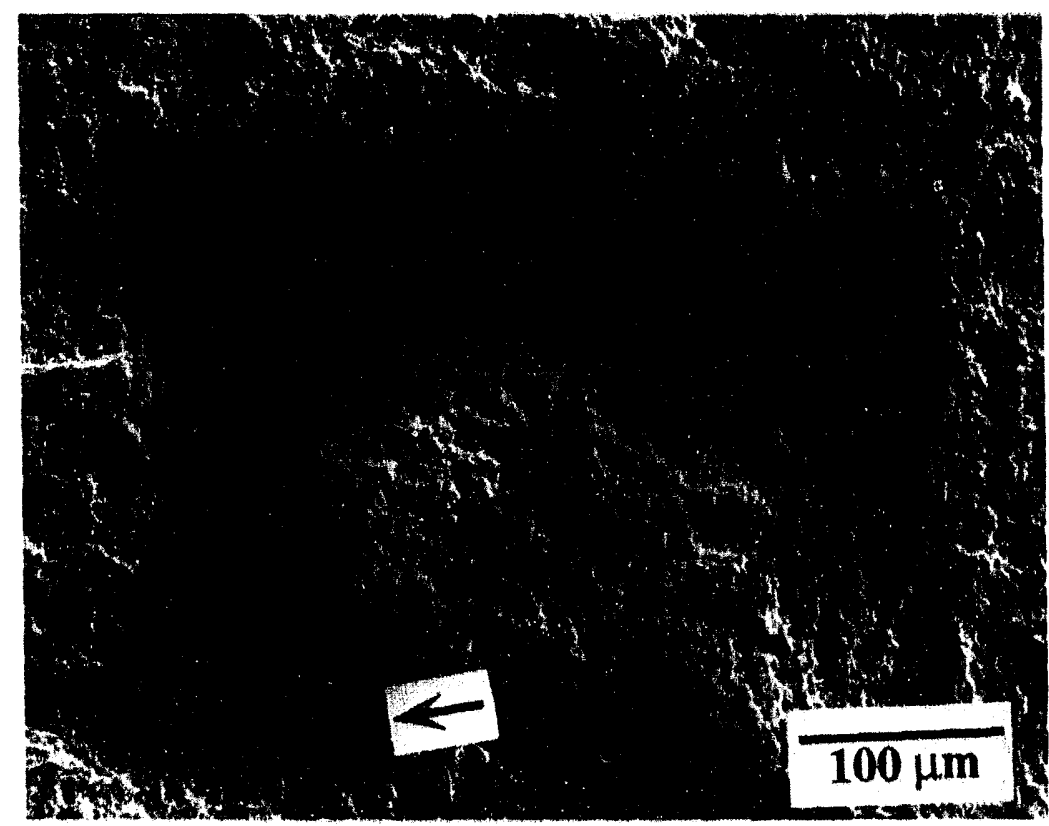

(a)

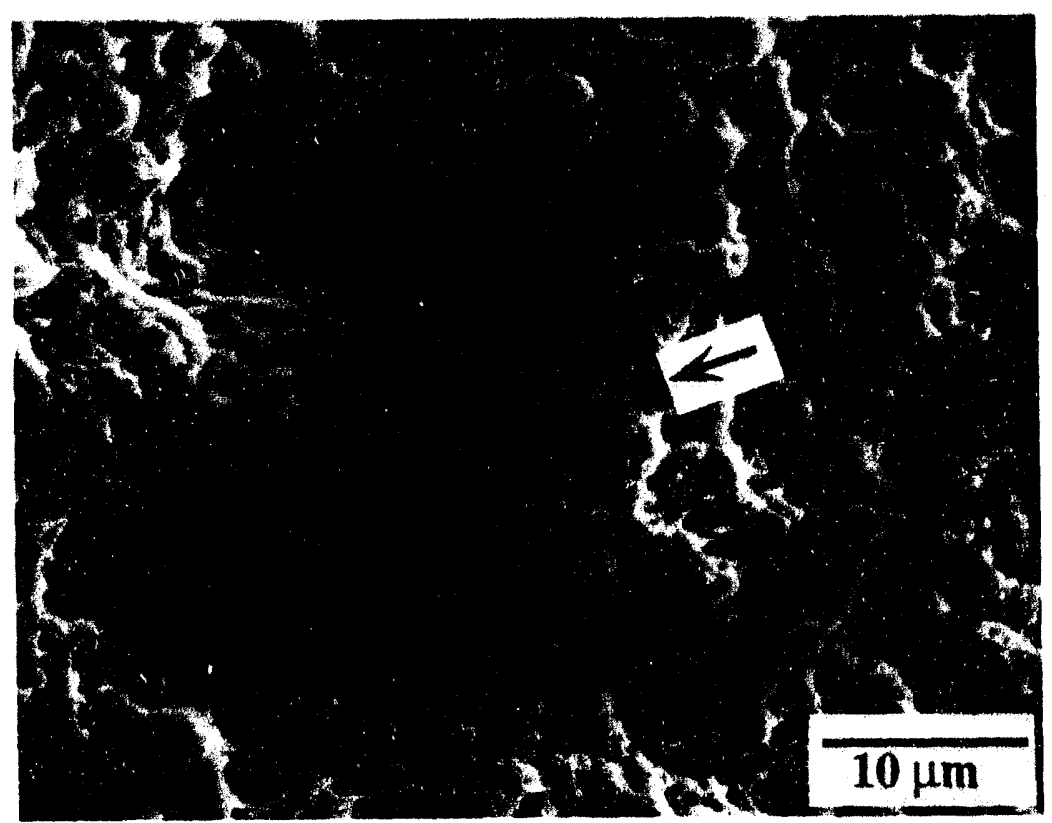

(b)

Fig. 10. SEM fractographs showing the morphology of a fracture surface of a mode III specimen, which consists of severely distorted voids and featureless facets. (a). Low magnification; the arrow indicates a featureless facet; (b). High magnification; the arrows indicate sulfide particles. 


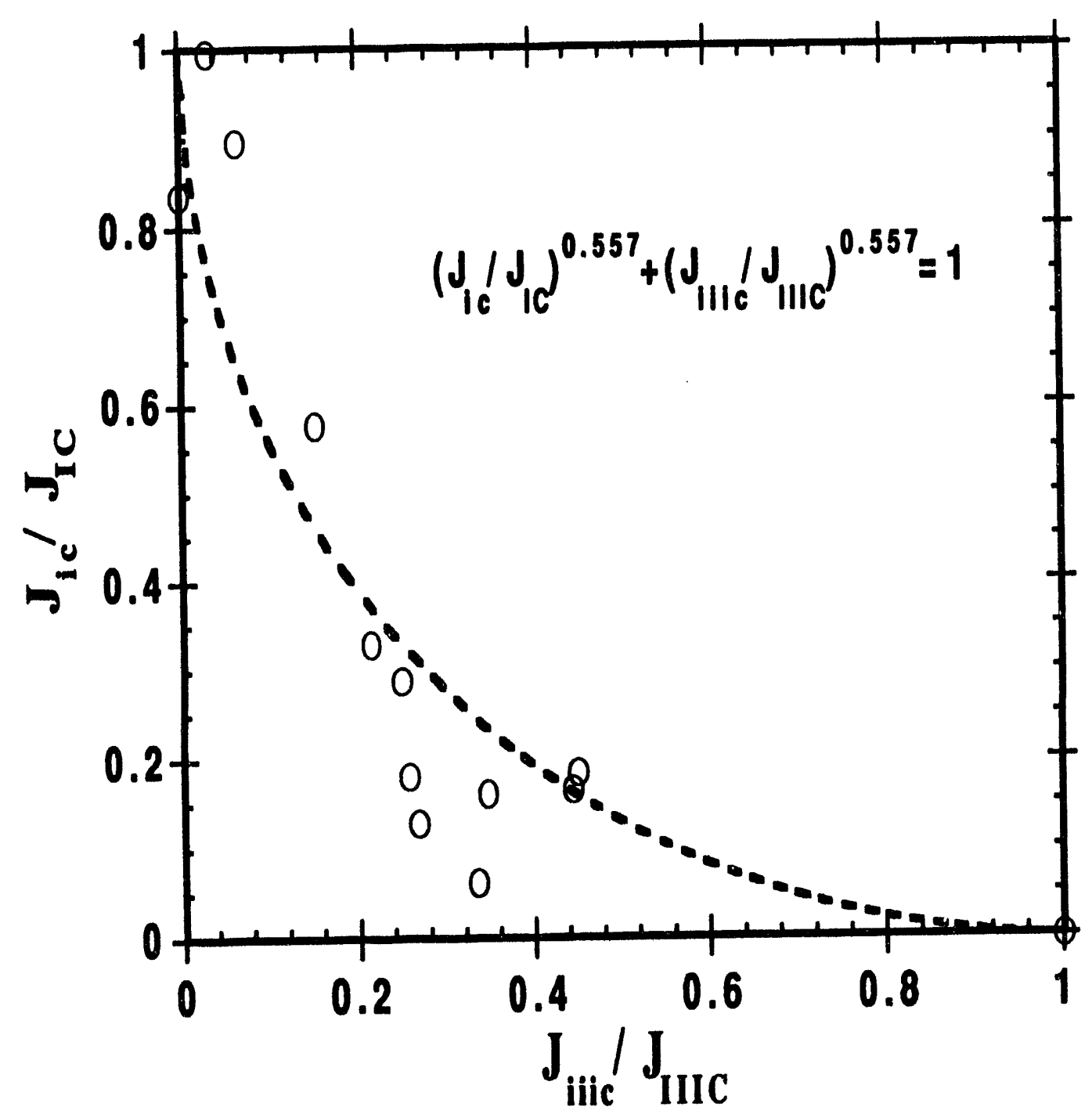

Fig. 11. The effect of the $J_{\text {iiic }}$ (mode III component) on the $J_{\mathrm{ic}}$ (mode I component), which represents the sensitivity of $\mathrm{F}-82 \mathrm{H}$ to the shear damage.

The significance of the present investigation shows once again that for tough materials, mode I loading may not be the most severe stress condition for a pre-existing crack to initiate and propagate, and it might be necessary to measure the mixed mode $\mathrm{K}$ or $\mathrm{J}$ values for a tough material and use them as design criteria. In a complex engineering component, it is expected that cracks will exist at a variety of angles relative to the principal stresses. Therefore, the results of this study indicate that $J_{\min }$ is probably the safest value to be used in design.

\section{CONCLUSION}

F-82H steel is a very tough steel. Both $J_{I C}$ and $J_{m c}$ are about $500 \mathrm{~kJ} / \mathrm{m}^{2}$, and $T_{1}$ is about $\left(360 \mathrm{~kJ} / \mathrm{m}^{2}\right) / \mathrm{mm}$. Mixed mode $\mathrm{I} / \mathrm{III}$ loading dramatically lowers both the $\mathrm{J}_{M C}$ and $\mathrm{T}_{M}$. The lowest $\mathrm{J}_{M C}$ and $T_{M}$ are about 240 $\mathrm{kJ} / \mathrm{m}^{2}$ and $\left(110 \mathrm{~kJ} / \mathrm{m}^{2}\right) / \mathrm{mm}$, respectively, and occur at a crack angle between 40 to 50 degrees, where the 
consists of microvoids and some featureless facets. The voids initiated also at sulfides/oxides particles (Fig. $10 \mathrm{~b}$ ) and were severely distorted in the shear direction by the shear stress, showing intensive plastic deformation during crack initiation and propagation. Most particles were believed to be covered by the distorted voids. Consequently, only some of them were exposed to SEM. The featureless facets are believed to be caused by the friction of two fracture surfaces during mode III testing. A more comprehensive analysis of the fracture-surface morphology and its dependency on $\Phi$ is currently underway.

\section{Discussion}

It has been found recently that adding mode III component to mode I loading could increase, decrease, or have little or no effect on the $\mathrm{J}_{\mathrm{MC}}$, depending on the toughness of the materials. For brittle materials, such as glass [16], 0.29C-0.83Cu steel [4,8-10] and $1.25 \mathrm{C}$ bainitic steels $[4,8-10]$, where fracture was controlled by tensile stress and the local crack-opening displacements, adding mode III components had little or no effect on the $\mathrm{J}_{\mathrm{iC}}$ (mode I J component of $\mathrm{J}_{\mathrm{MC}}$ ), but tended to increase $\mathrm{J}_{\mathrm{MC}}$. For tough steels, such as HPRS, which failed primarily by microvoid coalescence, additional shear stress produced incompatibility stresses at the particle interfaces in the trajectory of the crack, causing decohesion or particle fracture (shear damage). This process led to void formation that limits the mode I plastic flow field and caused premature separation of voids by mode I stress. Accordingly, tough materials exhibited lower fracture toughness for a mixed-mode crack than that for mode I crack. For those materials with intermediate toughnesses, such as AISI 1090 steel, introducing a mode III component decreased $\mathrm{J}_{\mathrm{iC}}$ moderately, and had little effect on $\mathrm{J}_{\mathrm{MC}}$.

F-82H steel is a very tough steel and very sensitive to incompatibility stresses at particles interfaces caused by the mode III component. F-82H steel shows a similar trend to HPRS, i. e. $\mathrm{J}_{\mathrm{MC}}$ decreased as mode III load component increased until reaching a minimum at a crack angle between 40 and 50 degrees. Then critical $\mathrm{J}$ value tended to increase until reaching $\mathrm{J}_{\text {IIIC }}$. The higher $\mathrm{J}_{\text {IIIC }}$ is believed due to intensive shear deformation and friction between two fracture surfaces. The $\mathrm{J}_{\mathrm{III}}$ reported here is believed higher than what it should be, because there was some strain-energy was found stored in specimen after testing. The strain-energy would lead to an overestimate of $\mathrm{J}_{\mathrm{IIC}}$. The overestimate of $\mathrm{J}_{\mathrm{IIIC}}$ is shown indirectly by Fig. 5 in which the $J_{\text {IIIC }}$ is well above the best fit line. The residual strain-energy depends upon the toughness of a material. The tougher the material, the higher the strain-energy. In the case of F-82H steel, $\mathrm{J}_{\text {IIIC }}$ is believed $15 \%$ higher than the actual value. In order to measure $\mathrm{J}_{\mathrm{IIIC}}$ accurately, a small modification to the fixture is needed. The sensitivity to shear damage was manifested in Fig. 11 by plotting normalized $\mathrm{J}_{\mathrm{iC}} / \mathrm{J}_{\mathrm{IC}}$ vs $\mathrm{J}_{\mathrm{iiic}} / \mathrm{J}_{\mathrm{IIIC}}$. One can see that adding mode III loading greatly reduced $\mathrm{J}_{\mathrm{iC}}$ values. The least-square curve fit showed that $\mathrm{J}_{\mathrm{iC}} / \mathrm{J}_{\mathrm{IC}}$ was related by an equation of $\left(\mathrm{J}_{\mathrm{iC}} / \mathrm{J}_{\mathrm{IC}}\right)^{\mathrm{m}}+\left(\mathrm{J}_{\mathrm{iiic}} / \mathrm{J}_{\mathrm{IICC}}\right)^{\mathrm{m}}=1$ with $\mathrm{m}=0.56$, as shown also in Fig. 11. The value of $m$ is an index to the sensitivity of a material to shear damage. The greater the value of $m$, the less sensitive the material is to shear damage. Accordingly, $m$ would be greater than 1 for brittle materials, such as ceramics, glasses, $0.29 \mathrm{C}-0.83 \mathrm{Cu}$ steel, and $1.25 \mathrm{C}$ bainitic steel; $\mathrm{m}$ would be approximately equal to unity for intermediate-toughness steel, such as AISI 1090 steel and less than unity for tough materials, such as HPRS and F-82H steel. Furthermore, a curve fit to the data from Ref. 5 for HPRS yielded $m=0.74$, which was greater than 0.56 for $\mathrm{F}-82 \mathrm{H}$ steel and indicated that F-82H steel was more sensitive to shear damage. However, F-82H steel had a higher toughness, and the minimum mixed-mode toughness (J integral) was still more than $200 \mathrm{~kJ} / \mathrm{m}^{2}$, higher than $\mathrm{J}_{\mathrm{IC}}$ of some tough and intermediately tough steels, such 2 S HPRS $\left(\mathrm{J}_{\mathrm{IC}}: 186 \mathrm{~kJ} / \mathrm{m}^{2}, \mathrm{~J}_{\text {min }}: 100 \mathrm{~kJ} / \mathrm{m}^{2}\right)$ [5] and AISI 1090 steel $\left(\mathrm{J}_{\mathrm{IC}}: 73 \mathrm{~kJ} / \mathrm{m}^{2}, \mathrm{~J}_{\min }: 73 \mathrm{~kJ} / \mathrm{m}^{2}\right)$ [7]. 
ratio of of mode I to mode III loading, $\sigma_{i} / \sigma_{i i i}$, is 0.84 to 1.2 . The fracture surface roughness is also reduced by the presence of mode III components. The fracture surface of a mode I specimen consisted of both large and small voids, but those for the specimens with crack angles of 30 to 55 degrees consisted of only small voids, which corresponded with low $J_{M C}$ and $T_{M}$ values. While the upper shelf toughness of $\mathrm{F}-82 \mathrm{H}$ depends on the loading mode, the $\mathrm{J}_{\min }$ remains higher than many tough materials.

\section{FUTURE WORK}

Further research is in progress to evaluate the effect of mixed-mode loading on the ductile-brittle-transition temperature, and effects of hydrogen and irradiation on $\mathrm{J}_{\min }$.

\section{ACKNOWLEDGEMENTS}

The assistance of Dr. A. Kumar at Washington State University, Pullman and Mr. J. L. Humason at Pacific Northwest Laboratory in developing the test methods is gratefully acknowledged. The material was supplied by Dr. A. Hishinuma of JAERI whose help is gratefully acknowledged. This research was supported by the Office of Fusion Energy of the U. S. Department of Energy under Contract DE-AC0676RLO 1830 with Battelle Memorial Institute.

\section{REFERENCES}

1. M. T. Miglin, I.-H. Lin, J. P. Hirth, and A. R. Rosenfield, Fracture Mechanics: 14th Symp. --Vol. II: Testing and Applications, ASTM STP 791, J. C. Lewis and G. Sines, Eds., ASTM, Philadelphia, 1983, pp. II-353-II-369.

2. M. T. Miglin, J. P. Hirth and A. R. Rosenfield, Res. Mech. 11 (1984), pp. 85-95.

3. J. G. Schroth, J. P. Hirth, R. G. Hoagland, and A. R. Rosenfield, Met. Trans. A, 18A (1987), pp. 1061-1072.

4. M. Manoharan, J. P. Hirth, and A. R. Rosenfield, J. of Test. and Eval., 18 (1990), No.2, pp. 106114.

5. S. Raghavachary, A. R. Rosenfield, and J. P. Hirth, Met. Trars. A, 21A (1990), pp. 2539-45.

6. J. A. Gordon, J. P. Hirth, A. M. Kumar, and N. R. Moody, Jr., Met. Trans. A, 23A (1991), pp. 1013-1020.

7. M. Manoharan, S. Raghavachary, J. P. Hirth, and A. R. Rosenfield, J. Eng. Mater. Technol. 111 (1989), October, pp. 440-442.

8. A. M. Kumar and J. P. Hirth, Scripta Metall, Mater., 25 (1991), pp. 985-90.

9. M. Manoharan, Scripta Metall. Mater., 26 (1992), pp. 1187-1192.

10. M. Manoharan, J. P. Hirth and A. R. Rosenfield, Scripta Metall. Mater., 23 (1989), pp. 763-766 and pp. 1647-1648. 
11. Yoshiro Kuriki, Akihide Yoshitake, and Manabu Tamura, "Fracture Toughness Test Results of Low Activation Ferritic Steel for First Wall Material (F-82H)", NKK Steel Research Center, Japan, April, 1989.

12. H. Li, R. H. Jones, P. J. Hirth and D. S. Gelles, Fusion Reactor Materials Semiannual Progress Report DOE/ER-0313/7, Oak Ridge National Lab., Oak Ridge, TN (March, 1993).

13. Ashok Saxena and S. J. Hudak, Jr, Int. J. Fract., 14 (1978), pp. 453-468.

14. T. Foecke, P. G. Marsh, N. R. Moody, and W. W. Gerberich, Scripta Metall. Mater., 28 (1993), pp. 77-80.

15. J. R. Rice, P. C. Paris, and.J. G. Merkle, ASTM STP 536, ASTM, Philadelphia, 1973, pp. 231235.

16. A. R. Rosenfield and W. H. Duckworth, Int. J. Fract., 32, (1987), p. R59. 
IMPACT TOUGHNESS OF IRRADIATED REDUCED-ACTIVATION FERRITIC STEELS -. R. L. Klueh and D. J. Alexander (Oak Ridge National Laboratory)

\section{OBJECTIVE}

The goal of this study is the development of a reduced-activation ferritic steel.

\section{SUMMARY}

Eight chromium-tungsten steels ranging from 2.25 to $12 \mathrm{wt} \% \mathrm{Cr}$ were irradiated at $365^{\circ} \mathrm{C}$ to 13 14 dpa in the Fast Flux Test Facility. Post irradiation Charpy impact tests showed a loss of toughness for all steels, as measured by an increase in the ductile-brittle transition temperature (DBTT) and a decrease in the upper-shelf energy. The most irradiation-resistant steels were two $9 \% \mathrm{Cr}$ steels: the DBTT of a $9 \mathrm{Cr}$ $2 \mathrm{~W}-0.25 \mathrm{~V}-0.1 \mathrm{C}$ steel increased $29^{\circ} \mathrm{C}$, and for the same composition with an addition of $0.07 \% \mathrm{Ta}$ the DBTT increased only $15^{\circ} \mathrm{C}$. This is the smallest shift ever observed for such a steel irradiated to these levels. The other steels developed shifts in DBTT of 100 to $300^{\circ} \mathrm{C}$. A $2.25 \% \mathrm{Cr}$ steel with $2 \% \mathrm{~W}, 0.25 \%$ $\mathrm{V}$, and $0.1 \% \mathrm{C}$ was less severely affected by irradiation than $2.25 \% \mathrm{Cr}$ steels with $0.25 \% \mathrm{~V}$ and no tungsten, $2 \% \mathrm{~W}$ and no vanadium, and with $1 \% \mathrm{~W}$ and $0.25 \% \mathrm{~V}$. Irradiation resistance appears to be associated with microstructure, and microstructural manipulation may lead to improved properties.

\section{PROGRESS AND STATUS}

\section{Introduction}

Reduced-activation or fast induced-radioactivity decay (FIRD) ferritic steels are being developed for fusion power plant applications ${ }^{1}$. Reduced-activation steels can be more readily disposed of or recycled after the reactor service lifetime than conventional alloys ${ }^{2}$. A FIRD alloy cannot contain molybdenum and niobium ${ }^{2}$, important constituents in conventional $\mathrm{Cr}$-Mo steels (i.e., $21 / 4 \mathrm{Cr}-1 \mathrm{Mo}, 9 \mathrm{Cr}-1 \mathrm{MoVNb}$, and $12 \mathrm{Cr}-1 \mathrm{MoVW}$ ) of interest for fusion. The experimental FIRD steels discussed in this paper were developed based on compositions of conventional $\mathrm{Cr}$-Mo steels with molybdenum replaced by tungsten and niobium replaced by tantalum ${ }^{1}$. Compositions are given in Table 1, along with the designation for each alloy*.

Information on microstructure ${ }^{3}$, tempering and tensile behavior ${ }^{4}$, and Charpy impact behavior ${ }^{5}$ of the FIRD steels in the unirradiated condition has been reported. Results were also published on the tensile ${ }^{6}$ and Charpy properties ${ }^{7}$ after irradiation to $\approx 7 \mathrm{dpa}$ at $365^{\circ} \mathrm{C}$ in the Fast Flux Test Facility (FFTF).

In this paper, the effect on Charpy-impact toughness of the FIRD steels irradiated to 13-14 dpa at $365^{\circ} \mathrm{C}$ in the FFTF is presented. Impact behavior is extremely useful, because neutron irradiation causes an increase in the ductile-brittle transition temperature (DBTT) and a decrease in upper-shelf energy (USE) of ferritic steels; those effects generally (but not always) reflect a degradation in fracture toughness. Developing steels with minimal changes in these parameters is crucial if ferritic stcels are to be useful structural materials for fusion.

*As a generic designation, the new class of steels are referred to as $\mathrm{Cr}$-W steels. (The only exception is the $21 / 4 \mathrm{CrV}$ steel, which contains no tungsten.) This designation follows the procedure used for the $\mathrm{Cr}$-Mo steels, after which these steels are patterned, even though both types of steel may contain other alloying elements. 
Table 1. Nominal Compositions for Reduced-Activation Steels

\begin{tabular}{|c|c|c|c|c|c|}
\hline Alloy & \multicolumn{4}{|c|}{ Nominal Chemical Composition ${ }^{\mathrm{a}}$} & $\underset{C}{W L} \%$ \\
\hline $2.25 \mathrm{CrV}$ & 2.25 & & 0.25 & & 0.1 \\
\hline $2.25 \mathrm{Cr}-1 \mathrm{WV}$ & 2.25 & 1 & 0.25 & & 0.1 \\
\hline $2.25 \mathrm{Cr}-2 \mathrm{~W}$ & 2.25 & 2 & & & 0.1 \\
\hline $2.25 \mathrm{Cr}-2 \mathrm{WV}$ & 2.25 & 2 & 0.25 & & 0.1 \\
\hline $5 \mathrm{Cr}-2 \mathrm{WV}$ & 5 & 2 & 0.25 & & 0.1 \\
\hline $9 \mathrm{Cr}-2 \mathrm{WV}$ & 9 & 2 & 0.25 & & 0.1 \\
\hline $9 \mathrm{Cr}-2 \mathrm{WVTa}$ & 9 & 2 & 0.25 & 0.12 & 0.1 \\
\hline $12 \mathrm{Cr}-2 \mathrm{WV}$ & 12 & 2 & 0.25 & & 0.1 \\
\hline
\end{tabular}

a Balance iron

\section{Experimental Procedure}

Eight electroslag-remelted heats of FIRD steel with the nominal compositions given in Table 1 were prepared by Combustion Engineering, Inc. These steels were used in previous studies, and melt compositions have been published ${ }^{3-7}$. In addition to nominal compositions of $\mathrm{Cr}, \mathrm{V}, \mathrm{W}, \mathrm{C}$, and $\mathrm{Ta}$, concentrations of elements normally found in steels, such as $\mathrm{Mn}, \mathrm{P}, \mathrm{Si}$, etc., were adjusted to levels typical of commercial practice ${ }^{3}$.

Steels were normalized and tempered as $15.9-\mathrm{mm}$-thick plate. The $21 / 4 \mathrm{Cr}-2 \mathrm{~W}$ steel was austenitized $1 \mathrm{~h}$ at $900^{\circ} \mathrm{C}$ and air cooled. The other seven heats were austenitized $1 \mathrm{~h}$ at $1050^{\circ} \mathrm{C}$ and air cooled; the higher normalizing temperature assured that any vanadium carbide present dissolved during austenitization. The $21 / 4 \mathrm{CrV}, 21 / 4 \mathrm{Cr}-1 \mathrm{WV}$, and $21 / 4 \mathrm{Cr}-2 \mathrm{~W}$ steels were tempered $1 \mathrm{~h}$ at $700^{\circ} \mathrm{C}$; the other five heats were tempered $1 \mathrm{~h}$ at $750^{\circ} \mathrm{C}$.

Six Charpy specimens from each heat were irradiated in the Materials Open Test Assembly (MOTA) of FFTF in the below-core specimen canister, a sodium "weeper" operating at $\approx 365^{\circ} \mathrm{C}$. The $21 / 4 \mathrm{Cr}$ steels, the $9 \mathrm{Cr}-2 \mathrm{WVTa}$, and the $12 \mathrm{Cr}-2 \mathrm{WV}$ were irradiated to $3.4-3.5 \times 10^{26} \mathrm{n} / \mathrm{m}^{2}(>0.1 \mathrm{MeV})$, which produced $\approx 13 \mathrm{dpa}$. The $5 \mathrm{Cr}-2 \mathrm{WV}$ and $9 \mathrm{Cr}-2 \mathrm{WV}$ steels were irradiated to $3.6 \times 10^{26} \mathrm{n} / \mathrm{m}^{2}, \approx 14 \mathrm{dpa}$. Less than $1 \mathrm{appm}$ He formed in the specimens.

One-third-size Charpy specimens measuring $3.3 \times 3.3 \times 25.4 \mathrm{~mm}$ with a 0.51 -mm-deep $30^{\circ} \mathrm{V}$ notch and a $0.05-$ to $0.08-\mathrm{mm}$-root radius were irradiated and tested. Specimens were machined along the rolling direction with the notch transverse to the rolling direction (L-T orientation). Details on the test procedure for the subsize Charpy specimens have been published 8 . 
Table 2.Impact Properties of Cr-W Steels Irradiated in FFTF at $365^{\circ} \mathrm{C}$

\begin{tabular}{|c|c|c|c|c|c|c|}
\hline $\begin{array}{c}\text { Alloy } \\
\text { Designation }\end{array}$ & $\begin{array}{l}\text { Specimen } \\
\text { Condition } \\
\text { (dpa) }\end{array}$ & $\begin{array}{l}\text { DBTT }^{b} \\
(\cdot C)\end{array}$ & $\begin{array}{c}\triangle \mathrm{DBTT} \\
\left({ }^{\circ} \mathrm{C}\right)\end{array}$ & $\begin{array}{l}\text { Upper-Shelf } \\
\text { Energy }(J)\end{array}$ & $\begin{array}{c}\Delta \mathrm{USE} \\
(\%)\end{array}$ & $\begin{array}{c}\Delta \sigma_{y} \\
(\mathrm{MPa})^{\mathrm{c}}\end{array}$ \\
\hline $21 / 4 \mathrm{CrV}$ & $\begin{array}{l}\text { N\&T } \\
\text { I (7) } \\
\text { I (13) }\end{array}$ & $\begin{array}{c}14 \\
250 \\
317\end{array}$ & $\begin{array}{l}236 \\
303\end{array}$ & $\begin{array}{r}10.0 \\
4.2 \\
2.1\end{array}$ & $\begin{array}{l}-58 \\
-79\end{array}$ & $\begin{array}{l}301 \\
270\end{array}$ \\
\hline $\begin{array}{l}21 / 4 \mathrm{Cr}- \\
1 \mathrm{WV}\end{array}$ & $\begin{array}{l}\text { N\&T } \\
\text { I (7) } \\
\text { I (13) }\end{array}$ & $\begin{array}{l}-28 \\
192 \\
243\end{array}$ & $\begin{array}{l}220 \\
271\end{array}$ & $\begin{array}{r}11.8 \\
5.6 \\
2.8\end{array}$ & $\begin{array}{l}-53 \\
-76\end{array}$ & $\begin{array}{l}282 \\
337\end{array}$ \\
\hline $21 / 4 C r-2 W$ & $\begin{array}{l}\text { N\&T } \\
\text { I (7) } \\
\text { I (13) }\end{array}$ & $\begin{array}{l}-19 \\
140 \\
231\end{array}$ & $\begin{array}{l}150 \\
250\end{array}$ & $\begin{array}{l}9.2 \\
4.6 \\
3.9\end{array}$ & $\begin{array}{l}-50 \\
-58\end{array}$ & $\begin{array}{l}262 \\
295\end{array}$ \\
\hline $\begin{array}{l}21 / 4 \mathrm{Cr}^{-} \\
2 \mathrm{WV}\end{array}$ & $\begin{array}{l}\text { N\&T } \\
I(7) \\
I(13)\end{array}$ & $\begin{array}{c}4 \\
111 \\
145\end{array}$ & $\begin{array}{l}115 \\
141\end{array}$ & $\begin{array}{l}9.1 \\
5.2 \\
4.2\end{array}$ & $\begin{array}{l}-43 \\
-54\end{array}$ & $\begin{array}{l}261 \\
298\end{array}$ \\
\hline sCr-2WV & $\begin{array}{l}\text { N\&T } \\
\text { I (7) } \\
\text { I (14) }\end{array}$ & $\begin{array}{l}-70 \\
33 \\
46\end{array}$ & $\begin{array}{l}103 \\
116\end{array}$ & $\begin{array}{l}9.2 \\
6.5 \\
6.0\end{array}$ & $\begin{array}{l}-29 \\
-35\end{array}$ & $\begin{array}{l}192 \\
190\end{array}$ \\
\hline 9Cr-2WV & $\begin{array}{l}\text { N\&T } \\
\text { I (7) } \\
\text { I (14) }\end{array}$ & $\begin{array}{c}-60 \\
8 \\
-31\end{array}$ & $\begin{array}{l}68 \\
29\end{array}$ & $\begin{array}{l}8.4 \\
6.4 \\
6.3\end{array}$ & $\begin{array}{l}-24 \\
-25\end{array}$ & $\begin{array}{l}161 \\
141\end{array}$ \\
\hline 9Cr-2WVTa & $\begin{array}{l}\text { N\&T } \\
\text { I (7) } \\
I(13)\end{array}$ & $\begin{array}{l}-88 \\
-84 \\
-73\end{array}$ & $\begin{array}{c}4 \\
15\end{array}$ & $\begin{array}{r}11.2 \\
8.6 \\
8.5\end{array}$ & $\begin{array}{l}-23 \\
-24\end{array}$ & $\begin{array}{l}125 \\
147\end{array}$ \\
\hline $12 \mathrm{Cr}-2 \mathrm{WV}$ & $\begin{array}{l}\text { N\&T } \\
\text { I (7) } \\
\text { I (13) }\end{array}$ & $\begin{array}{l}-18 \\
156 \\
126\end{array}$ & $\begin{array}{l}174 \\
134\end{array}$ & $\begin{array}{l}8.3 \\
5.9 \\
4.8\end{array}$ & $\begin{array}{l}-29 \\
-42\end{array}$ & $\begin{array}{l}335 \\
339\end{array}$ \\
\hline
\end{tabular}

a N\&T -- Normalized and tempered; I -- Irradiated; dpa in parentheses.

b Evaluated at an energy level halfway between the upper and lower shelves.

c Increase in yield stress caused by irradiation to $\approx 7$ and 14 dpa were calculated from data in reference 6 and unpublished data, respectively.

\section{Results}

Table 2 gives the DBTT and USE for each FIRD steel in the unirradiated condition and after irradiation in FFTF at $365^{\circ} \mathrm{C}$ to $13-14$ dpa. The shift (increase) in DBTT ( $\triangle D B T T$ ) and the percent change (decrease) in USE ( $\triangle U S E$ ) caused by irradiation are also given. The DBTT was determined at an energy 
level midway between the upper-and lower-shelf energies. For comparison, results after $\approx 7 \mathrm{dpa}$ at $365^{\circ} \mathrm{C}$ are also given?.

All four $21 / 4 \mathrm{Cr}$ steels had a large $\triangle \mathrm{DBTT}$ and $\triangle \mathrm{USE}$ after $7 \mathrm{dpa}^{7}$, with a larger increase in $\triangle \mathrm{DBTT}$ and decrease in $\triangle \mathrm{USE}$ after $13 \mathrm{dpa}$ than after $7 \mathrm{dpa}$ (Table 2). The magnitude of the changes decreased in going from $21 / 4 \mathrm{CrV}$ to $21 / 4 \mathrm{Cr}$ - $1 \mathrm{WV}$ to $21 / 4 \mathrm{Cr}-2 \mathrm{~W}$ to $21 / 4 \mathrm{Cr}-2 \mathrm{WV}$. Of the $21 / 4 \mathrm{Cr}$ steels, $21 / 4 \mathrm{Cr}-2 \mathrm{WV}$ had the smallest $\triangle \mathrm{DBTT}$ and $\triangle \mathrm{USE}$ after 7 and $13 \mathrm{dpa}$ and had the smallest increase in $\triangle \mathrm{DBTT}$ in going from 7 to $13 \mathrm{dpa}$.

The 5-12Cr steels showed a much smaller difference in $\triangle \mathrm{DBTT}$ and $\triangle \mathrm{USE}$ between 7 and 13-14 dpa (Table 2). The $9 \mathrm{Cr}-2 \mathrm{WV}$ and the $12 \mathrm{Cr}-2 \mathrm{WV}$ steels actually had a smaller $\triangle \mathrm{DBTT}$ after the higher fluence. In both cases, however, the difference was relatively small, and it was concluded that the $\triangle D B T T$ for the $5-9 \mathrm{Cr}$ steels saturated with fluence by $\approx 7 \mathrm{dpa}$. Except for the $12 \mathrm{Cr}-2 \mathrm{WV}$, the USE of these steels also showed no large change beyond the $7 \mathrm{dpa}$ irradiation. The most significant observation is the small $\triangle \mathrm{DBTT}$ and small $\triangle \mathrm{USE}$ for the $9 \mathrm{Cr}-2 \mathrm{WV}$ and $9 \mathrm{Cr}-2 \mathrm{WVTa}$ steels.

\section{Discussion}

The observations confirmed the previous results that showed the $9 \mathrm{Cr}-2 \mathrm{WVTa}$ steel to have the smallest $\triangle \mathrm{DBTT}$ ever observed for this type of steel for such irradiation conditions ${ }^{7}$. The present work also showed the $9 \mathrm{Cr}-2 \mathrm{WV}$ to have excellent properties.

Microstructures of the normalized-and-tempered $15.9 \cdot \mathrm{mm}$ steels have been published ${ }^{3}$. The $21 / 4 \mathrm{Cr}$ steels contained tempered bainite and polygonal or proeutectoid ferrite: $21 / 4 \mathrm{CrV}$ contained $\approx 30 \%$ bainite, $70 \%$ ferrite; $\quad 21 / 4 \mathrm{Cr}-1 \mathrm{WV}$ contained $\approx 55 \%$ bainite, $45 \%$ ferrite; $21 / 4 \mathrm{Cr}-2 \mathrm{~W}$ steel was $100 \%$ bainite; and $21 / 4 \mathrm{Cr}-2 \mathrm{WV}$ steel was $\approx 80 \%$ bainite, $20 \%$ ferrite. The $5 \mathrm{Cr}-2 \mathrm{WV}, 9 \mathrm{Cr}-2 \mathrm{WV}$, and $9 \mathrm{Cr}$ $2 \mathrm{WVTa}$ steels were $100 \%$ tempered martensite, and the $12 \mathrm{Cr}-2 \mathrm{WV}$ steel was martensite with $\approx 25 \%$ deltaferrite ${ }^{3}$

In the previous work ${ }^{7}$, the $7 \mathrm{dpa}$ data for $\triangle \mathrm{DBTT}$ and $\triangle \mathrm{USE}$ were plotted against the change in yield stress, $\Delta \sigma_{\mathrm{y}}$. Tensile data were obtained on specimens from $0.76-\mathrm{mm}$-thick sheet that were irradiated in MOTA to $\approx 7 \mathrm{dpa}$ at $365^{\circ} \mathrm{C}$ and then tensile tested at $365^{\circ} \mathrm{C}^{6}$. Note that in this case the $0.76-\mathrm{mm}$-thick tensile specimens were heat treated, and because of the thinner sections, all $21 / 4 \mathrm{Cr}$ steels were $100 \%$. bainite.

Odette et al. ${ }^{9}$ found a direct proportionality between $\Delta \mathrm{DBTT}$ and $\Delta \sigma_{\mathrm{y}}$ for pressure-vessel steels irradiated in light-water reactors. The data for the eight steels irradiated to $\approx 7 \mathrm{dpa}$ were fit with a straight line through the origin, and although there was considerable sratter, it appeared that such a relationship between $\triangle \mathrm{DBTT}$ and hardening might apply ${ }^{7}$. However, it was concluded that the $9 \mathrm{Cr}$-2WVTa steel deviated excessively from the line; it had a very small $\triangle \mathrm{DBTT}\left(4^{\circ} \mathrm{C}\right)$ for a large $\Delta \sigma_{\mathrm{y}}(125 \mathrm{MPa})$, based on the observations for the other steels. This was taken to mean that some mechanism other than hardening dominated the shift in DBTT for this steel?

Figure 1 shows the $\Delta D B T T-\Delta \sigma_{y}$ data for the combined 7 and 13-14 dpa tests (yield stress changes after 7 and $14 \mathrm{dpa}$ are listed in Table 2). Also included in the figure are data for $9 \mathrm{Cr}-1 \mathrm{MoVNb}$ and $12 \mathrm{Cr}$ $1 \mathrm{MoVW}$ steels after irradiation to $7 \mathrm{dpa}$ at $365^{\circ} \mathrm{C}$ in MOTA 6,10 . Individual data points have been identified according to which steel they represent. The linear relationship between $\Delta D B T T$ and $\Delta \sigma_{y}$ postulated for the $7 \mathrm{dpa}$ data ${ }^{7}$ was not confirmed for the combined data. (A line through the origin could be fit to the four data points near the top of the figures, but since this is only a small portion of the data, such a curve was not drawn.) A linear relationship is suggested at small $\triangle \mathrm{DBTT}$ values, but not with a line passing through the origin. These data, which include the $5 \mathrm{Cr}-2 \mathrm{WV}, 9 \mathrm{Cr}-2 \mathrm{WV}, 9 \mathrm{Cr}-2 \mathrm{WVTa}$, and $9 \mathrm{Cr}$ $1 \mathrm{MoVNb}$ steels, suggest a threshold $\Delta \sigma_{y}$ that must be exceeded for a shift in DBTT to occur. A more 
realistic conclusion is that no general $\triangle D B T T-\Delta \sigma_{y}$ relationship exists that applies to all steels, and different relationships apply to different steels or classes of steels. The $21 / 4 \mathrm{Cr}$ steels are bunched near the top of the figure, the $12 \mathrm{Cr}-2 \mathrm{WV}$ and $12 \mathrm{Cr}-1 \mathrm{MoVW}$ steels to the right center, and the $5 \mathrm{Cr}$ and $9 \mathrm{Cr}$ steels at the bottom.

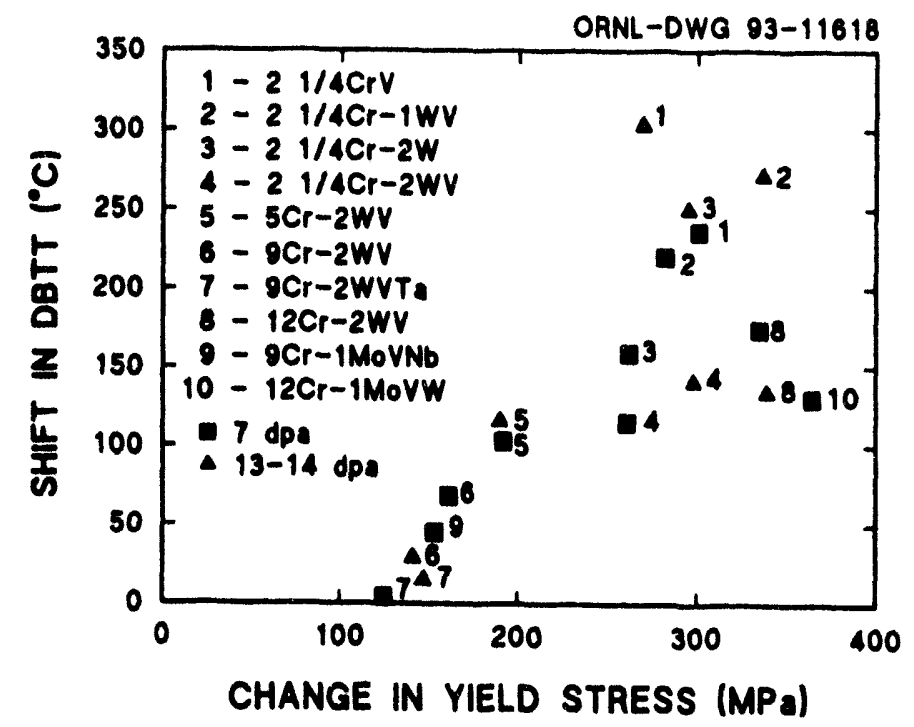

Fig. 1. The shift in DBTT plotted against increase in yield stress for ferritic steels irradiated to 7 and $14 \mathrm{dpa}$ at $365^{\circ} \mathrm{C}$.

Figure 2 shows schematically for two steels how the steel with the lower DBTT will have a smaller $\triangle D B T T$. Flow stress and fracture stress are shown as a function of temperature, with their intersection defining the DBTT. For simplicity, the two stecls are assumed to have the same flow curves before and after irradiation, but to have different fracture curves. If irradiation shifts the flow stress by $\Delta \sigma_{y}$ and the fracture stress is unaffected, the difference between $T_{1}$ and $T_{1}{ }^{0}$ and between $T_{2}$ and $T_{2}{ }^{0}$ defines $\triangle D B T T_{1}$ and $\triangle D B T T_{2}$, respectively. A similar argument follows for two steels with different unirradiated and irradiated flow curves having the same or different fracture stresses and the same or different $\Delta \sigma_{y}$. The idealized conditions described here imply that the steel with the lowest DBTT in the unirradiated condition should always develop the lowest $\triangle D B T T$, thus illustrating the importance of a low DBTT in the unirradiated condition.

The diagram also indicates why a single linear relationship would not be expected to apply to the different steels plotted in Fig. 1. For the case where the steels have different fracture stress curves and a similar $\Delta \sigma_{y}, \Delta \mathrm{DBTT}_{1}=\mathrm{K}_{1} \Delta \sigma_{\mathrm{y}}$ and $\Delta \mathrm{DBTT} \mathrm{K}_{2}=\mathrm{K}_{2} \Delta \sigma_{\mathrm{y}}$, where $\mathrm{K}_{1}$ and $\mathrm{K}_{2}$ are constants. This means a single $\triangle D B T T-\Delta \sigma_{y}$ relationship does not apply. The only time a single relationship would apply is if the steels have the same fracture stress and flow curves, which is unlikely for the variation of microstructures observed in the $\mathrm{Cr}$-W steels tested here. Although the pressure-vessel steels examined by Odette et al. ${ }^{9}$ fit a single $\triangle \mathrm{DBTT}=\mathrm{K} \Delta \sigma_{\mathrm{y}}$ relation, those steels encompass much less chemical and microstructural variation than the steels tested here. 


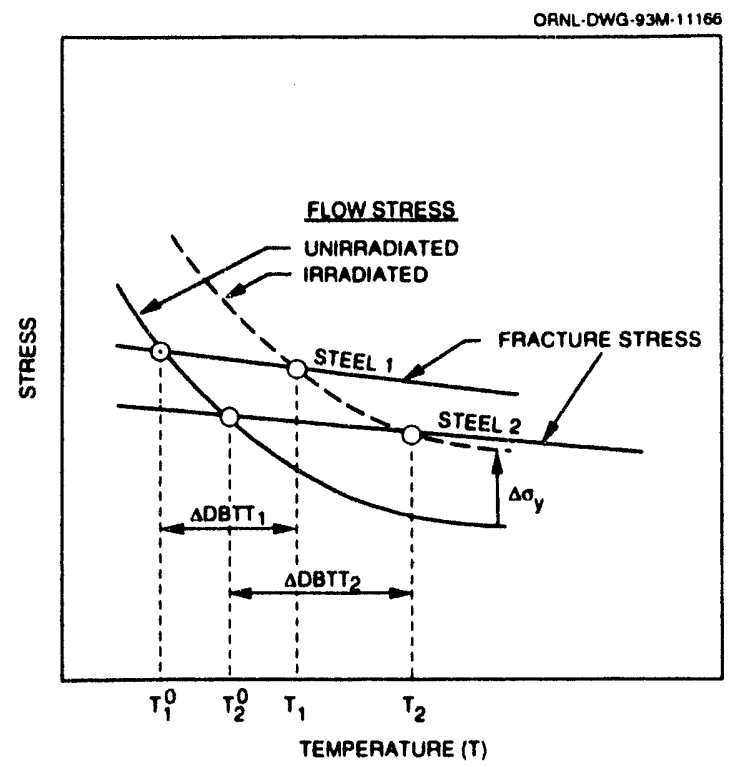

Fig. 2. Schematic diagram illustrating how the same strength increase due to irradiation of two steels causes a different shift in DBTT in the steels.

It was concluded previously that the low DBTT and small $\triangle \mathrm{DBTT}$ for $9 \mathrm{Cr}-2 \mathrm{WVTa}$ may be due to the smaller prior-austenite grain size and/or smaller lath size caused by the tantalum?. A small lath and grain size leads to a low DBTT and could provide a more effective sink for irradiation-produced defects. The $9 \mathrm{Cr}-2 \mathrm{WV}$ and $9 \mathrm{Cr}-2 \mathrm{WVTa}$ had ASTM grain size numbers of 5 and 7, respectively, and the $9 \mathrm{Cr}-1 \mathrm{MoVNb}$ had a grain size number 8 . Re-examination of lath size indicated that there are only minor differences among the three steels. A more probable explanation for the superior behavior is a combination of the $9 \mathrm{Cr}$ composition and microstructure. Variations among the $9 \mathrm{Cr}$ steels are then determined by how microstructure is affected by composition (i.e., by additions of $\mathrm{W}, \mathrm{Mo}, \mathrm{Ta}$, and $\mathrm{Nb}$ ). There is some indication that the $9 \mathrm{Cr}-2 \mathrm{WVTa}$ has a finer carbide distribution than the other $\mathrm{two}^{9 \mathrm{Cr} \text { steels }}{ }^{7}$, which may explain part of the difference in the $9 \mathrm{Cr}$ steels.

The $9 \mathrm{Cr}$ composition may be the reason for the superior behavior of these steels over other compositions. To a large extent, the mechanical properties of the $9 \mathrm{Cr}$ and $12 \mathrm{Cr}$ steels are determined by $\mathrm{M}_{23} \mathrm{C}_{6}$ precipitates. It has been suggested that the larger, more plentiful precipitates in the $12 \mathrm{Cr}-1 \mathrm{MoVW}$, with $0.2 \% \mathrm{C}$, compared to the $9 \mathrm{Cr}-1 \mathrm{MoVNb}$, with $0.1 \% \mathrm{C}$ and only half as much precipitate, give the $9 \mathrm{Cr}-1 \mathrm{MoVNb}$ the lower DBTT in the unirradiated condition and the smallest $\triangle \mathrm{DBTT}$ after irradiation 10 . The $12 \mathrm{Cr}-2 \mathrm{WV}$ contains only $0.1 \% \mathrm{C}$, but behaves as the $12 \mathrm{Cr}-1 \mathrm{MoVW}$. However, the $12 \mathrm{Cr}-2 \mathrm{WV}$ also contains $25 \% \delta$-ferrite; no ferrite was detected in the $12 \mathrm{Cr}-1 \mathrm{MoVW}^{10}$.

Anderko et al. ${ }^{11}$ showed that for $12 \mathrm{Cr}$ steels containing $\delta$-ferrite, it is $\mathrm{M}_{23} \mathrm{C}_{6}$ on martensite/dferrite boundaries that lowers the DBTT. Considerable $\mathrm{M}_{23} \mathrm{C}_{6}$ forms on the interfaces in the $12 \mathrm{Cr}-2 \mathrm{WV}$ in the unirradiated condition ${ }^{3}$. This could mean that $\mathrm{M}_{23} \mathrm{C}_{6}$ controls fracture in both $12 \mathrm{Cr}-2 \mathrm{WV}$ and $12 \mathrm{Cr}$ $1 \mathrm{MoVW}$. Precipitates (mainly $\mathrm{M}_{7} \mathrm{C}_{3}$ ) may also control the behavior of the $2 \mathrm{l} / 4 \mathrm{Cr}-2 \mathrm{WV}$, which contained $\approx 20 \%$ ferrite with extensive precipitation on the ferrite/bainite interface ${ }^{3}$. This implies that reducing the size of the precipitates in the $12 \mathrm{Cr}-1 \mathrm{MoVW}^{10}$ or the elimination of ferrite or precipitates at ferrite/martensite or ferrite/bainite boundaries would be the most likely way to minimize $\triangle \mathrm{DBTT}$. In the $21 / 4 \mathrm{Cr}-2 \mathrm{WV}$, the polygonal ferrite can be eliminated by heat treating. It has been demonstrated that heat treating to produce $100 \%$ bainite significantly lowered the DBTT of unirradiated $21 / 4 \mathrm{Cr}-2 \mathrm{WV}^{12}$. 
Odette et al..$^{9}$ found a direct proportionality between $\triangle U S E$ and $\Delta \sigma_{y}$ for pressure-vessel steels, and such a plot was presented for the $7 \mathrm{dpa}$ results ${ }^{7}$. Although there was considerable scatter in the data, a direct proportionality appeared to exist. The only exception was the $12 \mathrm{Cr}-2 \mathrm{WV}$ steel, which developed a relatively small change in USE for a large increase in yield stress, compared to the other seven steels 7 . A first glance at Fig. 3 for the combined data indicates that a straight line through the origin might fit all the data but that for $12 \mathrm{Cr}-2 \mathrm{WV}$ ( 7 and $13 \mathrm{dpa}$ ), $12 \mathrm{Cr}-1 \mathrm{MoVW}$ ( $7 \mathrm{dpa}$ ), and the $13 \mathrm{dpa}$ data of $21 / 4 \mathrm{CV}$ and $21 / 4 \mathrm{Cr}-1 \mathrm{WV}$. On closer examination, however, it appears that separate curves would better fit the $5 \mathrm{Cr}$ and $9 \mathrm{Cr}$ martensitic steels and the $21 / 4 \mathrm{Cr}$ bainitic-ferritic steels. Therefore, just as was true for $\triangle D B T T$, it is concluded that chemistry and microstructure affect the relationship between fracture and hardening.

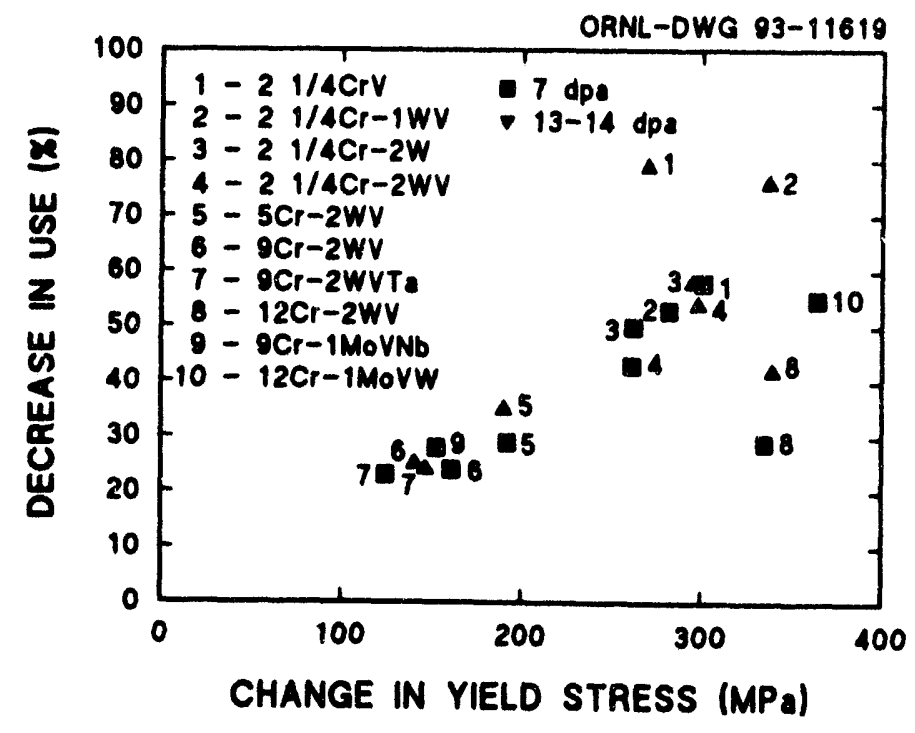

Fig. 3. The decrease in USE plotted against increase in yield stress for ferritic steels irradiated to 7 and 14 dpa at $365^{\circ} \mathrm{C}$.

\section{SUMMARY AND CONCLUSION}

Miniature Charpy specimens from eight reduced-activation Cr-W ferritic steels were irradiated to 13-14 dpa in FFTF at $365^{\circ} \mathrm{C}$. Chromium concentrations ranged from 2.25 to $12 \mathrm{wt} \% \mathrm{Cr}$. The 9Cr steels were least affected by irradiation, with the $9 \mathrm{Cr}-2 \mathrm{WVTa}$ showing only a $15^{\circ} \mathrm{C}$ increase in DBTT after 13 dpa. This steel showed only a $4^{\circ} \mathrm{C}$ shift in DBTT in a previous irradiation to $7 \mathrm{dpa}$ at $365^{\circ} \mathrm{C}$. These are the lowest shifts in DBTT for this type of steel irradiated to these conditions. The results are encouraging because they indicate that the effect of irradiation on toughness can be favorably affected by changing the composition and microstructure. 


\section{REFERENCES}

1. R. L. Klueh and E. E. Bloom, Alloy Development for Fast Induced Radioactivity Decay for Fusion Reactor Applications, Oak Ridge National Laboratory, ORNL/TM-8894 (March 1984).

2. R. W. Conn et al., Panel Report on Low Activation Materials--Report to DOE, University of California, Los Angeles, PPG-753 (March 1983)

3. R. L. Klueh and P. J. Maziasz, Met. Trans. 20A (1989) 373.

4. R. L. Klueh, Met. Trans. 20A (1989) 463.

5. R. L. Klueh and W. R. Corwin, J. Materials Eng. 11 (1989) 169.

6. R. L. Klueh, J. Nucl. Mater. 179-181 (1991) 728.

7. R. L. Klueh and D. J. Alexander, J. Nucl. Mater. 186 (1992) 185.

8. D. J. Alexander, R. K. Nanstad, W. R. Corwin, and J. T. Hutton, Applications of Automation Technology to Fatigue and Fracture Testing, ASTM STP 1092, A. A. Braun, N. E. Ashbaugh, and F. M. Smith, Eds. (American Society for Testing and Materials, Philadelphia, 1990) p. 83. 9. G. R. Odette, P. M. Lombrozo, and R. A. Wullaert, Effects of Radiation on Materials: Twelfth International Symposium, ASTM STP 870, Eds. F. A. Garner and J. S. Perrin, (American Society for Testing and Materials, Philadelphia, 1985) p. 840.

10. R. L. Klueh and D. J. Alexander, J. Nucl. Mater. 191-194 (1992) 896.

11. K. Anderko, L. Schafer, and E. Materna-Morris, J. Nucl. Mater. 179-181 (1991) 492.

12. R. L. Klueh and D. J. Alexander, J. Nucl. Mater. 179-181 (1991) 728. 
MICROSTRUCTURAL DEVELOPMENT IN REDUCED ACTIVATION FERRITIC ALLOYS IRRADIATED TO 200 DPA AT $420^{\circ} \mathrm{C}$ - D. S. Gelles, (Pacific Northwest Laboratory)

\section{OBJECTIVE}

The objective of this work is to determine lifetime limits for reduced activation ferritic alloys.

\section{SUMMARY}

Density change and microstructural development are reported for nine reduced activation ferritic steels covering the range 2.3 to $12 \mathrm{Cr}$ with varying additions of $\mathrm{V}$ and/or $\mathrm{W}$ for hardening and up to $6.5 \mathrm{Mn}$ for austenite stability. Specimens were examined following irradiation in FFTF/MOTA at $420^{\circ} \mathrm{C}$ to a dose exceeding $200 \mathrm{dpa}$. Void swelling was found, but the swelling remained at $5 \%$ or below, with the worst case in an alloy of $9 \mathrm{Cr}-2 \mathrm{Mn}-1 \mathrm{WV}$. The carbide structure pinning Martensite lath boundaries remains in place.

\section{PROGRESS AND STATUS}

Introduction

Reduced activation ferritic alloys appear to be promising first wall and structural materials for commercial fusion reactors. A design window is viable using these steels that should provide long reactor vessel lifetimes, limited primarily by the buildup of manganese by transmutation from iron. The present effort investigates the high dose limit of these steels by examining the effect of irradiation in a fast reactor for a series of experimental reduced activation ferritic/Martensitic steels.

This report is the fifth in a series describing microstructural response in the same series of reduced activation alloys following fast neutron irradiation in the Fast Flux Test Facility (FFTF) Materials Open Test Assembly (MOTA)..$^{1-4}$ The present effort examines these alloys after irradiation to a dose in excess of $4 \times 10^{23} \mathrm{n} / \mathrm{cm}^{2}(\mathrm{E}>0.1 \mathrm{MeV})$, or $200 \mathrm{dpa}$, at a temperature corresponding to the peak swelling temperature for this alloy class.

\section{Experimental Procedure}

Compositions for the reduced activation alloys of interest are given in Table 1. Alloy preparation was described in earlier reports. ${ }^{1-3}$ Specimens of the reduced activation ferritic alloys for transmission electron microscopy (TEM) were put into in-core weeper positions of the FFTF/MOTA at the beginning of cycle 4 and were reinserted for each of the following cycles throughout the operation of FFTF. The irradiation history was as follows: MOTA 1B basket $1 \mathrm{E}-4$ to $2.21 \times 10^{22} \mathrm{n} / \mathrm{cm}^{2}$ (all fluences are given as E $>0.1 \mathrm{MeV}$ ) at an average temperature of $407^{\circ} \mathrm{C}$, MOTA $1 \mathrm{C}$ basket $2 \mathrm{C}-4$ to $7.25 \times 10^{22} \mathrm{n} / \mathrm{cm}^{2}$ at $425^{\circ} \mathrm{C}$, MOTA $1 \mathrm{D}$ basket $2 \mathrm{C}-2$ to $5.46 \times 10^{22} \mathrm{n} / \mathrm{cm}^{2}$ at $406^{\circ} \mathrm{C}$, MOTA $1 \mathrm{E}$ basket $2 \mathrm{C}-2$ to $7.81 \times 10^{22} \mathrm{n} / \mathrm{cm}^{2}$ at $403^{\circ} \mathrm{C}$, MOTA $1 \mathrm{~F}$ basket $2 \mathrm{C}-1$ to $9.58 \times 10^{22} \mathrm{n} / \mathrm{cm}^{2}$ at $406^{\circ} \mathrm{C}$, MOTA $1 \mathrm{G}$ basket $3 \mathrm{~A}-1$ to $8.26 \times 10^{22} \mathrm{n} / \mathrm{cm}^{2}$ at $431{ }^{\circ} \mathrm{C}$, and MOTA $2 \mathrm{~B}$ basket $3 \mathrm{~A}-4$ to $8.50 \times 10^{22} \mathrm{n} / \mathrm{cm}^{2}$ at $430^{\circ} \mathrm{C}$. Therefore, during that period, the

'Operated for the U.S. Department of Energy by Battelle Memorial Institute under Contract DE-AC0676RLO 1830. 
Table 1. COMPOSITIONS OF REDUCED ACTIVATION FERRITIC ALLOYS AS SUPPLIED BY THE VENDOR

\begin{tabular}{|c|c|c|c|c|c|c|c|c|c|c|c|c|}
\hline \multirow{2}{*}{$\begin{array}{l}\text { Alloy } \\
\text { No. }\end{array}$} & \multirow{2}{*}{$\begin{array}{l}\text { Heat } \\
\text { No. }\end{array}$} & \multicolumn{10}{|c|}{ Composition (w/o) } & \multirow{2}{*}{$\begin{array}{c}\text { Heat } \\
\text { Treațment }\end{array}$} \\
\hline & & $\mathrm{Cr}$ & $\mathrm{C}$ & $\mathrm{v}$ & w & Mn & Si & $\mathbf{N}$ & $\mathbf{P}$ & $\mathbf{s}$ & Other & \\
\hline$L_{1}$ & VO2262 & 2.32 & 0.086 & 0.50 & $<0.01$ & $<0.01$ & 0.08 & 0.004 & $<0.005$ & 0.003 & & $\mathbf{A}$ \\
\hline $\mathbf{L} 2$ & VO2263 & 2.38 & 0.093 & 1.01 & $<0.01$ & $<0.01$ & 0.08 & 0.003 & $<0.005$ & 0.002 & & $\mathbf{A}$ \\
\hline L3 & UC-19 & 2.46 & 0.11 & 1.50 & -- & 0.30 & 0.30 & 0.015 & 0.007 & 0.015 & $\begin{array}{l}\text { Ti: } 0.003 \\
\text { Cu: } 0.04\end{array}$ & $\mathbf{A}$ \\
\hline $\mathrm{L} 4$ & VO2264 & 9.13 & 0.096 & 0.52 & 0.01 & 0.02 & 0.09 & 0.003 & $<0.005$ & 0.003 & & B \\
\hline L5 & vO2265 & 9.14 & 0.197 & 1.23 & 0.02 & 1.08 & 0.09 & 0.003 & $<0.005$ & 0.003 & & $\mathrm{C}$ \\
\hline L6 & VO2266 & 9.02 & 0.097 & 0.51 & 0.01 & 2.68 & 0.09 & 0.003 & $<0.005$ & 0.003 & & $\mathrm{C}$ \\
\hline L7 & VO2267 & 12.19 & 0.089 & 1.05 & $<0.01$ & 6.47 & 0.10 & 0.003 & $<0.005$ & 0.005 & & $\mathrm{C}$ \\
\hline $\mathrm{L8}$ & VO2268 & 8.82 & 0.101 & 0.27 & 0.89 & 2.44 & 0.10 & 0.002 & $<0.005$ & 0.004 & & C \\
\hline L9 & VO2269 & 11.81 & 0.097 & 0.28 & 0.89 & 6.47 & 0.11 & 0.003 & $<0.005$ & 0.005 & & C \\
\hline
\end{tabular}

* $\mathrm{A}=900^{\circ} \mathrm{C} / 20 \mathrm{hr} / \mathrm{WQ}$ to $\mathrm{RT}+950 / 20 \mathrm{~min} / \mathrm{WQ}$ to $\mathrm{RT}+650 / 2 \mathrm{hr} / \mathrm{AC}$

$\mathrm{B}=1000^{\circ} \mathrm{C} / 20 \mathrm{hr} / \mathrm{AC}$ to $\mathrm{RT}+1100 / 5 \mathrm{~min} / \mathrm{AC}$ to $\mathrm{RT}+700 / 2 \mathrm{hr} / \mathrm{AC}$

$\mathrm{C}=1000^{\circ} \mathrm{C} / 20 \mathrm{hr} / \mathrm{AC}$ to $\mathrm{RT}+1100 / 10 \mathrm{~min} / \mathrm{AC}$ to $\mathrm{RT}+700 / 2 \mathrm{hr} / \mathrm{AC}$ 
specimens received a dose of $4.91 \times 10^{23} \mathrm{n} / \mathrm{cm}^{2}$ at an average temperaiure of $416 \pm 13^{\circ} \mathrm{C}$, hereafter reported as $420^{\circ} \mathrm{C}$. The dose achieved, calculated from reference ${ }^{5}$ which is based on dosimetry measurements from MOTA IF, varies from 203 to $209 \mathrm{dpa}$, depending on alloy composition.

Microstructural examinations were performed on a JEM 1200EX scanning transmission electron microscope operating at $120 \mathrm{kV}$ and outfitted with a Tracor Northern EDX detector and TN5500 computer and with a Gatan Electron energy loss spectrometer. Determination of precipitate compositions from extraction replicas involved computer analysis of EDX spectra which included analysis for tungsten.

Results

Swelling

Results of density change measurements for reduced activation alloy specimens irradiated at $420^{\circ} \mathrm{C}$ to 200 dpa are provided in Table 2. Table 2 contains dose estimates for each alloy based on conversions from reference. $^{5}$ Table 2 also included results for Modified $9 \mathrm{Cr}-1 \mathrm{Mo}$ (T9), and HT-9 in two conditions (due to different preirradiation tempering treatments as described in reference. ${ }^{6}$ ) As shown from Table 2, swelling values are $5 \%$ or less. The highest swelling value, $5.04 \%$, is found in alloy $\mathbf{L 8}$, and the next highest swelling, $4.66 \%$, is in alloy L6. These alloys contain $9 \% \mathrm{Cr}$ and $2.5 \% \mathrm{Mn}, \mathrm{L8}$ with $0.9 \% \mathrm{~W}$ and $\mathrm{L} 6$ with $0.5 \% \mathrm{~V}$. In comparison, reducing the manganese level to $1.0 \%$ and increasing the vanadium to $1.2 \%$ (L5) reduces the swelling to $2.20 \%$, and reducing the manganese to negligible levels (L4) reduces the swelling to $0.54 \%$. Swelling values for the $2.3 \mathrm{Cr}$ and $12 \mathrm{Cr}$ alloys are lower, in the $1 \%$ range. Comparisons with

Table 2. Swelling as measured by density change for reduced activation ferritic alloys specimens with comparison of Modified $9 \mathrm{Cr}-1 \mathrm{Mo}$ and HT-9.

\begin{tabular}{|c|c|c|c|c|c|}
\hline CODE & Alloy & $\begin{array}{c}\text { Dose } \\
\text { (dpa) }\end{array}$ & $\begin{array}{c}\text { Density } \\
\text { Irradiated }\end{array}$ & $\begin{array}{c}\text { Density } \\
\text { Unirradiated }\end{array}$ & $\begin{array}{c}\text { Swelling } \\
(\%)\end{array}$ \\
\hline P3FL & L1 & 203.2 & 7.74366 & 7.8298 & 1.11 \\
\hline P4FL & L2 & 203.5 & 7.78771 & 7.88886 & 1.30 \\
\hline P5FL & L3-UC19 & 204.0 & 7.71331 & 7.83021 & 1.52 \\
\hline P6FL & L4 & 204.8 & 7.7434 & 7.78532 & 0.54 \\
\hline P7FL & L5 & 205.7 & 7.63738 & 7.80516 & 2.20 \\
\hline P9FL & L6 & 206.0 & 7.48531 & 7.83446 & 4.66 \\
\hline RAFL & L7 & 208.8 & 7.55892 & 7.6673 & 1.43 \\
\hline RBFL & L8 & 204.4 & 7.44347 & 7.8188 & 5.04 \\
\hline REFL & L9 & 206.9 & 7.81535 & 7.7552 & -0.77 \\
\hline PTFL & 9Cr-1Mo & 204.5 & 7.65245 & 7.7869 & 1.76 \\
\hline RFFL & HT-9@700 & 204.5 & 7.78535 & 7.7924 & 0.09 \\
\hline RHFL & HT-9@760 & 204.5 & 7.76143 & 7.84079 & 1.02 \\
\hline
\end{tabular}


the data for commercial alloys T9 and HT-9 show that irradiation of the reduced activation alloys produces similar levels of swelling, and T9 swells slightly more than HT-9. Therefore, reduced activation ferritic alloys, and ferritic alloys in general, are further demonstrated to be highly swelling resistant.

\section{Microstructural examination}

Microstructural examinations confirmed that swelling, as measured by density change, was generally due to void swelling. The highest void swelling levels were found in alloys L8 and L6. However, void distributions were not uniform, with voids forming within Martensite laths, and boundary regions containing void-free zones. In comparison, alloys with less swelling contained lower void densities and smaller voids within martensite laths.

Examples of the microstructures at low magnification are given in Figure 1, and the microstructural observations are summarized in Table 3. As shown from Figure 1, void swelling is present in all conditions but the highest swelling is generally in those alloys with the largest voids. The exceptions are alloys L7 [Figures 1 (g)] and L9 [Figure 1 (i)] where the voids are large but the number densities are low. The L9 specimen yielded a negative swelling value of -0.77 , indicative of phase change during irradiation; therefore, the densification due to phase change was greater than $-0.77 \%$. All conditions retained carbide precipitation in the form of equiaxed particles at grain and lath boundaries, and alloys L7 and L9 contain fine equiaxed particles previously identified as $\alpha^{\prime} .^{1-4}$ However, alloys L1, L2, L3, L4, L5, L7 and L9 also contain elongated precipitate particles within grains and subgrains. These features correspond to vanadium carbide particles $\left(\mathrm{V}_{4} \mathrm{C}_{3}\right)$ except perhaps in the cases of $\mathrm{L} 7$ and $\mathrm{L} 9$, where $\mathrm{FeCrMn}$ chi is expected. Also, the L7 and the $\mathrm{L} 9$ conditions shown in Figures 1 (g) and (i) had been selectively etched during electropolishing, possibly in association with the indicated phase change. Therefore, it is apparent that the Bainite and tempered Martensite structures created before irradiation remain stable, that precipitation of both vanadium carbide and $\mathrm{M}_{23} \mathrm{C}_{6}$ coarsens, and that void swelling develops in regions away from grain and lath boundaries.

Microstructural examinations included attempts to define the dislocation structure in each of these alloys by assuming that only $\frac{a}{2}<111>$ and $a<001>$ Burgers vectors coexisted, and by comparison of $\vec{g}=002$ and 110 images to indicate relative proportions. Void shape information could also be extracted from these images. ${ }^{7}$ Examples are shown in Figure 2 and the results are summarized in Table 3. Figures 2 (a) and (b) compare the same region in a specimen of alloy L4. Figures 2 (c) and (d) and Figures 2 (e) and (f) provide similar images for alloys L6 and L8 respectively. In each pair, the 110 image appears on the left and the 002 image appears on the right. Dislocations that appear in the 110 image and not in the 002 image must be of type $a<001>$ whereas dislocations that appear only in the 002 image may be of both types, $\frac{a}{2}<111>$ or $a<001>$, but the $a<001>$ dislocations will appear in much stronger contrast. Therefore, from comparison of Figures 2 (a) and (b), both Burgers vector types are present in alloy L4 following irradiation but the majority are $\mathrm{a}<001>$, whereas in alloys L6 and L8, at least in the vicinities of martensite lath boundaries, the dislocations are predominantly $\frac{a}{2}<111>$. The voids are found to be shaped as follows: in alloy L4, voids are primarily dodecahedra with minor 100 truncation, and in alloys L6 and L8, two void shapes appear, primarily larger dodecahedra voids with minor 100 truncation, but also containing smaller voids of an intermediate shape between cube and dodecahedra, with voids in alloy L8 tending more towards cuboidal shapes.

\section{Discussion}

The present results provide encouragement for using a reduced activation ferritic alloy as a fusion reactor structural material. The microstructures are very resistant to radiation damage, with excellent resistance to swelling, good phase stability, and normal dislocation evolution, albeit with a second Burgers vector (a $<100>$ ) developing during irradiation. Vanadium additions promote precipitation within grains, manganese 


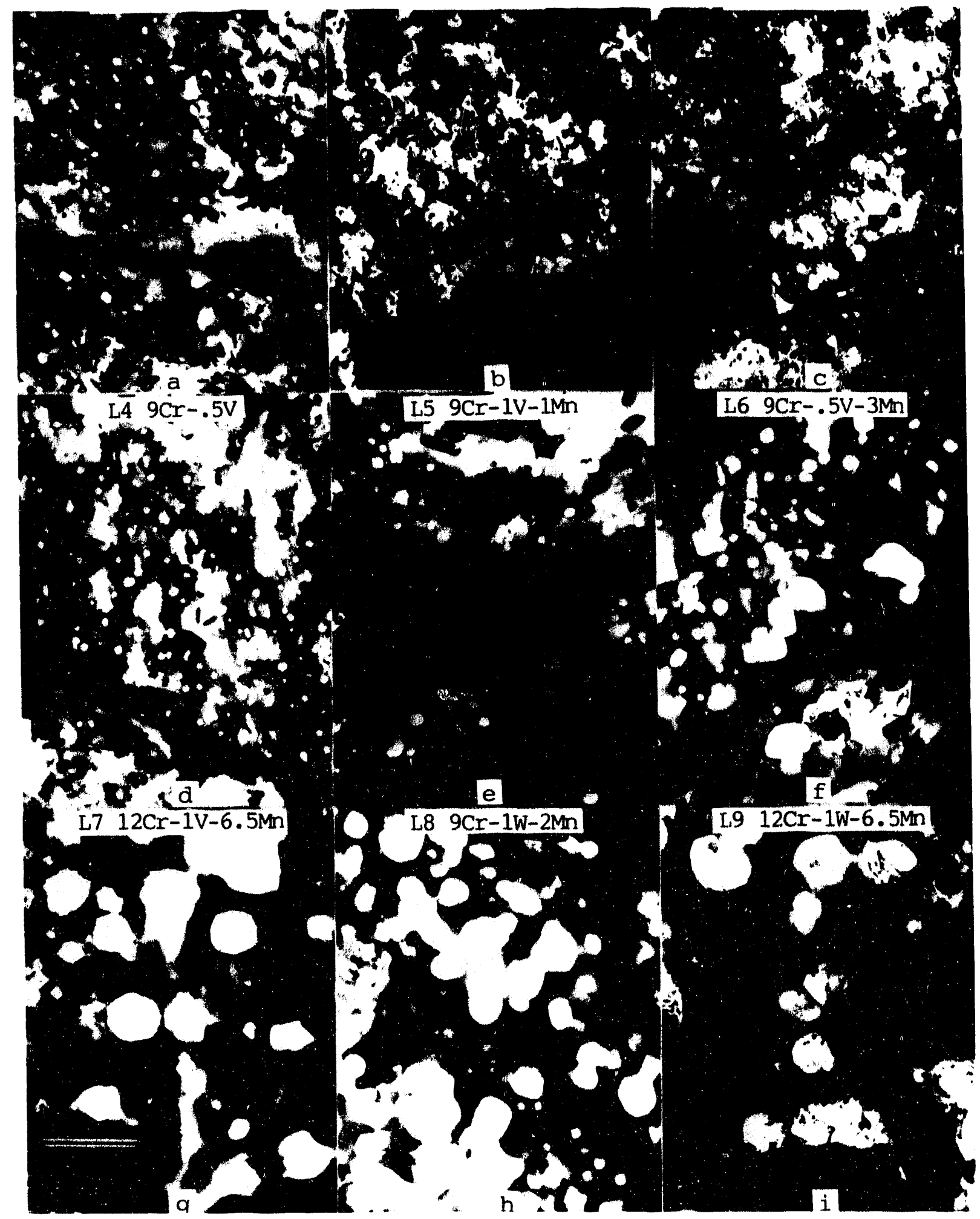

Figure 1. Microstructures of Reduced Activation Ferritic Alloys Following Irradiation at $420^{\circ} \mathrm{C}$ to 200 dpa (a) L1, (b) L2, (c) L3, (d) L4, (e) L5, (f) L6, (g) L7, (h) L8, and (i) L9. 


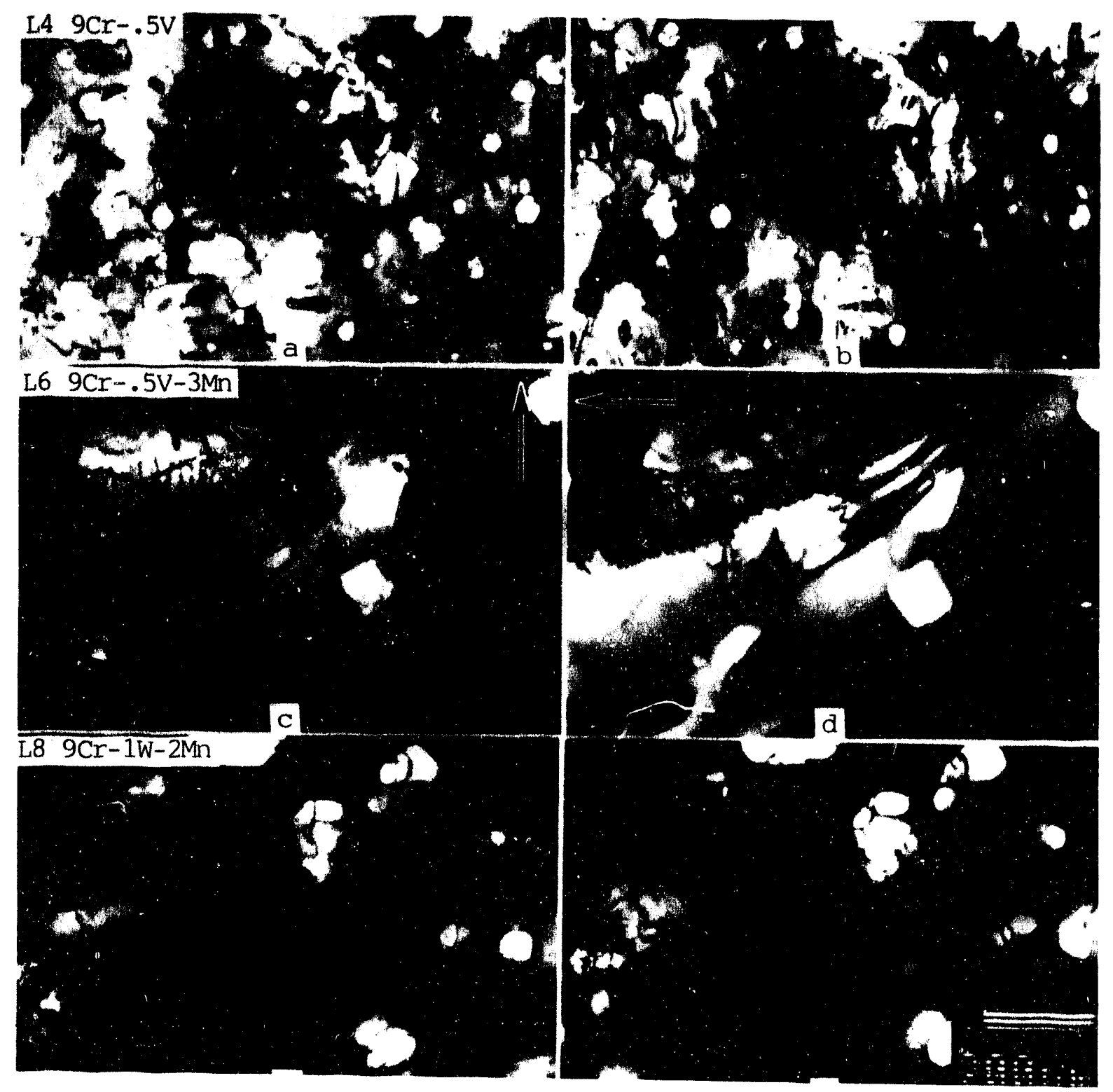

Figure 2. Dislocation and Void Microstructures for $\overrightarrow{\mathrm{g}}=\mathbf{i} 10$ and 002 near (110) in L4 in (a) and (b), L6 in (c) and (d) and L8 in (e) and (f).

additions promote phase instability in the form of chi (and austenite at $\left.600^{\circ} \mathrm{C}\right)^{4}$ as well as a coarsening of the boundary precipitate structures, but tungsten appears only to promote growth of the $M_{23} C_{6}$ phase.

If the present gross microstructural features are compared with the preirradiation microstructures described in, ${ }^{\prime}$ it can be demonstrated that coarsening of the lath structure does occur and subgrain structure is rearranged with some carbide pinning removed, but the maximum carbide particle size stabilizing the lath structure is relatively unchanged, except in the cases of L6, L8, and L9. In alloys L6, L8, and L9, the volume fraction of precipitate stabilizing the boundary positions appears to increase significantly. The increase has not been quantified, but estimates of a factor of 2 or 3 are not unreasonable. The net result is that the subgrain structure is retained, and mechanical properties can be expected to be maintained. 
Table 3. Summary of microstructural observations.

\begin{tabular}{|c|c|c|c|c|}
\hline CODE & Alloy & $\begin{array}{l}\text { Dose } \\
\text { (dpa) }\end{array}$ & Dislocation Structure & Void Shape \\
\hline P3FL & $\mathrm{Ll}$ & 203.2 & $\begin{array}{l}\text { network of equal parts } a<100> \\
\qquad \& \frac{a}{2}<111>\end{array}$ & truncated dodecahedra \\
\hline P4FL & L2 & 203.5 & $\begin{array}{c}a<100>\text { loops } \\
\& \frac{a}{2}<111>\text { network }\end{array}$ & truncated dodecahedra \\
\hline P5FL & L3-UC19 & 204.0 & primarily $a<100>$ loops & $\begin{array}{l}\text { truncated dodecahedra and } \\
\text { cubes }\end{array}$ \\
\hline P6FL & L4 & 204.8 & $\begin{array}{c}\text { primarily a }<100>\text { network, } \\
\text { some } \frac{a}{2}<111>\end{array}$ & $\begin{array}{l}\text { primarily dodecahedra, } \\
\text { some large } \\
\text { dodecahedra/cubes }\end{array}$ \\
\hline P7FL & L5 & 205.7 & $\begin{array}{c}\text { primarily } \\
\stackrel{a}{2}<111>\text { network }\end{array}$ & $\begin{array}{c}\text { primarily dodecahedra, } \\
\text { some large } \\
\text { dodecahedra/cubes }\end{array}$ \\
\hline P9FL & L6 & 206.0 & $\begin{array}{c}\text { primarily } \\
\frac{a}{2}<111>\text { network }\end{array}$ & $\begin{array}{l}\text { primarily dodecahedra, } \\
\text { some smaller dodecahedra/cubes }\end{array}$ \\
\hline RAFL & L7 & 208.8 & $\begin{array}{l}\quad \text { primarily } \\
\frac{a}{2}<111>\text { network } \\
\text { with some loops }\end{array}$ & $\begin{array}{l}\text { dodecahedra with slight } \\
\text { truncation, some smaller cubes }\end{array}$ \\
\hline RBFL & L8 & 204.4 & $\begin{array}{c}\text { primarily } \\
\frac{a}{2}<111>\text { network, } \\
\text { some } a<100>\end{array}$ & $\begin{array}{l}\text { primarily dodecahedra, } \\
\text { some smaller dodecahedra/cubes }\end{array}$ \\
\hline REFL & L9 & 206.9 & $\begin{array}{c}\text { primarily } \\
\frac{a}{2}<111>\text { network, } \\
\text { some a }<100>\end{array}$ & $\begin{array}{l}\text { primarily cuboidal/ } \\
\text { dodecahedra }\end{array}$ \\
\hline
\end{tabular}

It is not yet clear how much of the precipitate volume fraction increase is due to manganese addition, as opposed to tungsten and vanadium additions. Formation of manganese-containing chi phase has been demonstrated in $\mathrm{L} 9,{ }^{2}$ but chi has not been observed in alloys containing tungsten or in alloys containing lower levels of chromium. It is reasonable to expect that manganese is promoting precipitate formation at boundaries, and that alloys containing lower manganese will be less susceptible to such precipitation. Degradation of mechanical properties in some reduced activation ferritic alloys has been attributed to the presence of manganese. ${ }^{8,9}$ As a result, manganese is no longer recommended as an alloying ingredient in reduced activation ferritic steels. Unfortunately, manganese will be formed by transmutation from iron in service in a fusion device. One can anticipate about $1 \% \mathrm{Mn}$ produced by transmutation in a ferritic alloy following irradiation to about $200 \mathrm{dpa}^{10}$ Therefore, the effects of manganese will be unavoidable. 


\section{CONCLUSIONS}

Reduced activation ferritic alloys are highly resistant to fast neutron irradiation. Predictions that swelling will remain low in these materials are upheld, with a maximum of $5 \%$ swelling observed after $200 \mathrm{dpa}$ at the peak swelling temperature. Microstructural evolution is moderate, with precipitates forming due to vanadium or manganese additions, and dislocation network development generally incorporating both $\frac{a}{2}<111>$ and $a<100>$ Burgers vectors.

\section{FUTURE WORK}

This work is a continuing effort.

\section{REFERENCES}

1. D. S. Gelles and M. L. Hamilton, "Effects of Irradiation on Low Activation Ferritic Alloys," Alloy Development for Irradiation Performance Semiannual Progress Report, DOE/ER-0045/13 (September 1984) 128.

2. D. S. Gelles and M. L. Hamilton, "Effects of Irradiation on Low Activation Ferritic Alloys to 45 dpa," IBID, DOE/ER-0045/16 (March 1986)

3. D. S. Gelles and M. L. Hamilton, J. Nucl. Mater. 148 (1987) 272.

4. D. S. Gelles, in Reduced Activation Materials for Fusion Reactors, ASTM STP 1047, R. L. Klueh, D. S. Gelles, M. Okada,and N. H. Packan, Eds. (ASTM, Philadelphia, PA 1990) 113.

5. F. A. Garner and L. R. Greenwood, "Calculation of Displacement Levels for Pure Elements and Most Multicomponent All ys Irradiated in FFTF MOTA-1F," Fusion Reactor Materials Semiannual Progress Report for the Period Ending March 31,1992, DOE/ER-0313/12 (July 1992) 54.

6. D. S. Gelles and A. Kohyama, "Microstructural Examination of HT-9 Irradiated in the FFTF/MOTA to $110 \mathrm{dpa}$," Fusion Reactor Materials Semiannual Progress Report for the Period Ending March 31, 1989, DOE/ER-0313/6 (March 1989) 193.

7. D. S. Gelles, R. M. Claudson and L. E. Thomas, Proc. 8th International Congress for Electron Microscopy, (San Francisco Press, San Francisco CA, 1990) 844.

8. N. S. Cannon and D. S. Gelles, J. Nucl. Mater. 186 (1991) 68.

9. A. Kimura, L. A. Charlot, D. S. Gelles, D. R. Baer and R. H. Jones, J. Nucl. Mater. $\underline{191-194}$ (1992) 885.

10. F. M. Mann, "Transmutation of alloys in MFE Facilities as Calculated by REAC," HEDL-TME 81-37, August 1982. 
IRRADIATION CREEP AND SWELLING OF THE U.S. FUSION HEATS OF HT9 AND 9Cr-1Mo TO 208 DPA AT $\sim 400^{\circ} \mathrm{C}-\mathrm{M}$. B. Toloczko (University of California at Santa Barbara), F. A. Garner (Pacific Northwest Laboratory"), C. R. Eiholzer (Westinghouse Hanford Company)

\section{OBJECTIVE}

The objective of this effort is to determine the relationship between void swelling and irradiation creep in steels of interest to the U.S. fusion materials program.

\section{SUMMARY}

The irradiation creep and swelling behaviors of the fusion heats of $\mathrm{HT} 9$ and $9 \mathrm{Cr}-1 \mathrm{Mo}$ at $\sim 400^{\circ} \mathrm{C}$ have been measured to exposures as large as $208 \mathrm{dpa}$, using both diametral and density measurements of helium-pressurized creep tubes. Void swelling was found in both alloys at $208 \mathrm{dpa}$ to occur at rates of $0.012 \% / \mathrm{dpa}$ or less, with the swelling of HT9 exhibiting a larger degree of stress enhancement than $9 \mathrm{Cr}$ 1Mo. The creep rate of HT9 is rather nonlinear in its response to hoop stress level in the range $\mathbf{0 - 2 0 0}$ $\mathrm{MPa}$, but $9 \mathrm{Cr}-1 \mathrm{Mo}$ exhibits only slightly greater than linear behavior with stress level. The creep-swelling coupling coefficients for $9 \mathrm{Cr}-1 \mathrm{Mo}$ are consistent with values obtained for other steels.

\section{PROGRESS AND STATUS}

\section{Introduction}

Ferritic-martensitic steels are being considered for structural applications in fusion reactors. In order to provide data on the response of such steels to radiation, a series of experiments have been conducted in FFTF. One of these experiments involves the simultaneous measurement of irradiation creep and void swelling. Helium-pressurized creep tubes constructed from the ferritic-martensitic alloys HT9 and 9Cr1Mo (U.S. fusion heats 9607R2 and 30176) have completed their irradiation in the Materials Open Test Assembly (MOTA) in the Fast Flux Test Facility (FFTF) at a nominal temperature of $\sim 400^{\circ} \mathrm{C}$.

\section{Experimental Details}

The composition and heat treatment of these two alloys is listed in Table 1 . These tubes $(2.24 \mathrm{~cm}$ long by $0.46 \mathrm{~cm}$ diameter) were periodically discharged from the reactor, and prior to reinsertion into reactor, diameter measurements were made using laser profilometry.' The tubes were inserted in all MOTA vehicles from MOTA-1B through MOTA-1G and then continued into MOTA-2B. Both alloys were irradiated at hoop stress levels of $0,60,100$, and $140 \mathrm{MPa}$, and HT9 was also irradiated at $200 \mathrm{MPa}$. Irradiation temperatures varied somewhat from one MOTA to the next, but during any one irradiation interval, the temperature was actively controlled within $\pm 5^{\circ} \mathrm{C}$ of the nominal temperature. Table 2 presents the target temperatures of these tubes in each MOTA irradiation segment. These tubes reached exposure dpa levels as large as $208 \mathrm{dpa}$. The strains of these tubes were last reported at $\sim 150 \mathrm{dpa}{ }^{2}$

"Pacific Northwest Laboratory is operated for the U.S. Department of Energy by Battelle Memorial Institute under Contract DE-AC06-76RLO 1830. 
Table 1. Composition of Alloys in Weight Percent

\begin{tabular}{||l|c|c|c|c|c|c|c|c|c|c|c|c|c|}
\hline & $\mathrm{C}$ & $\mathrm{Si}$ & $\mathrm{Mn}$ & $\mathrm{P}$ & $\mathrm{S}$ & $\mathrm{Cr}$ & $\mathrm{Mo}$ & $\mathrm{Ni}$ & $\mathrm{V}$ & $\mathrm{W}$ & $\mathrm{N}$ & $\mathrm{Al}$ & $\mathrm{Ti}$ \\
\hline HT9 & 0.20 & 0.17 & 0.57 & 0.016 & 0.003 & 12.1 & 1.04 & 0.51 & 0.28 & 0.45 & 0.027 & 0.006 & 0.001 \\
$9 \mathrm{Cr}-1 \mathrm{Mo}$ & 0.08 & 0.11 & 0.37 & 0.010 & 0.003 & 8.61 & 0.89 & 0.09 & 0.21 & $<0.01$ & 0.055 & 0.007 & 0.004 \\
\hline
\end{tabular}

Table 2. Irradiation History of Pressurized Tubes

\begin{tabular}{|c|c|c|}
\hline MOTA & $\begin{array}{c}\text { TARGET } \\
\text { TEMPERATURE, }{ }^{\circ} \mathrm{C}\end{array}$ & $\begin{array}{l}\text { INCREMENTAL } \\
\text { DOSE, dpa }\end{array}$ \\
\hline 1B & 407 & $\sim 11$ \\
\hline 1C & 425 & $\sim 34$ \\
\hline ID & 406 & $\sim 26$ \\
\hline $1 E$ & 403 & $\sim 37$ \\
\hline $1 \mathrm{~F}$ & 406 & $\sim 40$ \\
\hline $1 G$ & 420 & $\sim 35$ \\
\hline $2 B$ & 433 & $\sim 24$ \\
\hline
\end{tabular}

Upon termination of the experiment, each tube was sectioned to produce two rings approximately $7.5 \mathrm{~mm}$ in length, one from each side of the axial center line. Each ring was then sliced in half, and the density of each of the four half-sections was determined using an immersion density technique known to be accurate to $\pm 0.2 \%$ change in density. Upon sectioning, it was found that the HT9 tube at $60 \mathrm{MPa}$ contained some sodium, indicating that a small unnoticed failure had occurred earlier in the irradiation sequence. Thus, this tube was unpressurized for some unknown period.

\section{$\underline{\text { Results and Discussion }}$}

Figure 1 presents both the total diametral strain and midwall creep strain for HT9, and Figure 2 presents the strains for $9 \mathrm{Cr}-1 \mathrm{Mo}$. The midwall creep strain is calculated $\mathrm{u}$ ing the traditional assumptions that the strain at zero stress arises only from void swelling, and that swelling is isotropic and unaffected by stress.

The strains observed in $9 \mathrm{Cr}-1 \mathrm{Mo}$ exhibit some complexity, especially at higher fluence. Since such complexity was not observed in HT9, and both sets of tubes were irradiated together, it is assumed that the origin of the complexity is related to a material difference from HT9, rather than some artifact of reactor history. Note that the $0.8 \%$ linear swelling strain at zero stress for $9 \mathrm{Cr}-1 \mathrm{Mo}$ is somewhat larger than that of HT9 at $0.35 \%$ and implies swelling levels of 2.4 vs. 1.1 vol.\%. 

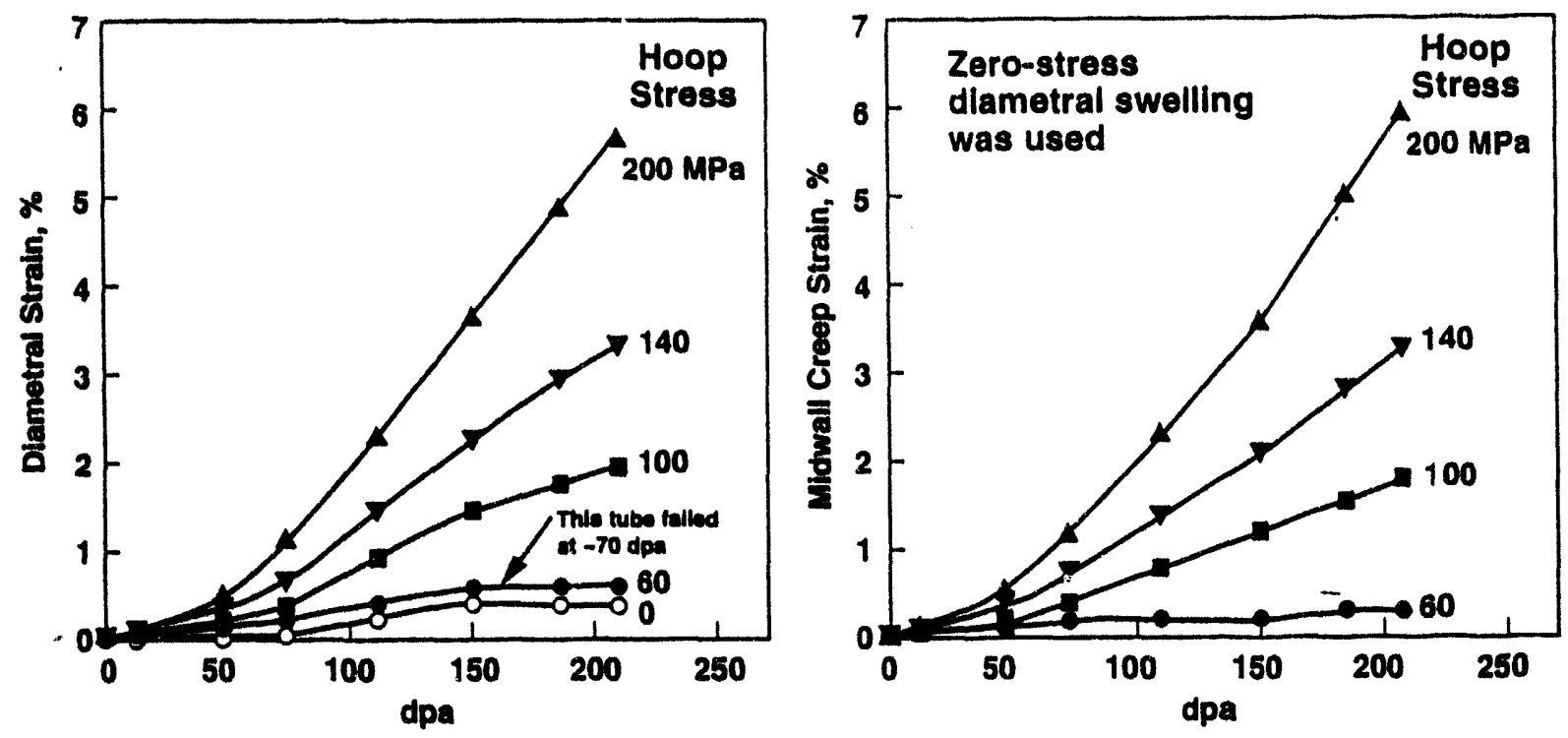

Fig. 1. Total diametral strains and midwall creep strains for HT9.
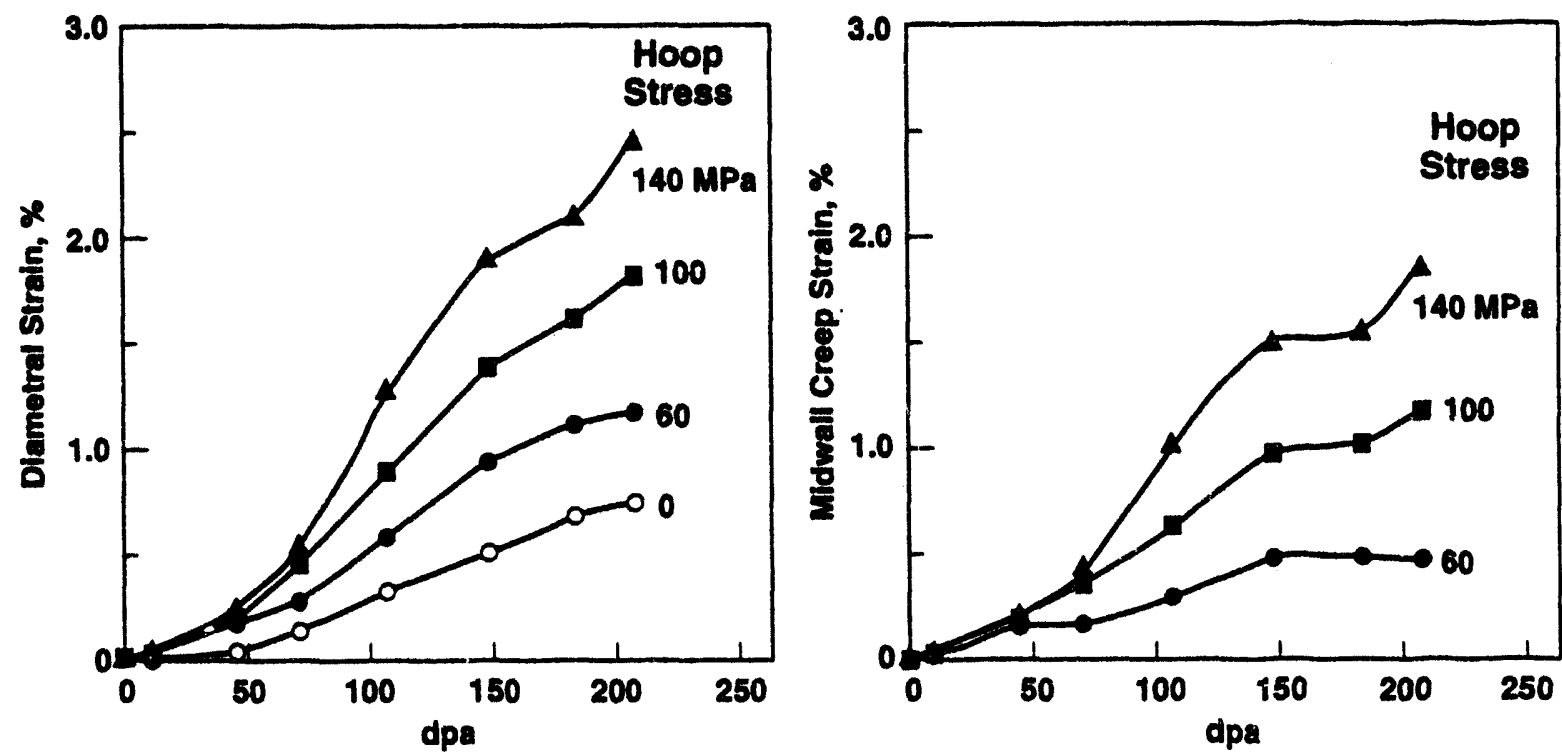

Fig. 2. Total diametral strains and midwall creep strains for $9 \mathrm{Cr}-1 \mathrm{Mo}$. 


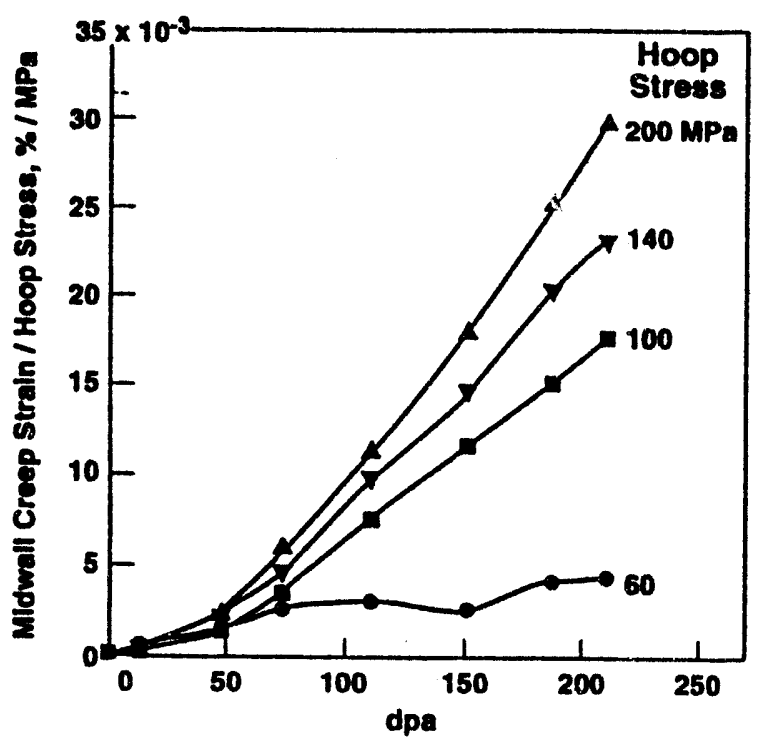

Fig. 3. Stress-normalized midwall creep strairs for HT9, ignoring stress-enhancement of swelling.

When the midwall cre is are normalized to their respec tresses and the possibility of uhanced swelling is ignored, it is obvious that the response to stress of HT9 is quite non-linear as shown in Figure 3. Figure 4, however, demonstrates that the stress exponent of $9 \mathrm{Cr}$ IMo is only slightly greater than 1.0 to doses of $\leq 150 \mathrm{dpa}$. Above $150 \mathrm{dpa}$ the complexity of response mentioned earlier dominates the normalized creep behavior of $9 \mathrm{Cr}-1 \mathrm{Mo}$.

As shown in Figure 5, the swelling strains measured by immersion density at $208 \mathrm{dpa}$ show that at zero stress, the swelling strains of $9 \mathrm{Cr}-1 \mathrm{Mo}$ and $\mathrm{HT} 9$ are somewhat variable for the four different tube segments, with mean values of $\sim 2.3 \pm 0.3$ and $1.2 \pm 0.1$ volume percent, respectively. The mean values agree very well with the swelling values deduced from diameter changes, however. While the swelling of $9 \mathrm{Cr}-1 \mathrm{Mo}$ appears to be only slightly sensitive to stress level, there is a fairly large effect of stress on

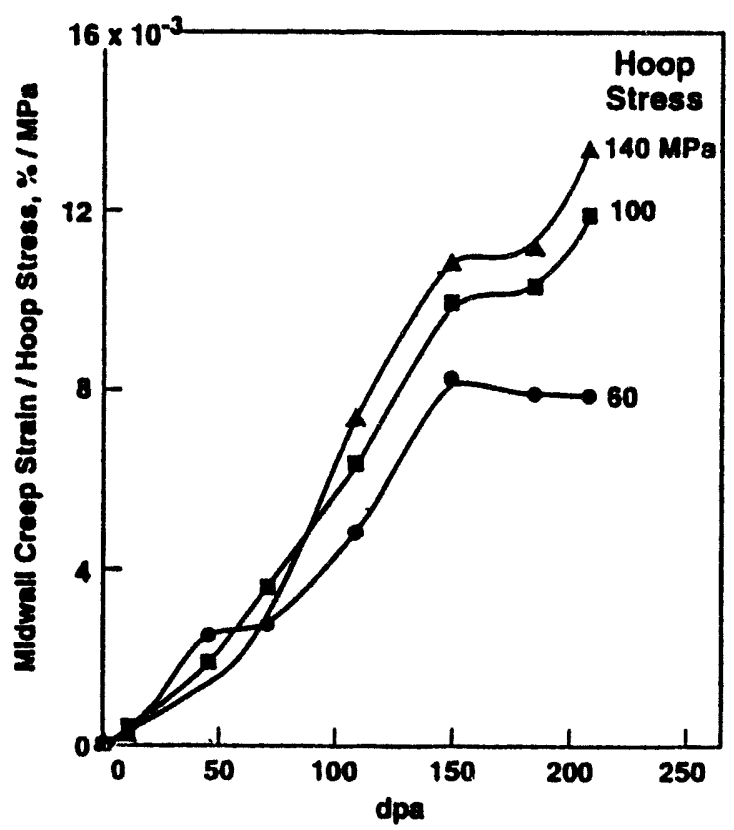

Fig. 4. Stress-normalized midwall creep strains for $9 \mathrm{Cr}-1 \mathrm{Mo}$, ignoring stressenhancement of swelling.

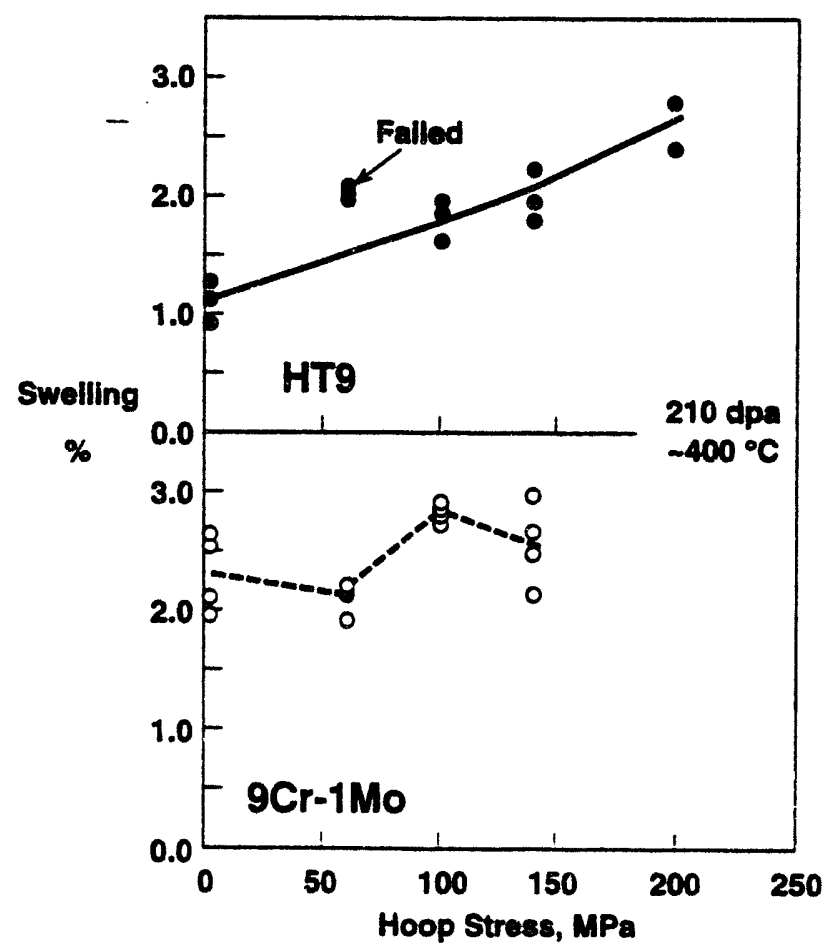

Fig. 5. Swelling measured for individual tube segments at $208 \mathrm{dpa}$. 
the swelling of HT9, increasing from $\sim 1.2 \%$ at $0 \mathrm{MPa}$ to $\sim 2.6 \%$ at $200 \mathrm{MPa}$. Since the $60 \mathrm{MPa}$ tube failed, its density was discounted as not being stress-enhanced throughout the irradiation.

Microscopy examination confirmed that void swelling indeed had occurred by $208 \mathrm{dpa}$ and was accelerated by stress, as demonstrated in Figure 6. If all the density change is ascribed to voids, this implies that the average swelling rates in this experiment were $\leq 0.012 \% / \mathrm{dpa}$.

Since the influence of stress-enhanced swelling can only be assessed at $208 \mathrm{dpa}$, it was ignored in deriving the stress-normalized creep rates shown in Figures 3 and 4. The impact of including the stress enhancement at $208 \mathrm{dpa}$ can be seen to be relatively small, however, as shown in Figure 7 . The stress exponent for HT9 appears to be $\sim 2$.

If we assume that stress enhancement for $9 \mathrm{Cr}$-1Mo is small enough that it can be ignored, and that the creep rate responds linearly with stress, then we can obtain creep coefficients for the $\bar{g} \bar{\sigma}=B_{0}+D S$ creep model, ${ }^{3}$ where $\bar{\varepsilon}^{2}$ is the effective strain rate, $\bar{\sigma}$ is the effective stress, $B_{o}$ is the creep compliance, $D$ is the creep-swelling coupling coefficient and $\dot{\mathrm{S}}$ is the instantaneous swelling rate. Using this approach, the derived values for $B_{0}$ and $D$ are on the order of $0.5 \times 10^{-6} \mathrm{MPa}^{-1} \mathrm{dpa}^{-1}$ and0.7-1.0 $\times 10^{-2} \mathrm{MPa}^{-1}$, respectively. This $B_{0}$ value agrees rather well with the $0.44 \times 10^{-6}$ value obtained for the ferritic steels EM10 and EM12 at $400-490^{\circ} \mathrm{C}$ in the PHENIX reactor ${ }^{4}$, and the D coefficient is comparable to the values near $0.6 \times 10^{-2} \mathrm{MPa}$ that are routinely observed in austenitic steels. ${ }^{5}$

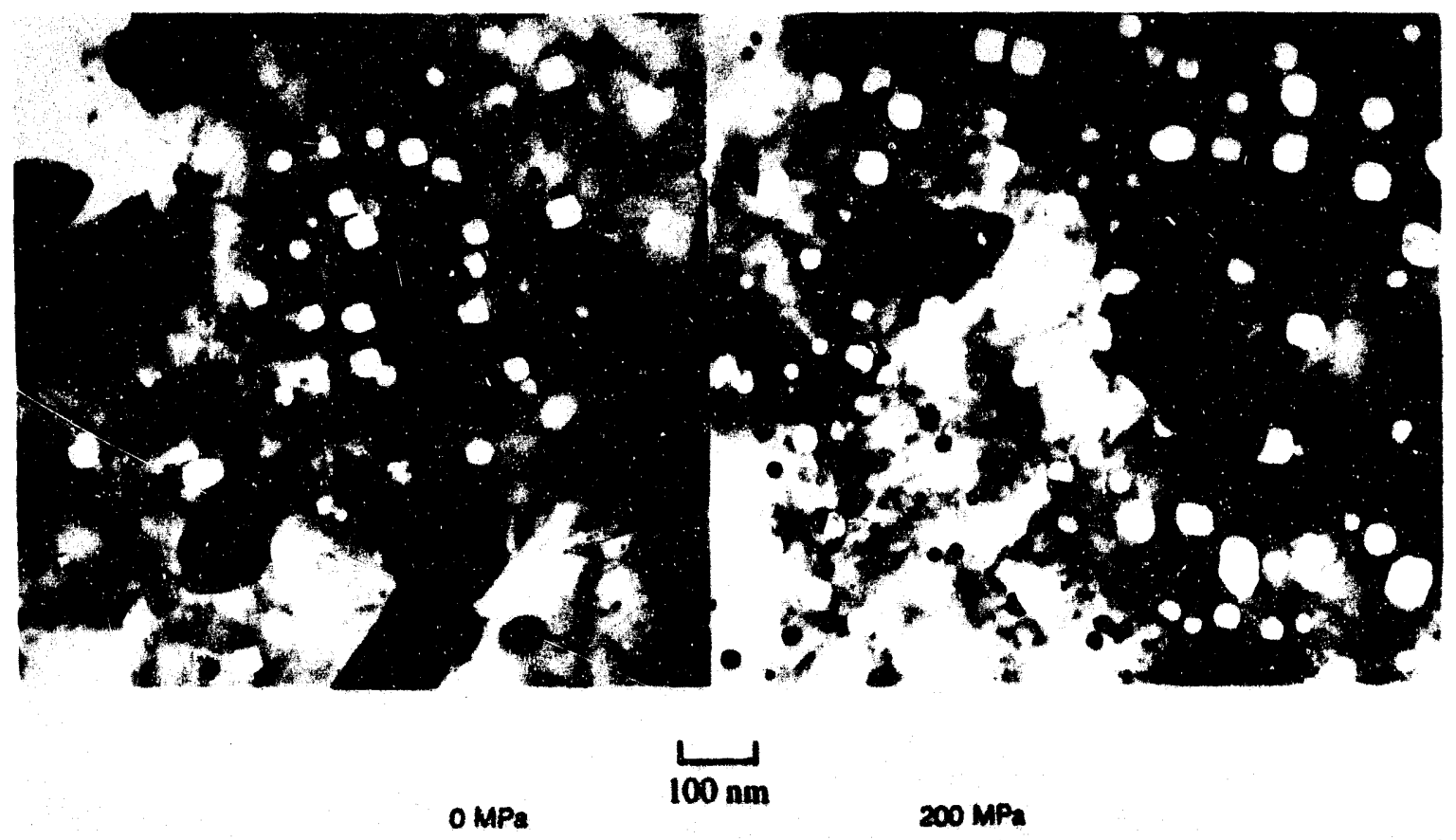

Fig. 6. Void microstructures observed at hoop stresses of 0 and $200 \mathrm{MPa}$ in HT9 after irradiation at $\sim 400^{\circ} \mathrm{C}$ to $208 \mathrm{dpa}$. 


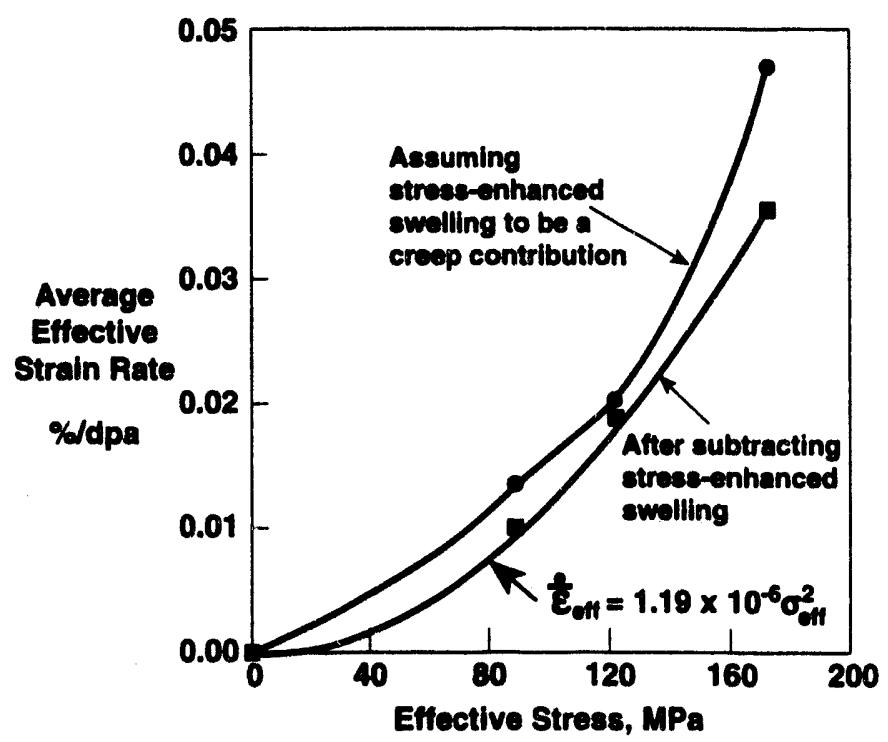

Fig. 7. Comparison of creep strains for HT9 at $208 \mathrm{dpa}$, calculated using both stress-free and stressatiected swelling.

\section{CONCLUSIONS}

Irradiation of $\mathrm{HT} 9$ and $9 \mathrm{Cr}-1 \mathrm{Mo}$ to very high neutron exposure at $\sim 400^{\circ} \mathrm{C}$ confirms the inherent swelling resistance of this class of steels, although the application of high stress levels accelerates swelling somewhat. The irradiation creep rate of $9 \mathrm{Cr}-1 \mathrm{Mo}$ is roughly linear with stress and comparable to that of other ferritic steels. The creep rate of HT9, however, exhibits a stress exponent of $\sim 2$ at this temperature.

\section{REFERENCES}

1. E. R. Gilbert and B. A. Chin, in Effects of Radiation on Materials: Tenth Conference, ASTM STP 725 (1981) 665-679.

2. F. A. Garner and R. J. Puigh, J. Nucl. Mater., 179-181 (1991) 577-580.

3. K. Ehrlich, J. Nucl. Mater., 100 (1981) 149.

4. J. L. Seran, V. Levy, P. Dubuisson, D. Gilbon, A. Maillard, A. Fissolo, H. Touron, R. Cauvin, A. Chalony, and E. Le Boulbin, Effects of Radiation on Materials: 15th Inter. Symposium, STP 1125, Philadelphia, American Society for Testing and Materials (1992) 1209-1233.

5. F. A. Garner, M. B. Toloczko, and C. H. Woo, presented at ICFRM-6. 
6.2 Austenitic Stainless Steels 
FRACTURE TOUGHNESS OF CANDIDATE MATERIALS FOR ITER FIRST WALL, BLANKET, AND SHIELD STRUCTURES -. J. E. Pawel, D. J. Alexander, M. L. Grossbeck, A. W. Longest, A. F. Rowcliffe (Oak Ridge National Laboratory), G. E. Lucas (University of California, Santa Barbara), S. Jitsukawa, A. Hishinuma, and K. Shiba (Japan Atomic Energy Research Institute)

\section{OBJECTIVE}

The purpose of this work is to determine the effect of irradiation at low temperatures (less than $300^{\circ} \mathrm{C}$ ) to damage levels of about $3 \mathrm{dpa}$ on the mechanical properties, in particular the fracture toughness, of candidate materials for the International Thermonuclear Experimental Reactor (ITER) first wall/blanket structures.

\section{SUMMARY}

Although the design of the International Thermonuclear Experimental Reactor is still in an evolutionary phase, the most probable choice for a structural material is a $\mathbf{3 0 0}$ series austenitic stainless steel. An experiment was carried out in the High Flux Isotope Reactor to quantify the effects of neutron irradiation on the fracture toughness properties of a range of austenitic stainless steels. The alloys investigated were provided by programs in the European Community, United States, and Japan; they included 316,316L, and titanium-stabilized steels in cold-worked, annealed, and welded conditions. Subsize disk compact tension specimens were irradiated to a dose of about 3 dpa and $50 \mathrm{appm}$ helium (the expected fusion value) at temperatures of either 60 to $125^{\circ} \mathrm{C}$ or 250 to $300^{\circ} \mathrm{C}$. With the exception of a cold-worked air-melted heat of 316 , all materials retained excellent fracture toughness, with $K_{\mathrm{J}}$ values varying from 150 to $400 \mathrm{MPa} / \mathrm{m}$ over the test temperature range from 90 to $250^{\circ} \mathrm{C}$.

\section{PROGRESS AND STATUS}

\section{Introduction}

The choice of an alloy system for the first wall/shield (FW/S) structure for the International Thermonuclear Experimental Reactor (ITER) is a subject of continuing debate. Four classes of materials are under consideration: austenitic stainless steels, ferritic-martensitic steels, vanadium alloys, and high strength copper alloys. Of these four groups, the austenitic steels have the lowest capacity to withstand thermal stresses and their selection for the FW/S could restrict the thermal performance of ITEI. On the other hand, there is an enormous reservoir of experience in fabricating and operating corle qualified austenitic stainless steel components in nuclear systems. In addition, the austenitics do not suffer from the transition from ductile-to-brittle fracture behavior that is characteristic of body-centered-cubic alloy systems. However, there are several problems with the irradiation performance of austenitics over the temperature range of 100 to $400^{\circ} \mathrm{C}$. For example, a drastic loss of work hardening capacity is frequently observed in tensile tests following neutron irradiation in the range 200 to $350^{\circ} \mathrm{C}$. Uniform elongation values below $1 \%$ have been reported [1]. This phenomenon may be related to the development of microstructures which encourage flow localization, rather than generalized flow and dislocation multiplication. A correlation has been observed, for example, between loss of work hardening capacity over the range 200 to $350^{\circ} \mathrm{C}$ and the 
development of microstructures dominated by faulted Frank loops 10 to $20 \mathrm{~nm}$ in diameter [2]. A major concern is that this deformation mode may restrict crack tip ductility and lead to low values of fracture toughness properties.

This paper describes some initial results from a study of the effects of neutron irradiation in the range 60 to $300^{\circ} \mathrm{C}$ on the fracture toughness of several austenitic stainless steels. The first part of this study deals with irradiation to a dose of about $3 \mathrm{dpa}$, which approaches the accumulated dose at the end of the physics or basic phase of operation of ITER.

\section{Experimental Procedure}

To accommodate the high nuclear heating rate in the High Flux Isotope Reactor (HFIR) target region, where the irradiations were conducted, a small disk compact tension specimen, designated $\mathrm{DC}(\mathrm{T}), 12.5 \mathrm{~mm}$ in diameter and $4.63 \mathrm{~mm}$ thick was developed [3]. Techniques were developed for generating the J-integral resistance (J-R) curves using unloading compliance (UC) to monitor crack extension $[4,5]$. Initial trials showed that useful fracture toughness data could be generated with these small specimens [3-5].

Four major alloy types were included in this experiment: EC316L, JPCA, J316, and US316. The compositions of the alloys are given in Table 1. Specimens were in solution annealed (SA), coldworked $(\mathrm{CW})$, or welded conditions. There were a total of 11 variants in composition and thermomechanical treatment. The EC316L was welded using 16-8-2 filler metal (see Table 1) and gas tungsten arc (GTA) welding with argon cover gas. Both the plate and the filler wire were provided by Joint Research Centre-Ispra from the European Fusion Stockpile. The JPCA and J316 plate material were supplied by the Japan Atomic Energy Research Institute. The JPCA specimens were welded with filler wire of composition not significantly different from the base metal (see Table 1) for both the case of GTA welding and electron beam (EB) welding. The US316 material was from the U. S. fusion program standard heat. In addition to the $\mathrm{DC}(\mathrm{T})$ specimens, each capsule also contained $0.76 \mathrm{~mm}$ thick sheet tensile specimens and transmission electron microscopy disks.

Table 1. Specimen alloy compositions.

\begin{tabular}{||l|c|c|c|c|c|c|c|c|c||}
\hline \multirow{2}{*}{ Alloy } & \multicolumn{9}{|c|}{$\begin{array}{c}\text { Composition } \\
\text { (wt \%) }\end{array}$} \\
\cline { 2 - 12 } & $\mathrm{Fe}$ & $\mathrm{Ni}$ & $\mathrm{Cr}$ & $\mathrm{Ti}$ & $\mathrm{Mo}$ & $\mathrm{Mn}$ & $\mathrm{Si}$ & $\mathrm{C}$ & $\mathrm{N}$ \\
\hline \hline JPCA & $\mathrm{Bal}$ & 15.95 & 14.3 & 0.21 & 2.4 & 1.6 & 0.54 & 0.064 & 0.003 \\
\hline US316 & $\mathrm{Bal}$ & 12.4 & 17.3 & -- & 2.1 & 1.7 & 0.67 & 0.061 & \\
\hline EC316L & $\mathrm{Bal}$ & 12.3 & 17.4 & -- & 2.3 & 1.8 & 0.46 & 0.024 & 0.06 \\
\hline J316 & $\mathrm{Bal}$ & 13.95 & 16.77 & -- & 2.31 & 0.23 & 0.04 & 0.038 & 0.011 \\
\hline $\begin{array}{l}16-8-2 \\
\text { weld wire }\end{array}$ & $\mathrm{Bal}$ & 8.98 & 16.28 & -- & 2.16 & 1.82 & 0.060 & 0.036 & 0.029 \\
\hline $\begin{array}{l}\text { JPCA } \\
\text { weld wire }\end{array}$ & $\mathrm{Bal}$ & 16.06 & 14.39 & 0.23 & 2.44 & 1.77 & 0.35 & 0.057 & 0.0095 \\
\hline
\end{tabular}


All specimens were fabricated from the middle of the thickness of the parent plate of material, with the notch oriented so that crack growth would occur parallel to the rolling direction (T-L orientation). The EC316L was found to contain stringers of delta ferrite. Because there was concern that this anisotropy might influence fracture toughness, a limited number of specimens were also machined such that the crack propagated perpendicular to the rolling direction (L-T orientation). All specimens were fatigue precracked at room temperature and side grooved $10 \%$ of their thickness on each side, prior to irradiation, in order to promote a straight crack front. Filler pieces were inserted in the loading holes and in the notches to reduce disturbances in the flow of cooling water over the specimens in the capsules during irradiation and to improve the uniformity of heat transfer across the specimens.

The irradiation took place in the HFIR target capsules designated HFIR-MFE-JP17, -18 and -19. Details on the irradiation capsules are available elsewhere [6-8]. The capsules were irradiated for two cycles to a peak damage level of $3.2 \mathrm{dpa}$. They were designed to give crack growth region temperatures between 250 and $300^{\circ} \mathrm{C}$ for JP17, and 60 and $125^{\circ} \mathrm{C}$ for the other two capsules [6]. The specimens in the low-temperature capsules were cooled directly by reactor cooling water. The helium concentration generated as a result of transmutation of nickel was about 50 appm; this is in the range expected for the ITER first wall blanket and shield structure after a neutron exposure of about 3 dpa.

Fracture tests were conducted in general accordance with American Society for Testing and Materials (ASTM) standards E813-89, "Standard Test Method for $\mathrm{J}_{\mathrm{lc}}$, A Measure of Fracture Toughness," and E1152-87, "Standard Test Method for Determining J-R Curves." The specimens were tested with a computer-controlled testing and data acquisition system [9]. Tests in the cold laboratory used an $89-\mathrm{kN}$ capacity servohydraulic test machine. In the hot cell, a $445-\mathrm{kN}$ servohydraulic testing machine with an ultraprecision $22-\mathrm{kN}$ load cell was used. All tests were run in strain control. The displacements were measured with an "outboard" clip gage that seated in grooves machined on the outer edge of the specimen along the load line $[4,5]$. This arrangement provided very good loaddisplacement and UC results. Test temperatures were maintained within $\pm 2^{\circ} \mathrm{C}$ of the desired temperature with a split-box furnace that enclosed the specimen and the grips during the test. Temperature was monitored throughout the testing with a thermocouple that was held in contact with the specimen by a spring-loaded clip. Tensile data from the corresponding tensile specimens were used, where available, in the calculations for the J-R curves (see Table 2). Estimated values of the yield and ultimate tensile strengths and Young's moduli were used in the remaining cases. These estimated values are given in Table 2.

After testing, the specimens were heat tinted on a hot plate, cooled, and then broken open. The initial and final crack lengths for the unirradiated specimens were measured with an optical measuring microscope. For the irradiated specimens, photographs of the fracture surfaces were fastened to a digitizing tablet to measure the crack lengths.

\section{Results and Discussion}

Fracture toughness data for both unirradiated and irradiated specimens are shown in Table 2. Testing of the full specimen matrix is not complete at this time.

Materials with very high toughness and low yield strength, such as the annealed austenitic stainless steels, proved to be more difficult to test than material with lower toughness such as the US316 material. The soft, tough materials showed enormous crack-tip blunting before stable crack 
Table 2. Fracture Toughness Data for Austenitic Stainless Steels.

\begin{tabular}{|c|c|c|c|c|c|c|c|c|c|}
\hline \multirow{2}{*}{ Material } & \multirow{2}{*}{$\begin{array}{c}\text { Specimen } \\
\text { number }\end{array}$} & \multirow{2}{*}{$\begin{array}{c}\text { Calculated } \\
\text { irradiation } \\
\text { temperature } \\
\text { ('C) }\end{array}$} & \multirow{2}{*}{$\begin{array}{c}\text { Test } \\
\text { temperature } \\
\left({ }^{\circ} \mathrm{C}\right)\end{array}$} & \multirow{2}{*}{$\underset{\left(\mathrm{k} / \mathrm{m}^{2}\right)}{\mathrm{J}^{\mathrm{b}}}$} & \multirow{2}{*}{$\begin{array}{c}\mathbf{K}_{\mathbf{J}^{\mathrm{c}}} \\
(\mathrm{MPa} \sqrt{\mathrm{m}})\end{array}$} & \multirow{2}{*}{$\mathbf{T}$} & \multicolumn{2}{|c|}{$\begin{array}{l}\text { Strength }{ }^{d} \\
\left.\left(M^{2}\right)^{2}\right)\end{array}$} & \multirow{2}{*}{$\begin{array}{c}\text { Young's } \\
\text { modulus d } \\
(\mathrm{GPa})\end{array}$} \\
\hline & & & & & & & Yield & $\begin{array}{l}\text { Ultimate } \\
\text { tensile }\end{array}$ & \\
\hline $\begin{array}{l}\text { EC316L } \\
\text { annealed }\end{array}$ & $\begin{array}{r}\text { FA14 } \\
\text { FA22 } \\
\text { FA5 } \\
\text { FA16 } \\
\text { FA3 } \\
\text { FA6 } \\
\text { FA17 } \\
\text { FA18 } \\
\end{array}$ & $\begin{array}{r}e \\
e \\
e \\
75 \\
75 \\
75 \\
75 \\
270 \\
\end{array}$ & $\begin{array}{r}22 \\
100 \\
200 \\
25 \\
25 \\
100 \\
200 \\
250\end{array}$ & $\begin{array}{l}769 \\
889 \\
696 \\
775 \\
799 \\
658 \\
498 \\
351 \\
\end{array}$ & $\begin{array}{l}385 \\
407 \\
353 \\
387 \\
393 \\
350 \\
299 \\
251\end{array}$ & $\begin{array}{r}f \\
f \\
f \\
109 \\
95 \\
130 \\
168 \\
62\end{array}$ & $\begin{array}{l}275 \\
230 \\
190 \\
620 \\
620 \\
610^{8} \\
600 \\
575\end{array}$ & $\begin{array}{r}580 \\
510 \\
480 \\
690 \\
690 \\
6758 \\
675 \\
700\end{array}$ & $\begin{array}{l}193 \\
186 \\
179 \\
193 \\
193 \\
186 \\
179 \\
179\end{array}$ \\
\hline $\begin{array}{l}\text { EC316L } \\
\perp \\
\text { annealed }\end{array}$ & FS1 & 90 & 90 & 831 & 393 & 102 & 610 & 675 & 186 \\
\hline $\begin{array}{l}\text { EC316L } \\
\text { weld }\end{array}$ & $\begin{array}{c}\text { FB14 } \\
\text { FB4 }\end{array}$ & $\begin{array}{r}\text { e } \\
80\end{array}$ & $\begin{array}{l}90 \\
90\end{array}$ & $\begin{array}{l}676 \\
340\end{array}$ & $\begin{array}{l}355 \\
252\end{array}$ & $\begin{array}{r}f \\
119\end{array}$ & $\begin{array}{l}230 \\
610\end{array}$ & $\begin{array}{l}510 \\
670\end{array}$ & $\begin{array}{l}186 \\
186\end{array}$ \\
\hline $\begin{array}{l}\text { J316 } \\
\text { annealed }\end{array}$ & $\begin{array}{r}\text { FC8 } \\
\text { FC24 } \\
\text { FC12 } \\
\end{array}$ & $\begin{array}{r}\mathrm{e} \\
\mathrm{e} \\
85\end{array}$ & $\begin{array}{l}22 \\
90 \\
90\end{array}$ & $\begin{array}{l}798 \\
958 \\
733 \\
\end{array}$ & $\begin{array}{l}393 \\
422 \\
369 \\
\end{array}$ & $\begin{array}{r}f \\
100 \\
\end{array}$ & $\begin{array}{r}275 \\
230 \\
690^{3}\end{array}$ & $\begin{array}{r}575 \\
500 \\
6958 \\
\end{array}$ & $\begin{array}{l}193 \\
186 \\
186 \\
\end{array}$ \\
\hline $\begin{array}{l}\text { J316 } \\
\text { cold- } \\
\text { worked }\end{array}$ & $\begin{array}{l}\text { FD5 } \\
\text { FD12 } \\
\text { FD11 }\end{array}$ & $\begin{array}{r}e \\
90 \\
270\end{array}$ & $\begin{array}{r}90 \\
90 \\
250\end{array}$ & $\begin{array}{l}538 \\
479 \\
136\end{array}$ & $\begin{array}{l}317 \\
299 \\
156\end{array}$ & $\begin{array}{l}88 \\
46 \\
18\end{array}$ & $\begin{array}{r}675 \\
8258 \\
800\end{array}$ & $\begin{array}{r}770 \\
8358 \\
825\end{array}$ & $\begin{array}{l}186 \\
186 \\
179\end{array}$ \\
\hline $\begin{array}{l}\text { JPCA } \\
\text { annealed }\end{array}$ & $\begin{array}{r}\text { FF10 } \\
\text { FF13 } \\
\text { FF20 } \\
\text { FF5 } \\
\text { FF16 } \\
\text { FF2 } \\
\text { FF18 }\end{array}$ & $\begin{array}{r}e \\
e \\
e \\
70 \\
70 \\
70 \\
270\end{array}$ & $\begin{array}{r}25 \\
100 \\
200 \\
22 \\
100 \\
200 \\
250\end{array}$ & $\begin{array}{l}672 \\
705 \\
499 \\
360 \\
306 \\
220 \\
123\end{array}$ & $\begin{array}{l}360 \\
362 \\
299 \\
264 \\
239 \\
198 \\
148\end{array}$ & $\begin{array}{r}f \\
f \\
f \\
41 \\
34 \\
38 \\
21\end{array}$ & $\begin{array}{r}255 \\
240 \\
215 \\
725 \\
7158 \\
675 \\
620 \\
\end{array}$ & $\begin{array}{r}580 \\
525 \\
490 \\
750 \\
7408 \\
700 \\
670 \\
\end{array}$ & $\begin{array}{l}193 \\
186 \\
179 \\
193 \\
186 \\
179 \\
179\end{array}$ \\
\hline $\begin{array}{l}\text { JPCA } \\
\text { cold. } \\
\text { worked }\end{array}$ & $\begin{array}{l}\text { FE6 } \\
\text { FE3 } \\
\text { FE8 }\end{array}$ & $\begin{array}{l}e \\
90\end{array}$ & $\begin{array}{l}22 \\
90 \\
90\end{array}$ & $\begin{array}{l}356 \\
296 \\
168\end{array}$ & $\begin{array}{l}262 \\
234 \\
177\end{array}$ & $\begin{array}{l}43 \\
48 \\
25\end{array}$ & $\begin{array}{r}675 \\
655 \\
9258\end{array}$ & $\begin{array}{r}725 \\
705 \\
9508\end{array}$ & $\begin{array}{l}193 \\
186 \\
186\end{array}$ \\
\hline $\begin{array}{l}\text { JPCA } \\
\text { weld }\end{array}$ & $\begin{array}{c}\text { FG13 } \\
\text { FG8 } \\
\text { FG12 }\end{array}$ & $\begin{array}{r}e \\
90 \\
270\end{array}$ & $\begin{array}{r}90 \\
90 \\
250\end{array}$ & $\begin{array}{r}1026 \\
317 \\
237\end{array}$ & $\begin{array}{l}437 \\
242 \\
206\end{array}$ & $\begin{array}{r}f \\
46 \\
42\end{array}$ & $\begin{array}{l}240 \\
715 \\
620\end{array}$ & $\begin{array}{l}525 \\
740 \\
670\end{array}$ & $\begin{array}{l}186 \\
186 \\
179\end{array}$ \\
\hline $\begin{array}{l}\text { JPCA } \\
\text { EB weld }\end{array}$ & FR11 & 85 & 90 & 882 & 405 & 102 & 715 & 740 & 186 \\
\hline $\begin{array}{l}\text { US316 } \\
\text { annealed }\end{array}$ & $\begin{array}{l}\text { FK6 } \\
\text { FK7 }\end{array}$ & $\begin{array}{r}e \\
80\end{array}$ & $\begin{array}{l}90 \\
90\end{array}$ & $\begin{array}{l}233 \\
155\end{array}$ & $\begin{array}{l}208 \\
170\end{array}$ & $\begin{array}{l}70 \\
10\end{array}$ & $\begin{array}{l}230 \\
690\end{array}$ & $\begin{array}{l}500 \\
695\end{array}$ & $\begin{array}{l}186 \\
186\end{array}$ \\
\hline $\begin{array}{l}\text { US316 } \\
\text { cold- } \\
\text { worked }\end{array}$ & $\begin{array}{r}\text { FL13 } \\
\text { FL8 } \\
\text { FL15 } \\
\text { FLS }\end{array}$ & $\begin{array}{r}e \\
e \\
80 \\
270\end{array}$ & $\begin{array}{r}22 \\
90 \\
90 \\
250\end{array}$ & $\begin{array}{l}37 \\
39 \\
21 \\
20\end{array}$ & $\begin{array}{l}85 \\
85 \\
62 \\
60\end{array}$ & $\begin{array}{c}-1 \\
0 \\
0\end{array}$ & $\begin{array}{r}725 \\
715 \\
8508 \\
825\end{array}$ & $\begin{array}{r}785 \\
770 \\
8658 \\
860\end{array}$ & $\begin{array}{l}193 \\
186 \\
186 \\
179\end{array}$ \\
\hline 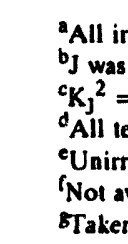 & $\begin{array}{l}\text { liated spec } \\
\text { lculated ac } \\
\mathrm{E} \text {, where } \mathrm{E} \\
\text { ile propert } \\
\text { iated. } \\
\text { lable; not } \\
\text { rom tensile }\end{array}$ & $\begin{array}{l}\text { ens were irradi: } \\
\text { ding to ASTM } \\
\text { Young's modu } \\
\text { are estimated f } \\
\text { ugh data were } \\
\text { st at } 90^{\circ} \mathrm{C} \text {. }\end{array}$ & $\begin{array}{l}\text { d to approxim } \\
1152-87 . \\
\text { m literature v } \\
\text { lained to cact }\end{array}$ & $\begin{array}{l}\text { ly } 3 \text { dpa. } \\
\text { es, except } \\
\text { e a J-R c }\end{array}$ & noted. & & & & \\
\hline
\end{tabular}


growth began. This resulted in gross changes in the specimen geometry, and so the crack length predictions were not very accurate. The J-R curves for such materials are generally much steeper than the calculated blunting line. In these cases, the data were used to calculate a blunting line. A straight line was fit by eye through the initial portion of the data points, and a second line was drawn parallel to the first but offset by an amount corresponding to a crack extension of $0.2 \mathrm{~mm}$ as dictated in the ASTM standards. The candidate toughness $\mathrm{J}_{\mathrm{Q}}$ value was then determined from the intersection of the data with this offset line. In cases where the data rose very steeply, the test was terminated before there was enough crack growth to cross the second exclusion line (drawn corresponding to a crack extension of $1.5 \mathrm{~mm}$ as defined in the ASTM standards). As a result, no tearing modulus (T) value could be calculated. Materials with lower toughness, such as the cold-worked austenitic stainless steels, behaved in a conventional manner. For these materials, the data followed the calculated blunting line quite closely, so no additional construction was required. These specimens also showed good agreement between the measured and predicted final crack lengths.

During neutron irradiation at temperatures in the range $60^{\circ}$ to $300^{\circ} \mathrm{C}$, rapid hardening occurs due to the formation of a high density of black spot defect clusters and faulted Frank loops [2]. Following irradiations to $10 \mathrm{dpa}$, yield stresses for annealed austenitic steels are usually of the order 750 to $800 \mathrm{MPa}$; yield stresses for cold-worked materials range from 850 to $950 \mathrm{MPa}[2,10]$. In the current experiments, irradiated to $3 \mathrm{dpa}$, yield stresses are in the range 610 to $715 \mathrm{MPa}$ for annealed materials and 825 to $925 \mathrm{MPa}$ for cold-worked materials (see Fig. 1). Thus, these cold-worked materials are close to the maximum hardness level and the annealed materials have reached approximately $75 \%$ of the saturation level.

Both before and after irradiation, the fracture toughnesses of the solution annealed materials, as shown in Fig. 2, are generally very high $\left(\mathrm{K}_{\mathrm{J}}>150 \mathrm{MPa} / \mathrm{m}\right)$ in the test temperature range. The toughness decreases slightly as the temperature increases, but remains very high, even after irradiation and testing at $250^{\circ} \mathrm{C}$. The EC316 L and $\mathrm{J} 316$ annealed steels show only a slight decrease in toughness (about $50 \mathrm{MPa} \sqrt{\mathrm{m}}$ ) after irradiation. The JPCA annealed material undergoes a larger decrease in toughness (about $100 \mathrm{MPa} / \mathrm{m}$ ) after irradiation. Even in this case, the toughness is still high, with a $\mathrm{K}_{\mathrm{J}}$ value of $150 \mathrm{MPa} / \mathrm{m}$ (Table 2). The range of fracture toughness values of these materials is in the upper range of previously reported data from a variety of steels, reactor environments, and test methods [11-13]. The US316 material has the lowest toughness both before and after irradiation. This heat of material was air melted and contains an unusually high volume fraction of nonmetallic inclusions which are likely to promote rapid microvoid growth and coalescence.

The fracture toughness of the cold-worked material is generally lower than that of the annealed material by about $75 \mathrm{MPa} \vee \mathrm{m}$, both before and after irradiation. Even so, the fracture toughnesses of the cold-worked JPCA and J316 materials remain high. It is important to note that the uniform elongations of these materials, tested at $90^{\circ} \mathrm{C}$, are less than $1 \%$, while the fracture toughness and tearing modulus values are still high. The toughness of the cold-worked US316 material, which had the lowest toughness of the austenitic steels in the solution annealed condition, was by far the lowest toughness value of the set, with a $\mathrm{K}_{\mathrm{J}}$ value of $65 \mathrm{MPa} / \mathrm{m}$. This material also had very low values of tearing modulus. Note that the negative value reported in Table 2 is not physically real, but is merely an artifact of the curve-fitting procedure.

Electron beam welds of JF CA and GTA welds of JPCA and EC316L proved to be very tough, both before and after irradiation. The JPCA GTA welded material had approximately the same toughness as the JPCA SA material $\left(\mathrm{K}_{\mathrm{J}} * 240 \mathrm{MPa} \vee \mathrm{m}\right)$ after irradiation and testing at $90^{\circ} \mathrm{C}$, while the JPCA EB-welded material had an even higher toughness. 


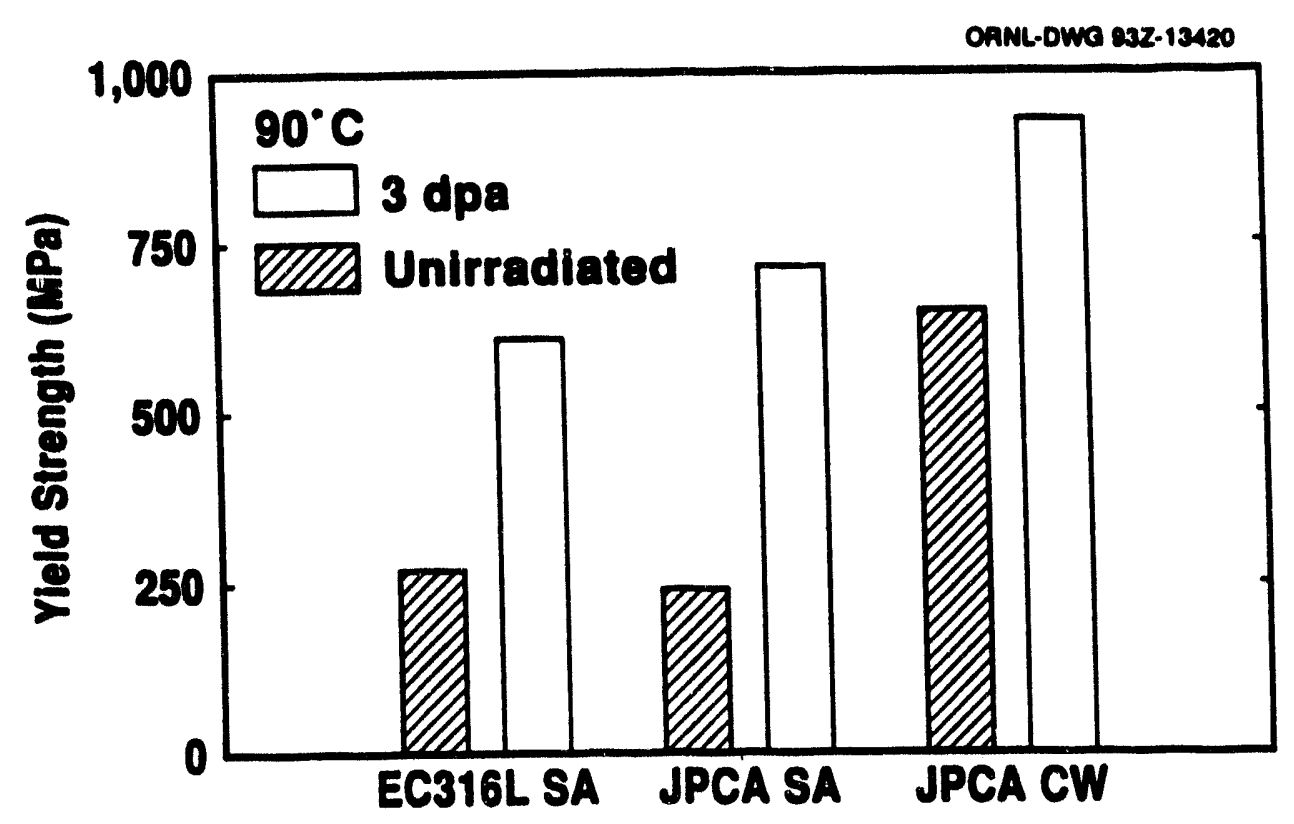

1. Radiation-induced increase in yield strength after irradiation to $3 \mathrm{dpa}$. Irradiation and test temperatures were $90^{\circ} \mathrm{C}$.

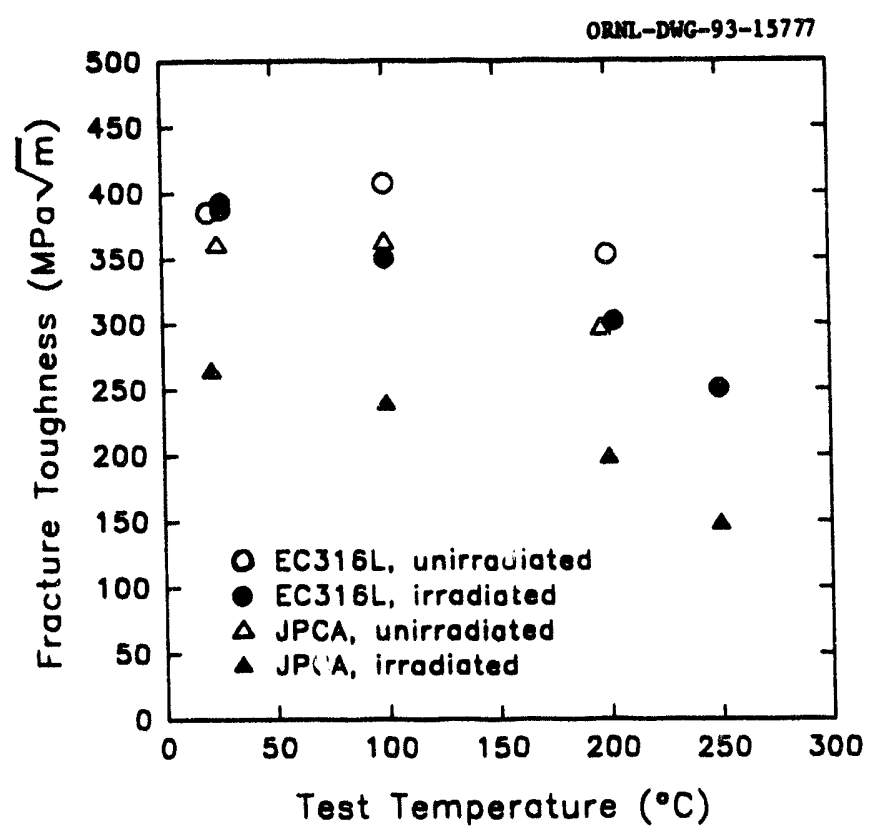

2. Fracture toughness values of solution annealed materials as a function of test temperature. The open symbols represent unirradiated specimens and the closed symbols represent irradiated specimens. $A_{\Lambda}$ specimens tested at $20-200^{\circ} \mathrm{C}$ were irradiated at $90^{\circ} \mathrm{C}$. The specimens tested at $250^{\circ} \mathrm{C}$ were ir:ustiaied at $250^{\circ} \mathrm{C}$. 
As pointed out above, the unirradiated EC316L material contained ferrite stringers running along the rolling direction of the plate. However, it was found that specimens with the crack propagation direction parallel to the direction of the delta ferrite stringers had essentially the same toughness as specimens with the crack propagation perpendicular to the stringer direction.

\section{CONCLUSIONS}

Specimens of several austenitic stainless steels have been irradiated in HFIR to about 3 dpa at either 60 to $125^{\circ} \mathrm{C}$ or 250 to $300^{\circ} \mathrm{C}$ with fusion levels of helium. Eleven variants in composition and thermomechanical treatment have been investigated. With the exception of the air-melted coldworked US316 alloy, all exhibited high fracture toughness after irradiation with $\mathrm{K}_{\mathrm{J}}$ values in the range of 150 to $400 \mathrm{MPa} / \mathrm{m}$ over a temperature range of 20 to $250^{\circ} \mathrm{C}$. Fracture toughness generally decreases with increasing temperature, both before and after irradiation. The effect of irradiation is most noticeable at higher test temperatures. The JPCA alloy undergoes a larger decrease in fracture toughness after irradiation than does either the EC316L or the J316 alloy. Both before and after irradiation, the cold-worked materials have lower fracture toughness than the annealed steels. The welded specimens have lower toughness than the base metals but the toughness is still high, both before and after irradiation. Ferrite stringers in EC316L in the rolling direction do not significantly affect the toughness.

\section{FUTURE WORK}

Additional fracture toughness specimens will be tested in both the irradiated and unirradiated conditions in order to complete the experimental matrix. Tensile tests will be completed for each alloy variant. Transmission electron microscopy will also be performed.

\section{ACKNOWLEDGMENTS}

The fracture toughness testing was performed by R. L. Swain. The authors are grateful to Drs. R. L. Klueh and S. K. Iskander for constructive reviews of the manuscript. The authors also would like to thank J. L. Bishop and G. L. Burn for the preparation of the manuscript. Research sponsored by the Office of Fusion Energy, U.S. Department of Energy, under contract DE-AC05-84OR21400 with Martin Marietta Energy Systems, Inc, and Japan Atomic Energy Research Institute.

\section{REFERENCES}

[1] M. L. Grossbeck, J. Nucl. Mater. 179-181 (1991) 568.

[2] M. L. Grossbeck, P. J. Maziasz and A. F. Rowcliffe, J. Nucl. Mater. 191-194 (1992) 808.

[3] C. Elliot, M. Enmark, G. E. Lucas, G. R. Odette and A. Rowcliffe, J. Nucl. Mater. 179-181 (1991) 434.

[4] D. J. Alexander, "Fracture Toughness Measurements with Subsize Disk Compact Specimens," Fusion Reactor Materials Semiannual Progress Report for Period Ending March 31, 1992, DOE/ER-0313/12, U. S. DOE Office of Fusion Energy, 1992, p. 35. 
[5] D. J. Alexander, in: Small Specimen Test Techniques Applied to Nuclear Reactor Vessel Thermal Annealing and Plant Life Extension, ASTM STP 1204, Eds. W. R. Corwin, F. M. Haggag, and W. L. Server (American Society for Testing and Materials, Philadelphia, 1993) p. 130.

[6] A. W. Longest, D. W. Heatherly, K. R. Thoms and J. E. Corum, "Design and Fabrication of HFIR-MFE-JP Target Irradiation Capsules," Fusion Reactor Materials Semiannual Progress Report for Period Ending March 31, 1991, DOE/ER-0313/10, U. S. DOE Office of Fusion Energy, 1991, p. 3. [7] A. W. Longest, D. W. Heatherly, J. E. Wolfe, K. R. Thoms and J. E. Corum, "Fabrication and Irradiation of HFIR-MFE-JP-17, -18, and -19 Target Irradiation Capsules," Fusion Reactor Materials Semiannual Progress Report for Period Ending September 30, 1991, DOE/ER-0313/11, U. S. DOE Office of Fusion Energy, 1992, p. 30.

[8] A. W. Longest, D. W. Heatherly, K. R. Thoms and J. E. Corum, "Fabrication and Irradiation of HFIR-MFE-JP-17, -18, and -19 Target Irradiation Capsules," Fusion Reactor Materials Semiannual Progress Report for Period Ending March 31, 1992, DOE/ER-0313/12, U. S. DOE Office of Fusion Energy, 1992, p. 24.

[9] R. K. Nanstad, D. J. Alexander, R. L Swain, J. T. Hutton and D. L. Thomas, in: Applications of Automation Technology to Fatigue and Fracture Testing, ASTM STP 1092, Eds. A. A. Braun, N. E. Ashbaugh and F. M. Smith (American Society for Testing and Materials, Philadelphia, 1990) p. 7.

[10] M. L. Grossbeck, K. Ehrlich and C. Wassilew, J. Nucl. Mater. 174 (1990) 264.

[11] G. E. Lucas, J. Nucl. Mater. 206 (1993) in press.

[12] G. R. Odette and G. E. Lucas, J. Nucl. Mater. 179-181 (1991) 572.

[13] G. R. Odette and G. E. Lucas, J. Nucl. Mater. 191-194 (1992) 50. 
Tensile Properties of Base and Weld Metal Specimens of Austenitic Stainless Steels Irradiated in the High Flux Isotope Reactor - K. Shiba and S. Jitsukawa (Japan Atomic Energy Research Institute) and J. E. Pawel and A. F. Rowcliffe (Oak Ridge National Laboratory)

\section{OBJECTIVE}

The objective of this work is to determine the neutron irradiation effects on the tensile properties of weld joints of type 316 stainless steel.

\section{SUMMARY}

Tensile properties of Japanese Primary Candidate Alloy (JPCA) base metal and welded specimens irradiated in HFIR target positions were investigated. Electron beam (EB) and tungsten inert gas (TIG) welding techniques were used to make welded specimens. Welded specimens included weld metal and weld joint specimens. These specimens were irradiated up to $18 \mathrm{dpa}$ at $300,400,500$ and $600^{\circ} \mathrm{C}$. JPCA solution annealed base metal had maximum irradiation hardening. at $300{ }^{\circ} \mathrm{C}$, and it showed minimum elongation at that temperature. EB welded specimens exhibited almost the same tensile properties as the base metal, with the strength of the EB weld metal and weld joint specimens being only slightly lower than that of the base metal. EB welded specimens retained uniform elongations in the range of 2 to $7 \%$ after irradiation. TIG welded specimens had less ductility than the EB welded specimens, however the other tensile properties of the TIG welded specimens were almost same as for the EB welded specimens.

\section{PROGRESS AND STATUS}

\section{Introduction}

Austenitic stainless steels are the prime candidate alloy for the first wall and shield of the International Thermonuclear Experimental Reactor (ITER). Although the design of ITER is not fixed yet, welding will be used extensively in the construction of the structural components. Therefore, it is important to know the irradiation behavior of the welded joint. Unfortunately only limited irradiation data are available currently on welded joints. The welded joint consists of different structural parts, such as base metal, weld metal and heat affected zones. These parts have different thermal histories and variations in solute concentration due to solidification of molten metal. These structural differences cause differences in irradiation behavior ${ }^{1,2}$. To get good irradiation response of a welded joint, welding techniques have to be optimized. This study examines the effect of neutron irradiation in HFIR on the tensile properties of JPCA weldments.

\section{Experimental Procedure}

The alloy investigated was the Japanese Primary Candidate Alloy (JPCA) in both the solution annealed (SA) and 15\% cold worked (CW) conditions. The chemical composition of this alloy is shown in Table 1. Electron beam (EB) welding and tungsten inert gas (TTG) welding techniques were used to make welded specimens. EB welding was performed without using filler metal. The chemical composition of the filler metal used for TIG welding is also listed in Table 1. Tensile specimens were fabricated to contain all weld metal (WM) or to contain the weld joint at the center of the gage (WJ), Fig. 1. One side of the fusion line was placed at the center of the weld joint specimen. Some EB welds were made with a titanium foil insert to increase the titanium content of the weld metal. The thickness of Ti foil was $10 \mu \mathrm{m}$. Sheet tensile (SS-3) specimens with a gage section of $7.62 \mathrm{~mm}$ in length, $0.762 \mathrm{~mm}$ in thickness and $1.524 \mathrm{~mm}$ 
in width were used. The lengths of weld metal of the weld joints were $2-3 \mathrm{~mm}$ and 5-10 $\mathrm{mm}$ for EB and TIG respectively.

Table 1 Chemical composition of alloys (wt\%)

\begin{tabular}{c|cccccccccccccc}
\hline Alloy & $\mathrm{C}$ & $\mathrm{Si}$ & $\mathrm{Mn}$ & $\mathrm{P}$ & $\mathrm{S}$ & $\mathrm{Cr}$ & $\mathrm{Ni}$ & $\mathrm{Mo}$ & $\mathrm{Ti}$ & $\mathrm{B}$ & $\mathrm{N}$ & $\mathrm{Co}$ & $\mathrm{Cu}$ & $\mathrm{Fe}$ \\
\hline JPCA & 0.052 & 0.51 & 1.78 & 0.028 & 0.005 & 14.3 & 15.5 & 2.3 & 0.24 & 0.003 & 0.004 & 0.003 & - & $\mathrm{bal}$ \\
\hline JPCAW & 0.057 & 0.35 & 1.77 & 0.008 & 0.002 & 14.4 & 16.1 & 2.4 & 0.23 & 0.0023 & 0.0095 & 0.008 & - & bal. \\
\hline JPCAW is filler metal for TIG welding, EB welding was performed without filler.
\end{tabular}

Tensile specimens were irradiated in HFIR target position capsules JP-10, 11, 13 and 16 for 11 cycles to $20279 \mathrm{MWd}$. Damage level at mid-plane of capsule was approximately $18 \mathrm{dpa}$. Nominal irradiation temperatures were $300,400,500$ and $600{ }^{\circ} \mathrm{C}$. Helium concentration due to the two-step $\mathrm{Ni}$ reaction with thermal neutrons was about $400-1400 \mathrm{appm}^{3}$.

Specimens were tested in vacuum on an Instron universal testing machine at the nominal irradiation temperature of each specimen. The strain rate was $1 \times 10^{-3} \mathrm{~s}^{-1}$. Fracture surface areas were measured using an optical microscope and video system after tensile testing.

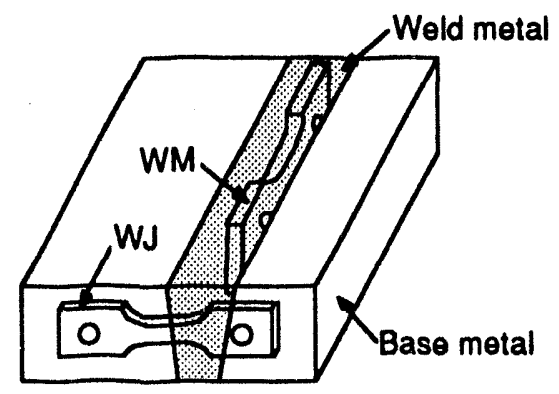

Fig. 1 Sampling location for welded specimens from weld joint.

\section{Results and Discussion}

Tensile data, including $0.2 \%$ offset yield stress (YS), ultimate tensile stress (UTS), uniform elongation $\left(E_{W}\right)$, total elongation $\left(E_{\mathfrak{t}}\right)$, reduction of area (RA) and fracture stress $(F S)$ were measured. The $R_{A}$ value was calculated by the formula $\left(A_{0}-A_{f}\right) / A_{0}$, where $A_{0}$ is the initial cross sectional area and $A_{f}$ is the fracture surface area, measured by optical microscopy after the tensile test was completed. Fracture stress was calculated from the RA value and the nominal fracture stress obtained from the stress-strain curve. The results of tensile testing are listed in Table 2.

There was some scatter in the data taken at 400 and $500^{\circ} \mathrm{C}$. Because irradiation hardening is very sensitive to irradiation temperature around $400^{\circ} \mathrm{C}^{4,5}$, small deviations in temperature in this range can have a large effect on mechanical properties. These temperature deviations could be the result of irradiation capsule and vertical reactor position differences in the experiinent. The accumulated dose also varied among the specimens, from 8 to $18 \mathrm{dpa}$. The RA values and fracture stress tended to be lower for specimens receiving the higuler dose.

\section{Base Metal}

The unirradiated yield stress decreases slightly with temperature over the range investigated (236 $\mathrm{MPa}$ at $300^{\circ} \mathrm{C}$ and $194 \mathrm{MPa}$ at $600^{\circ} \mathrm{C}$ ). At each temperature investigated, the irradiation-induced strength increase of the base metal (BM) was accompanied by a decrease in elongation. Maximum irradiation 
Table 2

Tensile properties of JPCA base metal and welded specimens before and after irradiation in HFIR target position.

\begin{tabular}{|c|c|c|c|c|c|c|c|c|}
\hline \multirow[b]{2}{*}{ Material } & \multirow{2}{*}{$\begin{array}{l}\text { Irrad. \& Test } \\
\text { Temp. }\left({ }^{\circ} \mathrm{C}\right)\end{array}$} & \multirow{2}{*}{$\begin{array}{c}\text { Damage } \\
\text { (dpa) }\end{array}$} & \multicolumn{3}{|c|}{ Strength $(\mathrm{MPa})$} & \multicolumn{2}{|c|}{ Elongation $(\%)$} & \multirow[t]{2}{*}{$\mathbf{R A}$} \\
\hline & & & YS & UTS & FS & $\mathrm{Eu}$ & $\mathrm{Et}$ & \\
\hline \multirow[t]{10}{*}{ SA/BM } & 300 & 15 & 809 & 845 & 1322 & 4.2 & 12.3 & 0.55 \\
\hline & 400 & 18 & 599 & 693 & 999 & 8.3 & 14.2 & 0.48 \\
\hline & 400 & 8 & 591 & 662 & - & 7.7 & 14.2 & - \\
\hline & 400 & 18 & 785 & 789 & - & - & - & - \\
\hline & 500 & 18 & 470 & 562 & 794 & 9.5 & 16.5 & 0.47 \\
\hline & 500 & 10 & 500 & 611 & 1279 & 10.7 & 15.8 & 0.63 \\
\hline & 600 & 10 & 363 & 467 & 664 & 12.7 & 19.7 & 0.45 \\
\hline & 300 & 0 & 236 & 460 & - & 36.0 & 44.0 & 0.87 \\
\hline & 400 & 0 & 238 & 488 & 1218 & 40.3 & 48.0 & 0.75 \\
\hline & 600 & 0 & 194 & 451 & 1027 & 36.3 & 46.7 & 0.77 \\
\hline \multirow[t]{2}{*}{$\overline{\mathrm{CW} / \mathrm{BM}}$} & 500 & 18 & 655 & 743 & 995 & 7.8 & 13.8 & $\overline{0.42}$ \\
\hline & 500 & 0 & 547 & 612 & - & 8.0 & 15.7 & - \\
\hline \multirow[t]{10}{*}{$\overline{S A / E B / W M}$} & 300 & 15 & 783 & 787 & 1248 & 3.0 & 10.7 & 0.55 \\
\hline & 400 & 18 & 563 & 645 & 882 & 7.4 & 14.5 & 0.48 \\
\hline & 400 & 10 & 727 & 749 & - & 1.8 & 8.3 & - \\
\hline & 400 & 10 & 443 & 518 & 917 & 6.3 & 11.3 & 0.56 \\
\hline & 500 & 18 & 428 & 528 & 900 & 12.0 & 17.3 & 0.53 \\
\hline & 600 & 10 & 337 & 388 & 389 & 2.8 & 2.8 & 0.02 \\
\hline & 300 & 0 & 257 & 455 & 1483 & 30.7 & 39.7 & 0.81 \\
\hline & 400 & 0 & 251 & 464 & 1010 & 36.7 & 42.0 & 0.69 \\
\hline & 500 & 0 & 246 & 441 & 1053 & 36.0 & 45.3 & 0.74 \\
\hline & 600 & 0 & 230 & 428 & 1087 & 32.3 & 39.0 & 0.77 \\
\hline \multirow[t]{8}{*}{ SA/EB/WJ } & 300 & 15 & 728 & 746 & 1109 & 3.1 & 12.3 & 0.54 \\
\hline & 400 & 17 & 679 & 692 & 1110 & 1.3 & 6.8 & 0.56 \\
\hline & 500 & 18 & 427 & 498 & 865 & 7.0 & 14.0 & 0.59 \\
\hline & 600 & 10 & 335 & 416 & 759 & 7.3 & 14.6 & 0.61 \\
\hline & 300 & 0 & 275 & 440 & 1312 & 9.0 & 16.0 & 0.81 \\
\hline & 400 & 0 & 271 & 435 & 1381 & 9.7 & 17.3 & 0.80 \\
\hline & 500 & 0 & 250 & 408 & 1396 & 10.7 & 17.3 & 0.79 \\
\hline & 600 & 0 & 247 & 401 & 1237 & 10.3 & 17.3 & 0.77 \\
\hline \multirow[t]{4}{*}{ SA/TIG/WM } & 400 & 16 & 680 & 689 & - & 1.7 & 8.7 & - \\
\hline & 500 & 16 & 610 & 622 & 745 & 2.0 & 6.8 & 0.34 \\
\hline & 400 & 0 & 250 & 417 & 1558 & 11.3 & 20.7 & 0.85 \\
\hline & 500 & 0 & 311 & 288 & 1216 & 12.0 & 17.7 & 0.79 \\
\hline \multirow[t]{4}{*}{ SA/TIG/WJ } & 400 & 16 & 665 & 673 & 848 & 1.2 & 7.0 & 0.44 \\
\hline & 500 & 16 & 647 & 657 & 735 & 1.3 & 10.3 & 0.37 \\
\hline & 400 & 0 & 348 & 448 & 1323 & 14.3 & 19.3 & 0.74 \\
\hline & 500 & 0 & 332 & 423 & 1500 & 13.7 & 16.7 & 0.84 \\
\hline \multirow[t]{2}{*}{ SA/Ti-insert EB/WM } & 600 & 8 & 245 & 356 & 554 & 14.7 & 23.2 & 0.51 \\
\hline & 600 & 0 & 175 & 403 & 1062 & 18.0 & 56.0 & 0.74 \\
\hline
\end{tabular}

hardening was observed at $300{ }^{\circ} \mathrm{C}$ for the solution annealed (SA) specimens, as shown in Fig. 2. As the irradiation temperature increased, the hardening decreased and a corresponding increase in elongation was observed. Uniform elongation and total elongation of JPCA/SA/BM were $4.2 \%$ and $12.3 \%$, respectively, at $300{ }^{\circ} \mathrm{C}$. Thus, it retained relatively high elongation even at the temperature at which maximum hardening occurred. Many austenitic stainless steels have less than $1 \%$ uniform elongation under similar irradiation conditions ${ }^{6}$. The fracture stresses were generally reduced with increasing temperature. RA values decreased from $300^{\circ} \mathrm{C}$ to $400^{\circ} \mathrm{C}$ and then remained generally constant.

The base metal in the $15 \%$ cold worked $(\mathrm{CW})$ condition was tested only at $500^{\circ} \mathrm{C}$. Both before and after irradiation, the CW material had higher strength and lower elongation than the SA material, indicating that the influence of cold work before irradiation was still apparent after irradiation. 

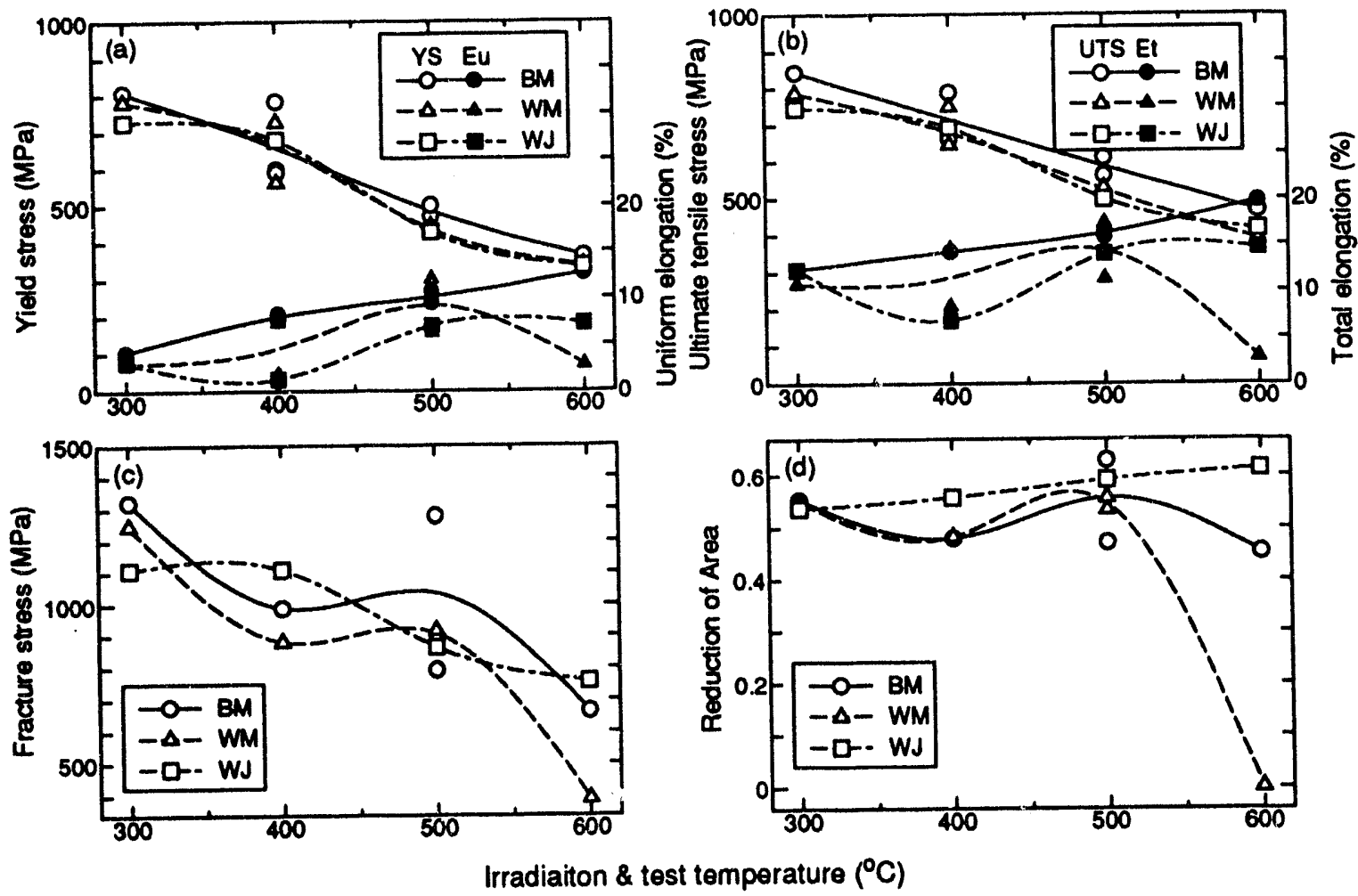

Fig. 2 Tensile properties as a function of temperature for JPCA SA base metal and welded specimens irradiated in HFIR up to $18 \mathrm{dpa}$ in the temperature range of 300 to $600^{\circ} \mathrm{C}$. (a) yield stress and uniform elongation, (b) ultimate tensile stress and total elongation, (c) fracture stress and (d) reduction of area.

\section{Electron Beam Welded Specimens}

Before irradiation, the weld metal and the weld joint specimens both had higher yield strengths and smaller uniform elongations at each temperature than the corresponding base metal specimens. After irradiation, the weld metal and weld joint specimens had slightly smaller yield strengths and uniform elongations than the base metal specimens, as shown in Fig. 2. The differences between the three types of specimens (base metal, weld metal, weld joint) at a given temperature were not very large. The temperature dependencies of $Y S$ and $E_{u}$ of the weld metal and weld joint specimens were generally the same as those of the base metal specimens across this temperature range. However, the uniform elongation of EB/WJ and WM specimens appeared to have a relative minimum at $400^{\circ} \mathrm{C}$.

Both before and after irradiation, all of the weld joint specimens fractured in the weld metal region. The yield stresses of the weld joint specimens were almost the same as those of the weld metal specimens, but the elongations of the WJ specimens were smaller. This suggests initial deformation occurred in the weld metal region of the weld joint specimens because of its lower yield stress, compared to the base metal. Furthermore, deformation was observed at a narrow weld metal region for an EB weld joint. The weld metal region of the weld joint specimens was about one-third of the gage length for the EB specimens. Therefore, the small elongation of weld joint specimens may be caused by the nonuniform deformation in the weld metal region. Because of this, $\mathrm{E}_{\mathrm{u}}$ may not adequately indicate the ductility of the weld joint specimens. In such cases, the RA value can be used as an estimate of the ductility. The RA values for the three types of specimens were essentially the same at $300^{\circ} \mathrm{C}$. The RA values of EB/WJ specimens were higher than BM or WM above $400^{\circ} \mathrm{C}$, and the RA values of WJ specimens increased with temperature although the BM and WM values decreased. This indicates that the weld joint specimens do retain some ductility after irradiation up to $18 \mathrm{dpa}$ and $1400 \mathrm{appm}$ He. 
The EB weld metal exhibited a large ductility loss at $600^{\circ} \mathrm{C}$. After irradiation at this temperature, the uniform elongation was only $2.8 \%$, compared to $12 \%$ at $500{ }^{\circ} \mathrm{C}$, and the RA value was essentially zero, compared to 0.76 at $500^{\circ} \mathrm{C}$. It is known that the precipitation of TiC can modify the distribution of helium, especially above $500^{\circ} \mathrm{C}^{7}$, and that titanium can segregate during the welding process $[1,2]$. To investigate the possibility of improving weld properties, specimens were EB welded using a titanium-foil insert in the weld metal. For the standard EB weld, irradiation to $\sim 10 \mathrm{dpa}$ at $600{ }^{\circ} \mathrm{C}$ lowers the uniform elongation to $2.8 \%$. For the specimen made with a Ti-foil insert in the EB weld, the $E_{\mathbf{u}}$ decreased only from 18 to $15 \%$ after irradiation. The post-irradiation $E_{u}$ and $R A$ values were even larger than those of the base metal. The Ti-foil insert EB weld metal had an irradiation-induced hardening of about $30 \%$ whereas the base metal hardened by $45 \%$ at this temperature. These data indicate that the Ti-foil insert is effective in minimizing irradiation hardening and loss of ductility under these conditions.

\section{TlG Welded Specimens}

The TIG weld material, consisting of both weld metal and weld joint specimens, was irradiated at 400 and $500{ }^{\circ} \mathrm{C}$. The TIG weld joint and weld metal specimens showed higher strength and lower elongation than EB welded specimens at $500{ }^{\circ} \mathrm{C}$. The strength and elongation of TIG WM and WJ were generally the same as EB welded specimens at $400^{\circ} \mathrm{C}$. The RA values of the TIG welded specimens were smaller than EB welded specimens at these temperatures. The fracture stresses of TIG welded specimens were also lower than for corresponding specimens made by EB.

\section{Comparison With Previous ORR Results}

In general, for this experiment, the TIG welded specimens broke at lower fracture stresses and with less reduction in area than did the corresponding EB welded specimens, even at $400{ }^{\circ} \mathrm{C}$ where the yield strengths and uniform elongations were essentially the same. This tendency of TIG welds was also observed for type 316 stainless steel (J316) TIG welds irradiated in spectrally tailored capsules in the Oak Ridge Research Reactor (ORR) ${ }^{8,9}$. The results of the ORR irradiation showed that the TIG welds had a significantly lower RA after irradiation and testing between 330 and $400^{\circ} \mathrm{C}$ than did EB welds. The EB joints retained relatively high ductility in this experiment. These results, combined with the current investigation, suggest that EB welds of JPCA will perform satisfactorily after neutron irradiation to about 20 dpa from 300 to $600{ }^{\circ} \mathrm{C}$.

\section{Conclusions}

JPCA solution annealed base metal had maximum strength and minimum elongation after irradiation at $300^{\circ} \mathrm{C}$. The electron beam welded specimens had only slightly lower strength than the base metal and retained uniform elongations greater than $2 \%$ after irradiation at temperatures less than $600^{\circ} \mathrm{C}$. The reduction of area of the electron beam weld metal is very low at $600^{\circ} \mathrm{C}$ but the titanium-foil insert in the weld lessened the effect of irradiation at this temperature. Radiation-induced hardening was also reduced in this specimen. The TIG welded specimens had about the same strength but less ductility than the EB specimens after irradiation. These results, combined with those of previous experiments, suggest that the tensile properties of EB welds of JPCA will be satisfactory after neutron irradiation to about $20 \mathrm{dpa}$ in the temperature range of $300-600^{\circ} \mathrm{C}$.

\section{FUTURE WORK}

Microstructural studies on irradiated specimens are scheduled to begin during the next reporting period. A higher dose capsule (JP-14, $34 \mathrm{dpa}$ ) has been irradiated and disassembled. Specimens irradiated in this capsule will be tested soon. 


\section{REFERENCES}

1. T. Sawai, K. Fukai, S. Hamada, K. Suzuki and A. Hishinuma, J. Nucl. Mater. 141-143 (1986) 444-447.

2. T. Sawai, K. Fukai, T. Kodaira, T. Nishida, M. Nayama and A. Hishinuma, J. Nucl. Mater. 155157 (1988) 861-865.

3. L.R. Greenwood, J. Nucl. Mater. 115 (1983) 137-142.

4. M.P. Tanaka, S. Hamada, A. Hishinuma and M.L. Grossbeck, J. Nucl. Mater. 155-157 (1988) 957.962.

5. M.P. Tanaka, M. Suzuki, S. Hamada, A. Hishinuma and T. Kondo, Fusion Engineering and Design 9 (1989) 153-158.

6. M.L. Grossbeck, K. Ehrlich and C. Wassilew, J. Nucl. Mater. 174 (1990) 264-281.

7. T. Sawai, P.J. Maziasz and A. Hishinuma, J. Nucl. Mater. 179-181 (1991) 519-522.

8. S. Jitsukawa, PJ. Maziasz, T. Ishiyama, L.T. Gibson and A. Hishinuma, J. Nucl. Mater. 191194 (1992) 771-775.

9. A. Hishinuma, S. Jitsukawa and M.L. Grossbeck, Fusion Reactor Material Semiannual Progress Report, DOE/ER-0313/11, Office of Fusion Energy (1991) 163-166. 


\section{A PRELIMINARY ANALYSIS OF CRACK GROWTH IN TYPE 316L STAINLESS STEEL IN AIR AND WATER UNDER CYCLIC LOADING CONDITIONS FOR ITER FIRST-WALL DESIGN*} M. R. Fox, W. K. Soppet, W. E. Ruther, and T. F. Kassner (Argonne National Laboratory)

\section{OBJECTIVE}

Austenitic stainless steels (SSs) are being considered as a structural material for first-wall/blanket systems in the International Thermonuclear Experimental Reactor (ITER). ${ }^{1}$ Information on the corrosion fatigue properties of candidate SSs under ITER-relevant conditions will help to identify an optimal combination of structural material, coolant chemistry, and operational conditions for ongoing ITER design work. The objective of this task is to provide baseline information on corrosion fatigue of candidate SSs in oxygenated water that simulates many important parameters anticipated in ITER first-wall/blanket systems.

\section{SUMMARY}

Initial results on stress corrosion cracking (SCC) susceptibility ${ }^{2-6}$ and crack growth rate ${ }^{7}$ (CGR) of Type 316L SS in oxygenated water were used with fracture-mechanics relations to compare the fatigue life (cycles to failure) in air and water at $200^{\circ} \mathrm{C}$ of a coolant tube within the ITER first-wall structure for burn and pulse times of 480 and $1000 \mathrm{~s}$, respectively. Fatigue life was evaluated as a function of maximum stress intensity, initial flaw depth in the $3.2-\mathrm{mm}$ wall of the tube, water purity, and threshold stress intensity for SCC.

\section{PROGRESS AND STATUS}

Research and development needs of the ITER with respect to aqueous corrosion include establishing a reliable data base on reference materials, viz., Types $316,316 \mathrm{~L}$, and $316 \mathrm{NG}$ SS in the solution-annealed, coldworked, and welded conditions. A nominal ITER water chemistry would most likely be high-purity (HP) water containing (a) stable radiolysis/electrolysis products, e.g., dissolved $\mathrm{O}_{2}, \mathrm{H}_{2} \mathrm{O}_{2}$, and $\mathrm{H}_{2}$, at ppm levels, and (b) ionic species (at ppb levels), e.g., soluble corrosion products and impurities in the makeup water and from release by ion-exchange resins in water purification systems.

The nominal ITER coolant pressure $(\approx 10 \mathrm{MPa})$, mechanical loads, and temperature gradients across the first-wall structure will produce both static and cyclic stresses, which, when coupled with residual tensile stresses associated with welds, can exceed the yield strength of the material. High tensile stresses under ITER cyclic operation $\left(\approx 10^{4}\right.$ cycles) are conducive to crack initiation and propagation under corrosion fatigue conditions.

Previous work focused on the susceptibility to SCC of Types 316NG, 316L, and 304 SS by conducting slow-strain-rate-tensile (SSRT) tests under crevice and noncrevice conditions. ${ }^{2-6}$ Crack growth data on fracture-mechanics specimens fabricated from Type 316L and two heats of Type 316NG SS were also obtained from corrosion fatigue tests in water containing dissolved oxygen and chloride $\left(\mathrm{Cl}^{-}\right)$at 150,185 , and $225^{\circ} \mathrm{C}^{7}$ The experimental results were used to formulate analytical expressions that quantify the effects of water chemistry and temperature on the CGR of the material. The SSRT and crack growth properties of Type 316L SS were used with fracture-mechanics relations, postulated surface flaws of various size, and a range of loading conditions that may encompass those encountered in ITER design analyses to assess fatigue life of a coolant tube with a wall thickness of $3.2 \mathrm{~mm}$.

\footnotetext{
* Work supported by the U.S. Department of Energy, under Contract W-31-109-Eng-38.
} 
Background

Under normal operating conditions, a heat-transport system can be subjected to combinations of loads acting at the same time. Current design codes specify allowable stress intensities for four load categories. 8,9 The first category addresses primary mean stresses $P_{m}$ that act over the full cross section of a tube or pipe. These stresses are associated with the internal pressure of the coolant and must not exceed the stress intensity limit $S_{m}$, which is $2 / 3$ of the yield stress of the material. The tangential (hoop), axial, and radial stresses are given by

$$
\sigma_{\mathrm{t}}=\mathrm{P} \cdot \mathrm{r}_{\mathrm{j}} / \mathrm{h}, \sigma_{\mathrm{a}}=\mathrm{P} \cdot \mathrm{r}_{\mathrm{j}} / 2 \mathrm{~h}, \text { and } \sigma_{\mathrm{r}}=-\mathrm{P} / 2 \text {, }
$$

respectively, where $P$ is the internal pressure and $r_{i}$ and $h$, respectively, are the inside radius and thickness of the tube. The value of $S_{m}$ limits sustained loads that could cause gross collapse of the structure. The second category limits to $1.5 \mathrm{~S}_{\mathrm{m}}$ the combined stresses of $\mathrm{P}_{\mathrm{m}}$, the primary bending stress $\mathrm{P}_{b}$ by weights and other forms of sustained loads and by internal pressure on flanges, and any secondary mean stresses $\mathrm{Q}_{m}(\mathrm{~s})$ caused by bending loads at junctions with attachments to a pipe. If the tube or pipe is also subjected to thermal transients, a third category limits to $3 \mathrm{~S}_{\mathrm{m}}$ the above loads plus those attributed to secondary mean stress due to temperature $\mathrm{Q}_{m}(t)$, secondary bending stress due to sustained loads $\mathrm{Q}_{b}(\mathrm{~s})$, and secondary bending stress due to linear temperature distribution $\mathrm{Q}_{b}(t)$. The fourth load category addresses peak stresses due to temperature and localized stress concentration.

The dependence of tangential stress on temperature for Type 316L SS piping of several sizes is shown in Fig. 1, along with the variation of ultimate tensile stress (UTS), yield stress (YS), and $S_{m}$ with temperature, taken from the ASME Code. ${ }^{8}$ In relation to ITER first wall designs, 3/8-80S pipe with an O.D. and thickness of 17 and $3.2 \mathrm{~mm}$, respectively, was used in the following analysis of fatigue life in air and water. As can be seen in Fig. 1, the honp stresses due to coolant pressure at temperatures $\leq 200^{\circ} \mathrm{C}$ are $\leq 12 \mathrm{MPa}$ for pipes of all sizes. If the pressure of water in the coolant system is set at $10 \mathrm{MPa}$, a value that is larger by a factor of 7 than the pressure of saturated steam at $200^{\circ} \mathrm{C}$, a hoop stress of $\approx 17 \mathrm{MPa}$ for the $3 / 8-80 \mathrm{~S}$ pipe is still much lower than $\mathrm{S}_{\mathrm{m}}(106 \mathrm{MPa})$ at $200^{\circ} \mathrm{C}$.

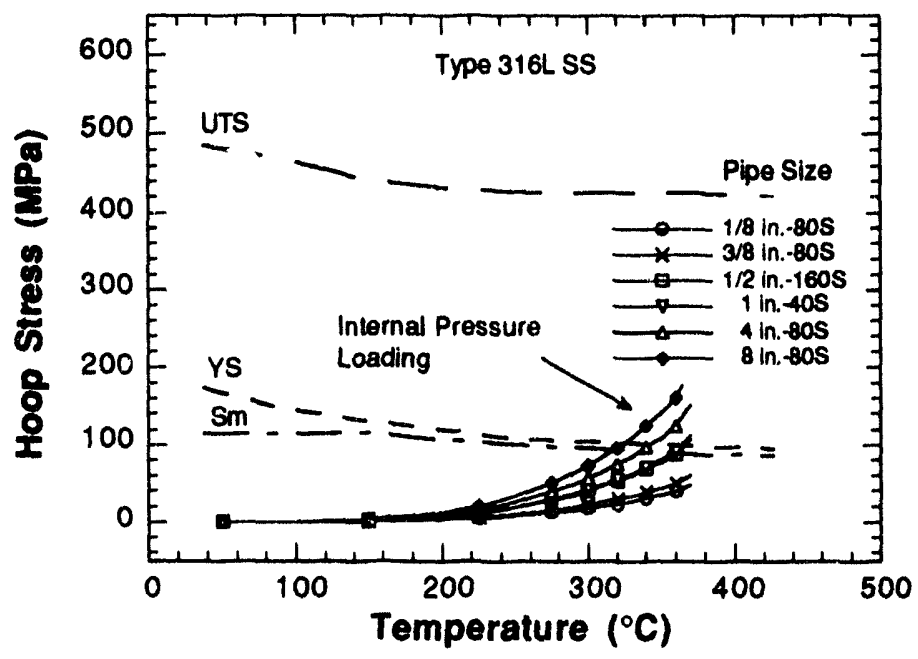

Figure 1. Dependence of hoop stress of Type $316 L$ SS pipe on temperature of saturated steam in relation to UTS, YS, and $S_{m}$ of the material

\section{Corrosion Fatigue Analysis in Air}

In an analysis of propagation of small surface cracks in a tube that could be introduced by fabrication (lack of penetration during welding), fatigue, or localized corrosion, a semiellipsoid shape is frequently chosen. 
The stress intensity factor $K$ associated with a surface crack of depth a, with its major axis in either the axial or circumferential directions, is given by 10,11

$$
\mathrm{K}=1.12 \sigma(\pi \mathrm{a})^{1 / 2} \text {. }
$$

This expression is valid for flat plates with a crack length-to-depth ratio of 2; however, it is a good approximation for small flaws in pipes. 12 Figure 2 shows the relationship between stress and flaw depth for several values of $\mathrm{K}$ between 10 and $50 \mathrm{MPa} \cdot \mathrm{m}^{1 / 2}$ (Eq. 2). The YS, UTS, and $S_{m}$ levels for Type 316L SS at $200^{\circ} \mathrm{C}$ and the range of initial flaw depths corresponding $10 \approx 10 \%$ of the wall thickness of pipes of various size are denoted on the figure. Figure 2 also shows that, for stress levels to $3 \mathrm{~S}_{\mathrm{m}}$ and flaw depths between $\approx 0.2$ and $3.2 \mathrm{~mm}$ (through wall in the case of the $3 / 8-80 \mathrm{~S}$ pipe), $\mathrm{K}$ values range from $\approx 10$ to $40 \mathrm{MPa} \cdot \mathrm{m}^{1 / 2}$. Threshold stress intensity factors for SCC of SSs in oxygenated water are not well known, but reported values for sensitized Type $304 \mathrm{SS}^{13}$ and Type $316 \mathrm{NG} \mathrm{SS^{14 }}$ at $289^{\circ} \mathrm{C}$ are $\approx 10$ and $20 \mathrm{MPa} \cdot \mathrm{m}^{1 / 2}$, respectively. Consequently, for initial flaw depths of $\approx 10 \%$ of the wall thickness and maximum stress levels near $3 \mathrm{~S}_{\mathrm{m}}$ during cyclic loading from thermal transients, propagation of existing flaws in the piping appears to be possible.

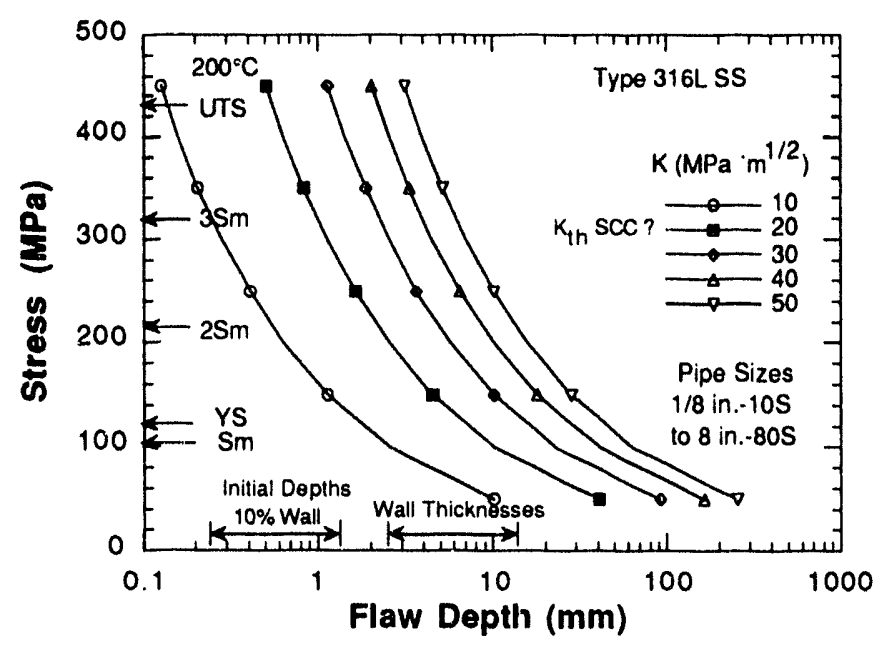

Figure 2. Relationship between stress level and flaw depth for several stress intensity values

Nondestructive evaluation methods are used to detect corrosion wastage, pitting, and stress corrosion cracks in tubes and pipes of various sizes. The probability of detecting pitting and wastage is $\approx 90 \%$ for wall losses $>40 \% .{ }^{15}$ However, reliable detection and sizing of cracks by eddy current testing is difficult. The probability of detecting a crack increases with crack depth because the voltage response of the probe increases. Estimates of the probability of detection are $50 \%$ for relatively shallow flaws $(<40 \%$ through wall) and better than $80 \%$ for deep flaws $>80 \%$ through wall. ${ }^{16}$

To determine the CGR of the stecl in air (CGR $a$ air $)$, we used the relations (Eq. 3) given by the current ASME Section XI correlation at $288^{\circ} \mathrm{C}$, based on the work of James and Jones, ${ }^{17}$ i.e.,

$$
\begin{array}{ll}
\mathrm{CGR}_{\text {air }}=3.43 \times 10^{-12} \mathrm{~S}(\mathrm{R}) \Delta \mathrm{K}^{3.3} / \mathrm{t}_{\mathrm{r}}\left(\mathrm{m} \cdot \mathrm{s}^{-1}\right), \\
\mathrm{S}(\mathrm{R})=1+1.18 \mathrm{R} & \mathrm{R} \leq 0.8, \\
\mathrm{~S}(\mathrm{R}) \quad=-43.35+57.97 \mathrm{R} & \mathrm{R}<0.8,
\end{array}
$$

where $t_{r}$ is the rise time of the loading wave form, $R$ is the load ratio $\left(\sigma_{\min } / \sigma_{\max }\right.$ or $\left.K_{\min } / K_{\max }\right)$ and $\Delta \mathrm{K}=\mathrm{K}_{\max }-\mathrm{K}_{\min }$. The dependence of $\mathrm{CGR}_{\text {air }}$ on load ratio for $\mathrm{K}_{\max }$ values of 20,30 , and $40 \mathrm{MPa} \cdot \mathrm{m}^{1 / 2}$ and rise times of 10 and $480 \mathrm{~s}$, from Eq. 3, is shown in Fig. 3. The rise times of 10 and $480 \mathrm{~s}$ correspond to a 
postulated excursion duration and burn time, respectively, in ITER. For the purpose of this analysis, we assume that the crack grows only during the heating phase of a pulse (i.e., during the tensile-going portion of a strain cycle).

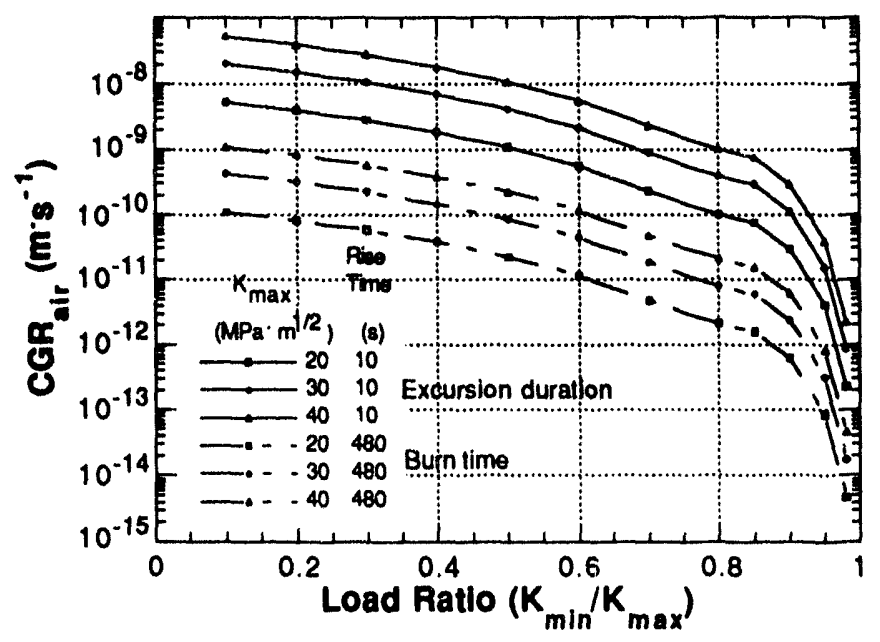

Figure 3. Dependence of $C G R_{\text {air }}$ on load ratio for several $K_{\max }$ values and rise times of 10 and $480 \mathrm{~s}$

The load ratios applicable to the present analysis are typically rather low $(<0.2)$, based upon a circumferential stress $\left(\sigma_{\min }\right)$ of $\approx 17 \mathrm{MPa}$ and maximum stress levels $\left(\sigma_{\max }\right)$ from $\mathrm{S}_{\mathrm{m}}$ to $3 \mathrm{~S}_{\mathrm{m}}$ (106 to 320 $\mathrm{MPa}$ ). Therefore, the relevant values for $\mathrm{CGR}_{\text {air }}$ are $10^{-10}-10^{-9} \mathrm{~m} \cdot \mathrm{s}^{-1}$ for stress intensities between 20 and $40 \mathrm{MPa} \cdot \mathrm{m}^{1 / 2}$ and a burn time of $480 \mathrm{~s}$. Figure 4 shows that CGR values of this magnitude would imply that cracks would grow $t^{\prime}$ ugh wall in $\approx 2$ to 24 months of continuous operation for a thin-wall component such as a 3/8-80S pipe, if ck growth occurred only during the 480-s burn of an $\approx 1000-\mathrm{s}$ pulse. The estimated service life may oxcrease when the steel is exposed to water. The decrease is caused by environmental enhancement of the CGRs, which depends on water purity and the threshold stress intensity $K_{t h}$ for SCC.

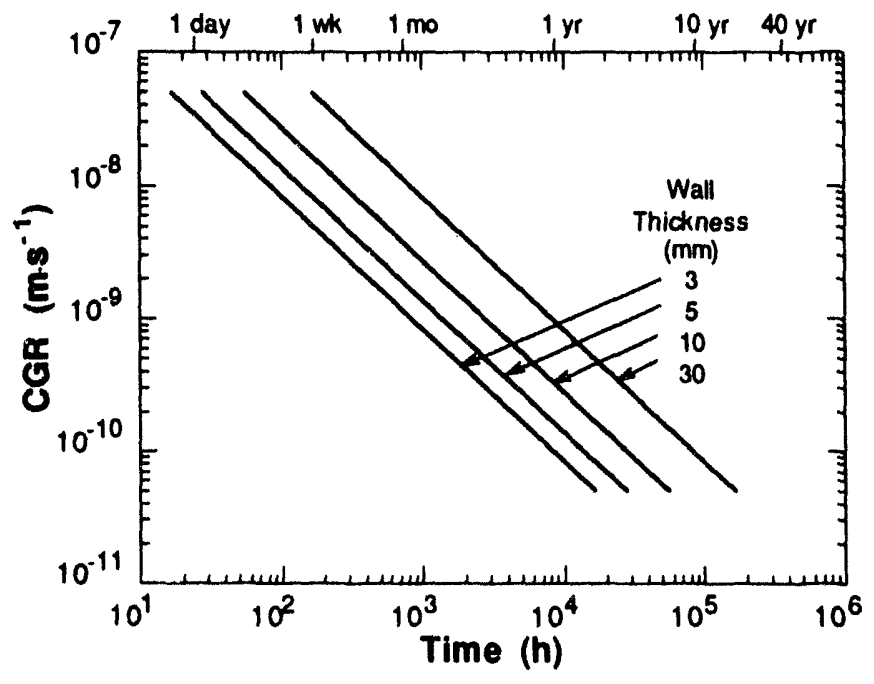

Figure 4. Relationship between CGR and time for a crack to penetrate walls of various thickness 


\section{Corrosion Fatigue Analysis in Water}

Because Section XI of the ASME Code currently provides only an in-air design curve, corrosion fatigue data in simulated boiling-water-reactor environments, obtained at Argonne National Laboratory and from the literature, have been analyzed to develop corrosion fatigue curves for SSs in aqueous environments. ${ }^{18}$ The approach is basically an update of the work of Gilman et al., ${ }^{19}$ incorporating additional data that are now available. The modified equations from Section XI of the ASME Code for fatigue crack growth of Type 304 SS in air (ASME air curve) and crack growth curves for Types 316L and 304 SS in water ${ }^{7}, 17$ form the basis for predictions under specific loading conditions at lower temperatures.

As was described previously, ${ }^{7} \mathrm{CGR}_{\text {water }}$ is written as a superposition of terms that represent the contribution of SCC, CGRSCC; a corrosion fatigue term CGR $_{\text {env }}$, for additional CGR under cyclic loading due to the environment; and a mechanical fatigue term $\mathrm{CGR}_{\text {air }}$, for fatigue crack growth in air:

$$
\mathrm{CGR}_{\text {water }}=\mathrm{CGR}_{\mathrm{SCC}}+\mathrm{CGR}_{\mathrm{env}}+\mathrm{CGR}_{\mathrm{air}} \text {. }
$$

For the SCC term, the correlation given in the U.S. Nuclear Regulatory Commission Report NUREG0313, Rev. 2, January 1988, is used for water chemistries with 8 ppm dissolved oxygen:

$$
\text { CGRSCC }=2.1 \times 10^{-13} \mathrm{~K}^{2.161}\left(\mathrm{~m} \cdot \mathrm{s}^{-1}\right) \text {. }
$$

The air term is given by the current ASME Section XI correlation at $288^{\circ} \mathrm{C}$ (Eq. 3), and following Shoji et al. ${ }^{20}$ and Gilman et al., ${ }^{19}$ the corrosion fatigue term is assumed to be related to CGR ${ }_{\text {air }}$ through a power law,

$$
\mathrm{CGR}_{\mathrm{env}}=\mathrm{A} \cdot\left(\mathrm{CGR}_{\mathrm{air}}\right)^{\mathrm{m}} .
$$

The values of the coefficient $A$ and the exponent $m$ for water with $8 \mathrm{ppm}$ dissolved oxygen at $288^{\circ} \mathrm{C}$, obtained by an empirical power-law curve fit to the existing data for $\mathrm{R}<0.9$ (where cyclic loading dominates and the stress corrosion term in the superposition model Eq. 4, can be ignored), are

$$
\begin{aligned}
& A=1.5 \times 10^{-4} \\
& m=0.5
\end{aligned}
$$

for CGRs in $\mathrm{m} \cdot \mathrm{s}^{-1}$ and $\mathrm{K}$ in MPa $\cdot \mathrm{m}^{1 / 2}$. Available experimental data ${ }^{7}$ for Type $316 \mathrm{~L}$ SS in oxygenated water at 185 and $225^{\circ} \mathrm{C}$ are consistent with correlations based on Eqs. 3-7.

A hyperbolic tangent expression was used to relate $\mathrm{CGR}_{\text {water }}$ to a SCC susceptibility parameter (namely, the strain ratio from SSRT tests in water and in air) ${ }^{6}$ that further accounts for the effect of water purity on crack propagation. The dependence of the strain ratio, i.e., the strain at failure in water to that in air, on concentration in oxygenated water and temperature is shown in Fig. 5. The dependence of this parameter at $200^{\circ} \mathrm{C}$ on the concentration of $\mathrm{Cl}^{-}$and conductivity of the water is shown in Fig. 6. The strain ratio is 1.0 in $\mathrm{HP}$ water $\left(<0.1 \mu \mathrm{S} \cdot \mathrm{cm}^{-1}\right)$ containing $<0.01 \mathrm{ppm} \mathrm{Cl}^{-}$; however, as the $\mathrm{Cl}^{-}$level and conductivity increase, the strain ratio decreases. ${ }^{6}$ For the purpose of this analysis, strain ratios of $\approx 0.7$ and 0.5 , which correspond to water conductivity values of $\approx 0.3$ and $1.0 \mu \mathrm{S} \cdot \mathrm{cm}^{-1}$, respectively, were used to assess the effect of water purity on crack growth in the tube. From the standpoint of susceptibility to SCC, a further increase in conductivity (decrease in water purity) will not produce additional degradation of the material. 


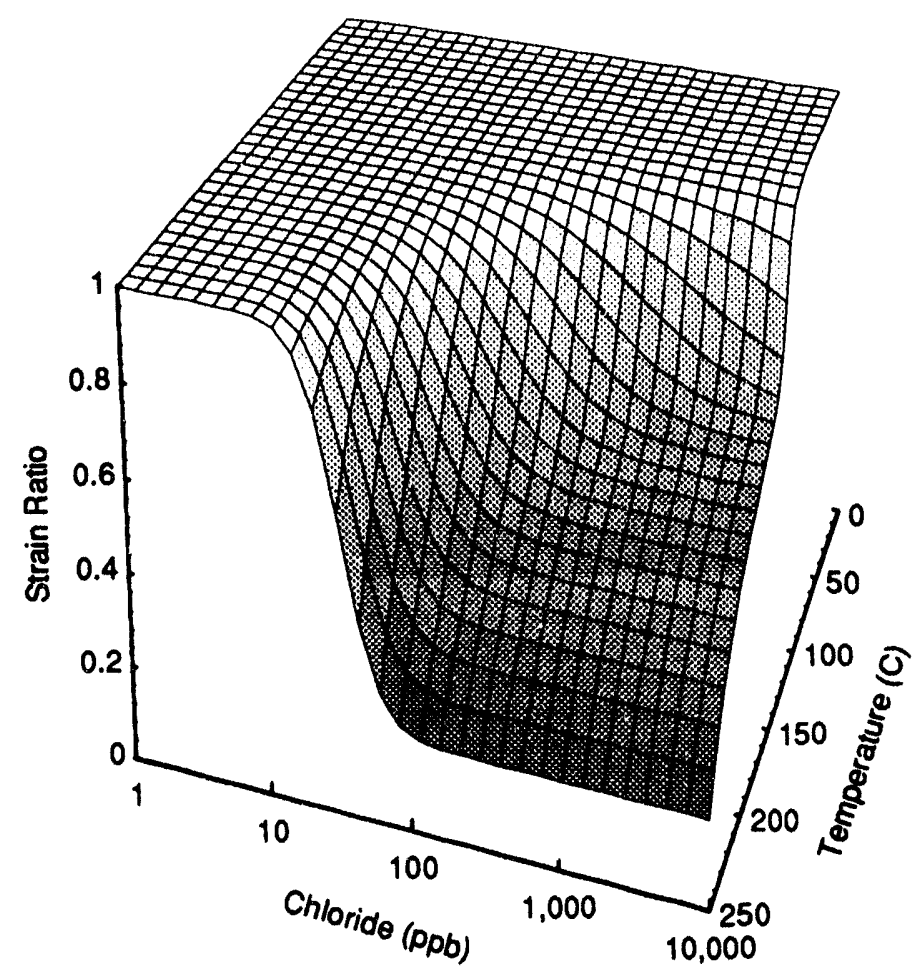

Figure 5. SCC susceptibility of Type $316 \mathrm{~L}$ SS as a function of $\mathrm{Cl}^{-}$ concentration in oxygenated water and temperature. determined by a strain ratio parameter in SSRT tests
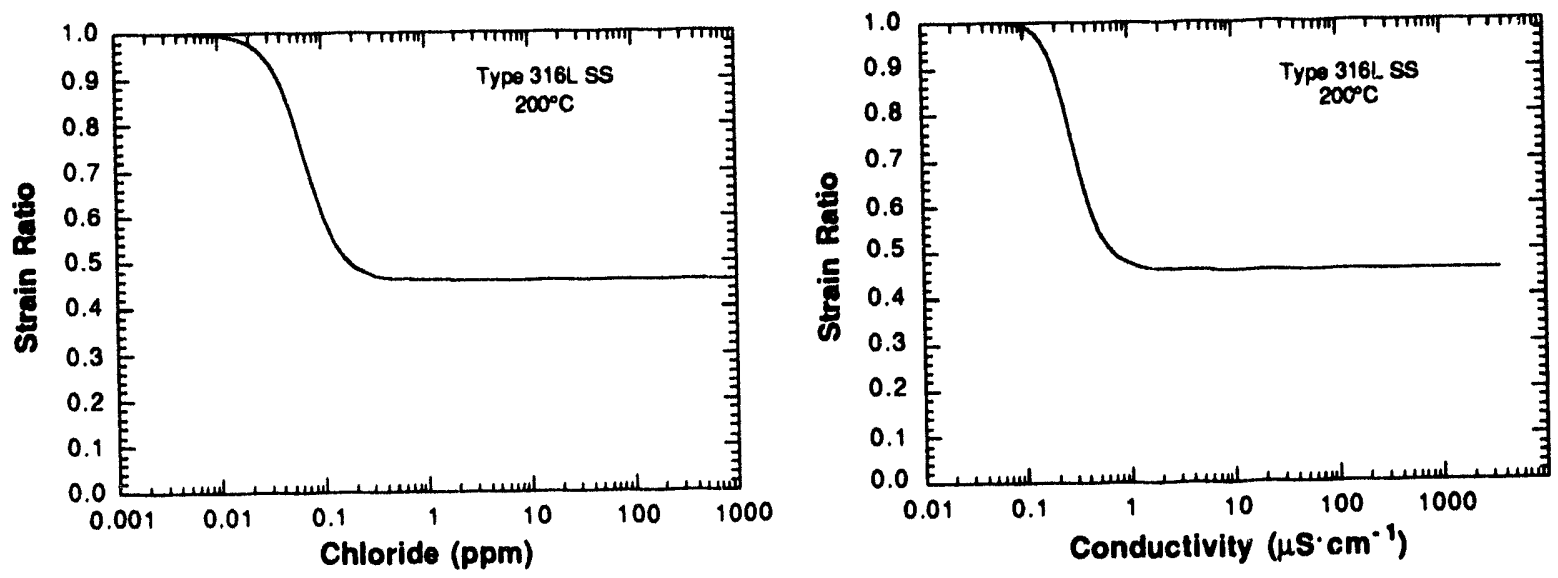

Figure 6. Dependence of strain ratio SCC parameter for Type 316L SS on Ct-concentration and conductivity of oxygenated water at $200^{\circ} \mathrm{C}$

In Fig $7, \mathrm{CGR}_{\text {water }}$ is plotted as a function of strain ratio for several values of $\mathrm{CGR}_{\text {air }}$ in the range of $10^{-7}$ to $10^{-12} \mathrm{~m} \cdot \mathrm{s}^{-1}$. The results show that, for conditions that produce high CGRs in air (e.g., the top curve in the figure, $10^{-7} \mathrm{~m} \cdot \mathrm{s}^{-1}$ ), environmental enhancement of CGRs in water under cyclic loading is relatively small when the strain ratio decreases from a value of 1.0 , which denotes no environmental effect. For loading conditions that produce a low CGR air, e.g., $10^{-11}$ or $10^{-12} \mathrm{~m} \cdot \mathrm{s}^{-1}$, environmental enhancement becomes significant $\left(C_{\text {G }}\right.$ water $\approx 10^{-9} \mathrm{~m} \cdot \mathrm{s}^{-1}$ ) as the strain ratio decreases from $\approx 0.8$ to 0.4 , reflecting the influence of poorer water quality on crack propagation. Mechanical fatigue is predominant at high CGRs, whereas the contribution of SCC to crack propagation can become significant under loading conditions that produce low CGRs in air. 


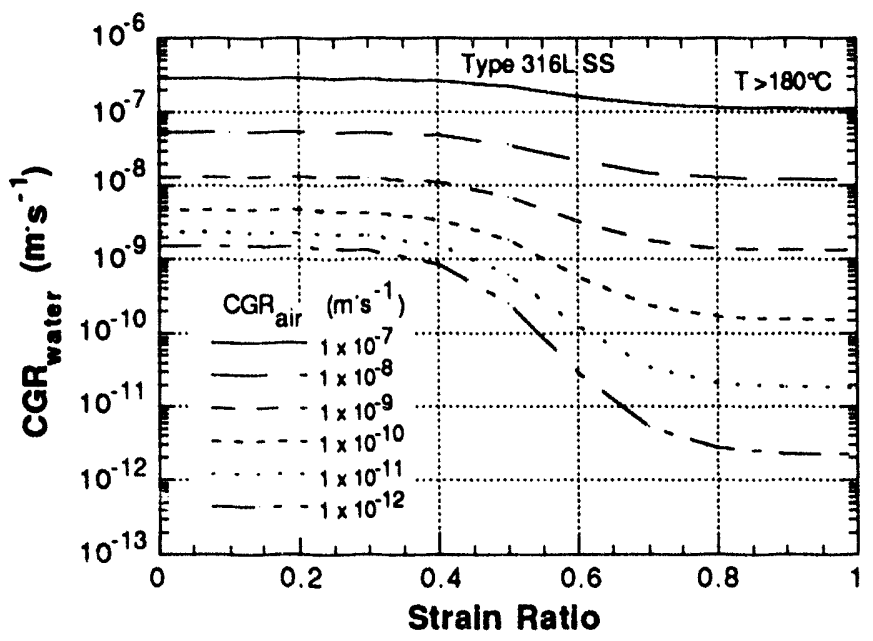

Figure 7. Relationship between CGRs for Type 316L SS in water to those in air for various levels of water purity obtained from a strain ratio parameter from SSRT tests on the material

Figures $8 \mathrm{a}$ and $\mathrm{b}$ show crack depth (\% of wall thickness) as a function of time for an initial crack depth of $0.4 \mathrm{~mm}$ in a $3.2-\mathrm{mm}$-thick tube in air and water (conductivity $1 \mu \mathrm{S} \cdot \mathrm{cm}^{-1}$ ). The curves correspond to maximum stress levels of $3 \mathrm{~S}_{\mathrm{m}}, 2 \mathrm{~S}_{\mathrm{m}}$, and $1.5 \mathrm{~S}_{\mathrm{m}}$ at an $\mathrm{R}$ value of 0.1 , a threshold stress intensity for $\mathrm{SCC}$ of $10 \mathrm{MPa} \cdot \mathrm{m}^{1 / 2}$, and a rise time of $480 \mathrm{~s}$. Crack growth was assumed to occur only during the 480 -s rise time of the 1000-s pulse duration. The marked influence of water, compared to that of an air environment, and stress level on the time for a crack to grow through wall is depicted in the two figures. The effect of a relatively low value of $K_{t h}$ (i.e., $10 \mathrm{MPa} \cdot \mathrm{m}^{1 / 2}$ ) on time to failure in water is evident, particularly at a stress level of $3 \mathrm{~S}_{\mathrm{m}}$.

Crack depth is shown as a function of the number of burn cycles in Figs. $9 \mathrm{a}$ and $\mathrm{b}$ for the same water chemistry and loading conditions depicted in Figs. 8 a and b. At a maximum stress level of $3 \mathrm{~S}_{\mathrm{m}}$, the crack grows through wall in $\approx 2000$ cycles in water and $\approx 47,000$ cycles in air. Whereas the life in air exceeds the design life of 10,000 cycles for normal operation, the life in water is lower than the design life under these conditions. However, as the stress level decreases from $3 S_{m}$ to $2 S_{m}$, the design life of 10,000 cycles for normal operation is achieved in both air and water. At the $1.5 \mathrm{~S}_{\mathrm{m}}$ level, the design goal of 100,000 cycles at reduced power operation can be achieved with some margin of conservatism.
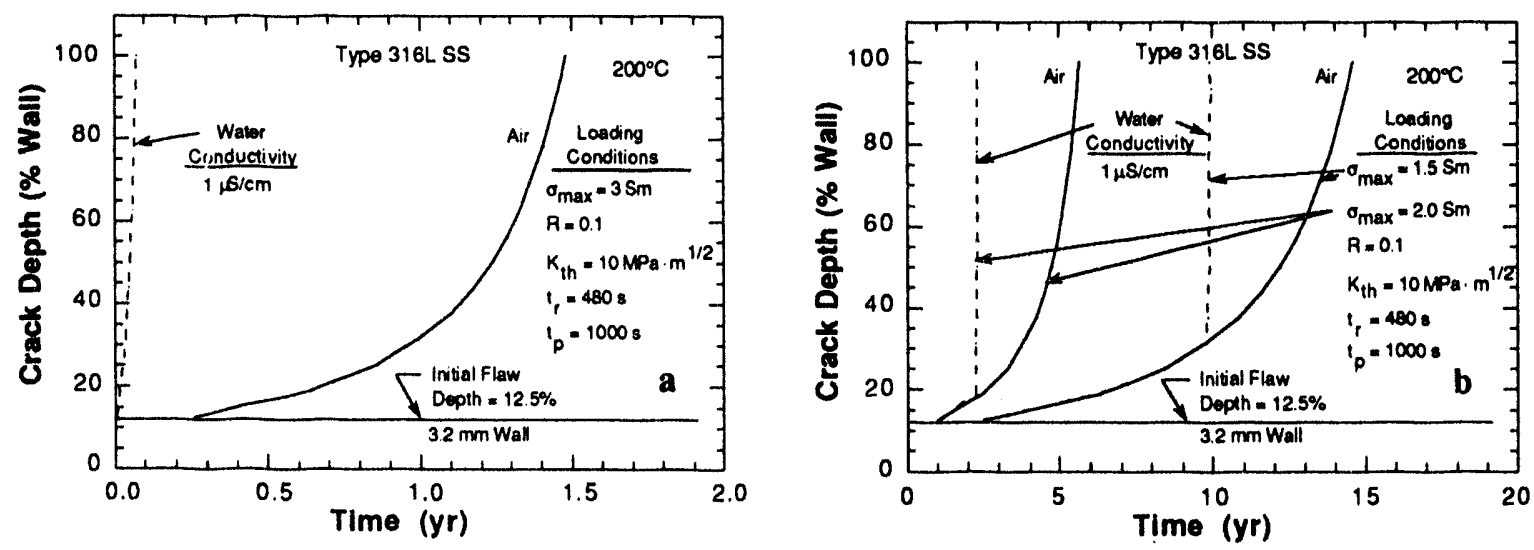

Figure 8. Crack depth versus time in air and water at $200^{\circ} \mathrm{C}$ for an initial crack depth of $12.5 \%$ in a 3.2mm-thick Type $316 L$ SS tube under low-R loading at nuaximum stress levels of (a) $3 S_{m}$, and (b) $2 S_{m}$ and $1.5 S_{m}$ 

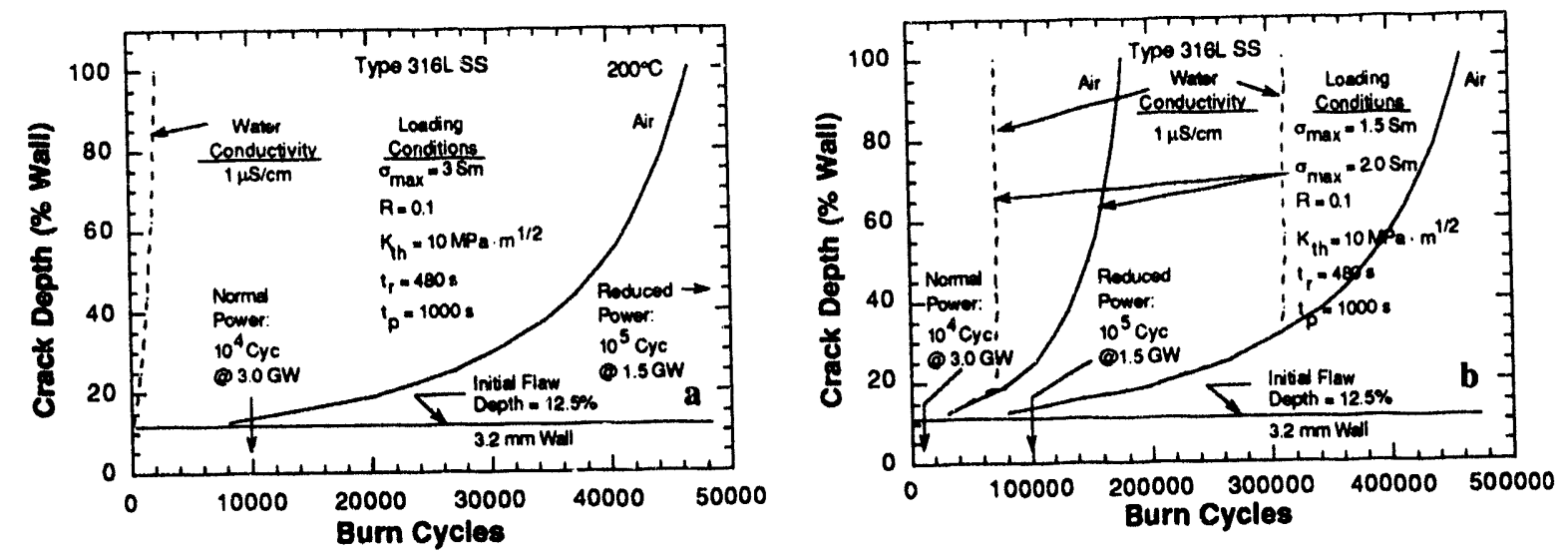

Figure 9. Crack depth versus burn cycles in air and water at $200^{\circ} \mathrm{C}$ for an initial crack depth of $12.5 \%$ in a 3.2-mm-thick tube under low-R loading at stress levels of $(a) 3 S_{m}$, and $(b) 2 S_{m}$ and $1.5 S_{m}$

The dependence of the cycles to failure on $K_{t h}$ was determined for water with conductivity levels of 0.3 and $1.0 \mu \mathrm{S} \cdot \mathrm{cm}^{-1}$. Results at the three stress levels are shown in Fig. 10 along with the cycles to failure in air.
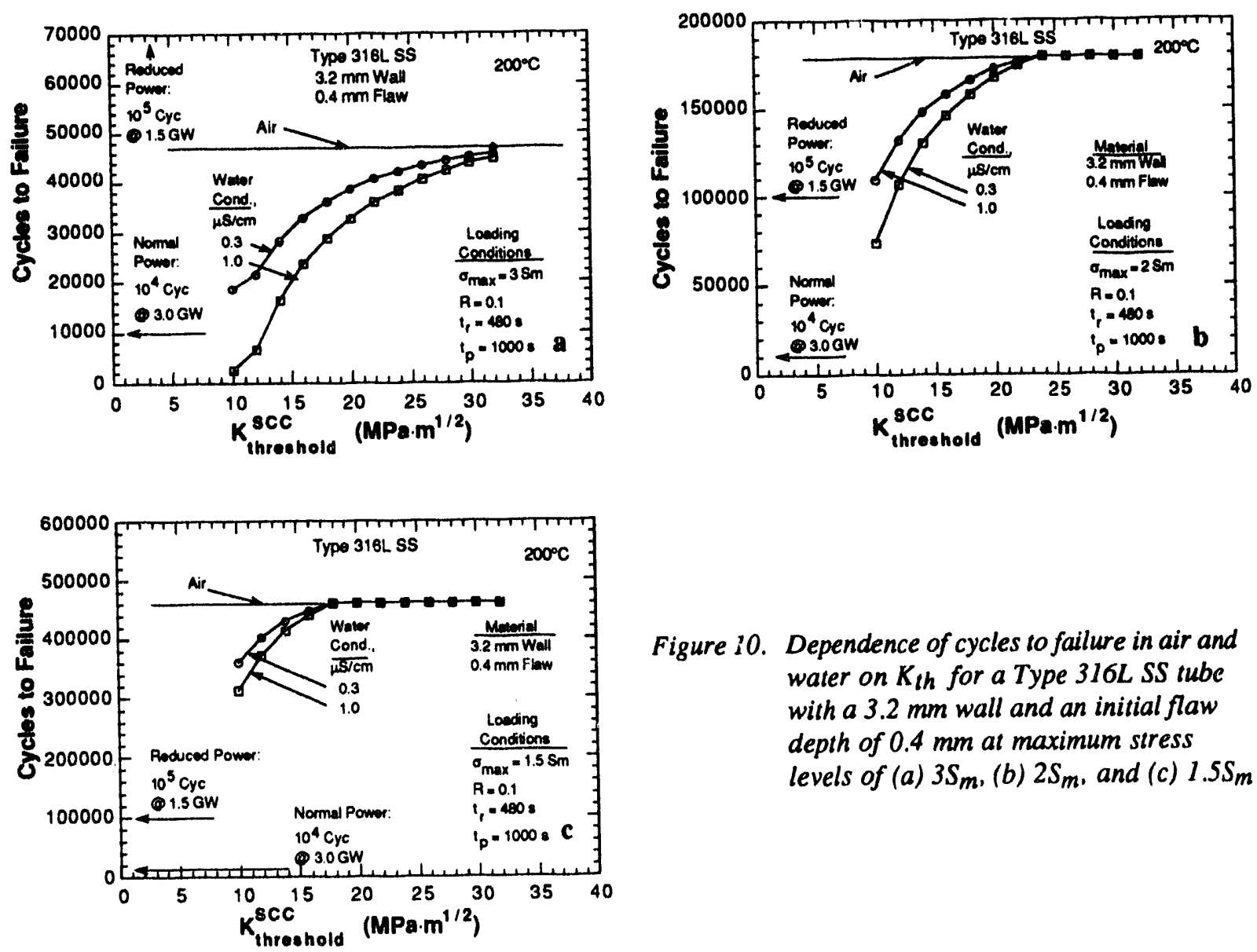

Figure 10. Dependence of cycles to failure in air and water on $K_{\text {th }}$ for a Type $316 \mathrm{~L}$ SS tube with a $3.2 \mathrm{~mm}$ wall and an initial flaw depth of $0.4 \mathrm{~mm}$ at maximum stress levels of (a) $3 S_{m}$, (b) $2 S_{m}$, and (c) $1.5 S_{m}$ 
At $3 S_{m}$, the design goal of 10,000 cycles can be attained when $K_{t h}$ is $>13 \mathrm{MPa} \cdot \mathrm{m}^{1 / 2}$ in water with a conductivity of $1 \mu \mathrm{S} \cdot \mathrm{cm}^{-1}$. At any value of $\mathrm{K}_{\mathrm{th}}$, life is longer in water of higher purity (e.g., $0.3 \mu \mathrm{S} \cdot \mathrm{cm}^{-1}$ ). At $2 S_{m}$, a design goal of 100,000 cycles can be achieved at this threshold stress intensity and both water purity levels. Virtually no decrease of life in water compared with that in air is predicted when $\mathrm{K}_{\mathrm{th}}$ is $>20 \mathrm{MPa} \cdot \mathrm{m}^{1 / 2}$ at stress levels of $2 \mathrm{~S}_{\mathrm{m}}$ and $1.5 \mathrm{~S}_{\mathrm{m}}$. These figures illustrate the effects of water chemistry, $\mathrm{K}_{\mathrm{th}}$, and stress level on expected life of a $3.2-\mathrm{mm}-$ wall tube with an initial flaw depth of $12.5 \%$ or $\approx 0.4 \mathrm{~mm}$.

In addition to the other variables, initial flaw depth plays an important role in component lifetime. Figure 11 shows cycles to failure as a function of initial flaw size at the three stress levels in air and in water of two purity levels at a somewhat higher $K_{t h}$ value of $16 \mathrm{MPa} \cdot \mathrm{m}^{1 / 2}$. The $R$ value and rise time are the same as in the previous figures. The results show that lifetime increases markedly for small initial flaw sizes of $<5 \%$ of the wall thickness at all stress levels. Life also increases significantly, i.e., from $\approx 15,000$ to 250,000 cycles, in $0.3 \mu \mathrm{S} \cdot \mathrm{cm}^{-1}$ water, for a tube with larger initial flaw sizes of $\approx 15-20 \%$ of the wall thickness as the stress level decreases from $3 \mathrm{~S}_{\mathrm{m}}$ to $1.5 \mathrm{~S}_{\mathrm{m}}$.
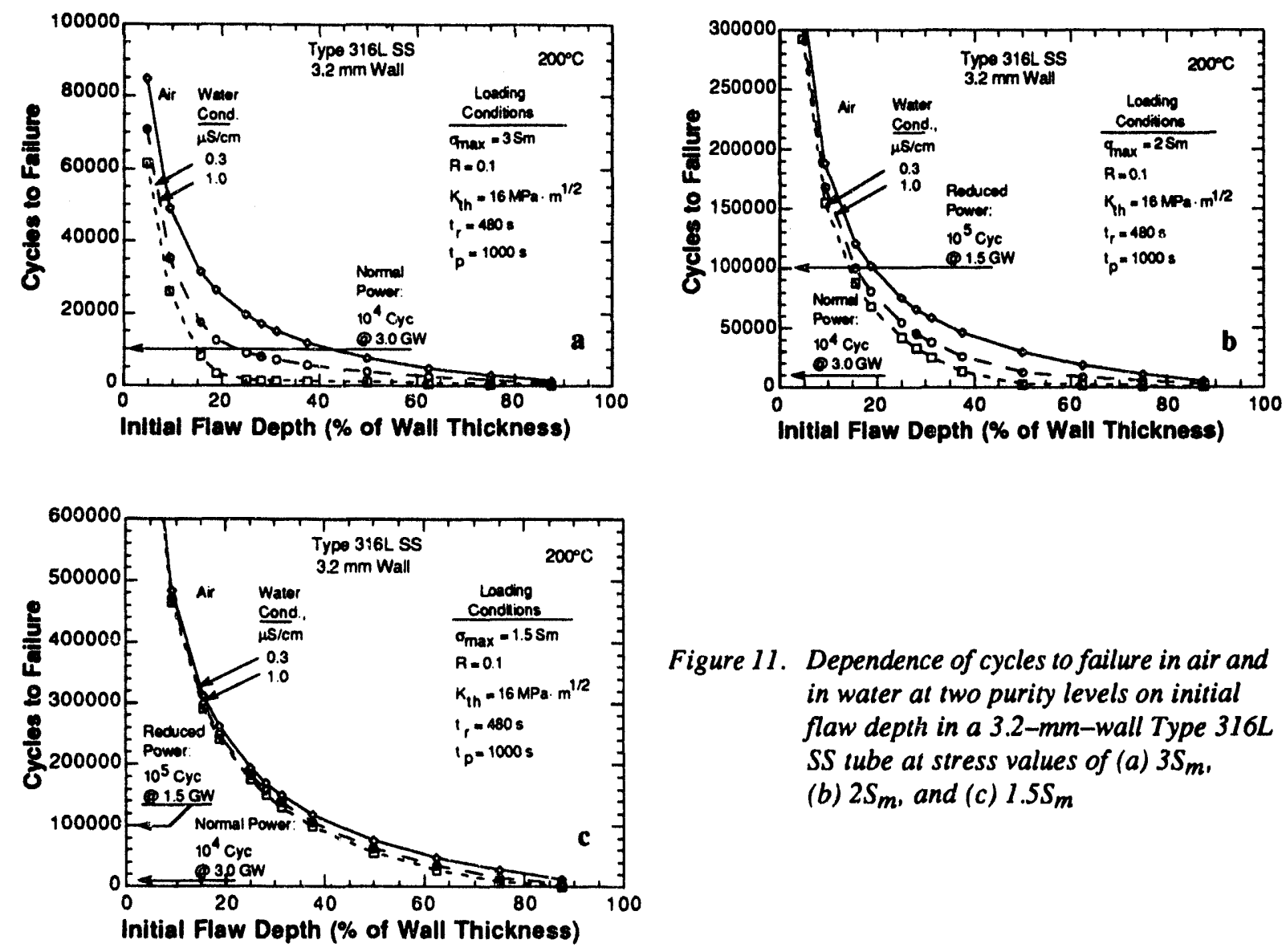

Figure 11. Dependence of cycles to failure in air and in water at two purity levels on initial flaw depth in a 3.2-mm-wall Type 316L SS tube at stress values of (a) $3 S_{m}$, (b) $2 S_{m}$, and (c) $1.5 S_{m}$

\section{DISCUSSION}

Environmental, material, and loading parameters can have a major influence on the operational life of a coolant system. Components such as steam generators, heat exchangers, and large-diameter piping in electric 
generating plants typically have a design life of $\approx 40 \mathrm{yr}$. Although corrosion and cracking processes in watercooled nuclear power plants are controlled through system design, materials selection and fabrication, coolant chemistry, and operating procedures, numerous thermal-fluctuation- and mechanical-vibration-induced fatigue failures have occurred. During normal operation, the components are not subjected to frequent thermal transients, and stresses in piping due to internal coolant pressure or differential coolant pressure across tubes in a steam generator are relatively constant $(R=\approx 1)$ and well within Code-allowable values. Nevertheless, these stresses, coupled with residual stresses from welding, can be near the YS, where environmentally enhanced crack growth can occur. At high load ratios (>0.95 in Fig. 3), CGRs in air are quite low $\left(<10^{-12} \mathrm{~m} \cdot \mathrm{s}^{-1}\right)$ and significant enhancement in the rates may not occur in HP water (Figs. 6 and 7). This indeed must be valid for components containing postulated small flaws and wall thicknesses of 1-30 mm to achieve a design life of $\approx 40 \mathrm{yr}$ (by extrapolation of the lines in Fig. 4). However, failures have occurred in relatively short times when thermal striping (mixing of hot and cold water) and cyclic thermal stratification (hot fluid riding on the top of a cold fluid in horizontal lengths of pipe) produce temperature gradients with peak-to-peak amplitudes of $\approx 40^{\circ} \mathrm{C}$ and time periods of $\approx 120$ to $1200 \mathrm{~s}$.

Although primary stresses in coolant tubes in ITER designs may be lower than those in water reactor components, mainly because of lower operating temperature, secondary thermal and bending stresses inherent in a pulse mode of heat generation may be higher than those encountered in conventional nuclear plants.

\section{CONCLUSIONS}

The present results show that although a defect-free coolant tube may achieve the design life in terms of number of cycles to failure in air, based on Section III of Appendix I of the ASME Code, small flaws that are introduced in a tube during fabrication, fatigue, or localized corrosion can propagate and decrease fatigue life in air and in water, particularly if high secondary stress levels associated with thermal cycling are present. These conditions would require high initial quality during fabrication, reliable pre- and in-service inspection by nondestructive evaluation methods, and capability to repair or remove coolant tubes from service before cracks progress through wall. A more quantitative assessment of flaw tolerance of a coolant system within the firstwall structure of ITER will require better knowledge of the threshold stress intensity for SCC and a detailed analysis of secondary stresses that arise from cyclic loading. Regions where high stresses occur must be identified and attempts should be made to minimize their magnitude to achieve design life.

\section{FUTURE WORK}

CGR tests will be conducted on another set of compact-tension specimens from several heats of Type 316NG SS in oxygenated water to determine $K_{t h}$ at lower load ratios and lower frequencies that are typical of ITER loading conditions. The tests will provide a technical basis for selecting appropriate crack growth curves for design and analysis of first-wall structures.

\section{REFERENCES}

1. R. W. Conn, V. A. Chuyanov, N. Inoue, and D. R. Sweetman, The International Thermonuclear Experimental Reactor, Scientific American 226 (4) 1992.

2. A. B. Hull, M. R. Fox, J. W. Pascoe, and T. F. Kassner, Environmental Effects on Aqueous Stress Corrosion of Candidate Austenitic Steels for ITER Structural Applications, 9th Fusion Reactor Materials Semiannual Progress Report for Period Ending September 30, 1990, DOE/ER-0313/9, Oak Ridge National Laboratory, p. 228.

3. A. B. Hull and T. F. Kassner, Aqueous Stress Corrosion of Candidate Austenitic Steels for ITER Structural Applications, 10th Fusion Reactor Materials Semiannual Progress Report for Period Ending March 31, 1991, DOE/ER-0313/10, Oak Ridge National Laboratory, p. 241. 
4. M. R. Fox, A. B. Hull, and T. F. Kassner, Stress Corrosion Cracking of Candidate Structural Materials under Simulated First-Wall/Aqueous Coolant Environments, Fusion Technol. 19, 1619-1628 (1991).

5. A. B. Hull, P. R. Luebbers, M. R. Fox, W. K. Soppet, and T. F. Kassner, Aqueous Stress Corrosion of Candidate Austenitic Steels for ITER Structural Applications, 12th Fusion Reactor Materials Semiannual Progress Report for Period Ending March 31, 1992, DOE/ER-0313/12, Oak Ridge National Laboratory, p. 225.

6. W. K. Soppet, D. M. French, and T. F. Kassner, Aqueous Stress Corrosion of Candidate Austenitic Steels for ITER Structural Applications, 14th Fusion Reactor Materials Semiannual Progress Report for Period Ending March 31, 1993, DOE/ER-0313/14, Oak Ridge National Laboratory, p. 380.

7. W. E. Ruther and T. F. Kassner, Corrosion Fatigue of Candidate Austenitic Steels for ITER Structural Applications, 14th Fusion Reactor Materials Semiannual Progress Report for Period Ending March 31, 1993, DOE/ER-0313/14, Oak Ridge National Laboratory, p. 395.

8. Cases of ASME boiler and Pressure Vessel Code, Case N-47-28, Class 1 Components in Elevated Temperature Service, Section III, Division 1, (1989), American Society of Mechanical Engineers, New York.

9. D. Burgreen, Design Methods for Power Plant Structures, 1st ed., C. P. Press, Jamaica, NY (1975).

10. P. C. Paris and G. C. Sih, Stress Analysis of Cracks, in Fracture Toughness Testing and Its Applications, ASTM STP 381, American Society of Testing and Materials, Philadelphia, p. 30 (1965).

11. W. E. Senschak and O. E. Widera, Application of Fracture Mechanics to Nuclear Piping Systems, Eng. Fracture Mechanics 4, 877-982 (1972).

12. D. D. Dedhia and D. O. Harris, Stress-Intensity Factors for Surface Cracks in Pipes: A Computer Code for Evaluation by Use of Influence Functions, EPRI NP-2425, Electric Power Research Institute, Palo Alto, CA (June 1982).

13. D. A. Hale, J. D. Heald, R. M. Horn, C. W. Jewett, J. N. Kass, H. S. Mehta, S. Ranganath, and S. R. Sharma, The Growth and Stability of Stress Corrosion Cracks in Large Diameter BWR Piping Vol. 2: Appendices, EPRI NP-2472 Vol. 2 (July 1982).

14. W. E. Ruther, J. Y. Park, W. K. Soppet, and T. F. Kassner, in Environmentally Assisted Cracking in Light Water Reactors, Semiannual Report October 1988-March 1989, NUREG/CR-4667 Vol. 8, ANL-90/4, pp. 2-5 (June 1990).

15. E. R. Bradley, P. G. Doctor, R. H. Ferris, J. A. Buchanan, Steam Generator Group Project Task 13 Final Report: Nondestructive Examination Validation, NUREG/CR-5185, PNL-6399 (August 1988).

16. R. A. Kurtz, Steam Generator Tube Integrity Program/Steam Generator Group Project, Final Project Summary Report, NUREG/CR-5117 (May 1990).

17. L. A. James and D. P. Jones, Fatigue Crack Growth Correlation for Austenitic Stainless Steels in Air, Proc. Conf. on Predictive Capabilities in Environmentally-Assisted Cracking, R. Rungta, ed., PVP Vol. 99, American Society of Mechanical Engineers, New York, pp. 363-414 (1985).

18. W. J. Shack, in Environmentally Assisted Cracking in Light Water Reactors Semiannual Report, October 1990-March 1991, NUREG/CR-4667 Vol. 12, ANL-91/24, pp. 31-37 (August 1991).

19. J. D. Gilman, R. Rungta, P. Hinds, and H. Mindlan, Corrosion-Fatigue Crack Growth Rates in Austenitic Stainless Steels in Light Water Reactor Environments, Int. J. Pressure Vessel Piping 31, 55-68 (1988).

20. T. Shoji, H. Takahashi, M. Suzuki, and T. Kondo, A New Parameter for Characterizing Corrosion Fatigue Crack Growth, J. Eng. Mater. Technol. 103, 298-304 (1981). 
DENSITY MEASUREMENTS PERFORMED ON ISPRA SECOND GENERATION AMCR ALLOYS IRRADIATED IN MOTA-2A AND MOTA-2B - F. A. Garner (Pacific Northwest Laboratory), $P$. Schiller (Ispra Establishment), and $\mathrm{H}$. Takahashi (Hokkaido University)

\section{OBJECTIVE}

The objective of this effort is to provide information on the radiation response of reduced activation alloys considered for fusion application.

\section{SUMMARY}

Density change measurements have been completed on the Ispra second generation AMCR alloys irradiated in MOTA-2A and MOTA-2B. The various compositional modifications induce a wide variation of swelling behavior in the range $423-600^{\circ} \mathrm{C}$ at $32-61 \mathrm{dpa}$.

\section{PROGRESS AND STATUS}

\section{Introduction}

In the early FFTF irradiation studies on commercial Fe-Cr-Mn alloys it was shown that the AMCR alloy supplied by Creusot-Marrel (Fe-10Cr-18Mn-0.7Ni-0.6Si-0.06N-0.2C) exhibited somewhat better performance than the other alloys investigated. ${ }^{\prime}$ Researchers at the Ispra Establishment have developed a series of lower activation variations on this steel, ${ }^{2}$ which was inserted for irradiation in MOTA-2A during FFTF cycle 11 and MOTA-2B during cycle 12 at 423,520 , and $600^{\circ} \mathrm{C}$. (See Table 1 for the composition of these steels.) Cycle 12 has been completed and density measurements performed. The results for cycle 11 were reported earlier. ${ }^{3}$

Table 1

Composition (wt\%) of ISPRA Second Generation AMCR Alloys

\begin{tabular}{|c|c|c|c|c|c|c|c|c|c|}
\hline Alloy & $\mathrm{Cr}$ & $\mathrm{Mn}$ & $\mathrm{Ni}$ & $\mathrm{Mo}$ & $\mathrm{C}$ & $\mathrm{N}$ & $\mathrm{Si}$ & $\mathrm{S}$ & $\mathrm{P}$ \\
\hline \hline ISPRA-A & 12.5 & 10.5 & 2 & $<0.1$ & 0.10 & $<0.05$ & 0.5 & $<0.01$ & $<0.02$ \\
\hline ISPRA-B & 12.5 & 10.5 & $<0.25$ & $<0.1$ & 0.30 & $<0.05$ & 0.5 & $<0.01$ & $<0.02$ \\
\hline ISPRA-C & 12.5 & 17.5 & 2 & $<0.1$ & 0.10 & $<0.05$ & 0.5 & $<0.01$ & $<0.02$ \\
\hline ISPRA-D & 10.0 & 17.5 & $<0.25$ & $<0.1$ & 0.30 & $<0.05$ & 0.5 & $<0.01$ & $<0.02$ \\
\hline ISPRA-E & 17.0 & 10.5 & 2 & $<0.1$ & 0.10 & $<0.05$ & 0.5 & $<0.01$ & $<0.02$ \\
\hline
\end{tabular}

aPacific Northwest Laboratory is operated for the U.S. Department of Energy by Battelle Memorial Institute under Contract DE-AC06-76RLO 1830. 


\begin{tabular}{|c|c|c|c|c|c|c|c|c|c||}
\hline Alloy & $\mathrm{Cu}$ & $\mathrm{Al}$ & $\mathrm{Nb}$ & $\mathrm{V}$ & $\mathrm{W}$ & $\mathrm{Ta}$ & $\mathrm{Pb}$ & $\mathrm{Co}$ & $\mathrm{B}$ \\
\hline $\mathrm{A}$ & $<0.1$ & $<0.05$ & $<0.001$ & 0.75 & 1.4 & $<0.005$ & $<0.001$ & $<0.1$ & $<0.005$ \\
\hline $\mathrm{B}$ & $<0.1$ & $<0.05$ & $<0.001$ & 0.75 & 1.4 & $<0.005$ & $<0.001$ & $<0.1$ & $<0.005$ \\
\hline $\mathrm{C}$ & $<0.1$ & $<0.05$ & $<0.001$ & $<0.1$ & 2.0 & $<0.005$ & $<0.001$ & $<0.1$ & $<0.005$ \\
\hline $\mathrm{D}$ & $<0.1$ & $<0.05$ & $<0.001$ & $<0.1$ & 2.0 & $<0.005$ & $<0.001$ & $<0.1$ & $<0.005$ \\
\hline $\mathrm{E}$ & $<0.1$ & $<0.05$ & $<0.001$ & 0.75 & 2.0 & $<0.005$ & $<0.001$ & $<0.1$ & $<0.005$ \\
\hline
\end{tabular}

$\underline{\text { Results }}$

Table 2 presents the results of the density measurements, and demonstrates that a large variation in swelling behavior occurs. Note that the AMCR steel used in the previous U.S. studies was also included in MOTA-2A and MOTA-2/13 for comparison with the behavior of the new Ispra alloys. Figures la and lb show that the swelling of all alloys at $423-427$ and $600^{\circ} \mathrm{C}$ is relatively small compared to that of several alloys at $520^{\circ} \mathrm{C}$. The relative swelling varies from one temperature to the next, but alloys Ispra-C and Ispra-E seem to be more prone to accelerated swelling at the two lowest temperatures. The data at $600^{\circ} \mathrm{C}$ are suggestive of phase instabilities, indicated by late term densification.

Table 2

Swelling (\%) of FeCrMn Ispra Alloys and AMCR in MOTA-2A and MOTA-2B*

\begin{tabular}{||c||c|c|c|c|c|c|c||}
\hline Alloy & $\begin{array}{l}\text { Original } \\
\text { Density } \\
\left(\mathrm{g} \mathrm{cm}^{-3}\right)\end{array}$ & $\begin{array}{c}423^{\circ} \mathrm{C} \\
\mathrm{dpa}^{* *}\end{array}$ & $\begin{array}{c}427^{\circ} \mathrm{C} \\
60.3 \\
\mathrm{dpa}^{* *}\end{array}$ & $\begin{array}{c}520^{\circ} \mathrm{C} \\
36.3 \\
\mathrm{dpa}^{* *}\end{array}$ & $\begin{array}{c}520^{\circ} \mathrm{C} \\
60.8 \\
\mathrm{dpa}^{* *}\end{array}$ & $\begin{array}{c}600^{\circ} \mathrm{C} \\
32.3 \\
\mathrm{dpa}^{* *}\end{array}$ & $\begin{array}{c}600^{\circ} \mathrm{C} \\
54.2 \\
\mathrm{dpa}^{* *}\end{array}$ \\
\hline \hline ISPRA-A & 7.94768 & 0.96 & 1.56 & $1.23 / 0.28$ & 2.36 & -0.15 & -.86 \\
\hline ISPRA-B & 7.94965 & 0.30 & 0.08 & 0.07 & 0.04 & 0.99 & 0.37 \\
\hline ISPRA-C & 7.98265 & 1.49 & 3.71 & 3.97 & 11.9 & 1.96 & 1.91 \\
\hline ISPRA-D & 7.97152 & 0.28 & 0.55 & 0.58 & 2.58 & -0.72 & -0.99 \\
\hline ISPRA-E & 7.85483 & 0.52 & 1.91 & 4.08 & 8.40 & 0.58 & 1.66 \\
\hline AMCR & 7.86452 & 0.96 & 1.16 & 0.71 & 1.82 & 1.19 & 3.49 \\
\hline
\end{tabular}

*Unless two yalues are given, the swelling quoted is the average of two separate specimens that exhibited nearly identical densities.

** Corresponding to neutron exposures of 8.53, 8.58 and $7.64 \times 10^{22} \mathrm{n} \mathrm{cm}^{-2}(\mathrm{E}>0.1 \mathrm{MeV})$ at 423,520 , and $600^{\circ} \mathrm{C}$, respectively in MOTA-2A and $1.42,1.44$ and $1.28 \times 10^{23} \mathrm{~cm}^{2} \mathrm{E}>0.1 \mathrm{MeV}$ in MOTA-2B. 


\section{FUTURE WORK}

The specimens from MOTA-2A have been examined by microscopy at Hokkaido University. The MOTA-2B specimens will be shipped to Hokkaido during the next reporting period.
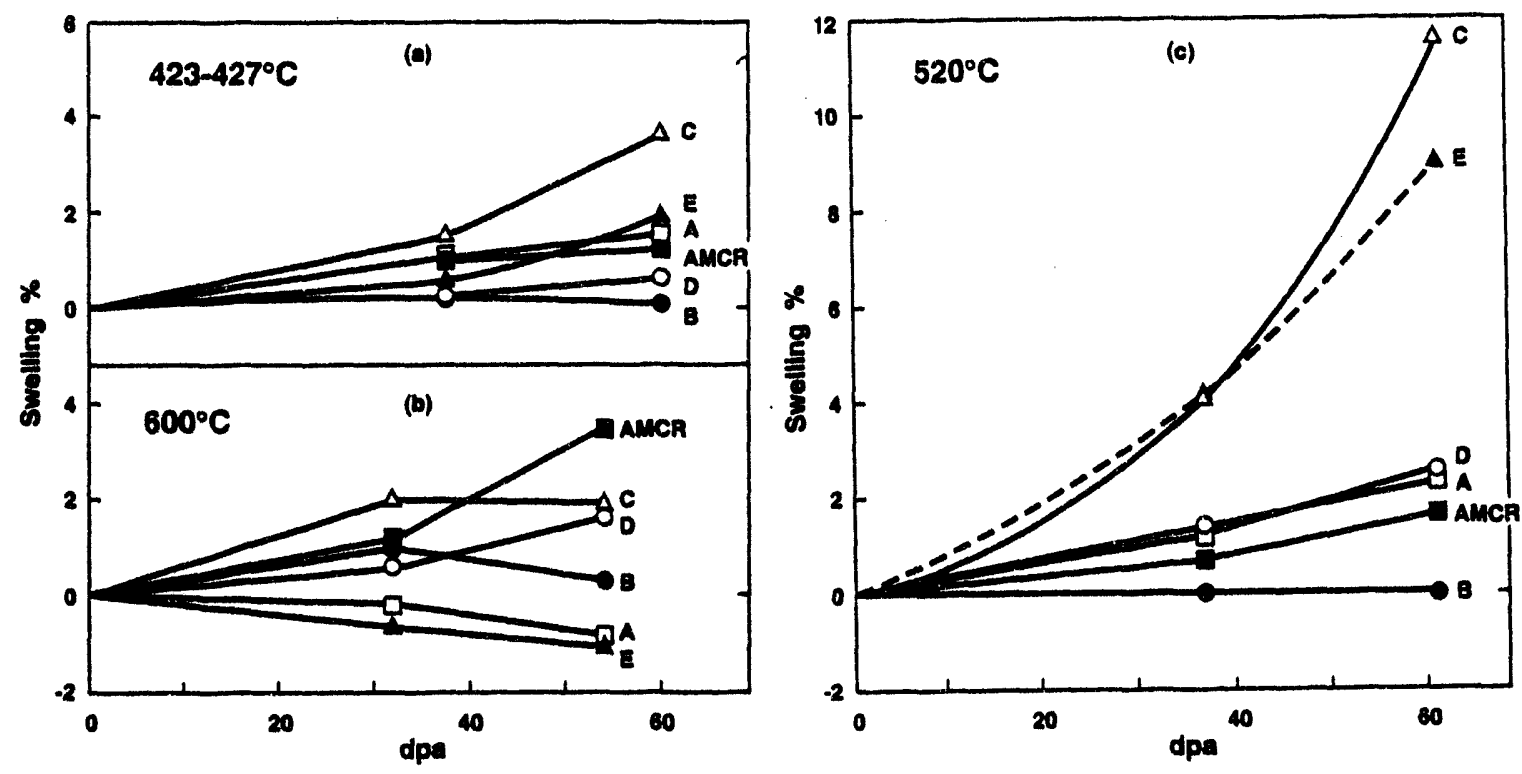

Fig. 1. Swelling measured in AMCR and five Ispra variants irradiated in MOTA-2A and MOTA-2B.

\section{REFERENCES}

1. F. A. Garner and J. M. McCarthy in Reduced Activation Materials for Fusion Reactors, ASTM STP 1047, American Society for Testing and Materials, Philadelphia (1990) 19-29.

2. G. Piatti, D. Boerman and J. Heritier in Fusion Technology 1988, Proceedings of 15 th Symposium on Fusion Technology (1989) 983-990.

3. F. A. Garner, P. Schiller and H. Takahashi, Fusion Reactor Semiannual Progress Report DOE/ER$0313 / 14(1993)$ in press. 
DENSITY CHANGES INDUCED BY NEUTRON IRRADIATION IN DYNAMICALLY COMPACTED TUNGSTEN AND PCA IN MOTA's 2A AND 2B - F. A. Garner (Pacific Northwest Laboratory) ${ }^{\mathfrak{a}}$ and J. Megusar (Massachusetts Institute of Technology)

\section{OBJECTIVE}

The objective of this effort is to determine the potential of rapid solidification and dynamic compaction as tools for improving the performance of candidate fusion materials.

\section{SUMMARY}

Dynamically compacted tungsten with a starting density of $95.3 \%$ of the theoretical value densified 2 to $3 \%$ when irradiated in FFTF/MOTAs 2A and 2B at three temperatures between 423 and $600^{\circ} \mathrm{C}$ and displacement levels corresponding to 32 to $36 \mathrm{dpa}$ in stainless steel during the first irradiation segment and 54.2 to 60.8 dpa during the second segment. Rapidly solidified and dynamically compacted PCA with high levels of titanium and carbon were also irradiated at these conditions. The density changes were variable between nominally identical specimens but were small enough to determine that significant swelling had not occurred. Microscopy is necessary to determine whether any void growth occurred in addition to precipitate-related strains.

\section{PROGRESS AND STATUS}

\section{Introduction}

Rapid solidification and dynamic compaction have been proposed as methods to produce alloys for use in fusion environments. ${ }^{1,2}$ One such material, a titanium-modified austenitic stainless steel designated PCA, was irradiated earlier in EBR-II to $15 \mathrm{dpa}$ in the range 395 to $550^{\circ} \mathrm{C}$. A total absence of swelling was observed in this alloy, although some swelling was observed in fully annealed specimens that were also irradiated. ${ }^{3}$

Both the as-produced and fully annealed materials were also irradiated in MOTA-2A and MOTA-2B at 423, 520 and $600^{\circ} \mathrm{C}$. Density measurements have now been performed on all specimens. Dynamically compacted tungsten was also included in the same packets. This latter material might serve as an armor material for the first wall or divertor.

\section{Experimental Procedure}

The titanium-modified austenitic stainless steel (PCA) was provided by the Oak Ridge National Laboratory, with the following composition (in wt\%): 16.59 nickel, 14.27 chromium, 1.96 molybdenum, 0.32 titanium, 1.62 manganese, 0.53 silicon, 0.046 carbon, 0.008 nitrogen, 0.04 cobalt, 0.014 phosphorus, 0.002 sulfur, and balance iron. Additional carbon and titanium were added in a remelt followed by rapid solidification and dynamic compaction. This material contained approximately triple the nominal amounts of carbon and titanium (that is, $0.17 \mathrm{wt} \%$ carbon and $0.92 \mathrm{wt} \%$ titanium) originally in PCA. Rapid solidification was performed in a roller quenching apparatus, with an estimated cooling rate of $10^{5} \mathrm{~K} / \mathrm{s}$.

aPacific Northwest Laboratory is operated for the U.S. Department of Energy by Battelle Memorial Institute under Contract DE-AC06-76RLO 1830. 
Dynamic compaction was performed at the Institut Cerac, Ecublens, Switzerland. Rapidly solidified foils were cut into pieces with a length to thickness ratio of 30 to 1 or less and were compacted with the gun speed at $1200 \mathrm{~m} / \mathrm{s}$. The diameter of the compacted material was $5 \mathrm{~cm}$, and the height was $1 \mathrm{~cm}$. Compaction was achieved with a shock wave that was produced by impact of the projectile on the powder. Calculations showed the following relation between the shock speed, particle velocity, and the internal energy. Steel powder of $\sim 50 \%$ loose density and compacted to a shock pressure of $5 \mathrm{GPa}$ gave a shock velocity of $1600 \mathrm{~m} / \mathrm{s}$, a particle velocity of $800 \mathrm{~m} / \mathrm{s}$, and an internal energy change of $3 \times 10^{5} \mathrm{~J} / \mathrm{kg}$. This energy change corresponds to a temperature rise of $600 \mathrm{~K}$, and if the energy is considered to be deposited predominantly at the powder particle surface, the value of $2 \times 10^{4} \mathrm{~J} / \mathrm{m}^{2}$ for energy density is deduced.

Some of this material was subsequently annealed $8 \mathrm{~h}$ at $650^{\circ} \mathrm{C}$, resulting in a homogeneous precipitation of coherent TiC precipitates approximately $5 \mathrm{~nm}$ in size. Some recovery of dislocation structure probably took place during annealing, as evidenced by a large drop in the Knoop microhardness. Both the asproduced and annealed conditions were irradiated in MOTA-2A and MOTA-2B along with dynamically compacted tungsten. The latter was produced at Lawrence Livermore National Laboratory. Density changes were measured by an immersion density technique determined to be accurate to $\pm 0.15 \%$ swelling. The density change data for MOTA-2A was presented earlier. ${ }^{4}$

\section{Results}

Table 1 presents the density change data for the specimens discharged from both MOTA-2A and MOTA-2B. It is obvious that the dynamically compacted tungsten is densifying on the order of 2 to $3 \%$, with most of the change occurring in MOTA-2A. The preirradiation density of $18.4 \mathrm{~g} \mathrm{~cm}^{-3}$ is $95.3 \%$ of the textbook value of $19.3 \mathrm{~g} \mathrm{~cm}^{-3}$. Therefore, during irradiation the compacted tungsten is approaching, but has not yet reached, the theoretical density. Some portion of the densification may also result from transmutation of tungsten to rhenium and osmium. ${ }^{5}$ At $427^{\circ} \mathrm{C}$ and $60.3 \mathrm{dpa}$, the specimens were found to be very brittle and broke into many small pieces during density measurements. This embrittlement will be studied in more detail in the next reporting period.

Table 1

Swelling in Percent from Dynamically Compacted Specimens in MOTA's 2A and 2B*

\begin{tabular}{|c|l|c|c|c|c|c|c||}
\hline Specimen & $\begin{array}{l}\text { Pre- } \\
\text { Irradiation } \\
\text { Density }\end{array}$ & $\begin{array}{c}423^{\circ} \mathrm{C} \\
36.1 \\
\mathrm{dpa}\end{array}$ & $\begin{array}{c}427^{\circ} \mathrm{C} \\
60.3 \\
\mathrm{dpa}\end{array}$ & $\begin{array}{c}520^{\circ} \mathrm{C} \\
36.3 \\
\mathrm{dpa}\end{array}$ & $\begin{array}{c}520^{\circ} \mathrm{C} \\
60.8 \\
\mathrm{dpa}\end{array}$ & $\begin{array}{c}600^{\circ} \mathrm{C} \\
32.3 \\
\mathrm{dpa}\end{array}$ & $\begin{array}{c}600^{\circ} \mathrm{C} \\
54.2 \\
\mathrm{dpa}\end{array}$ \\
\hline $\mathrm{W}^{* *}$ & 18.4098 & -2.23 & -2.75 & $\begin{array}{c}-2.05 / \\
-3.19\end{array}$ & -29.5 & -2.07 & -2.59 \\
\hline PCA & 7.8677 & -0.29 & -0.87 & +0.28 & 0.03 & -0.04 & $\begin{array}{c}+0.09 / \\
-0.07\end{array}$ \\
\hline $\begin{array}{c}\text { PCA- } \\
\text { Annealed }\end{array}$ & 7.9083 & +0.51 & 0.08 & +0.37 & 0.64 & $\begin{array}{c}+0.13 / \\
-1.04\end{array}$ & $\begin{array}{c}+0.67 / \\
-0.32\end{array}$ \\
\hline
\end{tabular}

*Unless two values are given, the swelling is the average of two separate specimens which agreed within $\pm 0.2 \%$.

**dpa for $\mathrm{W}$ is less than that of steel, but has not yet been calculated. 
The density changes for PCA in both starting conditions are small enough to preclude drawing conclusions concerning the onset of swelling. Both positive and negative changes were observed, indicating that precipitation-related changes in lattice parameter are occurring.

\section{FUTURE WORK}

Microscopy and EDX analyses will be performed by J. Megusar.

\section{REFERENCES}

1. N. J. Grant, O. K. Harling, G. Kohse, J. Megusar, and T. Lee, J. Nucl. Mater. 141-143 (1986) 427.

2. D. Imeson et al., three successive papers in J. Nucl. Mater. 122 \& 123 (1984) 266-271; 272-277; 278 283.

3. J. Megusar, in Effects of Radiation on Materials: 14th International Symposium, Volume 1, ASTM STP 1046, N. H. Packan R. E. Stoller, and A. S. Kumar, Eds., American Society for Testing and Materials, Philadelphia, 1989, pp. 185-192.

4. F. A. Garner and J. Megusar, Fusion Reactor Materials Semiannual Progress Report DOE/ER-0313-14 (1992) in press.

5. F. A. Garner and L. R. Greenwood, Fusion Reactor Materials Semiannual Progress Report DOE/ER0313/14 (1993) in press. 
6.3 Refractory Metal Alloys 
EFFECTS OF FABRICATION VARIABLES ON IMPACT PROPERTIES AND MICROSTRUCTURE OF V-CR-TI ALLOYS* H. M. Chung, J. Gazda, L. J. Nowicki, J. E. Sanecki, and D. L. Smith (Argonne National Laboratory)

\section{OBJECTIVE}

The objective of this work is to determine the effects of thermomechanical treatment and trace impurities on the impact properties and microstructure of $\mathrm{V}-(4-5) \mathrm{Cr}-(3-5) \mathrm{Ti}$ alloys, and thereby to identify undesirable variables of alloy fabrication that are detrimental to material toughness.

\section{SUMMARY}

In spite of the small differences in composition of alloying elements, $\mathrm{V}-4 \mathrm{Cr}-4 \mathrm{Ti}, \mathrm{V}-5 \mathrm{Cr}-5 \mathrm{Ti}$, and $\mathrm{V}-5 \mathrm{Cr}-3 \mathrm{Ti}$ alloys exhibited surprisingly large variations in ductile-brittle transition temperatures (DBTTs) $\left(<-190,-60\right.$, and $-85^{\circ} \mathrm{C}$, respectively) in previous investigations. To provide a better understanding of the origin of the variation, effects of fabrication parameters (extrusion, forging, annealing temperature, and quality of $\mathrm{Ti}$ raw material) on the microstructure and impact properties were investigated in this work. Fracture surfaces of $\mathrm{V}-5 \mathrm{Cr}-5 \mathrm{Ti}$ and $\mathrm{V}-5 \mathrm{Cr}-3 \mathrm{Ti}$ alloys, which exhibited DBTTs $\approx 110^{\circ} \mathrm{C}$ higher than that of $\mathrm{V}-4 \mathrm{Cr}-4 \mathrm{Ti}$, were characterized by relatively large precipitates $(2,000-17,000 \mathrm{~nm})$ which appear to be complex vanadium compounds containing different compositions of $\mathrm{C}, \mathrm{S}, \mathrm{O}, \mathrm{Cl}, \mathrm{Ca}, \mathrm{Na}, \mathrm{K}, \mathrm{Cr}$, and $\mathrm{Cu}$. The two alloys also contained high-density precipitates $30-70 \mathrm{~nm}$ in size that seem to be vanadium compounds rich in $\mathrm{O}, \mathrm{C}$, $\mathrm{S}$, and $\mathrm{Ca}$. This unusual precipitation of vanadium compounds in the $\mathrm{V}-5 \mathrm{Cr}-5 \mathrm{Ti}$ and $\mathrm{V}-5 \mathrm{Cr}-3 \mathrm{Ti}$ alloys seems to be associated in part with $\mathrm{Ti}$ sponge (rclatively rich in $\mathrm{Cl}, \mathrm{Na}$, and $\mathrm{K}$ ) that was used to prepare the alloy ingots. Based on thermodynamic consideration, formation of some of the complex precipitates (e.g., vanadium oxycarbochloride) is preferred to titanium oxycarbonitrides in alloys containing a high level of $\mathrm{Cl}$. Vanadiumbased precipitates were absent in $\mathrm{V}-4 \mathrm{Cr}-4 \mathrm{Ti}$, which was fabricated using vacuum-arc-melted $\mathrm{Ti}$ plates low in $\mathrm{Cl}$, $\mathrm{Na}$, and $\mathrm{K}$. V. $5 \mathrm{Cr} \cdot 3 \mathrm{Ti}$, which was forged at $=650^{\circ} \mathrm{C}$ rather than extruded at the usual temperature of $1150^{\circ} \mathrm{C}$, also contained unusually small titanium oxycarbonitrides in high-density. Cleavage was the predominant process in brittle fracture of $\mathrm{V}-5 \mathrm{Cr}-5 \mathrm{Ti}$. However, evidence of intergranular separation, apparently associated with grain-boundary segregation of $\mathrm{Ti}, \mathrm{S}$, and $\mathrm{P}$, was also observed in the material. The origin of the higherthan-expected DBTTs of the $\mathrm{V}-5 \mathrm{Cr}-5 \mathrm{Ti}$ and $\mathrm{V}-5 \mathrm{Cr}-3 \mathrm{Ti}$ alloys seems to be associated with the unusual precipitation of vanadium compounds and intergranular separation. Effect of post-fabrication annealing on ductile-brittle-transition behavior was sccondary, although annealing at $\approx 1050^{\circ} \mathrm{C}$ produced the most favorable impact propertics. In contrast to $\mathrm{V}-5 \mathrm{Cr}-5 \mathrm{Ti}$ and $\mathrm{V}-5 \mathrm{Cr}-3 \mathrm{Ti}, \mathrm{V}-4 \mathrm{Cr}-4 \mathrm{Ti}$ remained ductile for impact temperatures higher than $-196^{\circ} \mathrm{C}$ regardless of annealing at 1050 or $1125^{\circ} \mathrm{C}$.

\section{INTRODUCTION}

Vanadium-base alloys are considered promising candidate structural materials for a fusion reactor first wall because they offer many important advantages, e.g., inherently low irradiation-induced activity, good mechanical properties, good compatibility with lithium, high thermal conductivity, and good resistance to irradiation damage. Based on previous investigations in which an alloy composition of $\approx 5 \mathrm{wt} . \% \mathrm{Cr}$ and $\approx 5 \mathrm{wt} . \% \mathrm{Ti}$ has been identified as the most promising, mechanical properties of $\mathrm{V}-5 \mathrm{Cr}-5 \mathrm{Ti}, \mathrm{V}-4 \mathrm{Cr}-4 \mathrm{Ti}$, and $\mathrm{V}-5 \mathrm{Cr}-3 \mathrm{Ti}$ alloys have recently been examined in detail. ${ }^{1-6}$ Among the three alloys, the $\mathrm{V}-4 \mathrm{Cr}-4 \mathrm{Ti}$ alloy in particular exhibited good tensile, ${ }^{1}$ creep, ${ }^{2}$ and impact propertics ${ }^{3}$ and superior resistance to irradiation-induced embrittement ${ }^{4-5}$ and swelling. ${ }^{6}$

Despite the small difference in composition of alloying elements, DBTTs of unirradiated V-5Cr-5Ti $\left(-60^{\circ} \mathrm{C}\right)$ and $\mathrm{V}-5 \mathrm{Cr}-3 \mathrm{Ti}\left(-85^{\circ} \mathrm{C}\right)$ alloys were, however, significantly higher than that of $\mathrm{V}-4 \mathrm{Cr}-4 \mathrm{Ti}\left(<-190^{\circ} \mathrm{C}\right) .^{3}$ Although these DBTTs are still very low compared to those of any other candidate structural materials for application in a fusion reactor, a concern has been raised as to the origin of the variation in DBTT and the reproducibility of the excellent propertics of the $\mathrm{V}-4 \mathrm{Cr}-4 \mathrm{Ti}$ alloy. Therefore, supplementary impact tests and

\footnotetext{
"Work supported by the Office of Fusion Energy, U.S. Department of Energy, under Contract W-31-109-Eng-38.
} 
microstructural analyses were conducted in this work to determine the effects of thermomechanical treatment and trace impurities on the variation in DBTTs of the three alloys, and thereby to identify undesirable variables of alloy fabrication that are detrimental to material toughness.

\section{MATERIALS AND PROCEDURES}

The chemical composition and fabrication parameters (i.e., extrusion, forging, and annealing temperatures) of the 3.8-mm-thick plates of the three alloys, from which the one-third-size Charpy impact specimens were machined, are given in Table 1. In the table, compositions of unalloyed V and V-3Ti are also given. As indicated in the table, different types of Ti raw material were used to arc-melt the alloys. Titanium is usually produced by the Kroll process, in which $\mathrm{TiCl}_{4}$ is passed over and reduced by molten sodium. The raw Ti sponge produced from this process contains significant levels of $\mathrm{Cl}, \mathrm{Na}$, and $\mathrm{K}$. In contrast, Ti plates, processed further by vacuum-arc-melting of the sponge, contains a relatively low level of $\mathrm{Cl}$, as indicated in the table.

Table 1. Chemical composition and fabrication parameters of V-4Cr-4Ti, V-5Cr-5Ti, and V-5Cr-3Ti alloys

\begin{tabular}{|c|c|c|c|c|c|c|c|c|c|c|c|c|}
\hline $\begin{array}{l}\text { ANL } \\
\text { ID No. }\end{array}$ & $\begin{array}{l}\text { Alloy } \\
\text { Type }\end{array}$ & $\begin{array}{c}\text { DBTT } \\
\left({ }^{\circ} \mathrm{C}\right)\end{array}$ & $\begin{array}{c}\mathrm{Cr} \\
(\mathrm{w} .90)\end{array}$ & $\begin{array}{c}\mathrm{Ti} \\
\text { (wL.\%) }\end{array}$ & $\begin{array}{c}0 \\
\text { (wppm) }\end{array}$ & $\begin{array}{c}\mathrm{N} \\
\text { (wppm) }\end{array}$ & $\begin{array}{c}\mathrm{C} \\
\text { (wppm) }\end{array}$ & $\begin{array}{c}\mathrm{Si} \\
\text { (wppm) }\end{array}$ & $\begin{array}{l}\text { Extrude or } \\
\text { Forge }\left({ }^{\circ} \mathrm{C}\right)\end{array}$ & $\begin{array}{l}\text { Rolling } \\
\text { Temp. }\left({ }^{\circ} \mathrm{C}\right)\end{array}$ & $\begin{array}{l}\text { Annealing } \\
\text { Temp. }\left({ }^{\circ} \mathrm{C}\right)^{\mathrm{a}}\end{array}$ & $\begin{array}{l}\text { Ti Raw } \\
\text { Material }\end{array}$ \\
\hline BL-47 & $4 \mathrm{Cr}-4 \mathrm{Ti}$ & $<-190$ & 4.1 & 4.3 & 350 & 220 & 200 & 870 & $\begin{array}{l}\text { extrude } \\
1150\end{array}$ & 400 & $\begin{array}{c}1050 \\
4 \mathrm{~h}\end{array}$ & plate $^{6}$ \\
\hline BL-63 & $5 \mathrm{Cr}-5 \mathrm{Ti}$ & .60 & 4.6 & 5.1 & 440 & 28 & 73 & 310 & $\begin{array}{c}\text { extrude } \\
1150\end{array}$ & 25 & $\begin{array}{c}1100 \\
2 \mathrm{~h}\end{array}$ & sponge $c$ \\
\hline BL-54 & $5 \mathrm{Cr}-3 \mathrm{Ti}$ & .85 & 5.1 & 3.0 & 480 & 82 & 133 & 655 & $\begin{array}{l}\text { forge } \\
650\end{array}$ & 25 & $\begin{array}{c}1175 \\
1 \mathrm{~h}\end{array}$ & sponge ${ }^{c}$ \\
\hline BL-62 & $3 \mathrm{Ti}$ & $<-196$ & & 3.1 & 320 & 86 & 109 & 660 & - & - & - & sponge $c$ \\
\hline BL-51 & v & -150 & - & - & 570 & 49 & 56 & 370 & - & - & - & - \\
\hline
\end{tabular}

annealed after rolling by the supplier.

${ }^{b} \mathrm{Cl} 5-8$ wppm.

$\mathrm{c}_{\mathrm{Cl}} \approx \mathbf{3 8 0}$ wppm.

Final annealing of the Charpy specimens was performed for $1 \mathrm{~h}$ at $950-1125^{\circ} \mathrm{C}$ in a vacuum of $2.6 \times 10^{-6}$ $\mathrm{Pa}$ in an ion-pump system. Hydrogen content in the specimens reached after the final annealing is typically $<30$ appm. The Charpy-impact tests were conducted with an instrumented Dynatup drop-weight impact test machine at temperatures higher than $-190^{\circ} \mathrm{C}$. Impact velocity and load for the tests were $2.56 \mathrm{~m} \cdot \mathrm{s}^{-1}$ and $15 \mathrm{~kg}$, respectively.

Microstructure of the alloys was characterized by JEOL JSM-50 scanning electron microscope (SEM), JEM 100CX-II (100 keV) and Philips CM-30T (200 keV) transmission electron microscopes (TEMs), and JEOL JAMP-10 scanning Auger electron microscope (SAM). The JEOL JAMP-10 SAM was equipped with an in-situ fracture device operated at $-196^{\circ} \mathrm{C}$. Clean fracture surfaces of the alloy specimens were produced in-situ in the ultrahigh vacuum $\left(2.6 \times 10^{-7} \mathrm{~Pa}\right)$ environment of the SAM using this device. The fracture surface chemical composition was analyzed by Auger electron spectroscopy (AES) immediately following the fracture without an exposure of the surface to atmosphere.

\section{EFFECT OF ANNEALING TEMPERATURE}

Effects of the final $(1 \mathrm{~h})$ annealing temperature on the impact properties of $\mathrm{V}-5 \mathrm{Cr}-5 \mathrm{Ti}$ and $\mathrm{V}-4 \mathrm{Cr}-4 \mathrm{Ti}$ alloys are shown in Fig. 1. For V-5Cr-5Ti alloy, annealing at 1050 and $1125^{\circ} \mathrm{C}$ for $1 \mathrm{~h}$ resulted in a DBTT of $\approx-110$ and $\approx-60^{\circ} \mathrm{C}$, respectively (Fig. 1A). DBTT of the specimens annealed at $950^{\circ} \mathrm{C}$ appears to be comparable to or higher than that of the material annealed at $1050^{\circ} \mathrm{C}$. Impact behavior of unannealed as-received specimens indicated the highest DBTT for this alloy. The DBTT of V-5Cr-3Ti was similar to that of V-5Cr-5Ti, i.e., $-85^{\circ} \mathrm{C}$. Based on these observations, it was concluded that the optimal annealing temperature is close to $\approx 1050^{\circ} \mathrm{C}$. However, it became clear that, contrary to the initial expectation, a high impact energy 
$\left(C_{V} \approx 140 \mathrm{~J} \cdot \mathrm{cm}^{-2}\right)$ and a ductile behavior at $>-196^{\circ} \mathrm{C}$ (remarkable behavior exhibited by $\mathrm{V}-4 \mathrm{Cr}-4 \mathrm{Ti}$, Fig. 1B), 3,5 cannot be induced by laboratory annealing of $\mathrm{V}-5 \mathrm{Cr}-5 \mathrm{Ti}$ and $\mathrm{V}-5 \mathrm{Cr}-3 \mathrm{Ti}$ alloys. In contrast, $\mathrm{V}-4 \mathrm{Cr}-4 \mathrm{Ti}$ exhibited superior impact behavior regardless of annealing condition. Therefore, it was suspected that the variation in DBTTs of $\mathrm{V}-5 \mathrm{Cr}-5 \mathrm{Ti}, \mathrm{V}-5 \mathrm{Cr}-3 \mathrm{Ti}$, and $\mathrm{V}-4 \mathrm{Cr}-4 \mathrm{Ti}$ is probably due to a fundamental microstructural character that cannot be modified by the simple annealing treatments; hence, extensive analyses by SEM, TEM, and SAM were conducted to identify the microstructure and relevant metallurgical process.
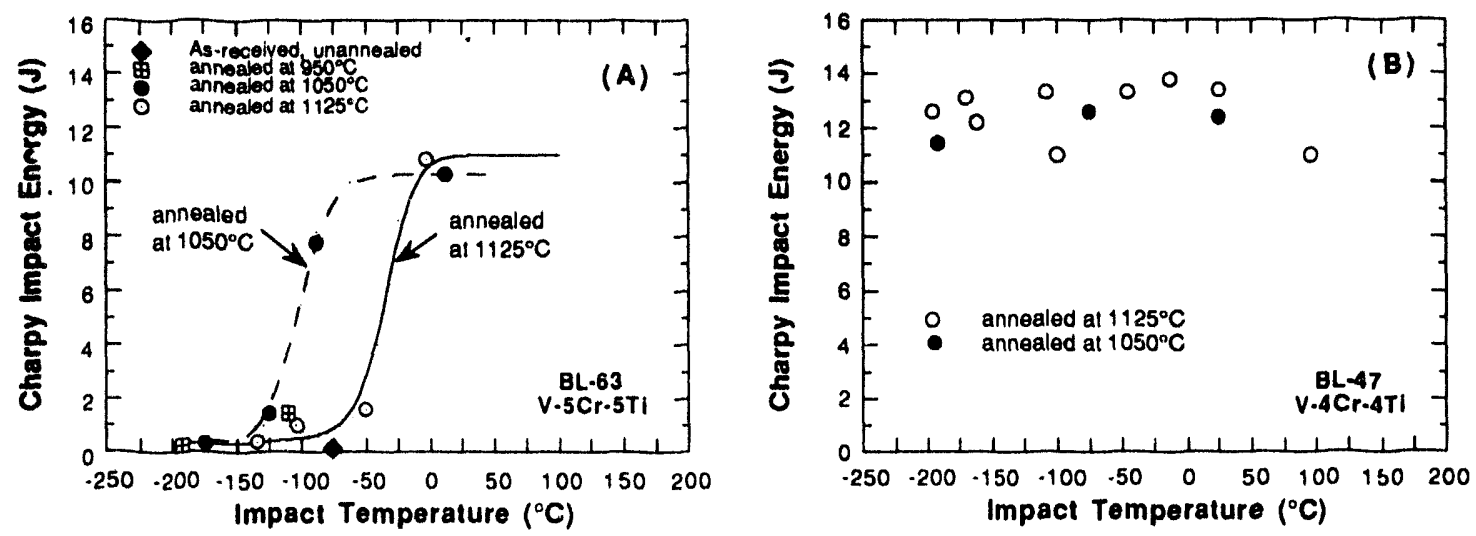

Figure 1. Effects of annealing temperature on impact properties of $\mathrm{V}-5 \mathrm{Cr}-5 \mathrm{Ti}(\mathrm{A})$ and $\mathrm{V}-4 \mathrm{Cr}-4 \mathrm{Ti}(B)$

\section{MICROSTRUCTURAL CHARACTERIZATION}

\section{SEM-EDS Analysis}

Brittle-cleavage surfaces of the Charpy specimens of $\mathrm{V}-5 \mathrm{Cr}-3 \mathrm{Ti}$ and $\mathrm{V}-5 \mathrm{Cr}-5 \mathrm{Ti}$ alloys, produced from impact tests at $<-100^{\circ} \mathrm{C}$, were characterized by hitherto unknown large precipitates. They could be readily imaged and analyzed by energy-dispersive X-ray spectroscopy (EDS) in SEM. Examples of the fracture surfaces of the two alloys are shown in Figs. 2 and 3, respectivcly. In $\mathrm{V}-5 \mathrm{Cr}-5 \mathrm{Ti}$, intergranular-fracture morphology was observed in minor proportion. Some of the large precipitates (2-15 $\mathrm{mm}$ in size) appear to be embedded in the alloy material. Others seemed to be located looscly on the free cleavage surfaces, raising a question that they may be artifact particles. However, holes that are comparable to the protruding particles in size, density, and shape were observed on the fracture surfaces, indicating that they are true precipitates contained in the alloys. Under a focused electron bcam that heats a localized area under examination, the irregular-shaped precipitates were observed to change shape (to oval or spherical shape), indicating that these precipitates softened or decomposed at a relatively low temperaturc.

Neither cleavage nor intergranular fracture could be produced in $\mathrm{V}-4 \mathrm{Cr}-4 \mathrm{Ti}$, even at an impact temperature of $-196^{\circ} \mathrm{C}$ (liquid nitrogen temperature), unless a sufficient amount of hydrogen was charged in the specimens. None of these precipitates, however, were observed on the cleavage fracture surfaces of $\mathrm{V}-4 \mathrm{Cr}-4 \mathrm{Ti}$.

Also shown in Figs. 2 and 3 are EDS spectra of the precipitates. The precipitates were generally rich in $\mathrm{V}, \mathrm{C}, \mathrm{O}$, and $\mathrm{Cl}$. In addition to these clements, some precipitates indicated $\mathrm{Na}, \mathrm{S}, \mathrm{Ca}$, or $\mathrm{K}$ in their composition (c.g., Fig. 3B). Examination of EDS spectra similar to those of Figs. 2 and 3 indicated that Ti is not a constituent element. Note that the Ti peak in Fig. $2 \mathrm{~B}$ is from background material. Elements that were found to be higher in composition in the $V$-base precipitates than in matrix are summarized for each alloy in Table 2.

\section{AES Analysis}

Clean in-situ fracture surfaces, produced in the ultrahigh vacuum environment of SAM, were examined primarily to determine if the characteristic precipitates are indeed contamination-induced artifacts formed on the 

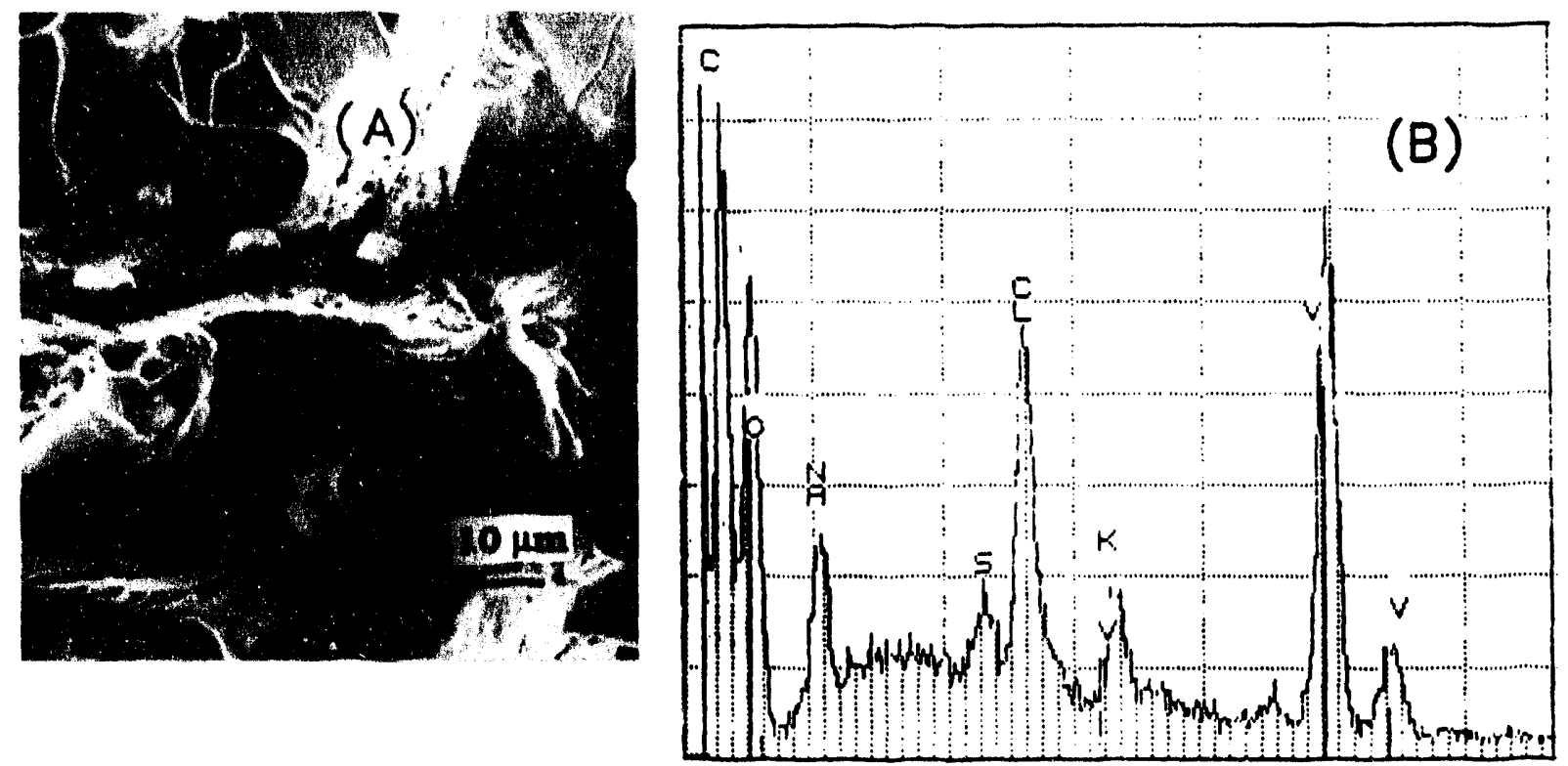

Figure 2. SEM morphology $(A)$ and EDS spectra $(B)$ of characteristic precipitates observed on brittle-fracture surface of Charpy-impact specimen of $V-5 C r-3 T i$
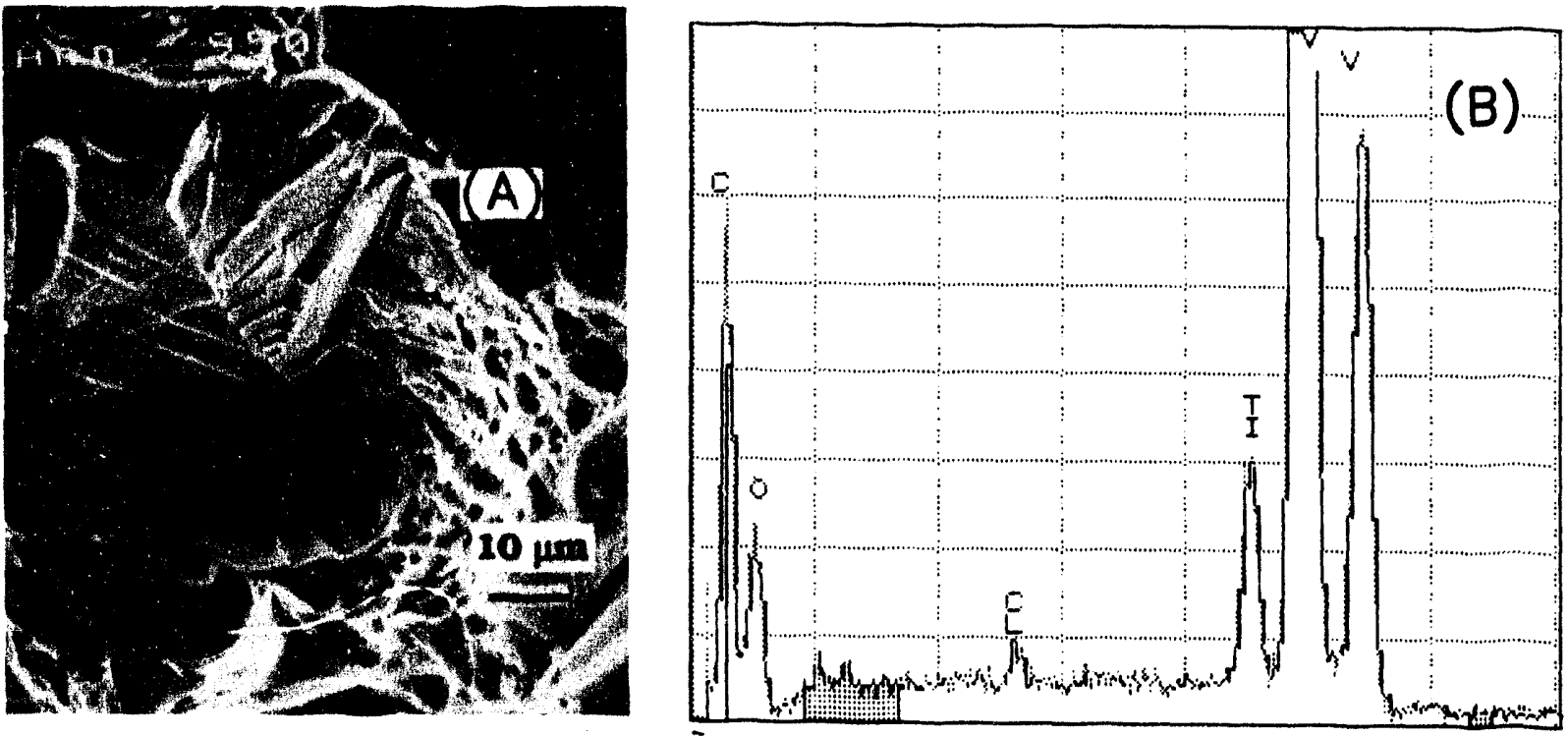

Figure 3. SEM morphology $(A)$ and EDS spectra $(B)$ of characteristic precipitates observed on brittle-fracture surface of Charpy-impact specimen of V-5Cr-5Ti

Charpy specimens after impact testing. Results, however, were essentially similar to those observed in SEM. An example of the Auger analyses is given in Fig. 4. In Fig. 4A, cleavage- and intergranular-fracture surfaces and precipitates are visible. AES spectra, obtained from the three types of microstructural features, are shown in Figs. 4B, 4C, and 4D, respectively.

Intergranular-fracture surfaces exhibited generally higher levels of $\mathrm{Ti}, \mathrm{O}, \mathrm{S}, \mathrm{N}$, and $\mathrm{P}$ than cleavage surfaces. Clear resolution of grain-boundary segregation of Ti or $\mathrm{N}$ was difficult because AES peaks from the two elements virtually overlap. There was indication of slightly higher level of $\mathrm{Cl}$ on some grain boundaries (see Table 2); however, the evidence was inconclusive. 
Table 2. Summary of constituent elements in vanadium-base precipitates and elements found to segregate to grain boundaries

\begin{tabular}{|c|c|c|c|c|c|c|c|c|c|c|c|c|c|c|c|c|c|c|c|}
\hline $\begin{array}{l}\text { Heat } \\
\text { ID No. }\end{array}$ & $\begin{array}{l}\text { Alloy } \\
\text { Type }\end{array}$ & $\begin{array}{l}\mathrm{PPT}^{\mathrm{P}} \\
\mathrm{DD}\end{array}$ & $\begin{array}{l}\mathrm{GB}^{\mathrm{b}} \\
\mathrm{D}\end{array}$ & $\begin{array}{l}\text { Analysis } \\
\text { Method }\end{array}$ & $\begin{array}{l}\text { Size } \\
(\mathrm{nm})\end{array}$ & V & $\mathrm{Cr}$ & $\mathrm{Ti}$ & $\mathrm{Cu}$ & 0 & C & $\mathbf{N}$ & $\mathbf{S}$ & $\mathbf{P}$ & $\mathrm{Cl}$ & $\mathrm{Na}$ & $\mathrm{Ca}$ & $\mathrm{Si}$ & K \\
\hline BL-63 & SCr-STi & $17 \mathrm{~N}$ & & SEM-EDS & 11,000 & $x$ & & & $\cdot$ & $x$ & $x$ & & & & $x$ & & & & \\
\hline ' & 1 & Al & & AES & 4,500 & $x$ & $x$ & & $x$ & $x$ & $x$ & & $x$ & & $x$ & & & & \\
\hline ' & ' & B3 & & AES & 2,600 & $x$ & $x$ & & $x$ & $x$ & $x$ & $x$ & $x$ & & $x$ & & $x$ & & \\
\hline ' & 1 & B5 & & AES & 1,700 & $x$ & $x$ & & $x$ & $x$ & $x$ & $x$ & $x$ & & $x$ & & $x$ & $x$ & \\
\hline ' & 1 & D5 & & AES & 2,100 & $x$ & $x$ & & $x$ & $x$ & $\mathbf{x}$ & & $\mathbf{x}$ & $x$ & $x$ & & & & \\
\hline I & I & & $\mathrm{Cl}$ & AES & - & & $x$ & $x$ & & $\mathbf{x}$ & & $x$ & $x$ & $x$ & $x$ & & & & \\
\hline I & ' & & B2 & AES & - & & $x$ & $x$ & & $x$ & & $x$ & $\mathrm{x}$ & $x$ & & & & & \\
\hline I & 1 & & B4 & AES & - & & & $x$ & & $x$ & & $x$ & $x$ & $x$ & & & & & \\
\hline I & ' & & C3 & AES & - & & & $x$ & & $x$ & & $x$ & $x$ & $x$ & & & & & \\
\hline 1 & ' & & $D 1$ & AFS & - & & & $x$ & & $x$ & & $x$ & $x$ & $x$ & $x$ & & & & \\
\hline ' & ' & & D2 & AES & - & & & $x$ & & $x$ & & $x$ & $x$ & $x$ & & & & & \\
\hline BL-54 & $5 \mathrm{Cr}-3 \mathrm{Ti}$ & p4 & & SEM-EDS & 15,000 & $x$ & & & & $x$ & $x$ & & $x$ & & $x$ & $x$ & & & $x$ \\
\hline ' & ' & P3 & & SIEM-EDS & 17,000 & $x$ & & & & $x$ & $x$ & & $x$ & & $x$ & $x$ & & & \\
\hline ' & 1 & P2 & & SEM-EDS & 8,000 & $x$ & & & & $x$ & $x$ & & & & $x$ & $x$ & & & \\
\hline ' & 1 & P6 & & SEM-EDS & 11,000 & $x$ & & & & , & Y & & & & $x$ & $x$ & & & \\
\hline I & 1 & 8305 & & AEM-EDS & 35 & $x$ & & & & $\lambda$ & & & $x$ & & & & $x$ & & \\
\hline BL-62 & $3 \mathrm{Ti}$ & 621 & & SEM-EDS & 9,000 & $x$ & & & & $\mathbf{x}$ & $x$ & & & & $x$ & $x$ & & & $x$ \\
\hline 1 & 1 & 622 & & SEM-EDS & 11,000 & $x$ & & & & $x$ & $x$ & & & & $x$ & $x$ & & & \\
\hline 1 & I & 623 & & SEM-EDS & 10,000 & $x$ & & & & $x$ & $x$ & & & & $x$ & $x$ & & & \\
\hline ' & 1 & 624 & & SEM-IEDS & 8,000 & $x$ & & & & $x$ & $x$ & & & & $x$ & $x$ & $x$ & & $x$ \\
\hline BL-51 & $\mathrm{v}$ & v1 & & AFM-EEDS & 70 & $x$ & & & & $x$ & $x$ & & $x$ & & & & $x$ & & \\
\hline ' & ' & $v_{2}$ & & AEM-EDS & 50 & $x$ & & & & $x$ & $x$ & & & & & & & $\mathbf{x}$ & \\
\hline ' & 1 & V3 & & AEM-EDS & 60 & $\mathbf{x}$ & & & & & $x$ & & & & & $x$ & & & \\
\hline
\end{tabular}

aPPT $=$ precipitate.

$\mathrm{b}_{\mathrm{GB}}=$ grain boundary.

On the in-situ fracture surface shown in Fig. 4A, two types of precipitates were identified. One was the $\mathrm{Ti}(\mathrm{O}, \mathrm{N}, \mathrm{C})$ precipitates $(300-500 \mathrm{~nm}$ in size) that are normally present in Ti-containing vanadium-base alloys. The other type was complex vanadium compounds, most of them rich in $\mathrm{V}, \mathrm{Cr}, \mathrm{Cu}, \mathrm{O}, \mathrm{C}, \mathrm{S}$, and $\mathrm{Cl}$, and some of them rich in N, Ca, and Si as well (Table 2). The higher O content in the precipitate analyzed in Fig. 4D can be deduced from a comparison of the spectra of Figs. 4D and 4B, the latter spectra being the background signal from a cleavage surface.

To show more directly $\mathrm{Cl}, \mathrm{Cr}, \mathrm{Cu}, \mathrm{Ti}, \mathrm{N}$, and $\mathrm{O}$ contents of the precipitates relative to those of cleavage surfaces, raw intensities of these elements are compared in Figs. 5A to 5F. AES peaks of some of the elements are superimposed, e.g., $\mathrm{O}(510 \mathrm{eV})$ and $\mathrm{V}(509 \mathrm{eV})$ peaks and $\mathrm{N}(381 \mathrm{eV})$ and $\mathrm{Ti}(383 \mathrm{eV})$ peaks. From Fig. 5 , it is clear that V-base precipitates are rich in $\mathrm{Cl}, \mathrm{Cr}, \mathrm{Cu}, \mathrm{N}$, and $\mathrm{O}$. However, Fig. 5D indicates that $\mathrm{Ti}$ is not a constituent element of the precipitates, because peak heights of $\mathrm{Ti}(418 \mathrm{eV})$ from the precipitates were somewhat lower than those from cleavage surfaces. Higher $\mathrm{N}$ content in the precipitates can be deduced from a comparison of Figs. 5D and 5E. The larger precipitates analyzed by SEM-EDS did not contain Cr (Figs. 2 and 3). In contrast, all V-base precipitates analyzed by AES that were significantly smaller than those analyzed by SEM contained $\mathrm{Cr}$ and $\mathrm{Cu}$ (sec Table 2). 

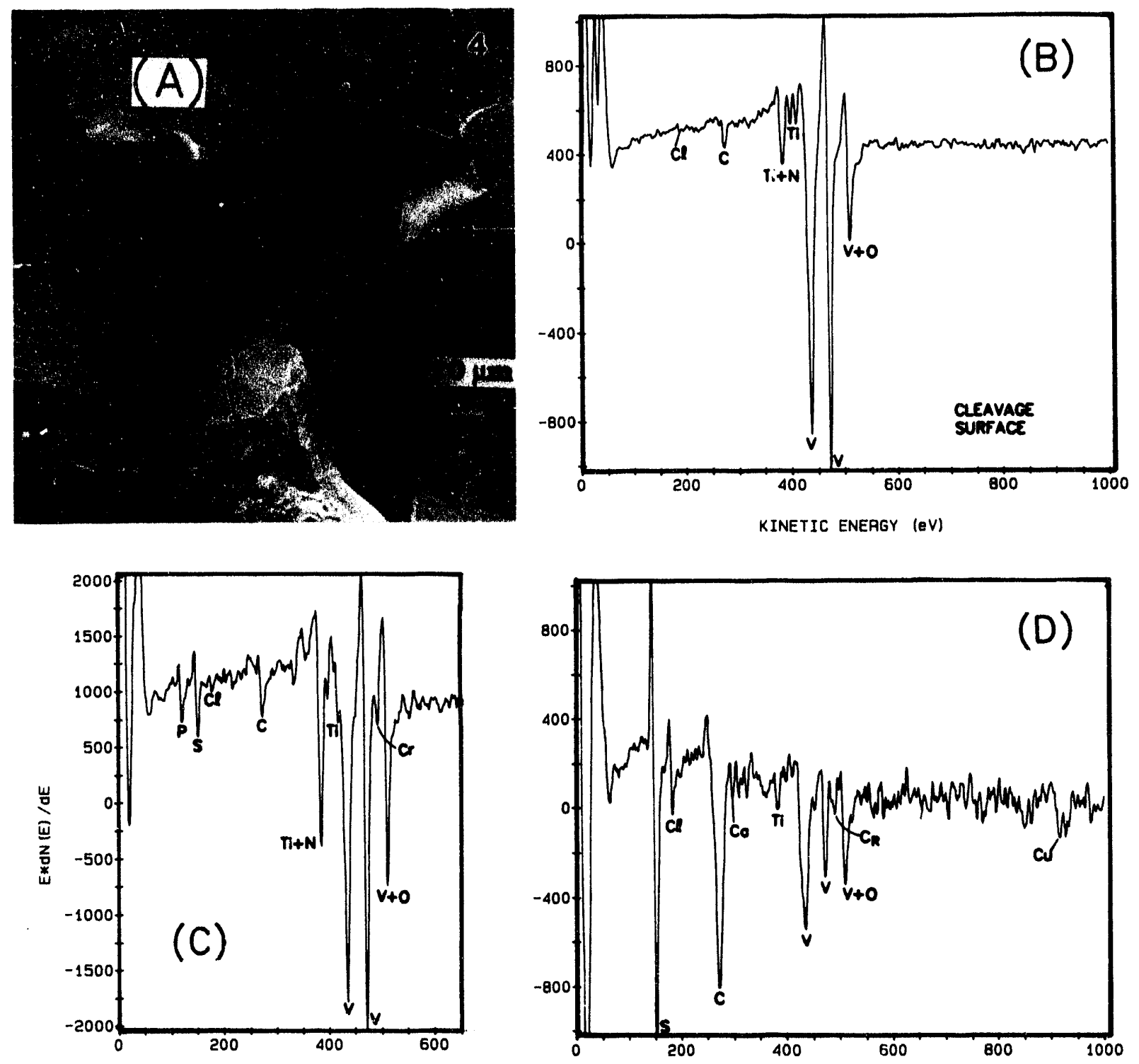

Figure 4. In-situ fracture surface morphology of V-5Cr-5Ti (A). Typical AES spectra from cleavageand intergranular-fracture surfaces and precipitates are shown in $(B),(C)$, and $(D)$, respectively.

Fracture surfaces of $\mathrm{V}-4 \mathrm{Cr}-4 \mathrm{Ti}$ produced in-situ at $-196^{\circ} \mathrm{C}$ had a ductile-dimple morphology and none of them exhibited precipitates similar to those of Fig. 2 or 3 (i.e., precipitates rich in V, O, C, and $\mathrm{Cl}$ ). Only relatively large $\mathrm{Ti}(\mathrm{O}, \mathrm{N}, \mathrm{C})$ precipitates $300-500 \mathrm{~nm}$ in size were observed. $\mathrm{Cl}$ or Na peak was absent in AES spectra obtained from precipitates or ductile-dimple surfaces in $\mathrm{V}-4 \mathrm{Cr}-4 \mathrm{Ti}$.

\section{TEM Analysis of Ti Precipitates}

TEM microstructures of V-5Cr-3Ti and V-5Cr-5Ti alloys were similar and were characterized by dual-size distribution of precipitates; a group of relatively large precipitates $(300-500 \mathrm{~nm}$ in diameter) in low density and a group of relatively small precipitates $(30-80 \mathrm{~nm}$ in diameter) in high density. In $\mathrm{V}-4 \mathrm{Cr}-4 \mathrm{Ti}$, only the former group of precipitates, identified as the normal $\mathrm{Ti}(\mathrm{O}, \mathrm{N}, \mathrm{C})$, was observed. ${ }^{1}$ These two contrasting precipitate distributions are shown in Fig. 6. 

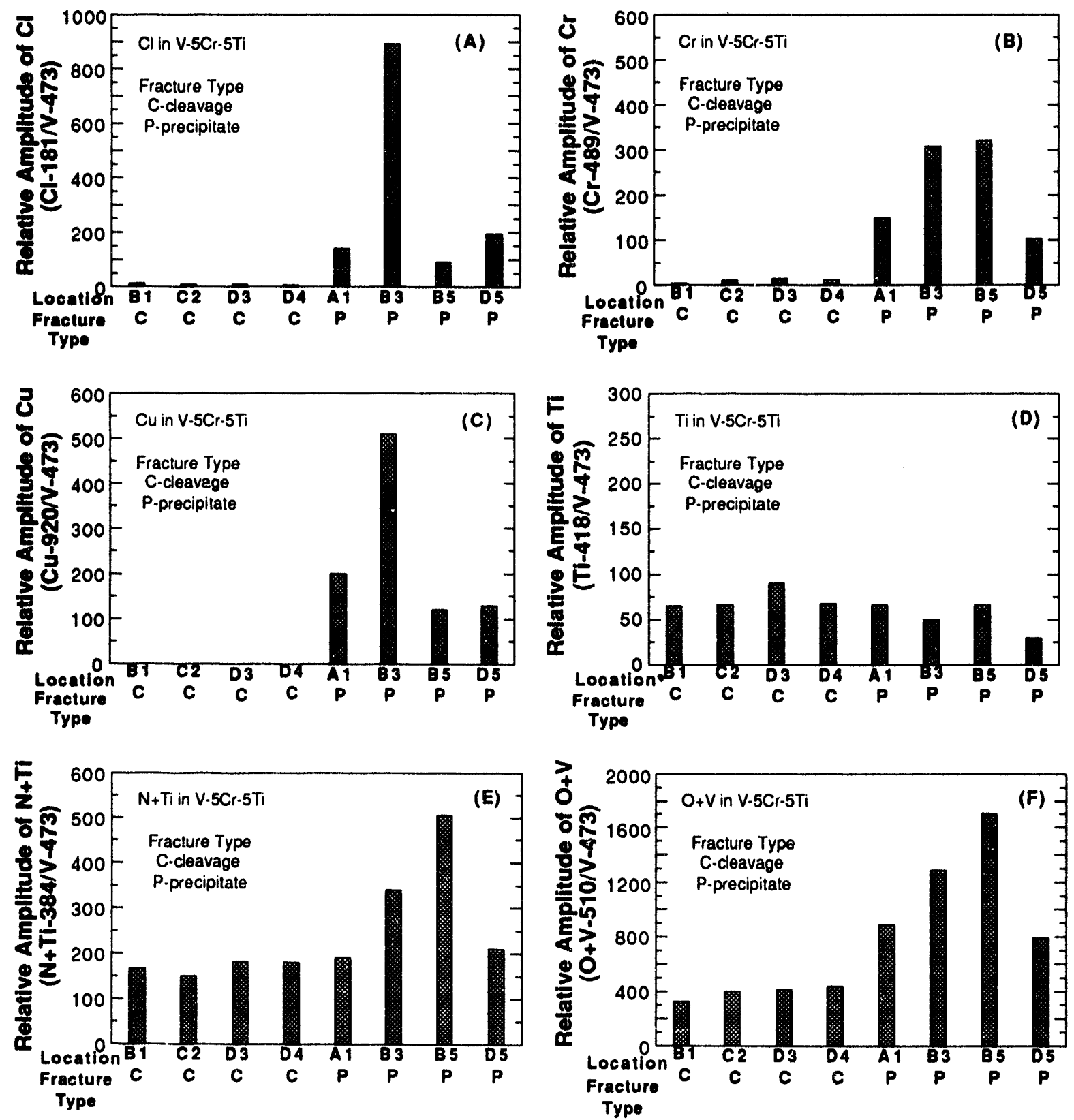

Figure 5. Relative intensities of Auger electrons of alloying and impurity elements from cleavage surfaces (denoted " $C$ ") and precipitates (denoted " $P$ ") in V-5Cr-5Ti. Source elements and Auger electrons are id"ntified in insets.

Further analysis showed that the $\mathrm{Ti}(\mathrm{O}, \mathrm{N}, \mathrm{C})$ phase in $\mathrm{V}-5 \mathrm{Cr}-3 \mathrm{Ti}$ had a dual-size distribution, i.e., $\mathrm{Ti}(\mathrm{O}, \mathrm{N}, \mathrm{C})$ precipitates of $300-500$ and $30-80 \mathrm{~nm}$. These are shown in the dark-field image in Fig. 7A. Small $\mathrm{Ti}(\mathrm{O}, \mathrm{N}, \mathrm{C})$ precipitates, shown in the dark-field image in Fig. 7B, are aligned along linear features that appear to be dislocations, probably formed in association with forging at $650^{\circ} \mathrm{C}$. In $\mathrm{V}-5 \mathrm{Cr}-5 \mathrm{Ti}$, which was extruded at $\approx 1150^{\circ} \mathrm{C}$, small $\mathrm{Ti}(\mathrm{O}, \mathrm{N}, \mathrm{C})$ precipitates were not seen. 


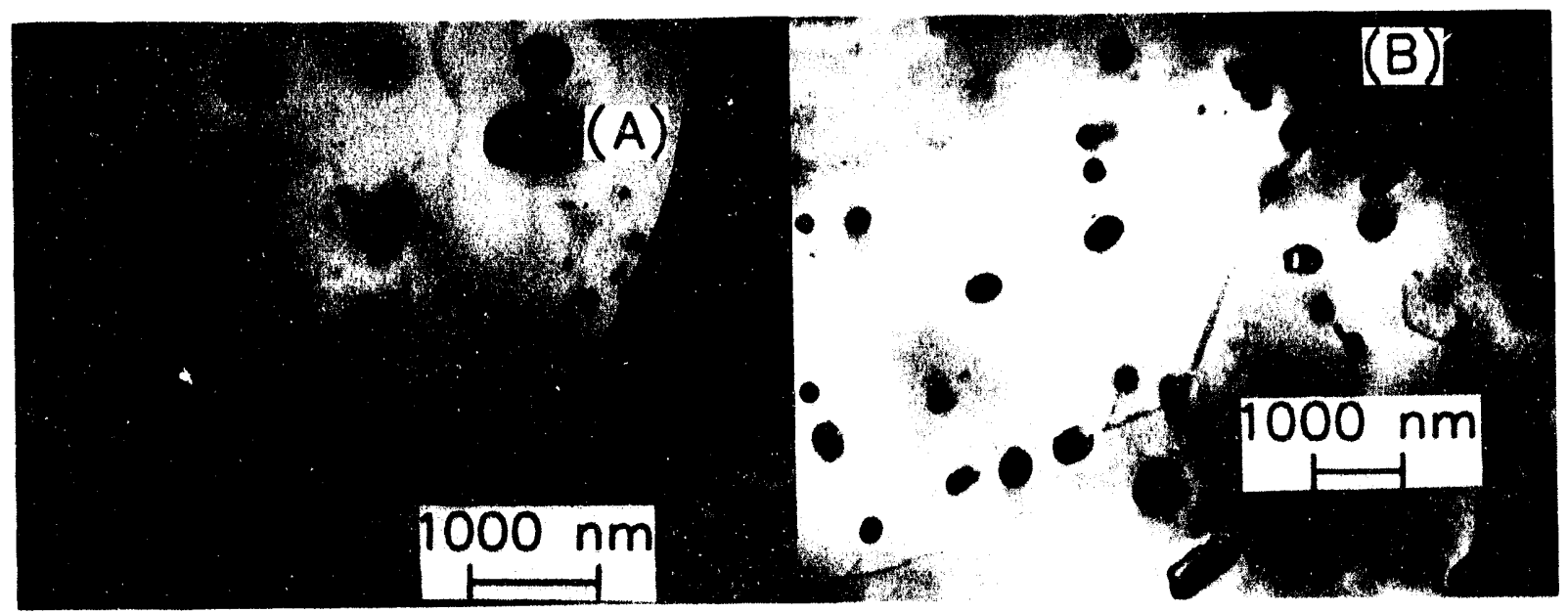

Figure 6. Unusual dual-size distribution of precipitates characteristic of $V-5 C r-3 T i$ and $V-5 C r-5 T i(A)$ and normal distribution of $T i(O, N, C)$ in $V-4 C r-4 T i(B)$
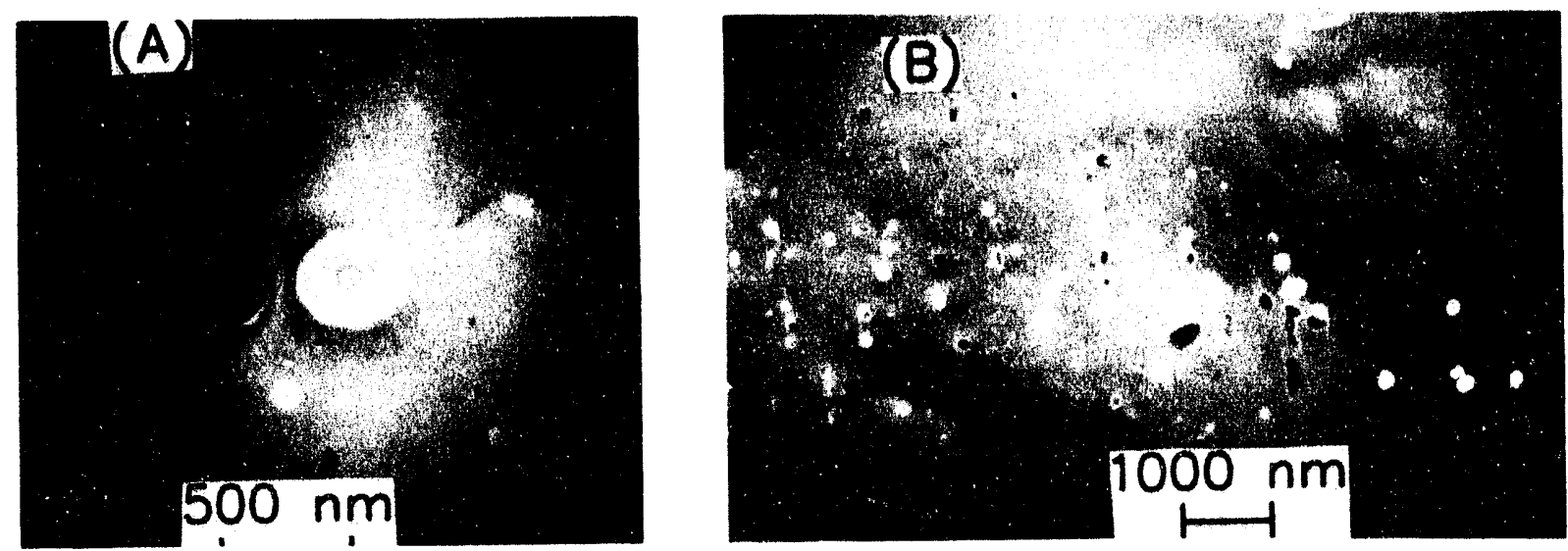

Figure 7. Dark-field images of Ti(O,N,C) in V-5Cr-3Ti showing dual-size distribution (A) and small Ti $(O, N, C)$ linearly aligned in high density $(B)$

\section{TEM Analysis of $V$ Precipitates}

Diffraction characteristics of the regions containing the smaller precipitates $(30-80 \mathrm{~nm}$ in size) of high density in both $\mathrm{V}-5 \mathrm{Cr}-3 \mathrm{Ti}$ and $\mathrm{V}-5 \mathrm{Cr}-5 \mathrm{Ti}$ specimens were examined in more detail. An example of such regions in $\mathrm{V}-5 \mathrm{Cr}-3 \mathrm{Ti}$ is shown in Fig. 8A. Diffraction analysis of such regions showed that at least one type of hitherto unidentified precipitates was present in both alloys in high density. Reciprocal lattice spacings of $\approx 0.652,0.620,0.605,0.450,0.363,0.311,0.235,0.219,0.168,0.153$, and $0.147 \mathrm{~nm}$ were measured from selected-area-diffraction (SAD) patterns characteristic of the regions containing the unknown type(s) of precipitates. These d-spacings could have originated from more than one type of precipitate. The diffraction patterns, however, could not be indexed. An example of such SADs is shown in Fig. 8B. The dark-field image in Fig. 8A was produced using one of the precipitate reflections. The characteristic SADs indicated that the unidentified phase is a low-symmetry structure, most likely a monoclinic system.

The dark-field image (Fig. $8 \mathrm{~B}$ ) indicates that most of them are $30-70 \mathrm{~nm}$ in size, although some are as large as $\approx 1,000 \mathrm{~nm}$, a size similar to the precipitates of Fig. 4 that were shown to be rich in $\mathrm{V}, \mathrm{O}, \mathrm{C}, \mathrm{Cl}, \mathrm{S}$, and $\mathrm{Ca}$. From a selected area containing one of the small precipitates, EDS spectra were obtained in the Philips CM-30 analytical electron microscope. EDS spectra from the precipitate and matrix are shown in Figs. $8 \mathrm{C}$ and $8 \mathrm{D}$, respectively. Based on these results, it is believed that most of the small precipitates in Fig. 8A are indeed 
vanadium precipitates rich in $\mathrm{O}, \mathrm{S}$, and $\mathrm{Ca}$. The same type of precipitate was also observed in unalloyed $\mathrm{V}(\mathrm{BL}-51){ }^{7}$ This is shown in Fig. 9. The coherent precipitate shown in Fig. 9A produced an oval-shaped dark strain contrast on the right side of the precipitatc. Precipitate reflections (d-spacing of $0.620 \mathrm{~nm}$ ) shown in the corresponding diffraction pattern (Fig. 9B) and EDS spectra (Fig. 9C) are essentially the same as those observed in $\mathrm{V}-5 \mathrm{Cr}-3 \mathrm{Ti}$ (Figs. 8B and 8C), except for double diffraction spots in Fig. 9B and a higher $\mathrm{C}$ content in Fig. 9C. In the unalloyed $\mathrm{V}$, similar vanadium precipitates of somewhat different compositions were also observed (Table 2). ${ }^{7}$
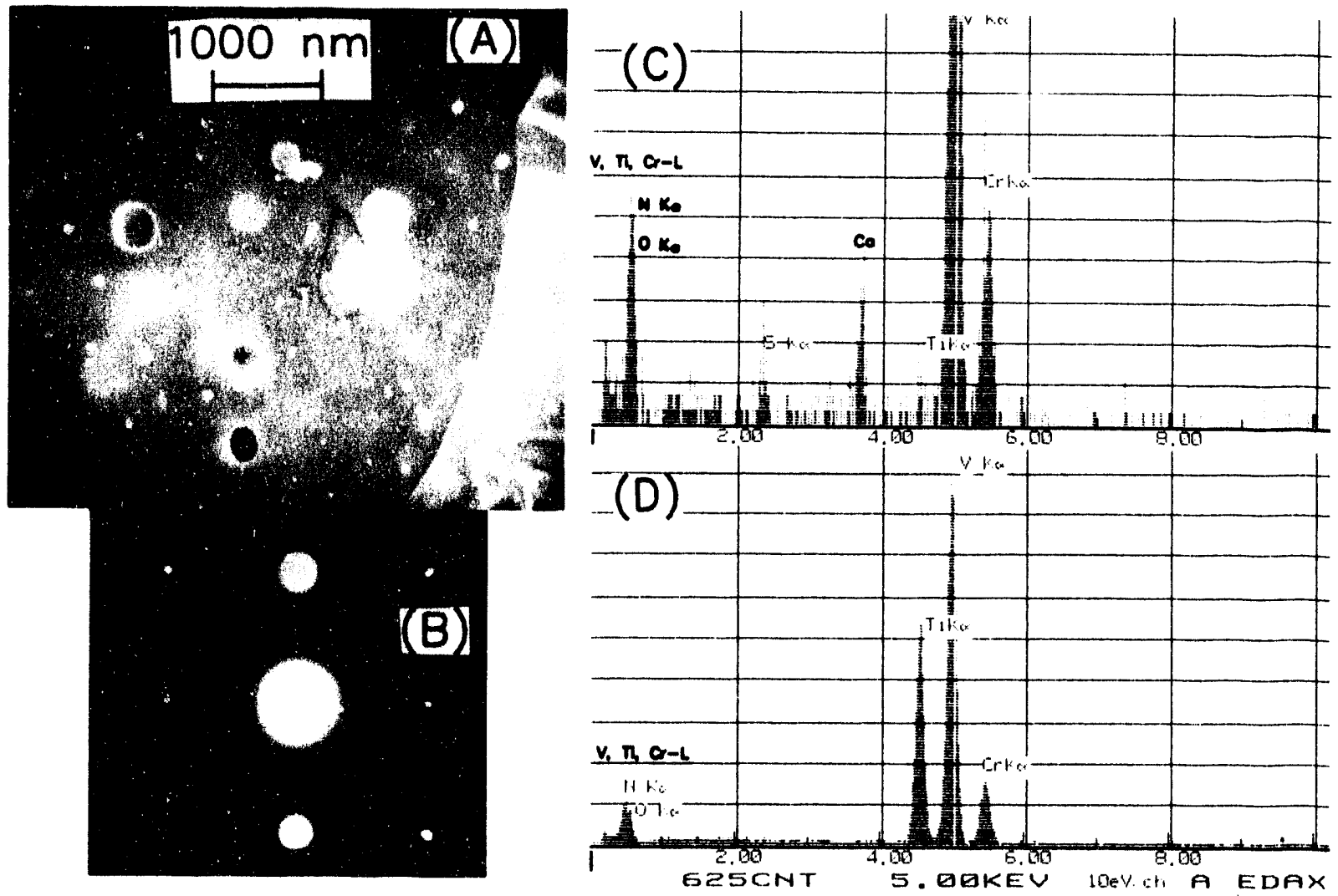

Figure 8. V-base precipitates in V-5Cr-3Ti. (A) dark-field image showing dual-size distribution; $(B)$ selected area diffraction pallern showing (100) zone of $V$ and weak reflections (d-spacing $0.620 \mathrm{~nm}$ ) from $a$ small precipitate in $(A) ;(C) E D S$ signal from the precipitate; and $(D)$ signal from nearby matrix.

Based on these results, it secms cvident that some of the vanadium precipitates, relatively large in size $(2,000-17,000 \mathrm{~nm})$, form during ingol melting and solidification. Smaller $(30-80 \mathrm{~nm})$ vanadium precipitates of somewhat different compositions scem to form in high density during secondary fabrication processes (extrusion, forging, and annealing).

\section{TEM Analysis of Grain Boundaries}

Some grain boundaries in $\mathrm{V}-5 \mathrm{Cr}-5 \mathrm{Ti}$ were characterized by unknown precipitates, although most of them were free of precipitate phase. There were two different types of precipitates; a continuous film and irregularshaped particles. These are shown in dark-ficld images in Figs. 10A and 10B, respectively. Diffraction patterns from both types of precipitates could not be indexed.

\section{DISCUSSION}

Based on microstructural analyses, the higher-than-expected DBTTs of V-5Cr-3Ti and V-5Cr-5Ti seem to be associated with an unusual precipitate structure characterized by dual-size distribution of two types of phases. 
One type was a Ti compound, namely, the relatively large Ti(O,N,C) precipitates $(300-500 \mathrm{~nm}$ in size) that apparently form during ingot melting and solidification, and small $T i(O, N, C)$ particles $30-80 \mathrm{~nm}$ in size that form in the forged $\mathrm{V}-5 \mathrm{Cr}-3 \mathrm{Ti}$ alloy during secondary fabrication. In $\mathrm{V}-4 \mathrm{Cr}-4 \mathrm{Ti}$ or $\mathrm{V}-5 \mathrm{Cr}-5 \mathrm{Ti}$, both of which were extruded, small Ti(O,N,C) particles did not form.

In $\mathrm{V}-5 \mathrm{Cr}-3 \mathrm{Ti}, \mathrm{V}-5 \mathrm{Cr}-5 \mathrm{Ti}$, and $\mathrm{V}$-3Ti alloys for which sponge $\mathrm{Ti}$ was used in ingot melting, complex $\mathrm{V}$ base precipitates seem to have formed unexpectedly. The results of SEM, AES, and AEM analyses in Table 2 summarize of the constituent elements of V-base precipitates and elements that segregate to grain boundaries. Although $\mathrm{V}$ compounds have slightly different combinations of impurity and trace elements, $\mathrm{O}, \mathrm{C}, \mathrm{Cl}, \mathrm{S}, \mathrm{Ca}$, $\mathrm{Cr}$, and $\mathrm{Cu}$ seem to promote precipitation.

AES analyses indicate that many of the $\mathrm{V}$-base precipitates are a form of vanadium oxycarbochloride, most likely a variation of vanadium dioxychloride $\left(\mathrm{VO}_{2} \mathrm{Cl}\right)$. To this basic composition, impurities such as $\mathrm{Cr}$, $\mathrm{Cu}, \mathrm{S}, \mathrm{Ca}, \mathrm{K}$, or $\mathrm{Na}$ seem to be incorporated in different proportions. Sulfur has been known to dissolve readily in some vanadium oxychlorides. ${ }^{8}$

Normally, compounds of VO, VC, VN, or $\mathrm{V}(\mathrm{O}, \mathrm{N}, \mathrm{C})$ are not present in V-base alloys containing Ti because the free energies of formation of $\mathrm{TiO}, \mathrm{TiN}, \mathrm{TiC}$, or $\mathrm{Ti}(\mathrm{O}, \mathrm{N}, \mathrm{C})$ are significantly larger than those of the $\mathrm{V}$ compounds. However, in alloys that contain a high level of $\mathrm{Cl}$, the formation of vanadium oxychlorides or vanadnium oxycarbochlorides is favored thermodynamically. The free energy of formation and crystal structure of $\mathrm{VO}_{2} \mathrm{Cl}$ or $\mathrm{V}\left(\mathrm{O}_{1-\mathrm{x}} \mathrm{C}_{\mathrm{x}}\right)_{2} \mathrm{Cl}$ could not be found in the literature; however, thermodynamic data for similar vanadium oxychlorides are available. ${ }^{8}$ Based on this information, the free energies of formation of vanadium oxychlorides at $1000^{\circ} \mathrm{C}$ have been calculated and are summarized in Table 3 along with values for $\mathrm{V}$ and $\mathrm{Ti}$ compounds. ${ }^{9}$ According to Table 3 , the formation of a vanadium oxychloride is strongly favored in a $\mathrm{Cl}$-rich alloy, in particular $\mathrm{VO}_{2} \mathrm{Cl}$. A similar rationale could be extended to other types of complex $\mathrm{V}$ compounds, e.g., a compound rich in $\mathrm{O}, \mathrm{Ca}$, and $\mathrm{S}$ (Fig. 8).

Based on these observations, we believe that the higher-than-expected DBTTs of V-5Cr-3Ti and V-5Cr$5 \mathrm{Ti}$ alloys are associated primarily with the precipitation of $\mathrm{V}$ compounds high in $\mathrm{O}, \mathrm{C}, \mathrm{Cl}, \mathrm{Na}, \mathrm{K}, \mathrm{S}$, and $\mathrm{Ca}$. The use of higher-quality raw materials could, in principle, lower the DBTTs. A more deleterious microstructure that contains grain-boundary phases (Fig. 10) is present in the V-5Cr-5Ti alloy.

\section{CONCLUSIONS}

1. Despite the small difference in composition of the alloying elements, $\mathrm{V}-4 \mathrm{Cr}-4 \mathrm{Ti}, \mathrm{V}-5 \mathrm{Cr}-5 \mathrm{Ti}$, and $\mathrm{V}-5 \mathrm{Cr}$ 3Ti alloys exhibited a surprisingly large variation in ductile-brittle-transition temperatures (DBTTs). To provide a better understanding of the origin of this variation, effects of fabrication variables on microstructure and impact properties were investigated in this work. V-5Cr-5Ti and V-5Cr-3Ti alloys were characterized by high-density precipitation of complex V-base compounds, which seems to be aggravated by higher levels of $\mathrm{Cl}, \mathrm{S}, \mathrm{Ca}, \mathrm{Na}$, or $\mathrm{K}$. Higher levels of $\mathrm{O}$ and $\mathrm{C}$, not scavenged by $\mathrm{Ti}$ and left in solution in the matrix, could also promote precipitation of $\mathrm{V}$ compounds under an otherwise similar condition.

2. V-5Cr-3Ti, which was forged al $\approx 650^{\circ} \mathrm{C}$ rather than extruded, was also characterized by an unusual dual-size distribution of titanium oxycarbonitrides. Small titanium oxycarbonitrides $(30-80 \mathrm{~nm}$ in size) seem to have formed in high density during secondary fabrication.

3. Intergranular separation, apparently associated with grain-boundary segregation of $\mathrm{Ti}, \mathrm{S}$, and $\mathrm{P}$, was observed in V-5Cr-5Ti.

4. The origin of the higher-than-expected DBTTs of the V-5Cr-5Ti and V-5Cr-3Ti alloys seems to be associated primarily with the unusual precipitation of complex $\mathrm{V}$ compounds and the small $\mathrm{Ti}$ oxycarbonitrides that formed during secondary fabrication. It is believed that an excellent ductile-brittletransition behavior, similar to that of $\mathrm{V}-4 \mathrm{Cr}-4 \mathrm{Ti}$, can be produced in $\mathrm{V}-(4-5) \mathrm{Cr}-(3-5) \mathrm{Ti}$ alloys by using high-quality raw materials low in $\mathrm{Cl}, \mathrm{S}, \mathrm{P}, \mathrm{Ca}, \mathrm{Na}$, and $\mathrm{K}$.

5. The effect of postfabrication annealing on ductile-brittle-transition behavior was secondary, although annealing at $\approx 1050^{\circ} \mathrm{C}$ produced the most favorable impact properties. 

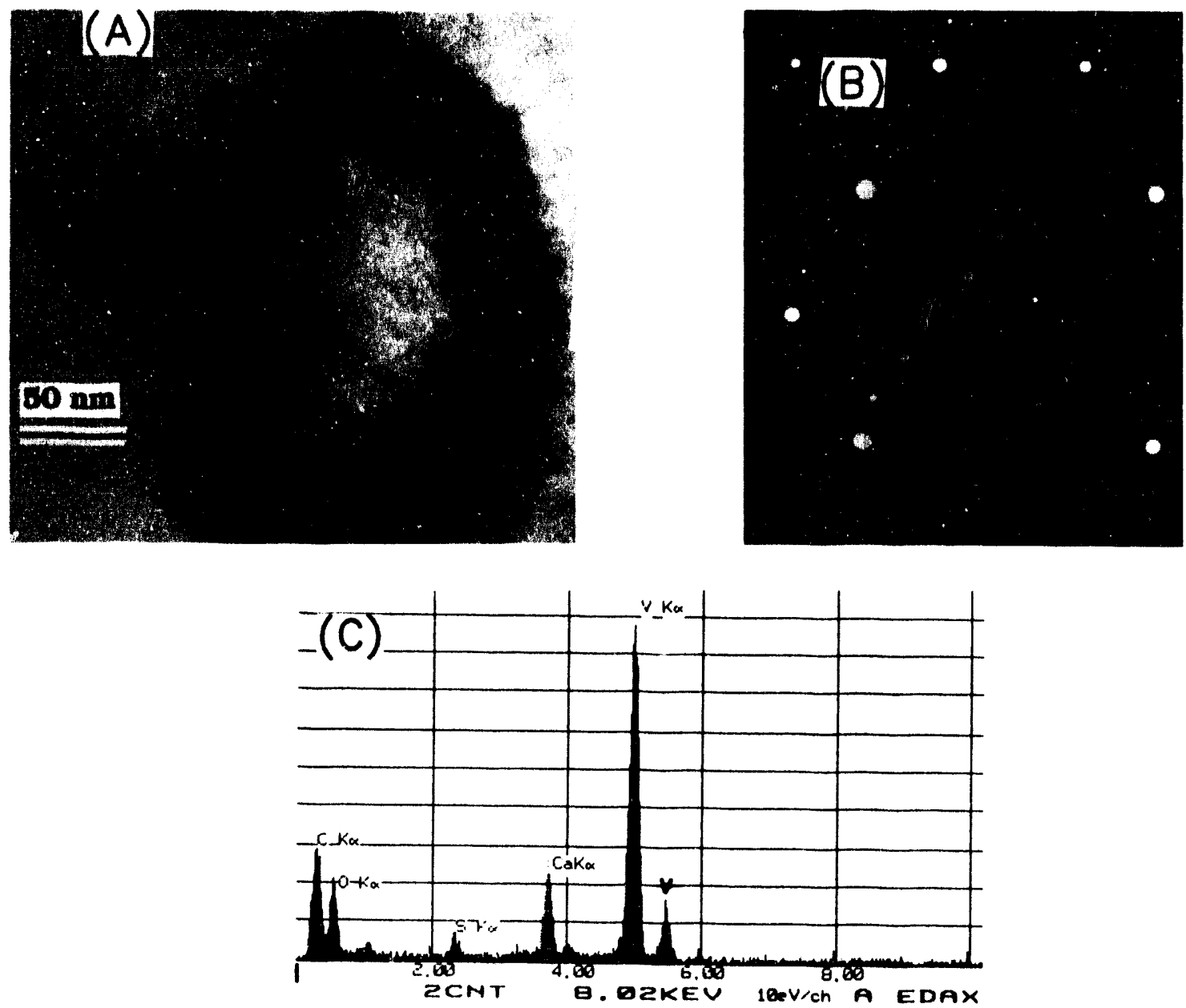

Figure 9. Vanadium-base precipilate in unalloyed $V$. (A) bright-field image showing strain contrast near a precipitate; $(B)$ selected area diffraction pattern of $(A)$ showing (111) zone of $V$, precipitate reflections (d-spacing $0.620 \mathrm{~nm}$ ), and double diffraction spots; and $(C) E D S$ signal from the precipitate in $(A)$.
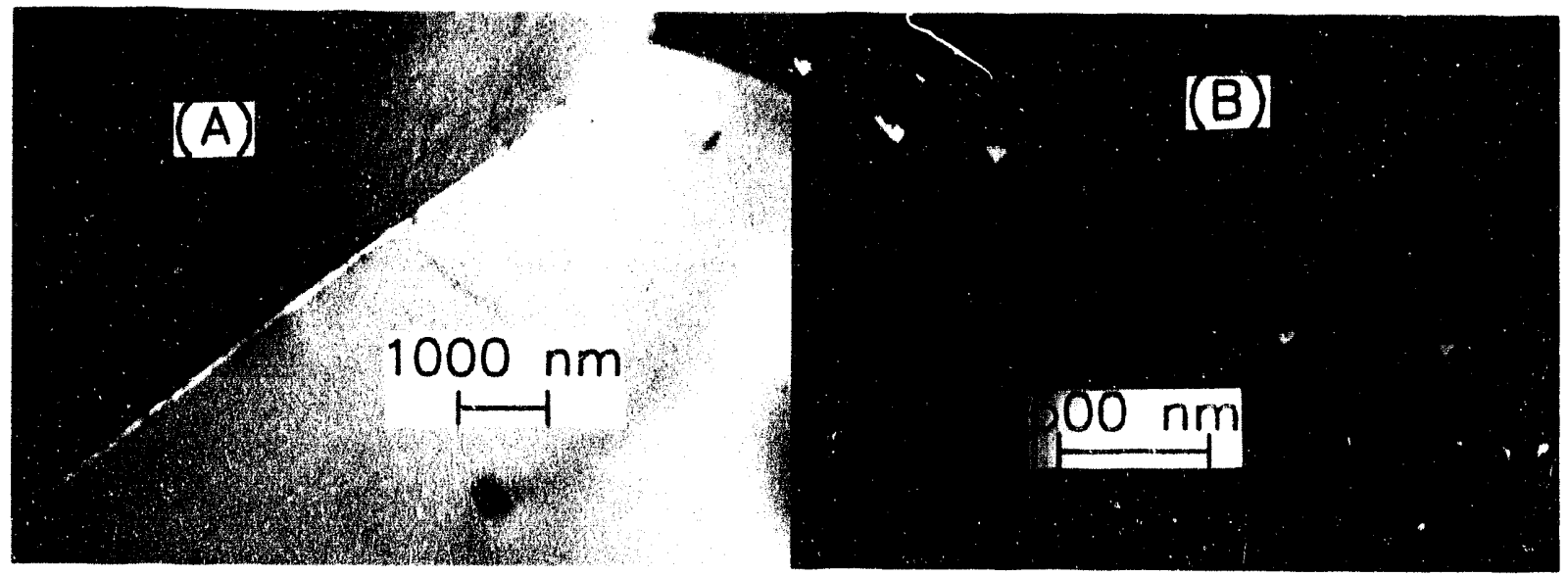

Figure 10. Dark-field images of two types of grain-boundary precipitates in V-5Cr-5Ti; (A) continuous film and $(B)$ irregular-shaped particles 
Table 3. Free energy of formation of selected reactions that produce $\mathrm{Ti}$ and $V$ compounds (calculated for $1000^{\circ} \mathrm{C}$ )

\begin{tabular}{|c|c|c|c|}
\hline Resction & $\Delta G^{0}(\mathrm{~kJ} / \mathrm{mol})$ & Reaction & $\Delta G^{\circ}(\mathrm{kJ} / \mathrm{mol})$ \\
\hline $\mathrm{Ti}+1 / 2 \mathrm{~N}_{2}=\mathrm{TiN}$ & .435 & $\mathrm{~V}+\mathrm{Cl}_{2}=\mathrm{VCl}_{2}$ & -245 \\
\hline $\mathrm{Ti}+1 / 2 \mathrm{O}_{2}=\mathrm{TiO}$ & .398 & $\mathrm{~V}+3 / 2 \mathrm{Cl}_{2}=\mathrm{VCl}_{3}$ & -200 \\
\hline $\mathrm{Ti}+\mathrm{C}=\mathrm{TiC}$ & .170 & $\mathrm{~V}+2 \mathrm{Cl}_{2}=\mathrm{VCl}_{4}$ & -195 \\
\hline$V+1 / 2 N_{2}=V N$ & .240 & $\mathrm{~V}+1 / 2 \mathrm{O}_{2}+1 / 2 \mathrm{Cl}_{2}=\mathrm{VOCl}$ & -507 \\
\hline $\mathrm{V}+1 / 2 \mathrm{O}_{2}=\mathrm{VO}$ & -335 & $\mathrm{~V}+1 / 2 \mathrm{O}_{2}+\mathrm{Cl}_{2}=\mathrm{VOCl}_{2}$ & .539 \\
\hline$v+C=v C$ & -93 & $\mathrm{~V}+1 / 2 \mathrm{O}_{2}+3 / 2 \mathrm{Cl}_{2}=\mathrm{VOCl}_{3}$ & -303 \\
\hline $2 V+C=V_{2} C$ & .145 & $\mathrm{~V}+\mathrm{O}_{2}+\mathrm{Cl}=\mathrm{VO}_{2} \mathrm{Cl}$ & -575 to $-614^{a}$ \\
\hline
\end{tabular}

\section{FUTURE WORK}

New V-(4-5)Cr-(3-5)Ti alloys will be fabricated with high-purity raw matsials and extrusion at $\approx 1150^{\circ} \mathrm{C}$. Charpy impact tests will be conducted to confirm the effects of impurities and secondary fabrication on DBTT.

\section{REFERENCES}

1. B. A. Loomis, J. Gazda, L. J. Nowicki, and D. L. Smith, "Relationship of Microstructure and Mechanical Properties for $\mathrm{V}$-Cr-Ti Alloys," this report; also presented at the 6th Intl. Conf. on Fusion Reactor Materials, Sept. 27-Oct. 1, 1993, Stresa, Italy.

2. H. M. Chung, B. A. Loomis, L. J. Nowicki, and D. L. Smith, "Thermal Creep Behavior of V-5Cr-5Ti and V-10Cr-5Ti Alloys," Fusion Reactor Materials Semiannual Progress Report for Period Ending March 31, 1993, DOE/ER-0313/14, Oak Ridge National Laboratory, Oak Ridge, TN, pp. 309-317.

3. B. A. Loomis, L. J. Nowicki, J. Gazda, and D. L. Smith, "Ductile-Brittle Transition Temperatures of Unirradiated Vanadium Alloys Based on Charpy-Impact Testing," ibid. pp. 318-325.

4. B. A. Loomis, L. J. Nowicki, and D. L. Smith, "Effects of Neutron Irradiation on Tensile Properties of V-Cr-Ti Alloys," this report; also presented at the 6th Intl. Conf. on Fusion Reactor Materials, Sept. 27. Oct. 1, 1993, Stresa, Italy.

5. B. A. Loomis, H. M. Chung, L. J. Nowicki, and D. L. Smith, "Effects of Neutron Irradiation and Hydrogen on Ductile-Brittle Transition Temperatures of V-Cr.Ti Alloys," ibid.

6. H. M. Chung, B. A. Loomis, L. J. Nowicki, and D. L. Smith, "Effect of Irradiation Damage and Helium on the Swelling and Structure of Vanadium-Base Alloys," ibid.

7. J. Gazda, "Analytical Electron Microscopy Study of Vanadium and Vanadium-Base Alloys," MS Thesis, University of Illinois at Chicago, 1993.

8. C. K. Gupta and N. Krishnamurty, Extractive Metallurgy of Vanadium, Elsevier Science, Amsterdam, 1992, pp. 395-474.

9. T. Schober and D. N. Braski, Met. Trans. 20A (1989) 1927-1932. 
Effect of Neutron Irradiation on Tensile Properties of V-Cr-Ti Alloys ${ }^{1}$ - B. A. Loomis, L. J. Nowicki, and D. L. Smith. Argonne National Laboratory, 9700 South Cass Avenue, Argonne, Il 60439.

\begin{abstract}
The tensile properties of V-4Cr-4Ti, V-9Cr-5Ti, V-14Cr-5Ti, V-3Ti-1Si, V-5Ti, and V-18Ti alloys were determined at $25,420,520$, and $600^{\circ} \mathrm{C}$ after neutron irradiation to $28-46$ atom displacements per atom at 420,520 , and $600^{\circ} \mathrm{C}$. The yield strength of the unirradiated alloys increased significantly $(-50 \%)$ upon neutron irradiation. Irradiation hardening of the alloys at $25^{\circ} \mathrm{C}$ after irradiation at $420^{\circ} \mathrm{C}$ was in the order of V-18Ti $<$ V-3Ti-1Si $<$ V-5Ti $<$ V-4Cr-4Ti $<$ V-9Cr-5Ti $<$ V-14Cr-5Ti. Total elongation of the irradiated alloys at $25^{\circ} \mathrm{C}$ after irradiation at $420^{\circ} \mathrm{C}$ ranged from $3 \%$ to $11 \%$, with total elongation of the alloys in the order of $\mathrm{V}-14 \mathrm{Cr}-5 \mathrm{Ti}<\mathrm{V}-9 \mathrm{Cr}-5 \mathrm{Ti}<\mathrm{V}-3 \mathrm{Ti}-1 \mathrm{Si}<\mathrm{V}-5 \mathrm{Ti}<\mathrm{V}-4 \mathrm{Cr}-4 \mathrm{Ti}<\mathrm{V}-18 \mathrm{Ti}$. The total elongation of the alloys at $600^{\circ} \mathrm{C}$ after irradiation ranged from $11 \%$ to $23 \%$, with total elongation of the alloys in the order of V-14Cr-5Ti $<$ V-9Cr-5Ti $<$ V-4Cr-4Ti $<$ V-5Ti $<$ V-3Ti-1Si $<$ V-18Ti.
\end{abstract}

\title{
1. Introduction
}

Vanadium-base alloys with $\mathrm{Cr}$ and $\mathrm{Ti}$ as the principal alloying additions have a number of attractive physical and mechanical properties for application as structural material in the International Thermonuclear Experimental Reactor (ITER) and in fusion reactors that may be constructed in the future [1]. These alloys offer an excellent combination of low, long-term radioactivation, hightemperature capability, and resistance to irradiation damage [1-5]. At the present time, the V-4Cr-4Ti alloy is recommended for the near-optimal combination of desirable physical and mechanical properties for a vanadium alloy structural material [1]. In this paper, we present the tensile properties of the $V$ 4Cr-4Ti alloy and, in addition, tensile properties of $\mathrm{V}-14 \mathrm{Cr}-5 \mathrm{Ti}, \mathrm{V}-9 \mathrm{Cr}-5 \mathrm{Ti}, \mathrm{V}-3 \mathrm{Ti}-1 \mathrm{Si}, \mathrm{V}-5 \mathrm{Ti}$, and $\mathrm{V}-18 \mathrm{Ti}$ alloys after neutron irradiation to $28-46$ atom displacements per atom (dpa) at 420,520 , and $600^{\circ} \mathrm{C}$.

\section{Materials and procedure}

Vanadium alloys with compositions listed in Table 1 were obtained in the form of $50 \%$ coldworked sheet with a thickness of $0.9 \mathrm{~mm}$. Tensile specimens with a gauge length of $7.62 \mathrm{~mm}$ and a gauge width of $1.52 \mathrm{~mm}$ were machined from the as-received sheet. The surfaces of the tensile specimens were mechanically ground and polished to a surface finish of $0.3 \mu \mathrm{m}$. The surface-finished specimens were recrystallized by annealing for $1 \mathrm{~h}$ in a vacuum of $2 \times 10^{-5} \mathrm{~Pa}$. The $\mathrm{V}-14 \mathrm{Cr}-5 \mathrm{Ti}, \mathrm{V}-9 \mathrm{Cr}-5 \mathrm{Ti}$, and $\mathrm{V}-4 \mathrm{Cr}-4 \mathrm{Ti}$ alloys were annealed at $1125^{\circ} \mathrm{C}$. The V-5Ti, V-3Ti, and V-3Ti-1Si alloys were annealed at $1050^{\circ} \mathrm{C}$. These annealing conditions resulted in an average recrystallized-grain diameter of $0.02-0.04 \mathrm{~mm}$ and a dislocation density of $-10^{13} / \mathrm{m}^{2}$ in the specimens.

The tensile specimens were irradiated in $\mathrm{Li}^{7}$-filled TZM molybdenum capsules at 420,520 , and $600^{\circ} \mathrm{C}$ in the Materials Open Test Assembly (MOTA) of the Fast Flux Test Facility (FFTF) during Cycles 9-11 of the reactor.

The tensile specimens were tested at a tensile strain rate of $0.0011 \mathrm{~s}^{-1}$ and a crosshead speed of $0.008 \mathrm{~mm} \cdot \mathrm{s}^{-1}$. All of the tensile tests were conducted in an environment of flowing argon of $99.9999 \%$ purity. Specimen temperature during the tensile test was determined from a chromel-alume! thermocouple that was arc-welded to the edge of the specimen in the guage length.

\section{Experimental results}

3.1. Yield and ultimate tensile strength

The dependence of yield strength $(0.2 \%$ strain) on $(\mathrm{Cr}+\mathrm{Ti})$ concentration for unirradiated vanadium alloys at $25^{\circ} \mathrm{C}$ and $420-600^{\circ} \mathrm{C}$ from Ref. [6] is shown in Fig. 1. Yield strength of the alloys

\footnotetext{
1 Work supported by the U.S. Department of Energy, Office of Fusion Energy, under Contract W-31109-Eng-38.
} 
Table 1. Compositions of V-Cr-Ti alloys.

\begin{tabular}{llccccccc}
\hline $\begin{array}{l}\text { Nominal } \\
\text { Composition }\end{array}$ & $\begin{array}{l}\text { ANL } \\
\text { I.D. }\end{array}$ & \multicolumn{3}{c}{$\begin{array}{c}\text { Composition } \\
\text { (wt.\%) }\end{array}$} & \multicolumn{5}{c}{$\begin{array}{c}\text { Composition } \\
\text { (wt. ppm) }\end{array}$} \\
\cline { 3 - 9 } & & Cr & Ti & Fe & O & N & C & Si \\
\hline V-3Ti-1Si & BL 45 & - & 2.5 & 0.01 & 345 & 125 & 90 & 9900 \\
V-5Ti & BL 46 & - & 4.6 & - & 300 & 53 & 85 & 160 \\
V-18Ti & BL 15 & - & 17.7 & 0.04 & 830 & 160 & 380 & 480 \\
V-4Cr-4Ti & BL 47 & 4.1 & 4.3 & - & 350 & 220 & 200 & 870 \\
V-9Cr-5Ti & BL 43 & 9.2 & 4.9 & 0.02 & 230 & 31 & 100 & 340 \\
V-14Cr-5Ti & BL 24 & 13.5 & 5.2 & 0.05 & 1190 & 360 & 500 & 390 \\
\hline
\end{tabular}

generally increases with increase of $(\mathrm{Cr}+\mathrm{Ti})$ concentration in an alloy. Yield strength of an alloy in the range of $420-600^{\circ} \mathrm{C}$ is essentially unchanged with test temperature. The data in Fig. 1 show a significant increase of yield strength for alloys on increasing the $(\mathrm{Cr}+\mathrm{Ti})$ concentration in an alloy from 8 to 10 wt.\%. The yield strength of the unirradiated alloys at $25^{\circ} \mathrm{C}$ and $420-600^{\circ} \mathrm{C}$ is in the order of V-20Ti > V-14Cr-5Ti > V-9Cr-5Ti > V-3Ti-1Si > V-4Cr-4Ti > V-5Ti.

Yield strength and ultimate tensile strength of V-14Cr-5Ti, V-9Cr-5Ti, V-4Cr-4Ti, V-18Ti, V-5Ti, and V-3Ti-1Si alloys at $25,420,520$, and $600^{\circ} \mathrm{C}$ after neutron irradiation at 420,520 , and $600^{\circ} \mathrm{C}$ to $28-46$ dpa are shown in Figs. 2 and 3, respectively. Irradiation hardening, i.e., increase of yield strength, of the alloys is shown in Fig. 4. The irradiation hardening of the alloys after irradiation at 420,520 , and $600^{\circ} \mathrm{C}$ to 28-46 dpa is in the order of V-14Cr-5Ti > V-9Cr-5Ti > V-4Cr-4Ti > V-5Ti > V-3Ti-1Si > V-18Ti. Irradiation hardening of the alloys decreases significantly with increase of irradiation temperature from $420^{\circ} \mathrm{C}$ to $600^{\circ} \mathrm{C}$; yield strength of the V-18Ti alloy is nearly unchanged after irradiation at $600^{\circ} \mathrm{C}$.

\subsection{Uniform and total elongation}

Figures 5 and 6 show uniform and total elongation, respectively, of $\mathrm{V}-14 \mathrm{Cr}-5 \mathrm{Ti}, \mathrm{V}-9 \mathrm{Cr}-5 \mathrm{Ti}, \mathrm{V}$ $4 \mathrm{Cr}-4 \mathrm{Ti}, \mathrm{V}-18 \mathrm{Ti}, \mathrm{V}-5 \mathrm{Ti}$, and V-3Ti-1Si alloys at $25,420,520$, and $600^{\circ} \mathrm{C}$ after irradiation at 420,520 , and $600^{\circ} \mathrm{C}$ to $28-46 \mathrm{dpa}$. Uniform elongation of the alloys (Fig. 5) at $25^{\circ} \mathrm{C}$ after irradiation at $420^{\circ} \mathrm{C}$ ranges from $3 \%$ to $11 \%$ with the uniform elongation of the alloys in the order of V-18Ti > V-5Ti > V-3Ti-1Si $>\mathrm{V}-4 \mathrm{Cr}-4 \mathrm{Ti}>\mathrm{V}-9 \mathrm{Cr}-5 \mathrm{Ti}>\mathrm{V}-14 \mathrm{Cr}-5 \mathrm{Ti}$. The uniform elongation of unirradiated $\mathrm{V}-18 \mathrm{Ti}, \mathrm{V}-5 \mathrm{Ti}, \mathrm{V}-$ $3 \mathrm{Ti}-1 \mathrm{Si}$, and $\mathrm{V}-4 \mathrm{Cr}-4 \mathrm{Ti}$ alloys $\left(25^{\circ} \mathrm{C}\right)$ after irradiation at $420^{\circ} \mathrm{C}$ is reduced $-60 \%$, whereas the uniform elongation of unirradiated $\mathrm{V}-9 \mathrm{Cr}-5 \mathrm{Ti}$ and $\mathrm{V}-14 \mathrm{Cr}-5 \mathrm{Ti}$ alloys $\left(25^{\circ} \mathrm{C}\right)$ is reduced $-80 \%$ by this irradiation. Uniform elongation of the unirradiated alloys is described in Ref. [6]. The uniform elongation of the alloys after irradiation at $600^{\circ} \mathrm{C}$ ranges from $9 \%$ (V-14Cr-5Ti) to $17 \%$ (V-18Ti). Total elongation of the alloys (Fig. 6) at $25^{\circ} \mathrm{C}$ after irradiation at $420^{\circ} \mathrm{C}$ ranges from $3 \%(\mathrm{~V}-14 \mathrm{Cr}-5 \mathrm{Ti})$ to $11 \%$ (V-18Ti), but total elongation after irradiation at $600^{\circ} \mathrm{C}$ ranges from $11 \%(\mathrm{~V}-14 \mathrm{Cr}-5 \mathrm{Ti})$ to $23 \%(\mathrm{~V}-18 \mathrm{Ti})$. The $\mathrm{V}-14 \mathrm{Cr}-5 \mathrm{Ti}$ alloy on tensile testing at $25^{\circ} \mathrm{C}$ exhibits no significant capability to withstand plastic deformation, whereas the V-9Cr-5Ti, V-4Cr-4Ti, V-20Ti, V-5Ti; and V-3Ti-1Si alloys at $25^{\circ} \mathrm{C}$ can undergo $-2 \%$ plastic deformation.

\section{Discussion}

The experimental results presented in this paper tend to confirm the selection of the $\mathrm{V}-4 \mathrm{Cr}-4 \mathrm{Ti}$ alloy as the vanadium alloy with the near-optimal combination of physical and mechanical properties for use as structural material in a fusion reactor. Although irradiation hardening of this alloy is significant, its ductility at $25^{\circ} \mathrm{C}$ is $>8 \%$ after irradiation at $420^{\circ} \mathrm{C}$ to $34 \mathrm{dpa}$. Even though the V-3Ti-1Si, V-5Ti, and 


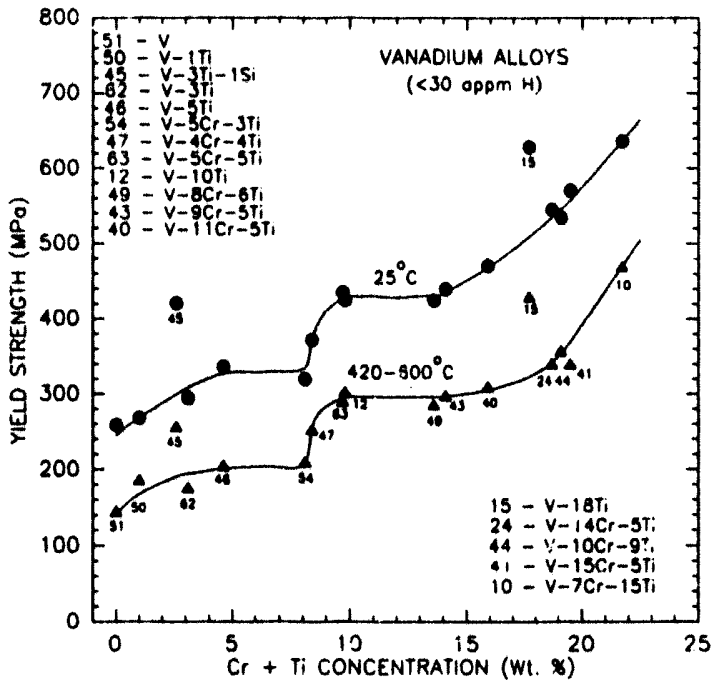

Fig. 1. Dependence of yield strength on $(\mathrm{Cr}+\mathrm{Ti})$ concentration in unirradiated vanadium alloys at $25^{\circ} \mathrm{C}$ and $420-600^{\circ} \mathrm{C}$.

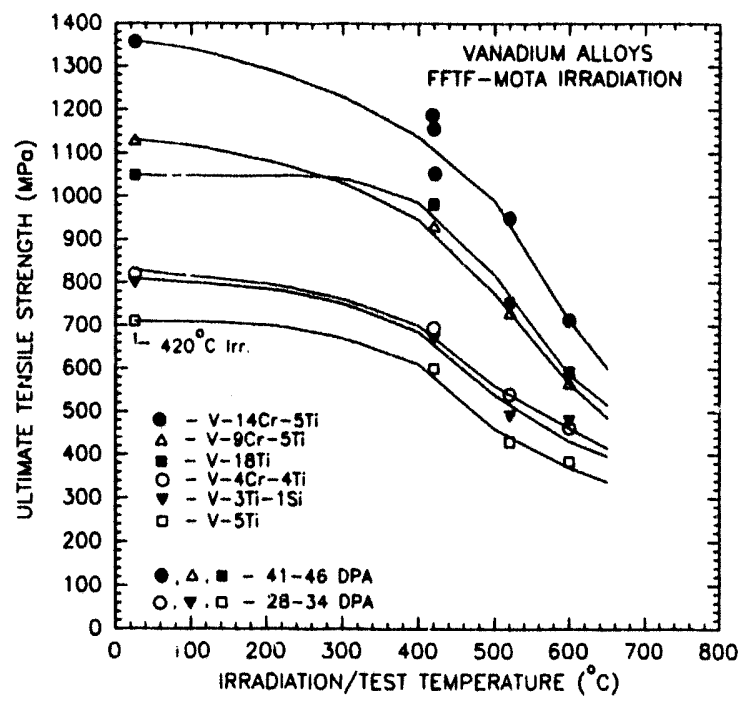

Fig. 3. Dependence of ultimate tensile strength of irradiated vanadium alloys on irradiation/test temperature.

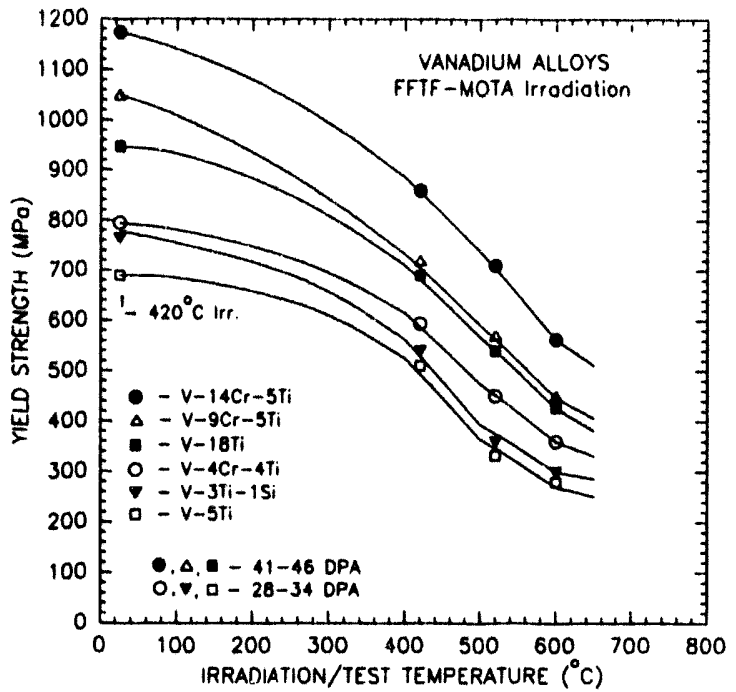

Fig. 2. Dependence of yield strength of irradiated vanadium alloys on irradiation/test temperature.

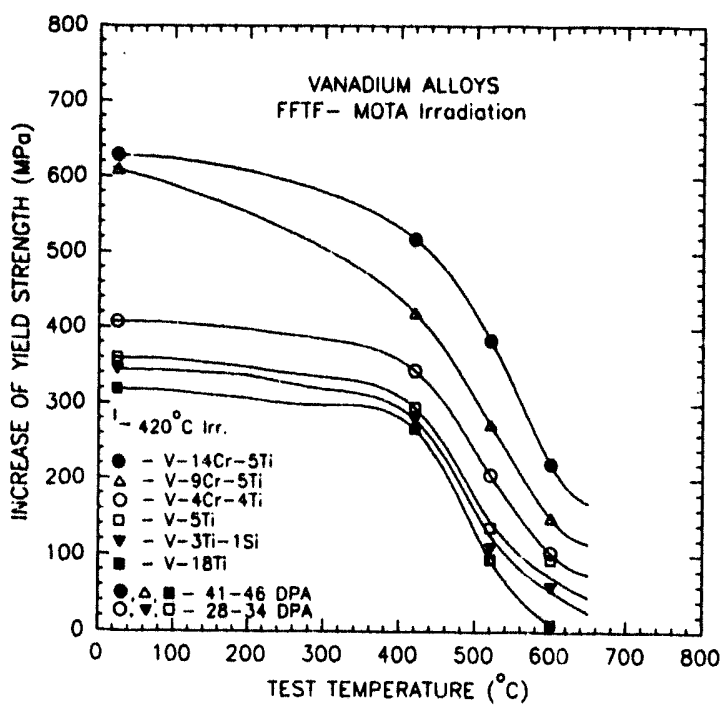

Fig. 4. Dependence of irradiation hardening (increase of yield strength) of irradiated vanadium alloys on irradiation/test temperature. 


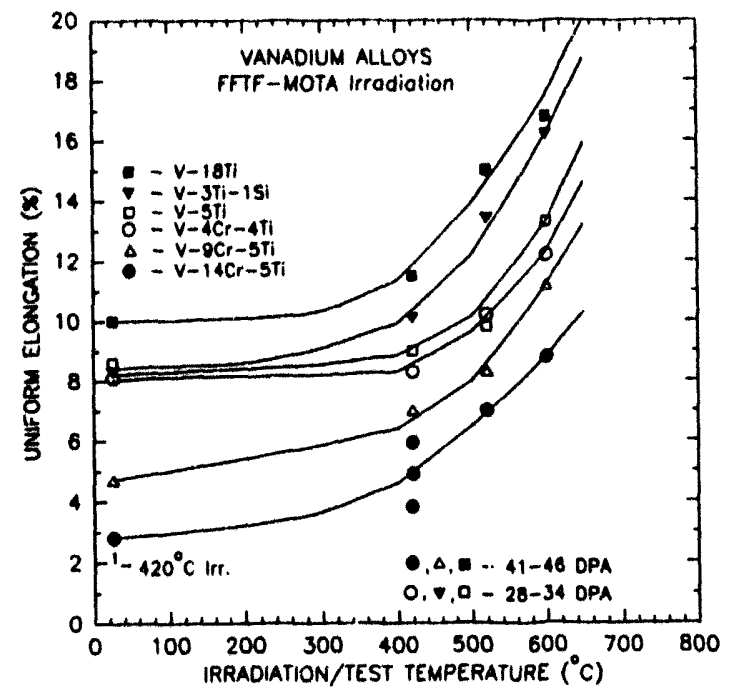

Fig. 5. Dependence of uniform elongation of irradiated vanadium alloys on irradiation/est temperature.

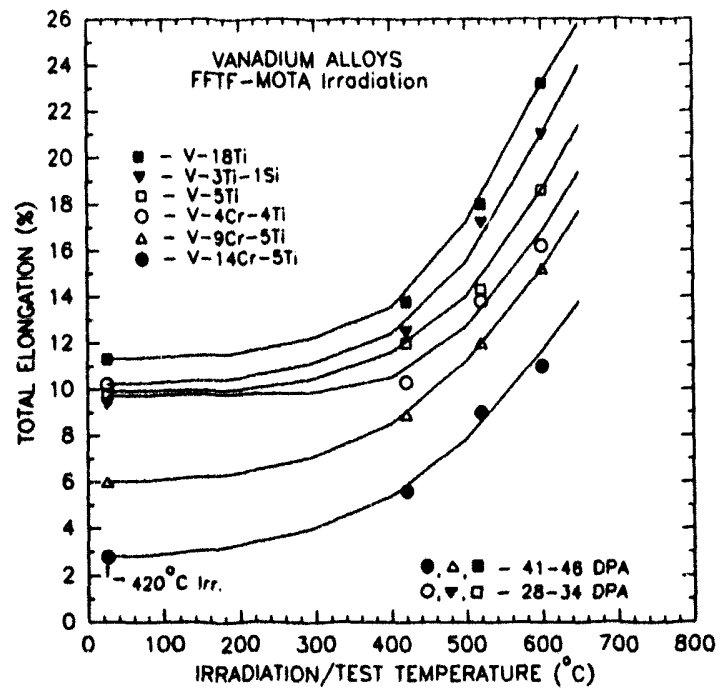

Fig. 6. Dependence of total elongation of irradiated vanadium alloys on irradiation/test temperature.

V-18Ti alloys undergo less irradiation hardening and have higher ductility after irradiation, it has been shown that a vanadium alloy structural material will benefit from $3.5 \mathrm{wt} . \% \mathrm{Cr}$ in the alloy for hightemperature creep strength [1]. Although the creep strength of a V-(3-5) Ti alloy is increased significantly by the presence of $>5 \mathrm{wt} . \% \mathrm{Cr}$ in the alloy [1], the ductile-brittle transition temperature (DBTT) of these alloys on irradiation is also significantly increased $\left(>100^{\circ} \mathrm{C}\right)$ [7]. Moreover, the DBTT (on impact loading) of the V-4Cr-4Ti alloy is lower than the V-3Ti-1Si and V-18Ti alloys after neutron irradiation at $420^{\circ} \mathrm{C}$ to $34 \mathrm{dpa}$ [7]; and swelling of the $\mathrm{V}-4 \mathrm{Cr}-4 \mathrm{Ti}$ alloy is low $(<0.3 \%)$ after neutron irradiation at $420-600^{\circ} \mathrm{C}$ to $24-34 \mathrm{dpa}[8]$.

\section{Conclusions}

- Irradiation hardening of vanadium alloys after irradiation at $420-600^{\circ} \mathrm{C}$ to $28-46 \mathrm{dpa}$ is in the order of V-14Cr-5Ti > V-9Cr-5Ti > V-4Cr-4Ti > V-5Ti > V-3Ti-1Si > V-18Ti.

- The total elongation of vanadium alloys after irradiation at $420-600^{\circ} \mathrm{C}$ to $28-46 \mathrm{dpa}$ is $5.24 \%$, with total alongation of the alloys in the order of $\mathrm{V}-14 \mathrm{Cr}-5 \mathrm{Ti}<\mathrm{V}-9 \mathrm{Cr}-5 \mathrm{Ti}<\mathrm{V}-4 \mathrm{Cr}-4 \mathrm{Ti}<\mathrm{V}-5 \mathrm{Ti}<\mathrm{V}-3 \mathrm{Ti}$ 1Si $<$ V-18Ti.

\section{References}

[1] B. A. Loomis and D. L. Smith, J. Nucl. Mater. 191-194 (1992) 84.

[2] T. Noda, F. Abe, H. Araki and M. Okada, J. Nucl. Mater. 155-157 (1988) 581.

[3] R. Santos, J. Nucl. Mater. 155-157 (1988) 589.

[4] S. J. Piet, H. G. Kraus, R. M. Neilson, Jr. and J. L. Jones, J. Nucl. Mater. 141-143 (1986) 24.

[5] D. L. Smith, B. A. Loomis and D. R. Diercks, J. Nucl. Mater. 135 (1985) 125.

[6] B. A. Loomis, L. J. Nowicki and D. L. Smith, Fusiun Reactor Materials, Semiann. Prog. Rep. DOE/ER-0313/10, Oak Ridge National Laboratory, Oak Ridge, TN (1991) p. 145.

[7] B. A. Loomis, H. M. Chung, J. Gazda, L. J. Nowicki and D. L. Smith, Proceedings of the Sixth Int. Conf. on Fusion Reactor Materials (ICFRM-6), Stresa, Lago Maggiore, Italy, 1993.

[8] H. M. Chung, B. A. Loomis and D. L. Smith, Proceedings of the Sixth Int. Conf. on Fusion Reactor Materials (ICFRM-6), Stresa, Lago Maggiore, Italy, 1993. 


\section{IRRADIATION-INDUCED DENSITY CHANGE AND MICROSTRUCTURAL EVOLUTION OF VANADIUM-BASE ALLOYS* H. M. Chung, B. A. Loomis, L. Nowicki, J. Gazda, and D. L. Smith (Argonne National Laboratory)}

\section{OBJECTIVE}

$\mathrm{V}-(4-5) \mathrm{Ti}$ and $\mathrm{V}-(3-5) \mathrm{Cr}-(4-5) \mathrm{Ti}$ alloys have been identified recently as very promising for application as fusion reactor first-wall structure. The objective of this work is to determine resistance of these alloys to irradiation-induced density change and provide an understanding of the swelling behavior in correlation with microstructural evolution.

\section{SUMMARY}

Irradiation-induced density change (swelling) and microstructural evolution of $\mathrm{V}-\mathrm{Ti}, \mathrm{V}-\mathrm{Cr}-\mathrm{Ti}$, and $\mathrm{V}$-Ti-Si alloys were investigated after irradiation in a fast reactor at $420-600^{\circ} \mathrm{C}$ up to $114 \mathrm{dpa}$. The alloys exhibited swelling maxima in the damage range of $30-70 \mathrm{dpa}$ and swelling decreased on irradiation to higher dpa. The swelling resistance of the alloys was associated with high-density precipitation of ultrafine $\mathrm{Ti}_{5} \mathrm{Si}_{3}$, and it was concluded that $\mathrm{Ti}>4 \mathrm{wt} . \%$ and $400-1000 \mathrm{wppm} \mathrm{Si}$ are desirable to effectively suppress swelling. Swelling resistance of $\mathrm{V}-4 \mathrm{Cr}-4 \mathrm{Ti}$ was excellent, and this alloy is virtually immune to irradiation embrittlement. The excellent swelling resistance was associated with ultrafine $\mathrm{Ti}_{5} \mathrm{Si}_{3}$ for irradiation at 520 $600^{\circ} \mathrm{C}$ and dense formation of dislocation loops for irradiation at $<420^{\circ} \mathrm{C}$.

\section{INTRODUCTION}

Vanadium-base alloys have significant advantages over other candidate alloys (such as austenitic and ferritic steels) for use as structural materials in fusion devices, e.g., in the International Thermonuclear Experimental Reactor (ITER) and in magnetic fusion reactors (MFRs). These advantages include intrinsically lower levels of long-term activation, irradiation afterheat, neutron-induced helium- and hydrogen-transmutation rates, biological hazard potential, and thermal stress factor. ${ }^{1-5}$ However, to make use of the favorable ncutronic and physical properties of these structural materials in fusion systems, the alloys must be resistant to neutron-induced density change, creep, and embrittlement, and they must also be. compatible with the reactor coolant and environment.

As part of a program to screen candidate alloys and develop an optimal alloy, extensive investigations have been conducted on the swelling behavior, tensile properties, impact toughness, and microstructural evolution of $\mathrm{V}, \mathrm{V}-\mathrm{Ti}, \mathrm{V}-\mathrm{Cr}, \mathrm{V}-\mathrm{Cr}$ - $\mathrm{Ti}$, and $\mathrm{V}$ - Ti-Si alloys after irradiation by fast neutrons at 420,520 , and $600^{\circ} \mathrm{C}$. From these investigations, $\mathrm{V}-\mathrm{Cr}-\mathrm{Ti}$ alloys containing $5-7 \mathrm{wt} . \% \mathrm{Cr}, 3-5 \mathrm{at} . \% \mathrm{Ti}$, 400-1000 wt. ppm Si, and $<1000$ wt. ppm $\mathrm{O}+\mathrm{N}+\mathrm{C}$ were identified as most desirable alloys that exhibit superior resistance to swelling, embrittlement, and hydrogen-induced effects during fast-neutron irradiation in lithium. ${ }^{6-10}$ As a result, recent attention has focused primarily on the ternary alloys $\mathrm{V}-4 \mathrm{Cr}-4 \mathrm{Ti}$, V-5Cr-5Ti, and V-5Cr-3Ti, and on the binary alloy V-5Ti containing 400-1000 wt. ppm Si. Recent studies on tensile properties, ${ }^{11}$ impact toughness, ${ }^{12}$ and ductile-brittle transition temperature (DBTT) ${ }^{12}, 13$ of unirradiated ${ }^{13}$ and irradiated ${ }^{11,12}$ specimens showed excellent mechanical properties and superior resistance to irradiation-induced embrittlement of some of these alloys, in particular V-4Cr-4Ti and V-5Ti. Thermal creep behavior of $\mathrm{V}-4 \mathrm{Cr}-4 \mathrm{Ti}$ has been also reported to be superior to those of austenitic and ferritic steels. ${ }^{14}$ For these alloys, however, no data base has been reported on irradiation-induced swelling, and a favorable irradiation-induced microstructural evolution commensurate with the superior resistance of the alloys to embrittlement and creep has not been demonstrated. In the work reported here, irradiation-induced density

\footnotetext{
* Work supported by the Office of Fusion Energy, U.S. Department of Energy, under Contract W-31-109-Eng-38.
} 
change and microstructural evolution of a number of the promising binary and ternary alloys were investigated after irradiation at $420-600^{\circ} \mathrm{C}$ up to 114 dpa in the Fast Flux Test Facility (FFTF).

\section{MATERIALS AND PROCEDURES}

Density measurement and transmission electron microscopy (TEM) were conducted on standard-size disk specimens irradiated in the FFTF, a sodium-cooled fast reactor located in Richland, Washington, USA. The chemical composition of the alloys is given in Table 1. One of the alloys (V-20Ti, BL-15) was contaminated inadvertently with a significant level of boron. ${ }^{15}$ The boron content in the alloy was not known prior to irradiation. TEM disks were irradiated at 420,520 , and $600^{\circ} \mathrm{C}$ to neutron fluences $(E>0.1 \mathrm{MeV})$ of $7.8 \times 10^{22} \mathrm{n} \cdot \mathrm{cm}^{-2}(\approx 44 \mathrm{dpa})$ and $1.9 \times 10^{23} \mathrm{n} \cdot \mathrm{cm}^{-2}(\approx 114 \mathrm{dpa})$. They were sealed in TZM capsules filled with $99.99 \%$-enriched $\mathrm{Li}$ during irradiation to prevent contamination with $\mathrm{O}, \mathrm{N}$, and C impurities dissolved in the sodium coolant of the FFTF, and also to prevent formation of unacceptable levels of helium and tritium from ${ }^{6} \mathrm{Li}$. The irradiated specimens were jet-thinned for TEM in a solution of $15 \%$ sulfuric acid- $72 \%$ methanol-13\% butyl cellosolve maintained at $-5^{\circ} \mathrm{C}$. TEM was conducted with a JEOL $100 \mathrm{CX}$-II scanning transmission electron microscope operating at $100 \mathrm{keV}$.

Table 1. Composition of vanadium alloys irradiated in fast flux test facility materials open test assembly

\begin{tabular}{lcrrrr}
\hline & Nominal & \multicolumn{4}{c}{ Concentration (wt.ppm) } \\
\cline { 3 - 6 } ANL ID & (wt.\%) & \multicolumn{1}{c}{ Composition } & N & \multicolumn{1}{c}{ C } & Si \\
\hline BL-11 & $4.9 \mathrm{Ti}$ & 1820 & 530 & 470 & 220 \\
BL-46 & $4.6 \mathrm{Ti}$ & 305 & 53 & 85 & 160 \\
BL-34 & $8.6 \mathrm{Ti}$ & 990 & 180 & 420 & 290 \\
BL-12 & $9.8 \mathrm{Ti}$ & 1670 & 390 & 450 & 245 \\
BL-13 & $14.4 \mathrm{Ti}$ & 1580 & 370 & 440 & 205 \\
BL-15 & $17.7 \mathrm{Ti}$ & 830 & 160 & 380 & 480 \\
BL-16 & $20.4 \mathrm{Ti}$ & 390 & 530 & 210 & 480 \\
& & & & & \\
BL-21 & $13.7 \mathrm{Cr}-4.8 \mathrm{Ti}$ & 340 & 510 & 180 & 1150 \\
BL-22 & $13.4 \mathrm{Cr}-5.1 \mathrm{Ti}$ & 300 & 52 & 150 & 56 \\
BL-23 & $12.9 \mathrm{Cr}-5.9 \mathrm{Ti}$ & 400 & 490 & 280 & 1230 \\
BL-24 & $13.5 \mathrm{Cr}-5.2 \mathrm{Ti}$ & 1190 & 360 & 500 & 390 \\
BL-40 & $10.9 \mathrm{Cr}-5.0 \mathrm{Ti}$ & 470 & 80 & 90 & 270 \\
BL-43 & $9.2 \mathrm{Cr}-4.9 \mathrm{Ti}$ & 230 & 31 & 100 & 340 \\
BL-44 & $9.9 \mathrm{Cr}-9.2 \mathrm{Ti}$ & 300 & 87 & 150 & 270 \\
BL-47 & $4.1 \mathrm{Cr}-4.3 \mathrm{Ti}$ & 350 & 220 & 200 & 870 \\
& & & & & \\
BL-27 & $3.1 \mathrm{Ti}-0.25 \mathrm{Si}$ & 210 & 310 & 310 & 2500 \\
BL-42 & $3.1 \mathrm{Ti}-0.5 \mathrm{Si}$ & 580 & 190 & 140 & 5400 \\
BL-45 & $2.5 \mathrm{Ti}-1 \mathrm{Si}$ & 345 & 125 & 90 & 9900 \\
\hline
\end{tabular}

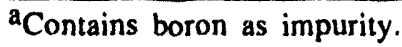




\section{RESULTS AND DISCUSSION}

\section{Swelling Behavior-Density Change}

Swelling of the V-Ti, V-Cr-Ti, and V-3Ti-Si alloys, determined from density measurements after irradiation at 420 and $600^{\circ} \mathrm{C}$, is shown as a function of irradiation damage (dpa) in Figs. 1-3, respectively. Most of the Ti-containing alloys exhibited swelling maxima in the damage range of 30-80 dpa. When irradiated to higher dpa, swelling in these alloys decreased monotonically. However, for irradiation at $600^{\circ} \mathrm{C}$, sufficient data for higher dpa were not available for some of the alloys, i.e., V-5Ti, V-10Ti, V-15Ti, V-20Ti (BL-16), and V-15Cr-5Ti (BL-24), and it was not possible to verify whether swelling actually deereased or saturated at higher dpa. The anomalous behavior that exhibited actual decrease of swelling (i.e., increase of density) for increased irradiation damage is in distinct contrast to the normal swelling of other binary alloys of $\mathrm{V}$ containing $\mathrm{Fe}, \mathrm{Ni}, \mathrm{Cr}, \mathrm{Mo}, \mathrm{W}$, and $\mathrm{Si}$, which increases monotonically for increasing dpa. ${ }^{7,10}$ Swelling determined from measurements of density and void distribution by TEM was generally consistent. Closer examination of Figs. 1 and 2 indicates the tendency for a higher content of Ti (except the B-containing V-20Ti [BL-15]) to lower maximum swelling in the V-Ti binary alloys, whereas a higher content of $\mathrm{Cr}$ is conducive to a higher level of swelling maxima in the $\mathrm{V}-\mathrm{Cr}$-Ti ternary alloys. Therefore, it seems evident that $\mathrm{Cr}$ addition $>9 \mathrm{wt} . \%$ in the ternary alloys is not desirable from the standpoint of not only irradiation embrittlement ${ }^{10}$ but also of irradiation-induced swelling.
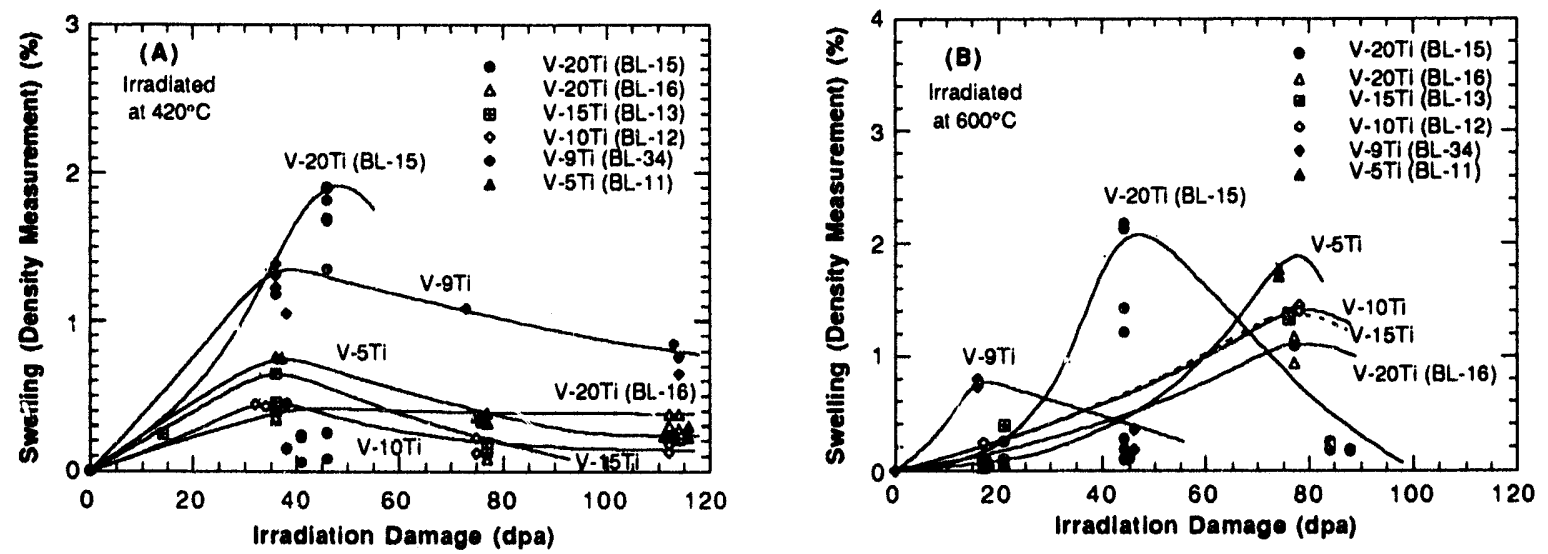

Figure 1. Density change of V-Ti alloys as function of dose (dpa) after irradiation at 420 (A) and $600^{\circ} \mathrm{C}(B)$
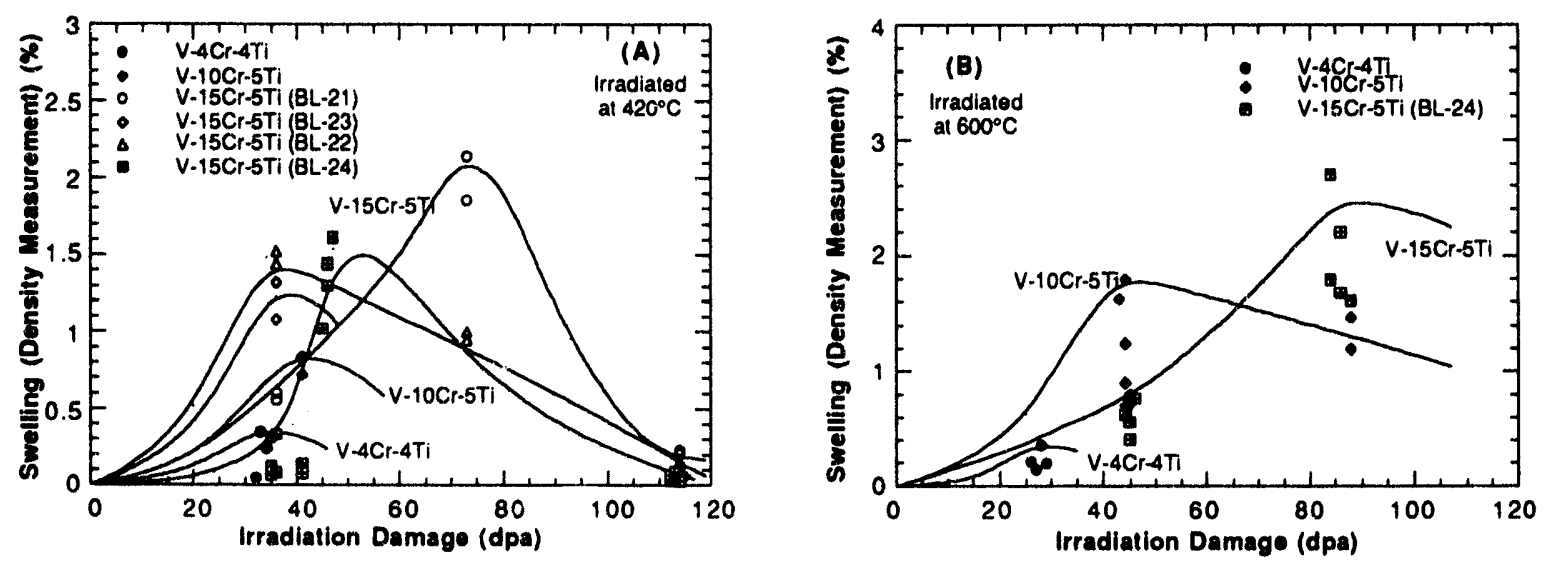

Figure 2. Density change of V-Cr-Ti alloys as function of dose (dpa) after irradiation at $420(A)$ and $6000^{\circ} \mathrm{C}(B)$ 

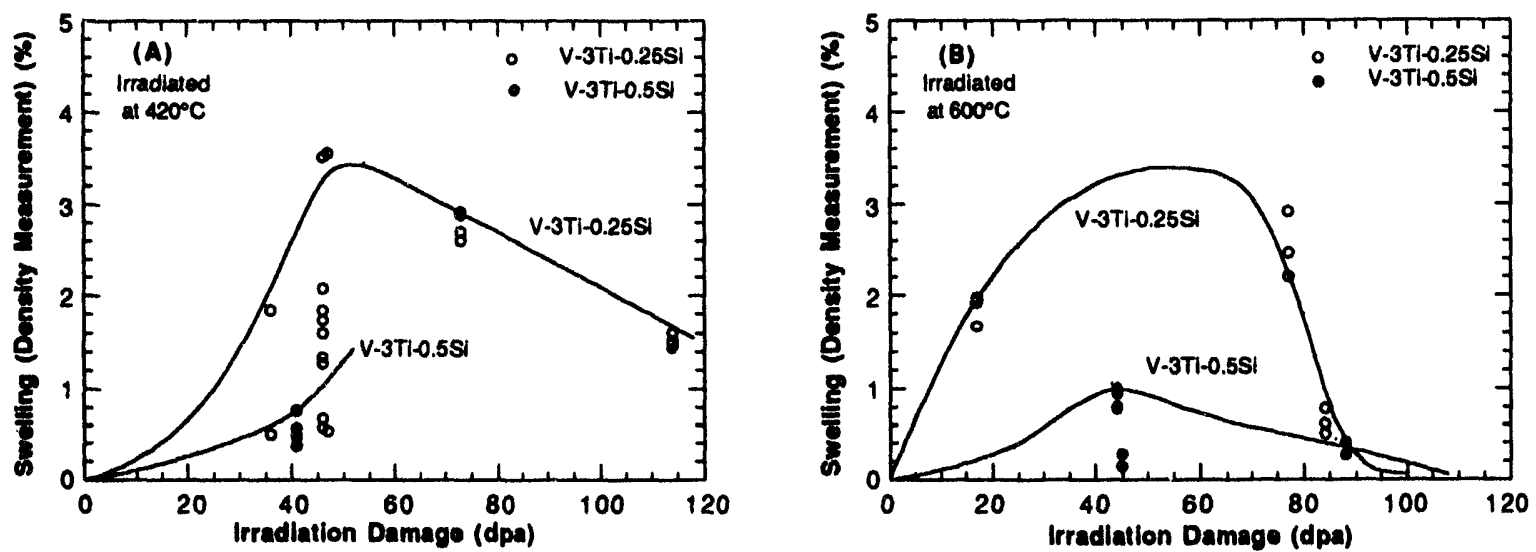

Figure 3. Density change of V-3Ti-Si alloys as function of dose (dpa) after irradiation at 420 (A) and $600^{\circ} \mathrm{C}(\mathrm{B})$

Swelling of the V-3Ti-0.25Si and V-3Ti-0.5Si alloys was relatively higher despite the high level of Si. These alloys are known to exhibit relatively higher yield ${ }^{13}$ and creep ${ }^{16}$ strengths, which have been attributed to a tendency to form a relatively high density of $\mathrm{Ti}(\mathrm{O}, \mathrm{N}, \mathrm{C})$ precipitates during ingot melting and fabrication. ${ }^{13}$ Therefore, unless the combined impurity level of $O, N$, and $C$ is extremely low, virtually all of the Ti solutes in the alloys are believed to be tied up in $\mathrm{Ti}(\mathrm{O}, \mathrm{N}, \mathrm{C})$ precipitates. This will prevent irradiation-induced precipitation of ultrafine $\mathrm{Ti}_{5} \mathrm{Si}_{3}$ particles, to which resistance to swelling of Ti-containing V-base alloys has been attributed. ${ }^{9}$ It has been reported previously that the relatively high swelling observed for the V-3Ti-0.25Si alloy was associated with absence of the Ti5Si3 precipitates in the alloy. ${ }^{17}$ It has been also reported that $\mathrm{Ti}(\mathrm{O}, \mathrm{N}, \mathrm{C})$ precipitates are absent in Ti-containing vanadium alloys when $\mathrm{O}+\mathrm{N}+\mathrm{C}$ content is $<400$ wppm. ${ }^{18}$ Therefore, it is expected that by limiting the impurity contents in the V-3Ti-Si alloys below $<400 \mathrm{wppm}$ (hence, preventing thermal precipitation of titanium oxycarbonitrides) swelling can be effectively suppressed in the alloys.

However, Loomis et al. ${ }^{12}$ have reported that high Si content in the V-3Ti-Si alloys is conducive to higher DBTT and increased effect of hydrogen. Accordingly, unless $\mathrm{O}+\mathrm{N}+\mathrm{C}$ and $\mathrm{Si}$ levels in a V-3Ti-Si alloy are strictly controlled to $<400$ and $400-1000$ wppm, respectively, V-(4-5)Ti alloys containing 4001000 wppm Si appear to be a more attractive choice than V-3Ti-Si alloys. V-5Ti alloy containing 220 wppm Si (BL-11, Table 1) exhibited relatively low swelling in the present investigation, i.e., maximum swelling of $\approx 0.8$ and $\approx 1.8 \%$ for irradiation to $<120 \mathrm{dpa}$ at 420 and $600^{\circ} \mathrm{C}$, respectively. V-5Ti alloy containing somewhat less $\mathrm{Si}(=160 \mathrm{wppm})$ exhibited relative higher level of density change, 2,2, 2.2, and $1.7 \%$, respectively, after irradiation at 420,520 , and $600^{\circ} \mathrm{C}$ to $\approx 34 \mathrm{dpa}$.

Swelling resistance of the $\mathrm{V}-4 \mathrm{Cr}-4 \mathrm{Ti}$ alloy (BL-47) containing $\mathrm{O}+\mathrm{N}+\mathrm{C}$ and $\mathrm{Si}$ of $\approx 770$ and $\approx 870 \mathrm{wppm}$, respectively, was excellent $(<0.4 \%$ for $<120 \mathrm{dpa})$ compared to those of other alloys. This is shown in Fig. 4. V-4Cr-4Ti, designated as one the primary candidate alloys, also exhibited an excellent resistance to irradiation embrittlement. That is, after irradiation to $\approx 34 \mathrm{dpa}$ at 420,520 , and $600^{\circ} \mathrm{C}, \mathrm{DBTT}$ remained below $-196^{\circ} \mathrm{C} .12$ Uniform and total elongations of the alloy measured at room temperature after the same irradiations were 8.1 and $10.2 \%$, respectively. ${ }^{11}$ Thermal creep behavior of the alloy was also excellent compared to those of austenitic and ferritic/martensitic steels. ${ }^{14}$ 


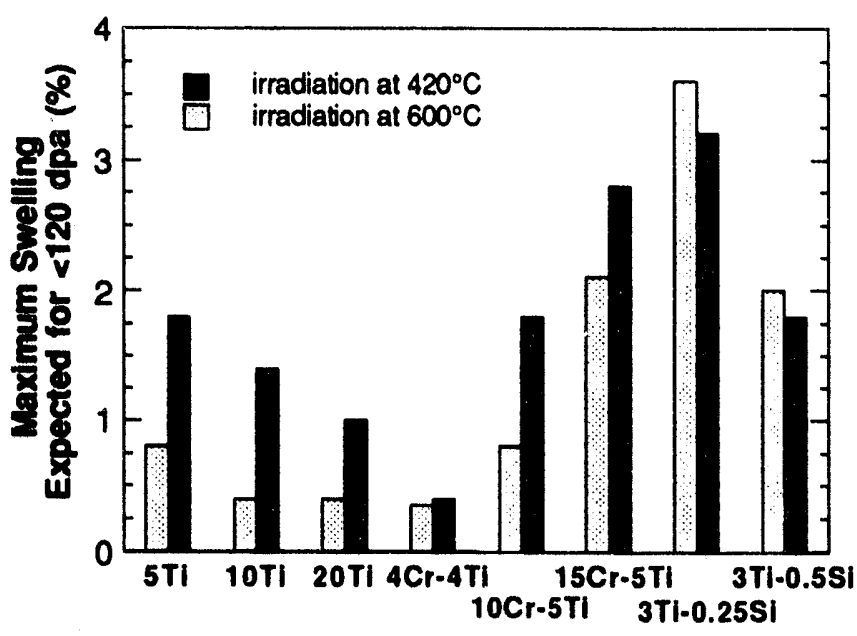

Figure 4. Maximum swelling (density change) of several vanadiumbase alloys for irradiation at $420-600{ }^{\circ} \mathrm{C}$ up to $\approx 120 \mathrm{dpa}$

\section{Model of Swelling Dependence on Irradiation Damage}

The Ti-containing alloys that exhibited relatively low swelling contained high-density ultrafine precipitates of $\mathrm{Ti}_{5} \mathrm{Si}_{3}$. These precipitates were not visible in bright-field imaging condition and could be imaged only under dark-field condition. As an example, dark-field images of $\mathrm{Ti}_{5} \mathrm{Si}_{3}$ precipitates are shown in Fig. 5 for $\mathrm{V}-4 \mathrm{Cr}-4 \mathrm{Ti}$ and $\mathrm{V}-20 \mathrm{Ti}$ specimens that were irradiated at various conditions.

Void swelling and density change in Ti-containing alloys were generally consistent and could be correlated well with the number density of the ultrafine Tis $\mathrm{Si}_{3}$ precipitates. That is, a greater number density of the precipitates is conducive to lower swelling during irradiation. This could be attributed to the large interface area generated between the matrix and the high-density precipitates of $\mathrm{Ti}_{5} \mathrm{Si}_{3}$. This interface area is believed to act as an efficient sink for vacancies and thereby inhibits nucleation and growth of voids. Swelling was in general significant in Ti-containing alloys in which $\mathrm{Ti}_{5} \mathrm{Si}_{3}$ precipitation was absent or negligible.

Anomalous swelling behavior (i.e., maximum in density change vs. dpa) has been also reported by Maziasz ${ }^{19}$ for some heats of $14 \mathrm{Cr}-16 \mathrm{Ni}-2.5 \mathrm{Mo}-2 \mathrm{Mn}$ austenitic stainless steels stabilized by an addition of $\mathrm{Ti}$ of $=0.25 \%$ with and without $\mathrm{P}$ doping. In these steels, irradiated in the High Flux Isotope Reactor (HFIR) at $500^{\circ} \mathrm{C}$, swelling reached maxima of $\approx 2 \%$ at $\approx 34$ dpa and decreased to $0.6-1.1 \%$ at $57 \mathrm{dpa}$. The decrease of swelling was accompanied by high-density precipitation of ultrafine MC carbides. According to Maziasz, such profound microstructural changes could disrupt the balance between sink strengths of dislocations, voids, and precipitates, so that MC precipitates and voids now become the dominant sinks for vacancies and interstitials. The breakdown of the "steady-state" biased partitioning of defects then would lead to increased defect recombination at the large interface area generated between the matrix and precipitates, leading to reduction or elimination of the vacancy supersaturation. When changes in microstructure, defect partitioning, and recombination behavior are dramatic, they could cause the critical radius of voids (necessary to maintain stability) to increase enough so that small existing voids would become unstable. Existing subcritical-size voids will then stop growing or actually begin shrinking with increasing damage level, and further nucleation of voids will be prevented.

The anomalous swelling maxima of the vanadium-base alloys could be explained in a similar manner, with the high-density ultrafine precipitates of $\mathrm{Ti}_{5} \mathrm{Si}_{3}$ playing a role similar to that of $\mathrm{MC}$ carbide in the steels. Apparently, the dramatic changes in microstructure, sink density, and upset of the "steady- 
state" biased partitioning of defects are produced only when the size of the ultrafine precipitates is comparable to those of critical-size microvoids and when precipitation occurs in a very high density, e.g., as seen in Fig. 5.
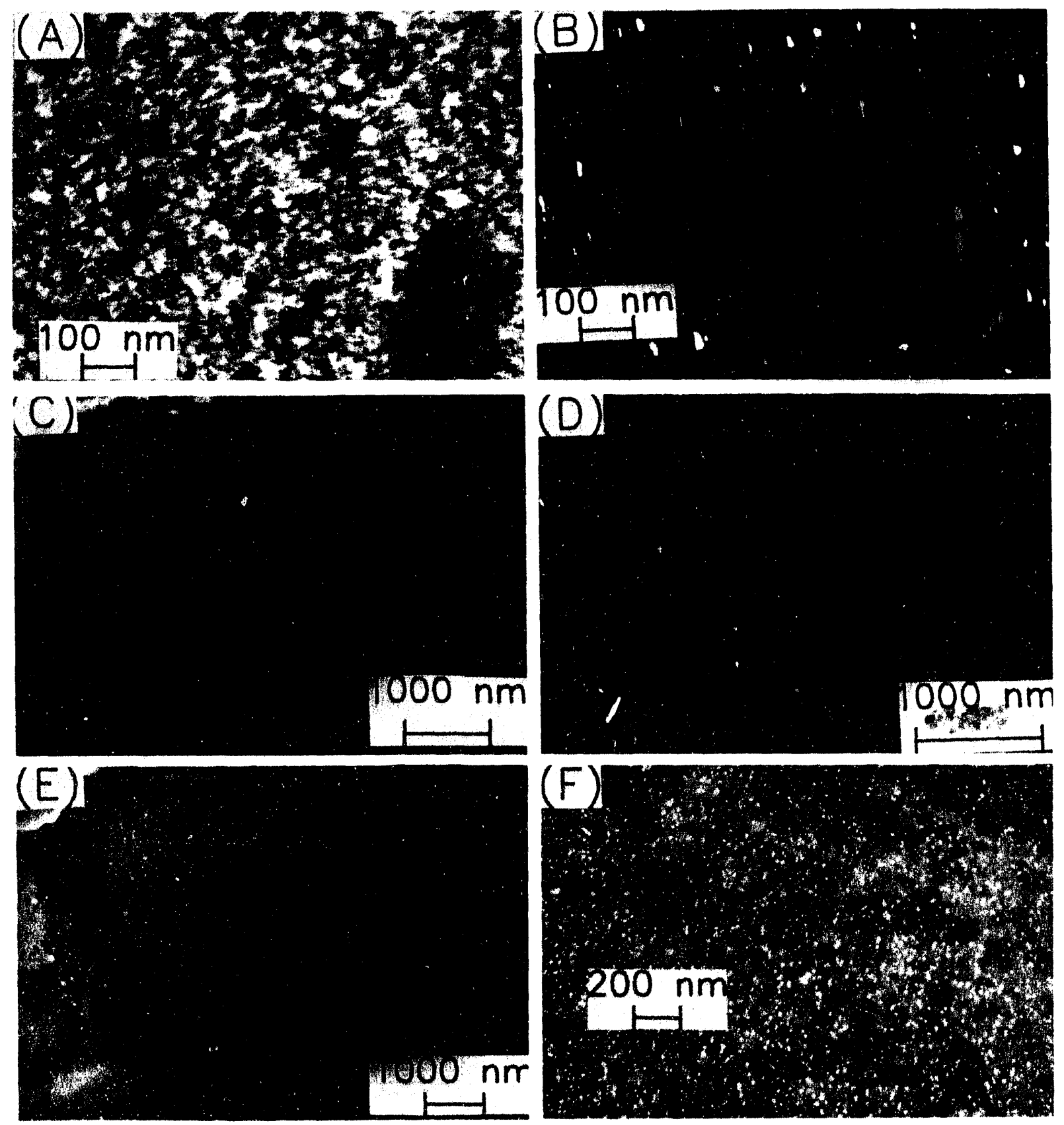

Figure 5. Bright- $(B F)$ and dark-field $(D F)$ microstructures of vanadium-base alloys showing void and TisSiz distributions $(A) B F$ and $(B) D F$ of Tis $\mathrm{Si}_{3}$ in $\mathrm{V}-4 \mathrm{Cr}-4 \mathrm{Ti}$ irradiated at 420 and $600^{\circ} \mathrm{C}$, respectively, $10 \approx 34 \mathrm{dpa} ;(C) \mathrm{BF}$ of voids and (D) DF of TisSi3 in V-20Ti (without $B, B L-16$ ) irradiated at $420^{\circ} \mathrm{C}$ to $114 \mathrm{dpa}$; $(E) B F$ of voids and $(F) D F$ of TisSiz in V-20Ti (containing $B, B L-15$ ) irradiated at $420^{\circ} \mathrm{C}$ to $46 \mathrm{dpa}$ 
According to this model, swelling dependence on the damage level is expected to be strongly influenced by the kinetics of the irradiation-induced precipitation of $\mathrm{Ti}_{5} \mathrm{Si}_{3}$ phase, as illustrated in Fig. 6 . For Case I irradiation in the figure, irradiation-induced precipitation of ultrafine particles, such as $\mathrm{Ti}_{5} \mathrm{Si}_{3}$ in vanadium-base alloys or MC in the multiply stabilized austenitic steels, does not occur and swelling will increase monotonically with dose. For Case II, swelling is expected to exhibit a maximum after an incubation period and diminish subsequently at higher damage levels. For Case III, the precipitation kinetics are relatively faster, and only minimal swelling is observed. The swelling kinetics schematically illustrated in Fig. 6 seem to be consistent with the observed swelling behaviors shown in Figs. 1-3.
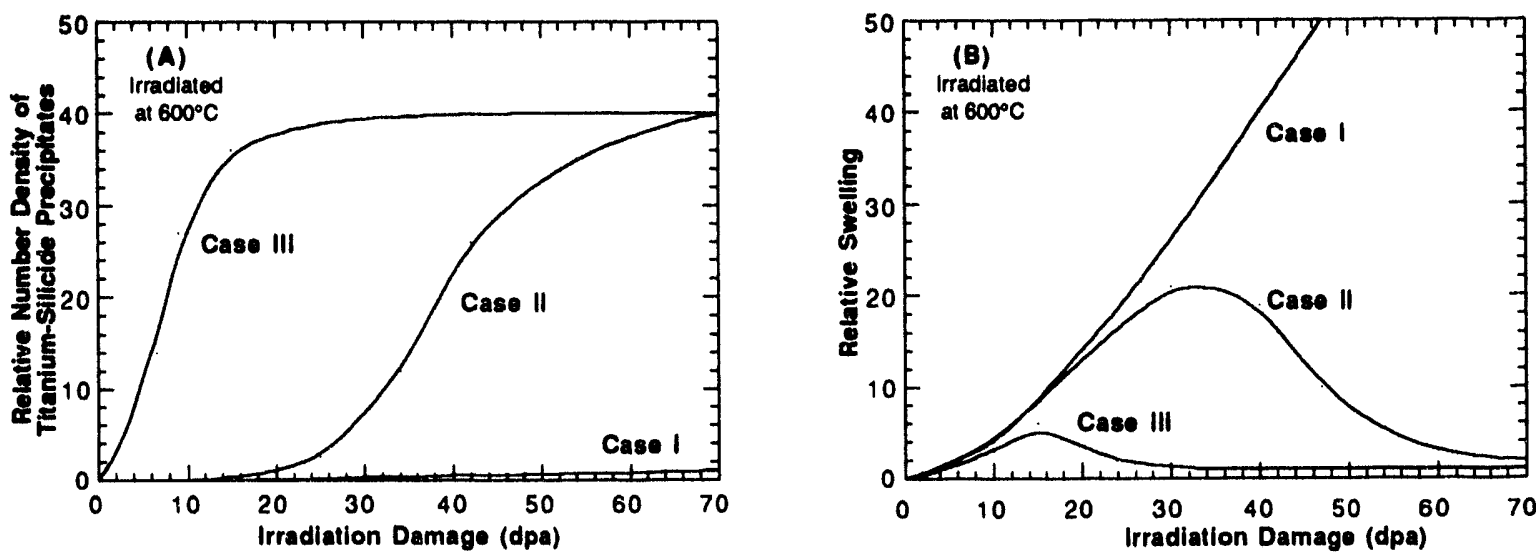

Figure 6. Schematic illustration of relationship between kinetics of Ti5Si 3 precipitation $(A)$ and swelling (B) as function of irradiation damage in Ti-containing vanadium alloys

Density of $\mathrm{Ti}_{5} \mathrm{Si}_{3}$ has been reported to be $\approx 4.32 \mathrm{~g} / \mathrm{cm}^{3}$, approximately 1.4 times less than the estimated density of $\approx 6.1$ for $\mathrm{V}-4 \mathrm{Cr}-4 \mathrm{Ti}$. 20 Therefore, the specific volumes of vanadium-base alloys will increase rather than decrease on precipitation of $\mathrm{Ti}_{5} \mathrm{Si}_{3}$. Thus, the decrease in specific volume shown in Figs. 1-3 and illustrated schematically in Fig. 6 cannot be explained on the basis of density change associated with precipitation of $\mathrm{Ti}_{5} \mathrm{Si}_{3}$.

It seems that the effect of irradiation temperature on the kinetics of the irradiation-induced precipitation of $\mathrm{Ti}_{5} \mathrm{Si}_{3}$ phase is strongly dependent on alloy type. In previous papers, observations of high-density precipitation of ultrafine $\mathrm{Ti}_{5} \mathrm{Si}_{3}$ have been reported for V-20Ti alloys (BL-15 and BL-16, Table 1) that were irradiated at $420^{\circ} \mathrm{C} .9,21$ In contrast to this, no evidence of precipitation of ultrafine $\mathrm{Ti}_{5} \mathrm{Si}_{3}$ was observed in a specimen of $\mathrm{V}-4 \mathrm{Cr}-4 \mathrm{Ti}$ alloy irradiated at $420^{\circ} \mathrm{C}$ to $\approx 34 \mathrm{dpa}$. In this specimen, the primary feature of irradiation-induced microstructural change was dense formation of small dislocation loops ("black-dot defects") $<2 \mathrm{~nm}$ in size. Similar observation of dense dislocation loops in the absence of irradiation-induced $\mathrm{Ti}_{5} \mathrm{Si}_{3}$ precipitates was also reported for $\mathrm{V}-5 \mathrm{Cr}-5 \mathrm{Ti}-1 \mathrm{Al}-1 \mathrm{Si}-0.8 \mathrm{Y}$ irradiated at $406^{\circ} \mathrm{C}$ to 51 dpa (density change $0.27 \%$ ). ${ }^{18}$ Thus, for irradiation at relatively low temperatures, dense formation of ultrafine dislocation loops seems to be associated with the low irradiation-induced density change of the $\mathrm{V}$ (4-5) Cr-(4-5)Ti alloys.

\section{Effect of Boron and Helium Production}

Swelling (density change) in the B-containing V-20Ti alloy (BL-15) was found to be somewhat higher than that in the similar V-20Ti alloy (BL-16) that contained a negligible level of B at all the irradiation temperatures $\left(420,520\right.$, and $\left.600^{\circ} \mathrm{C}\right)$. This is shown in more detail in Fig. 7. TEM examination of the two alloys indicated a similar trend; the volume fraction of voids was significantly higher in the 
former alloy after irradiation at $420^{\circ} \mathrm{C}$ to $46 \mathrm{dpa}$ (Fig. 5E). Evidently, the higher swelling is a result of helium generation in the B-containing alloy from transmutation of ${ }^{10}{ }_{\mathrm{B}}$. However, sink strength of the ultrafine high-density $\mathrm{Ti}_{5} \mathrm{Si}_{3}$ precipitates in both alloys seems to have been so strong after irradiation to 114 dpa that swelling was decreased to $<0.4 \%$ at the high dose.
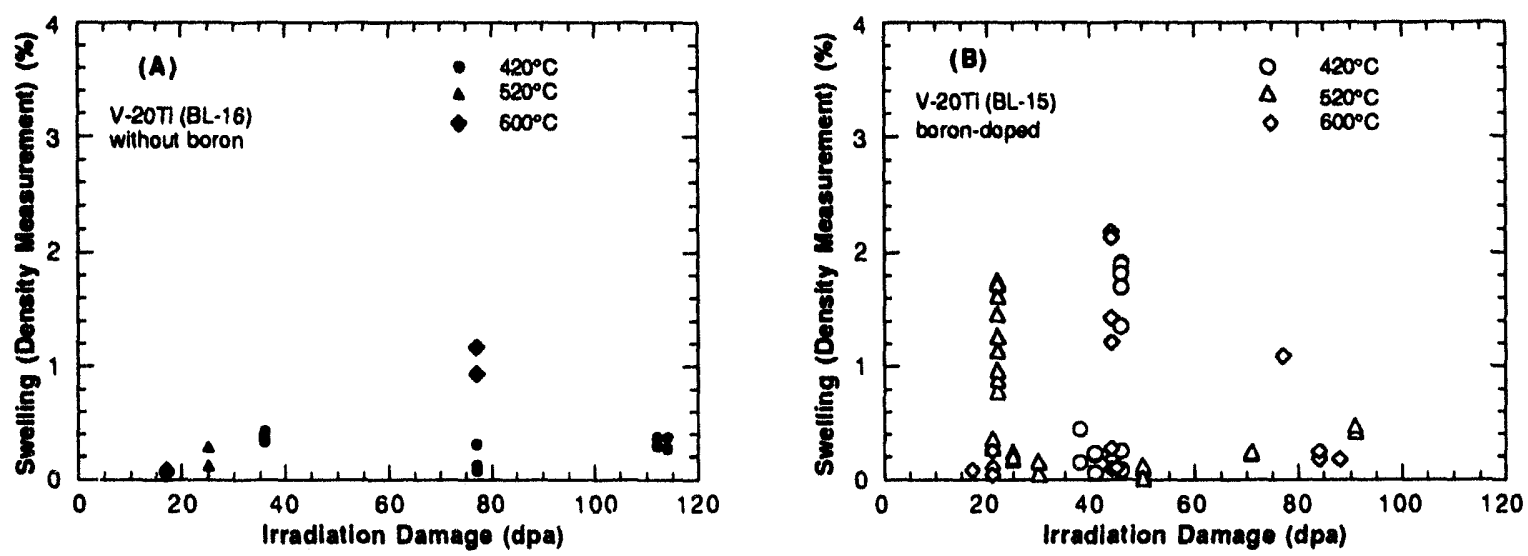

Figure 7. Density change of V-20Ti (A) without $B(B L-16)$ and $(B)$ with $B$ impurity (BL-15) as function of dose (dpa) after irradiation at 420,520 , and $600^{\circ} \mathrm{C}$

\section{CONCLUSIONS}

1. Sw lling of V-(5-20)Ti, V-Cr-(4-5)Ti, and V-3Ti-Si alloys was determined by density measurement and TEM microvoid examination after irradiation at 420,520 , and $600^{\circ} \mathrm{C}$ in lithium up to $114 \mathrm{dpa}$. Swelling resistance of $\mathrm{V}-4 \mathrm{Cr}-4 \mathrm{Ti}$, identified as the most promising candidate alloy primarily on the basis of its good mechanical properties and superior resistance to irradiation embrittlement and creep, was excellent (density change $<0.3 \%$ after irradiation up to $\approx 34 \mathrm{dpa}$ at these temperatures).

2. Most of the Ti-containing alloys exhibited swelling maxima in the damage range of $30-80 \mathrm{dpa}$. When irradiated to higher dpa, swelling in these alloys decreased monotonically. The anomalous swelling behavior that exhibited actual decrease of swelling for increased dose is in distinct contrast to the normal swelling behavior of other binary alloys of $\mathrm{V}$ containing $\mathrm{Fe}, \mathrm{Ni}, \mathrm{Cr}, \mathrm{Mo}, \mathrm{W}$, and $\mathrm{Si}$, which increases monotonically for increasing dose.

3. Void swelling and density change in Ti-containing alloys were generally consistent and could be correlated well with the number density of the ultrafine $\mathrm{Ti}_{5} \mathrm{Si}_{3}$ precipitates for irradiation at 520 and $600^{\circ} \mathrm{C}$. That is, a greater number density of the $\mathrm{Ti}_{5} \mathrm{Si}_{3}$ precipitates is conducive to lower swelling during irradiation. The anomalous swelling behavior seems to be caused by the profound microstructural evolution associated with the high-density precipitation of ultrafine Tis $\mathrm{Si}_{3}$, which could upset the steady-state balance between sink strengths of dislocations and voids. Large interface area created between the matrix and precipitates seems to act as dominant sinks, leading to increased defect recombination to reduce or eliminate the vacancy supersaturation. When changes in microstructure and defect partitioning are dramatic, it could increase the critical size of stable voids significantly and cause existing voids to become unstable. A model of swelling dependence on damage level has been developed to show that the kinetics of irradiation-induced precipitation of $\mathrm{Ti}_{5} \mathrm{Si}_{3}$ play an important role.

4. The excellent resistance to swelling of $\mathrm{V}-4 \mathrm{Cr}-4 \mathrm{Ti}$ under irradiation at $\angle 420^{\circ} \mathrm{C}$ appears to be associated with dense formation of ultrafine dislocation loops. 


\section{REFERENCES}

1. T. Noda, F. Abe, H. Araki, and M. Okada, J. Nucl. Mater. 155-157 (1988) 581.

2. R. Santos, J. Nucl. Mater. 155-157 (1988) 589.

3. S. J. Piet et al., J. Nucl. Mater. 141-143 (1986) 24.

4. F. L. Yaggee, E. R. Gilbert and J. W. Styles, J. Less-Comm. Met. 19 (1969) 39.

5. D. L. Smith, B. A. Loomis, and D. R. Diercks, J. Nucl. Mater. 135 (1985) 125.

6. B. A. Loomis, A. B. Hull, and D. L. Smith, J. Nucl. Mater., 179-181 (1991) 148-154.

7. B. A. Loomis and D. L. Smith, J. Nucl. Mater., 191-194 (1992) 84-91.

8. H. M. Chung and D. L. Smith, J. Nucl. Mater. 191-194 (1992) 942-947.

9. H. M. Chung, B. A. Loomis, and D. L. Smith, "Irradiation-Induced Precipitation in Vanadium-Base Alloys Containing Titanium," Effects of Radiation on Materials: 16th International Symposium, ASTM STP 1175, A. S. Kumar, D. S. Gelles, R. K. Nanstad, and T. A. Little, eds., American Society for Testing and Matcrials, Philadelphia, 1993.

10. D. L. Smith, B. A. Loomis, and H. M. Chung, "Effects of Neutron Irradiation on Vanadium-Base Alloys," Plasma Devices and Operations, Vol. 3, 1992.

11. B. A. Loomis, H. Tsai, H. M. Chung, J. Gazda, L. Nowicki, and D. L. Smith, "Effects of Neutron Irradiation and Helium on Tensile Properties of Vanadium-Base Alloys," paper presented at the Sixth Int. Conf. on Fusion Reactor Materials, September 27-October 1, 1993, Stresa, Italy.

12. B. A. Loomis, H. M. Chung, H. Tsai, J. Gazda, L. Nowicki, and D. L. Smith, "Effects of Neutron Irradiation, Hydrogen, and Helium on Ductilc-Brittle Transition Temperatures of Vanadium-Base Alloys," ibid.

13. B. A. Loomis, J. Gazda, and D. L. Smith, "Relationship of Microstructure and Mechanical Properties for V-Cr-Ti Alloys," ibid.

14. H. M. Chung, B. A. Loomis, and D. L. Smith, "Creep Properties of Vanadium-Base Alloys," ibid.

15. H. M. Chung, "Microstructural Evolution Induced by Boron Transmutation in Neutron-Irradiated Vanadium Alloys," in Fusion Reactor Materials. Semiannual. Prog. Reporl, DOE/ER-0313/14, Oak Ridge National Laboratory, Oak Ridge, TN (1993), pp. 299-305.

16. D. Harrod and R. Gold, "Mechanical Properties of Vanadium and Vanadium Base Alloys," Int. Met. Rev. 25 (1980) 163-221.

17. H. M. Chung, L. J. Nowicki, and D. L. Smith, in Eusion Reactor Materials. Semiannual. Prog. Report, DOE/ER-0313/11, Oak Ridge National Laboratory, Oak Ridge, TN (1992) 215-226.

18. M. Satou and H. M. Chung, in Fusion Reactor Materials. Semiannual. Prog. Report, DOE/ER0313/13, Oak Ridge National Laboratory, Oak Ridge, TN (1993) 227-234.

19. P. J. Maziasz, in Fusion Reactor Materials, Semiannual, Prog. Report, DOE/ER-0313/12, Oak Ridge National Laboratory, Oak Ridge, TN (1992), 163-174.

20. G. Frommeycr, R. Rosenkranz, and C. Luedecke, Z. Metallkunde 81 (1990) 307.

21. H. M. Chung, "Effects of Irradiation-Induced Precipitation on Properties of Vanadium Alloys," in Fusion Reacior Materials, Semiannual. Prog. Report, DOE/ER-0313/13, Oak Ridge National Laboratory, Oak Ridge, TN (1992), pp. 194-202. 
Relationship of Microstructure and Mechanical Properties of V-Cr-Ti Alloys - J. Gazda' ${ }^{1}$ B. A. Loomis ${ }^{1}$, L. J. Nowicki ${ }^{1}$, D. L. Smith ${ }^{1}$, and S. Danyluk ${ }^{2}$

\section{Summary}

The rejationship of composition, number density, and diameter of precipitates in the microstructures of unalloyed $\mathrm{V}$ and $\mathrm{V}$-Cr-Ti alloys to the yield strength, hardness, creep stress, and ductile-brittle transition temperature (DBTT) of these materials was determined from electron microscopy analyses of precipitates in these materials and from mechanical property data. Unalloyed V and V-Cr-Ti alloys with $\leq 3$ wt.\% Ti contained VC and Ti(CNO) precipitates, which were coherent with the matrix. The most common precipitates in the alloys were $\mathrm{Ti}\left(\mathrm{C}_{1 \cdot-\mathrm{x}-\mathrm{N}} \mathrm{N}_{\mathrm{z}} \mathrm{O}_{\mathrm{y}}\right)$ that were noncoherent with the matrix. The number density of noncoherent precipitates was maximal in $\mathrm{V}-3 \mathrm{Ti}$ and $\mathrm{V}-5 \mathrm{Cr}-3 \mathrm{Ti}$ alloys, and the average diameter of noncoherent precipitates was minimal in V-(1-3) Ti and V-5Cr-3Ti alloys. The increase of yield strength and hardness of $\mathrm{V}$ on alloying with $\mathrm{Tl}$ and $\mathrm{Cr}$ was shown to be primarily due to coherent precipitates, solute-atom misfit, and shear-modulus difference effects. The creep stress for rupture in $1000 \mathrm{~h}$ was related to the number density of precipitates, whereas the DBTT was related to the volume fraction of precipitates.

\section{Introduction}

Vanadium alloys are being considered for use as structural material in the International Thermonuclear Experimental Reactor (ITER) and in fusion reactors that may be constructed in the future [1]. When compared with other candidate materials, e.g., austenitic and ferritic steels, vanadium alloys exhibit an eminent combination of low long-term neutron activation, low neutron irradiation afterheat, low neutron-induced helium and hydrogen transmutation rates, low biological-hazard potential, low thermal stress factor, high-temperature tensile and long-term creep strength, low ductile-brittle transition temperature (DBTT), and resistance to irradiation damage [1-6]. At present, the $\mathrm{V}-4 \mathrm{Cr}-4 \mathrm{Ti}$ alloy is recommended for the near-optimal combination of desirable physical and mechanical properties for a vanadium alloy structural material [1]. To further optimize the combination of physical and mechanical properties of a vanadium alloy, the relationship of yield strength, hardness, creep stress, and DBTT to the composition, number density, and diameter of precipitates in unalloyed $\mathrm{V}$ and $\mathrm{V}$-Cr-Ti alloys was determined from comprehensive electron microscopy analyses of these materials and from mechanicalproperty data.

\section{Materials and procedure}

Unalloyed $\mathrm{V}$ and $\mathrm{V}$-Cr-Ti alloys with the nominal compositions listed in Table 1 were obtained in sheet form with $50 \%$ thickness reduction for preparation of specimens for observation by transmission electron microscopy (TEM). Unalloyed $\mathrm{V}$ and $\mathrm{V}$-Cr-Ti alloys were annealed at 1050 and $1125^{\circ} \mathrm{C}$, respectively, for $1 \mathrm{~h}$ in a vacuum of $2 \times 10^{-5} \mathrm{~Pa}$. These annealing conditions resulted in an average recrystallized-grain diameter of $0.02-0.04 \mathrm{~mm}$ and a dislocation density of $-10^{13} \mathrm{~m}^{-2}$ in the specimens.

Specimens for observation by TEM were obtained by electrolytic polishing in a solution composed of $15 \%$ (by volume) sulfuric acid, $72 \%$ methanol, and $13 \%$ butyl cellosolve at $-35^{\circ} \mathrm{C}$. The general observations of the specimens for determination of the number density and size of precipitates in the specimens were conducted on a JEOL $100 \mathrm{CX}$-II scanning-transmission electron microscope equipped

- Work supported by the U.S. Department of Energy, Office of Fusion Energy, under Contract W-31109-Eng-38.

1 Argonne National Laboratory, 9700 S. Cass Ave. Argonne, II, 60439.

2 University of Illinois at Chicago, CEMM Department,Chicago, Il; present address: Georgia Institute of Technology, The G.W. Woodruff School of Mechanical Engineering, Atlanta, Ga. 30332. 
Table 1. Compositions of V and V-Cr-Ti alloys.

\begin{tabular}{|c|c|c|c|c|c|c|c|c|}
\hline \multirow[t]{2}{*}{$\begin{array}{l}\text { Nominal } \\
\text { Composition }\end{array}$} & \multirow[t]{2}{*}{$\begin{array}{l}\text { ANL } \\
\text { I.D. }\end{array}$} & \multicolumn{3}{|c|}{$\begin{array}{l}\text { Concentration } \\
(w t . \%)\end{array}$} & \multicolumn{4}{|c|}{$\begin{array}{c}\text { Concentration } \\
(\mathrm{ppm})\end{array}$} \\
\hline & & $\mathrm{Cr}$ & $\mathrm{Ti}$ & $\overline{\mathrm{Fe}}$ & 0 & $\mathbf{N}$ & $\mathrm{C}$ & $\mathbf{S i}$ \\
\hline V & BL 51 & - & - & - & 570 & 49 & 56 & 370 \\
\hline $\mathrm{V}-1 \mathrm{Ti}$ & BL 50 & - & 1.0 & - & 230 & 130 & 235 & 1050 \\
\hline V-3Ti & BL 62 & - & 3.1 & - & 320 & 86 & 109 & 660 \\
\hline V-3Ti-1Si & BL 45 & - & 2.5 & 0.01 & 345 & 125 & 90 & 9900 \\
\hline V-5Ti & BL 46 & - & 4.6 & - & 300 & 53 & 85 & 160 \\
\hline V-10Ti & BL 12 & $\because$ & 9.8 & 0.63 & 1670 & 390 & 450 & 245 \\
\hline V-18Ti & BL 15 & - & 17.7 & 0.04 & 830 & 160 & 380 & 480 \\
\hline $\mathrm{V}-14 \mathrm{Cr}$ & BL 5 & 14.1 & - & 0.06 & 330 & 69 & 200 & 50 \\
\hline $\mathrm{V}-14 \mathrm{Cr}-1 \mathrm{Ti}$ & BL 26 & 14.1 & 1.0 & 0.06 & 560 & 86 & 140 & 50 \\
\hline $\mathrm{V}-5 \mathrm{Cr}-3 \mathrm{Ti}$ & BL 54 & 5.1 & 3.0 & - & 480 & 82 & 133 & 655 \\
\hline $\mathrm{V}-4 \mathrm{Cr}-4 \mathrm{Ti}$ & BL 47 & 4.1 & 4.3 & - & 350 & 220 & 200 & 870 \\
\hline V-5Cr-5Ti & BL 63 & 4.6 & 5.1 & - & 440 & 28 & 73 & 310 \\
\hline $\mathrm{V}-8 \mathrm{Cr}-6 \mathrm{Ti}$ & BL 49 & 7.9 & 5.7 & - & 400 & 150 & 127 & 360 \\
\hline V-9Cr-5Ti & BL 43 & 9.2 & 4.9 & 0.02 & 230 & 31 & 100 & 340 \\
\hline $\mathrm{V}-14 \mathrm{Cr}-5 \mathrm{Ti}$ & BL 24 & 13.5 & 5.2 & 0.05 & 1190 & 360 & 500 & 390 \\
\hline $\mathrm{V}-15 \mathrm{Cr}-5 \mathrm{Ti}$ & BL 41 & 14.5 & 5.0 & 0.02 & 330 & 96 & 120 & 400 \\
\hline V-10Cr-9Ti & BL 44 & 9.9 & 9.2 & 0.04 & 300 & 87 & 150 & 270 \\
\hline $\mathrm{V}-7 \mathrm{Cr}-15 \mathrm{Ti}$ & BL 10 & 7.2 & 14.5 & 0.09 & 1110 & 250 & 400 & 400 \\
\hline
\end{tabular}

with an X-ray energy dispersive spectroscopy (EDS) attachment. For detailed analyses of the structure and composition of precipitates, the specimens were observed on a Phillips CM30 analytical transmission electron microscope equipped with a thin-window EDS detector. Additional information on observations and procedures for analysis of precipitates in the specimens is presented in Ref. 7. The yield strength (at $0.2 \%$ strain) and Vickers hardness number (VHN) for the unalloyed $\mathrm{V}$ and V-Cr-Ti alloys in Table 1 were obtained from Refs. 8 and 9, respectively. The stress (on creep deformation) for rupture in 1000 $h$ of unalloyed $V$ and V-Cr-Ti alloys at $650^{\circ} \mathrm{C}$ was obtained from Refs. 1, 10, and 11. The DBTTs of unalloyed $\mathrm{V}$ and $\mathrm{V}$-Cr-Ti alloys (on impact testing) were obtained from Refs. 1, 12, and 13.

\section{Experimental results}

\subsection{Precipitate compositions}

Three types of precipitates that were noncoherent with the matrix were observed in the V-Cr-Ti alloys. (1) The most common noncoherent precipitates in the alloys were faceted, rectangular-shaped $\mathrm{Ti}\left(\mathrm{N}_{1-x-y} \mathrm{C}_{\mathrm{x}} \mathrm{O}_{\mathrm{y}}\right)$ with face-centered-cubic (fcc) $\mathrm{NaCl}$ structure. (2) A second type of noncoherent precipitate was observed either on high-angle grain boundaries or in the immediate vicinity of such boundaries. These precipitates were not as common as the $\mathrm{Ti}\left(\mathrm{N}_{1-x \cdot \mathrm{y}} \mathrm{C}_{\mathrm{x}} \mathrm{O}_{\mathrm{y}}\right)$ precipitates and were identified as $\mathrm{Ti}_{17} \mathrm{P}_{10}$ from selected-area-diffraction (SAD) and EOS data. (3) The third type of noncoherent precipitate was a titanium-sulfur compound. These precipitates were identified as $\mathrm{Ti}_{8} \mathrm{~S}_{3}$ and were found only in the matrix of $\mathrm{V}-\mathrm{Cr}-\mathrm{Ti}$ alloys. Noncoherent precipitates containing $\mathrm{V}$ or $\mathrm{Cr}$ were not found in the $\mathrm{V}-\mathrm{Cr}$ - $\mathrm{Ti}$ alloys. However, in unalloyed $V$, most of the precipitates were $V$ compounds. The most common precipitate in unalloyed $\mathrm{V}$ was $\mathrm{V}_{6} \mathrm{O}_{13}$, with rectangular, faceted shape, and large variation in length (100$900 \mathrm{~nm}$ ). The second most common precipitate in $V$ was $\mathrm{VS}_{4}$, with rectangular shape and $\boldsymbol{\sim 5 0 0} \mathbf{n m}$ length. $A$ third type of precipitate identified in unalloyed $V$ was oval-shaped $\gamma-\mathrm{Ti}_{3} \mathrm{O}_{5}$ with a diameter of 200-300 nm.

The characteristic images of strain fields associated with precipitates that were coherent with the matrix were only observed in unalloyed $\mathrm{V}, \mathrm{V}$-Ti alloys containing $\leq 3.1 \mathrm{wt} . \% \mathrm{Ti}$, and $\mathrm{V}$-Cr-Ti alloys containing $\leq 1.0 \mathrm{wt} . \% \mathrm{Ti}$. All of the coherent precipitates were rectangular (with eight facets) or oval 
shaped with a diameter of 50-100 $\mathrm{nm}$. Two distinct types of coherent precipitates were found in the alloys. The $V_{4} C_{3}$ precipitate, with fcc structure, was found in $\mathrm{V}-1 \mathrm{Ti}, \mathrm{V}-3 \mathrm{Ti}, \mathrm{V}-14 \mathrm{Cr}$, and $\mathrm{V}-14 \mathrm{Cr}-1 \mathrm{Ti}$ alloys, and the TiO precipitate, with hexagonal-close-packed (hcp) structure, was only found in the V-3Ti alloy. The composition of the coherent precipitates in unalloyed $V$ could not be positively identified. A combination of TEM imaging, SAD patterns, and EDS spectra allowed only the identification of elements present in these precipitates and some of the lattice-plane spacings. Compounds that were consistent with the lattice-plane spacing, EDS, and SAD data were $\gamma-\mathrm{Na}_{3} \mathrm{VO}_{4}, \mathrm{CaV}_{4} \mathrm{O}_{9}, \mathrm{Ca}_{5} \mathrm{Si}_{2} \mathrm{O}_{7}\left(\mathrm{CO}_{3}\right)_{2}$, and $(\mathrm{Na}, \mathrm{Ca})_{2} \mathrm{Si}_{6}(\mathrm{O}, \mathrm{OH})_{12}\left(\mathrm{CO}_{3}\right)_{a, 5}$. Additional information on the precipitates and the lattice parameters of the alloys can be found in Ref. 7.

\subsection{Precipitate number density and diameter}

The number density, average diameter, and volume fraction of precipitates in unalloyed V, V-Ti alloys, and V-Cr-Ti alloys are listed in Table 2. The number density of noncoherent precipitates in the alloys was maximal $\left(-2 \times 10^{19} \mathrm{~m}^{-3}\right)$ in the V-3Ti and V-5Cr-3Ti alloys, and the average diameter of noncoherent precipitates was minimal $(100-175 \mathrm{~nm})$ in the $\mathrm{V}-(1-3) \mathrm{Ti}$ and $\mathrm{V}-5 \mathrm{Cr}-3 \mathrm{Ti}$ alloys. In the case of V-Ti alloys, coherent precipitates with average diameter of 75-100 nm and number density of $\sim 0.5 \times 10^{18}$ $\mathrm{m}^{-3}$ were present only in $\mathrm{V}, \mathrm{V}-1 \mathrm{Ti}$, and $\mathrm{V}-3 \mathrm{Ti}$ alloys. In the case of $\mathrm{V}-\mathrm{Cr}-\mathrm{Ti}$ alloys, coherent precipitates with average diameter of $50-60 \mathrm{~nm}$ were present only in the $\mathrm{V}-15 \mathrm{Cr}$ and $\mathrm{V}-15 \mathrm{Cr}-1 \mathrm{Ti}$ alloys. The number

Table 2. Number density, average diameter, and volume fraction of precipitates in V and V-Cr-Ti alloys.

\begin{tabular}{|c|c|c|c|c|}
\hline \multirow[b]{2}{*}{ Alloy } & \multirow[b]{2}{*}{$\begin{array}{l}\text { ANL } \\
\text { I.D. }\end{array}$} & \multicolumn{3}{|c|}{ Precipitate } \\
\hline & & $\begin{array}{l}\text { Number Density } \\
\left(\mathrm{m}^{-3}\right)\end{array}$ & $\begin{array}{l}\text { Average Dia. } \\
\quad(\mathrm{nm})\end{array}$ & $\begin{array}{c}\text { Volume Fraction }{ }^{\mathrm{a}} \\
\text { (nm) }\end{array}$ \\
\hline \multirow[t]{2}{*}{$\mathbf{V}$} & BL 51 & $5.0 \times 10^{18}$ & 300 & 0.071 \\
\hline & & $0.5 \times 10^{18 b}$ & $90^{6}$ & $<0.001^{b}$ \\
\hline \multirow[t]{2}{*}{ V-1Ti } & BL 50 & $9.0 \times 10^{18}$ & 100 & 0.005 \\
\hline & & $0.5 \times 10^{18 b}$ & $100^{b}$ & $<0.001^{b}$ \\
\hline \multirow[t]{2}{*}{ V-3Ti } & BL 62 & $1.9 \times 10^{19}$ & 175 & 0.053 \\
\hline & & $0.5 \times 10^{18 b}$ & $75^{b}$ & $<0.001^{b}$ \\
\hline V-5Ti & BL 46 & $8.1 \times 10^{18}$ & 310 & 0.126 \\
\hline V-10Ti & BL 12 & $3.2 \times 10^{18}$ & 575 & 0.318 \\
\hline V-18Ti & BL 15 & $1.4 \times 10^{18}$ & 800 & 0.375 \\
\hline \multirow{2}{*}{$\mathrm{V}-14 \mathrm{Cr}$} & BL 5 & $0.5 \times 10^{18}$ & 200 & 0.002 \\
\hline & & $4.1 \times 10^{19 b}$ & $50^{b}$ & $0.003^{b}$ \\
\hline \multirow[t]{2}{*}{$\mathrm{V}-14 \mathrm{Cr}-1 \mathrm{Ti}$} & BL 26 & $6.0 \times 10^{18}$ & 275 & 0.066 \\
\hline & & $5.0 \times 10^{19 b}$ & $60^{b}$ & $0.006^{b}$ \\
\hline \multirow[t]{2}{*}{$\mathrm{V}-5 \mathrm{Cr}-3 \mathrm{Ti}$} & BL 54 & $2.1 \times 10^{19}$ & 100 & 0.011 \\
\hline & & $2.6 \times 10^{18}$ & 400 & 0.087 \\
\hline $\mathrm{V}-4 \mathrm{Cr}-4 \mathrm{Ti}$ & BL 47 & $3.4 \times 10^{18}$ & 500 & 0.222 \\
\hline V-9Cr-5Ti & BL 43 & $6.5 \times 10^{18}$ & 300 & 0.092 \\
\hline \multirow[t]{2}{*}{$\mathrm{V}-14 \mathrm{Cr}-5 \mathrm{Ti}$} & BL 24 & $2.2 \times 10^{16}$ & 500 & 0.143 \\
\hline & & $4.8 \times 10^{18}$ & 150 & 0.008 \\
\hline V-10Cr-9Ti & BL 44 & $3.3 \times 10^{18}$ & 400 & 0.110 \\
\hline \multirow{2}{*}{ V-7Cr-15Ti } & BL 10 & $1.4 \times 10^{18}$ & 500 & 0.092 \\
\hline & & $9.3 \times 10^{18}$ & 200 & 0.039 \\
\hline
\end{tabular}

Volume Fraction $=1 / 6 \pi \mathrm{d}^{3} \mathrm{~N}$

Coherent precipitates. 


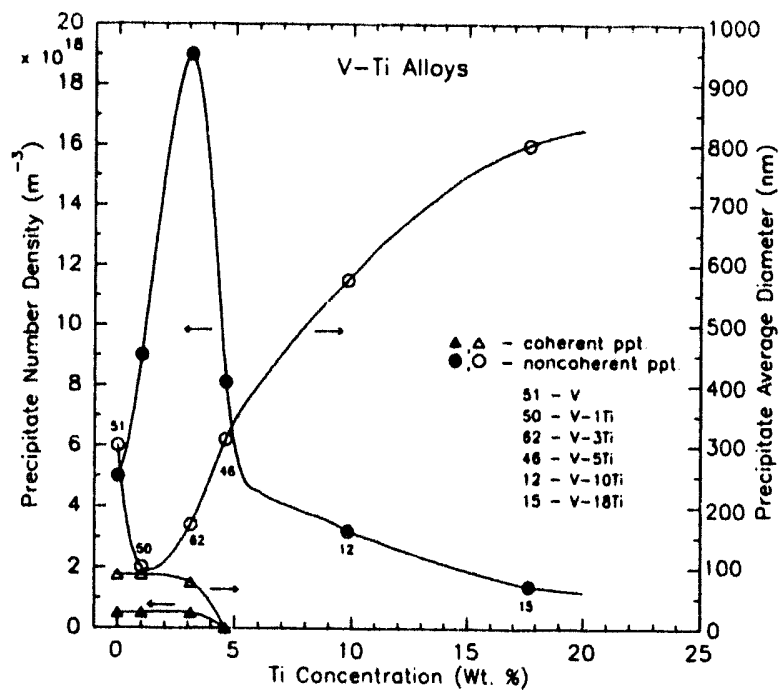

Fig. 1. Dependence of number density and diameter for precipitates in V.Ti alloys.

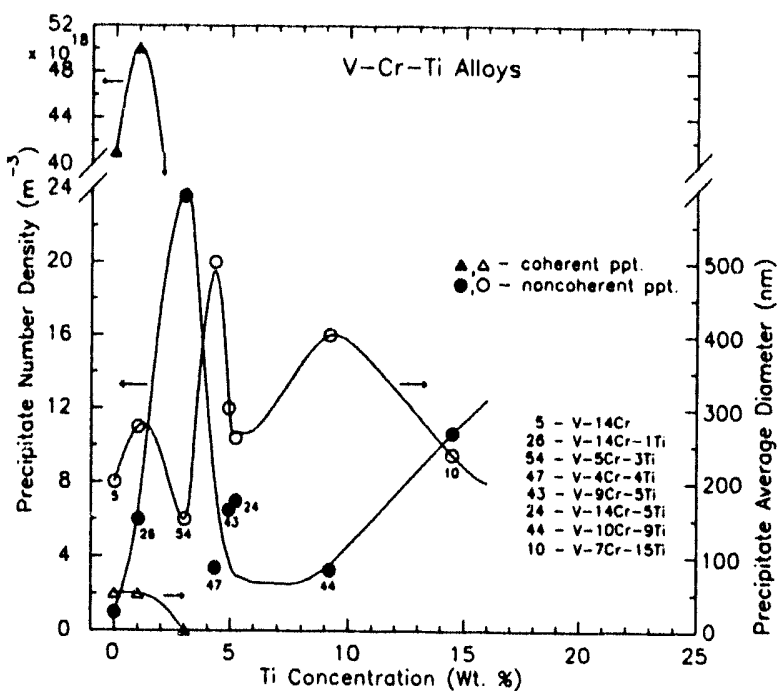

Fig. 2. Dependence of number density and diameter for precipitates in $\mathrm{V}$-Cr-Ti alloys.

density of coherent precipitates in the $\mathrm{V}-15 \mathrm{Cr}$ and $\mathrm{V}-15 \mathrm{Cr}-1 \mathrm{Ti}$ alloys was exceptionally high $\left(4-5 \times 10^{19}\right.$ $\mathrm{m}^{-3}$ ), but decreased significantly, to $0.5 \times 10^{18} \mathrm{~m}^{-3}$, in the $\mathrm{V}-15 \mathrm{Cr}-1 \mathrm{Ti}$ alloy. The volume fraction of precipitates (coherent and noncoherent) in the V-Ti alloys was minimal $(0.005-0.054)$ in the V-(1-3)Ti alloys and increased substantially with increasing concentration of $\mathrm{Ti}$ in these alloys to 0.375 volume fraction in the V-18Ti alloy. The volume fraction of precipitates (coherent and noncoherent) in the V$\mathrm{Cr}$ - Ti alloys was maximal $(0.222)$ in the $\mathrm{V}-4 \mathrm{Cr}-4 \mathrm{Ti}$ alloy. Figures 1 and 2 show the dependence of number density and average precipitate diameter on concentration of $\mathrm{Ti}$ and $\mathrm{Cr}$ for $\mathrm{V}-\mathrm{Ti}$ and $\mathrm{V}-\mathrm{Cr}-\mathrm{Ti}$ alloys, respectively.

\subsection{Relationships of microstructure to mechanical properties}

\subsubsection{Yield strength and hardness}

The contributions of several strengthening mechanisms to the yield strength of $\mathrm{V}-\mathrm{Ti}$ and $\mathrm{V}-\mathrm{Cr}-\mathrm{Ti}$ alloys were calculated from theoretical models. The yield strength of unalloyed $\mathrm{V}\left(259 \mathrm{MPa}\right.$ at $\left.25^{\circ} \mathrm{C}\right)$ was chosen as the reference for these calculations [8]. The strengthening $\left(\Delta \sigma_{\mathrm{ys}}\right)$ mechanisms that were considered included coherent precipitate strengthening $\left(\Delta \sigma_{c \text {-pp }}\right)$, noncoherent precipitate strengthening $\left(\Delta \sigma_{\text {nc-ppt }}\right)$, solid solution strengthening $\left(\Delta \sigma_{\mathrm{ss}}\right)$, and strengthening due to shear-modulus difference $\left(\Delta \sigma_{\mathrm{mod}}\right)$. The increase of yield strength of $\mathrm{V}$ on alloying with $\mathrm{Ti}$ and $\mathrm{Cr}$ was evaluated with

$$
\Delta \sigma_{\mathrm{ys}}{ }^{\mathrm{n}}=\left(\Delta \sigma_{\mathrm{nc-ppt}}\right)^{\mathrm{n}}+\left(\Delta \sigma_{\mathrm{c}-\mathrm{ppt}}\right)^{\mathrm{n}}+\left(\Delta \sigma_{\mathrm{ss}}\right)^{\mathrm{n}}+\left(\Delta \sigma_{\mathrm{mod}}\right)^{\mathrm{n}} \text {, with } \mathrm{n}=1.55
$$

Strengthening of $V$ alloys by non-coherent precipitates was evaluated [14] with

$$
\Delta \sigma_{\text {nc-ppt }}=1.73\left[\alpha_{\mathrm{p}} \mathrm{Gb}\left(\rho_{\mathrm{d}}\right)^{0.5}+\beta_{\mathrm{p}} \mathrm{Gb}\left(\mathrm{N}_{\mathrm{p}} \mathrm{d}_{\mathrm{p}}\right)^{0.5}\right] .
$$

In Eq. 2, $\rho_{d}, N_{p}$, and $d_{p}$ are the dislocation density $\left(\sim 10^{13} / \mathrm{m}^{2}\right)$, number density of precipitates, and average diameter of precipitates, respectively, and $\alpha_{p}$ and $\beta_{p}$ are interaction parameters of gliding dislocations with forest dislocations and noncoherent precipitates. For the purpose of this paper, we shall use $\alpha_{p}=$ 0.5 and $\beta_{\mathrm{p}}=0.2[15]$. Also in Eq. 2, $\mathrm{G}$ is the shear modulus and $\mathrm{b}$ is the Burgers vector for $\mathrm{V}$, with values of $4.7 \times 10^{4} \mathrm{MPa}$ and $0.26 \mathrm{~nm}$, respectively [14]. 
Alloy strengthening by coherent precipitates was evaluated from the following equation $[7,15,16]$

$$
\Delta \sigma_{\text {c.ppt }}=6 \mathrm{G}\left(\mathrm{r}_{\mathrm{p}} \mathrm{f} / \mathrm{b}\right)^{0.5} \mathrm{e}^{1.5} .
$$

In Eq. 3, $G, r_{p}, f, b$, and $e$ are the shear modulus, average precipitate radius, volume fraction of precipitates, length of the Burgers vector, and strain factor (equal to normalized difference in lattice parameters of matrix and the precipitate), respectively.

Solid solution strengthening of $\mathrm{V}$ by $\mathrm{Ti}$ and $\mathrm{Cr}$ was evaluated from the following equation $[7,8,18,19]$

$$
\Delta \sigma_{n}=\left[0.25 \mathrm{Gec}^{0.5}\right]_{0<c<s}+[0.25 \mathrm{Gec}]_{s<c<20},
$$

where $\mathrm{c}$ is the concentration of either $\mathrm{Ti}$ or $\mathrm{Cr}$.

Strengthening of $\mathrm{V}$ alloys due to shear-modulus difference effects was evaluated with the equation

$$
\Delta \sigma_{\bmod }=0.25 \mathrm{G} \eta \mathrm{c}[7,16] \text {. }
$$

In Eq. $5, \eta=\left(G_{\mathrm{v}}-G_{\mathrm{T}, \mathrm{C}}\right) / \mathrm{G}_{\mathrm{v}}$.

The yield strength of the V-Cr-Ti alloys was calculated with Eqs. 1-5 and experimental data in Table 2. The dependence of the theoretical and experimental yield strength and VHN of V-Cr-Ti alloys on (Cr $+\mathrm{Ti}$ ) concentration is shown in Fig. 3. Although the yield strength of the $\mathrm{V}$ alloys computed Egs. 1-5 overestimates the experimental yield strength [8] by $50-100 \mathrm{MPa}$, the agreement of the theoretical and experimental yield strength dependence on $(\mathrm{Cr}+\mathrm{Ti})$ concentration suggests that $\mathrm{Eq} .1$ incorporates the principal strengthening processes in $\mathrm{V}$ on alloying with $\mathrm{Cr}$ and $\mathrm{Ti}$. The VHN data (Fig. 3) also suggest that Eq. 1 incorporates the principal strengthening processes, which could be expected because the yield strength of V-Cr-Ti alloys is linearly related to the VHN of the alloys [9], viz.,

$$
\begin{aligned}
& \text { yield strength }=2.22(\mathrm{VHN})+20 \text { for } \mathrm{V}-\mathrm{Ti} \text { alloys, and } \\
& \text { yield strength }=3(\mathrm{VHN})-110 \text { for } \mathrm{V}-\mathrm{Cr}-\mathrm{Ti} \text { alloys. }
\end{aligned}
$$

Evaluation of the separate contributions of the strengthening processes, i.e., Eq. 1, to the strengthening of $\mathrm{V}$ on addition of $\mathrm{Ti}$ and $\mathrm{Cr}$ is presented in Table 3 . In summary, noncoherent precipitates contribute minimally (30-40 MPa) to the strengthening of $\mathrm{V}$ on addition of $\mathrm{Ti}$ and $\mathrm{Cr}$, whereas coherent precipitates, solute-atom misfit (solid solution), and shear-modulus difference effects contribute approximately equally to the strengthening of $\mathrm{V}$ on addition of $\mathrm{Ti}$ and $\mathrm{Cr}$.

\subsubsection{Creep stress-to-rupture}

The dependence on Ti concentration of creep stress for rupture in $1000 \mathrm{~h}$ of V-Ti alloys at $650^{\circ} \mathrm{C}$ and the number density of precipitates in V-Ti alloys is shown in Fig. 4. These results suggest that the creep strength of V-Ti alloys is primarily determined by the number density of precipitates (coherent and noncoherent) in the alloys, and the highest creep strength of a V-Ti alloy is obtained for an alloy with the highest number density of precipitates, i.e., the V-3Ti alloy. The creep stress for rupture of the V$13 \mathrm{Cr}-3 \mathrm{Ti}$ and $\mathrm{V}-15 \mathrm{Cr}-5 \mathrm{Ti}$ alloys at $650^{\circ} \mathrm{C}$ is also shown in Fig. 4. These limited experimental data for creep of $\mathrm{V}$-Cr-Ti alloys suggest that the highest creep strength of $\mathrm{V}-\mathrm{Cr}$-Ti alloys (with comparable $\mathrm{Cr}$ concentration) is also obtained for a V-Cr-Ti alloy containing $\sim 3 \mathrm{wt}$.\% Ti. Although creep data are not currently available for $\mathrm{V}-(4-5) \mathrm{Cr}-(3-4) \mathrm{Ti}$ alloys, it might be expected that the creep strength of the $\mathrm{V}-5 \mathrm{Cr}$ 3Ti alloy will be significantly higher than that of the $\mathrm{V}-4 \mathrm{Cr}-4 \mathrm{Ti}$ alloy on the basis of the higher number density of precipitates in the V-5Cr-3Ti alloy (shown in Table 2).

The stress-to-rupture in $1000 \mathrm{~h}$ for the V-Ti alloys is significantly increased by the addition of $\mathrm{Cr}$ to the alloys [1]. The data in Table 2 suggest that the higher stress-to-rupture for $\mathrm{V}-\mathrm{Cr}$ - Ti alloys can, in general, be attributed to a higher number density of precipitates with smaller average diameter. 
Table 3. Contributions of various strengthening mechanisms to the Yield Strength of Vanadium-base alloys (in MPa).

\begin{tabular}{lrrrrrrr}
\hline $\begin{array}{l}\text { Alloy } \\
\text { Comp }\end{array}$ & ANL ID & $\Delta \sigma_{\text {nc-ppt }}$ & $\Delta \sigma_{\text {c.ppl }}$ & \multicolumn{1}{c}{$\Delta \sigma_{\text {Ss }}$} & \multicolumn{1}{c}{$\Delta \sigma_{\text {mod }}$} & $\Delta \sigma_{\text {ys }}$ & $\sigma_{\text {ys }}$ theoretical \\
\hline V & BL 51 & 0 & 0 & 0 & 0 & 0 & 259 \\
V-1Ti & BL 50 & 37.43 & 74.56 & 13.44 & 17.17 & 97.58 & 357.52 \\
V-3Ti & BL 62 & 35.86 & 74.56 & 23.35 & 51.69 & 118.65 & 378.65 \\
V-5Ti & BL 46 & 40.12 & 0 & 61.05 & 76.05 & 122.05 & 382.05 \\
V-10Ti & BL 12 & 39.15 & 0 & 129.61 & 166.70 & 242.01 & 502.01 \\
V-18Ti & BL 15 & 37.89 & 0 & 234.82 & 295.10 & 422.35 & 682.35 \\
V-14Cr & BL 5 & 34.75 & 88.5 & 96.60 & 225.00 & 299.82 & 559.82 \\
V-14Cr-1Ti & BL 26 & 38.85 & 212.4 & 142.10 & 239.70 & 414.01 & 674.01 \\
V-5Cr-3Ti & BL 54 & 35.35 & 0 & 78.27 & 125.39 & 171.31 & 431.31 \\
V-4Cr-4Ti & BL 47 & 38.93 & 0 & 90.35 & 128.48 & 183.47 & 443.47 \\
V-9Cr-5Ti & BL 43 & 39.32 & 0 & 133.80 & 218.66 & 288.53 & 548.53 \\
V-14Cr-5Ti & BL 24 & 37.85 & 0 & 167.70 & 291.70 & 373.38 & 633.38 \\
V-10Cr-9Ti & BL 44 & 38.27 & 0 & 201.00 & 292.85 & 396.63 & 656.63 \\
V-7Cr-15Ti & BL 10 & 36.95 & 0 & 259.90 & 327.60 & 467.07 & 727.07 \\
\hline
\end{tabular}

3.3.3. DBTT

The dependence of DBTT and volume fraction of precipitates on Ti concentration in V-Ti and V-CrTi alloys is shown in Figs. 5 and 6, respectively. The data in Fig. 5 suggest that the minimum DBTT for $\mathrm{V}-(1-5) \mathrm{Ti}$ alloys is related to a minimum volume fraction of precipitates with small average-diameter $(100-310 \mathrm{~nm})$ in these alloys. The relationship between volume fraction of precipitates and DBTT for V-Ti alloys may be more significant than is apparent in Fig. 5, inasmuch as the lowest possible test temperature $\left(-190^{\circ} \mathrm{C}\right)$ was above the DBTT. The data in Fig. 6, to the contrary, suggest that the low $\left(<-220^{\circ} \mathrm{C}\right)$ DBTT of the $\mathrm{V}-4 \mathrm{Cr}-4 \mathrm{Ti}$ alloy is due to the high volume-fraction of relatively large averagediameter $(500 \mathrm{~nm})$ precipitates in this alloy. The V-5Cr-3Ti alloy has an unexpectedly high DBTT $\left(-85^{\circ} \mathrm{C}\right)$, which may be related to a high number-density of precipitates with small average diameter $(100$ $\mathrm{nm})$.

The data in Fig. 6 also show that the minimum DBTT for a V-4Cr-4Ti alloy increases significantly $\left(\sim 100^{\circ} \mathrm{C}\right)$ with \pm 1 wt.\%-change of Ti concentration. Moreover, the minimum DBTT of a V-4Cr-4Ti alloy $\mathrm{Z}$ increases significantly with increase of $\mathrm{Cr}$ concentration; the DBTTs for $\mathrm{V}-4 \mathrm{Cr}-4 \mathrm{Ti}, \mathrm{V}-5 \mathrm{Cr}-5 \mathrm{Ti}$, and $\mathrm{V}-9 \mathrm{Cr}-5 \mathrm{Ti}$ are $<-220^{\circ} \mathrm{C},-112^{\circ} \mathrm{C}$, and $-60^{\circ} \mathrm{C}$, respectively.

\section{Discussion}

Vanadium-base alloys with $\mathrm{Cr}$ and $\mathrm{Ti}$ as the principal alloying additions exhibit several attractive physical and mechanical properties for application as structural material in ITER and future fusion reactors. These alloys offer an excellent combination of low, long-term radioactivation, high-temperature tolerance, and resistance to irradiation damage. The $\mathrm{V}-4 \mathrm{Cr}-4 \mathrm{Ti}$ alloy is believed to exhibit the nearoptimal combination of these properties. The DBTT (on Charpy-impact testing) of this alloy is particularly noteworthy in that the DBTT is $<-200^{\circ} \mathrm{C}$ before and after neutron irradiation at $420-600^{\circ} \mathrm{C}$ to 24-34 atom displacements per atom (dpa) $[1,19]$. Moreover, the swelling of the $\mathrm{V}-4 \mathrm{Cr}-4 \mathrm{Ti}$ alloy is 


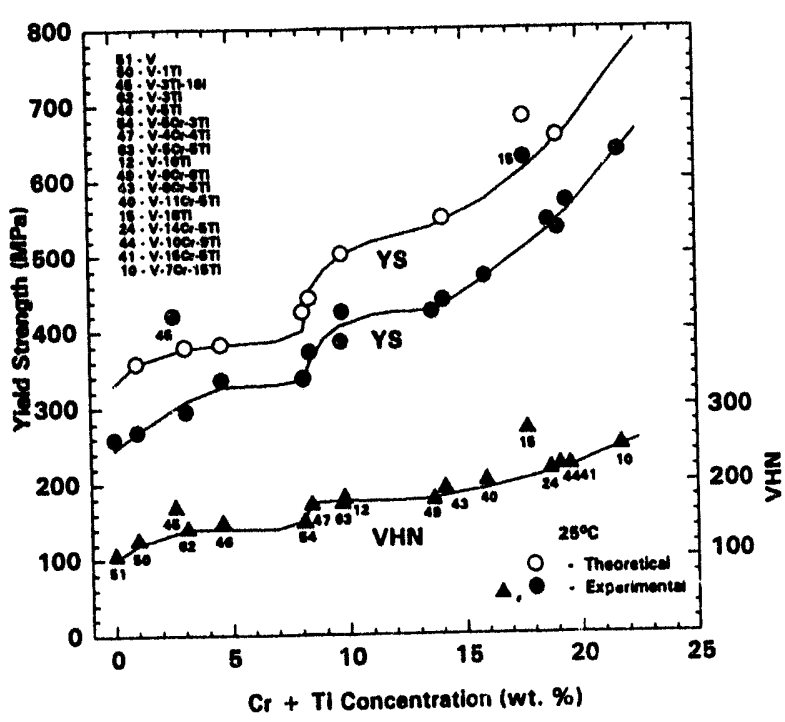

Fig. 3. Dependence of theoretical and experimental yield strength and $\mathrm{VHN}$ of $\mathrm{V}$ - $\mathrm{Cr}-\mathrm{Ti}$ alloys on $\mathrm{Cr}+\mathrm{Ti}$ concentration.

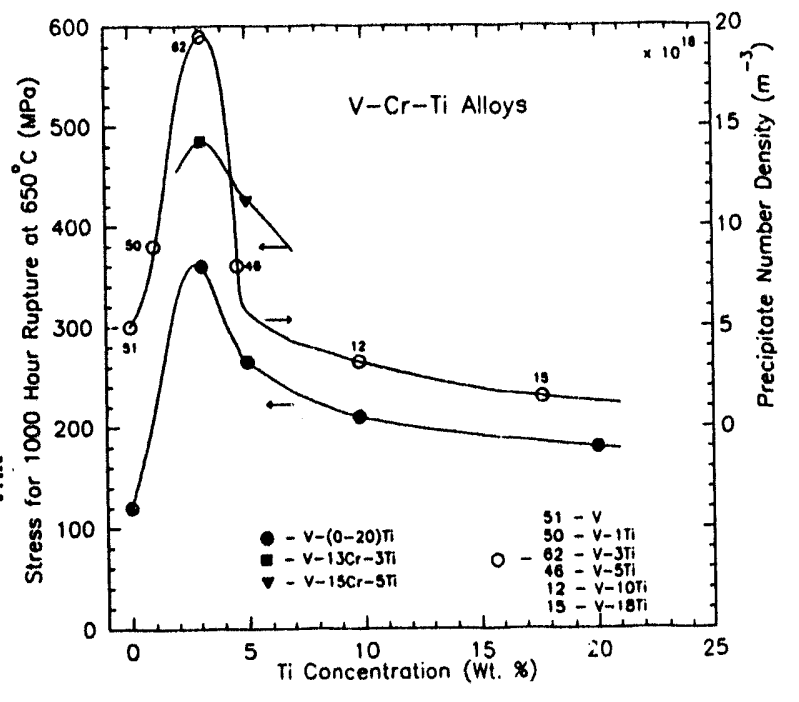

Fig. 4. Dependence of creep stress for $1000-h$ rupture at $650^{\circ} \mathrm{C}$ and of number density of precipitates in $\mathrm{V}-\mathrm{Cr}-\mathrm{Ti}$ alloys on $\mathrm{Ti}$ concentration.

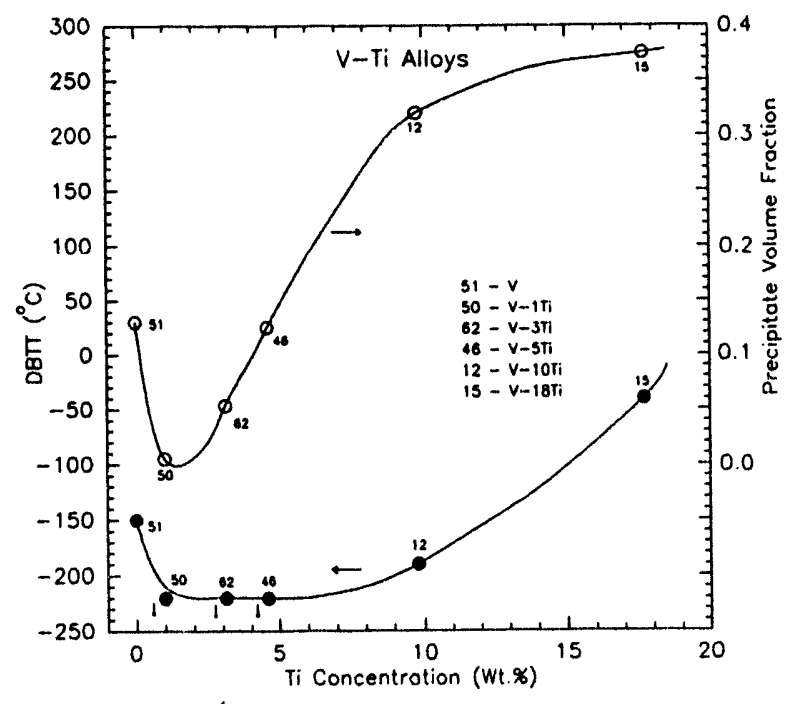

Fig. 5. Dependence of DBTT and volume fraction of precipitates in $\mathrm{V}$-Ti alloys on $\mathrm{Ti}$ concentration.

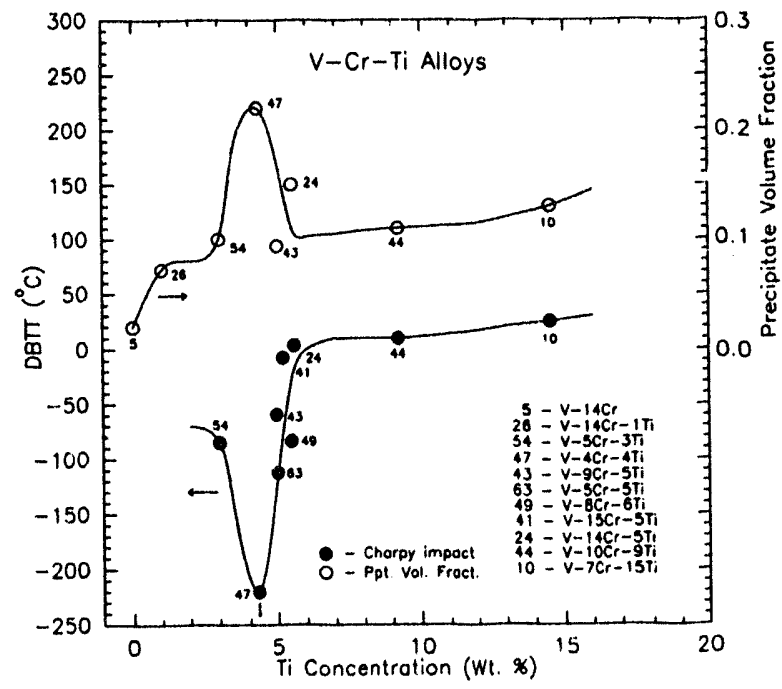

Fig. 6. Dependence of DBTT and volume fraction of precipitates in $\mathrm{V}$-Cr-Ti alloys on Ti concentration. 
0.1-0.2\% after neutron irradiation at $420-600^{\circ} \mathrm{C}$ to $24-34 \mathrm{dpa}$, and the ductility of the alloy is substantial $(10-16 \%)$ after irradiation at $420-600^{\circ} \mathrm{C}$ to $28-34 \mathrm{dpa}[1,19]$. However, the experimental DBTT data presented in this paper suggest that $\mathrm{Cr}$ and, in particular, $\mathrm{Ti}$ concentration in the $\mathrm{V}-4 \mathrm{Cr}-4 \mathrm{Ti}$ alloy should be controlled to $\pm 0.5 \mathrm{wt} . \%$ deviation from the nominal composition. It is possible that the deviation of $\mathrm{Cr}$ and $\mathrm{Ti}$ concentration could be increased to $\pm 1.0 \mathrm{wt} . \%$, which would result in an increase of creep strength, without significant impact on the DBTT by suitable heat treatment of a V-(4-5)Cr-3Ti alloy.

\section{Conclusions}

- Non-coherent precipitates contribute minimally (30-40 MPa) to the strengthening of $\mathrm{V}$ on addition of $\mathrm{Ti}$ and $\mathrm{Cr}$, whereas coherent precipitates, solute-atom misfit, and shear-modulus difference effects contribute approximately equally to the strengthening of $\mathrm{V}$ on addition of $\mathrm{Ti}$ and $\mathrm{Cr}$.

- The highest creep strength of V-Ti and V-Cr-Ti alloys is obtained for alloys containing $\sim 3 \mathrm{wt} . \% \mathrm{Ti}$ because of the highest number density of precipitates.

- The lowest $\left(<-220^{\circ} \mathrm{C}\right)$ DBTT for V-Ti alloys is obtained for V-(1-5)Ti alloys because of the presence of a minimum volume fraction of precipitates with small average diameter in these alloys.

- The lowest DBTT $\left(<-220^{\circ} \mathrm{C}\right)$ for V-Cr-Ti alloys with $>1 \mathrm{wt}$.\% Ti is obtained for the V-4Cr-4Ti alloy because of a high volume fraction of relatively large average-diameter precipitates in this alloy.

- The nominal composition of the V-4Cr-4Ti alloy should deviate $<0.5 \mathrm{wt} . \%$ to maintain the nearoptimal combination of mechanical properties.

\section{References}

[1] B. A. Loomis and D. L. Smith, J. Nucl. Mater. 191-194 (1992) 84.

[2] T. Noda, F. Abe, H. Araki and M. Okada, J. Nucl. Mater. 155-157 (1988) 581.

[3] R. Santos, J. Nucl. Mater. 155-157 (1988) 589.

[4] S. J. Piet, H. G. Kraus, R. M. Neilson, Jr. and J. L. Jones, J. Nucl. Mater. 141-143 (1986) 24.

[5] F. L. Yaggee, E. R. Gilbert, and J. W. Styles, J. Less-Comm. Met. 19 (1969) 39.

[6] D. L. Smith, B. A. Loornis and D. R. Diercks, J. Nucl. Mater. 135 (1985) 125.

[7] J. Gazda, Analytical Electron Microscopy Study of Vanadium and Vanadium-Base Alloys, Submitted in partial fulfillment of the requirements for degree of Master of Science, University of Illinois at Chicago, 1993.

[8] B. A. Loomis, L. J. Nowicki, and D. L. Smith, Fusion Reactor Materials, Semiann. Prog. Rep. DOE/ER-0313/10, Oak Ridge National Laboratory, Oak Ridge, TN (1991) p. 145.

[9] B. A. Loomis, L. J. Nowicki, and D. L. Smith, Fusion Reactor Materials, Semiann. Prog. Rep. DOE/ER-0313/13, Oak Ridge National Laboratory, Oak Ridge, TN (1992) p. 217.

[10] B. A. Loomis, L. J. Nowicki, and D. L. Smith, Fusion Reactor Materials, Semiann. Prog. Rep. DOE/ER-0313/13, Oak Ridge National Laboratory, Oak Ridge, TN (1992) p. 214.

[11] H. Böhm, in: Proceedings of Second International Conference on the Strength of Metals and Alloys, Vol. 1 (American Society of Metals, Pacific Grove, CA, 1970) 341.

[12] B. A. Loomis, L. J. Nowicki, and D. L. Smith, Fusion Reactor Materials, Semiann. Prog. Rep. DOE/ER-0313/11, Oak Ridge National Laboratory, Oak Ridge, TN (1991) p. 227.

[13] B. A. Loomis, L. J. Nowicki, J. Gazda, and D. L. Smith, Fusion Reactor Materials, Semiann. Prog. Rep. DOE/ER-0313/14, Oak Ridge National Laboratory, Oak Ridge, TN (1993).

[14] B. A. Loomis, B. J. Kestel and D. L. Smith, J. Nucl. Mater. 155-157 (1988) 1305.

[15] G. E. Dieter, Mechanical Metallurgy (McGraw-Hill Inc., New York,1986) p. 216.

[16] I. Le May, Principles of Mechanical Metallurgy (Elsavier, New York, 1981) p. 177.

[17] J. Friedel, Dislocations (Pergamon Press, New York, 1964) p. 381.

[18] J. P. Hirth and J. Lothe, Theory of Dislocations (McGraw-Hill Inc., New York, 1968) p. 626.

[19] B. A. Loomis, H. Chung, J. Gazda, L. J. Nowicki, and D. L. Smith, presented at the 6th Int. Conf. on Fusion Reactor Materials (ICFRM-6), Stresa, Lago Maggiore, Italy, 1993. 


\section{MICROSTRUCTURAL STABILITY OF V-4Cr-4Ti DURING NEUTRON IRRADIATION* \\ H. Matsui and M. Tanno (Tohoku University) and J. Gazda and H. M. Chung (Argonne National Laboratory)}

\section{OBJECTIVE}

The objective of this work is to characterize the microstructural stability of $\mathrm{V}-4 \mathrm{Cr}-4 \mathrm{Ti}$ alloy during irradiation by fast neutrons, and thereby to provide a better understanding of long-term performance of the alloy under fusion conditions.

\section{SUMMARY}

Microstructural evolution of $\mathrm{V}-4 \mathrm{Cr}-4 \mathrm{Ti}$, an alloy recently shown to exhibit excellent tensile and creep properties, virtual immunity to irradiation embrittlement, and good resistance to swelling, was characterized after irradiation in a lithium environment in the Fast Flux Test Facility (FFTF) (a sodium-cooled fast reactor located in Richland, Washington) at 420,520 , and $600^{\circ} \mathrm{C}$ to $24-34 \mathrm{dpa}$. The primary feature of microstructural evolution during irradiation at 520 and $600^{\circ} \mathrm{C}$ was high-density formation of ultrafine Tis $\mathrm{Si}_{3}$ precipitates and short dislocations. For irradiation at $420^{\circ} \mathrm{C}$, precipitation of $\mathrm{Ti}_{5} \mathrm{Si}_{3}$ was negligible, and "black-dot" defects and dislocations were observed in significantly higher densities. In spite of tieir extremely high densities, neither the "black-dot" defects nor TisSiz precipitates are overly detrimental to ductility and toughness of the alloy, yet they very effectively suppress irradiation-induced swelling. Therefore, these features, normally observed in $\mathrm{V}$-base alloys containing $\mathrm{Ti}$ and $\mathrm{Si}$, are considered stable. Unstable microstructural modifications that are likely to degrade mechanical properties significantly were not observed, e.g., irradiation-induced formation of fine oxides, carbides, nitrides, or $\mathrm{Cr}$-rich clusters.

\section{INTRODUCTION}

Vanadium-base alloys have significant advantages over other candidate alloys (such as austenitic and ferritic steels) for use as structural materials in fusion devices, e.g., in the International Thermonuclear Experimental Reactor (ITER) and in magnetic fusion reactors. These advantages include intrinsically lower levels of long-term activation, irradiation afterheat, neutron-induced helium- and hydrogen-transmutation rates, biological hazard potential, and thermal stress factor.

As part of a program to screen candidate alloys and develop an optimal alloy, extensive investigations have been conducted on the swelling behavior, tensile properties, impact toughness, and microstructural evolution of V, V-Ti, V-Cr, V-Cr-Ti, and V-Ti-Si alloys after irradiation by fast neutrons at 420,520 , and $600^{\circ} \mathrm{C}$ up to $\approx 120 \mathrm{dpa}$. From these investigations, V-Cr-Ti alloys containing $\approx 4-5 \mathrm{wt} . \% \mathrm{Cr}, 3-5 \mathrm{wt} . \% \mathrm{Ti}$, 400-1000 wt. ppm Si, and $<1000 \mathrm{wl}$. ppm O+N+C were identified as the most desirable alloys that exhibit superior resistance to swelling, embrittlement, and hydrogen-induced effects during fast-neutron irradiation in $\mathrm{Li}^{1-5}$ Of these alloys, $\mathrm{V}-4 \mathrm{Cr}-4 \mathrm{Ti}$ has been shown recently to exhibit the most attractive combination of mechanical properties, ${ }^{6-12}$ i.e., tensile properties, ${ }^{7}$ impact energy, ${ }^{8,11}$ and ductile-brittle-transition temperature (DBTT) before ${ }^{6,11}$ and after irradiation ${ }^{8}$ in the FFTF. In these investigations, it was shown that $\mathrm{V}-4 \mathrm{Cr}-4 \mathrm{Ti}$ is virtually immune to irradiation-induced embrittlement, a property very remarkable for a body-centered-cubic or hexagonal-close-packed alloy. Thermal creep behavior of $\mathrm{V}-4 \mathrm{Cr}-4 \mathrm{Ti}$ has also been reported to be superior to that of austenitic and ferritic steels, ${ }^{10}$ and resistance of the alloy to irradiation-induced density change was also reported to be very good. ${ }^{9}$

In view of the excellent performance of the $\mathrm{V}-4 \mathrm{Cr}-4 \mathrm{Ti}$ alloy during fission-neutron irradiation, it was considered important that we understand the nature of the irradiation-induced microstructural evolution and

\footnotetext{
* Work supported by the Office of Fusion Energy, U.S. Department of Energy, under Contract W-31-109-Eng-38.
} 
thereby provide a sound basis for predicting the alloy performance during irradiation under fusion-neutron conditions to higher damage levels. Therefore, microstructural evolution of the alloy was investigated in this work after irradiation at $420-600^{\circ} \mathrm{C}$ up to $34 \mathrm{dpa}$ under the fission-neutron spectrum of the FFTF.

\section{MATERIALS AND PROCEDURES}

The elemental composition of the V-4Cr-4Ti alloy is given in Table 1. Microstructural characterization of the alloy was conducted on standard transmission electron microscopy (TEM) disks after irradiation in the FFTF. TEM disks were irradiated at 420,520 , and $600^{\circ} \mathrm{C}$ to neutron fluences $(\mathrm{E}>0.1 \mathrm{MeV})$ of $6.0 \times 10^{22}$ $\mathrm{n} \cdot \mathrm{cm}^{-2}(\approx 34 \mathrm{dpa}), 4.3 \times 10^{22} \mathrm{n} \cdot \mathrm{cm}^{-2}(\approx 24 \mathrm{dpa})$, and $5.0 \times 10^{22} \mathrm{n} \cdot \mathrm{cm}^{-2}(\approx 28 \mathrm{dpa})$, respectively. The disks werre seạled in TZM capsules filled with $99.99 \%$-enriched ${ }^{7} \mathrm{Li}$ during irradiation to prevent contamination with $\mathrm{O}, \mathrm{N}$, and $\mathrm{C}$ impurities dissolved in the $\mathrm{Na}$ coolant of the FFTF and formation of unacceptable levels of $\mathrm{He}$ and tritium from transmutation of ${ }^{6} \mathrm{Li}$.

After irradiation, the specimens were thoroughly cleaned of $\mathrm{Li}$ and annealed at $400^{\circ} \mathrm{C}$ for $1 \mathrm{~h}$ in a vacuum of $2.6 \times 10^{-7} \mathrm{~Pa}$ to expel residual $\mathrm{H}$ and tritium. The irradiated specimens were jet-thinned in a solution of $15 \%$ sulfuric acid- $72 \%$ methanol- $13 \%$ butyl cellosolve maintained at $-5^{\circ} \mathrm{C}$. TEM was conducter with a JEOL $100 \mathrm{CX}-\mathrm{II}$ scanning transmission electron microscope operating at $100 \mathrm{keV}$ or with a Philips CM-30T transmission electron microscope operating at $200 \mathrm{keV}$.

Table 1. Elemental composition and irradiation conditions of V-4Cr-4Ti alloy (ANL ID BL-47) in FFTF

\begin{tabular}{cccccccccc}
\hline $\begin{array}{c}\mathrm{Cr} \\
(\mathrm{wt} . \%)\end{array}$ & $\begin{array}{c}\mathrm{Ti} \\
(\mathrm{wt} . \%)\end{array}$ & $\begin{array}{c}\mathrm{O} \\
(\mathrm{wppm})\end{array}$ & $\begin{array}{c}\mathrm{N} \\
(\mathrm{wppm})\end{array}$ & $\begin{array}{c}\mathrm{C} \\
(\mathrm{wppm})\end{array}$ & $\begin{array}{c}\mathrm{Si} \\
(\mathrm{wppm})\end{array}$ & $\begin{array}{c}\text { DBTT before } \\
\text { imradiation }\left({ }^{\circ} \mathrm{C}\right)\end{array}$ & $\begin{array}{c}\text { Irradiation } \\
\text { temperature }\left({ }^{\circ} \mathrm{C}\right)\end{array}$ & $\begin{array}{c}\text { Damage level } \\
(\mathrm{dpp})\end{array}$ & $\begin{array}{c}\text { DBTT after } \\
\text { irradiation }\left({ }^{\circ} \mathrm{C}\right)\end{array}$ \\
\hline 4.1 & 4.3 & 350 & 220 & 200 & 870 & $<-190$ & 420 & 34 & $<-190$ \\
- & - & - & - & - & - & - & 520 & 24 & $<-190$ \\
- & - & - & - & - & - & - & 600 & 28 & $<-190$ \\
\hline
\end{tabular}

\section{MICROSTRUCTURAL EVOLUTION}

\section{Structure of Unirradiated Material}

An ingot of $\mathrm{V}-4 \mathrm{Cr}-4 \mathrm{Ti}$ was produced by vacuum arc melting. The ingot was extruded at $1150^{\circ} \mathrm{C}$, followed by several repeated steps of rolling (at $400^{\circ} \mathrm{C}$ ) and annealing (at $1100^{\circ} \mathrm{C}$ ) to produce sheets 3.80 and $0.89 \mathrm{~mm}$ thick. ${ }^{12}$ These sheets were then annealed and recrystallized at $1125^{\circ} \mathrm{C}$ for $1 \mathrm{~h}$ in a vacuum of $2.6 \times 10^{-7} \mathrm{~Pa}$ before they were machined into TEM disks and tensile specimens. Subsequently, the specimens were encapsulated for irradiation. A typical TEM microstructure of the alloy after the final anneal at $1125^{\circ} \mathrm{C}$ is shown in Fig. 1. In the figure, Ti(O,N,C) precipitates, $200-600 \mathrm{~nm}$ in size, were observed in a number density of $\approx 3 \times 10^{18} \mathrm{~m}^{-3}$ and a volume fraction of $\approx 10 \%$. The Ti $(O, N, C)$ phase has been observed to precipitate in most of the $\mathrm{V}$-base alloys containing $\mathrm{Ti}$ during ingot melting and solidification. ${ }^{4,13} \mathrm{~A}$ few titanium phosphide precipitates in the form of $\mathrm{Ti}_{5} \mathrm{P}_{3}$ (hcp structure, $\mathrm{a}_{\mathrm{o}}=0.7234 \mathrm{~nm}, \mathrm{c}_{\mathrm{o}}=0.5090 \mathrm{~nm}$ ) were also observed in a number density approximately one order of magnitude lower than that of the Ti(O,N,C). The phosphides, shaped as stretched ellipsoids, were $\approx 200-400 \mathrm{~nm}$ thick and $400-800 \mathrm{~nm}$ long (see Fig. 2).

\section{Specimens Irradiated at $600^{\circ} \mathrm{C}$}

An example of typical microstructures of specimens irradiated at $600^{\circ} \mathrm{C}$ is shown in Fig. 2. In the bright-field micrograph of Fig. 2A, images of nearly spherical Ti(O,N,C), large elongated-ellipsoid-shaped $\mathrm{Ti}_{5} \mathrm{P}_{3}$ (denoted " $\mathrm{P}$ "), dislocation loops, and short dislocations are visible. In addition to these features, ultrafine precipitates $\approx 1 \mathrm{~nm}$ thick and $2-10 \mathrm{~nm}$ long are visible in high density. From dark-field imaging and indexing of selected-area diffraction (SAD) patterns, these fine precipitates were identified as $\mathrm{Ti}_{5} \mathrm{Si}_{3}$ (hcp structure, 
$\left.\mathrm{a}_{0}=0.7463 \mathrm{~nm}, \mathrm{c}_{\mathrm{o}}=0.5165 \mathrm{~nm}\right) .{ }^{4}$ A dark-field image produced with (210) reflection of the titanium silicide is shown in Fig. 2B. In previous investigations, good resistance to swelling of $\mathrm{V}$ - $\mathrm{Ti}$ and $\mathrm{V}-\mathrm{Cr}-\mathrm{Ti}$ alloys was attributed to dense precipitation of $\mathrm{Ti}_{5} \mathrm{Si}_{3} .3,4$

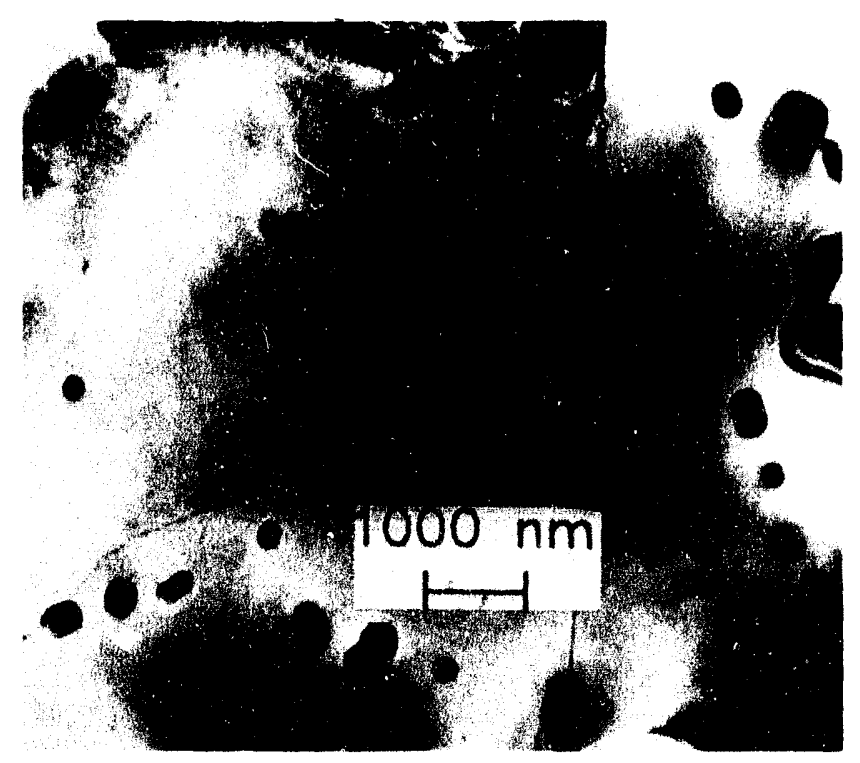

Figure 1. TEM microstructure of unirradiated $V-4 C r-4 T i$ showing a normal distribution of $T i(O, N, C)$

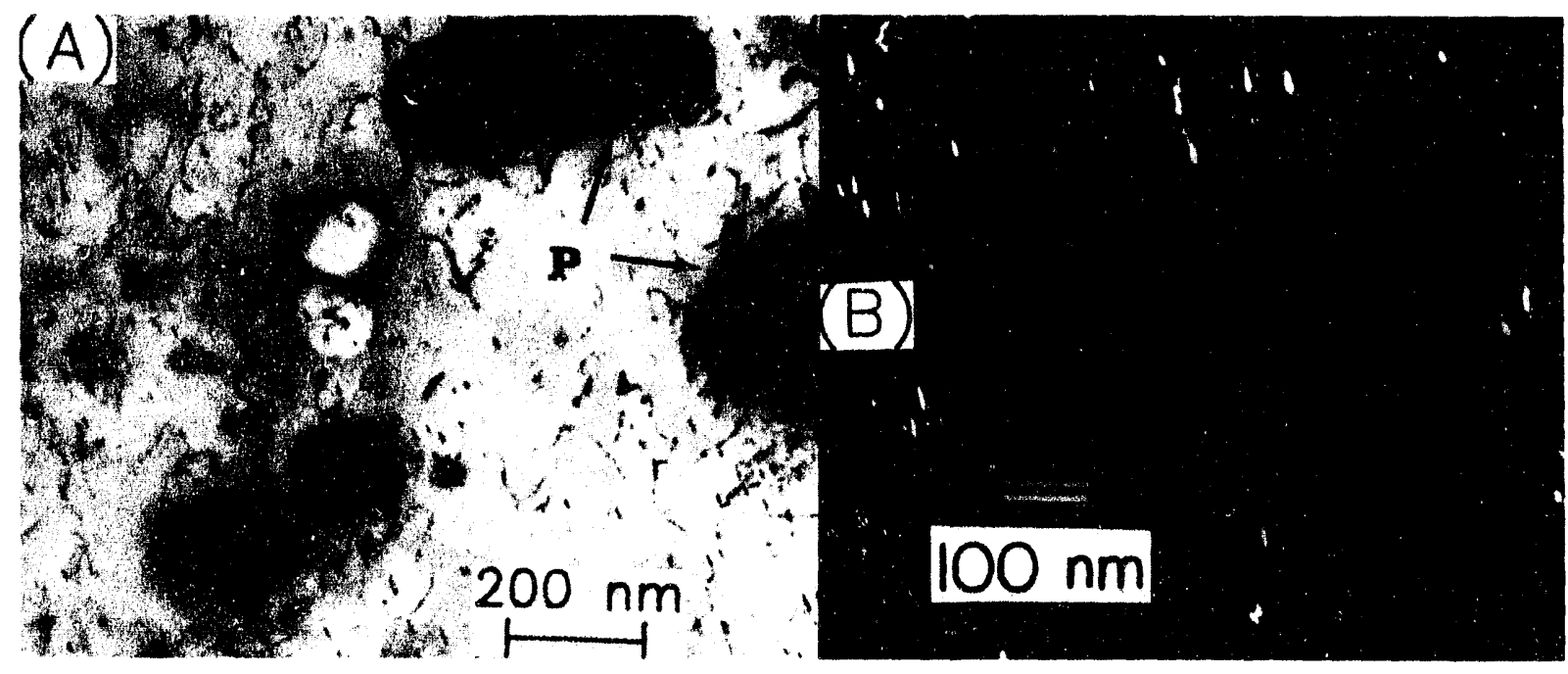

Figure 2. Microstructure of $\mathrm{V}-4 \mathrm{Cr}-4 \mathrm{Ti}$ irradiated at $600^{\circ} \mathrm{C}$ to $\approx 28 \mathrm{dpa} ;(A)$ bright-field image of large $T i(O, N, C)$ and $T i_{5} P_{3}$ (denoted "P"), dislocation loops, short dislocations, and ultrafine $\mathrm{Ti}_{5} \mathrm{Si}_{3}$ in high density; $(B)$ dark-field image produced with (210) reflection of TisSi3

The average size of the $\mathrm{Ti}(\mathrm{O}, \mathrm{N}, \mathrm{C})$ precipitates in the irradiated material (Fig. 2A) was considerably smaller than that of unirradiated material (Fig. 1), i.e., $\approx 130 \mathrm{~nm}$ vs. $\approx 250 \mathrm{~nm}$. This is probably because of transfer of $\mathrm{O}$ atoms from the $\mathrm{V}$-alloy matrix to $\mathrm{Li}$ during irradiation, which, consequently, resulted in partial dissolution of $\mathrm{Ti}(\mathrm{O}, \mathrm{N}, \mathrm{C})$ precipitates. 


\section{Specimens Irradiated at $520^{\circ} \mathrm{C}$}

Microstructures of the specimens irradiated at $520^{\circ} \mathrm{C}$ were similar to those of specimens irradiated at $600^{\circ} \mathrm{C}$. Examples of bright- and dark-field images of the alloy irradiated at $520^{\circ} \mathrm{C}$ to $\approx 24 \mathrm{dpa}$ are shown in Figs. $3 \mathrm{~A}$ and $3 \mathrm{~B}$, respectively. The density of short dislocations was higher in this material than in the specimens irradiated at $600^{\circ} \mathrm{C}$. The precipitation behavior of $\mathrm{Ti}_{5} \mathrm{Si}_{3}$ at both 600 and $520^{\circ} \mathrm{C}$ seemed to be similar, although size was somewhat smaller after irradiation at $520^{\circ} \mathrm{C}$ (Fig. 3B). The dark-field micrograph (Fig. 3B), produced with (110) reflection of V (d-spacing $0.218 \mathrm{~nm}$ ) superimposed on (300) reflection of Ti5Si3 (d-spacing $0.215 \mathrm{~nm}$ ), shows images of short line dislocations, Ti5Si3 precipitates, and "black-dot" defects (clusters of vacancy or interstitial defects) $<1 \mathrm{~nm}$ in size. Although care must be exercised to discern "blackdot" defects (spherical dots) and TisSi3 precipitates (small platelets), the density of "black-dot" defects seems to be higher in specimens irradiated at $520^{\circ} \mathrm{C}$ (Fig. 3A) than in specimens irradiated at $600^{\circ} \mathrm{C}$ (Fig. 2A).

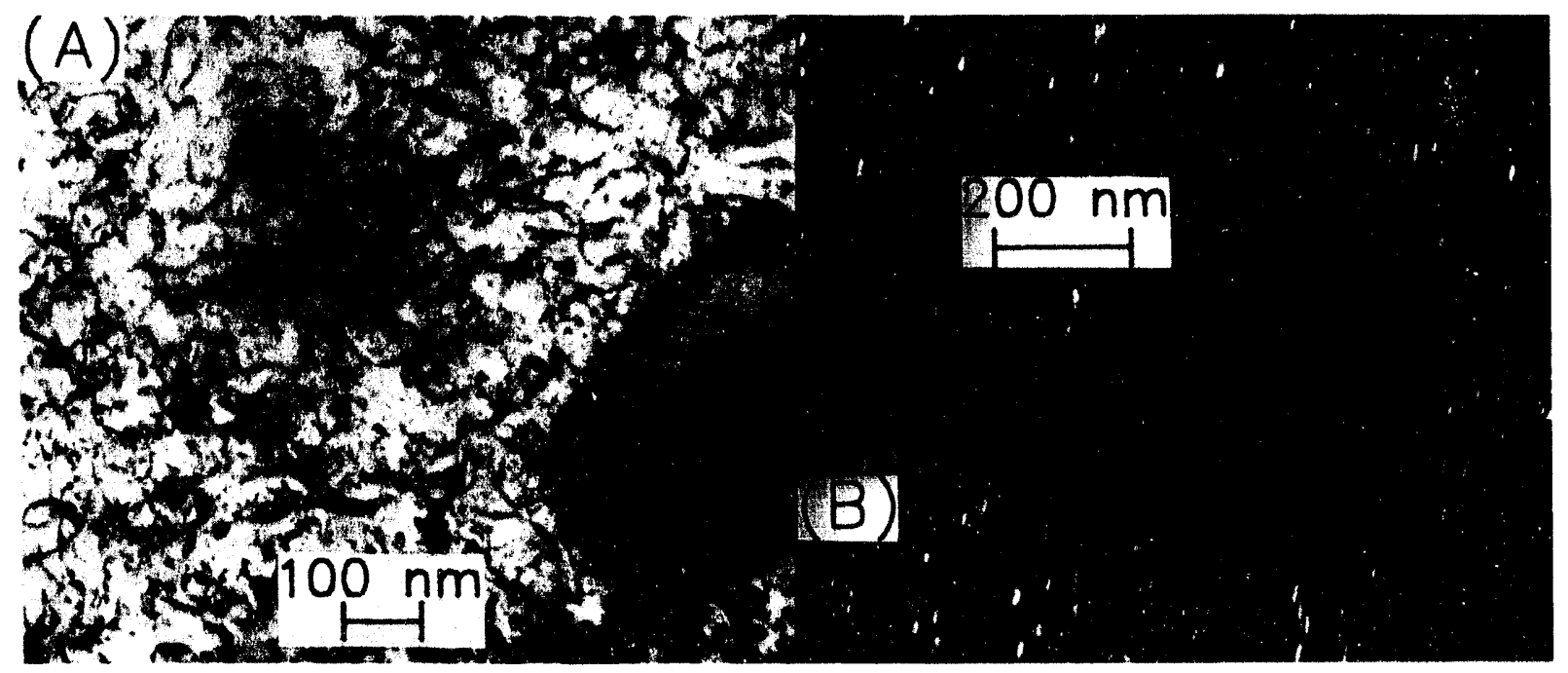

Figure 3. Microstructure of $\mathrm{V}-4 \mathrm{Cr}-4 \mathrm{Ti}$ irradiated at $520^{\circ} \mathrm{C}$ to $\approx 24 \mathrm{dpa}$; (A) bright-field image of large Ti $(O, N, C)$, "black-dot" defects, short dislocations, and TisSi3 in high density; $(B)$ dark-field image of dislocations and TisSiz produced with (110) reflection of $V$ superimposed on (300) reflection of $\mathrm{Ti}_{5} \mathrm{Si}_{3}$

\section{Specimens Irradiated at $420^{\circ} \mathrm{C}$}

Examples of typical microstructures of specimens irradiated at $420^{\circ} \mathrm{C}$ to $\approx 34$ dpa are shown in Fig. 4. In the low-magnification micrograph (Fig. 4A), the overall grain size and phase structure are shown. In this micrograph, most of the $\mathrm{Ti}(\mathrm{O}, \mathrm{N}, \mathrm{C})$ precipitates $100-200 \mathrm{~nm}$ in size are surrounded by concentric shells of distinct contrast, indicating that larger original $\mathrm{Ti}(\mathrm{O}, \mathrm{N}, \mathrm{C})$ precipitates, $200-500 \mathrm{~nm}$ in size, dissolved partially in the matrix during the irradiation in $\mathrm{Li}$. This feature is visible more clearly in the high-magnification micrograph of Fig. 4B.

High-magnification micrographs, such as Fig. 4B, were characterized by "black-dot" defects in extremely high density. This is shown in a more direct manner in the dark-field image, Fig. 4C. The image, produced with (110) reflection of the $\mathrm{V}$ matrix superimposed on the (300) reflection of a $\mathrm{Ti}_{5} \mathrm{P}_{3}$ precipitate, shows line dislocations, as well as "black-dot" defects, concentrated in higher density around a Tis $\mathrm{P}_{3}$ precipitate. However, in contrast to irradiation at 520 and $600^{\circ} \mathrm{C}$, no cvidence of irradiation-induced precipitation of the $\mathrm{Ti}_{5} \mathrm{Si}_{3}$ phase was observed at $420^{\circ} \mathrm{C}$. The density of dislocation loops was also negligible at this temperature. 


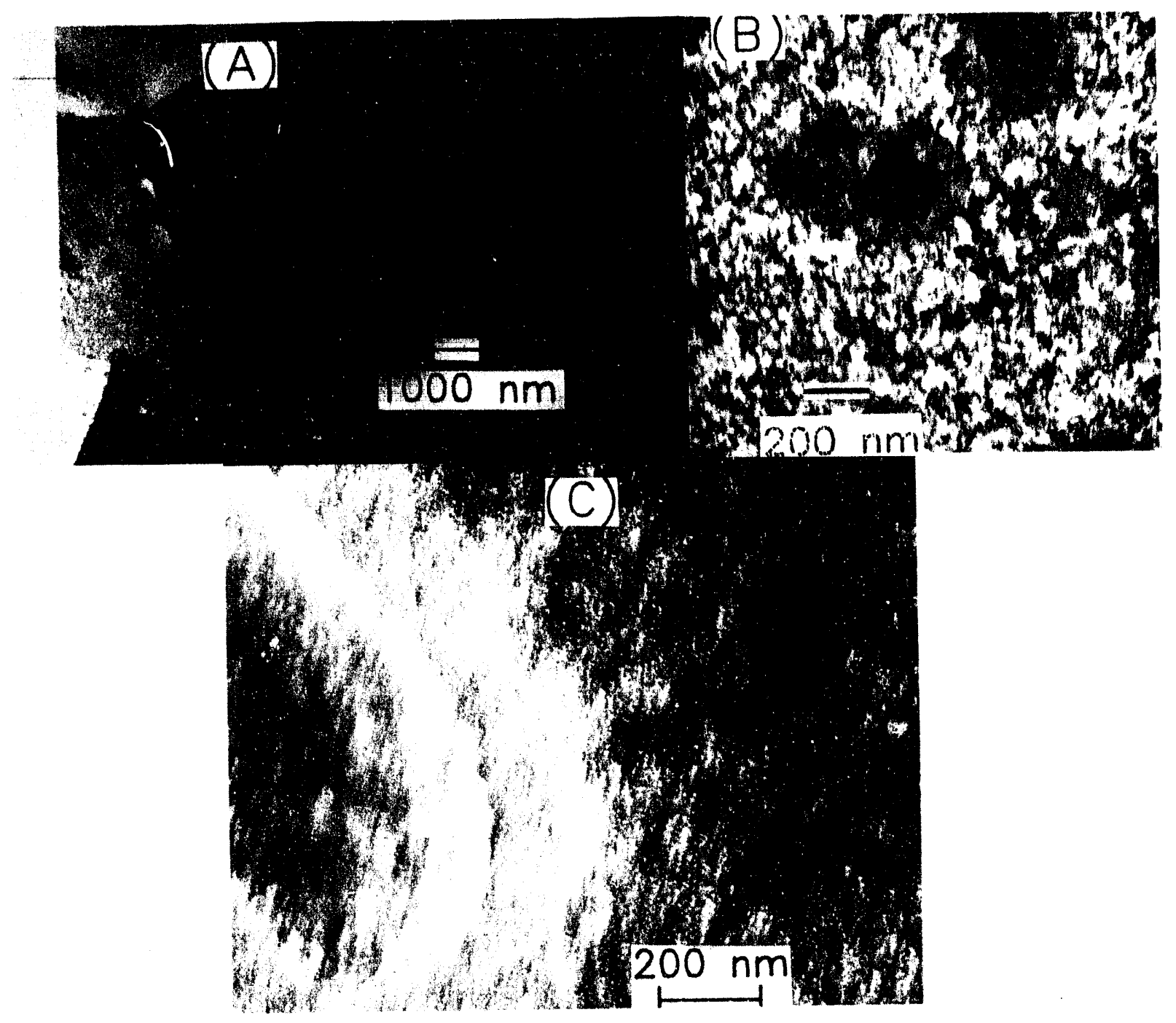

Figure 4. Microstructure of V-4Cr-4Ti irradiated at $420^{\circ} \mathrm{C}$ to $\approx 34 \mathrm{dpa}$; (A) lowmagnification bright-field image showing size and distribution of $\operatorname{Ti}(O, N, C)$; $(B)$ higher-magnification of $(A)$ showing distinct darker contrast surrounding $\mathrm{Ti}(O, N, C)$; and $(C)$ dark-field image of dislocations and "black-dot" defects in higher density, surrounding a large $\mathrm{Tis}_{3} P_{3}$ precipitate

\section{DISCUSSION}

In view of the results from previous investigations on irradiation-induced microstructural evolution of V-Ti, V-Cr-Ti, and V-3Ti-1Si alloys, ${ }^{4,6,15}$ no surprising microstructural features were found in $\mathrm{V}-4 \mathrm{Cr}-4 \mathrm{Ti}$ after irradiation at $420-600^{\circ} \mathrm{C}$ up to $34 \mathrm{dpa}$. The characteristic partial dissolution of $\mathrm{Ti}(\mathrm{O}, \mathrm{N}, \mathrm{C})$ precipitates, precipitates normally present in as-fabricated alloys in significant number density, is apparently due to $\mathrm{O}$ transfer from the matrix to $\mathrm{Li}$ during irradiation. Any effect of this process on the reduction of alloy strength seems to have been more than compensated for by the hardening effect of displacement damage.

Precipitation of the ultrafine $\mathrm{Ti}_{5} \mathrm{Si}_{3}$ precipitates was observed, as expected, after irradiation at 520 and $600^{\circ} \mathrm{C}$. However, in contrast to V-20Ti, in which high-density $\mathrm{Ti}_{5} \mathrm{Si}_{3}$ precipitated during irradiation at $420^{\circ} \mathrm{C}$ 
to $\approx 114 \mathrm{dpa},{ }^{15}$ no precipitation of $\mathrm{Ti}_{5} \mathrm{Si}_{3}$ was observed in $\mathrm{V}-4 \mathrm{Cr}-4 \mathrm{Ti}$ after irradiation at the same temperature to $\approx 34 \mathrm{dpa}$. In a similar recrystallized material of $\mathrm{V}-5 \mathrm{Cr}-5 \mathrm{Ti}$ alloy doped with $\mathrm{Si}, \mathrm{Al}$, and $\mathrm{Y}$, precipitation of $\mathrm{Ti}_{5} \mathrm{Si}_{3}$ was reported to be negligible after irradiation at $406^{\circ} \mathrm{C}$ to $\approx 51 \mathrm{dpa}$ but significant after irradiation at $600^{\circ} \mathrm{C}$ to $31 \mathrm{dpa} .{ }^{14}$ In view of these observations, it is not quite clear if the absence of $\mathrm{Ti}_{5} \mathrm{Si}_{3}$ precipitates in the present $\mathrm{V}-4 \mathrm{Cr}-4 \mathrm{Ti}$ is due to the lower dose or to inherently slower kinetics of precipitation in $\mathrm{V}-(4-5) \mathrm{Cr}-(4-5) \mathrm{Ti}$ alloys than in V-20Ti. On the other hand, one cannot rule out the possibility that clusters of $\mathrm{Ti}$ and $\mathrm{Si}$ atoms, precursors of $\mathrm{Ti}_{5} \mathrm{Si}_{3}$, formed in the $\mathrm{V}-4 \mathrm{Cr}-4 \mathrm{Ti}$ and $\mathrm{V}-5 \mathrm{Cr}-5 \mathrm{Ti}$ alloys during the lowtemperature irradiation, most likely in association with "black-dot" defects. Such clusters would be too small to be detected by TEM.

Similar to V-4Cr-4Ti irradiated at $420^{\circ} \mathrm{C}$, the V-5Cr-5Ti-1Si-1 Al- $1 \mathrm{Y}$ alloy irradiated at $406^{\circ} \mathrm{C}$ contained "black-dot" defects in extremely high density. In spite of the negligible precipitation of Ti5Si3, swelling both in $\mathrm{V}-4 \mathrm{Cr}-4 \mathrm{Ti}^{9}$ and $\mathrm{V}-5 \mathrm{Cr}-5 \mathrm{Ti}-1 \mathrm{Si}-1 \mathrm{Al}-1 \mathrm{Y}^{16,17}$ was negligible after irradiation at $406-420^{\circ} \mathrm{C}$ to $34-40 \mathrm{dpa}$. This indicates that high-density precipitation of ultrafine TisSi3 produces good resistance to swelling, but it is not necessarily the only condition that is conducive to low swelling.

Despite the formation of ultrafine "black-dot" damage and/or TisSi3 precipitates in high density, Charpy impact and tensile specimens irradiated under the three irradiation conditions exhibited excellent toughness (DBTT $<-190^{\circ} \mathrm{C}$ and Charpy energy $\left.\approx 140 \mathrm{~J} / \mathrm{cm}^{2}\right)^{8}$ and tensile ductility (uniform and total elongation $\approx 8$ and $\approx 10 \%$, respectiv iy, at $25^{\circ} \mathrm{C}$ ). ${ }^{7}$ Comparable tensile properties (total elongation of $8-16 \%$ at $25^{\circ} \mathrm{C}$ ) have been reported for the V-5Cr-5Ti-1Si-1 Al-1Y alloy, which exhibited similar microstructures characterized by highdensity "black-dot" damage and $\mathrm{Ti}_{5} \mathrm{Si}_{3}$ precipitates. ${ }^{18}$ Based on these observations, it is concluded that neither the high-density "black-dot" defects nor $\mathrm{Ti}_{5} \mathrm{Si}_{3}$ precipitates are overly detrimental, and a sufficient level of ductility and toughness is retained in V-(4-5)Cr-(4-5)Ti-type alloys. .

\section{CONCLUSIONS}

1. Microstructural evolution of $\mathrm{V}-4 \mathrm{Cr}-4 \mathrm{Ti}$ alloy was characterized after irradiation in a lithium environment in FFTF at 420,520 , and $600^{\circ} \mathrm{C}$ to $24-34$ dpa. Thermally formed $\mathrm{Ti}(\mathrm{O}, \mathrm{N}, \mathrm{C})$ precipitates were found to dissolve partially in the matrix, probably because of oxygen transfer from the alloy to Li during irradiation.

2. The primary feature of microstructural evolution during irradiation at 520 and $600^{\circ} \mathrm{C}$ is high-density formation of ultrafine $\mathrm{Ti}_{5} \mathrm{Si}_{3}$ precipitates and short dislocations. For irradiation at $420^{\circ} \mathrm{C}$, precipitation of $\mathrm{Ti}_{5} \mathrm{Si}_{3}$ was negligible, and "black-dot" defects and dislocations were observed in significantly higher density.

3. In spite of their extremely high densities, neither the high-density "black-dot" defects nor the Ti5Si3 precipitates are sufficiently detrimental to significantly degrade material ductility and toughness, yet they effectively suppress irradiation-induced swelling. Therefore, these features of microstructural evolution are considered stable. No unstable microstructural modifications that are likely to degrade mechanical properties significantly were observed in $\mathrm{V}-4 \mathrm{Cr}-4 \mathrm{Ti}$, e.g., irradiation-induced formation of fine oxides, carbides, nitrides, or $\mathrm{Cr}$-rich clusters.

4. Void formation was negligible in $\mathrm{V}-4 \mathrm{Cr}-4 \mathrm{Ti}$ for all the irradiated conditions.

\section{FUTURE WORK}

Microstructure of $\mathrm{V}-4 \mathrm{Cr}-4 \mathrm{Ti}$ specimens irradiated at 420,520 , and $600^{\circ} \mathrm{C}$ in the Dynamic Helium Charging Experiment (DHCE) will be characterized to determine the effects of dynamically charged helium. 


\section{ACKNOWLEDGMENTS}

The authors are grateful to L. J. Nowicki for his contributions to the preparation of the irradiated specimens, and to B. A. Loomis for many helpful discussions.

\section{REFERENCES}

1. B. A. Loomis, A. B. Hull, and D. L. Smith, J. Nucl. Mater., 179-181 (1991) 148-154.

2. B. A. Loomis and D. L. Smith, J. Nucl. Mater., 191-194 (1992) 84-91.

3. H. M. Chung and D. L. Smith, J. Nucl. Mater. ibid., 942-947.

4. H. M. Chung, B. A. Loomis, and D. L. Smith, "Irradiation-Induced Precipitation in Vanadium-Base Alloys Containing Titanium," Effects of Radiation on Materials: 16th International Symposium, ASTM STP 1175, A. S. Kumar, D. S. Gelles, R. K. Nanstad, and T. A. Little, eds., American Society for Testing and Materials, Philadelphia, 1993.

5. D. L. Smith, B. A. Loomis, and H. M. Chung, "Effects of Neutron Irradiation on Vanadium-Base Alloys," Plasma Devices and Operations, Vol. 3, 1993, in press.

6. B. A. Loomis, J. Gazda, L. J. Nowicki, and D. L. Smith, "Relationship of Microstructure and Mechanical Properties for V-Cr-Ti Alloys," this report, also presented at the Sixth Intl. Conf. on Fusion Reactor Materials, Sept. 27-Oct. 1, 1993, Stresa, Italy.

7. B. A. Loomis, L. J. Nowicki, and D. L. Smith, "Effects of Neutron Irradiation on Tensile Properties of V-Cr-Ti Alloys," ibid.

8. B. A. Loomis, H. M. Chung, L. J. Nowicki, and D. L. Smith, "Effects of Neutron Irradiation and Hydrogen on Ductile-Brittle Transition Temperatures of V-Cr-Ti Alloys," ibid.

9. H. M. Chung, B. A. Loomis, L. J. Nowicki, J. Gazda, and D. L. Smith, "Irradiation-Induced Density Change and Microstructural Evolution of Vanadium-Base Alloys," ibid.

10. H. M. Chung, B. A. Loomis, L. J. Nowicki, and D. L. Smith, "Thermal Creep Behavior of V-5Cr-5Ti and V-10Cr-5Ti Alloys," Fusion Reactor Materials Semiannual Progress Report for Period Ending March 31, 1993, DOE/ER-0313/14, Oak Ridge National Laboratory, Oak Ridge, TN, pp. 309-317.

11. B. A. Loomis, L. J. Nowicki, J. Gazda, and D. L. Smith, "Ductile-Britile Transition Temperatures of Unirradiated Vanadium Alloys Based on Charpy-Impact Testing," ibid., pp. 318-325.

12. H. M. Chung, L. J. Nowicki, J. E. Sanecki, J. Gazda, and D. L. Smith, "Effects of Fabrication Variables on the Impact Properties and Microstructure of V-Cr-Ti Alloys," this report.

13. T. Schober and D. N. Braski, Met. Trans. 20A (1989) 1927-1932.

14. M. Satou and H. M. Chung, in Fusion Reactor Materials Semiannual Progress Report for Period Ending September 30, 1992, DOE/ER-0313/13, Oak Ridge National Laboratory, Oak Ridge, TN, (1993) pp. 227-234.

15. H. M. Chung "Effects of Irradiation-Induced Precipitation on Properties of Vanadium Alloys," ibid., pp. 194-202.

16. M. Satou, K. Abe, and H. Matsui, J. Nucl. Mater. 191-194 (1992) 938-941.

17. M. Satou, K. Abe, H. Kayano, and H. Takahashi, J. Nucl. Mater. 191-194 (1992) 956-959.

18. M. Satou, K. Abe, and H. Kayano, "Tensile Properties and Microstructures of Neutron Irradiated V-Cr-T-Si Type Alloys," paper presented at the 6th Intl. Conf. on Fusion Reactor Materials, Sept. 27-Oct. 1, 1993, Stresa, Italy. 
STATUS OF THE DYNAMIC HELIUM CHARGING EXPERIMENT (DHCE) H. Tsai, H. M. Chung, B. A. Loomis, and D. L. Smith (Argonne National Laboratory)

\section{OBJECTIVE}

The objective of this experiment is to investigate the effects of concurrent helium production and fast-neutron irradiation on the physical and mechanical properties of vanadium-base alloys. The measured properties will be compared with those of sibling samples irradiated under fast-neutron-fluence only, to isolate the helium effects.

\section{SUMMARY}

Irradiation of the seven DHCE capsules was completed in MOTA-2B at the end of FFTF Cycle 12B. The accrued exposure was 203.3 effective full power days (EFPDs) and the peak damage in the samples was $\approx 23$ dpa. All seven capsules have been discharged from the FFTF and shipped to ANL-East. Procedures have been developed to disassemble the tritium-containing capsules to retrieve the specimens for examination and testing.

\section{PROGRESS AND STATUS}

\section{Introduction}

Helium generation by $(n, \alpha)$ reactions in vanadium-based structural materials in fusion reactors may affect the physical and mechanical properties of the materials. To study these effects, it is important that the prototypical rates of helium generation be achieved in specimens during the irradiation testing. In the FFTF, because of the fission neutron spectrum, the rate of helium production in vanadium is normally low, i.e., $\approx 0.02 \mathrm{appm} / \mathrm{dpa}$. The production rate in fusion reactors, on the other hand, is much higher $(\approx 5 \mathrm{appm} / \mathrm{dpa})$ due to the higherenergy $14 \mathrm{MeV}$ fusion neutrons. The objective of the DHCE in the FFTF is to enhance helium production by in-situ decay of tritium, which is generated in the capsule's lithium bond and subsequently diffuses into the vanadium alloy samples. A detailed description of the DHCE capsules is provided in Refs. 1 and 2.

\section{Test Matrix}

Seven capsules containing tensile specimens and transmission electron microscope (TEM) disks were built and irradiated. The test matrix is shown in Table 1, and detailed listing of specimens is provided in Ref. 1. So that helium generation starts immediately after reactor startup, each capsule was precharged with a controlled amount of tritium contained in a tritiated vanadium foil. The ${ }^{6} \mathrm{Li}$ content in the lithium bond in each capsule was adjusted to maintain a near-constant rate of tritium influx into the samples during irradiation.

\section{Irradiation History}

The MOTA-2B DHCE was irradiated in two FFTF cycles (12A and 12B) for a total exposure of 203.3 EFPDs. Two capsules (4D1 and 4D2) located at Level 4 in FFTF/MOTA, attained a peak fluence of $\approx 6.4 \times 10^{22}$ $\mathrm{n} \cdot \mathrm{cm}^{-2}$ and a damage of $\approx 24 \mathrm{dpa}$ in vanadium. The other five capsules $(5 \mathrm{C} 1,5 \mathrm{C} 2,5 \mathrm{D} 1,5 \mathrm{E} 1$ and $5 \mathrm{E} 2)$ were located in Level 5 and attained fluence and damage of $3.7 \times 10^{22} \mathrm{n} \cdot \mathrm{cm}^{-2}$ and $13 \mathrm{dpa}$, respectively. A summary of irradiation conditions for the capsules is provided in Table 2.

\section{Status on Capsule Disassembly}

All seven DHCE capsules have been discharged from the MOTA-2B vehicle and shipped to ANL-East for capsule disassembly and specimen retrieval. A major effort in this reporting period was the design and

\footnotetext{
"Work supported by the Office of Fusion Energy, U.S. Department of Energy, under Contract W-31-109-Eng-38.
} 
Table 1. MOTA-2B DHCE Test Matrix

\begin{tabular}{|c|c|c|c|c|c|c|c|c|}
\hline \multirow[b]{3}{*}{ Capsule } & \multirow{3}{*}{$\begin{array}{c}\text { Irradiation } \\
\text { Temperature } \\
\left({ }^{\circ} \mathrm{C}\right) \\
\end{array}$} & \multirow{3}{*}{$\begin{array}{c}\text { Initial } \\
\text { Tritium } \\
\text { (Ci) }\end{array}$} & \multirow{3}{*}{$\begin{array}{c}{ }^{6} \mathrm{Li}^{\mathrm{a}} \\
\text { Fraction } \\
(\%)\end{array}$} & \multicolumn{4}{|c|}{ Number of Specimens $b$} & \multirow{3}{*}{$\begin{array}{c}\text { Total } \\
\text { Specimen } \\
\text { Mass (g) }\end{array}$} \\
\hline & & & & \multicolumn{2}{|c|}{ Japan } & \multicolumn{2}{|c|}{ U.S. } & \\
\hline & & & & $\mathrm{TS}(\mathrm{S})$ & D3 & SS3 & TEM & \\
\hline 4D1 & 425 & 99 & 5.0 & 24 & 94 & 8 & 45 & 5.86 \\
\hline 4D2 & 425 & 70 & 4.5 & 16 & 96 & 8 & 44 & 5.38 \\
\hline $5 E 2$ & 425 & 26 & 1.0 & 16 & 100 & 8 & 42 & 5.38 \\
\hline 5D1 & 500 & 74 & 6.5 & 23 & 94 & 8 & 42 & 5.77 \\
\hline $5 E 1$ & 500 & 57 & 1.0 & 24 & 102 & 8 & 43 & 5.82 \\
\hline $5 \mathrm{C} 1$ & 600 & 16 & 8.0 & 24 & 93 & 8 & 45 & 5.82 \\
\hline $5 C_{2}$ & 600 & 18 & 8.0 & 24 & 108 & 8 & 45 & 5.95 \\
\hline
\end{tabular}

Atomic ratio of ${ }^{6} \mathrm{Li}$ to total lithium.

bTS(S) and SS3 are tensile specimens; D3 and TEM are TEM disks.

'Does not include tritiated vanadium foil.

Table 2. Preliminary Calculated Conditions for DHCE Irradiation (203.3 EFPDs)

\begin{tabular}{lccccc}
\hline Capsule & $\begin{array}{c}\text { Imadiation } \\
\text { Temperature } \\
\left({ }^{\circ} \mathrm{C}\right)\end{array}$ & $\begin{array}{c}\text { Plenum } \\
\text { Volume } \\
(\mathrm{mL})\end{array}$ & $\begin{array}{c}\text { Fast Fluence } \\
\left(\times 10^{22} \mathrm{n} \cdot \mathrm{cm}^{-2}\right)\end{array}$ & $\begin{array}{c}\text { Damage } \\
(\mathrm{dpa})\end{array}$ & $\begin{array}{c}\text { He(appm)/dpa, } \\
\text { End of Irradiation } \\
(3 / 92)\end{array}$ \\
\hline 4D1 & 425 & 2.85 & 5.3 & 29 & $3.8-23.2$ \\
4D2 & 425 & 2.93 & 5.3 & 29 & $2.8-17.4$ \\
$5 \mathrm{SE} 2$ & 425 & 3.11 & 2.9 & 15 & $2.1-12.5$ \\
SD1 & 500 & 2.53 & 2.9 & 15 & $4.4-29.0$ \\
5E1 & 500 & 2.49 & 2.9 & 15 & $3.1-20.2$ \\
$5 \mathrm{SC} 1$ & 600 & 2.77 & 2.9 & 15 & $1.1-6.7$ \\
$5 \mathrm{C} 2$ & 600 & 2.47 & 2.9 & 15 & $1.1-6.8$ \\
\hline
\end{tabular}

The first numbers assume $\mathrm{Ka}$, the equilibrium ratio of tritium in vanadium alloy to that in the lithium bond, to be 0.073 . The second numbers assume $\mathrm{Ka}$ to be 0.73 . Thus, the two numbers cover the estimated possible range.

construction of an apparatus at the Irradiated Materials Laboratory (IML) at ANL-East for processing the capsules (i.e., puncturing, cutting, and lithium removal). Because of the considerable tritium contents (up to $\approx 100 \mathrm{Ci}$ per capsule), the capsules must be processed in enclosed systems to the maximum extent possible to trap the released tritium.

Due to radioactivity, the capsules will be processed remotely in an IML hot cell. Two enclosed chambers, one for capsule puncturing and the other for lithium removal, will be used to facilitate tritium trapping during these two processes. The system for tritium trapping and monitoring, consisting of three cold traps, two tritium getters and two ionization chambers, is located in a vented cabinet opposite the hot cell in the same room. High-purity nitrogen will be used as the purge and sweep gas. (Unexpectedly, helium gas-the first choice-was found to cause arcing in the ionization chambers of the tritium detectors.) A schematic diagram of the processing setup is shown in Fig. 1, and photographs of the systems in the cell and the cabinet are shown in Figs. 2 and 3, respectively.

The first operation will be to puncture the capsule in a jig to release the high-pressure plenum gas, which contains tritium. The jig will be isolated and a pressure gauge will monitor gas released during puncturing. Released gas will be carried away by the nitrogen sweep gas to the two tritium getters (containing reactive metal alloys at elevated temperatures) to remove the tritium before venting to the cell exhaust. Because the tritium 




Figure 1. Schematic of DHCE capsule disassembly system 


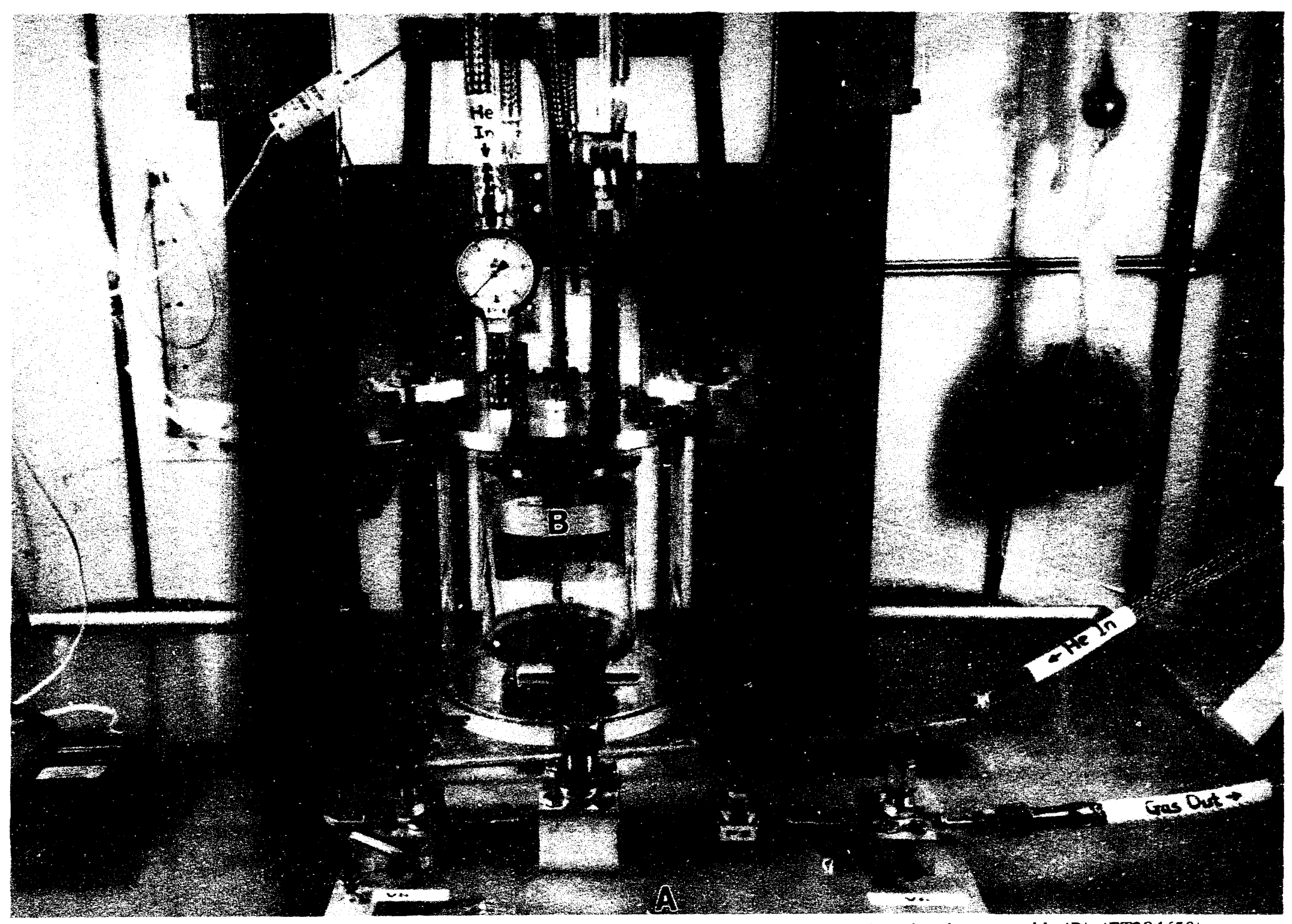

Figure 2. DHCE capsule disassembly system in cell, consisting of capsule punçture jig (A) and dissolution chamber assembly (B) (ET284650) 


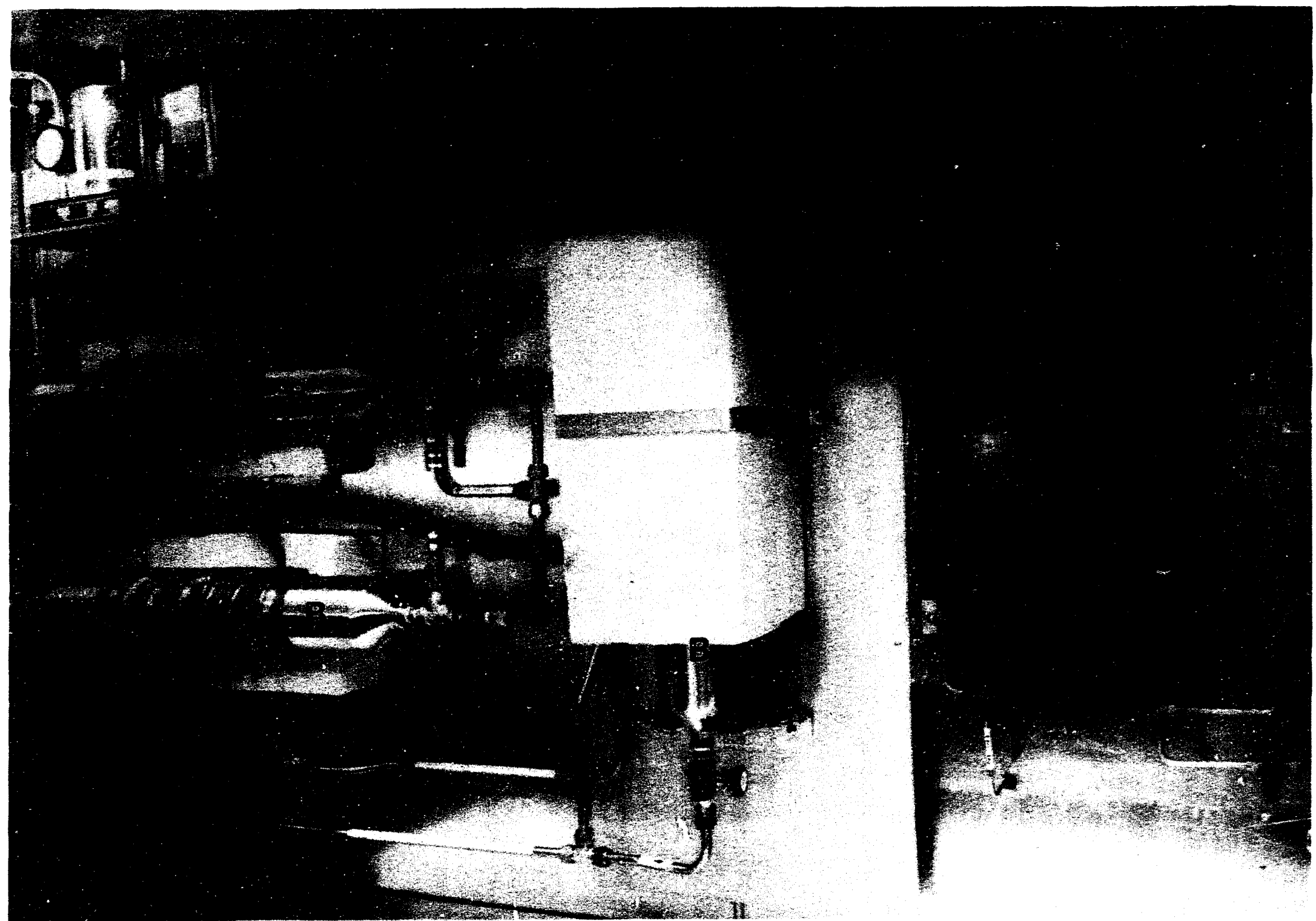

Figure 3. DHCE capsule disassembly system in the vented cabinet consisting of two tritium monitors (A). three cold traps, or ammonia condensers $(B)$, and two tritium getters $(C)$

(ET284651) 
getters have only a limited capacity for impurities (oxygen, carbon dioxide, moisture, etc.), the jig and the connecting gas lines will be thoroughly purged before each puncturing operation.

Next, the capsule will be removed from the jig and opened with a tubing cutter at both the top and bottom ends. Removal and cutting will be done in the open cell atmosphere, and the tritium released during these two steps will not be trapped. Any release, however, is expected to be small because most of the tritium in the lithium will be in the stable form of LiT and would remain in the lithium bond.

After the capsule is opened, it will be loaded into the dissolution chamber where the lithium bond encasing the specimens will be dissolved with liquid ammonia. Substantial releases of tritium and tritiated ammonia are expected during this operation. The process gas will pass through three cold traps (condensers) maintained at liquid-nitrogen temperature to remove the ammonia vapor before entering the tritium getters. Ammonia trapping is necessary to preserve the limited capacity of the tritium getters.

The dried residue on the specimens and the wire-mesh basket holding the specimens after lithium dissolution will be removed by an alcohol rinse. Because the residue (containing lithium and LiT) will react chemically with alcohol and release tritium gas, this operation will be conducted in the same dissolution chamber to facilitate tritium trapping. A second alcohol rinse will complete the final in-cell cleaning of the specimens before they are discharged from the cell for testing and examination.

A substantial fraction of the total tritium inventory is expected to be contained in the dried residue from the ammonia and alcohol rinses. To mitumize the spread of contamination, disposable beakers will be used in the dissolution chamber. They will be replaced after each dissolution/rinsing operation. This and the other functional requirements have made the design and construction of the dissolution chamber a significant technical challenge. The other functional requircments include leak-tightness of the removable top cover, capability to purge the volumes both inside and outside the beaker, remote loading of liquid ammonia, pressure-pulse protection, pressure and temperature measurement capability, ability to adjust the axial position of the basket holding the specimens, and means of externally heating the beaker to accelerate the drying of ammonia or alcohol after the processing. All of these requirements were successfully met in the preoperational tests of the assembled chamber.

The design of the cold traps, i.e., the ammonia condensers, presented another area of significant technical challenge. The initial attempt with a shop-fabricated unit was aborted when a weld failed at liquid-nitrogen temperature. The final design utilizes three commercially available pressure vessels arranged in two stages-two in parallel as the first stage and a single as the second stage. (Pressure-bearing capability is necessary due to the high vapor pressure of ammonia at room temperature, i.e., $\approx 10 \mathrm{~atm}$.) To prevent plugging of the inlet or outlet of the vessels by solidified ammonia, only the middle section of the vessels will be chilled by liquid nitrogen. The satisfactory performance (i.e., high capacity and high efficiency) of the final design was demonstrated in a series of preoperational tests with clean ammonia at flow rates substantially greater than anticipated in the actual DHCE work.

The DHCE disassembly system has been constructed and the procedure for the operation has been prepared. All necessary safety and ESH approvals for the operation have been obtained. Two dry runs with low-tritium capsules from the FFTF MOTA-2B vehicle are scheduled for early October. If the results from the dry runs are satisfactory, processing of the DHCE capsules will follow immediately.

\section{REFERENCES}

1. D. L. Smith, et al., "Status of the Dynamic Helium Charging Experiment (DHCE) in FFTF/MOTA," Fusion Reactor Materials Semiannual Progress Report DOE/ER-0313/10, March 31, 1991, pp. 159-163.

2. L. R. Greenwood, "Revised Calculations for the Dynamic Helium Charging Experiment in FFTF/MOTA 2B," Fusion Reactor Materials Semiannual Progress Report DOE/ER-0313/10, March 31, 1991, pp. 156-158. 
Effects of Neutron Irradiation and Hydrogen on Ductile-Brittle Transition Temperatures of V-Cr-Ti Alloys ${ }^{1}$-B. A. Loomis, H. M. Chung, L. J. Nowicki, and D. L. Smith Argonne National Laboratory, 9700 South Cass Avenue, Argonne, Illinois, USA

\section{Summary}

The effects of neutron irradiation and hydrogen on the ductile-brittle transition temperatures (DBTTs) of unalloyed vanadium and V-Cr-Ti alloys were determined from Charpy-impact tests on $1 / 3$ ASTM-standard-size specimens and from impact tests on 3-mm diameter discs. The tests were conducted on specimens containing $<30$ appm hydrogen and 600-1200 appm hydrogen and on specimens after neutron irradiation to $28-46$ atom displacements per atom at 420,520 , and $600^{\circ} \mathrm{C}$. The DBTTs were minimum $\left(<-220^{\circ} \mathrm{C}\right)$ for $\mathrm{V}-(1-5) \mathrm{Ti}$ alloys and for $\mathrm{V}-4 \mathrm{Cr}-4 \mathrm{Ti}$ alloy with $<30 \mathrm{appm}$ hydrogen. The effect of 600-1200 appm hydrogen in the specimens was to raise the DBTTs by $60-100^{\circ} \mathrm{C}$. The DBTTs were minimum $\left(<-200^{\circ} \mathrm{C}\right)$ for $\mathrm{V}-(3-5) \mathrm{Ti}$ and $\mathrm{V}-4 \mathrm{Cr}-4 \mathrm{Ti}$ alloys after neutron irradiation.

\section{Introduction}

Vanadium-base alloys have significant advantages over other candidate alloys, e.g., austenitic and ferritic steels, for use as structural material in the International Thermonuclear Experimental Reactor (ITER) and in fusion reactors that may be constructed in the future [1]. These advantages include intrinsically lower long-term neutron activation, neutron irradiation after-heat, neutron-induced helium and hydrogen transmutation rates, biological hazard potential, and thermal-stress factor [1-6]. Moreover, vanadium-base alloys have high-temperature strength and resistance to irradiation damage [1]. At the present time, the $\mathrm{V}-4 \mathrm{Cr}-4 \mathrm{Ti}$ alloy is recommended for the near-optimal combination of these desirable neutronic, physical, and mechanical properties for a vanadium alloy structural material [1]. However, to make use of these favorable properties in structural material in fusion systems, an alloy should have a low ductile-brittle transition temperature (DBTT). For confirmation of the selection of the $\mathrm{V}-4 \mathrm{Cr}-4 \mathrm{Ti}$ alloy as the prime-candidate vanadium alloy, we present in this paper the results of experimental investigations to determine the DBTTs (on impact loading) of vanadium alloys after either neutron irradiation at $420-600^{\circ} \mathrm{C}$ to $21-41$ atom displacements per atom (dpa) or hydrogenation to $600-1200 \mathrm{appm}$ H.

\section{Materials and procedures}

Unalloyed vanadium and $\mathrm{V}-\mathrm{Cr}$-Ti alloys with the nominal compositions listed in Table 1 were obtained in sheet form with a 50\% thickness reduction, resulting in a nominal thickness of $3.8 \mathrm{~mm}$. Miniature Charpy-impact specimens (1/3 ASTM standard size) with overall dimensions of $3.30 \times 3.30 \times$ $25.4 \mathrm{~mm}$ and a notch depth of $0.61 \mathrm{~mm}$ were prepared from these materials. Discs with 3-mm diameter and $0.25-\mathrm{mm}$ thickness, i.e., transmission electron microscopy (TEM) discs, were also prepared for impact tests on these materials. Dehydrogenated Charpy and TEM impact-test specimens in the fully recrystallized condition were prepared from the $50 \%$ cold-worked materials by annealing for $1 \mathrm{~h}$ in a vacuum of $2 \times 10^{-5} \mathrm{~Pa}$. The $\mathrm{V}$ and $\mathrm{V}-1 \mathrm{Ti}$ alloy specimens were annealed at $1025^{\circ} \mathrm{C}$, and the V-3Ti-1Si, $\mathrm{V}-(3-20) \mathrm{Ti}$ alloy specimens were annealed at $1100^{\circ} \mathrm{C}$. The V-Cr-Ti alloys (Table 1) were annealed at $1125^{\circ} \mathrm{C}$, except for $\mathrm{V}-5 \mathrm{Cr}-5 \mathrm{Ti}$ which was annealed at $1050^{\circ} \mathrm{C}$. These annealing conditions for the coldworked materials resulted in an average recrystallized-grain diameter of 0.02-0.04 $\mathrm{mm}$ and a dislocation density of $-10^{13} / \mathrm{m}^{2}$ in the specimens. Hydrogen was introduced into the surface layers of the asfabricated Charpy specimens by abrasion of the specimen surfaces in contact with water. The hydrogencharged specimens (wrapped in tantalum foil) were annealed in evacuated and sealed quartz tubes for $1 \mathrm{~h}$ for recrystallization of the specimens and for homogenization of the hydrogen concentration.

\footnotetext{
1 Work supported by the U.S. Department of Energy, Office of Fusion Energy, under Contract W-31109-Eng-38.
} 
Table 1. Compositions of V and V-Cr-Ti alloys.

\begin{tabular}{|c|c|c|c|c|c|c|c|c|}
\hline \multirow[t]{2}{*}{$\begin{array}{l}\text { Nominal } \\
\text { Composition }\end{array}$} & \multirow[t]{2}{*}{$\begin{array}{l}\text { ANL } \\
\text { I.D. }\end{array}$} & \multicolumn{3}{|c|}{$\begin{array}{l}\text { Concentration } \\
\text { (wt.\%) }\end{array}$} & \multicolumn{4}{|c|}{$\begin{array}{l}\text { Concentration } \\
\text { (Wt. ppm) }\end{array}$} \\
\hline & & $\mathrm{Cr}$ & $\mathrm{Ti}$ & Fe & 0 & $\mathbf{N}$ & C & $\mathbf{S i}$ \\
\hline $\mathbf{V}$ & BL 51 & - & - & - & 570 & 49 & 56 & 370 \\
\hline V-1Ti & BL 50 & - & 1.0 & - & 230 & 130 & 235 & 1050 \\
\hline V-3Ti & BL 62 & - & 3.1 & - & 320 & 86 & 109 & 660 \\
\hline V-3Ti-1Si & BL 45 & - & 2.5 & 0.01 & 345 & 125 & 90 & 9900 \\
\hline V-5Ti & BL 46 & - & 4.6 & - & 300 & 53 & 85 & 160 \\
\hline V-10Ti & BL 12 & - & 9.8 & 0.63 & 1670 & 390 & 450 & 245 \\
\hline V-18Ti & BL 15 & - & 17.7 & 0.04 & 830 & 160 & 380 & 480 \\
\hline $\mathrm{V}-14 \mathrm{Cr}$ & BL 5 & 14.1 & - & 0.06 & 330 & 69 & 200 & 50 \\
\hline V-14Cr-1Ti & BL 26 & 14.1 & 1.0 & 0.06 & 560 & 86 & 140 & 50 \\
\hline V-5Cr-3Ti & BL 54 & 5.1 & 3.0 & - & 480 & 82 & 133 & 655 \\
\hline $\mathrm{V}-4 \mathrm{Cr}-4 \mathrm{Ti}$ & BL 47 & 4.1 & 4.3 & - & 350 & 220 & 200 & 870 \\
\hline V-5Cr-5Ti & BL 63 & 4.6 & 5.1 & - & 440 & 28 & 73 & 310 \\
\hline $\mathrm{V}-8 \mathrm{Cr}-6 \mathrm{Ti}$ & BL 49 & 7.9 & 5.7 & - & 400 & 150 & 127 & 360 \\
\hline V-9Cr-5Ti & BL 43 & 9.2 & 4.9 & 0.02 & 230 & 31 & 100 & 340 \\
\hline V-14Cr-5Ti & BL 24 & 13.5 & 5.2 & 0.05 & 1190 & 360 & 500 & 390 \\
\hline V-15Cr-5Ti & BL 41 & 14.5 & 5.0 & 0.02 & 330 & 96 & 120 & 400 \\
\hline V-10Cr-9Ti & BL 44 & 9.9 & 9.2 & 0.04 & 300 & 87 & 150 & 270 \\
\hline V-7Cr-15Ti & BL 10 & 7.2 & 14.5 & 0.09 & 1110 & 250 & 400 & 400 \\
\hline
\end{tabular}

The Charpy and TEM specimens were irradiated in $\mathrm{Li}^{7}$-filled TZM molybdenum capsules at 420 , 520 , and $600^{\circ} \mathrm{C}$ in the Materials Open Test Assembly (MOTA) of the Fast Flux Test Facility (FFTF) during Cycles 9-11 of the reactor. The irradiated specimens were annealed at $400^{\circ} \mathrm{C}$ for $1 \mathrm{~h}$ (prior to impact testing) for removal of hydrogen that was introduced into the specimens during irradiation and/or on dissolution of the $\mathrm{Li}$ for removal of the specimens from the capsules.

Charpy-impact tests were performed with an instrumented Dynatup Drop-Weight Test machine. Impact velocity and load for these tests were $2.56 \mathrm{~m} / \mathrm{s}$ and $14.995 \mathrm{~kg}$, respectively. Energy absorption during impact was determined from applied load-timc data acquired during the impact. The specimen temperature at the instant of impact was determined from a thermocouple arc-welded near the notch, and the lowest, attainable test temperature was $-190^{\circ} \mathrm{C}$. The DBTT of an alloy was designated at $\sim 50 \%$ absorbed-energy reduction from the energy-absorbed versus test-temperature curve. However, in the case of Charpy-impact tests on unirradiated V-1Ti (BL 50), V-3Ti (BL 62), V-3Ti-1Si (BL 45), V-5Ti (BL 46), and $\mathrm{V}-4 \mathrm{Cr}-4 \mathrm{Ti}$ (BL 47) alloys and on irradiated V-3Ti-1Si (BL 45), V-5Ti (BL 46), and V-4Cr-4Ti (BL 47) alloys, the specimens bent without fracture at the lowest test temperature, i.e., $-190^{\circ} \mathrm{C}$. DBTTs of $<-220^{\circ} \mathrm{C}$ and $<-200^{\circ} \mathrm{C}$ were attributed respectively to these unirradiated and irradiated alloys.

In the case of impact tests on TEM discs, a specimen was mounted for impact by a swinging pendulum on $1 / 2$ of the specimen. Disc temperature $\left(\geq-190^{\circ} \mathrm{C}\right)$ was determined from a thermocouple arc-welded to the TEM disc. The DBTT of an alloy was determined from impact tests at several temperatures and from optical and scanning-electron-microscope (SEM) observations of the fractured surfaces of specimens for $-50 \%$ cleavage appearance. However, impact tests at $-190^{\circ} \mathrm{C}$ on unirradiated and irradiated TEM discs of the above-mentioned alloys also resulted in bending of the discs without fracture. DBTTs of $<-220^{\circ} \mathrm{C}$ and $<-200^{\circ} \mathrm{C}$ were also attributed respectively to these unirradiated and irradiated alloys. 


\section{Experimental results}

The temperature dependence of energy absorption during impact on dehydrogenated (unirradiated), hydrogenated (unirradiated), and irradiated Charpy specimens of V-14Cr-5Ti, V-9Cr-5Ti, V-5Ti, and V$4 \mathrm{Cr}-4 \mathrm{Ti}$ alloys is shown in Figs. 1a, 1b, 1c, and 1d, respectively. The DBTTs for dehydrogenated ( $<30$ appm $\mathrm{H}$ ), hydrogenated $(590 \mathrm{appm} \mathrm{H})$, and irradiated $\left(41-50 \mathrm{dpa}\right.$ at $\left.420-600^{\circ} \mathrm{C}\right) \mathrm{V}-14 \mathrm{Cr}-5 \mathrm{Ti}$ alloy are -10 , 130 , and $>400^{\circ} \mathrm{C}$, respectively. The DBTTs for dehydrogenated ( $<30$ appm H), hydrogenated $(670 \mathrm{appm}$ $\mathrm{H})$, and irradiated $\left(41-50 \mathrm{dpa}\right.$ at $\left.420-600^{\circ} \mathrm{C}\right) \mathrm{V}-9 \mathrm{Cr}-5 \mathrm{Ti}$ alloy are -55 , 45 , and $150^{\circ} \mathrm{C}$, respectively.


Fig. 1. Dependence on test temperature of energy absorbed in Charpy-impact tests on V-14Cr-5Ti, V. $9 \mathrm{Cr}-5 \mathrm{Ti}, \mathrm{V}-5 \mathrm{Ti}$, and $\mathrm{V}-4 \mathrm{Cr}-4 \mathrm{Ti}$ alloys. 
The DBTTs for dehydrogenated, hydrogenated $(860 \mathrm{appm} \mathrm{H})$, and irradiated $\left(24-34 \mathrm{dpa}\right.$ at $\left.427-599^{\circ} \mathrm{C}\right)$ V-5Ti alloy are $<-220,-160,<-200^{\circ} \mathrm{C}$, respectively; and the DBTTs for dehydrogenated, hydrogenated $(1200 \mathrm{appm} \mathrm{H})$, and irradiated $\left(24-34 \mathrm{dpa}\right.$ at $\left.427-599^{\circ} \mathrm{C}\right) \mathrm{V}-4 \mathrm{Cr}-4 \mathrm{Ti}$ alloy are $<-220,-150$, and $<-200^{\circ} \mathrm{C}$, respectively.

The dependence of DBTT in V-(0-18)Ti alloys on Ti concentration in the alloy is shown in Fig. 2. DBTTs are minimum $\left(<-220^{\circ} \mathrm{C}\right)$ in $\mathrm{V}-(1-5) \mathrm{Ti}$ alloys with $<30 \mathrm{appm} \mathrm{H}$; and DBTTs for hydrogenated alloys (600-1000 appm $\mathrm{H}$ ) are minimum for the V-5Ti alloy. The DBTTs for V-(0-18)Ti alloys $(<30$ appm $\mathrm{H}$ ) after irradiation at $420^{\circ} \mathrm{C}$ to $34-44 \mathrm{dpa}$ are minimum $\left(<-220^{\circ} \mathrm{C}\right)$ for $\mathrm{V}-(3-5) \mathrm{Ti}$ alloys. DBTT data for alloys irradiated at 520 and $600^{\circ} \mathrm{C}$ are not shown in Fig. 2, but the DBTTs for V-(3-5)Ti alloys are also $<-220^{\circ} \mathrm{C}$. The dependence of DBTT in dehydrogenated, hydrogenated, and irradiated V-Cr-(45) Ti alloys on $\mathrm{Cr}$ concentration in the alloy is shown in Fig. 3. The DBTTs of dehydrogenated, hydrogenated, and irradiated $\mathrm{V}$-Cr-(4-5)Ti alloys increased significantly when $>4.1 \mathrm{wt} . \% \mathrm{Cr}$ was present in an alloy.

The dependence of DBTTs in vanadium alloys on the combined $(\mathrm{Cr}+\mathrm{Ti})$ concentration in an alloy is shown in Fig. 4. These results suggest that the minimum DBTT for either unirradiated, hydrogenated, or neutron-irradiated $\mathrm{V}-\mathrm{Cr}$ - $\mathrm{Ti}$ alloys is obtained for a vanadium alloy containing $0-4 \mathrm{wt} . \% \mathrm{Cr}$ and $4-5$ wt.\% $\mathrm{Ti}$ and a combined $(\mathrm{Cr}+\mathrm{Ti})$ concentration of 4.6 to $8.4 \mathrm{wt} . \%$.

\section{Discussion}

The experimental results presented in this paper tend to confirm the selection of the $\mathrm{V}-4 \mathrm{Cr}-4 \mathrm{Ti}$ alloy as the vanadium alloy with the near-optimal combination of physical and mechanical properties for use as structural material in a fusion reactor. The DBTT for the unirradiated and irradiated (24-34 dpa at $427-599^{\circ} \mathrm{C}$ ) V-4Cr-4Ti alloy is $<-200^{\circ} \mathrm{C}$; ductility of this alloy at $25^{\circ} \mathrm{C}$ is $>8 \%$ after irradiation at $420^{\circ} \mathrm{C}$ to $34 \mathrm{dpa}$ [7]; and swelling of this alloy is low $(<0.3 \%)$ after neutron irradiation at $420-600^{\circ} \mathrm{C}$ to $24-34$ dpa $[8]$.

The number-density and average diameter of precipitates in V-Cr-Ti alloys have been determined by Gazda et al. [9]. The low DBTT for V-(1-5)Ti alloys may be related to a low volume-fraction of noncoherent precipitates $\left(\mathrm{Ti}\left(\mathrm{N}_{1-x-y} \mathrm{C}_{x} \mathrm{O}_{\mathrm{y}}\right), \mathrm{Ti}_{17} \mathrm{P}_{10}, \mathrm{Ti}_{8} \mathrm{~S}_{3}\right)$ and coherent precipitates $\left(\mathrm{V}_{4} \mathrm{C}_{3}, \mathrm{TiO}\right)$ in these $\mathrm{V}$ Ti alloys. The low DBTT for the $\mathrm{V}-4 \mathrm{Cr}-4 \mathrm{Ti}$ alloy may be related to a high volume-fraction of noncoherent precipitates $\left(\mathrm{Ti}\left(\mathrm{N}_{1-x y} \mathrm{C}_{x} \mathrm{O}_{y}\right)\right.$ with relatively large average-diameter and to absence of coherent precipitates.

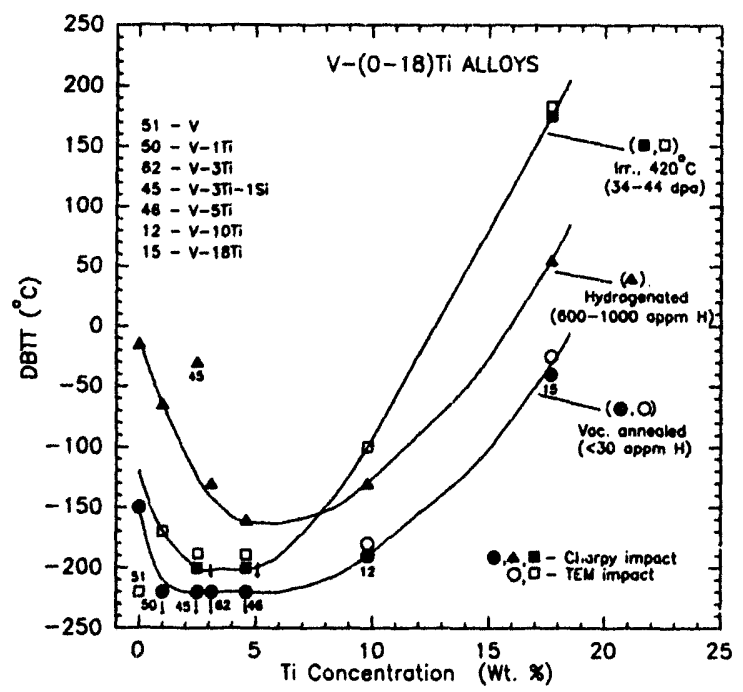

Fig. 2. Dependence of DBTT for V-(0-18)Ti alloys on Ti concentration.

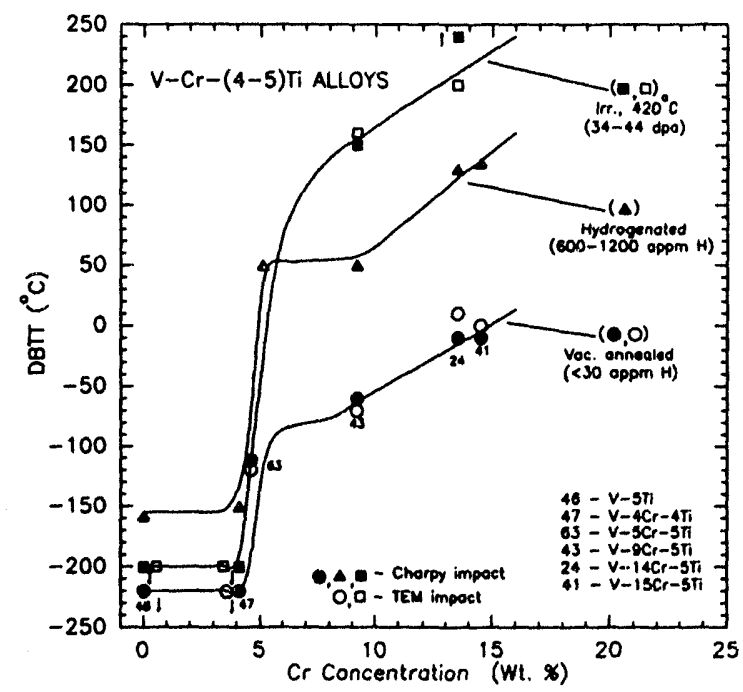

Fig. 3. Dependence of DBTT for V-Cr-(3-5)Ti alloys on $\mathrm{Cr}$ concentration. 


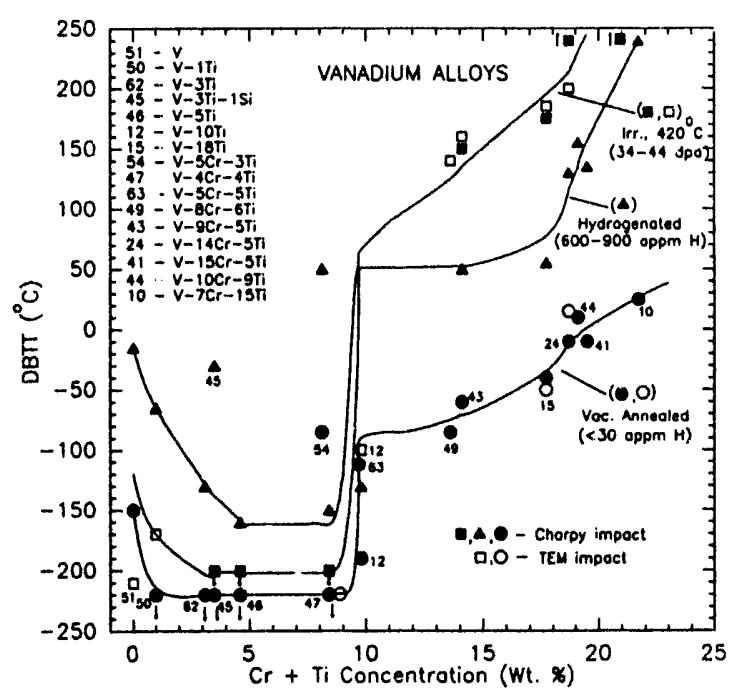

Fig. 4. Dependence of DBTT for vanadium alloys on $(\mathrm{Cr}+\mathrm{Ti})$ concentration.

\section{Conclusions}

- DBTTs for unirradiated V-(1-5)Ti and V-4Cr-4Ti alloys are $<-220^{\circ} \mathrm{C}$.

- DBTTs for V-Ti and V-Cr-Ti alloys are increased $60-100^{\circ} \mathrm{C}$ by the presence of $600-1200$ appm hydrogen in the alloys.

- DBTTs of V-Ti and V-Cr-Ti alloys after neutron irradiation at $420-600^{\circ} \mathrm{C}$ to $28-46 \mathrm{dpa}$ are minimum $\left(<-200^{\circ} \mathrm{C}\right)$ for $\mathrm{V}-(3-5) \mathrm{Ti}$ and $\mathrm{V}-4 \mathrm{Cr}-4 \mathrm{Ti}$ alloys.

- DBTTs for either unirradiated, irradiated, or hydrogenated $\mathrm{V}-\mathrm{Cr}-(4-5) \mathrm{Ti}$ alloys increase significantly for $>4 \mathrm{wt} . \% \mathrm{Cr}$ in an alloy.

\section{References}

[1] B. A. Loomis and D. L. Smith, J. Nucl. Mater. 191-194 (1992) 84.

[2] T. Noda, F. Abe, H. Araki and M. Okada, J. Nucl. Mater. 155-157 (1988) 581.

[3] R. Santos, J. Nucl. Mater. 155-157 (1988) 589.

[4] S. J. Piet, H. G. Kraus, R. M. Neilson, Jr. and J. L. Jones, J. Nucl. Mater. 141-143 (1986) 24.

[5] F. L. Yaggee, E. R. Gilbert and J. W. Styles, J. Less-Comm. Met. 19 (1969) 39.

[6] D. L. Smith, B. A. Loomis and D. R. Diercks, J. Nucl. Mater. 135 (1985) 125.

[7] B. A. Loomis, L. J. Nowicki and D. L. Smith, Proceedings of the Sixth Int. Conf. on Fusion Reactor Materials (ICFRM-6), Stresa, Lago Maggiore, Italy, 1993.

[8] H. M. Chung B. A. Loomis and D. L. Smith, Proceedings of the Sixth Int. Conf. on Fusion Reactor Materials (ICFRM-6), Stresa, Lago Maggiore, Italy, 1993.

[9] J. Gazda, B. A. Loomis, L. J. Nowicki, D. L. Smith and S. Danyluk, Fusion Reactor Materials, Semiann. Prog. Rep. DOE-ER-0313/15, Oak Ridge National Laboratory, Oak Ridge, TN (1993). 
WELDING OF VANADIUM ALLOYS ${ }^{*}$

D. R. Diercks, C. F. Konicek, and R. H. Lee (Argonne National Laboratory)

\section{OBJECTIVE}

The objective of this activity is to evaluate processes for welding candidate vanadium-base alloys and to determine the effects of the welding processes on the microstructural, mechanical, and physical properties of the alloys.

\section{SUMMARY}

An exploratory activity has been initiated to investigate potential welding processes and the effects of these processes on the properties of candidate vanadium-base alloys has been initiated. Weldments of V-5Cr-5Ti and V-15Ti-7.5Cr have been prepared by the tungsten/inert-gas process without the use of filler metal. The weldments were examined metallographically and found to be free of significant defects. Chemical analyses of the weldments indicate only slight oxygen pickup during welding, and microhardness profiles indicate no unusual effects.

\section{INTRODUCTION}

The fabrication of large fusion reactor structures from vanadium-base alloys will require the joining of smaller components by welding. Industrial experience with the welding of vanadium alloys is limited, and the optimal processes and parameters for welding fusion reactor candidate alloys have not been established. Welding can potentially adversely affect the mechanical and physical properties of these alloys through a number of metallurgical processes, including interstitial element pickup from the welding environment, possible second-phase precipitation in the base-metal heat-affected zone, development of preferred grain orientation and solute segregation in the weld metal, and excessive grain growth in both the weld-metal and heat-affected zones. An exploratory activity to investigate potential welding processes and the effects of these processes on the properties of candidate vanadium-base alloys has been initiated.

\section{MÁTERIALS AND PROCEDURES}

Two trial weldments were fabricated from a 1.9-mm-thick sheet of annealed V-5Cr-5Ti using the tungsten/inert-gas welding process. The pieces joined were each $\approx 13 \times 34 \mathrm{~mm}$ in size, and one of the two 34-mm-long edges on each piece was machined to produce a square and flat geometry prior to welding. The two pieces were then clamped into position with the machined edges butted tightly against each other in a $\mathrm{Cu}$ fixture. Run-on and run-off tabs were placed at each end of the weld pieces. The fixture was then placed in a weld chamber inside a He-atmosphere glovebox. The weld chamber was pumped down to a pressure of $\approx 2 \mathrm{~mm}$ and back-filled with $\mathrm{He}(99.995 \%$ purity).

The welding process used a $2 \%$ thoriated tungsten electrode ( $1 \mathrm{~mm} \mathrm{dia}$ ), a current of $50 \mathrm{~A}$, and an automatically controlled welding speed of $125 \mathrm{~mm} / \mathrm{min}$ without the use of filler metal. The gap between the workpiece and the electrode was $0.64 \mathrm{~mm}$. The He atmosphere of the weld chamber was supplemented by a 30\% Ar-70\% He flowing cover-gas mixture at the weld zone. The first welding pass resulted in a weld penetration slightly more than halfway through the thickness of the work pieces. The two pieces were then inverted, and a second weld pass was applied to the other side to complete the welding process.

Also studied was a trial weldment of $\mathrm{V}-15 \mathrm{Ti}-7.5 \mathrm{Cr}$ that had been fabricated approximately two years earlier as a part of an evaluation of mechanical properties. ${ }^{1}$ In this case, the starting material was $1.0 \mathrm{~mm}$

\footnotetext{
* Work supported by Office of Fusion Energy, U.S. Department of Energy, under Contract W-31-109-Eng-38.
} 


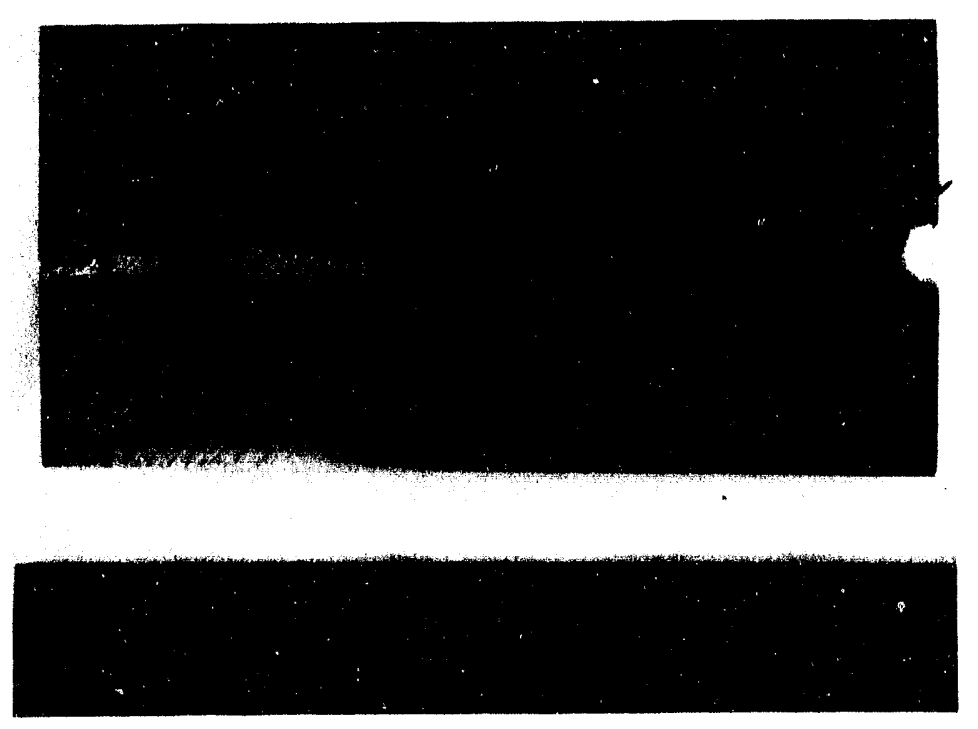

Figure 1. Macroscopic appearance of as-fabricated V-5Cr-5Ti weldment.

thick, and welding was accomplished in a single pass. The welding conditions and parameters were otherwise essentially identical to those described above for the V-5Cr-5Ti weldments.

\section{RESULTS AND DISCUSSION}

A photograph of one of the two V-5Cr-5Ti weldments is shown in Fig. 1; the appearance of the V-15Ti-7.5Cr weldment was similar. A macroscopic examination of both weldments indicated relatively smooth weld zones with full penetration; no cracks, porosity, or other significant weld flaws were observed.

Metallographic sections were prepared from each of the two weldment types. The section through the V-5Cr-5Ti weldment is shown in Fig. 2. Complete weld penetration is apparent, and the fused region is seen to blend smoothly into the adjacent metal with no undercutting or other geometrical discontinuities. No cracks or porosity are visible, and the fused metal is distinguished from the adjacent base metal only by a modest increase in grain size. A higher magnification examination indicated a single-phase microstructure in both the fused metal and the heat-affected zone.

The metallographic section through the V-15Ti-7.5Cr weldment (Fig. 3) also revealed complete weld penetration, a smooth transition between the weld zone and the base metal, and the absence of weld flaws. The grain enlargement in the fusion zone relative to the base metal is substantially more pronounced here than in the V-5Cr-5Ti weldment. In addition, the grains exhibit a columnar orientation along the direction of heat flow during resolidification. An unidentified second phase is observed at the interdentritic boundaries in the weld zone (Fig. 4) and, after heavier etching, at the grain boundaries and within the grains of the heat-affected base metal (Fig. 5).

Chemical analyses were performed on fusion-zone and unaffected base-metal samples from both weldments to determine the extent of oxygen pickup during welding. The results are summarized in 


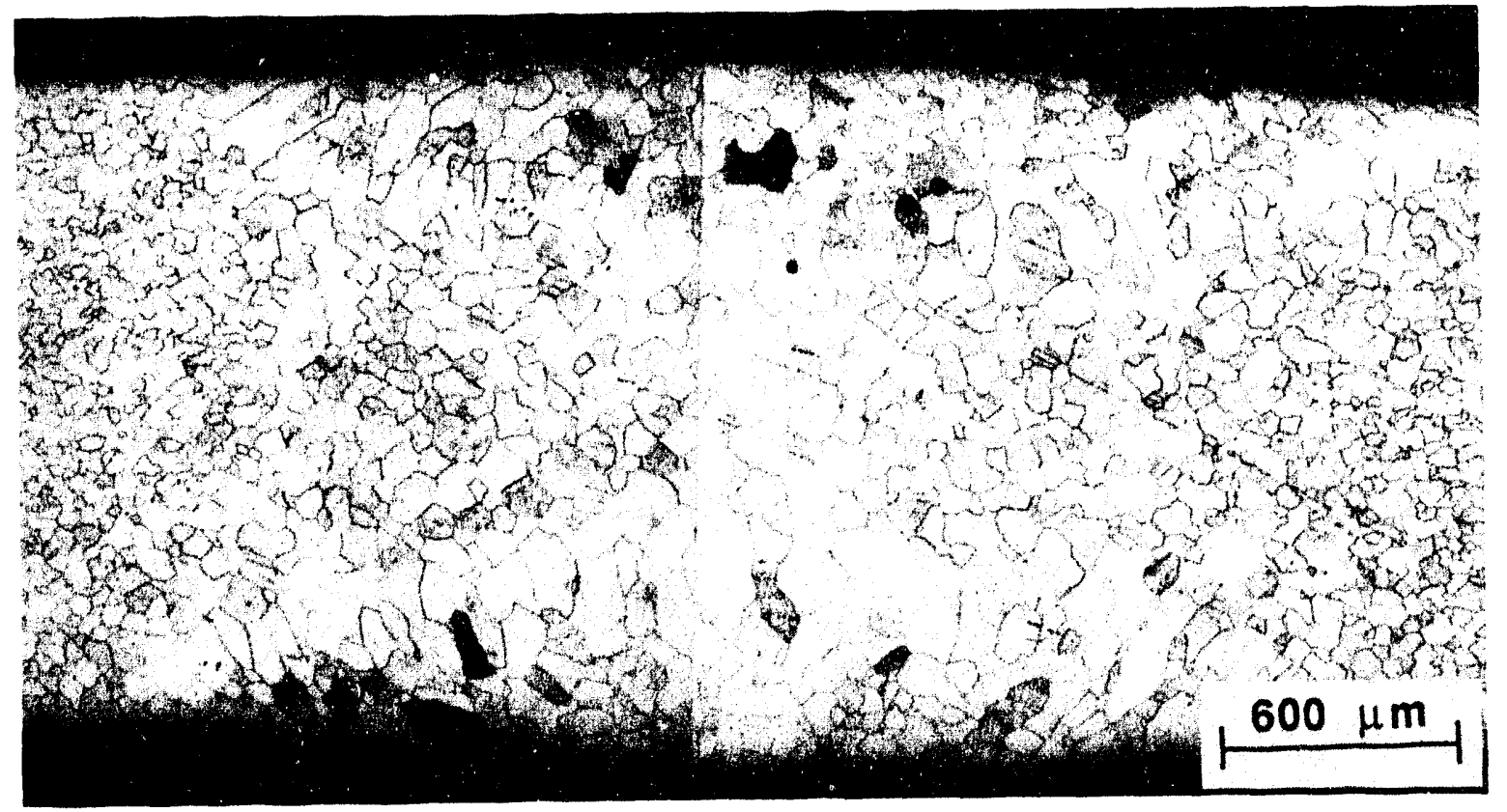

Figure 2. Metallographic cross-section through V-5Cr-5Ti weldment.

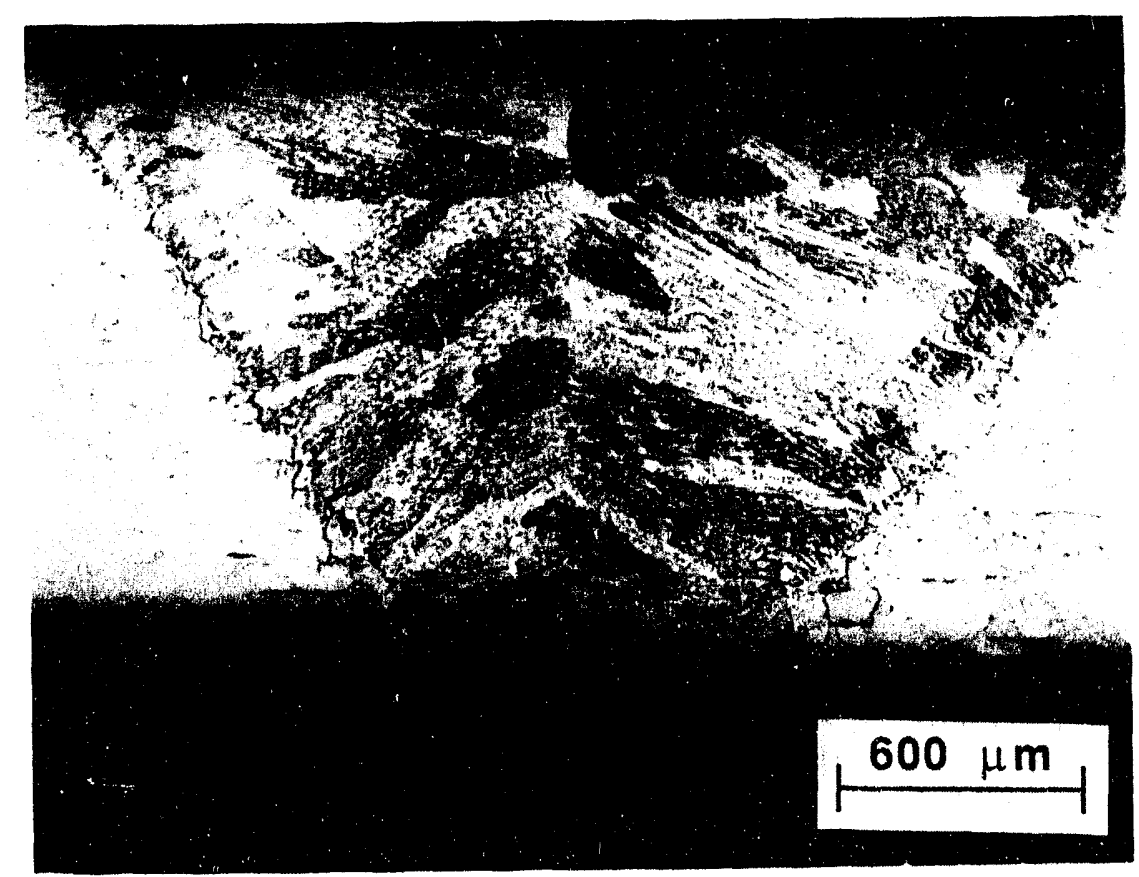

Figure 3. Metallographic cross-section through V-15Ti-7.5Cr weldment. 


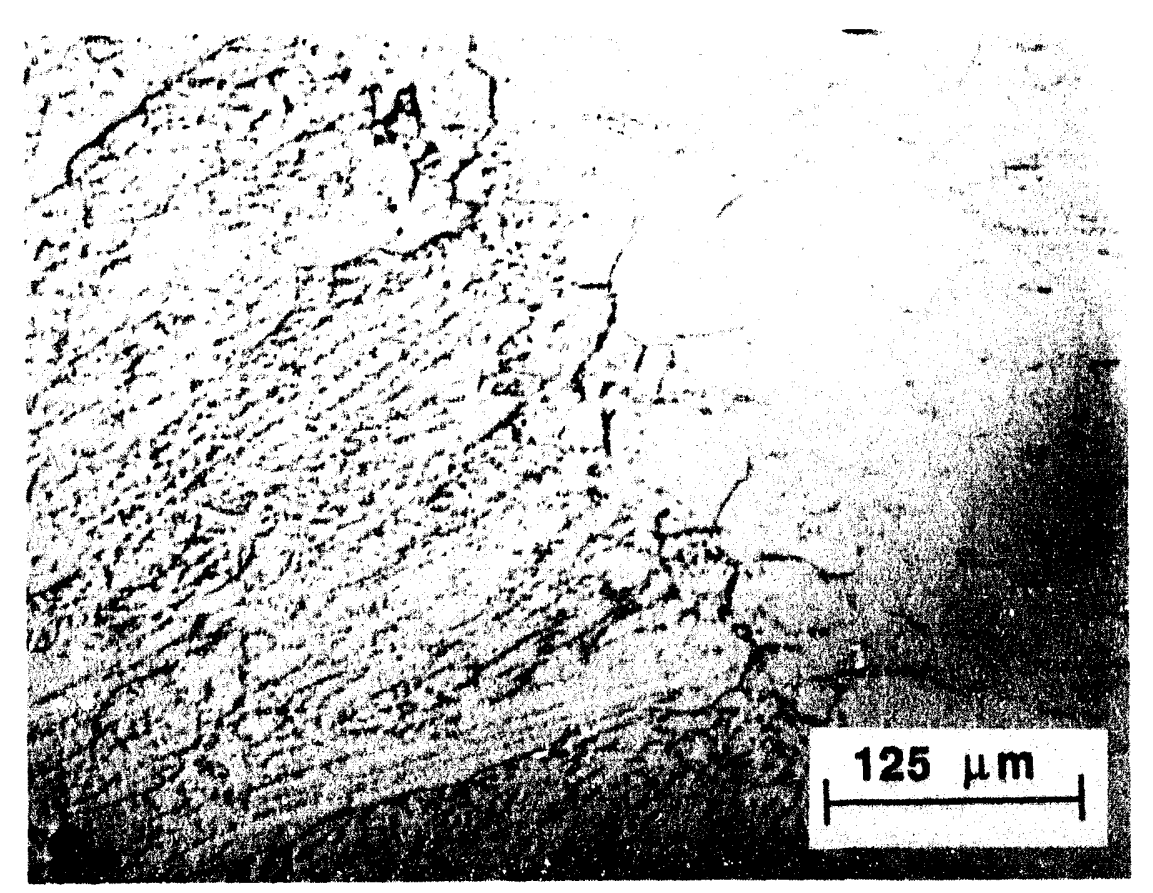

Figure 4. Higher-magnification metallographic cross-section through boundary between fusion zone and heat-affected base metal in V-5Cr-5Ti weldment.

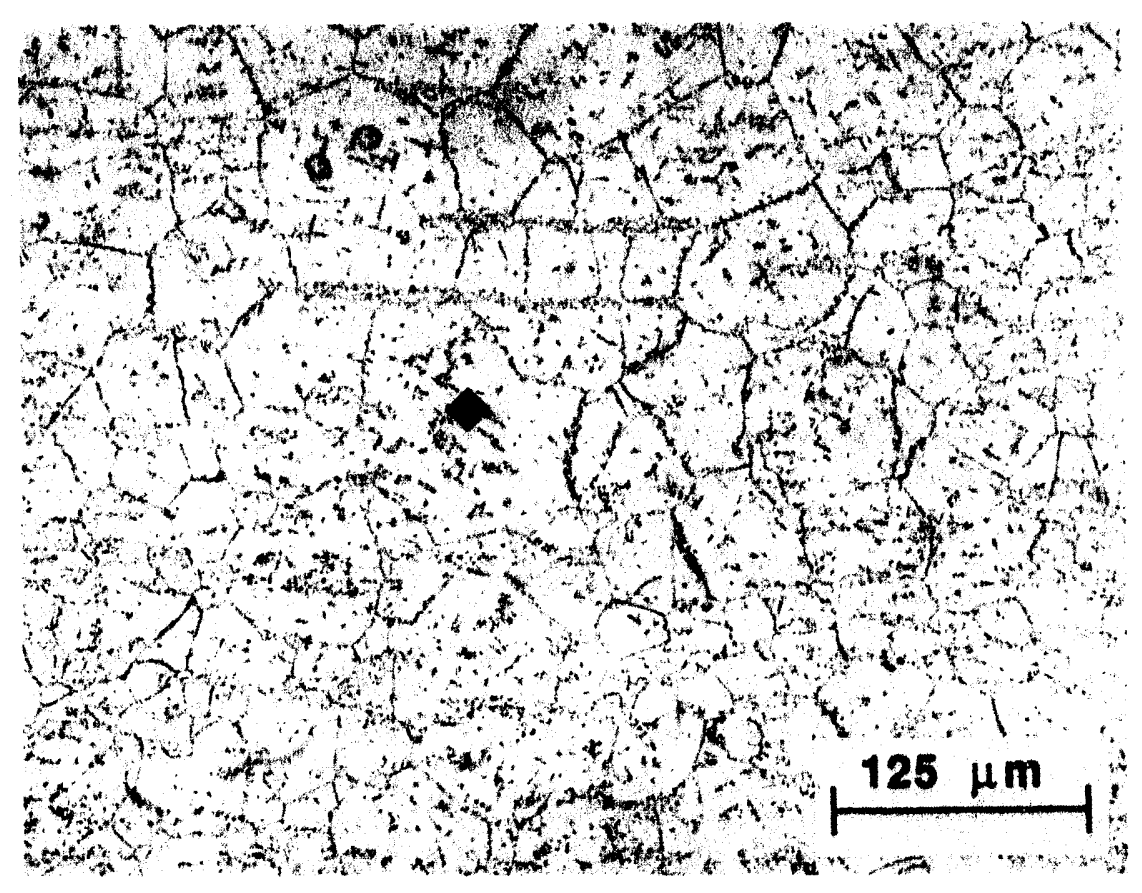

Figure 5. Higher-magnification metallographic cross-section through heat-affected base metal near fusion zone in V-5Cr-5Ti weldment. 
Table 1. Results of oxygen analyses of fusion-zone and base-metal samples from V-5Cr-5Ti and V-15Ti-7.5Cr weldments

\begin{tabular}{lcc}
\hline Weldment & Sample Description & $\begin{array}{c}\text { Oxygen Content } \\
\text { (wt. ppm) }\end{array}$ \\
\hline V-5Cr-5Ti & base metal & 210 \\
& base metal & 310 \\
& fusion zone & 300 \\
V-15Ti-7.5 Cr & fusion zone & 550 \\
& base metal & 550 \\
& base metal & 570 \\
& fusion zone & 620 \\
\hline
\end{tabular}

Table 1. Within the scatter of the data, only siight oxygen pickup is indicated for the fusion zone of the $\mathrm{V}-5 \mathrm{Cr}-5 \mathrm{Ti}$ weldment, as compared to the base metal, and little or no pickup is indicated for the V-15Ti7.SCr weldment.

Microhardness profiles were taken across both weldments with a Vickers pyramidal indenter and a $100-\mathrm{g}$ load. For the V-5Cr-5Ti weldment, Vickers microhardnesses (HV) of $\approx 180-250$ were observed in the weld fusion zone, with the higher values near the surfaces and the lower values near the center of the weld. The unaffected base metal away from the weld had hardnesses of $\approx 140-160$. The hardening in the weld zone may be attributed to residual stresses and possible minor interstitial element pickup.

The V-15Ti-7.5Cr weldment displayed higher hardnesses overall because of its greater alloyingelement content. This is consistent with prior observations that the tensile and yield strengths of $V$-base alloys increase with increasing combined $\mathrm{Cr}$ and $\mathrm{Ti}$ concentrations. ${ }^{2}$ However, the variation in hardness between the weld fusion zone and the unaffected base metal was much lower. The hardness of the fusion zone ranged from $\approx 280$ near one surface to 260 at the weld center and 270 at the other surface. The unaffected base metal had a hardness of $\approx 240$.

\section{CONCLUSIONS}

These preliminary results indicate that $\mathrm{V}$ alloys can be successfully welded with the tungsten/inertgas process.

\section{FUTURE WORK}

Further characterization will be carried out of the two types of weldments that have been prepared, and additional studies will be conducted to optimize the weld parameters.

\section{REFERENCES}

1. B. A. Loomis, L. J. Nowicki, and D. L. Smith, "Tensile Properties of Vanadium-Base Alloys with a Tungsten/Inert-Gas Weld Zone," in Fusion Reactor Materials, Semiannual Progress Report for Period Ending September 30, 1992, DOE/ER-0313/13, U.S. Department of Energy, pp. 187-193.

2. B. A. Loomis, R. H. Lee, and D. L. Smith, "Strength, Ductility, and Ductile-Brittle Transition Temperature for MFR Candidate Vanadium Alloys," in Fusion Reactor Materials, Semiannual Progress Report for Period Ending September 30, 1987, DOE/ER-0313/3, U.S. Department of Energy, March 1988, pp. 246-253. 


\section{DEVELOPMENT OF MINIATURE-SPECIMEN TECHNOLOGY TO DETERMINE DUCTILE- BRITTLE 'TRANSITION BEHAVIOR OF IRRADIATED VANADIUM ALLOYS* H. M. Chung, L. J. Nowicki, J. Gazda, D. E. Busch, and D. L. Smith (Argonne National Laboratory)}

\section{OBJECTIVE}

The objective of this work is to develop a technique to determine ductile-brittle transition behavior of irradiated vanadium-base alloys based on quantitative fractographic characterization of miniaturized specimens following uninstrumented impact tests.

\section{SUMMARY}

Simple uninstrumented impact tests were conducted on unirradiated and irradiated transmission electron microscopy (TEM) disks of vanadium alloys between -196 and $300^{\circ} \mathrm{C}$. The results were combined with quantitative fractography of the fractured specimens in a scanning electron microscope (SEM) to determine the effect of impact temperature on fracture behavior. Based on the fractographic information, ductile-brittle transition behavior of several alloys was determined before and after irradiation. The ductilebrittle transition temperature (DBTT) obtained from this technique was then compared with the DBTT from Charpy impact lesting of the same material. A correlation curve was then obtained for use in estimating DBTTs of irradiated vanadium-base alloys based on ductile-brittle transition behavior of standard-size TEM disks. The method seems to be adequate to estimate the ductile-brittle transition behavior of a material whose Charpy-impact DBTT is higher than approximately $-70^{\circ} \mathrm{C}$. For a material whose Charpy DBTT is $<-70^{\circ} \mathrm{C}$, the method can provide an estimation of upper limit of the DBTT. Compared to a similar method based on slow-strain-rate small-punch testing, the present method seems to be significantly more advantageous in evaluating ductile-brittle transition behavior.

\section{INTRODUCTION}

Miniaturized-specimen technology is an attractive alternative to full-size-specimen irradiation and testing because of the reduced irradiation volume, flux gradient in specimens, gamma heating effect, radioactivity, and radiation hazard, as well as simplicity of testing and significant savings in cost and time. For example, in the vei y difficult and costly Dynamic Helium Charging Experiment (DHCE) of vanadiumbase alloys, ${ }^{1}$ only a limited number of tensile and TEM-disk specimens could be accommodated in the irradiation capsules in the Fast Flux Test Facility (FFTF). Naturally, it is extremely important in such a case to be able to extract the maximum information on mechanical and physical properties of the test alloys from available miniature specimens such as TEM disks.

In the past, many investigators have utilized TEM disks to extract useful mechanical properties from bend, ${ }^{2,3}$ small-punch, ${ }^{4-8}$ and microbulge ${ }^{9-11}$ tests. In these types of tests, information on mechanical properties is obtained based on load-vs.-displacement curves measured during loading at a relatively slow strain rate. Under impact loading, instrumentation of load as a function of time is not practical for a miniature specimen such as a TEM disk. Therefore, in the present investigation, simple uninstrumented impact tests were conducted on standard-size TEM disks over a wide range of temperatures, and fracture morphology of the specimens was determined quantitatively by SEM to determine the effect of impact temperature on fracture behavior. The objective of this study was to examine ductile-brittle transition behavior of vanadium-base alloys based on the uninstrumented impact tests of TEM disks and quantitative fractography.

\footnotetext{
*Work supported by the Office of Fusion Energy, U.S. Department of Energy, under Contract W-31-109-Eng-38.
} 


\section{MATERIALS AND PROCEDURES}

Chemical composition of the vanadium-base alloys, from which Charpy-impact and TEM-disk specimens have been machined, is given in Table 1. After machining, the specimens were annealed and recrystallized at $1125^{\circ} \mathrm{C}$ for $1 \mathrm{~h}$. Some of the specimens were irradiated in FFTF, a sodium-cooled fast reactor located in Richland, Washington, at $420-600^{\circ} \mathrm{C}$.

Table 1. Chemical composition and irradiation conditions of vanadium-base alloys from which TEMdisk and Charpy-impact specimens were machined and tested

\begin{tabular}{|c|c|c|c|c|c|c|c|c|c|c|}
\hline $\begin{array}{l}\text { Alloy } \\
\text { ID No. }\end{array}$ & $\underset{\text { (wt.\%) }}{\mathrm{Cr}_{\mathrm{r}}}$ & $\begin{array}{c}\mathrm{Ti} \\
\text { (wt.\%) }\end{array}$ & $\begin{array}{c}0 \\
\text { (wppm) }\end{array}$ & $\begin{array}{c}\mathbf{N} \\
\text { (wppm) }\end{array}$ & $\begin{array}{c}\mathrm{C} \\
\text { (wppm) }\end{array}$ & $\begin{array}{c}\mathbf{S i} \\
\text { (wppm) }\end{array}$ & $\begin{array}{l}\text { DBTT before } \\
\text { irradiation } \\
\left({ }^{\circ} \mathrm{C}\right)^{A}\end{array}$ & $\begin{array}{l}\text { Irradiation } \\
\text { temperature } \\
\left({ }^{\circ} \mathrm{C}\right)\end{array}$ & $\begin{array}{l}\text { Damage } \\
\text { level } \\
\text { (dpa) }\end{array}$ & $\begin{array}{l}\text { DBTT after } \\
\text { irradiation } \\
\left({ }^{\circ} \mathrm{C}\right)^{\mathrm{a}}\end{array}$ \\
\hline BL-47 & 4.1 & 4.3 & 350 & 220 & 200 & 870 & $<-190^{\circ} \mathrm{C}$ & $420-600$ & $24-34$ & $<-190^{\circ} \mathrm{C}$ \\
\hline BL-63 & 4.6 & 5.1 & 440 & 28 & 73 & 310 & -110 & - & - & - \\
\hline BL-43 & 9.2 & 4.9 & 230 & 31 & 100 & 340 & -40 & 420 & $34-44$ & 140 \\
\hline BL-24 & 13.5 & 5.2 & 1190 & 360 & 500 & 390 & 10 & 420 & 34.44 & 260 \\
\hline BL-15 & - & 17.7 & 830 & 160 & 380 & 480 & -80 & 420 & $34-44$ & 160 \\
\hline
\end{tabular}

aDBTT determined from Charpy-impact testing of one-third-size specimens.

A simple gripping and pendulum impact device, schematically shown in Fig. 1, was assembled. Approximately $40 \%$ of the vertical surface of a disk was gripped tightly in a vise, and the other (upper) half was impacted by a massive pendulum. Standard-size TEM disks (3- $\mathrm{mm}$ diameter and $0.26-\mathrm{mm}$ thickness) were fractured in the device between -196 and $400^{\circ} \mathrm{C}$. The thickness of each disk was measured, and the clearance between the upper surface of the vise and the lower surface of the pendulum head was adjusted for each test at a given temperature. The clearance was always $0.05 \mathrm{~mm}$ larger than the thermally equilibrated thickness of each disk. In this way, the pendulum head did not shear disks that bent in ductile manner.

After pendulum impact, a disk cracked fully or partially or simply bent without producing a fracture surface. Morphology of the fracture surface was examined quantitatively by SEM. A few dozen SEM fractographs were taken at a magnification of $\approx 125 \mathrm{X}$, and a composite of the whole fracture surface was made. Four types of fracture morphology were observed, i.e., cleavage, quasicleavage, ductile-dimple, and intergranular separation. From the fracture surface composite, the percentage of ductile-dimple morphology was measured for each specimen with a planimeter.

DBTT from Charpy tests ${ }^{12}$ was determined for notched one-third-size specimens $(3.30 \times 3.30 \times$ $25.4 \mathrm{~mm} ; 0.61-\mathrm{mm}$ notch depth). Charpy absorbed energy and DBTT, determined from the Charpy-impact tests, are given in Fig. 2 and Table 1, respectively.

\section{RESULTS AND DISCUSSION}

The percentage of ductile-dimple morphology on fracture surfaces of TEM disk specimens is plouted in Fig. 2 as a function of impact temperature. When a disk specimen simply bent in a ductile manner without fracturing, $100 \%$ ductile-dimple morphology was assumed. When a disk cracked fully or partially, the actual percentage ductile-dimple morphology was plotted in Fig. 2. Also plotted in the figure are Charpy energies of the corsesponding materials as a function of impact temperature. 


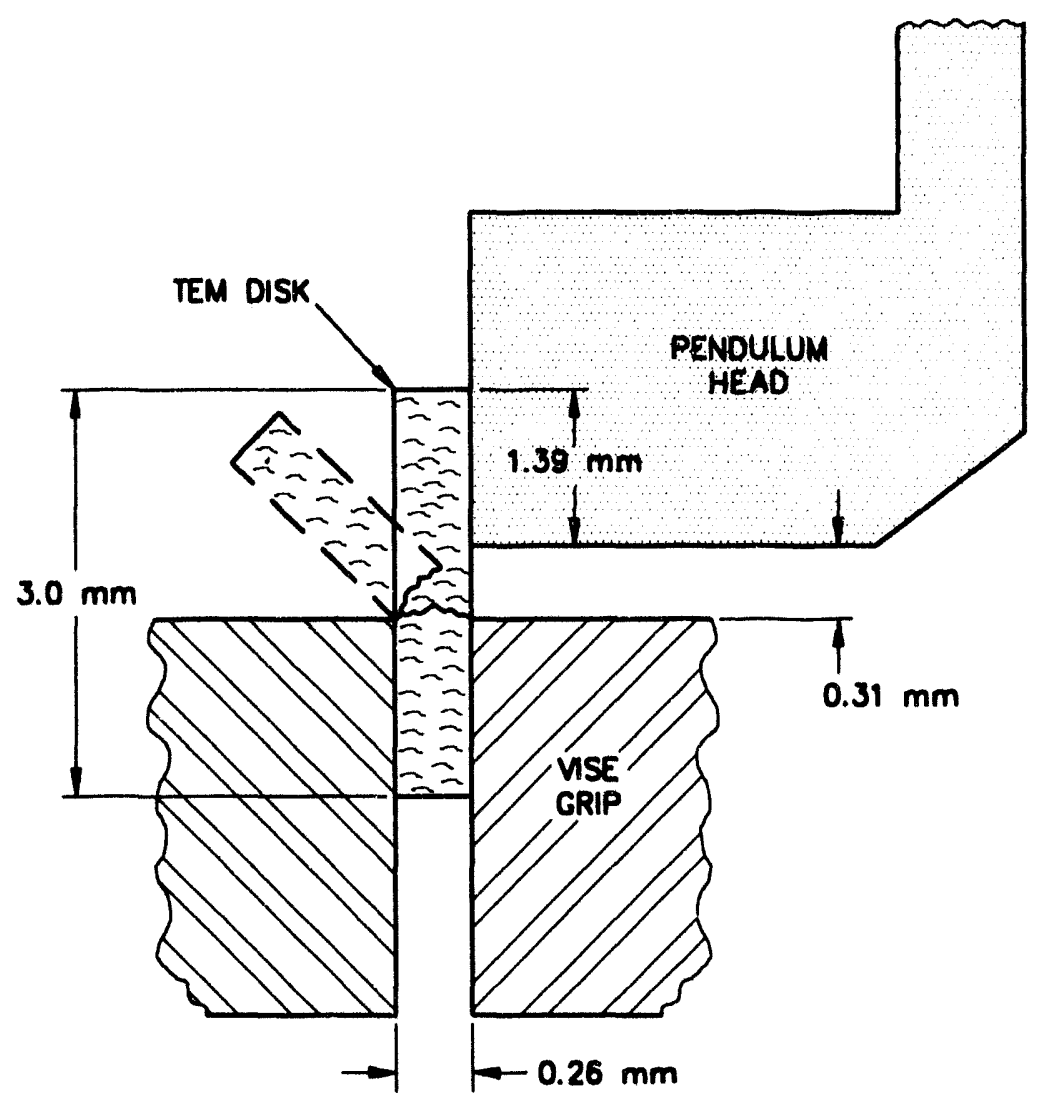

Figure 1. Schematic of pendulum-impact device used to evaluate ductile-brittle transition behavior of TEM disks in combination with quantitative fractography

Two sets of DBTT, determined from ductile-dimple percentage and Charpy-impact energy in Fig. 2, seem to agree well for $\mathrm{V}-15 \mathrm{Cr}-5 \mathrm{Ti}, \mathrm{V}-9 \mathrm{Cr}-5 \mathrm{Ti}, \mathrm{V}-20 \mathrm{Ti}$, and $\mathrm{V}-4 \mathrm{Cr}-4 \mathrm{Ti}$ (Figs. 2A-2D). V-4Cr-4Ti, a very ductile material that is virtually immune to irradiation embrittlement, ${ }^{12}$ did not exhibit ductile-brittle transition behavior above $-196^{\circ} \mathrm{C}$ in either the present disk-impact or Charpy-impact tests of one-third-size specimens. Therefore, the exact DBTT of this material could not be determined for either the unirradiated or irradiated condition. For V-5Cr-5Ti, DBTTs determined from the two techniques differed significantly (Fig. 2E).

DBTTs determined from the two tcchniques are plotted in Fig. 3. One can deduce from the figure that the disk-impact method is reasonably accurate for a material with a DBTT (i.e., DBTT from Charpy impact test of one-third-size specimens) greater than approximately $-70^{\circ} \mathrm{C}$. For a material with a Charpy DBTT $<-70^{\circ} \mathrm{C}$, the method seems to be adequate for estimating the DBTT upper limit. For example, if no ductile-britte transition is observed from the disk-impact test of a vanadium-base alloy, one can reasonably deduce that the DBTT of the material is no higher than $-100^{\circ} \mathrm{C}$.

For most enginecring materials, a DBTT lower than 0 to $-15^{\circ} \mathrm{C}$ would be considered satisfactory. The present test method can indicate if a material DBTT is lower than these temperatures, although information on other mechanical properties (such as upper-shelf impact energy, ductility, or yield strength) cannot be obtained from this technique. Also, quantitative fractography is a time-consuming technique. Figure 3 shows DBTTs of ferritic steels obtained from small-punch and Charpy-impact tests reported by Kameda. ${ }^{4,5}$ For evaluating ductile-brittle transition behavior, the present disk-impact method seems to be better than the small-punch method. 


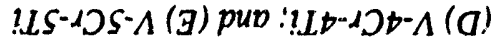

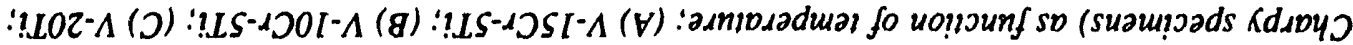

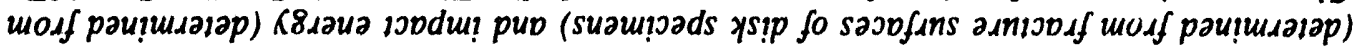

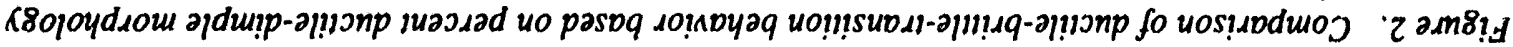

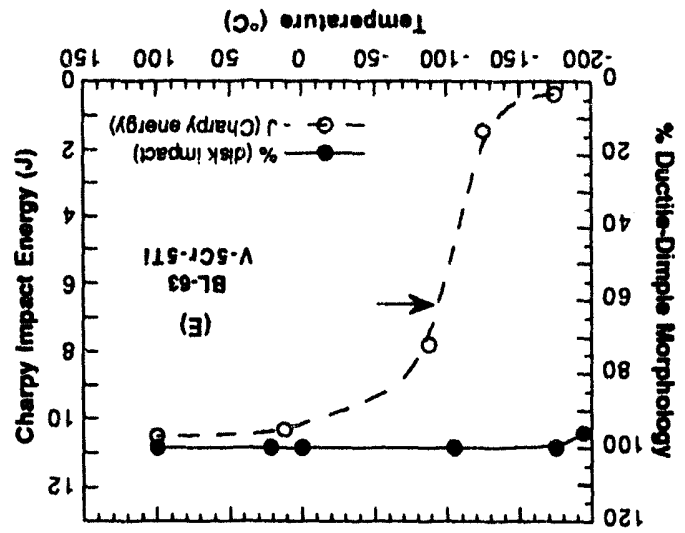

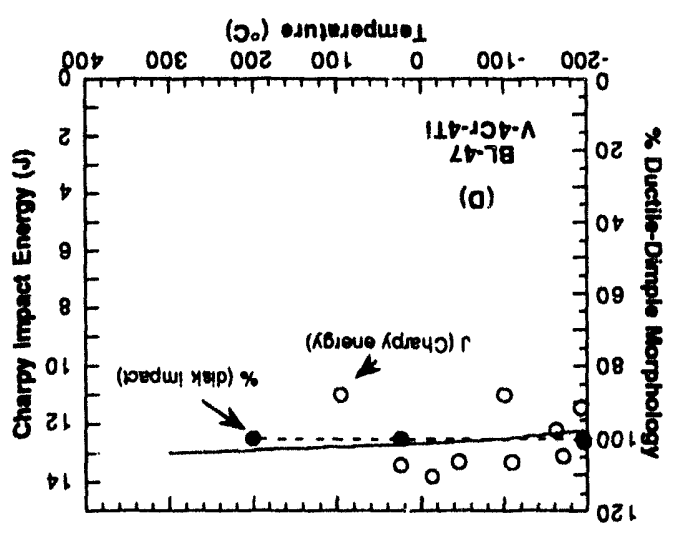

(0.) esnjesedued

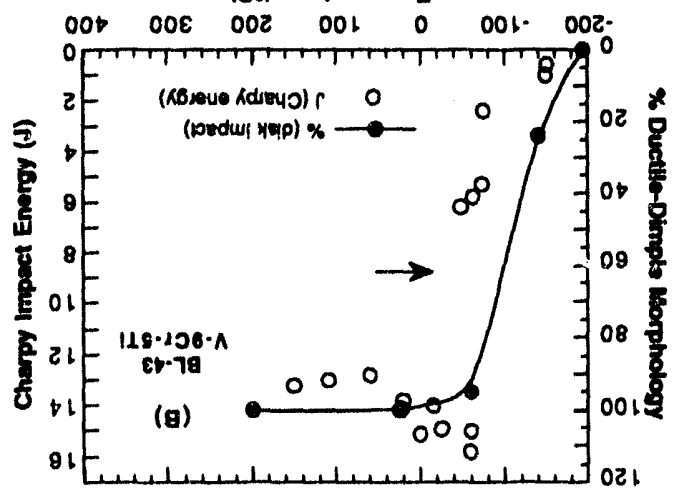

(O.) esnjesoduel

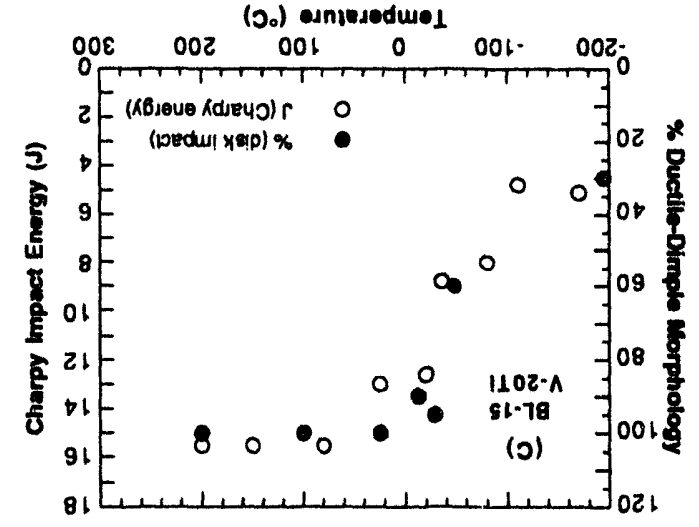

(5o) einjesodwol

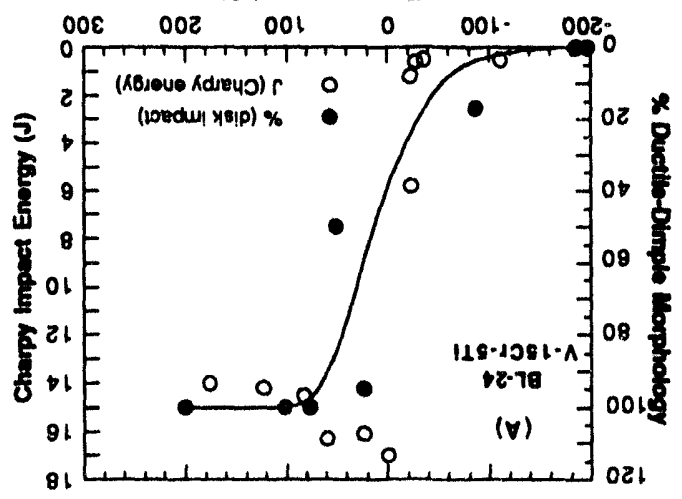




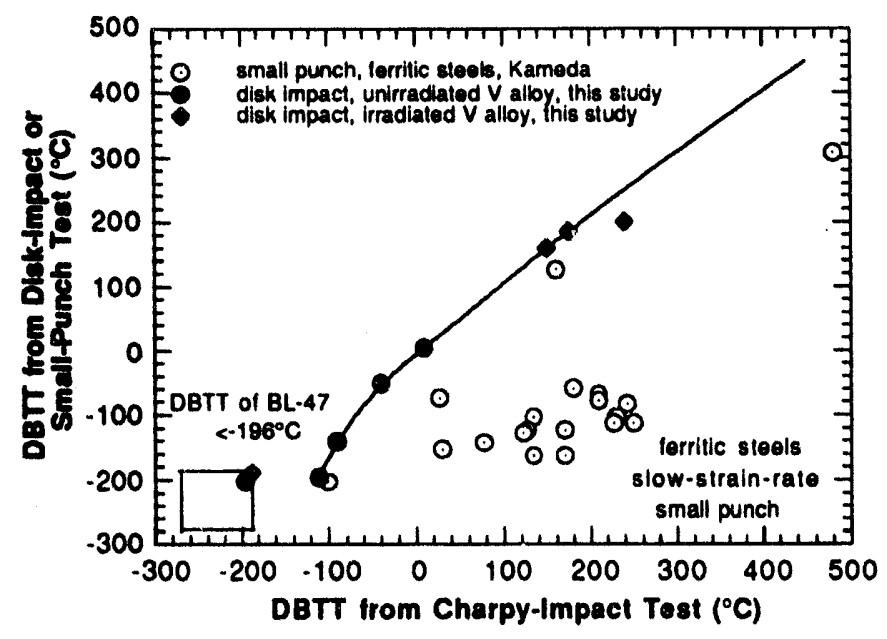

Figure 3. DBTTs from disk-impact and Charpy-impact tests on vanadium-base alloys and similar data from smallpunch tests on ferritic steels by Kameda ${ }^{4,5}$

\section{CONCLUSIONS}

Simple uninstrumented impact tests were conducted on unirradiated and irradiated TEM disks of vanadium alloys, combined with quantitative fractography of test specimens, to determine the effect of temperature on fracture behavior. Based on the fractographic information, ductile-brittle transition behavior can be determined. The method is adequate for estimating ductile-brittle transition behavior of a material whose Charpy-impact DBTT is higher than approximately $-70^{\circ} \mathrm{C}$. For a material with a Charpy DBTT of $<-70^{\circ} \mathrm{C}$, the method can provide an estimation of the upper limit of DBTT. Compared to a similar method hased on slow-strain-rate small-punch testing, the present method seems to be significantly more advantageous in evaluating ductile-brittle transition behavior, although it cannot be used to determine other mechanical properties (such as un "elf impact energy, ductility, or yield strength).

\section{REFERENCES}

1. D. L. Smith, H. Matsui, L. R. Greenwood, and B. A. Loomis, J. Nucl. Mater. 155-157 (1988) 1359.

2. F. H. Huang, M. L. Hamilton, and G. L. Wire, Nucl. Technology, 57 (1982) 234.

3. M. P. Manahan, A. S. Argon, and O. K. Harling, J. Nucl. Mater., 103-104 (1981) 1545.

4. J. M. Baik, J. Kameda, and O. Buck, Scripta Met., 17 (1983) 1443.

5. J. Kameda, Acta Met., 34 (1986) 2391.

6. Y. Hamaguchi, H. Kuwano, T. Misawa, R. Miura, and T. Yamada, J. Nucl. Mater., 141-143 (1986) 781.

7. J. Kameda and X. Mao, Mat. Sci. Eng., A112 (1989).

8. J. McNaney, G. E. Lucas, and G. R. Odette, in Eusion Reactor Materials. Semiannual. Prog. Rept. DOE/EP.-0313/9, Oak Ridge National Laboratory, Oak Ridge, TN (1990) 15.

9. G. E. Lucas, J. Nucl. Mater., 117 (1983) 327.

10. M. Dooley, G. E. Lucas, and J. W. Sheckherd, J. Nucl. Mater., 103-104 (1981) 1533.

11. G. E. Lucas, A. Okada, and M. Kiritani, J. Nucl. Mater., 141-143 (1986) 532.

12. B. A. Loomis, H. M. Chung, L. J. Nowicki, and D. L. Smith, "Effects of Neutron Irradiation and Hydrogen on Ductile-Brittle Transition Tempesatures of V-Cr-Ti Alloys," this report, also presented at the 6th Intl. Conf. on Fusion Reactor Materials, Sept. 27-Oct. 1, 1993, Stresa, Italy. 


\section{ASSESSMENT OF NIOBIUM-BASE ALLOYS FOR STRUCTURAL APPLICATIONS} IN THE ITER DIVERTOR* I. M. Purdy (Argonne National Laboratory)

\section{OBJECTIVE}

Niobium-base alloys are under consideration as candidate materials for the divertor structure of the International Thermonuclear Experimental Reactor (ITER). Suitability criteria of the alloys include resistance to aqueous corrosion, erosion/corrosion, fatigue, stress corrosion cracking, hydrogen embrittlement, and radiation-induced embrittlement. Because high thermal fluxes are predicted, thermal conductivity, thermal expansion, and heat capacity are important properties. Corrosion resistance, mechanical properties, and physical characteristics are being investigated to identify the most promising Nb-base alloys.

\section{SUMMARY}

The corrosion and embrittlement of pure $\mathrm{Nb}, \mathrm{Nb}-1 \mathrm{Zr}, \mathrm{Nb}-5 \mathrm{Mo}-1 \mathrm{Zr}$, and $\mathrm{Nb}-5 \mathrm{~V}-1.25 \mathrm{Zr}$ (alloy elements in wt.\%) were evaluated in high-purity (HP) deoxygenated water at $300^{\circ} \mathrm{C}$ for up to 120 days. One heat of the Nb-5V-1.25Zr alloy ("O" lot) exhibited both a modest corrosion rate and good resistance to embrittlement relative to other Nb-base alloys. At present, $\mathrm{Nb}-5 \mathrm{~V}-1.25 \mathrm{Zr}$ is the most promising $\mathrm{Nb}$-base alloy with respect to both corrosion and embrittlement characteristics in HP deoxygenated water at $300^{\circ} \mathrm{C}$.

\section{PROGRESS AND STATUS}

In previous work, ${ }^{1-4}$ the corrosion behavior of $\mathrm{Nb}$-base alloys $(\mathrm{Nb}-2.5 \mathrm{~V}, \mathrm{Nb}-2.5 \mathrm{Ta}, \mathrm{Nb}-2.5 \mathrm{~W}$, $\mathrm{Nb}-2.5 \mathrm{Zr}, \mathrm{Nb}-2.5 \mathrm{Hf}, \mathrm{Nb}-2.5 \mathrm{Mo}, \mathrm{Nb}-2.5 \mathrm{Fe}$, and several ternary alloys, namely, $\mathrm{Nb}-2.5 \mathrm{Ti}-2.5 \mathrm{Ta}$, $\mathrm{Nb}-2.5 \mathrm{Mo}-2.5 \mathrm{Ti}, \mathrm{Nb}-2.5 \mathrm{Mo}-2.5 \mathrm{Hf}, \mathrm{Nb}-5 \mathrm{Mo}-1 \mathrm{Zr}$, and $\mathrm{Nb}-5 \mathrm{~V}-1.25 \mathrm{Zr}$ ) was investigated in $\mathrm{HP}$ deoxygenated water at $300^{\circ} \mathrm{C}$. Most of the alloys were deemed brittle, i.e., fracture occurred during a $90^{\circ}$ bend test; however, the ternary alloys exhibited the best fracture resistance. ${ }^{4}$ The results suggest that $\mathrm{Nb}$ alloys with higher concentrations of certain alloying elements (namely, $\mathrm{V}, \mathrm{Mo}$, and $\mathrm{Zr}$ ) are required to improve the protective nature of the corrosion-product layers and to decrease hydrogen uptake and embrittlement. During this reporting period, specimens of pure $\mathrm{Nb}, \mathrm{Nb}-1 \mathrm{Zr}, \mathrm{Nb}-5 \mathrm{Mo}-1 \mathrm{Zr}$, and $\mathrm{Nb}-5 \mathrm{~V}-1.25 \mathrm{Z}$ were examined by optical and scanning electron microscopy (SEM).

\section{Experimental procedures}

The details of the experimental procedure were described previously. ${ }^{4}$ Thin sheets of pure $\mathrm{Nb}$ and selected $\mathrm{Nb}$-base alloys were sheared to approximate dimensions of $8 \times 20 \mathrm{~mm}$. The $\mathrm{Nb}-5 \mathrm{~V}-1.25 \mathrm{Zr}$ alloy, formerly designated " $\mathrm{Cb} 753$ " by Haynes, was obtained from two different lots; hence the " $\mathrm{N}$ " and "O" designations in Table 1. Thickness of the $\mathrm{Nb}$ and " $\mathrm{O}$ " lot sheet was $0.5 \mathrm{~mm}$; that of the other materials was $0.8 \mathrm{~mm}$. The materials designated " $\mathrm{O}$ " and " $\mathrm{N}$ " differ mainly in impurity content; the levels of impurities in the " $\mathrm{N}$ " material are higher by a factor of $\approx 2$.

The surface area of each specimen was determined by an image analysis technique, with Image ${ }^{\mathrm{TM}}$ software. ${ }^{5}$ The specimens were annealed in vacuo prior to exposure in a refreshed autoclave system at $300^{\circ} \mathrm{C}\left( \pm 2^{\circ} \mathrm{C}\right)$ and $1400 \mathrm{psi}$. The dissolved-oxygen concentration of the inlet water was maintained at $<12 \mathrm{ppb}$. The 120-day immersion test was interrupted at approximately 30,60 , and 90 days for removal of

\footnotetext{
* Work supported by the U.S. Department of Energy, under Contract W-31-109-Eng-38.
} 
specimens. Weight changes of the specimens were determined to $\pm 0.001 \mathrm{mg}$. Ductility changes in specimens were evaluated by a bend test. For microstructural evaluation, the specimens were sectioned with a low-speed diamond saw, and polished to $0.05 \mu \mathrm{m}$ with an alumina slurry on a Syntron vibratory polisher.

Table 1. Composition of niobium and niobium-base alloys

\begin{tabular}{|c|c|c|c|c|c|c|c|c|c|c|c|}
\hline \multirow[t]{2}{*}{ Alloy ${ }^{2}$} & \multicolumn{3}{|c|}{ Elements, wt.\% } & \multicolumn{8}{|c|}{ Elements, ppm } \\
\hline & Mo & $\mathbf{v}$ & $\mathbf{Z}$ & 0 & $\mathbf{N}$ & C & H & Si & Al & $\mathrm{Fe}$ & $\mathbf{C r}$ \\
\hline$\overline{\mathbf{N b}}$ & 0.01 & $<0.01$ & $<0.01$ & 5700 & 1700 & 130 & 2.9 & $<100$ & 50 & $<50$ & $<20$ \\
\hline $\mathrm{Nb}-1 \mathrm{Zr}$ & $<0.01$ & $<0.01$ & 0.82 & 153 & 57 & 70 & 4.0 & $<100$ & 65 & $<50$ & $<20$ \\
\hline $\mathrm{Nb}-5 \mathrm{Mo}-1 \mathrm{Zr}$ & 4.86 & $<0.01$ & 0.81 & 186 & 56 & 70 & 8.5 & $<100$ & 70 & $<50$ & $<20$ \\
\hline $\mathrm{Nb}-5 \mathrm{~V}-1.25 \mathrm{Zr}(\mathrm{N})$ & $<0.01$ & 5.76 & 1.11 & 720 & 75 & 300 & 10.3 & 150 & 155 & 100 & 150 \\
\hline $\mathrm{Nb}-5 \mathrm{~V}-1.25 \mathrm{Zr}(\mathrm{O})$ & $<0.01$ & 5.69 & 0.84 & 310 & 95 & 130 & 4.1 & 260 & 65 & 35 & 25 \\
\hline
\end{tabular}

aconcentrations of $\mathrm{Hf}, \mathrm{W}, \mathrm{Ta}$, and $\mathrm{Ti}$ are $\leq 100 \mathrm{ppm} ; \mathrm{Mn}, \mathrm{Cu}$, and $\mathrm{Ni} \leq 50 \mathrm{ppm}$; and $\mathrm{Mg} \leq 5 \mathrm{ppm}$.

\section{Oxidation kinetics}

Oxidation rates of the alloys followed power-law kinetics, as, shown in Fig. 1. The weight-gain-vstime data for $\mathrm{Nb}-\mathrm{Zr}, \mathrm{Nb}-5 \mathrm{Mo}-1 \mathrm{Zr}$, and $\mathrm{Nb}-5 \mathrm{~V}-1.25 \mathrm{Zr}$ alloys indicate $\mathrm{t}^{0.68}, \mathrm{t}^{0.58}$, and $\approx \mathrm{t}^{0.35}$ kinetics, respectively. The two heats of the $\mathrm{Nb}-5 \mathrm{~V}-1.25 \mathrm{Zr}$ alloy showed similar behavior and significantly slower weight gain than the other materials.

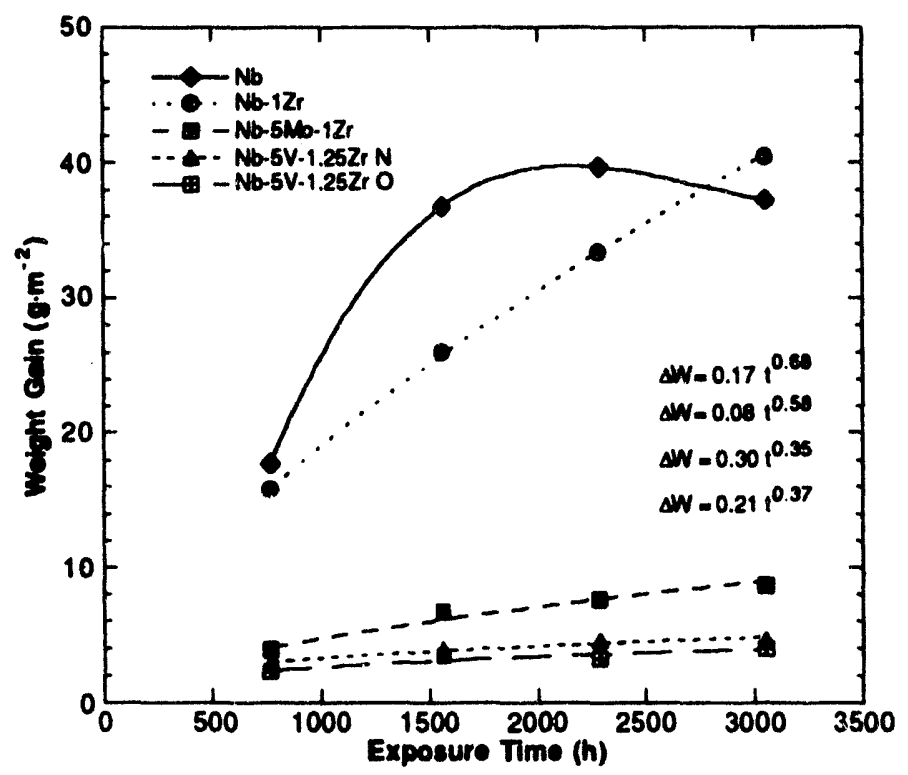

Figure 1. Weight gain vs. time for $\mathrm{Nb}$ and $\mathrm{Nb}$-base alloys exposed to HP deoxygenated water at $300{ }^{\circ} \mathrm{C}$ 


\section{Embrittlement characteristics}

The embrittlement characteristics of the ternary alloys determined from this and a previous experiment ${ }^{1}$ after 120 days at $300^{\circ} \mathrm{C}$ are shown in Fig. 2. Fracture susceptibility, as determined from room-temperature bend tests, was categorized according to the following fracture index (FI): an FI of 6 indicates breakage before bending began; $F I$ of 5 denotes fracture at a $90^{\circ}$ bend; FI of 4 , fracture occurs after a $180^{\circ}$ bend; FI of 3 , the specimen fractures only after unbending of a fold; an FI of 2 , no fracture even on unbending of a fold; and FI of 1 , no fracture or surface cracking of the oxide scale that formed during exposure. Lot " $\mathrm{O}$ " of the $\mathrm{Nb}-5 \mathrm{~V}-2.5 \mathrm{Zr}$ alloy indicates less embrittlement than any of the $\mathrm{Nb}$-base alloys evaluated thus far.

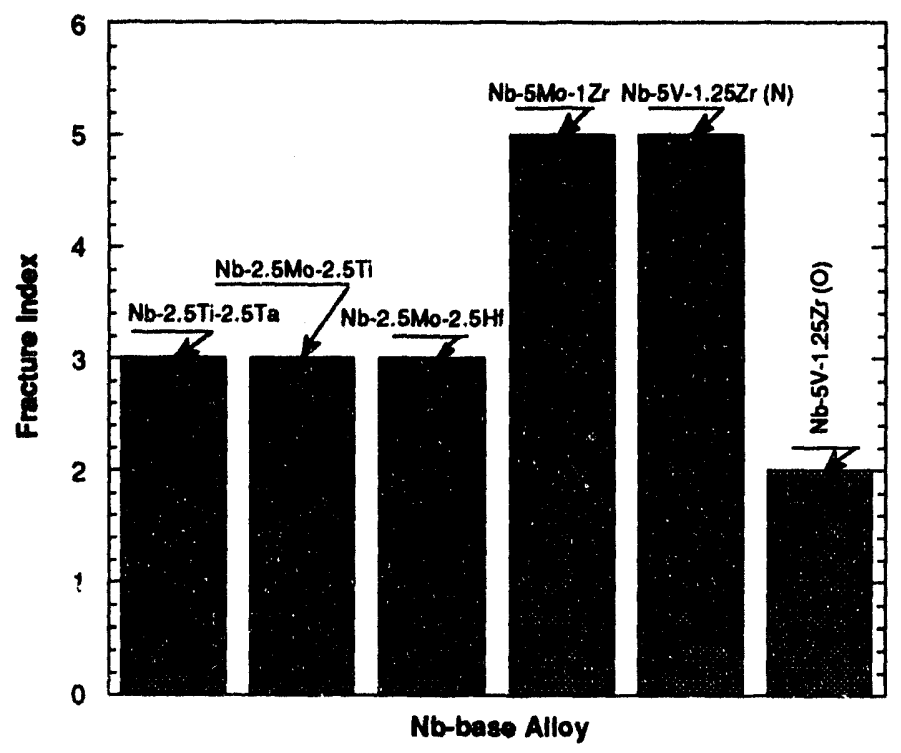

Figure 2. Fracture index for $\mathrm{Nb}$-base alloys after exposure to $H P$ deoxygenated water for 120 days at $300^{\circ} \mathrm{C}$

\section{Microstructural observations}

As in a previous study, ${ }^{2}$ the surface appearance of the alloys changed little after $30-60$ days of exposure. The oxide scale appeared somewhat filamentary at shorter exposure times. In Fig. 3, there is little difference in surface appearance between $\mathrm{Nb}$ and the $\mathrm{Nb}-5 \mathrm{~V}-1.25 \mathrm{Zr}$ at 30 - and 120-day exposure periods, except for the somewhat larger grain size at the longer exposure time.

On the basis of film thicknesses $(\approx 10 \mu \mathrm{m})$ in polished cross sections, the oxidation behavior of $\mathrm{Nb}$ and $\mathrm{Nb}-1 \mathrm{Zr}$ after 30 days of exposure is similar (Fig. 4). Similar photomicrographs of specimens of the ternary alloys after the 30-day exposure are not shown because the oxide layers were barely perceptible. Figure 5 shows cross sections of the films on the five materials after 120 days of exposure. Scale thicknesses are $20-30 \mu \mathrm{m}$ for $\mathrm{Nb}, 10 \mu \mathrm{m}$ for $\mathrm{Nb}-1 \mathrm{Zr}$, and $2 \mu \mathrm{m}$ for each of the ternary alloys. All scales at the oxide-metal interface appear to be tightly adherent but some porosity is apparent near the external surface. Although the scale on $\mathrm{Nb}$ is thicker than on the alloys, $\mathrm{Nb}$ exhibited a net weight loss, indicating that some of the corrosion product is soluble in high-temperature water. 


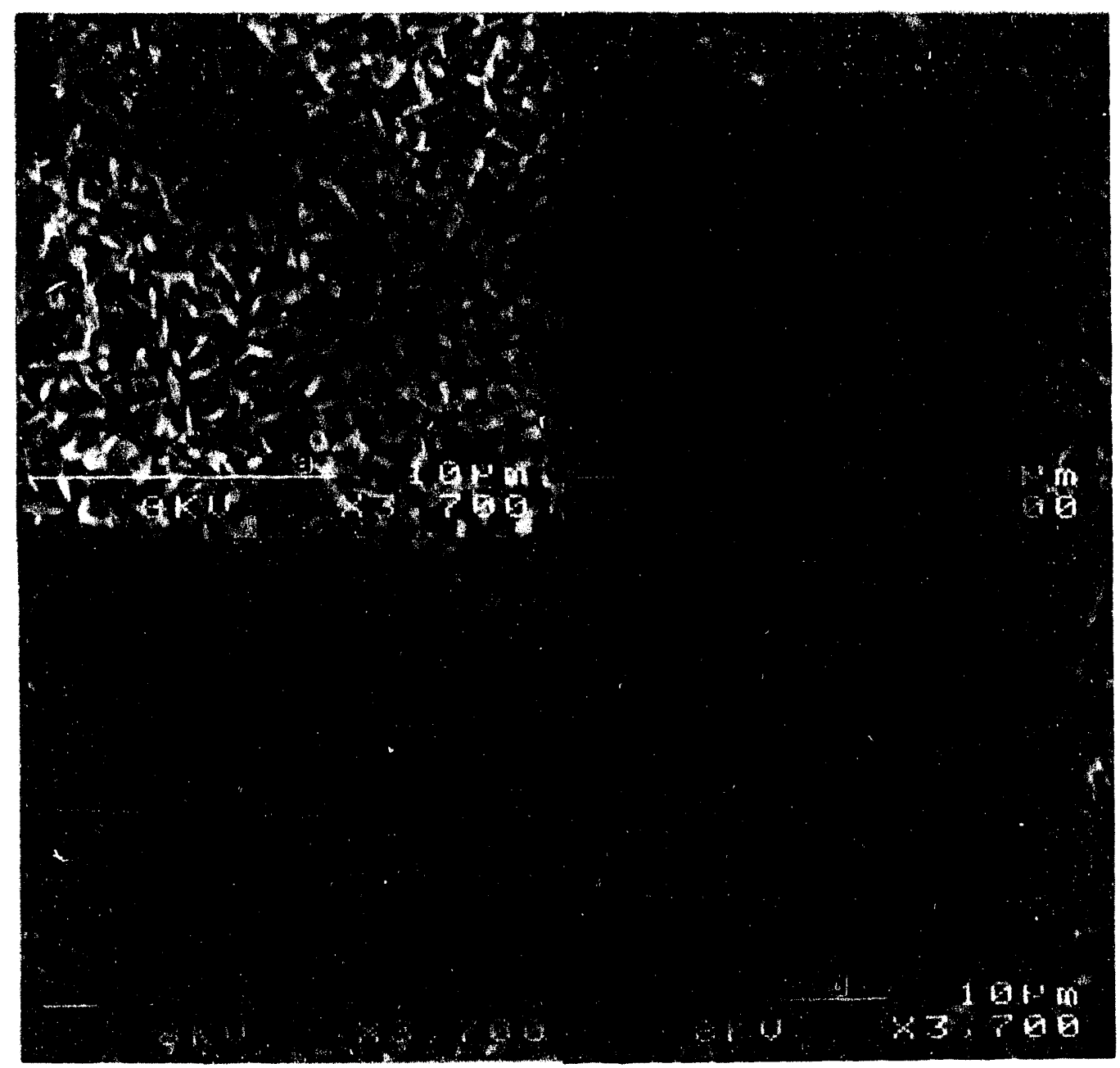

Figure 3. SEM photomicrographs showing the surface of $N b$ ( $a$ and $b$ ) and $N b-5 V-1.25 Z r(O)$ ( $c$ and $d$ ) specimens after exposure for 30 and 120 days, $a$ and $c$ and $b$ and $d$, respectively. Both oxides show a larger grain size at 120 days than at 30 days.

\section{CONCLUSIONS}

Experience has shown that alloys with high W $(\approx 10 \mathrm{wt} . \%)$ and Mo $(\approx 5 \mathrm{wt} . \%)$ content are difficult to fabricate and weld, and that a high Ta content reduces the irradiation resistance of a material. ${ }^{3}$ Our results show that (a) $\mathrm{V}$ additions lower the corrosion rate and (b) $\mathrm{Hf}$ and $\mathrm{Zr}$ additions lower both the $\mathrm{H}$ concentration and the percentage of corrosion-product $\mathrm{H}$ that is absorbed by $\mathrm{Nb}$-base alloys ${ }^{3}$ (compared to $\mathrm{Nb}-\mathrm{V}$ alloys). The $\mathrm{Nb}-5 \mathrm{~V}-1.25 \mathrm{Zr}$ alloy shows the greatest promise in terms of resistance to both corrosion and embrittlement in high-temperature deoxygenated water.

\section{FUTURE WORK}

Because of priorities within the ITER materials development program, no further work will be conducted on the corrosion of $\mathrm{Nb}$-base alloys for the divertor structure. 


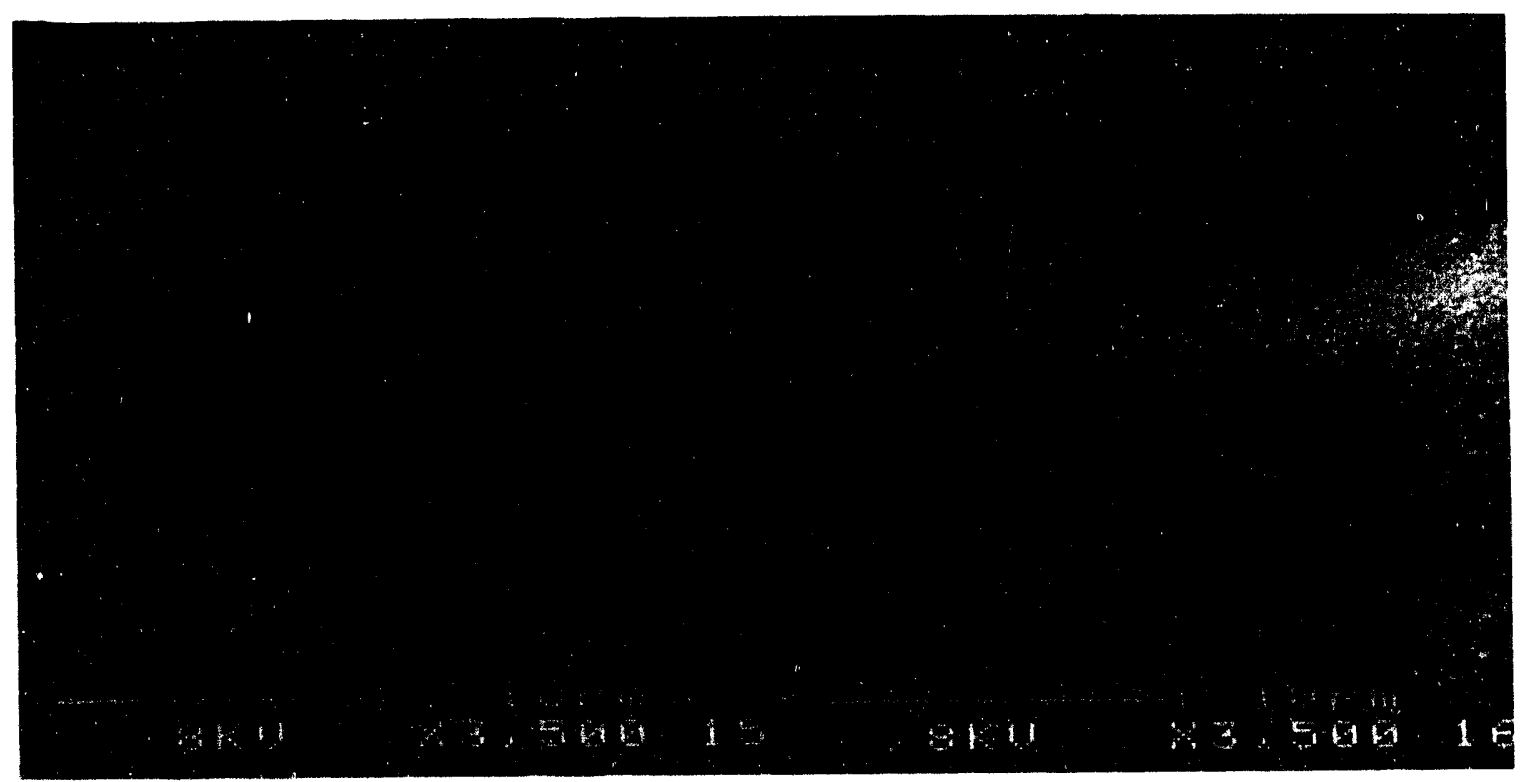

Figure 4. SEM photomicrographs showing cross sections of $(a) N b$ and $(b) N b-1 Z r$ after 30 -day exposure to HP water at $300^{\circ} \mathrm{C}$

\section{REFERENCES}

1. A. B. Hull, B. A. Loomis, and L. J. Nowicki, Preliminary Assessment of Aqueous Corrosion of Niobium Alloys for Structural Applications in the ITER Divertor, Fusion Reactor Materials Semiannual Report for Period Ending March 31, 1991, DOE/ER-0313/10, Oak Ridge National Laboratory, p. 248 (July 1991).

2. J. A. Todd and I. M. Purdy, Preliminary Assessment of Candidate Niobium Alloys for the Divertor Structures, Fusion Reactor Materials Semiannual Report for Period Ending September 30, 1992, DOE/ER-0313/13, Oak Ridge National Laboratory, p. 203.

3. D. T. Peterson, A. B. Hull, and B. A. Loomis, Hydrogen Embrittlement of Niobium-Base Alloys for Application in the ITER Divertor, Fusion Reactor Materials Semiannual Report for Period Ending September 30, 1992, DOE/ER-0313/13, Oak Ridge National Laboratory, p. 182.

4. I. M. Purdy, Assessment of Niobium-Base Alloys for Structural Applications in the ITER Divertor, Fusion Reactor Materials Semiannual Report for Period Ending March 31, 1993, DOE/ER-0313/14, Oak Ridge National Laboratory, p. 294 (July 1993).

5. W. Rasband, Image, Public Domain Program for the Macintosh Computer, distributed by Twilight Clone BBS, Silver Spring, MD, 1990. 


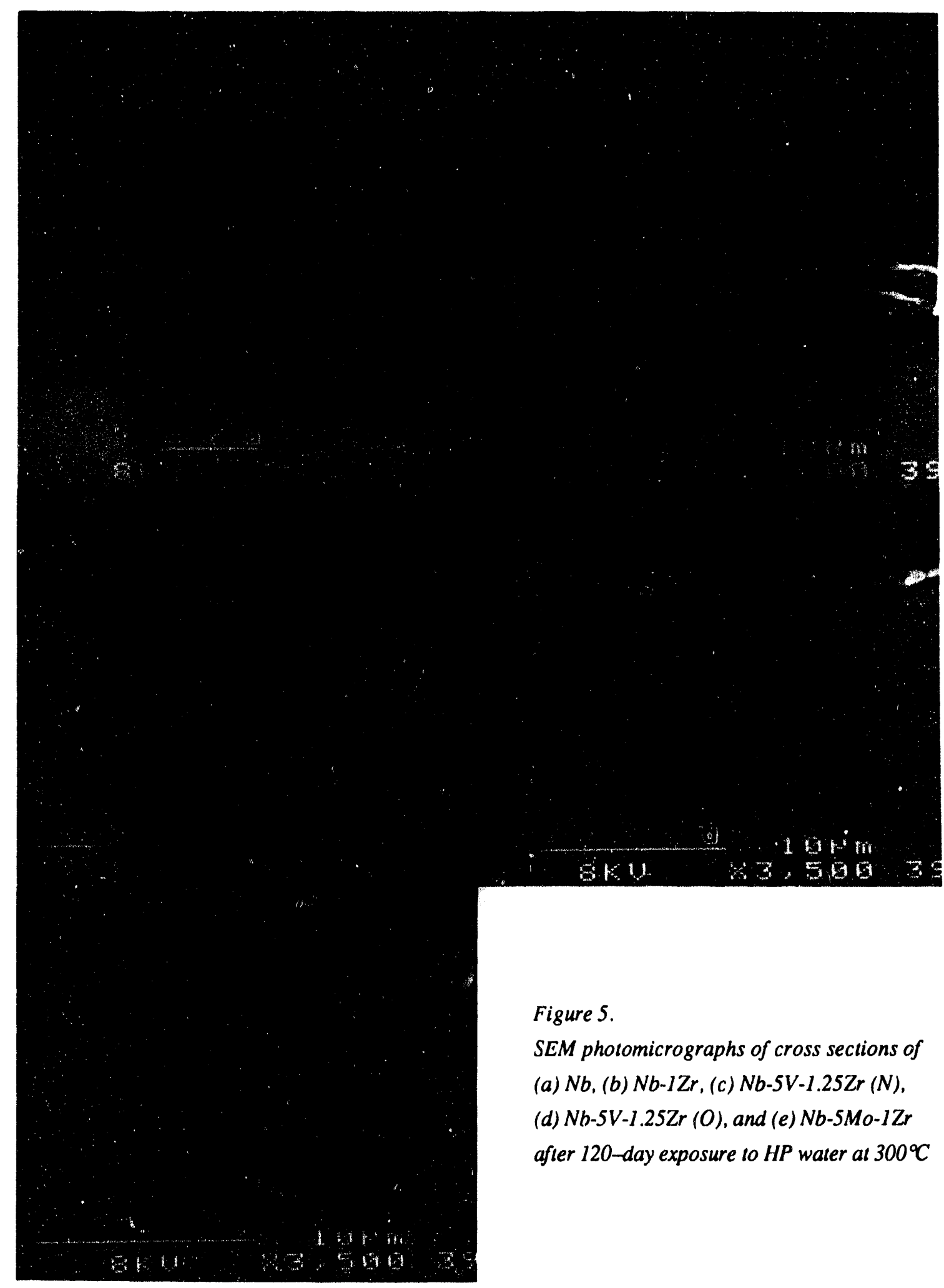


THE INFLUENCE OF STARTING STATE ON NEUTRON INDUCED DENSITY CHANGES OBSERVED IN Nb-1Zr AND Mo-41Re AT HIGH EXPOSURES - F. A. Garner, L. R. Greenwood, and D. J. Edwards, (Pacific Northwest Laboratory) ${ }^{a}$

\section{OBJECTIVE}

The objective of this effort is to determine the suitability of various refractory alloys for possible fusion applications.

\section{SUMMARY}

Both $\mathrm{Nb}-1 \mathrm{Zr}$ and Mo-41Re were irradiated in FFTF at five temperatures between 420 and $730^{\circ} \mathrm{C}$, reaching maximum exposure levels of 58 to $111 \mathrm{dpa}$, depending on the irradiation temperature. Each alloy was irradiated in two starting conditions, cold-worked and aged or annealed and aged. The neutron-induced swelling behavior in response to starting condition was quite different for the two alloys and appeared to reflect a strong role of precipitation in each. While transmutation does not play a major role in the response of $\mathrm{Nb}-1 \mathrm{Zr}$, it plays a significant role in the behavior of $\mathrm{Mo}-41 \mathrm{Re}$, which becomes a heavilyprecipitated Mo-Re-Os-Tc-Ru alloy. This strong response may preclude the use of Mo-Re alloys for fusion application.

\section{PROGRESS AND STATUS}

Introduction

Both $\mathrm{Mo}-41 \mathrm{Re}$ and $\mathrm{Nb}-1 \mathrm{Zr}$ have at times been proposed as candidates for use in fusion reactors, usually for high heat flux applications. Irradiation data on these materials are rather limited, however, and additional data are required to properly evaluate the potential of these refractory alloys for fusion service. Therefore, these alloys were irradiated side-by-side in FFTF along with pure molybdenum, whose behavior is presented elsewhere.'

\section{Experimental Details}

The specimens were in the form of $3 \mathrm{~mm}$ diameter microscopy disks that were $0.25 \mathrm{~mm}$ thick. Each alloy was irradiated in two thermomechanical starting conditions. The first condition involved solution annealing for $1 \mathrm{hr}$ at $760^{\circ} \mathrm{C}$ and then aging for $2 \mathrm{hrs}$ at $320^{\circ} \mathrm{C}$. The second used $20 \%$ cold-working, following the $760^{\circ} \mathrm{C}, 1 \mathrm{hr}$ annealing, and then aging at $320^{\circ} \mathrm{C}$ for $2 \mathrm{hrs}$. Irradiation proceeded in weeper packets in the Materials Open Test Assembly (MOTA), and thus the specimens were in contact with the sodiurn coolant of the Fast Flux Test Facility (FFTF) reactor. Table 1 lists the irradiation conditions.

Although irradiation in MOTA proceeded largely under active temperature control $\left( \pm 5^{\circ} \mathrm{C}\right)$ in MOTA's $1 \mathrm{~B}$, $1 \mathrm{C}$ and $1 \mathrm{E}$, there was a short ( 50 minutes) temperature excursion in MOTA ID during FFTF cycle 7, referred to as an over-temperature event. The event compromised the integrity of many of the other experiments in MOTA ID. Therefore, a programmatic decision was made to run MOTA-1D in the

\footnotetext{
"Pacific Northwest Laboratory is operated for the U.S. Department of Energy by Battelle Memorial
} Institute under Contract DE-AC06-76RLO 1830. 
Table 1. Target Temperatures During Irradiation in FFTF-MOTA

During Four Successive Irradiation Segments

\begin{tabular}{|c|c|c|c|c|}
\hline \multirow[b]{2}{*}{ Group } & \multicolumn{3}{|c|}{ MOTA DESIGNATION } & \multirow[b]{2}{*}{$1 \mathrm{E}$} \\
\hline & $1 \mathrm{~B}$ & $1 \mathrm{C}$ & $1 D^{*}$ & \\
\hline 1 & $431^{\circ} \mathrm{C}$ & $420^{\circ} \mathrm{C}$ & $404^{\circ} \mathrm{C}$ & $414^{\circ} \mathrm{C}$ \\
\hline 2 & $471^{\circ} \mathrm{C}$ & $470^{\circ} \mathrm{C}$ & $470^{\circ} \mathrm{C}$ & --- \\
\hline 3 & $569^{\circ} \mathrm{C}$ & $550^{\circ} \mathrm{C}$ & $549^{\circ} \mathrm{C}$ & -- \\
\hline 4 & $645^{\circ} \mathrm{C}$ & $652^{\circ} \mathrm{C}$ & $650^{\circ} \mathrm{C}$ & -- \\
\hline 5 & $722^{\circ} \mathrm{C}$ & $730^{\circ} \mathrm{C}$ & $730^{\circ} \mathrm{C}$ & $\cdots$ \\
\hline
\end{tabular}

* The first one-third of this segment proceeded at the target temperature. A short $(\sim 1 \mathrm{hr})$ overtemperature period was then followed by a variable temperature history, with temperatures below the target temperature.

helium-purged mode for the remainder of FFTF cycles 7 and 8 while a series of reactor feedback tests were conducted. The majority of the MOTA canisters, therefore, operated at variable but lower than target temperatures until the end of FFTF cycle 8. Isothermal irradiation was reestablished in MOTA IE, but only the $420^{\circ} \mathrm{C}$ specimens were included in that irradiation segment.

Density measurements were performed using an immersion density technique whose accuracy has been established to be $\pm 0.16 \%$ density change. The displacement levels quoted are thos calculated for stainless steel. Detailed calculations for the dilute alloy $\mathrm{Nb}-1 \mathrm{Zr}$ have not yet been performed, but should be on the order of $114 \%$ of those of steel, assuming the alloy to be pure $\mathrm{Nb}$. It is more difficult, however, to specify the displacement level for a concentrated binary alloy such as Mo-41Re, whose constituents vary greatly in atomic weight.

Results

Figure 1 presents the results of density measurements $\left(-\Delta \rho / \rho_{0}\right)$ performed on the $\mathrm{Nb}-1 \mathrm{Zr}$ specimens. It is obvious that some phase-related dilation of the alloy matrix probably occurs in the cold-worked alloy early in the irradiation, producing a density decrease of $0.5 \pm 0.1 \%$. This conclusion is supported by the relative temperature independence of the density change. This change may also include small contributions from void swelling, however, a possibility that will be examined during microscopy. The swelling behavior thereafter appears to be rather somplex, both with irradiation temperature and increasing neutron exposure. In general, however, there is a tendency at the higher temperatures for swelling to continue. There are indications of late-term densification at 420 and $569^{\circ} \mathrm{C}$.

The annealed and aged condition, with one exception at $645^{\circ} \mathrm{C}$, also appears to densify, probably as a result of some precipitation reaction. The exception is significant in that the behavior at $645^{\circ} \mathrm{C}$ parallels that of the cold-worked and aged condition at this same temperature, with the offset between the behavior of the twn conditions consistent with their respective differences in phase-related density change.

Of particular interest is the parallel behavior of both starting conditions observed at $420^{\circ} \mathrm{C}$, leading to densification. It is obvious that two or more processes are competing to produce the observed changes in density and that the starting state affects at least one of these processes. It is surmised that the primary difference between the two starting states resides in the distribution of grain sizes. In companion studies conducted on molybdenum in this same irradiation series, small grain sizes produced by an identical heat treatment were found to cause earlier and, therefore, larger swelling.' 


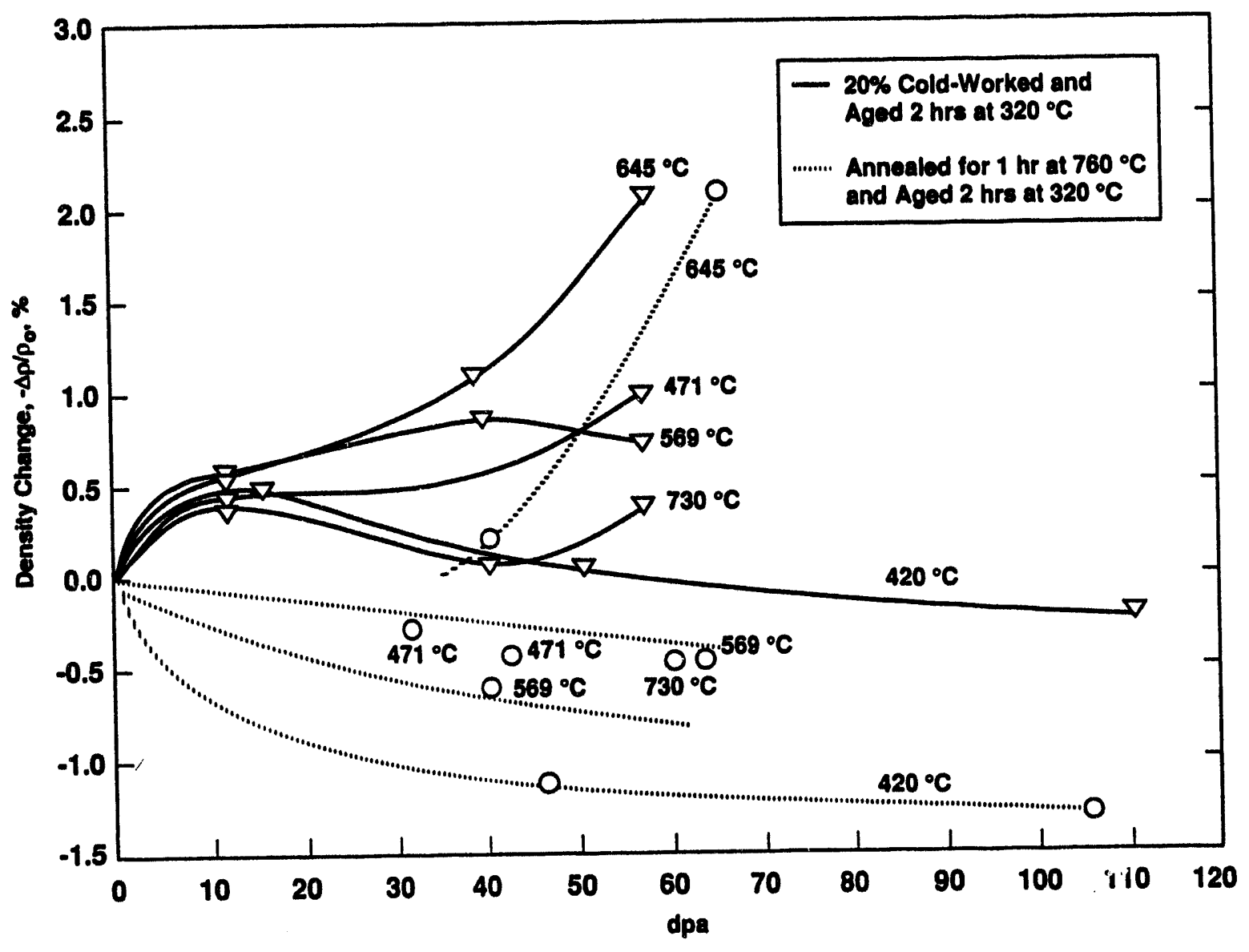

Figure 1. Density changes observed in $\mathrm{Nb}-1 \mathrm{Zr}$ after irradiation in FFTF-MOTA.

Figures 2 and 3 present the swelling behavior observed in Mo 41 Re. The behavior is rather complex, with the annealed and aged state usually swelling more initially, but then declining to levels comparable to that of the cold-worked and aged condition. Preliminary microscopy examination shows that this alloy is subject to intense precipitation of a hexagonal close packed (hcp) phase, as shown in Figure 4. Therefore, phase-related density changes associated with such precipitation may also contribute to the observed behavior.

\section{Discussion}

$\mathrm{Nb}-1 \mathrm{Zr}$ does not undergo a significant amount of transmutation, with the largest calculated change being the formation of $0.13 \%$ Mo at 60 dpa in the FFTF core center. Its behavior in this study probably reflects the influence of dislocation substructure on both precipitation and void nucleation, possibilities that will be explored in later microstructural st idies.

The complexity exhibited by the swelling of $\mathrm{Nb}-1 \mathrm{Zr}$ in response to differences in starting state and temperature indicate that caution is advised in compilation and use of swelling data from oiner sources. ${ }^{3.5}$ Most earlier studies concentrated on the annealed condition only, and may contain varying levels of precipitate contribution to the apparent swelling. In compilation of such data, care should be taken 


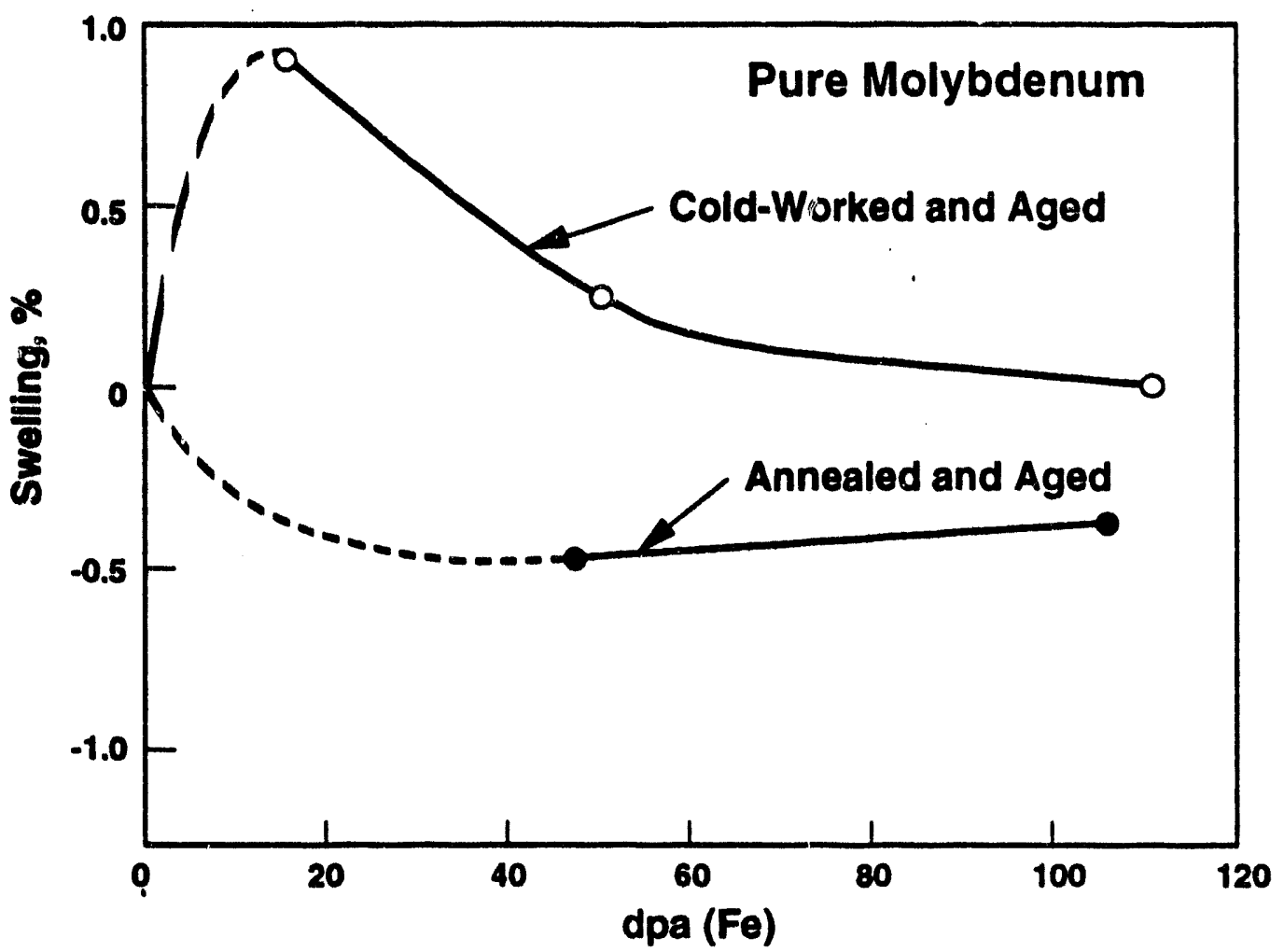

Figure 2. Swelling of Mo-41Re after irradiation at a target ${ }^{\circ}$ temperature of $420^{\circ} \mathrm{C}$.

to differentiate between swelling levels derived from density change and those derived from microscopy measurements.

The late-term decreases in swelling in Mo-41Re may partially reflect some influence of the non-isothermal temperature history toward the end of the irradiation sequence, but these decreases may also be related to void shrinkage, which was observed in companion specimens of pure molybdenum. ${ }^{1}$ The role of precipitation is also much more complex in this alloy since molybdenum transmutes strongly in FFTF to technicium and ruthenium, and rhenium transmutes even more strongly to osmium. Based on examination of the phase diagrams for various Mo-binary alloy's, all of these transmutants are expected to participate in the precipitation process. It is difficult to exactly predict the final composition of the alloys since the transmutation rates are very sensitive to neutron spectra, varying strongly within and near the FFTF core, as shown in Figures $j$ and 6 . Osmium was detected in the irradiated alloys, however, providing initial estimates of the composition. Figure 7 demonstrates that the precipitates shown in Figure 4 are $8.6 \% \mathrm{Mo}$, $74.9 \% \mathrm{Re}$, and $16.5 \%$ Os. Measurements of the bulk osmium level are $~ 9 \%$, in good agreement with the level predicted in Figure 6. However, due to the selective electro-polishing of the matrix, this value may overestimate the osmium level somewhat.

The rate of transmutation in rhenium is much stronger in mixed spectrum reactors. ${ }^{2}$ Recent Russian studies showed that Mo-Re alloys irradiated in the mixed spectrum reactor SM-2 lost 20 to $30 \%$ of their electrical conductivity and much of their fracture resistance at relatively low exposures $\left(\sim 5 \times 10^{21} \mathrm{n} \mathrm{cm}^{-2}\right)^{6,7}$ Based on calculations for a typical mixed spectrum, osmium formation was probably the major cause of the conductivity degradation, but the loss of fracture resistance was probably due to precipitation more than to osmium formation. 


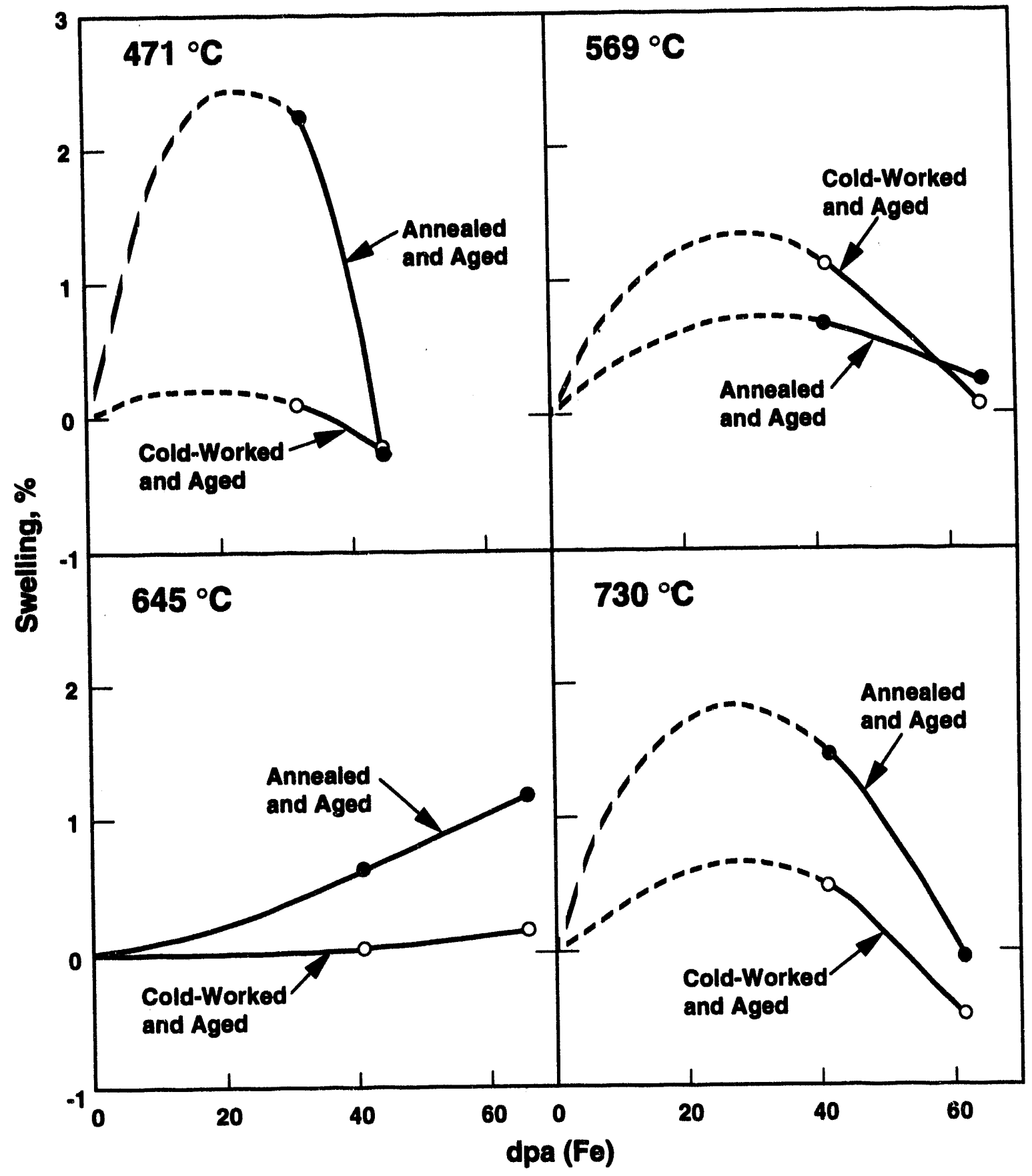

Figure 3. Density changes of Mo-41Re at temperatures between 471 and $730^{\circ} \mathrm{C}$.

The relative roles of transmutation, precipitation, and void formation in determining the measured density changes are difficult to separate. Microscopy examination is in progress to sort out the relative contributions. The separation is necessary to apply these FFTF data to applications in fusion spectra where the transmutation rate will be different. Reference 2 shows that the STARFIRE spectra will produce a transmutation rate per dpa that is significantly higher than that at FFTF core center 


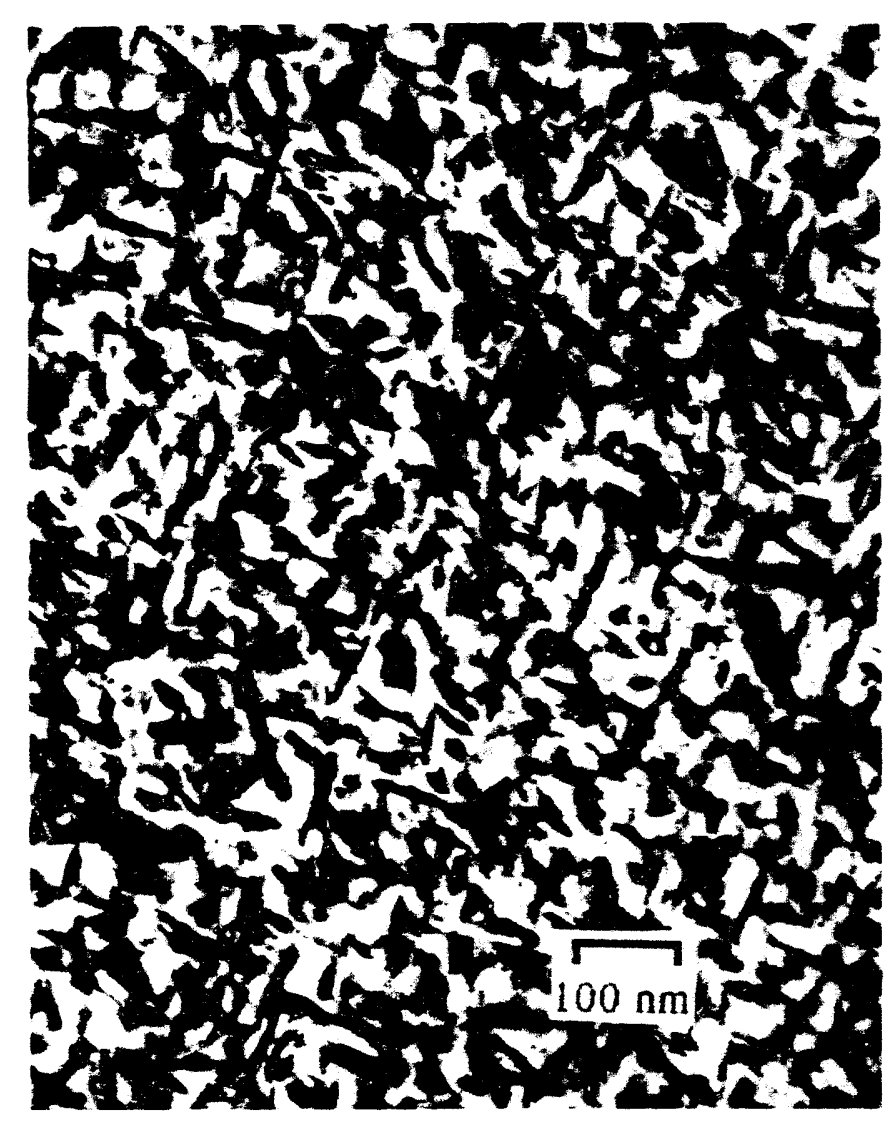

(a)

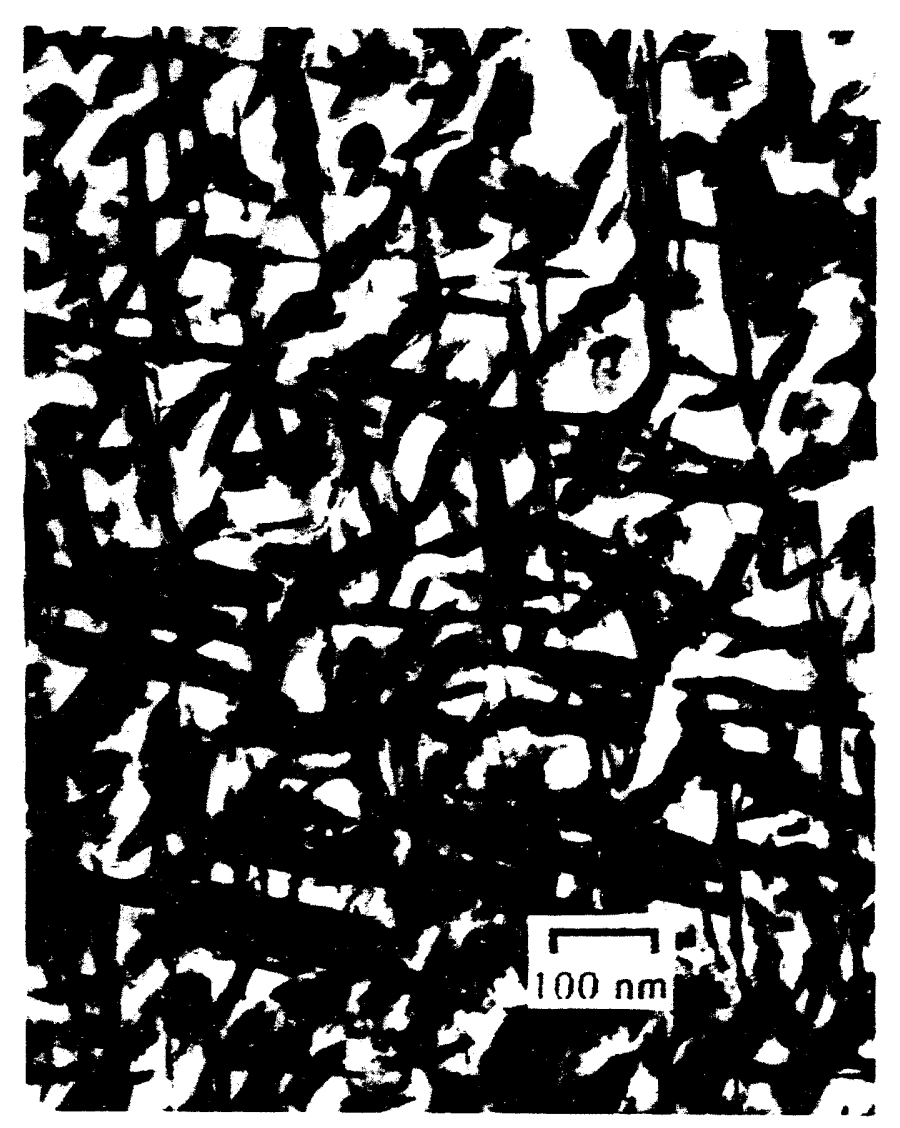

(b)

Figure 4. Radiation-induced hep precipitates in Mo-41Re irradiated to $\sim 60 \mathrm{dpa}(\mathrm{Fe})$ at a) $645^{\circ} \mathrm{C}$ and b) $730^{\circ} \mathrm{C}$. 


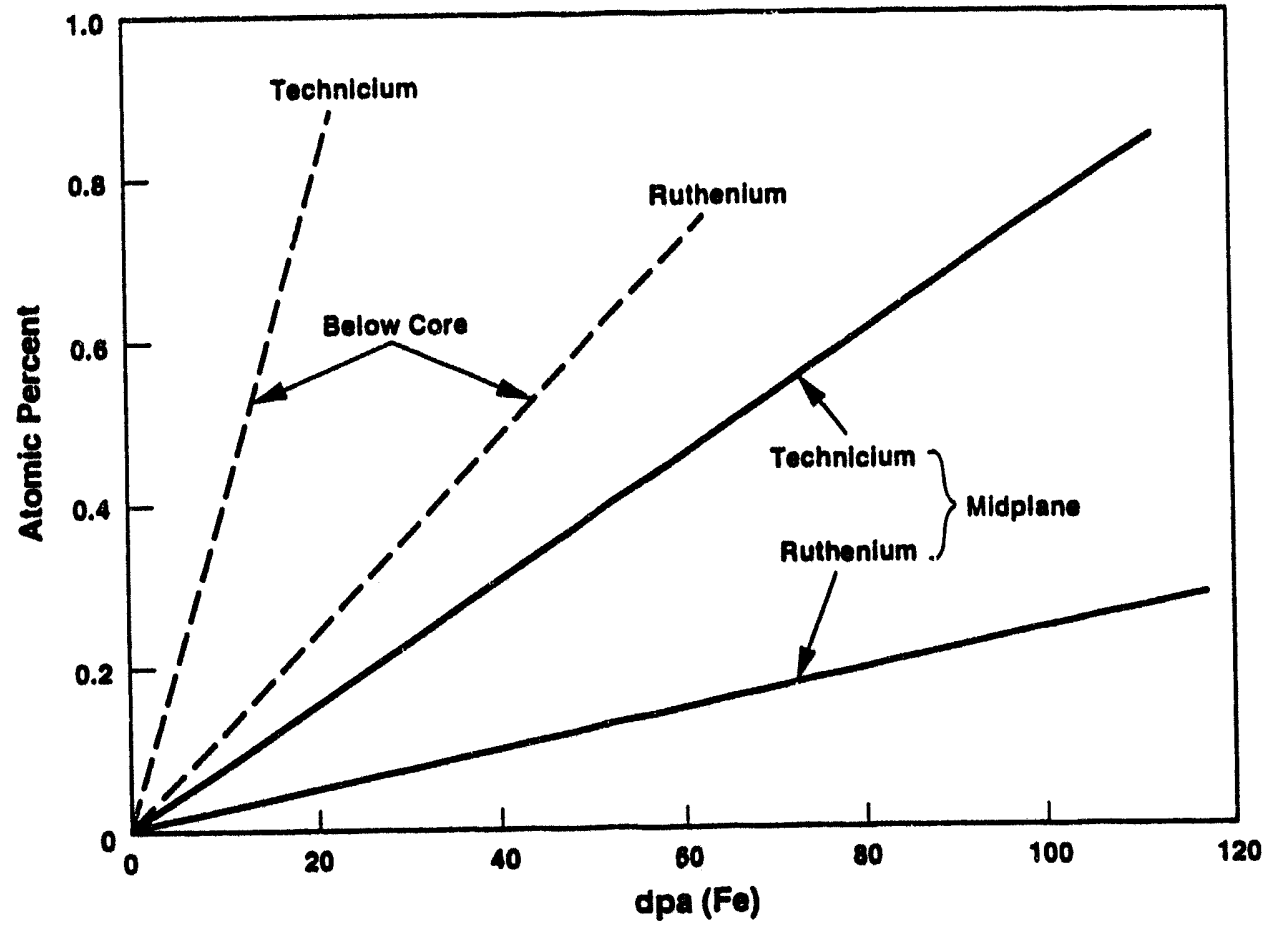

Figure 5. Predictions of technicium and ruthenium formation in pure molybdenum during irradiation in FFTF. ${ }^{2}$

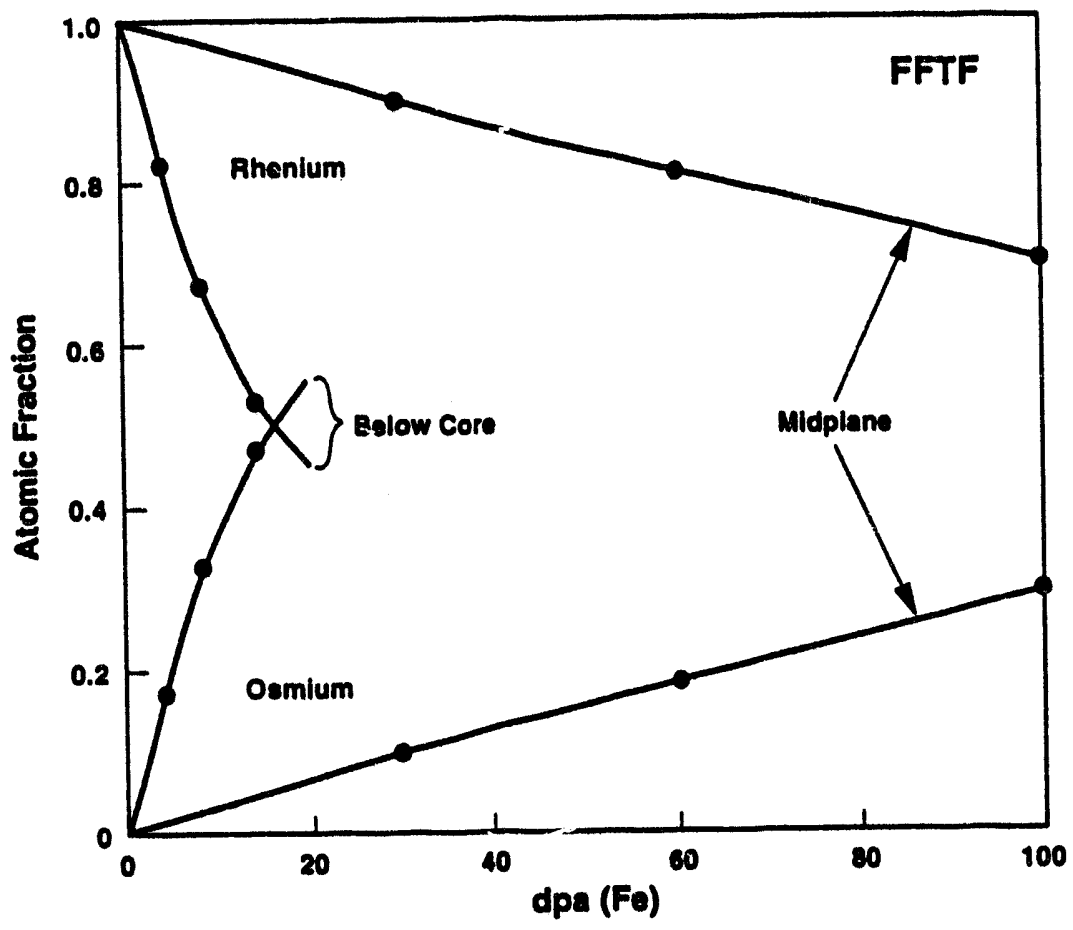

Figure 6. Prediction of osmium formation in rhenium during irradiation in FFTF. ${ }^{2}$ 


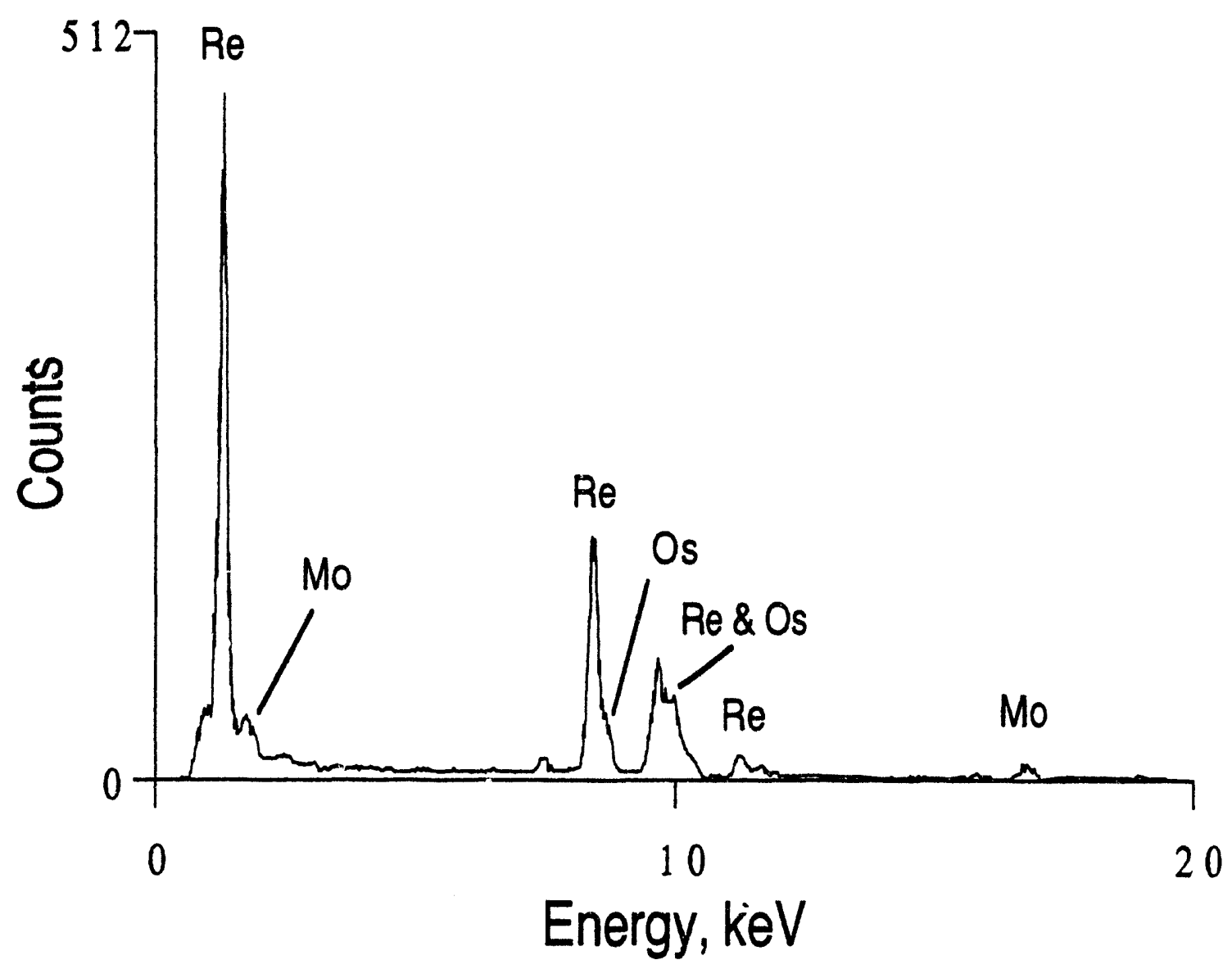

Figure 7. EDS spectrum of precipitates formed in Mo-41 Re irradiated at $730^{\circ} \mathrm{C}$ to $\sim 60 \mathrm{dpa}(\mathrm{Fe})$ in FFTF.

but somewhat less than that of the FFTF below core basket position. It is also anticipated that the precipitation may be sensitive to displacement rate, since it probably involves non-equilibrium segregation to produce phase distributions not predicted by equilibrium phase diagrams. Chi-phase precipitates, for instance, are known to develop in ion-irradiated Mo-Re alloys, ${ }^{8-10}$ even though the equilibrium phase diagram would not have predicted its formation at this composition unless non-equilibrium segregation was involved. Ion bombardment, of course, does not result in transmutation. The combined influence of transmutation and segregation in this study has produced a completely unexpected hcp phase.

\section{CONCLUSIONS}

The thermomechanical starting state influences the response to irradiation of Mo- $41 \mathrm{Re}$ and $\mathrm{Nb}-1 \mathrm{Zr}$. It appears that precipitation processes contribute to and affect the density change behavior, with the precipitation processes themselves being sensitive to the starting state. While transmutation plays no significant role in the radiation-induced evolution of $\mathrm{Nb}-1 \mathrm{Zr}$, it exerts a very significant influence on that of Mo-4IRe. 


\section{ACKNOWLEDGEMENTS}

This work was supported by the U.S. Department of Energy, under Contract DE-AC06-76RLO 1830 at Pacific Northwest Labcratory, operated for the U.S. Department of Energy by Battelle Memorial Institute. The assistance of Jill Walters and Diane Forsyth in preparing the manuscript is gratefully acknowledged.

\section{REFERENCES}

1. J. F. Stubbins and F. A. Garner, in this Semiannual Report.

2. L. R. Greenwoud and F. A. Garner, in this Semiannual Report.

3. R. W. Powell, D. T. Peterson, M. K. Zimmershied, and J. F. Bates, J. Nucl. Mater. 103\&104 (1981) 969-974.

4. D. S. Gelles, J. Nucl. Mater. $122 \& 123$ (1984) 207-213.

5. H. Jang and J. Moteff, in: Proc. Conf. on Radiation Effects and Tritium Technology for Fusion Reactors, Vol. I, CONF-750989 (1975), pp. I-106 to I-121.

6. S. A. Fabritsiev et al., J. Nucl. Mater. 191-194 (1992) 426-429.

7. I. V. Gorynin et al., J. Nucl. Mater. 191-194 (1992) 421-425.

8. R. A. Erck and L. E. Rehn, Phil. Mag. A. 62 (1990) 29-51.

9. R. A. Erck and L. E. Rehn, J. Nucl. Mater. 168 (9189) 208-219.

10. R. A. Erck, C. M. Wayman and L. E. Rehn, in Radiation-Induced Changes in Microstructure: 13th International Symposium (Part I), ASTM STP 955, F.A. Garner, N.H. Packan, and A.S. Kumar, Eds., (American Society for Testing and Materials, Philadelphia, 1987), pp. 721-729. 
283

6.4 Copper Alloys 
NEUTRON-INDUCED MICROSTRUCTURAL ALTERATION OF GLIDCOP ${ }^{\mathrm{TM}}$ ALLOYS AT $415^{\circ} \mathrm{C}$ AND HIGH INEUTRON EXPOSURE - D. J. Edwards, F. A. Garner, (Pacific Northwest Laboratory)", J. W. Newkirk, (University of Missuuri) and A. Nadkarni, (SCM Metal Products)

\section{OBJECTIVE}

The objective of this effort is to determine the factors which control the response to irradiation of copper alloys intended for high heat flux application in fusion reactors.

\section{SUMMARY}

GlidCop ${ }^{\mathrm{TM}}$ internally oxidized copper alloys remain the leading candidates for high heat flux applications in fusion reactors. This paper presents the microstructural changes incurred in three GlidCop ${ }^{\mathrm{TM}}$ alloys exposed to long term, high temperature neutron irradiation.

Irradiation at high temperature produced a microstructure containing a much lower dislocation density than the unirradiated specimens. Although 10-50 nm size triangular oxide particles were observed in areas with a very low number density of particles, spherical oxide particles on the order of 5-7 nm in diameter, thought to be $\mathrm{CuAl}_{2} \mathrm{O}_{4}$, were the predominant morphology. The changes in grain size distribution, dislocation density, and precipitate type and distribution saturate in the range of 34 to $50 \mathrm{dpa}$, as reflected in the saturation of mechanical properties.

\section{PROGRESS AND STATUS}

Copper alloys have been investigated for several years as potential candidates for use in the divertor assembly of the International Thermonuclear Experimental Reactor [1-7]. These studies have demonstrated that the commercial $\mathrm{Cu}-\mathrm{Al}_{2} \mathrm{O}_{3}$ alloys produced by $\mathrm{SCM}$ Metal Products, known as $\mathrm{GlidCop}{ }^{\mathrm{TM}}$ alloys, are the most viable candidate alloys. These alloys exhibit the best combination of swelling resistance, retention of strength, and electrical conductivity of any copper alloy examined to date.

While much of the previous work concentrated on the mechanical and physical properties of the alloys, the microstructural origins of the changes observed were not clearly elucidated. In recent years a number of studies utilizing either neutron irradiation or ion irradiation have attempted to ascertain the mechanisms responsible for the observed behavior. Previous researchers such as Spitznagel et al. [8] and Anderson et al. [3] provided evidence that the aluminum oxide particles in the GlidCop ${ }^{\mathrm{TM}}$ alloys were dissolved by recoil dissolution during ion or neutron irradiation, respectively. Other ion irradiation experiments [9-11] have shown that the oxide particles experience a shift in the size distribution and density of particles, although there is some disagreement concerning the degree and direction of the shift.

Despite the evidence provided by these ion irradiation studies, some uncertainty still exists concerning the stability of the oxide dispersion in the GlidCop ${ }^{\mathrm{TM}}$ alloys after being exposed to high temperature neutron irradiation. The irradiations performed in FFTF entail longer irradiation periods at high temperatures $(\geq$ $0.5 \mathrm{~T}_{\mathrm{MP}}$ ) than experienced in the ion irradiation experiments.

aPacific Northwest Laboratory is operated for the U.S. Department of Energy by Battelle Memorial Institute under Contract DE-AC06-76RLO 1830. 


\section{Experimental}

The GlidCop ${ }^{\mathrm{TM}}$ alloys irradiated in this study were CuAl25 (50\% cold worked (CW), 0.25 wt $\%$ Al as $\left.\mathrm{Al}_{2} \mathrm{O}_{3}\right), \mathrm{CuAl} 20\left(20 \% \mathrm{CW}, 0.20 \mathrm{wt} \% \mathrm{Al}\right.$ as $\left.\mathrm{Al}_{2} \mathrm{O}_{3}\right)$, and $\mathrm{CuAl} 15\left(900^{\circ} \mathrm{C} / 0.5 \mathrm{hr} /\right.$ air cooled $(\mathrm{AC}), 0.15 \mathrm{wt} \%$ $\mathrm{Al}$ as $\mathrm{Al}_{2} \mathrm{O}_{3}$ ) containing $200 \mathrm{ppm}$ boron as a deoxidant. For comparison, specimens of $\mathrm{CuAl} 25$ were aged at $700^{\circ} \mathrm{C}$ for 1000 hours under an argon atmosphere. Both miniature tensile specimens and transmission electron microscopy specimens were irradiated together in FFTF at $\sim 415^{\circ} \mathrm{C}$. The specimens were irradiated to dpa levels of $48 \mathrm{dpa}, 103.5 \mathrm{dpa}$, and $150 \mathrm{dpa}$. TEM specimens were only available for the CuAl15 at 103.5 and $150 \mathrm{dpa}$. The results of the tensile tests and electrical conductivity measurements have been presented previously $[4,6-7]$.

TEM specimens were prepared by jet polishing using an electrolyte of $25 \%$ phosphoric, $25 \%$ ethylene glycol, and $50 \%$ distilled water in a Tenupol-3 at 14 volts, $150-200 \mathrm{~mA}$, and room temperature. Microscopy was performed on a JEOL 2000ES using a weak beam technique to image the oxide particles. Particle sizes and densities were ineasured from images taken at a $(\mathrm{g}, 4 \mathrm{~g})$ or $(\mathrm{g}, 5 \mathrm{~g})$ weak beam condition on the $\{111\}_{C_{u}}$ reflections. Foil thicknesses were determined for each area using convergent beam electron diffraction on the $\{220\}_{\mathrm{Cu}}$ or $\{311\}_{\mathrm{Cu}}$ reflections, with an estimated error of approximately $\pm 5 \%$.

\section{$\underline{\text { Results and Discussion }}$}

Grain size and spatial distribution of particles and dislocations

The microstructure of the unirradiated GlidCop ${ }^{\mathrm{TM}}$ alloys consisted of highly cold worked, elongated grains. The average grain size ranged from 0.5-2 $\mu \mathrm{m}$ in length and 0.1-0.7 $\mu \mathrm{m}$ in width. Considerable heterogeneity in the microstructure was observed in these alloys, and was particularly prominent in the aged CuAl25, with a mixture of completely recrystallized grains, recovered grains, and heavily cold worked grains. This heterogeneity appeared to be associated with localized variations in the number density of oxide particles. The recrystallized grains, which comprised $\sim 15 \%$ of the microstructure, ranged in size from $1 \mu \mathrm{m}$ to several microns in size, and were always associated with a much lower number density of small triangular oxide particles, 10-50 in diameter. Oxide particles observed in those grains that still contained a high density of dislocations were invariably associated with a high density of smaller, spherical oxide particles, on the order of $6 \mathrm{~nm}$ in diameter.

The irradiated GlidCop ${ }^{\mathrm{TM}}$ alloys experienced recovery and recrystallization, the degree of which decreased as the amount of oxide increased. The grain sizes ranged from $0.5-4 \mu \mathrm{m}$ in all three irradiated alloys. The CuAl15 had completely recrystallized, with the exception of a few isolated areas, by $103.5 \mathrm{dpa}$. The CuAl20 alloy had experienced almost complete recovery and recrystallization by $48 \mathrm{dpa}$, while the irradiated CuAl25 experienced a large degree of recovery but less recrystallization. Changes in the dislocation and grain structure of the CuAl20 and CuAl25 appeared to have saturated by $48 \mathrm{dpa}$. The stable subgrain structure present in the CuAl20 and the CuAl 25 was associated with a higher density of small, spherical particles compared to that of recrystallized grains. 


\section{Characterization of the oxide phase}

A dispersion of small, spherical oxide particles existed throughout the grains in the irradiated GlidCop ${ }^{\mathrm{TM}}$ alloys, an example of which is shown in fig. 1 for CuAl20. The spherical particles appeared to be coherent with the matrix. A small degree of strain contrast could be seen around the particles when they were imaged using a $\{220\}_{\mathrm{Cu}}$ reflection. Triangular platelets existed primarily in large, isolated grains that had completely recrystallized, and in each case the particles were few in number and much larger than the spherical particles, often as large as $30 \mathrm{~nm}$ in edge length. Zinkle et al. [11] reported both circular disks and spheres following an ion irradiation study of a CuAl25, but predominantly triangular platelets in the unirradiated specimens.

A cube-on-cube orientation relationship, illustrated in fig. 2, was identified for the oxide particles in the irradiated material. Ernst et al. [12] identified the triangular oxide particles in an unirradiated GlidCop ${ }^{\mathrm{TM}}$ $\mathrm{CuAl60}$ alloy as the cubic spinel $\eta^{\prime}-\mathrm{Al}_{2} \mathrm{O}_{3}$. Based on the diffraction patterns, however, the oxide phase in the irradiated material more closely matched that of copper aluminate $\mathrm{CuAl}_{2} \mathrm{O}_{4}$. The diffraction patterns of the iradiated material were found in all cases to be missing the $\{111\}$ oxide reflections, which is characteristic of $\mathrm{CuAl}_{2} \mathrm{O}_{4}$. According to Ernst et al., the diffraction patterns from $\eta^{\prime}-\mathrm{Al}_{2} \mathrm{O}_{3}$ had the $\{111\}$ reflections present. Both of these oxide phases are cubic spinel compounds possessing similar lattice constants $\left(0.808 \mathrm{~nm}\right.$ for $\mathrm{CuAl}_{2} \mathrm{O}_{4}, 0.795$ for $\left.\eta^{\prime}-\mathrm{Al}_{2} \mathrm{O}_{3}\right)$ so there is little to distinguish them except for the missing $\{111\}$ reflections of the $\mathrm{CuAl}_{2} \mathrm{O}_{4}$.

When the oxide particles were imaged with the $(200)_{\mathrm{Cu}}$ and the $(400)_{\text {oxide }}$ reflections, Moire fringes were observed. The spacing between the fringes was proportional to the distance between the matrix and oxide reflection. A comparison between the measured spacing of the fringes and the predicted values [6] revealed that the spacings more closely matched that expected of $\eta^{\prime}-\mathrm{Al}_{2} \mathrm{O}_{3}$. Despite the conflicting evidence from the Moire fringe measurements, the authors feel that the missing $\{111\}_{\text {oxide }}$ reflections favor $\mathrm{CuAl}{ }_{2} \mathrm{O}_{4}$ over $\eta^{\prime} \cdot \mathrm{Al}_{2} \mathrm{O}_{3}$ as the identity of the spherical oxide particles.

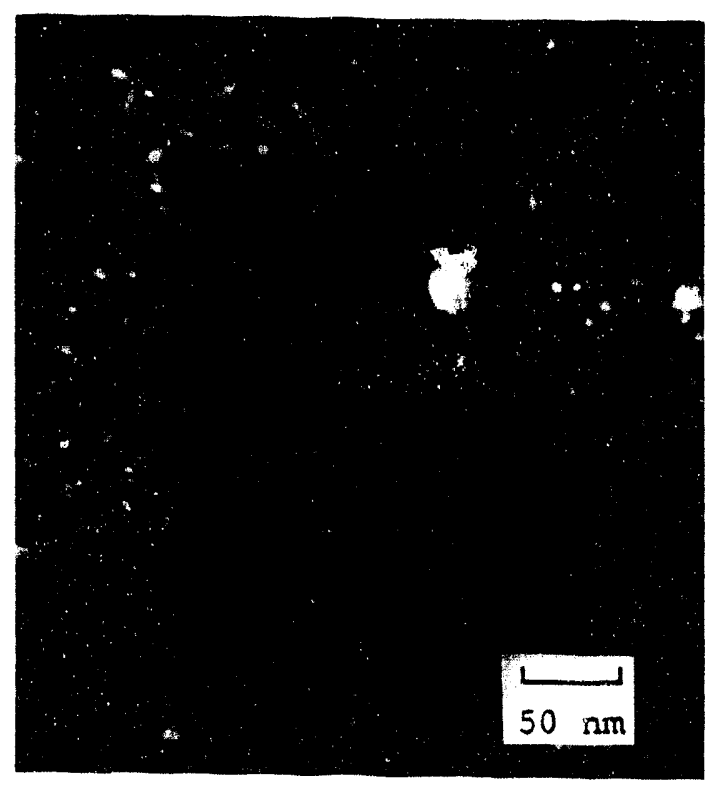

(a)

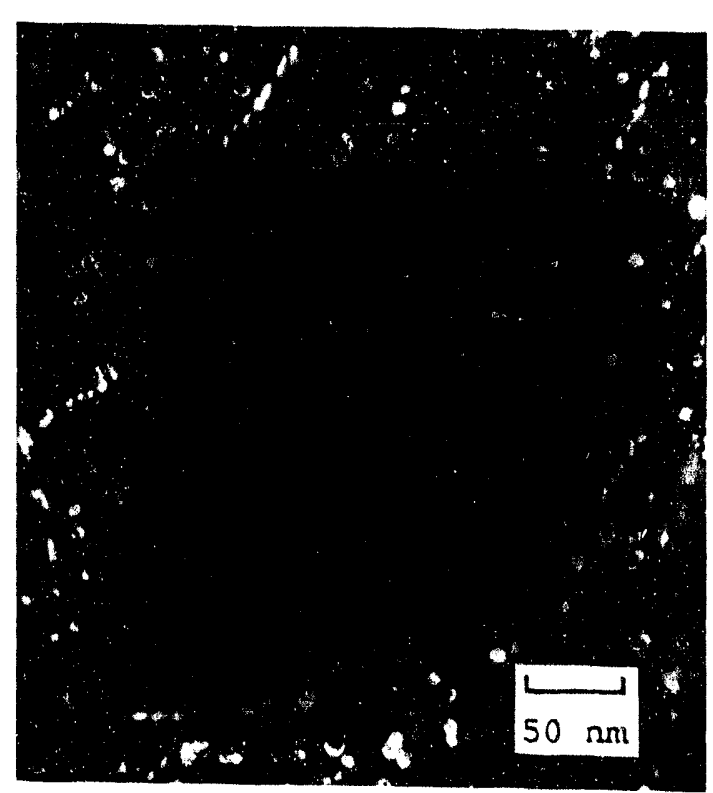

(b)

Figure 1. The spherical $\mathrm{CuAl}_{2} \mathrm{O}_{4}$ in $\mathrm{CuAl} 20$ are shown after irradiation to (a) $48 \mathrm{dpa}$ and (b) $103.5 \mathrm{dpa}$. 
Although both triangular platelets and spherical particles were observed in the unirradiated s pecimens, the predominant morphology was the spherical oxide particles. As previously discussed, the identity of the spherical morphology remains unclear. The study of Ernst et al. showed that the triangular particles in CuAl60 were n'- $\mathrm{Al}_{2} \mathrm{O}_{3}$, however, the particles shown in their work were on the order of $100 \mathrm{~nm}$ in size, much larger than the 2-6 nm diameter particles measured in this study.

The diffraction patterns from the unirradiated specimens yielded no supporting evidence of either $\mathrm{CuAl}_{2} \mathrm{O}_{4}$ or $\eta$ '$\mathrm{Al}_{2} \mathrm{O}_{3}$, although the particles could clearly be seen in the foil. The lack of diffraction spots from the oxide particles reflects the small size and orientation difference, with respect to neighboring grains, of the individual grains due to cold working. Since the intensity of the diffraction spots will be directly proportional to the number of particles located in the field limiting aperture, the authors assume that the number of oxide particles of the same orientation was insufficient to produce noticeable diffraction spots.

\section{Quantitative characterization of the oxide dispersion}

The CuAl15 alloy exhibited some swelling during irradiation [4,6-7]. This study revealed that a high density of small bubbles was primarily responsible for the swelling, demonstrating that boron additions were undesirable because of the formation of helium and lithium by transmutation. The helium bubbles and oxide particles were often associated with each other, possibly because the bubbles formed at the particle interfaces. 
The weak beam technique imaged both the oxide particles and the helium bubbles simultaneously, making it very difficult to separately measure the size distributions of the particles and bubbles. The mean size of the bubble-particle pairs was therefore measured in the irradiated specimens. The oxide particles had a mean size of $\sim 5 \mathrm{~nm}$ in the unirradiated specimens, and the mean size of the bubble-particle pairs was measured to be $\sim 9 \mathrm{~nm}$ in the specimens irradiated to $150 \mathrm{dpa}$. The density changed very little, decreasing from $\sim 3 \times 10^{22}$ particles $\mathrm{m}^{-3}$ in the unirradiated material to $\sim 1.5 \times 10^{22} \mathrm{~m}^{-3}$ in the 150 dpa specimen.

The density of particles in the CuAl20 and CuAl25 decreased after irradiation to $150 \mathrm{dpa}$. The triangular platelets in both the aged and irradiated specimens were not included in the analysis because they represented only a small fraction of the oxide dispersion. A comparison of the size distributions in the CuAl25 as a function of irradiation is presented in fig. 3, along with the overall change in mean particle size and density of particles. Note that the density and mean particle size of the irradiated CuAl25 are close to those measured for the aged CuAl25. The CuAl20 alloy exhibited similar behavior, starting at $4.7 \times 10^{22} \mathrm{~m}^{-3}$ in the unirradiated state and decreasing to an average density of $3 \times 10^{22} \mathrm{~m}^{-3}$ after irradiation. The mean particle size increased from $3.3 \mathrm{~nm}$ to $6.5 \mathrm{~nm}$. No void swelling was observed for either $\mathrm{CuAl} 20$ or $\mathrm{CuAl} 25$, so the small changes in density measured by Edwards and coworkers $[3,4,6,7]$ appear to be the result of precipitation and possibly transmutation [13].

The small size of the oxide particles measured in the unirradiated CuAl20 and CuAl25 may be questionable. These two alloys were $20 \%$ and $50 \%$ cold worked, respectively, producing a dislocation density that severely hampered the analysis, making it difficult to distinguish between the oxide particles and dislocations. Ageing the CuAl25 produced a cleaner microstructure that

allowed for clearer images of the oxide particles. The analysis on the aged specimen showed a size distribution and number density of particles much different than that of the cold-worked, unirradiated specimen. This raises the possibility that the measurements from the unirradiated
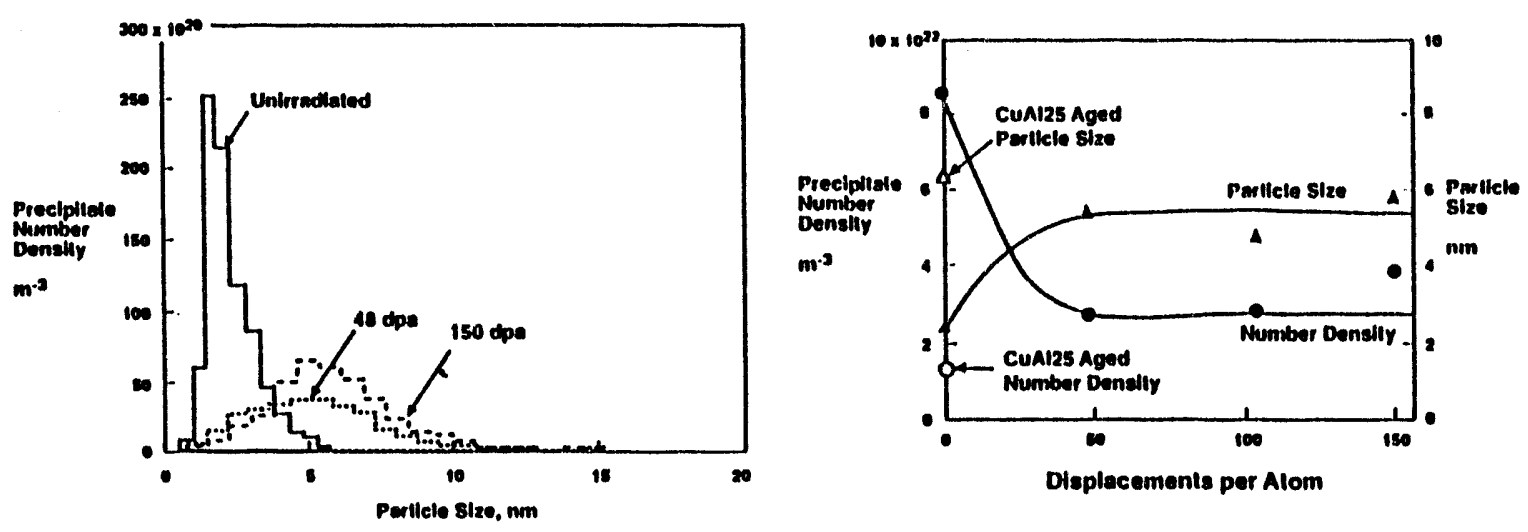

Figure 3. A comparison of size distributions for CuAl25 is provided, along with a graph of the mean particle size and density. 
material incorporated some features that were not oxide particles, and that the oxide dispersion in the aged material is more representative of the unirradiated specimens. This of course assumes that the oxide dispersion in the aged material did not undergo any significant thermal coarsening. Given the large thermodynamic stability of the aluminum oxide, it seems unlikely that any appreciable diffusion occurred during ageing, thus preserving the original characteristics of the oxide dispersion.

The data shown in fig. 3 can therefore be interpreted in two ways, depending on whether the unirradiated data or the aged data is the most representative of the oxide dispersion. Assuming that the unirradiated data is correct implies that an enhanced thermal coarsening occurs during irradiation, producing an oxide dispersion similar to that of the aged CuAl25. If the data from the aged specimen is a more accurate representation of the actual oxide dispersion in the unirradiated specimens, then high temperature irradiation produced recovery and recrystallization, but yielded an oxide dispersion of roughly the same size and density as in the unirradiated specimens. Efforts are currently being directed toward determining the actual size distribution and number density of the oxide dispersion using different imaging techniques.

The volume fractions of the oxide dispersion were found to be much lower than the theoretical volume fraction of 0.015 . This value is based on the reported density of $4.579 \mathrm{~g} / \mathrm{cm}^{3}$ for $\mathrm{CuAl}_{2} \mathrm{O}_{4}$, and assumes that all of the aluminum is internally oxidized. Calculated volume fractions for the irradiated CuAl25 and CuAl20 ranged from 0.0026 to 0.0043 , respectively. The low values are thought to be related to the large number of $\alpha-\mathrm{Al}_{2} \mathrm{O}_{3}$ inclusions discovered in these specimens. The formation of these inclusions lowered the amount of aluminum available in solution to be internally oxidized, thereby lowering the volume fraction of the oxide dispersion. The $\alpha-\mathrm{Al}_{2} \mathrm{O}_{3}$ inclusions are probably the result of premature oxidation of the surface of the atomized $\mathrm{Cu}-\mathrm{Al}$ powders. Fracture surfaces of tensile specimens $[6,7]$ were found to contain a significant number of these large particles $(\sim 1 \mu \mathrm{m}$ dia.), although the actual number density and volume fraction were not determined.

Evidence of ballistic dissolution of the inclusions is presented in fig. 4 , which shows the remnant of an inclusion that is surrounded by a shell of much smaller, plate-like precipitates. Diffraction patterns and measurement of the Moiré fringes on the small platelets indicated that they are $\eta^{\prime}$ $\mathrm{Al}_{2} \mathrm{O}_{3}$, and not $\mathrm{CuAl}_{2} \mathrm{O}_{4}$.

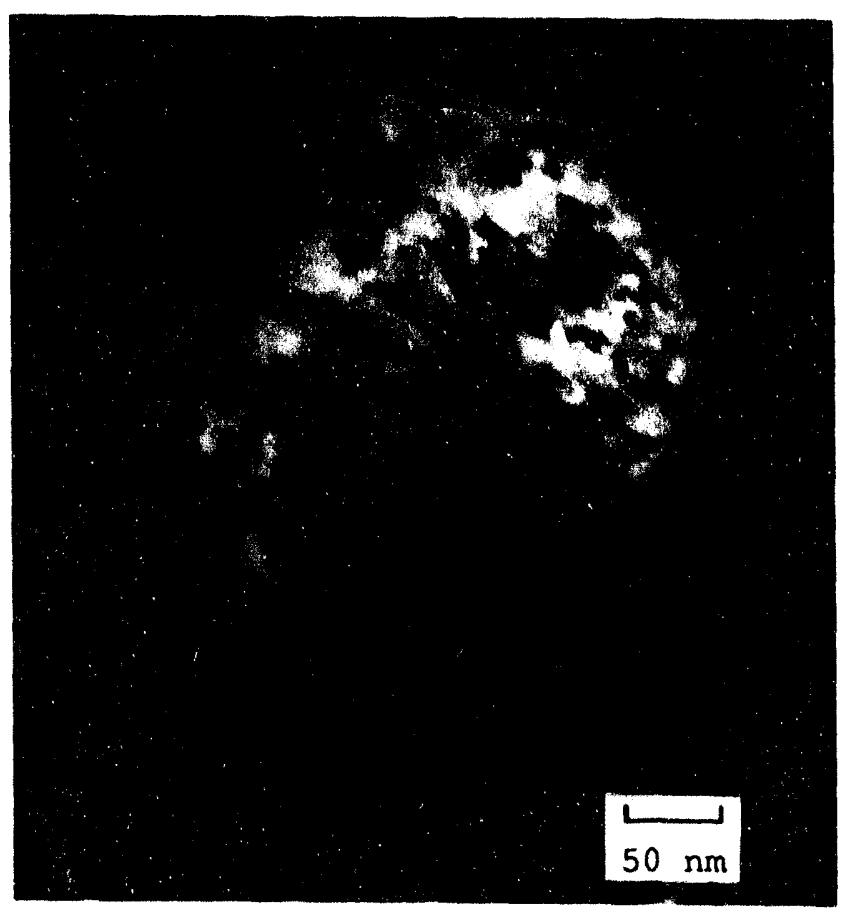

Figure 4. Recoil dissolution of a $\alpha-\mathrm{Al}_{2} \mathrm{O}_{3}$ inclusion has produced a shell of $\eta^{\prime}-\mathrm{Al}_{2} \mathrm{O}_{3}$ platelets in the immediate vicinity. 


\section{Relationship of Oxide Dispersion to Bulk Properties}

The mechanical strength of the CuAl20 and CuAl25 decreased slightly upon irradiation, and then maintained a constant level beyond $\sim 50$ dpa [3-4,6-7]. This corresponds quite well with the microstructural evolution of these alloys, where the changes in the grain structure, dislocation structure, and oxide dispersion were completed by $48 \mathrm{dpa}$. The initial decrease in strength is a direct result of the recovery and recrystallization that occurred during irradiation. Given the uncertainties in the precipitate data for the unirradiated GlidCop ${ }^{\mathrm{TM}}$, it is not clear at this point whether coarsening occurred in the oxide dispersion as a result of irradiation, so the contribution to the mechanical properties cannot be ascertained at this time.

\section{CONCLUSIONS}

The microstructural evolution of the GlidCop ${ }^{\mathrm{TM}}$ alloys irradiated at $\sim 415^{\circ} \mathrm{C}$ saturates at $\sim 50 \mathrm{dpa}$, corresponding closely to the observed saturation in the changes in mechanical properties. Although the size and number density of the oxide dispersion in the unirradiated material remains uncertain, it is clear that the oxide dispersion is present in the irradiated specimens, and is quite stable as evident from the lack of significant change in the size distributions and number densities.

The volume fraction of oxide dispersion is much lower than expected, and is thought to be due to removal of the aluminum to form large, micron size $\alpha-\mathrm{Al}_{2} \mathrm{O}_{3}$ inclusions during the gas-atomization of the starting $\mathrm{Cu}-\mathrm{Al}$ melt. Direct evidence of ballistic dissolution of the large inclusions was obtained, as revealed by the presence of a shell of $\eta^{\prime}-\mathrm{Al}_{2} \mathrm{O}_{3}$ platelets around the inclusions.

\section{FUTURE WORK}

This effort will continue, focusing on the radiation-induced evolution of $\mathrm{Cu}-\mathrm{HfO}_{2}$ alloys.

\section{REFERENCES}

1. H. R. Brager, H. L. Heinisch, and F. A. Garner, J. Nuc. Mater., Vol. 133 \& 134, (1985), p. 679.

2. F. A. Garner, H. R. Brager, and K. R. Anderson, J. Nucl. Mater., 179-181 (1991) p. 250.

3. K. R. Anderson, F. A. Garner, M. L. Hamilton, J. F. Stubbins, Proceedings of the 15th ASTM International Symposium on Effects of Radiation on Materials, June 1990, ASTM STP 1125 (1992) p. 854.

4. D. J. Edwards, J. W. Newkirk, F. A. Garner, M. L. Hamilton, A. Nadkarny, and P. Samal, J. Nucl. Mater. 191-194 (1992) p. 416.

5. F. A. Garner, M. L. Hamilton, D. J. Edwards, J. W. Newkirk, J. F. Stubbins, and M. A. Mitchell, J. Nucl. Mater. 191-194 (1992) p. 386.

6. D. J. Edwards, Ph.D. Dissertation, University of Missouri-Rolla, (May 1993). 
7. D. J. Edwards, J. W. Newkirk, F. A. Garner, M. L. Hamilton, A. Nadkarny, and P. Samal, Proceedings of the 16th ASTM Symposium of the Effects of Radiation on Materials, (June 1992), in press.

8. J. A. Spitzragel, N. J. Doyle, W. J. Choyke, J. G. Greggi Jr., J. N. McGruer, and J. W. Davis, Nucl. Instr. and Meth., 16B (1986) p. 279.

9. N. Wanderka, Y. Yuan, L. Jiao, R. P. Wahi, and H. Wollenberger, J. Nucl. Mat., 191-194 (1992) p. 1356.

10. S. J. Zinkle, A. Horsewell, B. N. Singh, and W. F. Sommer, J. Nuc. Mater., 195 (1992) p. 11.

11. S. J. Zinkle, E. V. Nesterova, V. R. Barabash, V. V. Rybin, and A. V. Naberenkov, accepted for publication in J. Nucl. Mater. (1993).

12. F. Ernst, P. Pirouz, A. H. Heuer, Phil. Mag. A, 63 (1991) p. 259.

13. D. J. Edwards and F. A. Garner, in Fusion Reactor Materials Semiannual Progress Report DOE/ER-0313/13 (1992) pp. 258-264. 
DISTRIBUTION OF TRANSMUTANT NICKEL FORMED IN FAST NEUTRON IRRADIATED

COPPER - T. Muroga (Kyushu University) and F. A. Garner (Pacific Northwest Laboratory ${ }^{\mathrm{a}}$ )

\section{OBJECTIVE}

The objective of this effort is to determine those factors which impact the use of copper and its alloys for fusion applications.

\section{SUMMARY}

Nickel formed by transmutation of pure copper after irradiation to 95.4 dpa in FFTF was measured using the EDS technique. The nickel measurements agree rather well with the predicted level, although the foil-averaged value is higher than the bulk-averaged value due to the large amount of void intersections that occur in this specimen, which swelled $\sim 45 \%$. Nickel was shown to segregate strongly at void surfaces.

\section{PROGRESS AND STATUS}

\section{Introduction}

Copper and some of its alloys have been proposed to serve as high heat flux components in future fusion energy devices. ${ }^{1}$ Unfortunately, both the thermal and electrical conductivities of copper-base alloys will decline during neutron irradiation as a result of void swelling and solid transmutants. ${ }^{2}$ The two most important transmutants are nickel and zinc, with nickel having the largest influence on conductivity degradation on a per atom basis.

Recent calculation of the transmutations formed in pure copper during irradiation in the Fast Flux Test Facility (FFTF) predicted that $\sim 0.41$ at $\%$ nickel and $\sim 0.40$ at $\%$ zinc would be produced in pure copper after full power operation for 300 effective full power days. ${ }^{3}$ These calculations also showed that the generation rate of nickel in typical fusion spectra would be roughly twice as large and therefore the conductivity loss would be even greater for a given level of atomic displacement.

The formation and distribution of transmutants in irradiated copper alloys is currently being studied. Using copper-nickel alloys, it has been shown that during electron irradiation, nickel exerts significant influence on the evolution of dislocation microstructure and on void swelling. ${ }^{4-6}$ Radiation-induced segregation of nickel at defect sinks such as voids and grain boundaries was also reported. ${ }^{5,6}$ Zinc was shown not to segregate, but to migrate away from such sinks, however. ${ }^{6}$ From these studies it is clear that the properties of copper will change during neutron irradiation as nickel and zinc accumulate and then interact with point defect fluxes near microstructural sinks.

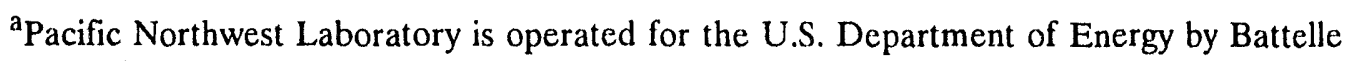
Memorial Institute under Contract DE-AC06-76RL0 1830. 
The objective of the present study is to verify experimentally the transmutation calculations and to investigate whether transmutant nickel also behaves in the same manner as observed in electron irradiations of $\mathrm{Cu}-\mathrm{Ni}$ alloys.

\section{Experimental Details}

MARZ(99.999\%) pure copper specimens were irradiated with fast neutrons at $696 \pm 5 \mathrm{~K}$ in the core of FFTF during cycle 11 and 12 for 503 effective full power days. The total fluence was $1.69 \times 10^{23} \mathrm{n} / \mathrm{m}^{2}$, which is equivalent to $95.4 \mathrm{dpa}$ for copper.

The specimens were standard $3 \mathrm{~mm}$ diameter microscopy discs that were $0.25 \mathrm{~mm}$ thick. The swelling of the specimens were determined to be $45.4 \%$ using an immersion density technique known to be accurate with $\pm 0.2 \%$ swelling. One specimen was prepared for transmission electron microscopy (TEM) observation. The thickness of the specimen was reduced electrochemically to $0.1 \mathrm{~mm}$ and then it was perforated using standard electropolishing technique. The prethinning was also useful for reducing the radiation level of the specimens and thereby improving the accuracy of the compositional analysis.

Microstructural observations and microchemical analyses were carried ou with a JEM-2000FX electron microscope equipped with an Energy Dispersive X-ray Spectrometer (EDS), at facilities located at Pacific Northwest Laboratory. Since the radioactivity of the specimen was still quite large after thinning, the energy spectrum due to X-ray excitation alone was derived by subtranting the radiation component of the spectrum from the total spectrum.

\section{$\underline{\text { Results }}$}

It is known that the microstructural observation by TEM is quite difficult for very highly swollen samples because of the high density of coarsened voids. In the present study, therefore, it was not possible to derive void density, size distribution or swelling from the individual micrographs, an example of which is shown in Figure 1. Many of the larger voids have intersected the specimen surface during the electropolishing. However, a relatively small void in the center of the thin foil was used for EDS microchemistry measurements.

EDS measurements were used to obtain both average and local compositions. First, broad-beam EDS measurements were performed with a probe beam of $5 \mu \mathrm{m}$ in diameter to obtain a bulk-averaged composition of the foil. An example of the $\mathrm{X}$-ray spectra is shown in Figure 2. A distinct peak of Ni$\mathrm{K}_{\alpha}$ was observed, but the $\mathrm{Zn}-\mathrm{K}_{\alpha}$ peak overlapped with the $\mathrm{Cu}-\mathrm{K}_{\beta}$ peak. A very small $\mathrm{Zn}-\mathrm{K}_{\beta}$ peak was also observed. Because of the overlapping, it was found that a reliable quantitative analysis was not possible for the zinc concentration. 


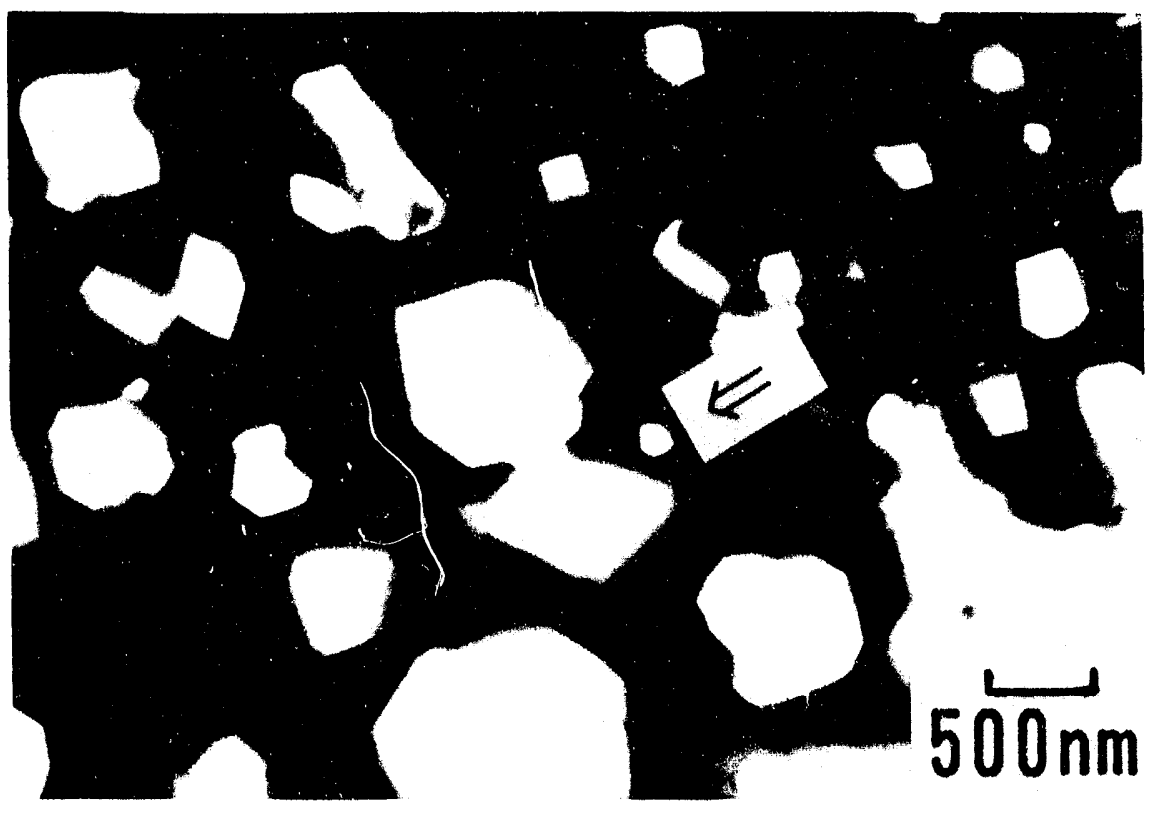

Fig. 1. Microstructure of copper irradiated with fast neutrons at $696 \mathrm{~K}$ to $95.4 \mathrm{dpa}$. The relatively small void indicated with an arrow was used for $\mathrm{n}^{\circ}$ rochemical analysis.

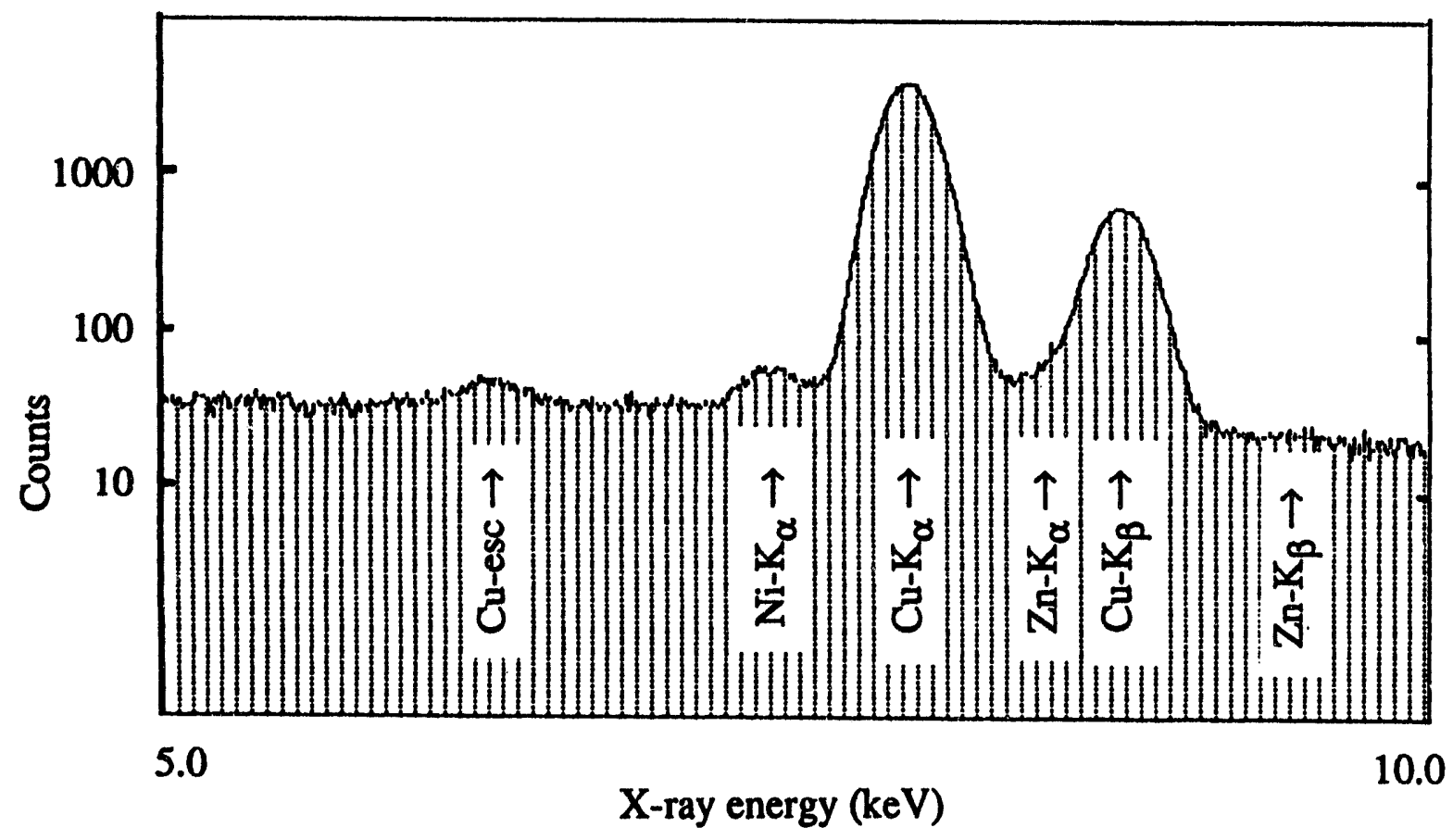

Fig. 2. X-ray spectrum using an electron beam of $5 \mu \mathrm{m}$ in diameter excited from a pure copper specimen irradiated with fast neutrons in FFTF at $696 \mathrm{~K}$ to $95.4 \mathrm{dpa}$. 
Table 1 summarizes the bulk-averaged nickel concentrations measured at eight different positions with the large electron beam probe. The accuracy shown in Table 1 will be explained in the discussion section.

Figure 3 shows the measured concentration profile of nickel across the small void shown in Figure 1. The basis of the error bar will be explained in the following section. The significant enrichment of nickel at the void is consistent with the results of previous studies on $\mathrm{Cu}-\mathrm{Ni}$ alloys that were electronirradiated. $^{5,6}$ It is obvious that the transmutant nickel interacts with the point defects created during irradiation.

Table 1. Bulk-averaged nickel concentration in copper at $95.4 \mathrm{dpa}$ measured for eight different areas using an electron beam of $5 \mu \mathrm{m}$ in diameter. The basis of the accuracy estimation is explained in the discussion section.

\begin{tabular}{cc}
\hline Position & Nickel concentration (at\%) \\
1 & 0.79 \\
2 & 0.94 \\
3 & 0.90 \\
4 & 0.93 \\
5 & 0.99 \\
6 & 0.94 \\
7 & 0.98 \\
8 & 0.88 \\
\hline Average & - \\
Accuracy & 0.92 \\
\hline
\end{tabular}

$\underline{\text { Discussion }}$

As is well known, EDS measurements do not give highly accurate chemical compositions. The accuracy should be carefully estimated, especially when the measured solute concentration is low, like the present case. The accuracy and the error bar in Table 1 and Figure 3 respectively, were estimated based on the EDS measurements performed on unirradiated $\mathrm{Cu}-1 \mathrm{Ni}$. The EDS measurement of nickel content in the $\mathrm{Cu}-1 \mathrm{Ni}$ showed variation within $\pm 0.21 \%$. Some of the EDS measurement data in electron-irradiated $\mathrm{Cu}-1 \mathrm{Ni}$ were reported earlier. ${ }^{6}$ However, it is possible that the error in the present study might be even larger because of the background radiation effects. 


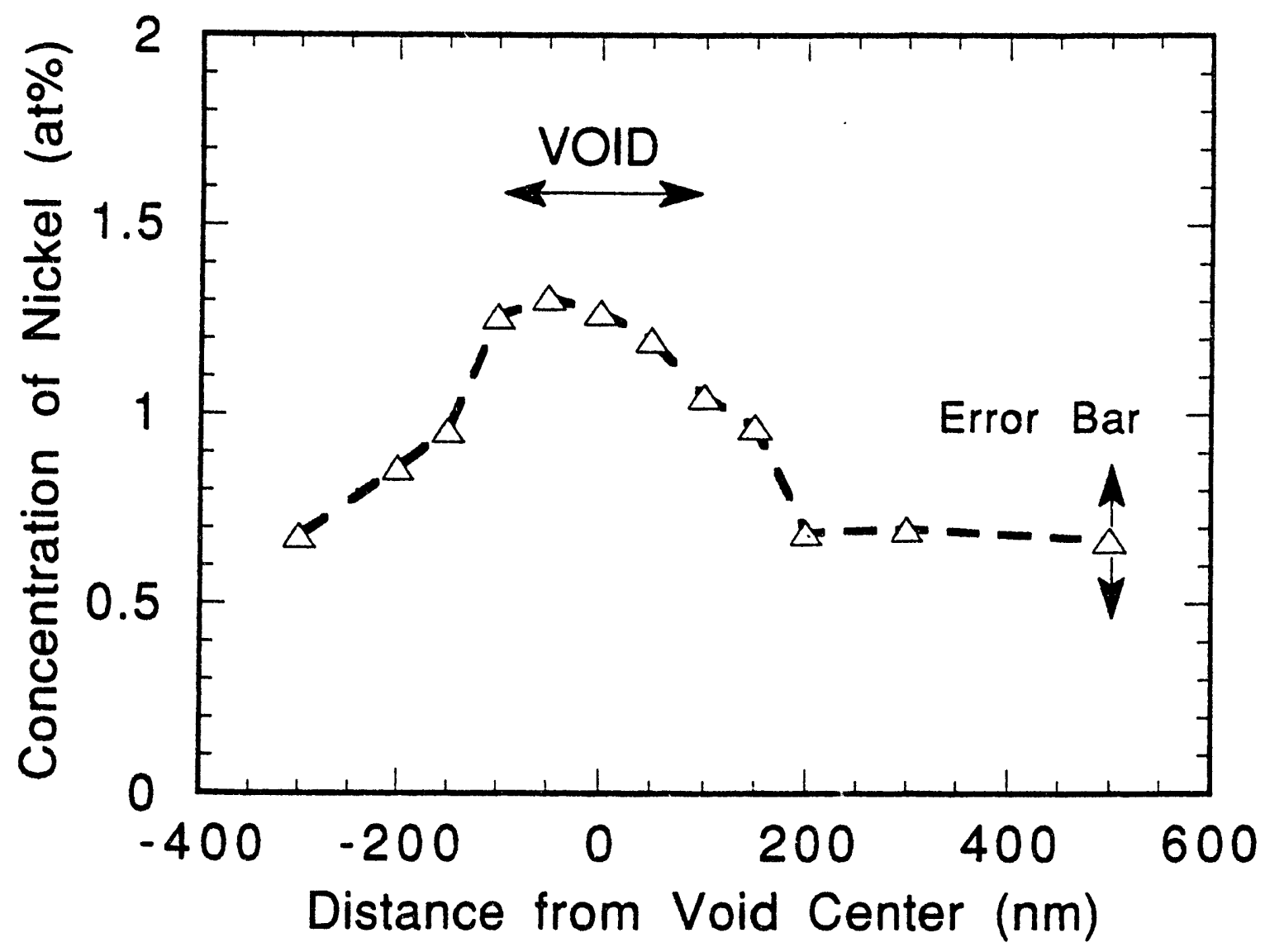

Fig. 3. Nickel concentration profile across the void shown in Fig. 1, using an electron beam probe $20^{\circ}$ $\mathrm{nm}$ in diameter.

If we scale the transmutant calculations to the exposure level for these specimens, the predicted nickel level is 0.69 at $\%$, somewhat smaller than the measured value of $0.92 \pm 0.21$ at $\%$. The difference between 0.69 at $\%$ and 0.92 at $\%$ is somewhat larger than the $15 \%$ accuracy determined from back-calculations of the nickel and zinc concentrations required to produce the observed changes in electrical conductivity.

It is anticipated, however, that the measured bulk-averaged composition reflects the disproportionate influence of the segregated nickel that lies on the bottom surface of each of the many large voids that intersect the surface. This would lead to a "foil-averaged" composition that is somewhat larger than a true bulk-averaged composition. Even with this difference, however, the present experimental results are felt to be in good agreement with the calculated values, especially when the uncertainties associated with the EDS measurements, discussed above, are considered. Note that the peak concentration measured across the small void in Figure 3 is 1.3 at\%. Since this void lay in the center of a relatively thick foil and was measured with a probe of finite size, the peak concentration at the void surface is larger than 1.3 at $\%$. 


\section{Conclusions}

The previously calculated generation of nickel by transmutation during neutron irradiation of pure copper was verified experimentally using microchemical analysis of a neutron-irradiated specimen. Enrichment of nickel at void surfaces was also found, exceeding 1.3 at\%, and is evidence of the interaction of the transmutant nickel with radiation-produced point defects. It is expected that the properties of copper will change continuously during neutron irradiation in response to the transmutant nickel and its subsequent interaction with radiation-produced defects.

\section{Future Work}

No further effort is planned.

\section{Acknowledgments}

This work was supported in part by the Japan-USA Fusion Cooperation in "Fundamental Studies of Irradiation Effects in Fusion Materials Utilizing Fission Reactors" sponsored by Monbusho, the Japanese Ministry of Education, Science and Culture. This work was also supported by the US Department of Energy under Contract DE-AC06-76RLO 1830.

\section{References} 1992, 103.

1. R. W. Conn, V. A. Chuyanov, N. Inoue and D. R. Sweetman, Scientific American, April

2. F. A. Garner, M. L. Hamilton, T. Shikama, D. J. Edwards and J. W. Newkirk, J. Nucl. Mater. 101-194 (1992) 386.

3. F. A. Garner, L. R. Greenwood and F. M. Mann, Fusion Reactor Materials Semiannual Report DOE/ER-0313/13 (1993) 42.

4. P. Barlow and T. Leffers, Phil. Mag., 36 (1997) 565.

5. H. Takahashi, S. Ohnuki and T. Takeyama, J. Nucl. Mater. 103\&104 (1981) 1415.

6. T. Muroga, E. Ishimaru and N. Yoshida, Effects of radiation on materials: 16th Int. Symp., ASTM STP 1175, A. S. Kumar, D. S. Gelles, R. K. Nanstad and E. A. Little, Eds. (ASTM, 1993) in press.

7. D. J. Edwards and F. A. Garner, Fusion Reactor Materials Semiannual Progress Report DOE/ER-0313/14 (1993) in press. 
6.5 Environmental Effects in Structural Materials 
CONSIDERATION OF TRITIUM AND HYDROGEN DISTRIBUTIONS IN LAYERED STRUCTURES

FOR ITER - E. P. Simonen, J. L. Brimhall and R. H. Jones, (Pacific Northwest Laboratorya)

Richland, WA 99352

\section{OBJECTIVE}

To evaluate hydrogen isotope concentrations and transport for multiple sources of hydrogen and for layered composite structures.

\section{SUMMARY}

The distributions of tritium from the plasma and hydrogen from the coolant in candidate ITER structures depends on the selection of base alloys as well as layered materials that are applied to improve compatibility with the plasma or the coolant. Two hydrogen sources are considered in the present calculations using the DIFFUSE 83 code, namely, implantation-driven permeation of tritium from the plasma and gas-driven permeation of hydrogen from the coolant. A third source, hydrogen from $(n, p)$ reactions has not yet been considered in this analysis. A plasma facing Be layer effectively prevents permeation of hydrogen to the plasma but does not effectively prevent permeation of tritium to the coolant. A stainless steel layer in contact with the coolant can achieve significant tritium and hydrogen concentrations depending on choice of base material, temperature, ion implantation flux and coolant pressure of hydrogen. Hydrogen ingress through a stainless steel layer to $\mathrm{V}$ structures may be significant but ingress through layers to $\mathrm{Cu}$-based alloys is not expected to be significant.

\section{TECHNICAL PROGRESS}

\section{Background}

Management of hydrogen isotopes within ITER structural components is important for control of both plasma fuel inventories and structural material properties. Sources of hydrogen isotopes include tritium and deuterium implantation from the plasma, hydrogen absorption from the coolant, and transmutation reactions within the neutron-bombarded structure. The distribution of isotopes in these components depends on hydrogen solubility and diffusivity in the specific materials of construction. Structural design (composite geometry), material selection, implantation flux, temperature, and hydrogen reactions at surfaces all affect the distribution of hydrogen isotopes in ITER structures.

A primary hydrogen isotope source is the plasma-driven implantation of tritium and deuterium. Implanted isotopes in structures are either recycled to the plasma, retained in the structure or diffused out as a permeation flux to the coolant. Coolant flowing through plasma-facing components may also be a significant source of hydrogen. Uptake of hydrogen from water or helium gas, for example, can occur and may influence hydrogen degradation processes of the component materials. Neutron irradiation can induce $(n, p)$ reactions which over time may result in significant hydrogen buildup. Hydrogen from transmutation reactions has not yet been included in the present model calculations.

In this paper, a preliminary examination of hydrogen transport and concentration in iayered components is calculated. Furthermore, the integrated quantities of tritium in the structures are compared to integrated quantities lost by permeation to the coolant. The calculations were performed using the DIFFUSE 83

aPacific Northwest Laboratory is operated for the U.S. Department of Energy by Battelle Memorial Institute under Contract DE-AC06-76RLO 1830. 
permeation code ${ }^{1}$ to demonstrate considerations for ITER component design related to control of hydrogen isotopes.

\section{Permeation Behavior and Material Selection}

Hydrogen permeation from the gas phase is a process of hydrogen solution followed by diffusion. Permeability is a property that can be represented as the product of solubility and diffusivity. In the case of Sievert's law controlling solubility, the steady-state permeation flux, $\mathrm{J}$, is expressed as

$$
J\left(\frac{\text { atoms }-H}{\mathrm{~cm}^{2}-\mathrm{s}}\right)=-\frac{\mathrm{D} \mathrm{S} \rho \sqrt{\mathrm{P}}}{\Delta \mathrm{x}}
$$

Thickness of the permeable membrane is $\Delta x, \mathrm{~cm}$, and the material density is $\rho$, atoms $/ \mathrm{cm}^{3}$. The permeability, $P_{m}$, is defined as the product of the diffusivity, $D$, and the solubility, $S$.

$$
P_{m}\left(\frac{\mathrm{cm}^{2}}{\mathrm{~s}} \frac{\text { atoms-H }}{\text { atoms-metal- } \sqrt{\mathrm{atm}}}\right)=\mathrm{D}\left(\frac{\mathrm{cm}^{2}}{\mathrm{~s}}\right) \mathrm{S}\left(\frac{\text { atoms }-\mathrm{H}}{\text { atoms-metal- } \sqrt{\mathrm{atm}}}\right)
$$

The total loss of atoms through a material is obtained by multiplying the flux by the area and the time of exposure to the pressure, $P$, atm.

A compilation of solubility, diffusivity and permeation for several metals and alloys is included in the DIFFUSE 83 permeation code. A bar chart of permeation related parameters at $300^{\circ} \mathrm{C}$ is shown in Figure 1 and are ordered from low $(\mathrm{W})$ to high $(\mathrm{Zr})$ permeabilities. "SS" refers to stainless steel and "inc" refers to Inconel. Trend lines are drawn to show that the permeability variation is primarily controlled by the solubility variation and not the diffusivity variation.

Materials of interest for ITER structural components include a Be layer for plasma compatibility and a stainless steel layer for coolant compatibility. The base alloy material is either $\mathrm{Cu}$ or $\mathrm{V}$. From the ranking in Figure 1, it is seen that Be exhibits excellent permeation resistance and $\mathrm{V}$ exhibits poor permeation resistance. Intermediate permeation resistance is exhibited by stainless steel and $\mathrm{Cu}$. Although permeabilities shown in Figure 1 indicate relative responses for single layer structures, the simple permeabilities do not indicate how multilayered structures will respond or how effects such as plasma implantation and temperature gradients may affect ITER structures.

\section{Reference Conditions for Calculated Permeation}

Even though detailed ITER designs have not been established, estimates of approximate conditions that are relevant to ITER can be evaluated. Of primary importance is the definition of the environment, material selection and geometry for structures. The plasma-side environment dictates the surface temperature and the ion implantation flux. The coolant-side environment dictates the surface temperature and the pressure for ingress of hydrogen into the structure. A coolant hydrogen pressure of $0.001 \mathrm{~atm}$ was assumed in the present analysis to represent a small but significant pressure.

Environmental parameters assumed for the present calculations are shown in Table 1. The temperature profile through the structure is assumed to be linear and differences in thermal conductivity from one layer to another are not accounted for. The reference coolant temperature for the $\mathrm{Cu}$ structure was $200^{\circ} \mathrm{C}$ and was $500^{\circ} \mathrm{C}$ for the $\mathrm{V}$ structure. The temperature increase across the wall was assumed to be $200^{\circ} \mathrm{C}$. 


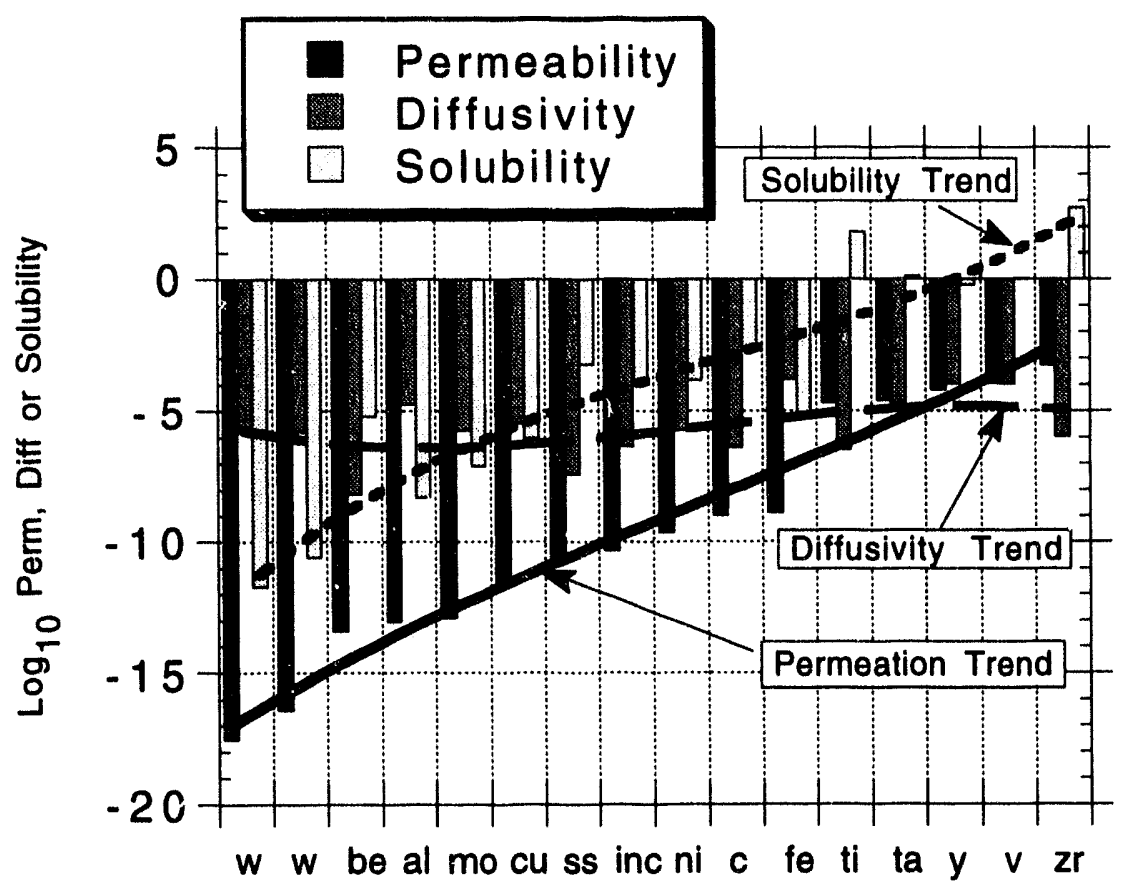

Figure 1. Permeability, diffusivity and solubility of hydrogen are shown for several materials. The trend lines show that variation in permeability follows variation in solubility and not diffusivity. Proposed ITER structures span the range from Be to V. "ss" and "inc" represent stainless steel and Inconel, respectively. Alternative parameters for $\mathrm{W}$ are shown.

Table 1 Environmental parameters for assumed boundary conditions.

\begin{tabular}{|c|c|c|c|c|}
\hline Structure & $\begin{array}{l}\text { Coolant } \\
\text { Interface } \\
\text { Temperature }{ }^{\circ} \mathrm{C}\end{array}$ & $\begin{array}{l}\text { Plasma } \\
\text { Interface } \\
\text { Temperature }{ }^{\circ} \mathrm{C}\end{array}$ & $\begin{array}{l}\text { Tritium } \\
\text { Implantation } \\
\text { ions/cm²-s }\end{array}$ & $\begin{array}{l}\text { Coolant } \\
\text { Hydrogen } \\
\text { Pressure, atm }\end{array}$ \\
\hline $\mathrm{Cu}$ & 200 & 400 & $10^{16}$ & 0.001 \\
\hline $\mathrm{Cu}$ & 200 & 400 & $10^{19}$ & 0.001 \\
\hline $\mathrm{Cu}$ & 500 & 700 & $10^{19}$ & 0.001 \\
\hline V & 500 & 700 & 1016 & 0.001 \\
\hline
\end{tabular}

Recombination of atomic hydrogen was assumed to control the plasma surface concentrations. The coolant surface concentration is assumed to be controlled by Sievert's law. TRIM code ${ }^{2}$ simulations were used to estimate the implantation profile for $100 \mathrm{eV}$ tritium in Be. Both a low implantation flux, $10^{16}$ ions $/ \mathrm{cm}^{2}$, and a high implantation flux, 1019 ions $/ \mathrm{cm}^{2}$, were considered to represent first wall and divertor conditions, respectively. ${ }^{3}$ 
Material solubilities and diffusivities were used as defined in the DIFFUSE 83 code for all materials except $\mathrm{V}$ and are shown in Table 2. For V, parameters recommended by Baskes et al. ${ }^{4}$ were assumed. Although

Table 2 Permeation parameters assumed for the present calculations. The diffusivity $D$ is defined by $D=D_{\alpha} / A M U$ exp $\left(-E_{d} / k T\right)$ and the solubility is $S=S_{0} \exp \left(-E_{s} / k T\right)$, where AMU is atomic mass units. "Intermediate" and "high resistance" refers to assumed materials of intermediate and high permeation resistance.

\begin{tabular}{|c|c|c|c|c|}
\hline Material & $\begin{array}{l}\mathrm{D}_{\mathrm{o}} \\
\mathrm{cm}^{2}-\mathrm{AMU}^{0.5} / \mathrm{s}\end{array}$ & $\begin{array}{l}E_{d} \\
e V\end{array}$ & $\begin{array}{l}S_{0} \\
\text { A t o } \quad \text { m } \\
\text { Frac/atm } 0.5\end{array}$ & $\begin{array}{l}E_{s} \\
e V\end{array}$ \\
\hline $\mathrm{Be}$ & $3.0 \times 10^{-7}$ & 0.19 & $6.1 \times 10^{-6}$ & 0.0 \\
\hline $\mathrm{Cu}$ & $1.1 \times 10^{-2}$ & 0.40 & $1.59 \times 10^{-3}$ & 0.37 \\
\hline SS & $2.0 \times 10^{-3}$ & 0.535 & $5.0 \times 10^{-3}$ & 0.107 \\
\hline V & $5.2 \times 10^{-4}$ & 0.08 & $6.0 \times 10^{-4}$ & -0.37 \\
\hline Intermediate & $1.1 \times 10^{-2}$ & 0.40 & $1.59 \times 10^{-3}$ & 0.37 \\
\hline High Resistance & $4.1 \times 10^{-3}$ & 0.39 & $8.2 \times 10^{-4}$ & 0.98 \\
\hline
\end{tabular}

structural materials will not likely be simple materials as shown in Table 2, the structural alloys will exhibit permeation behaviors in the range displayed in Figure 1. The material selections made for the present evaluations are intended to represent realistic ITER possibilities and to represent contrasts in assumed permeation behaviors for base alloy and layers. The thicknesses of structural layers were assumed to be $0.5 \mathrm{~cm}$ for the base material and $0.1 \mathrm{~cm}$ for the surface layers. Layered structures assumed for the calculations are shown in Table 3.

Table 3 Layered structures considered in the evaluation.

\begin{tabular}{|l|l|l|}
\hline Plasma Layer & Base Layer & Coolant Layer \\
\hline $\mathrm{Be}$ & $\mathrm{Cu}$ & Stainless Steel \\
$\mathrm{Be}$ & $\mathrm{Cu}$ & Intermediate \\
$\mathrm{Be}$ & $\mathrm{Cu}$ & High Resistance \\
$\mathrm{Be}$ & $\mathrm{V}$ & Stainless Steel \\
\hline
\end{tabular}




\section{Permeation Calculation Results}

The tritium and hydrogen concentration profiles were calculated for ITER structures. Also, the time dependencies of partitioning of nonrecycled tritium between permeation to the coolant and retention in the structure were obtained. An assumed Be layer faced the plasma whereas a stainless steel layer faced the coolant. The calculations provide estimates of expected hydrogen isotope content in the materials and provide estimates of tritium loss to the coolant and tritium inventory in the structures.

Calculated concentration profiles for plasma-driven permeation of tritium and gas-driven ingress of hydrogen are shown in Figures 2 and 3 for assumed $\mathrm{Cu}$ and $\mathrm{V}$ structures, respectively, and for an assumed low ion flux. The effect of increasing the ion flux to compare first wall and divertor flux magnitudes ${ }^{3}$ and the effect of coolant temperature on concentration profiles in a $\mathrm{Cu}$ structure are shown in Figures 4 and 5 , respectively.

The time dependencies of tritium partitioning between the first wall and loss to the coolant are shown in Figures 6 and 7. In comparison, the integrated recycled tritium flux is almost $10^{23}$ tritium atoms $/ \mathrm{cm}^{2}$ at $10^{7} \mathrm{~s}$. Most of the implanted tritium is recycled to the plasma. For low implantation fluxes, a small fraction, typically 1017 tritium atoms $/ \mathrm{cm}^{2}$, is retained in the structure or is lost to the coolant. The specific fractions depend on selection of material and environmental parameters as seen in Figures 6 and 7.

Alternative layered structures were evaluated to demonstrate influences of permeation resistance on evolution of hydrogen isotope concentration profiles. Effects of alternative materials in contact with the coolant were examined based on layer permeation resistance. Intermediate and highly resistant layers were considered as shown in Figures 8 and 9. Similarly, the effects of permeation resistance on the time dependence of tritium inventory in the structure and permeation flux to the coolant are shown in Figures 10 and 11 , respectively.

\section{Discussion of Calculated Permeation Behavior}

The calculated concentration profiles of tritium and hydrogen in $\mathrm{Cu}$ structures indicate that both concentrations can exceed several appm depending on isotope and layer material. For copper structures, the concentration buildup is more significant in the surface layers, whereas for $\mathrm{V}$ structures the concentration buildup is more significant in the base material. Vanadium acts as a getter for hydrogen at the expense of the neighboring layers. Copper, on the other hand, has a lesser hydrogen solubility than stainless steel, hence hydrogen accumulates preferentially in the stainless steel layer.

The effective permeation resistance of Be shown in Figure 1 is caused by the low hydrogen solubility limit for Be. Because the tritium concentration is driven by implantation and not absorption, the expected permeation resistance of $\mathrm{Be}$ is not realized for implanted tritium but is realized for the ingress of hydrogen to the plasma.

Increase in the implantation flux causes a proportional increase in the tritium concentration as seen in the comparison of Figures 2 and 4. The tritium concentration near the plasma surface is directly proportional to the implantation rate and this concentration influences the tritium concentration profile through the thickness of the structure. Increase in the material temperature causes a decrease in the tritium inventory at the expense of an increase in the permeation leakage to the coolant. The temperature increase effect reflects the fact that it is more difficult to buildup high concentrations when permeation out of the structure is easier.

The permeation resistance of the layer in contact with the coolant can significantly affect the distribution of tritium as seen in Figure 8 for $\mathrm{Be} / \mathrm{Cu} / \mathrm{X}$ multilayers where $\mathrm{X}$ is an intermediate or highly resistant 


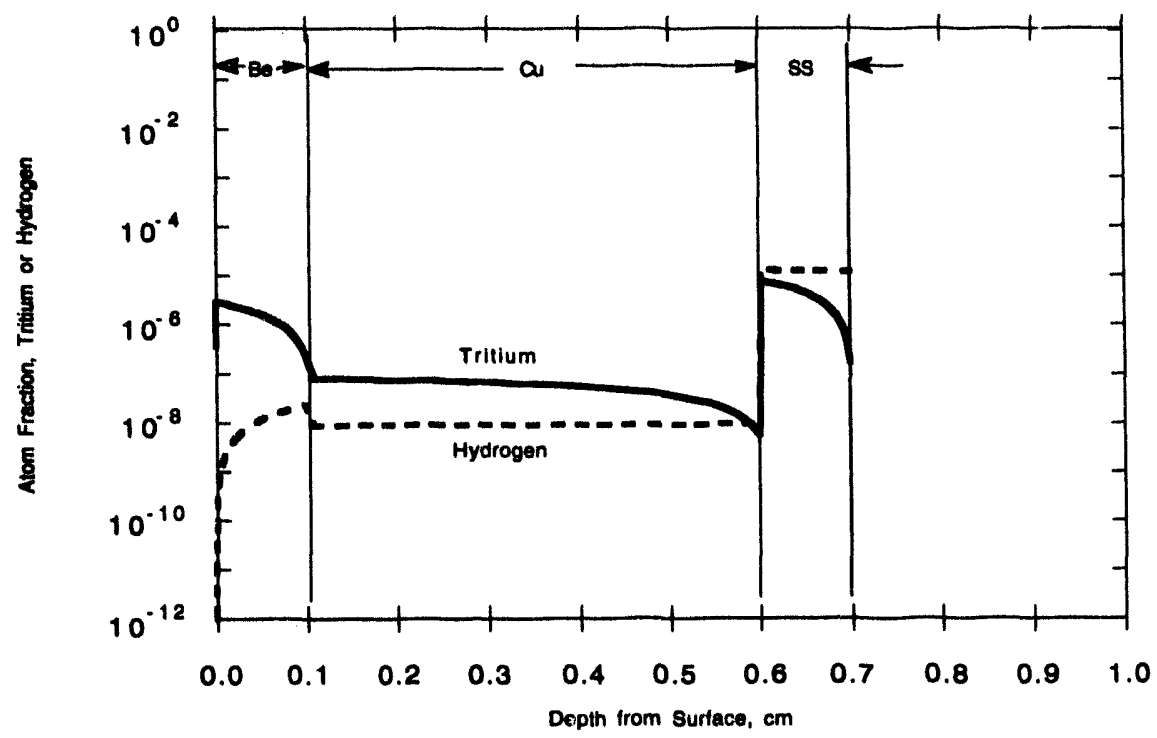

Figure 2. Calculated tritium and hydrogen concentration profiles in a multilayered $\mathrm{Be} / \mathrm{Cu} / \mathrm{SS}$ structure at $10^{7} \mathrm{~s}$. The tritium implantation flux is $1016 \mathrm{ions} / \mathrm{cm}^{2}-\mathrm{s}$ and the hydrogen coolant pressure is $0.001 \mathrm{~atm}$ and the coolant temperature is $200^{\circ} \mathrm{C}$.

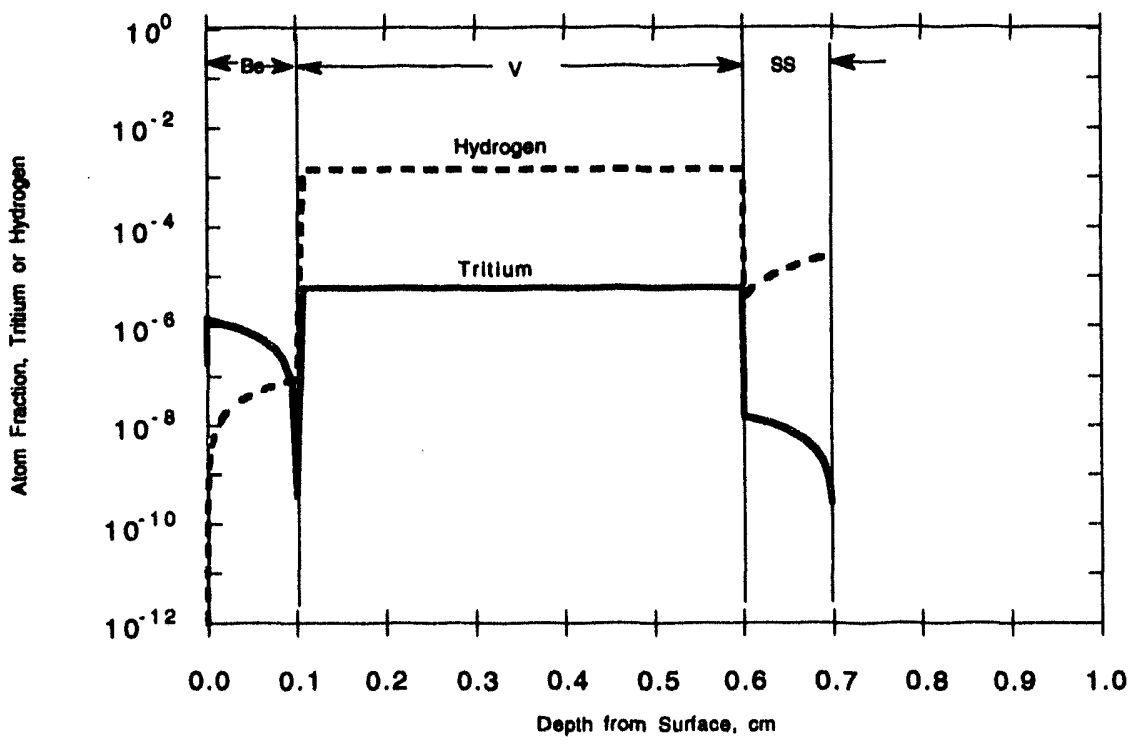

Figure 3. Calculated tritium and hydrogen concentration profiles in a multilayered Be/V/SS structure at $10^{7} \mathrm{~s}$. The tritium implantation flux is $1016 \mathrm{ions} / \mathrm{cm}^{2}-\mathrm{s}$ and the hydrogen coolant pressure is $0.001 \mathrm{~atm}$ and the coolant temperature is $500^{\circ} \mathrm{C}$. 


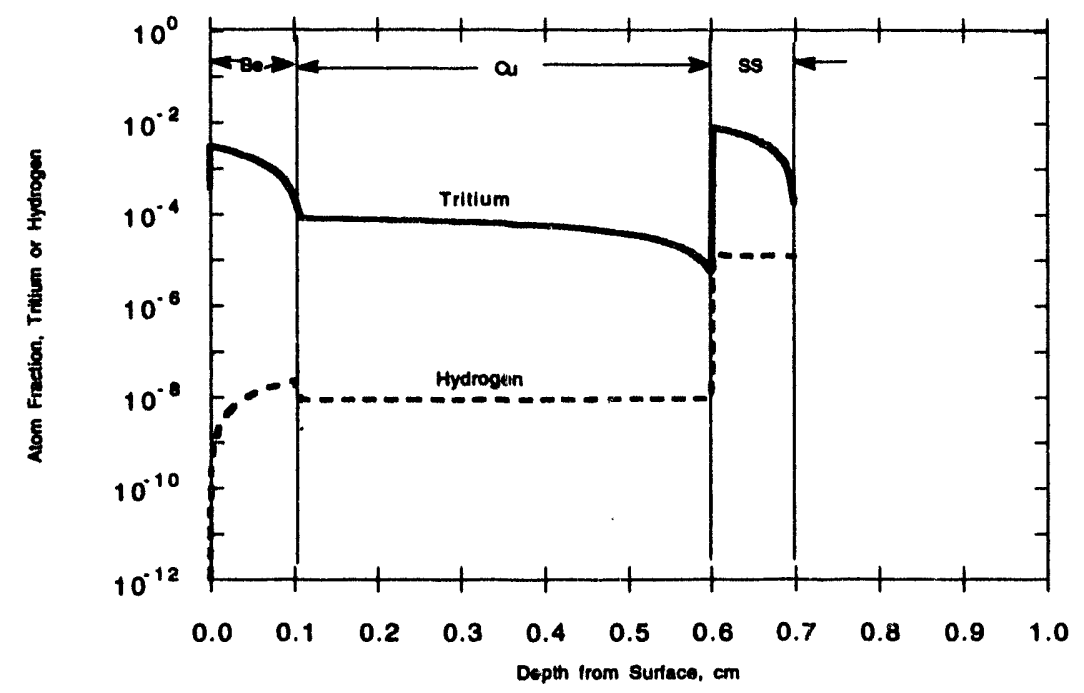

Figure 4. Calculated tritium and hydrogen concentration profiles in a multilayered $\mathrm{Be} / \mathrm{Cu} / \mathrm{SS}$ structure at $10^{7} \mathrm{~s}$. The tritium implantation flux is $10^{19} \mathrm{ions} / \mathrm{cm}^{2}-\mathrm{s}$ and the hydrogen coolant pressure is $0.001 \mathrm{~atm}$ and the coolant temperature is $200^{\circ} \mathrm{C}$.

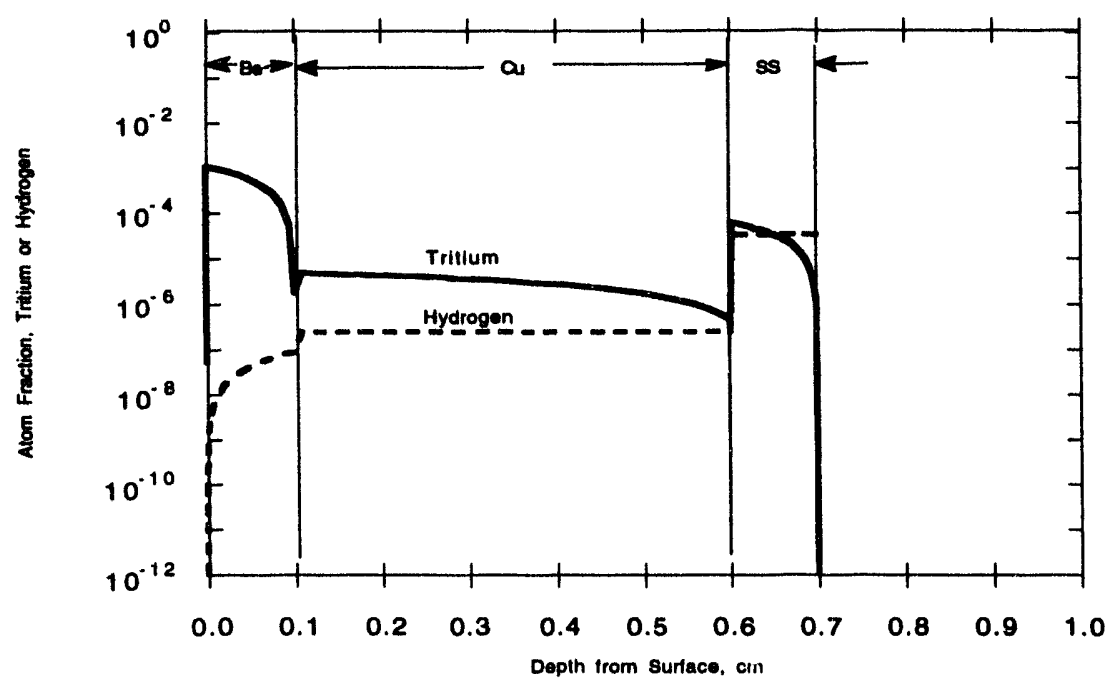

Figure 5. Calculated tritium and hydrogen concentration profiles in a multilayered $\mathrm{Be} / \mathrm{Cu} / \mathrm{SS}$ structure at $10^{7} \mathrm{~s}$. The tritium implantation flux is $10^{19} \mathrm{ions} / \mathrm{cm}^{2}-\mathrm{s}$ and the hydrogen coolant pressure is $0.001 \mathrm{~atm}$ and the coolant temperature is $500^{\circ} \mathrm{C}$. 


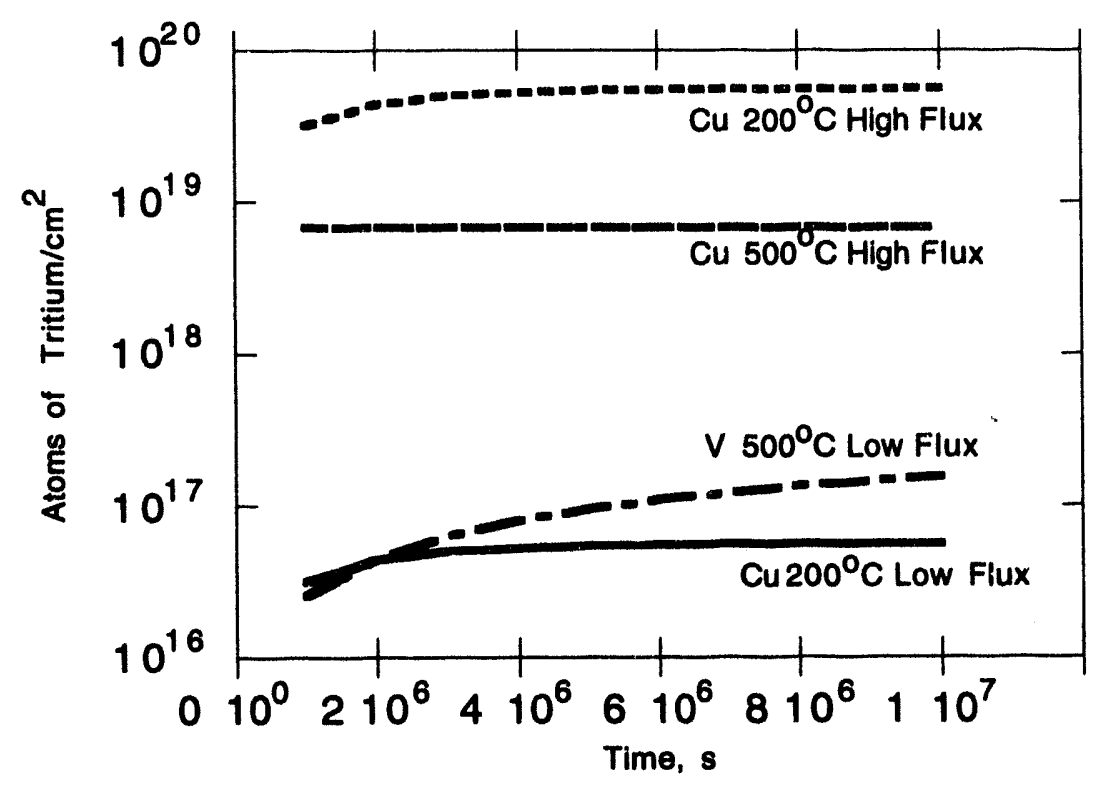

Figure 6. Calculated tritium inventory for $\mathrm{Be} / \mathrm{Cu} / \mathrm{SS}$ or $\mathrm{Be} / \mathrm{V} / \mathrm{SS}$ structures for the indicated implantation flux and coolant temperature.

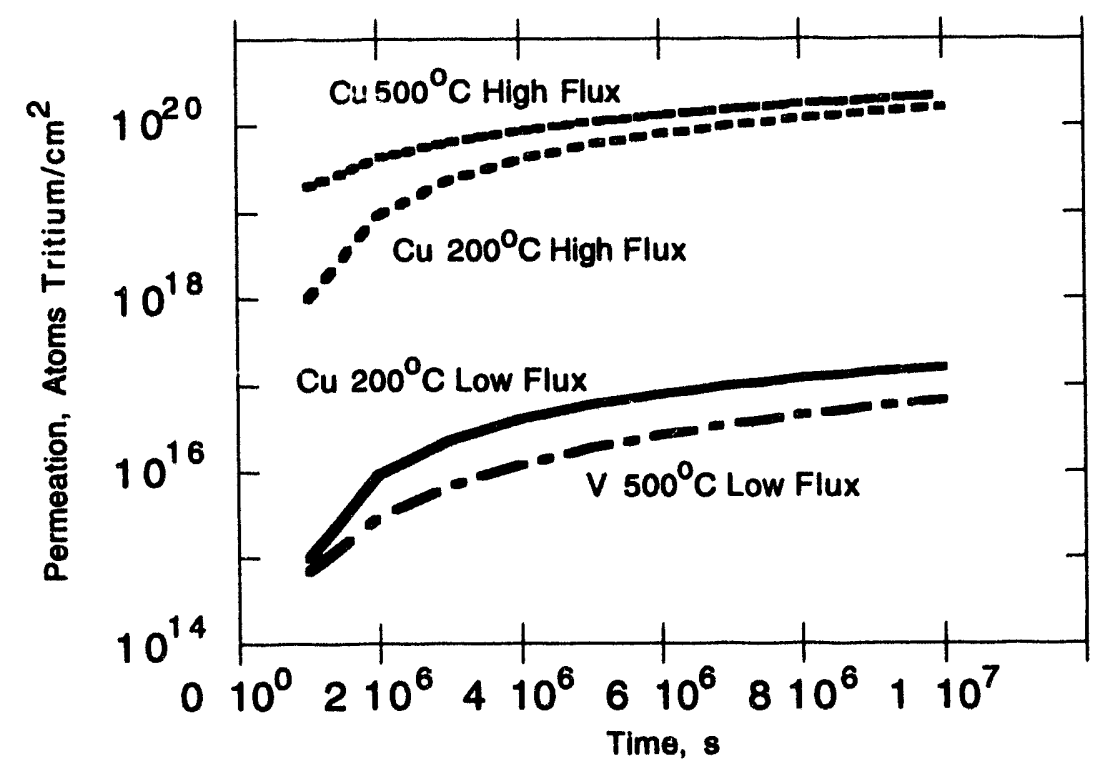

Figure 7. Calculated tritium permeation to the coolant for $\mathrm{Be} / \mathrm{Cu} / \mathrm{SS}$ or $\mathrm{Be} / \mathrm{V} / \mathrm{SS}$ structures for the indicated implantation flux and coolant temperature. 


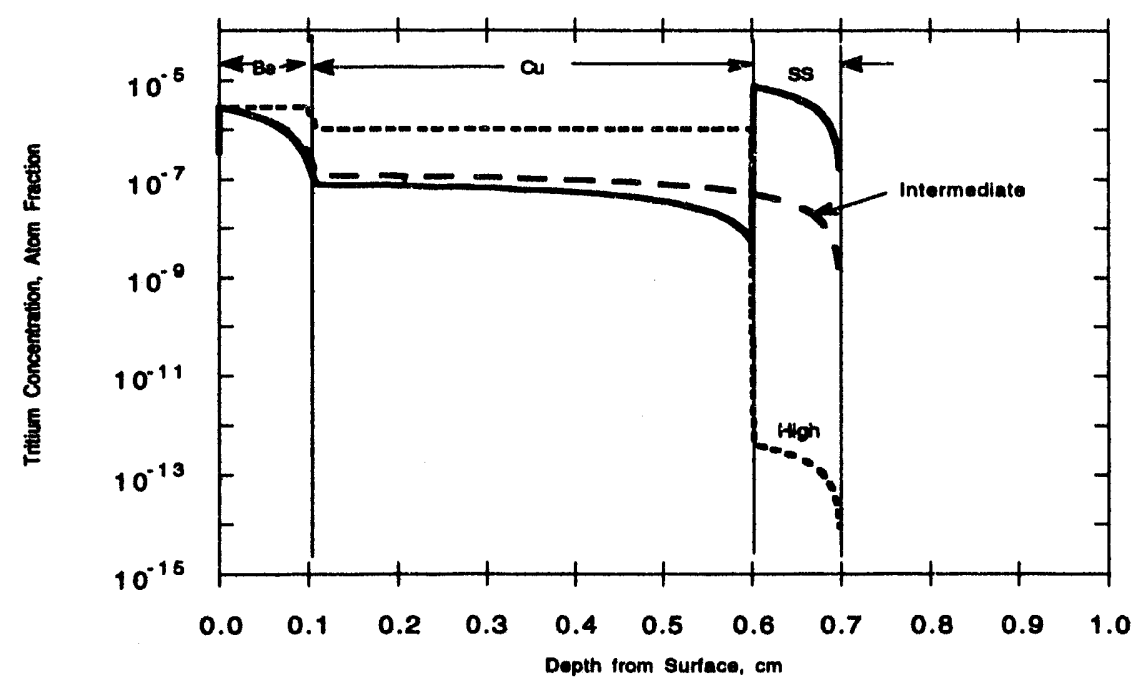

Figure 8. Calculated tritium concentration profiles in a multilayered $\mathrm{Be} / \mathrm{Cu} / \mathrm{X}$ structure at $10^{7} \mathrm{~s}$.

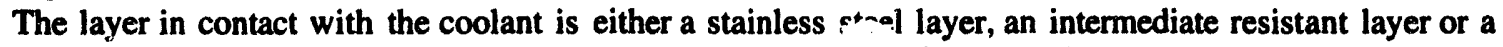
highly resistant layer. The tritium implantation flux is $: 6$ ions $/ \mathrm{cm}^{2}-\mathrm{s}$ and the hydrogen coolant pressure is $0.001 \mathrm{~atm}$ and the coolant temperature is $200^{\circ} \mathrm{C}$.

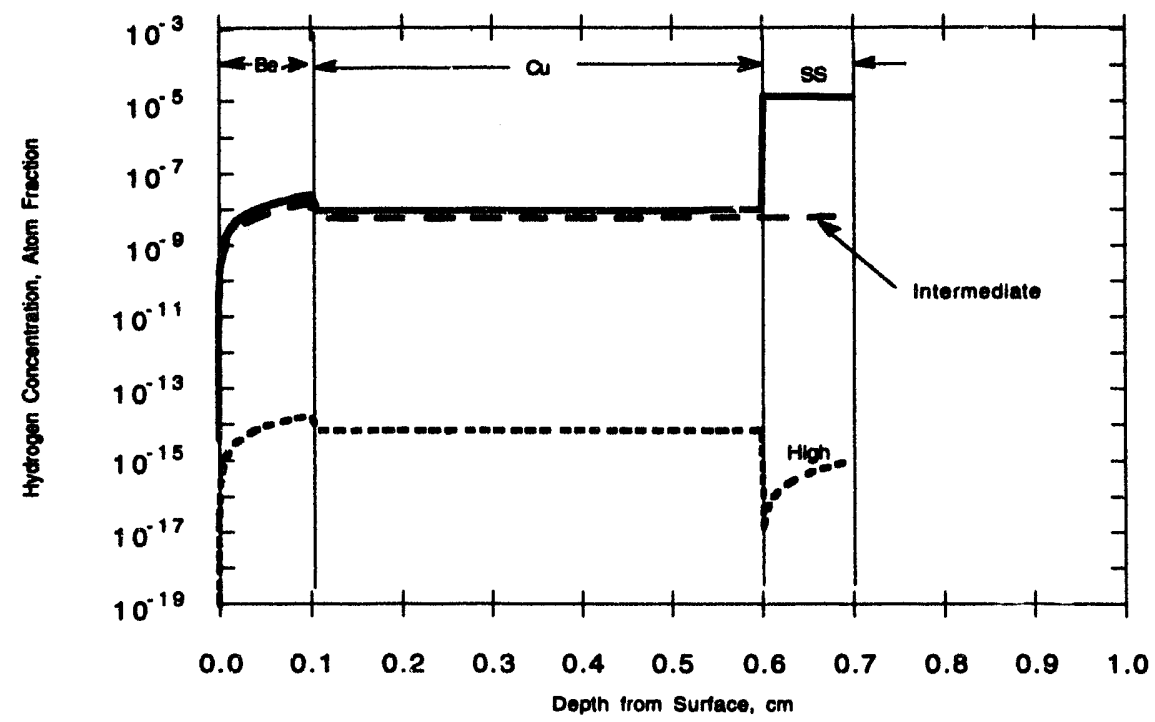

Figure 9. Calculated hydrogen concentration profiles in a multilayered $\mathrm{Be} / \mathrm{Cu} / \mathrm{X}$ structure at $10^{7} \mathrm{~s}$. The layer in contact with the coolant is either a stainless steel layer, an intermediate resistant layer or a highly resistant layer. The tritium implantation flux is $10^{16}-\mathrm{s}$ ions $/ \mathrm{cm}^{2}$ and the hydrogen coolant pressure is $0.001 \mathrm{~atm}$ and the coolant temperature is $200^{\circ} \mathrm{C}$. 


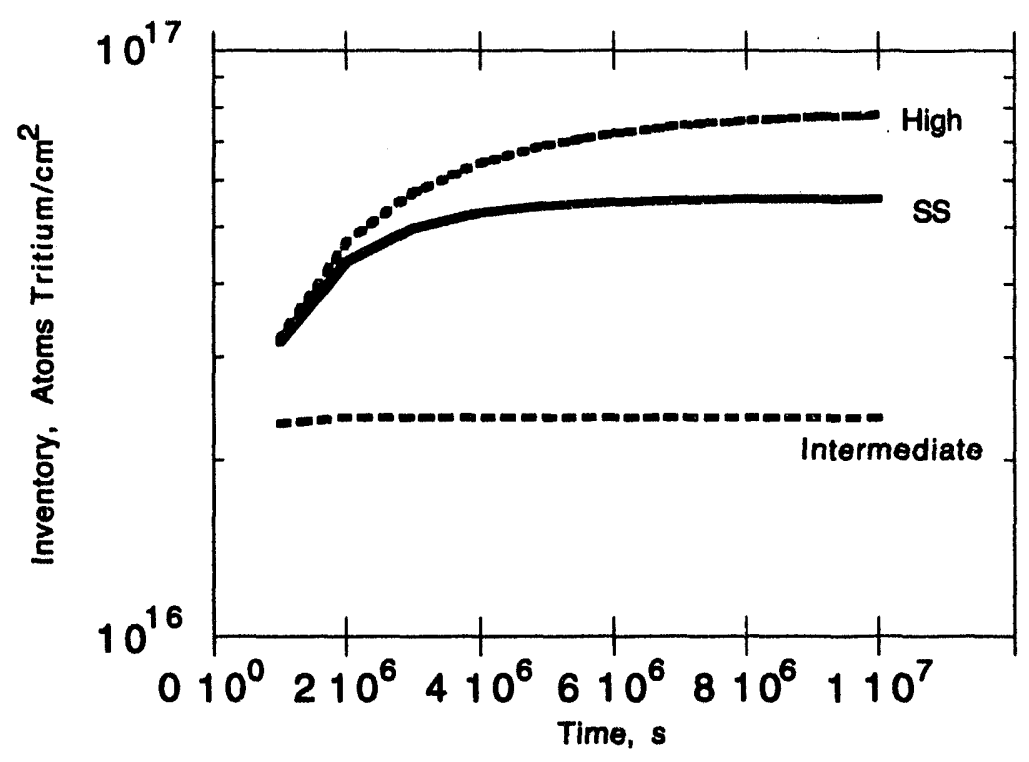

Figure 10. Calculated tritium inventory for $\mathrm{Be} / \mathrm{Cu} / \mathrm{X}$ structures and for an implantation flux of $10^{16}$ ions $/ \mathrm{cm}^{2}$ and coolant temperature of $200^{\circ} \mathrm{C}$.

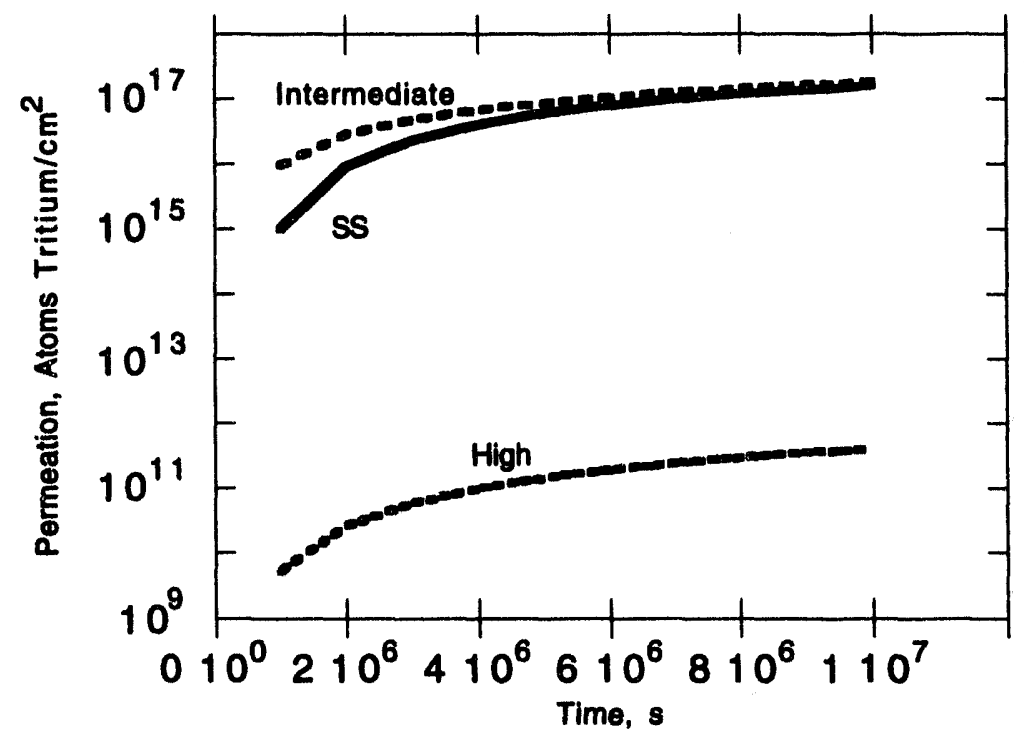

Figure 11. Calculated tritium permeation to the coolant for $\mathrm{Be} / \mathrm{Cu} / \mathrm{X}$ structures and for an implantation flux of $10^{16} \mathrm{ions} / \mathrm{cm}^{2}-\mathrm{s}$ and coolant temperature of $200^{\circ} \mathrm{C}$. 
barrier. An effective downstream barrier for tritium increases the tritium inventory (Figure 10) but decreases the tritium permeation losses to the coolant (Figure 11). Hydrogen ingress from the coolant through the permeation layer, $\mathrm{X}$, is low in $\mathrm{Be} / \mathrm{Cu} / \mathrm{X}$ multilayers because of the low hydrogen solubility in $\mathrm{Cu}$. The presence of an upstream hydrogen barrier is not significant because the hydrogen concentrations are already low even without a barrier in contact with the coolant.

The calculated hydrogen concentrations in the barrier layers are proportional to the square root of the assumed hydrogen pressure in the coolant. Therefore, estimates of hydrogen concentrations for pressures different from $0.001 \mathrm{~atm}$ can be obtained by using the square root proportionality dictated by Sievert's law.

Several significant assumptions have been made in the present analysis to simplify the examination of permeation behavior for ITER structures. Although time-dependent permeation was considered, the influence of radiation-induced hydrogen traps and surface oxide films may significantly retard permeation transients and hence permeation losses to the coolant. These effects will be examined in future work.

Complex alloys may or may not perform as for assumed simple base materials. However, there is some evidence that alloy structure does not strongly affect permeation behavior which is indicated in Figure 1 by comparing Inconel with $\mathrm{Ni}$ behaviors. An exception may exist for Be layers. The microstructure, such as porosity, in the Be layer may not be the same as for the data used in the analysis. These differences may affect Be permeation resistance and will be considered in future calculations.

\section{Conclusions}

Candidate alloy components for ITER structures exhibit a wide range of hydrogen isotope permeation behaviors. The distribution of tritium and hydrogen in candidate structures depends on the selection of base alloy as well as the selection of layer materials that may be applied to the alloy to improve compatibility with the plasma or the coolant.

Tritium and hydrogen concentrations may achieve levels of several appm or more based on an assumed plasma-driven tritium implantation of $10^{16}$ ions $/ \mathrm{cm}^{2} \mathrm{~s}$ and an assumed hydrogen coolant pressure of $0.001 \mathrm{~atm}$. For $\mathrm{Cu}$ structures, the calculated tritium concentration increased significantly for more resistant coolant-side permeation barriers. However, the calculated hydrogen concentration was low even for ineffective coolant-side permeation barriers.

\section{FUTURE WORK}

Contributions to hydrogen content from $(n, p)$ reactions will be evaluated as well as affects on transient permeation associated with radiation-induced hydrogen traps. Also, permeation through $\mathrm{Be} / \mathrm{Cu} / \mathrm{V}$ layered structures will be calculated.

\section{REFERENCES}

1. M. K. Baskes, DIFFUSE 83, SAND83-8231 (1983).

2. J. F. Ziegler, J. P. Biersack and U. Littmark, "The Stopping and Range of Ions in Solids," Pergamon Press, New York, New York.

3. G. Vieder, A. Cardella, M. Akiba, R. Matera and R. Watson, J. of Nucl. Mater., 16, 23 (1991).

4. M. I. Baskes, A. E. Pontau, and K. L. Wilson, J. of Nucl. Mater., 122\&123, 1511 (1984). 
MEASUREMENT OF ELECTRICAL RESISTIVITY OF THERMALLY GROWN TITANIUM NITRIDE THIN FILMS IN LIQUID LITHIUM* J.-H. Park and T. Domenico (Argonne National Laboratory)

\section{OBJECTIVE}

Corrosion resistance of structural materials and magnetohydrodynamic (MHD) force and its influence on thermal hydraulics and corrosion are major concerns in the design of liquid-metal blankets for magnetic fusion reactors (MFRs). ${ }^{1-3}$ The objective of this study is to develop in-situ TiN coatings and obtain insitu electrical resistivity measurements on $\mathrm{TiN}$ in a liquid $\mathrm{Li}$ environment.

\section{SUMMARY}

A sample of pure $\mathrm{Ti}$ and a pair of $\mathrm{Ti}$ electrodes were placed in small capsules containing liquid $\mathrm{Li}$ and $\mathrm{Li3} \mathrm{N}$ for seven days at $710^{\circ} \mathrm{C}$ to investigate the formation of titanium nitride (TiN). An attempt was made to enhance the resistivity of in-situ-formed $\mathrm{TiN}$ films by adding to the $\mathrm{Li}$ small amounts of $\mathrm{Al}, \mathrm{Si}$, and $\mathrm{Mg}$, which might be incorporated into the films. One sample and set of electrodes was nitrided in Li containing $\mathrm{Li}_{3} \mathrm{~N}$ and another was immersed in pure $\mathrm{Li}$. The electrical resistance of the films was $\approx 1.0-1.5 \Omega$ and the values increased slightly with temperature, which is indicative of metallic conduction. Energy-dispersivespectroscopy (EDS) analyses of the films by scanning electron microscopy (SEM) showed that none of the dopants was incorporated into the TiN lattice.

\section{INTRODUCTION}

Titanium nitride (TiN) thin films have shown utility in the fields of semiconductor fabrication as a diffusion barrier between semiconducting and conducting films, ${ }^{4-14}$ and in tribology as a wear-resistant surface coating. TiN exhibits several properties that have been useful, namely, a high melting point, high hardness, and electrical conductivity comparable to that of pure $\mathrm{Ti}^{15}$ Previous studies on thermally formed TiN on Ti show that this transition metal nitride, which may act as corrosion barrier and exhibit higher electrical resistivity when doped with additives such as $\mathrm{Al}, \mathrm{Si}$, or $\mathrm{Mg}$, may be formed in a liquid $\mathrm{Li}$ environment. Some of the physical properties of Ti and TiN are shown in Table 1.15

This study focuses on the possible use of thin TiN films to coat surfaces of structural alloys exposed to a Li coolant in a magnetic fusion reactor (MFR). Because many elements have very low diffusivities in TiN, it is desirable for use as a corrosion barrier in fusion power applications. However, because high electromagnetic fields are present in reactors, the high electrical conductivity of TiN may adversely affect the coolant flow properties in the system. To overcome this problem, several sets of metallographic samples and electrodes of $\mathrm{Ti}$ were nitrided in a $\mathrm{Li}$ environment to which we added small amounts of dopant elements in the hope of decreasing the electrical conductivity of the films, but still maintaining their usefulness as diffusion barriers.

\section{BACKGROUND}

Titanium nitride is one of the most thermodynamically stable transition metal nitrides, i.e., the nitrogen partial pressure for formation is low when compared to many other metal nitrides. Traditional methods for producing thin films of TiN have included chemical vapor deposition (CVD), wherein gases containing $\mathbf{N}$ $\left(\mathrm{N}_{2}, \mathrm{NH}_{3}\right)$ and $\mathrm{Ti}$ (usually $\mathrm{TiCl}_{4}$ ) are passed over a substrate surface at elevated temperatures. ${ }^{16} \mathrm{The} \mathrm{Ti}$ and $\mathbf{N}$ present in the gases react to form TiN and coat the surface. Another method for TiN film deposition is

*This work has been supported by the U.S. Department of Energy, under Contract W-31-109-Eng-38. 
ion implantation, wherein $\mathrm{Ti}$ and/or $\mathrm{N}$ is ionized, accelerated through a large potential difference, and bombarded onto a substrate surface.

Table 1. Physical properties of Ti and TiN 15

\begin{tabular}{lcr}
\hline Property & Ti & TiN \\
\hline Unit cell & hexagonal & cubic \\
Density, $\mathrm{g} / \mathrm{cm}^{3}$ & 4.5 & 5.4 \\
Melting temperature, ${ }^{\circ} \mathrm{C}$ & 1820 & 3200 \\
Boiling temperature, ${ }^{\circ} \mathrm{C}$ & 3287 & $\mathrm{~N} / \mathrm{A}$ \\
Thermal conductivity, $\mathrm{W} / \mathrm{mK}$ & 20 & 24 \\
Elastic modulus, $\mathrm{GPa}$ & 118 & 251 \\
Resistivity, $\mu \Omega \mathrm{cm}$ & 43 & 30 \\
Coefficient of Thermal & 9 & 8 \\
Expansion, $10^{-6} /{ }^{\circ} \mathrm{C}$ & & \\
Hardness, $\mathrm{kg} / \mathrm{mm}^{2}$ & & 1770 \\
\hline
\end{tabular}

In this study, TiN was produced in a liquid $\mathrm{Li}$ environment. ${ }^{17}$ Titanium samples and electrodes were placed into a liquid $\mathrm{Li}$ reservoir at $710^{\circ} \mathrm{C}$ in the presence of $\mathrm{Li}_{3} \mathrm{~N}$. The nitration process is as follows. $\mathrm{Li}_{3} \mathrm{~N}$ dissolves in liquid $\mathrm{Li}$ and the dissolved $\mathrm{N}$ diffuses into the Ti surface. Once the concentration of $\mathrm{N}$ in the surface is sufficiently high (saturation), the $\mathrm{N}$ and Ti react to form TiN.

Park 18 has proposed a model for electrical conductivity in TiN, which usually does not form stoichiometrically. In general, the TiN lattice contains many $\mathrm{N}$ vacancies, or, less frequently, $\mathrm{Ti}$ interstitials. These defects in the crystal may produce an increase in free-electron concentration to maintain the electrical neutrality of the solid. In the absence of a negative charge near a nitrogen anion vacancy in the lattice, a positively charged hole may appear. A solid, however, must remain electrically neutral, so this positive hole must be neutralized by a negative charge, possibly in the form of a free electron. This increased concentration of charge carriers could increase the electrical conductivity of the solid. Based on this model, we attempted to lower the conductivity of TiN by substituting dopant elements into the abovementioned film to decrease the concentration of free-charge carriers.

\section{EXPERIMENT}

Changes in resistance between two Ti electrodes that were immersed in liquid $\mathrm{Li}$ containing $\mathrm{Li}_{3} \mathrm{~N}$ and the dopant materials were measured at $710^{\circ} \mathrm{C}$. The high temperature should promote diffusion of $\mathrm{N}$ into the surface of the Ti electiodes, thereby facilitating the formation of a thin TiN coating. The experimental setup consisted of five $\mathrm{Ta}$ tubes that contained the electrodes, a small $\mathrm{Ti}$ specimen, $\mathrm{Li}, \mathrm{Li}_{3} \mathrm{~N}$, and the dopant materials. The bottom of the tubes was sealed with a Swagelok cap. The tubes (numbered 1 to 5) and their contents are listed in Table 2.

Tubes 1-3 contained $\mathrm{Al}, \mathrm{Si}$, and $\mathrm{Mg}$ in addition to $\mathrm{Li}$ and $\mathrm{Li}_{3} \mathrm{~N}$. To obtain baseline data on pure $\mathrm{TiN}$, Tube 4 contained no dopants and Tube 5 contained only $\mathrm{Li}$. Each tube was equipped with a pair of small electrodes and one small $\mathrm{Ti}$ sample $(\approx 3 \mathrm{~mm}$ square by $1.6 \mathrm{~mm}$ thick) for microscopic analysis and 
characterization. A 6-mm-diameter alumina $\operatorname{rod}\left(\mathrm{Al}_{2} \mathrm{O}_{3}\right)$ with two small holes running through its length was inserted into the Ta tube ( $-7 \mathrm{~mm}$ ID). The Ti electrodes were spot welded to stainless steel wires and the wires were fed through the holes in the Ta tube. The alumina tubes were specially machined at the bottom end with a low-speed diamond wafer saw to prevent contact between the two Ti electrodes (Fig. 1).

Table 2. Composition of Li environment $(g)$ in Ta capsules for nitration of $T i$

\begin{tabular}{lccccc}
\hline & \multicolumn{5}{c}{ Tube number } \\
\cline { 2 - 6 } Dopant & 1 & 2 & 3 & 4 & 5 \\
\hline $\mathrm{Li}$ & 0.96 & 0.96 & 0.91 & 0.83 & 1.03 \\
$\mathrm{Li} 3 \mathrm{~N}$ & 0.15 & 0.14 & 0.17 & 0.15 & - \\
$\mathrm{Al}$ & 0.08 & - & - & - & - \\
$\mathrm{Si}$ & - & 0.07 & - & - & - \\
$\mathrm{Mg}$ & - & - & 0.05 & - & - \\
$\mathrm{Li}$ & 1.30 & 0.13 & 0.13 & - & - \\
\hline
\end{tabular}

The experimental procedure was as follows. Each of the five Ta tubes was loaded with solid $\mathrm{Li}_{1} \mathrm{Li}_{3} \mathrm{~N}$, dopant materials, and a small Ti sample. The bottoms of the tubes were then mechanically sealed with Swagelok caps. After loading, the tubes were placed into a large stainless steel chamber. The alumina rods with the Ti electrodes were placed into the Ta tubes. Separate tubing was attached for purging, evacuation, and Ar pressurization to minimize ingress of air. A schematic diagram of the experimental setup is shown in Fig. 2 (without the air evacuation and Ar purging systems).

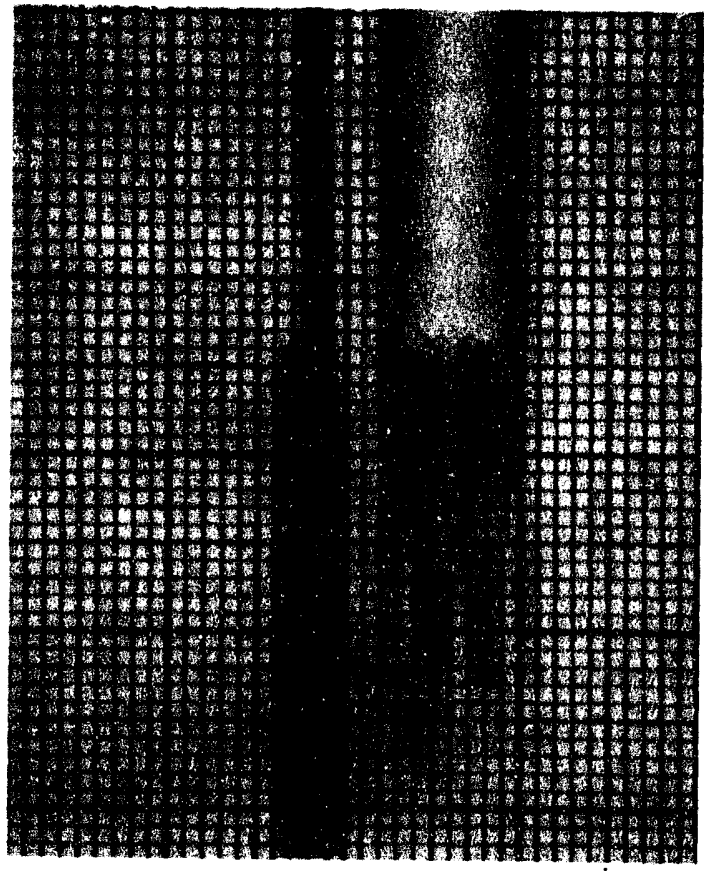

Figure 1. Ti electrodes and specially cut alumina tubes 


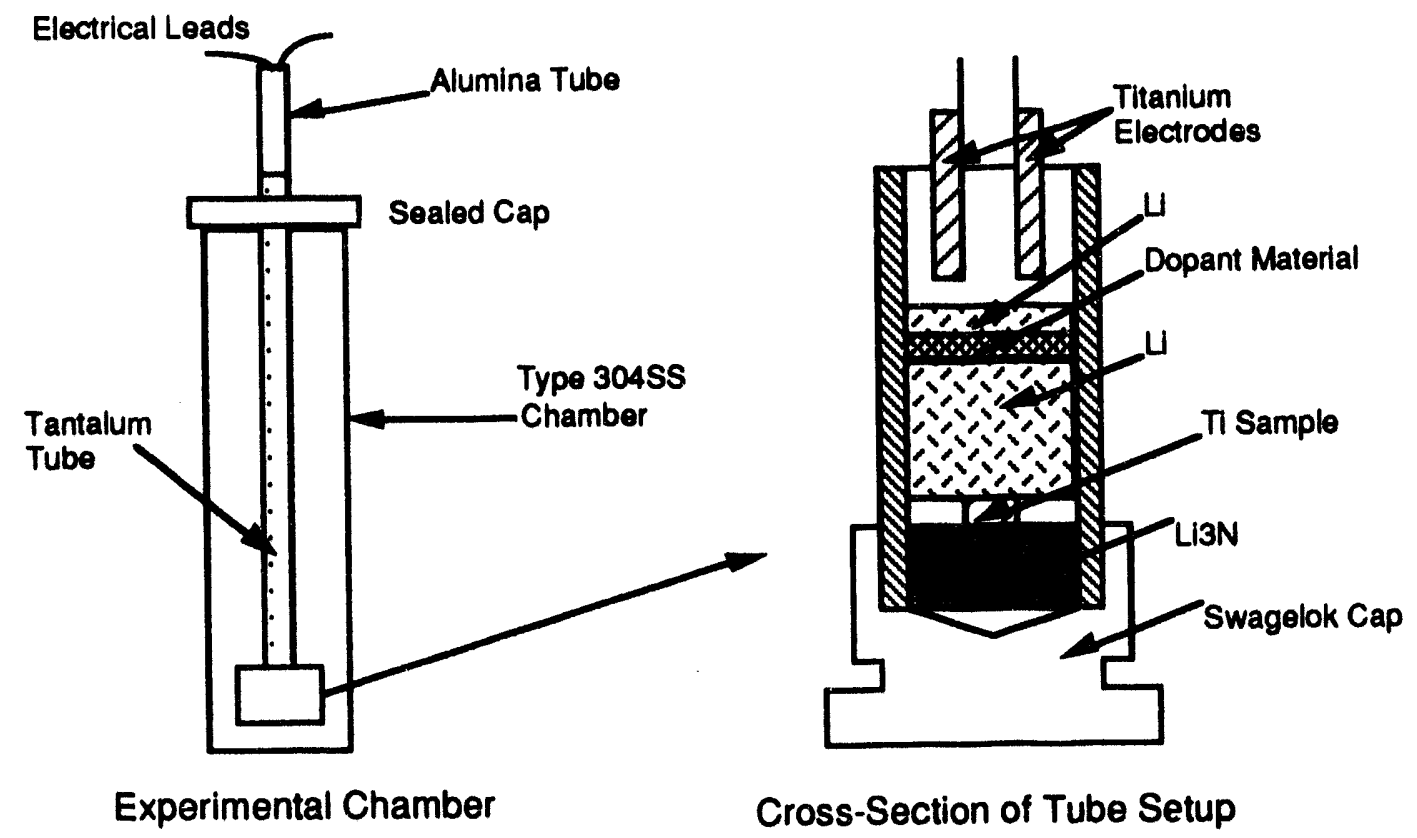

Figure 2. Schematic diagram of experimental setup

The cross section of the bottom of the Ta tube in Fig. 2 shows the order in which the $\mathrm{Li}_{3} \mathrm{~N}$, the Ti sample, $\mathrm{Li}$, and dopant materials were loaded. When melting occurs, all of the components mix to form a homogeneous liquid (with the exception of the Ti sample, which remains solid at the temperature of the experiment).

Each set of stainless steel leads was then wired so they could be easily attached to a constant current source and voltmeter. The entire assembly was then placed into a furnace and brought to $710^{\circ} \mathrm{C}$. The goal was to measure the resistance in each of the pairs of Ti electrodes during the nitration process over the entire period of nitration $(\approx 146 \mathrm{~h})$. Using a constant current source, we determ: nd the resistance by varying the current through the circuit from -15 to $+15 \mathrm{~mA}$, and measuring the $\mathrm{v}_{\mathrm{agge}}$ across the circuit with a voltmeter. The collected data were then fit with a straight line, the slope of which was (from Ohm's Law) the resistance in the circuit. The resistance as a function of temperature was also measured by continuing the above procedure at $50^{\circ} \mathrm{C}$ intervals during cooling from $\approx 700$ to $300^{\circ} \mathrm{C}$, after nitration had taken place.

\section{EXPERIMENTAL RESULTS}

The resistance of each Ti electrode pair was measured at the beginning of nitration and $\approx 3$ times per day for the duration of the nitration experiment ( 7 days). The furnace was then cooled to obtain resistance-versustemperature data. However, on the seventh day of the experiment, it was discovered that the wire connections between the stainless steel leads and the current source were improperly soldered so that all resistance data taken up to that point were invalid. The electrical connections were rejoined correctly and the furnace was brought back to $695^{\circ} \mathrm{C}$. Because nitration had already taken place, it was not possible at this point to record changes in resistance during the nitration process. However, resistance versus temperature upon cooling could still be obtained and these data are listed in Table 3 and plotted in Fig. 3. 
Table 3. Resistance of TiN versus temperature

\begin{tabular}{llllll}
\hline \multirow{2}{*}{ Temp., } & \multicolumn{5}{c}{ Resistance, $\Omega$} \\
\cline { 2 - 6 }${ }^{\circ} \mathrm{C}$ & Tube 1 & Tube 2 & Tube 3 & Tube 4 & Tube 5 \\
\hline 695 & 0.980 & 0.990 & 1.130 & 1.187 & 1.153 \\
640 & 0.980 & 0.990 & 1.127 & 1.173 & 1.147 \\
600 & 0.977 & 0.987 & 1.127 & 1.173 & 1.140 \\
550 & 0.974 & 0.986 & 1.124 & 1.166 & 1.136 \\
505 & 0.971 & 0.984 & 1.121 & 1.155 & 1.131 \\
450 & 0.969 & 0.982 & 1.119 & 1.146 & 1.125 \\
400 & 0.969 & 0.981 & 1.117 & 1.132 & 1.118 \\
350 & 0.968 & 0.979 & 1.115 & 1.127 & 1.112 \\
300 & 0.966 & 0.978 & 1.113 & 1.122 & 1.106 \\
\hline
\end{tabular}

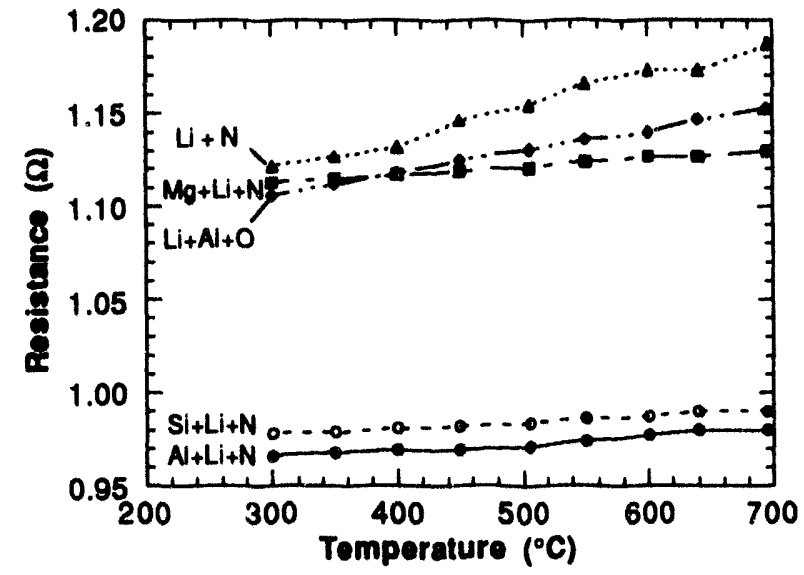

Figure 3. Resistance versus temperature for TiN layers formed in liquid $\mathrm{Li}$

After the system was cooled to room temperature and the apparatus was disassembled, it appeared that the alumina insulator in Tube 5 had been submerged in the liquid $\mathrm{Li}$ during the experiment, i.e., the bottom portion of the rod was black and a large amount of a solidified, white powdery substance was found on the outside of the Ta tubes (Fig. 4). This substance flaked off very easily at the touch of a finger, was very slippery, and exuded a very strong odor. We believe it to be lithium oxide, $\mathrm{Li}_{2} \mathrm{O}$, which formed after $\mathrm{Li}$ leaked from the bottom of two of the tubes.

The bottom ends of the tubes were cut off $=40-50 \mathrm{~mm}$ from the bottom of the Swagelok caps, and the solid $\mathrm{Li}$ was dissolved in water. Two of the caps (from Tubes 2 and 5) appeared to be empty of solid Li, indicating that these were the tubes that leaked at the bottom (Swagelok). The small Ti samples were then retrieved and cleaned for microscopic analysis by SEM. SEM photomicrographs of the surfaces of the samples are shown in Fig. 5. 

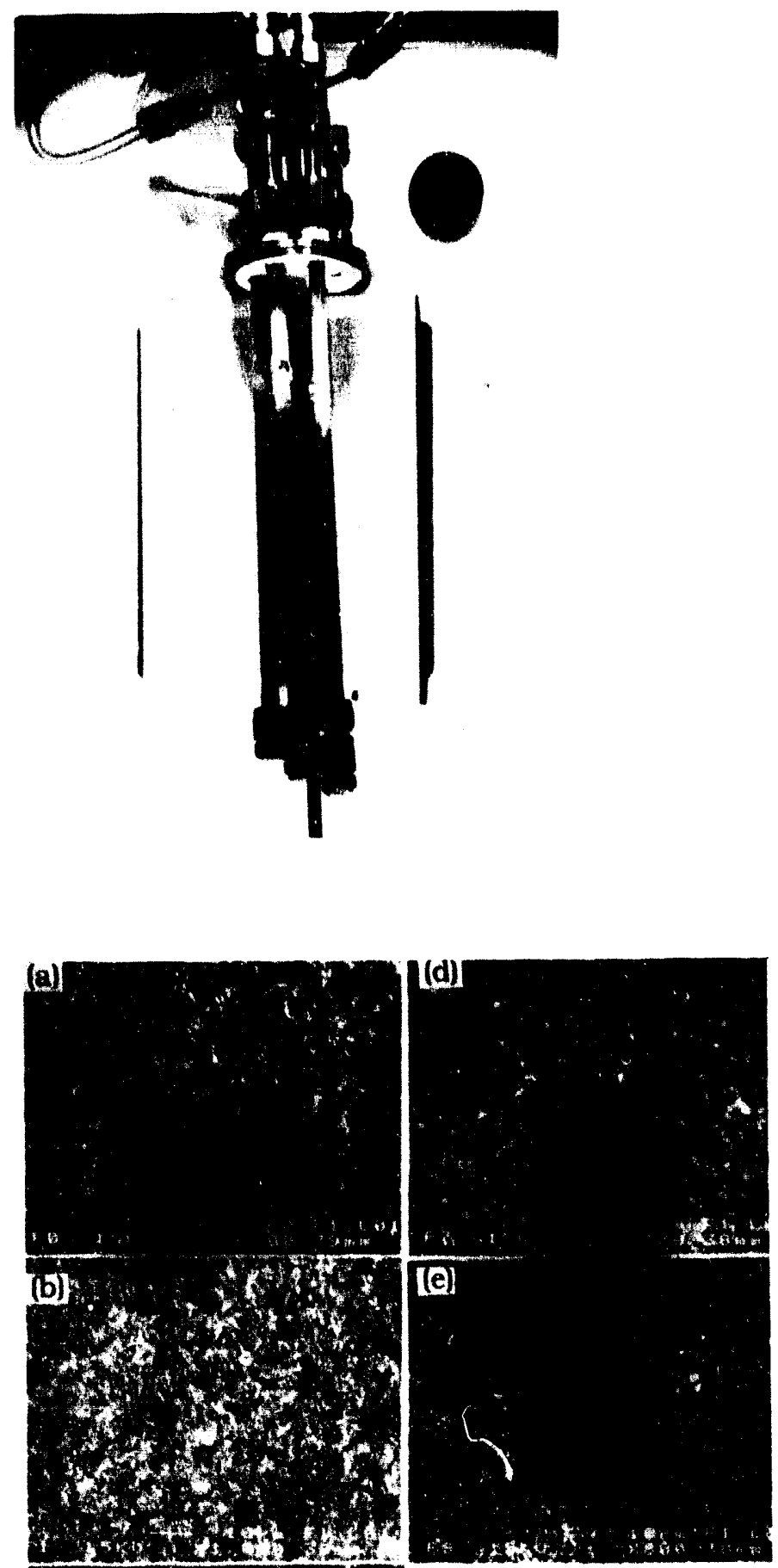

(c)

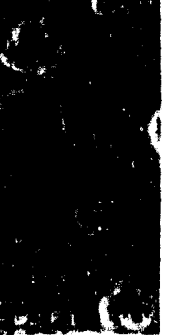

Figure 4. $\mathrm{Li}_{2} \mathrm{O}$ on the outside of the Ta tubes

Figure 5. SEM photomicrographs of surface of Ti samples exposed in liquid Li:

(a) Tube $1(A l+L i+N)$,

(b) Tube $2(\mathrm{Si}+\mathrm{Li}+\mathrm{N})$,

(c) Tube $3(\mathrm{Mg}+\mathrm{Li}+\mathrm{N})$,

(d) Tube $4(\mathrm{Li}+\mathrm{N})$, and

(e) Tube $5(A l+O+L i)$ 


\section{DISCUSSION}

EDS spectra of the surfaces of the samples in Tubes $1-4$ indicate that $T i$ and $N$ are the principle elements present in the surface coatings, i.e., TiN. Qualitative analysis of the spectra revealed some Si in all of the samples, but this is believed to be an error. The X-ray energies for Si and Ta are very similar (1.740 and $1.710 \mathrm{eV}$, respectively), and because all experiments were conducted in Ta tubes, and Si was present in only one of the capsules, this peak is believed to indicate the presence of $\mathrm{Ta}$, not $\mathrm{Si}$. None of the dopant materials ( $\mathrm{Al}, \mathrm{Si}$, and $\mathrm{Mg}$ ) was detected in the three samples. This was verified later when sample cross sections were investigated by SEM. The cross-sectional analysis yielded the approximate film thicknesses shown in Table 4.

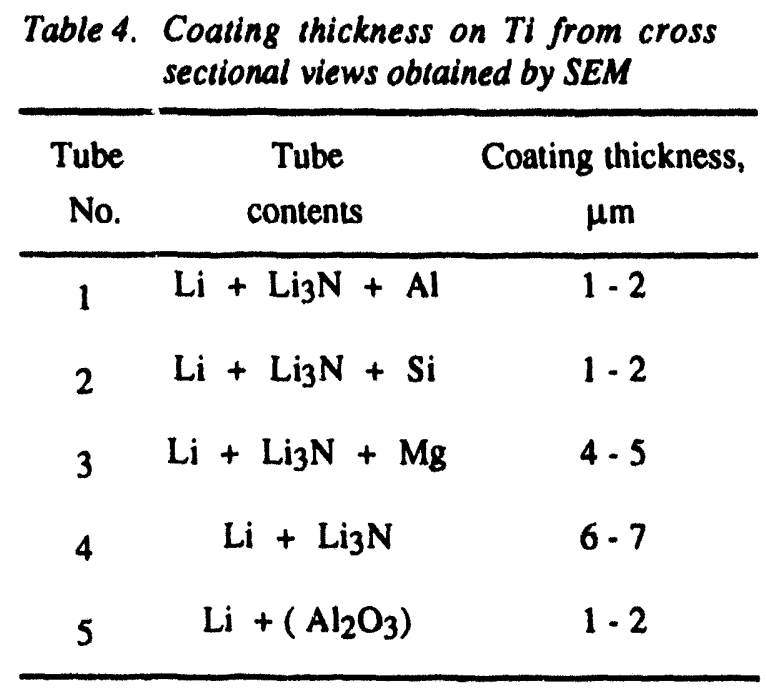

The $\mathrm{Ti}$ sample with $\mathrm{Mg}$ as a dopant exhibited an interesting surface microstructure. The entire surface appeared to have been scarred and pitted by a corrosive process. EDS spectra of the flat surface and of the bottom of one of the pits revealed that the composition was nearly the same. In an optical microscope, the cross section of the sample had a very rough surface, but the TiN layer was uniform in thickness in all areas. This finding suggests that whatever mechanism was responsible for corrosion took place before the coating formed on the surface of the Ti; it also shows that the nitration process in situ in liquid Li coats irregular surfaces quite well, as was demonstrated previously. ${ }^{17}$

The Ti sample in Tube 5 also showed an irregular surface marked by small flakes. Examination of the surface spectrum indicated the presence of $\mathrm{Al}$ and $\mathrm{O}$. This was probably caused by dissolution of the bottom end of the alumina insulator, which was submerged in the liquid Li during the experiment, as mentioned previously. Apparently $\mathrm{Al}$ and $\mathrm{O}$ from the alumina rod deposited on the surface of the $\mathrm{Ti}$ sample.

All electrodes showed metallic resistance characteristics, i.e., the resistance increased slightly with increasing temperature. The dopant elements were not found in any of the surface coatings by EDS analysis because their concentrations were probably too small to be observed by the EDS technique. Surfaces of samples in Tubes 1--4 seem to be similar in composition. The electrodes in Tube 4, which contained $\mathrm{Li}$ and $\mathrm{Li}_{3} \mathrm{~N}$, showed the highest resistance and the largest change in resistance with temperature. The electrodes in Tube 5, which was contaminated with $\mathrm{Al}$ and $\mathrm{O}$, and those in Tube 3 (containing $\mathrm{Mg}$ ) exhibited a similar resistance, but the electrodes in the former tube showed a greater increase in resistance with temperature. The electrodes in $\mathrm{Li}$ doped with $\mathrm{Al}$ and $\mathrm{Si}$ showed the smallest resistance (Tubes 1 and 2), and very little chanize in resistance with temperature. 
It is interesting to compare the measured resistances based on the thickness of the films and the area of the electrodes immersed in $\mathrm{Li}$. The resistance data in Table 3, average film thicknesses from Table 4 , and the area of the electrodes in contact with the $\mathrm{Li}\left(\approx 100 \mathrm{~mm}^{2} \pm 20 \%\right)$ were used to obtain the ohmic resistivity of TiN shown in Fig. 6. Because there was no $\mathrm{Li}_{3} \mathrm{~N}$ added to the $\mathrm{Li}$ in Tube 5, the resistivity is attributed to the Al-Li-O layer $(-1-2 \mu \mathrm{m}$ thick), which showed the highest $r$.stivity.

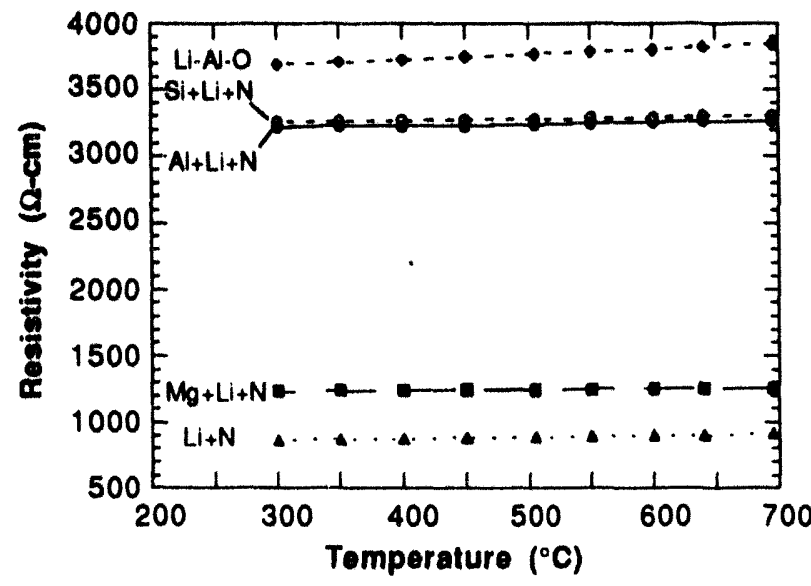

Figure 6. Ohmic resistivity versus temperature for thermally grown TiN with various dopants

\section{CONCLUSION}

In this experiment, an attempt was made to produce an insulator coating of TiN on a pure Ti substrate during nitration in a liquid $\mathrm{Li}$ environment containing differing elements. Because an error was made in the experimental setup, reliable resistance data were not obtained during nitration and only data on the variation of resistance with temperature could be collected. All coated electrodes exhibited metallic conduction, in that their resistance decreased with decreasing temperature. Moreover, no dopant materials were found in any of the nitrated samples, i.e., all samples appeared to be compositionally similar, except for the one that was obviously contaminated by $\mathrm{Al}$ and $\mathrm{O}$ as a result of dissolution the alumina rod in $\mathrm{Li}$.

The SEM analysis revealed that TiN films had, indeed, been produced as thin coatings on the surface of the Ti substrates. The coating on the rough surface of the sample in Tube 3 showed that the nitration process can be useful in coating an irregular surface. The samples showed variations in coating thickness, suggesting a possible method for controlling coating thicknesses in future operations.

\section{REFERENCES}

1. C. C. Baker, et al., Tokamak Power System Studies FY 1985, Argonne National Laboratory Report ANL/FPP-85-2 (December 1985).

2. Y. Y. Liu and D. L. Smith, Ceramic Electrical Insulators for Liquid Metal Blankets, J. Nucl. Mater., 141-143, 38 (1986).

3. T. Kammash, Fusion Reactor Physics, Chapter 15, Ann Arbor Science Pub. Inc., Ann Arbor, MI (1975) pp. 405-439.

4. J. N. Musher and R. G. Gordon, Low-Temperature CVD TiN as a Diffusion Barrier between Gold and Silicon, J. Electron. Mater., 20, 1105 (1991). 
5. J. O. Olowolafe, Effect of Oxygen in TiNx on the Diffusion of $\mathrm{Cu}$ in Cu/TiN/Al and Cu/TiNx/Si Structures, Appl. Phys. Lett., 58, 469 (1991).

6. M. Mundl, H. Hoffmann, and P. Kucher, Diffusion Barrier Properties of Ti/TiN Investigated by Transmission Electron Microscopy, J. Appl. Phys., 68, 2127 (1990).

7. E. Metin and O. T. Inal, Kinetics of Layer Growth and Multiphase Diffusion in Ion-Nitrided Titanium, Met. Trans., 20A, 1819, (1989).

8. M. Wittmer, B. Studer, and H. Melchior, Electrical Characteristics of TiN Contact to N Silicon, J. Appl. Phys., 52, 5722, (1981).

9. M. A. Nicolet, Diffusion Barrier in Thin Films, Thin Solid Films, 52, 415 (1978).

10. J. M. Poitevin, G. Lemperiere, and J. Tardy, Influence of Substrate Bias on the Composition, Structure and Electrical Properties of Reactively D.C.-Sputtered TiN Films, Thin Solid Films, 97, 69 (1982).

11. A. Sherman, Growth and Properties of LPCVD TiN as a Diffusion Barrier for Silicon Device Technology, J. Electrochem. Soc., 137, 1892 (1990).

12. M. J. Buiting and A. F. Otterloo, Relationship between the Process Parameters and Film Properties of "Low Temperature" Low Pressure CVD TiN Films, J. Electrochem. Soc., 139, 2580 (1992).

13. T. P. Thorpe, S. B. Qadri, S. A. Wolf, and J. H. Claassen, Electrical and Optical Properties of Sputtered TiNx Films as a Function of Substrate Deposition Temperature, Appl. Phys. Lett., 49, 1239 (1986).

14. C. Y. Ting, TiN as a High-Temperature Diffusion Barrier for Arsenic and Boron, Thin Solid Films, 119, 11 (1984).

15. D. R. Lide, Handbook of Chemistry and Physics, 71st ed. (1990).

16. Chemical Vapor Deposiled Materials, F. S. Galasso, CRC Press, Boston, (1991).

17. J.-H. Park and G. Dragel, Development of In-Situ-Formed Electrical Insulator Coatings on HighTemperature Alloys in Lithium, Fusion Reactor Materials Semiannual Progress Report for the Period Ending March 31, 1993. DOE/ER-0313/13, Oak Ridge National Laboratory, Oak Ridge, TN, pp. 285-289.

18. J.-H. Park, Unpublished work, Argonne National Laboratory (1993). 


\section{DEVELOPMENT OF ELECTRICAL-INSULATOR COATINGS: IN-SITU ELECTRICAL RESISTANCE MEASUREMENTS ON V-5\%Cr-5\%Ti IN LIQUID LITHIUM* \\ J.-H. Park and G. Dragel (Argonne National Laboratory)}

\section{OBJECTIVE}

Corrosion resistance of structural materials and magnetohydrodynamic (MHD) force and its influence on thermal hydraulics and corrosion are major concerns in the design of liquid-metal blankets for magnetic fusion reactors (MFRs). The objective of this study is to develop in situ stable coatings at the liquidmetal/structural-material interface, with emphasis on electrically insulating coatings that prevent adverse currents that are generated by MHD forces from passing through structural walls. ${ }^{1-3}$

\section{SUMMARY}

The electrical resistance of insulator coatings produced on $\mathrm{V}-5 \% \mathrm{Cr}-5 \% \mathrm{Ti}$ by exposure of the alloy to liquid $\mathrm{Li}$ that contained 5 at.\% $\mathrm{N}$, with and without 5 at.\% dissolved $\mathrm{Al}$, was measured as a function of time at temperatures between 250 and $500^{\circ} \mathrm{C}$. The solute elements $(\mathrm{N}$ and $\mathrm{Al})$ reacted in liquid $\mathrm{Li}$ with the alloy substrate at $415^{\circ} \mathrm{C}$ to produce thin adherent coatings. The resistance of the coating layer was $\approx 1.5$ and $1.0 \Omega$ at 415 and $500^{\circ} \mathrm{C}$, respectively. Thermal cycling between 250 and $415^{\circ} \mathrm{C}$ did not change the resistance of the coating layers. These results and those reported previously 4,5 suggest that thin homogeneous coatings can be produced on variously shaped surfaces by controlling the exposure time, temperature, and composition of the liquid metal. The integrity of the coatings does not appear to sensitive to defects (e.g., open pores, fissures, or microcracks) present in the alloy substrate in liquid Li.

\section{INTRODUCTION}

Corrosion resistance of structural materials and magnetohydrodynamic (MHD) force and its influence on thermal hydraulics are major concerns in the design of liquid-metal cooling systems. ${ }^{1-6}$ The objective of this study is to develop in situ stable, corrosion-resistant coatings, as well as insulator coatings at the liquid-metal/structural-material interface. The electrically insulating coatings should be capable of forming on various shapes such as the inside of tubes or irregular shapes during operational conditions to prevent adverse currents that are generated by MHD forces from passing through the structural walls. The coatings could also improve general corrosion resistance and act as a diffusion barrier for hydrogen isotopes, viz., deuterium and tritium. In-situ electrical resistance of insulator coatings on $\mathrm{V}-5 \% \mathrm{Cr}-5 \% \mathrm{Ti}$ was monitored as a function of time in $\mathrm{Li}$ at 415 and $500^{\circ} \mathrm{C}$. Thermal cycling was conducted to investigate the integrity of the coating layers that formed in situ.

\section{EXPERIMENTAL PROCEDURE}

Aluminide coatings that form on structural alloys ${ }^{4-6}$ during exposure to liquid $\mathrm{Li}$ containing dissolved $\mathrm{Al}$ suggest a means for producing stable electrical insulator layers, such as AlN, by subsequent nitration of the intermetallic layer in the liquid-metal environment, as we proposed in previous reports. ${ }^{4,5}$ Table 1 shows the type and amount of solute in $\approx 2.5 \mathrm{~g}$ of Li contained in V and V-20\% Ti capsules for in-situ electrical conductivity measurements on $\mathrm{V}-5 \% \mathrm{Cr}-5 \% \mathrm{Ti}$ in two cells. Figure 1 shows the cell assembly. An aluminide coating was applied to the inside surface of $\mathrm{V}$ and V-20\%Ti capsules, as described previously, 4,5

*This work has been supported by the U.S. Department of Energy, under Contract W-31-109-Eng-38. 
Table 1. Type and amount of solute in $2.5 \mathrm{~g}$ of $\mathrm{Li}$ in $V$ and $V-20 \% T i$ capsules in two cells

\begin{tabular}{lccccc}
\hline Cell & Li, g & Li3N, g & N, at.\% & Al, g & Y, g \\
\hline A & 2.28 & 0.75 & 5.06 & 0.6 & 0.24 \\
B & 2.52 & 0.77 & 4.90 & - & 0.22 \\
\hline
\end{tabular}

To investigate the differences in the ohmic resistance of in-situ formed AlN and (V,Ti)N layers on the $\mathrm{V}-5 \% \mathrm{Cr}-5 \% \mathrm{Ti}$, Cell A contained $=0.6 \mathrm{~g}$ of Al, whereas no $\mathrm{Al}$ was added to the $\mathrm{Li}$ in Cell B (Table 1). The postulated coating reactions at the liquid/V-5\% Cr-5\% Ti alloy interface in the two cells are

Cell A;

$$
\left.A l_{(\text {in }} \mathrm{Li}\right)+\mathrm{N}_{(\text {in } \mathrm{Li})}=\mathrm{AlN} \text { (in.Li and on substrate) }
$$

Cell B;

$$
(\mathrm{V}, \mathrm{Ti}) \text { (substrate) }+\mathrm{N}_{(\text {in } \mathrm{Li})}=(\mathrm{V}, \mathrm{Ti}) \mathrm{N}_{\text {(on substrate) }} \text {. }
$$

In-situ electrical resistance of each cell was monitored as a function of time for $400 \mathrm{~h}$. The effect of thermal cycling on resistance of the films was investigated by dropping the temperature to just above the melting point of $\mathrm{Li}$ and then increasing the temperature to the original value and higher $\left(\right.$ to $\left.500^{\circ} \mathrm{C}\right)$. The tests yielded insight into the integrity of the in-situ-formed coating layers and into the nature of the temperature dependence of resistance. General procedures were similar to those described in our previous report. ${ }^{4}$ Ohmic values were monitored between two V-5Cr-5Ti samples in the liquid-Li environment in each of the cells.

\section{Li reservoir}

Lithium, $\mathrm{Li}_{3} \mathrm{~N}$, and $\mathrm{Al}$ were loaded in the aluminized $\mathrm{V}$ or $\mathrm{V}-20 \% \mathrm{Ti}$ capsules by the following method. Pieces of solid $\mathrm{Li}$, in the form of wire ( $3 \mathrm{~mm}$ in diameter and 25 to $50 \mathrm{~mm}$ long) were placed in the capsule and compacted with a steel plunger to reduce the void space. A weighed amount of $\mathrm{Li}_{3} \mathrm{~N}$ and $\mathrm{Al}(\mathrm{Cell} \mathrm{A}$ ) in the form of fine powder was poured into the capsule and additional $\mathrm{Li}$ was loaded, as described previously. The V and V-20\%Ti capsules were placed in a larger stainless steel (SS) container with an inert gas environment.

\section{Electrical resistance cell assembly}

Four V-5\%Cr-5\%Ti specimens $(1.0 \mathrm{~mm} \times 4.0 \mathrm{~mm} \times 40 \mathrm{~mm})$ were attached to Type 304 SS wire by spot welding to ensure good contact and mechanical strength. Two V-5\%Cr-5\%Ti specimens were placed in each resistance cell suspended from the SS wires which passed through holes in high-purity alumina rods (1/4 in. OD). Two electrical resistance cells were placed in a vertical furnace, as shown in Fig. 1. During all procedures, care was taken to minimize oxidation of the materials.

After assembly, the ohmic contact resistance between solid $\mathrm{Li}$ and the $\mathrm{V}-5 \% \mathrm{Cr}-5 \% \mathrm{Ti}$ samples was checked, and in most instances, the values were quite high because of surface oxidation of $\mathrm{Li}$. However, one or two of the samples indicated values near zero. An Ar cover gas (99.999\%) was maintained in the system to prevent oxidation of the $\mathrm{V}$ capsules and the $\mathrm{Li}$ during the test. When the temperature reached $\approx 250^{\circ} \mathrm{C}$ (the melting point of $\mathrm{Li}$ is $180^{\circ} \mathrm{C}$ ), the $\mathrm{V}-5 \% \mathrm{Cr}-5 \% \mathrm{Ti}$ samples were partially immersed in the $\mathrm{Li}$ by lowering the alumina rods so that $15 \mathrm{~mm}$ of the $40-\mathrm{mm}$-long specimen was below the surface. 
The surface level of liquid $\mathrm{Li}$ in the capsule was deduced from the mass of the liquid and the geometry of the capsule and samples, but it could not be determined very accurately. Therefore, the ohmic resistance was noted as the samples were lowered, and after contact with the liquid was made, the rod was lowered $15 \mathrm{~mm}$. The contact area between liquid $\mathrm{Li}$ and each of the V-5\%Cr-5\%Ti samples was $\approx 150 \mathrm{~mm}^{2}$ in each of the cells. After heating to $415^{\circ} \mathrm{C}$, the ohmic values were measured as a function of time. At $\approx 190 \mathrm{~h}$ of the 400-h experiment, the temperature was cycled from 415 to $250^{\circ} \mathrm{C}$ and then raised to $500^{\circ} \mathrm{C}$, as is shown in Fig. 2. At the end of the test, the samples were withdrawn to a level above the liquid $\mathrm{Li}$ and the furnace was turned off. The samples were removed from the furnace and placed in a beaker of water to dissolve the small volume of adherent $\mathrm{Li}$, cleaned ultrasonically in acetone and ethanol, and dried in air for examination.
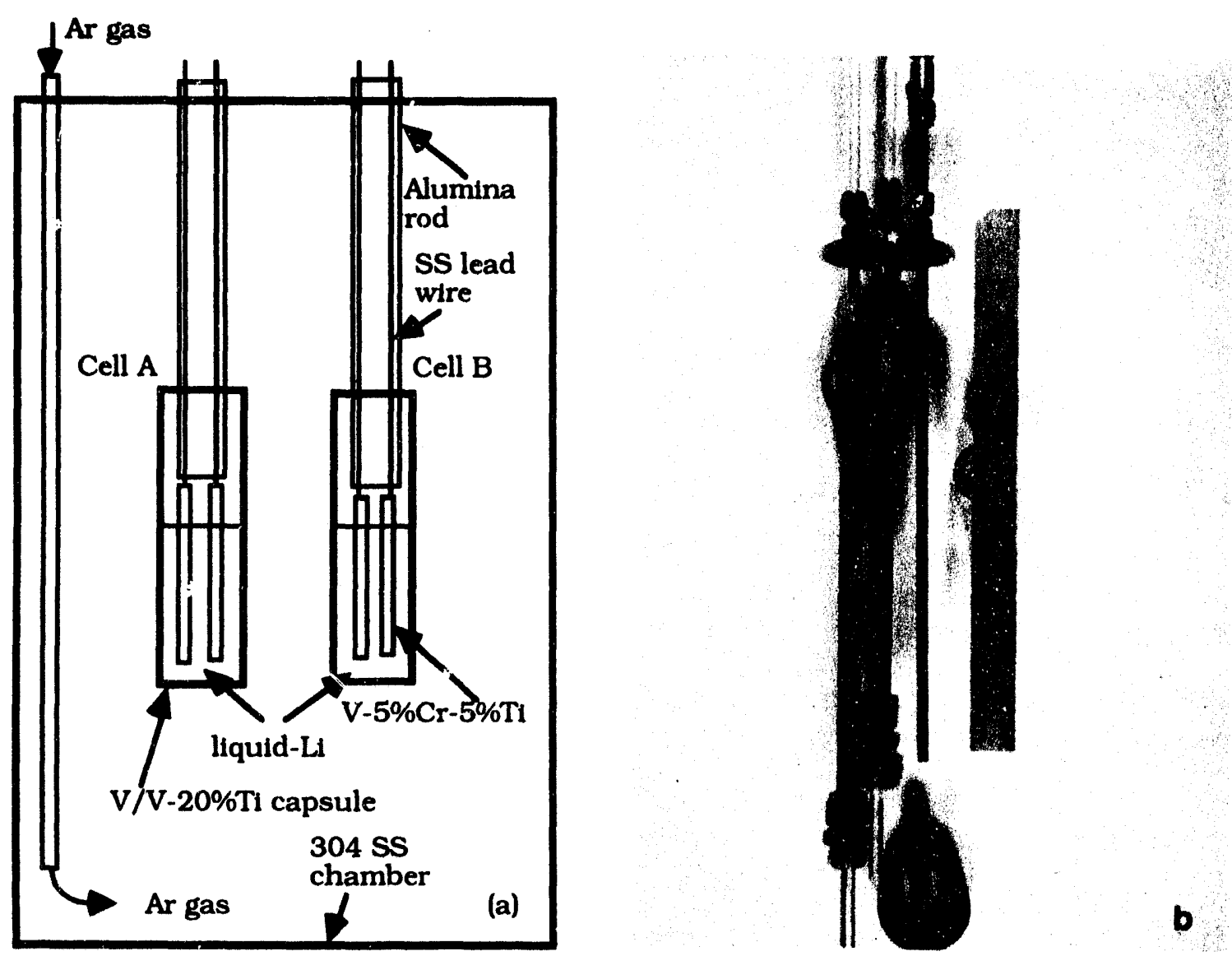

Figure 1. Electrical resistance cells (a) schematic representation and (b) components before assembly

\section{RESULTS AND DISCUSSION}

\section{In-situ electrical resistance}

The test conditions and results from the in-situ electrical resistance of $150 \mathrm{~mm}^{2}$ of $\mathrm{V}-5 \% \mathrm{Cr}-5 \% \mathrm{Ti}$ in contact with liquid $\mathrm{Li}$ are given in Fig. 2. Initially, Cell A exhibited higher ohmic values than did Cell B up to $150 \mathrm{~h}$, but the ohmic values of both cells were almost identical thereafter. During thermal cycling between 415 and $250^{\circ} \mathrm{C}$ the changes in resistance were small. This result presumably indicates that the layers did not show any degradation such as spallation or local defects. When the temperature was increased from 415 to $500^{\circ} \mathrm{C}$, the ohmic resistance dropped from $\approx 1.4$ to $1.0 \Omega$ for Cell $\mathrm{A}$, and from $\approx 1.5$ to $0.95 \Omega$ 
for Cell B. We had expected that the reaction between the aluminide layer and $N$ would proceed at a higher rate at $500^{\circ} \mathrm{C}$, and thereby show an increase in resistance above $\approx 1.5 \Omega$, however, this did not occur.
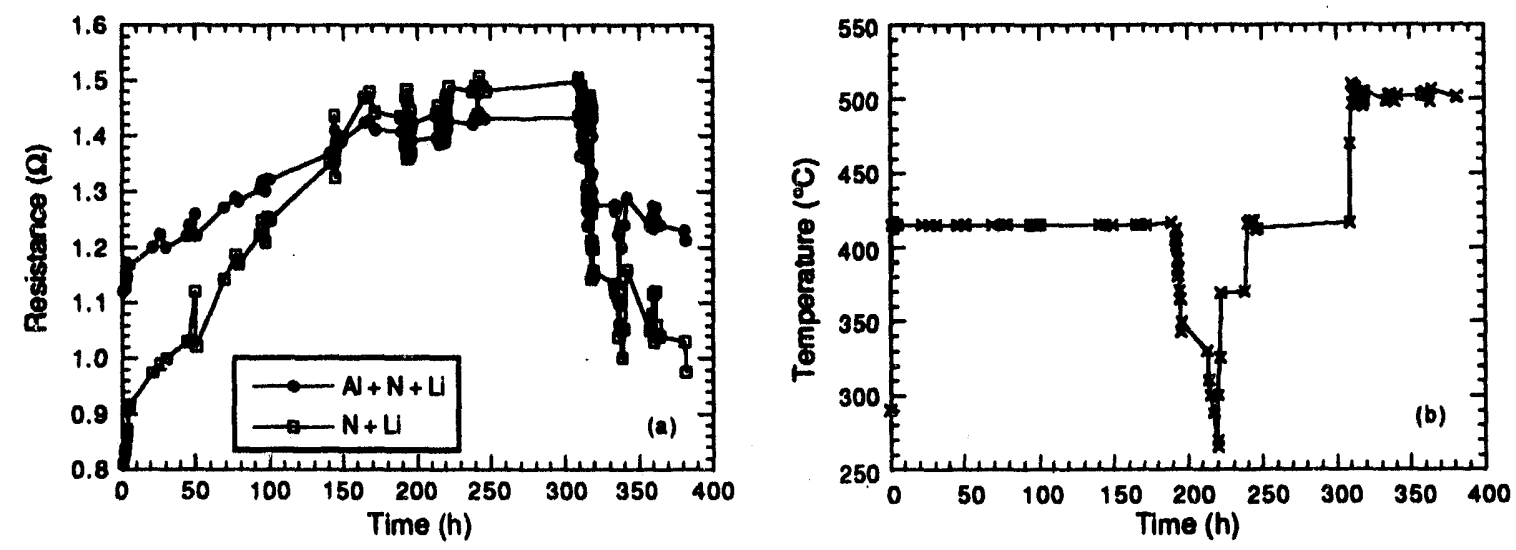

Figure 2. (a) Electrical resistance of $V-5 \% C r-5 \% T i$ in Li containing $N$ and $A l$ (Cell $A$ ) and $N$ (Cell B) and (b) temperature versus time of exposure in the liquid Li environments

The decrease in resistance could be attributed to the temperature dependence of the electrical resistivity of the coatings, i.e., the equilibrium composition of ionic and electronic species varies as a function of temperature, whereas normally, more defects are expected at higher temperatures. Thus, more electronic mobile carriers could form and act as charge-compensating defects at higher temperatures. Alternatively, as the temperature was increased, the level of $\mathrm{Li}$ in the capsule rose owing to thermal expansion. Consequently, additional alloy surface was exposed to the liquid. As shown in Fig. 2, at $500^{\circ} \mathrm{C}$ the resistance of both cells returned to their initial values at $415^{\circ} \mathrm{C}$, which may indicate that a fully developed coating was not present on the alloy surface above the original liquid/gas interface. During the last $\approx 80 \mathrm{~h}$ of the test, the resistance of the film did not increase as expected because of possible $\mathrm{N}$ depletion in the liquid due to reaction with the surface of the aluminized capsule $\left(150 \mathrm{~mm}^{2}\right)$ that was in contact with liquid $\mathrm{Li}$ and to loss of $\mathrm{N}$ to the gas phase.

In principle, the time variation of electrical resistance at $500^{\circ} \mathrm{C}$ can provide kinetic information on the reequilibration process; Cell $A$ showed slower kinetics than did Cell $B$, which can be expected because the thin layer of AIN on Cell A presumably is more insulating.

Questions remain on the details of the kinetics of reactions in Eqs. 1 and 2 that describe in-situ formation of an insulator coating in liquid $\mathrm{Li}$ environments. Throughout the experiment, a high-purity Ar cover gas was present and no attempt was made to maintain $\mathrm{N}_{2}$ in the gas phase. Because the cells could not be sealed, loss of $\mathrm{N}$ to the gas phase probably occurred, which could influence in-situ formation or rehealing of the coating layer under conditions of the experiment. However, had the alloy surface been in direct contact with the liquid because of partial spallation or cracking of the insulator layer without healing, the ohmic resistance would decrease to zero (i.e., short circuit by metallic contact). Neither of the cells exhibited short-circuit behavior during the $400-\mathrm{h}$ experiment.

\section{CONCLUSION}

Insulator coatings formed in situ on $\mathrm{V}-5 \% \mathrm{Cr}-5 \% \mathrm{Ti}$ in liquid $\mathrm{Li}$ that contained $\mathrm{Li3} \mathrm{N}$, with and without dissolved $\mathrm{Al}$, at $415^{\circ} \mathrm{C}$. The ohmic resistance of the coatings was $\approx 1.0-1.5 \Omega$. Thermal cycling between 415 and $250^{\circ} \mathrm{C}$ did not produce changes in the resistance of the coatings. The ohmic resistance of AlN may be adequate for an insulator coating in MFR applications. 


\section{FUTURE STUDIES}

Results of mechanical-property and irradiation-damage studies indicate that the V-5\%Cr-5\%Ti alloy holds the most promise for MFR structural applications. Consequently, the insulator development study will focus on this alloy. The performance of AlN coatings produced by chemical vapor deposition will be evaluated by in-situ electrical resistance measurements in capsule tests and in a liquid Li loop at temperatures between 410 and $500^{\circ} \mathrm{C}$.

\section{REFERENCES}

1. C. C. Baker, et al., Tokamak Power System Studies FY 1985, Argonne National Laboratory Report ANL/FPP-85-2 (December 1985).

2. Y. Y. Liu and D. L. Smith, Ceramic Electrical Insulators for Liquid Metal Blankets, J. Nucl. Mater., 141-143, 38 (1986).

3. T. Kammash, Fusion Reactor Physics, Chapter 15, Ann Arbor Science Pub. Inc., Ann Arbor, MI, pp. $405-439$ (1975).

4. J.-H. Park and G. Dragel, Development of In-Situ-Formed Electrical Insulator Coatings on HighTemperature Alloys in Lithium, Fusion Reactor Materials Semiannual Progress Report for the Period Ending March 31, 1993, DOE/ER-0313/14, Oak Ridge National Laboratory, Oak Ridge, TN, pp. 389-394 (July 1993).

5. J.-H. Park and G. Dragel, Development of In-Situ-Formed Electrical Insulator Coatings on HighTemperature Alloys in Lithium, Fusion Reactor Materials Semiannual Progress Report for the Period Ending September 30, 1992, DOE/ER-0313/14, Oak Ridge National Laboratory, Oak Ridge, TN, pp. $405-410$ (July 1993).

6. H. Glasbrenner and H. U. Borgstedt, Development of Aluminide Coatings on Vanadium and V-3Ti-1Si, Institut für Materialforschung III, Kernforschungszentrum Karlsruhe GmbH, Germany (July 1993). 


\section{INVESTIGATION OF A MAGNETIC TRAP USED IN A LITHIUM/STAINLESS STEEL TEST LOOP*} P. R. Luebbers and O. K. Chopra (Argonne National Laboratory)

\section{OBJECTIVE}

The objective of this program is to investigate the influence of a lithium environment on the compatibility, corrosion, and mechanical properties of candidate vanadium alloys for first-wall/blanket systems in fusion reactors.

\section{SUMMARY}

The magnetic trap from a plugged cold-trap purification loop of a forced-circulation lithium system was examined to study mass transfer/deposition behavior in liquid lithium systems. Two types of particles, large faceted crystals and globules, were observed in the residue collected from the magnetic trap. These particles are similar to the $(\mathrm{Mn}, \mathrm{Fe}) \mathrm{Ni}$ and $(\mathrm{Mn}, \mathrm{Fe}) \mathrm{Ni}_{3}$ compounds that had been identified earlier in the particulate collected from plugged sections of a cold-trap loop. The ternary nitride $\mathrm{Li}_{9} \mathrm{CrN}_{5}$ was also identified in the residue. Results indicate that a magnetic trap is effective for capturing magnetic particles within a liquid lithium loop.

\section{PROGRESS AND STATUS}

The compatibility of structural materials with liquid metals influences material selection and imposes temperature limitations for liquid-metal blankets. Corrosion in the form of uniform or selective dissolution, intergranular attack, and transfer of interstitial elements to and from the liquid metal can reduce the effective section thickness of structural components. Radioactive mass transfer/deposition of corrosion products may cause severe flow restrictions and excessive accumulation of radioactive material in unshielded regions. Corrosion/dissolution can reduce mechanical integrity, and mass transfer/deposition phenomena can increase pumping-power requirements, decrease energy conversion efficiency, and complicate system maintenance.

Mass transfer/deposition occurs in nonisothermal systems because of temperature and concentration gradients. Alloy elements dissolve in the hot regions of a liquid-metal loop because their concentrations in the liquid metal are lower than their solubilities, and they deposit in cold regions of the loop where their concentrations in the liquid metal are greater than their solubility limits. Severity of corrosion and mass transfer varies with the combinations of containment material and liquid metal and depends on many variables. These include the liquid metal and its purity (i.e., concentrations of nitrogen, carbon, oxygen, etc.); composition and microstructure of the containment material; time and temperature of exposure; and system parameters such as flow velocity (including magnetohydrodynamic effects), $\Delta T$ (difference of temperature across the circulating system), surface area and temperature profile of the system, and material combination (i.e., bimetallic or monometallic system). Several studies have been conducted to evaluate the influence of various material and system parameters on the corrosion behavior of candidate structural materials in lithium. ${ }^{1,2}$ Most studies have been conducted in circulating lithium systems such as thermalconvection or forced-circulation loops. The present investigation was undertaken to increase our understanding of the process of mass transfer/deposition in circulating lithium systems.

\section{Loop History}

Since 1981, corrosion/compatibility studies at Argonne National L.aboratory have been conducted in a test facility consisting of a forced-circulation lithium loop and an MTS servohydraulic fatigue machine for

\footnotetext{
* Work supported by Office of Fusion Energy, U.S. Department of Energy, under Contract W-31-109-Eng-38.
} 
performing mechanical tests in the liquid-metal environment. A schematic diagram of the lithium loop is shown in Fig. 1. The lithium system, which is constructed of Type 304 stainless steel (SS), consists of a primary loop with three test vessels and a secondary cold-trap purification loop. The quantity of lithium in the loop is $\approx 20 \mathrm{~L}$ which is circulated at $\approx 16 \mathrm{~cm}^{3} / \mathrm{s}$ in the primary loop. The concentration of interstitial elements in the lithium is controlled by maintaining the cold-trap temperature at $200-220^{\circ} \mathrm{C}$.

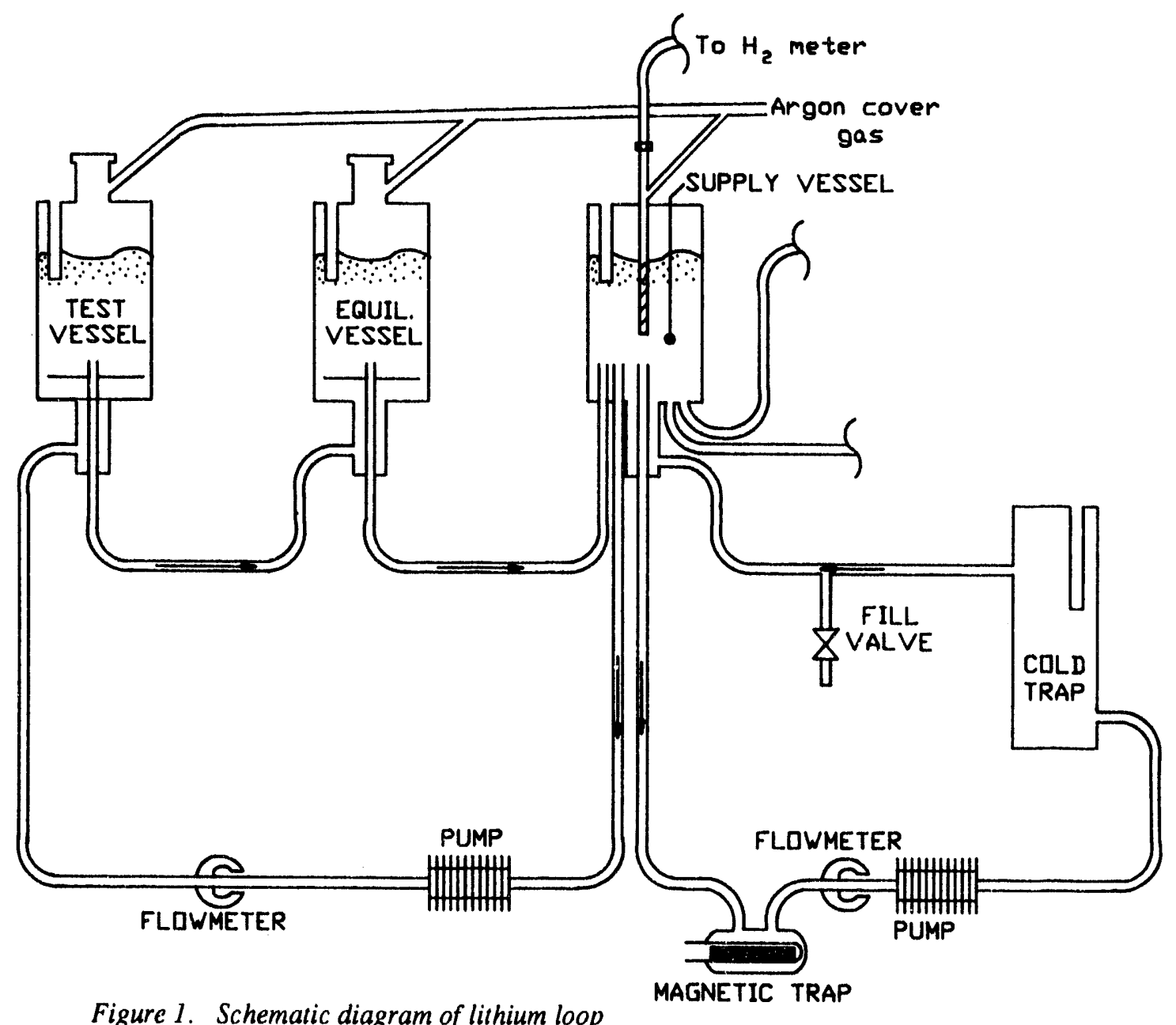

The concentration of nitrogen in lithium during the early phases of operation increased to $\approx 1200 \mathrm{wppm}$ as a result of contamination from the fixture that was used when performing mechanical tests. Nitrogen concentration in the lithium was reduced to $<100$ wppm by hot-trapping with $\mathrm{Ti}$ foils and by dissolved getters such as calcium. Nitrogen content is reduced by formation of $\mathrm{TiN}$ or $\mathrm{Ca}_{3} \mathrm{~N}_{2}$, which are more stable than $\mathrm{Li}_{3} \mathrm{~N}$. In the latter case, $\mathrm{Ca}_{3} \mathrm{~N}_{2}$ is trapped in cooler regions of the loop, e.g., the cold trap.

During the initial six months of operation, the lithium system was shut down several times because of plugging of the flowmeter and pump section of the cold-trap loop. Examination of the plugged pipe sections indicated an accumulation of $\mathrm{MnNi}$ and $\mathrm{MnNi}_{3}$ particles (which are paramagnetic below $360^{\circ} \mathrm{C}$ ) inside the pipe sections within the pump coil and flow-meter magnet. ${ }^{3}$ Particles of $(\mathrm{Mn}, \mathrm{Fe}) \mathrm{Ni}_{3}$ were also detected in the metallic residue collected from the plugged sections. Chromium was present as a ternary nitride $\left(\mathrm{Li}_{9} \mathrm{CrN}_{5}\right)$ that decomposed into ammonia and lithium chromate when the lithium was dissolved in a solution of methyl alcohol and water. Subsequently, a magnetic trap (Fig. 1) was installed upstream of the 
flowmeter and pump section of the cold-trap loop. The lithium loop has operated with few interruptions after installation of the magnetic trap.

Since 1988, the lithium loop has been used to study the stability of various nitride and oxide coatings on vanadium-base alloys. The nitrogen content in lithium has occasionally increased to $>1000 \mathrm{wppm}$. Consequently, $\approx 3 \mathrm{~g}$ of calcium was added (as dissolved getter) to reduce the nitrogen concentration. The cold-trap loop became plugged within $24 \mathrm{~h}$ of the calcium addition. The magnetic trap, flowmeter, and pump section of the cold-trap purification loop were removed for examination. The results from an investigation of the flow meter and pump sections were presented previously. ${ }^{4}$ The primary plugging component was $(\mathrm{Ca}, \mathrm{Zn}) \mathrm{Ni}_{5}$ crystals" that were trapped in the magnetic field of the pump and flowmeter magnet. Deposits of manganese/zinc/nickel dendrites and manganese/iron/nickel globules, as well as $\mathrm{Li}_{9} \mathrm{CrN}_{5}$ and possibly $\mathrm{Ca}_{3} \mathrm{~N}_{2}$, were also identified in the residue collected from the plugged cold-trap pipe. The results of the investigation of the magnetic trap are presented in this report.

\section{Examination of the Magnetic Trap}

The magnetic trap, which consists of a Type 304 SS canister with a tube in the center for placing a cylindrical magnet, is connected in-line within the cold-trap loop, upstream from the pump and flowmeter. The lithium contained in the magnetic trap and the associated tubing was removed in an argon environment by heating to $\approx 270^{\circ} \mathrm{C}$ and applying a differential pressure of $\approx 3 \mathrm{psig}$ to push out the lithium. The trap canister was sectioned and the contents were cleaned in a 50:50 solution of methyl and ethyl alcohol. The solution and residue that were collected from different sections were examined to study mass transfer/deposition behavior.

The trap, after sectioning and partial cleaning, is shown in Fig. 2. The internal tube that contained the magnet is covered by deposits, the thickness of which is greatest at the poles of the magnet, where the magnetic flux density is greatest. The results indicate that a magnetic trap is an effective method for
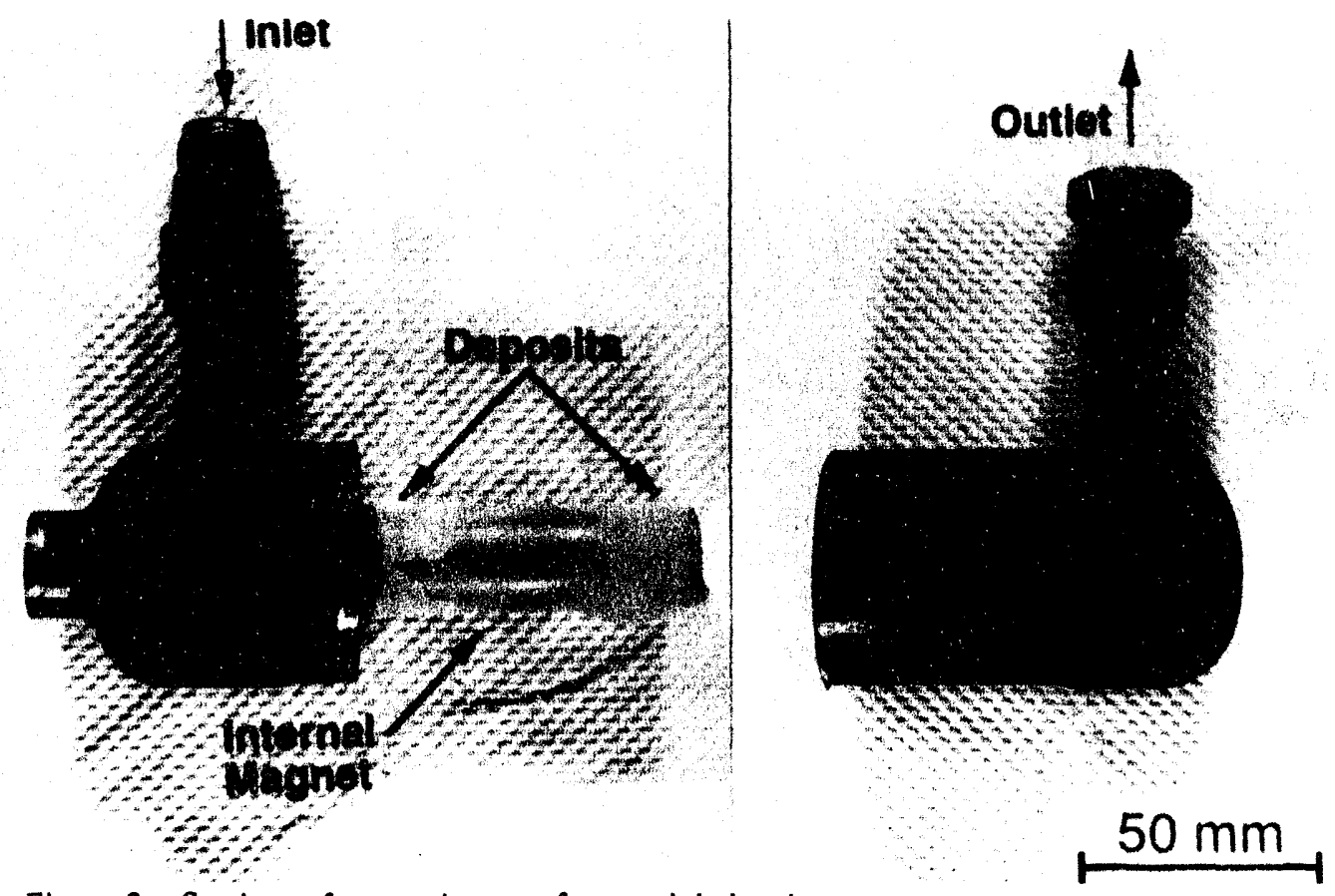

Figure 2. Sections of magnetic trap after partial cleaning

\footnotetext{
* The source of zinc is a Korloy ( $\mathrm{Zn}-11 \mathrm{Al})$ clamp that accidentally fell into the test vessel of the loop.
} 
capturing magnetic particles within a liquid lithium loop. The solutions used to clean the magnet tubing and trap internals became dark yellow with a thick gray sludge. A strong odor of ammonia was detected during cleaning. Previous spectrographic analysis 3,4 of the yellow solution showed a high concentration of chromium and indicated the presence of $\mathrm{Li}_{9} \mathrm{CrN}_{5}$, which decomposes in alcohol.

The gray sludge was cleaned in an $0.5 \mathrm{M} \mathrm{HCl}$ solution, rinsed in alcohol, and dried. Only fine darkgray particles remained. Exposure to a magnetic field indicated that these particles were highly magnetic. Two types of particles, faceted crystals and unordered globules, were observed. Energy-dispersive spectroscopy (EDS) analyses indicate that these particles are similar to the $(\mathrm{Mn}, \mathrm{Fe}) \mathrm{Ni}$ and $(\mathrm{Mn}, \mathrm{Fe}) \mathrm{Ni}_{3}$ compounds that had been identified earlier in the particulate collected from plugged sections of the cold-trap loop. ${ }^{3}$ Large $(\mathrm{Ca}, \mathrm{Zn}) \mathrm{Ni}_{5}$ crystals and manganese/zinc/nickel dendrites, previously observed in the plugged flowmeter and pump sections of the loop, were not detected in the residue collected from the magnetic trap. The results indicate that flow through the cold-trap loop (Fig. 1) was reversed when calcium was added and the magnetic trap was downstream from the pump and flowmeter.

Photomicrographs of several faceted particles and globules are shown in Figs. 3 and 4, and 5 and 6 , respectively. The surface morphology of the particles is dependent upon composition. The EDS spectra demonstrate the differences in composition of the particles: the faceted crystals tend to contain more manganese than iron, and the globules tend to contain more iron. Some of the particles also contain small amounts of chromium. The presence of chromium seems to be random, because both faceted crystals (Fig. 4) and globules (Fig. 5) contain chromium. Particle (c) in Fig. 6 is similar to the faceted crystals, whereas particle (c) in Fig. 4 is similar to the globules.

Large pieces of what appear to be broken ferrite layers were also detected in the residue; these are shown in Fig. 7. Austenitic SSs exposed to lithium develop a very porous ferrite layer because of preferential dissolution of nickel and, to some extent, chromium from the steel. The large metallic particles most likely are spalled ferrite layers from the loop material.

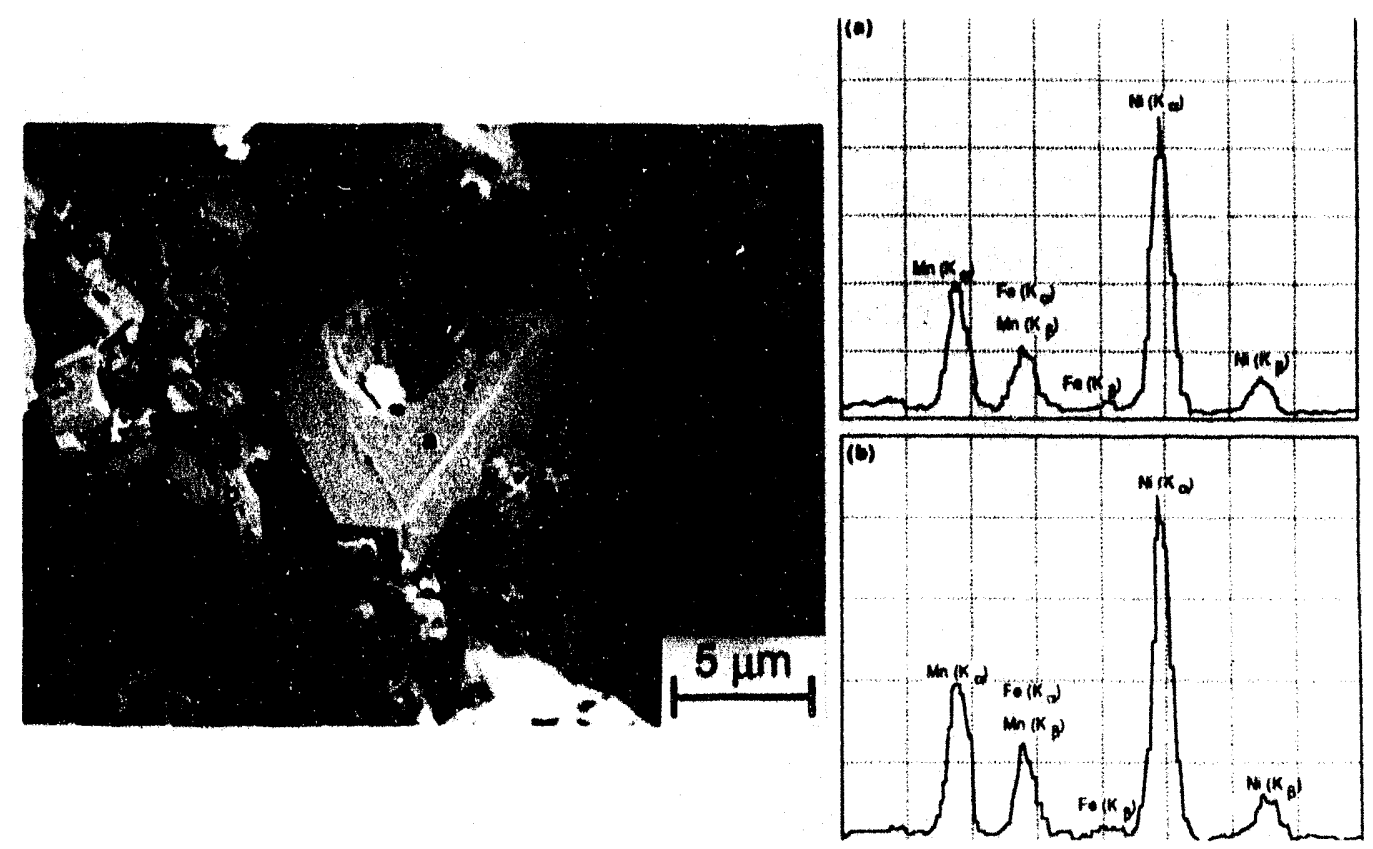

Figure 3. Photomicrograph of faceted $(\mathrm{Mn}, \mathrm{Fe}) \mathrm{Ni}$ crystals and corresponding $\mathrm{X}$-ray spectra 


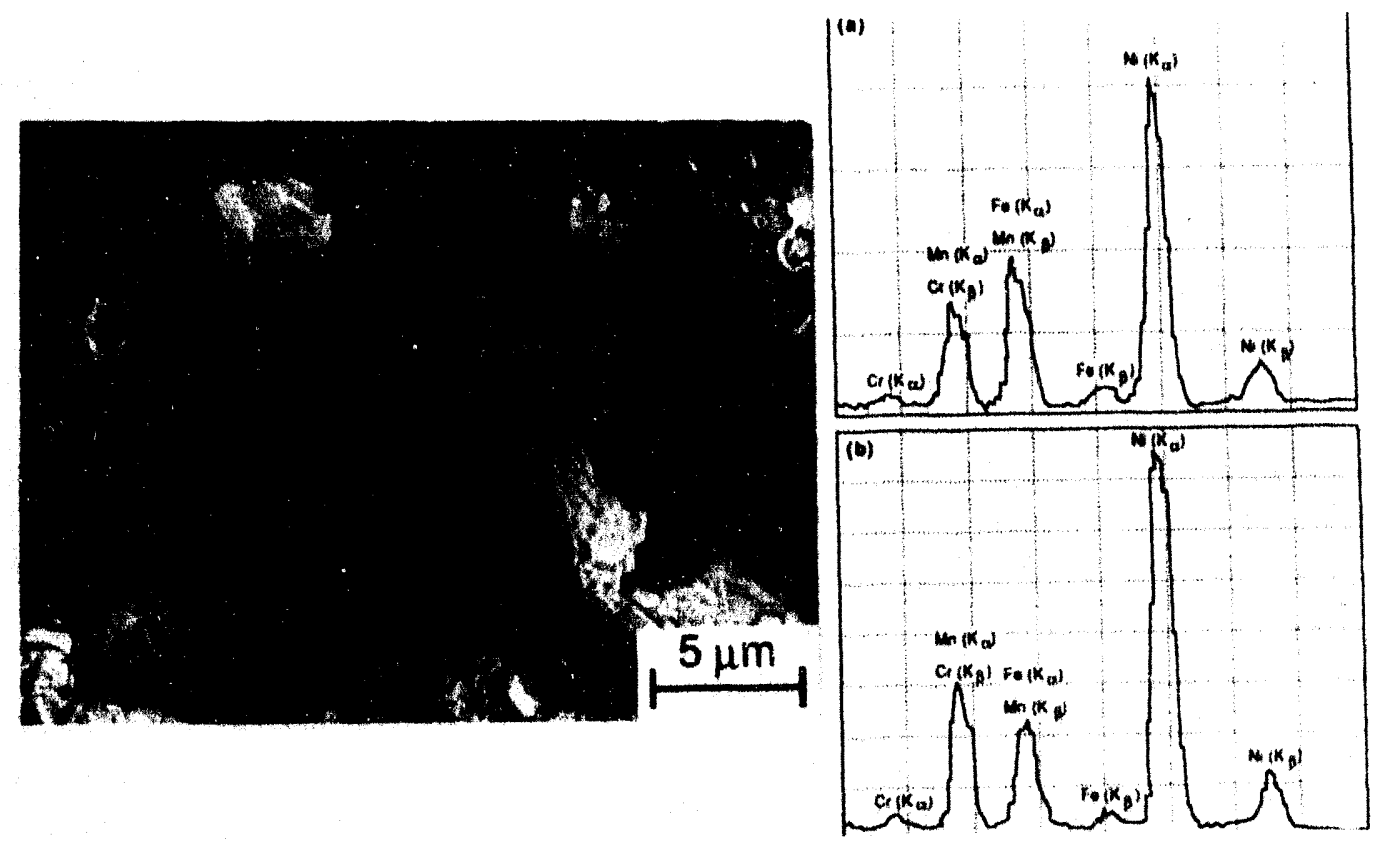

Figure 4. Photomicrograph of faceted $(\mathrm{Mn}, \mathrm{Fe}) \mathrm{Ni}$ crystals and corresponding $\mathrm{X}$-ray spectra

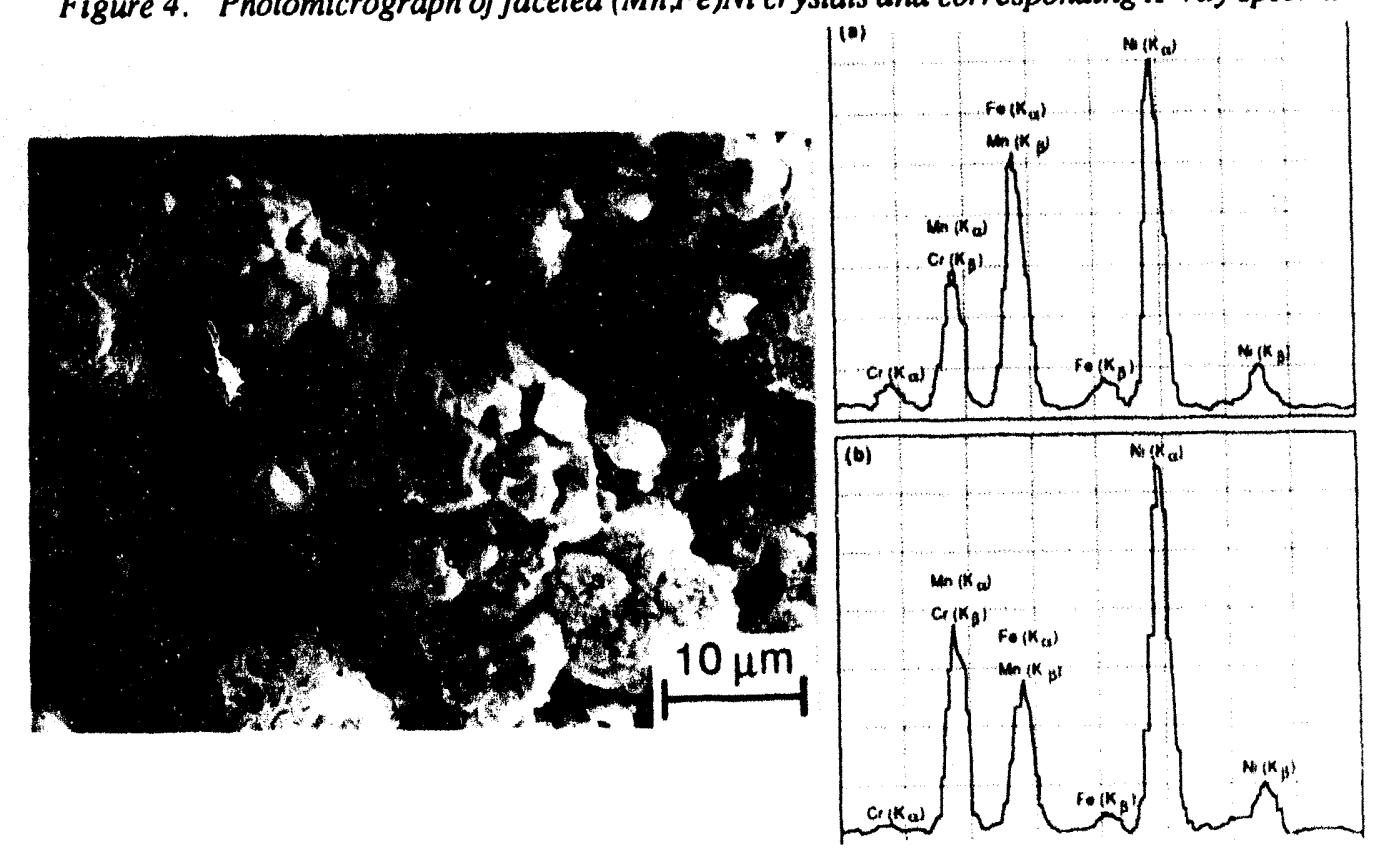

Figure S. Photomicrograph of (Mn,Fe)Ni particles and corresponding X-ray spectra

EDS analysis of the cross section of the trap canister indicated a high concentration of nickel adhering to the inside surface of the SS. Further investigation revealed that the high nickel concentration is due to a layer of globular deposits that are enriched in nickel and manganese on the inside surface of the canister. A photomicrograph of this surface is shown in Fig. 8. The surface has an etched appearance that is typical of austenitic SSs that have been exposed to lithium. However, the etched appearance is not caused by corrosion. The examined cross section of the trap canister did not show depletion of nickel or chromium from the steel because temperatures within the magnetic trap were too low for corrosion. 


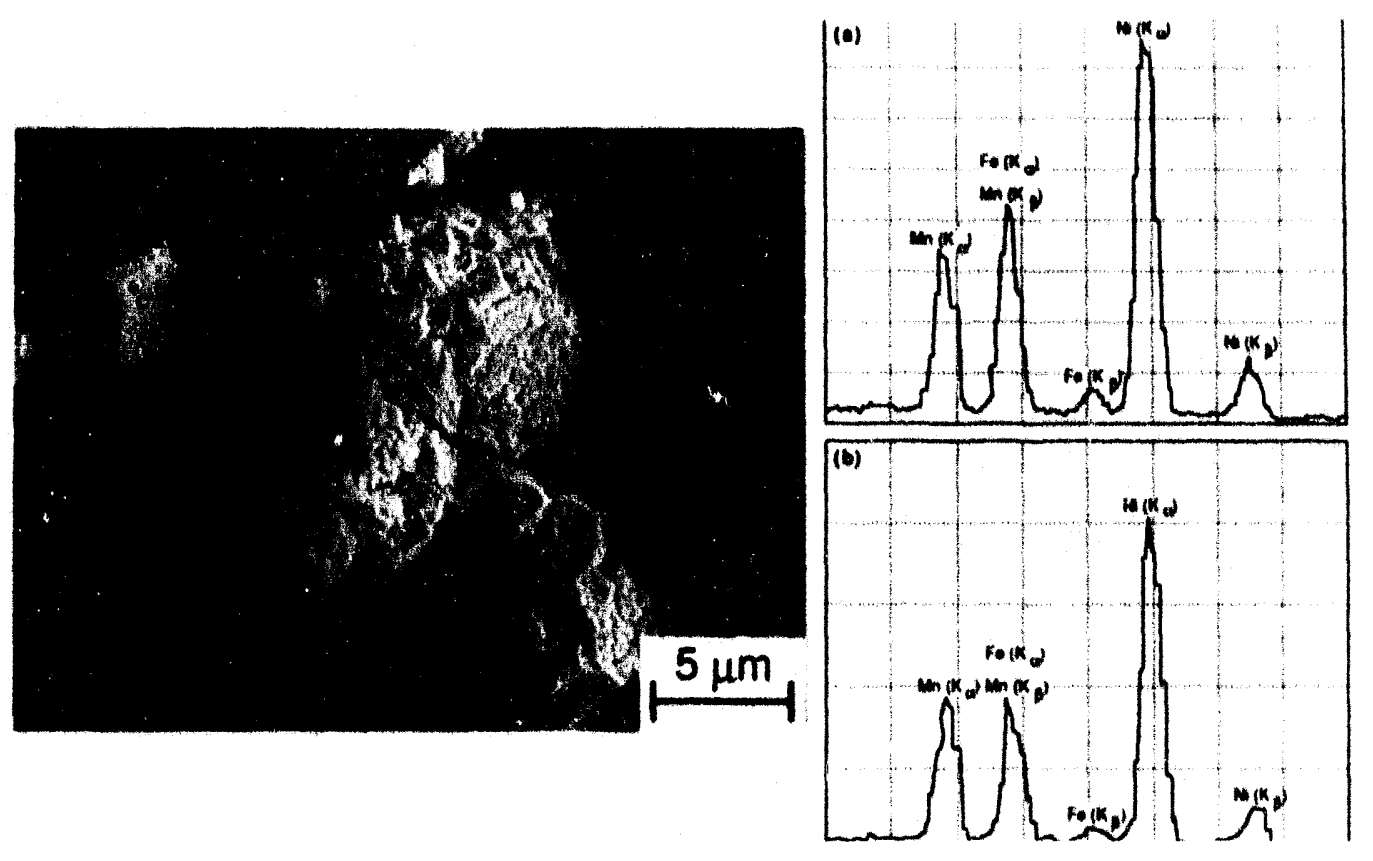

Figure 6. Photomicrograph of (Mn,Fe)Ni particles and corresponding X-ray spectra

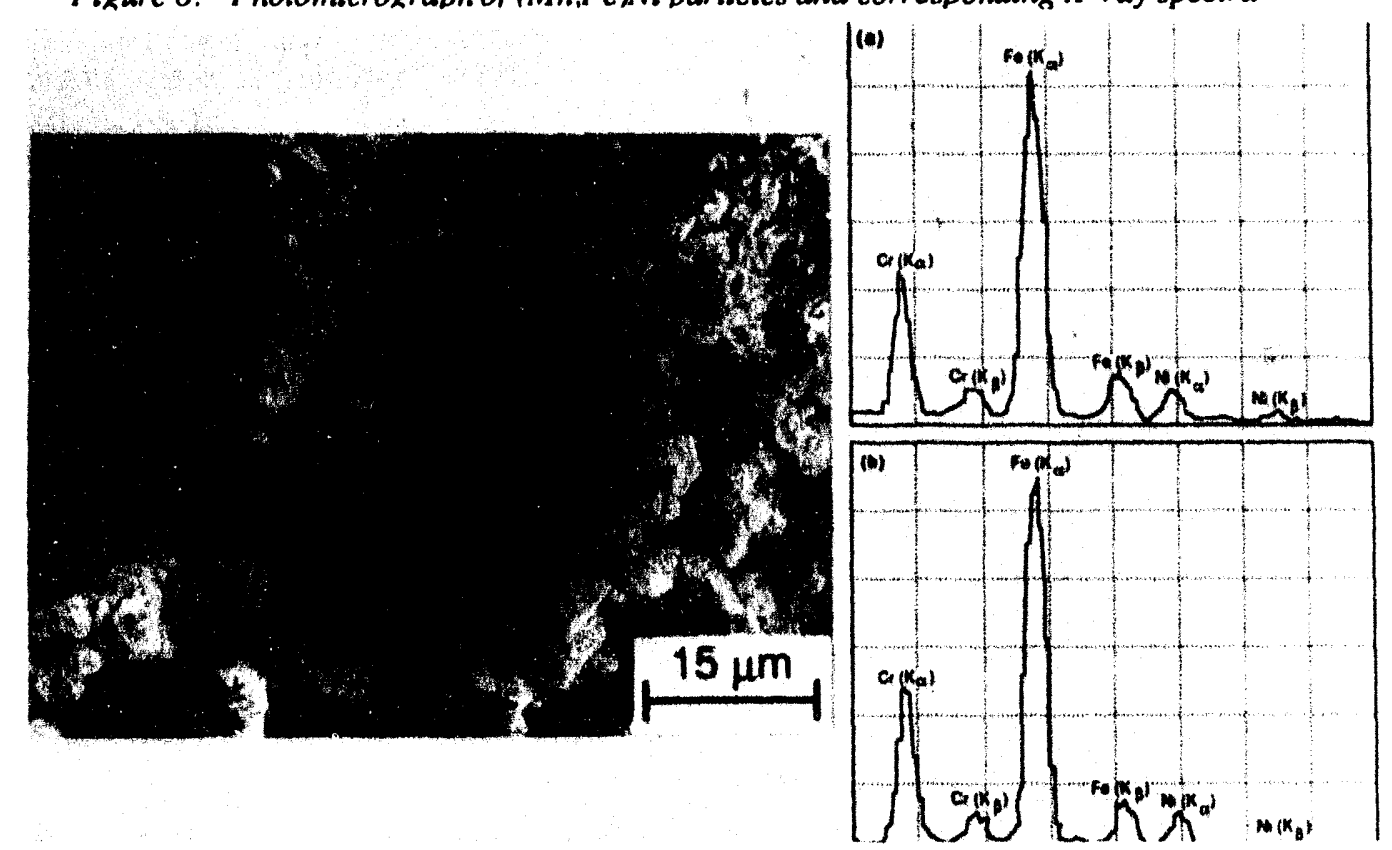

Figure 7. Pholomicrograph of ferrile particles and corresponding $X$-ray spectra

The etched appearance is produced by deposition of major alloy elements on the surface of the trap canister. The deposits seem to have a preferred crystallographic orientation with respect to the substrate, thereby creating a distinct interface at the grain boundaries of the SS substrate. Region (a) in Fig. 8 contains the primary elements of Type 304 SS, i.s., $\mathrm{Fe}, \mathrm{Cr}$, and Ni. Manganese was not detected, although there is a higher concentration of iron than normal for Type 304 SS. Region (b) shows considerable Fe, $\mathrm{Ni}$, and $\mathrm{Mn}$, with a lower concentration of $\mathrm{Cr}$ than Region (a). Particles at (c) and (d) are similar to the $(\mathrm{Mn}, \mathrm{Fe}) \mathrm{Ni}$ compounds shown in Figs. 3-6. The metallography results suggest that the globular particles on the canister surfacc are produced by deposition of nickel, manganese, and iron from lithium. Such 
deposits of nickel and manganese on loop materials have not been observed in lithium/SS systems. Earlier studies on mass transfer deposits in lithium/Type 316 SS loops showed deposition of chromium dendrites and chromium-rich nodules containing small amounts of iron and nickel. ${ }^{5}$

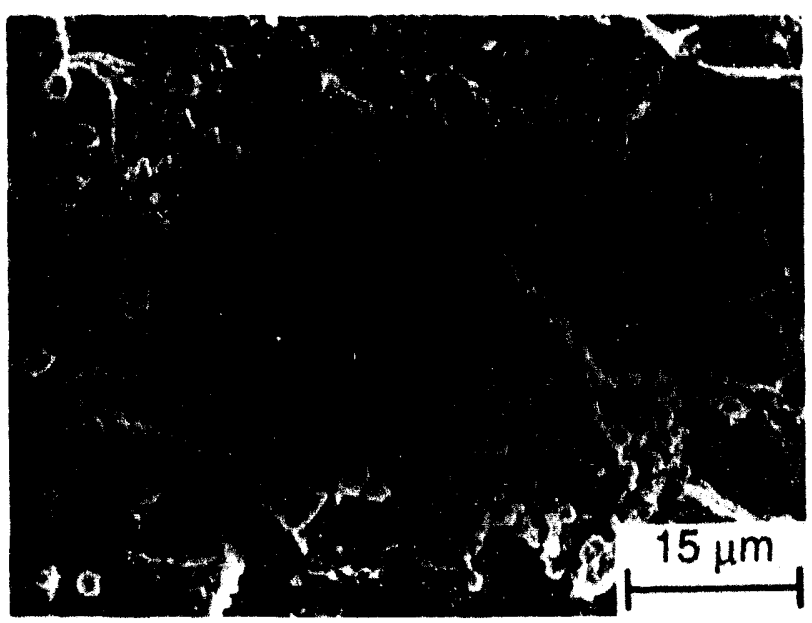

Figure 8.

Photomicrograph of interior

surface of magnetic-trap canister

CONCLUSIONS

Metallographic examination indicates that a magnetic trap is an effective method for capturing magnetic particles within a liquid lithium loop. Two types of particles, faceted crystals and globules, were observed in the residue collected from the magnetic trap. These particles are similar to the $(\mathrm{Mn}, \mathrm{Fe}) \mathrm{Ni}$ and $(\mathrm{Mn}, \mathrm{Fe}) \mathrm{Ni}_{3}$ compounds that had been identified earlier in the particulate collected from plugged sections of the cold-trap loop that was used in this study. The large $(\mathrm{Ca}, \mathrm{Zn}) \mathrm{Nis}$ crystals and manganese/zinc/nickel dendrites, previously observed in the plugged flowmeter and pump sections of the cold-trap loop, were not detected. The results indicate that the deposition of $(\mathrm{Mn}, \mathrm{Fe}) \mathrm{Ni}$ compounds in cooler regions is abundant in lithium/SS test loops.

\section{FUTURE WORK}

No future work is planned.

\section{REFERENCES}

1. O. K. Chopra, D. L. Smith, P. F. Tortorelli, J. H. DeVan, and D. K. Sze, Liquid-Metal Corrosion, Fusion Technol., 8, 1956-1969 (1985).

2. O. K. Chopra and P. F. Tortorelli, Compatibility of Materials for Use in Liquid-Metal Blankets of Fusion Reactors, J. Nucl. Mater., 122 \& 123, 1201-1212 (1984).

3. O. K. Chopra and D. L. Smith, Corrosion of Ferrous Alloys in a Flowing Lithium Environment, J. Nucl. Mater., 133 \& 134, 861-866 (1985).

4. P. R. Luebbers and O. K. Chopra, Mass Transfer in Lithium/Stainless Steel Test Loop, 14th Fusion Reactor Materials Semiannual Progress Report for Period Ending March 31, 1993, DOE/ER0313/14, 365-369 (1993).

5. P. F. Tortorelli and J. H. DeVan, Mass Transfer Deposits in Lithium-Type 316 Stainless Steel Thermal-Convection Loops, Proc. 2nd International Conf. on Liquid Metal Technology in Energy Production, CONF-800401-P2, ANS/DOE, Washington, D. C., 13.55-13.63 (1980). 
COMPATIBILITY OF OXIDIZED TYPE 316 SS WITH STATIC GALLIUM*

P. R. Luebbers, W. F. Michaud, and O. K. Chopra (Argonne National Laboratory)

\section{OBJECTIVE}

Gallium has been considered as a possible heat transport liquid in the International Thermonuclear Experimental Reactor (ITER). Gallium is attractive for such applications because the temperature range over which it remains liquid is wider than that of any other metal, i.e., from near room temperature $\left(30^{\circ} \mathrm{C}\right)$ to $\approx 2300^{\circ} \mathrm{C}$, and because it has good thermal conductivity and very low vapor pressure at high temperatures. However, gallium has high chemical reactivity with most metals. The objective of this study is to investigate the compatibility of gallium with candidate structural materials for ITER first-wall/blanket systems. In this reporting period, the stability of an iron[II] chromite coating on Type 316 stainless steel (SS) in liquid gallium was investigated.

\section{SUMMARY}

Scoping tests were conducted on compatibility of gallium with Type 316 SS in three conditions: as-received, oxidized in water at $290^{\circ} \mathrm{C}$ for $100 \mathrm{~h}$, and oxidized in air at $350^{\circ} \mathrm{C}$ for $100 \mathrm{~h}$. Corrosion tests were conducted at $400^{\circ} \mathrm{C}$ for times up to $3000 \mathrm{~h}$. The results indicate that at $400^{\circ} \mathrm{C}$, an iron[II] chromite coating does not provide protection against corrosion. The oxide coating dissociates to form $\beta-\mathrm{Ga}_{2} \mathrm{O}_{3}$, and corrosion of the alloy proceeds by dissolution accompanied by formation of $\mathrm{FeGa}_{3}$ and other gallium/intermetallic compounds. However, oxidized specimens have a lower corrosion rate than nonoxidized Type $316 \mathrm{SS}$. Corrosion rates are 4.0, 2.2, and $2.7 \mathrm{~mm} / \mathrm{y}$ for Type $316 \mathrm{SS}$ as-received, oxidized in water, and oxidized in air, respectively.

\section{PROGRESS AND STATUS}

Refractory metals and ceramics show the greatest stability in gallium. Gallium can be contained successfully in beryllium, tantalum, stabilized $\mathrm{ZrO}_{2}$, or Pyrex glass at temperatures up to $450^{\circ} \mathrm{C}$; in tungsten, rhenium, or graphite at temperatures up to $800^{\circ} \mathrm{C}$; and in refractory oxides (such as sintered $\mathrm{BeO}$ or $\mathrm{Al}_{2} \mathrm{O}_{3}$ ) and vitreous quartz at $1000^{\circ} \mathrm{C}$ or higher. ${ }^{1-3}$ The corrosion resistance of refractory oxides at high temperatures encourages investigation into the possibility of establishing corrosion-resistant coatings on alloys that otherwise disintegrate in liquid gallium.

Oxygen reacts with gallium to form three compounds: the oxide $\mathrm{GaO}$, the suboxide $\mathrm{Ga}_{2} \mathrm{O}$, and the sesquioxide $\beta-\mathrm{Ga}_{2} \mathrm{O}_{3}$. The allotrope $\beta-\mathrm{Ga}_{2} \mathrm{O}_{3}$ (gallium sesquioxide) is the most stable. Alcock and Jacob ${ }^{4}$ have reported the following equations for the solubility of oxygen in gallium $\left(c_{0}\right)$, the standard free energy of solution of oxygen in gallium $\left(\Delta \mathrm{G}_{0}^{\circ}\right)$, and the standard free energy of formation of $\beta-\mathrm{Ga}_{2} \mathrm{O}_{3}\left(\Delta \mathrm{G}^{\circ}\right)$ as:

$$
\begin{aligned}
& \log \left[\mathrm{c}_{\mathrm{O}}(\mathrm{ppm})\right]=4.264-7380 / \mathrm{T} \quad(1048 \mathrm{~K} \leq \mathrm{T} \leq 1398 \mathrm{~K}) \\
& \frac{1}{2} \mathrm{O}_{2(\mathrm{~g})} \rightarrow \mathrm{O}_{\mathrm{Ga}} \\
& \Delta \mathrm{G}_{\mathrm{O}}^{\circ}=-220.73+0.0274 \mathrm{~T} \quad( \pm 0.84) \mathrm{kJ} \\
& 2 \mathrm{Ga}_{(1)}+\frac{3}{2} \mathrm{O}_{2(\mathrm{~g})} \rightarrow \beta \mathrm{Ga}_{2} \mathrm{O}_{3} \\
& \Delta \mathrm{G}^{\circ}=-1086.63+0.3273 \mathrm{~T} \quad( \pm 1.26) \mathrm{kJ}
\end{aligned}
$$

\footnotetext{
* Work supported by Office of Fusion Energy, U.S. Department of Energy, under Contract W-31-109-Eng-38.
} 
Natesan ${ }^{5}$ has compiled thermodynamic data on the free energy of formation of oxides and the solubility of oxygen in liquid-alkali metals and structural metals. This information has been adapted to the case of liquid gallium using the above equations for oxygen in gallium. Results that are relevant for ITER applications are shown in Fig. 1. ${ }^{4-6}$ Based upon free energy of formation alone, all of the metal oxides shown, except for $\mathrm{MoO}_{2}, \mathrm{FeO}$, and $\mathrm{NiO}$, should be stable in the presence of $\mathrm{Ga}_{2} \mathrm{O}_{3}$. The iron[II] chromite $\mathrm{FeCr}_{2} \mathrm{O}_{4}$ may be stable at elevated temperatures.

Figure 1 shows that oxides such as $\mathrm{Cr}_{2} \mathrm{O}_{3}, \mathrm{Al}_{2} \mathrm{O}_{3}$, and $\mathrm{SiO}_{2}$ should provide protection against corrosion in liquid gallium. Unstable compounds, such as $\mathrm{FeO}$ and $\mathrm{NiO}$, dissociate in liquid gallium to form $\beta-\mathrm{Ga}_{2} \mathrm{O}_{3}$, and alloy corrosion would proceed by dissolution of metallic elements to form metal/gallium intermetallic compounds.

\section{Experimental Procedures}

Corrosion tests were conducted in sealed alumina capsules, which were filled with $\approx 11 \mathrm{~cm}^{3}(\approx 65 \mathrm{~g})$ of gallium in a high-purity argon environment. Each capsule contained a single corrosion test coupon held in place by an alumina positioning rod. The coupons were bent into a $U$ shape to study the effect of cold work. Dimensions and weights of the specimens were recorded after degreasing and cleaning. Details of the experimental procedure have been reported previously. ${ }^{7}$ Corrosion coupons were prepared from Type 316 SS; five specimens were tested in as-received condition, four were oxidized in deionized water containing $\approx 6 \mathrm{ppm}$ dissolved oxygen at $290^{\circ} \mathrm{C}$ for $100 \mathrm{~h}$, and four specimens were oxidized in air at $350^{\circ} \mathrm{C}$ for $100 \mathrm{~h}$ prior to liquid gallium exposure. $\mathrm{X}$-ray diffraction analysis (XRD) revealed the presence of the single-phase spinel compound $\mathrm{FeCr}_{2} \mathrm{O}_{4}$ (iron[II] chromite) on the surface of the specimens oxidized in water, and it is assumed that the same compound existed on the specimens oxidized in air. Thicknesses of iron[II] chromite on specimens oxidized in water and air were 0.3 and $\leq 0.1 \mu \mathrm{m}$, respectively by scanning electron microscopy (SEM). Corrosion tests were conducted at $400^{\circ} \mathrm{C}$ for times up to $1,076 \mathrm{~h}$ for as-received specimens, and $3,000 \mathrm{~h}$ for oxidized specimens.

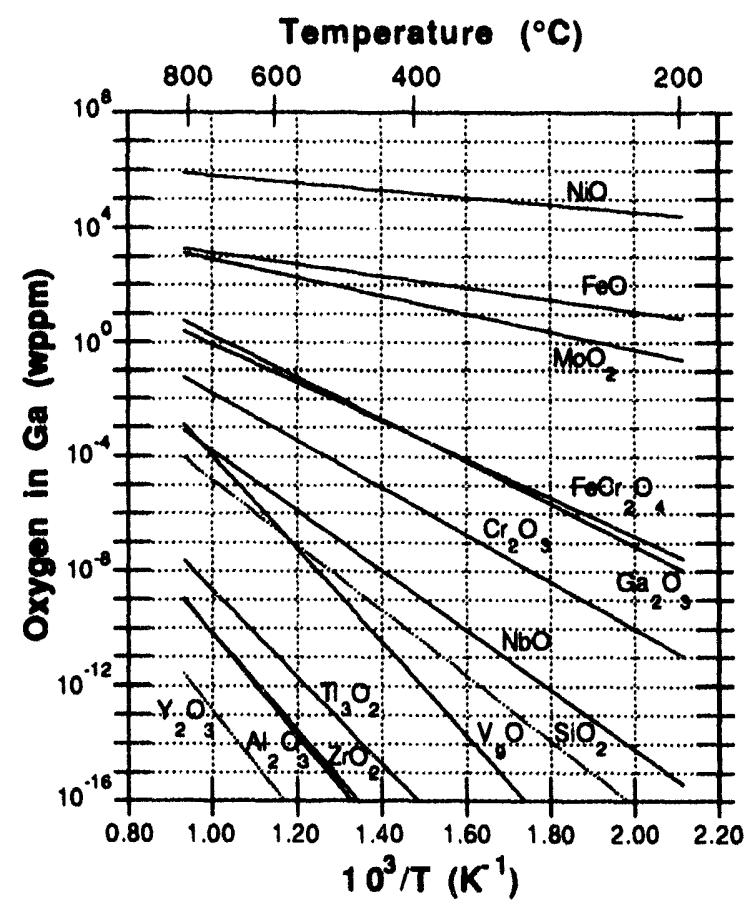

Figure 1.

Temperature dependence of minimum oxygen concentration in gallium for oxide formation in metals 


\section{Results and Analysis}

Corrosion test results for the Type 316 SS specimens are given in Table 1. All corrosion coupons gained weight during exposure. Corrosion rates at $400^{\circ} \mathrm{C}$ decrease with time. This behavior may be attributed to changes in experimental conditions within the capsule. Corrosion may slow or stop completely when the intermetallic compounds form. This may happen in several ways because of the limited quantity of gallium used in the experiments and also because of space restrictions. For example, corrosion on the inner surface of the U-shaped coupon will stop when the space between the two sides of the specimen fills with reaction layer. Consequently, only values of metal loss up to $300 \mathrm{~h}$ were used to determine the corrosion rate of Type $316 \mathrm{SS}$ at $400^{\circ} \mathrm{C}$. The corrosion rates at $400^{\circ} \mathrm{C}$ were estimated as 2.2 and $2.7 \mathrm{~mm} / \mathrm{y}$ for specimens oxidized in water and air, respectively. A corrosion rate for as-received specimens was estimated as $4.0 \mathrm{~mm} / \mathrm{y}$. Metal loss for the oxidized and the as-received specimens is plotted as a function of time in Fig. 2.

As reported previously, ${ }^{7}$ corrosion of Type 316 SS occurs by dissolution accompanied by formation of $\mathrm{Ga}$ intermetallic compounds with the constituent elements. $\mathrm{FeGa}_{3}$ forms from the saturated solution of $\mathrm{Fe}$ in $\mathrm{Ga}$. The reaction occurs at the alloy/liquid-gallium interface. As the intermetallic compound forms and grows outward into the melt, a zone of liquid gallium resides close to the base metal, encapsulated in the porous crystalline structure of the intermetallic compound. The process continues as long as gallium can reach the reaction interface. Other constituent elements also dissolve in gallium and form intermetallic compounds with $\mathrm{Ga}$ that are dispersed throughout the reaction layer. Corrosion or dissolution can occur only with the growth of intermetallic compounds. The growth of these compounds may control the overall rate of corrosion of the alloy. Micrographs of a Type $316 \mathrm{SS}$ specimen tested in liquid gallium at $400^{\circ} \mathrm{C}$ for $1,076 \mathrm{~h}$ are shown in Fig. 3. The reaction layer $\approx 10 \mu \mathrm{m}$ from the remaining base metal is porous.

Table 1. Corrosion data for Type 316 SS in gallium contained in sealed alumina capsules at $400^{\circ} \mathrm{C}$

\begin{tabular}{|c|c|c|c|c|c|c|}
\hline \multirow[b]{2}{*}{$\begin{array}{c}\text { Specimen } \\
\text { No. }\end{array}$} & \multicolumn{2}{|c|}{ Before Exposure } & \multirow[b]{2}{*}{$\begin{array}{l}\text { Time } \\
\text { (h) }\end{array}$} & \multicolumn{3}{|c|}{ After Exposure } \\
\hline & $\begin{array}{c}\text { Weight } \\
\text { (mg) }\end{array}$ & $\begin{array}{c}\text { Thickness } \\
(\mu \mathrm{m})\end{array}$ & & $\begin{array}{l}\text { Weight } \\
\text { Change } \\
\left(\mathrm{mg} / \mathrm{cm}^{2}\right)\end{array}$ & $\begin{array}{l}\text { Metal } \\
\text { Loss }^{2} \\
(\mu \mathrm{m})\end{array}$ & $\begin{array}{c}\text { Reaction } \\
\text { Layer }^{a} \\
\text { ( } \mu \mathrm{m})\end{array}$ \\
\hline \multicolumn{7}{|c|}{ As-received } \\
\hline SS $-4 \mathrm{~A}$ & 860.6 & $540 . \overline{5}$ & 24 & 31.2 & 21.3 & 90.2 \\
\hline$S S-4 F$ & 854.1 & 513.5 & 48 & 19.8 & -3.0 & 37.1 \\
\hline SS-4B & 900.1 & 540.5 & 100 & 36.5 & 60.5 & 280.3 \\
\hline SS-4C & 834.2 & 567.5 & 300 & 362.6 & 130.0 & 620.2 \\
\hline$S S-4 E$ & 770.0 & 567.5 & 1076 & 394.5 & 160.1 & 802.2 \\
\hline \multicolumn{7}{|c|}{ Oxidized in air at $350^{\circ} \mathrm{C}$ for $100 \mathrm{~h}$} \\
\hline SSA-4B & $757 . \overline{5}$ & 540.5 & 100 & 27.2 & 23.3 & 73.4 \\
\hline SSA $-4 C$ & 732.2 & 540.5 & 300 & 107.3 & 94.9 & 508.7 \\
\hline SSA-4D & 792.0 & 513.5 & 1000 & b & 215.6 & 1275.3 \\
\hline SSA-4E & 756.8 & 527.0 & 3000 & \multicolumn{3}{|c|}{ complete reaction ${ }^{c}$} \\
\hline \multicolumn{7}{|c|}{ Oxidized in water $\left(6 \mathrm{ppm}\right.$ dissolved $\left.\mathrm{O}_{2}\right)$ at $290^{\circ} \mathrm{C}$ for $100 \mathrm{~h}$} \\
\hline SSW- $\overline{-4 B}$ & 702.4 & 513.5 & 100 & 83.8 & 26.2 & 189.1 \\
\hline SSW $-4 \mathrm{C}$ & 721.3 & 513.5 & 300 & 135.8 & 76.3 & 465.8 \\
\hline SSW-4D & 761.6 & 513.5 & 1000 & b & 173.6 & 998.6 \\
\hline SSW-4E & 810.6 & 513.5 & 3000 & \multicolumn{3}{|c|}{ complete reaction $^{c}$} \\
\hline
\end{tabular}




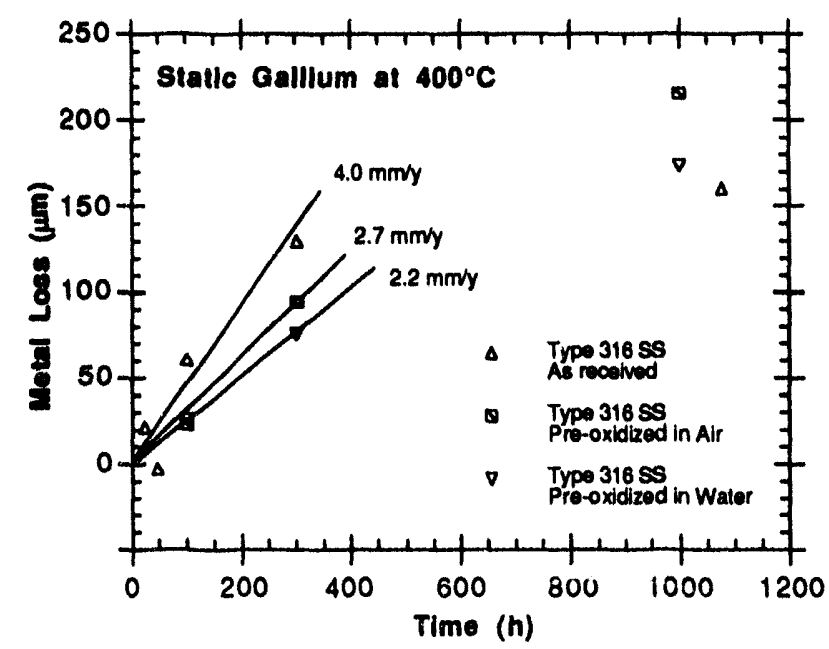

Figure 2.

Corrosion of oxidized Type 316 SS

in static gallium at $400^{\circ} \mathrm{C}$

Upon cooling, the gallium present in this region remains encapsulated within the pores. The black areas away from the base metal are most likely open pores. SEM/EDS did not reveal differences in composition around these areas. The region within $10 \mu \mathrm{m}$ of the base metal does not contain open pores. The sound metal remaining shows no signs of intergranular attack. However, the cold-work area seems to have broken away from the rest of the specimen, allowing more severe corrosion at the ends of the specimen.

Micrographs of water-and air-oxidized Type $316 \mathrm{SS}$ specimens tested in liquid gallium at $400^{\circ} \mathrm{C}$ for $1000 \mathrm{~h}$ are shown in Figs. 4 and 5, respectively. The general appearance of the oxidized specimens closely

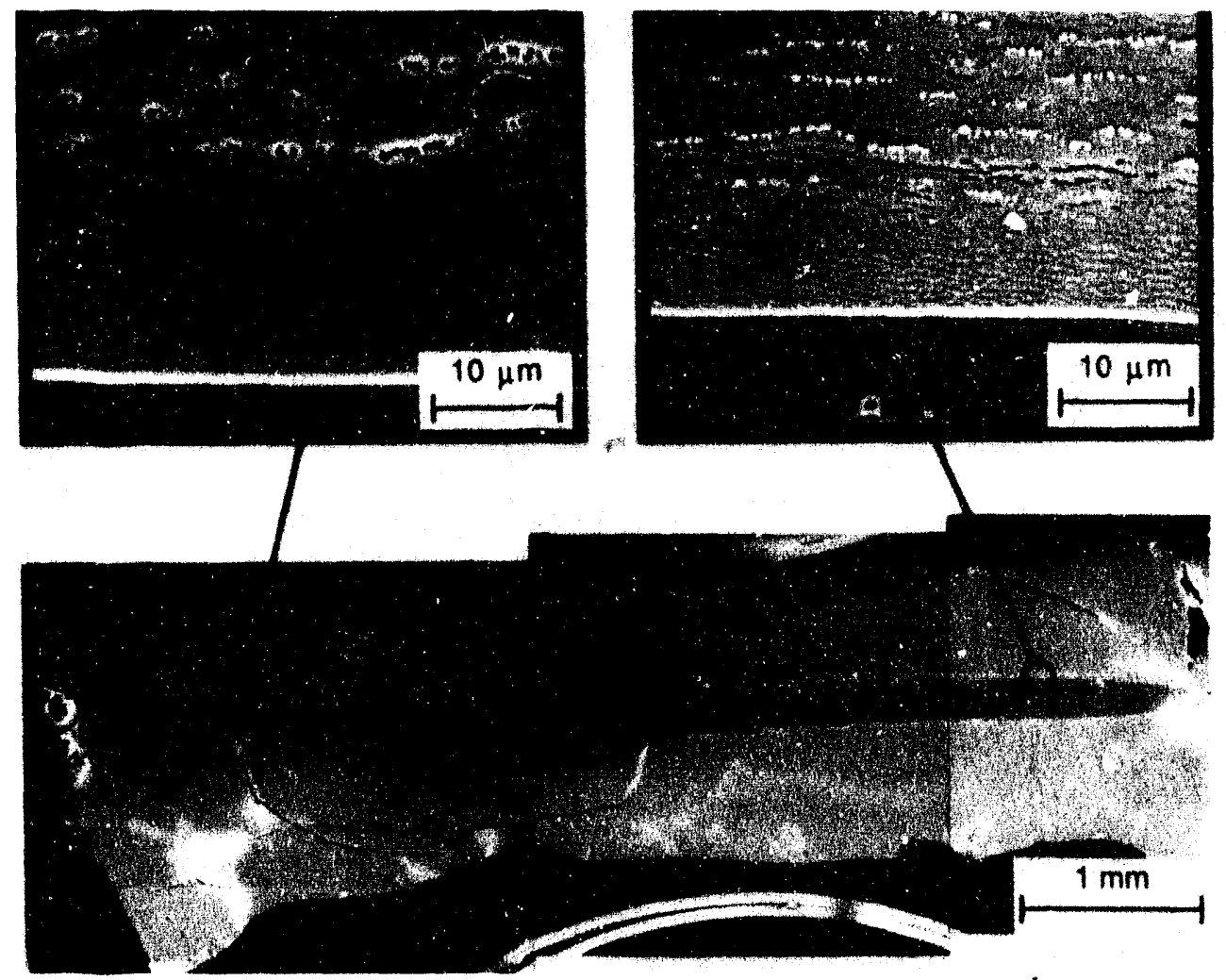

Figure 3. Cross section of Type $316 \mathrm{SS}$ specimen after exposure to gallium for $1076 \mathrm{~h}$ at $400^{\circ} \mathrm{C}$ 


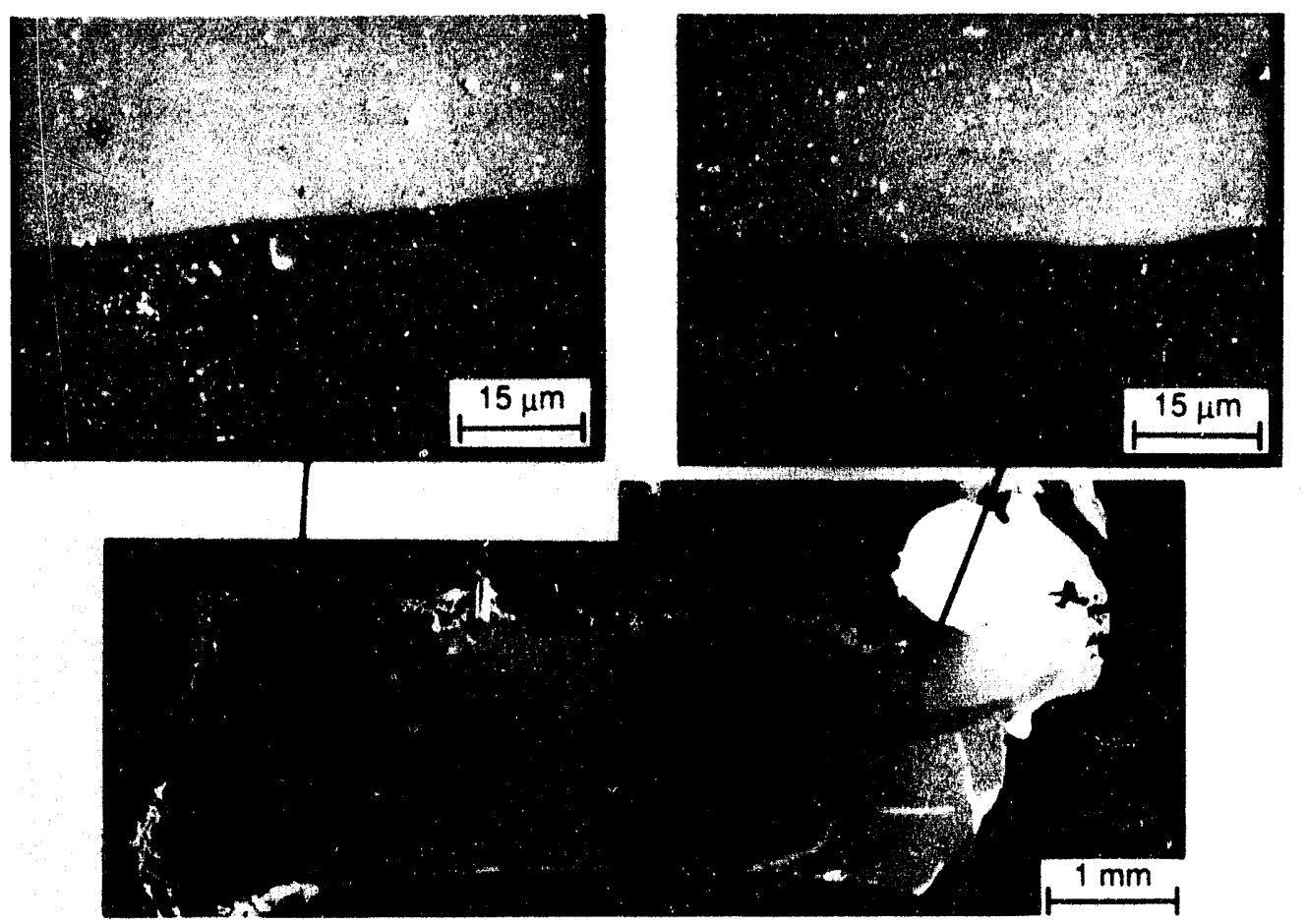

Figure 4. Cross section of Type 316 SS specimen oxidized in water and subsequently exposed to gallium for $1000 \mathrm{~h}$ at $400^{\circ} \mathrm{C}$

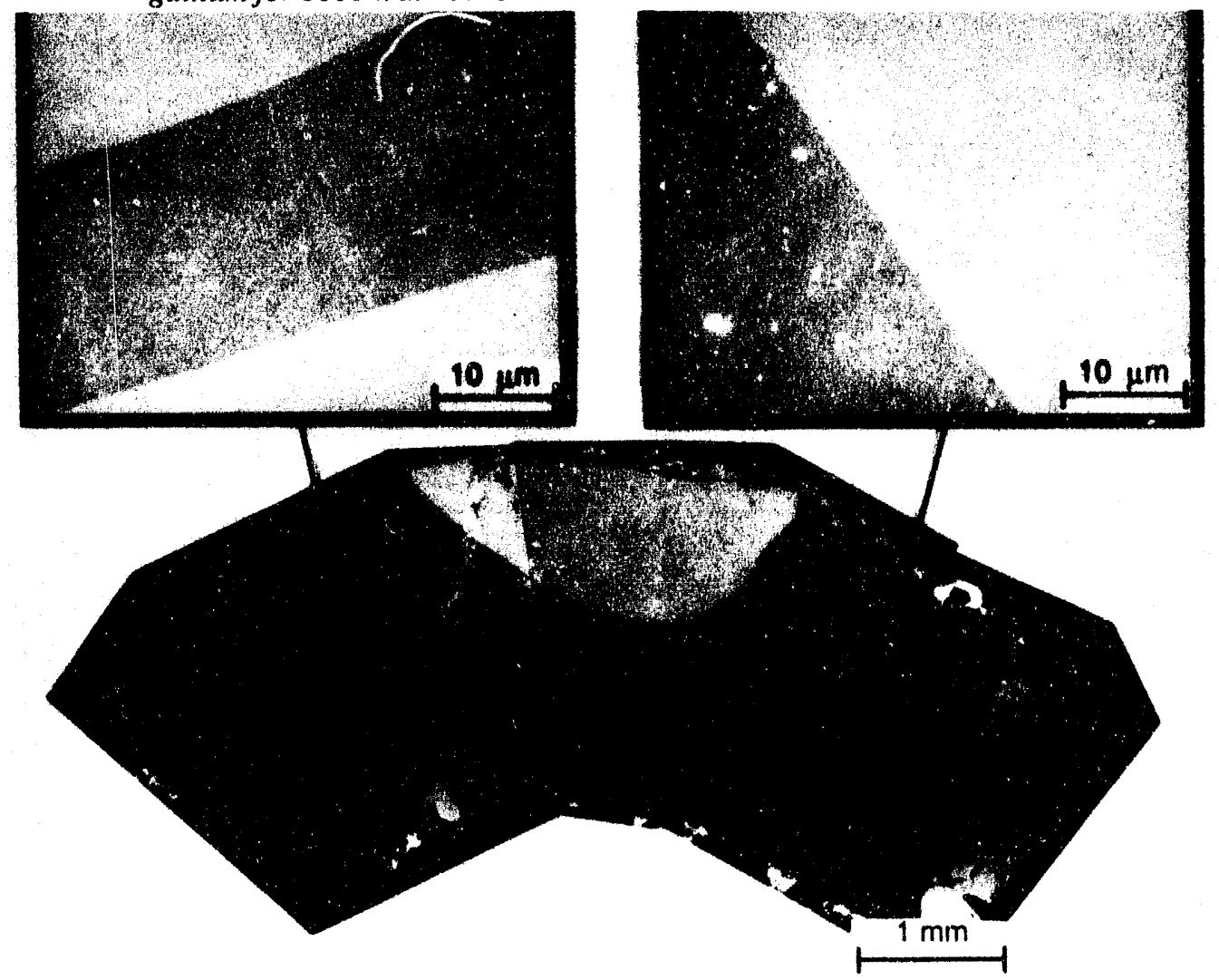

rigure S. Cross section of 1 ype $310 \mathrm{SS}$ specimen oxidized in atr and subsequently exposed to gallium for $1000 \mathrm{~h}$ at $400^{\circ} \mathrm{C}$ 
resembles that of the specimen in Fig. 3. In both preoxidized specimens, only a thin band of the base metal remains. Again, no sign of internal corrosive attack was observed, and the cold-worked area was not intact. The specimen oxidized in air was more heavily attacked than the specimen oxidized in water. Metallographic examination revealed $\beta-\mathrm{Ga}_{2} \mathrm{O}_{3}$ dispersed on the outside of the reaction layer. Between the $\boldsymbol{\beta}-\mathrm{Ga}_{2} \mathrm{O}_{3}$ and base metal is the $\mathrm{FeGa}$, which formed after the gallium sesquioxide. Examination of short-term-exposed specimens indicated that wetting of the specimen surface and/or dissociation of the surface oxide required $\approx 100 \mathrm{~h}$.

\section{Gallium Filaments}

During the course of examining mounted cross sections of specimens, an unusual phenomenon occurred. Specimens that developed an $\mathrm{FeGa}_{3}$ surface layer during corrosion, e.g., Type $316 \mathrm{SS}$ and Armco iron, subsequently developed what appeared to be extruded wires or whiskers of pure gallium "growing" on the surface of mounted cross sections. These wires were 0.1 to $0.5 \mathrm{~mm}$ thick and grew to various lengths up to $50 \mathrm{~mm}$. Electron diffraction spectroscopy (EDS) indicated that the wires were pure gallium. A typical wire growing out of the reaction scale on a Type 316 SS specimen is shown in Fig 6A. A micrograph of the same region but with the wire removed is shown in Fig. 6B. The fine surface markings observed on all the wires suggest that they are being extruded out of the material. The fine parallel lines on the top flat surface of the gallium wire (Fig. 6A) exactly match the lamellae observed in the surrounding region. These lamellae create the parallel markings on the sides of the wires. Also, the ridges on the top surface of the wire shown in Fig. 6A are indicative of a polycrystalline structure in the wire. However, Fig. 6B shows that there are no cavities or gallium-rich regions beneath these wires. They appear to be growing from the surface of the reaction scale. Region (a) in Fig. 6B was identified by EDS as FeGa Region (b), which was at the base of the wire, had the same composition as Region (a). Only Region (c) consisted of pure gallium; most likely this region was part of the wire that remained after the bulk of the wire was removed.
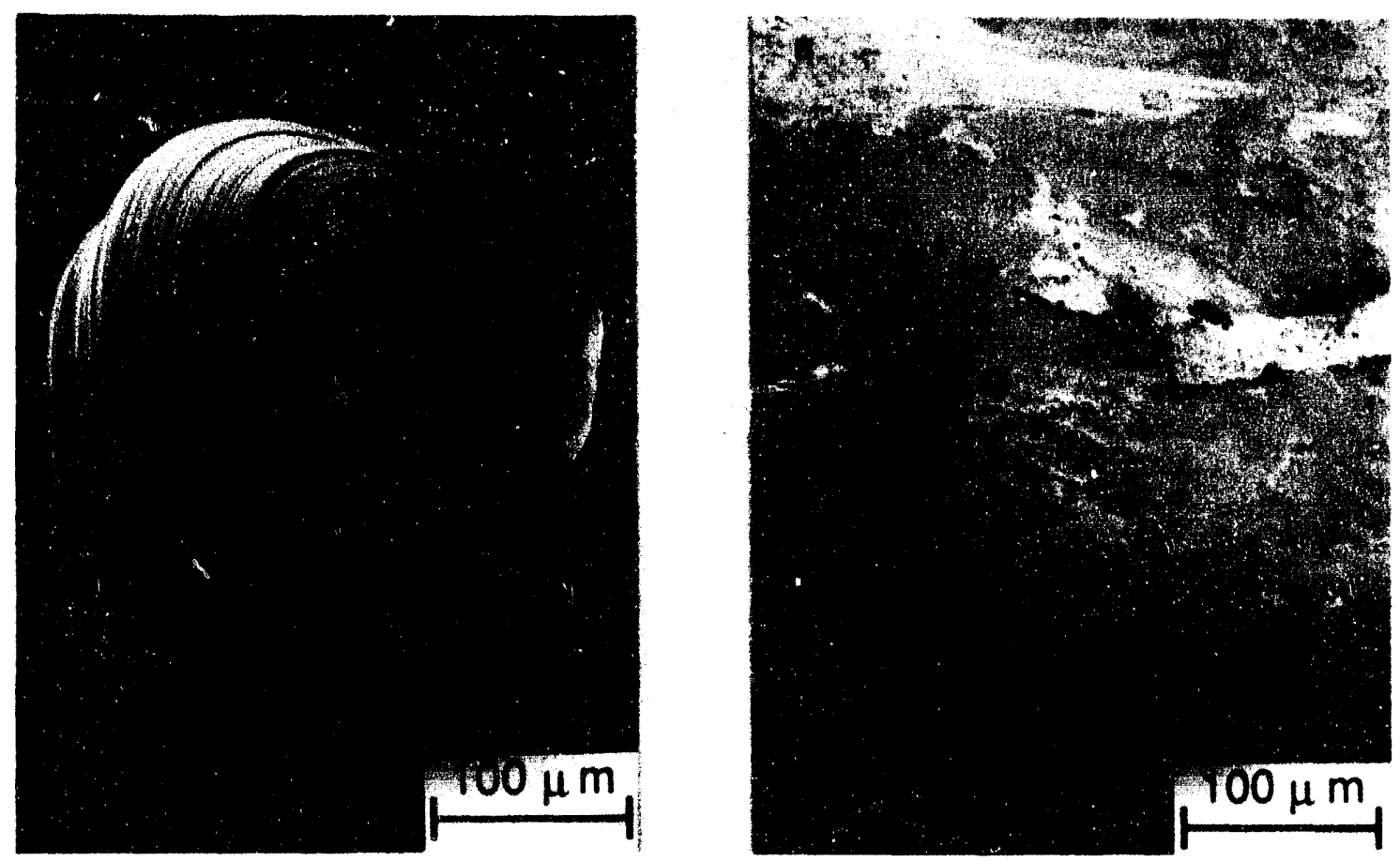

Figure 6. Micrographs of pure gallium whisker $(A)$ and specimen surface $(B)$ after wire removal. Regions $a, b$, and $c$ are described in text. 
A similar phenomenon has been reported in the manufacture of electronic components. Tin-base solders have caused component failure due to the formation of tin whiskers which cause a short to develop between contacts. Growth of Sn whiskers was observed in Au-Sn soldered lasers. ${ }^{8}$ The growth of Sn whiskers has been attributed to relaxation of internal strain. Oxidation was also considered to aid in whisker growth from nuclei formed on a metal surface. In the case of gallium whiskers, nuclei form on the metal surface; in fact they produce a fine replica of the surface. The strains caused by phase transformations may provide the necessary driving force for whisker formation.

\section{CONCLUSIONS}

Scoping tests have been conducted on compatibility of gallium with as-received and oxide-coated Type $316 \mathrm{SS}$ at $400^{\circ} \mathrm{C}$. Specimens oxidized in water containing $6 \mathrm{ppm}$ dissolved oxygen for $100 \mathrm{~h}$ at $290^{\circ} \mathrm{C}$ show the lowest corrosion rate $(2.2 \mu \mathrm{m} / \mathrm{y})$. Specimens oxidized in air at $350^{\circ} \mathrm{C}$ for $100 \mathrm{~h}$ have a corrosion rate of $2.7 \mu \mathrm{m} / \mathrm{y}$, and specimens tested in gallium with no oxide layer have a corrosion rate of $4.0 \mu \mathrm{m} / \mathrm{y}$. The difference in corrosion rates of the oxidized specimens are attributed to oxide thickness; water-oxidized specimens had a $0.3-\mu \mathrm{m}$-thick layer of $\mathrm{FeCr}_{2} \mathrm{O}_{4}$, and the specimens oxidized in air had a similar layer with a thickness of $\leq 0.1 \mu \mathrm{m}$. Corrosion rates based upon $300 \mathrm{~h}$ tests are lower for oxidized specimens because the iron(II)chromite layer prevented wetting of the metal for approximately $100 \mathrm{~h}$. Upon dissociation of the oxide layer, corrosion of the alloy proceeded.

\section{FUTURE WORK}

No further work is planned because gallium is no longer being considered for use in ITER.

\section{ACKNOWLEDGMENTS}

The authors thank C. Reed, P. Dombrowski, and R. Clark for experimental contributions, B. Tani for performing $X$-ray diffraction analyses, and T. F. Kassner for helpful discussions.

\section{REFERENCES}

1. L. R. Kelman, W. D. Wilkinson, and F. L. Yaggee, Resistance of Materials to Attack by Liquid Metals, Argonne National Laboratory Report ANL 4417 (July 1950).

2. W. D. Wilkinson, Effects of Gallium on Materials at Elevated Temperatures, Argonne National Laboratory Report ANL-5027 (August 1953).

3. W. D. Wilkinson, Effects of Gallium on Materials at Elevated Temperatures Supplementary Report, Argonne National Laboratory Report ANL-4582 (August 1953).

4. C. B. Alcock and K. T. Jacob, Solubility and Activity of Oxygen in Liquid Gallium and GalliumCopper Alloys, J. Less-Com. Met., 53, 211-222 (1977).

5. K. Natesan, Influence of Nonmetallic Elements on the Compatibility of Structural Materials with Liquid Alkali Metals, J. Nucl. Mat., 115, 251-262 (1983).

6. O. Kubaschewski, E. LL. Evans, and C. B. Alcock, Metallurgical Thermochemistry, 4th Ed., Pergamon Press, New York (1967) pp. 421-429.

7. P. R. Luebbers, W. F. Michaud, and O. K. Chopra, Compatibility of Structural Materials with Static Gallium, Fusion Reactor Materials Semiannual Progress Report for the Period Ending March 31, 1993, DOE/ER-0313/14, 370-379 (1993).

8. K. Mizuishi, Some Aspects of Bonding-Solder Deterioration Observed in Long-Lived Semiconductor Lasers: Solder Migration and Whisker Growth, J. Appl. Phys., 55 (2), 289-295 (1984). 
No contributions. 
RADIATION EFFECTS IN BERYLLIUM USED FOR PLASMA PROTECTION - D. S. Gelles (Pacific Northwest Laboratory) ${ }^{a}$, M. Dalle Donne, (Kernforschungszentrum Karlsruhe, Germany), G. A. Sernyaev (SF NIKIET, Russia Federation) and H. Kawamura (Blanket Irradiation \& Analysis Laboratory, JAERI, Japan)

\section{OBJECTIVE}

The objective of this work is to provide a literature review of irradiation effects studies in beryllium. It forms the basis for an invited paper presented at the Sixth International Conference on Fusion Reactor Materials held September 27 to October 1, 1993 in Stresa, Italy.

\section{SUMMARY}

This paper reviews the literature on beryllium, emphasizing the effects of irradiation on essential properties. Swelling and embrittlement experiments as a function of irradiation temperature and dose, and and as a function of neutron spectrum are described, and the results are quantified, where possible. Effects of impurity content are also reported, from which optimum composition specifications can be defined. Microstructural information has also been obtained to elucidate the processes controlling the property changes.

The available information indicates that beryllium divertors can be expected to embrittle quickly and may need frequent replacement.

\section{PROGRESS AND STATUS}

\section{Introduction}

Beryllium is presently a leading candidate material for fusion reactor first wall coating and divertor applications. This is largely a result of improved performance in the Joint European Torus (JET) after evaporated beryllium, and then beryllium tiles as a plasma facing material were installed in the limiter area.' In comparison with graphite that had been used previously, beryllium reduced the plasma radiation, increased the density limit, reduced the incidence of disruptions, and enhanced the deuteron pumping. Based in part on its good thermal and physical properties, but also a result of operating experience in JET, beryllium has recently been identified as the material of choice for the International Thermonuclear Experimental Reactor (ITER) both as a plasma facing material and as a divertor material. In that application, it would provide the interface material between plasma and confinement structure in the first fusion reactor to generate significant quantities of $14 \mathrm{MeV}$ neutrons.

Beryllium is also the candidate material of choice as the neutron multiplier in a solid breeder blanket design. In that capacity, it would provide additional neutrons for tritium production in a blanket containing lithium ceramics. However, design optimization studies have shown that the blanket must contain at least $70 \%$ beryllium to maximize tritium production. If beryllium is used as a plasma facing material, a divertor material, and blanket neutron multiplier in a fusion reactor design, it is apparent that the fusion reactor will incorporate beryllium as a major fraction of the materials making up the reactor

'Pacific Northwest Laboratory is operated for the U.S. Department of Energy by Battelle Memorial Institute under Contract DE-AC06-76RLO 1830. 
design. Operating such a fusion reactor may therefore be very dependent on the response of beryllium to $14 \mathrm{MeV}$ neutron damage.

However, beryllium is degraded by radiation damage, both as a result of displacement damage and of transmutation. Displacement damage leads to point defect clustering, irradiation hardening, and embrittlement. Transmutation produces helium (and lithium), resulting in high levels of gas-driven swelling and embrittlement at high temperatures. It is not yet clear what limitations this damage will place on fusion reactor applications. Results of experiments seem to be contradictory.

The purpose of this review is to present data concerning effects of irradiation on essential properties. Swelling and embrittlement experiments as a function of irradiation temperature and dose and as a function of the neutron spectrum are described, and the results are quantified where possible. Effects of impurity content are also reported, and the optimum composition specifications can be defined. Microstructural information has also been obtained to explain the processes controlling the property changes. Previously published reviews on radiation damage effects in beryllium may be noted.-5

\section{Neutronic considerations}

A major contributor to radiation damage in beryllium, in addition to displacement damage, is the production of helium and tritium from $(n, 2 n)$ and $(n, \alpha)$ reactions. Each beryllium atom can transmute to two helium atoms depending on neutron energy according to the following reactions:

$$
\begin{array}{rlr}
9 \mathrm{Be}+\mathrm{n} & \rightarrow{ }^{8} \mathrm{Be}+2 \mathrm{n} & \text { (effective threshold energy } 2.7 \mathrm{MeV} \text { ) } \\
{ }^{8} \mathrm{Be} & \rightarrow{ }^{4} \mathrm{He} \\
{ }^{9} \mathrm{Be}+\mathrm{n} & \rightarrow{ }^{6} \mathrm{He}+{ }^{4} \mathrm{He} \quad & \text { (effective threshold energy } 1.4 \mathrm{MeV} \text { ) } \\
{ }^{6} \mathrm{He} & \rightarrow{ }^{6} \mathrm{Li} \\
{ }^{6} \mathrm{Li}+\mathrm{n} & \rightarrow{ }^{4} \mathrm{He}+{ }^{3} \mathrm{H} & \text { (Primarily thermal neutrons) }
\end{array}
$$

As a consequence, under high energy neutron bombardment, helium is generated in much greater quantities in beryllium than in any other metal. It has been estimated that for a $14 \mathrm{MeV}$ neutron wall loading of $1 \mathrm{MW} / \mathrm{m}^{2}, 4.73 \mathrm{dpa} / \mathrm{yr}$ will be produced at a helium generation rate of $617 \mathrm{appm}-\mathrm{He} / \mathrm{dpa}$ or $2920 \mathrm{appm}$ $\mathrm{He} / \mathrm{yr}^{3}$

\section{Point Defect Accumulation and Swelling}

Radiation damage in beryllium can best be characterized by distinguishing between point defect accumulation, point defect coalescence, and gas driven swelling.

Gol'tsev and coworkers ${ }^{6}$ have determined that at low temperatures where mobility of point defects is high enough to efficiently recombine and accumulate at point defect sinks, but gas atoms are practically immobile, swelling in beryllium can be described by the expression:

$$
\Delta V \mid V_{o} \propto 8.2 \times 10^{-25} \phi t
$$


where $\phi t$ is fast fluence in $\mathrm{n} / \mathrm{cm}^{2}, \mathrm{E}>0.85 \mathrm{MeV}$. This is based on irradiations at $60^{\circ} \mathrm{C}$, but can be used over the range of temperatures where helium remains in supersaturated solid solution.

From this expression, it can be noted that at a fluence of $10^{22} \mathrm{n} / \mathrm{cm}^{2}$, a swelling level of $0.8 \%$ is predicted. Sernyaev ${ }^{7}$ has published swelling data for various grades of pure beryllium irradiated at between 450 and $500^{\circ} \mathrm{C}$ to doses between $5.7 \times 10^{21}$ and $1.02 \times 10^{22} \mathrm{n} / \mathrm{cm}^{2}, \mathrm{E}>0.85 \mathrm{MeV}$. Swelling levels of between 0.4 and $0.8 \%$ were recorded, the higher values corresponding to higher fluence levels. Sannen and De Raedt ${ }^{8}$ have published swelling data for vacluum hot pressed beryllium irradiated at 40 to $50^{\circ} \mathrm{C}$ to fluences of 0.8 , 2.8 , and $3.9 \times 10^{22} \mathrm{n} / \mathrm{cm}^{2}, \mathrm{E}>1 \mathrm{MeV}$. Swelling values of $0.65,1.57$, and $2.27 \%$ were obtained, and a somewhat lower correlation factor of $0.58 \pm 0.3 \times 10^{-25}$ was recommended for expression (3). Koonen ${ }^{9}$ has published swelling data for vacuum hot-pressed beryllium irradiated at 40 to $50^{\circ} \mathrm{C}$ to flusences as high as $8 \times 10^{22} \mathrm{n} / \mathrm{cm}^{2}, \mathrm{E}>1 \mathrm{MeV}$ with a maximum of $2.2 \%$ diametral swelling (corresponding to $6.6 \%$ volumetric swelling if swelling were isotropic.) Finally, Burmistrov and coworkers ${ }^{10}$ published measurements on the beryllium core moderator block of an MIR reactor irradiated to a fluence of $3.2 \times 10^{1.2} \mathrm{n} / \mathrm{cm}^{2}$ at $40^{\circ} \mathrm{C}$, noting that the swelling did not exceed $0.3 \%$, but that this was in agreement with expression (3). Therefore, the correlation factor of $8.2 \times 10^{-25}$ may not be valid for all materials.

For example, based on the review by Dalle Donne and co-workers," it can be shown that product form can control swelling response at low irradiation temperatures. Figure 1 provides a plot of volumetric swelling at temperatures below $100^{\circ} \mathrm{C}$ as a function of helium content, which is proportional to fluence. Significant differences are found between the swelling measurements of Sernyaev ${ }^{12}$ and those obtained in western experiments. ${ }^{13-15}$ The Sernyaev data points all fall above the trend line defining western measurements. The difference is attributed to modern beryllium production and processing. The Sernyaev results are based on beryllium irradiated in the $1960 \mathrm{~s}$, whereas the western data in Figure 1 are more recent and show response on modem beryllium production technology. The earlier Russian beryllium is very anisotropic, with large grains and relatively high amounts of impurities ( $\mathrm{BeO}$ and others) whereas modern beryllium made by powder processing techniques is fine grained and more isotropic. This therefore emphasizes an effect of microstructure on low temperature swelling response.

An effect of higher fluence is demonstrable from the Koonen measurements ${ }^{9}$ where beryllium was irradiated at 40 to $50^{\circ} \mathrm{C}$ in the BR2 Research Reactor. Non-linear response can be identified for fluences above $6.4 \times 10^{22} \mathrm{n} / \mathrm{cm}^{2}, \mathrm{E}>1 \mathrm{MeV}$ so that swelling increases either in a bilinear or quadratic fashion from that dose. Based on these measurements, safety issues have been satisfied to allow irradiation of beryllium as BR2 in-core structural components to this fluence of $6.4 \times 10^{22} \mathrm{n} / \mathrm{cm}^{2}, \mathrm{E}>1 \mathrm{MeV}$. This decision attests to the use of modern hot-pressed beryllium for use in high fluence irradiation applications.

Beeston and Miller ${ }^{16}$ provide a somewhat different expression for swelling as a function of fluence applicable to the temperature range 400 to $600^{\circ} \mathrm{C}$ :

$$
\Delta V \mid V_{o}=1.83 \times 10^{-58}(\phi t)^{2} T^{4}
$$

where $\phi t$ is fast fluence in $\mathrm{n} / \mathrm{cm}^{2}, \mathrm{E}>1 \mathrm{MeV}$, and $\mathrm{T}$ is the temperature in $\mathrm{K}$. This expression was derived from density change measurements made on a beryllium cylinder that was irradiated in a flux gradient in a fast breeder reactor for 4 years and cut into pieces, providing 26 samples with fluences between 0.7 and $1.3 \times 10^{22} \mathrm{n} / \mathrm{cm}^{2}, \mathrm{E}>1 \mathrm{MeV}$, at irradiation temperatures between 427 and $482^{\circ} \mathrm{C}$. From this expression, it can be noted that at $500^{\circ} \mathrm{C}$ and a fluence of $10^{22} \mathrm{n} / \mathrm{cm}^{2}$, a swelling level of $0.65 \%$ is predicted, in reasonable agreement with the data from Sernyaev. ${ }^{7}$ However, for an irradiation temperature of $50^{\circ} \mathrm{C}$ and a fluence of $10^{22} \mathrm{n} / \mathrm{cm}^{2}$, expression (4) predicts $0.02 \%$, and therefore, this equation cannot predict the results of Sannen and De Raedt ${ }^{8}$ or Koonen. ${ }^{9}$ 


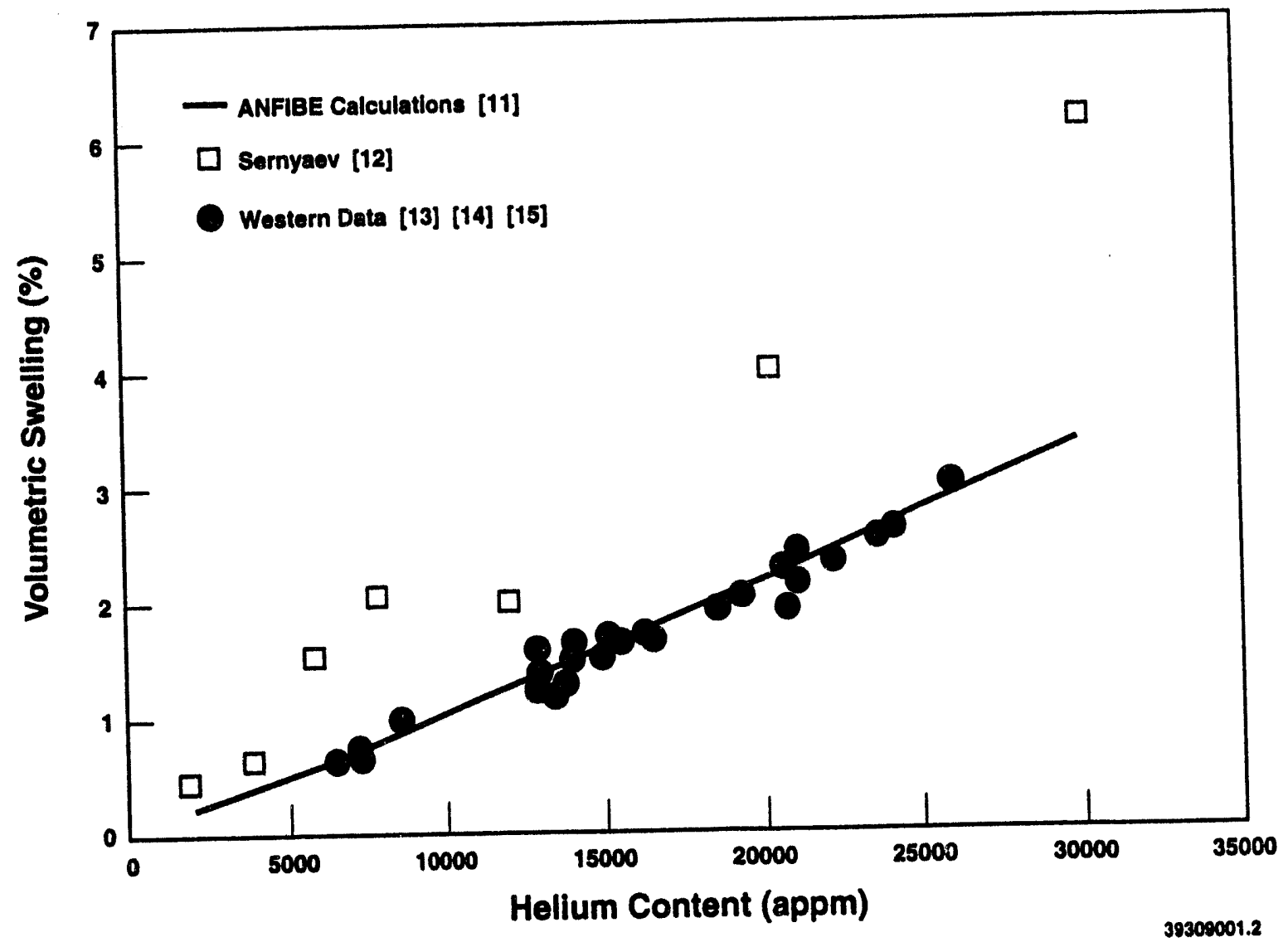

Fig. 1. Swelling in beryllium irradiated at temperatures below $100^{\circ} \mathrm{C}$ as a function of helium content.

At temperatures where helium and tritium mobility becomes large enough to allow consolidation into large bubbles, the swelling accumulation during neutron irradiation is larger by over an order of magnitude, and the swelling dependence on fluence and temperature is different. The dependence can be described by the expression from Sernyaev?

$$
\Delta V \mid V_{0}-M \cdot T \exp [-Q /(4 k T)](\phi t)^{3 / 2}
$$

where $M$ is a structure-sensitive factor and $T, Q, k$, and $\phi t$ have their usual meaning. Sernyaev has analyzed available da a and found that $Q$ is $2.1 \pm 0.1 \mathrm{eV} /$ at and $\mathrm{M}$ varies from 0.31 to $1.65 \times 10^{-34} \mathrm{~K}^{-1}$ $\left(\mathrm{n} / \mathrm{cm}^{2}\right)^{-3 / 2}$. The dependence of $\mathrm{M}$ on materials parameters was found to correlate best with a processing procedure such that hot pressing produced significantly higher values for $M$ than did extrusion. However, given a specific processing procedure, $M$ was found to increase with decreasing oxygen content and with increasing grain size. Therefore, to minimize high temperature swelling, extruded materials with oxygen levels on the order of $3 \%$ and grain diameters between 10 and $20 \mu \mathrm{m}$ would be recommended. 
Examples of swelling in beryllium irradiated at high temperatures are given in Figure 2. Figure 2 (a) shows the data of Sernyaev ${ }^{7}$ from which the structure-sensitive factor analysis described above is based and Figure 2 (b) gives results from Burmistrov. ${ }^{10}$ Swelling as high as $18 \%$ can be noted in hot-pressed $56 \mu \mathrm{m}$ grain size beryllium irradiated to $8.9 \times 10^{21} \mathrm{n} / \mathrm{cm}^{2}, \mathrm{E}>0.85 \mathrm{MeV}$. In both plots, it is apparent that swelling in beryllium is sensitive to manufacturing and processing variables.

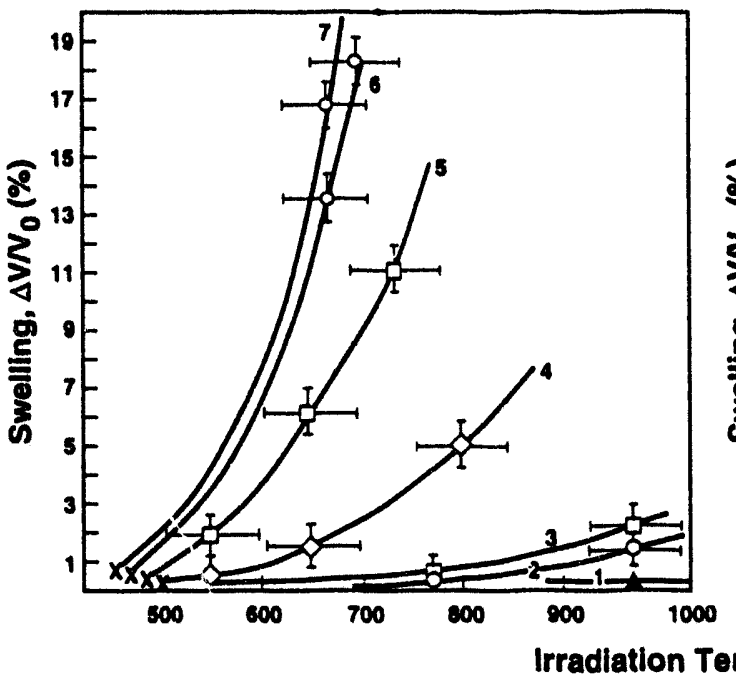

(a)

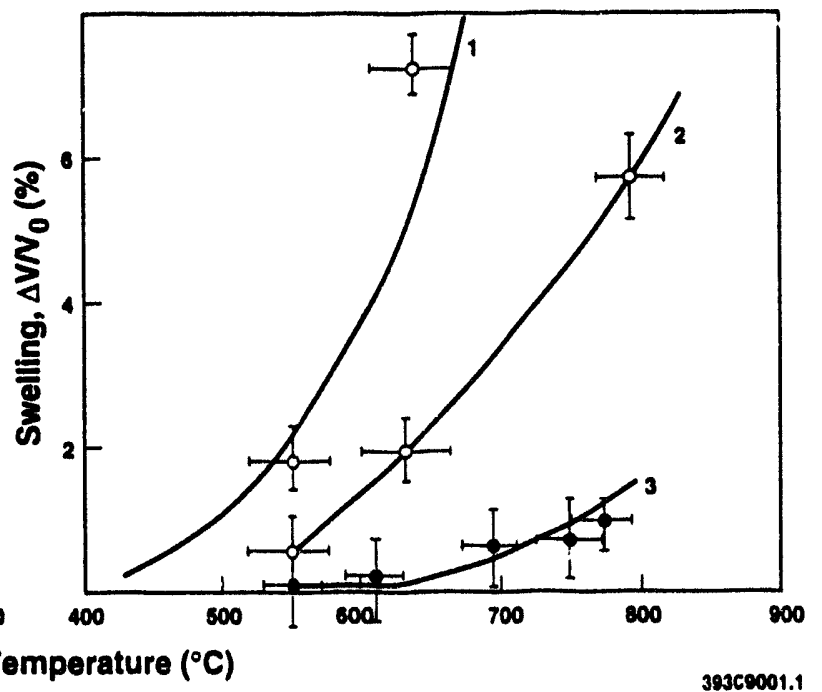

(b)

Fig. 2. Swelling in Beryllium as a function of irradiation temperature (a) from ref. 7 and (b) from ref. 10. Notation in (a) is as follows: (1) is single crystal; $(2,6,7)$ are hot pressed, grain size (g.s.) $56 \mu \mathrm{m}$; $(3,5)$ are hot pressed, g.s. $600 \mu \mathrm{m}$; (4) is thermally extruded, g.s. $400 \mu \mathrm{m}$. Also, $(1-3)$ are at $6 \times 10^{20},(4,5)$ are at $5.7 \times 10^{21},(6)$ is at $8.9 \times 10^{21}$ and (7) is at $1.02 \times 10^{22} \mathrm{n} / \mathrm{cm}^{2}, \mathrm{E}>0.85 \mathrm{MeV}$.; notation in (b) is as follows: (1) g.s. $30 \mu \mathrm{m}$, (2) g.s. $20 \mu \mathrm{m}$, and (3) g.s. 8 to $13 \mu \mathrm{m}$ and fluences for $(1,2) 5.7 \times 10^{21}$, and for (3) $3.5 \times 10^{21} \mathrm{n} / \mathrm{cm}^{2}(\mathrm{E}>0.1 \mathrm{MeV})$.

To understand the consequences on swelling of helium present in beryllium, a number of experiments have been performed where specimens irradiated at low temperatures were subsequently heated to higher temperatures, and the resultant increases in swelling were measured. ${ }^{16-22}$ Often, these experiments used 1 hour annealing increments, but many followed the same condition at temperature for many hours. The swelling produced depended somewhat on the neutron fluence, because higher doses produced higher helium levels. Doses were poorly quantified, but ranged from $5 \times 10^{20}$ to $10^{22} \mathrm{n} / \mathrm{cm}^{2}$. The general response of annealing experiments can be summarized as follows. Effects of annealing on swelling were only observed for temperatures of $600^{\circ} \mathrm{C}$ and above, but at 600 and $700^{\circ} \mathrm{C}$, all annealing experiments produced swelling levels of $1 \%$ or less. ${ }^{17,21}$ One hour anneals at $800^{\circ} \mathrm{C}$ produced swelling levels as high as $14 \%,{ }^{17}$ but generally the values were negligible $e^{18-20,22}$ or between 3 and $5.5 \% .^{21}$ One hour anneals at $900{ }^{\circ} \mathrm{C}$ raise the swelling somewhat, giving values ranging from 0.5 to $17 \%$, and $1000^{\circ} \mathrm{C}$ anneals raised the maximum values to about $32 \%,{ }^{17}$ but still higher annealing temperatures of 1100 and $1200^{\circ} \mathrm{C}$ produced swelling only on the order of $40 \% .{ }^{17,20}$ The data have been analyzed to show Arhenius behavior (with an activation energy of $40 \mathrm{kcal} / \mathrm{mole}$, about the value for self-diffusion in beryllium) for 1 hour anneals over the temperature range 600 to $900^{\circ} \mathrm{C}$, but a saturation in behavior at higher temperatures occurred, corresponding to about $30 \%$ (after heating to about $1000^{\circ} \mathrm{C}$ for 1 hour. $)^{17}$ 
When longer annealing times were used, ${ }^{19,20,22}$ swelling sometimes increased to much higher levels, approaching saturation behavior as noted above. For example, at $800^{\circ} \mathrm{C}$ where 1 hour anneals produced negligible swelling, anneals for 20 hours $^{20}$ and 1000 hours $^{22}$ produced swelling on the order of $10 \%$, and at $900^{\circ} \mathrm{C}$, anneals for 700 hours produced $10 \%$ swelling ${ }^{22}$ and for 10 hours produced $25 \%$ swelling. ${ }^{20}$ The swelling as a function of annealing time has been shown to give linear behavior on $\log -\log$ plots, and an activation energy of $22 \mathrm{kcal} / \mathrm{mole}$ was calculated for the controlling process. ${ }^{22}$ However, two examples of rapid swelling after apparent saturation are reported, ${ }^{20}$ probably similar in process to the tritium burstrelease identified in more recent experiments where most of the tritium was released in a sudden burst. ${ }^{8,23}$

More recently, Sernyaev ${ }^{23}$ has studied the initiation and growth of helium gas bubbles in single crystal beryllium irradiated at $60^{\circ} \mathrm{C}$ to fluences of 2.6 and $5.1 \times 10^{21} \mathrm{n} / \mathrm{cm}^{2}, \mathrm{E}>0.8 \mathrm{MeV}$, and then annealed at temperatures of 100 to $1100^{\circ} \mathrm{C}$ with 1 hour hold times. Techniques employed included small angle $\mathrm{x}$-ray scattering (SAS), differential microcalorimetry (DMC), and transmission electron microscopy (TEM), and it was possible to demonstrate that bubble nucleation occurred at temperatures from 350 to $600^{\circ} \mathrm{C}$ and that bubbles grew above $600^{\circ} \mathrm{C}$. The SAS measurement also allowed estimates of mean bubble diameter as a function of annealing time, with the interesting result that the specimen irradiated to lower fluence developed larger bubbles at temperatures above $775^{\circ} \mathrm{C}$ with bubbles approaching $12.5 \mathrm{~nm}$ in diameter.

\section{Mechanical properties - hardening and embrittlement}

Beryllium metal has the hexagonal close packed (HCP) crystal structure with a c/a ratio of 1.5677 at temperatures below $1254^{\circ} \mathrm{C}$. As with other HCP and body centered cubic crystal structures, beryllium displays a thermally activated deformation response at low temperatures, leading to increasing yield strength with decreasing temperature, and a tendency for twinning and brittle fracture at low temperatures. Slip has been observed on basal, prism, and pyramidal planes in beryllium, but due to the thermal activation process that controls at low temperatures, slip can become difficult, and embrittlem.ent results if the temperature is low enough. However, beryllium differs from other metals in that the elastic moduli are very high, the interatomic distance is very short, the Poisson's ratio is very low, and the Debye temperature is very high. ${ }^{24}$ All are indications of strong interatomic forces, and therefore beryllium is more sensitive than most metals to embrittlement at low temperatures.

However, manufacturers have successfully produced beryllium with reasonable room temperature mechanical properties. In general, two approaches are responsible: higher purity and refined grain size. This has generally necessitated the use of powder metallurgy fabrication techniques. However, there are few producers of beryllium in the world.

Irradiation adversely affects the mechanical properties of beryllium due to two processes. Point defects produced by radiation damage can cluster to form obstacles to dislocation motion, and helium can migrate to point defect sinks to form bubbles which are also obstacles to dislocation and grain boundary motion. These bubbles can provide nucleation sites for cracking. Resirictions to dislocation motion are manifested as hardening, strength increasus, ductility decreases, fracture toughness decreases, and embrittlement. A large number of studies on beryllium have included experiments to study these phenomena. ${ }^{17-20,22,25-42}$ These include results on strength and ductility changes due to irradiation, ${ }^{18-20,22,25-38}$ bend test response, ${ }^{17,38}$ hardness, ${ }^{17,18,20,25,27,36,39}$ fracture toughness, ${ }^{40-42}$ and stress rupture. ${ }^{36,39}$ However, most of those studies were performed about 30 years ago when an international effort was made to develop beryllium as a fuel cladding material for fission reactors. Unfortunately, the dosimetry is crude, and it is very difficult to quantitatively compare results of the different studies. The database on irradiation effects to mechanical properties has been reviewed previously. ${ }^{36,43}$

Studies on strength and ductility changes due to irradiation have shown that, as with swelling studies, irradiation temperature affects response. At low irradiation temperatures, strength increase due to 
irradiation is most evident, whereas at high irradiation temperatures on the order of $650^{\circ} \mathrm{C}$, irradiation embrittlement can occur without significant strength increase. To minimize the possibility of zero ductility response, a number of yield strength measurement techniques have been applied including uniaxial tensile strength, compressive strength, shear strength, splitting tensile strength, flexural strength and three point bend tests.

However, the general trend of the response following low-temperature irradiation is for strength to begin to increase at fluences on the order of $10^{19} \mathrm{n} / \mathrm{cm}^{2}(\mathrm{E}>1 \mathrm{MeV})$, to saturate as ductility approaches zero, and then to decrease with further fluence. An example is shown in Figure 3 (a) providing comparison of available data for increase in tensile yield strength as a function of fluence. The original plot, provided by Hickman, ${ }^{43}$ predicted linear behavior based on the " $\square$ " symbols, but more recent data do not support a linear description. Figure 3 (b), originally provided by Beeston and coworkers, ${ }^{32}$ shows compressive fracture or yield strength as a function of fluence for specimens irradiated at $120^{\circ} \mathrm{C}$ and emphasizes the tendency for reduced strength beyond fluences where saturation occurs. Note that saturation in compressive tests can be expected to occur at a higher fluence because compression allows testing to higher levels of strength before failure.

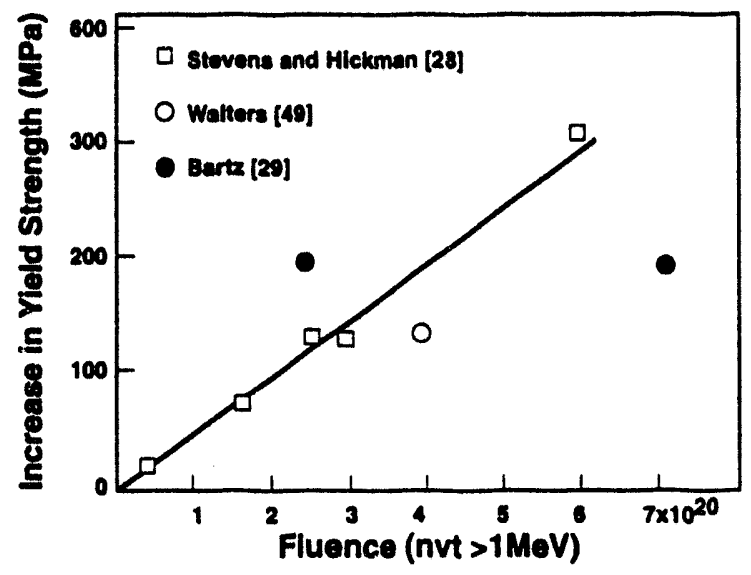

(a)

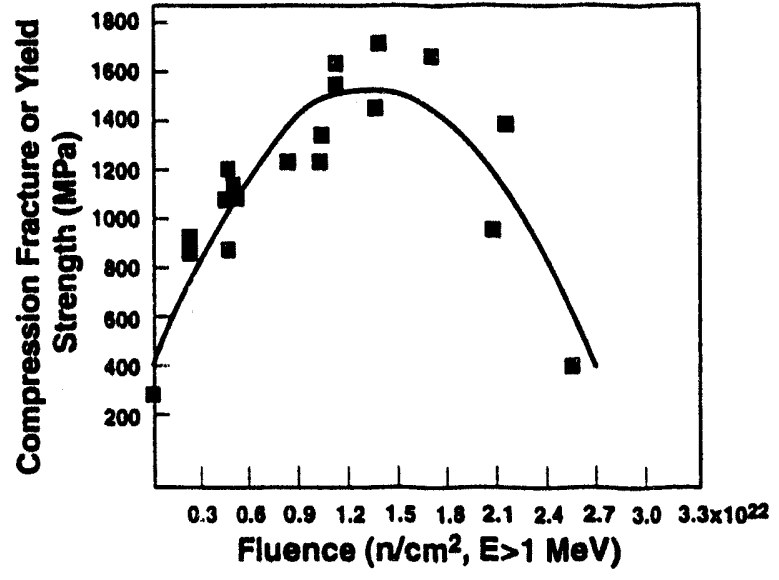

(b)

Fig. 3. Tensile strength increase (a) or compressive fracture or yield strength (b) as a function of Fluence $(\mathrm{E}>1 \mathrm{MeV})$ for beryllium specimens irradiated at 75 to $125^{\circ} \mathrm{C}$.

Hardness measurements further demonstrate linear response in strength with fluence at low temperatures. Figure 4 (a) shows diamond pyramid hardness for beryllium irradiated in the temperature range 35 to $100^{\circ} \mathrm{C}$, originally compiled by Hickman, ${ }^{43}$ but now including further data, ${ }^{29}$ plotted logarithmically as a function of fluence. Hardness values begin to increase at fluences on the order of $2 \times 10^{19} \mathrm{n} / \mathrm{cm}^{2}$, similar to the yield strength response. The plot is linear with only a hint of saturation.

However, response following irradiation at higher temperatures gives reduced hardening. Figure 4 (b) has been prepared to show this effect. The trend line from Figure 4 (a) is reproduced, and available data points showing hardness increase are plotted and labelled with the irradiation temperature. The tendency is for 280 to $400^{\circ} \mathrm{C}$ data points to lie close to the trend line, but as irradiation temperat: re is increased, hardness increase is reduced. Irradiation at $700^{\circ} \mathrm{C}^{39}$ produces softening, and those data points have not been included. 
Strength changes following irradiation at $280^{\circ} \mathrm{C}$ and above follow these trends, but the dependence of strength increase as a function of fluence may be different. Walters ${ }^{34}$ has noted that yield strength as a function of dose is linear when plotted as $(\phi t)^{\mathrm{h}}$ for specimens irradiated at $350^{\circ} \mathrm{C}$. Similar slopes are produced by the data from other experiments following irradiation from 280 to $500^{\circ} \mathrm{C}$. This response is shown in Figure 5.
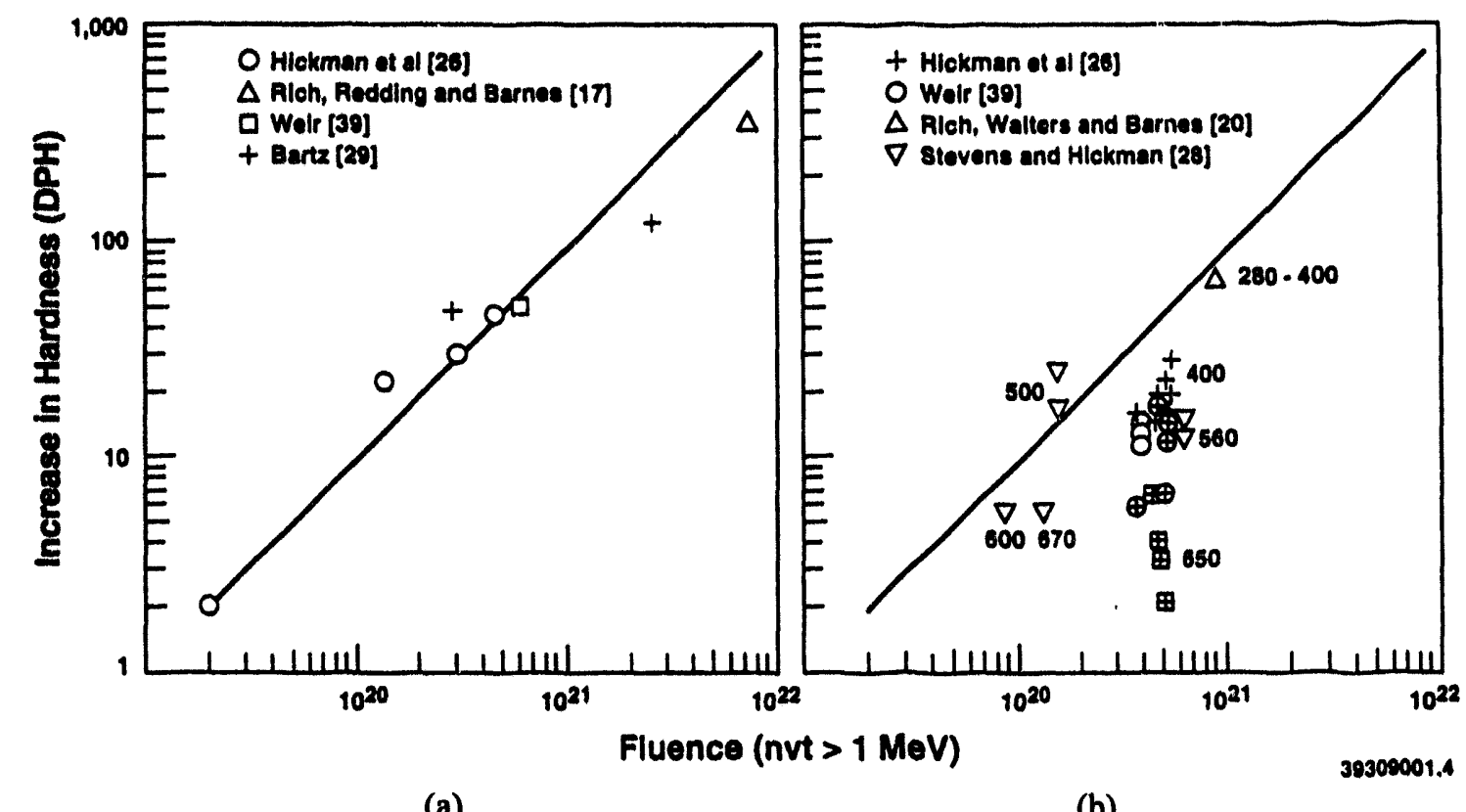

(a)

(b)

Fig. 4. Increase in hardness as a function of fluence for beryllium specimens (a) irradiated at 35 to $100^{\circ} \mathrm{C}$ and (b) irradiated at 280 to $650^{\circ} \mathrm{C}$.

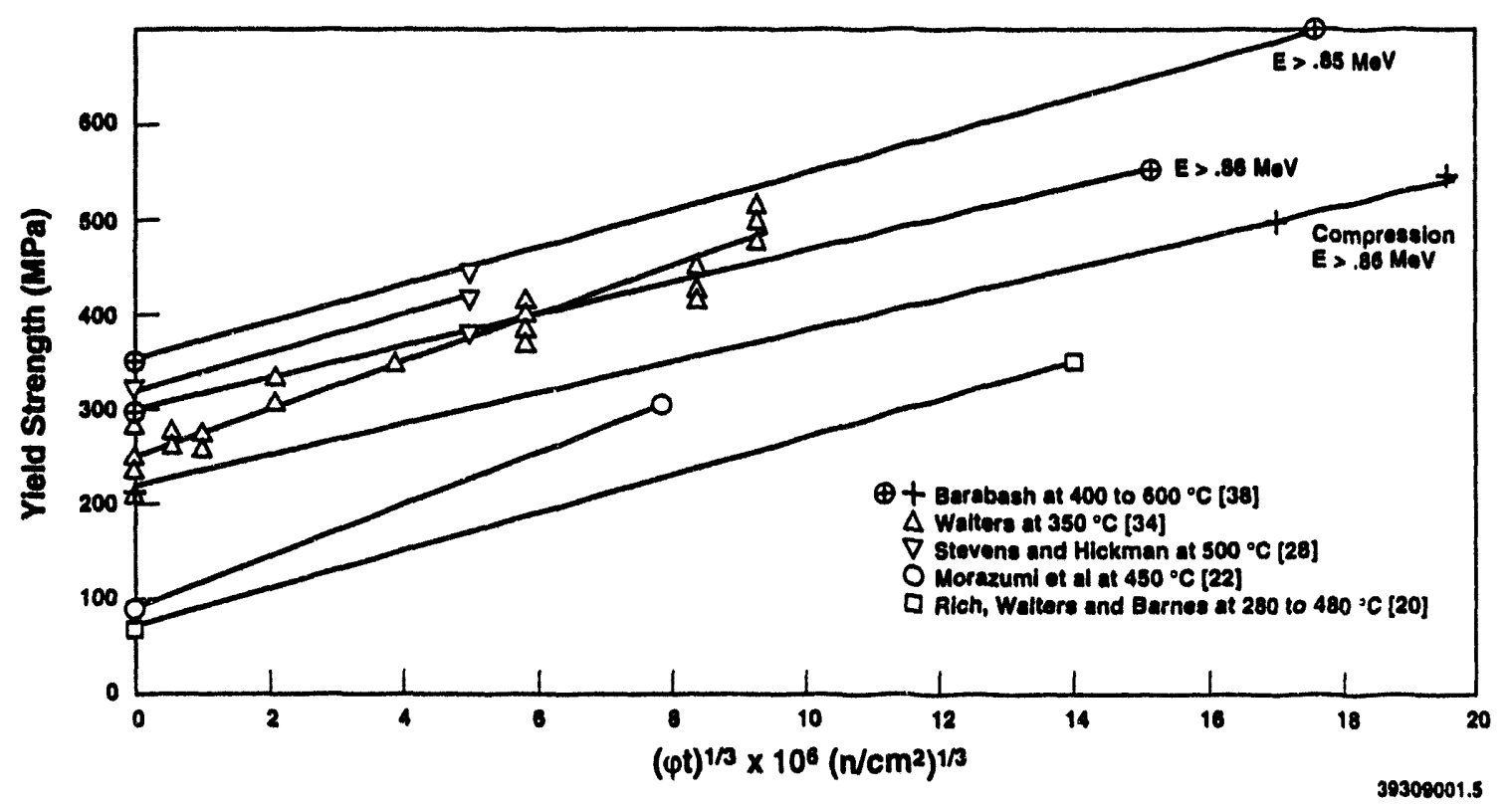

Fig. 5. Increase in yield strength as a function of fluence to the $1 / 3$ power for intermediate irradiation temperatures as per Walters. ${ }^{34}$ All measurements are in tension and for fluences of $\mathrm{E}>1 \mathrm{MeV}$ except where noted. 
At still higher temperatures, such as $650^{\circ} \mathrm{C}$ and above, the strength behavior is more complicated. About half the experiments indicate a strength increase, ${ }^{25,26,30}$ and the rest show a decrease. ${ }^{18,27,33,39}$ An explanation is provided in Figure 6, which shows an example of compressive yield strength at room temperature in beryllium specimens irradiated at $650^{\circ} \mathrm{C}$. $^{38}$ The strength is found to increase to a maximum at fluences on the order of $6 \times 10^{20} \mathrm{n} / \mathrm{cm}^{2}, E>0.85 \mathrm{MeV}$, and then to decrease to levels significantly lower than the unirradiated strength. This response would explain why, in Figure $4(b)$, the hardness values for several lower fluence, high temperature irradiation conditions appear near or on the trend line.

Concurrent with irradiation induced strengthening, reduction in ductility and embrittlement occurs. This was generally because ultimate tensile strength reduced with fluence, and therefore, the allowable plastic deformation was reduced. A number of examples are found in the literature where irradiation resulted in negligible ductility or complete embrittlement during bend testing ${ }^{16}$ and tensile testing. ${ }^{20,21,29,37,38}$ This included irradiations at temperatures of $100^{\circ} \mathrm{C}$ or below to fluences as low as $4 \times 10^{21} \mathrm{n} / \mathrm{cm}^{2},{ }^{17,20,29}$ irradiations at 280 to $400^{\circ} \mathrm{C}$ to fluences of $10^{21} \mathrm{n} / \mathrm{cm}^{2}, 20,37,38$ and irradiation at $650^{\circ} \mathrm{C}$ to $10^{21} \mathrm{n} / \mathrm{cm}^{2} .^{38}$ However, it is likely that in all cases, the sources of beryllium used older production techniques. No results on hot pressed powder products are reported showing completely brittle response.

Three reports have addressed the issue of fracture toughness degradation due to irradiation. ${ }^{40-42}$ However, the first two consider irradiation at liquid nitrogen temperature and are therefore not fusion relevant. Moderate reductions in fracture toughness were found in those cases following low fluence irradiation $\left(8 \times 10^{18}, 40\right.$ and $\left.7 \times 10^{17} \mathrm{n} / \mathrm{cm}^{2},{ }^{41}\right)$. They mainly serve to demonstrate the thermal activation nature of beryllium; testing at lower temperature gives lower fracture toughness values. A report by Beeston is more relevant. ${ }^{42}$ The material studied was nuclear-grade hot-pressed beryllium, including a porous product intended to expand understanding of porous material response, and irradiation was to fluences of 3.5 to

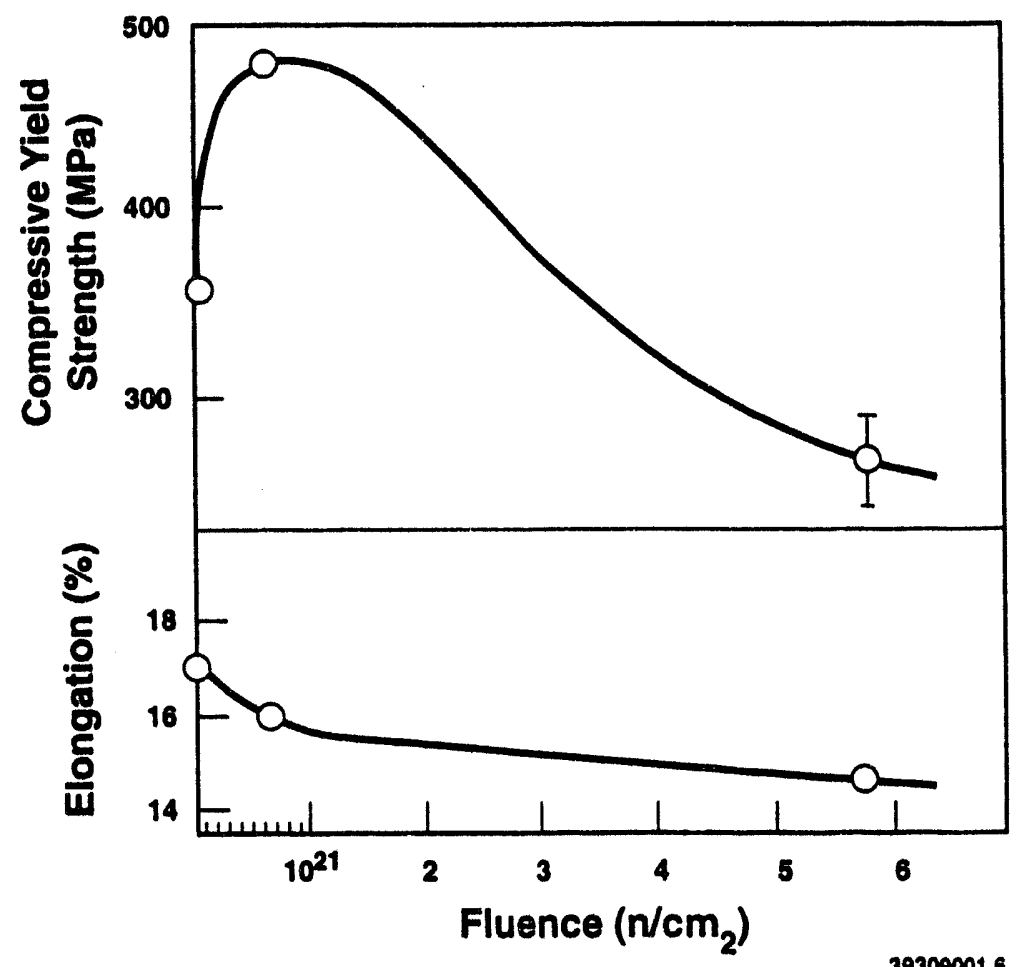

Fig. 6. Compressive strength and Elongation as a function of fluence $(E>0.85 \mathrm{MeV})$ for beryllium specimens irradiated at $650^{\circ} \mathrm{C} .^{38}$ 
$5.0 \times 10^{21} \mathrm{n} / \mathrm{cm}^{2}, \mathrm{E}>1 \mathrm{MeV}$ at $66^{\circ} \mathrm{C}$. The fracture toughness of solid beryllium was found to be reduced from $12.0 \mathrm{MPa} \mathrm{m} \mathrm{m}^{1 / 2}$ to $5 \mathrm{MPa}$ due to irradiation, and the fracture toughness of porous beryllium with a sightly higher unirradiated value of $13.1 \mathrm{MPa} \mathrm{m}^{1 / 2}$ was reduced to $4.2 \mathrm{MPa}$.

\section{Microstructural investigations}

A number of studies have included efforts to examine microstructural features to better understand irradiation phenomena in beryllium. These have included fractographic examinations to reveal bubbles on grain boundaries, transmission electron microscopy to reveal bubble distributions, and transmission electron microscopy to reveal dislocation loops and black spot damage. Early workers relied on either replica techniques, scanning microscopy, or even optical microscopy to show fracture initiation sites. ${ }^{17,20,25,26,28,30,33,39,44}$ Helium bubble investigations considered smaller bubble sizes by using transmission electron microscopy, ${ }^{10,16,20,23,37,45-48}$ and often employed annealing experiments to better understand bubble development. ${ }^{17,19,20,22,32,34,44-48}$ Several studies havenoted dislocation loop development as well. ${ }^{19,23,32,34,37,49-51}$

These microstructural investigations confirmed the different regimes of response as a function of temperature noted previously. At irradiation temperatures of $400^{\circ} \mathrm{C}$ and below, damage consisted of black spot or loop damage. ${ }^{19,23,32,34,37,45,47,49,50}$ Burgers vector analysis of the loop structure in irradiated beryllium, when attempted, gave different results. Following neutron irradiation at $350^{\circ} \mathrm{C}$ to $2 \times 10^{20}$ fast $\mathrm{n} / \mathrm{cm}^{2}$, dislocation loops 20 to $70 \mathrm{~nm}$ in diameter were generally found on $\{11 \overline{20}\}$ planes, but additional small numbers were also observed on $\{1010\},\{1101\}$, and $\{1122\}$ planes, and the Burgers vector responsible in these latter cases was expected to be $\frac{1}{3}<1123>{ }^{49}$ Following neutron irradiation to $4 \times 10^{21} \mathrm{n} / \mathrm{cm}^{2}, \mathrm{E}>$ $1 \mathrm{MeV}$, at $400^{\circ} \mathrm{C}$, a low density of ${ }_{3}^{\mathrm{a}}<1120>$ dislocation tangles and a high density of $\mathrm{c}<0002>$ loops, approximately $20 \mathrm{~nm}$ in diameter, were found.$^{37}$ Finally, following $1 \mathrm{MeV}$ electron irradiation at $100^{\circ} \mathrm{C}$ to a dose of $4 \mathrm{dpa}$, loops appeared to be close to end-on orientation near $\{11 \overline{20}\}$ planes, and therefore, a Burgers vector of ${ }_{3}^{a}<1120>$ was indicated. This probably means that the common Burgers vector for loops in irradiated beryllium is ${ }_{3}^{a}<1120>$, but loops with a $\vec{c}$ component do form at a slower rate.

At higher temperatures, the microstructural product of irradiation is mainly bubbles. Helium bubbles are observed at grain boundaries following irradiation in the temperature range 325 to $400^{\circ} \mathrm{C}$, ${ }^{16,37}$ and are reported on dislocations within grains following irradiation at 450 to $550{ }^{20,37,46,47}$ However, following irradiation at temperatures of $600^{\circ} \mathrm{C}$ and above, all investigators report bubbles, generally on grain boundaries. ${ }^{10,19,25,26,28,30,33,39,44,46,47}$ Many of the fractographic studies revealed that large bubbles located on grain boundaries were facetted. This was also noted for smaller cavities, ${ }^{37,46,47}$ but in general, bubbles were considered to be spherical.

Many studies included microstructural examinations following high temperature annealing treatments. ${ }^{17,19,20,22,23,32,34,44-18}$ The results reported can be summarized with three observations: bubbles formed on dislocations as a result of anneals in the temperature range 300 to $900^{\circ} \mathrm{C}, 20,39,45,46,48$ dislocation loops were annihilated following annealing in the temperature range 500 to $600^{\circ} \mathrm{C}, 9^{19,34,47,48}$ and only bubbles were present following anneals at $600^{\circ} \mathrm{C}$ and above. ${ }^{17,20,22,32,34,48}$ Also of note is an observation of Shiozawa and co-workers ${ }^{46,47}$ that bubbles attached to dislocation networks did not change size and distribution below $900^{\circ} \mathrm{C}$. Bubble growth under annealing conditions was presumed to occur only under dislocation and grain boundary sweeping conditions. However, this observation may only apply to annealing experiments; under neutron irradiation, helium atom migration was feasible.

\section{Composition optimization}

Three examples of composition optimization have been provided above. Beryllium fabrication is optimized by purification and refined grain size. Analysis of swelling response at high temperatures by 
Sernyaev ${ }^{7}$ showed that swelling is increased (when the $M$ parameter is increased) with decreasing oxygen content and with increasing grain size. Extruded materials with oxygen levels on the order of $3 \%$ and grain diameters between 10 and $20 \mu \mathrm{m}$ would be recommended to minimize swelling at high temperatures. Finally, comparison of swelling response at low temperatures ${ }^{11}$ showed that modern fine-grained isotropic materials provide greater swelling resistance than older, coarse grained, anisotropic material with high levels of impurity. All three optimizations indicated that modern fine-grained beryllium will be more serviceable for plasma protection than the materials on which early experiments were based.

\section{Health issues}

Use of beryllium is associated with a hazard to health. It has been reputed to be one of the most toxic elements known. However, the toxicity of beryllium metal and its oxide is usually manifested as a lung disease, resulting from inhaling the powder. ${ }^{52,53}$ Now known by the name berylliosis, the disease is understood to arise from inhaling powder particles of sufficient fineness $(<5 \mu \mathrm{m})$ to reach certain lung membranes where they can cause allergic reaction. Large amounts of particles can overwhelm the lungs and lead to respiratory failure. This response may occur relatively soon after excessive exposure, or after a latent period of several years, and the severity of response is variable from one person to another. In fact, other health risks from beryllium, such as cancer, are now discounted. ${ }^{33}$

Therefore, the use of beryllium, per se, in a fusion device does not constitute a hazard to health. Only inhaling significant quantities of fine powders of beryllium leads to berylliosis. It can be argued that the presence of tritium in a fusion device constitutes a much greater safety issue.

\section{Discussion}

The preceding description of neutron damage to beryllium indicates that beryllium components must be designed with care. Response is different as a function of irradiation temperature, and damage at low temperatures can lead to gross property changes following heating to higher temperatures. The basic mechanisms controlling behavior are displacement damage and gas production by transmutation. Response can best be divided into four regimes of temperature: (1) low temperature $(<R T)$ response where point defects are created, but mobility is so low that coalescence is rare, (2) somewhat higher temperatures (RT to $300^{\circ} \mathrm{C}$ ), where point defects are mobile, but gas atoms are practically immobile, (3) still higher temperatures $\left(300\right.$ to $\left.600^{\circ} \mathrm{C}\right)$, where gas atoms become mobile, and (4) very high temperatures where gas pressure driven swelling becomes dominant $\left(>600^{\circ} \mathrm{C}\right)$. The lowest temperature regime has been ignored in this report.

Microstructural evolution in these temperature regimes is as follows. At temperatures from room temperature to $300^{\circ} \mathrm{C}$ where point defects are mobile but gas atoms are not, point defects coalesce into dislocation loops, and the loops grow and evolve into a complex dislocation network with basal and nonbasal Burgers vectors represented. Gas atoms become trapped in the microstructure. Therefore, at these temperatures, beryllium swells at a modest rate, and hardens, which leads to embrittlement. Growth (change in shape under irradiation) can also be anticipated. At temperatures from 300 to $600^{\circ} \mathrm{r}$. where gas atoms become mobile, gas bubbles form, most visibly on grain boundaries, but they are also probably present on dislocations. The accumulation of helium at bubbles is probably by a mechanism similar to solute segregation, in which impurity atoms are dragged to point defect sinks by interaction with moving point defects. Swelling and mechanical property degradation occur at somewhat different rates in this temperature range than at lower temperatures. At temperatures over $600^{\circ} \mathrm{C}$ where gas bubbles can come into thermal equilibrium, bubbles grow in response to internal pressurization, leading to enhanced swelling and the creation of very large bubbles on grain boundaries. These large bubbles provide crack nucleation sites resulting in embrittlement without significant increases in strength. 
Mechanical property degradation can be severe. Examples are provided showing complete ductility loss in beryllium following irradiation to doses on the order of $10^{21} \mathrm{n} / \mathrm{cm}^{2}$. However, it is apparent that large variations in response are possible, depending on fabrication procedures and the resultant product form. Results on more modern materials prepared by powder processing and hot pressing show acceptable ductility and fracture toughness, or lower swelling, and even porous beryllium made in this way gives acceptable ductility and toughness. ${ }^{31,42}$ Therefore, it appears that the disappointing results obtained during beryllium fuel cladding development efforts can be mitigated by improved fabrication procedures.

Given the significant property degradation of beryllium under neutron irradiation, it may be necessary to design blanket and first wall areas so that beryllium components are not required to provide structural support. For example, beryllium can be encapsulated in the blanket and can be replaced by plasma spraying procedures on the first wall. The divertor design my pose greater problems.

However, it must be emphasized that available database information is extremely limited with regard to material produced by modern methods. Also, all irradiation tests have been performed using fission reactors where the major transmutation response is defined by equation (2). As a consequence, effects of lithium and tritium production are overemphasized, and the effects of helium production are somewhat reduced in comparison with the fusion condition where large numbers of neutrons have energies above $2.7 \mathrm{MeV}$, and therefore equation (1) applies. A more complete database is required, using prototypic materials irradiated at high temperatures appropriate for divertor applications. Also, high energy neutron irradiation is needed.

\section{CONCLUSIONS}

This review of neutron irradiation effects to beryllium demonstrates that beryllium is degraded by radiation damage both as a result of displacement damage and of transmutation. Swelling and embrittlement are significant with complex temperature dependencies. Degradation in the properties of beryllium can be expected to be of concern for divertor applications, may lead to thermal conductivity changes at high swelling levels in blanket applications, and may contribute to flaking of beryllium first wall coatings. However, more modern fabrication techniques provide materials with greater radiation resistance, and there is cause for hope that modern materials will have sufficient radiation resistance to allow components to operate to fluences on the order of $6 \times 10^{22} \mathrm{n} / \mathrm{cm}^{2}, \mathrm{E}=1 \mathrm{MeV}$ or higher.

A much more complete testing program, including high energy neutron irradiation, is required to qualify these newer materials for fusion applications and to determine lifetime limits.

\section{FUTURE WORK}

This effort is completed.

\section{REFERENCES}

1. P. R. Thomas and the JET Team, 9th International Conference on Plasma Surface Interactions and Controlled Fusion Devices, JET-P (90) 41,1.

2. M. F. Smith and A. W. Mullendore, J. Nucl. Mater., 122 \& 123 (1984) 855. 
3. W. G. Wolfer and T. J. McCarville, Fusion Tech., 8 (1985) 1157.

4. J. B. Mitchell, J. Fusion Energy, 5 (1986) 327.

5. K. L. Wilson, R. A. Causey, W. L. Hsu, B. E. Mills, M. F. Smith and J. B. Whitley, J. Vac. Sci. Technol. A, 8 (1990) 1750.

6. V. P. Gol'tsev, G. A. Sernyaev and Z. I. Chechetkina, Radiatsionnoe Materialovedenie Berilliya, Minsk: Nauka i Tekhnika (1977) 38.

7. G. A. Sernyaev, "Swelling of Beryllium in a Mode of High-Temperature Neutron Irradiation," Voprosy Atomnoi Nauki i Tekniki. No 2 (56), (1991) 16, PNL-TR-488.

8. L. Sannen and Ch. De Raedt, "The Effects of Neutron Irradiation on Beryllium," presented at 17th Symposium on Fusion Technology, Rome Sept. 14-18, 1992.

9. E. Koonen, in Proceedings of the International Symposium on Research Reactor Safety, Operations and Modification, AECL-9926, Vol. 3 (1990) 737.

10. V. N. Burmistrov, Yu. D. Goncharenko, V. A. Kazakov, O. Yu. Shvedov, V. A. Gorokhov, and I. B. Kupriyanov, "Certain Aspects of the Radiation Stability of Beryllium with Application to Synthesis Reactor Conditions from Results of Tests in a Fission Reactor," presented at the Second International Conference on Effects of Irradiation on Materials for Fusion Reactors, held September 21-24, 1992 in St. Petersburg, Russia, PNL-TR-487.

11. M. Dalle Donne, F. Scaffidi-Argentina, C. Ferrero and C. Ronchi, "Modelling of Swelling and Tritium Release in Irradiated Beryllium," proceeding of ICFRM-6.

12. G. A. Sernyaev, "Some Physical Properties of Beryllium as a Material for Neutron Multiplier," in Modular Variant of ITER Ceramic Bianket (ITER, Garching, July 1990).

13. J. M. Beeston, "Properties of Irradiated Beryllium: Statistical Evaluation, EG\&G Idaho Report TREE-1063 (1976).

14. E. Koonen, "Study of Irradiation Effects and Swelling of Irradiated Beryllium," CEN/SCK Report, Reactor Safety Analysis BR2 Department (1989). (See also')

15. J. M. Beeston, G. R. Longhurst, L. G. Miller and R. A. Causey, "Gas Retention in Irradiated Beryllium," EGG-FSP-9125 (1990).

16. J. M. Beeston, L. G. Miller, E. L. Wood, Jr., and R. W. Moir, J. Nucl. Mater. 122 \& 123 (1984) 802.

17. J. B. Rich, G. B. Redding and R. S. Barnes, J. Nucl. Mater. 1 (1959) 96.

18. B. S. Hickman, in The Metallurgy of Beryllium, Itst of Metals Monograph No. 28 (Institute of Metals, London, 1961) 410.

19. J. B. Rich and G. P. Walters, in The Metallurgy of Beryllium, Inst of Metals Monograph No. 28 (Institute of Metals, London, 1961) 362. 
20. J. B. Rich, G. P. Walters and R. S. Barnes, J. Nucl. Mater., 4 (1961) 287.

21. C. E. Ells and E. C. W. Perryman, J. Nucl. Mater., 1 (1959) 73.

22. S. Morozumi, S. Goto and M. Kinno, J. Nucl. Mater., 68 (1977) 82.

23. G. A. Sernyaev, "The Formation of Helium Bubbles and Energy Phenomena in Beryllium," Voprosy Atomnoi Nauki i Tekniki, No 2 (56), (1991) 82, PNL-TR-490.

24. D. McLean in Conference Internationale sur la Metallurgie du Beryllium (Presses Universitaires de France, Grenoble, 1965) 3.

25. B. S. Hickman, G. Bannister, J. H. Chute, J. G. McCracken, R. Smith and J. C. Bell, "Irradiation of Beryllium at Elevated Temperatures," TRG Report 540, UKAEA, 1963.

26. B. S. Hickman and G. Bannister, "Irradiation of Beryllium at Elevated Temperatures," Part II, AAEC/E-115, 1963, also issued as TRG Report 532.

27. B. S. Hickman and G. T. Stevens, "The Effect of Neutron Irradiation on the Mechanical Properties of Irradiation of Beryllium at Elevated Temperatures," Part II, AAEC/E-115, 1963, also issued as TRG Report 532.

28. G.T. Stevens and B. S. Hickman, "Effect of Irradiation on the Mechanical Properties of Beryllium Metal," AAEC/E-133, 1965.

29. M. H. Bartz, in Proceedings of the 2nd United Nations International Conference on the Peaceful Uses of Atomic Energy, Vol. 5 (United Nations, Geneva 1958) 466.

30. J. M. Beeston, in Effects of Radiation on Structural Materials, ASTM STP 426, (ASTM, Philadelphia PA, 1967) 135.

31. J. M. Beeston, G. R. Longhurst, R. S. Wallace and A. P. Abeln, J. Nucl. Mater., 195 (1992) 102.

32. J. M. Beeston, M. R. Martin, C. R. Brinkman, G. E. Korth and W. C. Francis, in Symposium on Materials Performance in Operating Nuclear Systems, M. S. Wechsler and W. H. Smith, Eds., CONF730801, 1973, 59.

33. E. D. Hyam and G. Sumner, in Radiation Damage in Solids, I (IAEA, Vienna, 1962) 323.

34. G. P. Walters, J. Less Common Metals, 11 (1966) 77. (Earlier version in Conference on the Physical Metallurgy of Beryllium, Gatlinburg, 1963, CONF-170, 138.)

35. E. H. Smith, J. L. Liebenthal, B. V. Winkel, J. M. Beeston and W. C. Francis, in Symposium on Materials Performance in Operating Nuclear Systems, M. S. Wechsler and W. H. Smith, Eds., CONF730801, 1973, 41.

36. J. M. Beeston, Nucl. Engineering and Design, 14 (1970) 445.

37. D. S. Gelles and H. L. Heinisch, J. Nucl. Mater. 191-194 (1992) 194. 
38. V. Barabash, "Brief Review of Be Study for Plasma Facing Component in RF for ITER Reactor," presented at the US/RF Exchange Meeting, September 17-19, 1992 in St. Petersburg, Russia.

39. J. R. Weir, in The Metallurgy of Beryllium, Inst of Metals Monograph No. 28 (Institute of Metals, London, 1961) 395 .

40. D. L. Harrod, T. F. Hengstenberg and M. J. Manjoine, J. Mater. 4 (1969) 618.

41. R. L. Kesterson, Trans. Amer. Nucl. Soc., 14 (1971) 607.

42. J. M. Beeston, in Effects of Radiation on Structural Materials, ASTM STP 683, (ASTM, Philadelphia PA, 1979) 309.

43. B. S. Hickman, in Studies in Radiation Effects, Series A, Vol. 1, G. J. Dienes, Ed. (Gordon \& Breach Science Publishers, Inc., N.Y., 1966) 72.

44. R. Sumerling and E. D. Hyam, in The Metallurgy of Beryllium, Inst of Metals Monograph No. 28 (Institute of Metals, London, 1961) 381.

45. R. S. Barnes in The Metallurgy of Beryllium, Inst of Metals Monograph No. 28 (Institute of Metals, London, 1961) 372.

46. Y. Mishima, S. Ishino and S. Shiozawa, in Beryllium 1977, (The Royal Society, London, 1977) 25/1.

47. S. Shiozawa, thesis, "the Electron Microscopic Studies on the Irradiated and Deformed HexagonalClose-Packed Metals, University of Tokyo, 1977.

48. R. Nagasaki, S. Ohashi, S, Kawasaki, Y Karita and N Tsuno, J. Nucl. Sci. Tech., 8 (1981) 546.

49. G. P. Walters, C. M. Van Der Walt and M. J. Makin, J. Nucl. Mater., 11 (1964) 335. (Earlier version in Conference on the Physical Metallurgy of Beryllium, Gatlinburg, 1963, CONF-170, 126.)

50. G. J. C. Carpenter and R. G. Fleck, in Beryllium 1977, (The Royal Society, London, 1977) 26/1.

51. R. G. Fleck, in Effects of Radiation on Materials, ASTM STP 782, (ASTM, Philadelphia PA, 1982) 735.

52. W. Jones Williams, in Beryllium 1977, (The Royal Society, London, 1977) 47/1.

53. O. P. Preuss, Fusion Tech. $\underline{8}$ (1985) 1137. 
POSTIRRADIATION EXAMINATION OF BEATRIX-II, PHASE I - O. D. Slagle ${ }^{1}$, T. Takahashi ${ }^{2}$, F. D. Hobbs ${ }^{1}$, K. Noda ${ }^{2}$, D. L. Baldwin 1, G. W. Hollenberg ${ }^{1}$ and R. A. Verrall ${ }^{3}$

1 Pacific Northwest Laboratory", Richland, Washington, USA

2 Japan Atomic Energy Research Institute, Tokai-mura, Ibaraki-Ken, Japan

${ }^{3}$ AECL Research, Chalk River Laboratories, Chalk River, Ontario, Canada

\section{OBJECTIVE}

The objective of this work is to carry out the postirradiation examination of the BEATRIX-II, Phase I vented canisters.

\section{SUMMARY}

BEATRIX-II is an in situ tritium recovery experiment that was designed to characterize the behavior of lithium ceramics irradiated to high burnup in a fast neutron flux. Postirradiation examination was carried out on the Phase I vented canisters: one containing a $\mathrm{Li}_{2} \mathrm{O}$ ring capable of temperature changes and the other a $\mathrm{Li}_{2} \mathrm{O}$ solid specimen with a center temperature of $1000^{\circ} \mathrm{C}$.

The tritium inventory of the ring specimen at $650^{\circ} \mathrm{C}$ was determined to be in the range from $0.2-0.6$ wppm while for the solid specimen the inventory varied from $1.4 \mathrm{wppm}$ at the surface to $0.06 \mathrm{wppm}$ at the inner surface. Downstream transport of the $\mathrm{Li}_{2} \mathrm{O}$ by the sweep gas was determined to be insignificant from analyses of acid rinses of selected canister surfaces. Densification and restructuring of the solid specimen during irradiation resulted in the development of a central annulus. Ceramography was used to characterize the columnar grain structure and the mechanisms involved in its evolution.

\section{PROGRESS AND STATUS}

\section{Introduction}

BEATRIX-II is an IEA sponsored experiment with emphasis on tritium recovery from lithium ceramic materials irradiated in a fast neutron reactor(FFTF) that simulates the environment of a fusion blanket. The participants are Japan, Canada, and the U.S. The in situ tritium recovery experiments provided data on the performance of $\mathrm{Li}_{2} \mathrm{O}$ and $\mathrm{Li}_{2} \mathrm{ZrO}_{3}$ under irradiation conditions covering a range of sweep gas compositions and temperatures. The experiment consisted of two separate irradiation cycles which included two vented tritium recovery canisters each. Phase I started in January 1990 and operated for 300 Effective Full Power Days (EFPD) while Phase II started in May 1991 and operated for 200 EFPD of irradiation. Both Phase I and II resulted in lithium burnups of 5\%. In addition to the vented canisters, BEATRIX-II also included nonvented canisters to provide data on irradiation damage in $\mathrm{Li}_{2} \mathrm{O}$ single crystals and the compatibility of lithium ceramics and beryllium in a fast neutron environment.

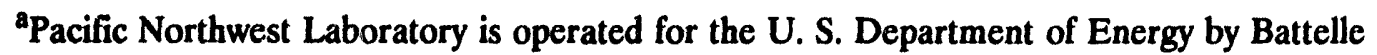
Memorial Institute under Contract DE-ACO6-76RLO 1830. 
Postirradiation examination of the irradiated lithium ceramics is being carried out to evaluate their physical and chemical stability during irradiation and to determine the final tritium inventory. This final inventory establishes a baseline for determining the tritium inventory for various testing temperatures and sweep gas compositions. This paper presents the results of the postirradiation examination of the Phase I vented-canister $\mathrm{Li}_{2} \mathrm{O}$ specimens. The results of a spectroscopic study of the $\mathrm{Li}_{2} \mathrm{O}$ single crystals irradiated in Phase $\mathrm{I}$ are presented in another paper elsewhere [1]. Postirradiation examination of the $\mathrm{Phase} \mathrm{II}, \mathrm{Li}_{2} \mathrm{O}$ and $\mathrm{Li}_{2} \mathrm{ZrO}_{3}$ vented canisters is underway.

\section{Backoround}

The design and operation of the BEATRIX-II, Phase I in situ tritium recovery experiment has been described previously [2-5]. Phase I of the experiment involved two $\mathrm{Li}_{2} \mathrm{O}$ specimens with initial ${ }^{6} \mathrm{Li}$ enrichments of 61 at\% irradiated to lithium burnup exceeding $4 \%$. The ring specimen capable of temperature changes was $1.85 \mathrm{~cm}$ in diameter with a wall thickness of $1.5 \mathrm{~mm}$ and operated in the temperature range from 510 to $650^{\circ} \mathrm{C}$. The temperature-gradient solid specimen was $1.75 \mathrm{~cm}$ in diameter with a range of temperatures from 430 to $1000^{\circ} \mathrm{C}$.

The chemical and physical integrity of the specimen is expected to be influenced by the temperature and sweep gas compositions under which the material operated. In addition to temperature changes during startup/shutdown the ring specimen was subjected to a number of temperature transients on the order of 50 or $100^{\circ} \mathrm{C}$ which were incurred over times less than 15 seconds. The primary sweep gas used in the experiment was $\mathrm{He}-0.1 \% \mathrm{H}_{2}$; but $\mathrm{He}, \mathrm{He}-0.01 \% \mathrm{H}_{2}$, and $\mathrm{He}-1.0 \% \mathrm{H}_{2}$ were also used at times to evaluate the effect of hydrogen content on the tritium recovery behavior.

The experiment was terminated by a controlled "scram" or rapid decrease in reactor power. The reactor shut down occurred over 2 minutes time and is expected to have contributed on the order of a minute of generation rate to the tritium inventory of the specimens or $0.02 \mathrm{wppm}$. The microstructures of the specimens are expected to have changed very little during shut down.

\section{Experimental Results}

\section{Neutron Radiography}

After removal from the irradiation test vehicle and prior to disassembly, the two vented canisters were neutron radiographed. The radiographs indicated that both specimens were intact and that the initial specimen geometry had been maintained throughout the experiment. The ring specimen was observed to contain a number of cracks which could have occurred during the startup/shutdown thermal transients. In spite of the cracking, the cylindrical geometry and positioning of the ring specimen in the canister was maintained by the inner nickel screen. In the inlet gas plenum, located beneath the ring specimen, a region of neutron absorbing residue was found which appeared to be $\mathrm{Li}_{2} \mathrm{O}$. This residue will be discussed later. Because of the large diameter of the solid specimen, only the outer edges of the specimen were resolvable. The downstream boundary/edge of the solid specimen was intact and there appeared to be no discernable downstream transport of the specimen by the sweep gas.

\section{Capsule Disassembly}

The capsules were disassembled by slitting the outer canister lengthwise so that the cladding could be separated. The ring specimen was found to be fragmented into pieces of a nominal size of one $\mathrm{cm}^{2}$. There was no particular crack pattern. The eleven individual pellets in the solid specimen stack had interdiffused during irradiation and the interfaces between pellets were no longer discernable. The 
solid specimen was also found to be tightly bonded to the capsule walls and removal of the pellets left a layer of the specimen material on the capsule wall. In general, the solid specimen was fragmented into radial sections although the axial center portion of the specimen was an intact cylinder. This center portion had initially consisted of three solid cylindrical pellets but after irradiation a center void or annulus was found to have been formed throughout this section. This center annulus had a diameter which was in the range of 0.38 to $0.45 \mathrm{~cm}$. For a $1.7 \mathrm{~cm}$ diameter pellet, these diameters represent $5.7 \%$ of the volume. The center pellets were initially 86,87 and $92 \% \mathrm{TD}$. It is hypothesized that the center void was a result of additional pellet densification.

The sweep gas plenums on either end of the capsules were found to have a black "shiny" deposit on the surfaces that was thought to be vapor-transported $\mathrm{Li}_{2} \mathrm{O}$. The capsule components were acidwashed and the resulting solutions were found to contain lithium. The total weight of the deposit in the top and bottom gas plenums of the solid specimen was equivalent to $1.0 \times 10^{-3} \%$ and $0.4 \times 10^{-3} \%$ of the total specimen weight for the top and bottom, respectively. Thus the material transported out of the solid specimen region by the sweep gas was only a negligible percentage of the total specimen weight. For the ring specimen the equivalent weight of the deposit was the same for both the top and the bottom: $3.5 \times 10^{-3} \%$ of the total sample weight. The amount of material found in the bottom end cap or inlet gas plenum of the ring specimen was much smaller than expected based on the extent of the dark area seen in the neutron radiograph. During disassembly a black powder was observed to fall from the capsule. Unfortunately it was not possible to capture and quantify the amount of this material. This observation suggests that the residue seen in the radiograph was material which had physically fallen off the inner wall of the ring specimen and collected in the lower plenum area as opposed to vapor-deposited material.

\section{Microstructural Characterization}

On a macroscopic scale the postirradiation condition of the ring specimen was not noticeably different from the preirradiation condition. The thickness of the ring was found to have increased approximately $10 \%$ from its original thickness of $1.5 \mathrm{~mm}$. The associated density decrease from the initial density of 80\% TD was also evident in the scanning electron microscopy observations of the preand postirradiation specimens. The grain size of the material was observed to have increased from 5 to $10 \mu \mathrm{m}$ during irradiation.

The irradiated solid specimen was significantly different from the pre-irradiated specimen. In addition to the formation of a center annulus in the initially solid pellets, the occurrence of a large grain microstructure was visually apparent. An intact pellet from a location just below the center of the solid specimen was chosen for ceramography. This pellet had an initial density of $86 \%$ TD and developed a $0.45 \mathrm{~cm}$ diameter center annulus during irradiation. The resulting composite photomicrograph is shown in Figure 1. The microstructure of the solid specimen shown in Figure 1 exhibits classic columnar grain growth in a temperature gradient and is very similar to microstructures observed in fast reactor fuel elements [6]. This microstructure is characterized by a succession of regions starting at the outer surface: 1) as-fabricated structure with grain sizes in the range of 25$40 \mu \mathrm{m}$; 2) equiaxed grain region with grains on the order of $100 \mu \mathrm{m}$; and 3) columnar grain regions with grains sizes on the order of $200 \mu \mathrm{m}$ wide and $1500 \mu \mathrm{m}$ long. The formation of this type of microstructure in fission type fuels has been attributed to the formation and migration of lenticular pores up a steep temperature gradient. The equiaxed region is characterized by the formation of larger grains and lenticular shaped pores which are oriented perpendicular to the radius or thermal gradient. As the temperature increases these lenticular pores become sufficiently mobile to migrate up the temperature gradient. This pore migration sweeps out porosity in the path of the lenticular pore and enlarges the grain behind it, leading to the formation of large columnar grains parallel to the radius. In the columnar grain region of Figure 1, lenticular pores can be found at the high 
temperature end of the columnar grains. In fast reactor fuels the formation and movement of the lenticular shaped pores has been attributed a vapor-transport mechanism from the hot to cold side of the pore. The obvious similarity of the microstructure of the postirradiated BEATRIX-II solid specimen to fast reactor fuel provides strong evidence that the migration of the lenticular pores up the thermal gradient by a vapor-transport method plays a major role in the formation of the columnar grains in the BEATRIX-II solid specimen. This migration of the pores to the center of the solid specimen during irradiation also contributes to the formation of a center annulus.

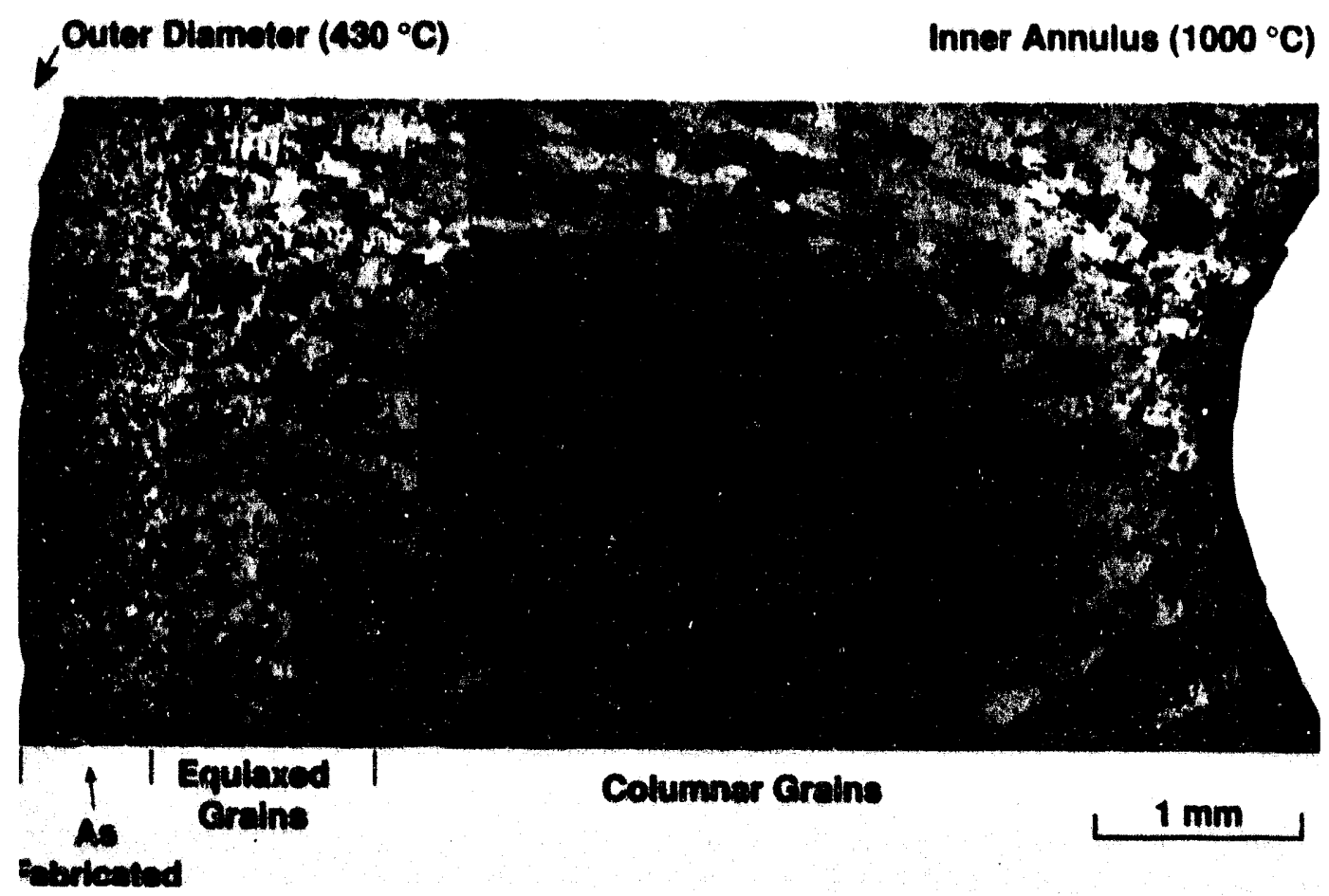

Figure 1. Microstructure of Radial Cross Section of the BEATRIX-II Solid Specimen

\section{Tritium Inventory}

Measurements of the retained tritium in selected sections of the ring and solid specimens were used to characterize the tritium inventory at the time of shutdown. As noted above, the experiment was terminated by a rapid decrease in reactor power that was expected to limit the increase in the tritium inventory to less than 0.02 wppm.

Measurement of the tritium inventory along the length of the ring specimen was carried out for four different axial locations. The results are given in Table 1. The top and bottom sections represented material within one $\mathrm{cm}$ from the end since the selected section contained end surfaces. Upper and lower center are only approximate locations. The analysis was done by melting the selected sections and determining the tritium released using a variation from the method described previously [7]. The present analysis used a gas sweep rather than evacuation for obtaining the gas sample. The measured tritium inventory increased smoothly from the bottom to top of the specimen. The top and bottom of the specimen are different in two aspects: the specimen temperature and the tritium concentration in the sweep gas. Because the specimen is located at the bottom of the reactor, the neutron flux 
decreases from top to bottom so that the top of the specimen is expected to be as much as $30^{\circ} \mathrm{C}$ hotter than the bottom. However, inreactor observations [2-4] have indicated that higher temperatures result in a lower tritium inventory which is contrary to the results in Table 1. Alternatively, the sweep gas flow is from the bottom to the top so that at the top of the specimen the sweep gas contains a higher partial pressure of HTO/HT. This higher partial pressure would tend to decrease the tritium recovery rate and therefore is one possible explanation for the increase in tritium inventory with axial position.

Table 1. Axial Distribution of the Tritium Inventory in the Ring Specimen

\begin{tabular}{|l|c|}
\hline \multicolumn{1}{|c|}{ Axial Position } & $\begin{array}{c}\text { Tritium Inventory } \\
\text { (wppm) }\end{array}$ \\
\hline Top & 0.61 \\
\hline Upper Center & 0.44 \\
\hline Lower Center & 0.26 \\
\hline Bottom & 0.23 \\
\hline
\end{tabular}

The radial variation of the tritium inventory in the solid specimen was determined by radially sectioning the specimen into five sections and determining the tritium retention by melting as above [6]. The pellet chosen for this analysis was the same one used in the microstructure characterization (Figure 1). The measured tritium inventories are listed in Table 2 along with the outer and inner radii of the section analyzed. Calculated temperatures were determined by proportionally increasing the original calculated radial thermal profile for the preirradiated specimen to fit the thermocouple measurements for the inner radius of the specimen. Measured centerline temperatures varied from 950 to $1030 \mathrm{C}$ compared to a calculated temperature at the radius of the center annulus of $910^{\circ} \mathrm{C}$. The temperature at the center annulus was chosen to be $1000^{\circ} \mathrm{C}$.

Table 2. Radial Distribution of the Tritium Inventory in the Solid Specimen Compared to Extrapolated Inventories for the Ring Specimen

\begin{tabular}{|c|c|c|c|c|}
\hline $\begin{array}{c}\text { Specimen } \\
\text { No. }\end{array}$ & $\begin{array}{c}\text { Radial } \\
\text { Position }\left(r / r_{0}\right)\end{array}$ & $\begin{array}{c}\text { Temperature } \\
\text { Calculated } \\
\left(\mathbf{C}^{\circ}\right)\end{array}$ & $\begin{array}{c}\text { Tritium } \\
\text { Inventory } \\
(\text { wppm })\end{array}$ & $\begin{array}{c}\text { Predicted } \\
\text { Inventory } \\
(\text { wppm })\end{array}$ \\
\hline 1 & $0.964-0.916$ & $467-514$ & 1.44 & $1.49-0.93$ \\
\hline 2 & $0.898-0.776$ & $532-649$ & 0.056 & $0.79-0.31$ \\
\hline 3 & $0.758-0.636$ & $665-772$ & 0.063 & $0.28-0.15$ \\
\hline 4 & $0.618-0.496$ & $787-876$ & 0.069 & $0.14-0.09$ \\
\hline 5 & $0.478-0.269$ & $886-1000$ & 0.062 & $0.09-0.05$ \\
\hline
\end{tabular}


Although there is considerable uncertainty in the radial position and the corresponding temperature, the data in Table 2 clearly indicate that the tritium inventory decreases rapidly as the temperature increases and appears to reach a minimum at sample $\# 2$ before increasing slightly as the temperature increases. This type behavior has been predicted by Billone et al. [8]. The decrease in inventory with increasing temperature in the outer regions of the specimen is associated diffusional/desorption release mechanisms while the increase in inventory at the higher temperature is associated with an increased solubility of tritium in $\mathrm{Li}_{2} \mathrm{O}$.

Axial measurement of the tritium retained in the outer surface of the solid specimen was carried out by dissolving four different axial segments of the material adhered to the cladding during disassembly. The resulting solutions were analyzed for tritium and lithium to determine the tritium inventories which ranged from 0.7 to $1.4 \mathrm{wppm}$. There was no consistent trend of the data with axial position and the range in data is consistent with the expected uncertainties in the measurement procedures. From the identifiable uncertainties in the data, the measured inventories are expected to represent lower limits on the tritium inventory in the outer region of the solid specimen. It was thought that the tritium inventory would increase at the outer edge of the specimen as a result of the lower temperature; however, because of the uncertainties, the radial dependence of the inventory near the outer edge of the solid specimen remains undefined.

\section{Discussion}

A comparison of the tritium inventories for the ring and solid specimen requires information on inventories at the same temperature. Because of the extensive database available for the operation of the ring specimen, it is possible to develop an empirical temperature relationship for the inventory of ring specimen. The tritium inventory has an inverse relationship to the controlling mechanisms for tritium release which are typically lattice/grain boundary diffusion and adsorption/desorption processes at the surface $[9,10]$. These release mechanisms are controlled by one or more processes with Arrhenius type temperature dependencies. As a first approximation the inventory (I) will be described by an inverse Arrhenius temperature $(T)$ dependence:

$$
(1 / \mathrm{I})=\left(1 / \mathrm{I}_{\mathrm{o}}\right) \exp (-\mathrm{Q} / \mathrm{RT})
$$

Evaluation of $I_{0}$ and the effective activation energy (Q) was carried out by analyzing a series of temperature transients carried out on the ring specimen just prior to shutdown. The temperature change series of $630-530-630^{\circ} \mathrm{C}$ was used to determine an inventory change of $0.43 \mathrm{wppm}$ for the temperature change of 530 to $630^{\circ} \mathrm{C}$. This inventory change together with the average of the inventories in Table 1 was used to determine $I_{0}=5.6 \times 10^{-4} \mathrm{wppm}$ and $Q=48 \mathrm{~kJ} / \mathrm{mol}$.

The empirical relationship for the inventory (Eqn 1) was used to calculate tritium inventories at the respective solid specimen temperatures listed in Table 2 . For the solid specimen sample \#1, the range of the predicted ring specimen inventories includes the measured inventory. The remaining four samples of the solid specimen had inventories that are much lower than predicted by the extrapolation of the ring specimen inventory. The reason for this large discrepancy may be related to the difference in microstructure between the ring and the inner regions of the solid. By comparing the radial position in the solid specimen listed in Table 2 with the microstructure in Figure 1, we find that sample \#1 is located in the as-fabricated region, sample \#2 is located primarily in the equiaxed grain region and samples 3-5 are in the columnar grain region. It appears as if the low tritium inventories are associated with the large grain size and high density of the restructured region of the solid specimen. 
Comparison of the final tritium inventory (0.2-0.6 wppm) for the ring specimen with similar experiments on $\mathrm{Li}_{2} \mathrm{O}$ is complicated because of the many variables which affect the final inventory. The shutdown conditions for BEATRIX-II were an average specimen temperature of $630^{\circ} \mathrm{C}$ and a helium sweep gas with $0.1 \% \mathrm{H}_{2}$. Lower temperatures and lower hydrogen concentrations in the sweep gas were found to result in higher inventories [2-5]. CRITIC-I [11] had final average inventories of 1 wppm for a temperature of $600^{\circ} \mathrm{C}$ and a final sweep gas of $\mathrm{He}-0.01 \% \mathrm{H}_{2}$. Both the lower temperature and lower hydrogen concentration favor the slightly higher inventory. The VOM experiment on $\mathrm{Li}_{2} \mathrm{O}$ pellets [12] had final inventories in the range of $0.5-0.9 \mathrm{wppm}$ after operation at $740^{\circ} \mathrm{C}$ in a helium sweep gas. The higher temperature favors a lower inventory, but this could easily be offset by the higher inventory expected for a helium sweep gas. This comparison suggests that, within the expected range of experimental parameters, the final inventories of these three experiments are in agreement.

\section{CONCLUSIONS}

Operation of the BEATRIX-II experiment provided an extensive data base on the tritium recovery from $\mathrm{Li}_{2} \mathrm{O}$ in a fast neutron environment. The $\mathrm{Li}_{2} \mathrm{O}$ in Phase $\mathrm{I}$ of the experiment was irradiated to lithium burnups in excess of $4 \%$ while operating at temperatures from 400 to $1000^{\circ} \mathrm{C}$ in helium sweep gases with additions of 0 to $0.1 \% \mathrm{H}_{2}$. Postirradiation examination of the specimens indicated that the material underwent extensive microstructural changes but remained physically intact while efficiently releasing the generated tritium to maintain a low tritium inventory. Lithium transport out of the specimen area was negligible. Based on these results, it is concluded that $\mathrm{Li}_{2} \mathrm{O}$ should be considered as one of the leading candidates for use in a solid breeder fusion blanket application.

\section{FUTURE WORK}

Postirradiation examination of BEATRIX-II, Phase II is underway. Characterization of the Phase II $\mathrm{Li}_{2} \mathrm{O}$ temperature-change specimen and the $\mathrm{Li}_{2} \mathrm{ZrO}_{3}$ spherebed temperature-gradient specimen will involve procedures similar to those used for the Phase I specimens.

\section{REFERENCES}

1. N. Masaki, K. Noda, H. Watanabe, R. G. Clemmer, and G. W. Hollenberg, presented at the 6th Int Conf on Fusion Reactor Materials (ICRFM-6), Stresa, Lago Maggiore, Italy, 1993.

2. G. W. Hollenberg, H. Watanabe, I. J. Hastings, and S. E. Berk, J Nucl Mater 191-194 (1992) 23.

3. T. Kurasawa, O. D. Slagle, G. W. Hollenberg, and R. A. Verrall, Fusion Technology 19 (1991) 931.

4. O. D. Slagle, T. Kurasawa, R. A. Verrall, and G. W. Hollenberg, J Nucl Mater 191-194 (1992) 214.

5. T. Kurasawa, O. D. Slagle, G. W. Hollenberg, and R. A. Verrall, in Ceramic Transactions, Vol 27 (The American Ceramic Society, Westerville, Ohio, 1991) p. 299. 
6. D. R. Olander, Fundamental Aspects of Nuclear Reactor Fuel Elements, Technical Information Center - Energy Research and Development Administration, TID-26711-P1 (1976).

7. D. L. Baldwin and G. W. Hollenberg, J Nucl Mater 141-143 (1986) 305.

8. M. C. Billone, H. Attaya, and J. P. Kopasz, in Proceeding of the International Workshop on Ceramic Breeder Interactions (University of Tokyo, Tokyo, Japan 1993) p. 101

9. M. C. Billone, H. Attaya, and J. P. Kopasz, Modeling of Tritium Behavior in $\mathrm{L}_{2} \mathrm{O}$, Argonne National Laboratory, ANL/FPP/TM-260 (August 1992).

10. G. Federici, A. R. Raffray and M. A. Abdou, J Nucl Mater 173, (1990) 185-213.

11. R. A. Verrall, D. H. Rose, J. M. Miller, I. J. Hastings, and D. S. MacDonald, J Nucl Mater 179-181, (1991) 855-858.

12. T. Kurasawa, H. Yoshida, H. Takeshita, H. Watanabe, T. Miyauchi, T. Matui, H. Umei, Y. Naruse, J Nucl Mater 133-134, (1985) 196-200. 
Tritium Release from Lithium Titanate, A Low Activation Tritium Breeding Material- J. P. Kopasz and C. E. Johnson (Argonne National Laboratory) and J. M. Miller (AECL Research, Canada)

\section{OBJECTIVE}

The objective of this work is to obtain tritium release information on a low activation ceramic tritium breeding material. Lithium titanate was chosen as the material of choice based on previous work.

\section{SUMMARY}

The goals for fusion power are to produce energy in as safe, economical, and environmentally benign a manner as possible. To ensure environmentally sound operation low activation materials should be used where feasible. The ARIES Tokamak Reactor Study has based reactor designs on the concept of using low activation materials throughout the fusion reactor. For the tritium breeding blanket, the choices for low activation tritium breeding materials are limited. Lithium titanate is an alternative low activation ceramic material for use in the tritium breeding blanket. To date, very little work has been done on characterizing the tritium release for lithium titanate. We have thus performed laboratory studies of tritium release from irradiated lithium titanate. The results indicate that tritium is easily removed from lithium titanate at temperatures as low as $600 \mathrm{~K}$. The method of titanate preparation was found to affect the tritium release, and the addition of $0.1 \% \mathrm{H}_{2}$ to the helium purge gas did not improve tritium recovery.

\section{PROGRESS AND STATUS}

\section{Introduction}

The goals for fusion power are to produce energy in as safe, economical, and environmentally benign a manner as possible. To ensure environmentally sound operation, low activation materials should be used where feasible.' The ARIES Tokamak Reactor Study has based reactor designs on the concept of using low activation materials throughout the fusion reactor. ${ }^{2}$ For the tritium breeding blanket, the choices for low activation tritium breeding materials are limited. Lithium titanate is an alternative low activation ceramic material for use in the tritium breeding blanket. To date, very little work has been done on characterizing the tritium release from lithium titanate and developing the requisite properties data base. Finn et al. performed some early work which showed that lithium titanate has some attractive properties, including excellent tritium release. ${ }^{3}$ To extend the data base on $\mathrm{Li}_{2} \mathrm{TiO}_{3}$, we have performed several tritium release tests, including tests on the effect of the purge gas composition and the ceramic fabrication method on the tritium release.

\section{Experimental}

Lithium titanate spheres were prepared by two methods: cold pressing of commercially available $\mathrm{Li}_{2} \mathrm{TiO}_{3}$ powder (Alfa Products) or extrusion/tumbling of a $\mathrm{Li}_{2} \mathrm{TiO}_{3}$-binder-water mixture. The latter were sintered at either 1498 or $1673 \mathrm{~K}^{4}$ The samples were then irradiated, and the tritium release examined in post-irradiation annealing tests, following procedures described previously. ${ }^{3.6}$ Anneals were carried out under a constant heating rate $(1,2$ or $5 \mathrm{~K} / \mathrm{min})$ in Temperature Programmed Desorption (TPD) experiments, or a series of constant-temperature anneals $(600-1223 \mathrm{~K})$ was performed on the same sample. The tritium release was monitored on-line using either an ionization chamber or a proportional counter. Integrated values for the tritium released during an anneal were obtained by oxidizing the tritium and collecting it in ethylene glycol traps. Constant temperature anneals were performed by preheating the oven to the initial anneal temperature while the sample was positioned in a cooled portion of the annealing apparatus. After the furnace had reached the desired temperature, the sample was introduced into the heated zone. Anneals generally lasted $24 \mathrm{~h}$ at each temperature, with the ethylene glycol traps removed for tritium analysis just 
prior to a temperature increase.

\section{$\underline{\text { Results and discussion }}$}

\section{Constant temperature anneals}

Constant temperature anneals under a purge gas of $\mathrm{He}+0.1 \% \mathrm{H}_{2}$ or $\mathrm{Ar}+0.1 \% \mathrm{H}_{2}$ were performed on extruded material sintered at $1673 \mathrm{~K}$. A typical set of tritium release curves is shown in Figure 1 . A large majority of the tritium in the sample is released at a relatively low anneal temperature, in this case $603 \mathrm{~K}$. However, it appears that there is tritium present in the sample which will not be released at this temperature, no matter how long the anneal continues. Similar behavior has been reported for tritium release from lithium aluminate. ${ }^{7}$ This behavior suggests that tritium is being released from several different types of sites. For all the samples subjected to constant temperature anneals, the percentage of the tritium released during the first anneal at temperatures between 603 and $723 \mathrm{~K}$ varied from 72 to $90 \%$ of the total tritium in the sample, with the percentage released not strictly dependent on the anneal temperature. The majority of the remaining tritium was released at the second anneal at temperatures between 806 and $926 \mathrm{~K}$. The fraction of the total released at these temperatures varied from 24 to about $5 \%$. The fraction still present in the sample after this second $24-\mathrm{h}$ anneal was less than $11 \%$ of the total amount released during all the anneals (final anneal at a temperature $>1100 \mathrm{~K}$ ).

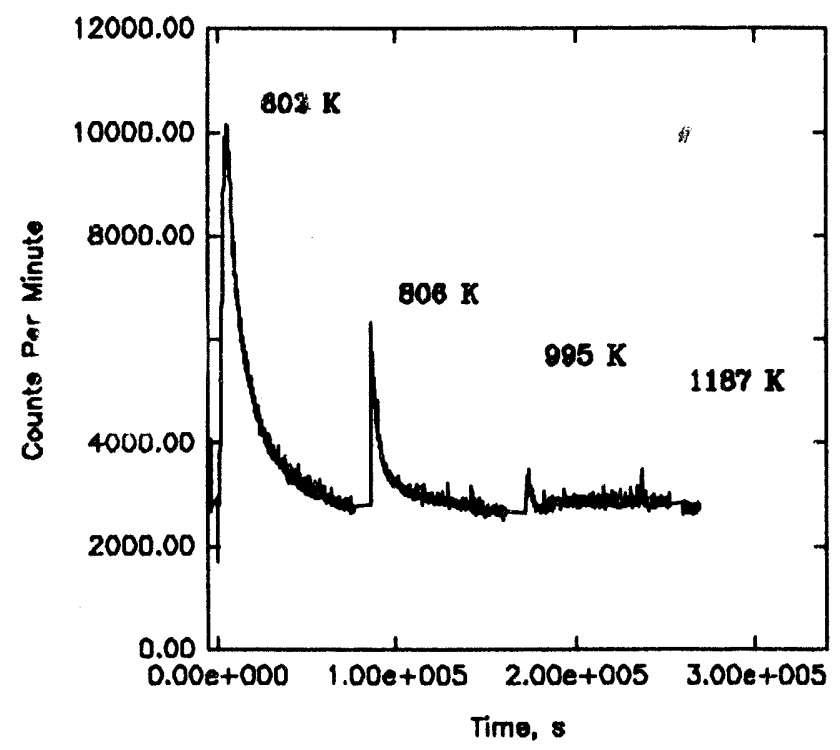

Figure 1. Tritium release from $\mathrm{Li}_{2} \mathrm{TiO}_{3}$ sintered at $1673 \mathrm{~K}$ for successive step anneals at $603,806,995$ and $1187 \mathrm{~K}$,

The tritium release during the first anneal was fit to a first-order desorption equation. The slope obtained from a plot of the natural log of the desorption rate constant versus the inverse temperature gave an activation energy of $40 \mathrm{~kJ} / \mathrm{mol}$. Following the same procedure for the second anneal yielded an activation energy of $128 \mathrm{~kJ} / \mathrm{mol}$. The tritium release peaks for the third and fourth anneals were generally too small to derive a meaningful desorption rate constant from them. As a result, no activation energies could be determined from these anneals. 
Temperature programmed desorption experiments

The TPD experiments were performed at ANL and AECL. Assuming a first-order desorption mechanism, one can calculate an activation energy (E) for a single peak in a TPD plot by using the following equation:

$$
\ln \left(\frac{T_{m}^{2}}{H}\right)=\frac{E}{R} * \frac{1}{T_{m}}+C
$$

Where $T_{m}$ is the temperature at which the peak maximum occurs, $E$ is the activation energy, $H$ is the heating rate, $\mathbf{R}$ is the gas constant and $\mathrm{C}$ is a constant. For overlapping peaks, it is difficult to determine the location of the maximum for each peak. Thus, we fit the complete TPD curve to the first-order desorption equation for a linear temperature increase. ${ }^{8}$ Equation 1 was then used as a check for consistency between runs at different heating rates.

$$
\begin{aligned}
& P=1-\theta^{-k H \frac{E}{A} * J} \\
& I=\int_{0}^{\frac{T}{E}} \theta^{-\frac{E}{T}} \propto\left(\frac{T^{\prime}}{E}\right) \\
& P=\text { Tritium pressure, } \mathrm{K}=\text { desorption rate constant } \\
& \mathrm{T}=\text { Temperature times the gas constant }
\end{aligned}
$$

\section{Table i}

Calculated activation energies, peak positions, and areas for deconvolutionof TPD curves for $\mathrm{Li}_{2} \mathrm{TiO}_{3}$ sintered at $1498 \mathrm{~K}$ (purge gas of pure helium) using first-order desorption mechanism

\begin{tabular}{llrrrr} 
& \multicolumn{2}{c}{$2 \mathrm{~K} / \mathrm{min}$} & \multicolumn{3}{c}{$5 \mathrm{~K} / \mathrm{min}$} \\
$\mathrm{E}_{2}, \mathrm{~kJ} / \mathrm{mol}$ & $\mathrm{T}_{\max }, \mathrm{K}$ Area & \multicolumn{1}{c}{$\mathrm{T}_{\max }, \mathrm{K}$} & Area \\
71 & 381 & $1.8 \%$ & 396 & $1.4 \%$ \\
48 & 510 & $43.4 \%$ & 511 & $25.5 \%$ \\
117 & 576 & $34.3 \%$ & 596 & $46.0 \%$ \\
143 & 620 & $12.2 \%$ & 641 & $17.3 \%$ \\
121 & 668 & & $8.3 \%$ & 697 & $9.8 \%$
\end{tabular}

In Figure 2, a typical TPD spectra obtained in a pure He purge gas for the spheres sintered at 1498 $K$ is shown for a heating rate of $2 \mathrm{~K} / \mathrm{min}$. Deconvolution of the peaks for heating rates of 2 and $5 \mathrm{~K} / \mathrm{min}$ 
using first order desorption yields five desorption peaks. The activation energies, maximum temperature, and relative area for each of these five peaks are given in Table $I$. All of the activation energies, except the $48 \mathrm{~kJ} / \mathrm{mol}$ for the second peak, are in good agreement with the activation energies calculated from Eq. 1 and the peak maxima in Table 1. For the second peak, an activation energy was obtained by starting with an activation energy of $40 \mathrm{~kJ} / \mathrm{mol}$ (determined from isothermal anneals) and then optimizing the fit to the overall TPD curve. Differences in the calculated pre-exponential terms cause the activation energy for peak 2 to be less than that for peak 1 and peak 5 less than that for peak 4, even though peaks 2 and 5 occur at higher temperatures.

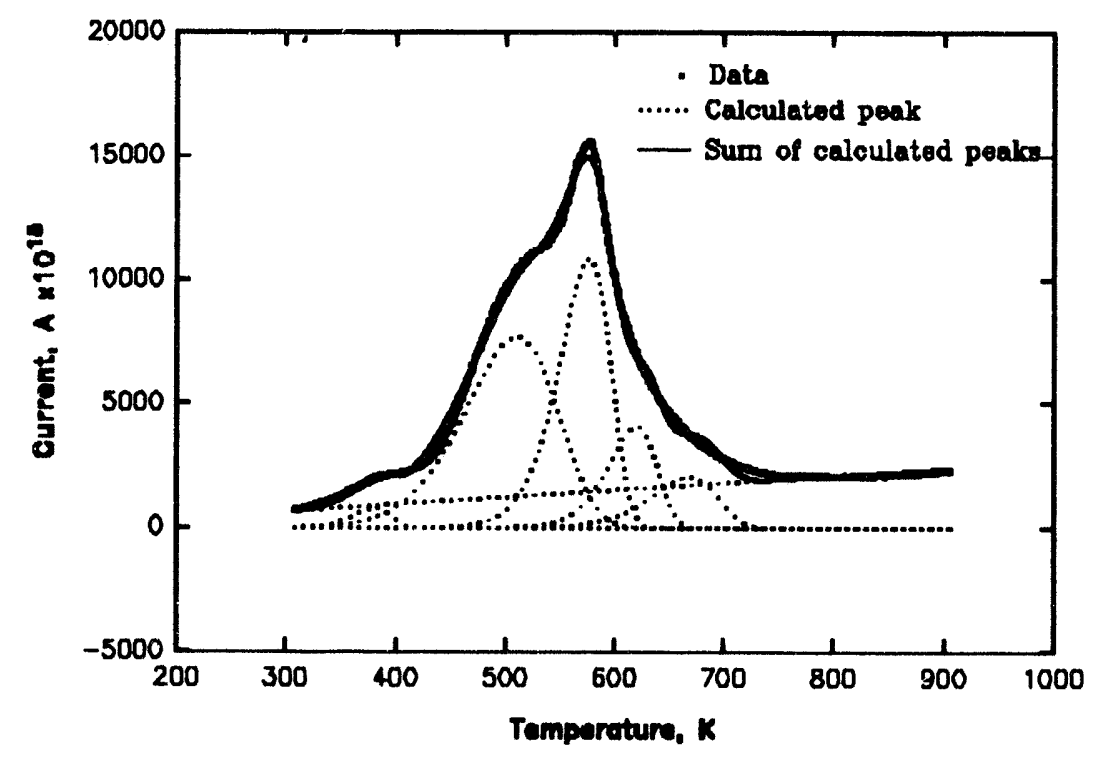

Figure 2.Temperature programmed desorption curves showing deconvolution for $\mathrm{Li}_{2} \mathrm{TiO}_{3}$ sintered at $1498 \mathrm{~K}$ with a purge gas of pure helium and a heating rate of $2 \mathrm{~K} / \mathrm{min}$.

Table 2

Calculated activation energies, peak positions, and areas for deconvolution of TPD curves for $\mathrm{Li}_{2} \mathrm{TiO}_{3}$ sintered at $1498 \mathrm{~K}$ (purge gas of pure helium) using second-order desorption mechanism.

\begin{tabular}{clclc} 
& \multicolumn{2}{c}{$2 \mathrm{~K} / \mathrm{min}$} & \multicolumn{2}{c}{$5 \mathrm{~K} / \mathrm{min}$} \\
$\mathrm{E}_{\mathrm{a}}, \mathrm{kJ} / \mathrm{mol}$ & $\mathrm{T}_{\max }, \mathrm{K}$ & Area & $\mathrm{T}_{\text {max }}, \mathrm{K}$ & Area \\
42 & 392 & $5.7 \%$ & 414 & $6.1 \%$ \\
75 & 505 & $41.5 \%$ & 509 & $23.3 \%$ \\
99 & 607 & $28.2 \%$ & 624 & $40.3 \%$ \\
117 & 573 & $24.6 \%$ & 596 & $30.2 \%$
\end{tabular}

The data can also be analyzed using second-order desorption. In this approach, the data are best fit to three second-order curves and one first-order curve. The activation energies, and relative amounts of 
tritium under each peak are given in table 2. For desorption into a pure purge gas, it may be expected that tritium desorption would follow a second-order mechanism. The activation energies calculated here are in very good agreement with those reported for desorption of water from anatase and rutile of $36 \mathrm{~kJ} / \mathrm{mol}, 55$ $69 \mathrm{~kJ} / \mathrm{mol}$, and $104 \mathrm{~kJ} / \mathrm{mol}$. $^{9}$ This suggests that the main mechanisms for desorption from $\mathrm{Li}_{2} \mathrm{TiO}_{3}$ involve dissociation of $\mathrm{Ti}-\mathrm{OH}$ species.

The TPD spectra for the cold-pressed sample of $\mathrm{Li}_{2} \mathrm{TiO}_{3}$ in pure helium or pure argon consisted of a single narrow peak centered at about $695 \mathrm{~K}$. The exact position of the peak varied from sample to sample, with the range covering about $20 \mathrm{~K}$. This variation made it impossible to use Eq. 1 to obtain an activation energy for this peak. However, the peak position is comparable to that for the peak with an activation energy of $121 \mathrm{~kJ} / \mathrm{mol}$ calculated for the material sintered at $1498 \mathrm{~K}$.

Effect of hydrogen in the purge gas

The TPD spectra of tritium desorption from lithium titanate were obtained for the cases of pure $\mathrm{He}$ and $\mathrm{He}+0.1 \% \mathrm{H}_{2}$. The tritium release in the two different gas streams at a heating rate of $2 \mathrm{~K} / \mathrm{min}$ is shown in Figure ? for the titanate sintered at $1498 \mathrm{~K}$. When hydrogen is added to the purge gas, the peaks centered at 381 and $668 \mathrm{~K}$ in the TPD curve for pure helium disappear, while the peak centered at $510 \mathrm{~K}$ shifts to higher temperature, $558 \mathrm{~K}$, and decreases in relative intensity from $43 \%$ of the total area under the curve to $10 \%$. The peak at $576 \mathrm{~K}$ in pure helium shifts to slightly lower temperature, $567 \mathrm{~K}$, and increases in intensity from 34 to $54 \%$, while the peak at $620 \mathrm{~K}$ shifts to $646 \mathrm{~K}$. There also appears to be new peaks centered at about $800 \mathrm{~K}$, which account for about $25 \%$ of the tritium released in $\mathrm{He}+0.1 \% \mathrm{H}_{2}$. The overall result is a shift in the tritium release to higher temperature. For the material sintered at $1673 \mathrm{~K}$, there is some irreproducibility in the TPD data in pure helium and the effect of hydrogen addition is less obvious; however, the hydrogen addition apparently shifts the temperature of the maximum for the highest peak to a higher temperature.

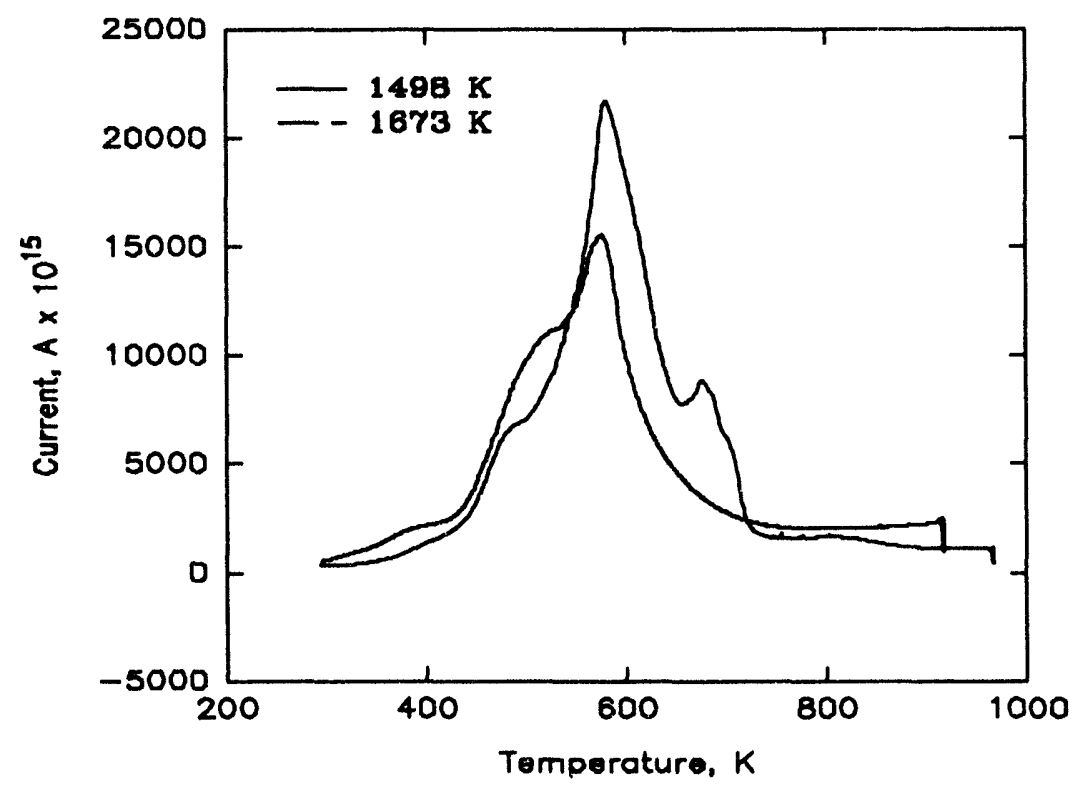

Figure 3. Effect of purge gas composition on tritium release for sample sintered at $1498 \mathrm{~K}$ and heating rate of $2 \mathrm{~K} / \mathrm{min}$. 
The magnitude of the shift varied from 20 to $100 \mathrm{~K}$. The relative intensities of the tritium release below $680 \mathrm{~K}$ decreased with hydrogen addition, while the relative contribution at or above $680 \mathrm{~K}$ increased. Again, the overall result appears to be a shift in tritium release to higher temperature when hydrogen is added to the purge gas. This is unusual since hydrogen addition has been shown to be beneficial to tritium release in other lithium ceramic systems. The mechanism involved in the shift of tritium release to higher temperature with hydrogen addition to the purge is not yet known.

\section{Effect of sample preparation}

The TPD curves obtained at $2 \mathrm{~K} / \mathrm{min}$ in pure helium for materials sintered at 1498 and $1673 \mathrm{~K}$ are shown in Figure 4. Tritium release from the material sintered at 1673 is shifted to higher temperature. This is caused by a decrease in the relative intensity of the peak centered near $500 \mathrm{~K}$ and an increase in the intensity of the peak near $670 \mathrm{~K}$. The changes in intensity of these two peaks varied some from sample to sample; however, for the material annealed at $1673 \mathrm{~K}$ the peak near $670 \mathrm{~K}$ was always larger than that near $500 \mathrm{~K}$. Analysis of the TPD curves indicated similar activation energies for the peaks from the two materials. For the cold-pressed material, a single peak was observed in the TPD curve, centered at roughly $700 \mathrm{~K}$ when in pure helium or argon. When hydrogen was added to the purge gas, the TPD curves for the cold-pressed materials consisted of several peaks and were similar to those for the material sintered at 1673 K.

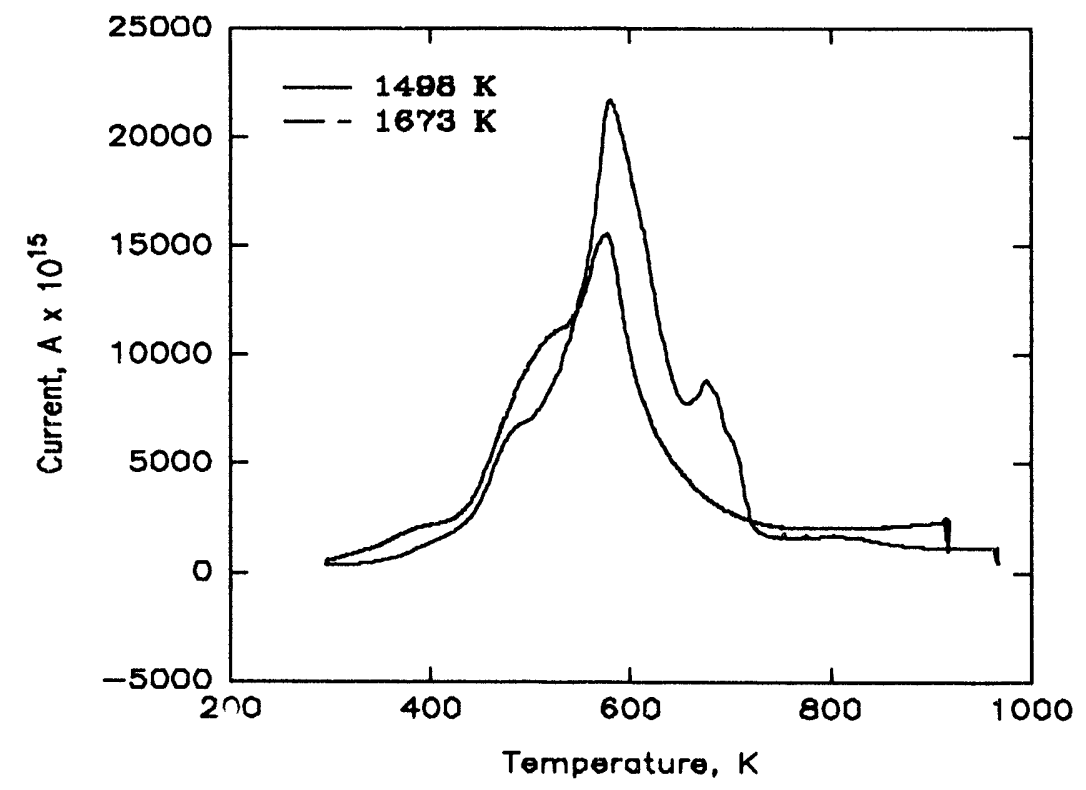

Figure 4. Effect of sintering temperature on tritium release for a purge gas of pure helium and heating rate of $2 \mathrm{~K} / \mathrm{min}$.

Conclusions

Tritium is released from lithium titanate at temperatures as low as $600 \mathrm{~K}$. Tritium release from this material compares favorably with other ceramics. ${ }^{4}$ The tritium is released from several types of sites. The exact nature of the release depends on the preparative method, with the material sintered at $1498 \mathrm{~K}$ 
giving the best tritium release. Hydrogen addition to the purge gas is not necessary for tritium recovery and is, in fact, detrimental to tritium recovery from lithium titanate.

\section{FUTURE WORK}

The affect of hydrogen on the tritium release from lithium titanate will be investigated further in light of the results of these tests which suggest tritium release from the titanate is hindered by addition of hydrogen to the purge stream. Temperature programmed desorption and constant temperature anneal tests will be performed under a variety of purge gas compositions to determine how the titanate differs from the other ceramics.

\section{References}

1. R. W. Conn, E. E. Bloom, J. W. Davis, R. E. Gold, R. Little, K. R. Schultz, D. L. Smith, and F. W. Wiffen, Nuclear Technology / Fusion 5 (1984) 291.

2. F. Najmabadi et. al. The ARIES Tokamak Reactor Study, University of California at Los Angeles Report UCLA-PPG-1323 (1991).

3. P. A. Finn, T. Kurasawa, S. Nasu, K. Noda, T. Takahashi, H. Takeshita, T. Tanifuji, and H. Watanabe, in Proceedings of the 9th Symposium on Engineering Problems of Fusion Research (IEEE, New York, 1981 ) p. 1200.

4. J. M. Miller, Proceedings of the Sixth International Conference on Fusion Reactor Materials, Stressa, Italy, 1993.

5. J. P. Kopasz, C. A. Seils, and C. E. Johnson, J. Nucl. Mater. 191-194 (1992) 231.

6. J. M. Miller, S. R. Bokwa, D. S. MacDonald, and R. A. Verrall, Fusion Technol. 19 (1991) 996.

7. J. P. Kopasz, S. Tistchenko, and F. Botter in Fabrication and Properties of Lithium Ceramics III, Eds., I. J. Hastings and G. W. Hollenberg (American Ceramic Society, Westerville, Ohio, 1992) p. 315.

8. A. W. Smith and S. Aranoff, J. Phys. Chem. 62 (1958) 684.

9. M. Egashira, S. Kawasumi, S. Kagawa, and T. Seiyama, Bull. Chem. Soc. Japan 51 (1978) 3144. 
Tritium Release from Beryllium Discs and Lithium Ceramics Irradiated in the SIBELIUS Experiment C.E. Johnson and J.P. Kopasz (Argonne National Laboratory) and D.L. Baldwin (Pacific Northwest Laboratory)

\section{OBJECTIVE}

The objective of the current studies was to critically examine the tritium release characteristics of the beryllium discs and to characterize any differences in tritium behavior from beryllium discs located adjacent to steel as and beryllium discs located adjacent to ceramic.

\section{SUMMARY}

The SIBELIUS experiment was designed to obtain information on the compatibility between beryllium and ceramics, as well as beryllium and steel, in a neutron environment. Four capsules were used to examine beryllium/ceramic $\left(\mathrm{Li}_{2} \mathrm{O}, \mathrm{LiAlO}_{2}, \mathrm{Li}_{4} \mathrm{SiO}_{4}\right.$, and $\left.\mathrm{Li}_{2} \mathrm{ZrO}_{3}\right)$ and beryllium/steel (Types $316 \mathrm{~L}$ and 1.4914) compacts. Isothermal anneal experiments have been run on representative beryllium and ceramic disks from each of the four capsules at $550^{\circ} \mathrm{C}$ to $850^{\circ} \mathrm{C}$ in steps of $100^{\circ} \mathrm{C}$. The results indicate that tritium release from the beryllium did not exhibit burst release behavior, as previously reported, but rather a progressive release with increasing temperature. Generally $\sim 99$ percent of the tritium was released by $850^{\circ} \mathrm{C}$. Tritium release from the ceramic discs was quite similar to the behavior shown in other dynamic tritium release experiments on lithium ceramics. The tritium content in beryllium discs adjacent to a steel sample was found to be significantly lower than that found in a beryllium disc adjacent to a ceramic sample. Recoil of tritium from the ceramic into the beryllium appears to be the source of tritium entering the beryllium, probably residing in the beryllium oxide layer.

\section{PROGRESS AND STATUS}

\section{Introduction}

The SIBELIUS experiment is an EC/USA collaborative test [1] to assess the compatibility of beryllium/ceramic and beryllium/steel compacts in a neutron environment and to understand the potential for acceleration of beryllium oxidation caused by enhanced diffusion of oxygen or altered phase stability. The irradiation vehicle consisted of eight capsules, seven of which were independently purged with an $\mathrm{He} / 0.1 \% \mathrm{H}_{2}$ gas mixture. The eighth capsule was not purged and contained beryllium pellets used to obtain data on lifetime void swelling. Seven capsules were operated at $550^{\circ} \mathrm{C}$ while the capsule containing the lithium orthosilicate pebbles was operaied at $450^{\circ} \mathrm{C}$. Four capsules were used to examine beryllium/ceramic $\left(\mathrm{Li}_{2} \mathrm{O}, \mathrm{LiAlO}_{2}, \mathrm{Li}_{4} \mathrm{SiO}_{4}, \mathrm{Li}_{2} \mathrm{ZrO}_{3}\right)$ and beryllium/steel (Types $316 \mathrm{~L}$ and 1.4914) compacts. Two capsules contain only ceramic $\left(\mathrm{Li}_{2} \mathrm{O}\right.$ and $\left.\mathrm{LiAlO}_{2}\right)$, one capsule contains beryllium pellets for lifetime void swelling tests, and one capsule contains $0.5-\mathrm{mm} \mathrm{Li} \mathrm{LiO}_{4}$ pebbles in contact with beryllium discs. These tests were designed to identify any performance-limiting issues associated with the use of beryllium as a neutron multiplier in ceramic breeder blankets.

Small quantities of tritium are generated in the beryllium via a ${ }^{9} \mathrm{Be}$-neutron reaction producing tritium and helium. Because the buildup of the tritium could become a safety issue, there is strong interest in tritium removal. Prior tritium release studies on beryllium have been on material that has served as a reflector in a nuclear reactor. Generally, these reflector materials have remained in place for several years at low temperature, e.g., $<100^{\circ} \mathrm{C}$. When these reflector materials have been examined under isothermal anneal conditions, they have exhibited burst release of tritium at high temperatures. Earlier studies on tritium release from SIBELIUS beryllium discs [2] reported that "excess" tritium was found in the beryllium discs, and that the source of the "excess" tritium was recoiled tritium from adjacent ceramic samples. How this tritium was supposed to collect in the beryllium was never fully explained. If truly recoiled tritium, its location would be in the near surface region at a depth of $\sim 40$ microns; at this depth the tritium would be expected to be easily released from the beryllium. 


\section{Experimental}

Stepped-temperature anneal experiments were run on the beryllium and ceramic discs from the SIBELIUS experiment. The anneals covered temperatures of $550,650,750$, and $850^{\circ} \mathrm{C}$ for 24 hours at each temperature. A He/0.1\% $\mathrm{H}_{2}$ gas mixture flowing at $100 \mathrm{~cm}^{3} / \mathrm{min}$ purged the sample contained in a quartz apparatus. Two independent release curves were obtained, one from an on-line ion-chamber measurement and one from a gas collection bubbler system followed by liquid scintillation counting. The gas collection bubbler data were considered to represent the principal data set, since the methodology is not subject to variation. This contrasts with the ion-chamber data, which are subject to variation because of the need to make time-dependent background corrections and the potential for calibration corrections due to changing characteristics in the electronics. Shifts in the ion-chamber background or shifts in system calibration need to be continually monitored to ensure high-quality data. For the current analysis, the ion-chamber release curve was background corrected to fit the bubbler curve.

\section{Results and Discussion}

Table I lists, in summary form, all the available data on tritium release from beryllium discs in the SIBELIUS experiment. The German data are taken from a recent publication by Dienst et al. [2]. The table is organized in a manner that closely corresponds to the location of a given sample in the SIBELIUS test vehicle[3]; the lithium orthosilicate capsule was at the bottom of the test vehicle, while the lithium metazirconate capsule was at the top. Each capsule contained a stack of 17 discs. The discs were arranged so that beryllium-steel and beryllium-ceramic discs alternated in the stack, with the first disc in each stack being a beryllium disc. The table lists the pellet weight, the amount of tritium released in $\mathrm{MBq}$, the measured and calculated amount of tritium in $10^{8} \mathrm{MBq} / \mathrm{g}$, and the measured-tocalculated ratio for retained tritium. Note that the beryllium discs within the body of the stack (adjacent to the ceramic) all show a higher tritium content than that expected from a transmutation reaction within the beryllium.

The last two columns in Table I enable a comparison between measured and calculated tritium concentrations for each of the different ceramic capsules. The importance of this ratio is its use to further investigate the concern expressed by Dienst et al. [2] that the original neutronic calculations had not computed the tritium generation rate correctly. The current data are not in good agreement with Dienst et al., especially with regard to the ratios of tritium measured to tritium calculated for the beryllium discs adjacent to steel, namely, samples 2-1, 3-1, 5-1, and 6-1, where the measured-tocalculated ratios are $1.10,0.94,0.86$, and 0.85 , respectively. These values are close to unity and thus suggest that the neutronic calculations for tritium generation are satisfactory. These results also indicate that very little tritium has left the beryllium at $550^{\circ} \mathrm{C}$, at least for this fluence level. However, beryllium sample $1-1$, from the capsule containing the orthosilicate pebbles operated at $450^{\circ} \mathrm{C}$, shows an abnormally high tritium content for a beryllium disc adjacent to steel. It is unlikely that the high tritium content is due solely to the lower temperature operation.

For the remainder of the beryllium discs within the body of the stack, where beryllium was in contact with a ceramic pellet, the measured-to-calculated tritium ratio is significantly greater than unity, ranging from 1.44 to 2.49 . In fact, the ratio reaches 10.57 if one includes the capsule with lithium orthosilicate pebbles at $450^{\circ} \mathrm{C}$. In examining the data further, we identified two numerical groupings for the measured-to-calculated tritium ratio. The lithium orthosilicate samples form one group, where the ratio ranges from 1.80 to 2.49 ( 10.57 if the pebbles are included), while the other ceramics form another 
Table I

TRITIUM CONTENT IN BERYLLIUM DISCS FROM THE SIBELIUS EXPERIMENT

$\begin{array}{llllrrr}\begin{array}{l}\text { Sample } \\ \text { Number }\end{array} & \text { Origin } & \begin{array}{c}\text { Pellet } \\ \text { Weight, }\end{array} & \begin{array}{c}\text { MBq Tritium } \\ \text { Released }\end{array} & \begin{array}{c}10^{8} \mathrm{~Bq} / \mathrm{g} \\ \text { Meas. }\end{array} & \begin{array}{c}\text { Calc. } \\ \text { Ratio }\end{array} \\ 1-1 & \text { Ger } & 0.1890 & 191 & & & \\ 1-6 & \text { Ger } & 0.1771 & 719 & 10.10 & 3.84 & 2.63 \\ & & & & 40.60 & 3.84 & 10.57 \\ 2-1 & \text { USA } & 0.1829 & 112 & & & \\ 2-7 & \text { USA } & 0.1891 & 190 & 6.12 & 5.57 & 1.10 \\ 2-9 & \text { Ger } & 0.1877 & 2.38 & 10.04 & 5.57 & 1.80 \\ 2-15 & \text { Ger } & 0.1761 & 244 & 12.67 & 5.57 & 2.27 \\ & & & & 13.85 & 5.57 & 2.49 \\ 3-1 & \text { USA } & 0.1882 & 136 & & & \\ 3-7 & \text { USA } & 0.1874 & 236 & 7.23 & 7.71 & 0.94 \\ & & & & 12.59 & 7.71 & 1.63 \\ 5-1 & \text { USA } & 0.1865 & 130 & & & \\ 5-7 & \text { USA } & 0.1861 & 218 & 6.97 & 8.12 & 0.86 \\ 5-9 & \text { Ger } & 0.1868 & 229 & 11.71 & 8.12 & 1.44 \\ 5-15 & \text { Ger } & 0.1720 & 271 & 12.26 & 8.12 & 1.51 \\ & & & & 15.75 & 8.12 & 1.94 \\ 6-1 & \text { USA } & 0.1858 & 105 & & & \\ 6-7 & \text { USA } & 0.1846 & 187 & 10.67 & 6.67 & 0.85 \\ & & & & 6.67 & 1.52\end{array}$

First digit in sample number indicates the following: $1=\mathrm{Li}_{4} \mathrm{SiO}_{4}$ pebbles, $2=\mathrm{Li}_{4} \mathrm{SiO}$, pellets, $3=$ $\mathrm{LiAlO}_{2}$ pellets, $5=\mathrm{Li}_{2} \mathrm{O}$ pellets, and $6=\mathrm{Li}_{2} \mathrm{ZrO}_{3}$ pellets

group, where the ratio ranges from 1.44 to 1.94 . There are also some differences in the measured-tocalculated ratio between laboratories and between materials. For the orthosilicate, the USA value $(1.80$. for disc 2-7) is somewhat lower than that of the German value (2.27 for disc 2-9). The comparison for lithium oxide is mixed; the measured-to-calculated ratios for discs 5-7 and 5-9 are quite similar, while the value for disc 5-15 is high at 1.94. This latter ratio is the only outlier in this data set.

As a first approximation, assume that the "excess" tritium came from recoil of tritium from the higher tritium-generating ceramic disc. This assumption may have some merit. However, the relative loading of tritium in the adjacent beryllium discs does not rigorously correspond to the relative tritium generation rates for each ceramic. The tritium generation rates in Bequerels per day are $7.10 \times 10^{\circ} \mathrm{for}$ lithium orthosilicate, $5.48 \times 10^{9}$ for lithium zirconate, $4.22 \times 10^{\circ}$ for lithium oxide, and $4.00 \times 10^{\circ}$ for lithium aluminate. Thus, the orthosilicate has the highest generation rate, the zirconate is in the mid-range, and the oxide and the aluminate have the lowest tritium generation rate. There is certainly correspondence between the high tritium content in the beryllium disc adjacent to the orthosilicate and its position with the highest tritium generation rate, but the correspondence is only marginal for the other three ceramics. The three ceramics differ by some $45 \%$ in tritium generation capability, but the beryllium discs adjacent to each of the other ceramics appear to have retained about the same amount of "excess" tritium. The tritium generation rate for lithium zirconate is some $35 \%$ lower than that of lithium orthosilicate. Does this suggest that one needs a minimum flux of tritium to ensure retention in the beryllium, and that $5.48 \times 10^{\circ} \mathrm{Bq} /$ day for the zirconate is below the threshold needed for retention? Maybe tritium retention improves at a lower temperature, as shown by the capsule at $450^{\circ} \mathrm{C}$ with orthosilicate pebbles (disc 1-6 
in Table I). Thus, it does not appear to be simply tritium recoil that sets the tritium concentration in the beryllium disc, but rather tritium recoil with additional material characteristics that ensure tritium retention.

The ceramic in each of the capsules is as follows: $\mathrm{Li}_{4} \mathrm{SiO}_{4}$ in capsule $2, \mathrm{LiAlO}_{2}$ in capsule $3, \mathrm{Li}_{2} \mathrm{O}$ in capsule 5 , and $\mathrm{Li}_{2} \mathrm{ZrO}_{3}$ in capsule 6 . A typical tritium release curve for the beryllium discs was found to be similar to that of previous isothermal anneal experiments on lithium ceramics [4]. That is, the tritium release generally showed a sharp increase in tritium release with each increasing temperature increment. This increased release reached a maximum, which quickly settled down with time. There did not appear to be any "burst" release with increasing temperature; indeed, the amount of tritium available for release decreased significantly once the temperature had been increased above $650^{\circ} \mathrm{C}$.
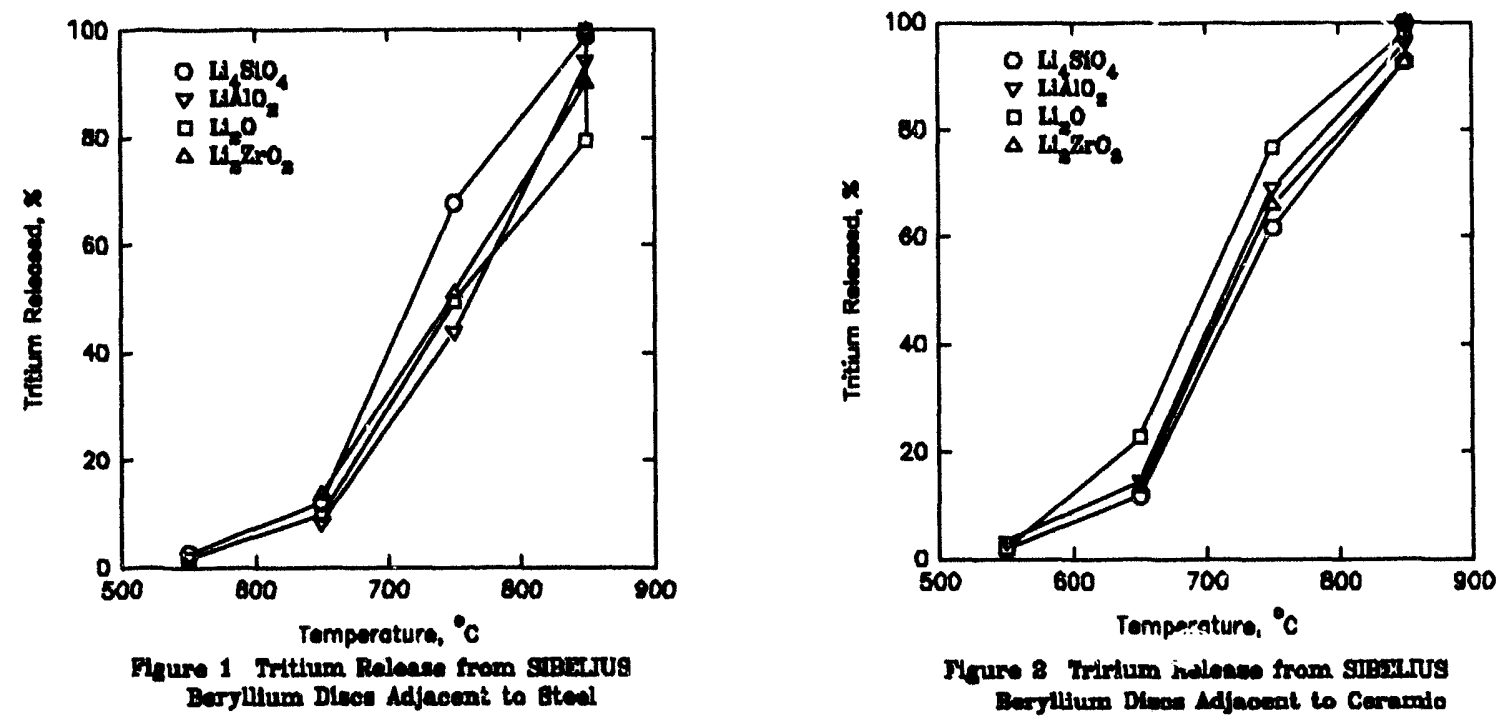

The tritium release data from the isothermal anneal experiments are plotted in Figs. 1 and 2 for beryllium discs adjacent to steel and beryllium discs adjacent to ceramic, respectively. The general characteristics of tritium release from the beryllium discs adjacent to a ceramic are easily seen in Figure 2 where the percent of tritium release from the beryllium is plotted against temperature. For these discs, the tritium release increased in the order lithium orthosilicate, lithium zirconate, lithium aluminate $_{v}$ and lithium oxide and is similar to the order for increased tritium generation rate, though we are not sure why. The differing tritium generation rates mean that the beryllium discs in each capsule were exposed to differing amounts of tritium in the purge gas flowing by the disc. For the four capsules investigated, the tritium generation rate in the ceramic increases in the order lithium aluminate, lithium oxide, lithium zirconate, and lithium orthosilicate. The largest amount of tritium was retained by the disc in the orthosilicate capsule followed by the aluminate, the oxide, and the zirconate. Tritium release from beryllium in the $\mathrm{Li}_{4} \mathrm{SiO}_{4}$ capsule was similar for both discs (no effect of ceramic or steel or fraction of tritium released at an anneal temperature), while for the other ceramics, a higher fraction of the tritium was released at $750^{\circ} \mathrm{C}$ for the beryllium adjacent to the ceramic.

Figure 3 presents data on tritium release from four different investigations covering four different beryllium samples. As arranged in the figure, these materials are a low density material ( $80.9 \%$ TD), 'igh density arc-cast material analyzed by Jones and Gibson [5], a high density arc-cast disc containing 
$<300 \mathrm{ppm}$ BeO from the SIBELIUS experiment, and a high density $(99.6 \%$ TD) beryllium sample analyzed by Billone and Baldwin[6]. The $80.9 \%$ TD material exhibits the best release characteristics, with significant tritium being released at $400^{\circ} \mathrm{C}$. The tritium release from the SIBELIUS beryllium discs is not as high as the Jones and Gibson data, at !east at temperatures below $800^{\circ} \mathrm{C}$, but is higher than the 99.6\% TD data at temperatures above $600^{\circ} \mathrm{C}$. Because of the many variables covered in these four experiments, it is difficult to develop a firm picture of the optimum material. What does appear to be attractive is to select a lower density beryllium and ensure that blanket designs include beryllium temperatures of $500^{\circ} \mathrm{C}$ or above. Optimizing the density and temperature parameters is certain to provide conditions that facilitate ease of tritium release.

A significant characteristic shown by the SIBELIUS beryllium discs was the lack of "burst" tritium release at higher temperatures as compared with earlier studies on high density material. This release behavior may be the result of irradiating at $550^{\circ} \mathrm{C}$ rather than the lower temperatures experienced by the reflector beryllium. Irradiating at this higher temperature may be sufficient for the diffusion and collection of tritium atoms into a more easily released molecular form. Also, the beryllium discs did not contain similar amounts of tritium, the amount retained depending on whether a disc was adjacent to a steel disc or adjacent to a ceramic disc. Those beryllium discs adjacent to a ceramic contained significantly more tritium, probably due to recoil from the ceramic. The beryllium oxide layer appears to influence the amount of tritium

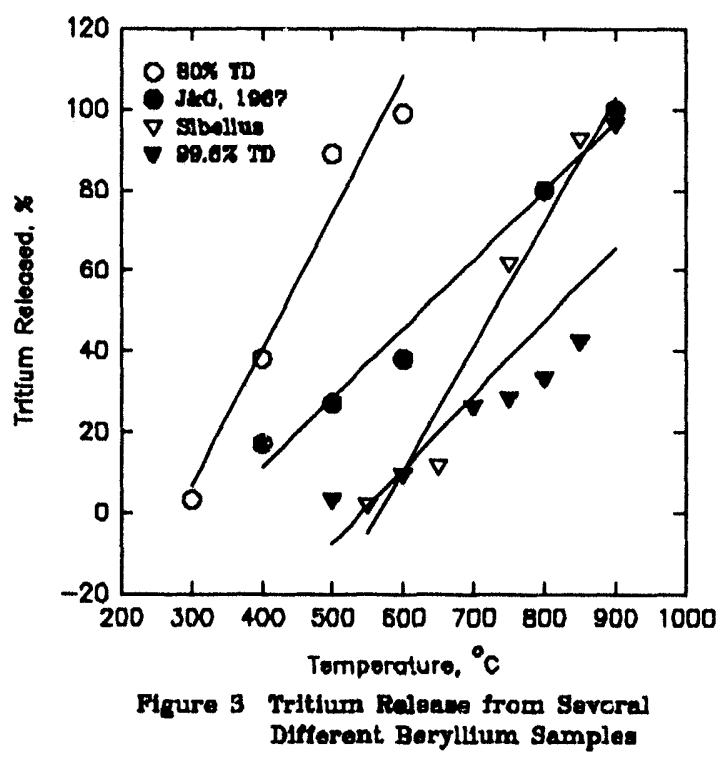
retained by the beryllium discs. The tritium release from the ceramic discs is consistent with other investigations of tritium release from ceramic materials [4], and there appears to be little or no effect from the adjacent beryllium. Further, all the ceramics exhibited little retention of tritium, the amount being similar to that shown in other experiments at $550^{\circ} \mathrm{C}$ with a $\mathrm{He} / 0.1 \% \mathrm{H}_{2}$ purge gas.

\section{Conclusions}

Investigations were carried out to determine the amount of retained tritium and the rates of tritium release from beryllium discs in the SIBELIUS experiment. These studies have shown that the bulk of the generated tritium was retained in the beryllium, and when the discs were heated to $650^{\circ} \mathrm{C}$ and above, the tritium was readily released. None of the samples examined exhibited the burst release characteristics observed earlier but rather an orderly release dependent solely upon temperature. In comparison with literature information on tritium release from beryllium, the SIBEL̈IUS data have a steeper slope for the temperature coefficient. Also, the literature information shows that for lower density beryllium ( $80.9 \%$ TD), tritium release is considerably enhanced.

\section{FUTURE WORK}

Future studies should place investigate further the attractive tritium release characteristics of lower density beryllium. 


\section{References}

[1] N. Roux, M. Briec, M. Bruet, T. Flament, C. Johnson, M. Masson, A. Terlain, and F. Tournebize, J. Nucl. Mater. 179-181 (1991) 827.

[2] W. Dienst, D. Schild, and H. Werle, Kernforschungszentrum, Karlsruhe, Report KfK-5109, December 1992.

[3] N. Roux, CE-Saclay, private communication, SIBELIUS meeting report, November 9, 1990.

[4] C.E. Johnson, T. Kondo, N. Roux, S. Tanaka, and D. Vollath, Fusion Engrg. and Des. 16 (1991) 127

[5] P.M.S. Jones and R. Gibson, J. Nucl. Mater. 21 (1967) 353.

[6] M.C. Billone and D.L. Baldwin, Proceedings, International Workshop on Ceramic

Breeder Blanket Interactions, University of Tokyo, Tokyo, Japan, October 26-29, 1992, P-267. 
8.0 CERAMICS 
TOUGHENING OF CERAMIC COMPOSITES WITH SLOW CRACK GROWTH - Christopher R. Jones, C. H. Henager, Jr. and Russell H. Jones (Pacific Northwest Laboratory")

\section{OBJECTIVE}

The purpose of this study is to evaluate the high-temperature mechanical properties of $\mathrm{SiC} / \mathrm{SiC}$ composites for fusion structural applications.

\section{SUMMARY}

Ceramic matrix composites show the uncommon and promising property of increasing their toughness and maintaining their load carrying capacity with increasing crack lengths under conditions of subcritical crack growth (SCG). As the crack grows, a more extensive bridging zone is formed allowing it to withstand far greater stress intensities than would be expected from fracture tests. It is also possible that crack bifurcation contributes to this effect, but is not likely to be the primary cause. It has not been determined whether or not an equilibrium crack-wake bridging zone will occur in these samples. Further testing may show that it occurs at greater crack lengths than those obtained in these tests or that it can't occur at all in these samples. Either way, the results of these tests are encouraging and expand the possible uses of these types of materials in applications that require long-term stability under stress.

\section{PROGRESS AND STATUS}

\section{Introduction}

Ceramic matrix composites (CMCs) offer the possibility of high-strength, corrosion-resistant, hightemperature materials having a fracture resistance adequate for use as structural materials in a variety of systems. Reinforcement of a brittle ceramic matrix material by brittle fibers or whiskers contributes to fracture resistance through reinforcement pull-out, crack bridging, crack deflection, and matrix microcracking [1]. Continuous-fiber-reinforced materials can exhibit fracture toughness values in the range 15$30 \mathrm{MPa} \mathrm{m}{ }^{1 / 2}$. This allows their consideration as advanced structural materials where use of monolithic ceramics would not be appropriate. If, however, CMCs are to be used in systems where long-term stability is required, a resistance to time-dependent crack growth (SCG, subcritical crack growth or slow crack growth) must be demonstrated. This is necessary because SCG controls the long-term life of materials when pre-existing flaws are present. Due to the brittleness of ceramic materials, the flaws are likely to exist, but must be shown not to pose a threat to the structural integrity of the material.

The mechanical response in continuous-fioer-reinforced CMCs is dominated by crack wake bridging by long fibers [1]. Fibers bridging the crack are stressed and at high temperatures can exhibit creep, timedependent interface fracture, time-dependent interface creep, and possibly visco-elastic effects at the interface. Previous work by C. H. Henager and R. H. Jones found that during SCG, the transition from stage II cracking to stage III occurred at a higher stress intensity (K) than expected from four-point bend fracture tests. This points to the possible increase in the toughness of a $\mathrm{CMC}$ at high temperatures under slow crack growth (SCG) conditions [3]. Fett et. al. found an increase in the toughness of a granular monolithic ceramic due to "crack wall interactions tehind the crack tip and an increase in the effective

"Pacific Northwest Laboratory is operated for the U.S. Department of Energy by Battelle Memorial Institute under Contract DE-AC06-76RLO 1830. 
crack front length due to an increase in the surface roughness." [2] This effect suggests the possibility of similar, but more pronounced behavior, in continuous-fiber-reinforced materials. The effect is likely to be more prominent because the fibers in CMCs would completely bridge the crack. The effect of fiber bridging is shown in previous work that suggested that high-temperature plasticity of fibers in the crackwake bridging zone controls the velocity of subcritical cracks in CMCs [3]. These materials exhibit Rcurve (crack growth resistance curve) behavior because of reduction, or shielding, of crack-tip stress intensities from applied far-field stress intensities. This behavior is due to crack bridging and is fundamentally different from the performance seen in monolithic ceramics [1]. In CMCs, the zone exhibiting this bridging is increased during SCG. The effect of the bridging is measured by comparing the toughness of samples, shown by $\mathrm{K}_{\mathrm{Q}}$ (peak load fracture toughness) and maximum load, with machine notched (no bridging) and SCG cracked (bridged) samples. It is anticipated that this bridging will make $\mathrm{K}_{\mathrm{Q}}$ rate dependent. This is because the slower the crack velocity, the larger the bridging zone will become. Thus, $K_{\mathrm{O}}$ will increase in SCG samples relative to samples without bridging and giving a result modeled by figure 1 .

Hypothetical $K_{Q}$ vs. alW Behavior

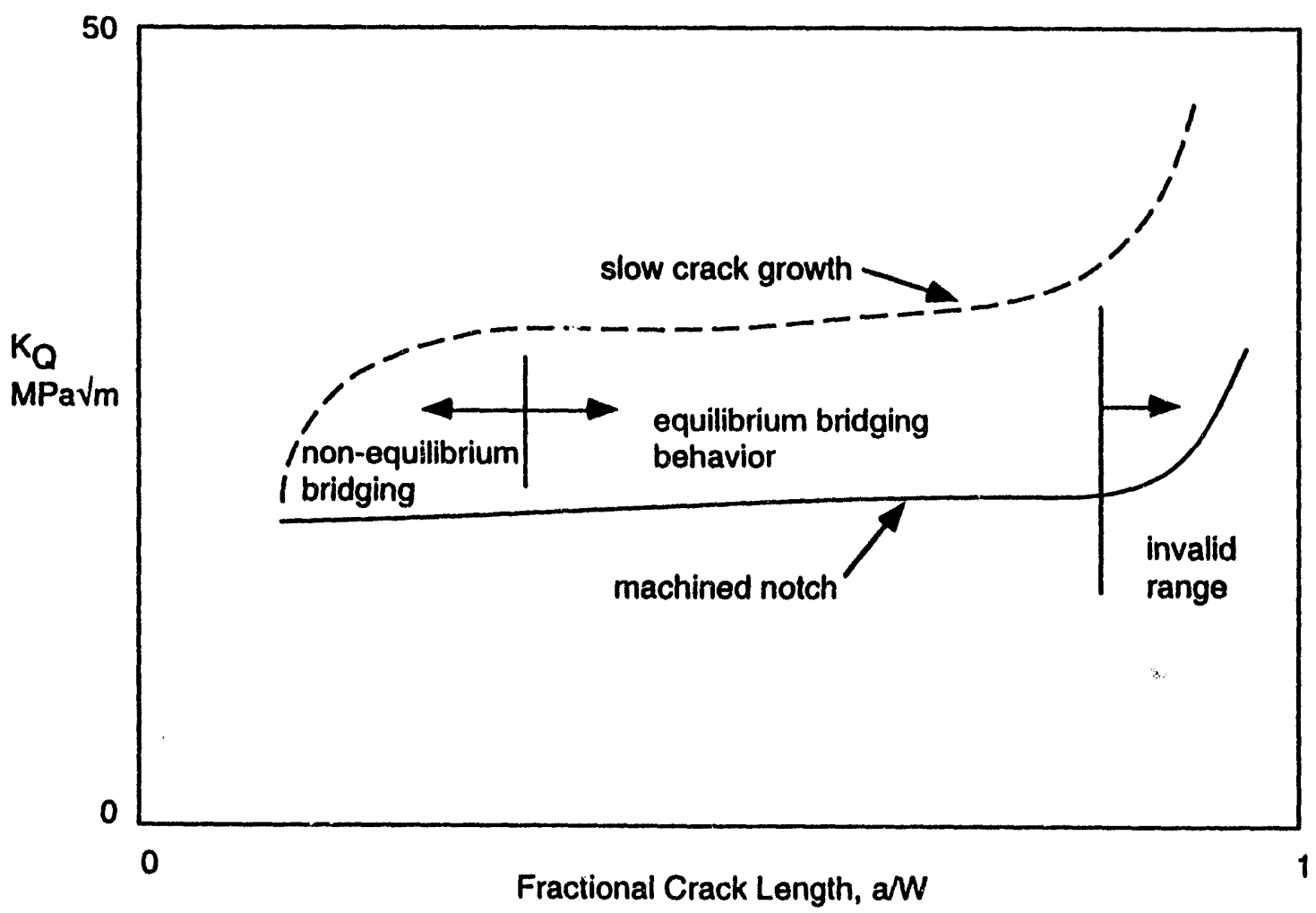

Fig. 1. Hypothetical model for behavior of $\mathrm{K}_{\mathrm{Q}}$ vs. $\mathrm{a} / \mathrm{w}$ or notch depth in machine notched and SCG samples. 
Figure 1 shows the predicted change in $\mathrm{K}_{\mathrm{Q}}$ behavior caused by fiber bridging formed during SCG. This is compared to machine notched samples that start out without any fiber bridging. If this model can be shown to be true, then these materials would display a unique increase in toughness during SCG, making them an effective material for systems that require long term stability. The extent of the non-equilibrium and equilibrium bridging zones is unknown for these materials.

\section{Experimental procedures}

Composites of Nicalon fiber cloth $\left(0 / 90^{\circ}\right)$ and CVI $\beta$-SiC with both $\mathrm{C}$ and $\mathrm{BN}$ interfaces were used for these tests. The composites, fabricated by RCI of Whittier, CA, are eight-ply laminates, $4 \mathrm{~mm}$ in thickness and are supplied in bars having dimensions of $4 \mathrm{~mm} \times 13 \mathrm{~mm} \times 50 \mathrm{~mm}$. Before the $\beta-S i C \mathrm{CVI}$ fabrication step, interfaces of $0.4 \mathrm{~mm} \mathrm{C}$ and $0.4 \mathrm{~mm} \mathrm{BN} \mathrm{(nominal} \mathrm{thicknesses)} \mathrm{were} \mathrm{deposited} \mathrm{onto} \mathrm{the}$ Nicalon fibers. The larger bars were cut into single-edge-notched bend bar (SENB) specimens having dimensions of $4 \mathrm{~mm} \times 5.5 \mathrm{~mm} \times 50 \mathrm{~mm}$. The SENB specimens were loaded in four-point bending using a fully articulated $\mathrm{SiC}$ bend fixture. The tests were performed inside a sealed mullite ceramic tube using a split clamshell furnace. The load was applied by a SiC pushrod attached to the top sealing flange of the sealed tube using a flexible metal bellows. Specimen midpoint displacement was measured by a alumina tube, holding a type $\mathrm{K}$ thermocouple, spring loaded against the bottom of the bend specimen. This deflected a strain gage extersometer positioned beneath the $\mathrm{SiC}$ support tube. The tests were run at $1100^{\circ} \mathrm{C}$ in gettered Ar. The data (load, deflection, ppm $\mathrm{O}_{2}$ and temperature) was collected at $r$, rate of one data point per second.

Two series of tests were run. In both series, the samples were loaded at a crosshead speed of $.002 \mathrm{in} . / \mathrm{min}$, until they failed. This was done in order to determine $\mathrm{P}_{\max }$ (maximum load) and $\mathrm{K}_{\mathrm{Q}}$. In the first series the samples were machine notched with a diamond blade saw to fractional crack lengths ( $a$ lpha $=a / W$ ) ranging from 0.17 to 0.7 and then tested. The notch had a radius of approximately $0.33 \mathrm{~mm}$.

In the second series, a crack was slowly grown (SCG) from an alpha of 0.17 to varying lengths, ranging from alpha equal to 0.3 to 0.5 . The SCG process was achieved by loading the sample to a $\mathrm{K}$ (stress intensity) of $7.5 \mathrm{MPa} \mathrm{m}^{1 / 2}$ and then holding the load within a range of $10 \mathrm{~N}$ until the desired crack length was reached. The crack length was determined by unloading the sample to $300 \mathrm{~N}$ in order to determine the secant compliance $\left(\mathrm{C}_{\text {load }}\right)$. The SENB specimen compliance depends on alpha in a known manner [3]. The measured compliance of the specimens, determined from the linear portion of the load-deflection curve, was used to calculate the modulus and, once that information was obtained, alpha was calculated for a given compliance by inverting the expression for $\mathrm{C}($ alpha). Once the correct crack length was reached, the sample was unloaded and then fractured in the same manner as was used for the machine notched samples.

\section{Experimental results}

A comparison of the load-displacement curves of SCG and machine notched samples at various values of alpha shows that the maximum load decreases with increasing notch depth in the machine notched samples. This is the response expected without bridging (figure 2). In the SCG samples (figure 3), however, the maximum load remains close to the same value. When the load-displacement curves at similar alphas are compared (figure 4), the SCG sample reaches a maximum load nearly twice that of the machine notched sample. 
Table 1. Maximum Load and $\mathrm{K}_{\mathrm{Q}}$ versus Notch Depth for Machined and SCG Prepared Cracks, $1100 \mathrm{C}$ in Ar. The two series of tests are listed in order of increasing alpha $(\mathrm{a} / \mathrm{w})$.

\begin{tabular}{||l|l|l|l|l|}
\hline Sample & Series & alpha $(\mathrm{a} / \mathrm{w})$ & $\mathrm{P}_{\max }$ & $\mathrm{K}_{\mathrm{Q}}$ \\
\hline 19 & machine notch & 0.18 & 963 & 13.41 \\
\hline 7 & machine notch & 0.22 & 924 & 15.07 \\
\hline 6 & machine notch & 0.31 & 860 & 16.37 \\
\hline 24 & machine notch & 0.31 & 744 & 15.74 \\
\hline 16 & machine notch & 0.41 & 546 & 12.83 \\
\hline 30 & machine notch & 0.42 & 611 & 15.99 \\
\hline 15 & machine notch & 0.50 & 466 & 15.69 \\
\hline 28 & machine notch & 0.59 & 294 & 13.60 \\
\hline 17 & machine notch & 0.60 & 391 & 17.29 \\
\hline 27 & machine notch & 0.66 & 184 & 13.05 \\
\hline 26 & machine notch & 0.69 & 184 & 13.05 \\
\hline 35 & SCG notch & 0.31 & 1082 & 21.60 \\
\hline 21 & SCG notch & 0.31 & 1062 & 20.58 \\
\hline 34 & SCG notch & 0.34 & 1036 & 22.81 \\
\hline 33 & SCG notch & 0.41 & 1161 & 29.69 \\
\hline 20 & SCG notch & 0.43 & 1029 & 26.23 \\
\hline 25 & SCG notch & 0.47 & 1231 & 36.12 \\
\hline
\end{tabular}




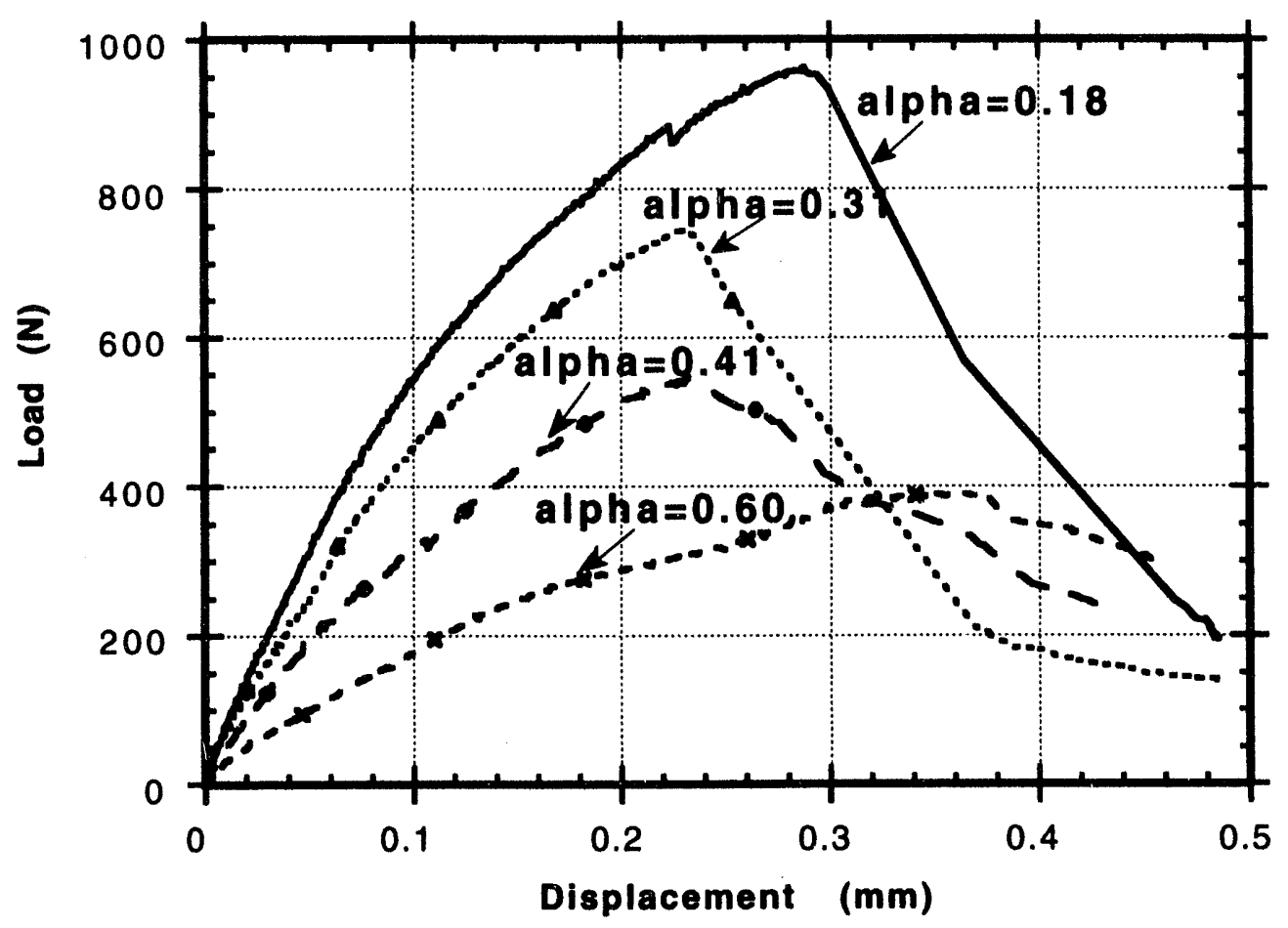

Fig. 2. Comparison of load-deflection curves for varying notch depths, values of alpha, of the machined notch specimens.

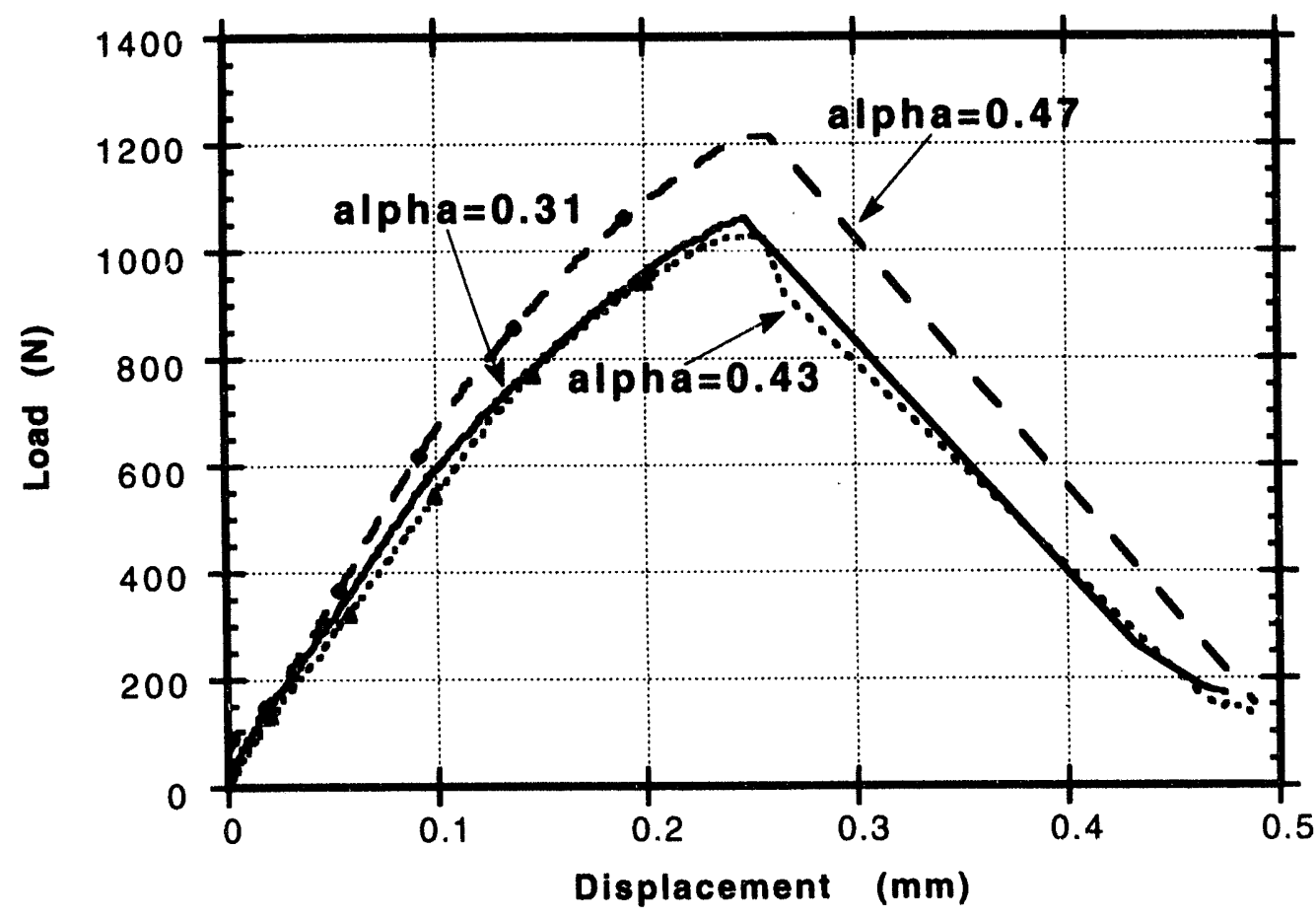

Fig. 3. Comparison of load defleciton curves for varying crack lengths, where the cracks were grown by SCG. 


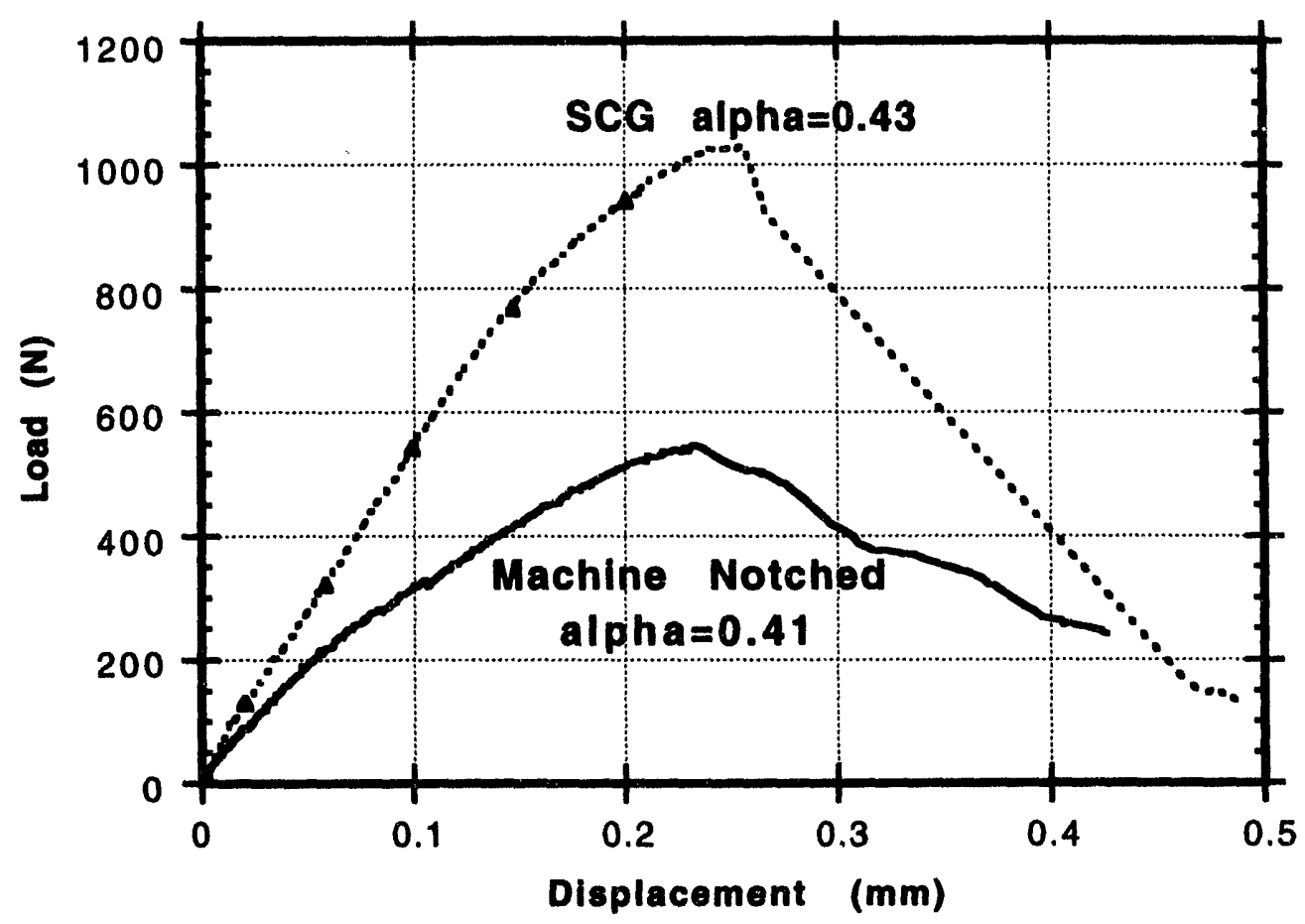

Fig. 4. Comparison of load-deflection curves for machine-notch specimen and SCG specimen for essentially equal crack lengths.

Finally the $K_{Q}$ values are compared in figure 5. The $K_{Q}$ values for these tests was determined from the peak load $\left(\mathrm{P}_{\max }\right)$ which the sample had reached. $\mathrm{K}_{\mathrm{Q}}$ is then calculated from:

$$
K_{Q}=P_{\max } Y_{1}(\text { alpha }) /(B \sqrt{ } W)
$$

were $P_{\max }$ is the peak load, $B$ is the specimen width, $W$ is the specimen thickness, and $Y_{1}$ (alpha) is the dimensionless stress intensity factor for the SENB specimen in pure bending [3]. The machine notched samples form a baseline $K_{Q}$ that is independent, within acceptable scatter, of alpha. The SCG samples, on the other hand, not only are tougher, starting at a higher $\mathrm{K}_{\mathrm{Q}}$, but also exhibit increasing $\mathrm{K}_{\mathrm{Q}}$ with increasing alpha. Contrary to expectations, however, they did not level out into an equilibrium zone, but indicate that the bridging zone is still developing even for values of alpha equal to 0.5 . 


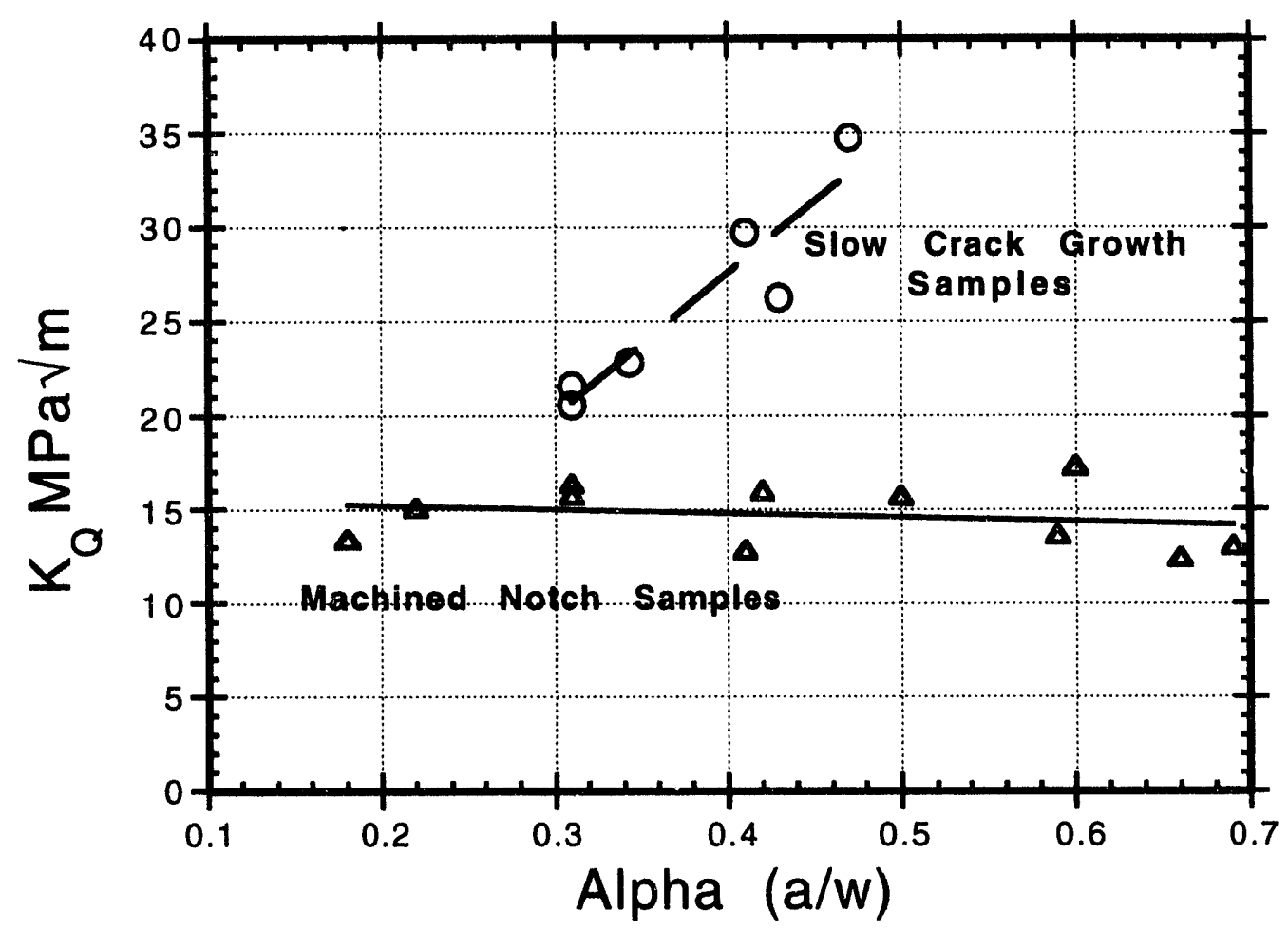

Fig. 5. Computed values of $\mathrm{K}_{\mathrm{Q}}$ as a function of alpha ( $\left.\mathrm{a} / \mathrm{w}\right)$ showing a comparison of the toughness of samples machine-notched and those with SCG cracks.

\section{$\underline{\text { Discussion }}$}

As predicted, the SCG samples had substantially higher $\mathrm{K}_{\mathrm{Q}}$ values and reached higher maximum loads than the machine-notched samples. There are two possible explanations for this behavior that are most likely acting in concert to create the observed result. The first and primary cause is crack wake bridging in the SCG samples that shields or reduces the crack-tip stress intensity. Thus, $\mathrm{K}_{\mathrm{Q}}$ becomes time-dependent. The slower the crack is grown, the more time the fibers have to creep and bridge the crack rather than break.

Therefore, up to some limit, the longer the crack is grown by SCG, the greater the $\mathrm{K}_{\mathrm{Q}}$ should be. This explains the increase in $\mathrm{K}_{\mathrm{Q}}$ in the SCG samples. At some point, the bridging zone should reach an equilibrium length and $\mathrm{K}_{0}$ would stop increasing. The bridging zone did not reach an equilibrium in crack lengths up to an alpha of 0.5 . Therefore, either the equilibrium length has not been reached or else it can't be reached under these test parameters or specimen size.

When the samples are fractured using a constant crosshead speed, the crack velocity exceeds the creep rate of the fibers and the bridging zone is shorter than it is during SCG. Consequently, if the fibers don't have time to creep, they break sooner and span a shorter bridging length. The increased $\mathrm{K}_{\mathrm{Q}}$ of the SCG sampies is due to bridging which has already been formed during the preparatory period of slow crack growth. The machine-notched specimens, however, start off without any bridging and only form a short bridging zone during the fracture test and therefore manifest a lower $\mathrm{K}_{\mathrm{Q}}$.

A second possible cause for the observed behavior is crack bifurcation (multiple cracking). The branching of cracks would cause a greater compliance for a given crack length. This is because no single crack-tip 
would experience the entire applied strain. The result of this greater compliance would be an increased toughness and higher $\mathrm{K}_{\mathrm{Q}}$. This result could also increase with greater crack length as cracks continued to branch, producing an exponentially increasing number of cracks. It is doubtful, however, that this behavior would produce an increase of the magnitude observed. It most likely contributes to the result, but is probably not the entire cause.

\section{FUTURE DIRECTION}

Physical and mechanical property tests will be conducted on samples irradiated in MOTA 2B and COBRA $1 \mathrm{~A}$ at temperatures of 400 to $800 \mathrm{C}$ and up to a fluence of $50 \mathrm{dpa}$. Also, further baseline testing will be conducted to evaluate effects such as effects of fatigue and oxygen on the increase in $\mathrm{K}_{\mathrm{Q}}$ with growth of cracks by SCG, and temperature dependence of crack growth.

\section{ACKNOWLEDGMENTS}

Special thanks are given to J. L. Humason for his testing expertise. This work was supported by Basic Energy Sciences under US Department of Energy (DOE) Contract DE-AC06-76RLO 1830 with Battelle Memorial Institute that operates Pacific Northwest Laboratory for DOE.

\section{REFERENCES}

1. A. G. Evans, J. Am. Ceram. Soc., 73 (1990) 187.

2. T. Fett, J. Am. Ceram. Soc., 75 (1992) 3133

3. C. H. Henager, Jr., and R. H. Jones, Materials Science and Engineering, A166 (1993) 211. 
POST-IRRADIATION ANALYSIS OF FIBER DEBONDING AND PULL-OUT IN SiC-SiC COMPOSITES ${ }^{1}$ A.El-Azab and N.M. Ghoniem, University of California, Los Angeles

\section{OBJECTIVE}

The objective of this work is to develop a calculational model for fiber debonding and pull-out in irradiated SiC-SiC composites, so that the effects of irradiation variables, such as neutron fluence and irradiation temperature, on debonding behavior and pull-out toughness can be studied.

\section{SUMMARY}

The toughness of SiC-SiC composites is contributed by crack bridging, matrix crack deflection, fiber debonding and pull-out and other minor effects. Fiber pull-out toughening relies on the debonding and frictional characteristics of the fiber-matrix interface. The interface friction depends on the interface pressure (i.e., on misfit strains) and interface roughness. An earlier study by the present authors [1] has shown that misfit strain in $\mathrm{SiC}-\mathrm{SiC}$ composites undergo complex changes under neutron irradiation due to irradiation-induced creep and swelling. The present work complements the study presented in Ref. [1] by developing a calculational model for post-irradiation fiber debonding and pull-out toughness in $\mathrm{SiC}-\mathrm{SiC}$ composites. It is shown that fiber debonding and pull-out toughness in SiC-SiC composites vary significantly with neutron fluence and irradiation temperature, which is a direct consequence of the dependence of the misfit strain on these irradiation variables.

\section{PROGRESS AND STATUS}

\section{Introduction}

$\mathrm{SiC}-\mathrm{SiC}$ composites ive been proposed for structural applications in fusion reactor first walls and blankets. The frac e toughness of these composites can be measured from work-of-fracture experiments, and can be theoretically determined by investigating the mechanisms of energy dissipation during composite failure. In addition to matrix toughness and matrix crack deflection, two other contributions are considered important in toughening $\mathrm{SiC}-\mathrm{SiC}$ materials. First is the crack-tip bridging by intact fibers, which contributes a closure traction and lowers the stress intensity at the cracktip. This contribution is important in case of small cracks. The sea ' contribution is caused by fiber debonding, fiber fracture and pull-out, which occurs at significant crack openings, thus involving energy dissipation by interface friction. Fiber bridging, debonding and pull-out depend on the composite mismatch stresses, i.e., on misfit strains.

Neutron irradiation alters the composite behavior in a complex fashion. In addition to basic property changes under irradiation, irradiation-induced swelling and creep change the mismatch stress state, which has a direct influence on the fracture strength and toughness of SiC-SiC composites. Detailed calculations of the time-evolution of mismatch stresses in SiC-SiC comnosites under high-temperature neutron irradiation are performed[1]. General inelastic constitutive equations for $\mathrm{SiC}$ fibers and $\mathrm{SiC}$ matrix, which are developed by the present authors [2] are used for that purpose. It is found that misfit strains change significantly during early irradiation, and that long term changes depend on helium swelling and creep only, regardless of the initial thermal mismatch state. Accordingly, fiber debonding and pull-out behavior are expected to depend on the neutron fluence. In the present work, we calculate the post-irradiation pull-out toughness and fiber debonding in $\mathrm{SiC}-\mathrm{SiC}$ composites as functions of neutron fluence and irradiation temperature.

\footnotetext{
${ }^{1}$ This material is based upon work supported by the U.S. Department of Energy under award number DE-FG0391ER54115.
} 


\section{Fiber debonding}

Micromechanics of fiber pull-out and debonding makes use of the concentric cylinder model. It consists of a single fiber in a matrix with the outer radius determined such that the fractional cross sectional area of fiber is equal to fiber volume fraction. While approximate models for fiber debonding have been developed $[3,4]$, a more accurate treatment is conducted by Gao et al. [5], which is followed in the present analysis. It relies on the principle of conservation of energy for debond crack extension with frictional sliding. The fiber debonding criterion is written as [5]:

$$
\frac{\gamma}{R_{f}}=-\frac{\sigma_{f}(0)}{4} \frac{\partial u_{f}(0)}{\partial L_{d}}-\frac{1}{2 R_{f}} \int_{0}^{L_{d}}\left[\tau_{0}-\mu q(z)\right] \frac{\partial u_{r}(z)}{\partial L_{d}} d z
$$

where $\gamma$ is the interface fracture energy, $R_{f}$ is the fiber radius, $\sigma_{f}(0)$ is the stress at the fiber's end, $u_{f}(0)$ is the fiber's end displacement, $L_{d}$ is the debond length, $\mu$ is the friction coefficient, $q(z)$, is the interface pressure at $0<z<L_{d}$, and $\tau_{0}$ is a constant friction stress due to roughening of the interface under irradiation. In the original model of Gao et al. [5] the parameter $\tau_{0}$ is not included. $u_{r}(z)$ is the relative displacement between fiber and matrix. Expressions for $u_{r}(z)$ and $u_{f}(0)$ are given in terms of the axial fiber and matrix strains, $\epsilon_{f}(z)$ and $\epsilon_{m}(z)$ by:

$$
u_{r}(z)=\int_{z}^{L_{d}}\left[\epsilon_{f}(z)-\epsilon_{m}(z)\right] d z, \quad u_{f}(0)=\int_{0}^{L_{d}} \epsilon_{f}(z) d z
$$

By representing the frictional shear stress at fiber-matrix interface as $\tau=\tau_{0}-\mu q$ and following Gao et al. [5], the axial fiber stress, $\sigma_{f}$, the axial matrix stress, $\sigma_{m}$, and the interface pressure, $q$, can be written as:

$$
\begin{aligned}
\sigma_{f}(z) & =\sigma_{f}(0)+\frac{\mu q(0)-\tau_{0}}{\mu c}\left[\exp \left(\frac{2 \mu c z}{R_{f}}\right)-1\right] \\
\sigma_{m}(z) & =-\frac{\mu q(0)-\tau_{0}}{\mu c}\left(\frac{f}{1-f}\right)\left[\exp \left(\frac{2 \mu c z}{R_{f}}\right)-1\right] \\
q(z) & =\frac{\tau_{0}}{\mu}\left[1-\exp \left(\frac{2 \mu c z}{R_{f}}\right)\right]+q(0) \exp \left(\frac{2 \mu c z}{R_{f}}\right)
\end{aligned}
$$

in which $f$ is the fiber volume fraction, and $g(0)$ is the interface stress at the fiber's end and is given by $q(0)=\left(c_{1} \sigma_{f}(o)+c_{3} \Delta \epsilon_{i n}\right) / c_{4}$. It can be shown that, by eliminating the terms containing $\tau_{0}$ in eq. (3), the expressions for $\sigma_{f}(z), \sigma_{m}(z)$, and $q(z)$ reduce to those given in Ref. [5]. The constants $c, c_{1}, c_{3}$ and $c_{4}$, depend on the elastic constants of fiber and matrix and given by: $c_{1}=E_{m}(1-f) \nu_{f}, c_{3}=$ $E_{m}(1-f) E_{f}, c_{4}=E_{m}(1-f)\left(1-\nu_{f}\right)+E_{f}\left[1+\nu_{m}+f\left(1-\nu_{m}\right)\right], c=\left(c_{1}-f E_{f} \nu_{m}\right) / c_{4}$. Using stress-strain relationships, and eq. $(2), u_{r}(z)$ and $u_{f}(0)$ can be found in terms of $L_{d}$ and $\sigma_{f}(0)$. Then by employing eq. (1), a transcendental equation for the debond length $L_{d}$ in terms of $\sigma_{f}(9)$, $\gamma$ and $\Delta \epsilon_{i n}$ can be obtained. The interface debonding energy is then given by $\Gamma=2 \pi R_{f} L_{d} \gamma$.

In SiC-SiC composites, a graphite thin layer $(\sim 1 \mu \mathrm{m})$ is employed as a fiber-matrix interface. If the composite is heavily irradiated, the specific fracture energy of the interface is expected to change due to two effects; atomic mixing and helium bubble formation at the interface. Considering helium bubble formation alone, it can be shown that the irradiated interface fracture energy is given by $\left(1-\frac{\Delta V}{V}\right) \gamma$, which does not deviate much from the unirradiated value since helium swelling, $\frac{\Delta V}{V}$, is only a few percent. Atomic mixing, on the other hand, can be the primary effect influencing the interface fracture energy, since the atomic composition in the interface layer will be altered. Specific experiments to measure the interface fracture energy as function of neutron fluence are not available at the present time. We will therefore consider the interface fracture energy as a parameter in our study. 
Fiber pull-out

Fiber failure follows debonding if the crack opening displacement (COD) is significant. It is a statistical process, which is described by a Weibull-type analysis [3]. Usually fibers start to fail at COD of the order of $R_{f}$. Fibers then are pulled out of the matrix, with significant energy dissipation by frictional sliding. Detailed treatment of fiber pull-out, with statistical failure distribution, is given in Ref. [6]. At failure, the average fiber failure length, $h$, depends on the fiber stress state and in turn on the misfit strain. Statistical failure of fibers is not included in the present analysis, and hence the average failure length, $h$, is fixed.

Upon fiber failure, the fiber stress at the failure location drops to zero. Using the first of eqs.(3), the relationship between $\sigma_{f}(0)$ and the crack opening displacement, $\Delta$, can be written as:

$$
\sigma_{f}(0)=\frac{2 c_{4}(h-\Delta)}{2 \mu c_{1}(h-\Delta)+c_{4} R_{f}}\left[\tau_{0}-\frac{\mu c_{3} \Delta \epsilon_{\text {in }}}{c_{4}}\right]
$$

where $\exp \left(\frac{2 \mu c z}{R_{f}}\right)$ is approximated by $1+\frac{2 \mu c z}{R_{f}}$. The steady state pull-out toughness is then determined by:

$$
W_{p}=f \int_{0}^{h} \sigma_{f}(0) d \Delta=\frac{2 f\left(c_{4} \tau_{0}-\mu c_{3} \Delta \epsilon_{i n}\right) R_{f}}{2 \mu c_{1}} H\left(h / R_{f}\right)
$$

where $H\left(h / R_{f}\right)$ is a dimensionless function given by:

$$
H\left(h / R_{f}\right)=\frac{\left(h / R_{f}\right)^{2}}{\left(h / R_{f}\right)+a}-a \log _{e}\left(\frac{a}{\left(h / R_{f}\right)+a}\right)+a^{2}\left(-a^{-1}+\frac{1}{\left(h / R_{f}\right)+a}\right)
$$

where $a=c_{4} / 2 \mu c_{1}$.

\section{Misfit strain history}

As shown in eqs. (4) and (5), the stress distribution in fiber and matrix, the interface pressure, and the pull-out toughness depend on the misfit strain, $\Delta \epsilon_{i n}$. Viscoelastic analysis of the evolution of the misfit strain conducted in Ref. [1] has shown that the misfit strain can be represented as a function of irradiation time, $t$, by:

$$
\Delta \epsilon_{i n}(t)=g(t) \Delta \epsilon_{t h}+\int_{0}^{t} g\left(t-t^{\prime}\right) \frac{d \Delta \epsilon_{s}\left(t^{\prime}\right)}{d t^{\prime}} d t^{\prime}
$$

in which $g(t)$ is a function of the relaxation moduli of fiber and matrix, $\Delta \epsilon_{t h}$ is the initial thermal misfit strain, and $\Delta \epsilon_{s}(t)$ is the differential swelling strain. The thermal misfit decays quickly as irradiation proceeds. A differential swelling of $10 \%$ of matrix swelling is considered. The latter consists of two components; lattice (loop) swelling which saturates early during irradiation and the long term helium swelling component [2]. Calculations are performed for the ARIES IV fusion reactor first wall conditions [7]. By defining the following set of constants,

$$
\begin{aligned}
& a_{1}=c_{4} \\
& a_{2}=-2\left[E_{m}(1-f) \nu_{f}+f E_{f} \mu_{m}\right] \\
& b_{1}=f \nu_{m} E_{f}-(1-f) \nu_{f} E_{m} \\
& b_{2}=(1-f) E_{m}+f E_{f} \\
& f_{e}=E_{f} E_{m}(1-f) \frac{b_{2}-b_{1}}{a_{1} b_{2}-a_{2} b_{1}}
\end{aligned}
$$




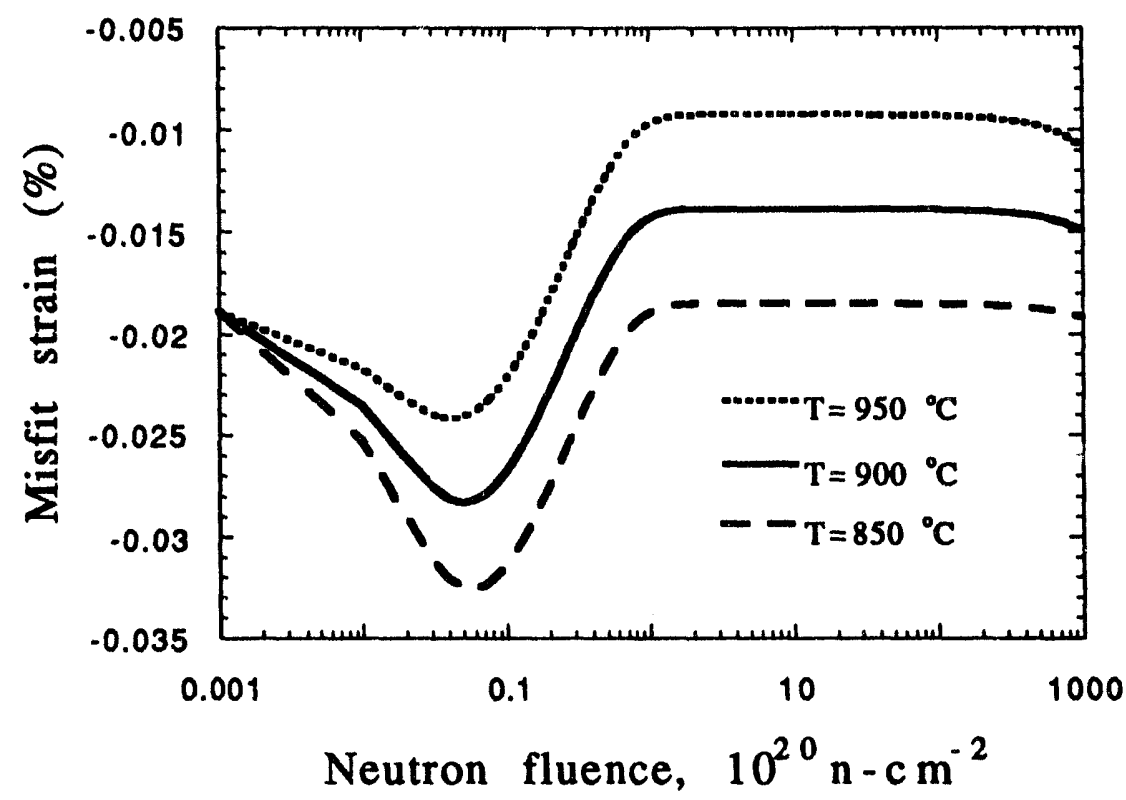

Figure 1: Evolution of misfit strain under ARIES IV First wall conditions

the function $g(t)$ is then given by $g(t)=f_{v}(t) / f_{e}$, where $f_{v}(t)$ has the same expression as $f_{e}$ with the elastic constants $E_{f}$ and $E_{m}$ being replaced by the time-dependent relaxation moduli $E_{f}(t)$ and $E_{m}(t)$, respectively.

\section{Discussion}

Calculations of debond length and pull-out toughness are carried out for SCS-6 fibers and CVD $\mathrm{SiC}$ matrix. The fibers and matrix properties are: $E_{f}=420 \mathrm{GPa}, \nu_{f}=0.3, E_{m}=380 \mathrm{GPa}$ and $\nu_{m}=0.2$. In ceramic matrix composites the interface fracture energy has been always designed to be less than $20 \%$ of the fracture energy of the matrix [8]. Therefore, the specific fracture energy of interface, $\gamma$, is taken to be one tenth of CVD SiC surface energy which is $1 \mathrm{~J}^{-m^{-2}}$ [2]. Nicalon fibers are excluded since they spontaneously debond from the matrix at low fluence, which has been shown theoretically [1] and confirmed experimentally [9]. Such behavior is attributed to the significant shrinkage of Nicalon fibers under irradiation. The temperature effect on the spontaneous debonding of Nicalon fibers from CVD SiC matrix has not been experimentally investigated.

In Fig. 1, the evolution of misfit strain in SiC-SiC composites is shown for ARIES IV first wall conditions. It is shown that the instantaneous state of misfit strain is far different from the initial value, which is left from the manufacturing step. Fig. 2 shows the debond length as a function of fluence and and temperature at $\sigma_{f}(0)$ of $100 \mathrm{MPa}$. At very low fluences, the debond length decreases since lattice swelling dominates relaxation by creep. After lattice swelling saturates, the misfit strain relaxes which reduces the interface pressure, thus allowing more debonding to occur. At large fluences, slower evolution of the debond length occurs since helium swelling and irradiation creep fairly balance each other. The saturation level depends on the misfit strain at the end of the loop swelling phase. The latter increases as the irradiation temperature decreases. Therefore, the debonding energy, which is proportional to $L_{d}$, depends on the irradiation temperature.

Fig. 3 shows the dependence of pull-out toughness on neutron fluence and the pull-out length, $h$. At low fluences, a sharp decrease is observed. This is caused by the fast relaxation of the misfit strain, which controls the interface friction. At higher fluences, however, a slow recovery is observed due to the recovery of misfit strain. The pull-out length, $h$, depends on the fiber Weibull parameters 


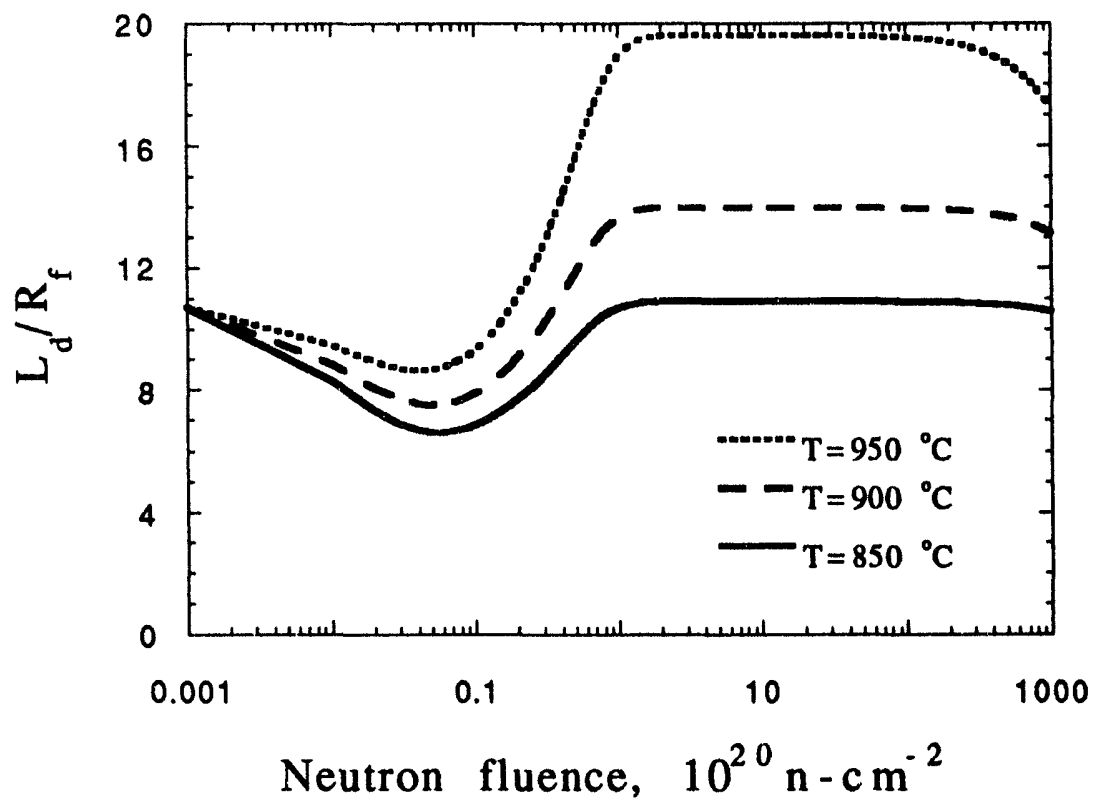

Figure 2: Debonding length as function of neutron fluence and irradiation temperature $\left(\sigma_{f}(0)=\right.$ $100 \mathrm{MPa}, \tau_{0}=2 \mathrm{MPa}, \mu=0.1$ ).

and the misfit, with the latter controlling the axial fiber stress state. However, larger values of pull-out length are favorable. Fig. 4 shows the trends of the pull-out toughness with irradiation temperature. At lower temperatures, since the saturation level of misfit strain is higher, friction at, the interface is enhanced and the pull-out resistance is higher. The calculated pull-out toughness for $\mathrm{SiC}-\mathrm{SiC}$ composites is within the range of pull-out toughness of typical ceramic matrix composites. For example, experimental measurements have shown a pull-out toughness of $80 \mathrm{MJ} / \mathrm{m}^{2}$ for silicon nitride matrix reinforced by carbon fibers [10].

The present calculations give first order estimation for the debonding and pull-out behavior of irradiated $\mathrm{SiC}-\mathrm{SiC}$ composites. In principle, it has been shown that fiber-matrix interface debonding and pull-out depend on the irradiation history (neutron fluence and temperature ). To obtain more accurate results for pull-out toughness, fiber failure statistics must be included to avoid the assumption of an average pull-out length. Since misfit strains change dramatically due to irradiation-induced creep and differential swelling between fibers and matrix, it is necessary to consider these changes in optimizing SiC-SiC composites for fusion first wall and blanket applications. Although postirradiation calculations are considered in the present work, modeling of in-service fiber debonding and pull-out toughness for $\mathrm{SiC}-\mathrm{SiC}$ composites requires consideration of the viscoelastic response of both fibers and matrix under neutron irradiation. Viscoelastic energy dissipation during fiber pull-out can be an important contribution to composite toughness. 


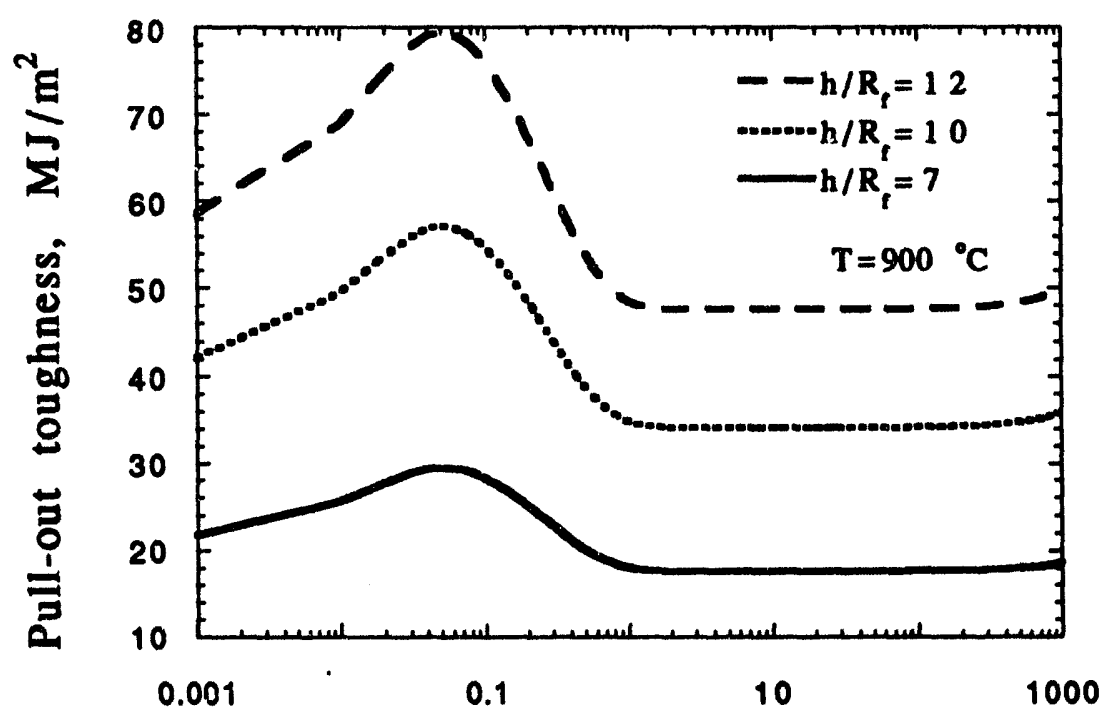

Neutron fluence, $10^{20} \mathrm{n}-\mathrm{cm}^{-2}$

Figure 3: Pull-out toughness as function of neutron fluence and pull-out length $\left(T=900^{\circ} \mathrm{C}, \tau_{0}=\right.$ $2 \mathrm{MPa}, \mu=0.1$ ).

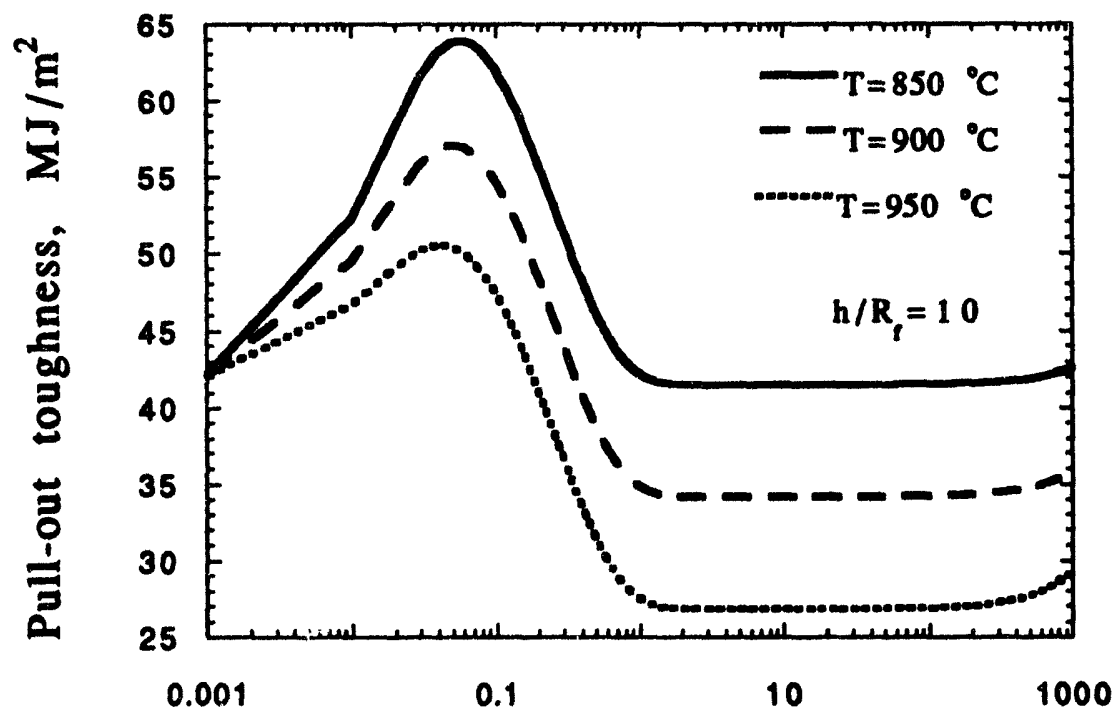

Neutron fluence, $10^{20} \mathrm{n}-\mathrm{cm}^{-2}$

Figure 4: Pull-out toughness as function of neutron fluence and irradiation temperature $\left(h / R_{f}=10\right.$, $\tau_{0}=2 \mathrm{MPa}, \mu=0.1$ ). 


\section{FUTURE WORK}

Viscoelastic effects are now under consideration to advance the developed model to predict the in-service toughness of $\mathrm{SiC}-\mathrm{SiC}$ composites under high-temperature neutron irradiation.

\section{References}

[1] A. El-Azab and N. M. Ghoniem, 'Viscoelasitic Analysis of Residual Mismatch Stresses in Ceramic-Matrix Composites Under High-Temperature Neutron Irradiation', submitted to Mech. of Materials (1993).

[2] A. El-Azab and N. M. Ghoniem, ' Phenomenological Inelastic Constitutive Equations for SiC$\mathrm{SiC}$ Composites Under Irradiation', submitted to Fusion Tech. (1993).

[3] L. S. Sigl and A. G. Evans, Mechanics of Materials 8 (1989) 1.

[4] J. W. Hutchinson and H. M. Jensen, Mech. of Materials 9 (1990) 139.

[5] Yu-Chen Gao, Yiu-Wing Mai, and Brian Cotterell, J. Appl. Math. Phys. 39 (1988) 550.

[6] M. D. Thouless and A. G. Evans, Acta Metall. 36 (1988) 517.

[7] F. Najmabadi, R. W. Conn and the ARIES Team,' The ARIES II and ARIES IV Second Stability Tokamak Reactor Study- Final Report,' UCLA-PPG 1461, In preparation.

[8] Anthony G. Evans, J. Am. Ceram. Soc. 73[2] (1990) 187.

[9] L. Sneed, D. Steiner and S. J. Zinkle, J. Nucl. Mater. 191-194(1992) 566.

[10] T. Suzuki, M. Sato and M. Sakai, J. Mater. Res. 7(1992) 2869. 
RADIATION EFFECTS ON NICALON POLYMER PRECURSOR FIBERS - L. L. Snead (Oak Ridge National Laboratory), M. Osborne (Rensselaer Polytechnic Institute), K. L. More (Oak Ridge National Laboratory)

\section{SUMMARY}

This paper presents a summary of the radiation effects in the Nicalon polymer precursor fiber. It is shown that the serious degradation previously seen in this fiber (and fiber composite) is primarily due to the presence of a silicon oxycarbide phase. Results supporting this interpretation include microstructural analysis as well as post irradiation mechanical property measurements. Preliminary results on the effects of radiation on low oxygen Nicalon fibers are presented. The reduced oxygen fibers have shown radiation induced density, strength, Weibull's and Young's moduli changes typical for ceramic materials. This contrasts sharply with the poor irradiation behavior of the standard Nicalon fiber and suggests that improved radiation resistance can be expected in $\mathrm{SiC} / \mathrm{SiC}$ composites fabricated with low oxygen Nicalon.

\section{PROGRESS AND STATUS}

Introduction

The use of silicon carbide ( $\mathrm{SiC}$ ) composites as structural materials in fusion systems has recently become attractive mainly due to the development of high strength, continuous $\mathrm{SiC}$ fibers. Such fibers can be woven in various architectures and the preforms infiltrated with a $\mathrm{SiC}$ matrix by various methods, yielding a composite with strengths reported as high as $600 \mathrm{MPa}$. Another very attractive feature of these materials is that a degree of toughness can be designed into the composite by the application of a compliant interfacial layer between fiber and matrix. This layer allows the load to be transferred from the matrix to the high strength fiber though at high loads debonds causing fiber pull-out and crack bridging, thus increasing toughness.

Silicon carbide fibers are commercially processed through many different routes. The most common route is by decomposition of polymer precursor material and will be discussed more fully later. A second, common commercial $\mathrm{SiC}$ fiber is processed by chemically vapor depositing CVD $\mathrm{SiC}$ onto a pitch carbon core. This is the process which is used to produce the AVCO SCS-6 fiber. The pitch carbon filament on which the CVD is grown is $8 \mathrm{~mm}$ in diameter onto which a $140 \mathrm{~mm} \mathrm{CVD} \mathrm{SiC} \mathrm{fiber} \mathrm{is} \mathrm{grown.} \mathrm{The} \mathrm{size}$ of this fiber and consequently its stiffness, yield a fiber which is impossible to weave and therefore is not desirable for fabricating composites. However, if the diameter were decreased substantially, this fiber would have very attractive features from a radiation resistance point of view as its unirradiated and irradiated properties would be very similar to a CVD SiC infiltrated matrix. A summary of the properties of the fibers to be discussed are given in Table 1.

Table 1. Silicon Carbide Fiber Data

\begin{tabular}{lccccc}
\hline & $\begin{array}{c}\text { Modulus } \\
(\mathrm{GPa})\end{array}$ & $\begin{array}{c}\text { Strength } \\
(\mathrm{GPa})\end{array}$ & $\begin{array}{c}\text { Density } \\
(\mathrm{g} / \mathrm{cc})\end{array}$ & $\begin{array}{c}\text { Diameter } \\
(\mu \mathrm{m})\end{array}$ & $\begin{array}{c}\text { Max. Use } \\
\text { Temp }\left({ }^{\circ} \mathrm{C}\right)\end{array}$ \\
\hline $\begin{array}{l}\text { Standand nicalon } \\
\text { Low Oxygen nicalon }\end{array}$ & 220 & 2.6 & 2.55 & 14 & $<1200$ \\
MER Conv. T-300 & 270 & 2.8 & 2.74 & 14 & $>1400$ \\
AVCO SCS-6 & - & 2.0 & 3.0 & 6 & $>1200$ \\
& 410 & 3.45 & 3.05 & 140 & 1300 \\
\hline
\end{tabular}

- A less common, but attractive option for the production of fibers is by direct conversion of graphite fibers to SiC. ${ }^{2}$ This has been demonstrated for both fiber tows and for batch processing of plain weave fabric by the MER Corporation. The process for conversion uses the general reaction:

$$
2 \mathrm{C}(\mathrm{s})+\mathrm{SiO}(\mathrm{g})=\mathrm{SiC}(\mathrm{s})+\mathrm{CO}(\mathrm{g})
$$


Graphite tows or fabric are simply reacted in a high temperature furnace with the carbon monoxide gas and begin to convert from the outside of the fiber inward. Strengths have been reported ${ }^{2}$ of over $2 \mathrm{GPa}$ for the fiber with elastic moduli approaching pure silicon carbide. Typically, the microstructure of these fibers depends on the grain structure of the starting graphite fiber but are microcrystalline with grain sizes varying from $0.025 \mathrm{~mm}$ to $0.1 \mathrm{~mm}$. Fiber density is in the range of 2.8 to $3.1 \mathrm{~g} / \mathrm{cc}$ depending on processing conditions. Of particular interest for these fibers is the very good high temperature strength and excellent creep resistance. While these fibers are attractive as composite reinforcement, the limited work to date on processing the fabric into composite has not yielded reasonable toughness and strength. Development is continuing, however.

The most widely studied, developed and commercialized $\mathrm{SiC}$ fiber system is derived from the polymer precursor process first introduced by Yajima. ${ }^{3}$ The fibers are commercially available under the trade name Nicalon. ${ }^{4}$ The first stage of the Nicalon process involves the low temperature melt-spinning of the organosilane polymer polycarbosilane (PCS). These spun fibers, which are in the fragile "green state" are then stabilized by elevated temperature exposure to oxygen and successively ceramized in an inert atmosphere to a final temperature of $1300^{\circ} \mathrm{C}$. Because of the relatively low price, good mechanical properties, and excellent weavability of these fibers, they have found use both in the laboratory as well as in industry.

It is important to note that because of the presence of oxygen that these can only be considered a SiC based fiber. The manufacturer's quoted composition for Nicalon NLM-202 is for a fiber containing $65 \% \mathrm{~b}-\mathrm{SiC}$ with $23 \% \mathrm{SiO} 2$ and $11 \%$ free carbon. It should be noted that the actual elemental content and structure of Nicalon has been widely debated. ${ }^{5-8}$ Laffon $^{9}$ and Porte ${ }^{8}$ have published comprehensive work on the structure of Nicalon and describe a crystal structure with approximately the same elemental content as provided by the manufacturer, though with a more complex structure. Both researchers describe the system as a dispersal of $\mathrm{b}$-SiC crystallites of a few nanometers size in a continuum of glassy silcon oxycarbide matrix $\left(\mathrm{Si}-\mathrm{O}_{x}-\mathrm{C}_{\mathbf{y}}\right.$, where $\mathrm{x}+\mathrm{y}$ is approximately 4 .)

The greatest drawback of the Nicalon fiber is its tendency for the oxygen to evolve from the fiber, forming $\mathrm{SiO}$ at temperatures $>1000^{\circ} \mathrm{C} .{ }^{14}$ For this reason the fiber is referred to as "thermally unstable," and as will be shown later, is also the reason for its instability under irradiation. Recently, the Nicalon fiber properties have been improved by altering the means of cross-linking the spun polymer. Rather than curing the PCS in air, the material was subjected to ionizing radiation in the presence of a helium environment. This method of cross linking the PCS was first used with ultraviolet light, ${ }^{11,12}$ though the most successful demonstration uses electron irradiation and is described by Seguchi ${ }^{13}$ and Okamura ${ }^{14}$ for Nicalon. This process has yielded fiber with oxygen content ranging from a few to one percent of oxygen. The resulting fiber has superior mechanical properties and has a service temperature hundreds of degrees higher than standard Nicalon $\left(>1400^{\circ} \mathrm{C}\right)$.

From a composite radiation damage point of view it will be most desirable to have fiber and matrix material of very similar material. If this is accomplished, the volumetric and strength changes in the constituents will be identical and interface related problems avoided. While the reduced oxygen material is still significantly less dense than CVD SiC (Table 1), the crystal structure is approaching "pure" silicon carbide. Figure 1 shows the $\mathrm{X}$-ray diffraction patterns from the four materials discussed. The first two plots (Figures 1a,b) show the effect of reducing the oxygen content in Nicalon. It is obvious that the silicon carbide peaks have been more clearly defined due to the supression of the silicon oxycarbide phase. The amorphous background has been significantly reduced. However, the peaks are still not as defined as is evidenced by the CVD material of Figure 1c. Figure 1d also shows the diffraction pattern for a $60 \%$ converted MER fiber. This fiber has been converted radially inward but still posesses an graphite core which makes up $40 \%$ (by volume) of the fiber. The silicon carbide peaks for this material are defined along with the (0002) peak for graphite. 


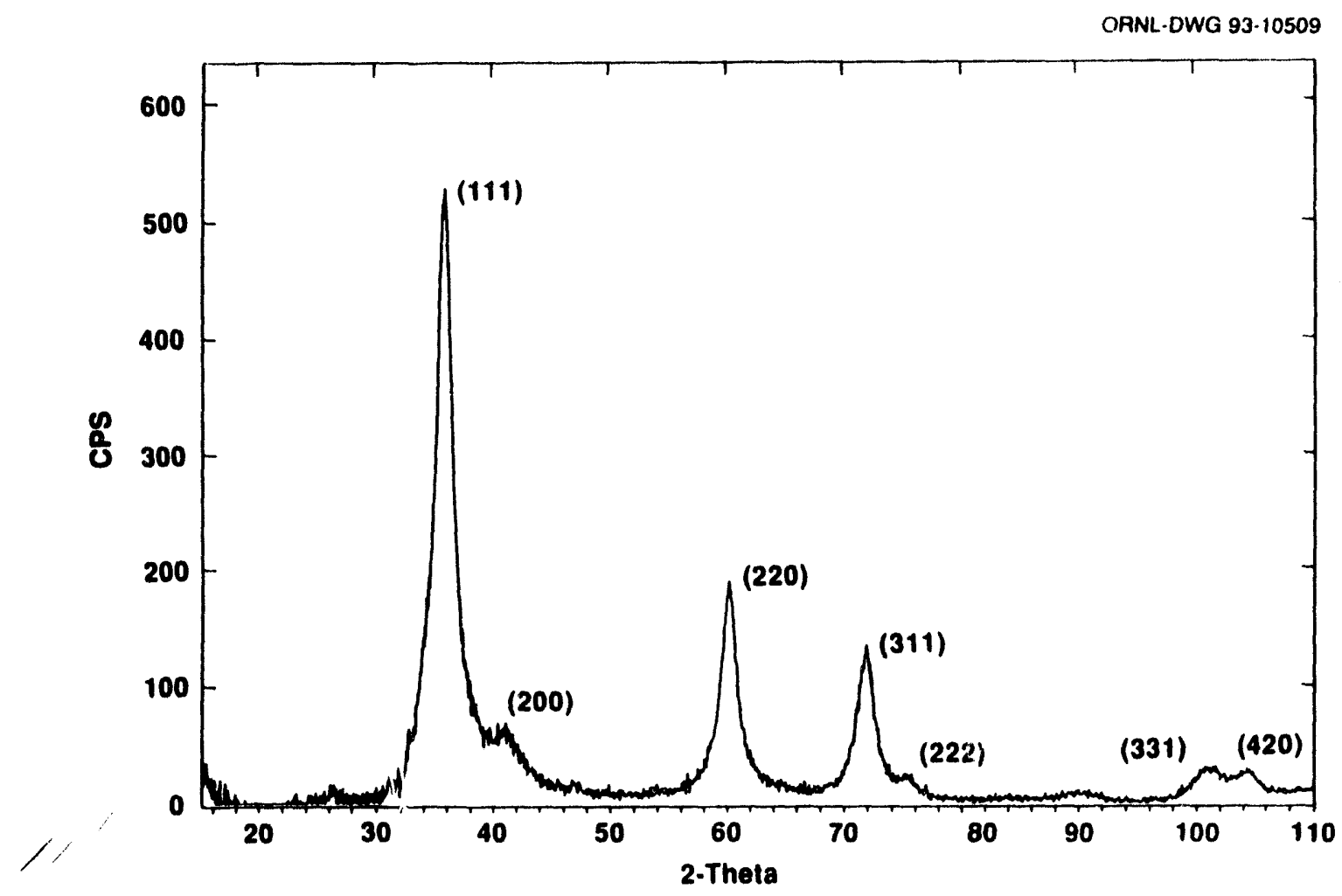

Fig. 1a. X-ray diffraction pattern for standard Nicalon.

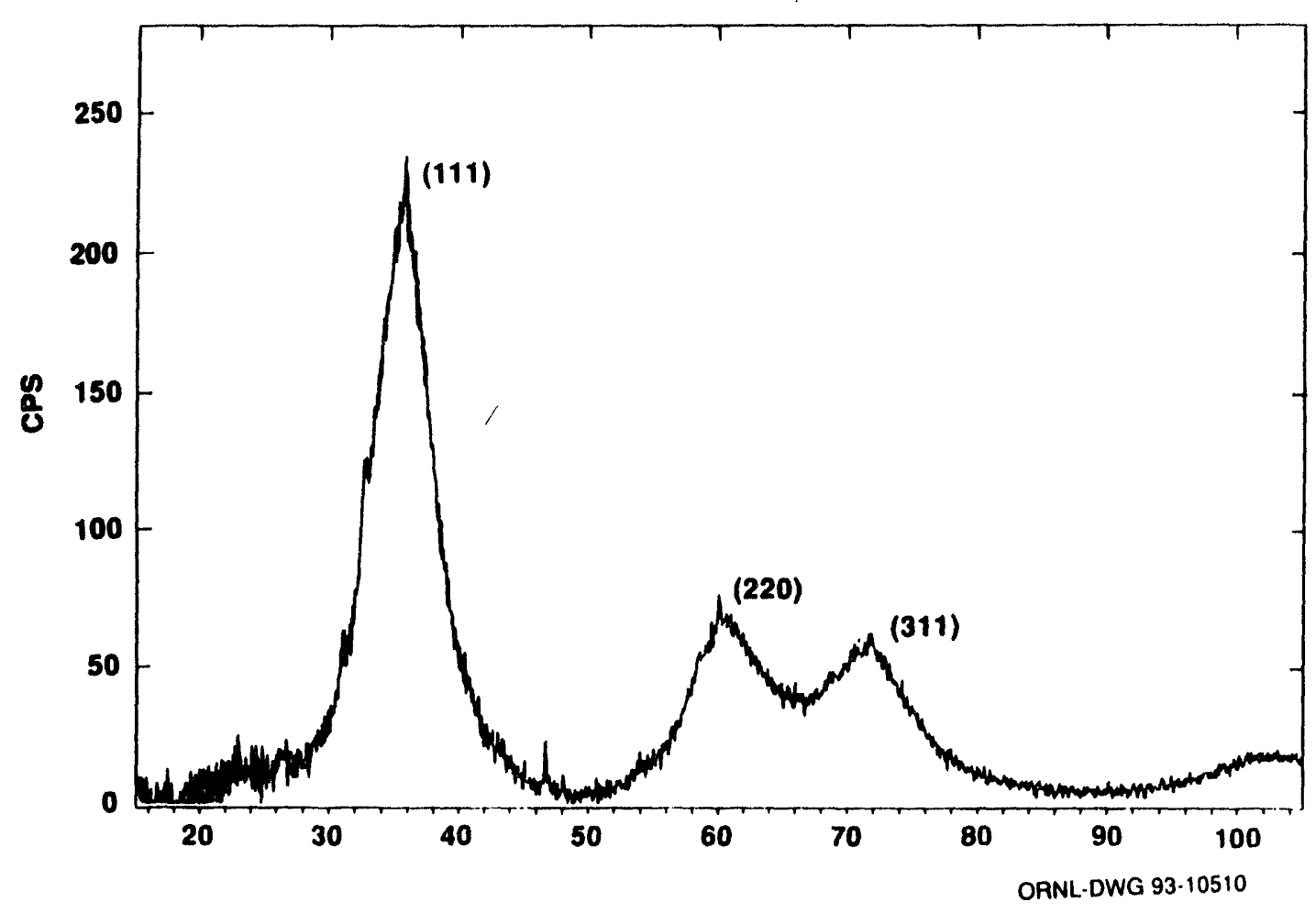

Fig. 1b. X-ray diffraction pattern for low oxygen Nicalon. 


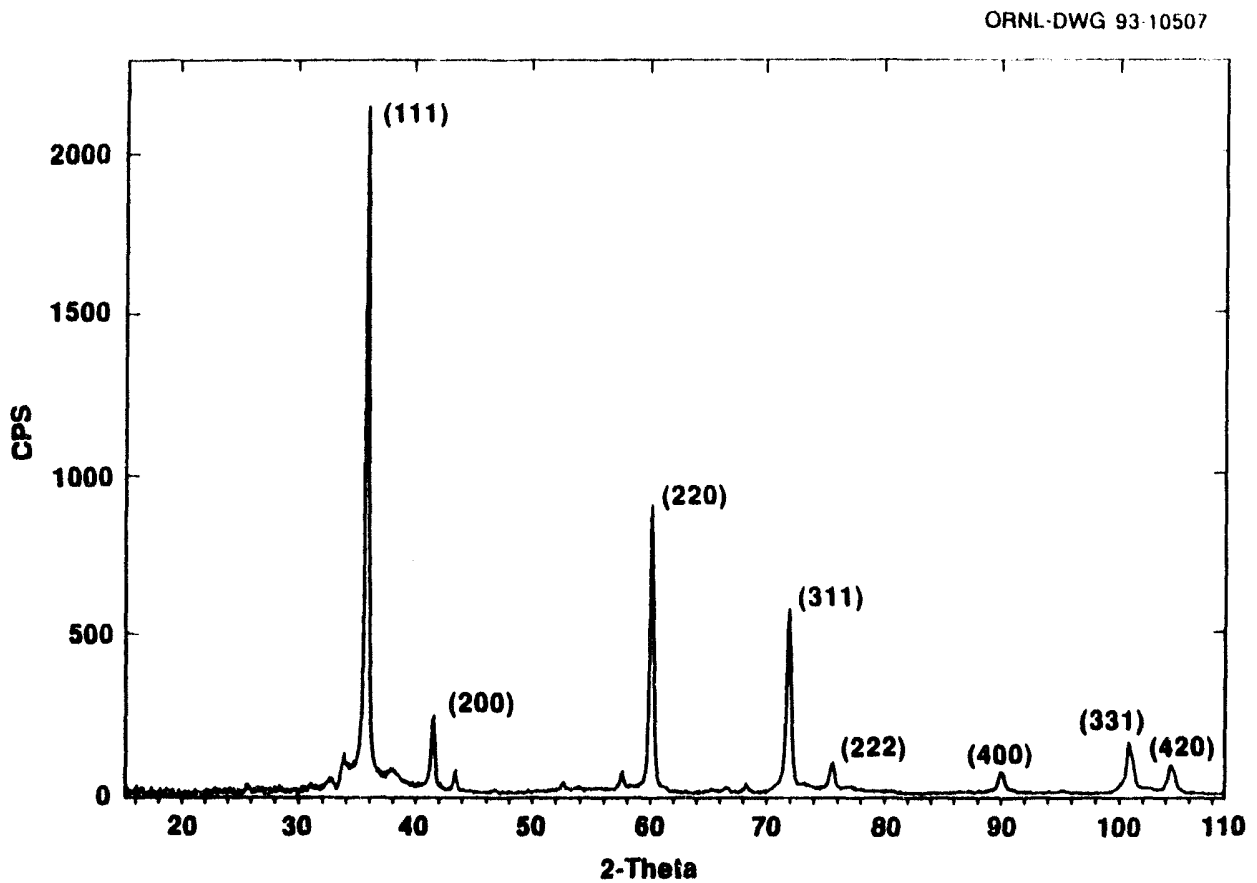

Fig. 1c. X-ray diffraction pattern for CVD SiC.

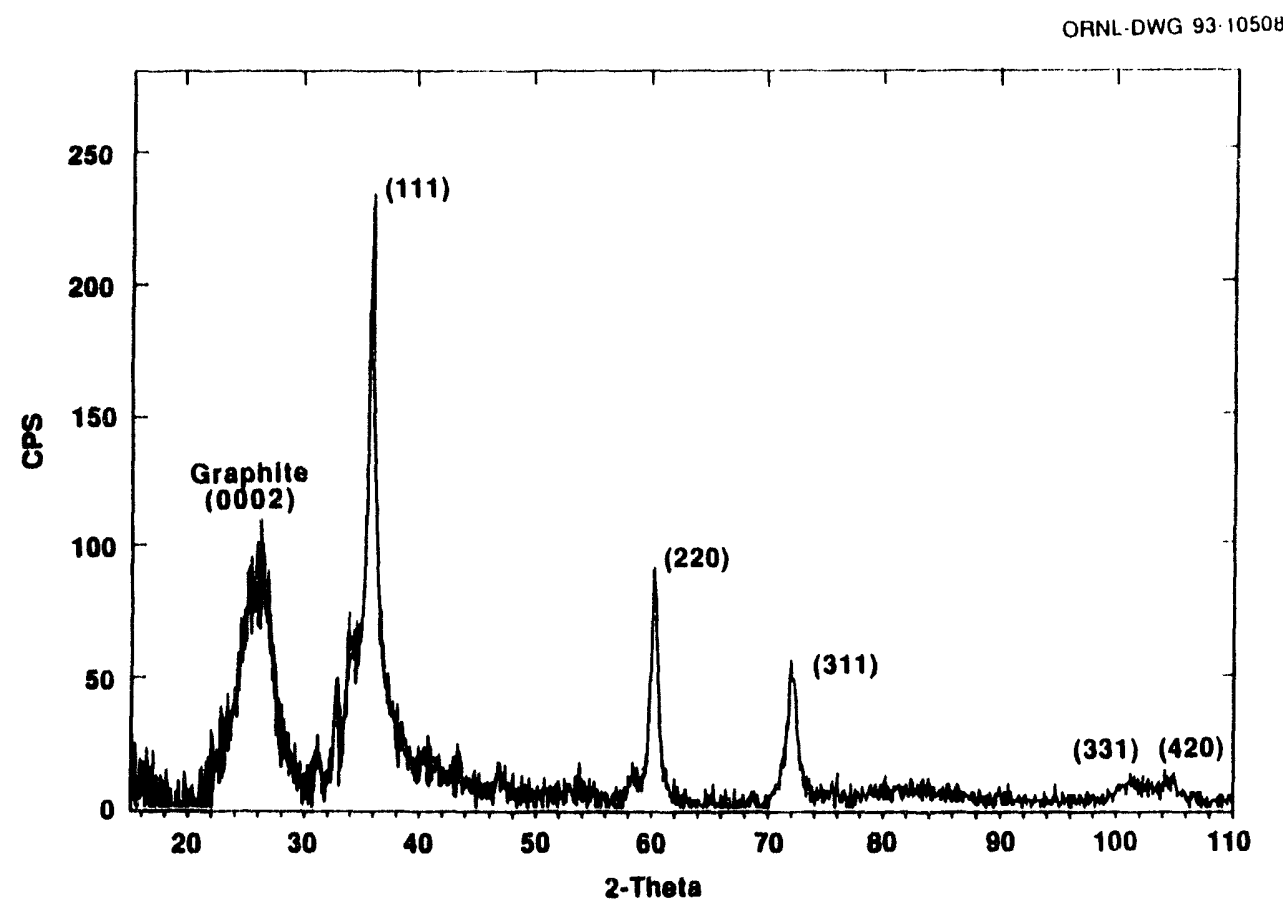

Fig. 1d. X-ray diffraction pattern for MER converted SiC fiber. 


\section{Experimental}

The material used in this study were in the form of both CVD SiC/Nicalon composite as well as in bare tow form. Bend bars of plane weave Nicalon were infiltrated with a forced chemical infiltration process ${ }^{15}$ at ORNL and were processed with a $0.17 \mathrm{~mm}$ graphitic fiber/matrix interface. Bend bars of dimension 0.19 $\times 0.25 \times 3.5 \mathrm{~cm}$ were three point bend tested with a cross head displacement speed of $8.5 \times 10^{-4} \mathrm{~cm} / \mathrm{s}$. Irradiation of the composite material took place in both the HFIR and FFIF fission reactors. The HFIR irradiated material was placed in the core region at $300^{\circ} \mathrm{C}$ for 1 and $3 \mathrm{dpa}$ irradiations while the FFTF material was irradiated to $20 \mathrm{dpa}$ at $485^{\circ} \mathrm{C}$. The Triple Ion Beam Facility at ORNL was used for carbon ion irradiation at ambient and $900^{\circ} \mathrm{C}$ to $15 \mathrm{dpa}$ (peak).

The density of the fibers was determined using the density gradient column method. The chemicals used were a mixture of ethylene bromide and methylene iodide. Linear gradients were built ranging from 0.15 to $0.2 \mathrm{~g} / \mathrm{cc}$ over a meter of height in the column. It should be noted that while these columns remained linear for several days, a chemical reaction took place after approximately three days which slowly turned the solution opaque. A more suitable choice of chemicals would be the ethylene bromide/carbon tetrachloride system, though it is somewhat more expensive.

In order to test the density of the fibers, tows were looped so that fibers would not disperse in the column fluid. To ensure that trapped air bubbles did not affect the density measurement, the loop and a crucible of (lighter) column fluid was placed in a chamber and pumped down to $<50 \mathrm{mTorr}$. The fiber was then dropped (while under vacuum) into the crucible and transferred in the fluid and immersed in the column. The fiber loop then sank and settled to its appropriate density level. At least three loops were tested at each condition.

The nicalon microstructure was observed using a JEOL 4000 transmission electron microscope. Nejtron irradiated maierials were thinned mechanically and ion milled in prepration for microstrucural analysis. Xray analysis was conducted using a Phillips diffractometer with a graphite diffraction beam monochromator.

Ion beam irradiated samples were prepared in cross section using standard thinning and ion milling techniques. Image analysis of microstructure used the Ultimage ${ }^{16}$ software package. The elastic modulus of the ion beam irradiated material was measured using a NanoInstruments Nanoindenter ${ }^{17}$ mechanical properties microprobe. These specimens were prepared identically to those of the TEM specimens with a final polish with $1 / 2 \mathrm{~mm}$ diamond paste.

Tensile testing of single fibers was performed with an Instron testing machine using a fiber gauge length of $25 \mathrm{~mm}$ and a cross head displacement speed of $8.5 \times 10^{-4} \mathrm{~cm} / \mathrm{s}$. Analysis of the fiber strength data assumed a Weibull probability distribution of the form:

$$
R(\sigma)=1-e^{-\left(\sigma / \sigma_{0}\right)} \beta
$$

where $R(\sigma)$ is the the probability of survival, $\beta$ is the Weibull modulus (shape parameter), $\sigma_{0}$ is the size parameter and $\sigma$ is the applied variable stress. The mean stress is calculated as the integral of the probability density function $(\mathrm{dR}(\mathrm{s}) / \mathrm{ds})$ :

$$
\text { Mean Strength }=\sigma_{0}\{\Gamma(1+1 / \beta)\}
$$

\section{Results}

\section{Degradation of Standard Nicalon Composite}

The effect of neutron irradiation on three point bend strength of the 2-d composite is shown in Figure 2, which includes results from previous papers. ${ }^{18,19}$ The composite selected for this irradiation was 
fabricated with a $0.17 \mathrm{~mm}$ graphite fiber/matrix interface which corresponds to a composite of maximum strength. Howcver, by noting the load drop off behavior after the ultimate bending load it is apparent that this composite still has reasonable toughness. It is seen from Figure 2 that at the lowest displacement level of $1 \mathrm{dpa}$, there has been a significant reduction in load carrying capability for this composite. In contrast, the load drop off following macroscopic yielding is significantly more gradual than the unirradiated composite, pointing to the fact that fiber pull-out has become enhanced. At $3 \mathrm{dpa}$ the ultimate bend load is approximately the same as the $1 \mathrm{dpa}$ irradiated material, though the load drop-off (pull-out) has become drastically reduced. Fracture surfaces corresponding to the unirradiated, 1 and 3 dpa composites are shown in Figure 3, which confirms this changing pull-out behavior. By inspection of the figure it can be seen that the toughness (post-ultimate load drop-off) corresponds well with the amount of fiber pull-out of the fracture surfaces. While the unirradiated and $3 \mathrm{dpa}$ irradiated material show minimal fiber pull-out, the $1 \mathrm{dpa}$ irradiated material shows significantly greater length and density of exposed fibers.

Also shown in Figure 2 is the load displacement curve for 20 dpa irradiated material which proved to be of very poor strength and toughness. By inspection of the residue remaining after the bend testing and by examination of fracture surfaces it became apparent that the Nicalon fiber had seriously embrittled and become friable.

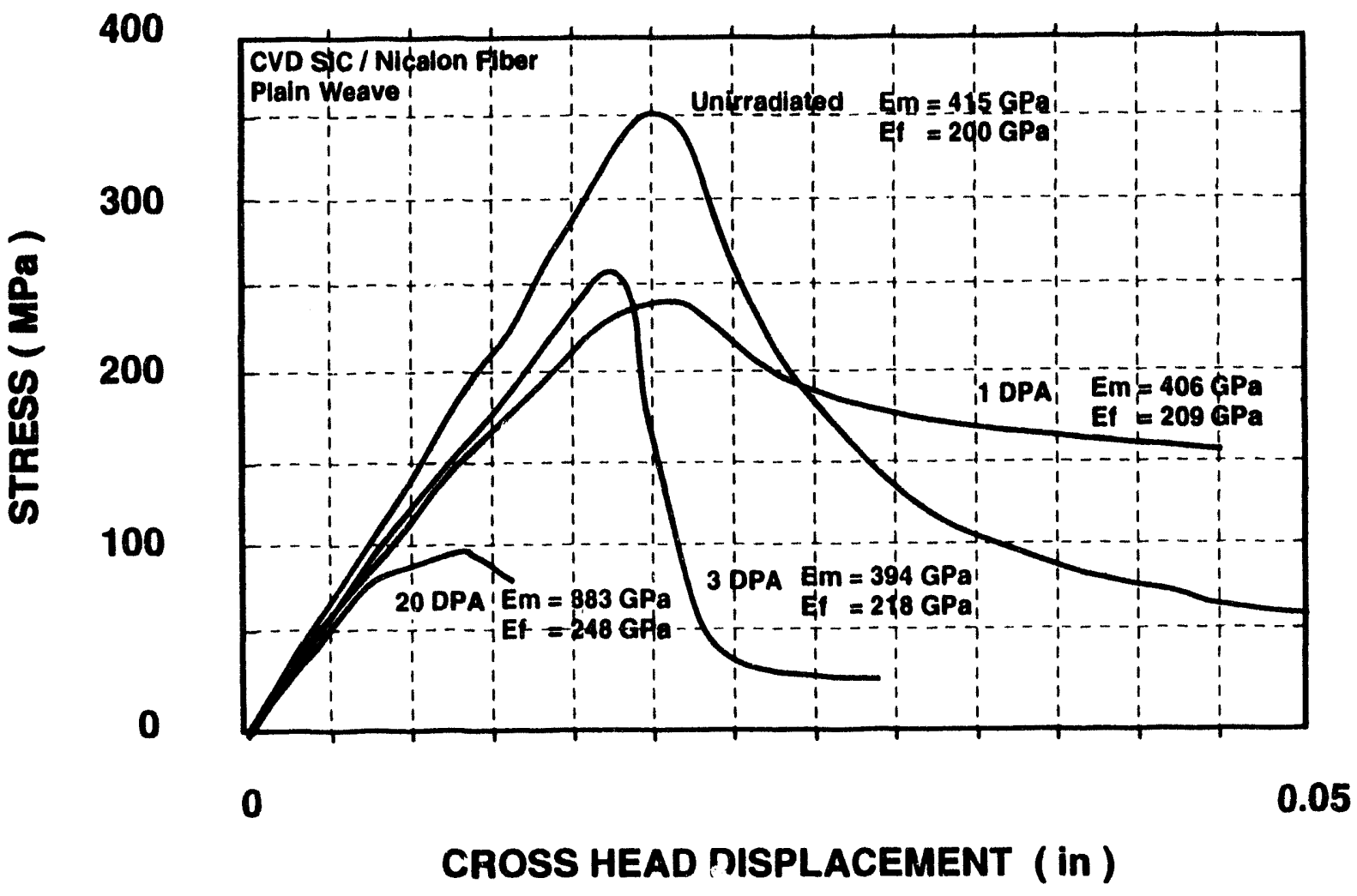

Fig. 2. Load-displacement curve for irradiated SiC/Nicalon composite. 


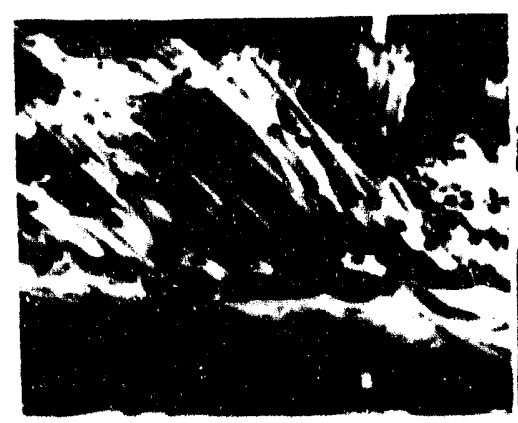

(*)

Unirradiated

(d)

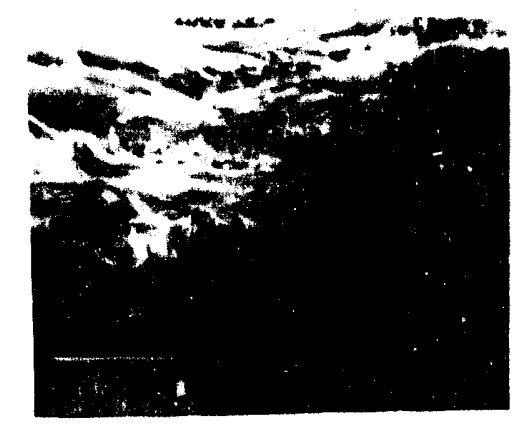

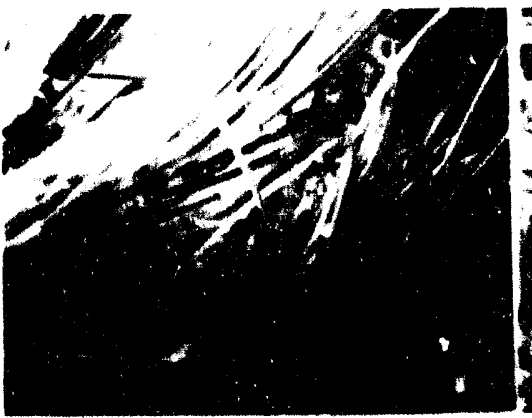

(b)

1 dpa

(e)

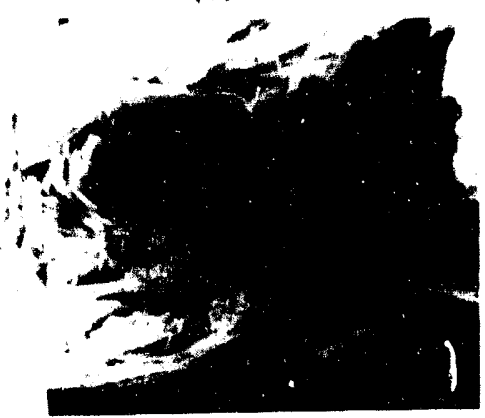

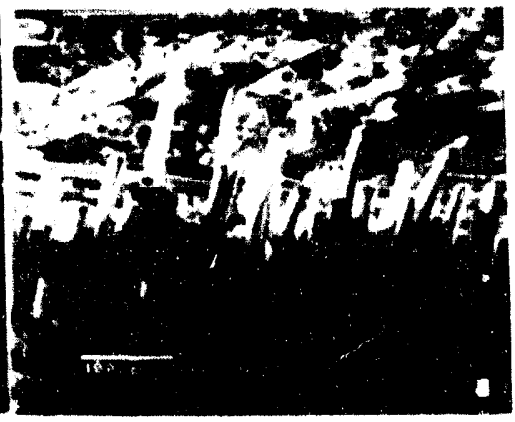

(c)

3 dpa

(f)

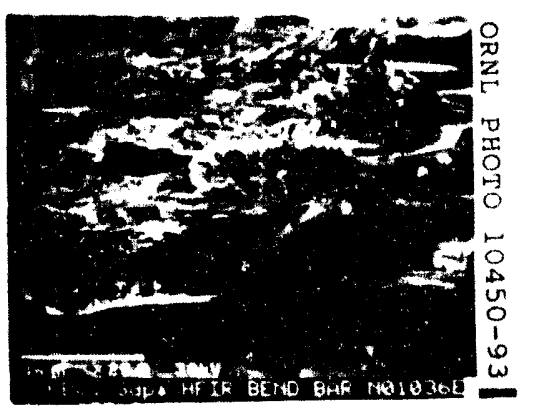

Fig. 3. Fracture surfaces for irradiated SiC/Nicalon composite.

\section{Measurement of Elastic Modulus of Nicalon}

The elastic moduli of both the fiber $\left(E_{f}\right)$ and matrix $\left(E_{m}\right)$ for the neutron irradiated Nicalon composites have been inset into Figure 2 . These measurements were taken utilizing a nanoindentation method discussed in a previous paper. ${ }^{20}$ These show the same trend as expected from previous ceramic work with the CVD SiC modulus decreasing from an unirradiated value of $415 \mathrm{GPa}$ to $394 \mathrm{GPa}$ at $3 \mathrm{dpa}$, further decreasing to $384 \mathrm{GPa}$ for the $20 \mathrm{dpa}$ material. Conversely, the Nicalon fiber is seen to increase in modulus steadily from a $200 \mathrm{GPa}$ unirradiated value to $218 \mathrm{GPa}$ at $3 \mathrm{dpa}$ and increased to $248 \mathrm{GPa}$ at $20 \mathrm{dpa}$. It should be noted, however, that there is a difference in irradiation sources and irradiation temperature for the 20 dpa material.

It has been previously reported ${ }^{20}$ from ambient temperature $30 \mathrm{dpa}$ (peak) carbon irradiated Nicalon that the elastic modulus also increased with displacement damage. These results were obtained by a cross sectional nanoindentation method from which plots of elastic modulus along the path of an ion could be generated (i.e. modulus-vs-dpa). Shown in Figures 4 and 5 are results using this nanoindentation method for $15 \mathrm{dpa}$ (peak) carbon beam damaged material at both ambient and $900^{\circ} \mathrm{C}$. For both temperatures it is seen that the elastic modulus increases near the region of maximum carbon ion damage. A corresponding reduction in elastic modulus for the CVD SiC matrix was also observed.

\section{Microstructure of Irradiated Nicalon}

A series of high resolution TEM micrographs were taken to study the effect of temperature and radiation on the microstructure of standard Nicalon. A semiquantitative analysis was performed on Nicalon irradiated with carbon ions at both room temperature and $900^{\circ} \mathrm{C}$ as well as neutron irradiated material. Micrographs were taken along the range of the ion irradiated material from beginning of range (very low damage), at the middle of range ( $<1 \mathrm{dpa})$, at the beginning of the maximum damaged region $(\sim 1 \mathrm{dpa})$, at the peak damage 


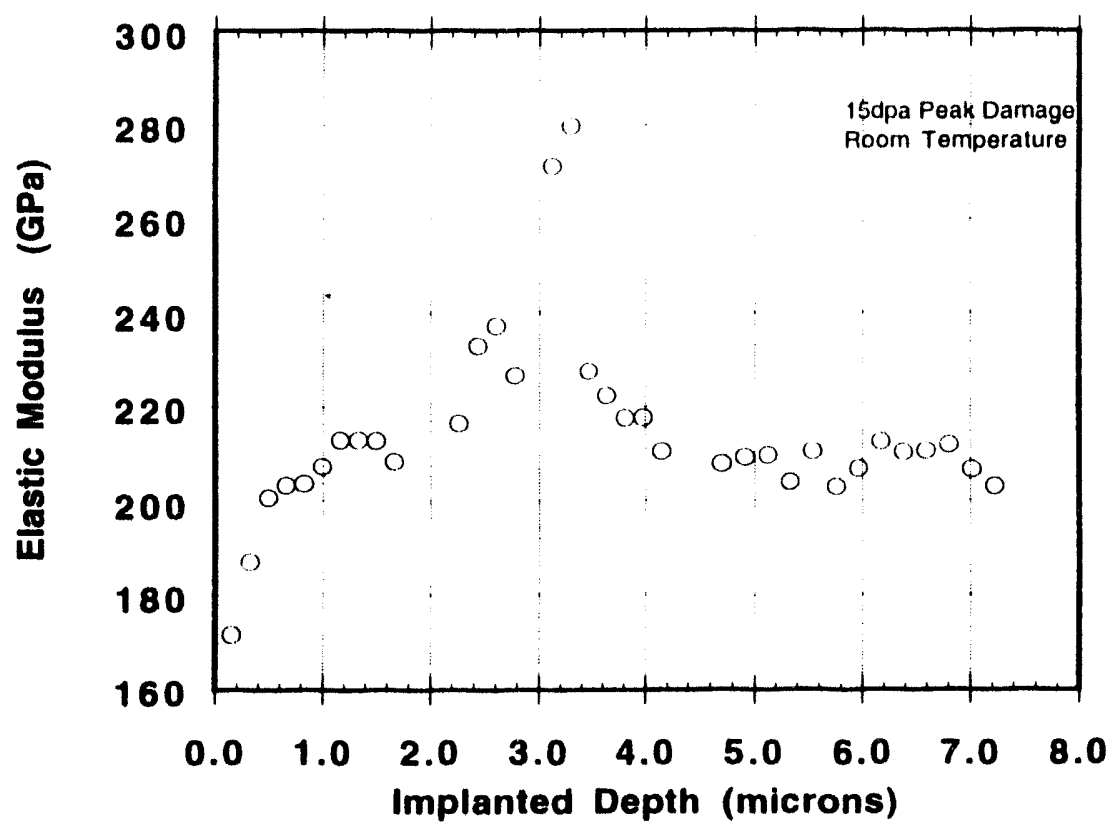

Fig. 4. Cross-sectional elastic modulus measurement for ambient temperature irradiated Nicalon.

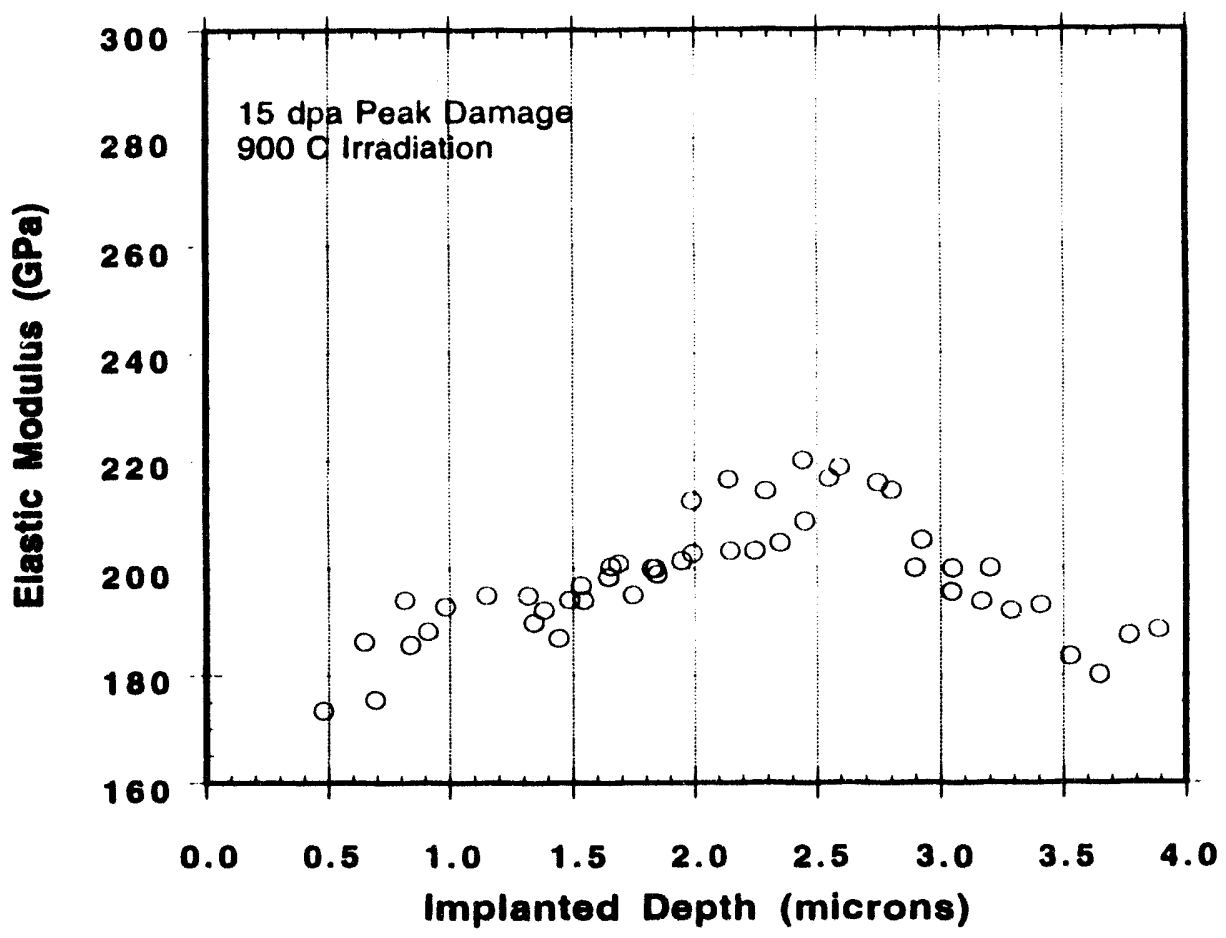

Fig. 5. Cross-sectional elastic modulus measurement for $900^{\circ} \mathrm{C}$ irradiated Nicalon. 
region of $15 \mathrm{dpa}$ and the past range "virgin" material. Examples of the microstructure are shown in Figs. 6 and 7. Figure 6 shows a micrograph for unirradiated (past range) Nicalon with representative $\beta \mathrm{SiC}$ crystallites highlighted. The effects of high dose ion beam damage on the microstructure is shown in Figure 7. This micrograph exhibits no crystalline structure and indicates that the $\beta-\mathrm{SiC}$ has amorphized $\mathrm{SiC}$.

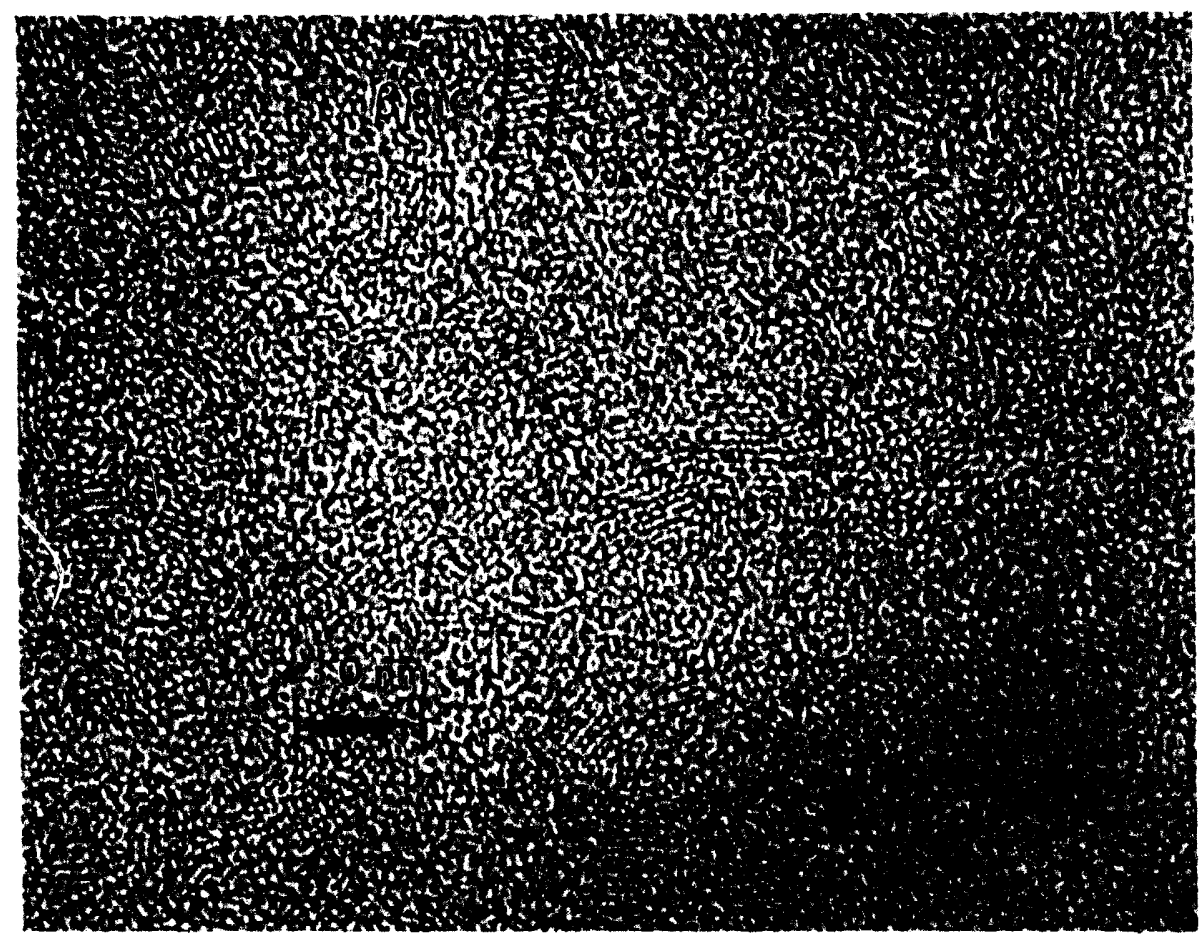

Fig. 6. High resolution TEM image of unirradiated Nicalon.

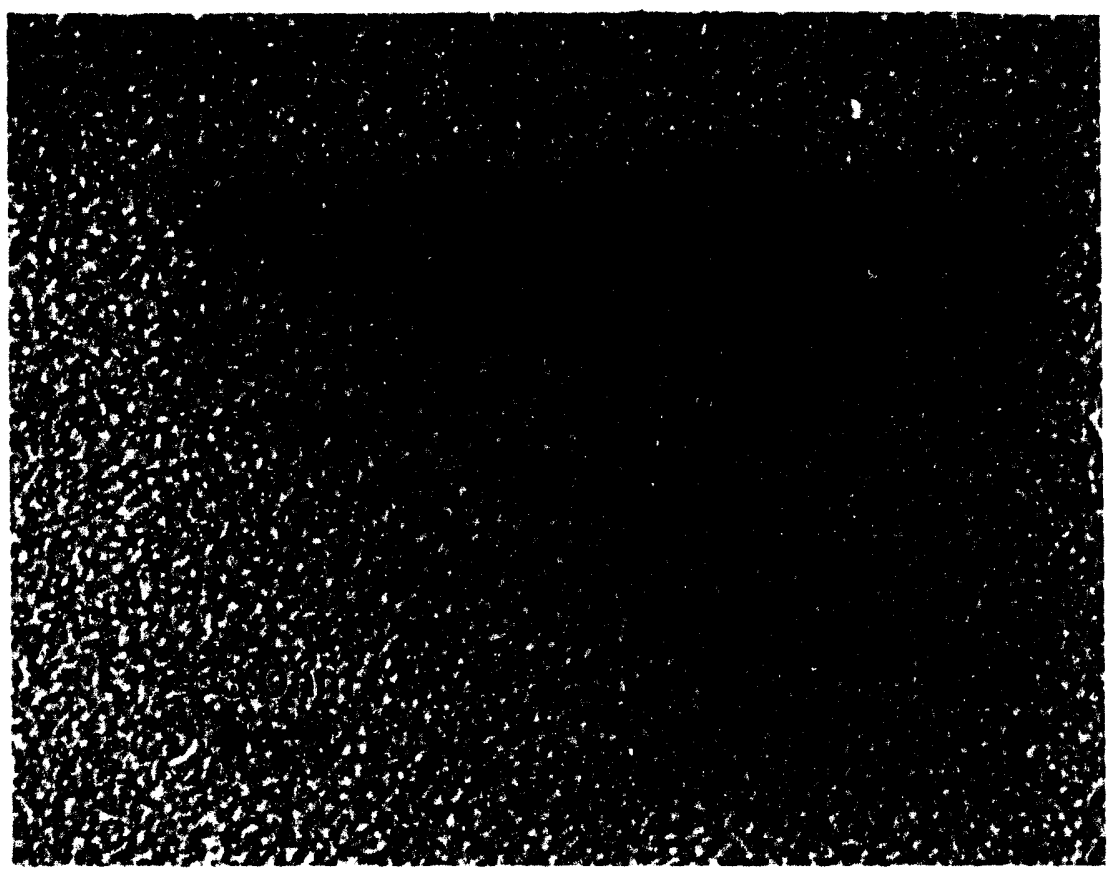

Fig. 7. High resolution TEM image of carbon beam amorphized Nicalon. 
Micrographs of the ion and neutron irradiated materials were scanned into a optical analysis program and individual SiC crystallites highlighted. Once the crystallites were selected the average crystallite size (the Waddel disc diameter) and the planar density of crystallites was determined. It should be noted that this method will only yield a planar density of crystallites rather than a true density of crystals in the material. This is due to the fact that the $\beta-\mathrm{SiC}$ crystals are randomly oriented throughout the material, though the TEM will only clearly image crystallites in certain orientations. This method then is only an relative indicator for density of crystallites, though it is accurate in assessing the crystallite size.

Table 2 shows the results of the optical analysis. A trend toward randomization and eventual amorphization of the Nicalon fiber with increasing carbon ion damage is seen. This is demonstrated by noting that for the $900^{\circ} \mathrm{C}$ irradiated material, the planar density and mean particle size of the beginning of range and virgin material was essentially the same while both the size and density decreased as the ion progressed along its range. Complete amorphization of the Nicalon structure occurred in the peak damage region at $900^{\circ} \mathrm{C}$. The room temperature carbon beam irradiated material was seen to behave similarly, though amorphization took place at a lower damage level than $1 \mathrm{dpa}$ while the $900^{\circ} \mathrm{C}$ irradiated material amorphized only inside the peak damaged region ( $>1 \mathrm{dpa})$.

Table 2. Results of Image Analysis of Irradiated Nicalon

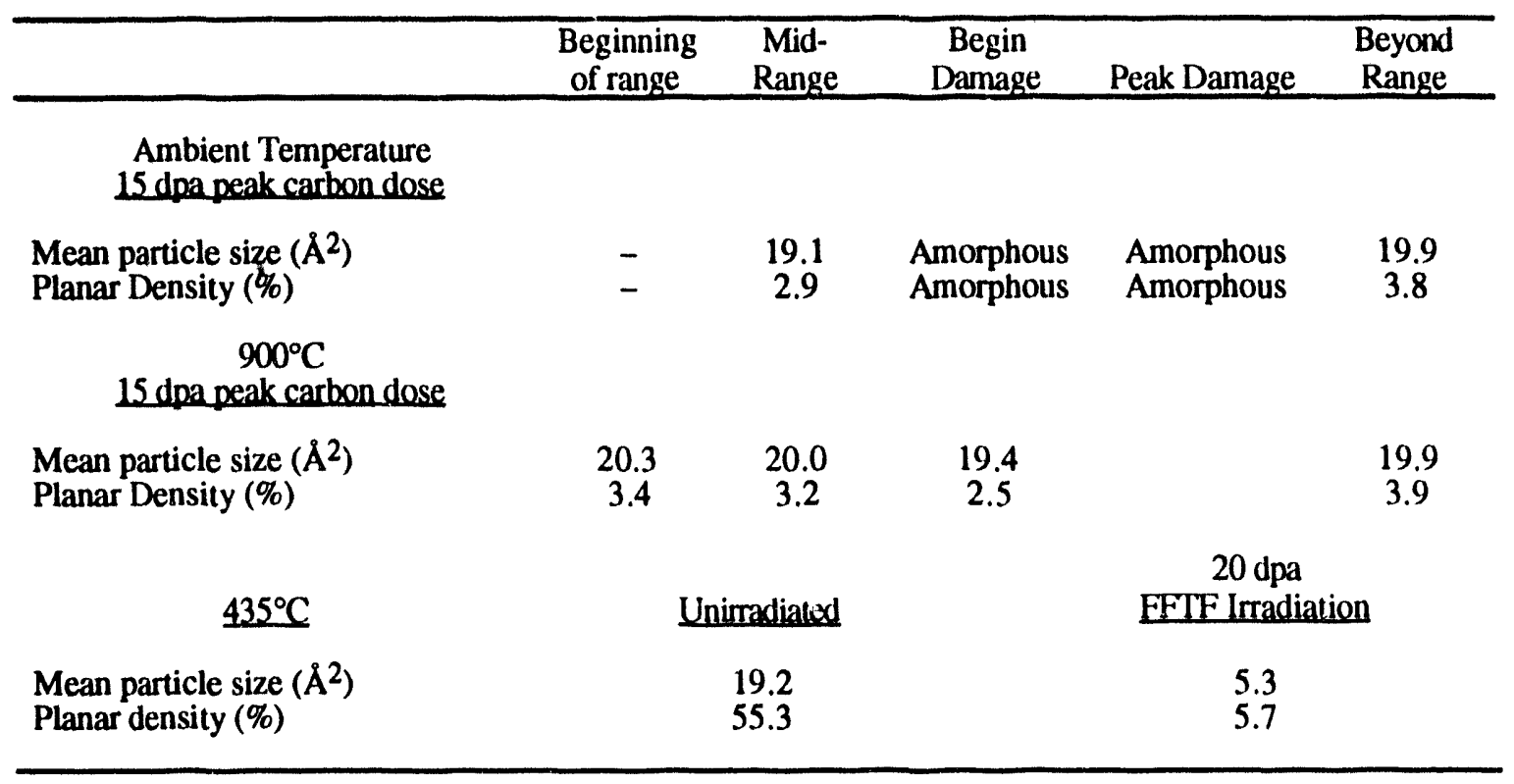

Also given in the table are numbers for the mean particle size and planar density for 15 dpa neutron irradiated material at $435^{\circ} \mathrm{C}$. While the planar density is higher than that of the ion irradiated material, due to an earlier grade of Nicalon fiber, the density and size of crystallites are essentially unchanged as compared to unirradiated fibers from the same batch. No significant amorphization or recrystallization has ocurred.

\section{Performance of Low Oxygen Nicalon Fiber}

The density of both standard and low oxygen Nicalon fiber following irradiation is plotted in Figure 8 . This includes data generated by Okamura $\mathrm{et} \mathrm{a}^{21}$ for standard fibers irradiated in the JMTR reactor as well as new data on standard and low oxygen Nicalon irradiated in FFTF and HFIR, respectively. Standard Nicalon is seen to increase in density by $4 \%$ at $2 \times 10^{24} \mathrm{n} / \mathrm{m}^{2}$ at $150^{\circ} \mathrm{C}$ and exhibits an $8 \%$ increase at the $650^{\circ} \mathrm{C}$ and $9 \times 10^{25} \mathrm{n} / \mathrm{m}^{2}$ Higher dose irradiations of standard Nicalon to $2 \times 10^{26} \mathrm{n} / \mathrm{m}^{2}$ also yielded a large densification of the fiber. It is also important to note that these fibers were seriously embrittled and became friable. Figure 8 also shows the behavior of low oxygen Nicalon to a dose of $3.4 \times 10^{24} \mathrm{n} / \mathrm{m}^{2}$. A 


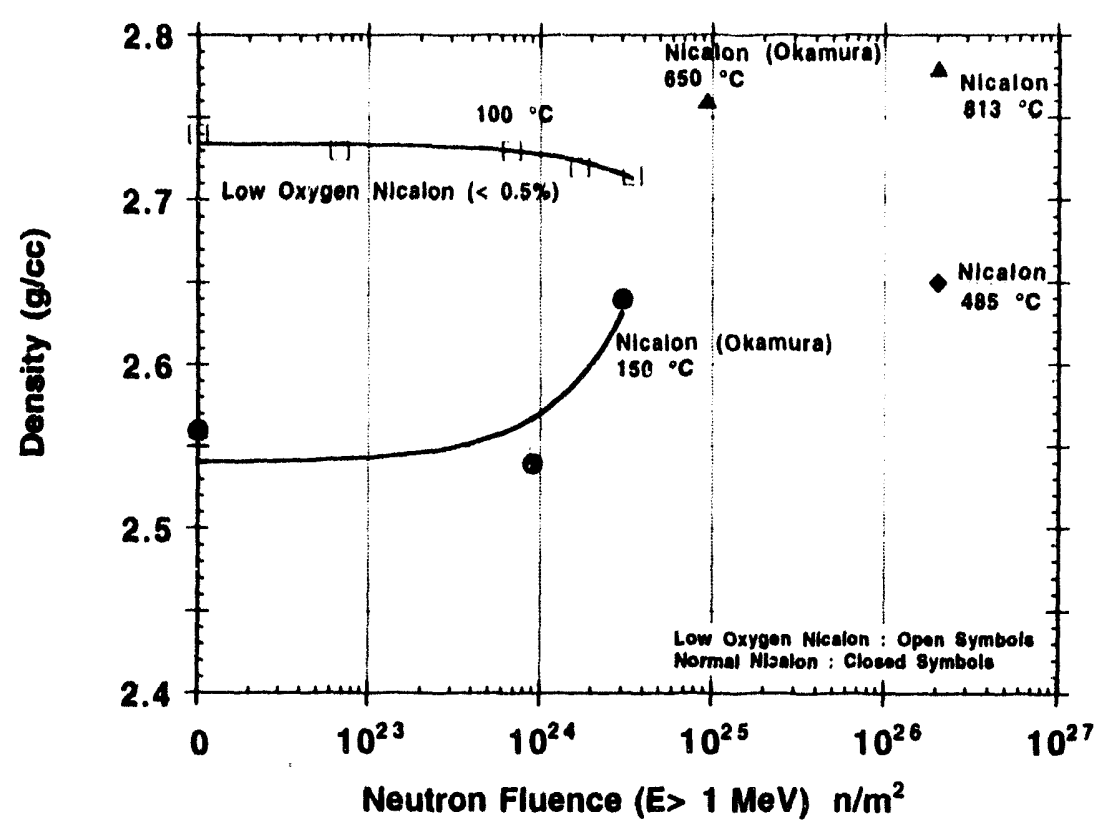

Fig. 8. Density of irradiated Nicalon fiber.

precise measurement of the effect of radiation on the density was difficult to measure in this case due to material nonuniformity, though after many trials a trend toward volumetric expansion was seen.

The effect of neutron irradiation on fiber strength is given in Figure 9. Again, Okamura data ${ }^{21}$ are included with new data on low oxygen Nicalon fiber. It is seen that the trend for standard Nicalon was for

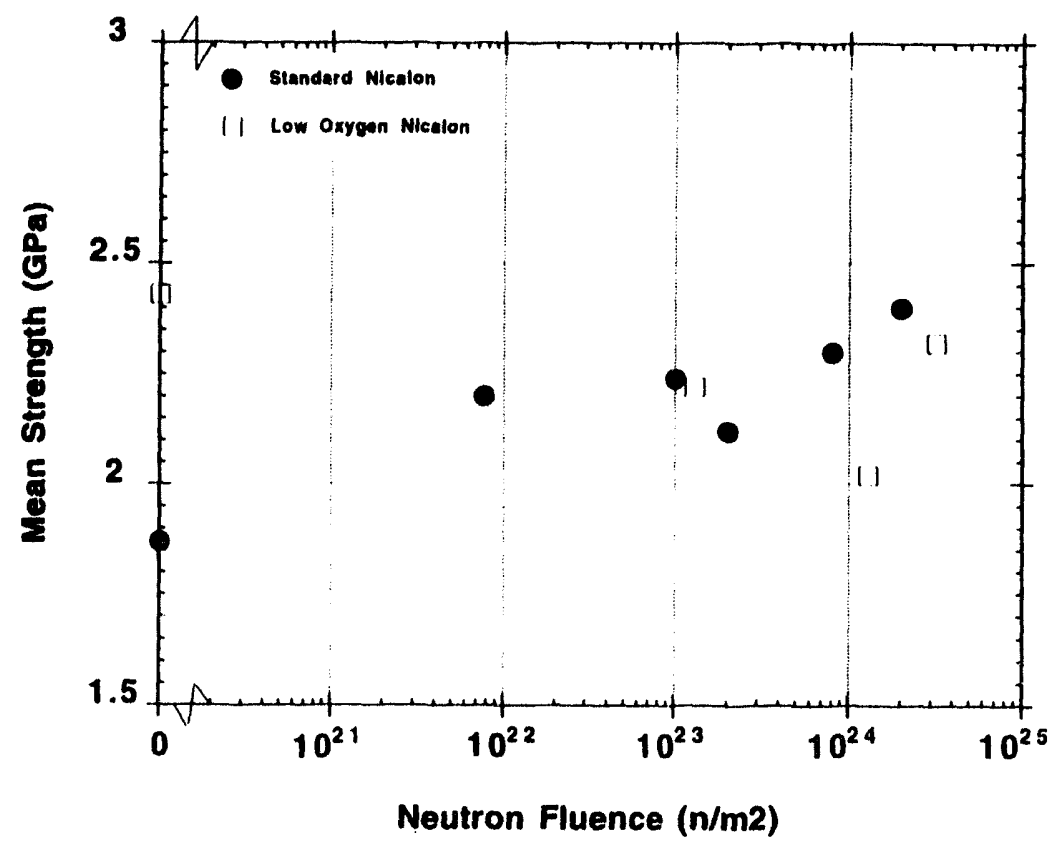

Fig. 9. Tensile strength of irradiated Nicalon fiber. 
an increase in mean fiber strength at low doses from a value of $1.8 \mathrm{GPa}$ (unirradiated, $150^{\circ} \mathrm{C}$ ) to a value of $2.4 \mathrm{GPa}$ after a JMTR irradiation fluence of $2 \times 10^{24} \mathrm{n} / \mathrm{m} .^{2}$ It was also seen from this data that the Weibull modulus increased slightly with irradiation dose.

The mean strength of low oxygen Nicalon fibers following irradiation at $100^{\circ} \mathrm{C}$ is also shown in Figure 9 . The low oxygen fiber unirradiated strength of $2.43 \mathrm{GPa}$ is somewhat greater than that of standard Nicalon and the trand following irradiation is for a slight reduction in strength. Table 3 gives specifics related to the low oxygen Nicalon fiber testing and shows that a significant reduction in strength occurred at relatively low dose levels with a corresponding reduction in Weibull's modulus. However, it is seen in this table that the highest dose level irradiation did not show the reduction in strength. This data behaved like a combination of two Weibull distributions (i.e. two separate linear regions) which makes the determination of the Weibull's modulus difficult. These two distinct linear regions can have several explanations including two seperate failure modes (flaw types) for the fibers, or simply an insufficient number of tests or other experimental error. In any event, barring experimental error, the mean value of strength is little changed by the selection of Weibull's modulus applied to the data, and always yields a value less than the unirradiated strength for any reasonable modulus applied to the data set.

Table 3. Reduced Data from Fiber Tensile Testing

\begin{tabular}{cccc}
\hline $\begin{array}{c}\text { Neutron Flux } \\
\left(1 / \mathrm{cm}^{2}\right)\end{array}$ & Weibull Modulus & $\begin{array}{c}\text { Shape Parameter } \\
(\mathrm{GPa})\end{array}$ & $\begin{array}{c}\text { Mean Strength } \\
(\mathrm{GPa})\end{array}$ \\
\hline Unirradiated & 2.9 & 2.72 & 2.43 \\
$1.3 \times 10^{19}$ & 2.69 & 2.5 & 2.22 \\
$1.3 \times 10^{19}$ & 2.58 & 2.28 & 2.02 \\
$3.2 \times 10^{19}$ & 2.32 & 2.91 & $2.3 \mathrm{i}$ \\
\hline
\end{tabular}

Discussion

As has been pointed out previously, 19 the major drawback to using the polymer precursor Nicalon fiber composite is that the densification of the fiber causes a debonding of the fiber/matrix interface. It has been shown that this densification occurs at fairly low fluence and temperature and that at higher fluences and temperature the fiber continues to densify and seriously embrittles and becomes useless as a reinforcement.

The reason for this densification has remained somewhat of a mystery until now, and is contrary to what occurs in all other silicon carbide based materials and ceramics in general. Typically, crystalline ceramics irradiated at low temperature $\left(<1000^{\circ} \mathrm{C}\right)$ will undergo volumetric expansion and reach saturation at relatively low fluences. This expansion is caused due to the lattice dilation associated with the accomodation of the displaced interstitial is larger than the lattice contraction of the vacancy. Radiation induced swelling in SiC has been seen by many researchers, ${ }^{20-31}$ though Price et al have performed the most comprehensive research in the area. This fundamental finding along with the annealing behavior of $\mathrm{SiC}$ is the principle behind the widespread use of $\mathrm{SiC}$ as temperature monitors for irradiation studies.

The neutron irradiation induced swelling in $\mathrm{SiC}$ is seen to saturate at a fairly low dose. At less than $1000^{\circ} \mathrm{C}$ this saturation dose is approximately $10^{24} \mathrm{n} / \mathrm{m}^{2}$. It has been shown 24 that the saturation linear expansion decreases from about $1 \%$ at irradiation near room temperature to approximately $0.05 \%$ at $1000^{\circ} \mathrm{C}$. As was stated by Blackstone, ${ }^{24}$ there does not seem to be a systematic dependence on grain size or porosity of the material, or a dependence on whether the initial SiC crystal structure is $\alpha$ (hcp) or $\beta$ (fcc). Studies since this time have supported this finding. At temperatures above $1000^{\circ} \mathrm{C}$ point defects can easily annihilate and tetrahedrally bounded voids nucleate ${ }^{26}$ and dominate the swelling of the silicon carbide structure. However, the amount of swelling is relatively low, peaking at $\sim 0.5 \%$ at $10^{26} \mathrm{n} / \mathrm{m}^{2}$ for an irradiation temperature of $1250^{\circ} \mathrm{C}$.

Other than the work on Nicalon, there have been two references in the literature on nominally pure SiC which are contrary to these results. Price ${ }^{26}$ reported a $-0.2 \%$ change in length of vapor deposited 
polycrystalline $\mathrm{SiC}$ filament which had undergone a $3100^{\circ} \mathrm{C}$ anneal prior to a $5 \times 10^{24} \mathrm{n} / \mathrm{m}^{2}$ irradiation. However, such a small change in length of this fiber may not have been statistically significant. The second reference is by Stevens ${ }^{24}$, also using silicon carbide whiskers, discusses a very small initial decrease in $\beta \mathrm{SiC}$ lattice parameters at low fluences (a of $-0.05 \%$ and $\mathrm{c}$ of $-0.05 \%$ ) followed by an order of magnitude larger increase in lattice parameter at fluences more representative of this study.

Several researchers have concluded that the explanation for the increase in Nicalon density and modulus is due to a closer atomic packing ${ }^{31}$ and radiation induced crystallization and growth of $\mathrm{SiC}$ crystallites at low temperature. 33-35 Kohyama asserted that even though there was clearly a diminution in size (or order) of the crystallites as as measured with XRDA, there must be a simultaneous formation and growth of SiC microcrystals due to the fact that there was an increase in the Young's modulus. This was in part supported by a quantitative analysis using dark field TEM of Nicalon irradiated with $\mathrm{Ni}$ ions at ambient temperature.

As was reviewed above, either a closer packing or low temperature formation and growth of SiC crystallites is highly unlikely. It is also clear from the results presented in Table 2, as well as the TEM micrographs, that no crystal growth was observed in either the carbon ion or neutron irradiated material. The mechanism behind the increase in Young's modulus is in fact independent of the radiation induced structural changes in the SiC. By inspection of Table 2 and Figures 6 and 7 it is seen that there is an increase in modulus even for material disordered by neutron irradiation or amorphized by carbon beam displacements. In essence, even though the $\mathrm{SiC}$ microstructure in Nicalon is becoming randomized, which should reduce the modulus significantly, the opposite effect occurs. It has been shown previously 19,36 that the amorphization of silicon carbide under similar irradiation conditions substantially reduces both hardness and modulus ov CVD material.

The mechanism behind the increase in elastic modulus of th andard Nicalon fiber is most likely the existence of the glassy silicon oxycarbide matrix which surrounds the $\beta-\mathrm{SiC}$ crystallites. It is well known that glassy materials such as vitreous silica undergo densification by neutron irradiation 37,38 and to a lesser extent by gamma irradiation. ${ }^{39}$ Figure 10 shows the behavior of crystalline quartz and vitreous (amorphous) silica which has undergone neutron irradiation. ${ }^{38}$ Both these materials (as well as crystobalite

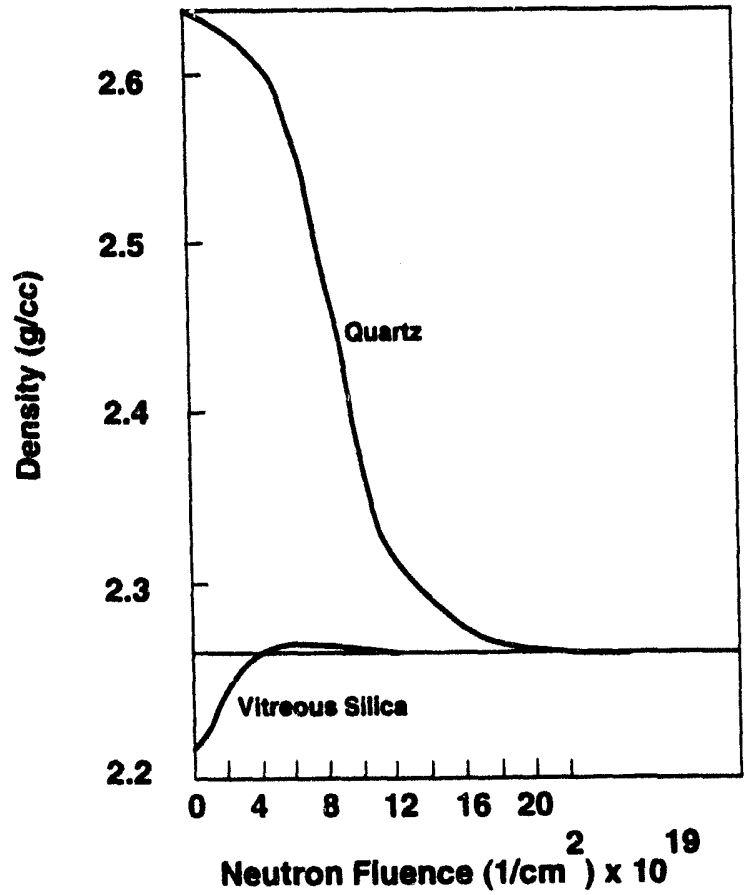

Fig. 10. Effect of neutron fluence on density of quartz and vitreous silica. 
and tridymite ${ }^{40}$ ) are seen to approach the same density and amorphous state. 41,42 In the case of (amorphous) vitreous silica, irradiation actually moves the material towards a more stable amorphous state. Associated with these changes are also slight increases in strength. ${ }^{43-45}$ Elastic modulus has been seen to decrease for quartz, and to undergo a small posititve or negative change in glarsy materials. ${ }^{37}$

The possibility of a transformation from one amorphous phase in the Nicalon matrix, to a second amorphous phase is still not entirely fulfilling explanation of the density and modulus changes observed. The saturation value for densification in silicates only approach $3 \%$ as an upper limit, $46-49$ and this occurs very quickly ( $0.1 \mathrm{dpa})$. However, the irradiation induced density increase in standard Nicalon has been shown to be several percent, and gives no sign of saturating below a value of $1 \mathrm{dpa}$. Also, only small changes in modulus (both positive and negative) have been reported in irradiated amorphous silicates, while Nicalon has yielded modulus increases approaching $25 \%$ following irradiation.

It is well known that the amount of densification of silicates depends on initial density. The effect of the degree of compaction of high-purity silica irradiation induced densification has been studied by Primak. 50 It was seen that these materials, which varied in density by up to $6 \%$ tended toward the same equilibrium density under irradiation. Also of interest is that it was shown ${ }^{51}$ that application of high pressure alone was sufficient to reach a saturation value of density equal to the saturation density for the irradiated silica. While the density of the $\mathrm{Si}_{x} \mathrm{C}_{y}$ is not known it is most likely that the density or this amorphous phase is substantially lower than vitreous silica and would undergo larger densification than observed in near fully dense silicates. This assertion would be difficult to show experimentally, however.

A further indication that the property changes of standard Nicalon are driven by the $\mathrm{Si} \mathrm{O}_{\mathrm{x}} \mathrm{C}_{\mathrm{y}}$ phase is that the reduced oxygen material exhibits behavior more typical of ceramics. At $100^{\circ} \mathrm{C}$, the fiber density was seen to remain essentially unchanged while the strength decreased slightly after irradiation. Both Weibull's and Young's moduli decreased for the irradiated low oxygen fiber also representative of the effect in pure $\mathrm{SiC}$.

These preliminary results of low oxygen Nicalon are very promising for the use of this polymer precursor fiber in an irradiation environment. As discussed earlier, the major drawback to the use of the standard Nicalon fiber was this fibers tendency to densify causing interfacial debonding and composite failure. The fact that the lower oxygen Nicalon has both higher modulus and higher strength, but more importantly does no undergo the catastrophic densification, will provide a more radiation resistant reinforcement of $\mathrm{SiC}$ composites.

\section{Conclusions}

1. Standard Nicalon fiber undergoes a significant increase in density with irradiation and eventually becomes embrittled to the point where it is useless as a composite reinforcement.

2. Microstructural analysis proves that the increase in Young's modulus of Standard Nicalon fiber is not caused by recrystallization or crystal growth of the "amorphous" SiC structure and is in fact independent of changes in the $\mathrm{SiC}$ crystallites.

3. The densification of the Nicalon structure is consistent with the irradiation induced transition toward a fully dense $\mathrm{Si} \mathrm{O}_{\mathrm{x}} \mathrm{C}_{\mathrm{y}}$ glassy phase.

4. Low oxygen Nicalon fiber behaved under low temperature irradiation as would be expected from previous work with nearfully dense $\mathrm{SiC}$. The fiber exhibits decreases in strength, Young's and Weibull's modulus and has virtually no change in density to an fluence of $3.2 \times 10^{24} \mathrm{n} / \mathrm{m}^{2}$ at $100^{\circ} \mathrm{C}$. These radiation induced changes should yield significantly more radiation resistant $\mathrm{SiC}$ composites than have been fabricated to this point. 


\section{FUTURE WORK}

This work needs to be extended to higher fluences and greater irradiation temperatures. Presently low oxygen Nicalon fibers are being irradiated in HFIR with plans for both higher fluence and temperature irradiations early in 1994. Two dimensional plain weave low oxygen composites are also being fabricated by Oak Ridge as well as one dimensional CVD SiC infiltrated composites. Once fabricated irradiation and testing will be conducted.

\section{References}

1. R. A. Lowden, "Characterization and Control of the Fiber/Matrix Interface in Ceramic Matrix Composites," ORNL/TM-11039. March 1989.

2. "The Development of Silicon Carbide Ceramic Composites for Fusion Reaction (sic) Applications" Final Report. SBIR Phase 1 Contract No: DEFG02-92ER 81271 (May 27, 1993). Materials Electrochemical Corporation.

3. S. Yajima et al., Chem. Letters. 9. (1975), p. 931.

4. Nicalon is a Tradename of the Nippon Carbon Corporation.

5. G. Simon and A. R. Bunsell, "Mechanical and Structural Characterization of the Nicalon Silicon Carbide Fibre," J. Mat. Sci., 19 (1984), pp. 3649-3657.

6. C. J. Macey et al., "Scanning Electron Microscopy," Vol. IV (SEM Inc., AMF O'Hare, Chicago, 1984), p. 1643.

7. S. Yajima et al., Rev. Chim. Min. 18, p. 412. (1981).

8. L. Porte and A. Sartre, "Evidence for a Silicon Oxycarbide Phase in the Nicalon Silicon Carbide Fibre," J. Mater. Sci. 24 (1989), pp. 271-275.

9. C. Laffon et al., "Study of Nicalon-based Ceramic Fibres and Powders by EXAFS Spectrometry, X-ray Diffractometry and Some Additional Methods," J. Mater. Sci. 24 (1989), pp. 1503-1512.

10. S. M. Johnson et al., "Degradation Mechanisms of Silicon Carbide Fibers," J. Am. Ceram. 71 [3] (1988), pp. C132-135.

11. R. West et al., Bull Amer. Ceram. Soc. 62 (1989) p. 899.

12. K. J. Wynne and R. W. Price, Ann. Rev. Mater. Sci. 14 (1984), p. 297.

13. T. Seguchi et al., "Preparation of Heat-Resistant Silicon Carbide Fiber from Polycarbosilane Fiber Cured by Electron Beam Irradiation," Proc. of International Conference on Evolution in Beam Applications, Nov. 5-8, Japan (1991).

14. K. Okamura and Tadao Sedguchi, "Application of Radiation Curing in the Preparation of Polycarbosilane-Derived SiC Fibers," J. Inorganic and Organometallic Polymers 2 [1], (1992) pp. $171-79$.

15. T. M. Besman et al., "A Method for Rapid Chemical Vapor Infiltration of Ceramic Composites," Proceedings of the Seventh European Conference on Chemical Vapor Deposition, Journal de Physique 50 (Conf-C-5), pp. 229-239, May (1988).

16. Ultimage is a trademark of Graftek-France.

17. Nanoindenter is a trademark of the NanoInstruments Corporation, Knoxville, Tennessee. 
18. L. L. Snead, S. J. Zinkle, D. Steiner, "Measurement of the Effect of Radiation Damage to Ceramic Composite Interfacial Strength," J. Nucl. Mat. 191-194 (1992), pp. 566-570.

19. L. L. Snead, "Development of SiC Composites for Fusion," Fus. Tech. 24 [1] (1993), pp. 65-82.

20. L. L. Snead, S. J. Zinkle, D. Steiner, "Radiation Induced Microstructure and Mechanical Property Evolution of SiC/C/SiC Composite Materials," J. Nucl. Mat. 191-194 (1992), pp. 560-565.

21. K. Okamura et al., "Effects of Neutron Irradiation on Fine Structure and Strength of SiC Fibers," J. Nucl. Mat., 155-157 (1988), pp. 329-333.

22. I. F. Ferguson, "Lattice Contraction Associated with the Neutron Irradiation of Self-Bonded Silicon Carbide," Phil. Mag. 10, Correspondence, pp. 635-636 (1967).

23. R. J. Price, "Effects of Fast-Neutron Irradiation on Pyrolytic Silicon Carbide," J. Nucl. Mat. 33 (1969) pp. 17-22.

24. R. Blackstone and E. H. Voice, "The Expansion of Silicon Carbide by Neutron Irradiation at High Temperature," J. Nucl. Mat. 39, pp. 319-322 (1971).

25. R. Stevens, "Neutron Irradiation Damage in SiC Whiskers," Phil. Mag. 25, pp. $523-528$ (1971).

26. R. J. Price, "Annealing Behavior of Neutron-Irradiated Silicon Carbide Temperature Monitors," Nucl. Tech. 16 (1972), pp. 536-542.

27. R. J. Price, "Neutron Irradiation-Induced Voids in $\beta$-Silicon Carbide," J. Nucl. Mat. 48 (1973) pp. 47-57.

28. R. B. Matthews, "Irradiation Damage in Reaction-Bonded Silicon Carbide." J. Nucl. Mater. 51 (1974) pp. 203-208.

29. S. D. Harrison and J. C. Corelli, "Microstructure of Polycrystalline SiC Containing Excess Si after Neutron and Ion Irradiation," J. Nucl. Mat. 99 (1981), pp. 203-212.

30. T. Suzuki et al., "Effects of Sntering Aids on the Length Change of Neutron Irradiated SiC Ceramics During Annealing at High Temperature," J. Nucl. Mater. 165 (1989), pp. 247-251.

31. T. Iseki et al., "Effects of Neturon Irradiation and Subsequent Annealing on Strength and Toughness of SiC Ceramics," 170 (1990) pp. 95-100.

32. K. Okamura et al., "Effects of Neutron Irradiation on Fine Structure and Strength of SiC Fibers." J. Nucl. Mater. 155-157 (1988), pp. 329-333.

33. A. Kohyama et al., "Radiation Induced Microstructure Evolution in SiC/Al Composite Materials." J. Nucl. Mater. 155-157 (1988), pp. 334-339.

34. A. Kohyama et al., "Effects of Neutron Irradiation on Ceramic Fiber Reinforced Composites," ASTM 1125 15th ASTM International Symposium on Effects of Radiation on Materials, Nashville, Tn. (1990), pp. 785-796.

35. A. Kohyama et al., "Microstructural Evolutions of PCS-SiC/Al Under Thermal Treatment and Radiation Damage," in Interfaces in Polymer. Ceramic. and Metal Matrix Composites, ed. Hatsuo Ishida, Elsevier Science Publishing Co., Inc. (1988).

36. C. W. White, "Ion Implantation and Annealing of Crystalline Oxides," Mat. Sci. Reports. 4, Number 2.3, (1989) p. 41-146. 
37. J. F. Kirchner and R. E. Bowman, Effects of Radiation on Materials and Components, Reinhold Publishing, New York (1964).

38. E. Lell et al., "Radiation Effects in Quartz, Silica and Glasses," from Progress in Ceramic Science. Vol. 4., ed. J. E. Burke, Pergamon Press. (1966).

39. W. Primak and E. Edwards, Phys. Rev. 128 (1962), p. 2580.

40. M. C. Wittels and F. A. Sherrill, Phys. Rev. 93 (1954), pp. 1117-1118.

41. W. Primak et al., Phys. Rev. 92 (1953), pp. 1064-1065.

42. W. Primak et al., "Effects of Nuclear Reactor Exposure on Some Properties of Vitreous Silica and Quartz," J. Am. Ceram. Soc. 38 (1955), pp. 135-139.

43. D. Billington and J. H. Crawford, Radiation Damage in Solids, Princeton University Press (1961).

44. R. L. Hines, J. Appl Phys. 28 (1957), pp. 587-591.

45. W. Primak, J. Appl. Phys. 35 (1962), pp. 1342-1347.

46. A. M. Bishay, J. Am. Ceram. Soc. 44 (1961) pp. 289-296.

47. V. Garino-Canina, Verr et Refract., 12 (1958), pp. 313-323.

48. V. Culler, Proceedings of the Seventh Hot Laboratory and Equipment Conference, Cleveland. (1959), pp. 119-128.

49. D. K. Stevens et al., J. Appl. Phys. 29 (1958), pp. 66-68.

50. W. Primak and E. Edwards, "Ionization Expansion of Compacted Silica and the Theory of RadiationInduced Dilations in Vitreous Silica," Phys. Rev. 133 [2A] (1964), pp. A531-535.

51. I. Simon, Phys. Rev. 103 (1956), pp. 1587.

52. I. Simon, J. Amer. Ceram Soc. 40 (1957), pp. 150. 
FATIGUE CRACK GROWTH RATE (FCGR) BEHAVIOR OF SiC/SiC COMPOSITES -- N. Miriyala, P. K. Liaw and C. J. McHargue (University of Tennessee) and L. L. Snead (Oak Ridge National Laboratory)

\section{OBJECTIVE}

To develop a basic understanding of fatigue crack growth characteristics in $\mathrm{SiC} / \mathrm{SiC}$ composites in both irradiated as well as non-irradiated conditions.

\section{SUMMARY}

Two different techniques, viz. compliance and FRACTOMAT methods, have been evaluated to precisely determine the crack length during fatigue crack propagation testing. A software program has been developed to compute da/dN and DK values. Facilities are being augmented to conduct the tests at temperatures as high as $2000^{\circ} \mathrm{C}$. Machining of $\mathrm{SiC} / \mathrm{SiC}$ composites has been successfully accomplished using the facilities at the University of Tennessee. Work has been initiated on the theoretical modeling of the various crack shielding mechanisms that can profoundly influence the crack propagation rates.

\section{PROGRESS AND STATUS}

\section{Introduction}

A perusal of the literature review on the fiber reinforced $\mathrm{SiC} / \mathrm{SiC}$ composites brought into sharp focus the scarcity of mechanical properties data of these composites. However, it is common knowledge that successful design and application of these composites call for a thorough understanding of their mechanical behavior. Although fiber reinforced ceramic matrix composites have been under active development for the last few years, the literature on the fatigue crack growth behavior of these materials ${ }^{1-5}$ is scarce and, in fact, there is only one paper concerning the $\mathrm{SiC} / \mathrm{SiC}$ composites ${ }^{6}$. Moreover, the investigators have used a variety of testing methods and specimen geometries which effectively precludes any attempts to compare the data even for similar materials. In view of the above, it has been decided to study the fatigue crack propagation behavior of the $\mathrm{SiC} / \mathrm{SiC}$ composites using the ASTM standard E 647-92 for the measurement of fatigue crack growth rate in metallic materials. The test method involves cyclic loading of notched specimens which have been precracked in fatigue loading. Crack length is measured, either visually or by an equivalent method, such as FRACTOMAT or compliance techniques, as a function of elapsed fatigue cycles, and the data are subjected to numerical analyses to establish the rate of crack growth, $\mathrm{da} / \mathrm{dN}$,expressed as a function of the stress intensity factor range, DK. The fatigue crack growth rate expressed as a function of the crack tip stress intensity factor range, da/dN vs DK, characterizes the material's resistance to crack extension under cyclic loading. Expressing da/dN as a function of DK provides results that are independent of planar geometry, thus enabling comparison of data obtained from a variety of specimen configurations and loading conditions. Moreover, this feature enables da/dN versus DK data to be utilized in the design and evaluation of engineering structures.

\section{Present Status}

(i) Fatigue crack growth rate tests have been performed on three plain carbon steel specimens, as a prelude to the testing of the more expensive $\mathrm{LAS} / \mathrm{SiC}$ and $\mathrm{SiC} / \mathrm{SiC}$ specimens, to evaluate the two independent crack length measurements techniques, viz. FRACTOMAT and compliance techniques. In the FRACTOMAT method, a thin film of constantan alloy (KRAK GAGE) is bonded to the specimen surface. Figure 1 shows the KRAK GAGE bonded to a steel specimen. A measured amount of current is passed 
increment in crack length, the crack length is accurately measured ${ }^{7.9}$. In the compliance technique, the compliance values are calculated from the load vs crack opening displacement values obtained at specified cycle intervals, and are subjected to numerical analyses to determine the crack length. A plot of da/dN vs DK is shown in Figure 2 for the steel specimen tested at a $R$ ratio (minimum load / maximum load) of 0.5 and a cycle frequency of $20 \mathrm{~Hz}$.

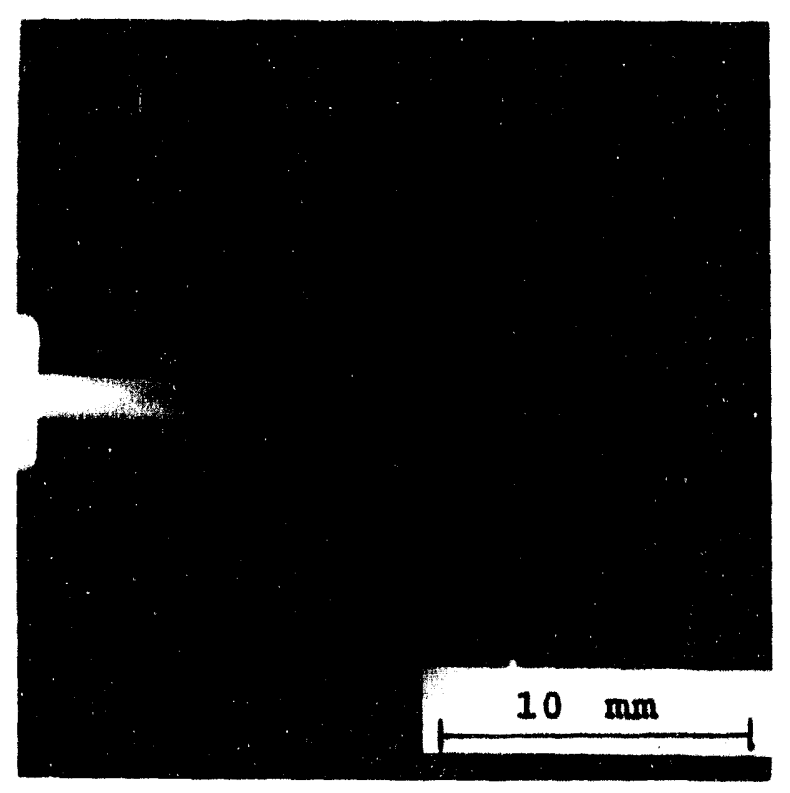

Figure 1. KRAK GAGE bonded to a steel specimen.

-

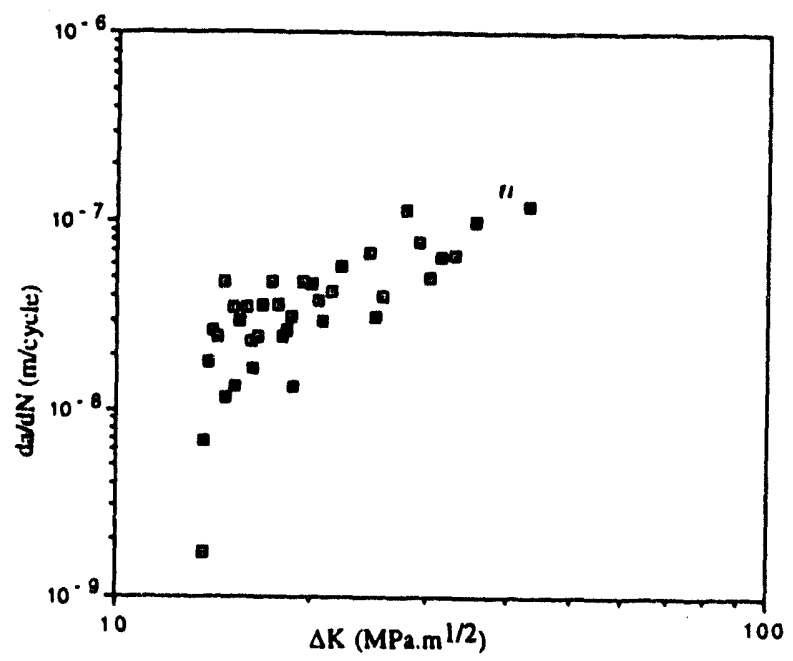

Figure 2. da/dN vs DK plot for a steel specimen tested at $R=0.5$. 
(ii) A software program has been developed to aid in the computation of $\mathrm{da} / \mathrm{dN}$ and $\mathrm{DK}$ values from the test data which runs into several kilobytes.

(iii) Two panels ( $100 \mathrm{~mm} \times 100 \mathrm{~mm}$ ) of LAS/SiC composites have been obtained from UTRC (United Technologies Research Center), Connecticut. Four side notch specimens (100 mm X $20 \mathrm{~mm} \mathrm{X} 4 \mathrm{~mm}$ ) have been fabricated, which will be tested shortly.

(iv) Since the machining of $\mathrm{SiC} / \mathrm{SiC}$ composites is well known to be a difficult task, it has been necessary to optimize the machining parameters to obtain reasonably good compact type $C(T)$ specimens of $\mathrm{SiC} / \mathrm{SiC}$ composites. It may be noted that the composite specimens were fabricated at HTML (High Temperature Materials Laboratory) of ORNL using the Forced Chemical Vapor Infiltuation (FCVI) process. A C(T) specimen of the composite is shown in Figure 3 which was machined using the in-house facilities at UT.

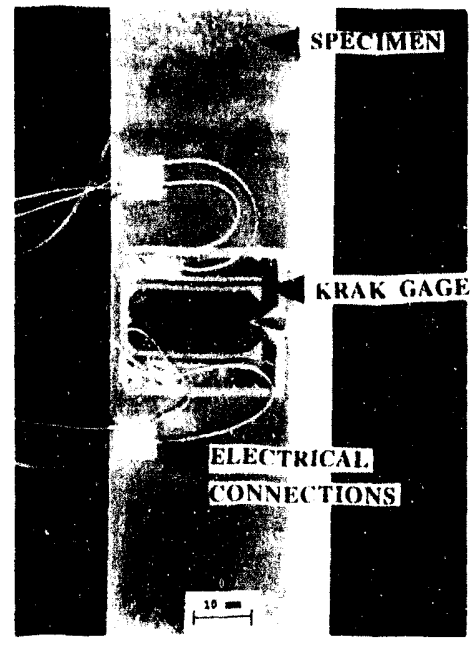

Figure 3. $\mathrm{SiC} / \mathrm{SiC} \mathrm{C}(\mathrm{T})$ specimen.

(v) A new MTS test frame has been acquired recently which will be used to test the samples at temperatures up to $2000^{\circ} \mathrm{C}$ in inert and vacuum atmospheres. Some $\mathrm{SiC} / \mathrm{SiC}$ specimens will be tested at elevated temperatures using this test frame.

(vi) Since KRAK GAGE can not be used at temperatures above $300^{\circ} \mathrm{C}$, a traveling microscope (Questar System) has been recently acquired to facilitate the measurement of crack length during elevated temperature testing.

(vii) Work has been initiated on the theoretical modeling of the various damage mechanisms, such as matrix cracking and fiber debonding, that operate at the tip of the crack as well as the various crack shielding mechanisms, such as crack bridging.

\section{FUTURE WORK}

(i) Testing of LAS/SiC, and subsequently $\mathrm{SiC} / \mathrm{SiC}$ specimens, under different load conditions both at ambient as well as elevated temperatures. Different sizes of samples will be tested to determine the smallest specimen size that can be tested, the results from which will truly represent the mechanical behavior of the composite under study. In view of the high costs associated with the irradiation experiments, it has 
become imperative to conduct such a study to determine the minimum specimen dimensions which will give valid fatigue crack growth rate results. It is hoped that this study will help in better planning the irradiation experiments.

(ii) Extensive electron microscopy characterization of the fracture surfaces to study the various damage and crack shielding mechanisms.

(iii) Investigation of the fatigue crack propagation behavior of the irradiated $\mathrm{SiC} / \mathrm{SiC}$ specimens and their characterization.

\section{ACKNOWLEDGEMENTS}

This work is supported by the Department of Energy under contract No. Martin Marietta 11X-SL261V. The authors are very grateful to $H$. R. Hartman for kindly supplying us the KRAK GAGE/FRACOMAT system. We would like to thank Gred Jones, Ted Long, Doug Fielden and Bill Matlin of the University of Tennessee and Marcelo Cescon of Instituto de Pesquisas Tecnologicas, Brazil for their help and support in pursuing this work. They are also grateful to Drs. Arthur Rowcliffe and Everett Bloom of the Oak Ridge National Laboratory for their encouragement and support.

\section{REFERENCES}

1. J. W. Holmes, Journal of American Ceramic Society, Vol. 74, pp. 1639-1645, 1991.

2. L. P. Zawada, L. M. Butkus and G. A. Hartman, Journal of American Ceramic Society, Vol. 74, pp. 2851-2858, 1991.

3. E. Y. Luh, R. H. Dauskardt and R. O. Ritchie, Journal Of Materials Science Letters, Vol. 9, pp. 719-725, 1990.

4. R. H. Dauskardt, D. B. Marshall and R. O. Ritchie, Journal of American Ceramic Society, Vol. 73, pp. 893-903, 1990.

5. K. M. Prewo, Journal Of Materials Science Letters, Vol. 22, pp. 2695-2701, 1987.

6. C. H. Henager, Jr. and R. H. Jones, Ceramic Engineering \& Science Proceedings, Vol. 13, pp. 411-419, 1992.

7. P. K. Liaw, H. R. Hartman and E. J. Helm, Engineering Fracture Mechanics, Vol. 18, pp. 121-131, 1983.

8. P. K. Liaw, H. R. Hartman and W. A. Logsdon, ASTM Journal of Testing and Evaluation, Vol. 11, pp. 202-207, 1983.

9. P. K. Liaw, W. A. Logsdon, L. D. Roth and H. R. Hartman, ASTM STP 877, pp. 177-196, 1985. 
SUMMARY OF IEA WORKSHOP ON RADIATION EFFECTS IN CERAMIC INSULATORS-S. J. Zinkle (Oak Ridge National Laboratory), G. P. Pells (Harwell National Laboratory, England) and F. W. Clinard, Jr. (Los Alamos National Laboratory)

\section{OBJECTIVE}

To summarize the discussions and recommendations from the IEA Workshop on Radiation Effects in Ceramic Insulators

\section{SUMMARY}

A workshop on radiation effects in ceramics was held during the 6th International Conference on Fusion Reactor Materials in Stresa, Italy. Recent work on radiation effects in ceramics was reviewed by participants from Europe, Japan and the United States. Most of the ensuing discussion centered on the phenomenon of radiation induced electrical degradation (RIED). A round robin RIED \& xperiment on the IEA reference ceramic (Wesgo AL995) was formulated.

\section{PROGRESS AND STATUS}

Introduction

An International Energy Agency (IEA) Working Group Annex II workshop was held on the subject of radiation effects in fusion ceramic insulators during the 6th International Conference on Fusion Reactor Materials in Stresa, Italy on September 27 and 29, 1993. The workshop was organized by S. J. Zinkle (ORNL) and E. H. Farnum (LANL). The agenda addressed a wide range of topics, ranging from the possiblility of radiation induced electrical degradation (RIED) of ceramics to communication . issues between the materials scientists and the International Thermonuclear Experimental Reactor (ITER) design staff (see Table 1). The wokshop attendees included 8 scientists from Japan, 11 scientists from Europe, 6 scientists from the US, and three Russian scientists who attended the workshop as observers.

\section{Qverviews of Recent and Planned Future Work}

R. Heidinger, KfK Karlsruhe: Work continues on the dielectric property measurements on ceramics at millimeter wavelengths. The study of radiation damage effects on thermai conductivity and mechanical properties above room temperature have now produced a reasonable data $b$ ise. Further work will continue at low temperatures.

E. R. Hodgson, CIEMAT: Study of the RIED effect continues, particularly at microwave frequencies. In-situ dielectric property measurements at $15 \mathrm{GHz}$ during electron irradiation are in progress. The lower temperature threshold for RIED in electron irradiated alumina has been established to be between 150 and $200^{\circ} \mathrm{C}$. 
Table 1. Agenda for IEA Workshop on Radiation Effects in Ceramic Insulators

\section{Monday. Septemher 22 (S. J. Zinkle, Chair)}

7:30 p.m.: $\quad$ Brief overviews of recent work.
R. Heidinger (KfK Karlsruhe)
E. R. Hodgson (CIEMAT)
T. Shikama (Tohoku University)
G. P. Pells (Harwell)
C. Kinoshita (Kyushu University)
K. Noda (JAERI)
E. H. Farnum (LANL)
S. J. Zinkle (ORNL)

8:30 p.m.: Importance of irradiation environment on the microstructural evolution and physical property changes of ceramics.

(A) Effect of imposed electric and magnetic fields
W. Kesternich (Jullich)
G. P. Pells (Harwell)
P. Jung (Jullich)
T. Shikama (Tohoku University)
A. Möslang (Karlsruhe)
E. R. Hodgson (CIEMAT)
E. H. Farnum (LANL)
L. L. Snead (ORNL)

(B) Irradiation spectrum (PKA and ionizing radiation)
G. P. Pells (Harwell)
C. Kinoshita (Kyushu University)
S. J. Zinkle (ORNL)

(C) Mechanical behavior under combined irradiation and applied stress

S. J. Zinkle (ORNL)

P. Jung (Jullich)

K. Abe (Tohoku University)

\section{Wednesday. September 29 (E.H. Farnum, Chair)}

7:00 p.m.: ITER design challenges, and how to improve communication with the ITER design team.

F. W. Clinard (LANL)

R. F. Mattas (ANL)

G. P. Pells (Harwell)

8:30 p.m.: Future plans, identification of critical problem areas, possible round robin/ collaborative experiments.

(A) Upcoming meetings of interest (S. J. Zinkle, ORNL)

(B) Define near-term critical research areas

G. P. Pells, Harwell: In-situ measurements show no RIED effects in silica glass during cyclotron (proton) irradiation at temperatures up to $300^{\circ} \mathrm{C}$. Transmission electron microscopy (TEM) studies of an electrically degraded sapphire sample provided by CIEMAT show the presence of $\gamma$-A $\mathrm{A}_{2} \mathrm{O}_{3}$ precipitates.

K. Noda, JAERI: Radiation induced conductivity measurements were reported for sapphire irradiated with $14 \mathrm{MeV}$ neutrons. RIED measurements during high-dose neutron irradiation in the HFIR reactor are planned. 
T. Shikama, Tohoku University: Work continues to improve the capsule design for in-reactor electrical conductivity measurements, in collaboration with LANL and ORNL scientists. Conductivity increases attributed to RIED have been observed in alumina. The optical loss in silica fibers has been measured in-situ during fission neutron irradiation.

C. Kinoshita, Kyushu University: There is ongoing work with an HVEM/ion accelerator system to investigate the effects of variations in the irradiation spectrum (ionizing and displacive irradiation) on the microstructural evolution of spinel. An in-situ HVEM electrical conductivity stage has been built for RIED measurements, and preliminary results have been obtained on $\mathrm{ZrO}_{2}$.

E. H. Farnum, LANL: In-situ measurements of electrical and optical properties during neutron irradiation have been made in the LASREF facility. The ac capsule requires further postirradiation tests, but the dc capsule results show only the usual transient radiation induced conductivity with no apparent permanent RIED. Postirradiation examination of the various samples is planned.

S. J. Zinkle, ORNL: Ceramic samples have been irradiated in four different fission reactors. Postirradiation examination is in progress to determine swelling, strength, fracture toughness, thermal conductivity, ac electrical properties and TEM. Dual ion beam irradiations are being used to investigate the effect of variations in ionization/dpa ratios on radiation damage processes in oxide and nitride ceramics. Insitu measurements of the thermal conductivity, dc electrical conductivity, and dielectric properties at 100 $\mathrm{MHz}$ during fission neutron irradiation are in progress or planned.

\section{Discussion of Radiation Induced Electrical Degradation}

An extended session was devoted to the subject of the RIED effect in ceramic insulators. Recent work at Forschungszentrum Jülich using high energy proton and alpha particle irradiation found no RIED effect in alumina irradiated at a nominal temperature of $500^{\circ} \mathrm{C}$ to $\sim 0.01 \mathrm{dpa}$. During the course of this work it was found that surface contamination of the sample with a conducting film that condensed from the surrounding atmosphere could introduce errors into the bulk conductivity measurement, even when a guard ring geometry was used. The superfluous surface current gave the erroneous appearance of a bulk RIED effect. Similar results were also reported by researchers from KfK Karlsruhe.

The opportunity was taken at this workshop to have extensive public discussions on the experimental techniques used by those workers who had previously reported the RIED phenomenon. It was concluded that these original experiments had been carefully performed using standard experimental techniques. Further experiments are required to resolve the apparent discrepancy between the original experiments at CIEMAT and Harwell and the more recent studies at Jülich and Karlsruhe. A round-robin RIED experiment was proposed on the IEA reference ceramic, Wesgo AL.995 polycrystalline alumina (available from R. E. Stoller, ORNL). The RIED experiments should be performed at a temperature of $450^{\circ} \mathrm{C}$ with an applied field of $>200 \mathrm{~V} / \mathrm{mm}$ and a damage rate between $10^{-9}$ and $10^{-8} \mathrm{dpa} / \mathrm{s}$ (see Table 2 for a summary of the experimental features).

The workshop participants prepared a list of experimental parameters that should be measured and reported in future RIED experiments. The list included the specimen surface temperature (for accelerator experiments), the surface conductivity (center-guard and guard-base), and the contact resistance to the guard electrode. In general, the participants emphasized the importance of reporting the full experimental details in journal publications. It was also noted that RIED experiments performed at a high damage rate will likely require higher doses to achieve the same level of degradation as low damage rate experiments. Participants were urged to perform extensive postirradiation examination of electrically degraded specimens, including electrical conductivity measurements and TEM. 
Table 2. Proposed IEA Round-Robin RIED Experiment

Material: Wesgo AL.995 polycrystalline $\mathrm{Al}_{2} \mathrm{O}_{3}$ (IEA reference material) -- available from R. E. Stoller (ORNL)

Temperature: $450^{\circ} \mathrm{C}$

Electric field: $>200 \mathrm{~V} / \mathrm{mm}$

Damage rate: $10^{-9}$ to $10^{-8} \mathrm{dpa} / \mathrm{s}$

\section{Essential Experimental Features}

1. The surface temperature of the specimen must be directly measured (2-wavelength optical pyrometry, etc.).

2. A guard ring geometry must be used for the specimen electrodes. The surface conductivities (centerguard and guard-base) must be measured and reported (at least the surface conductivities at the beginning and end of the irradiation, preferably with the beam on). If a spring-loaded electrical contact system is used, then the contact resistance to the guard electrode must be measured.

3. Ohmic behavior should be verified and reported.

4. A detailed description of the experiment should be reported (specimen thickness and diameter, electrode dimensions, irradiation atmosphere, apparatus to suppress secondary electron emission, etc.)

5. Detailed postirradiation examination of the specimens (including TEM) is strongly encouraged.

\section{Miscellaneous Topics}

Recent microstructural observations were summarized which show that the microstructures produced in spinel and alumina by light ion irradiation are considerably different from the heavy ion and neutron irradiation cases. These microstructural differences were discussed within the framework of ionization-enhanced diffusion and primary knock-on spectrum effects. Further work is needed to identify the physical mechanism responsible for the strong observed dependence on irradiation spectrum.

The effects of radiation, applied stress and environment on the mechanical properties of ceramics was discussed. There is a small amount of evidence to suggest that the irradiation of stressed ceramics in certain environments (e.g. aqueous) may lead to different mechanical behavior compared to conventional unstressed irradiation followed by PIE measurements. The workshop participants could not reach a concensus regarding the possible importance of irradiation environment on the mechanical behavior of ceramics, although there is no doubt that direct exposure to hot water will lead to stress corrosion cracking.

Dr. R. F. Mattas presented a useful talk on the present ITER design, in which the various options for ceramic insulators were discussed. Further discussion with the workshop participants led to the list of 
ceramic applications for ITER summarized in Table 3. It was recognized that better communications are required between materials scientists and ITER designers. However, a specific solution to eliminate this communication problem was not identified.

Table 3. List of Ceramic Applications for ITER

\begin{tabular}{ll}
\multicolumn{1}{c}{ Application } & \multicolumn{1}{c}{ Comments } \\
RF heating systems & ECRH and ICRH only \\
Magnet insulators & Maybe a sweeping magnet for the divertor \\
Toroidal current break & Probably not needed \\
MHD insulators & Only if liquid metal cooled blanket \\
Diagnostic ceramics: & \\
optical fibers . & \\
windows & Both optical \& RF \\
reflectors & \\
insulators & \\
Plasma dump in divertor
\end{tabular}


RADIATION-INDUCED ELECTRICAL DEGRADATION OF CERAMIC MATERIALS: AN ARTIFACT?--W. Kesternich and F. Scheuermann (Institut für Festkörperforschung, Jülich, Germany) and S. J. Zinkle (Oak Ridge National Laboratory)

\section{OBJECTIVE}

To investigate whether the phenomenon of radiation-induced electrical degradation is a bulk irradiation effect.

\section{SUMMARY}

Recent electrical conductivity measurements made on aluminum oxide during irradiation with 28 $\mathrm{MeV} \mathrm{He}+$ ions near $550^{\circ} \mathrm{C}$ indicate that radiation induced electrical degradation (RIED) does not occur for damage levels up to $\sim 0.2 \mathrm{dpa}$.

\section{PROGRESS AND STATUS}

Increases in electrical current that resemble the RIED effect have been observed in some cases, but were found to be due to an increase in the surface leakage current and are attributed to a buildup of surface contamination during irradiation.

\section{Introduction}

Recently three experimental groups around Hodgson(1,2), Pells $(3)$, and Shikama(4) have reported a phenomenon in irradiated ceramics, called radiation-induced electrical degradation (RIED). Their experimental results suggest that ceramic materials suffer a permanent loss of their electrically insulating ability after exposure to low doses of irradiation. Since the use of electrically insulating ceramic materials is essential for various components of a fusion reactor, such as rf windows, neutral beam injector insulators, first wall current creaks, magnetic coil insulators and diagnostic tools, the phenomenon has immediately become of serious concem for fusion reactor designers.

RIED has been found after electron ${ }^{(2)}$, proton ${ }^{(3)}$, and neutron ${ }^{(4)}$ irradiation in a temperature range between 300 and $600^{\circ} \mathrm{C}$ in $\mathrm{Al}_{2} \mathrm{O}_{3}$ and $\mathrm{MgAl}_{2} \mathrm{O}_{4}$ and at doses of only $10^{-5}, 10^{-3}$, and $10^{-2}$ dpa for electrons, protons, and neutrons, respectively. It occurred when the specimens were exposed to an electric field during the irradiation. The presence of both a displacive and ionizing effect of the irradiation has been shown to be essential for its occurrence(2). The microstructural origin is yet unresolved, but it was suggested that the formation of metallic colloids $(2,4)$, as they have previously been observed in irradiated alkaline halides and HVEM irradiated $\alpha$-alumina, is responsible for the permanent rise in electrical conductance. A review by Zinkle and Hodgson ${ }^{(5)}$ has recently been published in this field.

To contribute to the understanding of this phenomenon, two years ago we started a study on the influence of $10 \mathrm{MeV}$ proton and $28 \mathrm{MeV}$ alpha particle irradiations on the electrical resistivity of $\mathrm{Al}_{2} \mathrm{O}_{3}$, $\mathrm{MgAl}_{2} \mathrm{O}_{4}, \mathrm{Si}_{3} \mathrm{~N}_{4}$, and $\mathrm{AlN}$. The objectives of these experiments were (a) to further establish the correlation of RIED with the physical parameters, temperature, dose, dose rate, and electrical field strength, and (b) to explore possible differences between ionic bonding $\left(\mathrm{Al}_{2} \mathrm{O}_{3}\right.$ and $\left.\mathrm{MgAl} \mathrm{O}_{4}\right)$ and covalent bonding $\left(\mathrm{Si}_{3} \mathrm{~N}_{4}\right.$ and $\left.\mathrm{A} 1 \mathrm{~N}\right)$ in ceramics. Our prime objective, however, was the goal of clarifying the 
microstructural origin of this phenomenon (hopefully as a first step towards a possible solution of the problem it poses).

The irradiations reported were performed with $28 \mathrm{MeV}$ alpha particles in vacuum on 140-160 $\mu \mathrm{m}$ thick polycrystalline specimens. The specimens were solid state bonded to a nickel block which was kept at $500^{\circ} \mathrm{C}$ by a controlled resistance heater. A dc voltage of $50 \mathrm{~V}$ (corresponding to about $350 \mathrm{kV} / \mathrm{m}$ ) was applied across the specimens during irradiation. The standard irradiation configuration consisted of four specimens of $3 \mathrm{~mm}$ diameter mounted as a square array, with a $0.5 \mathrm{~cm}^{2}$ square beam aperture. The resistance was measured during irradiation and during intermissions, when the beam was turned off, by means of electrical current reading. For transport of the electrical signals from the target chamber to the remote measuring equipment triaxial cables were used with the inner shield of the cable held at the same potential as the signal carrying lead. A more detailed description of the irradiation chamber, measuring equipment and specimen preparation technique will be given in a forthcoming paper.

The present investigation used a standard three-terminal electrical guard technique for measuring the electrical resistances in the insulating ceramics. Its principle is shown in Fig. 1. Platinum electrodes were positioned on the specimens by sputter deposition. Contact to the platinum electrodes was made by spring loading tungsten wires. Between the central electrode kept at electrical potential $(P)$ and electrical ground (B) a guard ring $(G)$ is placed which is held at the same potential as the central electrode. Thus electrical leakage currents may flow between $G$ and $B$, but are prevented between $P$ and $G$ and hence $P$ and B. The intrinsic resistance of the specimen $R_{p}$, the surface resistances $R_{P G}$ and $R_{G}$, and the contact resistances $R_{c B}, R_{c P}$, and $R_{c G}$ are indicated. The surface resistances include the leakage resistances in the support posts for the tungsten springs and in the triaxial cable, the contact resistances include the resistance of the lead between voltage supply and specimen and the internal resistance of the current meter.

ORNL-DWG93-16570

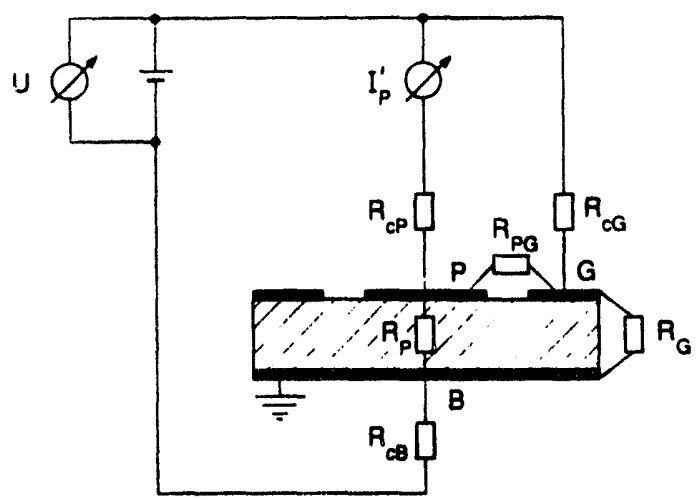

Fig. 1. Schematic of a cross section through the specimen and of the electrical diagram. The ceramic specimen (shaded) is contacted by metallic electrodes $P$ and $B$ and a ring electrode $G$. Voltage supply and meter $(U)$, current meter $I_{p}$ intrinsic resistance of the specimen $R_{p}$, surface resistances $R_{P G}$ and $R_{G}$, and contact resistances $R_{c P}, R_{c G}$ and $R_{c B}$ are indicated. The ions enter from the top side $(P)$ of the specimen, while the bottom (B) is soldered to a heat sink.

During the proton and alpha particle irradiations it became clear that the three-terminal guard technique, which under normal experimental conditions is a well suited method for measuring the electrical 
conductances of insulators, has to be carefully controlled when such measurements are carried out in an irradiation environment. It is necessary to determine the error $\Delta \sigma=\sigma_{a}-\sigma_{\mathfrak{i}}$, where $\sigma_{\mathrm{a}}$ is the apparent conductivity determined from the measurements of current $I_{p}$ and voltage $U$ (see Fig. 1 ) and $\sigma_{i}$ is the intrinsic volume conductivity of the specimen which is related to $R_{p}$ by the geometry factor $f=1 / \sigma_{\mathrm{i}} R_{\mathrm{p}}$. $\Delta \sigma$ can in principle be calculated for any combination of resistances indicated in Fig. 1 and depends in general in a complicated way on all of these resistances. For practically all cases of interest, however, a simple formula is obtained (the derivation will be included in the forthcoming paper):

$$
\Delta \sigma=\frac{1}{f} \frac{R_{c o}}{R_{a} R_{r \sigma}} \text {. }
$$

Thus the error is simply the contact resistance $R_{c G}$ divided by the product of the two surface resistances, while the contact resistance $R_{c P}$ is relatively insignificant.

The present irradiation experiments were generally performed in a vacuum around $1.3 \times 10^{-8}$ bar. On one occasion, however, the vacuum in the accelerator beam line was so poor that the pressure in front of the specimen had risen to the $10^{-7}$ bar range. On this irradiation day for the first time a significant increase of the apparent electrical conductivity was measured, an increase by four orders of magnitude in the $\mathrm{Al}_{2} \mathrm{O}_{3}$ specimen and by three orders of magnitude in $\mathrm{Si}_{3} \mathrm{~N}_{4}$ and $\mathrm{AlN}$ after an alpha particle dose of $1 \times 10^{-2} \mathrm{dpa}$ in the middle of the specimen $\left(4.5 \times 10^{21} \mathrm{He} / \mathrm{m}^{2}\right)$. The measurement in $\mathrm{Al}_{2} \mathrm{O}_{3}$ is shown in Fig. 2. The data were taken with the beam off, i.e. the so-called radiation-induced conductivity (RIC) is not included. At the same time the surface resistance $\mathbf{R}_{\mathbf{G}}$, which was constantly measured for control purposes, had dropped by three orders of magnitude due to irradiation under the poor vacuum condition. At the end of the irradiation, $R_{G}$ and $R_{P G}$ were only 1.0 and $2.1 \mathrm{k} \Omega$, respectively. Contact resistances could not be measured at this stage of the experiments. The calculation from eq. (1) yields a value for $R_{c G}$ of about 0.5 $\mathrm{k} \Omega$, an increase of two orders of magnitude as compared to the preirradiation value, indicating that the contact between tungsten spring and platinum electrode was also affected by the irradiation in a contaminating environment.

ORNL-DWG93-16571

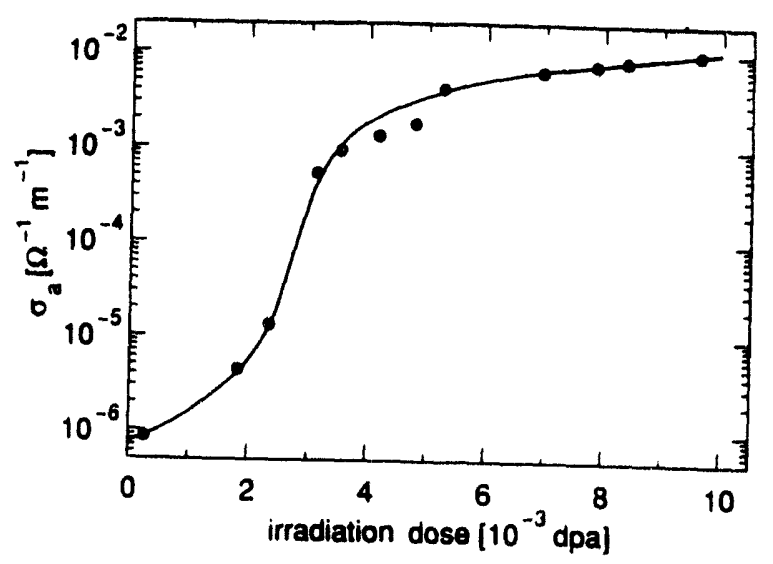

Fig. 2. Apparent conductivity of $\mathrm{Al}_{2} \mathrm{O}_{3}$ at $500^{\circ} \mathrm{C}$ as a function of alpha particle irradiation dose; whole specimen irradiated.

After the valve between accelerator beam line and irradiation chamber had been opened before the irradiation, the pressure increase had already caused an increase of the specimen conductivity while the beam 
was still off. This conductivity increase during beam-off (at $500^{\circ} \mathrm{C}$ and voltage applied to the specimen) was recorded for about $1 \mathrm{~h}$ and was found to be one to two orders of magnitude smaller in all specimens than during beam-on. However, these experimental results, which resemble RIED, are created by surface contamination.

For the next irradiation experiment three major changes were introduced. (1) Two independent contacts were attached to both the center electrode of the specimen and the guard electrode. By measuring through the two contacts on the same electrode the contact resistances $R_{c P}$ and $R_{c G}$ could be determined. Hence, all resistance values which are required to control the conductivity measurements could thereafter be measured as a function of the irradiation dose. (2) A $30 \mu \mathrm{m}$ thick Al window was introduced between beam line and specimen chamber which enabled us to keep the vacuum in front of the specimen at $3 \times 10^{-8}$ bar during the irradiation independent of the cyclotron vacuum. (3) Only a single $\mathrm{Al}_{2} \mathrm{O}_{3}$ specimen of $8 \mathrm{~mm}$ diameter was irradiated, and the beam defining aperture was reduced to $3 \mathrm{~mm}$ diameter, which was smaller than the central electrode $(5.6 \mathrm{~mm}$ diameter) on the specimen. While in the first experiment all specimens were irradiated over their full widths including guard rings and insulating rings, in this second experiment only part of the central electrode was exposed to the alpha particle beam, and in addition the two electrical contacts to the central specimen electrode were both placed outside the irradiated area. This was done in order to avoid irradiation-enhanced surface contamination on the insulating rings and at the position of the spring contacts which otherwise could have only been achieved by irradiation in ultrahigh vacuum.

The results for $\mathrm{Al}_{2} \mathrm{O}_{3}$, measured with beam-off, are given in Fig. 3. The RIC values measured with beam-on were much higher, i.e. $5 \times 10^{-7}(\Omega \mathrm{m})^{-1}$ for the present $3.3 \times 10^{-6} \mathrm{dpa} / \mathrm{s} \cong 1.8 \times 10^{18}$ $\left.\mathrm{He} / \mathrm{m}^{2} \mathrm{~s} \cong 6 \times 10^{6} \mathrm{~Gy} / \mathrm{s}\right)$. At the beginning of the irradiation the conductivity values decreased with saturation reached at about 0.05 dpa. Contrary to the first experiments, this looks like a cleaning of the specimen surface by the alpha particle beam. The irradiation was carried out in two periods, the first up to $0.09 \mathrm{dpa}$ and the second up to $0.22 \mathrm{dpa}$. Between both periods there was a break of two weeks which resulted in an increase of the saturation value, related to a decrease of the surface resistances $R_{\mathbf{G}}$ and $\mathbf{R}_{\mathbf{P G}}$. Estimation of $\Delta \sigma$ from eq. (1), using the measured values of $R_{G}, R_{P G}$, and $R_{c G}$ at three representative irradiation doses of $0.01,0.09$, and $0.2 \mathrm{dpa}$, resulted in values of $4.3 \times 10^{-9}, 6 \times 10^{-13}$, and $2 \times 10^{-10}$ $(\Omega \mathrm{m})^{-1}$, respectively. Comparison of these values with the measured conductivities in Fig. 3 shows that the measured conductivity represents the volume conductivity of the $\mathrm{Al}_{2} \mathrm{O}_{3}$ specimen only in the range between 0.04 and 0.09 dpa. At lower doses and after the irradiation break the measured conductivity is largely determined by the leakage currents.

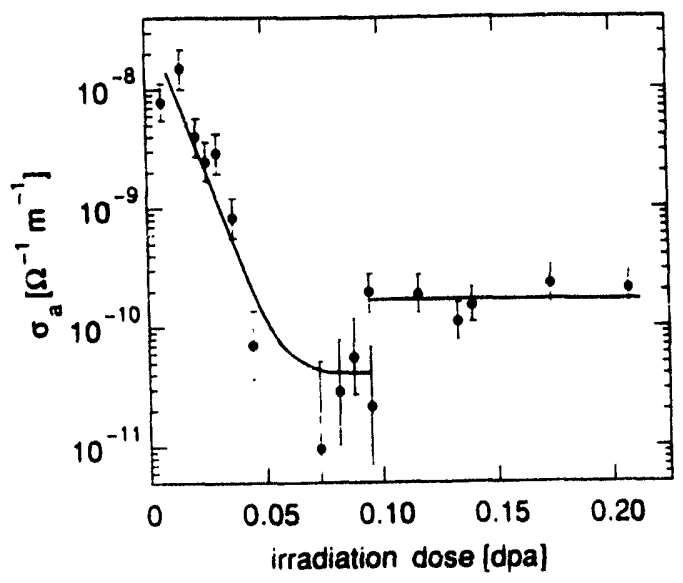

ORNL-DWG93-16572

Fig. 3. Apparent conductivity of $\mathrm{Al}_{2} \mathrm{O}_{3}$ at $500^{\circ} \mathrm{C}$ as a function of alpha particle irradiation dose; only part of the specimen below the central electrode irradiated. 
Our first experiment (Fig. 2) shows that electrical conductivity measurements under irradiation have to he performed with particular care. During irradiation the surface resistances may decrease and the contact resistance increase, i.e. all three resistances in eq. (2), which contribute significantly to the error in the measurement of volume conductivities of insulators, may be affected in an adverse way in an irradiation environment.

From the second experiment (Fig. 3) it is concluded that up to a dose of 0.2 dpa no permanent conductivity increase within the error limit of $2 \times 10^{-10}(\Omega \mathrm{m})^{-1}$ is produced in $\mathrm{Al}_{2} \mathrm{O}_{3}$ by alpha particle irradiation at $500^{\circ} \mathrm{C}$ and with an electric dc field of $350 \mathrm{kV} / \mathrm{m}$ applied across the specimen. This compares with a conductivity increase, ascribed to RIED, up to values close to $5 \times 10^{-5}(\Omega \mathrm{m})^{-1}$ observed in previous studies after irradiation doses of $2 \times 10^{-5} \mathrm{dpa}$ (electrons ${ }^{[2]}$ ), $2.3 \times 10^{-3} \mathrm{dpa}$ (protons ${ }^{[3]}$ ), and $0.6 \mathrm{dpa}$ (neutrons $[4]$ ).

Our result that no conductivity increase was observed under a typical experimental condition, where RIED is expected to occur, has changed our view on RIED since the recent review $(5)$. It is suggested that the reported conductivity increases $(1-4)$ are not due to degradation of the volume conductivity, but are created by irradiation-enhanced surface contamination.

It is suggested that this surface contamination occurs in a similar way as has long been known in transmission electron microscopy, i.e. via cracking of hydrocarbon molecules by the high energy particle beam and subsequent deposition on the specimen surface. This contamination is hence sensitive to the hydrocarbon partial pressure and to the high energy particle beam intensity. In the light of this mechanism the initially surprising decrease of the surface conductance at the beginning of the second experiment is really a cleaning effect by the beam. On TEM specimens, which are surface contaminated by hydrocarbon layers before insertion into the microscope, it is generally observed that the hydrocarbon molecules diffuse into the beam-heated zone and are then deposited as carbon contamination in the specimen area which is exposed to the electron beam. The complementary effect is suggested to be observed in the present experiment: the cleaning of that part of the specimen outside the irradiated area. It has been observed that significant "RIED" requires the presence of an electrical field $(2,4)$. Ionization of the residues from the cracked hydrocarbon molecules may enhance their deposition on the specimen surface in the presence of an electrical field.

\section{REFERENCES}

(1) E. R. Hodgson, Cryst. Latt. Def. Amorph. Mater. 18 (1989) 169.

(2) E. R. Hodgson, J. Nucl. Mater. 179-181 (1991) 383.

(3) G. P. Pells, j. Nucl. Mater. 184 (1991) 177.

575.

(4) T. Shikama, M. Narui, Y. Endo, T. Sagawa and H. Kayano, J. Nucl. Mater. 191-194 (1992)

(5) S. J. Zinkle and E. R. Hodgson, J. Nucl. Mater. 191-194 (1992) 58. 


\title{
SEARCH FOR RADIATION-INDUCED ELECTRICAL DEGRADATION IN ALUMINA DURING SPALLATION-NEUTRON IRRADIATION
}

\author{
Eugene H. Farnum*, Frank W. Clinard Jr.*, Walter F. Sommer*, James C. Kennedy III*, \\ and Tatsuo Shikama ${ }^{+}$,
}

\begin{abstract}
* Los Alamos National Laboratory, Los Alamos, NM 87545, USA
+ The Oarai Branch, Institute for Materials Research, Tohoku University, Oarai Ibaraki Ken 311-13, Japan
\end{abstract}

Introduction: Radiation-induced electrical degradation (RIED) and radiation-induced Conductivity (RIC) have been identified as the major electrical effects caused by radiation in ceramics. RIC is an electronic effect caused by excitation of electrons into the conduction band during ionizing radiation (Klaffkey ${ }^{1}$ and Farnum ${ }^{2}$ ). The origin of RIED is still unknown, but the effect has been observed during electron irradiation by Hodgson ${ }^{3}$ during proton irradiation, by Pells ${ }^{4}$ and possibly during neutron and gamma irradiation in a light-water reactor by Shikama ${ }^{5}$. In the previous work, the presence of an applied electric field of several hundred volts per centimeter is necessary to observe RIED as well as temperature above $300^{\circ} \mathrm{C}$ and radiation with both ionizing and displacive components. The onset of the RIED effect occurred at about $10^{-5}, 10^{-3}$ and $10^{-2} \mathrm{dpa}$ for the electron, proton and reactor irradiations respectively. Thus, RIED seems to depend on the amount of ionization, or perhaps, as suggested by Zinkle $^{6}$, the ratio of ionization to displacement energy deposited. Higher amounts of ionization make the effect begin at lower fluences.

This experiment measured electrical conductivity during irradiation in an attempt to determine the temperature dependence of the onset of RIED in alumina and to measure any difference between AC and DC applied electric field. The experiment contained two AC-measurement capsules and one, 4-sample DC capsule in each of three furnaces. In addition, two mineral-insulated cables with $\mathrm{MgO}$ insulation were passed through the hot zone of each furnace to evaluate RIED in the cables. Two passive capsules containing a variety of materials of interest for fusion diagnostic applications, and a spool of 4 aluminum-jacket fiberoptic cables were also irradiated in the volume outside the furnaces at approximately $100^{\circ} \mathrm{C}$. This paper will describe results of the DC measurements, $A C$ measurements made on the DC capsule samples and preliminary data on the AC capsules. Full analysis of the AC capsule data will be available after postirradiation conductivity tests. The results of the fiber optic cable experiment will be reported elsewhere. The mineral-insulated cables showed no measurable degradation during the experiment with either the AC or the DC measurements.

Experimental: The experiment described in this paper was conducted at the Los Alamos Spallation Radiation Effects Facility (LASREF) located at the beam stop of the 800-MeV Los Alamos Meson Physics Facility (LAMPF) proton accelerator. This source has a much lower amount of gamma radiation than fission reactors, about $0.3 \mathrm{~kW} / \mathrm{kg}(300 \mathrm{~Gy} / \mathrm{s})$ at a beam current of $1 \mathrm{~mA}$ vs. 5 to $15 \mathrm{~kW} / \mathrm{kg}$ ( 5 to $15 \mathrm{kGy} / \mathrm{s}$ ) in a typical fission reactor (Davidson7). The neutron fluence and spectrum at the sample location wcre measured by analysis of the activation products in $\mathrm{Fe}, \mathrm{Co}, \mathrm{Ni}, \mathrm{Cu}$ and $\mathrm{Nb}$ foils by Mueller ${ }^{8}$. Five sets of activation foils from various places within the experimental volume were analyzed. This spectrum is shown in Fig. 1. Neutron fluences reported here are total fluence because the component between $0.01 \mathrm{MeV}$ and $0.1 \mathrm{MeV}$ is significant and few thermal neutrons are present. Fluence with energy greater than $0.1 \mathrm{MeV}$ is about $67 \%$ of the quoted total fluence.

The LAMPF proton beam is pulsed with macropulses of $0.5 \mathrm{~ms}$ duration and $8 \mathrm{~ms}$ spacing. These pulses are also characteristic of the spallation neutrons that irradiated our samples. The proton beam also has fine structure pulses of about $5 \mathrm{~ns}$ separation, but at a distance of $0.15 \mathrm{~m}$ from the beam stop, the neutrons from these pulses overlap because of time of flight differences. Flux, as defined in the data presented here, is the average number of neutrons in a one-second period, not the instantaneous flux in the $0.5 \mathrm{~ms}$ pulse. The characteristics of The LASREF facility are further described by Sommer 9 . 


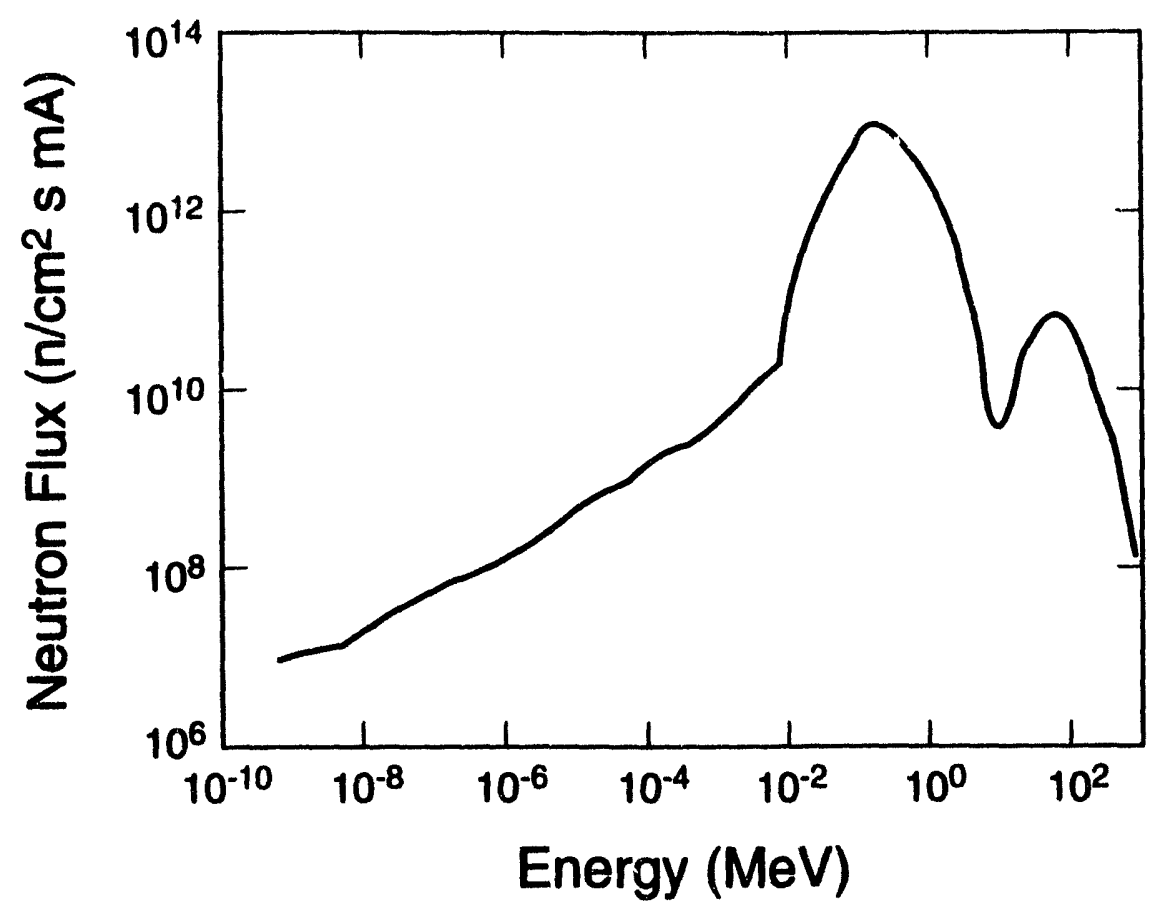

Fig. 1 Neutron spectrum (flux vs. energy) for a typical sample location at the Los Alamos Spallation Radiation Effects Facility (LASREF). The vertical scale represents flux per $\mathrm{mA}$ of proton beam current; the present experiments were carried out at 0.2 to $0.75 \mathrm{~mA}$. Measurement at $5 \mathrm{kHz}$,

Beam on, Beam off.

Three furraces, each $0.125 \mathrm{~m}$ diameter by $0.15 \mathrm{~m}$ long contained the capsules and mineral-insulated cables. Argon gas at about $100 \mathrm{kPa}$ ( $20 \mathrm{kPa}$ above atmospheric pressure in Los Alamos) was supplied continuously to the furnaces. The furnaces each had three type $\mathrm{K}$ thermocouples. These were located near the top, center and bottom of the heated zone. The top and bottom thermocouples were located radially about half-way between the axis and wall, and the center thermocouple was located on the axis. The temperature was controlled (held at a constant set point) using the center thermocouple and the other two temperatures were recorded continuously during the experiment. The furnace temperature profile from the three thermocouples was used to determine the temperature of the samples. These temperatures, for furnaces $\mathrm{A}, \mathrm{B}$, and $\mathrm{C}$ when the beam was on at high power $(0.75 \mathrm{~mA})$ were $655^{\circ} \mathrm{C}, 615^{\circ} \mathrm{C}$ and $395{ }^{\circ} \mathrm{C}$, all $\pm 5^{\circ} \mathrm{C}$.

During the experiment the proton beam was interrupted at frequent intervals and changed beam current several times. While these changes were not desired, we were able to measure the changes and used them to gain additional information. For example, we measured conductivity with the proton beam on and off at frequent intervals during the experiment. The furnace temperatures were initially set to $300^{\circ} \mathrm{C}, 400{ }^{\circ} \mathrm{C}$ and $500^{\circ} \mathrm{C}$. Early in the experiment, when the beam power was low, these temperatures were held. However, when the beam power was increased, the temperatures increased from gamma and neutron heating to their final values, and the control points were adjusted to maintain constant temperature (within $10^{\circ} \mathrm{C}$ ) with the proton beam on and off. The early part of the conductivity data is complicated by these temperature changes and the analysis of this part of the data is not yet complete. Therefore, in this paper we present conductivity data for fluences greater than $0.3 \times 10^{23} \mathrm{n} / \mathrm{m}^{2}$ (about 110 hours into the experiment) where the temperature is stable. The temperature was also measured in a temperature-uncontrolled capsule containing passive samples. The equilibrium beam-on therature of this capsule is directly related to average neutron flux and was used as an aid in determining the flux vs. time history.

The DC coaductivity measurements: Each furnace held one DC capsule that was open to the argon furnace atmosphere. Each DC capsule contained two 1-mm-thick and two 3-mm-thick, 19-mm-diameter 
alumina disks. The disks had a single 12.7-mm-diameter platinum electrode sputter-coated on each side. The disks were stacked with interleaved platinum foil electrodes such that disks of equal thickness were electrically parallel. An applied DC voltage of $150 \mathrm{~V}$ caused an electric field of $50 \mathrm{kV} / \mathrm{m}$ on the thick disks and $150 \mathrm{kV} / \mathrm{m}$ on the thin disks. This voltage was applied continuously during the experiment except for the short periods daily during which the AC conductivity measurements were made. Current was measured on the low (ground potential) side of the circuit. The alumina disks are part of the IEA round-robin 99.5 Wesgo al umina purchased by R. Stoller at ORNL. Each DC capsule had four electrodes, the high-voltage input, a thin-disk output, a thick-disk output, and a "dummy" output that entered the capsule and hung down beside the samples but was not connected to any disk electrode. The dummy electrode, placed closer to the high-voltage electrode than either of the other output electrodes, was intended to measure the maximum contribution to the sample current from gas and surface conduction. The three "output" electrodes and one $\mathrm{MgO}$-insulated cable in each furnace were scanned continuously with a computer-controlled switch and picoammeter. Sample current, time and proton-beam current were digitized and archived. Fig. 2 shows sample current versus tluence for a sample electrode $\left(655^{\circ} \mathrm{C}, 50 \mathrm{kV} / \mathrm{m}\right.$ samples) and a dummy electrode in the same furnace. Because of the small contribution, dummy electrode currents were not subtracted from sample currents in calculating conductivity.

At the two highest temperatures $\left(665^{\circ} \mathrm{C}\right.$ and $615^{\circ} \mathrm{C}$ ) the conductivity during irradiation (RIC) rapidly increased with onset of irradiation and then decreased steadily with increasing fluence. The beam-off residual conductivity also decreased with fluence.

During this experiment, the proton beam-on current varied from $200 \mu \mathrm{A}$ to $750 \mu \mathrm{A}$. This corresponds to a flux ${ }^{7}$ at the sample from about $2 \times 10^{16} \mathrm{n} / \mathrm{m}^{2} \mathrm{~s}$ to $7.2 \times 10^{16} \mathrm{n} / \mathrm{m}^{2} \mathrm{~s}$. These changes in neutron flux caused changes in the RIC. The effect of these changes can be seen in Fig. 3 in which The DC conductivity is plotted versus neutron fluence for both proton-beam-on and beam-off conditions.

By examining the points at which the flux changed, we corrected the the conductivity at fluences above 0.3 $x 10^{23} \mathrm{n} / \mathrm{m}^{2}$ in each range of constant flux (constant beam current) to account for the changing RIC. The flux was calculated from activation foil measurements and total beam charge during the experiment, measured proton beam current and measured beam-on temperature history of the Clinard capsule. Using this estimate of the flux, we corrected the conductivity data for the flux changes by increasing the conductivity of the lower-flux regions by the ratio of maximum flux (in the fluence region between 0.3 and $1.0 \times 10^{23}$ $\mathrm{n} / \mathrm{m}^{2}$ ) to flux in the corrected region. If this procedure is correct, the data at the points before and after each flux change (at the same fluence) should match to make a smooth curve. RIC is normally proportional to flux, $\phi$, and is described by the formula RIC $=\sigma_{0}+k \phi^{\delta}$, where $k$ and $\delta$ are constants and $\sigma_{0}$ is the beamoff conductiv $t y . \sigma_{0}$ is constant at each flux change point. We fit the data with various values of $\delta$ to try to get the best match at the flux changes and found that the observed RIC changes are best fit with $\delta=1.0$. The flux-corrected data for the sample set at $655^{\circ} \mathrm{C}, 50 \mathrm{kV} / \mathrm{m}$ are shown in Fig. 4. Flux-corrected data for the $615^{\circ} \mathrm{C}$ sample sets are similar, the beam-on conductivity decreasing from slightly less than $10^{-6} / \Omega \mathrm{m}$ at a fluence of $0.3 \times 10^{23} \mathrm{n} / \mathrm{m}^{2}$ to about $5 \times 10^{-8} / \Omega \mathrm{m}$ at $2 \times 10^{23} \mathrm{n} / \mathrm{m}^{2}$.

At $395^{\circ} \mathrm{C}$, within the resolution of the data, the beam-on and beam-off conductivity for both the $50 \mathrm{kV} / \mathrm{m}$ and $150 \mathrm{kV} / \mathrm{m}$ sample sets remained constant at about $1 \times 10^{-8} / 8 \mathrm{~m}$.

During the experiment, when the beam was off for a substantial period, we turned off the furnace power and measured electrical conductivity vs. temperature as the samples cooled, then again as they were reheated with furnace power on. Fig. 5 is an Arrhenius plot of the conductivity taken with beam off at a fluence of $0.4 \mathrm{x}$ $10^{23} \mathrm{n} / \mathrm{m}^{2}$. Heating and cooling data were identical. Pells ${ }^{10}$ has observed similar activation energies in proton-irradiated sapphire. 


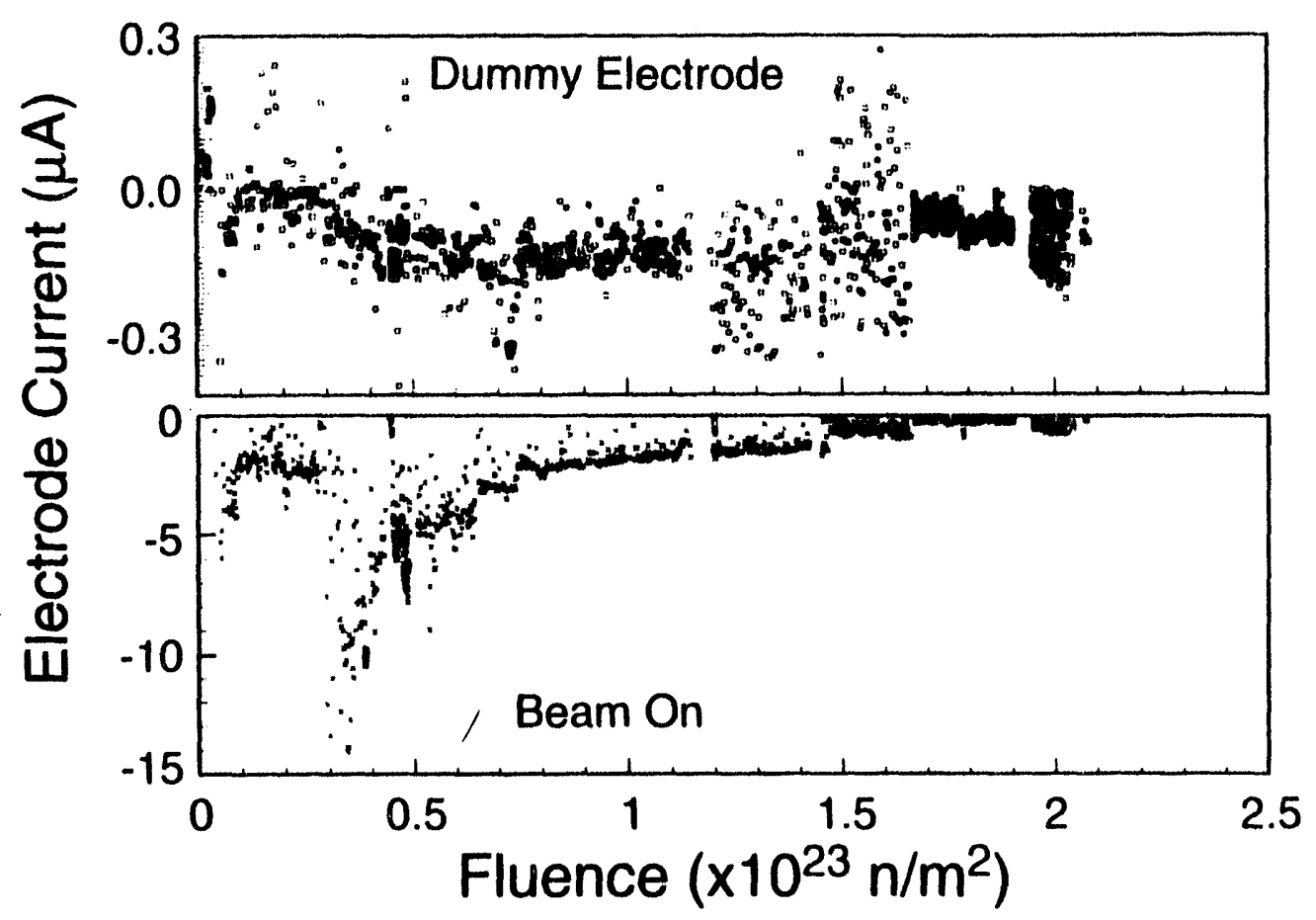

Fig. 2 Comparison of the electrode current vs. total neutron fluence for the $655^{\circ} \mathrm{C}, 50 \mathrm{kV} / \mathrm{m}$ samples and the dummy electrode in the same capsule.

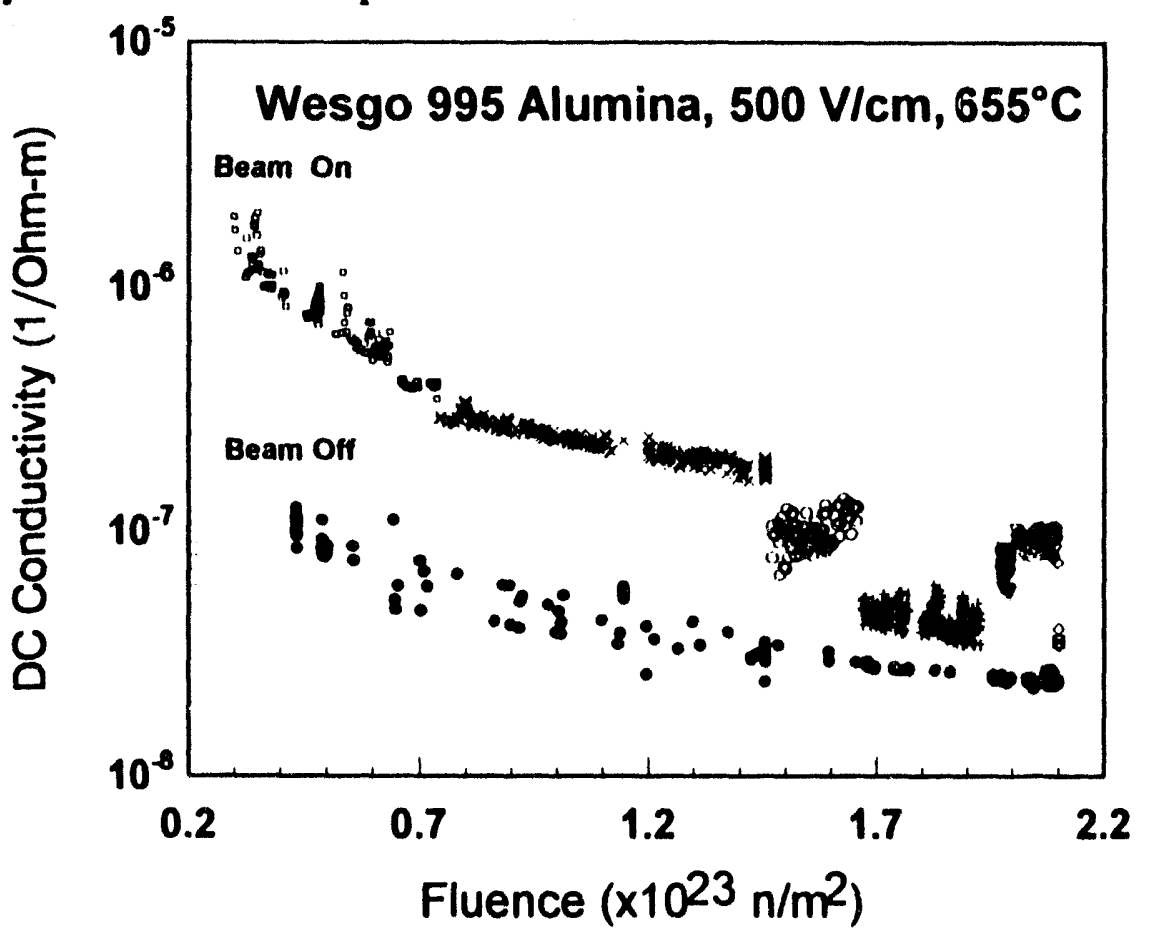

Fig. 3 As measured DC conductivity at $655^{\circ} \mathrm{C}$ and $50 \mathrm{kV} / \mathrm{m}$ vs. neutron fluence without correction for flux changes. Flux regions are identified as follows $\left(\times 10^{16} \mathrm{n} / \mathrm{m}^{2} \mathrm{~s}\right): \square 7.2, \times 6.0,05.0,+2.5, \Delta$ 2.0, $\nabla$ 2.3, $\diamond 4.3, \otimes 5.3, \triangle 2.1$, $\bullet$ beam off. 


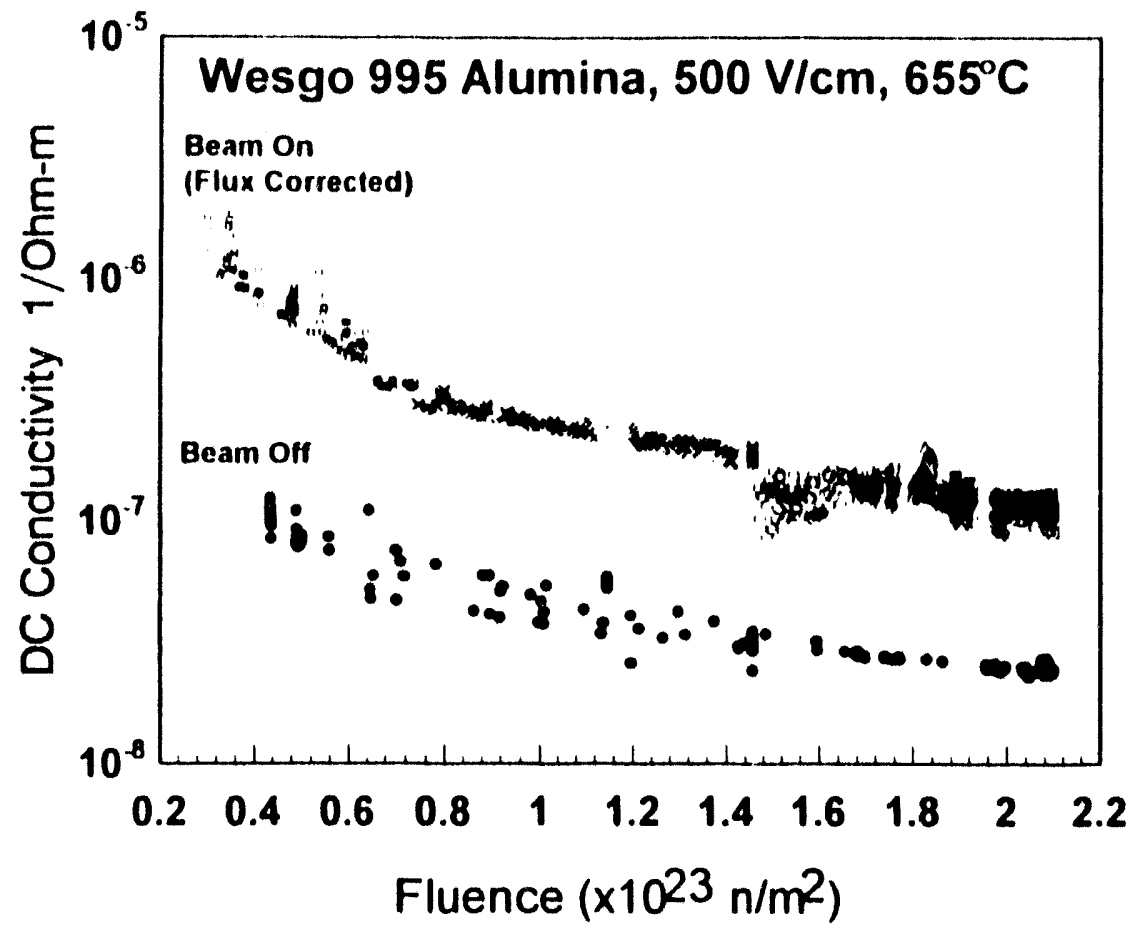

Fig. $4 \mathrm{DC}$ conductivity at $655^{\circ} \mathrm{C}, 50 \mathrm{kV} / \mathrm{m}$ vs. fluence corrected to a constant flux of $7.2 \times 10^{16} \mathrm{n} / \mathrm{m}^{2} \mathrm{~s}$.

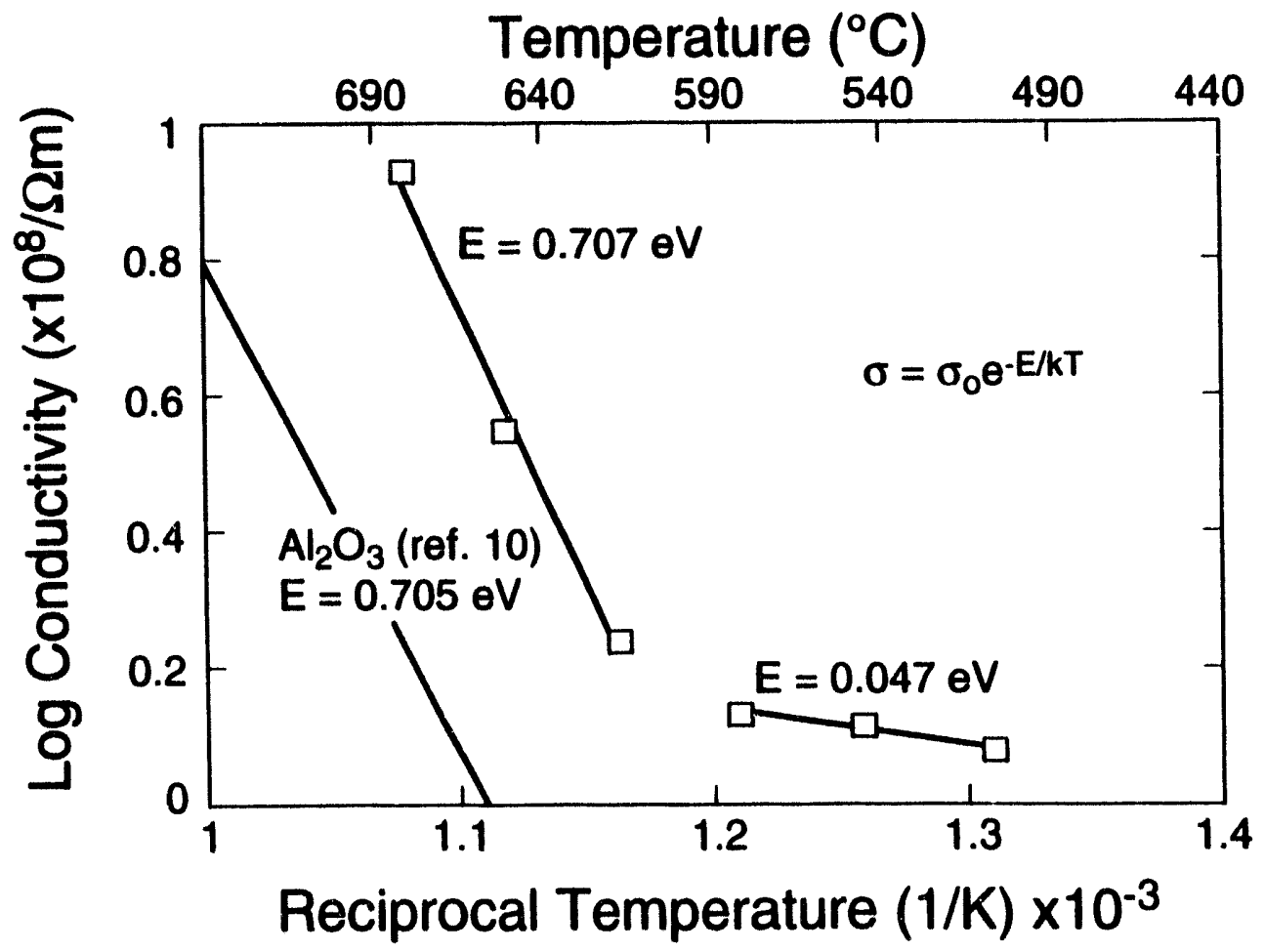

Fig. 5 Logarithm of the conductivity vs. reciprocal temperature for $655^{\circ} \mathrm{C}$ and $50 \mathrm{kV} / \mathrm{m}$. Fluence is constant at $0.4 \times 10^{23} \mathrm{n} / \mathrm{m}^{2}$ : beam off. Unirradiated conductivity data shown is from Pells 10 . 
The AC electrical measurementss Two sample capsules, one with single crystal and one with polycrystalline $\mathrm{Al}_{2} \mathrm{O}_{3}$, were contained in each of the three DC powered furnaces. Each capsule contained a single sample and was evacuated to an initial pressure of less than $0.1 \mathrm{~Pa}$. The AC samples had an applied voltage of $131 \mathrm{kV} / \mathrm{m}$ rms at $10 \mathrm{kHz}$. Impedance was measured from $100 \mathrm{~Hz}$ to $1 \mathrm{MHz}$ with a $\mathrm{HP} 4194 \mathrm{~A}$ Impedance Analyzer. During the impedance measurement, the $10 \mathrm{kHz}$ voltage was removed. The measured AC conductivity showed a dramatic increase similar to previous RIED measurements. The conductivity calculated from the maximum current was about

$10^{-2} / 8 \mathrm{~m}, 10^{-4} / 8 \mathrm{~m}$, and $10^{-5} / 8 \mathrm{~m}$ at $615^{\circ} \mathrm{C}, 655^{\circ} \mathrm{C}$ and $395^{\circ} \mathrm{C}$ respectively. The $395^{\circ} \mathrm{C}$ conductivity was not yet saturated at a fluence of $10^{23} \mathrm{n} / \mathrm{m}^{2}$. Conductivity data at $100 \mathrm{~Hz}$ for the three single-crystalsample capsules were reported in our Semi-annual Progress Report by Kennedy 11. However, we are not certain that the measured current can be attributed to increases in sample conductivity as opposed to environmental changes in the capsule. These results can be verified with post-irradiation conductivity measurements and will be fully reported when the post-irradiation analysis is complete. AC measurements of MgO-insulated cables during irradiation with an applied electric field peak strength of $175 \mathrm{kV} / \mathrm{m}$ at 10 $\mathbf{k H z}$, did not reveal any degradation curing the experiment.

AC measurements were also made on the $D C$ capsules. The $D C$ voltage was removed for these measurements and the impedance analyzer was connected in a two-terminal measurement on each two-sample stack. The AC measurements were all similar to the DC measurements. Fig. 6 shows AC conductivity at $5 \mathrm{kHz}$ on the $150 \mathrm{kV} / \mathrm{m}$ sample set at $615^{\circ} \mathrm{C}$.

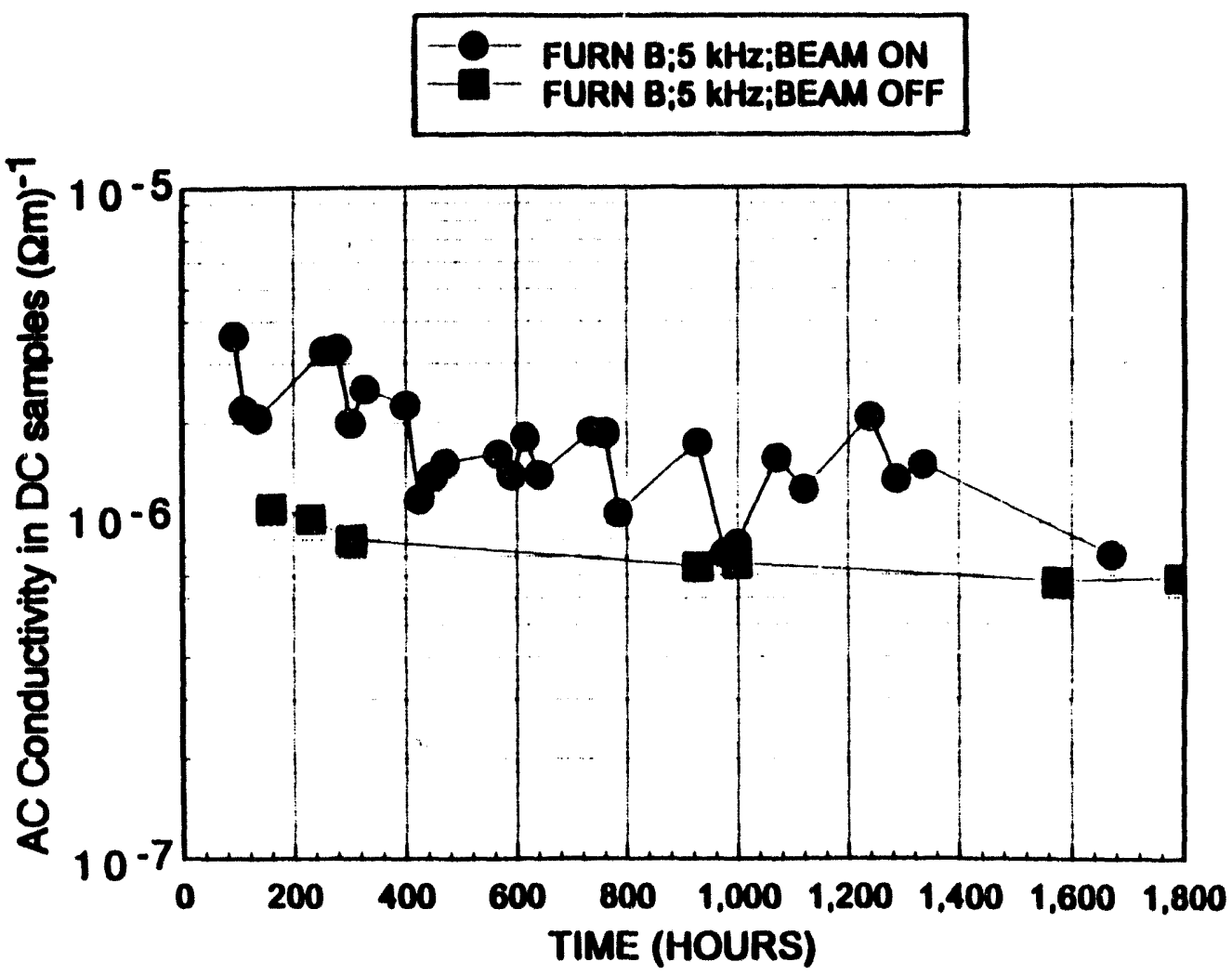

Fig. $6 \mathrm{AC}$ conductivity at $5 \mathrm{kHz}$ of the $\mathrm{DC}$ sample pair at $615^{\circ} \mathrm{C}, 150 \mathrm{kV} / \mathrm{m}$ vs. run time with beam on and off. 
Conclusions: We have measured the DC electrical conductivity during irradiation in Alumina with an applied electric field and at temperatures in the $400^{\circ} \mathrm{C}$ to $600^{\circ} \mathrm{C}$ range to fluences as high as $0.02 \mathrm{dpa}$. RIED was not observed. The conductivity showed a high initial RIC effect, but the RIC decreased during the irradiation in a manner similar to our previous proton irradiation measurements ${ }^{2}$. At the maximum fluence achieved in this experiment, RIED was well developed in electron (Hodgson) and proton (Pells) irradiations and was just beginning to increase in fission reactor (Shikama) irradiations . The present understanding of RIED effects is that the amount of ionization during the irradiation and the total radiation flux greatly affect the onset of the RIED increase, the onset occurring at lower fluences with higher ionization rates and lower fluxes. Since the LASREF radiation has the lowest ionization rate of any RIED experiment to date, and since our flux was relatively high $\left(10^{-4}\right.$ to $10^{-5} \mathrm{dpa} / \mathrm{s}$ range $v s$. less than $10^{-10} \mathrm{dpa} / \mathrm{s}$ for Hodgeson's data ${ }^{12}$ ) our DC data are consistent with current understanding.

In the AC electrical conductivity measurements, a yet to be explained effect similar to RIED was observed. The AC measurements on single-crystal alumina in evacuated capsules differs dramatically from both the DC data and the AC data taken on the DC capsule samples. We believe that these data must be verified with post-irradiation conductivity and inter-electrode resistance measurements before we can attribute them to RIED as opposed to capsule atmosphere effects. The post-irradiation measurements will be made during the coming year.

We continue to observe decreases in RIC with increasing fluence that follow an initially high RIC value. We believe these data to be correct and interpret the decrease as an increase in point defects that act as trapping sites for electrons and holes during irradiation. The data can be explained with a rate model based on electron trapping and recombination: such a model has been developed by $\operatorname{Coghlan}^{13}$ and will be published within the comming year.

\section{References:}

[1] R.W. Klaffky, B.H. Rose, A.N. Goland, and G.J Dienes, Phys. Rev. B 21 (1980) 3610.

[2] E. H. Farnum, J. C. Kennedy, F. W. Clinard and H. M. Frost, J. Nucl. Mat. 191-194 (1992) 548-551.

[3] E.R. Hodgson, J. Nucl. Mater. 179-181 (1991) 383-386.

[4] G.P. Pells, J. Nucl. Mater. 184 (1991) 177-182.

[5] T. Shikama, M. Narui, Y. Endo, T. Sagawa and H. Kayano, J. Nucl. Mater. 191-194 (1992) 575.

[6] S. Zinkle and W. Kesternich, Fusion Reactor Materials Semi-Annual Progress Report for the Period Ending March 31, 1993, DOE/ER-0313/14.

[7] D. R. Davidson, W. F. Sommer, J. N. Bradbury, R. E. Prael, and R. C. Little, J. Nucl. Mater. 122 \& 123 (1984) 989-994.

[8] We are indebted to G. Mueller at the U. of Missouri, Rolla for calculating the neutron spectrum from activation product data. The computer codes BCF and STAY'SL were used.

[9] Walter F. Sommer, Wolfgang Lohmann, Karl Graf, Ivan K. Taylor, and Raymond M. Chavez, Influence of Radiation on Material Properties: 13th International Symposium (Fari II), ASTM STP 956, F. A. Garner, C. H. Henager, Jr., and N. Igata, Eds., American Society for Testing and Materials, Philadelphia, 1987, pp. 718-729.

[10] G. P. Pells and G. J. Hill, J. Nucl. Mater. 141-143 (1986) 375-381.

[11] J. C. Kennedy, III, E. H. Farnum, W. F. Sommer and F. W. Clinard, Jr., Fusion Reactor Materials Semi-Annual Progress Report for the period ending March 31, 1993, DOE/ER-0313/14.

[12] E.R. Hodgson, J. Nucl. Mater. this volume, to be published.

[13] W. A. Coghlan, E. H. Farnum, F. W. Clinard, Jr. and J. C. Kennedy, III, "A Model for Radiation Induced Conductivity in $\mathrm{Al}_{2} \mathrm{O}_{3}$ Under Combined Displacement and Ionization Irradiation", to be published. 
TRANSIENT EFFECTS OF IONIZING AND DISPLACIVE RADIATION ON THE DIELECTRIC PROPERTIES OF CERAMICS -- R. H. Goulding, S. J. Zinkle, R. E. Stoller, and D. A. Rasmussen (Oak Ridge National Laboratory)

\section{OBJECTIVE}

The objective of this paper is to investigate the dielectric properties of candidate ceramic insulators during pulsed fission reactor irradiation.

\section{SUMMARY}

A resonant cavity technique was used to measure the dielectric constant and loss tangent of ceramic insulators at a frequency near $100 \mathrm{MHz}$ during gamma ray and pulsed fission reactor irradiation near room temperature. Tests were performed on single crystal and several different grades of polycrystalline $\mathrm{Al}_{2} \mathrm{O}_{3}$, $\mathrm{MgAl}_{2} \mathrm{O}_{4}$, AlN and $\mathrm{Si}_{3} \mathrm{~N}_{4}$. Lead shielding experiments were performed for some of the pulsed fission reactor irradiations in order to examine the importance of gamma ray versus neutron irradiation effects. With the exception of AlN, the dielectric constant of all of the ceramics decreased slightly during the pulsed fission reactor irradiation. Significant transient increases in the loss tangent to values as high as $6 \times 10^{-3}$ occurred during pulsed reactor irradiation with peak ionizing and displacements per atom (dpa) radiation fields of $4.2 \times 10^{4} \mathrm{~Gy} / \mathrm{s}$ and $2.4 \times 10^{-6} \mathrm{dpa} / \mathrm{s}$, respectively. The loss tangent measured during irradiation for the different ceramics did not show any correlation with the preirradiation or postirradiation values. Analysis of the results indicates that the transient increases in loss tangent are due to radiation induced increases in the electrical conductivity. The loss tangent increases were proportional to the ionizing dose rate.

PROGRESS AND STATUS

\section{Introduction}

Ceramic insulators are widely used as vacuum windows and mechanical supports in radiofrequency (rf) and microwave heating systems for fusion applications. ${ }^{1,2}$ In future devices such as the International Experimental Thermonuclear Reactor (ITER), these materials will be subjected to high levels of both ionizing and displacive radiation. ${ }^{1-4}$ Exposure of ceramics to these agents has been shown in many experiments to cause both transient and permanent changes in their dielectric properties, ${ }^{1-5}$ which can have a significant impact on their intended uses. Postirradiation measurements have provided useful information on the level of permanent damage to be expected, $2,6,7$ but transient effects that are only present during irradiation may produce additional degradation that is not detected in postirradiation measurements. ${ }^{3-15}$ There is some evidence that the loss tangent decreases rapidly following irradiation. 11 However, there is relatively little available information on the if dielectric properties of ceramics during irradiation. $5,12,13,16$

In this paper we examine transient effects of irradiation by both neutrons and gammas on the dielectric properties of ceramics at if frequencies. We felt that it was important to use neutrons rather than charged particles for the irradiation source, due to the possibility that the irradiation spectrum could have an effect on the results. The irradiation spectrum has been shown to have a pronounced effect on microstructural changes such as the formation of dislocation loops in ceramic insulators irradiated with light ions. ${ }^{17}$ The transient radiation pulses were produced in a pulsed fission reactor. This led to the choice of a resonant cavity technique for making measurements, in order to minimize sources of error in a difficult experimental environment. Data was obtained using both a swept frequency technique and time resolved 
impedance measurements, allowing us to obtain an accuracy in the loss tangent of $\sim 2 \times 10^{-5}$ and a time resolution of $1 \mathrm{~ms}$. The two methods showed good agreement between them. Several different materials were investigated, including single crystal and polycrystalline alumina of differing purities, spinel, aluminum nitride and silicon nitride.

\section{Description of the Experiment}

A range of ceramic materials were examined: single crystal sapphire (0001 orientation) from Crystal Systems, Inc.; polycrystalline alumina of different purities from Coors and WESGO; and magnesiumaluminate spinel, silicon nitride, and aluminum nitride from CERCOM. The materials were obtained from the vendors in the form of discs with a diameter of $35 \mathrm{~mm}$ and a thickness of $3.2 \mathrm{~mm}$. Specimen surfaces were specified to be polished using 20 micrometer or finer abrasive. The results of chemical analysis conducted on the materials by Coors Analytical Laboratory is shown in Table 1. No chemical analysis was obtained on the WESGO AL998 specimen.

The resonant cavity technique was chosen because the calibration of the system is relatively simple, and changes in the feed-line characteristics due to irradiation and temperature changes can easily be taken into account. This technique was first applied to in-situ measurements of ceramic dielectric properties during neutron irradiation by Edelson, Jaeger, and Williams, ${ }^{12}$ at frequencies in the microwave range. Operation at the lower frequencies of interest to us necessitated the use of a capacitively loaded coaxial cavity.

A typical cavity is shown in Fig. 1. The capacitor was formed by a plate at the end of the center conductor which was located opposite to a second plate in the end cap. The sample under test formed the capacitor dielectric. The cavities were fabricated from aluminum to minimize radiation exposure when changing samples. The interior was plated with a layer of copper $\sim 25 \mu \mathrm{m}$ thick, as was the center conductor, to reduce if losses in the cavity walls which would reduce the resolution of the loss measurements. The cavities were typically $360 \mathrm{~mm}$ long and $.76 \mathrm{~mm}$ in diameter. Cavities of slightly smaller diameter were used for irradiations that employed lead shielding. The samples were circular disks $35 \mathrm{~mm}$ in diameter and $3.2 \mathrm{~mm}$ thick. Each sample was held in place between the capacitor plates by a diaphragm which was machined into the end cap.

In order to eliminate effects due to photo-ionization of air by the gamma flux, the cavity was evacuated through a $25 \mathrm{~mm}$ ID vacuum line approximately $3.5 \mathrm{~m}$ long, connected to a $50 \mathrm{l} / \mathrm{s}$ turbo-pump. Vacuum pressures down to $7 \times 10^{-4} \mathrm{~Pa}$ were achieved, as measured by a cold-cathode ion gauge located in a section of the vacuum line $1 \mathrm{~m}$ from the cavity. A three piece cylindrical lead shield was fabricated for one of the cavities to modify the gamma to neutron ratio. This shield totally covered the bottom and sides of the cavity and was $25 \mathrm{~mm}$ thick everywhere except at the flanges and cover plates on the cavity ends, where it was $13 \mathrm{~mm}$ thick.

The cavities were designed to resonate at a frequency near $100 \mathrm{MHz}$, which is in the ion cyclotron range of frequencies (ICRF) commonly used for rf heating in large tokamaks. The exact frequency depended on the dielectric constant of the ceramic and on which of the 3 cavities were used, since the geometry could not be duplicated exactly. The resonance condition for such a cavity is given by the equation.

$$
Z_{c} \tan \beta l=\frac{1}{\omega C}
$$

where $Z_{c}$ is the characteristic impedance of the cavity, determined by the ratio of the outer to inner conductor radii, $\beta=\omega / c, \omega=2 \pi / f$, where $f$ is the operating frequency, $l$ is the length of the center conductor, and $C$ is the capacitance given by the expression 
Table 1. Chemical Analysis of Ceramic Specimens Used in TRIGA Irradiations, Values in Weight-Percent

\begin{tabular}{|c|c|c|c|c|c|c|c|}
\hline CERCOM & $\begin{array}{l}\text { Coors } \\
\text { CERCOM } \\
\text { AD94 }\end{array}$ & $\begin{array}{l}\text { Coors } \\
\text { AD998 }\end{array}$ & $\begin{array}{l}\text { Wesgo } \\
\text { AL300 }\end{array}$ & $\begin{array}{l}\text { Wesgo } \\
\text { Al995 }\end{array}$ & $\begin{array}{l}\text { CSI } \\
\text { Sapphire }\end{array}$ & $\begin{array}{l}\text { CERCOM } \\
\text { Spinel }\end{array}$ & $\mathrm{Si}_{3} \mathrm{~N}_{4}$ \\
\hline AlN & & & & & & & \\
\hline $\begin{array}{c}\mathrm{Al}_{2} \mathrm{O}_{3} \\
\mathrm{M}^{2}\end{array}$ & $93.4^{1}$ & $99.715^{1}$ & $97.328^{1}$ & $99.252^{1}$ & $M^{2}$ & $M^{2}$ & 0.86 \\
\hline $\begin{array}{c}\mathrm{SiO}_{2} \\
0.02\end{array}$ & 4.0 & 0.085 & 1.4 & 0.22 & 0.56 & 0.93 & $\mathbf{M}^{2}$ \\
\hline $\begin{array}{c}\mathrm{Fe}_{2} \mathrm{O}_{3} \\
0.0034\end{array}$ & 0.18 & 0.04 & 0.081 & 0.076 & 0.01 & 0.081 & 0.105 \\
\hline $\begin{array}{l}\mathrm{C} 2 \mathrm{O} \\
0.0024\end{array}$ & 0.26 & 0.042 & 1.1 & 0.095 & 0.003 & 0.0017 & 0.44 \\
\hline $\begin{array}{l}\mathrm{MgO} \\
0.0097\end{array}$ & 0.68 & 0.077 & 0.033 & 0.31 & 0.0103 & $\mathbf{M}^{2}$ & 0.026 \\
\hline $\begin{array}{l}\mathrm{ZrO}_{2} \\
0.0013\end{array}$ & 0.65 & 0.006 & 0.009 & 0.008 & 0.00074 & 0.0002 & 0.0032 \\
\hline $\begin{array}{l}\mathrm{B} 9 \mathrm{O} \\
0.00016\end{array}$ & 0.76 & $<0.005$ & $<0.005$ & $<0.005$ & $<0.0001$ & $<0.0001$ & 0.00053 \\
\hline $\begin{array}{l}\mathrm{Na}_{2} \mathrm{O} \\
0.0011\end{array}$ & 0.045 & 0.028 & 0.039 & 0.027 & 0.0062 & 0.014 & 0.016 \\
\hline $\begin{array}{l}\mathrm{TiO}_{2} \\
0.00085\end{array}$ & 0.02 & 0.003 & 0.003 & 0.005 & 0.0013 & 0.00097 & 0.024 \\
\hline $\begin{array}{l}\mathrm{K}_{2} \mathrm{O} \\
0.0034\end{array}$ & 0.06 & 0.004 & 0.007 & 0.007 & 0.043 & 0.054 & 0.30 \\
\hline $\begin{array}{c}\mathrm{Y}_{2} \mathrm{O}_{3} \\
0.23\end{array}$ & $n / a^{3}$ & n/a & n/a & n/a & $<0.0001$ & $<0.0001$ & 6.30 \\
\hline $\begin{array}{l}P \\
0.0003\end{array}$ & $\mathbf{n} / \mathbf{a}$ & n/a & $\mathrm{n} / \mathrm{a}$ & n/a & 0.013 & 0.0089 & 0.024 \\
\hline$\underset{0.00052}{\mathrm{Cr}}$ & $\mathbf{n} / \mathbf{a}$ & $n / a$ & n/a & n/a & 0.0084 & 0.0015 & 0.0030 \\
\hline $\begin{array}{l}\mathrm{Ni} \\
0.00017\end{array}$ & n/a & $n / a$ & $\mathrm{n} / \mathrm{a}$ & n/a & 0.0023 & 0.0014 & 0.016 \\
\hline $\begin{array}{l}\mathrm{Cu} \\
0.00028\end{array}$ & $\mathbf{n} / \mathbf{a}$ & $\mathbf{n} / \mathbf{a}$ & n/a & $\mathrm{n} / \mathbf{a}$ & 0.0019 & 0.0038 & 0.0092 \\
\hline $\begin{array}{l}\mathrm{Zn} \\
0.0002\end{array}$ & $\mathrm{n} / \mathrm{a}$ & n/a & $\mathrm{n} / \mathrm{a}$ & $\mathrm{n} / \mathrm{a}$ & 0.0035 & $<0.0001$ & 0.002 \\
\hline $\begin{array}{l}\mathrm{Mn} \\
0.0069\end{array}$ & $n / a$ & $\mathbf{n} / \mathbf{a}$ & $\mathrm{n} / \mathrm{a}$ & $\mathbf{n} / \mathbf{a}$ & 0.00058 & 0.00026 & 0.0044 \\
\hline${ }_{0.081}^{C}$ & $\mathbf{n} / \mathbf{a}$ & n/a & n/a & $n / a$ & 0.031 & 0.023 & 0.106 \\
\hline
\end{tabular}

1 by subtraction

2 major constituent, not reported

$3 \mathrm{n} / \mathrm{a}$ denotes not analyzed 


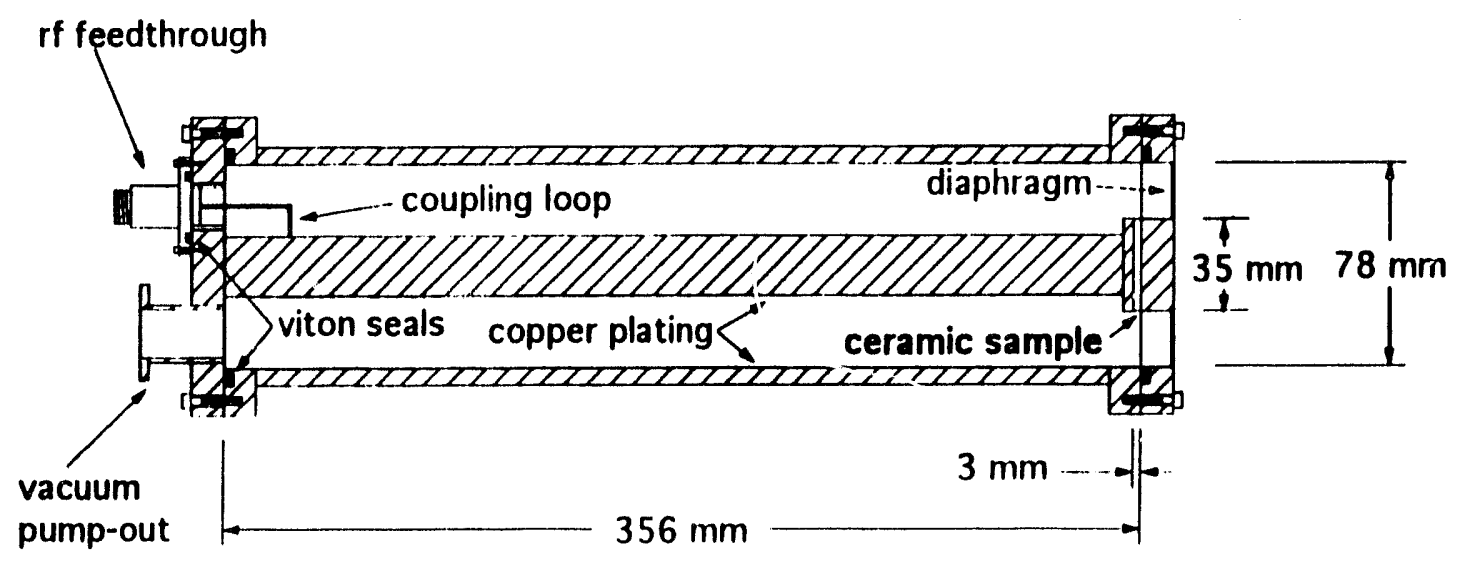

Fig. 1. Cavity for measurement of $\mathrm{f}$ parameters of ceramics during irradiation

$$
C=\frac{\pi a^{2} \varepsilon^{\prime}}{d}
$$

where $a$ is the sample radius, $d$ is the sample thickness, and $\varepsilon^{\prime}$ is the real part of the sample permittivity. Typical frequencies were 88.6 MHz for sapphire, 95.2 MHz for AL998 alumina, 100.7 MHz ... AL300 alumina, 101.4 MHz for spinel, 100.6 MHz for AlN, and 100.7 MHz for Si3N4.

The cavity input impedance was measured as a function of time and frequency using an HP8753A network analyzer with an HP S-parameter test set. A type $\mathrm{N}$ ceramic vacuum feedthrough connected the cavity coupling loop to the analyzer via a $6 \mathrm{~m}$ run of $1.3 \mathrm{~cm}$ diam heliax cable. In order to eliminate rf breakdown effects such as multipactoring in the cavity, a very low rf input power of $0.1 \mathrm{~mW}$ was used. This corresponds to a maximum voltage across the test sample of $5 \mathrm{~V}$ in the worst low loss case, and a maximum electric field of $1700 \mathrm{~V} / \mathrm{m}$. Several measurements made at a factor of 10 and 100 higher if power level showed no significant differences. Most of the data to be discussed was acquired using a Macintosh IIci computer running LabView software. An IEEE-488 (GPIB) interface card was used to control and transfer data from the network analyzer, and an $A / D$ card was used to acquire ion chamber data.

The irradiations were conducted using the TRIGA (Training, Research, Isotope production: General Atomic) reactor facility at the University of Illinois. The resonant cavity containing the specimens was placed adjacent to the reactor core in a transverse beam tube (termed the thru-port) that penetrates the reactor's biological shield and passes near the core midplane. The irradiation facility is shown schematically in Fig. 2. A set of activation monitors were irradiated in order to measure the neutron energy spectrum in this position. The set of monitors included: copper, iron, nickel, niobium, titanium, and aluminum with $1 \%$ cobalt. The monitors were shielded with $0.89 \mathrm{~mm}$ of gadolinium to remove thermal neutrons and a second Al-1\%Co monitor was irradiated without shielding to obtain the thermal flux. Since the thru-port passes so close to the core, the neutron spectrum is a slightly moderated fission spectrum with a thermal-to-fast flux ratio of about 1.5. The ionizing dose rate in the cavity location was measured using $\mathrm{CaF}_{2}$ thermoluminescent dosimeters (TLDs). The reactor power level was measured during the experiments using an ion chamber located in the reactor pool.

The reactor was used in the pulsed mode in order to obtain atomic displacement rates comparable to those expected in the first wall region of ITER. The reactor power was controlled by the amount of reactivity withdrawn by the transient control rods; $\$ 1$ of reactivity is the amount required for the reactor to be critical using prompt neutrons alone. The short pulse times $(\sim 50 \mathrm{~ns})$ permitted the transient response of the ceramic insulators to be examined. A comparison of the TRIGA and ITER ${ }^{18}$ irradiation conditions is shown in Table 2. The atomic displacement rate and ionizing damage rate are material-dependent for a given neutron flux; the values in Table 2 are valid for the materials listed under each individual heading. Since the total dose per pulse ranged from about $2 \times 10^{-9}$ to $1 \times 10^{-8} \mathrm{dpa}$ and the typical time between pulses was about $20 \mathrm{~min}$, it was not possible to obtain high fluences in these TRIGA reactor irradiations. One specimen accumulated $8.4 \times 10^{-8} \mathrm{dpa}$ ( $15 \$ 1.80$ pulses) and no clear effect of fluence was seen. 
OANL-DWG 92-9001R2

University of IIIInois TRIGA Reactor Facillty

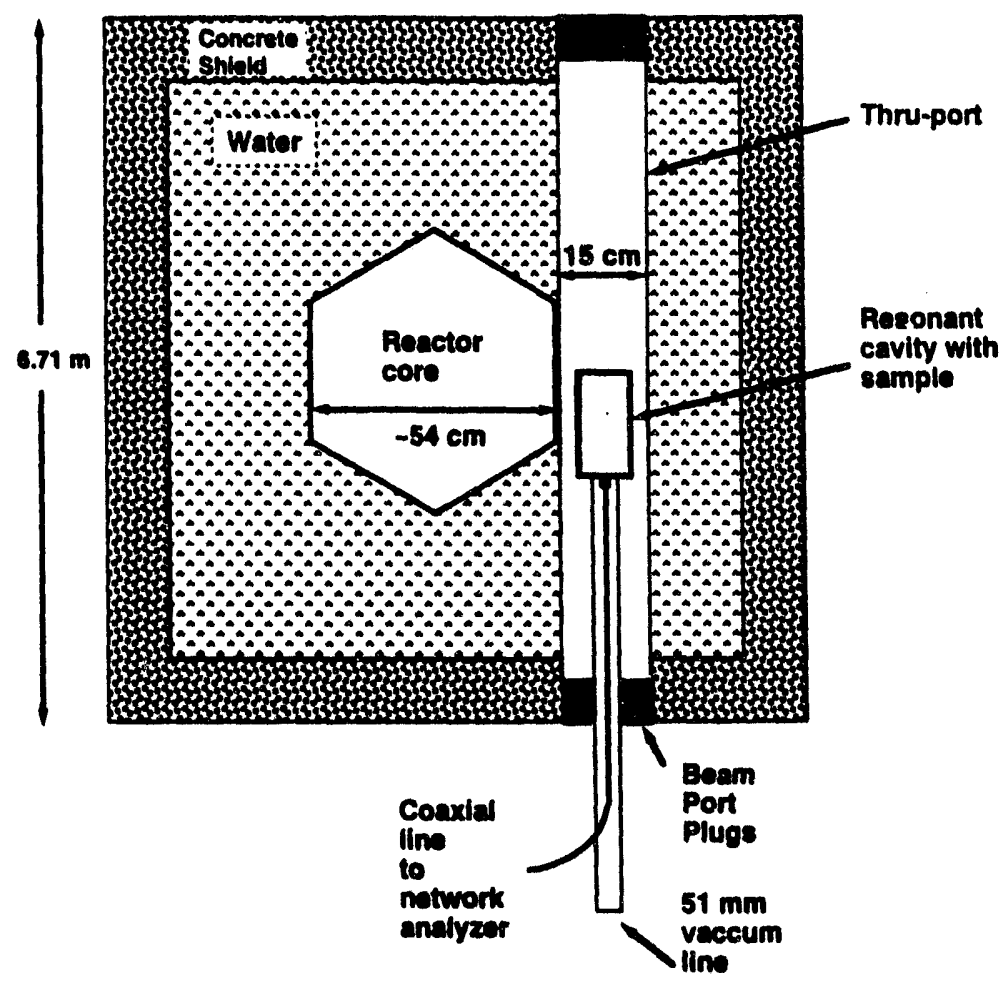

Fig. 2. Plan view of the University of Illinois TRIGA reactor.

\section{Determination of Tan $\delta$ and $\delta \varepsilon^{\prime}$}

The power dissipated in the ceramic dielectric is proportional to the loss tangent $(\tan \delta)$, which is the ratio $\varepsilon^{\prime \prime} / \varepsilon^{\prime}$ of the imaginary to the real part of the permittivity $\varepsilon$ of the material, where $\varepsilon=\varepsilon^{\prime}-i \varepsilon^{\prime \prime}$. It can be determined by measuring the decrease in the quality factor or " $Q$ " of the cavity ( $2 \pi$ times the ratio of the stored energy in the cavity to the energy dissipated in a single rf period) when a sample is introduced. More specifically, the quantity of interest is the "unloaded $Q$ ", represented here by the symbol $Q_{0}$, which excludes effects of the coupling circuit. It can be shown that the loss tangent is related to the unloaded $Q$ by the expression

$$
\tan \delta=\left(\frac{1}{2}+\frac{\beta l}{\sin 2 \beta l}\right)\left(\frac{1}{Q_{0}} \cdot \frac{1}{Q_{N C}}\right)
$$


Table 2. Comparison of ITER [18] Operating Conditions and Typical Irradiation Conditions Obtained Under Pulsed TRIGA Operation

ITER Parameters ( $3000 \mathrm{MW}$ fusion power, average wall loading $2 \mathrm{MW} / \mathrm{m}^{2}$ )

\begin{tabular}{|c|c|c|c|}
\hline Reactor Location & $\begin{array}{l}\text { Fast flux, } \\
\mathrm{E}>0.1 \mathrm{MeV} \\
\left(\mathrm{n}-\mathrm{m}^{-2} \mathrm{~s}^{-1}\right)\end{array}$ & $\begin{array}{l}\text { Displacement } \\
\text { damage rate } \\
\text { (dpa/s) }\end{array}$ & $\begin{array}{l}\text { lonizing } \\
\text { dose rate } \\
\text { (Gy/s) }\end{array}$ \\
\hline \multicolumn{4}{|l|}{ First wall (vanadium) } \\
\hline Li-cooled & $0.77-1.0 \times 10^{18}$ & $0.97-1.3 \times 10^{-6}$ & $2000-2400$ \\
\hline $\begin{array}{c}\text { He-cooled } \\
\text { Vacuum vessel (Inconel 625) }\end{array}$ & $0.88-1.2 \times 10^{19}$ & $0.99-1.3 \times 10^{-6}$ & $3300-4300$ \\
\hline Li-cooled & $1.4-1.6 \times 10^{18}$ & $0.93-1.1 \times 10^{-7}$ & $570-790$ \\
\hline $\begin{array}{c}\text { He-cooled } \\
\text { Magnets (copper) }\end{array}$ & $7.5-8.8 \times 10^{17}$ & $4.7-5.5 \times 10^{-8}$ & $360-450$ \\
\hline Li-conoled & $0.99-3.4 \times 10^{15}$ & $0.59-2.3 \times 10^{-10}$ & $0.41-0.95$ \\
\hline $\begin{array}{c}\text { He-cooled } \\
\text { (organic insulator) }\end{array}$ & $0.99-2.8 \times 10^{15}$ & $0.59-1.8 \times 10^{-10}$ & $0.42-0.77$ \\
\hline Li-cooled & - & $=$ & $1.2-3.6$ \\
\hline
\end{tabular}

Pulsed TRIGA Parameters in Thru-Port (at pulse peak)

\begin{tabular}{|c|c|c|c|c|c|c|}
\hline \multirow{2}{*}{$\begin{array}{l}\text { reactivity } \\
\text { (\$) }\end{array}$} & $\begin{array}{l}\text { se Para } \\
\text { Power }\end{array}$ & FWHM & \multirow{2}{*}{$\begin{array}{l}\text { Fast flux, } \\
\mathrm{E}>0.1 \mathrm{MeV} \\
\left(\mathrm{n} \cdot \mathrm{m}^{-2} \mathrm{~s}^{-1}\right)\end{array}$} & \multicolumn{2}{|c|}{$\begin{array}{c}\text { Displacement } \\
\text { damage rate }(\mathrm{dpa} / \mathrm{s})\end{array}$} & \multirow{2}{*}{$\begin{array}{l}\text { Ionizing dose } \\
\text { rate }(\mathrm{Gy} / \mathrm{s}) \\
\left.\text { (in } \mathrm{Al}_{2} \mathrm{O}_{3}\right)\end{array}$} \\
\hline & (MW) & (ms) & & (in $\mathrm{Al}_{2} \mathrm{O}_{3}$ ) & (in iron) & \\
\hline 1.25 & 35 & 73 & $5.30 \times 10^{17}$ & $5.95 \times 10^{-8}$ & $3.43 \times 10^{-8}$ & $1.1 \times 10^{3}$ \\
\hline 1.50 & 110 & 50 & $1.66 \times 10^{18}$ & $1.87 \times 10^{-7}$ & $1.08 \times 10^{-8}$ & $3.3 \times 10^{3}$ \\
\hline 1.80 & 220 & 30 & $3.33 \times 10^{18}$ & $3.74 \times 10^{-7}$ & $2.16 \times 10^{-7}$ & $6.6 \times 10^{3}$ \\
\hline 3.00 & 1400 & 14 & $2.12 \times 10^{19}$ & $2.38 \times 10^{-6}$ & $1.37 \times 10^{-6}$ & $4.2 \times 10^{4}$ \\
\hline
\end{tabular}

where $Q_{N C}$ is the unloaded $\mathrm{Q}$ of the cavity with no ceramic present, assuming the resonant frequency remains constant.

In practice, $Q_{N C}$ was obtained by a direct measurement using an empty cavity. The frequency was kept constant by replacing the end cap at the capacitor with one having a longer center post, thus compensating for the reduced value of the dielectric constant by reducing the gap between capacitor plates. A typical measured value of QNC for these cavities was 2300.

Two different types of measurements were used to determine changes in the unloaded $Q$ during a radiation pulse. In the first method, the frequency was swept over a small range of values in the neighborhood of the resonant frequency, and a resonance curve was obtained by plotting the voltage standing wave ratio (VSWR) vs frequency. In the second method, the input impedance of the cavity was measured directly as a function of time, and this quantity was related to the unloaded $Q$.

The analyses of the swept frequency and time-dependent data both begin with a lumped element model of the cavity, ${ }^{19}$ valid for frequencies close to that satisfying the resonance condition, Eqn. 1 . Based on this model, shown in Fig. 3, the normalized impedance at the input to the cavity (denoted as the point a-a) is given by the expression 


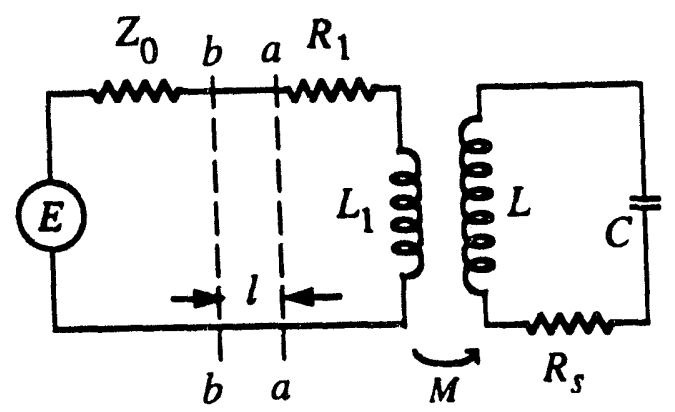

Fig. 3. Lumped parameter model of the resonant cavity and feed circuit.

$$
\frac{Z_{\text {in }}}{Z_{0}}=\frac{R_{1}+j X_{1}}{Z_{0}}+\frac{\zeta_{0}}{1+j 2 Q_{0} \delta}
$$

where $R_{1}$ is the resistance of the coupling circuit, $X_{1}$ is the reactance of the coupling circuit, $Z_{O}$ is the characteristic impedance of the feed line (not the cavity), $\zeta_{O}=(\omega M)^{2} / Z_{o} R_{S}$ is the ratio of the input resistance to the cavity resistance $R_{S}$, and $\delta=\left(\omega-\omega_{0}\right) / \omega$. In addition we have defined $\omega_{0}=1 / \sqrt{L C}$, where $L$ is the inductance in the cavity equivalent circuit, and $C$ is the capacitance of the cavity equivalent circuit.

The swept frequency method proceeds by identifying the two frequencies at which $2 Q_{o} \mid \delta=1$. Defining these frequencies as $f_{1}$, and $f_{2}$, it is easily seen from the definition of $\delta$ given above that

$$
Q_{0}=\frac{f}{f_{1}-f_{2}}
$$

The frequencies are found from a measurement of the VSWR vs frequency by determining the values of the VSWR at which $2 Q_{0} \delta= \pm 1$, using Eqn. 4 and the equation

$$
V S W R=\frac{1+|\rho|}{1-|\rho|}
$$

where $\rho=\rho_{\text {in }}=\left(Z_{i n}-Z_{0}\right) /\left(Z_{i n}+Z_{0}\right)$.

A simplification is obtained by noting that if the impedance is transformed a distance $l$ from the cavity, where $\tan \beta l=-X_{1} / Z_{0}$, then assuming $R_{1} * X_{1} * Z_{0}$, it can easily be shown that the coupling reactance drops out of Eqn. 4 , which then becomes

$$
\frac{Z_{i n}}{Z_{0}}=\frac{R_{1}}{Z_{0}}+\frac{\zeta_{0}}{1+j 2 Q_{0} \delta} .
$$


Inserting $2 Q_{o} \delta= \pm 1$, into Eqn. 7 and using Eqn. 6 , the value $S_{1 / 2}$ of the VSWR at the frequencies $f_{1}$ and $f 2$, which is the same for both frequencies, is finally obtained. After some manipulation, the result is

$$
S_{1 / 2}=\frac{2+\zeta^{2}\left(1+\gamma^{2}\right)+\sqrt{4+\zeta^{4}\left(1+\gamma^{4}\right)-2 \gamma \zeta^{2}\left(4-\gamma \zeta^{2}\right)}}{2 \zeta(1+\gamma)}
$$

where

$$
\zeta=\zeta_{o}+\frac{R_{1}}{Z_{o}}=\left\{\begin{array}{ll}
S_{o} & \frac{R_{o}}{Z_{o}}>1 \\
\frac{1}{S_{o}} & \frac{R_{o}}{Z_{o}}<1
\end{array},\right.
$$

$\gamma=\alpha / \zeta, \alpha=R_{1} / Z_{o}=1 / S_{m}, S_{o}$ is the minimum value of the VSWR, occurring at resonance, $R_{o}$ is the value of the cavity resistance at the minimum VSWR value, $Z_{O}$ is the characteristic impedance of the feed line, and $S_{m}$ is the maximum value of the VSWR, occurring at a frequency far from resonance. It is worthwhile to note that since the VSWR does not depend on the distance of the observation point from the cavity (ignoring unimportant effects due to line losses), this simplified analysis provides the correct answer independent of the observation point.

A graph of the VSWR vs frequency for a typical pulse is shown in Fig. 4. The data taken during the pulse is shown by the solid line. The dashed line shows a sweep that was taken $\sim 30$ s before the pulse. The triangles at the bottoms of the two curves indicate the positions of the VSWR minimums. The pairs of triangles above these indicate the locations of $f_{1}$ and $f_{2}$ at which the VSWR $=S_{1 / 2}$. The shift in the frequency at which the VSWR is a minimum indicates the shift in the resonant frequency during the pulse. If it is assumed that the shift in frequency is due entirely to the change in the real part of the ceramic dielectric constant, then from Eqn. 1, it can be shown that the change in this parameter is given by

$$
\frac{\varepsilon_{\text {during }}^{\prime}}{\varepsilon_{\text {before }}^{\prime}}=\frac{\tan \beta l}{(1-\delta) \tan [(1-\delta) \beta l]}
$$

The maximum value of the VSWR $\left(=S_{m}\right)$ is never reached by the data due to limitations of the network analyzer used for the impedance measurements. The measurement must be made during a time at which the reactor power is near its peak value, which limits the analyzer sweep time to $25 \mathrm{~ms}$ for $\$ 1.80$ pulses. In this time, only 51 data points can be obtained. In order to achieve an accuracy in $\mathrm{Q}$ of $3 \%$, corresponding to an accuracy in tan $\delta$ of $\sim 2 \times 10^{-5}$, the total range of the frequency sweep is limited to $200 \mathrm{kHz}$, which is too small to directly measure $S_{m}$. However, if the phase information for the impedance is retained, the value of $S_{m}$ can be estimated fairly accurately, without the need for additional calibration, in the following manner: Defining $r$ and $x$ as $\operatorname{Re}\left(Z_{i n} / Z_{o}\right)$ and $\operatorname{Im}\left(Z_{i n} / Z_{o}\right)$ respectively, eqn (4) can be recast as an equation for a circle in the normalized impedance plane: 


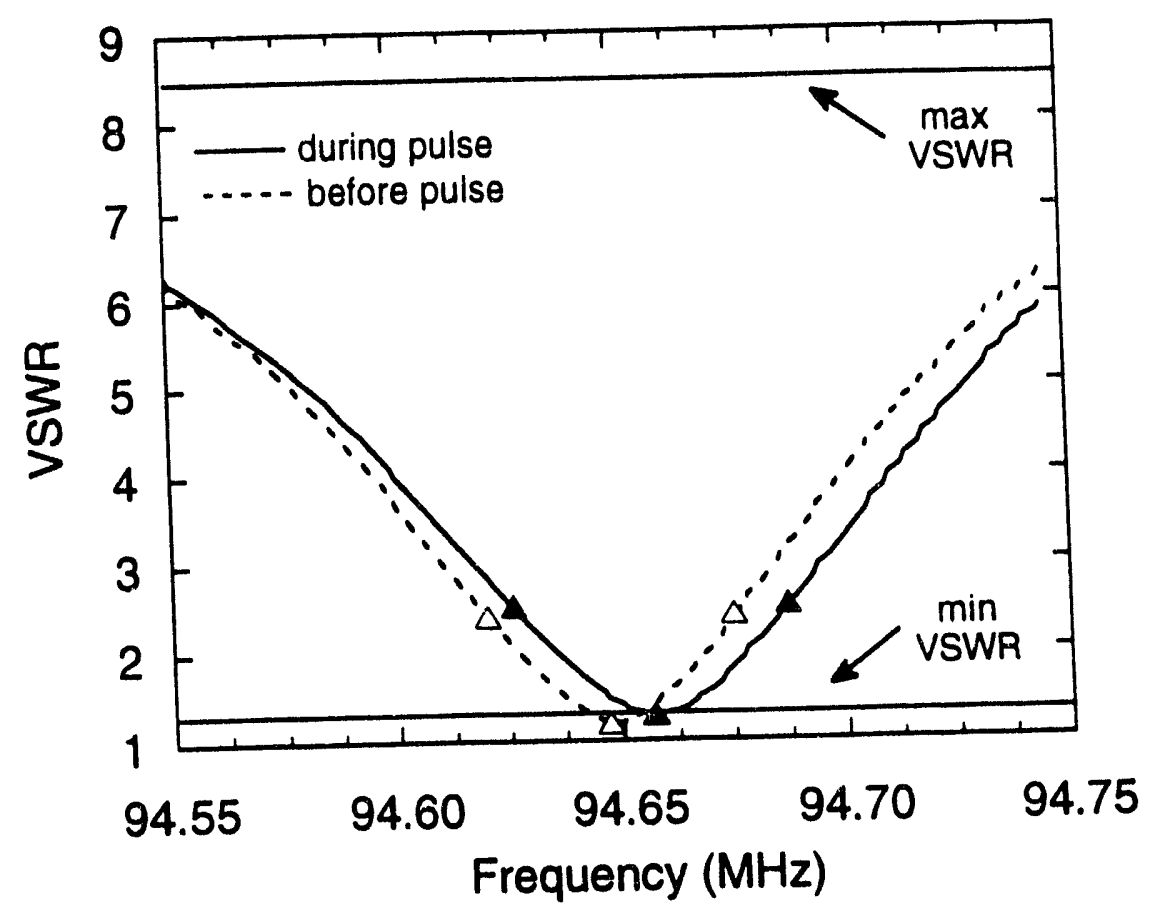

Fig. 4. VSWR vs frequency data for Wesgo AL998 alumina taken before and during $\$ 1.80$ pulse.

$$
\left(r-\frac{R_{1}}{Z_{o}}-\frac{\zeta_{0}}{2}\right)^{2}+\left(x-\frac{X_{1}}{Z_{0}}\right)^{2}=\frac{\zeta_{0}^{2}}{4}
$$

The swept frequency impedance data used to obtain the solid curve in Fig. 4 clearly shows this behavior, when replotted in the complex normalized impedance plane, as shown in Fig. 5 (crosses). From Eqn. 10, it is easily seen that the minimum on the real axis is $r=R_{1} / Z_{o}=1 / S_{m}$ and the maximum is $r=R_{1} / Z_{0}+\zeta_{0}=1 / S_{0}$. On the imaginary axis, the maxima and minima are at $x=X_{1} / Z_{0}+\zeta / 2$ and $x=X_{1} / Z_{0}$ $-\zeta / 2$ respectively. The diameter of the circle is simply $x_{\max }-x_{\min }=\zeta_{0}$. Using the value of $\zeta_{0}$ obtained in this way, the maximum VSWR is found from $1 / S_{m}=1 / S_{o}-\zeta_{0}$. This method is effective since a much narrower frequency sweep is required to obtain $x_{\max }$ and $x_{\min }$ than an accurate value of $r_{\min }$ directly. The circle having the diameter $\zeta_{0}$ and centered at $r=R_{1} / Z_{0}+\zeta_{0} 2, x=X_{1} / Z_{0}$ is also plotted as a solid line in Fig. 5 to show that the data fits this description very closely. Swept frequency data was taken during $\$ 1.80$ pulses only. It was not possible to obtain swept frequency data for the $\$ 3.00$ pulses due to their short duration.

In the case of the time dependent impedance measurements, a swept frequency measurement is taken immediately $(\sim 30 \mathrm{~s})$ before each pulse, so that changes in the cavity resonant frequency due to thermal expansion can be determined. The driving frequency is then set to the value corresponding to the minimum of the VSWR, and an impedance measurement is made during the pulse at this constant frequency. This frequency is not the resonant frequency of the cavity alone, because of the presence of $X_{1}$. However, $X_{1}$ is known from the swept frequency measurement made before the pulse, and is given by This value can be used in a modification of Eqn. 4, rewritten to describe the time varying impedance: 


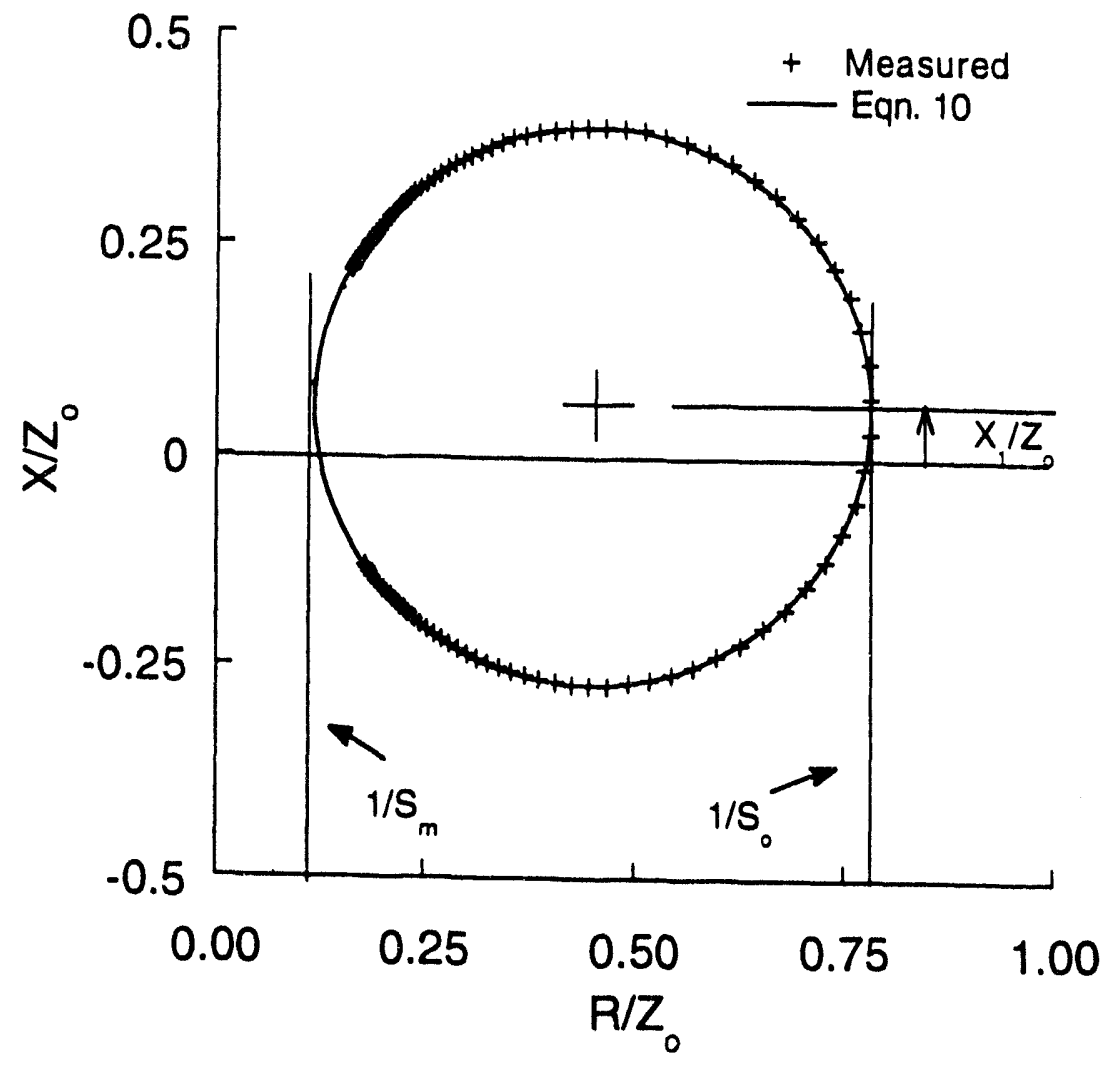

Fig. 5. Swept frequency data plotted in the complex impedance plane.

$$
\frac{Z_{\text {in }}(t)}{Z_{o}}=\frac{R_{1}+j X_{1}}{Z_{o}}+\frac{\zeta \eta(t)}{1+j 2 Q_{o} \eta(t) \delta(t)}
$$

where $\eta$ is the ratio $R_{\mathcal{S}}(0) / R_{\mathcal{S}}(t)$ of the total cavity losses before the pulse to those during the pulse. A rootfinder can then be used to determine $\eta(t)$ and $\delta(t)$ from the measured complex values of $Z_{\text {in }}(t)$, with $R_{1}$, $Q_{o}$ and $X_{1}$ determined from the swept frequency measurement before the pulse. Then $Q(t)=Q_{o} \eta(t)$ can be used in Eqn. 3 to determine tan $\delta$ as a function of time.

It is assumed in analysis of the time dependent data that during the pulse $R_{1}$ and $X_{1}$ remain equal to their values before the pulse. Measurements made at a frequency far off resonance showed that this is the case for $R_{1}$. In addition, the sensitivity of $Z_{\text {in }}$ to changes in $\tan \delta$ and $\Delta \varepsilon^{\prime}$ is approximately a factor of $Q_{o} / \zeta$ greater than the sensitivity to changes in $R_{1} / \mathrm{Z}_{o}$ and $X_{1} / \mathrm{Z}_{o}$. This is an important advantage of the resonant cavity techr ique. As described above, in the case of the swept frequency measurements $R_{1}$ can be determined during a pulse, and the results are insensitive to $X_{1}$. As will be shown, the two methods show good agreement for $\$ 1.80$ pulses, for which they can both be applied. 


\section{Results}

The solid line in Fig. 6 shows a typical measurement of the loss tangent in $\mathrm{Al}_{2} \mathrm{O}_{3}$ determined from the time dependent impedance data for conditions identical to those used to obtain the VSWR (swept frequency) data shown in Fig. 4. The value of $\tan \delta$ calculated from Fig. 4 is $1.43 \times 10^{-4}$, which agrees to within $12 \%$ with the peak value shown in Fig. 6 . The dashed line in Fig. 6 shows the effect on the calculated loss tangent of increasing $X_{1}$ by $50 \%$. Variations in $X_{1}$ during a pulse, if any, would be expected to be orders of magnitude below this $50 \%$ level. Despite the relative insensitivity of the time dependent impedance measurement to this quantity, it is worthwhile to have an accurate value of $X_{1}$ (from a swept frequency measurement) in order to retain the highest possible accuracy in the time dependent measurements.

Figure 7 shows corresponding graphs of the dielectric constant $\varepsilon^{\prime}(t) / \varepsilon^{\prime}(0)$ determined from the time dependent impedance data. In this case, a $50 \%$ change in $X_{1} / Z_{o}$ has little effect and the curves are almost identical. The value of $\Delta \varepsilon^{\prime} / \mathcal{E}^{\prime}$ calculated from the swept frequency data in Fig. 4 of $-2.3 \times 10^{-4}$ is within $10 \%$ of the minimum shown in Fig. 7. The magnitude of the maximum change of the dielectric constant during the $\$ 1.80$ pulsed irradiation was only about $0.1 \%$, which has a negligible effect on the ceramic losses. At the end of the pulse there was a residual change in $\varepsilon^{\prime}(t) / \varepsilon^{\prime}(0)$ which corresponds to an upwards shift in resonant frequency of $\sim 3 \mathrm{kHz}$. It is not clear at the present time whether or not this is a real effect. During the long time periods between pulses $(\geq 20 \mathrm{~min})$, the resonant frequency of the cavity usually decreased by a net value of several $\mathrm{kHz}$, corresponding either to a very slight increase in $\varepsilon^{\prime}$, or more likely, to a slight warming of the cavity. A temperature increase of 2 to $3 \mathrm{~K}$ over a period of $4 \mathrm{~h}$ was typically observed for cavities inserted in the reactor beam port.

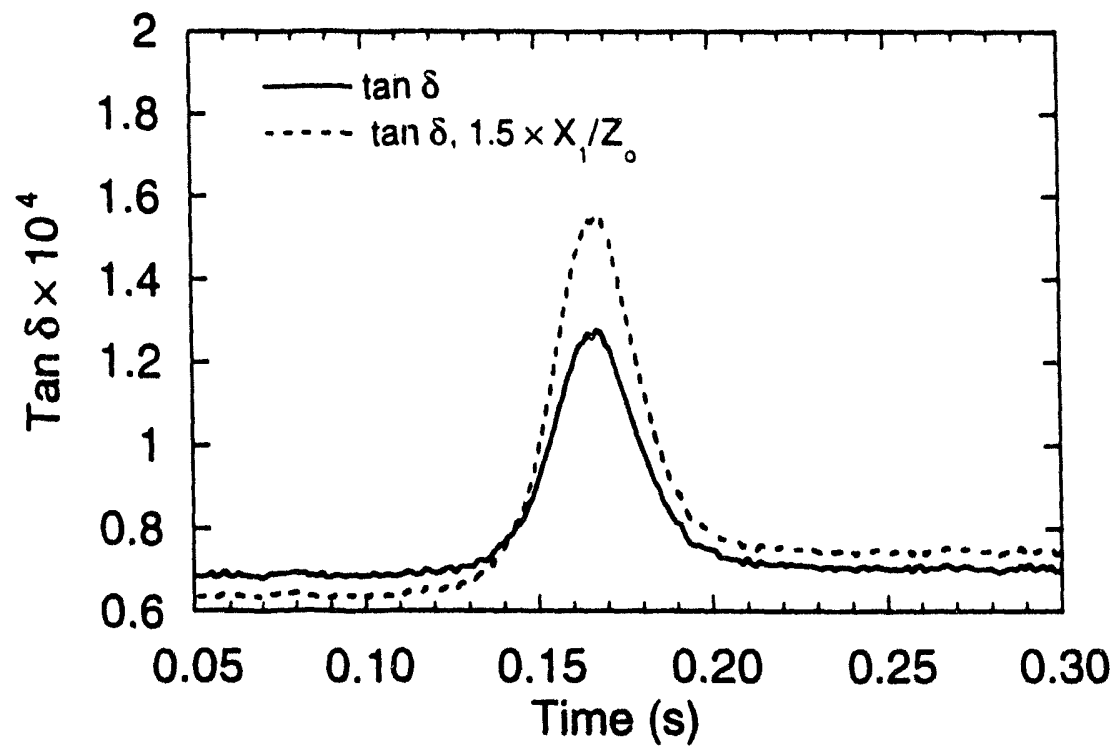

Fig. 6. Time dependent measurement of $\tan \delta$ for Wesgo AL998 during a $\$ 1.80$ pulse. 


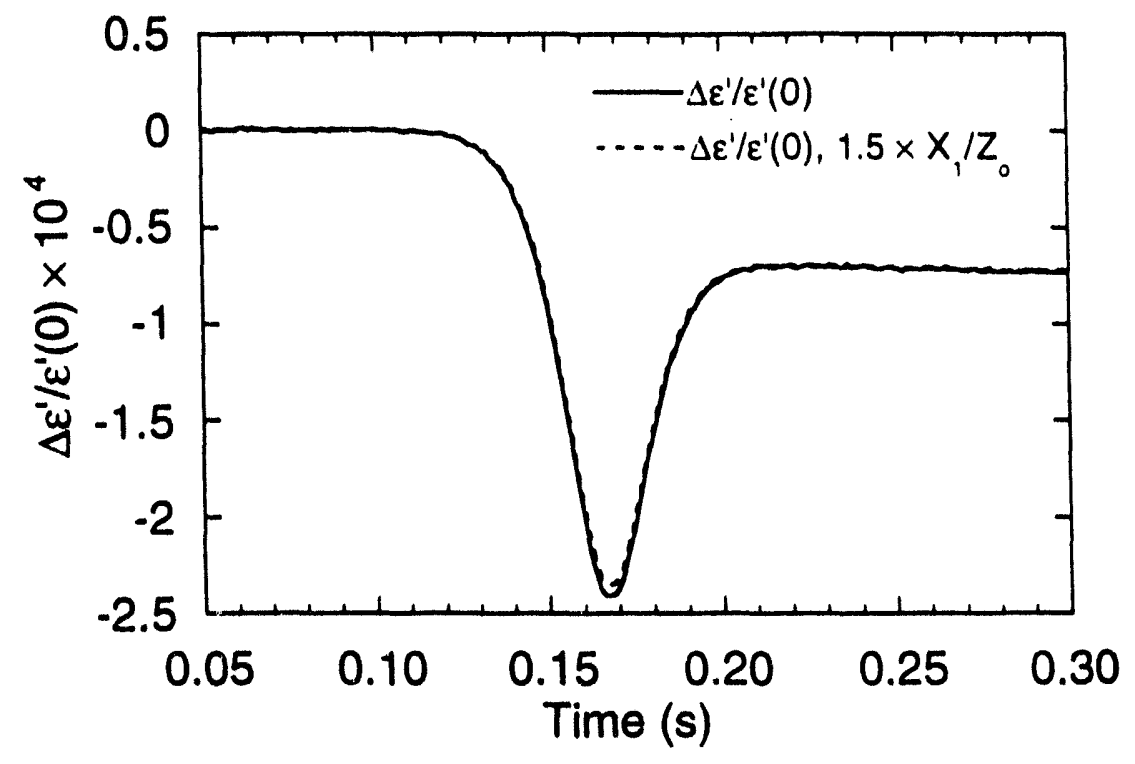

Fig. 7. Time dependent measurement of $\Delta \varepsilon^{\prime} / \varepsilon^{\prime}$ for Wesgo AL998 during a $\$ 1.80$ pulse.

Figure 8 is a graph of the ratio of the magnitude of the change in the loss tangent during the pulse to the change in the dielectric constant. The specific quantity plotted is

$$
\frac{\tan \delta(t)-\tan \delta(0)}{\left[\varepsilon^{\prime}(t)-\varepsilon^{\prime}(0)\right] / \varepsilon^{\prime}(0)} \cong \frac{\varepsilon^{\prime \prime}(t)-\varepsilon^{\prime \prime}(0)}{\varepsilon^{\prime}(t)-\varepsilon^{\prime}(0)}
$$

It can be seen that this ratio is nearly constant with time throughout most of the pulse, a phenomenon that will be discussed in more detail below.

\section{Pressure Effects}

An important test was a determination of the level of vacuum required in order to obtain accurate results. It is well known that the dielectric breakdown strength of gases reaches a minimum value at pressures between 10 and $100 \mathrm{~Pa}^{20}$ In addition, ionization of residual gas in the cavity can change the quality factor of the resonant cavity during irradiation. Each cavity and all of the associated pump-out pipe was attached to the turbo pump and baked for several hours to a temperature of $130^{\circ} \mathrm{C}$ using heating tapes. This temperature was the maximum sustainable by the cold cathode gauge during operation. After bakeout, it was possible to achieve a vacuum pressure of $7 \times 10^{-4} \mathrm{~Pa}$ with the cavity fully inserted into the reactor beam port. 


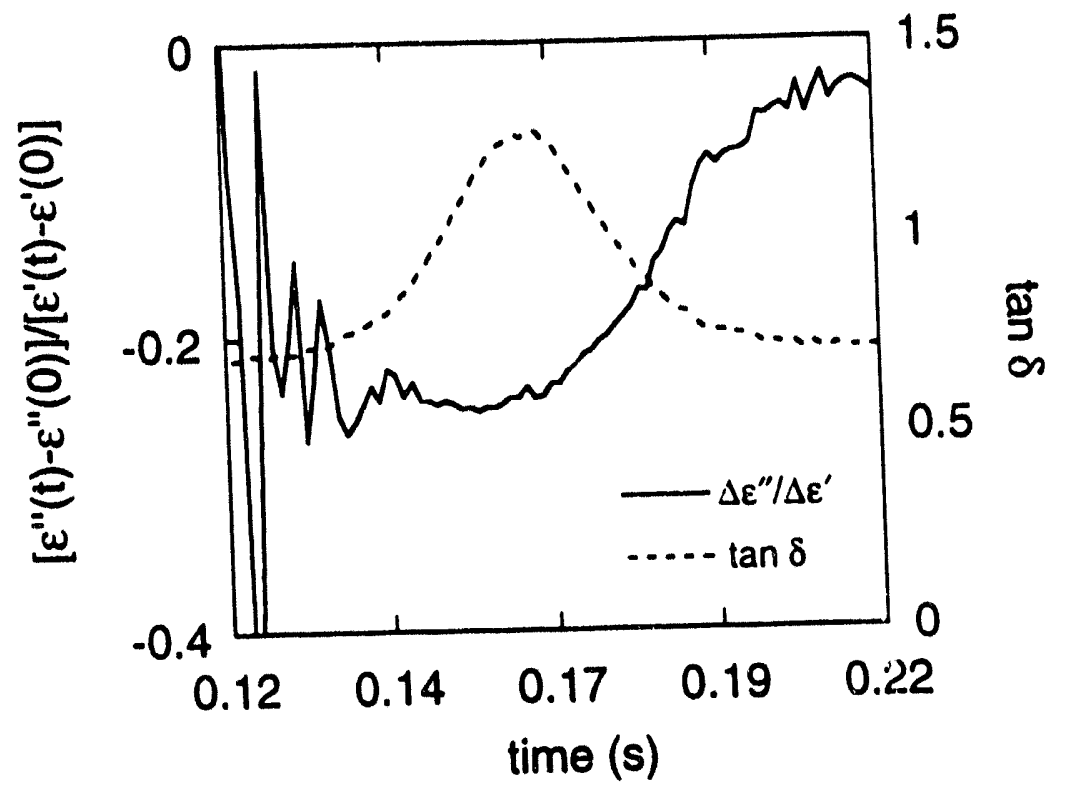

Fig. 8. $\Delta \varepsilon^{\prime \prime} / \Delta \varepsilon^{\prime}$ vs time calculated from data shown in figures 5 and 6.

A series of pulses were made, with the pressure increased each time by introducing nitrogen through a needle valve. Both the cavity $Q$ and the resonant frequency showed a strong dependence on pressure between $0.1 \mathrm{~Pa}$ and atmospheric pressure. Figure 9 shows the cavity $\mathrm{Q}$ as a function of pressure for cavities containing either sapphire or polycrystalline $\mathrm{Al}_{2} \mathrm{O}_{3}$. Figure 10 shows the effect on the calculated value of $\tan \delta$, which assumes that all losses occur in the ceramic, for an AL998 sample as a function of the cavity pressure. A very large increase in losses occurred at a pressure of $\sim 1 \mathrm{~Pa}$, together with large increases in the cavity resonant frequency (not shown). At pressures below $\sim 10^{-2} \mathrm{~Pa}$, our data suggest that ionized gas effects on the measured values of $\tan \delta$ and $\Delta \varepsilon^{\prime}$ are negligible. The observed dependencies of the measured $Q_{o}$ and frequency shift on the cavity pressure are consistent with the presence of a weakly ionized plasma produced by the gamma flux. Experiments performed with air and helium produced similar pressure-dependent results.

\section{Effect of Lead Shielding Surrounding the Cavity}

In order to investigate the relative importance of ionizing and displacive irradiation, a somewhat smaller cavity was fabricated to allow the fitting of a lead shield. Restrictions associated with the cavity and flange geometry caused the lead thickness to vary between 13 and $25 \mathrm{~mm}$, with an average lead thickness of about $19 \mathrm{~mm}$. One-dimensional shielding calculations indicated that this would reduce the gamma ray dose to the ceramic specimen by about a factor of 5 , but would not significantly attenuate the fast neutron flux ( $<10 \%$ change). A simple mockup chamber that held TLDs inside of $19 \mathrm{~mm}$ thick lead walls was used to measure the effect of the lead shielding. The measured reduction in the ionizing dose varied between 3 and 4 for several $\$ 1.80$ and $\$ 3.00$ pulses. 


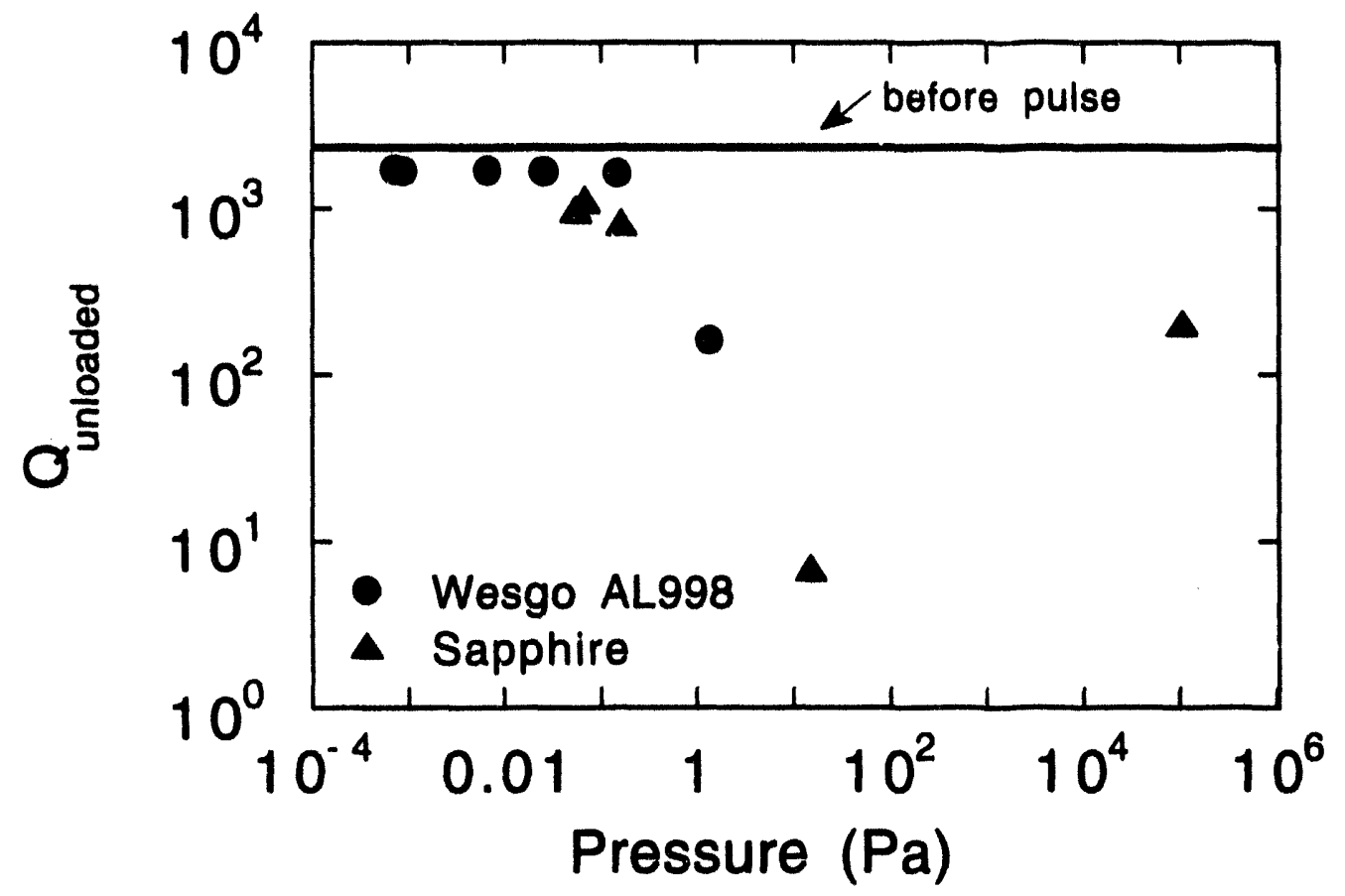

Fig. 9. Cavity $Q$ as a function of pressure measured during $\$ 3.00$ reactor pulses.

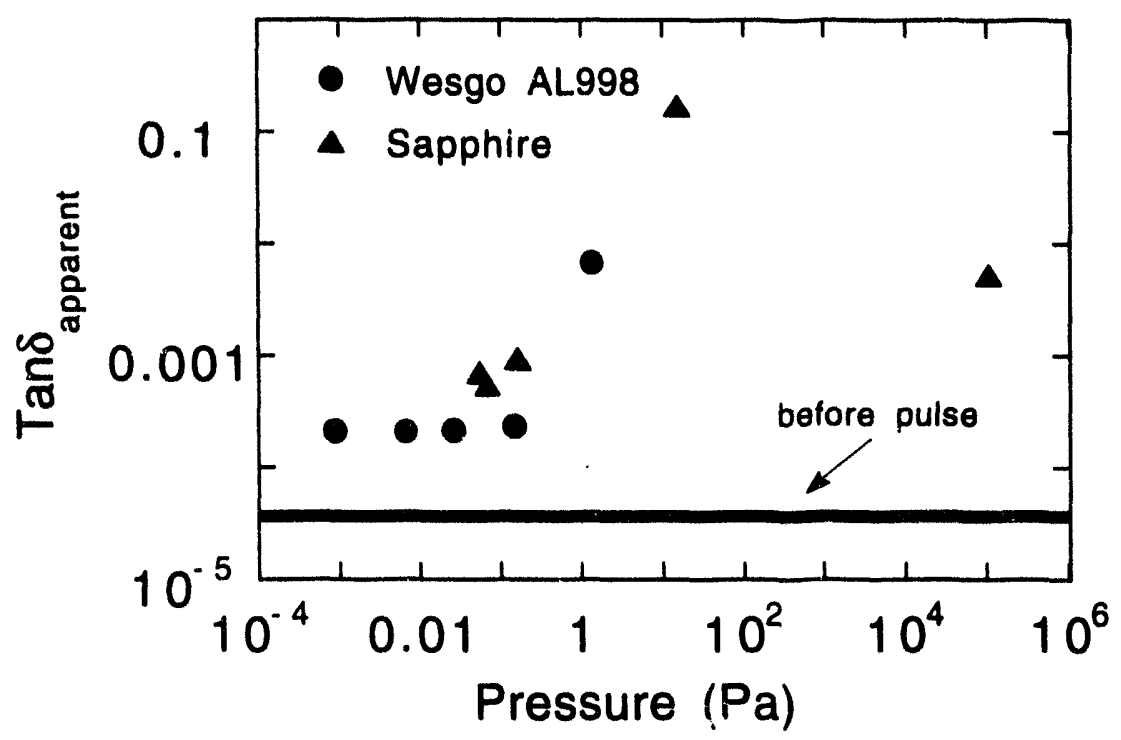

Fig. 10. Calculated value of apparent $\tan \delta$ of Wesgo AL998 as a function of the cavity pressure for $\$ 3.00$ pulses. 
Table 3 summarizes results for data taken in a cavity with and without lead shielding. The measured ionizing damage rate includes a relatively unchanged contribution from the neutrons, since they were not significantly attenuated. For data taken using both $\$ 1.80$ and $\$ 3.00$ pulses, the ratio of the change in $\tan \delta$ without shielding to that with shielding was 4.0. This ratio is comparable to the reduction in the gamma dose rate to within the accuracy of the dosimetry and loss tangent measurements.

Table 3. Summary of Data Taken with a Wesgo AL998 Sample With and Without Lead Shielding Around the Test Cavity

\begin{tabular}{|ccccc|}
\hline $\begin{array}{c}\text { Pulse } \\
\text { no. }\end{array}$ & $\begin{array}{c}\text { Lead } \\
\text { shielding }\end{array}$ & $\begin{array}{c}\text { Ionizing dose } \\
\text { rate (Gy/s) }\end{array}$ & $\tan \delta$ before pulse & $\tan \delta$ during pulse \\
\hline 134 & yes & $1.3 \times 10^{4}$ & $8.5 \mathrm{e}-5$ & $1.47 \mathrm{e}-4$ \\
147 & no & $4.2 \times 10^{4}$ & $7.2 \mathrm{e}-5$ & $3.23 \mathrm{e}-4$ \\
136 & yes & $2.1 \times 10^{3}$ & $9.8 \mathrm{e}-5$ & $1.12 \mathrm{e}-4$ \\
145 & no & $6.6 \times 10^{3}$ & $7.2 \mathrm{e}-5$ & $1.28 \mathrm{e}-4$ \\
\hline
\end{tabular}

\section{Time Response and Power Dependence}

Figure 11 compares the time-dependent behavior of the reactor power (dashed line) and tan $\delta$ for Wesgo AL998 (solid line) during a $\$ 3.00$ reactor pulse. The transient increase in loss tangent follows the power level very closely. A feature that is almost certainly an artifact is that the increase in the loss tangent always peaked 1-2 ms before the reactor power signal. This was observed in every case, for every material tested except for AIN. Data taken under identical conditions with an AIN sample in the cavity are shown in Fig. 12. In the case of this material only, the loss tangent peak appears later in time than the peak in the ion chamber signal. For this pulse the delay is $4.5 \mathrm{~ms}$. The decay time for the AlN loss tangent was substantially greater than that observed for the other materials.

Figure 13 shows the loss tangent with the baseline subtracted off, shifted by one sampling time $(1.25 \mathrm{~ms})$, and scaled to the ion chamber signal. When this is done the two curves overlay almost exactly, indicating that the dependence of the change in the loss tangent on reactor power is linear, and that the decay time is faster $1 \mathrm{~ms}$.

\section{Comparison of Different Materials}

Some of the results that we have obtained for various materials are summarized in Table 4. In the case of the time dependent measurements, the maximum value of the loss tangent observed during the pulse is given. In Figs. 14 (a) and (b), loss tangent results from Table 4 for which high power data were available are plotted vs. the peak ionizing dose rate. It can be seen that the peak in the loss tangent varies linearly with the ionizing dose rate for all materials except AIN, which increases more rapidly. The slope of the increase in the loss tangent is higher for the low purity alumina (AL300) than the high purity alumina (AL998), and is smallest for the silicon nitride, which had the highest initial loss tangent of all of the materials tested. From Table 4, it can be seen that the only material for which $\varepsilon^{\prime}$ was observed to increase during irradiation is AIN. In all other cases the dielectric constant was observed to decrease during the irradiation pulse. 


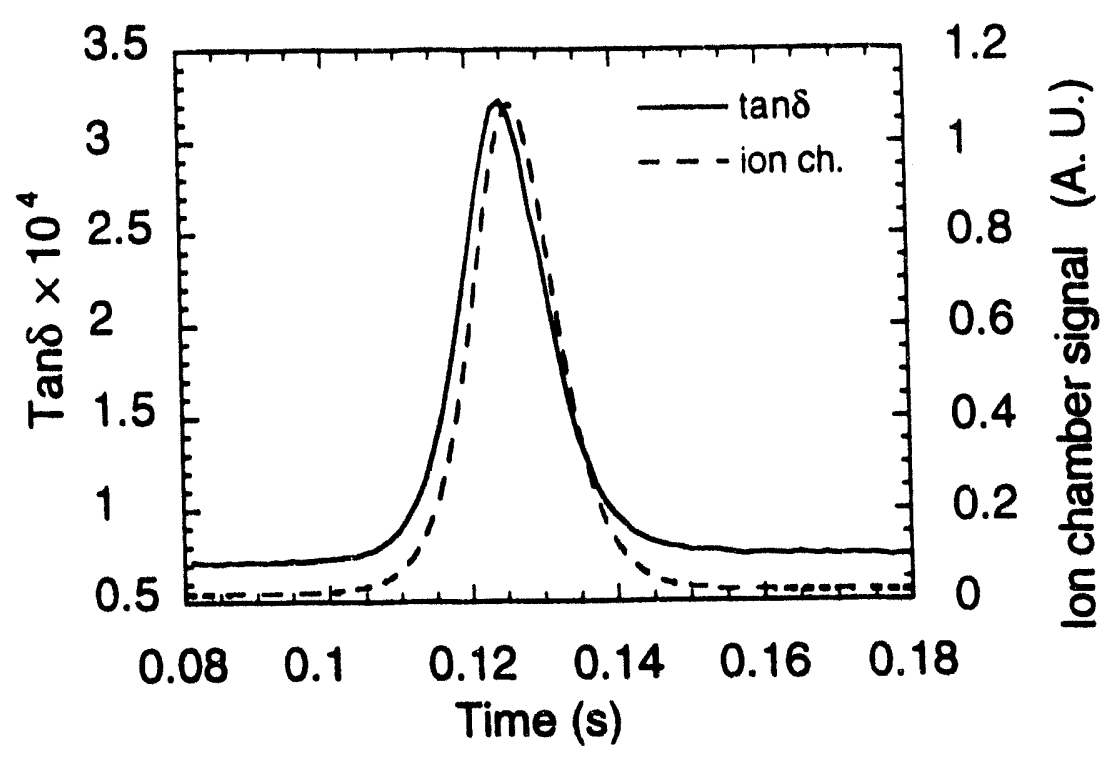

Fig. 11. Loss tangent vs time for Wesgo AL998, \$3.00 pulse, with reactor power signal measured by an ion chamber overlaid.

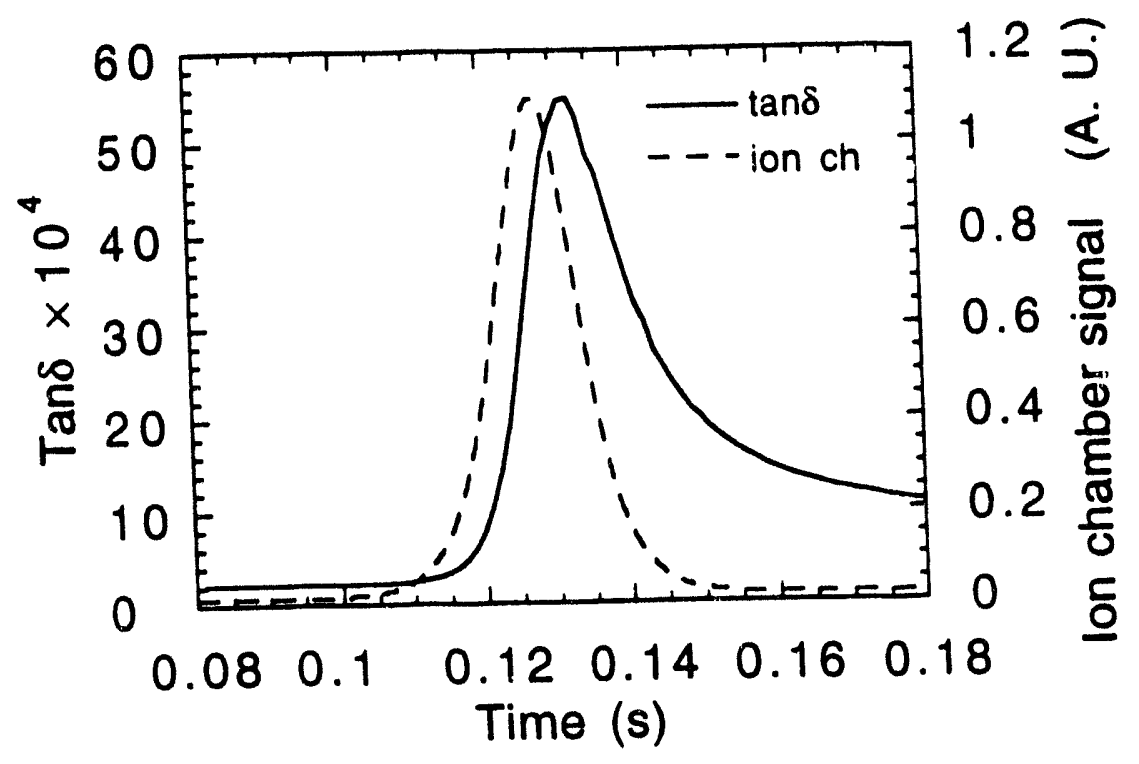

Fig. 12. Loss tangent vs time for AlN, $\$ 3.00$ pulse, also with reactor power signal overlaid. 


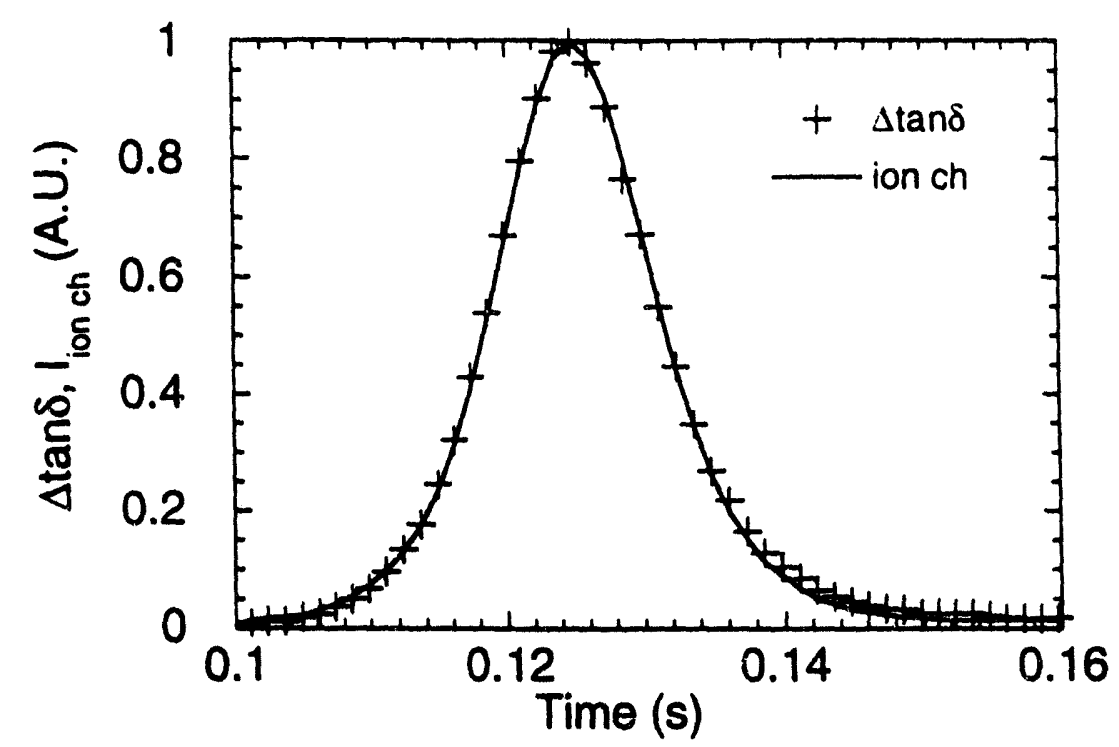
time shift.

Fig. 13. Overlay of loss tangent data and reactor power data with baseline subtraction and $1.2 \mathrm{~ms}$

Table 4. Changes in Loss Tangents and Dielectric Constants for Various Ceramic Materials During Irradiation

\begin{tabular}{|c|c|c|c|c|c|}
\hline Material & $\begin{array}{l}\text { Measurement } \\
\text { type }\end{array}$ & $\begin{array}{c}\text { Pulse } \\
\text { Size }\end{array}$ & $\begin{array}{c}\tan \delta \\
\text { before pulse }\end{array}$ & $\begin{array}{c}\tan \delta \\
\text { during pulse }\end{array}$ & $\Delta \varepsilon^{\prime} / \varepsilon_{0}^{\prime}$ \\
\hline Sapphire & Swept freq & $\$ 1.80$ & $1 \times 10^{-5} *$ & $8 \times 10^{-5}$ & $-2.6 \times 10^{-4}$ \\
\hline Wesgo AL998 & $\begin{array}{l}\text { Swept freq } \\
\text { Time dep } \\
\text { Time dep }\end{array}$ & $\begin{array}{l}1.80 \\
\$ 1.80 \\
\$ 3.00 \\
\end{array}$ & $\begin{array}{l}7.2 \times 10^{-5} \\
6.9 \times 10^{-5} \\
7.2 \times 10^{-5}\end{array}$ & $\begin{array}{r}1.43 \times 10^{-4} \\
1.28 \times 10^{-4} \\
3.23 \times 10^{-4}\end{array}$ & $\begin{array}{r}-2.30 \times 10^{-4} \\
-2.10 \times 10^{-4} \\
-1.03 \times 10^{-3} \\
\end{array}$ \\
\hline Wesgo AL300 & $\begin{array}{l}\text { Swept freq } \\
\text { Time dep } \\
\text { Time dep }\end{array}$ & $\begin{array}{l}\$ 1.80 \\
\$ 1.80 \\
\$ 3.00 \\
\end{array}$ & $\begin{array}{l}1.42 \times 10^{-4} \\
1.49 \times 10^{-4} \\
1.54 \times 10^{-4} \\
\end{array}$ & $\begin{array}{l}2.35 \times 10^{-4} \\
2.26 \times 10^{-4} \\
4.89 \times 10^{-4} \\
\end{array}$ & $\begin{array}{r}-3.06 \times 10^{-4} \\
-2.78 \times 10^{-4} \\
-1.35 \times 10^{-3} \\
\end{array}$ \\
\hline Spinel & Swept freq & $\$ 1.80$ & $3 \times 10^{-5}$ & $1 \times 10^{-4}$ & $-2.2 \times 10^{-4}$ \\
\hline AlN & $\begin{array}{l}\text { Swept freq } \\
\text { Time dep } \\
\text { Time dep } \\
\end{array}$ & $\begin{array}{l}\$ 1.80 \\
\$ 1.80 \\
\$ 3.00 \\
\end{array}$ & $\begin{array}{l}2.05 \times 10^{-4} \\
1.81 \times 10^{-4} \\
2.19 \times 10^{-4} \\
\end{array}$ & $\begin{array}{r}4.0 \times 10^{-4} \\
5.2 \times 10^{-4} \\
5.49 \times 10^{-3} \\
\end{array}$ & $\begin{array}{c}- \\
- \\
1.76 \times 10^{-3} \\
\end{array}$ \\
\hline $\mathrm{Si}_{3} \mathrm{~N}_{4}$ & $\begin{array}{l}\text { Swept freq } \\
\text { Time dep } \\
\text { Time dep }\end{array}$ & $\begin{array}{l}\$ 1.80 \\
\$ 1.80 \\
\$ 3.00\end{array}$ & $\begin{array}{l}3.20 \times 10^{-4} \\
3.13 \times 10^{-4} \\
3.12 \times 10^{-4} \\
\end{array}$ & $\begin{array}{l}3.52 \times 10^{-4} \\
3.33 \times 10^{-4} \\
3.99 \times 10^{-4}\end{array}$ & $\begin{array}{r}-1.93 \times 10^{-4} \\
-2.14 \times 10^{-4} \\
-1.00 \times 10^{-3} \\
\end{array}$ \\
\hline
\end{tabular}

Accuracy limited by calibration problems that were subsequently corrected. Actual pre-irradiation value could be as high as $3 \times 10^{-5}$. 

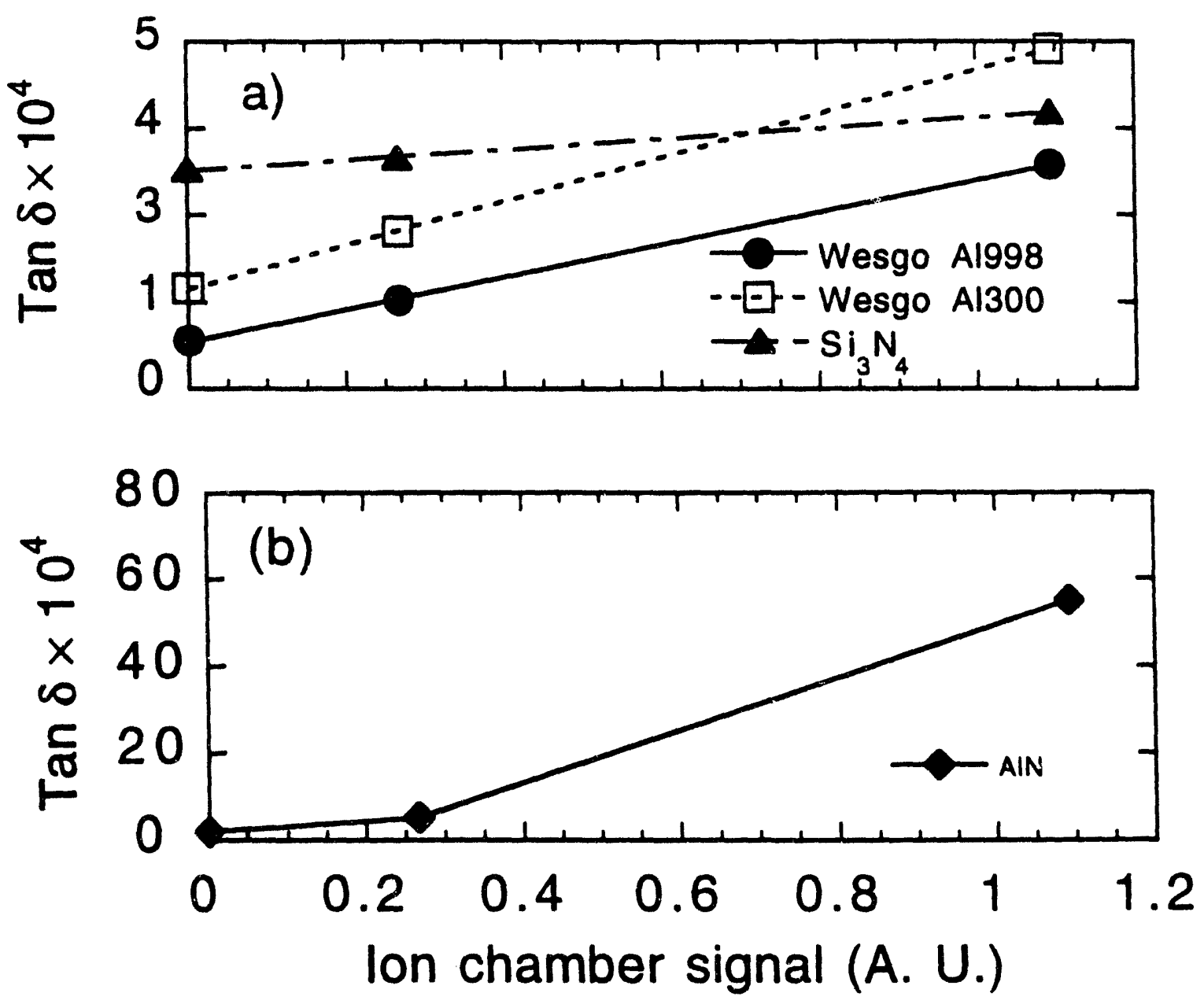

Fig. 14. Maximum value of $\tan \delta$ during reactor pulse vs ionizing dose rate for a) high and low purity aluminas, silicon nitride, and b) aluminum nitride.

\section{Discussion}

Several characteristics have been exhibited by all of the samples except for the AlN: 1) the increase in $\tan \delta$ was linear with the dose rate, as measured by the ion chamber signal, 2) the decay of $\tan \delta$ after the peak of the reactor pulse was faster than the sampling time used to make the impedance measurements of $1.25 \mathrm{~ms}, 3)$ the change in the relative dielectric constant during a pulse was always negative, and 4) the ratio of $\Delta \varepsilon^{\prime \prime} / \Delta \varepsilon^{\prime}$ was roughly constant during a pulse. In addition, when the cavity was shielded with lead, a reduction in the loss tangent increase in the AL998 alumina occurred which was proportional to the decrease in the gamma flux. In the case of the AIN, the increase in tan $\delta$ was supralinear with dose rate over the range which we have explored, there was an initial rapid decay in $\tan \delta$ followed by a slower decay when the value was $\sim 4$ times the pre-irradiation value, the change in the relative dielectric constant was positive, and the ratio $\Delta \varepsilon^{\prime \prime} / \Delta \varepsilon^{\prime}$ varied greatly, and even changed sign during the reactor pulse. 
The increases that we observed in the loss tangents of most of the materials is consistent with an increase in the dc conductivity. In order to see this, we write the loss tangent in terms of contributions due to the dc conductivity and ac losses due to polarization effects 9

$$
\tan \delta=\frac{\sigma_{D C}}{\omega \varepsilon^{\prime}}+\frac{\chi^{\prime \prime}}{\varepsilon^{\prime} / \varepsilon_{0}}
$$

where $\sigma_{\mathrm{DC}}$ is the dc conductivity, $\chi^{\prime \prime}$ is the imaginary part of the dielectric susceptibility $\chi\left(\varepsilon / \varepsilon_{O}=1+\chi\right)$, and $\varepsilon_{0}$ is the permittivity of free space.

In the case of an unirradiated ceramic insulator, the dc conductivity at $20^{\circ} \mathrm{C}$ is on the order of $10^{-12}$ $\mathrm{S} / \mathrm{m}$ or less, resulting in a negligible contribution to the loss tangent of $<2 \times 10^{-11}$ at $100 \mathrm{MHz}$. However, radiation induced conductivity (RIC) associated with electronic ionization has been shown to produce increases in $\sigma_{D C}$ of many orders of magnitude, $, 10,13-15,21-23$ which could produce a significant contribution to the loss tangent during irradiation. Figure 15 is a compilation of published dc and low frequency ac RIC data obtained on alumina irradiated near room temperature. $10,15,21,24$ The measured loss tangent changes obtained on the WESGO AL998 alumina specimen in the present study have been converted to electrical conductivity values in Fig. 15 for comparison, using the assumption that all of the loss tangent increase was solely due to RIC (Eqn. 13). The converted loss tangent values are in good agreement with the existing RIC data. The prompt conductivity coefficient derived for AL998 alumina is $\sim 1.9 \times 10^{-10} \mathrm{~S}_{-} \mathrm{m}^{-1}-\mathrm{Gy}^{-1} \mathrm{~s}$.

Previously reported measurements on the loss tangent of alumina measured during gamma irradiation near room temperature concluded that ionizing dose rates up to $35 \mathrm{~Gy} / \mathrm{s}$ did not have any measureable effect. ${ }^{5}$ According to the RIC data summarized in Fig. 15, this ionizing dose rate would induce an electrical conductivity of about $10^{-8} \mathrm{~S} / \mathrm{m}$ in aiumina. The corresponding loss tangent increase at $100 \mathrm{MHz}$ associated with this RIC (Eqn. 13) would be about $2 \times 10^{-7}$, which is negligible compared to the unirradiated room temperature loss tangents in these materials of $\sim 10^{-5}$ to $10^{-4}$.

The present theoretical understanding of RIC assumes that electrons are excited into the conduction band, creating free electron-hole pairs, which are eventually lost through trapping and annihilation.9,21,23 A simplified way to treat this system is as a weakly conducting semiconductor, ${ }^{25}$ in which case the complex dielectric constant at if frequencies can be modelled by the expression

$$
\varepsilon \equiv \varepsilon^{\prime}-i \varepsilon^{\prime \prime}=\varepsilon_{1}-\sigma_{D C}\left(\frac{1}{v}+i \frac{1}{\omega}\right)
$$

where $\varepsilon_{1}$ is the permittivity with no current flowing and $v$ is the effective electron collision frequency in the material. If it is assumed that there are no changes in the material over the time of the pulse ( $v$ remains constant), then Eqn. 14 predicts a reduction in the real part of the dielectric constant as $\sigma$ increases, and also that the ratio $\Delta \varepsilon^{\prime \prime} / \Delta \varepsilon^{\prime}$ remains constant. As shown in Figs. 7 and 8 and Table 4, these behaviors were observed in all the materials that we investigated other than AIN. If the increase in loss tangent were instead attributed to an increase in the number of dipoles present, 11 then we would expect the real part of the permittivity to increase as well as the imaginary part. 


\section{RADIATION INDUCED CONDUCTIVITY IN ALUMINA}

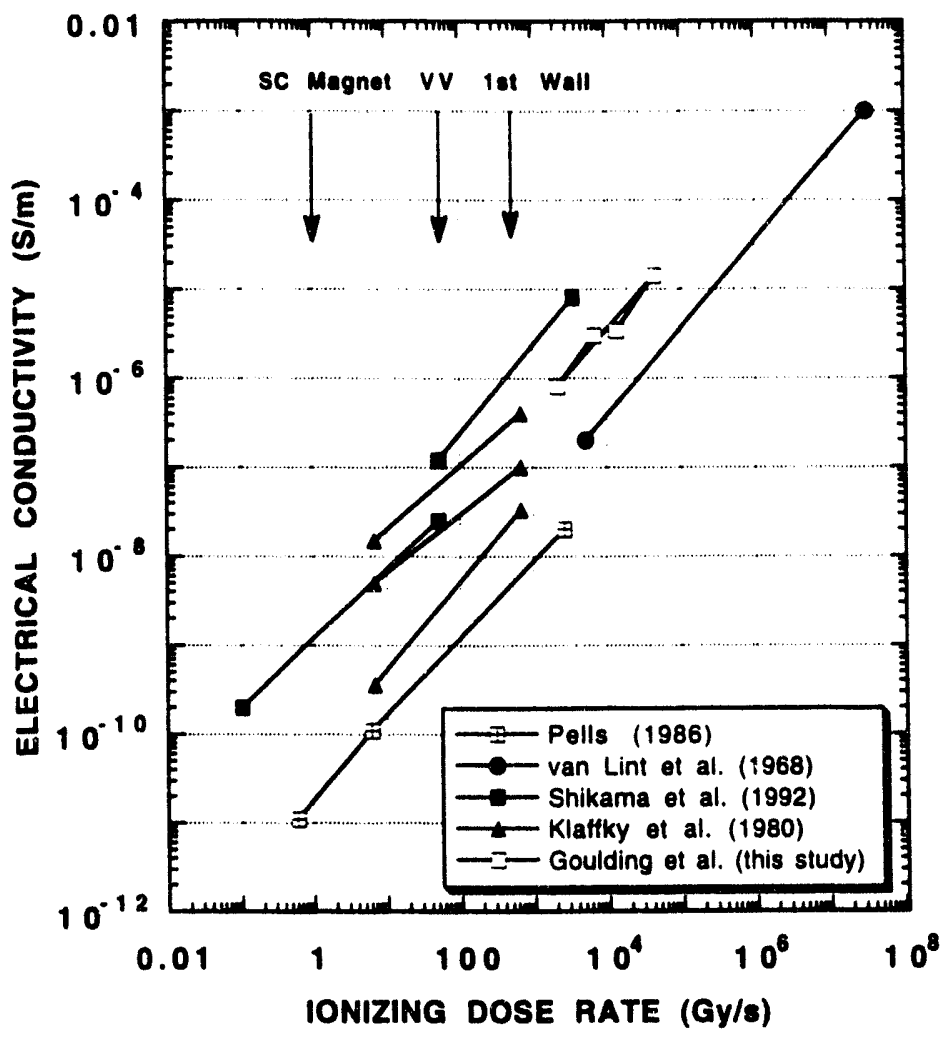

Fig. 15. Radiation induced conductivity in high-purity alumina $[10,15,21,24]$. The anticipated ionizing dose rates at the first wall, vacuum vessel and superconducting magnet of the ITER fusion reactor [18] are also shown.

The quantity $\sigma \mathrm{DC}=n_{e} e^{2} / m v$ is proportional to the free electron density $n_{e}$. . Therefore, the observed linear dependence of $\Delta \tan \delta$ on the dose rate for most of the ceramics in the present study implies that the free electron density is proportional to the ionizing dose rate. The magnitude and flux dependence of RIC in insulators is controlled by the concentration and average trapping level of electron-hole traps. Theoretical modelling of the free electron density in irradiated insulators generally predicts a dose rate exponent between 0.5 and 1 (refs. 21,23,24,26). Experimental studies (e.g., Fig. 15) have typically observed RIC dose rate exponents near unity, although values as low as 0.5 and as high as 1.6 have been reported. 3,21-24,26 The diffusion lifetime of electrons excited into the conduction band by ionizing radiation is typically between $10^{-11}$ and $10^{-6} \mathrm{~s}$ (refs. 23,27), although delayed effects with time constants as long as 1 day or longer have also been observed. The good agreement between the transient loss tangent increase and the reactor pulse profile (Figs. 11,13) for all of the ceramics in the present study except AlN indicates that the carrier lifetimes in these materials was less than the sampling time of $\sim 1 \mathrm{~ms}$. The peak in the loss tangent of AlN occurred about $4.5 \mathrm{~ms}$ after the peak in the reactor power (Fig. 12), which suggests that the average carrier lifetime in AlN may be $\sim 10 \mathrm{~ms}$ or longer. An exponential fit to the decay of the AlN loss tangent curve indicates that the carrier time constant is $>10 \mathrm{~ms}$. 
Figure 16 compares the derived electrical conductivity values of the various ceramic materials investigated in the present study. The derived RIC dose rate exponent was about one for spinel and all of the different grades of alumina. On the other hand, the dose rate exponent for $\mathrm{Si}_{3} \mathrm{~N}_{4}$ was apparently sublinear $(-0.65)$ and the dose rate exponent for AIN was supralinear $(-1.6)$.

From an examination of the AL998 alumina results obtained with shielded and unshielded cavities (Table 3), it is apparent that ionizing radiation is necessary for an appreciable effect to be seen, and that the loss tangent increase is proportional to the ionizing dose rate. We cannot completely rule out the possibility that neutron displacement damage contributes to the observed increase in the loss tangent (e.g., polarization effects); we have no data for instance on frequency dependence which would help to distinguish between ac and dc effects. However, it is clear from the shielded cavity measurements that the displacement damage contribution must be small compared to the ionization-induced conductivity losses for our experimental conditions. The relative unimportance of displacement damage effects in the present experiments is due to the use of a pulsed neutron source which produced high radiation fluxes but low accumulated damage levels. The maximum amount of displacement damage produced during each reactor pulse was $\sim 1 \times 10^{-8} \mathrm{dpa}$. An upper limit of the dielectric loss associated with this displacement damage can be estimated from Debye theory [11] to be $\sim 1 \times 10^{-5}$, assuming that all of the displaced atoms created during the reactor pulse survive as point defects. Defect production measurements performed on irradiated oxide ceramics have found that the fraction of defects produced during room temperature fission neutron irradiation is typically only about $10 \%$ of the calculated $\mathrm{dpa}^{26}$ which would reduce the associated loss tangent increase to $\sim 10^{-6}$. The displacement damage contribution to the measured loss tangent increase during pulsed reactor irradiation is therefore not detectable. This simple calculation demonstrates that the large observed difference between AIN and the other irradiated ceramics must be associated with ionizing radiation (RIC) effects.

\section{ELECTRICAL CONDUCTIVITY OF CERAMICS DERIVED FROM LOSS TANGENT MEASUREMENTS}

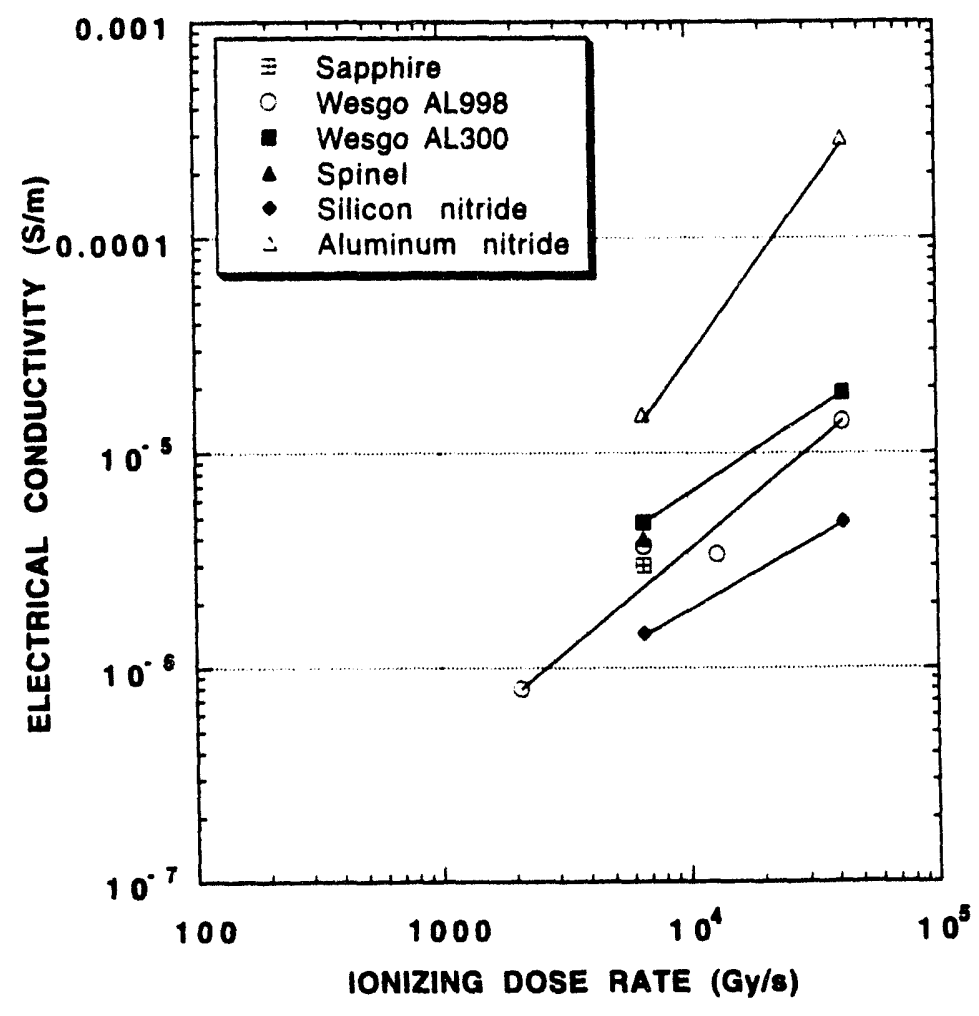

Fig. 16. Radiation induced conductivity of ceramic insulators derived from loss tangent measurements. 
Finally, these measurements were designed to examine only transient effects. They wire made in the presence of minimal electric fields and for small total fluences. Effects caused by higher electric fields, longer irradiation times, and higher fluences were not addressed. A very important example is the phenomenon of radiation-induced electrical degradation (RIED), which involves the synergistic combination of moderate electric fields and displacive radiation. This phenomenon has been shown to cause permanent degradation in the resistivity of certain ceramics, at substantially reduced damage levels when compared to degradation due to irradiation alone. $3,28,29$ This deterioration in resistivity could make these materials unacceptable for use in $\mathrm{rf}$ windows, even though they are acceptable from the standpoint of the transient effects that we have studied.

\section{CONCLUSIONS}

We have measured the effects of ionizing and displacive radiation on both the loss tangent and the dielectric constant of several ceramics which are possible candidates for use as vacuum windows in the rf heating systems of fusion devices. The main purpose of the measurements were to determine whether the presence of neutrons would cause effects on a transient time scale that would rule out the use of certain ceramics due to unacceptable increases in losses. A resonant cavity technique was used, which limited measurements to a fixed frequency ( $100 \mathrm{MHz}$ in our case), but allowed accurate measurements to be obtained without elaborate in-situ calibration.

It was found that in all but one of the materials examined, the increase in the loss tangent was proportional to the reactor power level. In the case of Wesgo AL998 alumina, the gamma/fast neutron ratio was modified using lead shielding and it was found that in this case the increase in the loss tangent was proportional specifically to the gamma dose rate to within the limits of the measurement. It is likely that this is true for the other materials as well, except for aluminum nitride. The magnitude of the increases observed are explainable by an ionization-induced increase in the dc conductivity of the materials, based on previous measuremients made by other investigators. This phenomenon is also consistent with the observed decrease in the dielectric constant observed during irradiation. In all cases except for AIN, the increase in the loss tangent was limited to about a factor of 4 or less, for a gamma dose rate substantially above that expected at the location of an if vacuum window in a fusion reactor. The maximum prompt values observed in these cases should not be of concern in the design of rf windows operating at $\sim 100 \mathrm{MHz}$ or below.

In the case of aluminum nitride, the factor of 25 increase in the loss tangent during irradiation by a $\$ 3.00$ pulse was much higher than that observed in any other material. The material $\mathrm{Si}_{3} \mathrm{~N}_{4}$, which has a somewhat higher unirradiated value of $\tan \delta$ than $\mathrm{AlN}$, and a similar dielectric constant, showed the smallest increase in the loss tangent proportional to the dose rate. The striking differences in the behavior of the two materials are not at present understood, and further investigation would clearly be of benefit.

\section{ACKNOWLEDGEMENTS}

The authors gratefully acknowledge the assistance of Wade Williams from the University of Illinois. The ionizing radiation and neutron dosimetry analyses were carried out by Dr. D.W. Vehar of Sandia National Laboratory and Dr. L. R. Greenwood at the Pacific Northwest Laboratory, respectively. This work was supported by the Office of Fusion Energy, US Department of Energy, under contract DE-AC05840R21400 with Martin Marietta Energy Systems, Inc. 


\section{REFERENCES}

1. F.W. Clinard, Jr., J. Nucl. Mater. 85\&86 (1979) 393.

2. J. L. Scott, F.W. Clinard, Jr. and F. W. Wiffen, J. Nucl. Mater. 133-134 (1985) 156.

3. S. J. Zinkle and E. R. Hodgson, J. Nucl. Mater. 191-194 (1992) 58.

4. S.J. Zinkle, Plasma Devices and Operations 3 (1993) in press.

5. R. E. Stoller, R. H. Goulding, and S. J. Zinkle, J. Nucl. Mater 191-194 (1992) 602.

6. G. J. Hill, G. P. Pells, and M. A. Barnett, Radiat. Eff. 97 (1986) 221.

7. H. M. Frost and F. W. Clinard, J. Nucl. Mater. 155-157 (1988) 315.

8. D. J. Huntley and J. R. Andrews, Can. J. Phys. 46 (1968) 147.

9. G.P. Pells and G. J. Hill, J. Nucl. Mater. $141-143$ (1986) 375.

10. G. P. Pells, Radiat. Eff. 97 (1986) 199.

11. S. N. Buckley and P. Agnew, J. Nucl. Mater. 155-157 (1988) 361.

12. D. Edelson, R.E. Jaeger, and J. C. Williams, J. Amer. Ceram. Soc. 52 (1969) 359.

13. E. H. Farnum, J.C Kennedy, F.W. Clinard and H.M. Frost, J. Nucl. Mater. 191-194 (1992) 548.

14. G. P. Pells, J. Nucl. Mater. 184 (1991) 183.

15. T. Shikama, M. Narui, Y. Endo, A. Ochiai and H. Kayano, J. Nucl. Mater. 191-194 (1992) 544.

16. S.N. Buckley and P. Agnew, in Microwave Processing of Materials II, MRS Symp. Proc. Vol, 189, eds. W.B. Snyder et al. (Materials Research Soc., Pittsburgh, 1991) p. 503.

17. S. J. Zinkle, Microstructural Changes in Oxide Ceramics Following Light Ion Irradiation, Fusion Reactor Materials, Semiann. Prog. Rep. DOE/ER-0313/10, Oak Ridge National Laboratory (1991) p. 302-309.

18. M.E. Sawan, University of Wisconsin, Madison, WI, private communication.

19. E. L. Ginzton, Microwave Measurements, (McGraw-Hill, New York, 1957).

20. T.W. Dakin and C.N. Works, in Measurement of Dielectric Properties under Space Conditions, ASTM STP 420 , ed. R.B. Feuchtbaum (Amer. Soc. for Testing and Materials, Philadelphia, 1967) p. 18.

21. R. W. Klaffky, B. H. Rose, A. N. Goland and G. J. Dienes, Phys. Rev. B21 (1980) 3610.

22. E. R. Hodgson and S. Clement, J. Nucl. Mater. 155-157 (1988) 357.

23. V.A.J, van Lint, T.M. Flanagan, R.E. Leadon, J.A. Nabor and V.C. Rogers, Mechanisms of Radiation Effects in Electronic Materials, Vol. 1(Wiley and Sons, New York, 1980)

24. V.A.J. van Lint, J.W. Harrity and T.M. Flanagan, IEEE Trans. on Nucl. Science, NS-15 (1968) 194.

25. S. Ramo, J. R. Whinnery, and T. Van Duzer, Fields and Waves in Communication Electronics, 2nd ed., (John Wiley \& Sons, New York, 1984).

26. G.P. Pells, J. Nucl. Mater. 155-157 (1988) 67.

27. J.C. King and H.H. Sander, IEEE Trans. on Nucl. Science, NS-20 (1973) 117.

28. G. P. Pells, J. Nucl. Mater. 184 (1991) 177.

29. E. R. Hodgson, J. Nucl. Mater. 191-194 (1992) 552. 
IN-CORE MEASUREMENT OF DC ELECTRICAL CONDUCTIVITY OF CERAMICS - L. L. Snead, D. P. White, and S. J. Zinkle (Oak Ridge National Laboratory), J. Oconor, G. Hartsough, and J. Errante (Brookhaven National Laboratory)

\section{OBJECTIVE}

The objective of this research is to A) Verify a new design for making in-core measurements of DC electrical conductivity of ceramics, and B) Study the RIED effect for polycrystalline alumina during neutron irradiation.

\section{SUMMARY}

An in-situ DC conductivity capsule has been constructed and tested at the High Flux Beam Reactor (HFBR) at Brookhaven National Laboratory. The prototype capsule contained two alumina and one silicon nitride polycrystalline samples. In-situ measurement of the DC conductivity was made utilizing custom-made mineral insulated triaxial cables with a guard ring configuration for the samples and the sample holders. Sample and capsule temperatures were also measured in-situ. This prototype capsule was designed to operate at ITER relevant temperatures of $80^{\circ} \mathrm{C}$ (alumina) and $300^{\circ} \mathrm{C}$ (alumina and silicon nitride) with an applied electric field of $133 \mathrm{~V} / \mathrm{mm}$. It is significant that a large prompt increase in conductivity occurred but that no permanent radiation induced electrical degradation was observed in alumina after irradiation at $80^{\circ} \mathrm{C}$ to a neutron dose of $>0.1 \mathrm{dpa}$.

\section{PROGRESS AND STATUS}

\section{Introduction}

Recent studies of radiation effects on the electrical conductivity of oxide ceramics have pointed out the need for in-situ measurements. The primary motivation for such work has been the need for design data for insulating ceramics in fusion systems. Typically, ceramic insulators in fusion systems will find application under a broad range of irradiation temperatures, fluxes (neutron and gamma) and electric fields. ${ }^{1}$ It has been known for many years that under irradiation there is a sizable, prompt increase in electrical conductivity in insulating materials, ${ }^{2}$ caused by populating the conduction band through excitation of valence band electrons. Due to tie high electron mobility and large electron trap cross section, conduction band electrons in ceramics typically recombine within $10^{-9}$ seconds, ${ }^{3}$ thus, in-situ measurements are necessary to study this effect.

Radiation induced conductivity (RIC) in oxide ceramics has been shown to increase electrical conductivity by many orders of magnitude at fusion relevant fluxes. Figure 1 gives a compilation of data from several studies $^{4-8}$ of $\mathrm{RIC}$ in alumina, $\mathrm{MgO}$ and $\mathrm{MgAl}_{2} \mathrm{O}_{4}$. As an example, it is seen that the room temperature electrical conductivity of sapphire increases by more than six orders of magnitude to a value of approximately $10^{-6}(\Omega-\mathrm{m})^{-1}$ at a representative first wall dose rate. While this increase in conductivity is dramatic, it is still two orders of magnitude less than the assumed upper limit due to joule heating concerns of $10^{-4}(\Omega-\mathrm{m})^{-1}$ for fusion insulators. ${ }^{9}$

In the past few years there have been several papers on a potentially more serious problem relating to the use of insulating ceramics in fusion systems. ${ }^{10-17}$ Three separate research groups ${ }^{11-15}$ have published studies in which electrical conductivity was measured in the presence of ionizing and displacive radiation fields while an electric field was applied. The results of these studies indicated that, in addition to the wellestablished increase in conductivity (RIC), a permanent increase in conductivity occurs which greatly exceeds the RIC value after some threshold fluence is reached. The point at which the permanent conductivity began to increase above the RIC level varied from approximately $2 \times 10^{-5} \mathrm{dpa}$ for electron irradiation, ${ }^{12} 1 \times 10^{-3} \mathrm{dpa}$ for proton irradiation, ${ }^{14}$ and $3 \times 10^{-2} \mathrm{dpa}$ for fission neutron irradiation ${ }^{15}$ near $500^{\circ} \mathrm{C}$. This effect has been classified as radiation induced electrical degradation (RIED) and has to this point not exhibited an upper limit in conductivity. While there has not been a systematic study of the 


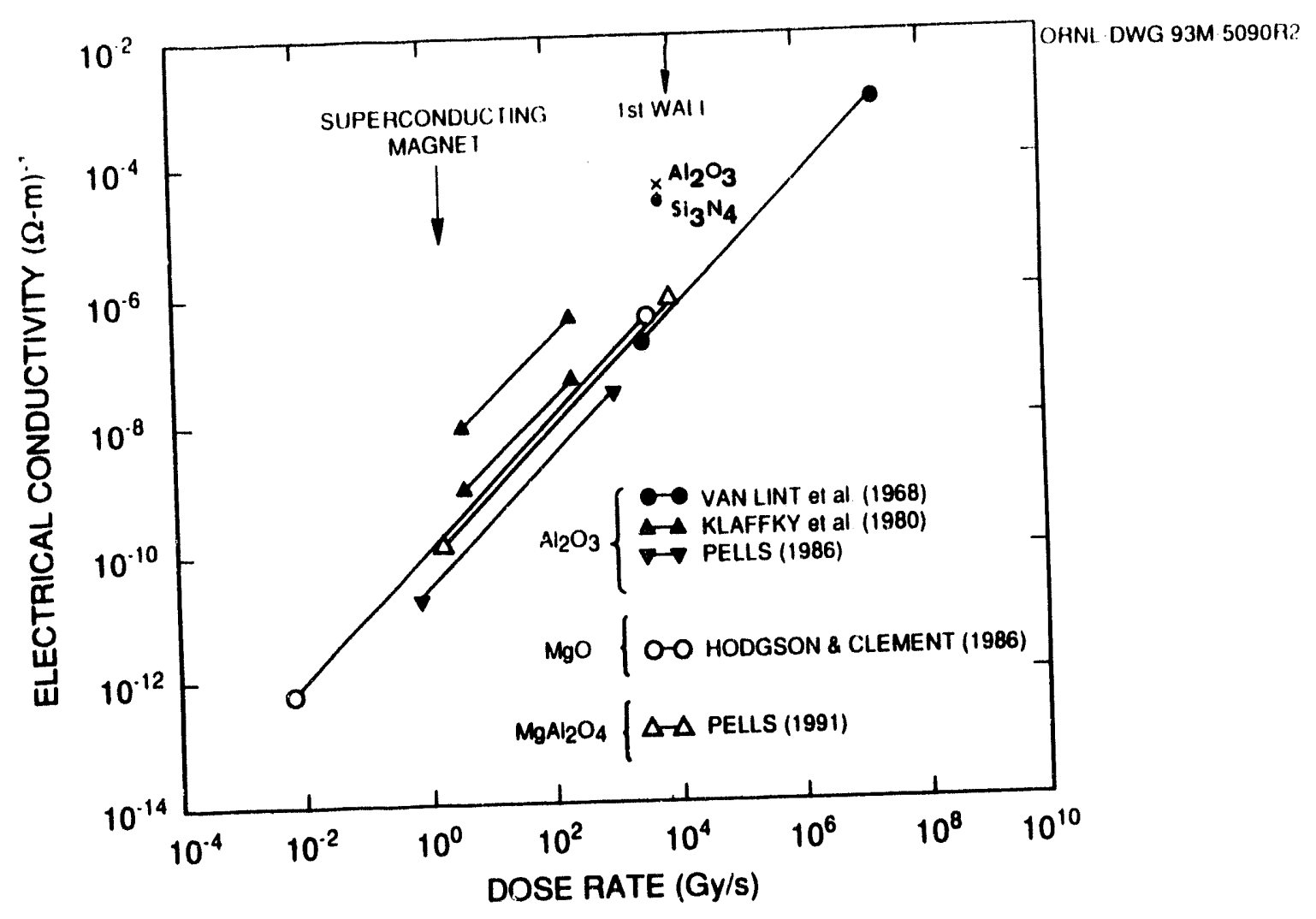

Fig. 1. Radiation induced conductivity in oxide ceramics.

variables underlying this effect, it is known that an applied electric field is necessary during irradiation, and there is evidence suggesting that RIED does not occur below $200^{\circ} \mathrm{C}$ or above $650^{\circ} \mathrm{C}^{9,13-14}$ The presence of both ionizing and displacive radiation is also required. Presently, there has been no definitive post irradiation testing of the degraded ceramic to determine the cause of the RIED. However, it has been speculated that radiation induced colloid formation is taking place similar to that seen in alkali-halides. ${ }^{12}$

The purpose of this paper is to outline the principles of a capsule designed for in-situ electrical conductivity measurements in a fission reactor and to summarize initial results obtained. Emphasis was placed on a design that would minimize signal noise and would provide thermal anchoring of all elements of the capsule including triaxial cables and electrically insulating materials. The prototype capsule was built and underwent preliminary testing in the High Flux Beam Reactor (HFBR) at the Brookhaven National Laboratory.

\section{Desion Considerations}

\section{(A) Electrical Design}

A schematic of the prototype capsule is shown in Figure 2. Each sample was brazed at $890^{\circ} \mathrm{C}$ (five minute hold time) in vacuum to a vanadium sample holder using a Ti-Cu-Si braze alloy. A sputter-deposited platinum guard ring and central electrode configuration was positioned on the sample top in accordance with ASTM standard D257-78: Standard Test Methods for D-C Resistance or Conductance of Insulating Materials. The purpose of the guard ring is to minimize surface conduction that could compromise the measurements by applying a potential equal to that of the central electrode. Each electrode was contacted by a spring loaded, platinum plated, vanadium contact pin that was isolated from ground by an alumina cap. Guard rings were deposited on the top and bottom of these alumina caps to eliminate surface currents from the central contact pins (not shown in Figure 2). 


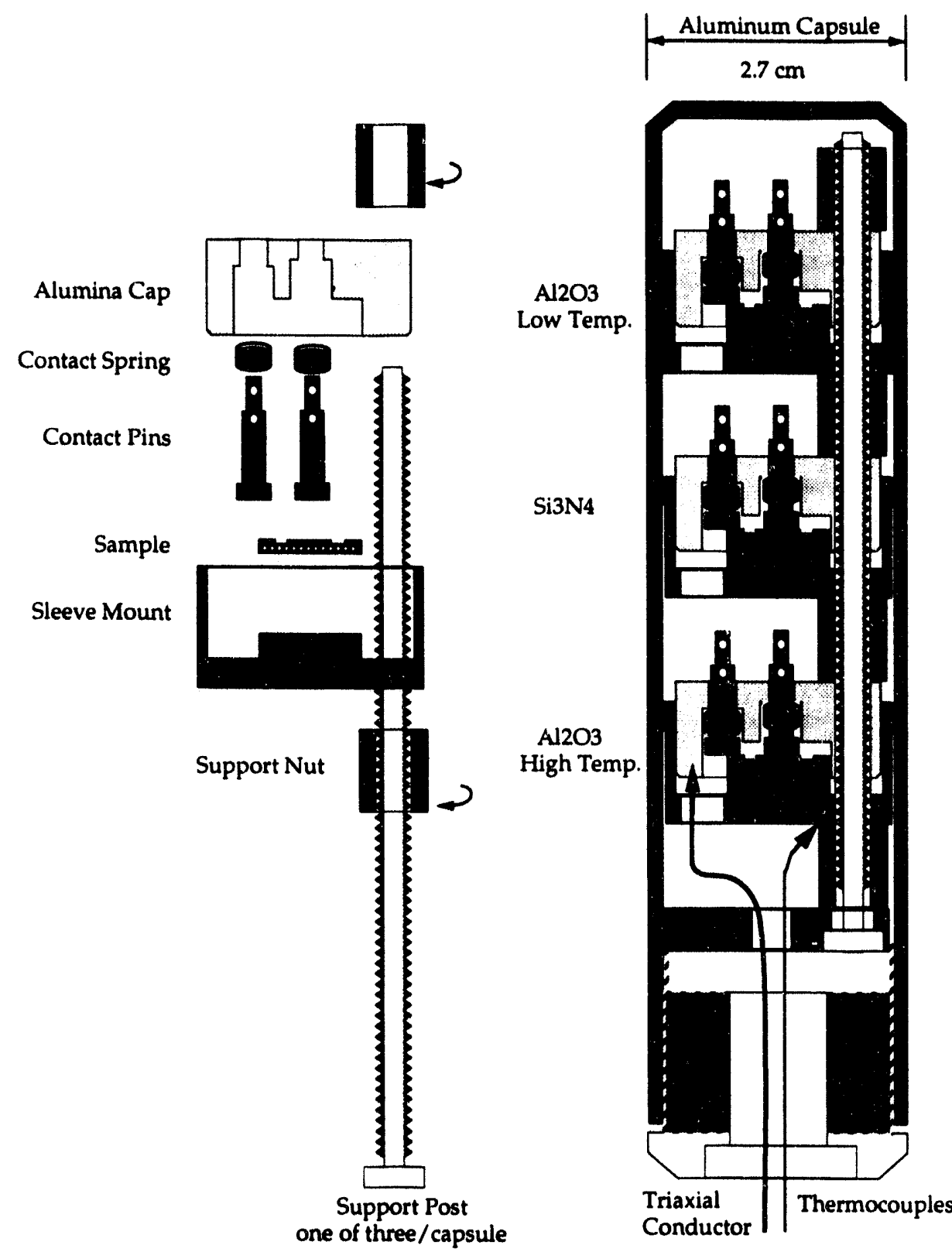

Fig. 2. Schematic of prototype capsule for in-core measurement of electrical conductivity.

Of primary importance in making in-situ measurements on highly resistive materials is the reduction of signal noise. Typically, currents for unirradiated materials will be $<10^{-9}$ amps and will have to be measured over the several meters of cable required to pass the capsule into the reactor core. There is also the added problem of limited space available for the cables into the reactor core and the presence of ionizing radiation which seriously degrades commercially available organically insulated cables. For this reason mineral insulated, triaxial cables were designed and fabricated. A cross section of the cables used in this experiment is shown in Figure 3. The center core and inner sheath are made of OFHC copper (both held at the same potential) with an outside ground sheath of stainless steel. High purity $\mathrm{MgO}$ powder was packed between the three conductors and the entire assembly was swaged to the final diameter of $1.5 \mathrm{~mm}$. 


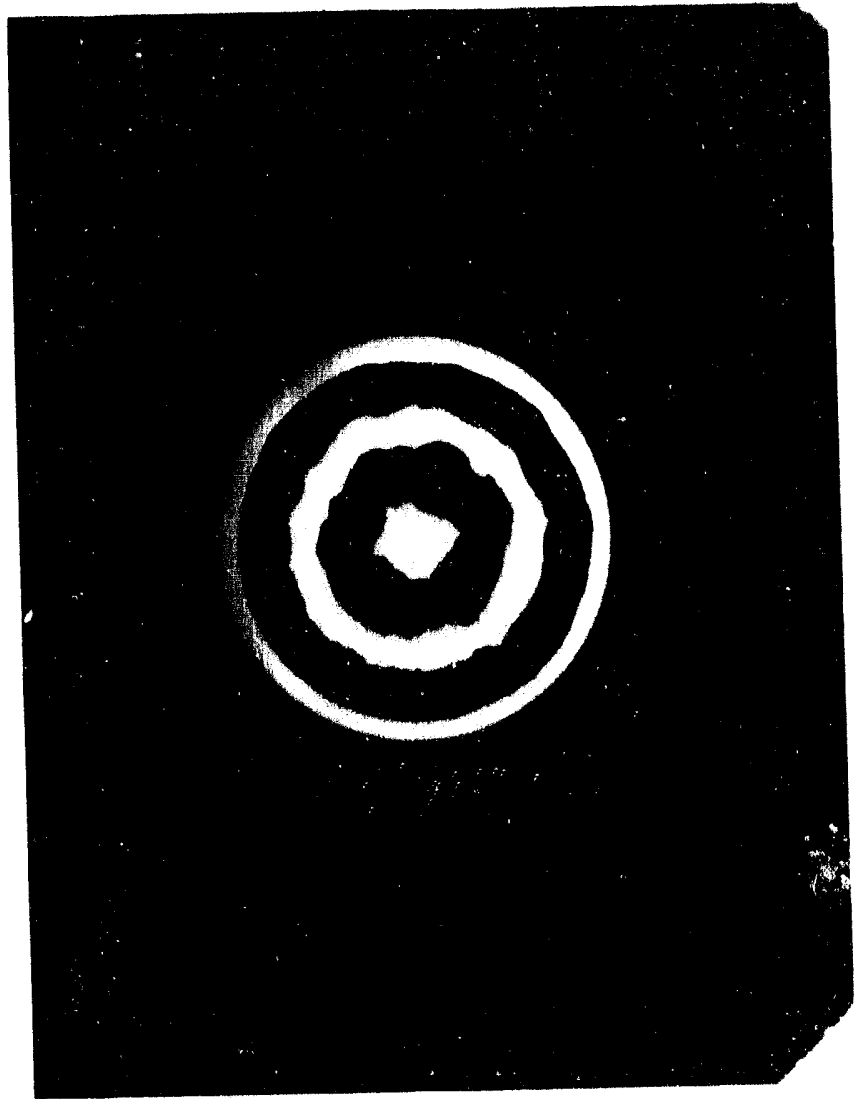

Fig. 3. Cross-section optical photograph showing triaxial, mineral insulated cable used in experiment.

In order to further reduce the possibility of surface conduction from the center electrode, it is important to ensure that the potentials applied to the center and guard ring are equal. In order to ensure this, the line resistances of the conductors applying potential to the center and guard electrodes should be as low as possible. Furthermore, it is desirable for the line resistance of the guard conductor to be less than that of the center conductor by at least the ratio of the resistances across the electrodes. In this case the line resistances were : pproximately $6 \mathrm{ohms}$ for the center conductor and $1.5 \mathrm{ohms}$ for the inner sheath over the cable length of 11 meters. The unirradiated resistances across the $\mathrm{MgO}$ powder insulation from center to inner sheath and inner sheath to ground were all $>35 \mathrm{M} \Omega$ (unirradiated). Contacts were made from the stripped triaxial cable to the electrodes inside of the irradiation capsule with bare copper wire.

\section{(B) Heat Transfer and Capsule Environment}

The primary thermal conduction path for this design is radial to the walls of the capsule assembly, which are in contact with the reactor coolant water. Design temperatures were achieved by selection of the helium gas gap thickness between the sample mount and the capsule wall. The low temperature alumina sample was in contact with the capsule wall (no gap) while the remaining two samples each had a $1.4 \mathrm{~mm}$ helium gas gap. The measured temperatures during reactor irradiation $(6 \mathrm{~W} / \mathrm{gm})$ were $80^{\circ} \mathrm{C}$ and $320^{\circ} \mathrm{C}$ for the alumina samples and $280^{\circ} \mathrm{C}$ for the silicon nitride specimen. The radial temperature rise across the sample was calculated to be less than $10^{\circ} \mathrm{C}$. The temperature was monitored during irradiation by mineral insulated, type $\mathrm{K}$ thermocouples in contact with the sample mount.

The choice of He gas instead of vacuum for the capsule environment was based on several considerations. First, the long distance between the reactor core and the equipment station $(\sim 11 \mathrm{~m})$ and the small tube diameter available for insertion into the core ( $\leq 6 \mathrm{~mm}$ I.D.) creates a very low pumping conductance. A straightforward calculation indicated that outgassing from the capsule surfaces would limit 
the pressure in the capsule to $\geq 1 \mathrm{mTorr}(0.13 \mathrm{~Pa})$. This pressure is rather close to the minimum in the Paschen curve for electrical breakdown in gases ${ }^{18}$ and is in the pressure regime where pronounced spurious results attributable to gas ionization were observed in a recent in-situ dielectric properties neutron irradiation experiment. ${ }^{19}$ In this latter study, it was demonstrated that it was preferable to operate the irradiation capsule at or above atmospheric pressure unless capsule pressures below $10^{-4}$ Torr could be reliably obtained. Helium has the highest ionization potential of the inert gases and therefore produces the fewest ion pairs per unit volume during exposure to ionizing radiation. ${ }^{3}$ The high thermal conductivity of He compared to other gases also helps to minimize temperature variations in capsule components that are in poor thermal contact with the heat sink. Calculations were made to estirr ate the contribution to the measured current made by the ionization and collection of the helium cover gas. Assuming the worst case scenario of an ideal cylindrical geometry and no recombination of ionized species, the calculated contribution to the signal current was in the microamp range and therefore negligible.

There has been recent work eluding to the potential problem of depositing thin films of carbonaceous material on the electrodes during irradiation. For an unguarded sample this would have the effect of increasing the system leakage current over what was measured prior to irradiation. If the film became conductive enough, however, even a guarded system would be compromised. ${ }^{20,21}$ In order to minimize this possibility, capsule elements were baked out $10500^{\circ} \mathrm{C}$ prior to assembly and were cleaned in acetone and alcohol baths. After assembly, the capsule was evacuated with a turbomolecular pump and back-filled with high purity helium. The process of evacuation and back-filling was carried out three times with the longest pump down period being 16 hours. The capsule was held at 10 psi over atmosphere of helium during the irradiation.

\section{(C) Measurement and Control}

The instrument control and data acquisition was accomplished via a computer fitted with an IEEE-488, General Purpose Interface Bus (GPIB), interface card. The instruments which were interfaced with the computer were; a Hewlett-Packard power supply to source the voltage to the samples, a Keithley model 237 electrometer to measure the current through the samples, a digital multimeter (DMM) to measure thermocouple voltages and a Keithley model 9001 switching unit to switch between the three different samples and to switch between the various thermocouples. The controlling software was written using National Instruments' LabVIEWII software. A schematic of the data acquisition and control system is shown in Figure 4. The switching unit contains two separate switch cards, a low current high voltage $4 \times 5$ matrix switching card used to source the voltage to the samples and a thermocouple switching card, which is supplied with a calibrated reference junction.

As shown in Figure 4, power is supplied for two separate triaxial inputs to the matrix card. For one of the matrix card inputs, the center conductor signal passes through the electrometer and for the other input the center conductor signal does not pass through the electrometer. With this arrangement it is possible to set the matrix card to source a constant voltage to the three outputs to the samples and when a current measurement is to be made each sample may be sourced individually through the electrometer. Thus when measurements are to be made the computer controls the matrix card and scans through each sample, acquiring and storing voltage and current readings for the sample.

In Figure 4 the thermocouple scanning card has seven separate inputs, one for each thermocouple to be measured, and one output to the DMM. When temperature measurements are taken the computer scans through the channels to which the thermocouples are connected as well as the reference junction channel. For each thermocouple, the voltage reading was read by the computer, converted to a temperature, and stored.

Thus with this system it is possible to measure the voltage across and the current through each ceramic sample and to measure the temperature of each thermocouple junction. These values are then stored for later data analysis. The software was written so that the measurements were being taken continuously with a cycle of sample current and thermocouple measurements taking approximately 30 seconds. Measurements were then compared to the most recently stored values, and if the data differed by $1 \%$ or more 


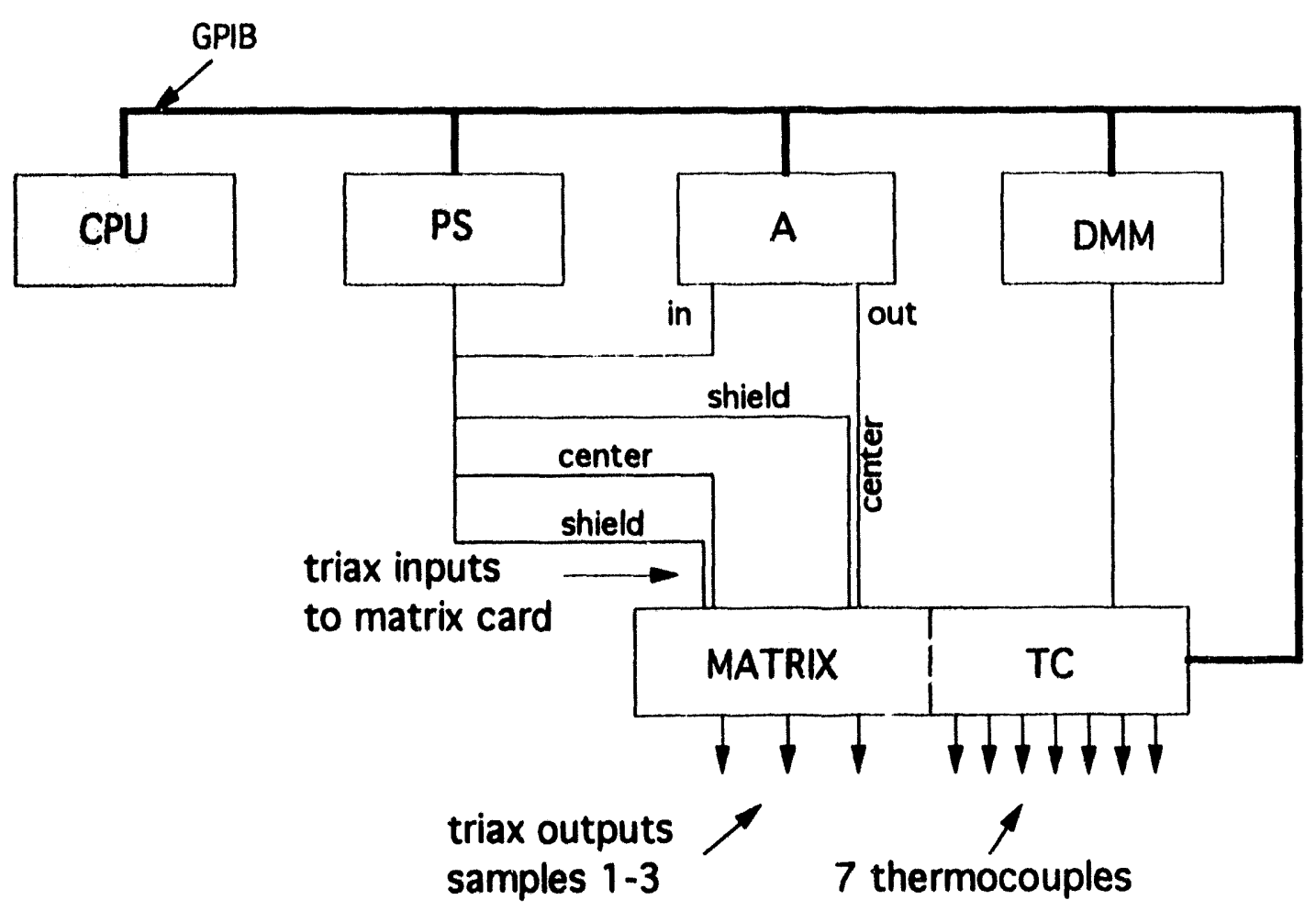

Fig. 4. Schematic of data acquisition and control system showing GPIB connections and connections to the current matrix and thermocouple cards. the inputs and outputs to the matrix card are triaxial connections (outer ground sheath is not shown).

from the previously stored values then the new measurements were stored. In the event of data not changed by more than $1 \%$, a measurement was stored hourly.

\section{Experimental Synopsis}

Materials for this study were polycrystalline Coors alumina AD-99822 and Kyocera SN-733 silicon nitride. Sample thicknesses of $0.75 \mathrm{~mm}$ were chosen with $4 \mathrm{~mm}$ ID central electrode and $1 \mathrm{~mm}$ gap between central and guard electrode. A DC electric field of 100 volts was applied to the sample which corresponds to an applied field strength of $133 \mathrm{~V} / \mathrm{mm}$.

The prototype capsule was assembled with triaxial cables and thermocouple leads being passed through a $0.39 \mathrm{~cm}$ ID aluminum tube of length $9.1 \mathrm{~m}$. The capsule was then pushed with the aluminum tube into the V-16 thimble of the HFBR during reactor operation. The capsule was located mid-core which has approximately $6 \mathrm{~W} / \mathrm{g}$ gamma heating and an associated fast flux of $1.5 \times 10^{18} \mathrm{n} / \mathrm{m}^{2}-\mathrm{s}(\mathrm{E}>1 \mathrm{MeV})$. The data measurement software was operating within ten minutes of capsule insertion. The capsule was irradiated for 8.1 days corresponding to a fast neutron $\left(E>1 \mathrm{MeV}\right.$ ) fluence of $1.1 \times 10^{24} \mathrm{n} / \mathrm{m}^{2}$ and a damage level of $\sim 0.11 \mathrm{dpa}$.

\section{Results and Discussion}

The capsule thermocouple measurements yielded $80^{\circ} \mathrm{C}$ ior the low temperature alumina specimen, $280^{\circ} \mathrm{C}$ for the silicon nitride and $320^{\circ} \mathrm{C}$ for the high temperature alumina sample during irradiation. Shown in Figure 5 is a plot showing the linear (ohmic) behavior of an alumina sample mounted in the capsule prior to irradiation at room temperature. At an applied voltage of $100 \mathrm{~V}$, the current through the specimen was $0.34 \mathrm{nA}$ corresponding to a conductivity of $1.3 \times 10^{-10}(\Omega 2-\mathrm{m})^{-1}$. 


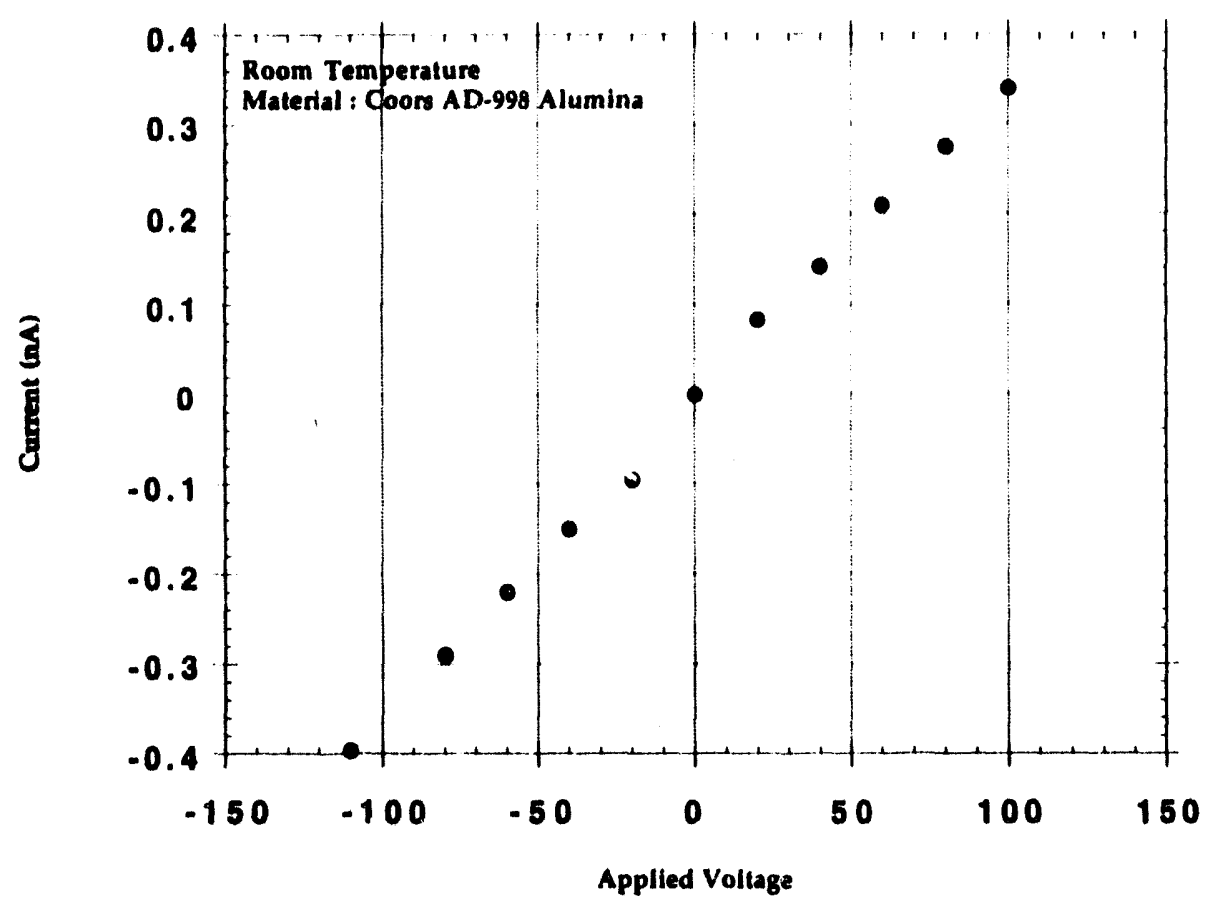

Fig. 5. Plot showing ohmic behavior of sample prior to core insertion.

Figure 6 shows data for the RIC at the beginning of irradiation for the alumina specimen irradiated at $80^{\circ} \mathrm{C}$. A large, prompt increase in conductivity of more than five orders of magnitude to approximately $4.6 \times 10^{-5}$ is observed $(\Omega-\mathrm{m})^{-1}$. During the early stages of irradiation there was a gradual decrease in the RIC, which can be attributed to the creation of point defects in the alumina which increase the scavenging of excited electrons. This effect is seen to be short term and is saturated in several hours of irradiation. Figure 1 includes this RIC data for the $80^{\circ} \mathrm{C}$ alumina sample following 9 hours of irradiation and it is seen to be on the high end of the scatter in the published data. Also included in Figure 1 is the value of RIC for the silicon nitride sample which reached $3.23 \times 10^{-5}(\Omega-\mathrm{m})^{-1}$.

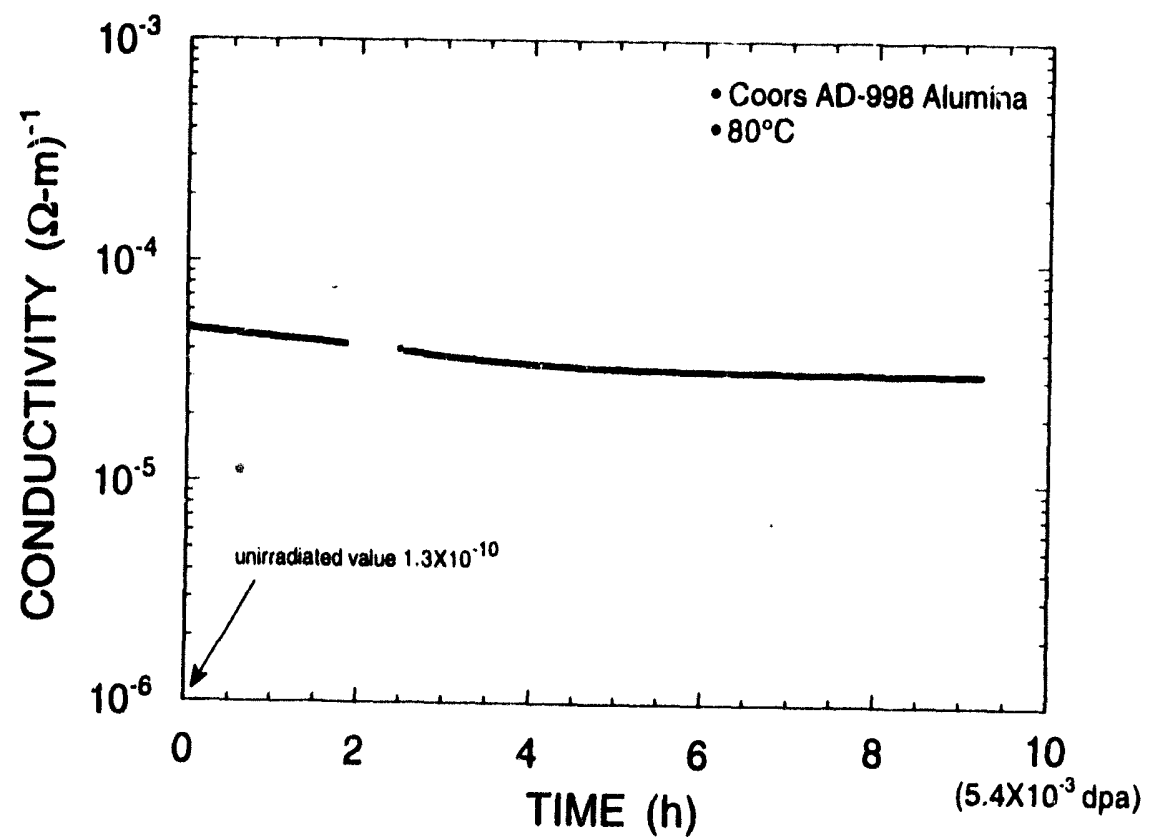

Fig. 6. Reduction in the radiation induced conductivity caused by point defect formation. 
Following two hours of irradiation the voltage was turned off and a series of diagnostic tests were performed. In particular, the voltages to all three samples were varied to check for ohmic behavior. The two high temperature samples were ohmic to approximately 60 volts and then became slightly supra linear. The surface conductance (leakage currents) were also measured. Also during the diagnostic period cooling water flow to the thimble was reduced from $12 \mathrm{~m} / \mathrm{s}$ to $6 \mathrm{~m} / \mathrm{s}$ to observe any change in signal noise and temperature. No effect was observed. The DC field was then reapplied to the samples for the duration of the experiment.

Of interest is the reduction in the in-core resistances of all the cables. As mentioned earlier, the center core to inner sheath and inner sheath to ground resistances were off scale of the digital meter being used (>35 $\mathrm{M} \Omega$ ) prior to exposure. However, during radiation these resistances promptly decreased to approximately $10 \mathrm{M} \Omega$. This can be explained by noting that $\mathrm{RIC}$ occurs in the $\mathrm{MgO}$ powder insulation. A straightforward calculation $1^{8,19}$ shows this reduction in resistance should have negligible effect on measurements, however.

In order to measure the effects of radiation on both the prompt RIC as well as the dose-dependent, permanent RIED in ceramic insulators, it is necessary to provide low noise measurements and to ensure adequate temperature control over the specimen. The current design has been demonstrated in the HFBR core and has yielded data with very low noise and temperatures within acceptable limits. Figure 7 shows the results of the low temperature irradiation from the point of insertion into the core until it was removed 195 hours later, or a total dose of $\sim 0.11 \mathrm{dpa}$. Of note is that there is no evidence that RIED has taken place in the polycrystalline alumina at $80^{\circ} \mathrm{C}$ to a fluence of more than a tenth of a dpa. The curve shows two gaps in the data where the program was stopped and diagnostics were performed.

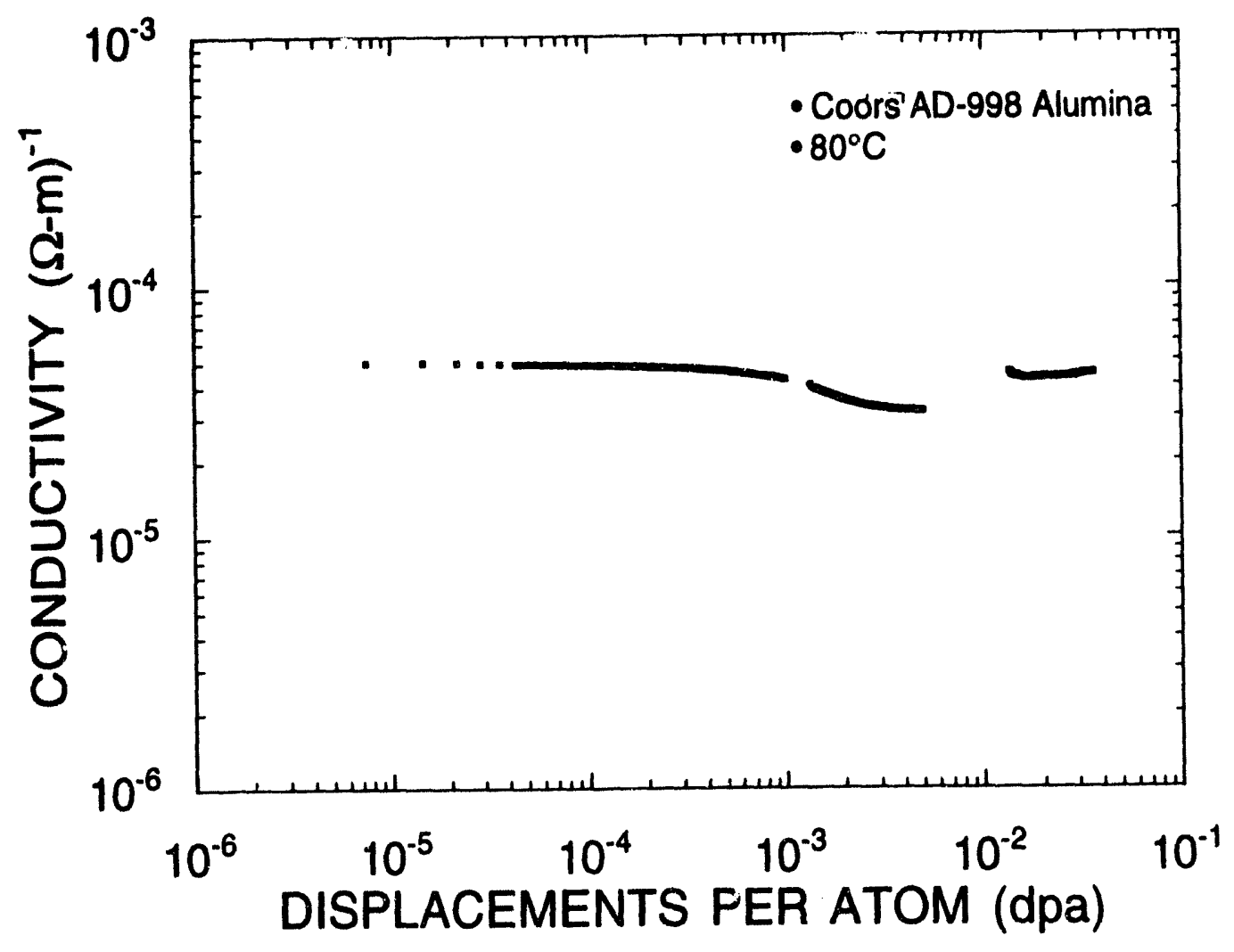

Fig. 7. Conductivity plot for alumina sample irradiated at $80^{\circ} \mathrm{C}$ during extended irradiation. 
The higher temperature samples initially yielded RIC for the guarded specimens in acceptable ranges but an anomalous leakage (a gradual increase in current) occurred after several hours of irradiation. This increase resembled the RIED effects seen by previous researchers but this was easily dismissed as surface leakage after analyzing diagnostic tests. In particular, measurement of leakage current (i.e. current supplied minus current measured through center electrode) indicated that there was significant leakage in either the cable termination or between the specimen guard and ground. Also of note is that this leakage problem was of a transient nature. If the potential was reduced to $\sim 15 \mathrm{~V}$ the sample measurements would gradually return to nearly their initial values after some time, supporting the idea of surface contamination. The most likely source of this problem was the unsealed cable termination. Final determination of any possible RIED will be found following post irradiation examination of the $280^{\circ} \mathrm{C} \mathrm{Si} 3 \mathrm{~N}_{4}$ and $320^{\circ} \mathrm{C} \mathrm{Al}_{2} \mathrm{O}_{3}$ samples.

The present measurements indicate that careful attention needs to be paid to the cable termination in the capsule, and demonstrate that significant anomalous leakage currents can be present even in a fully guarded irradiation capsule. Future neutron irradiation capsules will be sealed at the cable termination in an attempt to eliminate this spurious leakage current.

It should also be noted that $300^{\circ} \mathrm{C}$ may be too low a temperature for RIED to occur, as pointed out in References 8 and 9.

\section{Summary}

A prototype in-situ capsule designed for DC electrical conductivity measurements during neutron irradiation was verified to perform well during a test irradiation in the HFBR up to a fluence of $1.1 \times 10^{24} \mathrm{n} / \mathrm{m}^{2}$ $(\mathrm{E}>1 \mathrm{MeV})$. Some problems with anomalous leakage currents were observed and are tentatively ascribed to leakage at the triaxial cable termination. A large prompt increase in electrical conductivity due to RIC was observed in both $\mathrm{Al}_{2} \mathrm{O}_{3}$ and $\mathrm{Si}_{3} \mathrm{~N}_{4}$. However, there was no evidence for permanent radiation induced electrical degradation at 80 or $300^{\circ} \mathrm{C}$ with an applied DC field of $130 \mathrm{~V} / \mathrm{mm}$.

\section{Euture Work}

A follow-on experiment is currently being constructed at ORNL and is tentatively scheduled to be irradiated in the HFBR beginning in January of 1994. The experimental matrix is for a single material, Wesgo AD995 polycrystalline alumina at three temperatures which should bracket the assumed peak temperature. for RIED of $450^{\circ} \mathrm{C}$. The duration of the experiment is expected to last two cycles in the HFBR yielding approximately $0.5 \mathrm{dpa}$.

\section{Acknowledoments}

The AD-998 alumina was provided to the U.S. Fusion Ceramics Program as a reference material.

\section{References}

1. S. J. Zinkle, Ceramics Radiation Effects Issues for ITER, Plasma Dev. and Oper. [3] (1993), in press.

2. W. C. Roentgen and A. Joffe, Ann. Physik [41] (1913) 449; [64] (1921) 1.

3. V. A. J. van Linh, et al. Mechanisms of Radiation Effects in Electronic Materials, Vol. 1 (Wiley and Sons, New York, 1980).

4 V. A. J. van Lint, et al., IEEE Trans. on Nucl. Sci., NS-15, No. 6, 194 (1968).

5. R. W. Klaffky et. al., Phys. Rev., B21 (1980) 3610.

6. G. P. Pells, Rad. Effects, 97 (1986) 199.

7. E. R. Hodgson and S. Clement, Rad. Effects, 97 (1985) 251.

8. G. P. Pells, J. Nucl. Mater., 179-181 (1991) 383.

9. S. J. Zinkle and E. R. Hodgson, J. Nucl. Mater., 191-194 (1992) 58.

10. V. M. Ivanov, et al, Inorganic Mater., 17 (1981) 1203.

11. E. R. Hodgson, Cryst. Latt. Def. Amorph. Mat., [18], 169 (1989). 
12. E. R. Hodgson, J. Nucl. Mater., 179-181 (1991) 383.

13. E. R. Hodgson, J. Nucl. Mater., 191-194 (1992) 552.

14. G. P. Pells, J. Nucl. Mater., 184 (1991) 177.

15. T. Shikama, et al, J. Nucl. Mater., 191-194 (1992) 575.

16. E. H. Farnum, private comm. (LASREF irradiation of $\mathrm{Al}_{2} \mathrm{O}_{3}$ ).

17. E. R. Hodgson, Rad. Eff. Def. Solids, 119-121 (1991) 827.

18. R. Hawley, Vacuum 10 (1960) 310.

19. R. H. Goulding, D. A. Rasmussen, R. E. Stoller and S. J. Zinkle, manuscript in preparation.

20. W. Kestemich, F. Scheuermann, and S. J. Zinkle, submitted to J. Nucl. Mater.

21. P. Jung, Z. Zhu, and H. Klein, J. Nucl. Mater. (in press).

22. R. E. Stoller, Fusion Reactor Semiannual Progress Report DOE/ER-0313/8 (1990), 299. 
THE EFFECT OF IONIZING AND DISPLACIVE RADIATION ON THE THERMAL CONDUCTIVITY OF ALUMINA AT LOW TEMPERATURE - D.P. WHITE (Oak Ridge National Laboratory)

\section{OBJECTIVE}

The effects of radiation produced vacancies and of radiation induced electrical conductivity (RIC) on the thermal conductivity of alumina at low temperatures have been calculated. The phonon scattering relaxation times for these mechanisms have been used in the evaluation of the thermal conductivity integral in order to determine the effect each mechanism has on the lattice thermal conductivity of alumina.

\section{SUMMARY}

Microwave heating of plasmas in fusion reactors requires the development of windows through whicin the microwaves can pass without great losses. The degradation of the thermal conductivity of alumina in a radiation environment is an important consideration in reliability studies of these microwave windows. Several recent publications have calculated the radiation induced degradation at high temperature [1-3] and at low temperature $[4,5]$. The current paper extends the low temperature calculations in order to determine the effect of phonon scattering by radiation produced vacancies and by conduction band electrons due to RIC on the thermal conductivity at 77K. These low temperature calculations are of interest because the successful application of high power $(>1$ $\mathrm{MW}$ ) windows for electron cyclotron heating systems in fusion reactors will most likely require cryogenic cooling to take advantage of the low loss tangent and higher thermal conductivity of candidate window materials at these temperatures $[6,7]$.

It is found that vacancy scattering can significantly reduce the thermal conductivity; for example, a vacancy concentration of 0.01 per atom leads to a fractional change in thermal conductivity of about $90 \%$. It is also concluded that the scattering of phonons by electrons in the conduction band due to RIC does not lead to a large reduction in the thermal conductivity.

\section{PROGRESS AND STATUS}

\section{Introduction}

The lattice thermal conductivity of crystalline material is given by the following expression derived by Callaway [8],

$$
k_{l}=\frac{\left(6 \pi^{2}\right)^{1 / 3}}{2 \pi^{2}} \frac{k_{b}^{3}}{\hbar^{2}} \frac{T^{3}}{\Theta a}\left[I_{1}+I_{2}^{2} / I_{3}\right]
$$

where $k_{b}$ is Boltzmann's constant, $\hbar$ is Plank's constant divided by $2 \pi, \Theta$ is the Debye temperature of the material, $a^{3}$ is the volume per unit cell, and

$$
\begin{aligned}
& I_{1}=\int_{0}^{\Theta / T} \tau_{c} \frac{x^{4} e^{x}}{\left(e^{x}-1\right)^{2}} d x \\
& I_{2}=\int_{0}^{\Theta / T} \frac{\tau_{c}}{\tau_{n}} \frac{x^{4} e^{x}}{\left(e^{x}-1\right)^{2}} d x \\
& I_{3}=\int_{0}^{\Theta / T} \frac{\tau_{c}}{\tau_{n} \tau_{r}} \frac{x^{4} e^{x}}{\left(e^{x}-1\right)^{2}} d x .
\end{aligned}
$$


Here $x=\frac{\hbar \omega}{k_{b} T}, \omega$ is the circular phonon frequency, $\tau_{n}$ is the phonon relaxation time for normal processes, $1 / \tau_{c}=1 / \tau_{n}+1 / \tau_{r}$, and $1 / \tau_{r}=\sum_{j} 1 / \tau_{j}$, where the $\tau_{j}$ are the relaxation times of the various resistive phonon scattering processes, which include 3-phonon umklapp processes, boundary scattering, point defect scattering, and phonon-electron scattering.

\section{Calculations}

This formulation of the thermal conductivity takes into account the effect of phonon-phonon normal processes, which is particularly important in treating the low temperature case. In order to evaluate the expression in Eq. 1, a computer program was written to calculate the various integrals, given functional forms for the various phonon relaxation times. The forms used for the normal process relaxation time and umklapp process relaxation time are given in Eq. 2.

$$
\begin{aligned}
\tau_{n}^{-1} & =b_{n} \omega T^{4} \\
\tau_{u}^{-1} & =b_{u} \omega^{2} T \exp \left(-\frac{\Theta}{\alpha T}\right)
\end{aligned}
$$

for normal and umklapp processes respectively. The values of the parameters $b_{n}$ and $b_{u}$ for sapphire were obtained by de Goer [9] and are the values used in this case. These values were obtained by fitting the expression of Eq. 1 to experimental thermal conductivity data at high temperatures. The values obtained by de Goer are,

$$
\begin{aligned}
& b_{n}=2.7 \times 10^{-13} K^{-4} \\
& b_{u}=1.7 \times 10^{-18} s K^{-1}
\end{aligned}
$$

The parameter $\alpha$ is a numerical factor which depends on the details of the zone structure; de Goer found that $\alpha=2$ gives a good fit to experimental data.

The boundary scattering relaxation time has the form,

$$
\tau_{b}^{-1}=\frac{v}{L}
$$

where $v$ is the phonon velocity and $L$ is a parameter on the order of the dimensions of the crystal and is dependent on the geometry of the sample. The point defect scattering relaxation time has the form,

$$
\tau_{p}^{-1}=A \omega^{4}
$$

where $A$ is a parameter which is proportional to the defect concentration and depends on the nature of the defect, which in pure unirradiated samples will include thermodynamic vacancies, and trace impurities.

For a pure, single crystal, cylindrical sample $50 \mathrm{~mm}$ long and $5 \mathrm{~mm}$ in diameter (de Goer's sample 5 ) de Goer varied the values of $A$ and $L$ to fit the calculated values of the thermal conductivity to experimental values in the temperature range 2 to $100 \mathrm{~K}$. It was found that a good fit was found for $L=4.12 \times 10^{-3} \mathrm{~m}$ and $A=4.08 \times 10^{-46} \mathrm{~s}^{3}$. These values will be used in the present calculations. It should be noted however that the thermal conductivity below the conductivity maximum $(\sim 30 \mathrm{~K})$ is highly sensitive to the value of $L$.

In order to determine the effect of radiation produced vacancies on the thermal conductivity of sapphire, another term, dependent on the radiation produced vacancy concentration, must be added to the point defect relaxation time. For vacancies it has been shown $[10,11]$ that the phonon relaxation time is given by,

$$
\tau_{v}^{-1}=C_{v} \Omega\left(\frac{3 \Delta M}{M}\right)^{2} \frac{1}{4 \pi v^{3}} \omega^{4}
$$


where $C_{v}$ is the vacancy concentration per unit cell, $\Delta M$ is the change in mass of the unit cell due to a vacancy, and $M$ is the mass of the unit cell. In this case the unit cell is chosen to be the formula unit, $\mathrm{Al}_{2} \mathrm{O}_{3}$, with a mass of 102 and a volume of $42.6 \times 10^{-30} \mathrm{~m}^{3}$. The Debye temperature in this case is then $600 \mathrm{~K}$, and the phonon velocity is $7 \times 10^{3} \mathrm{~m} / \mathrm{s}$. Thus the form of the point defect relaxation time is given by,

$$
\tau_{v}^{-1}=\left(4.08 \times 10^{-46}+C_{v} \frac{\Omega}{4 \pi v^{3}} 0.624\right) \omega^{4}
$$

for aluminum vacancies. In this expression the first term in parentheses is that part of the relaxation time which is due to intrisic point defects, as found by de Goer, and the second term is that part which is due to radiation produced point defects. These relaxation times may now be substituted into Eq. 1 and the thermal conductivity calculated for a range of temperatures and radiation produced vacancy concentrations.

It should be noted that the relaxation time in Eq.6 applies to isolated, randomly distributed point defects. If the vacancies cluster then this relaxation time must be appropriately modified. For example, in the case of defect clustering in a region small compared to the phonon wavelength there is a reinforcement of the scattering matrix and the scattering probability varies as the square of the number of defects in the cluster. The calculations presented here will be for isolated point defects.

In order to determine the effect of phonon-electron scattering on the thermal conductivity, the phonon-electron relaxation time must be included as a resistive phonon scattering process in the Callaway formulation. The phonon-electron relaxation time may be obtained though a momentum balance argument $[3]$ and is of the form:

$$
\frac{1}{\tau_{p-e}}=\frac{3 v^{2}}{\mu^{2}} \frac{\sigma}{C T}
$$

where $v$ is the phonon velocity, $\mu$ is the electron mobility, $C$ is the phonon specific heat of those phonons which are allowed to interact with the conduction band electrons (due to energy and wave-vector conservation considerations), $\sigma$ is the electrical conductivity, and $T$ is the temperature.

The relaxation time given in Eq. 7 must be evaluated in order to use it in the thermal conductivity integral. Klaffky et. al. [12] found evidence of a temperature independent mobility for $T<300 \mathrm{~K}$, for single crystal alumina under conditions where RIC was produced by continuous irradiation with 1.5 $\mathrm{MeV}$ electrons at dose rates up to $6.6 \times 10^{2} \mathrm{~Gy} / \mathrm{s}$. Hughes [13] reported a temperature independent mobility of $(3 \pm 1) \times 10^{-4} \mathrm{~m}^{2} / V-s$ for an undoped aluminum sample $\mathrm{x}$-ray irradiated between 100 and $350 \mathrm{~K}$. In the calculations presented here it is assumed that this constant mobility holds to $77 \mathrm{~K}$.

The specific heat, $C$, of those phonons up to a cut off frequency of $\omega_{c}=\frac{2 v}{\hbar}\left(2 m k_{B} T\right)^{1 / 2}$ is given, in the Debye approximation, by:

$$
C=9 n k_{B}\left(\frac{T}{\Theta}\right)^{3} \int_{0}^{\Theta_{c} / T} \frac{x^{4} \exp x}{(\exp x-1)^{2}} d x .
$$

In these expressions, $m$ is the electron mass, $n$ is the number of unit cells per unit volume and $\Theta_{c}$ is the phonon-electron cut off temperature given by $\Theta_{c}=\hbar \omega_{c} / k_{B}$ and $x=\hbar \omega / k_{B} T$. The expression given in Eq. 8 may be evaluated by numerical integration for any particular temperature and then this value may be used in the relaxation time of Eq. 7. It is possible to calculate the changes in the thermal conductivity due to changes in $\sigma$ by numerically evaluating the Callaway thermal conductivity integral of Eq. 1 for different values of $\sigma$ in the phonon-electron relaxation time. 
Results

The results of the thermal conductivity calculations are given in Figs.1-4. In Fig. 1 the calculated

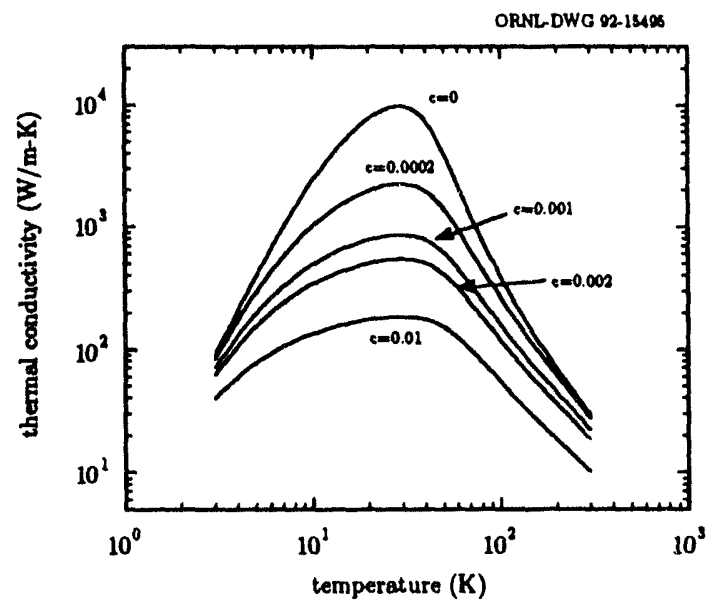

Figure 1: Plot of the thermal conductivity of single crystal alumina versus temperature. The different curves correspond to different vacancy concentrations, where $c$ is the vacancy concentration per atom.

thermal conductivity versus temperature is plotted for several values of the radiation produced vacancy concentration. The largest reduction in the thermal conductivity due to these vacancies is in the region of the conductivity maximum at approximately $30 \mathrm{~K}$. The curves in Fig. 1 compare favorably with the low temperature measurements of Berman et.al. [14] and of Salce et.al. [15], for neutron irradiated sapphire. For example, Berman et.al. found that the thermal conductivity maximum for a sapphire sample irradiated to a dose of $50.2 \times 10^{21} \mathrm{n} / \mathrm{m}^{2}(\sim 0.005 \mathrm{dpa})$ was reduced from a non-irradiated value of approximately $8000 \mathrm{~W} / \mathrm{m}-\mathrm{K}$ to about $400 \mathrm{~W} / \mathrm{m}-\mathrm{K}$. From Fig. 1 it is seen that the same fractional reduction occurs at a vacancy concentration of approximately 0.002 per atom. Figure 2 is a plot of the thermal conductivity versus vacancy concentration at $77 \mathrm{~K}$. This plot shows the reduction in the thermal conductivity at liquid nitrogen temperatures, where it has been proposed to cool ECRH microwave windows to take advantage of the high thermal conductivity and low loss tangent of alumina at these temperatures [6,7]. In Fig. 3 the fractional change in the thermal conductivity versus RIC is plotted. The three different curves correspond to different values of the electron mobility, covering the range of uncertainty in the electron mobility. From this plot it can be seen that at the highest values of the RIC plotted $\left(10^{-2}(\Omega-m)^{-1}\right)$, the change in the thermal conductivity approaches a maximum of about $9 \%$. This value corresponds to the case of all phonons below the cut off frequency being strongly scattered, and thus is the limiting value of the reduction in the thermal conductivity which can occur at this temperature due to phonon-electron scattering. In Fig. 4 the fractional change in the thermal conductivity is plotted as a function of vacancy concentration. This figure plots the fractional change with the RIC included and with no RIC included in the calculation. The value of the RIC chosen in this plot is $10^{-5}(\Omega-m)^{-1}$. This value was chosen because it represents the maximum of the range of expected prompt RIC values in sapphire in a fusion environment [3]. It is only at vacancy concentrations less than $10^{-5}$ per atom where there is any difference between the two cases. 


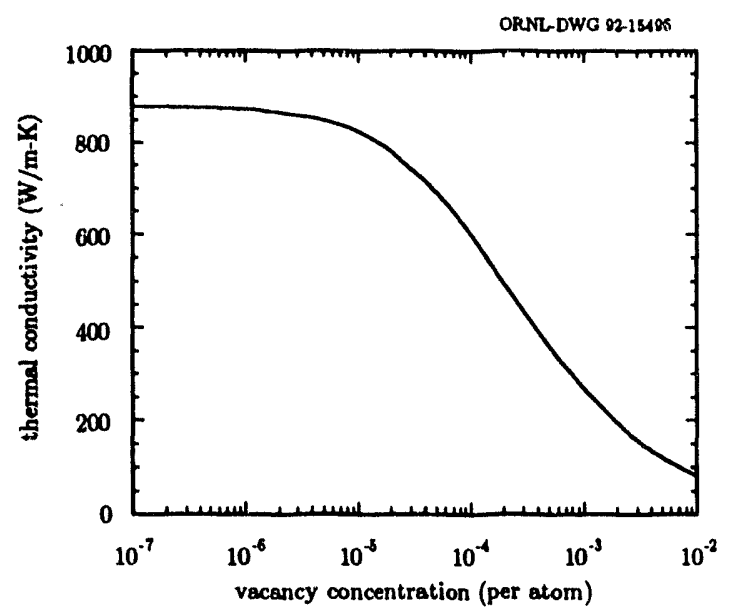

Figure 2: Plot of the thermal conductivity of single crystal alumina versus vacancy concentration at $77 \mathrm{~K}$.

The thermal conductivity of sapphire is significantly reduced by vacancies at low temperatures. From Fig. 1 it is seen that the major part of the reduction is in the area of the thermal conductivity maximum, which occurs at about $30 \mathrm{~K}$. There is however significant reduction in the thermal conductivity at liquid nitrogen temperature, as can be seen in Fig. 2. From Fig. 4 it can be seen that the fractional change in the thermal conductivity for a vacancy concentration of 0.01 per atom is expected to be about $90 \%$ at $77 \mathrm{~K}$. This is a very large reduction in the lattice thermal conductivity and it raises the question as to whether or not this reduction negates the increase in the thermal conductivity gained by going to low temperatures.

In Refs. $[1,3]$ it was shown that at $400 \mathrm{~K}$ the fractional reduction in the thermal conductivity due to a vacancy concentration of 0.01 per atom would be expected to be approximately $39 \%$ which is a much smaller fractional decrease in the lattice thermal conductivity compared to the $90 \%$ reduction expected with the same defect concentration at $77 \mathrm{~K}$. The larger fractional reduction at low temperatures is due to the fact that the umklapp scattering is much weaker at low temperatures and allows the point defect scattering to be the dominant scattering mechanism at lower phonon frequencies, thus scattering a larger fraction of the phonon spectrum. However at $400 \mathrm{~K}$ a $39 \%$ reduction in the thermal conductivity would result in a conductivity of approximately $16 \mathrm{~W} / \mathrm{m}-\mathrm{K}$, compared to an expected conductivity of $83 \mathrm{~W} / \mathrm{m}-\mathrm{K}$ after a $90 \%$ reduction in the conductivity at $77 \mathrm{~K}$. Thus even at defect concentrations as high as 0.01 per atom the thermal conductivity advantage gaincd by going to lower temperatures would be maintained. However, as pointed out in the next section, it may be that the thermal stability of point defects at $77 \mathrm{~K}$ versus $400 \mathrm{~K}$ is the deciding factor that determines which irradiation temperature has a higher thermal conductivity for a given fluence of vacancy producing radiation.

The maximum of the range of prompt RIC values in sapphire in a fusion environment is expected to be on the order of $10^{-5}(\Omega-m)^{-1}$. Using this value for the RIC the corresponding range for the fractional change in the thermal conductivity is from $0.05 \%$ to $0.2 \%$ at $77 \mathrm{~K}$. It was found $[1,3]$ that at $300 \mathrm{~K}$ the expected fractional change in the conductivity at this value of the RIC was about $0.01 \%$. Thus the effect of phonon-electron scattering on the thermal conductivity is larger at low temperatures but these are very small changes in the thermal conductivity and are not expected 


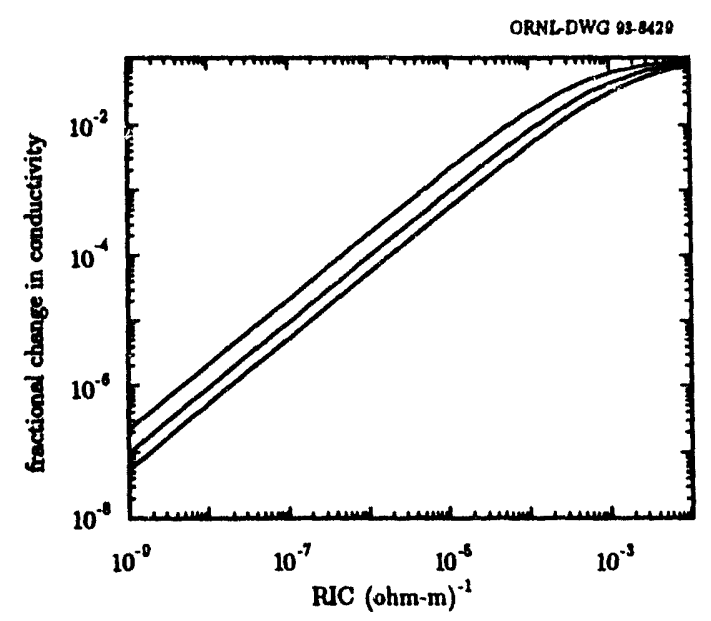

Figure 3: Fractional change in the lattice thermal conductivity versus RIC at $77 \mathrm{~K}$. Each curve corresponds to a different value of the electron mobility, covering the range of uncertainty in the mobility [13]. The upper curve corresponds to $\mu=2 \times 10^{-4} \mathrm{~m}^{2} / V-s$, the center curve to $\mu=3 \times 10^{-4} \mathrm{~m}^{2} / V-s$, and the lower curve to $\mu=$ $4 \times 10^{-4} \mathrm{~m}^{2} / V-s$.

to be of importance in the design of microwave windows. Even in the extreme case of very large values of the RIC $\left(10^{-2}(\Omega-m)^{-1}\right)$ the maximum effect the phoncin-electron interaction can have on the thermal conductivity is about $9 \%$, as pointed out in the previous section. It should also be noted that there is essentially no change in the thermal conductivity due to the smal' electronic component added by the RIC, as pointed out in Ref. [3].

\section{CONCLUSIONS AND FUTURE WORK}

The reduction in the thermal conductivity due to the scattering of phonons by vacancies is more pronounced at low temperatures than at high temperatures. It has been shown however that the thermal conductivity advantage gained by going to low temperature is maintained. However the vacancy concentration depends on the thermal stability of the vacancies. If many of the vacancies recombine at $400 \mathrm{~K}$ but are stable at $77 \mathrm{~K}$, then the low temperature thermal conductivity could be less than the $400 \mathrm{~K}$ thermal conduct vity for a given fluence of vacancy producing irradiation. The work of Rohde and Schulz [16] has shown that irradiation temperature has an important effect on the number of remaining stable defects in irradiated alumina. This effect has also been seen in $\mathrm{BeO}$, Pryor et.al. [17] compared the thermal resistance per fission neutron dose of samples irradiated at $348 \mathrm{~K}$ with samples irradiated at $90 \mathrm{~K}$ by McDonald [18]. The thermal resistance of the samples irradiated at low temperature was about 16 times larger than the resistance of the high temperature samples for a given neutron dose. This problem points to the need of performing in-situ cryogenic thermal conductivity tests or post irradiation thermal conductivity measurements on samples irradiated at cryogenic temperatures. An important consideration if post-irradiation measurements are to be performed is that there is evidence that significant annealing of defects may occur at room 


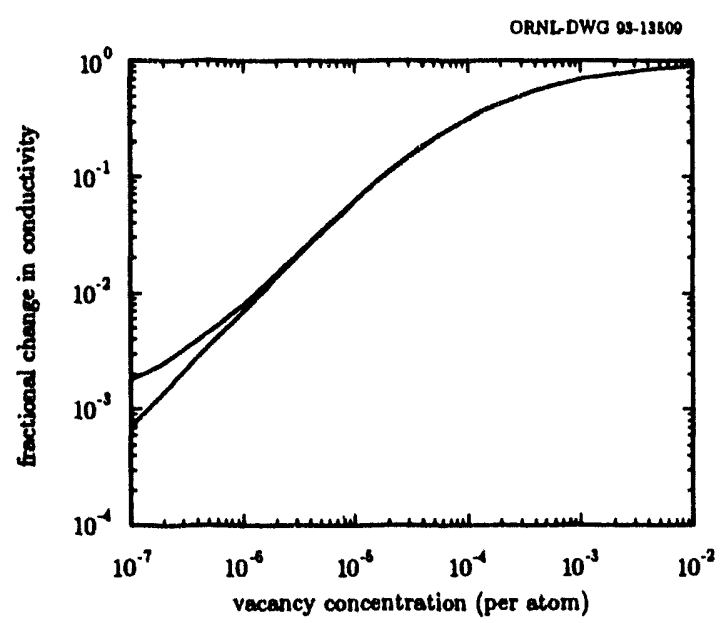

Figure 4: Fractional change in the thermal conductivity versus vacancy concentration at 77K. The upper curve corresponds to a RIC of $10^{-5}(\Omega-m)^{-1}$, and the lower curve corresponds to the case of no RIC.

temperature. This was seen by $\mathrm{McDonald}[18]$ in $\mathrm{BeO}$ which was irradiated at $95 \mathrm{~K}$, after a final anneal at $310 \mathrm{~K}$ approximately $25 \%$ of the radiation induced thermal resistance had recovered. Further evidence that significant room temperature annealing effects are important in ceramics is given by Coghlan et.al. [19] and Buckley et.al. [20]. Coghlan et.al. found that neutron irradiated spinel continued to swell after irradiation at room temperature, perhaps indicating cc itinuing diffusion and clustering of defects. Buckley et.al. found that the dielectric loss tangent of proton irradiated ceramics recovered significantly on the timescale of hours at room temperature. Thus, in order to rule out post-irradiation thermal effects on ceramics irradiated at low temperature it is important to maintain the samples at low temperature until the measurements are made.

It should also be noted that the flexibility of ECRH transmission systems will allow the windows to be located in low fluence positions, with the aim of maintaining the low temperature thermal conductivity advantage. However the magnitude of tolerable fluence levels must still be identified experimentally.

The changes in thermal conductivity due to phonon-electron scattering have been shown to be insignificant at the RIC levels expected in the fusion environment. These changes are particularly insignificant when the temperature dependence of the thermal conductivity at low temperatures is considered. In this low temperature region the thermal conductivity is strongly temperature dependent; for example, in the region around $77 \mathrm{~K}$ calculations show that a $1 \%$ change in the temperature leads to a $4 \%$ change in the thermal conductivity. Thus the effects of temperature fluctuations on the thermal conductivity are expected to be at least as important as any effects due to phonon-electron scattering. 
The small changes expected in the thermal conductivity due to phonon-electron scattering suggest that there is no need for in-situ cryogenic thermal conductivity measurements or post-irradiation measurements of samples held at low temperature in order to study this effect. However this does not rule out the need for performing these tests in order to study the effects of thermally unstable radiation produced defects.

\section{ACKNOWLEDGEMENTS}

This research was performed while the author was a participunt in the Oak Ridge National Laboratory Postdoctoral Research Associates Program, administered through the Oak Ridge Institute for Science and Education.

\section{REFERENCES}

1. D.P. White, Fusion Reactor Materials Semiann. Prog. Report DOE/ER-0313/11, (1991) 277.

2. D.P. White, Fusion Reactor Materials Semiann. Prog. Report DOE/ER-0313/12, (1992) 298.

3. D.P. White, J. Appl. Phys. 73 (1993) 2254.

4. D.P. White, Fusion Reactor Materials Semiann. Prog. Report DOE/ER-0313/13, (1992) 326.

5. D.P. White, Fusion Reactor Materials Semiann. Prog. Report DOE/ER-0313/14, (1993) 480.

6. G.R. Haste, H.D. Kimrey and J.D. Proisie, Report ORNL/TM-9906 (1986).

7. R. Heidinger, J. Nucl. Mater. 179-181 (1991) 64.

8. J. Callaway, Phys. Rev. 113 (1959) 1046.

9. A.M. de Goer, J. Phys. (Paris) 30 (1969) 389.

10. P.G. Klemens in: Solid State Physics, Vol. 7, Eds. F. Seitz and D. Turnbull (Academic Press, New York, 1958) p. 1.

11. C.A. Ratsifaritana in: Phonon Scattering in Condensed Matter, Ed. H.J. Maris (Plenum Press, New York, 1980) p. 259.

12. R.W. Klaffky, B.H. Rose, A.N. Goland and G.J. Dienes, Phys. Rev B 21 (1980) 3610.

13. R.C. Hughes, Phys. Rev. B 19 (1979) 5318.

14. R. Berman, E.L. Foster and H.M. Rosenberg in: Report of the Conf. on Defects in Crystalline Solids, Univ. of Bristol, 1954 (The Physical Society, London, 1955) p.321.

15. B. Salce and A.M. de Goer in: Proc. Conf. Digest of the Int. Conf. on Defects in Insulating Materials, Parma (1988) p.499.

16. M. Rohde and B. Schulz, J. Nucl. Mater. 173 (1990) 289.

17. A.W. Pryor, R.J. Tainsh and G.K. White, J. Nucl. Mater. 14 (1964) 208.

18. D.L. McDonald, Appl. Phys. Lett. 2 (1963) 175.

19. W.A. Coghlan, F.W. Clinard, Jr., N. Itoh and L.R. Greenwood, J. Nucl. Mater. 141-143 (1986) 382.

20. S.N. Buckley and P. Agnew, J. Nucl. Mater. 155-157 (1988) 361. 
MICROSTRUCTURE OF ION IRRADIATED CERAMIC INSULATORS .. S. J. Zinkle (Oak Ridge National Laboratory)

\section{OBJECTIVE}

The objective of this study is to summarize recent information that has been obtained at ORNL on the microstructure of ion irradiated ceramic insulators.

\section{SUMMARY}

Cross-section transmission electron microscopy was utilized to examine the radiation-induced microstructural changes in $\mathrm{Al}_{2} \mathrm{O}_{3}, \mathrm{MgO}, \mathrm{Si}_{3} \mathrm{~N}_{4}$ and $\mathrm{MgAl}_{2} \mathrm{O}_{4}$ after irradiation with a wide variety of energetic ion beams. The relative influence of ionizing and displacive radiation was studied by systematically varying the mass and energy of the bombarding ions between $1 \mathrm{MeV} \mathrm{H}^{+}$and $4 \mathrm{MeV} \mathrm{Zr}^{+}$ ions. The measured ion ranges were between 1 and $15 \%$ greater than the ranges calculated by the TRIM code, with the largest discrepancies occurring for intermediate mass ions. The implanted ions exerted a strong influence on the overall microstructural evolution of the irradiated ceramics. Numerous microstructural features (e.g., amorphization, colloids) were produced in the implanted ion regions which could not be produced in irradiated regions that were well separated from the implanted ions. The microstructural evolution in regions well separated from the implanted ions was found to depend strongly on the mass and energy of the bombarding ion. Light ion irradiation produced a significant enhancement in point defect diffusion (evidenced by defect-free zones at the surface and adjacent to internal defect sinks) compared to heavy ion irradiation at the same damage rate. Similarly, irradiation with a given ion at a higher flux generally produced an increased amount of observable diffusion. In some cases such as $1 \mathrm{MeV}$ proton irradiation, observable defect clusters did not form. This suppression in defect cluster formation is attributed to the high amount of point defect recombination associated with ionization enhanced diffusion that occurs during energetic light ion irradiation.

\section{PROGRESS AND STATUS}

\section{Introduction}

Analytical electron microscopy is a powerful tool for investigating the effects of irradiation on materials. ${ }^{1}$ Cross-section transmission electron microscope (TEM) investigations on ion irradiated specimens can provide a direct measurement of the ion and damage ranges, and can also provide quantitative microstructural information such as the presence of amorphous regions and the size, density and chemical nature of defect aggregates. One of the useful features associated with ion irradiations is the ability to systematically change the irradiation spectrum by appropriate selection of the ion mass and energy. Several studies have shown that the macroscopic properties of ceramics are sensitive to variations in the ionizing and displacive irradiation spectra. ${ }^{2-4}$ Unfortunately, there has been relatively little published information to date on the effect of irradiation spectrum on the microstructural evolution in ceramic insulators. ${ }^{5-8}$

The present paper reviews recent information $6-10$ obtained at Oak Ridge National Laboratory (ORNL) on the microstructure of ion-irradiated ceramics as determined by cross-section TEM. This paper will soncentrate on the microstructural response to ion irradiation of two oxide ceramics with predominantly ionic bonding, $\mathrm{Al}_{2} \mathrm{O}_{3}$ and $\mathrm{MgAl}_{2} \mathrm{O}_{4}$. A limited amount of results will also be summarized 
for ion irradiated $\mathrm{MgO}$ and $\mathrm{Si}_{3} \mathrm{~N}_{4}$. In all cases, the irradiated microstructure was observed to be strongly dependent on the irradiation spectrum (mass and energy of the irradiating ions). Ion energies greater than or equal to $1 \mathrm{MeV}$ were employed in these studies in order to allow the effects of displacement damage and implanted ions (chemical effects) to be separated. As discussed later (Section 4), it was generally observed that the microstructure of the irradiated regions was strongly affected by the implanted ions. Figure 1 shows the calculated ${ }^{11}$ depth-dependent displacement damage and implanted ion profiles for $\mathrm{MgAl}_{2} \mathrm{O}_{4}$ (spinel) irradiated with $2 \mathrm{MeV} \mathrm{Al}{ }^{+}$ions. From this figure, it can be anticipated that implanted ion effects would be maximized at irradiation depths between 1.0 and $1.6 \mu \mathrm{m}$, whereas displacement damage effects without the influence of implanted ions could be obtained at irradiation depths less than $1.0 \mu \mathrm{m}$. Analytical electron microscopy was used to experimentally verify the location of the implanted ions in the cross section specimens.

\section{Experimental Procedures}

Polycrystalline specimens of stoichiometric $\mathrm{MgAl}_{2} \mathrm{O}_{4}$ (Ceredyne, Inc.), $\mathrm{Al}_{2} \mathrm{O}_{3}$ (General Electric Lucalox or GTE Wesgo AL995), MgO (Ube Industries UMP) and $\mathrm{Si}_{3} \mathrm{~N}_{4}$ (Kyocera SN733) were used in the irradiation studies. The specimens were cut into dimensions of $3 \mathrm{~mm}$ diameter by $0.5 \mathrm{~mm}$ thickness, mechanically polished with $0.3 \mu \mathrm{m}$ diamond paste, and then irradiated in a $3 \times 3$ specimen array in the triple ion beam Van de Graaf accelerator facility at ORNL. 12 The results summarized in this paper will be confined to irradiation temperatures of 25 and $650^{\circ} \mathrm{C}\left(-0.15\right.$ and $0.4 \mathrm{TM}$, respectively for both $\mathrm{Al}_{2} \mathrm{O}_{3}$ and $\mathrm{MgAl}_{2} \mathrm{O}_{4}$ ). Different sets of ceramic specimens were irradiated with ions of varying mass and energy, ranging from $1 \mathrm{MeV} \mathrm{H}^{+}$to $4 \mathrm{MeV} \mathrm{Zr}^{+}$ions. Beam fluxes ranged from 0.2 to $60 \times 10^{16} \mathrm{ions} / \mathrm{m}^{2}-\mathrm{s}$, which produced midrange ionizing and displacement per atom (dpa) dose rates of 0.1 to $10 \mathrm{~Gy} / \mathrm{s}$ and $10^{-6}$ to $10^{-3}$ $\mathrm{dpa} / \mathrm{s}$, respectively. The TRIM-90 computer program 13 was used to calculate the ionizing and displacement damage doses. A sublattice-averaged threshold displacement energy of $40 \mathrm{eV}$ was used to

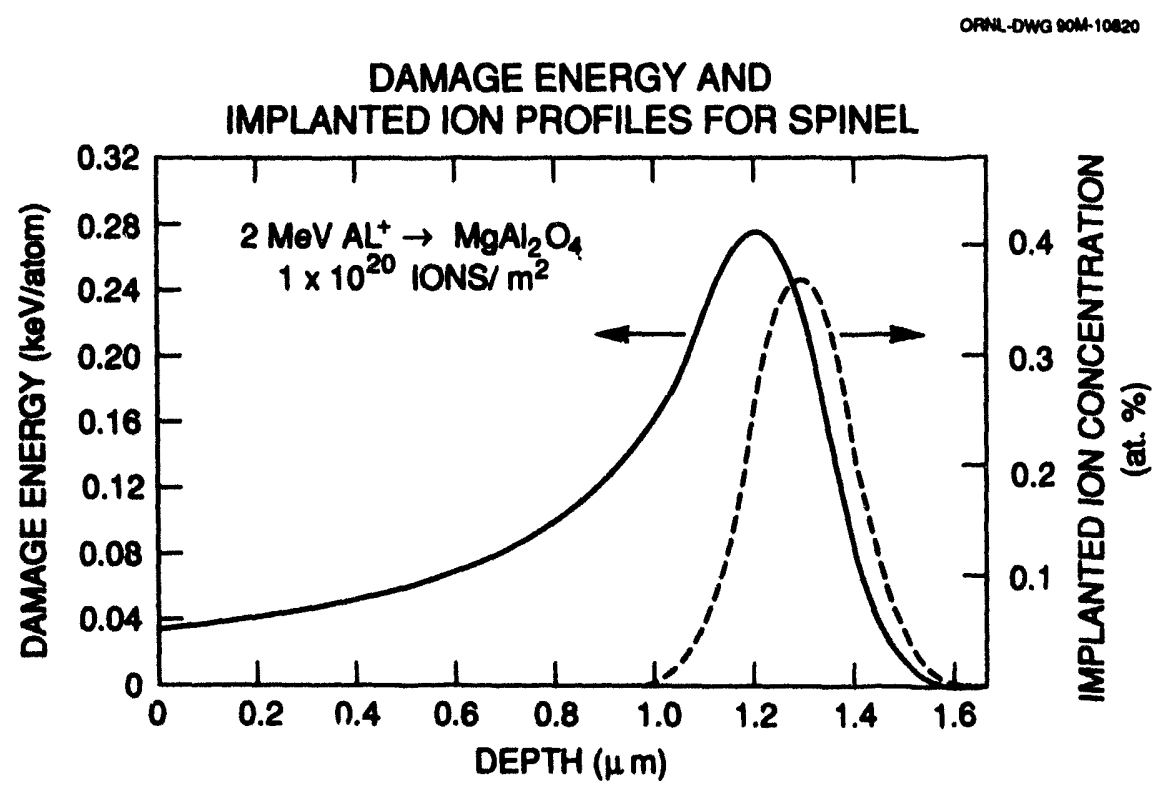

Fig. 1. Depth-dependent displacement damage energy density and implanted ion concentration for ion-irradiated spinel as determined from an EDEP-1 (ref. 11) calculation. 
convert the damage energies obtained from TRIM to the modified Kinchin-Pease dpa value. ${ }^{14}$ This value is intermediate between the measured ${ }^{15}$ threshold displacement energies of 24 and $78 \mathrm{eV}$ for the $\mathrm{Al}$ and $\mathrm{O}$ sublattices in $\mathrm{Al}_{2} \mathrm{O}_{3}$ which were used in the TRIM calculations. Further details of the irradiation conditions are given elsewhere. 7,9

Following irradiation, cross-section TEM specimens were prepared using standard techniques, ${ }^{16}$ which consisted of gluing the specimens face to face with a mechanically polished nonirradiated specimen, sectioning perpendicular to the irradiation surface, mechanical dimpling, and ion milling at room temperature or in a liquid nitrogen cooled stage $\left(6 \mathrm{kV} \mathrm{Ar}^{+}\right.$ions, $15^{\circ}$ sputtering angle) until perforation occurred at the glued interface. Most of the TEM analysis was performed using a Philips CM12 microscope operating at $120 \mathrm{kV}$. Some analysis was also performed using a Philips EM400T field emission gun microscope and a Philips CM30 microscope operating at 100 and $300 \mathrm{kV}$, respectively. Microchemical information was obtained using an EDAX 9100 or 9900 energy dispersive X-ray spectroscopy (EDS) system and a Gatan 666 parallel electron energy loss spectroscopy (PEELS) system mounted on the electron microscopes.

\section{Comparison of Experimental and Calculated lon Ranges in $\mathrm{Al}_{2} \mathrm{O}_{3}$}

The range of the implanted ions was experimentally measured in the irradiated cross-section TEM specimens by performing an EDS line scan that traversed the irradiation region [e.g., refs. 1,6]. The range of light ions such as $\mathrm{H}$ and $\mathrm{He}$ was deduced from the location of cavities which precipitated out in the implanted region. The measurements were generally made on specimens irradiated to fluences less than $5 \times 10^{20}$ ions $/ \mathrm{m}^{2}$ so that swelling associated with the irradiation and ion implantation was negligible. Table 1 compares the results of the mean ion ranges calculated by the TRIM program with the experimentally measured ion ranges in $\mathrm{Al}_{2} \mathrm{O}_{3}$. The agreement between the calculated and measured ion ranges is rather good for the light and heavy ions. The largest discrepancy between the calculated and measured values occurred for medium-light ions with incident energies between 75 and $250 \mathrm{keV}$ per atomic mass unit (amu), where the measured range was about 15\% larger than the calculated ion range. Similar discrepancies of this magnitude have been reported in numerous previous studies on ion-irradiated metals and ceramics. ${ }^{1}$ The electronic stopping cross-sections of heavy ions ( $\left.>4 \mathrm{amu}\right)$ for the energy interval between 25 and $200 \mathrm{keV} / \mathrm{amu}$ were determined by a complex bridging procedure between the more reliable low and high velocity regimes. ${ }^{17}$ Hence, the $15 \%$ discrepancy between the calculated and measured ion ranges for the medium-weight $\mathrm{MeV}$ ions is most likely attributable to errors in the elestronic stopping powers used in the TRIM calculations.

\section{Microstructural Effects Associated with Implanted Ions}

The depth-dependent microstructure observed in the irradiated cross-section ceramic specimens generally showed an abrupt transition near the implanted ion region. Comparison between specimens irradiated with the same ion species at different fluences ${ }^{7}$ and fluxes ${ }^{9}$ indicated that this difference in microstructure could not be attributable to differences in the total accumulated displacement damage or damage rate. Figure 2 shows an example of metallic aluminum precipitate (colloid) formation which occurred in the inuplanted ion region of $\mathrm{MgAl}_{2} \mathrm{O}_{4}$ following irradiation with $2 \mathrm{MeV} \mathrm{Al}{ }^{+}$ions to a fluence of $5.1 \times 10^{20} \mathrm{ions} / \mathrm{m}^{2}$ (ref. 18). The colloid formation was restricted to the $\mathrm{Al}^{+}$ion implanted region, and the colloids grew and coarsened with increasing fluence. ${ }^{18}$ Colloid formation was not observed in the irradiated regions outside of the implanted ion region even for fluences more than 7 times higher than shown in Fig. 2. Colloid formation has also been observed in the ion implanted regions of spinel irradiated with numerous other ions, including $\mathrm{Mg}$ and $\mathrm{Fe}$. 
Table 1. Comparison of Calculated ${ }^{13}$ and Observed Ion Ranges in $\mathrm{Al}_{2} \mathrm{O}_{3}$

\begin{tabular}{|c|c|c|c|c|}
\hline \multirow[b]{2}{*}{ Ion Beam } & \multirow[b]{2}{*}{$\begin{array}{c}\text { Energy Per } \\
\text { Nucleon } \\
\text { (keV/amu) }\end{array}$} & \multicolumn{3}{|c|}{ Mean Projected Range $(\mu \mathrm{m})$} \\
\hline & & Calculated & Measured & $\frac{\text { measured }}{\text { calculated }}$ range \\
\hline $1 \mathrm{MeV} \mathrm{H}^{+}$ & 1000 & 8.67 & 9.25 & 1.07 \\
\hline $1 \mathrm{MeV} \mathrm{He}+$ & 250 & 1.98 & 2.30 & 1.16 \\
\hline $3 \mathrm{MeV} \mathrm{C}^{+}$ & 250 & 1.82 & 2.02 & 1.11 \\
\hline $2.4 \mathrm{MeV} \mathrm{Mg}^{+}$ & 100 & 1.42 & 1.63 & 1.15 \\
\hline $2 \mathrm{MeV} \mathrm{Al}^{+}$ & 74 & 1.24 & 1.42 & 1.15 \\
\hline $4 \mathrm{MeV} \mathrm{Ar}^{+}$ & 100 & 1.36 & 1.56 & 1.15 \\
\hline $3.6 \mathrm{MeV} \mathrm{Fe}++$ & 64 & 1.36 & 1.43 & 1.05 \\
\hline $4 \mathrm{MeV} \mathrm{Zr}^{3+}$ & 44 & 1.24 & 1.25 & 1.01 \\
\hline $200 \mathrm{keV}^{3} \mathrm{He}^{+}$ & 66 & 0.57 & 0.58 & 1.01 \\
\hline
\end{tabular}

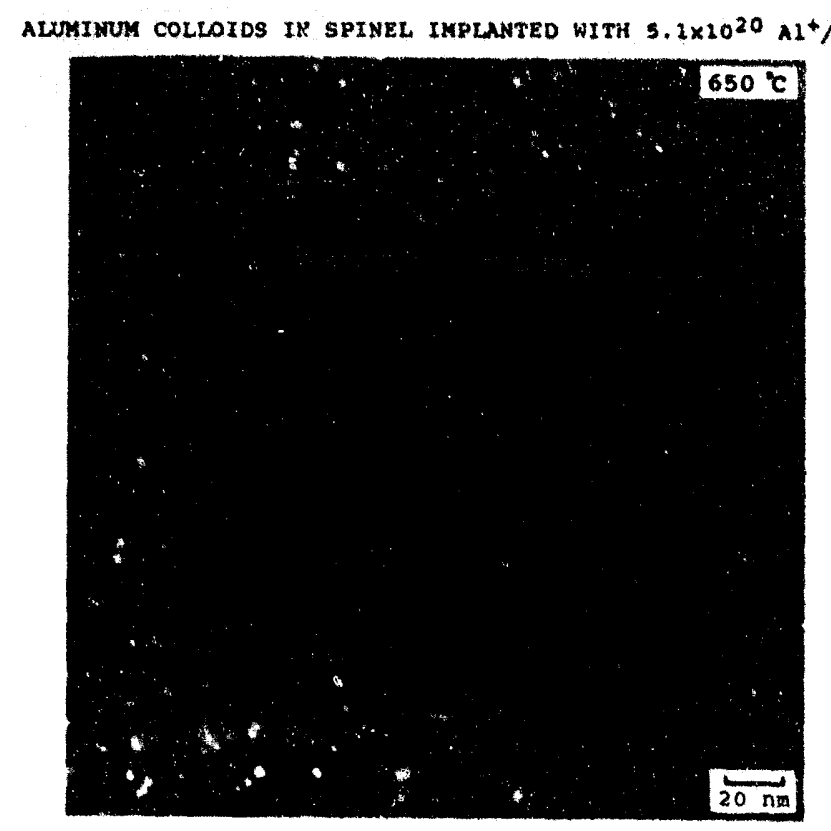

Fig. 2. Aluminum metal colloids produced in the ion-implanted region of $\mathrm{MgAl}_{2} \mathrm{O}_{4}$ after irradiation with $2 \mathrm{MeV} \mathrm{Al}{ }^{+}$ions to a fluence of $5.1 \times 10^{20}$ ions $/ \mathrm{m}^{2}$ at $650^{\circ} \mathrm{C}$ (centered dark field image using the 222 spinel lattice reflection). The maximum implanted $\mathrm{Al}$ concentration was about 2 at. \%. 
A second phenomenon associated with implanted ions is amorphization. Previous studies employing lower energy ions $(-200 \mathrm{keV})$ have noted that chemical effects associated with the implanted ions can be very effective for inducing amorphization in ceramics such as $\mathrm{Al}_{2} \mathrm{O}_{3}$ during room temperature irradiation. ${ }^{19}$ Almost all of the amorphization data obtained on irradiated ceramics to date has been obtained using ion energies $<200 \mathrm{keV}$, and hence the implanted ion region completely overlaps the irradiation region. Figure 3 shows the cross-section microstructure of $\mathrm{Si}_{3} \mathrm{~N}_{4}$ that was irradiated near room temperature with $3.6 \mathrm{MeV} \mathrm{Fe}+$ ions to a fluence of $1.1 \times 10^{20}$ ions $/ \mathrm{m}^{2}$. An amorphous band about $0.4 \mu \mathrm{m}$ wide was formed in the Fe-implanted region. According to published data using low energy ions, ${ }^{20} \mathrm{Si}_{3} \mathrm{~N}_{4}$ can be amorphized during room temperature irradiation for damage energy densities as low as 0.05 $\mathrm{keV} /$ atom ( $-0.5 \mathrm{dpa}$, assuming a displacement energy of $40 \mathrm{eV})$. However, the $\mathrm{Si}_{3} \mathrm{~N}_{4}$ specimen shown in Fig. 3 remained crystalline in the damaged regions outside of the implanted ion region for damage energy densities in excess of $0.7 \mathrm{keV} / \mathrm{atom}$. In this case, the amorphization of $\mathrm{Si}_{3} \mathrm{~N}_{4}$ can be directly linked to the presence of the implanted $\mathrm{Fe}$ atoms, which stabilize the displacement damage in a form that favors the formation of an amorphous phase.

Figure 4 shows an example of the dislocation microstructure that was formed near the implanted ion region in $\mathrm{MgAl}_{2} \mathrm{O}_{4}$ following irradiation with $2.4 \mathrm{MeV} \mathrm{Mg}+$ ions. The irradiated regions far from the implanted ion region contained a moderate density of dislocation loops, with no network dislocations. In contrast, the implanted ion region contained a mivderate density of small precipitates (not shown in Fig. 4) and tangled network dislocations, with very few dislocation loops. Similar pronounced microstructural differences attributable to implanted ion effects were observed in $\mathrm{MgAl}_{2} \mathrm{O}_{4}$ specimens irradiated with $\mathrm{Al}^{+}$,

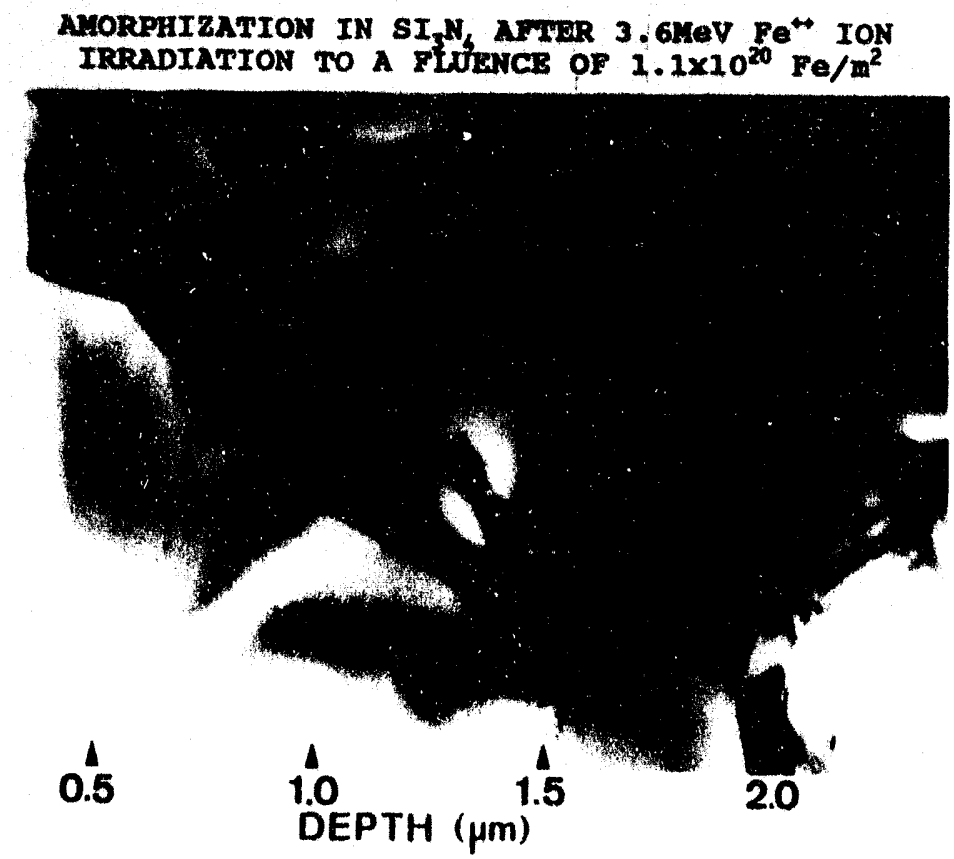

Fig. 3. Amorphous band produced in the ion-implanted region of $\mathrm{Si}_{3} \mathrm{~N}_{4}$ during irradiation with 3.6 $\mathrm{MeV} \mathrm{Fe}{ }^{++}$ions to a fluence of $1.1 \times 10^{20} \mathrm{ions} / \mathrm{m}^{2}$ at room temperature. The maximum damage level and implanted ion concentration in the ion-implanted region was about $10 \mathrm{dpa}$ and 0.4 at. \%, respectively. 


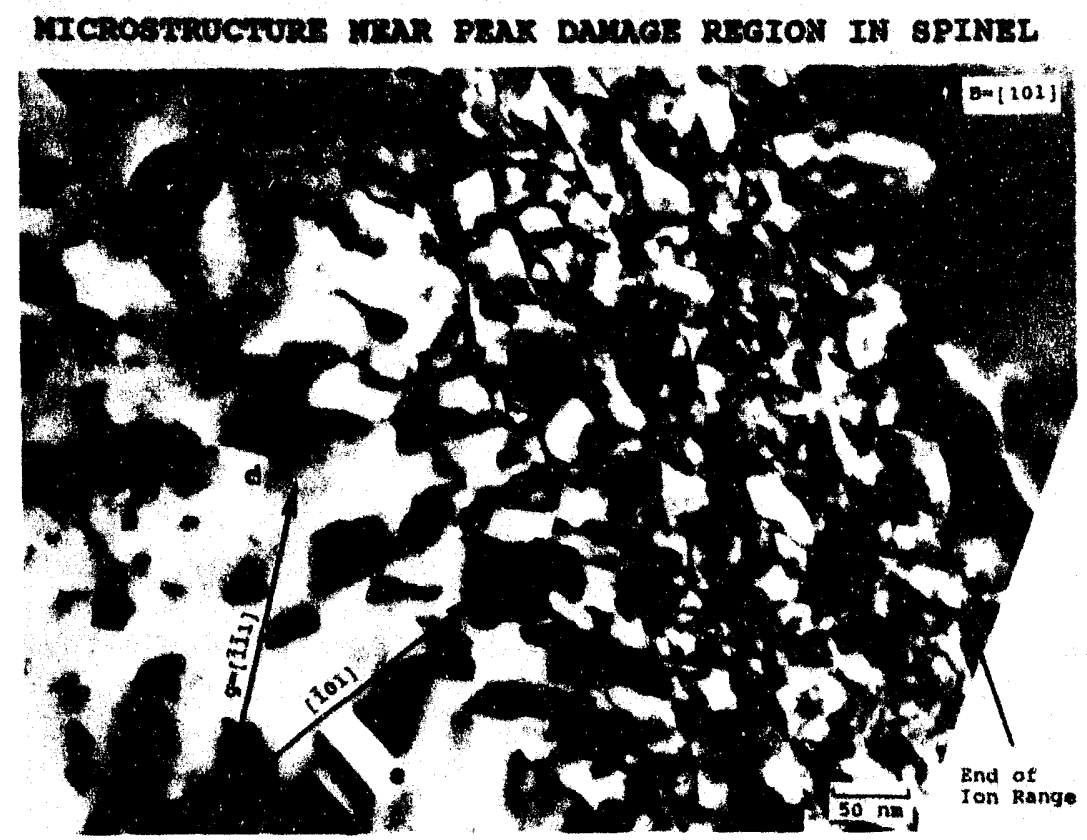

Fig. 4. Dislocation microstructure observed near the ion-implanted region of $\mathrm{MgAl}_{2} \mathrm{O}_{4}$ after irradiation with $2.4 \mathrm{MeV} \mathrm{Mg}+$ ions to a fluence of $1.4 \times 10^{21}$ ions $/ \mathrm{m}^{2}$ at $650^{\circ} \mathrm{C}$. The irradiation flux was about $1.5 \times 10^{17}$ ions $/ \mathrm{m}^{2}-\mathrm{s}$. The maximum damage level and implanted ion concentration in the ionimplanted region was about $40 \mathrm{dpa}$ and 5 at. \%, respectively.

$\mathrm{Ar}^{+}, \mathrm{Fe}^{+}$, and $\mathrm{Zr}^{+}$ions. The microstructure of $\mathrm{Al}_{2} \mathrm{O}_{3}$ was somewhat less sensitive than $\mathrm{MgAl}_{2} \mathrm{O}_{4}$ to implanted ion effects. However, it appears that the microstructures in both cases are affected by implanted ions even when the bombarding species is chemically inert, such as $\mathrm{He}^{+}$and $\mathrm{Ar}^{+}$ions.

Effect of Irradiation Spectrum on Microstructural Evolution

$\mathrm{MgAl}_{2} \mathrm{O}_{4}$

Figure 5 shows the cross-section microstructure of spinel irradiated with $3.6 \mathrm{MeV} \mathrm{Fe}$ ions to a peak damage level of $10 \mathrm{dpa}$ at $650^{\circ} \mathrm{C}$. The dominant microstructural feature observed in the irradiated region is a moderate to high density of interstitial dislocation loops. The microstructure produced by this ion irradiation condition is qualitatively similar to the microstructure reported for spinel irradiated with fission neutrons at comparable temperatures and damage levels. $5,21,22$ The density of loops formed in the $\mathrm{Fe}^{+}$ion irradiated material was somewhat higher than for neutron irradiated spinel (and the loop size was smaller), which is expected since the damage rate for the ion irradiated specimens was more than two orders of magnitude higher than the fission neutron cases. The midrange microstructure of spinel irradiated with 4 $\mathrm{MeV} \mathrm{Zr}^{+}$ions was found to be similar to the $\mathrm{Fe}^{+}$irradiated specimens (both irradiated at damage rates $\left.10^{-4} \mathrm{dpa} / \mathrm{s}\right)$. 


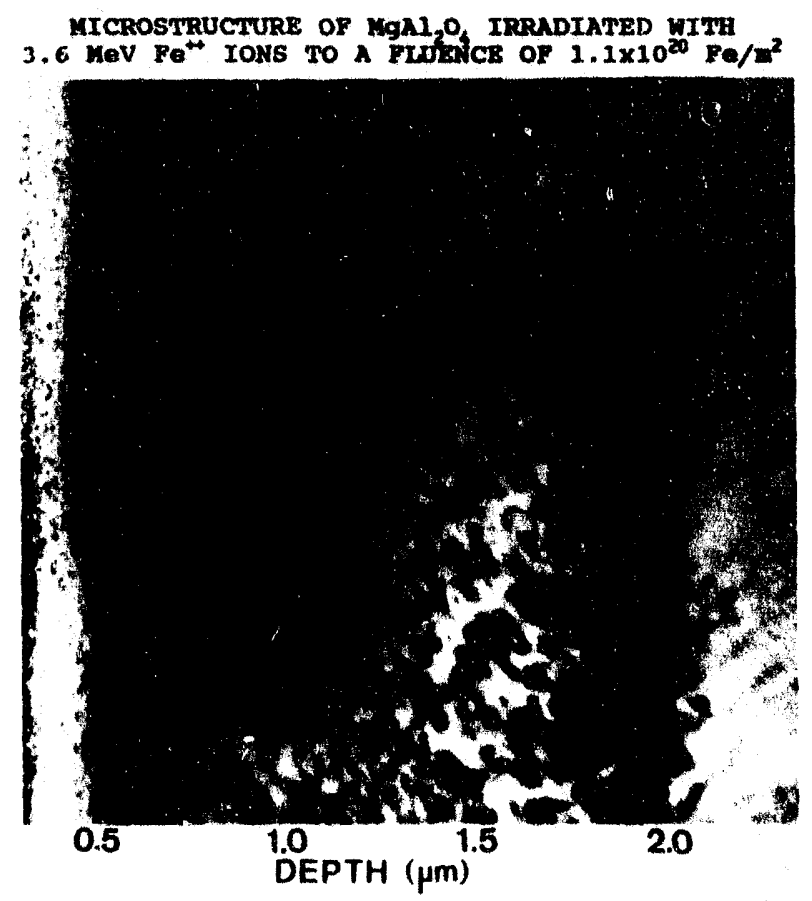

Fig. 5. Depth-dependent microstructure of $\mathrm{MgAl}_{2} \mathrm{O}_{4}$ irradiated with $3.6 \mathrm{MeV} \mathrm{Fe}$ ions to a fluence of $1.1 \times 10^{20}$ ions $/ \mathrm{m}^{2}$ at $650^{\circ} \mathrm{C}$. The irradiation flux was about $5 \times 10^{15} \mathrm{Fe} / \mathrm{m}^{2}$-s. The maximum damage level and implanted ion concentration in the ion-implanted region was about $10 \mathrm{dpa}$ and 0.4 at. \%, respectively.

Figure 6 shows the cross-section microstructure of spinel irradiated with $2 \mathrm{MeV} \mathrm{Al}{ }^{+}$ions to a peak damage level of $14 \mathrm{dpa}$ at $650^{\circ} \mathrm{C} .^{7} \mathrm{~A}$ defect-free region was present for depths up to $0.4 \mu \mathrm{m}$ from the surface. The microstructure at intermediate depths was similar to the $\mathrm{Fe}^{+}$ion irradiation case, consisting of prismatic interstitial dislocation loops lying on $[111\}$ and $[110)$ habit planes with Burgers vectors predominantly of the type $a / 4<110>$ (ref. 7 ). The microstructure in the implanted Al region (1.3 to 1.8 $\mu \mathrm{m})$ contained a mixture of small colloids and network dislocations. Irradiation with $2 \mathrm{MeV} \mathrm{Al}^{+}$ions to seven times higher fluence than Fig. 6 resulted in a very similar depth-dependent microstructure--defect cluster formation was not observed within $0.4 \mu \mathrm{m}$ of the irradiated surface even though this region was subjected to a displacement damage dose in excess of $20 \mathrm{dpa}^{7}$

The defect-free region was observed not only at the irradiated surface, but also adjacent to internal point defect sinks such as grain boundaries 7,23 and sintering pores. These observations demonstrate that the microstructural dependence on irradiation spectrum is a bulk effect, as opposed to an irradiated surface effect. Figure 7 shows an example of a depth-dependent defect-free region adjacent to a grain boundary in spinel irradiated with $2 \mathrm{MeV} \mathrm{Al}{ }^{+}$ions at $650^{\circ} \mathrm{C} .^{7}$ The width of the defect-free zone adjacent to the grain boundary decreased with increasing depth. Possible causes for this depth-dependent behavior will be discussed in Section 5.3.

Irradiation of spinel with lower mass energetic ions produced progressively wider defect-free regions near the irradiated surface. Figure 8 shows the microstructure of spinel irradiated with $1 \mathrm{MeV} \mathrm{He}$ ions at $650^{\circ} \mathrm{C}$. There was no observable defect cluster formation for irradiated depths up to $2 \mu \mathrm{m}$, despite displacement damage levels in excess of $0.1 \mathrm{dpa}$ in this region. Examination of $\mathrm{MgAl}_{2} \mathrm{O}_{4}$ specimens irradiated to an order of magnitude higher fluence produced similar results. ${ }^{8}$ Defect clusters were also not observed in spinel irradiated with $3 \mathrm{MeV} \mathrm{C}^{+}$or $1 \mathrm{MeV} \mathrm{H}^{+}$at $650^{\circ} \mathrm{C}$ except in the implanted ion region. 8 ,9 


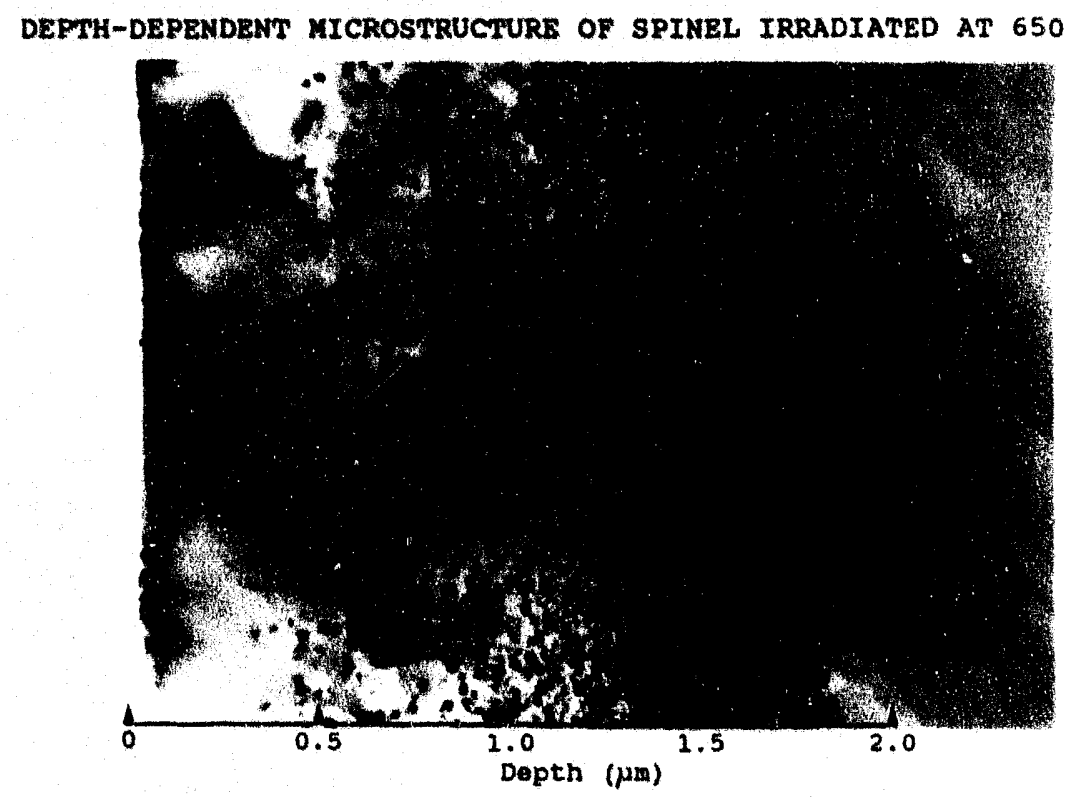

Fig. 6. Depth-dependent microstructure of $\mathrm{MgAl}_{2} \mathrm{O}_{4}$ irradiated with $2 \mathrm{MeV} \mathrm{Al}^{+}$ions to a fluence of $5 \times 10^{20}$ ions $/ \mathrm{m}^{2}$ at $650^{\circ} \mathrm{C}$. The irradiation flux was about $1.1 \times 10^{17} \mathrm{ions} / \mathrm{m}^{2}-\mathrm{s}$. The maximum damage level and implanted ion concentration in the ion-implanted region was about 14 dpa and 2 at. \%, respectively.

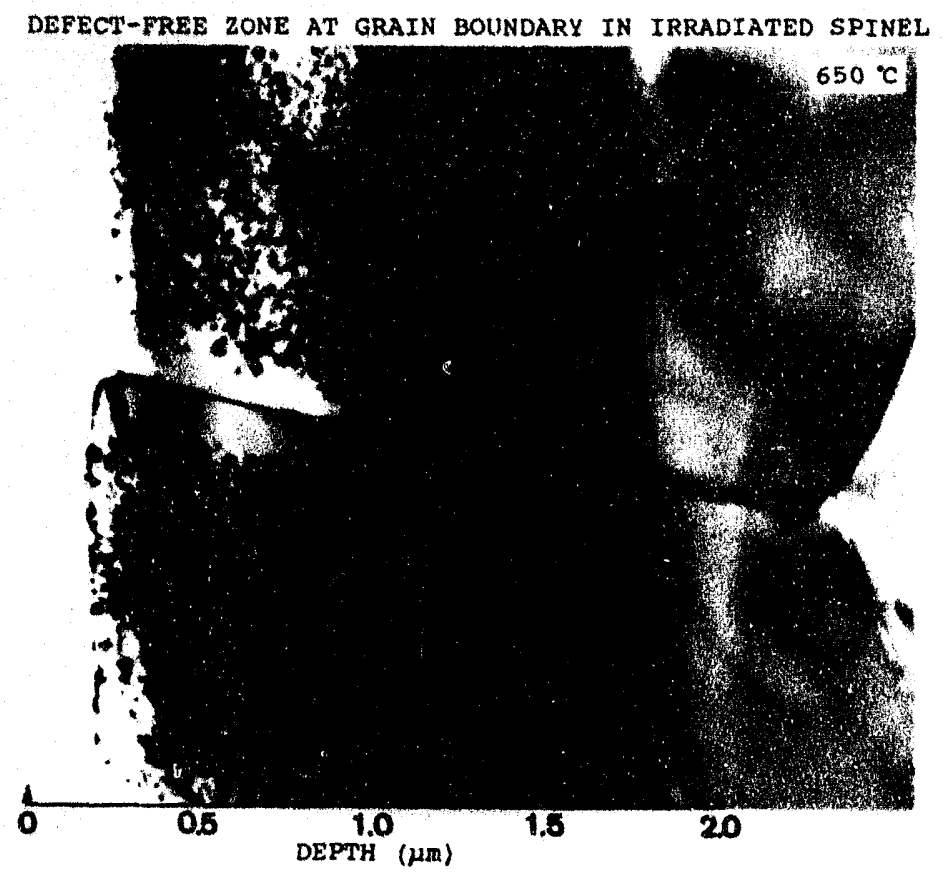

Fig. 7. Depth-dependent microstructure of $\mathrm{MgAl}_{2} \mathrm{O}_{4}$ in the vicinity of a grain boundary following irradiation with $2 \mathrm{MeV} \mathrm{Al}+$ ions to a fluence of $5 \times 10^{20} \mathrm{ions} / \mathrm{m}^{2}$ at $650^{\circ} \mathrm{C}$. The irradiation flux was about $1.1 \times 10^{17} \mathrm{icns} / \mathrm{m}^{2}-\mathrm{s}$ and the maximum damage level was about $14 \mathrm{dpa}$. 


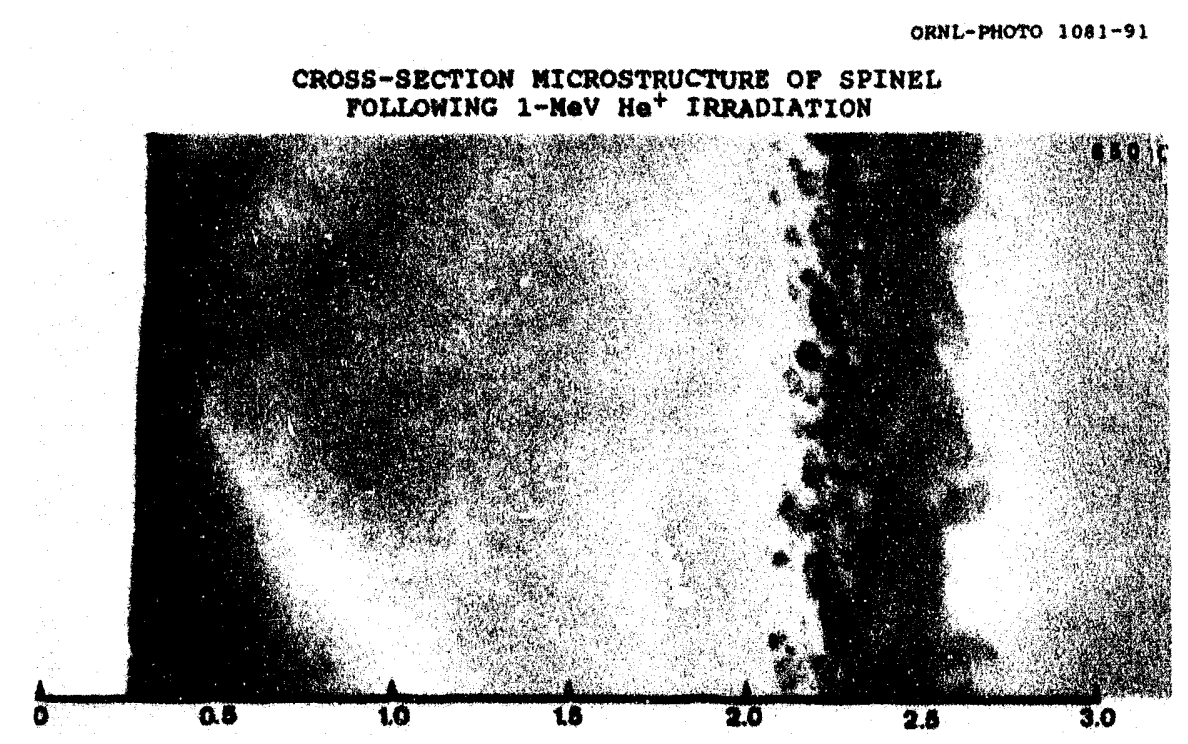

Fig. 8. Depth-dependent microstructure of $\mathrm{MgAl}_{2} \mathrm{O}_{4}$ irradiated with $1 \mathrm{MeV} \mathrm{He}{ }^{+}$ions to a fluence of $1 \times 10^{21}$ ions $/ \mathrm{m}^{2}$ at $650^{\circ} \mathrm{C}$. The irradiation flux was about $4 \times 10^{16} \mathrm{ions} / \mathrm{m}^{2}$-s. The maximum damage level and implanted ion concentration in the ion-implanted region was about $2.1 \mathrm{dpa}$ and 5 at. \%, respectively.

Low fluence irradiation experiments on spinel irradiated with heavy ions such as $\mathrm{Ar}, \mathrm{Fe}$ and $\mathrm{Zr}$ indicated that the threshold dose for producing observable defect clusters in $\mathrm{MgAl}_{2} \mathrm{O}_{4}$ was about 0.1 dpa at $650^{\circ} \mathrm{C} .^{9}$ The near-surface damage levels achieved in the light ion irradiation experiments performed on spinel were generally in excess of $1 \mathrm{dpa}$, without any observable defect cluster formation. This indicates that dislocation loop formation is strongly suppressed by some mechanism during irradiation with energetic light ions. Defect-free regions were also observed near the irradiation surface in spinel irradiated with light ions at room temperature. In some cases, a very low density of large dislocation loops were observed in the nominally "defect-free" region adjacent to the surface. This suggests that the absence of observable defect clusters is due to difficulties in dislocation loop nucleation, as opposed to a reduction in defect production.

\section{$\mathrm{Al}_{2} \mathrm{O}_{3}$}

Aluminum oxide was less sensitive than spinel to variations in the irradiation spectrum (mass and energy of bombarding ion). The microstructure of $\mathrm{Al}_{2} \mathrm{O}_{3}$ irradiated with ions more massive than $\mathrm{He}$ showed very little dependence on depth or irradiation temperature between 25 and $650^{\circ} \mathrm{C}(0.15$ to $0.4 \mathrm{TM})$. The dominant microstructural feature was a very high density of small dislocation loops lying on the basal and prism habit planes. 7,23 Figure 9 shows the depth-dependent microstructure of alumina irradiated with $1 \mathrm{MeV} \mathrm{He}{ }^{+}$ions at $650^{\circ} \mathrm{C}$. Dislocation loops were observed throughout the irradiated region, in contrast to the defect-free microstructure observed in spinel irradiated under the same conditions (Fig. 8). However, 


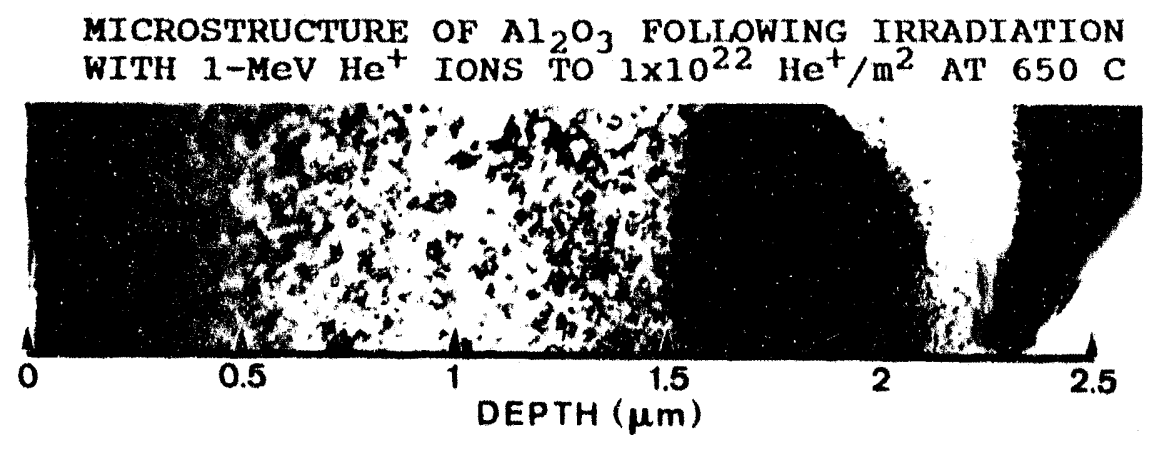

Fig. 9. Depth-dependent microstructure of $\mathrm{Al}_{2} \mathrm{O}_{3}$ irradiated with $1 \mathrm{MeV} \mathrm{He}+$ ions to a fluence of $1 \times 10^{22}$ ions $/ \mathrm{m}^{2}$ at $650^{\circ} \mathrm{C}$. The irradiation flux was about $4 \times 10^{17} \mathrm{ions} / \mathrm{m}^{2}$-s. The maximum damage level and implanted ion concentration in the ion-implanted region was about 21 dpa and 50 at. $\%$, respectively.

the size of the loops was somewhat larger and the loop density was reduced in the $1 \mathrm{MeV} \mathrm{He}^{+}$ion irradiated $\mathrm{Al}_{2} \mathrm{O}_{3}$ specimen compared to $\mathrm{Al}_{2} \mathrm{O}_{3}$ irradiated with heavier ions at the same temperature and damage rate. ${ }^{7-9}$

Dislocation loop formation was dramatically reduced in $\mathrm{Al}_{2} \mathrm{O}_{3}$ irradiated with $1 \mathrm{MeV}$ protons. As shown in Fig. 10, observable defect cluster formation did not occur in $\mathrm{Al}_{2} \mathrm{O}_{3}$ irradiated with a high flux of $1 \mathrm{MeV} \mathrm{H}^{+}$ions except in the vicinity of the implanted ion region. The displacement damage level in the defect-free region varied between 0.1 and $0.3 \mathrm{dpa}$. This damage level is in excess of the threshold dose to form observable defect clusters in $\mathrm{Al}_{2} \mathrm{O}_{3}$, which was experimentally determined from low fluence studies performed with heavier ions such as $\mathrm{He}$ and $\mathrm{Ar}$ to be $<0.05 \mathrm{dpa}$ at $650^{\circ} \mathrm{C} .^{9}$

\section{Possible Physical Causes Of The Irradiation Spectrum Effect}

The absence of observable dislocation loops in the spinel and alumina specimens irradiated with energetic light ions is somewhat difficult to rationalize from a displacement damage perspective. The fact that dislocation loops were not observed in the near surface region in $\mathrm{MgAl}_{2} \mathrm{O}_{4}$ irradiated with $2 \mathrm{MeV} \mathrm{Al}^{+}$ ions to damage levels in excess of $25 \mathrm{dpa}^{7}$ suggests that the defect free region is not simply due to a shift in the threshold dose to form observable defect clusters during light ion irradiation. Instead, some feature associated with light ion irradiation appears to effectively suppress dislocation loop nucleation. Table 2 summarizes the widths of the defect-free regions observed adjacent to the surface in $\mathrm{MgAl}_{2} \mathrm{O}_{4}$ irradiated with ions of different masses. The denuded zone width generally increased with decreasing mass of the bombarding ion, until defect clusters were only observed in the implanted ion regions of the irradiated specimens.

The mean energy of the primary knock on atoms (PKAs) created by collisions between the incident ion and lattice atoms is lower for light ions compared to heavy ion and neutron irradiations. Hence, one might speculate that the lack of dislocation loops in the light ion irradiated specimens might be associated with a threshold PKA energy for nucleating defect clusters in the displacement cascade. However, the mean PKA energy for a given ion is highest near the surface of the irradiated specimen, since this corresponds to the maximum incident ion energy. Therefore, the preferential absence of observable defect clusters in the near-surface regions of the light ion irradiated specimens (and the depth dependence of 


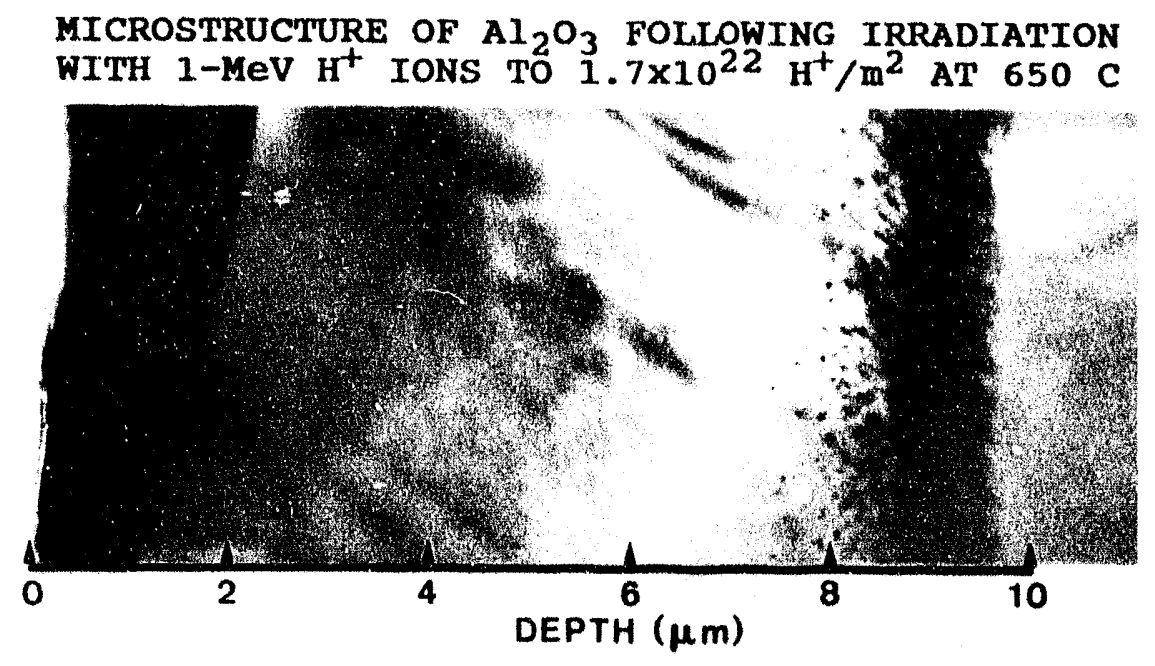

Fig. 10. Depth-dependent microstructure of $\mathrm{Al}_{2} \mathrm{O}_{3}$ irradiated with $1 \mathrm{MeV} \mathrm{H}{ }^{+}$ions to a fluence of $1.7 \times 10^{22}$ ions $/ \mathrm{m}^{2}$ at $650^{\circ} \mathrm{C}$. The irradiation flux was about $6 \times 10^{17} \mathrm{ions} / \mathrm{m}^{2}$-s. The maximum damage level and implanted ion concentration in the ion-implanted region was about 3 dpa and 60 at. \%, respectively.

Table 2. Width of Defect-Free Regions Near the Surface of Ion-Irradiated $\mathrm{MgAl}_{2} \mathrm{O}_{4}$ $\left(650^{\circ} \mathrm{C}, 10^{-6}\right.$ to $18 \mathrm{dpa} / \mathrm{s}, 10^{5}$ to $\left.10^{7} \mathrm{~Gy} / \mathrm{s}\right)$. The calculated ${ }^{13}$ ratio $f$ the electronic to nuclear stopping power at the den $\mathrm{d}$ zone boundary is also shown.

\begin{tabular}{|l|c|c|}
\hline Ion & Denuded Zone Width & $\begin{array}{c}\text { Calculated Se/Sn at } \\
\text { Denuded Zone Boundary }\end{array}$ \\
\hline $3.6 \mathrm{MeV} \mathrm{Fe}^{++}$ & $0.45 \mu \mathrm{m}$ & 7 \\
$4 \mathrm{MeV} \mathrm{Ar}^{+}$ & $0.1 \mu \mathrm{m}$ & 30 \\
$2 \mathrm{MeV} \mathrm{Al}^{+}$ & $0.4 \mu \mathrm{m}$ & 15 \\
$2.4 \mathrm{MeV} \mathrm{Mg}^{+}$ & $0.8 \mu \mathrm{m}$ & 10 \\
$3 \mathrm{MeV} \mathrm{C}^{+}$ & $1.9 \mu \mathrm{m}$ & $\sim 10$ \\
$1 \mathrm{MeV} \mathrm{He}^{+}$ & $2.1 \mu \mathrm{m}$ & $\sim 10$ \\
$1 \mathrm{MeV} \mathrm{H}^{+}$ & $10 \mu \mathrm{m}$ & $\sim 10$ \\
& & \\
\hline
\end{tabular}

denuded zones adjacent to grain boundaries, Fig. 7) cannot be directly attributable to PKA spectrum effects. Kinoshita and coworkers $5,24,25$ have shown that direct in-cascade formation of observable defect clusters is very difficult in ceramics such as $\mathrm{MgO}, \mathrm{Al}_{2} \mathrm{O}_{3}$ and $\mathrm{MgAl}_{2} \mathrm{O}_{4}$. Their studies indicated that dislocation loop nucleation in these ceramics occurred via simple point defect accumulation. 
A more likely explanation for the suppression in dislocation loop formation in the light ion irradiated ceramics is the low nuclear stopping power of light ions. The calculated ${ }^{13}$ energy transferred to recoil atoms per unit depth in $\mathrm{Al}_{2} \mathrm{O}_{3}$ is about $300 \mathrm{eV} / \mathrm{nm}$ for $3.6 \mathrm{MeV} \mathrm{Fe}$ ions versus about $0.04 \mathrm{eV} / \mathrm{nm}$ for $1 \mathrm{MeV} \mathrm{H}^{+}$ions. Therefore, heavy ion irradiation produces a relatively dense spatial concentration of displacement damage which is favorable for inducing the nucleation of dislocation loops. Since the nuclear stopping power increases as the incident ions begin to slow down, dislocation loop nucleation should become increasingly favorable with increasing depth. This mechanism is therefore in accordance with the defect free region being mainly observed at the specimen surface. However, it is not possible to define a unique critical value of the nuclear stopping power that can describe the width of the defect free zones observed for the various ion irradiation conditions (Table 2). For example, dislocation loops were not observed in the near-surface regions of $\mathrm{MgAl}_{2} \mathrm{O}_{4}$ irradiated with $\mathrm{He}, \mathrm{C}, \mathrm{Mg}$ and $\mathrm{Al}$ ions even for nuclear stopping powers in excess of $50 \mathrm{eV} / \mathrm{nm}$. On the other hand, dislocation loops were observed near the end of range in $1 \mathrm{MeV}$ proton irradiated $\mathrm{MgAl}_{2} \mathrm{O}_{4}$, which has a maximum nuclear stopping power of $\sim 1$ $\mathrm{eV} / \mathrm{nm}$. Of course, it is possible that the loop formation near the end of range of the proton irradiated specimens was assisted by implanted ion effects. Nevertheless, the widths of the denuded zones observed near the surface of $\mathrm{MgAl}_{2} \mathrm{O}_{4}$ specimens irradiated with $\mathrm{Fe}, \mathrm{Al}, \mathrm{Mg}, \mathrm{C}$ and $\mathrm{He}$ ions cannot be directly correlated with the respective depth-dependent nuclear stopping powers.

Consideration of ionizing radiation effects associated with the light ion irradiations yields another likely explanation for the absence of observable defect clusters. There is considerable evidence that ionizing radiation can enhance the diffusivities of point defects in ceramic insulators. ${ }^{26-28}$ This ionization-enhanced diffusion (IED) could promote the recombination of vacancies and interstitials, and thereby reduce the supersaturation of point defects to a level where dislocation loop nucleation would not occur to any significant extent. Several authors have derived the point defect profiles in the presence of a onedimensional sink. ${ }^{7,29,30}$ A schematic drawing of the variation of the interstitial concentration in the vicinity of a sink is shown in Fig. 11. Dislocation loop nucleation is suppressed in the region adjacent to the defect sink due to the low interstitial supersaturation. The quantitative width of the defect-free zone depends on the relative importance of interstitial annihilation at sinks versus matrix recombination with vacancies, and also on experimental variables such as the damage rate and interstitial diffusivity. ${ }^{7}$ Comparison of the experimental defect-free zone widths at grain boundaries and at the surface with the theoretical expressions indicates that the point defect diffusivities must be very high during energetic light ion irradiation.

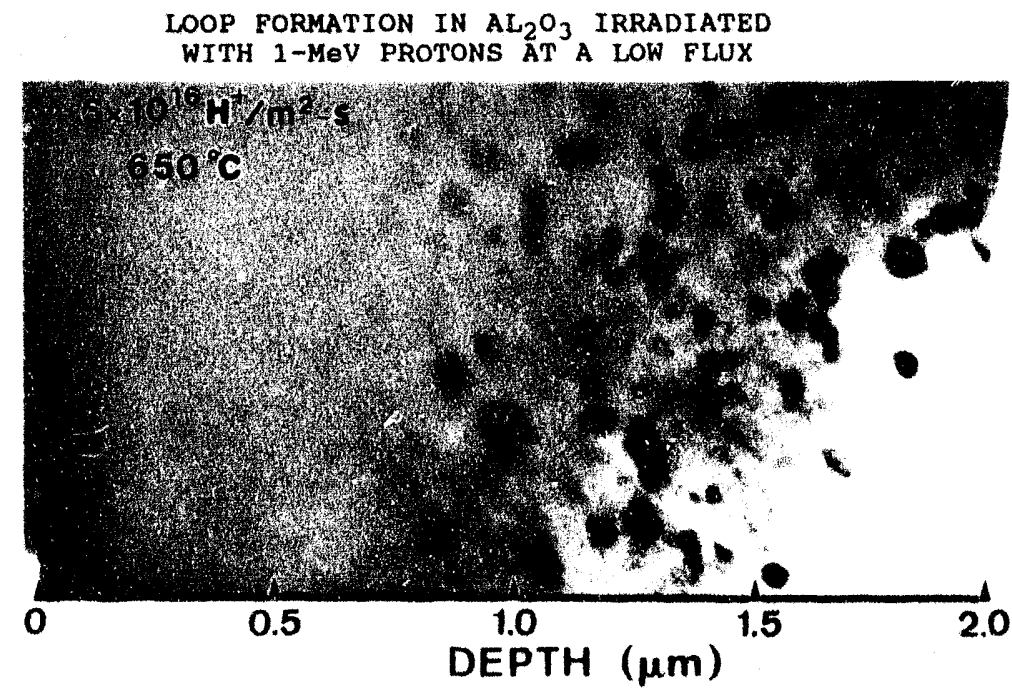

Fig. 11. Schematic of the point defect concentration profile in the vicinity of a planar sink. Defect free zones are created adjacent to the sink due to the low point defect supersaturation. 
Figure 12 shows the calculated 13 depth-dependent ratio of the energy transferred to electrons (electronic stopping power) to the energy transferred to recoil lattice atoms (nuclear stopping power) for various ions incident on an $\mathrm{Al}_{2} \mathrm{O}_{3}$ target. This ratio is approximately proportional to the amount of ionization per displaced atom (it is not exactly proportional since ionization events induced by the recoiling target atoms need to be subtracted from the nuclear stopping power to yield the damage energy, which is proportional to the number of Kinchin-Pease displacements). It can be seen from Fig. 11 that the electronic to nuclear stopping power (ENSP) ratio is highest for light ions, and the ratio decreases with increasing depth. In other words, energetic light ions are very effective in producing large amounts of ionization per unit of displacement damage. The decrease in the ENSP ratio with increasing depth is mainly due to the rapid increase in the nuclear stopping power as the ion slows down. It would be anticipated from Fig. 12 that the degree of ionization-enhanced diffusion would steadily decrease with increasing depth from the ion-irradiated surface. This behavior is very similar to the observed depth dependence of the defect-free region adjacent to grain boundaries in ion-irradiated $\mathrm{MgAl}_{2} \mathrm{O}_{4}$ (Fig. 7).

Table 2 compares the experimentally observed defect-free zone widths near the surfaces of ion irradiated $\mathrm{MgAl}_{2} \mathrm{O}_{4}$ with the calculated ENSP ratios at the boundary of the defect-free zone. Whereas the width of the defect-free zone varied by about a factor of 100 depending on the ion irradiation condition, the ENSP ratio at the defect-free zone boundary was approximately 10 in all cases. This empirical correlation suggests that observable defect aggregates do not form in spinel during irradiation at $650^{\circ} \mathrm{C}$ if the ENSP ratio is greater than about 10 (due to increased point defect recombination stimulated by ionization enhanced diffusion).

Table 3 summarizes the approximate upper bounds of the ENSP ratios for observable defect cluster formation in $\mathrm{Al}_{2} \mathrm{O}_{3}, \mathrm{MgO}$, and $\mathrm{MgAl}_{2} \mathrm{O}_{4}$. These critical ENSP ratios were derived by comparing the experimental defect-free zone widths and the calculated depth-dependent ratio of the electronic to nuclear stopping powers for various ions. Alumina was relatively insensitive to ionizing radiation effects--defect cluster formation was not suppressed unless the ENSP ratio was greater than about 1000 . This high ENSP ratio was only achieved with $1 \mathrm{MeV}$ protons. Magnesia exhibited intermediate sensitivity to ionizing radiation, with a critical ENSP ratio of about 500. These critical ENSP ratios were obtained at an irradiation temperature of $650^{\circ} \mathrm{C}$ and damage rates between $10^{-6}$ and $10^{-4} \mathrm{dpa} / \mathrm{s}$. It is uncertain if these critical ENSP ratios also hold at other temperatures and damage rates.

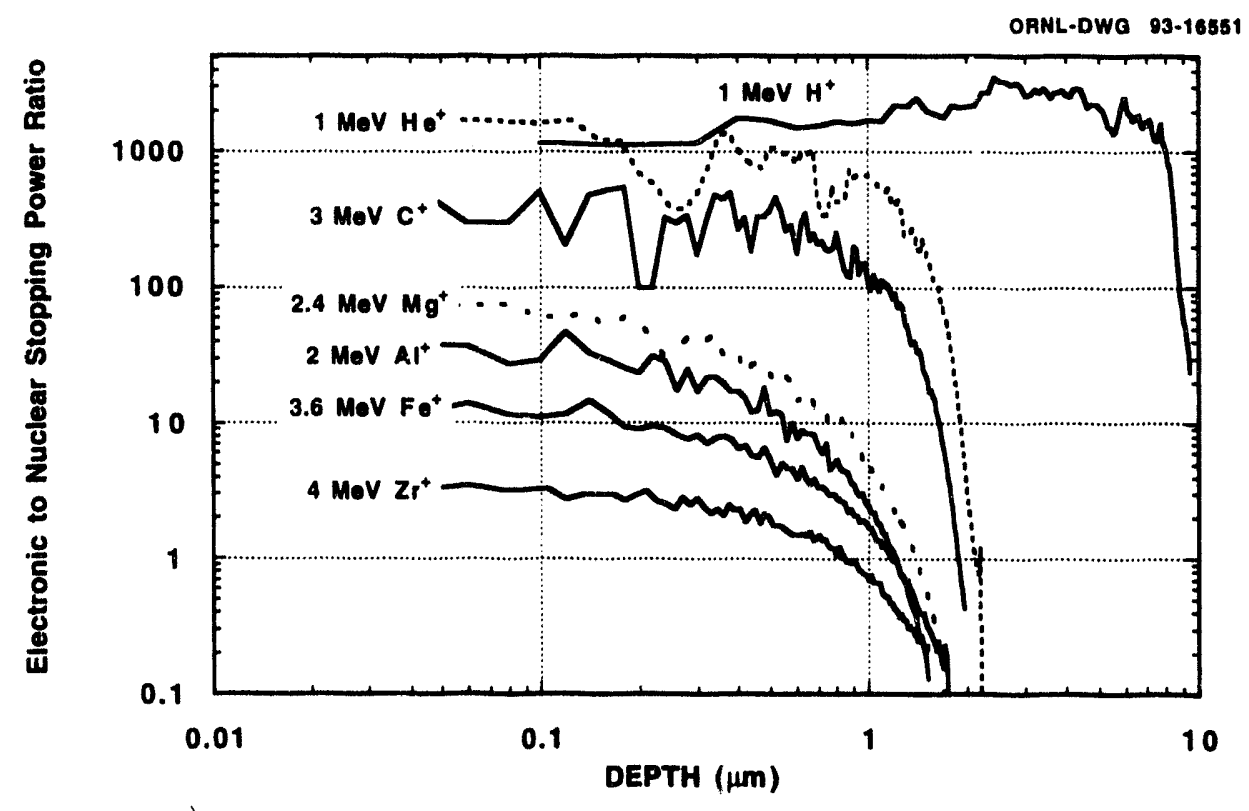

Fig. 12. Depth-dependent ratio of the electronic to nuclear stopping power for various energetic ions incident on an $\mathrm{Al}_{2} \mathrm{O}_{3}$ target, as calculated by the TRIM-90 computer code. ${ }^{13}$ 
Table 3. Upper limit of the ratio of the electronic to nuclear stopping power (ENSP) for observable defect cluster formation during single ion irradiation at $650^{\circ} \mathrm{C}, 10^{-6}$ to $10^{-4} \mathrm{dpa} / \mathrm{s}$.

\begin{tabular}{|c|c|c|}
\hline $\mathrm{Al}_{2} \mathrm{O}_{3}$ & $\mathrm{MgO}$ & $\mathrm{MgAl}_{2} \mathrm{O}_{4}$ \\
\hline 1000 & $500-1000$ & 10 \\
\hline
\end{tabular}

\section{Effect of Irradiation Flux}

A limited study of flux effects for a fixed ion mass and energy was performed in conjunction with the irradiation spectrum study. 8,9 The microstructural observations indicate that the absolute magnitude of the ionizing flux can influence the size and density of dislocation loops. The general effect of increased irradiation flux was to cause a decrease in the loop density and an increase in the loop size, which supports the concept of increased point defect diffusivities at the higher ion fluxes. Similar evidence of reduced densities and larger loops at high ion beam fluxes was recently reported for spinel specimens irradiated with $4 \mathrm{MeV} \mathrm{Ar}{ }^{+}$ions. ${ }^{23}$ Figure 13 shows the microstructure of $\mathrm{Al}_{2} \mathrm{O}_{3}$ irradiated with a low flux $\left(6 \times 10^{16}\right.$ ions $/ \mathrm{m}^{2}-\mathrm{s}$ ) of $1 \mathrm{MeV}$ protons at $650^{\circ} \mathrm{C}$. A moderate density of observable dislocation loops were produced at intermediate depths, even though the total accumulated dose at these depths was only about $0.01 \mathrm{dpa}$. In contrast, irradiation of $\mathrm{Al}_{2} \mathrm{O}_{3}$ at an order of magnitude higher flux did not produce any observable defect clusters in the midrange region for damage levels up to $0.1 \mathrm{dpa}$ (Fig. 10). This observation is consistent with the proposed interpretation that high fluxes of ionizing radiation suppress dislocation loop nucleation by promoting increased point defect recombination as a result of ionization enhanced diffusion.

Since the beam fluxes employed in the present experiment were moderately high $\left(\sim 1 \times 10^{17}\right.$ ions $/ \mathrm{m}^{2}$. $s)$, it is important to consider the possibility of beam heating effects on the experimental results. The localized energy deposition near the surface was between 0.1 and $10 \mathrm{MGy} / \mathrm{s}(0.1$ to $10 \mathrm{~kW} / \mathrm{g})$, and the heating rate decreased with increasing depth. If the local temperature near the surface was increased compared to deeper irradiated regions due to this deposited heat, then defect free regions could be created near the irradiated surface simply because of the higher localized temperature. However, it is easy to show that the temperature drop across an irradiated region of $2 \mu \mathrm{m}$ depth would only be $\sim 10^{-2}{ }^{\circ} \mathrm{C}$ in $\mathrm{Al}_{2} \mathrm{O}_{3}$ for heating rates of $10 \mathrm{MGy} / \mathrm{s}$. This calculation is supported by experimental results obtained on $\mathrm{Al}_{2} \mathrm{O}_{3}$ which cannot 'oe explained by beam heating: Dislocation loops were observed in the near surface regions of $\mathrm{Al}_{2} \mathrm{O}_{3}$ specimens irradiated at $650^{\circ} \mathrm{C}$ with high fluxes of $\mathrm{He}, \mathrm{Mg}$ and $\mathrm{At}$ ions (localized heating rates of about $10 \mathrm{MGy} / \mathrm{s}$ ), but were absent in the $\mathrm{Al}_{2} \mathrm{O}_{3}$ specimens irradiated with a high flux of $1 \mathrm{MeV}$ protons which deposited $3 \mathrm{MGy} / \mathrm{s}$ in the near-surface region.

\section{Discussion}

The empirical correlation summarized in Table 3 is supported by previous irradiation studies performed on these 3 ceramics. Dislocation loop formation has not been observed in spinel irradiated with $1 \mathrm{MeV}$ electrons over a wide range of temperatures and damage levels, ${ }^{31-33}$ whereas defect clusters can be created in $\mathrm{Al}_{2} \mathrm{O}_{3}$ and $\mathrm{MgO}$ during electron irradiation. 24,33,34 Similarly, irradiation of spinel with 3 $\mathrm{MeV}$ protons to damage levels in excess of $0.1 \mathrm{dpa}$ produced no observable defect clusters at $600^{\circ} \mathrm{C} .{ }^{35}$ Both the electron and proton irradiations would create a highly ionizing radiation environment (ENSP ratio greater than 1000), which should effectively suppress dislocation loop nucleation in spinel according to Table 3. The electron irradiation results on $\mathrm{MgO}$ and $\mathrm{Al}_{2} \mathrm{O}_{3}$ have a slight discrepancy with Table 3, since 


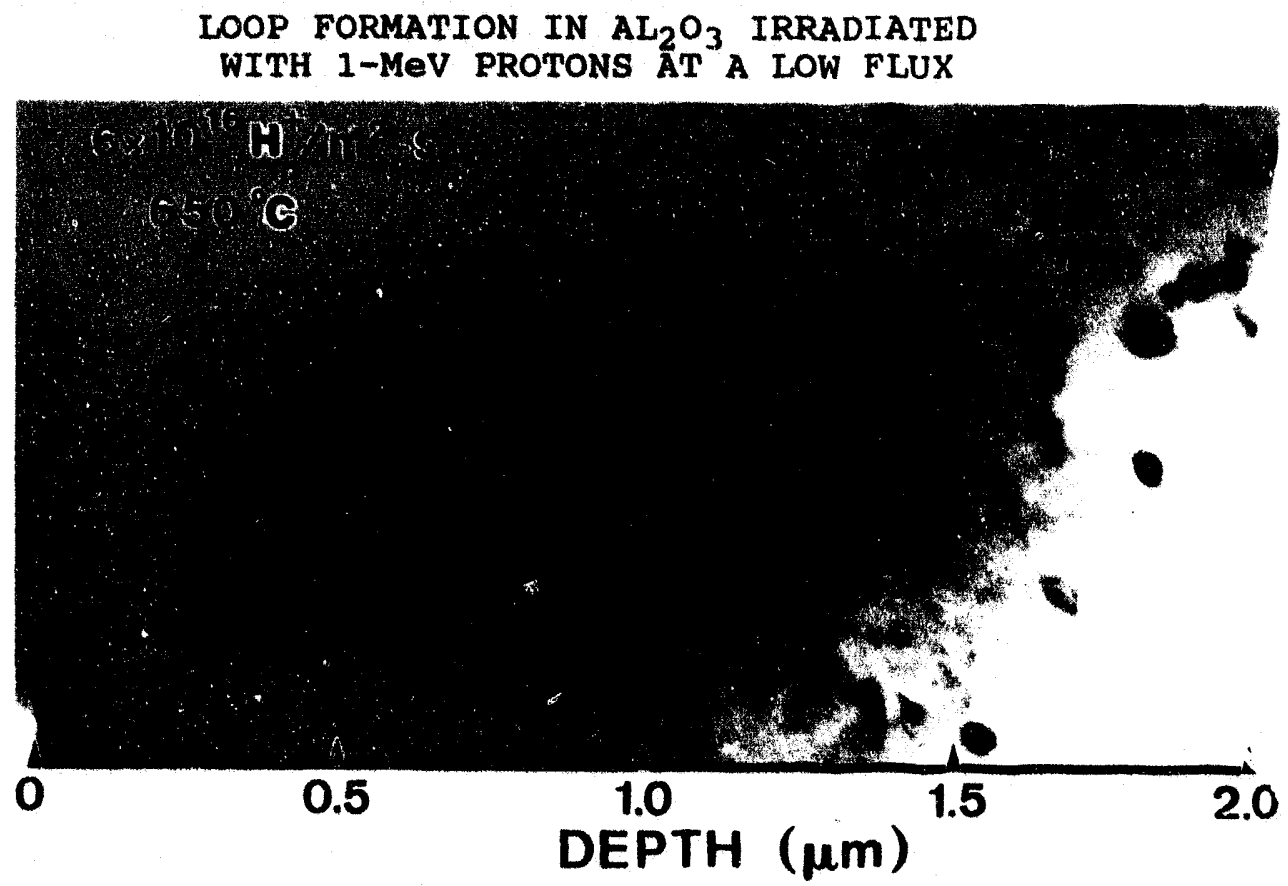

Fig. 13. Depth-dependent microstructure of $\mathrm{Al}_{2} \mathrm{O}_{3}$ irradiated with $1 \mathrm{MeV} \mathrm{H}^{+}$ions to a fluence of $1.5 \times 10^{21}$ ions $/ \mathrm{m}^{2}$ at $650^{\circ} \mathrm{C}$. The irradiation flux was about $6 \times 10^{16}$ ions $/ \mathrm{m}^{2}-\mathrm{s}$. Note the presence of dislocation loops in the midrange region $(\sim 2 \mu \mathrm{m}$ depth), where the damage level was only about $0.01 \mathrm{dpa}$.

defect clusters were otserved in these materials during HVEM irradiation even though the associated ENSP ratio for $1 \mathrm{MeV}$ electrons is $>1000$. This difference may be due to thin foil or damage rate effects, and requires further study.

Several studies have noted that spinel is more resistant to defect cluster formation during fission neutron irradiation than alumina and magnesia.5,36 The irradiation environment in a fission reactor corresponds to a ENSP ratio of about 20 (ref. 37). This value is above the critical ENSP ratio for spinel determined from the ion irradiations (Table 3 ), but below the critical values for alumina and magnesia. This would suggest that fission reactor irradiation represents a moderately high ionizing radiation environment to spinel, and that the observed resistance to defect cluster formation may be due to ionizationenhanced recombination of point defects. Structural vacancies which are often present in spinel due to nonstoichiometry ${ }^{33}$ may be favorable sites for ionization-enhanced point defect recombination. An alternative possible explanation for the observed radiation resistance of $\mathrm{MgAl}_{2} \mathrm{O}_{4}$ is based on the large number of interstitials (minimum of 7) which must be present to form the nucleus of a dislocation loop. $5,21,31,36$ Recent studies have also shown that the $a / 6<111>\{111\}$ dislocation loops that initially form in spinel are unstable when exposed to ionization-rich radiation such as $1 \mathrm{MeV}$ electrons. $5,24,33$ This difficulty in forming stable dislocation loop nuclei could explain why spinel is much more sensitive to irradiation spectrum effects compared to $\mathrm{MgO}$ and $\mathrm{Al}_{2} \mathrm{O}_{3}$.

Several previous studies have found that the radiation-induced changes in oxide ceramics are dependent on the irradiation spectrum. The most extensive study to date on spectrum effects was performed by EerNisse, Arnold and coworkers on $\mathrm{SiO}_{2}$ and $\mathrm{Al}_{2} \mathrm{O}_{3}$ (ref. 2-4). Energetic light ions such as $\mathrm{H}^{+}$and $\mathrm{He}^{+}$(which produce large amounts of ionization compared to displacement damage) produced less volume swelling per dpa in $\mathrm{Al}_{2} \mathrm{O}_{3}$ compared to heavier ions. In addition, the volume expansion induced by the heavy ion irradiation could be relieved by subsequent electron or proton irradiation. Walker ${ }^{38}$ reported similar annealing of volumetric swelling for $\mathrm{BeO}$ that was irradiated with fission neutrons and subsequently 
irradiated with $1 \mathrm{MeV}$ electrons. Irradiation of $\mathrm{BeO}$ with electrons alone did not produce any significant change in lattice parameter. It was suggested that electron irradiation enhanced the mobility of point defects, which led to enhanced point defect recombination. Kinoshita and coworkers 24,33 have recently shown that small dislocation loops produced in $\mathrm{MgAl}_{2} \mathrm{O}_{4}$ by $\mathrm{Ar}^{+}$ion and neutron irradiation disappeared during subsequent electron irradiation.

Further work is needed to identify the physical mechanism responsible for the microstructural dependence on irradiation spectrum. The most likely mechanism appears to be associated with ionization enhanced diffusion. Irradiation-assisted dissolution of interstitial loop nuclei ${ }^{5}$ may also be playing an important role. Dual beam irradiation experiments have recently been initiated 10 in an attempt to further the understanding of the importance of ionizing radiation. Spinel specimens were irradiated at $650^{\circ} \mathrm{C}$ with either $3.6 \mathrm{MeV} \mathrm{Fe}{ }^{+}$ions alone, or with simultaneous beams of $3.6 \mathrm{MeV} \mathrm{Fe}^{+}$and $1 \mathrm{MeV} \mathrm{He}+$ ions. ${ }^{10}$ For the dual beam irradiations, the displacement damage was nearly entirely due to the $\mathrm{Fe}^{+}$ions, whereas ionizing radiation was provided mainly by the $\mathrm{He}^{+}$ions. The midrange region of the dual beam specimens was observed to be qualitatively similar to the single $\mathrm{Fe}^{+}$ion beam specimens (both containing a moderate density of (islocation loops), even though the average ENSP ratio for the dual beam specimens was about 30. Other researchers ${ }^{39}$ have recently reported similar results: Global-averaged ENSP ratios as high as 60 did not affect the defect cluster formation process in spinel simultaneously irradiated with $1 \mathrm{MeV}$ electrons and $30 \mathrm{keV} \mathrm{Ar}{ }^{+}$ions. 39 According to the empirical relation derived from the single ion irradiation experiments (Table 3), dislocation loop formation should have been suppressed in spinel in both sets of dual beam experiments 10,39 since the overall ENSP ratio was greater than 10 .

In the single ion beam experiments used to derive Table 3, most of the ionization was generally produced in close proximity to the displacement damage since the same incident ion beam was responsible for both aspects of the radiation damage. In the dual beam experiments, ${ }^{10,39}$ the ionization introduced by the $\mathrm{He}^{+}$ion and electron beams was uniformly distributed whereas the displacement damage introduced by the $\mathrm{Fe}^{+}$and $\mathrm{Ar}^{+}$ion beams was mainly produced in spatially discrete collision cascades. Therefore, the localized ENSP ratio in the vicinity of the $\mathrm{Fe}^{+}$and $\mathrm{Ar}^{+}$ion collision cascades would be less than the global averaged ENSP ratio. The dual beam experimental results suggest that the macroscopic ENSP ratio is not the appropriate parameter for analyzing irradiation spectrum effects when spatially localized collision cascades are present along with a uniform background of ionizing radiation. A simple calculation provides further illustration of this point: The energy associated with an energetic PKA $(\sim 10 \mathrm{keV})$ is nearly equally divided between ionization and displacements within a spatially localized region of typical dimension $\sim 10$ $\mathrm{nm}$. The localized ionizing radiation associated with the $10 \mathrm{keV}$ PKA in $\mathrm{Al}_{2} \mathrm{O}_{3}$ amounts to about $2 \times 10^{5}$ Gy (assuming a displacement cascade volume of $\sim 10 \times 10 \times 10 \mathrm{~nm}$ ). Doubling this amount of localized ionizing radiation during a dual beam experiment would require about $0.1 \mathrm{~s}$ of simultaneous irradiation with a high flux ( $1 \times 10^{17}$ ions/m $\left./ \mathrm{m}^{2} \mathrm{~s}\right)$ of $1 \mathrm{MeV} \mathrm{He}+$ ions, which is a very long time compared to the typical lifetime of a displacement cascade of $<1$ ns. According to the published ${ }^{40}$ point defect diffusion data $\left(D_{\mathrm{i}}-4 \times 10^{-6} \mathrm{~m}^{2} / \mathrm{s}\right.$ at $650^{\circ} \mathrm{C}$ in $\mathrm{MgO}$ ), interstitials could migrate more than $50 \mu \mathrm{m}$ in this period of time. This suggests that simultaneous ionizing radiation would not have a large influence on the defect microstructure produced by energetic displacement cascades.

\section{CONCLUSIONS}

The ion ranges calculated by the TRIM program are reasonably accurate for the low and high stopping power regimes. However, the calculated ion ranges at intermediate energies ( 50 to $200 \mathrm{keV} / \mathrm{amu}$ ) are about $15 \%$ less than the experimental ion ranges. This discrepancy is apparently due to slight errors in the interpolated electronic stopping powers 17 between the low and high velocity regimes.

Implanted ions generally have a dominant role in the microstructural evolution of ceramics. The processes of defect aggregate formation and amorphization are strongly dependent on the concentration and chemical nature of the implanted ion. Implanted ion effects can be observed even for supposedly "inert" ion 
species such as $\mathrm{He}$ and $\mathrm{Ar}$. High energy $(>1 \mathrm{MeV})$ ion irradiations are essential for examining the relative influence of displacement damage and implanted ion effects.

Irradiation spectrum (and to a lesser extent, flux) has a pronounced effect on the microstructural evolution of irradiated ceramics. Dislocation loop nucleation is very difficult in ceramics irradiated with light ions. The main implication of this finding is that light ion irradiation results in general cannot be correlated with heavy ion or neutron irradiation results according to displacement damage (dpa) or absorbed dose (Gy). The physical mechanism responsible for this suppression of defect cluster formation is uncertain, although ionization enhanced diffusion, nuclear stopping power effects, and radiation-assisted dissolution of dislocation loop nuclei are likely causes.

\section{ACKNOWLEDGMENTS}

The cross-section transmission electron microscope specimens for this study were prepared by J.M. Cole, A.T. Fisher, J.W. Jones, and A.M. Williams. Most of the ion irradiations were performed by S.W.

Cook. The author thanks R.E. Stoller for stimulating discussions. This research was sponsored by the Office of Fusion Energy, US Department of Energy, under contract DE-AC05-84OR21400 with Martin Marietta Energy Systems, Inc.

\section{REFERENCES}

1. J. Bentiey, Nucl. Instr. and Meth. B16 (1986) 111.

2. E.P. EerNisse, J. Appl. Phys. 45 (1974) 167.

3. G.W. Arnold, G.B. Krefft and C.B. Norris, Appl. Phys. Lett. 25 (1974) 540.

4. G.B. Krefft and E.P. EerNisse, J. Appl. Phys. 49 (1978) 2725.

5. C. Kinoshita, J. Nucl. Mater. 191-194 (1992) 67.

6. S.J. Zinkle, J. Amer. Ceram. Soc. 72 (1989) 1343.

7. S.J. Zinkle, in Effects of Radiation on Materials: 15th Int. Symp., ASTM STP 1125, eds. R.E. Stoller, A.S. Kumar and D.S. Gelles (Amer. Soc. for Testing and Materials, Philadelphia, 1992) p. 749.

8. S.J. Zinkle, in Fusion Reactor Materials Semiann. Prog. Report for period ending March 31, 1991, DOE/ER-0313/10, p. 302.

9. S.J. Zinkle, in Fusion Reactor Materials Semiann. Prog. Report for period ending March 31, 1993, DOE/ER-0313/14, p. 426.

10. S.J. Zinkle, in Fusion Reactor Materials Semiann. Prog. Report for period ending Sept. 30, 1993, DOE/ER-0313/15, in press

11. I. Manning and G.P. Mueller, Comput. Phys. Commun. 7 (1974) 85.

12. M.B. Lewis, W.R. Allen, R.A. Buhl, N.H. Packan, S.W. Cook and L.K. Mansur, Nucl. Instr. Meth. B43 (1989)243.

13. J.F. Ziegler, J.P. Biersak and U.L. Littmark, The Stopping and Range of Ions in Solids (Pergamon Press, New York, 1985)

14. M.J. Norgett, M.T. Robinson and I.M. Torrens, Nucl. Eng. Des. 33 (1975) 50.

15. P. Agnew, Phil. Mag. A65 (1992) 355.

16. S.J. Zinkle, C.P. Haltom, L.C. Jenkins and C.K.H. DuBose, J. Electron Microsc. Techn. 19 (1991) 452.

17. J.F. Ziegler, Handbook of Ion Implantation Technology (Elsevier Science Publ., Amsterdam, 1992) p. 1.

18. N.D. Evans, S.J. Zinkle, J. Bentley and E.A. Kenik, in Proc. 49th Ann. Mtg. of the Electron Microscopy Society of America, ed. G.W. Bailey (San Francisco Press, 1991) p.728. (1989) 41 .

19. C.W. White, C.J. McHargue, P.S. Sklad, L.A. Boatner and G.C. Farlow, Mat. Sci. Reports 4

20. P.J. Burnett and T.F. Page, Rad. Effects 97 (1986) 283.

21. L.W. Hobbs and F.W. Clinard, Jr., J. de Phys., Suppl. 7, 41 (1980) C6-232. 
22. C.A. Parker, L.W. Hobbs, K.C. Russell and F.W. Clinard, Jr., J. Nucl. Mater. 133\&134 (1985) 741.

23. R. Yamada, S.J. Zinkle and G.P. Pells, J. Nucl. Mater. 191-194 (1992) 640.

24. C. Kinoshita, J. Nucl. Mater. 179-181 (1991) 53.

25. H. Abe, C. Kinoshita and K. Nakai, J. Nucl. Mater. 179-181 (1991) 917.

26. J.C. Bourgoin and J.W. Corbett, Rad. Effects 36 (1978) 157.

27. Y. Chen and R. Gonzalez, Int. Materials Research Society Symposium, Tokyo, Sept. 1993, in press

28. S.J. Zinkle, submitted to Phil. Mag. A (1993)

29. N.Q. Lam, S.J. Rothman and R. Sizmann, Rad. Effects 23 (1974) 53.

30. L.K. Mansur and M.H. Yoo, J. Nucl. Mater. 85\&86 (1979) 523.

31. S.J. Shaibani, D. Phil. Thesis, Univ. Oxford, UK (1986)

32. S.N. Buckley and S.J. Shaibani, Phil. Mag. Lett. 55 (1987) 15.

33. Y. Satoh, C. Kinoshita and K. Nakai, J. Nucl. Mater. 179-181 (1991) 399.

34. G.P. Pells and A.Y. Stathopoulos, Rad. Effects 74 (1983) 181.

35. P.A. Knight, D. Phil. Thesis, Univ. Oxford, UK (1989)

36. F.W. Clinard, Jr., G.F. Hurley and L.W. Hobbs, J. Nucl. Mater. 108\&109 (1982) 655.

37. S.J. Zinkle and L.R. Greenwood, in Fusion Reactor Materials Semiann. progress report for period ending March 31, 1993, DOE/ER-0313/14, p. 74.

38. D.G. Walker, J. Nucl. Mater. 14 (1964) 195.

39. K. Fukumoto, C. Kinoshita, S. Maeda and K. Nakai, REI-7 proceedings, Nucl. Instr. Meth. B, in press

40. R.E. Stoller, J. Amer. Cer. Soc. 73 (1990) 2446. 
ISSUES RELATED TO MECHANICAL PROPERTIES OF NEUTRON-IRRADIATED CERAMICS -F. W. Clinard, Jr. (Los Alamos National Laboratory), W. Dienst (KfK Karlsruhe), and E. H. Farnum (Los Alamos National Laboratory)

\section{OBJECTIVE}

The objective of this work is to review the mechanical behavior of neutron-irradiated ceramics, identify major issues related to degradation effects, and recommend future studies needed to select appropriate ceramics for use in a fusion reactor environment.

\section{SUMMARY}

Ceramics will be used for a number of applications in fusion devices, where their dielectric properties, high strength, refractoriness, or low activation characteristics are required. In all cases starting mechanical properties must be adequate to preserve structural integrity, and the material must tolerate irradiation damage without undue degradation. A review of the irradiation response of four prototypical candidate ceramics shows that significant deterioration of mechanical properties can be expected for most applications in ITER. Future studies are identified that will establish the basis for specifying developing ceramics that can meet the needs of ITER and subsequent fusion reactor concepts.

\section{PROGRESS AND STATUS}

\section{Introduction}

Ceramics are specified for a number of applications in the intense neutron flux of advanced fusion devices such as the International Thermonuclear Experimental Reactor (ITER). Included are electrical insulators for lightly-shielded magnets, toroidal current breaks, if heating systems, neutral beam injectors, diagnostic devices, and insulating coatings for suppression of MHD forces in liquid metal-cooled blankets. In addition, ceramic optical components are required for some diagnostic systems. Further, ceramics may be specified for first wall protection or for structural applications where low activation characteristics and good high-temperature performance are required.

For all of these applications adequate resistance to radiation-induced mechanical failure during the design lifetime is a necessity. Such failure can result from dimensional changes or a reduction of strength resulting from displacement of lattice ions and their subsequent aggregation. Thus the issues addressed here fall into the broad categories of swelling, reduction of strength, and the microstructural alterations that cause such degradation.

The diversity of applications for ceramics in fusion reactors implies that there is a wide choice among candidate materials, and that is indeed the case. In order to keep this discussion of materials behavior within bounds, we focus on four candidate materials, $\mathrm{Al}_{2} \mathrm{O}_{3}, \mathrm{MgAl}_{2} \mathrm{O}_{4}, \mathrm{SiC}_{\text {and }} \mathrm{SiO}_{2}$, assessing the response of each to neutron irradiation. Taken together, the behavior of this set of materials is illustrative as to the types of damage response that can be expected for most ceramics in fusion applications.

\section{Neutron Damage in Four Candidate Ceramics}

\section{$\mathrm{Al}_{2} \mathrm{O}_{3}$}

$\mathrm{Al}_{2} \mathrm{O}_{3}$ is probably the most commonly-specified ceramic insulator where good structural and electrical performance are required. With respect to fusion requirements, this material in either its polycrystalline 
form (alumina) or single-crystal form (sapphire) is a candidate for most applications. The crystal structure of this ceramic is hexagonal. The greatest shortcoming of $\mathrm{Al}_{2} \mathrm{O}_{3}$ with respect to fusion applications is its relatively high sensitivity to neutron damage.

Irradiation of this ceramic to a fluence of $2 \times 10^{26} \mathrm{n} / \mathrm{m}^{2}$ near room temperature results in near-isotropic swelling on the order of 2 vol.\% [1]; such growth is believed to result primarily from accumulation of point defects. Irradiation at higher temperatures leads to greater swelling, with most of the growth being in the c-axis direction (Fig.1). This behavior has been shown to result from preferential aggregation of displaced atoms in interstitial loops having Burgers vectors that contribute primarily to growth perpendicular to basal planes [2].

This preference for c-axis dilation leads to macroscopic distortion of single crystals, and can present problems in developing mounting systems for sapphire windows for diagnostic applications. This behavior also presents problems for the polycrystalline form, in which each grain grows anisotropically. As a result alumina irradiated at elevated temperatures can suffer a buildup of internal strains, in some cases leading to grain boundary microcracking or separation. [1,2].

Strength of ceramics is represented by the relationship

$$
\left.\sigma=\text { const. }(E \gamma)^{1 / 2 /(c)}\right)^{1 / 2}=\text { const. } K_{c} /(c)^{1 / 2},
$$

where $\sigma=$ fracture strength, $\mathrm{E}=$ Young's modulus, $\gamma=$ fracture energy, $\mathrm{c}=$ critical flaw size, and $\mathrm{K}_{\mathrm{c}}=$ fracture toughness. The grain boundary microcracking or separation observed in alumina represents an increase in flaw size, and can therefore lead to weakening unless other flaws (e.g., those from fabrication) dominate. This equation does not take into account internal stresses, which for alumina will result both from anisotropic thermal contraction upon cooling from the sintering temperature and from anisotropic swelling; such stresses will have a weakening effect on this ceramic.

Fracture toughness is affected by interaction of propagating cracks with the damage microstructure. As mentioned earlier, irradiation near room temperature results primarily in the accumulation of point defects. Irradiation to a fluence of $2 \times 10^{26} \mathrm{n} / \mathrm{m}^{2}$ at $430 \mathrm{~K}$ leads to formation of a dense array of small loops [2]. Exposure to a similar fluence at 925 and $1100 \mathrm{~K}$ induces a microstructure consisting of dense dislocation networks (formed by the interaction of interstitial loops) and aligned voids [2].

Fracture toughness of sapphire has been found to be doubled by irradiation at $1100 \mathrm{~K}$, an effect attributed to interaction of the crack tip with voids of diameter $9 \mathrm{~nm}$ [3]. Results for sapphire and two other ceramics (AIN and $\mathrm{SiC}$ ) after irradiation to fluences up to $4 \times 10^{26} \mathrm{n} / \mathrm{m}^{2}$ at moderate to high temperatures also show increases, although of a lesser magnitude [4]

Room-temperature strength measurements on single-crystal $\mathrm{Al}_{2} \mathrm{O}_{3}$ exhibit considerable variation. This material showed a moderate decrease of strength after irradiation to $2 \times 10^{25} \mathrm{n} / \mathrm{m}^{2}$ at $373-388 \mathrm{~K}$ [4] and a similar decrease after a fluence of $2 \times 10^{26} \mathrm{n} / \mathrm{m}^{2}$ at 673-873 K [5] (Fig. 2); however, no significant change was observed after irradiation at 680 and $815 \mathrm{~K}$ [6]. It is unfortunate that no results are available at higher temperatures where void formation has been reported.

Polycrystalline $\mathrm{Al}_{2} \mathrm{O}_{3}$ irradiated to $2 \times 10^{25} \mathrm{n} / \mathrm{m}^{2}$ at $373-388 \mathrm{~K}$ showed a moderate decrease of strength [4]. That result is consistent with strength losses reported for other grades of alumina irradiated to ten times higher fluence at 673-873 K [5] (Fig. 2) and is similar to results for another alumina after $2 \times 10^{26} \mathrm{n} / \mathrm{m}^{2}$ at $660 \mathrm{~K}$ [7]. In contrast, Colin [8] found an $80 \%$ strength loss after a fluence of $5 \times 10^{25} \mathrm{n} / \mathrm{m}^{2}$ at $823 \mathrm{~K}$.

The role of grain size in determining extent of strength loss in alumina has not yet been resolved: Wilks et al. [9] presented calculations indicating that a fine grain size should lessen internal strains and postpone microcracking to higher fluences, and Keilholtz et al. [1] found that their finest-grained material 


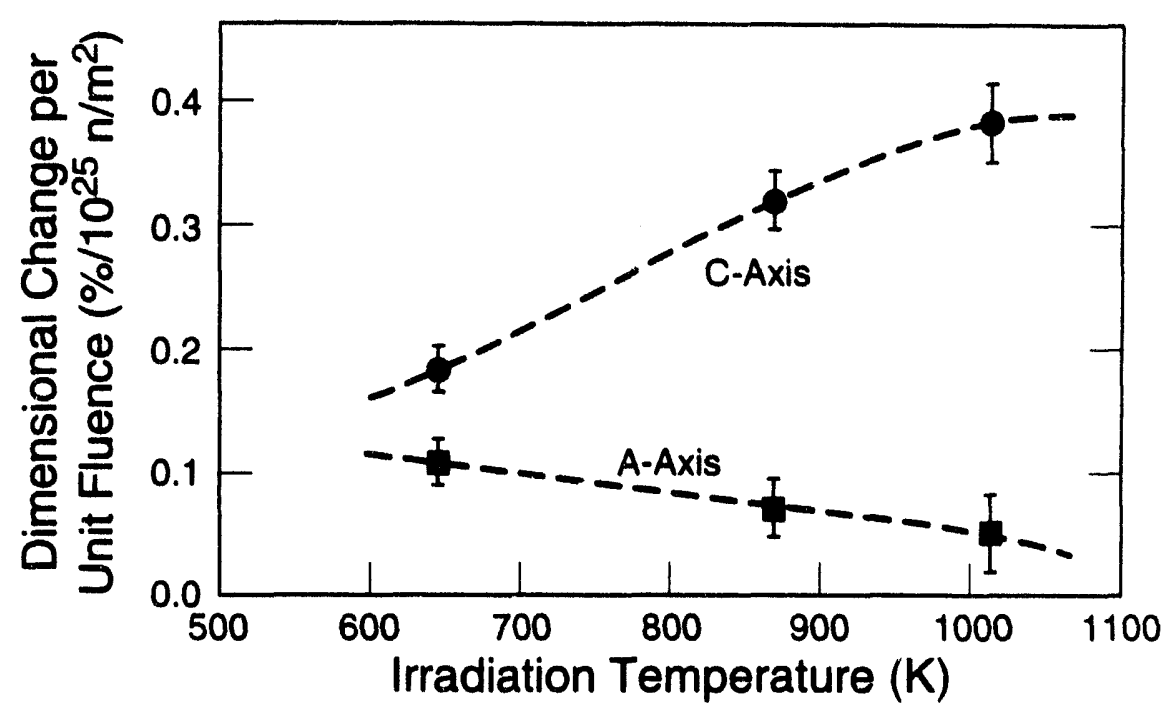

Figure 1. Dilation along a- and c-axes in neutron-irradiated single-crystal $\mathrm{Al}_{2} \mathrm{O}_{3}$ as a function of irradiation temperature [2].

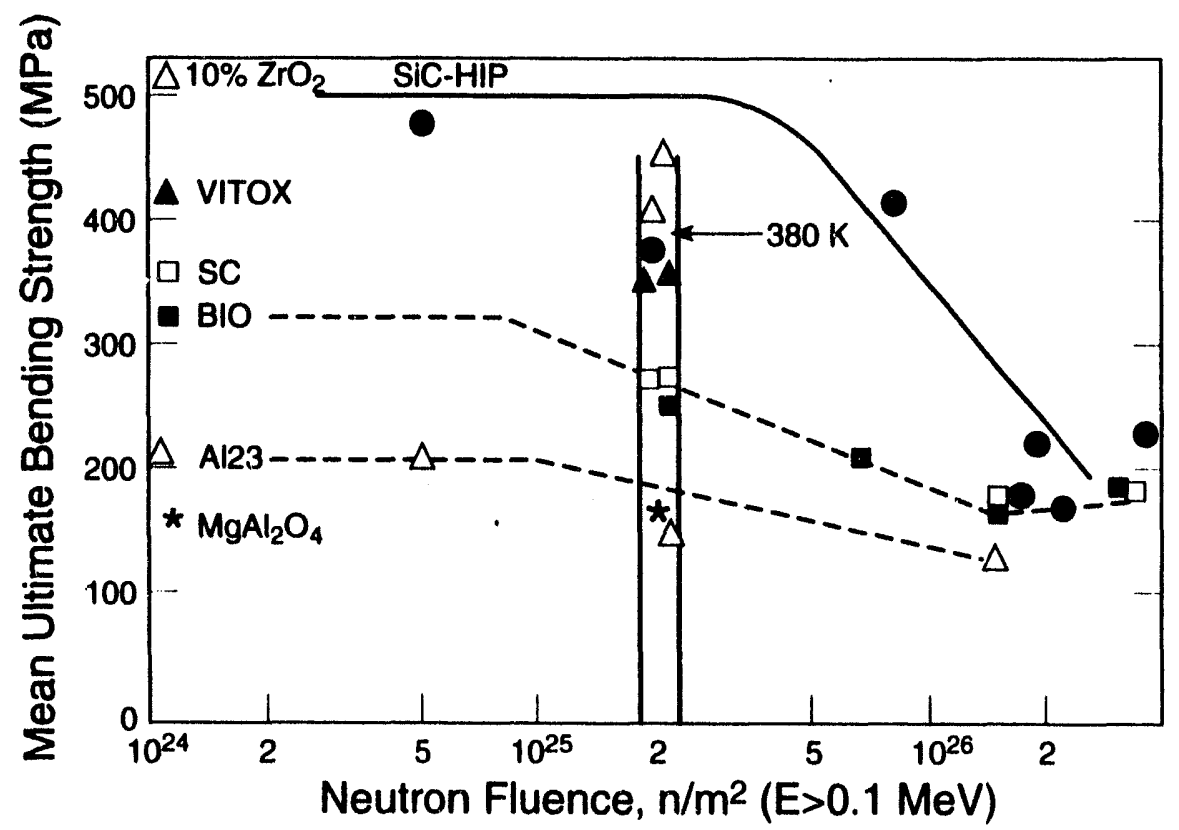

Figure 2. Strength change of various $\mathrm{Al}_{2} \mathrm{O}_{3}$ grades including single-crystal samples (SC), HIP-SiC, and $\mathrm{MgAl}_{2} \mathrm{O}_{4}$ after neutron irradiation at $673-873 \mathrm{~K}$ [5]; and the same materials after irradiation at about $380 \mathrm{~K}$ (data band around $2 \times 10^{25} \mathrm{n} / \mathrm{m}^{2}$ ) [4]. 
was most resistant to grain boundary cracking. On the other hand, Dienst [5] saw no major difference in damage response between materials of grain size 0.9 and 8 microns.

\section{$\mathrm{MgAl}_{2} \mathrm{O}_{4}$}

Magnesium aluminate spinel is an electrically-insulating ceramic with reasonably good mechanical properties, and is usable in most applications for which $\mathrm{Al}_{2} \mathrm{O}_{3}$ is a candidate material. The greatest virtue of $\mathrm{MgAl}_{2} \mathrm{O}_{4}$ is its good performance under neutron irradiation.

Spinel is for the most part a low-swelling ceramic. Dimensional changes are near-zero for both single-crystal and polycrystalline material after irradiation to fluences on the order of $1 \times 10^{26} \mathrm{n} / \mathrm{m}^{2}$ [2], with the exception of 0.8 vol.\% swelling at $430 \mathrm{~K}$ [10] and 0.2 to 1.6 vol.\% at $925-1100 \mathrm{~K}$ [2]; both of the exceptions are for the polycrystalline form. Recent measurements on single-crystal and polycrystalline material irradiated at temperatures of 658,678 , and $1023 \mathrm{~K}$ to fluences as high as $24 \times 10^{26} \mathrm{n} / \mathrm{m}^{2}$ have shown that dimensional stability extends even to that high damage level [11].

It has been proposed that the characteristic low swelling of spinel is attributable to predominant recombination of point defects rather than their aggregation; the open crystal structure with its large number of structural vacancies, along with the capability to intermix the site occupancy of $\mathrm{Mg}$ and $\mathrm{Al}$ ions, may also play a role in the dimensional stability of this ceramic [2]. Further, the fact that spinel has a cubic crystal structure means that anisotropic swelling is not an issue in this material.

The most common response of spinel in either single-crystal or polycrystalline form to neutron irradiation is to exhibit strengthening $[4,6,7,10]$ (Fig. 2). However, it must be pointed out that Colin [8] found a large decrease of strength in his spinel material. It has been proposed [6] that the strengthening behavior results from impedance of crack propagation by the damage microstructure, specifically by the intense strain fields around interstitial dislocation loops. Another explanation for the observed strengthening has been suggested, namely the blunting of atomically-sharp tips of pre-existing flaws by displacement damage [12].

The damage microstructure of polycrystalline spinel differs from that in single-crystal material in ways that may explain the lesser strengthening observed in the polycrystalline form [6]. After irradiation at $430 \mathrm{~K}[10]$ and $660 \mathrm{~K}$ [7], areas near the grain boundaries are found to be denuded of the characteristic interstitial loops that are found within the grains. Such a damage microstructure may induce misfit stresses near grain boundaries that work against the inherent strengthening effect that apparently operates in the bulk material.

$\mathrm{SiC}$

Silicon carbide is a high-strength ceramic. In most forms this material is a semiconductor rather than an insulator, and therefore its principal use for fusion reactors is as a structural material. Possible applications include use as first wall protection, as reflectors in diagnostic systems, and as structural members where good high-temperature mechanical properties and/or low nuclear activation are desired. SiC is available in either the alpha (hexagonal crystal structure) or beta (cubic) form.

The swelling behavior of pyrolytic beta SiC from room temperature to $1313 \mathrm{~K}$ has been characterized by Price $[13,14]$. Swelling of this cubic material exhibited saturation between $1 \times 10^{24}$ and $4 \times 10^{25} \mathrm{n} / \mathrm{m}^{2}$, and decreased from 3 vol. \% at the lowest temperature to near zero at the highest. Lack of a difference between macroscopic linear expansion and lattice parameter expansion implied that most of the swelling was due to the creation of point defects or small clusters. Work by others [6] subsequently showed that swelling in beta-SiC irradiated to $2 \times 10^{26} \mathrm{n} / \mathrm{m}^{2}$ at $680 \mathrm{~K}$ was of the same magnitude as that reported by Price [13], thus demonstrating that saturation persists at least up to that fluence. At irradiation temperatures of 1523 and $1773 \mathrm{~K}$ Price observed void formation and significant swelling [14]. However, growth did not achieve the levels measured at room temperature. 
Strength of irradiated silicon carbide is strongly dependent on the form of the material tested. Price found that pyrolytic beta $\mathrm{SiC}$ exhibited no significant change in strength after irradiation to 2 to $4 \times 10^{25}$ $\mathrm{n} / \mathrm{m}^{2}$ at temperatures ranging from 733 to $1313 \mathrm{~K}$. [13], and the same was true for that material after a fluence of $2 \times 10^{26} \mathrm{n} / \mathrm{m}^{2}$ at $1013 \mathrm{~K}$ [15]. However, strength of sintered alpha SiC was reduced $34 \%$ by the same irradiation conditions, and reaction-bonded $\mathrm{SiC}$ was weakened by $58 \%$. It was proposed that weakening of the sintered material resulted from transmutation of the boron sintering aid to helium through the ${ }^{10} \mathrm{~B}$ (n,alpha) reaction, which resulted in an increase of critical flaw size [15]. The larger strength reduction for the reaction-bonded $\mathrm{SiC}$ was attributed to dissimilar swelling between the $\mathrm{SiC}$ and the 8 to $10 \%$ free silicon that was present in that material.

Strength measurements for $\mathrm{SiC}$ show some disagreement: Dienst [5] has reported strength losses on the order of $60 \%$ for both isostatically hot-pressed (HIP) and chemically vapor-deposited SiC (alpha and beta phase, respectively) after irradiation to $2 \times 10^{26} \mathrm{n} / \mathrm{m} 2$ at 773 to $873 \mathrm{~K}$. The behavior of the HIP material (Fig. 2) could be due to anisotropic swelling, but the observed differences in high-dose behavior of beta SiC $[5,15]$ remain unexplained.

$\mathrm{SiO}_{2}$

Silicon dioxide is commonly used in both the crystalline form (usually quartz, with a trigonal or hexagonal structure) and the glassy form (vitreous or fused silica). Both exhibit modest strength but have excellent electrical and optical properties. $\mathrm{SiO}_{2}$ may be used in a variety of diagnostic applications, including windows, substrates for reflectors, and optical fibers; in addition, silicate-based ceramics may, because of their fabricability, be specified for the large neutral beam injector ion source insulators. This material is unique among the four discussed here in that both forms can undergo atomic displacements from ionizing radiation (e.g., gamma rays), although Hobbs and Pascucci [16] have shown that this mode of damage is relatively inefficient in $\mathrm{SiO}_{2}$.

Both crystalline and glassy $\mathrm{SiO}_{2}$ undergo large changes in density at low neutron fluences (Fig. 3), with quartz swelling and fused silica densifying to a common value [17]. In the case of quartz, atomic displacements rearrange $\mathrm{Si}$ and $\mathrm{O}$ atoms into the disordered or metamict state. The atoms of fused silica are already in a disordered state before irradiation damage, but that condition is different from the metamict state; the effect of neutron damage is to transform the original amorphous structure to the metamict form that is unique to irradiated material.

Little information is available on mechanical properties of either crystalline or glassy $\mathrm{SiO}_{2}$, before of after irradiation. Strength of these materials is on the order of 100 to $200 \mathrm{MPa}$, with fracture toughness of approximately $1 \mathrm{MPa} \mathrm{m} \mathrm{m}^{1 / 2}$ The authors are not aware of any strength measurements on either form of $\mathrm{SiO}_{2}$ under irradiation conditions that approximate those to be found in a fusion reactor. However, neutron damage in a machinable glass-ceramic made up of $50 \mathrm{vol} . \%$ silicate mica crystals in a silicate glass matrix has been investigated after irradiation to fluences of $1 \times 10^{22}$ and $1 \times 10^{23} 14 \mathrm{MeV} \mathrm{n} / \mathrm{m}^{2}$ at room temperature $[18,19]$. Density and fracture toughness were essentially unaltered after exposure to the lower fluence; however, as fluence increased to the higher dose, swelling first reached a value of $1.6 \mathrm{vol} . \%$ and then lessened to a value half that level. It was concluded that this unusual behavior resulted from swelling of the mica phase and contraction of the glass phase [19].

The greatest concern with respect to the use of quartz, and to a lesser extent fused silica, is the large dimensional changes at low radiation levels. Such behavior in a free-standing material does not in itself threaten diagnostic systems except for possible warpage of reflectors. However, any component whose design involves mechanical constraint, as in the case of optical fibers and sealed windows, will suffer high stresses and the possibility of fracture. Analysis of expected dilation and resulting stresses in quartz and fused silica windows mounted in window assemblies suggests an upper fluence limit of about $5 \times 10^{21}$ $\mathrm{n} / \mathrm{m}^{2}$, unless sliding seal assemblies can be developed [20]. 


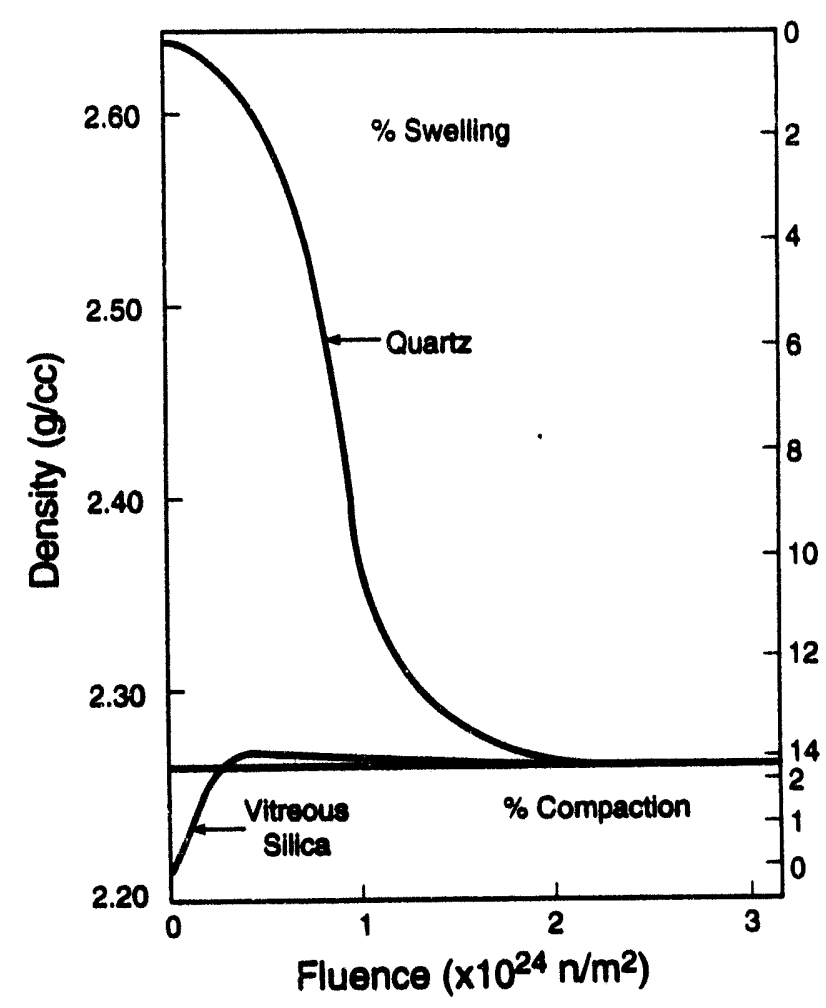

Figure 3. Density change in alpha-quartz and vitreous $\mathrm{SiO}_{2}$ neutron-irradiated near room temperature [17].

\section{Major Issues}

The above review of dimensional, microstructural, and mechanical property changes in four candidate materials illustrates the variety and complexity of damage responses likely to be encountered. We now take a broader view of the subject, identifying what we believe to be the major issues in this area.

Two problems result from the current necessity of employing fission neutrons to achieve high damage levels in materials to be used in fusion reactors: the probability that primary damage events from fission and fusion neutrons differ significantly, and the fact that greater concentrations of transmutation products will be generated by high-energy fusion neutrons. Of these two problems, the latter is probably the more significant. Rovner and Hopkins [21] have calculated the levels of gaseous and metallic transmutation products that will be generated in four ceramics under first wall conditions (Table 1); it may be shown that, given a realistic first wall loading and lifetime, impurity levels on the order of 1 at.\% can be expected. The effect of these transmutation products on physical properties can only be surmised, but given the effect on $\mathrm{SiC}$ of helium generated by transmutation of boron sintering aid $[15,22]$, there is cause for concern.

Table 1. Major transmutation products induced in ceramics by first wall neutrons (appm/y at a first wall loading of $\left.1 \mathrm{MW} / \mathrm{m}^{2}\right)[21]$.

\begin{tabular}{lrrrr}
\hline & $\mathrm{SiC}$ & $\mathrm{Si}_{3} \mathrm{~N}_{4}$ & $\mathrm{Al}_{2} \mathrm{O}_{3}$ & $\mathrm{BeO}$ \\
\hline Hydrogen & 440 & 667 & 456 & 103 \\
Carbon & $\ldots-$ & 328 & 624 & 569 \\
Helium & 1595 & 758 & 787 & 2920 \\
Magnesium & 458 & 455 & 434 & $\ldots$ \\
\hline
\end{tabular}


It has been observed that values of Weibull modulus for $\mathrm{Al}_{2} \mathrm{O}_{3}$ [5] and $\mathrm{SiC}[15,22]$ are significantly reduced by neutron damage. Such a broadening of strength distribution means that even a material with an acceptably high average strength under laboratory conditions may when fabricated into components exhibit an unacceptably high failure rate. Proof testing of unirradiated components to eliminate those most likely to fail will not necessarily be of significant help [15]. Thus a high Weibull modulus can be as important a property as high strength, and must be given more attention than has been the case to date.

Some non-cubic ceramics suffer from anisotropic swelling of individual grains, with consequent generation of internal stresses and possible grain boundary separation. As discussed earlier, swelling anisotropy and grain boundary separation have been observed for alumina $[1,2,9]$, and could play a role in irradiation-induced degradation of other non-cubic ceramics such as $\mathrm{AlN}_{\mathrm{N}} \mathrm{Si}_{3} \mathrm{~N}_{4}$, and alpha-phase $\mathrm{SiC}$. There has been no work quantifying the reduction of strength that is expected to accompany anisotropic swelling, although the severe microcracking observed by Keilholtz et al. [1] indicates qualitatively that this can be a significant problem. On the other hand, the observation by Dienst [5] that fine-grained $\mathrm{Al}_{2} \mathrm{O}_{3}$ suffers a strength reduction similar to that for coarse-grained material and that single-crystal sapphire shows a decrease of strength similar to that for polycrystalline materials indicates that other factors can mask the consequences of anisotropic swelling.

A little-considered source of premature strength loss in technical ceramics is the presence of a damagesensitive grain boundary phase. Such a situation has been encountered in sialon [23], where a silicate grain boundary phase was found to exhibit significantly more damage (in the form of pore-like aggregates) than did the bulk material. When damage-sensitive grain boundary phases are identified, it may be possible to alleviate the problem by making appropriate adjustments to the composition of the bulk material.

Some applications for ceramics in fusion devices involve bonded or coated systems, e.g., protective tiles for the first wall, reflectors for diagnostic applications, and an insulating lining for piping in liquid metal-cooled blankets. A major potential problem area for these applications is differential swelling, which can lead to high interfacial stresses, warpage, and delamination or bulk fracture. An example is the response of a layered system consisting of a thick coating of chemically vapor-deposited beta $\mathrm{SiC}$ on graphite: after irradiation to $2 \times 10^{26} \mathrm{n} / \mathrm{m}^{2}$ at $680 \mathrm{~K}$ [6] the material was visibly bowed, and, and the interface had almost completely separated. It was found that the $\mathrm{SiC}$ had swelled 1.5 vol.\% while the graphite substrate had densified 7 vol.\%. The lesson here is that monolithic ceramics should be used whenever possible, and where a layered system is unavoidable the design should if possible employ a thin coating of deformable material as one of the components. Composite materials are also at risk from differential swelling. Where such materials are required, the best choice would be a two-phase ceramic in which the phases are as similar as possible; an example is bulk $\mathrm{SiC}$ reinforced with $\mathrm{SiC}$ fibers or whiskers, where toughening can be realized through interfacial debonding under applied stress.

Swelling under thermal and flux gradients may generate internal stresses that can reduce the loadbearing capability of irradiated ceramics. This is not expected to be a major problem for test samples or small components, but could prove to be a significant issue for large components such as neutral beam injector ion source insulators. Given an adequate data base, it should be possible to calculate the magnitude of macroscopic internal stresses and determine whether these stresses present a problem.

\section{FUTURE WORK}

As a general statement, we can say that work to date on mechanical properties of neutron-irradiated ceramics has identified major areas of concern, developed a useful if incomplete data base, and in some areas has established an understanding of basic damage effects. However, more effort is needed in these areas if ceramics with adequate performance and lifetime are to be available on a timely basis for construction of fusion reactors such as ITER.

At the fundamental level, an understanding is needed of primary damage events in ceramics. To achieve this understanding, modeling calculations and experiments should be carried out to follow the 
evolution of damage from cascade events involving time scales of a few atomic vibrations, (i.e. on the order of a picosecond) to the relaxed state that evolves over perhaps the next microsecond. Knowledge from such studies can guide the selection of critical experiments to define the evolution of a quasi-steady-state defect content that is characteristic of the material, test temperature, irradiation fluence, and dose rate.

Given an adequate understanding of damage effects, it should be possible to predict how generic classes of ceramics differ in their response to radiation damage and use that as a guide to selecting the most promising candidate materials. Examples of where some understanding already exists are the differences in damage response between ionically-bonded and covalently-bonded ceramics, and the propensity of certain crystal structures to support annihilation of vacancies and interstitials rather than their aggregation. Greater understanding in these areas could reduce the amount of time and effort spent in evaluating what might prove to be unpromising materials.

It is weil known that surface finish plays an important role in determining the critical flaw that propagates to cause fracture of a ceramic. For this reason, special care should be devoted to attaining a uniform and well-characterized surface condition both for test samples and for components themselves.

Studies of mechanical properties should be conducted in the appropriate test environment. Examples are an $\mathrm{SF}_{6}$ atmosphere for testing of $\mathrm{rf}$ windows and the appropriate liquid metal for studies of MHDsuppressing insulators. Since designs of fusion devices can be expected to continually evolve, it is incumbent on designers and materials researchers to communicate frequently in order to assure that tests are being conducted in the proper environment.

For non-cubic ceramics, swelling and orientation of applied stresses should be assessed with proper attention to crystallographic direction. The same attention to orientation is important for the understanding of the role of defect aggregates, in this case for both cubic and non-cubic materials.

Transmutation gases are an important part of the damage condition for ceramics irradiated with highenergy neutrons. More experiments are needed that combine high-fluence damage with concurrent production of hydrogen and helium, using techniques such as isotopic tailoring to aitain appropriate gas generation rates [24].

Little effort is currently being directed to development of improved ceramics for fusion applications. The present state of understanding of neutron damage effects is now adequate to support increased activity in this area, and so communication between researchers and manufacturers should be established now in order to assure timely development of qualified ceramic materials for ITER and beyond.

\section{REFERENCES}

[1] G. W. Keilholtz, R. E. Moore and H. E. Robertson, Nucl. Technology 17 (1973) 234.

[2] F. W. Clinard, Jr., G. F. Hurley and L. W. Hobbs, J. Nucl. Mater. 108 \& 109 (1982) 655.

[3] F. W. Clinard, Jr., G. F. Hurley, R. A. Youngman and L. W. Hobbs, J. Nucl. Mater. 133 \& 134 (1985) 701.

[4] W. Dienst and H. Zimmermann, this volume.

[5] W. Dienst, J Nucl. Mater. 191-194 (1992) 555.

[6] F. W. Clinard, Jr., G. F. Hurley, L. W. Hobbs, D. L. Rohr and R. A. Youngman, J. Nucl. Mater. 122 \& $123(1984) 1386$.

[7] D. S. Tucker, T. Zocco, C. D. Kise and J. C Kennedy, J. Nucl. Mater. 141-143 (1986) 401.

[8] M. Colin, in: Report EUR FU BRU/XII-358/89-MATIA 13, Proc. Workshop Radiation Effects in Ceramic Insulators, Garching, FRG, 1989.

[9] R. S. Wilks, J. A. Desport and J. A G. Smith, J. Nucl. Mater. 24 (1967) 80.

[10] G. F. Hurley, J. C. Kennedy, F. W. Clinard, Jr., R. A. Youngman and W. R. McDonell, J. Nucl. Mater. 103 \& 104 (1981) 761.

[11] C. A. Black, F. A. Garner and R. C. Bradt, this volume.

[12] R. W. Rice, W. R. Grace \& Co., private communication. 
[13] R. J. Price, J. Nucl. Mater. 33 (1969) 17.

[14] R. J. Price, J. Nucl. Mater. 48 (1973) 47.

[15] R. J. Price and G. R. Hopkins, J. Nucl. Mater. 108 \& 109 (1982) 732.

[16] L. W. Hobbs and M. R. Pascucci, J. Physique 41 (1980) C6-237.

[17] E. Lell, N. J. Kreidel, and J. R. Hensler, in: Progress in Ceramic Science, Vol. 4, Ed. J. E. Burke (Pergamon Press, New York, 1966) p. 1.

[18] J. D. Fowler, Jr., G. F. Hurley, J. C. Kennedy and F. W. Clinard, Jr., J. Nucl. Mater. 103 \& 104 (1981) 755.

[19] W. A. Coghlan and F W. Clinard, Jr., J. Nucl. Mater. 179-181 (1991) 391.

[20] F. W. Clinard, Jr., E. H. Farnum, D. L Griscom, R. F. Mattas, S. S. Medley, F. W. Wiffen, S. S.

Wojtowicz, K. M. Young and S. J. Zinkle, J. Nucl. Mater. 191-194 (1992) 1399.

[21] L. H. Rovner and G. R. Hopkins, Nucl. Technol. 29 (1976) 274.

[22] W. Dienst, Fusion Eng. and Design 16 (1991) 311.

[23] F. W. Clinard, Jr. and G. F. Hurley, J. Nucl. Mater. 103 \& 104 (1981) 705.

[24] R. J. LaBauve, R. J. Livak and F. W. Clinard, Jr., Advanced Cer. Materials 3 (1988) 353. 
DIMENSIONAL STABILITY, OPTICAL AND ELASTIC PROPERTIES OF $\mathrm{MgAl}_{2} \mathrm{O}_{4}$ SPINEL IRRADIATED IN FFTF TO VERY HIGH EXPOSURES - F. A. Garner, G. W. Hollenberg and J. L. Ryan (Pacific Northwest Laboratory) ${ }^{a}$, Z. Li (Argonne National Laboratory) ${ }^{b}$, C. A. Black and R. C. Bradt (University of Nevada-Reno)

\section{OBJECTIVE}

The objective of this effort is to identify ceramic materials that are suitable for fusion reactor applications.

\section{SUMMARY}

Stoichiometric $\mathrm{MgAl}_{2} \mathrm{O}_{4}$ spinel specimens irradiated in FFTF-MOTA at temperatures between 385 and $750^{\circ} \mathrm{C}$ to fluences ranging from 2.2 to $24.9 \times 10^{22} \mathrm{n} \mathrm{cm}^{-2}(\mathrm{E}>0.1 \mathrm{MeV})$ darken significantly, but do not develop any significant loss in weight or change in dimensions. Similar behavior was observed in both single crystal and fully dense polycrystalline specimens. Measurements of elastic constants by an ultrasonic technique show that no measurable changes occur as a result of the irradiation. These and other results confirm the stability of this material for fusion application as an electrical insulator.

\section{PROGRESS AND STATUS}

\section{Introduction}

Magnesium aluminate spinel is an electrical insulator that has been considered as a potential fusion reactor candidate material for service as dielectric windows for radio frequency heating systems or as insulators for magnetic coils.[1] Previous irradiation studies have shown that the dimensional stability of this material is remarkably insensitive to neutron-induced damage at exposures up to $2 \times 10^{22} \mathrm{n} / \mathrm{cm}^{2} \cdot[2-5]$

Irradiation to very high exposures in FFTF/MOTA of very high purity $\mathrm{MgAl}_{2} \mathrm{O}_{4}$ spinel, both single crystal and fully dense hot-pressed polycrystalline, is now complete. An extensive program of both nondestructive and destructive examination is now in progress. The first series of results are presented in this paper.

\section{Experimental Details}

Table 1 presents the composition of the three high-purity starting materials that were employed in this experiment, all of which were highly stoichiometric in composition, with $\mathrm{MgO}: \mathrm{Al}_{2} \mathrm{O}_{3}$ at $1: 1$. ${ }^{-}$Three specimen types and two specimen geometries were employed in this experiment. The three types are hot pressed (HP) polycrystals at 100\% of theoretical density, [100]-oriented single crystals, and [111]-oriented single crystals. The single crystal specimens were oriented with the specified crystalline direction in the axial or height direction of the specimen. Most of the specimens are in the form of $\sim 0.19$ in $(4.8 \mathrm{~mm})$

apacific Northwest Laboratory is operated for the U.S. Department of Energy by Battelle Memorial Institute under Contract DE-AC06-76RLO 1830.

${ }^{b}$ Work supported by U.S. Department of Energy, Basic Energy Sciences - Materials Science under Contract W-31-109-ENG-38. 
Table 1. Chemical composition ${ }^{(a)}$ of spinel specimens (appm) determined by spectrographic analysis

\begin{tabular}{|c|c|c|c|}
\hline & $100^{(b)}$ & $111^{(b)}$ & $H P^{(c)}$ \\
\hline $\mathrm{Li}$ & 0.01 & 0.1 & $>50$ \\
\hline B & 0.3 & $<0.1$ & $<0.1$ \\
\hline $\mathrm{Na}$ & 5 & 5 & 5 \\
\hline $\mathrm{Si}$ & 600 & $<60$ & 60 \\
\hline $\mathbf{P}$ & 1 & 0.5 & 10 \\
\hline $\mathbf{S}$ & 90 & 90 & 300 \\
\hline $\mathrm{Cl}$ & 10 & 10 & 10 \\
\hline $\mathrm{K}$ & $<10$ & $<10$ & $<10$ \\
\hline $\mathrm{Ca}$ & 10 & 40 & 10 \\
\hline Sc & 10 & 10 & 30 \\
\hline $\mathrm{Ti}$ & 10 & 10 & 40 \\
\hline $\mathbf{V}$ & 3 & 3 & 8 \\
\hline $\mathrm{Cr}$ & 4 & 10 & 4 \\
\hline $\mathrm{Mn}$ & 5 & $<2$ & $<2$ \\
\hline $\mathrm{Fe}$ & 80 & 30 & 30 \\
\hline Co & 0.2 & $<0.2$ & 0.2 \\
\hline $\mathrm{Ni}$ & 1 & 1 & 1 \\
\hline $\mathrm{Cu}$ & 3 & 1 & $<0.3$ \\
\hline $\mathrm{Ga}$ & 9 & 30 & 3 \\
\hline $\mathrm{Ge}$ & 10 & 4 & $<4$ \\
\hline Mo & 7 & $<2$ & $<2$ \\
\hline Sn & $<2$ & $<2$ & $<2$ \\
\hline
\end{tabular}

(a) Major constituents determined by stoichiometry derived from x-ray diffraction to be $37.9 \mathrm{wt} \%$ aluminum, $45.0 \mathrm{wt} \%$ oxygen, and $17.1 \mathrm{wt} \%$ magnesium

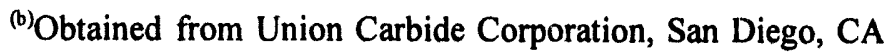

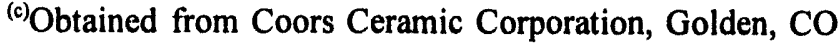


diameter cylindrical pellets. The height of the pellets varies with specimen type, as shown in Figure 1. The heights were $\sim 0.23$ in $(5.8 \mathrm{~mm})$ for HP, $\sim 0.17$ in $(4.3 \mathrm{~mm})$ for [111] and $\sim 0.11$ in $(2.8 \mathrm{~mm})$ for [100]-oriented specimens. The height variations were used as a back-up identification system in case radiation-induced darkening obscured the primary identification, whereby laser etching was employed to mark the sides of the specimens with an individual identification code.

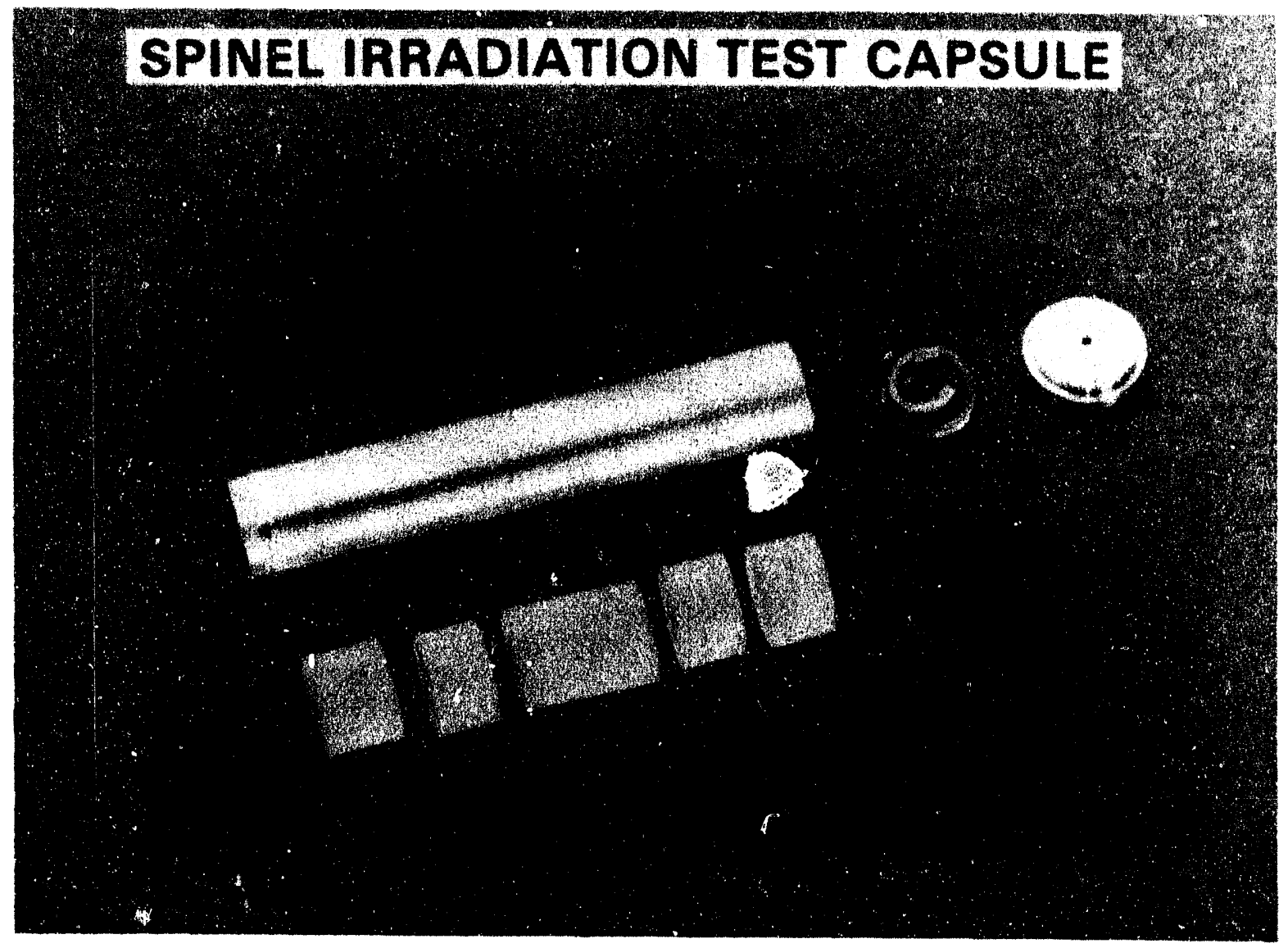

Fig. 1. Contents of typical irradiation capsule for pellet specimens.

The other specimen geometry is in the form of $\sim 0.5$ in $(12.7 \mathrm{~mm})$ square plates with thicknesses comparable to those of the heights of the pellet specimens. The plates were produced by diamond parallel sur face grinding, and the pellets were made by diamond core drilling of the plate material.

Prior to irradiation, the specimens were weighed and their dimensions measured to 0.0001 in $(0.00025 \mathrm{~cm})$ using a ZYGO 110 Laser Telemetric System. Diameters of the pellets were measured using the average of three measurements at orientations approximately $60^{\circ}$ apart. The heights of the plates were determined by averaging six measurements across both diagonals of the square plates. The specimens were then uitrasonically washed in distilled water, air dried, ultrasonically washed in ethyl alcohol, and then dried in air at $200^{\circ} \mathrm{C}$ for $24 \mathrm{~h}$ to remove adsorbed water before being sealed in a hermetic storage container.

The specimens were later removed from the storage container and placed in irradiation capsules filled with helium gas at $1 \mathrm{~atm}$ and room temperature. Each capsule was closed by electron beam welding under 
helium and then helium leak checked. The capsules were constructed of D9 titanium-modified steel. Each of the pellet-containing capsules contained a molybdenum spring and five specimens, specifically, one HP specimen and two each of the two single crystal orientations, as shown in Figure 1.

The nominal irradiation conditions experienced by the pellets in the FFTF reactor were 22.9 and $24.9 \mathrm{x}$ $10^{22} \mathrm{n} / \mathrm{cm}^{2}(\mathrm{E}>0.1 \mathrm{MeV})$ at $385^{\circ} \mathrm{C} ; 5.3 \times 10^{22} \mathrm{n} / \mathrm{cm}^{2}$ at $405^{\circ} \mathrm{C}$; and $5.6,13.7$, and $21.7 \times 10^{22} \mathrm{n} / \mathrm{cm}^{2}$ at $750^{\circ} \mathrm{C}$.

The emphasis on nominal irradiation conditions reflects the fact that these specimens started irradiation in the MOTA-ID experiment, in which the specimens experienced an overtemperature event in the middle of FFTF cycle 7 of about 50 min duration. This temperature excursion was followed by a prolonged and variable undertemperature history in cycle 8 . Only the $750^{\circ} \mathrm{C}$ irradiation experienced a significant variation in temperature, however, reaching $934^{\circ} \mathrm{C}$ for $50 \mathrm{~min}$ and then running at a range of temperatures well below $750^{\circ} \mathrm{C}$ throughout cycle 8 . For the second and third irradiation sequences conducted in FFTF cycles 9,10 , and 11 in MOTA-1E, $1 \mathrm{~F}$, and 1G, respectively, the temperatures were held to $\pm 5^{\circ} \mathrm{C}$ of the target temperatures.

The square plate specimens were placed in larger D-9 capsules in the MOTA below-core canister at $365^{\circ} \mathrm{C}$ and irradiated to 2.2 and $4.6 \times 10^{22} \mathrm{n} / \mathrm{cm}^{2}(E>0.1 \mathrm{MeV})$. No excursions in temperature occurred for these specimens.

After irradiation, the specimens were removed from the capsules and cleaned, and then their weights and dimensions measured using the same techniques employed prior to irradiation. The optical absorbance of the specimens at the 385 and $750^{\circ} \mathrm{C}$ irradiation conditions was measured with a CARY 14 spectrophotometer. An ultrasonic technique was used to determine the elastic moduli of the irradiated spinel specimens. The sound velocities of the [100] and [111] oriented single crystals were measured by the phase comparison method [6,7] in the 20 to $60 \mathrm{MHz}$ frequency range. Four sets of sound velocity measurements were made for the longitudinal and transverse acoustic modes in directions normal to the $(100)$ and (111) faces of the specimens. The elastic moduli $\left(C_{11}, C_{12}, C_{44}\right)$ were derived from those sound velocities $V_{L}$ and $V_{T}$ as

$$
\begin{aligned}
& \rho V_{L}^{2}=C_{11} \\
& \rho V_{T}^{2}=C_{44}
\end{aligned}
$$

for the $\{100\}$ oriented specimens and

$$
\begin{gathered}
\rho V_{L}^{2}=\left(C_{11}+2 C_{12}+4 C_{44}\right) / 3 \\
\rho V V_{T}^{2}=\left(C_{11}-C_{12}+C_{44}\right) / 3
\end{gathered}
$$


for the [111] oriented specimens, where $\mathrm{L}$ and $\mathrm{T}$ denote the longitudinal and transverse vibration modes, respectively, and $\rho$ is the density of the specimens at $3.55 \mathrm{gm} / \mathrm{cm}^{3}$. The measurements were carried out at room temperatures varying from 21 to $23^{\circ} \mathrm{C}$. For coupling of the longitudinal acoustic waves between the sample crystal and the fused silica buffer rod, "Nonaq" stopcock grease was used as a bonding material, whereas solid salol was used for coupling of the transverse acoustic wave.

\section{$\underline{\text { Results }}$}

Due to their high purity, the specimens were only mildly radioactive and non-smearable, and therefore could be easily handled. Prior to irradiation, the single crystal specimens were transparent, and the hotpressed specimens were translucent and white. In regular light, the irradiated specimens all appear to be very dark, but placing them in front of a high intensity microscope light showed that some light was transmitted, with colors ranging from yellow to dark red. The color change deepened with both the irradiation dose and the specimen thickness.

At these thicknesses and exposure levels, the specimens pressed the limits of the measurement capability of the spectrophotometer. Consistent with their red coloration, the absorbance was found to increase rapidly at lower wavelengths, becoming stronger with neutron exposure at both 385 and $750^{\circ} \mathrm{C}$. A shoulder peak in absorbance at $510 \mathrm{~nm}$ was evident in the lowest exposure specimens at both temperatures. The continued presence of this peak at higher fluence, and the possible presence of other peaks at lower wavelengths could not be determined at these large absorbance levels, however.

The weights of the specimens remained essentially unchanged, with all measurements ranging from 0.0 to $\sim 0.2 \%$ loss in weight. The loss, if any, was always in the fourth significant figure and may be related either to different levels of adsorbed moisture before and after irradiation or to small chips lost during handling.

All post-irradiation dimensional measurements fell within $\pm 1 \%$ of the preirradiation measurements, with most below $\pm 0.5 \%$. Combining the point-to-point variations observed in thickness and the reproducibility of the measurements, it appears that the measured variations in preirradiation dimensions were $\leq 1 \%$. There were no discernible trends of these small differences with respect to orientation, irradiation temperature, neutron fluence, or specimen type. The obvious conclusion is that no significant irradiationinduced changes occurred in the dimensions of these specimens.

Table 2 summarizes the elastic stiffness moduli of the spinels at each irradiation level. The values of $C_{11}$ and $C_{44}$ were directly determined from [100] oriented samples using equations $1 \mathrm{a}$ and $\mathrm{lb}$. The values of $C_{12}$ were obtained from [111] oriented samples by using either equation $2 a$ or $2 b$. The $C_{12}$ values listed in Table 2 are the average values determined from these equations. The potential errors in the velocity and elastic moduli are estimated to be less than $2 \%$, with the largest uncertainties coming from the measurement of the sample thickness and sample density. The error range was confirmed by crosschecking the $C_{12}$ values calculated from both equations $2 a$ and $2 b$. For example, the values of $C_{12}$ were 150 and 151 calculated from equations $2 \mathrm{a}$ and $2 \mathrm{~b}$, respectively, for samples irradiated at $750^{\circ} \mathrm{C}$ to 21.7 $x 10^{22} \mathrm{n} \mathrm{cn}^{2}{ }^{2}(\mathrm{E}>0.1 \mathrm{MeV})$. These values are in excellent agreement with each other.

From Table 2, it is evident that the elastic constants remain unchanged for different levels of neutron irradiation. Table 2 also lists the polycrystalline elastic moduli, Young's modulus E, shear modulus G, and Possion's ratio $v$ calculated from elastic constants of the single crystals using the Voigt-Reuss-Hill average scheme. These elastic moduli were also found to be independent of irradiation. 
Table 2 Elastic properties of $\mathrm{MgAl}_{2} \mathrm{O}_{4}$ spinel as a function of irradiation condition

\begin{tabular}{||l|c|c|c|c|c|c||}
\hline & $\mathrm{C}_{11}$ & $\mathrm{C}_{12}$ & $\mathrm{C}_{44}$ & $\mathrm{E}$ & $\mathrm{G}$ & $v$ \\
\hline & $(\mathrm{GPa})$ & $(\mathrm{GPa})$ & $(\mathrm{GPa})$ & $(\mathrm{GPa})$ & $(\mathrm{GPa})$ & \\
\hline Unirrad. & 280 & 155 & 156 & 274 & 108 & 0.27 \\
\hline $24.9^{\mathrm{a}} / 385^{\circ} \mathrm{C}$ & 288 & 157 & 150 & 274 & 108 & 0.27 \\
\hline $5.3 / 404^{\circ} \mathrm{C}$ & 285 & 158 & 153 & 273 & 108 & 0.27 \\
\hline $5.6 / 750^{\circ} \mathrm{C}$ & 283 & 156 & 156 & 276 & 109 & 0.27 \\
\hline $13.7 / 750^{\circ} \mathrm{C}$ & 283 & 154 & 152 & 273 & 108 & 0.27 \\
\hline $21.7 / 750^{\circ} \mathrm{C}$ & 278 & 151 & 152 & 271 & 107 & 0.27 \\
\hline
\end{tabular}

${ }^{\mathrm{a}}$ Fluence in units of $10^{22} \mathrm{n} \mathrm{cm}^{-2}(\mathrm{E}>0.1 \mathrm{MeV})$

\section{CONCLUSIONS}

The elastic mechanical properties and dimensional stability of high-purity stoichiometric $\mathrm{MgAl}_{2} \mathrm{O}_{4}$ spinel appear to be remarkably resistant to irradiation at temperatures in the range $385-750^{\circ} \mathrm{C}$. The single problem observed is its tendency to darken with neutron exposure, but this is not expected to interfere with the performance of this material as an electrical insulator.

\section{REFERENCES}

1. F. W. Clinard, Jr., G. F. Hurley, and R. W. Klaffky, Res. Mech. 8 (1983) 207.

2. G. F. Hurley and J. M. Bunch, Am. Ceram. Soc. Bull. 59 (1980) 456.

3. F. W. Clinard, Jr., G. F. Hurley, and L. W. Hobbs, J. Nucl. Mater. 108-109 (1982) 655.

4. Y. Fukushima, T. Yano, T. Maruyama, and T. Iseki, J. Nucl. Mater. 175 (1990) 203.

5. H. Suematsu, T. Iseki, T. Yano, Y. Saito, T. Suzuki, and T. Mori, J. Am. Ceram. Soc. 75 (1992) 1742.

6. E. S. Fisher and H. J. McSkimin, J. Appl. Phys. 29 (1958) 1473.

7. Z. Li, E. S. Fisher, J. Z. Liu, and M. V. Nevitt, J. Mater. Sci. 26 (1991) 2621. 
INFLUENCE OF HIGH DOSE NEUTRON IRRADIATION AT 385 AND $750^{\circ} \mathrm{C}$ ON THE MICROHARDNESS OF $\mathrm{MgAl}_{2} \mathrm{O}_{4}$ SPINEL C. A. Black (University of Nevada-Reno), F. A. Garner (Pacific Northwest Laboratory) ${ }^{2}$, R. C. Bradt (University of Nevada-Reno)

\section{OBJECTIVE}

The objective of this effort is to identify ceramic materials that are suitable for fusion reactor applications.

\section{SUMMARY}

High-purity specimens of stoichiometric $\mathrm{MgAl}_{2} \mathrm{O}_{4}$ single crystal spinel and a hot-pressed polycrystalline ceramic spinel were irradiated to exposures as large as $24.9 \times 10^{22} \mathrm{n} \mathrm{cm}^{-2}(\mathrm{E}>0.1 \mathrm{MeV})$ in FFTF at $385^{\circ} \mathrm{C}$ and $750^{\circ} \mathrm{C}$. The specimens did not develop any brittleness or fragility, and maintained their physical integrity. Microhardness measurements revealed that initially all specimens hardened a small amount and then recovered slightly. At the lower irradiation temperature, the dependence of microhardness on orientation observed prior to irradiation tended to disappear. There was also some evidence that a secondary slip system was being activated. Following $750^{\circ} \mathrm{C}$ irradiation, the orientation dependence was not lost, and the evidence for activation of a secondary slip system was stronger.

\section{PROGRESS AND STATUS}

Introduction

Stoichiometric $\mathrm{MgAl}_{2} \mathrm{O}_{4}$ spinel has been proposed as a potential electrical insulator ceramic for use in fusion reactors, primarily because, unlike other ceramics, it has demonstrated a remarkable insensitivity to neutron irradiation to levels as high as $2 \times 10^{22} \mathrm{n} \mathrm{cm}^{-2}(\mathrm{E}>0.1 \mathrm{MeV}){ }^{(1-9)}$ While spinels would most likely be employed in a dense hot-pressed polycrystalline form, it is advantageous to conduct fundamentally-oriented studies on the radiation response of this material using single crystal specimens in addition to hot-pressed specimens. Therefore, an extensive irradiation program using both types of specimens has been conducted in FFTF, reaching exposure levels an order of magnitude or more larger than those of all earlier studies ${ }^{(10)}$. The focus of the present paper is the effect of radiation on the microhardness of this material and its dependence on crystallographic orientation. This information will eventually be coupled with the results of examination by electron microscopy to determine the microstructural origins of the radiation resistance of this ceramic.

The single crystal spinel used in this study has been previously examined in the unirradiated condition and the results published by Akimuni and Bradt ${ }^{(11)}$. They showed that the (100) plane exhibits a maximum microhardness in the [001] direction and a minimum in the [011] direction, consistent with a primary slip system of $\{111\}<110\rangle$. The microhardness on the (111) plane was shown to be independent of indenter orientation, which is also consistent with that primary slip system. It was anticipated that the hardness response might change as radiation-induced microstructure was accumulated.

"Pacific Northwest Laboratory is operated for the U.S. Department of Energy by Battelle Memorial Institute under Contract DE-AC06-76RLO 1830. 


\section{Experimental Details}

High-purity stoichiometric $\mathrm{MgAl}_{2} \mathrm{O}_{4}$ was obtained as transparent 2-cm boules with either [100] or [111] growth direction from Union Carbide Corporation. Hot-pressed polycrystalline $\mathrm{MgAl}_{2} \mathrm{O}_{4}$ of $100 \%$ theoretical density and comparable purity was obtained from the Coors Ceramic Corporation. The detailed composition of the three starting materials, the fabrication of the individual specimens, and the details of the irradiation are presented in ref. 10. These materials were irradiated in the Materials Open Test Assembly (MOTA) of the Fast Flux Test Facility (FFTF) at $385^{\circ} \mathrm{C}$ to $2.2,4.6$, and $24.9 \times 10^{22} \mathrm{n} \mathrm{cm}^{-2}$ $(\mathrm{E}>0.1 \mathrm{MeV})$, and at $750^{\circ} \mathrm{C}$ to $5.6,13.7$, and $21.7 \times 10^{22} \mathrm{n} \mathrm{cm}^{-2}(\mathrm{E}>0.1 \mathrm{MeV})$. Using a rough conversion factor of $\sim 10 \mathrm{dpa}$ per $10^{22} \mathrm{n} \mathrm{cm}^{-2}(\mathrm{E}>0.1 \mathrm{MeV})$, the highest displacement level reached was $\sim 250 \mathrm{dpa}$.

Depending on the specific irradiation conditions, some specimens were in the form of $4.8 \mathrm{~mm}$ diameter cylinders, and some were in the form of square plates. The flat surfaces of the cylinders and the major flat surfaces of the plates were parallel to the (100) and (111) planes for the [100] and [111] specimens, respectively.

After irradiation, the specimens were vacuum-mounted with Buehler Epa-Thin epoxy, using three aluminum oxide thermocouple sheaths set around the specimen to insure that the original crystallographic orientation of the specimen surface was maintained during polishing. The mounted specimens were polished with progressively finer diamond pastes $(30,15,1 \mu \mathrm{m})$ on a vibratory polishing machine. Unirradiated specimens were also prepared in an identical manner. Contrary to expectations, the specimens did not develop any brittleness or fragility, and maintained their physical integrity during irradiation, polishing, and testing.

While still mounted, the specimens were measured for microhardness. Since the microhardness is loaddependent in these materials, especially for loads less than $500 \mathrm{~g}$, preliminary tests were conducted at 25, 50,100 , and $200 \mathrm{~g}$ force. Two load levels were then chosen to determine the true hardness.

Knoop microhardness was measured at room temperature using 100 and $200 \mathrm{~g}$ loads at a load application rate of $17 \mu \mathrm{m} / \mathrm{sec}$ for $15 \mathrm{sec}$. The microhardness tester was a Tukon Model 300 fitted with a Wilson digital filar eyepiece accurate to 0.1 micrometers. A goniometer with $\pm 1^{\circ}$ of accuracy was designed to hold the mounted crystal on the hardness tester. For each crystallographic orientation, 10 parallel indents were made with approximately $100 \mu \mathrm{m}$ between each measurement. Indentations resulting in cracks were not recorded, and repeat measurements were made. The tendency to occasionally develop cracks radiating from the hardness indents was minimal and did not appear to change with irradiation.

From the long diagonal length (d) in mm the Knoop microhardness $\left(\mathrm{H}_{\mathrm{k}}\right)$ was calculated using the standard equation where $\mathbf{P}$ is the test load:

$$
\mathrm{H}_{\mathrm{k}}=\mathrm{P}(\mathrm{g}) / 0.7028 \mathrm{~d}^{2} \text { in } \mathrm{Kg} \mathrm{mm} \mathrm{mm}^{-2}
$$

True hardness was calculated from the slope of a P/d vs. $d$ graph after applying the above equation to calculate the hardness value $\mathrm{H}_{\mathrm{k}}$.

On the cylindrical (100) single crystal specimens, nine equally spaced orientations were used over a total range of $90^{\circ}$. Because of the crystal symmetry, these were sufficient to characterize the microhardness anisotropy profile for the entire (100) plane. Indents on the (111) single crystals were also performed over $90^{\circ}$ at five equally spaced orientations.

The square (100) specimens were cut so that the [001] direction was parallel to the edge on the specimen, and in this manner, the orientation of the specimen was preserved. After confirming the already known 
anisotropy of the (100) plane on the square specimens, a random starting point was used on the cylindrical specimens. Later analysis of the (100) cylindrical specimen data assumed the maximum measured hardness to be the [001] direction and the minimum to be the [011] direction. Since the (111) plane showed no orientation dependence, the random starting point on the cylindrical specimens was chosen as the $0^{\circ}$ position.

\section{$\underline{\text { Results }}$}

Figure 1 shows the nearly identical hardness vs. load response of the hot-pressed polycrystalline ceramic spinel and the [111] single crystal specimens in the unirradiated condition. A similar dependence on load was also observed as the specimens hardened with irradiation, as shown in Figures 2 and 3 . Note in Figure 2 that a saturation level of hardness was reached in the hot-pressed specimens irradiated at $385^{\circ} \mathrm{C}$ for each load level, but the duration of the transient regime of hardening was found to be load-dependent, being slower to saturate at the higher load.

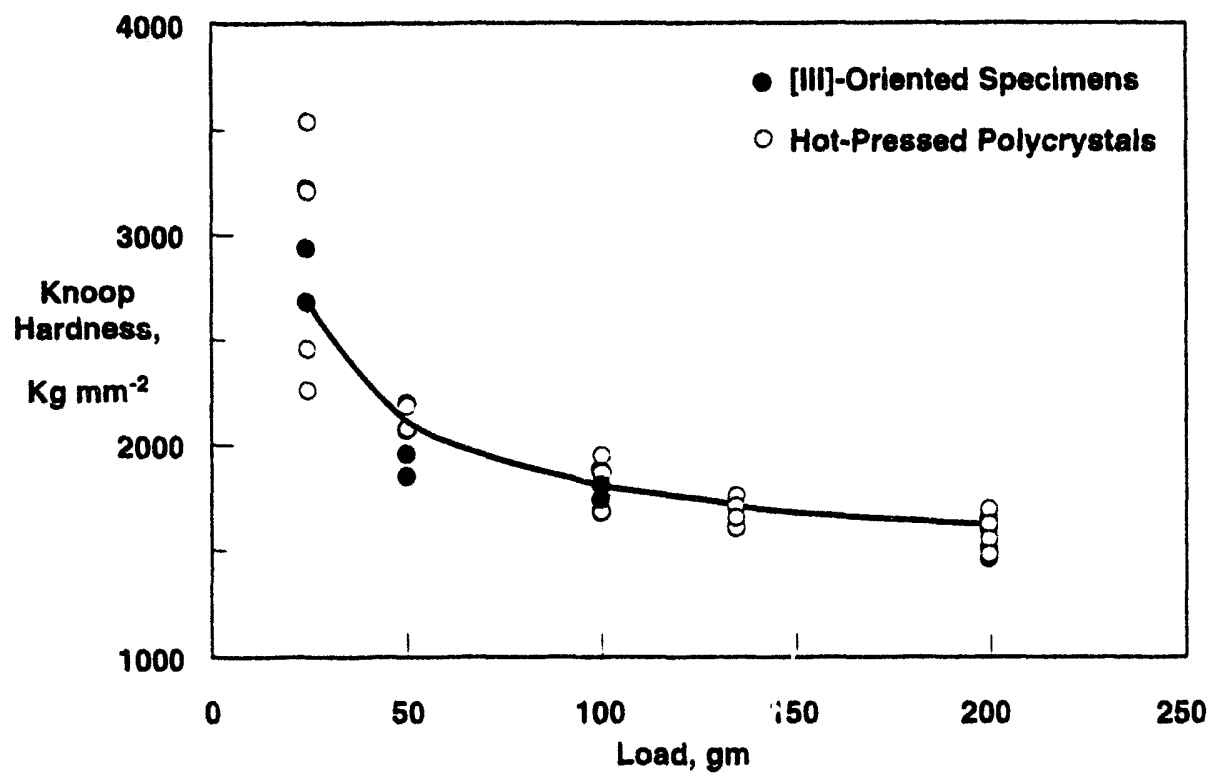

Fig. 1. Microhardness response vs applied load for unirradiated $\mathrm{MgAl}_{2} \mathrm{O}_{4}$ single crystal and hotpressed polycrystal specimens.

Similar levels of hardening were observed in the single crystal specimens irradiated at $385^{\circ} \mathrm{C}$, as shown in Figures 3 and 4 . In the unirradiated condition, the [100] specimens exhibited the same dependence on crystalline orientation that was observed earlier by Akimuni and Bradt ${ }^{(11)}$. However, but the degree of anisotropy of the orientation dependence on the (100) plane was observed to decrease as the specimens hardened. The majority of the hardening occurred during the first irradiation increment. In addition, there is some suggestion that a second minimum in hardness vs. orientation was developing at the highest exposures level, suggesting that a secondary' slip system may have been activated. 


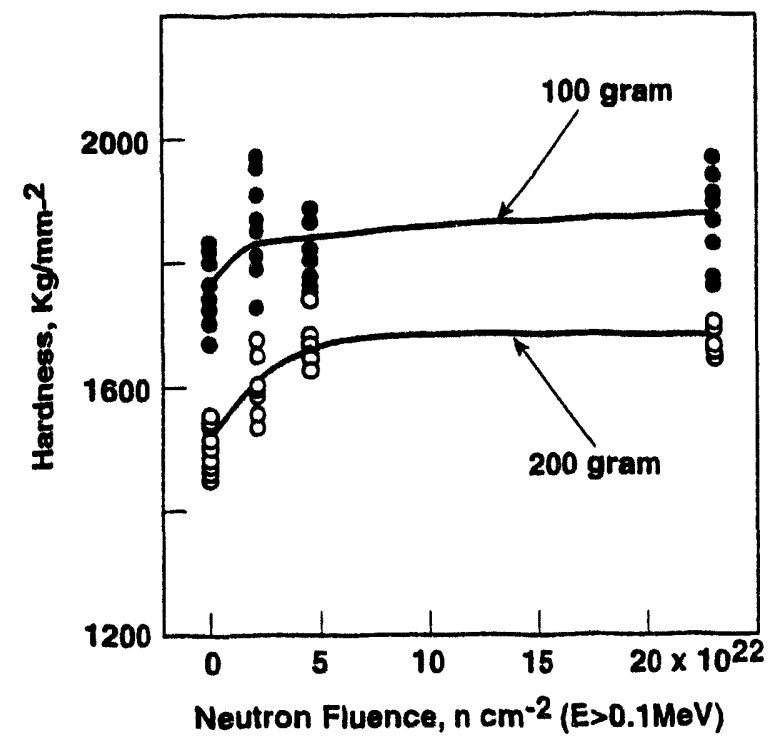

Fig. 2. Evolution of microhardness of hot-pressed polycrystals irradiated at $385^{\circ} \mathrm{C}$.
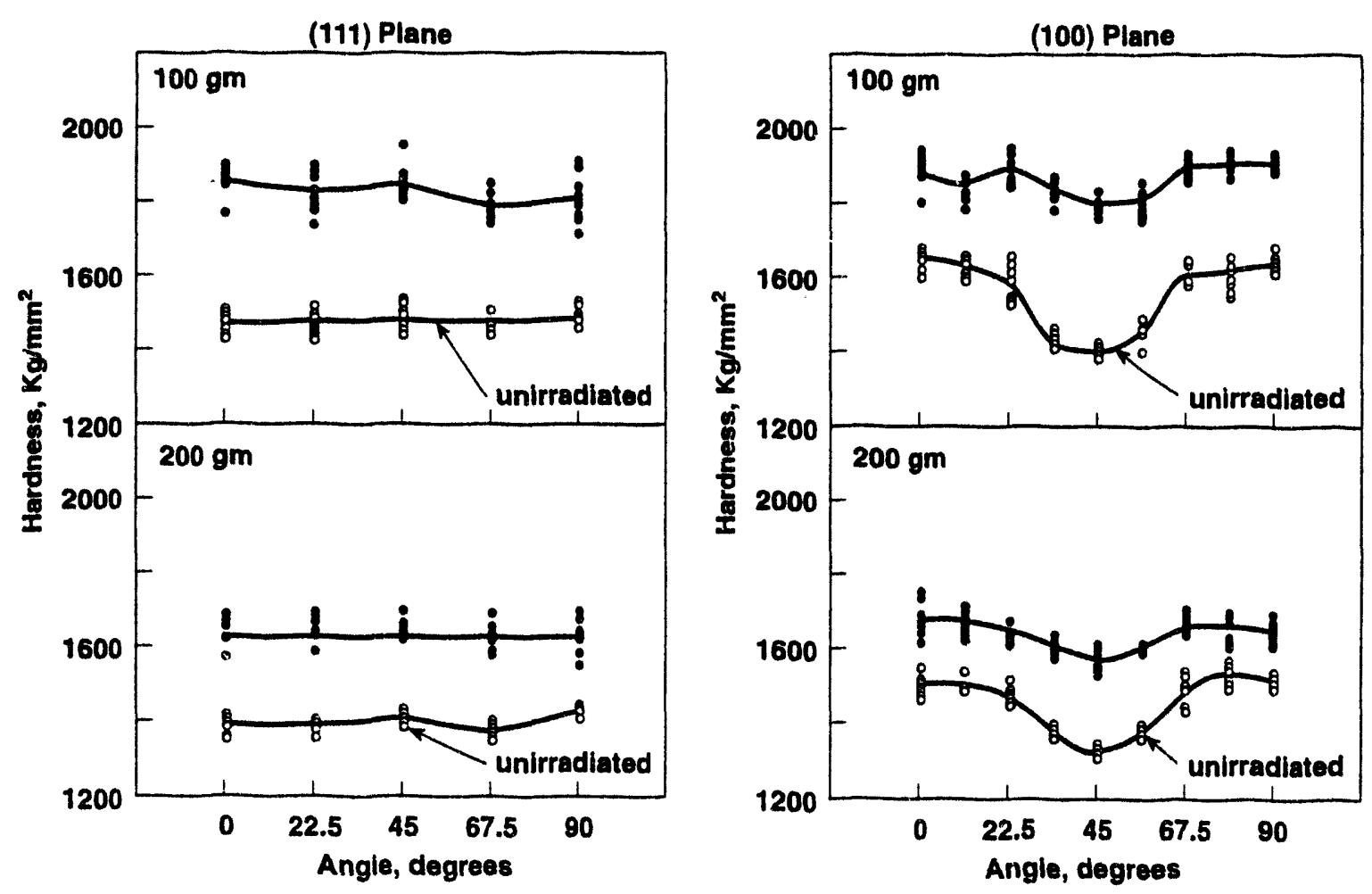

Fig. 3. Changes in microhardness induced in single crystal specimens irradiated to $2.2 \times 10^{22}$ $\mathrm{n} \mathrm{cm}^{-2}(\mathrm{E}>0.1 \mathrm{MeV})$ at $385^{\circ} \mathrm{C}$. 


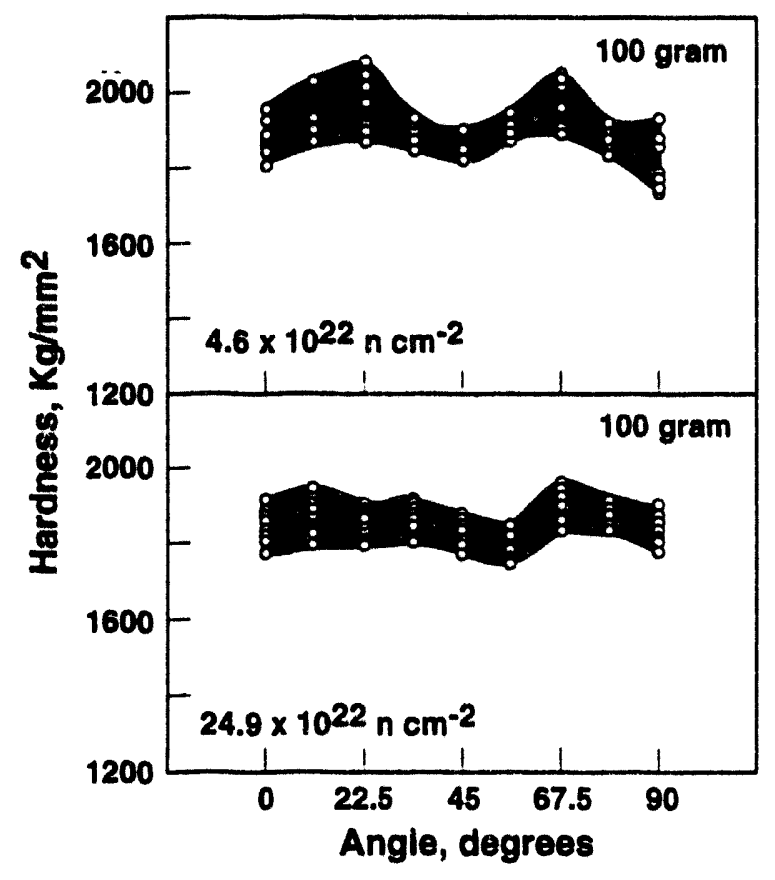

Fig. 4. Microhardness vs. orientation on the (100) plane for higher exposure levels at $385^{\circ} \mathrm{C}$.

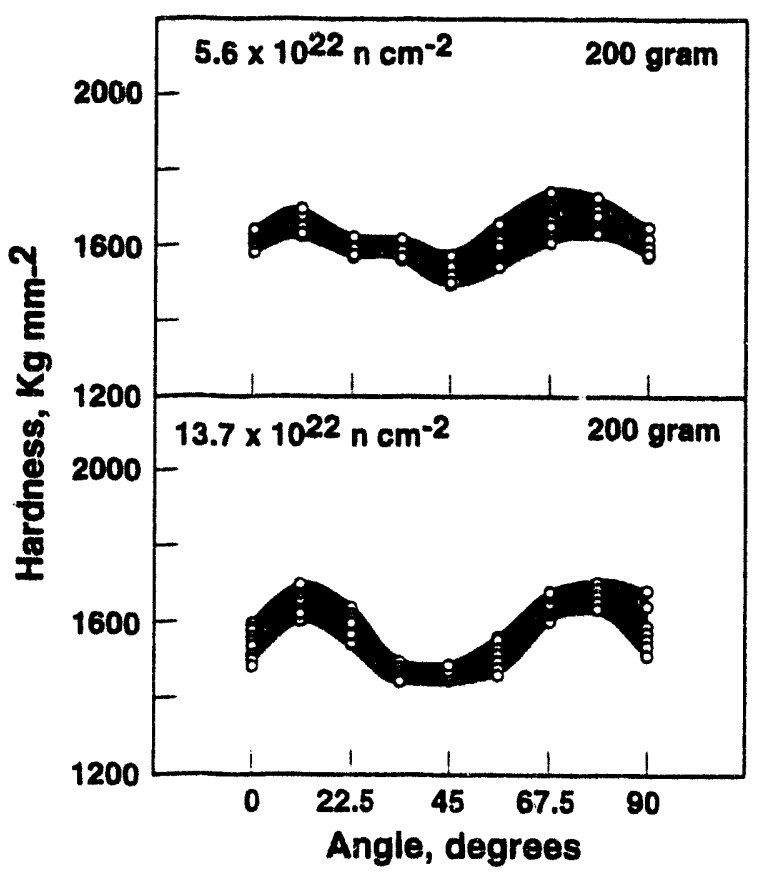

Fig. 6. Microhardness vs. (100) orientation dependence for single crystal specimensirradiated at $750^{\circ} \mathrm{C}$, observed using a $200 \mathrm{~g}$ load.

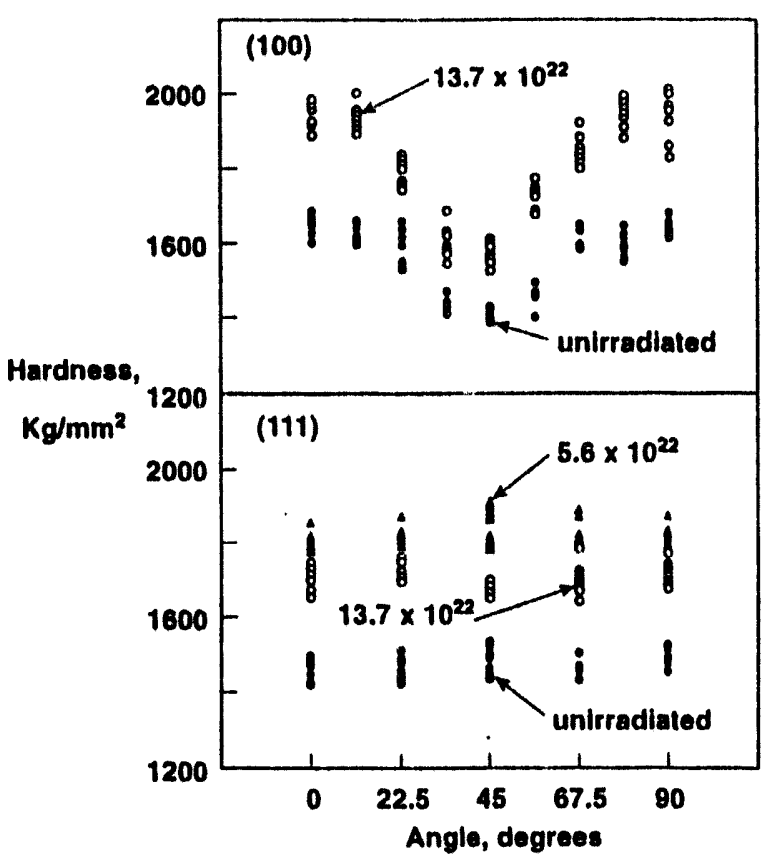

Fig. 5. Hardening and softening observed in single crystal specimens irradiated at $750^{\circ} \mathrm{C}$ and tested with a $100 \mathrm{~g}$ load.

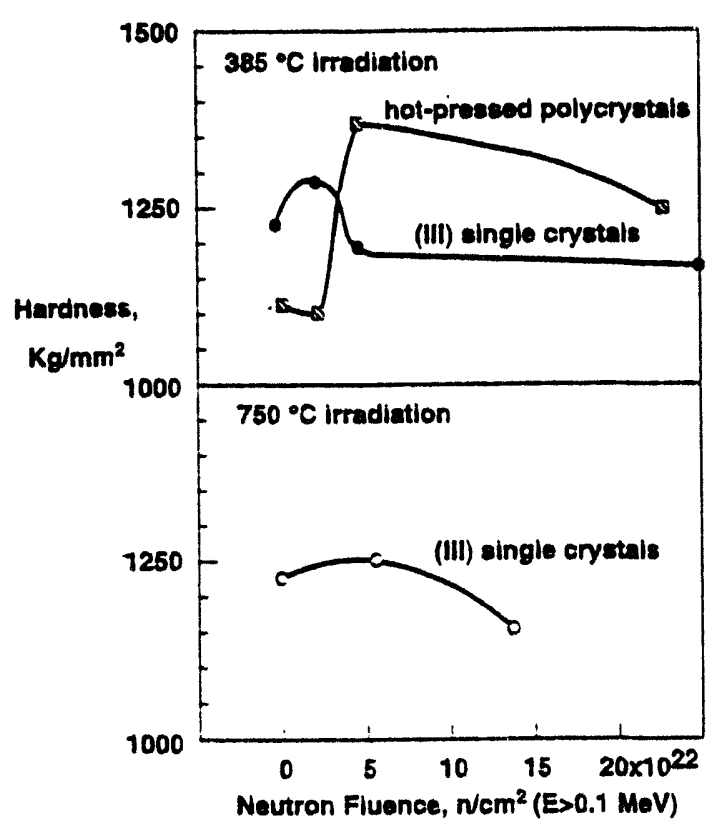

Fig. 7. Influence of radiation on "true" hardness. 
At an irradiation temperature of $750^{\circ} \mathrm{C}$, the microhardness first increased with irradiation and then subsequently decreased, as shown in Figure 5. Even more important, however, the orientation dependence on the (100) plane was not reduced as for irradiation at $385^{\circ} \mathrm{C}$. The tendency to develop a secondary minimum appeared to be stronger for irradiation at $750^{\circ} \mathrm{C}$, especially when higher indentation test loads were applied, as shown in Figure 6.

\section{Discussion}

Figure 7 shows the calculated true hardness values derived from the data generated at 100 and $200 \mathrm{~g}$ loads. The tendency to first harden and then soften with increasing exposure occurred for all three types of specimens, with the largest changes observed in the hot-pressed polycrystals at $385^{\circ} \mathrm{C}$. In each case, the radiation-induced increases in microhardness were relatively small and of no significan 9 for fusion application. The softening may be evidence for a self-healing process that may be unique to this spine and is operating throughout the irradiation to limit the cumulative damage.

It is interesting to note that the microhardness of the polycrystalline ceramics at $385^{\circ} \mathrm{C}$ appears to be approaching that of single crystals. The role of pre-existing grain boundaries and random grain orientations in the polycrystals seems to have produced a somewhat softer material before irradiation. However, the sink strength associated with these grain boundaries may also compete with the self-healing process and may therefore not allow the radiation-induced hardening to relax as quickly as was observed in the single crystals.

The loss of the orientation dependence on the $(100)$ plane at $385^{\circ} \mathrm{C}$ can be understood in terms of radiation-induced formation of defect aggregates that block the movement of dislocations on the primary slip system. The activation of a secondary slip system may have been facilitated by the development of radiation-induced dislocation microstructure. Microscopy analysis of these specimens at the highest fluence levels is in progress. Eariy results at $385^{\circ} \mathrm{C}$ show formation of high density of $1 / 4[110]$ dislocation loops $\left(15-70 \mathrm{~nm}\right.$ diameter) and tangled dislocations ${ }^{12}$. At $750^{\circ} \mathrm{C}$, there is a small number of voids ( $7 \mathrm{~nm}$ diameter) and extended 1/4[110] stacking faults. The substantially lower density of radiation-induced microstructure at $750^{\circ} \mathrm{C}$, compared to that at $385^{\circ} \mathrm{C}$, probably explains why the orientation dependence of hardness on the (100) plane persists to very high fluences.

The relatively small effect of radiation in hardening of this material at such high neutron exposure levels confirms its overall radiation resistance and its suitability for fusion use. As noted in ref. 10, the elastic properties and dimensional stability of these specimens were also unaffected by radiation.

\section{CONCLUSIONS}

High temperature irradiation of high-purity stoichiometric $\mathrm{MgAl}_{2} \mathrm{O}_{4}$ spinel to very high neutron exposures induces a small amount of hardening that does not impair its application to fusion needs. The hardening peaks early in the irradiation and then relaxes somewhat at higher exposure levels. The details of the hardening process are somewhat sensitive to applied load, crystal orientation, irradiation temperature, and the exposure level. The dimensional and mechanical stability to displacement levels as large as $250 \mathrm{dpa}$ suggests that an efficient self-healing process that does not operate in other ceramics may be operating in this material. 


\section{REFERENCES}

1. G. F. Hurley, and J. M. Bunch, Am. Ceram. Soc. Bull. 59 (1980) 456.

2. F. W. Clinard, Jr., G. F. Hurley and L. W. Hobbs, J. Nucl. Mater. 108-109 (1982) 655.

3. G. F. Hurley, J. C. Kennedy, F. W. Clinard Jr., R. A. Youngman, and W. R. McDonell, J. Nucl. Mater. 103\&104 (1981) 761.

4. F. W. Clinard, Jr., G. F. Hurley, and R. W. Klaffky, Res. Mech. 8 (1983) 207.

5. F. W. Clinard Jr., G. F. Hurley, L. W. Hobbs, D. L. Rohr, and R. A. Youngman, J. Nucl. Mater. $122 \& 123(1984) 1386$.

6. F. W. Clinard Jr., G. F. Hurley, R. A. Youngman, and L. W. Hobbs, J. Nucl. Mater. 133\&134 (1985) 701.

7. C. A. Parker, L. W. Hobbs, K. C. Russell, and F. W. Clinard Jr., J. Nucl. Mater. 133\&134 (1985) 741 .

8. Y. Fukushima, T. Yano, T. Maruyama, and T. Iseki, J. Nucl. Mater. 175 (1990) 203.

9. H. Suematsu, T. Iseki, T. Yano, Y. Saito, T. Suzuki, and T. Mori, J. Am. Ceram. Soc. 75 (1992) 1742.

10. F. A. Garner, G. W. Hollenberg, J. L. Ryan, Z. Li, C. A. Black, and R. C. Bradt, in this semiannual report.

11. Y. Akimuni and R. C. Bradt, J. Am. Cer. Soc. (1987) C84-C86.

12. K. Fukumoto, C. Kinoshita, and F. A. Garner, work in progress. 
Distribution

1-16. Argonne National Laboratory, 9700 South Cass Avenue, Argonne, IL 60439
M. C. Billone
Y. Gohar
L. A. Niemark
O. K. Chopra
A. B. Hull
J. H. Park
H. M. Chung
C. E. Johnson
D. L. Smith
D. R. Diercks
F. Kassner
S. W. Tam
R. Erck
B. A. Loomis
H. C. Tsai
A. K. Fisher
R. F. Mattas
H. Wiedersich

17-18. Argonne National Laboratory, EBR-II Division, P.O. Box 2528, Idaho Falls, ID 83403-2528
H. P. Planchon
D. L. Porter

19. Auburn University, Department of Mechanical Engineering, 201 Ross Hall, Auburn, AL 36849 B. A. Chin

20-33. Battelle-Pacific Northwest Laboratory, P.O. Box 999, Richland, WA 99352
J. L. Ethridge
M. L. Hamilton
R. H. Jones
F. A. Garner (5)
H. L. Heinisch
W. W. Laity
D. S. Gelles
G. W. Hollenberg
O. D. Slagle
L. R. Greenwood

34. Carnegie Institute of Technology, Carnegie-Mellon University, Schenley Park, Pittsburgh, PA 15213

W. M. Garrison, Jr.

35-36. EG\&G Idaho, Inc., Fusion Safety Program, P.O. Box 1625, Idaho Falls, ID 83415-3523
D. F. Holland
S. J. Piet

37. GE Astrospace Division, San Jose Operations, 6834 via Deloro, P.O. Box 530954, San Jose, CA 95153-5354

Mike Kangilaski

38-41. General Atomics, P.O. Box 85608, San Diego, CA 92138
T. A. Lechtenberg
D. I. Roberts
K. R. Schultz
C. Wong

42. General Dynamics Corp., 5001 Kearny Villa Rd., San Diego, CA 92138

T. L. Cookson

43. Georgia Institute of Technology, Fusion Research Center, 0225, Atlanta, GA 30332 W. M. Stacey

44. Grand Canyon University, Department of Natural Science, 3300 W. Camelback Rd., Phoenix, AZ 85017 W. A. Coghlan

45-47. Lawrence Livermore National Laboratory, P.O. Box 808, Livermore, CA 94550
E.C.N. Dalder
J. Perkins

M. Guinan

48-55. Los Alamos National Laboratory, P.O. Box 1663, Los Alamos, NM 87545
J. L. Anderson
F. W. Clinard
H. M. Frost
W. F. Sommer
E. H. Farnum
J. C. Kennedy
K. E. Sickafus
R. E. Siemon 
56. Manlabs, Inc., 231 Erie Street, Cambridge, MA 02139

D. Tognarelli

57-59. Massachusetts Institute of Technology, Department of Metallurgy and Materials Science,

Cambridge, MA 02139
L. W. Hobbs
K. C. Russell

N. J. Grant

60-61. Massachusette Institute of Technology, Plasma Fusion Center Headquarters,

Cambridge, MA 02139
H. D. Becker
D. B. Montgomery

62. McDonnell-Douglas Missile Systems Company, Mail Code 306 4204, P.O. Box 516,

St Louis, MO 63166

J. W. Davis

63-65. National Institute of Standards and Technology, Boulder, CO 80302
F. R. Fickett
R. P. Reed
H. I. McHenry

66. National Materials Advisory Board, 2101 Constitution Avenue, Washington, DC 20418 K. M. Zwilsky

67-68. Naval Research Laboratory, Code 6506, Washington, DC 20375
D. L. Gibson
J. A. Sprague

69-109. Oak Ridge National Laboratory, P.O. Box 2008, Oak Ridge, TN 37831
Central Research Library
Document Reference Section
Laboratory Records Department (2)
Laboratory Records-RC
Patent Section
D. J. Alexander
C. C. Baker
J. Bentley
E. E. Bloom
T. D. Burchell
J. H. DeVan
G. M. Goodwin

R. H. Goulding

M. L. Grossbeck

A. F. Rowcliffe (8)

E. A. Kenik

R. L. Klueh

R. L. Senn

J. Sheffield

E. H. Lee

L. L. Snead

R. E. Stoller

A. W. Longest K. R. Thoms

L. K. Mansur

P. F. Tortorelli

P. J. Maziasz

C. A. Wang

J. E. Pawel

D. P. White

T. C. Reuther

S. J. Zinkle

T. K. Roche

110. Oregon Graduate Institute, Dept. of Materials Science \& Engineering, 19600 N.W. Von Neumann Drive, Beaverton, OR 97006

$$
\text { J. M. McCarthy }
$$

111-113. Princeton University, Princeton Plasma Physics Laboratory, P.O. Box 451, Princeton, NJ 08540
C. Bushneil
Long-Poe Ku
H. Furth

114. Reactor Materials Technology, 272 Baywood Avenue, Pittsburgh, PA 15228

A. Boltax

115-116. Rensselaer Polytechnic Institute, Troy, NY 12181

D. Steiner

David Duquette 
117. Rockwell International Corporation, NA02, Rocketdyne Division, 6633 Canoga Avenue, Canoga Park, CA 91304

D. W. Kneff

118-120. Sandia National Laboratories, Fusion Technology Dept., Dept. No 6531, P.O. Box 5800, Albuquerque, NM 87185-5800

M. J. Davis

R. D. Watson

W. B. Gauster

121-122. Sandia National Laboratories, Livermore Division 8316, Livermore, CA 94550
W. Bauer
W. G. Wolfer

123. San Diego State University, Mechanical Engineering Dept., San Diego, CA 92182-0191

L. D. Thompson

124. TSI Research, 225 Stevens Ave., \#110, Solana Beach, CA 92075

E. T. Cheng

125-126. University of California, Dept. of Chemical and Nuclear Engineering, Santa Barbara, CA 93106 G. E. Lucas

G. R. Odette

127-129. University of California, Dept. of Chemical, Nuclear , and Thermal Engineering, Los Angeles, CA 90024
M. A. Abdou
N. M. Ghoniem
R. W. Conn

130. University of California, IPFR, 405 Hilgard Avenue, Los Angeles, CA 90024-1600

S. Sharafat

131. University of Michigan, Dept. of Nuclear Engineering, Ann Arbor, MI 48109

T. Kammash

132. University of Missouri, Department of Nuclear Engineering, Rolla, MO 65401
A. Kumar

133-134. University of Wisconsin, Nuclear Engineering Dept., 1600 Johnson Drive, Madison, W1 53706
J. B. Blanchard
G. L. Kulcinski

135. Washington State University-Tri-Cities, 6012 W. Ridgecrest Drive, Spokane, WA 99208

D. G. Doran

136-139. Westinghouse Hanford Company, P.O. Box 1970, Richland, WA 99352
R. E. Bauer
A. M. Ermi
F. M. Mann
R. J. Puigh

140-142. Hokkaido University, Faculty of Engineering, Kita 13, Nishi 8, Kita-ku, Sapporo 060, Japan Heischichiro Takahashi Akira Okada Somei Ohnuki

143-144. Japan Atomic Energy Research Institute, Tokai Research Establishment, Tokai-mura, Naka-gun, Ibaraki-ken 319-11, Japan Tatsuo Kondo Akimichi Hishinuma (3)

145. Kyushu University, Dept. of Nuclear Engineering, Faculty of Engineering, Kyushu University 36, Hakozaki, Fukuoka 812, Japan

C. Kinoshita 
146. Kyushu University, Research Institute of Applied Mechanics, 6-1, Kasuga-Koen, Kasuga-Shi, Fukuoka-Ken 816, Japan

Takeo Muroga

147-148. Muroran Institute of Technology, Dept. of Metallurgical Engineering, 27-1 Mizumoto-cho, Mororan 050, Japan Toshihei Misawa Akihiko Kimura

149. Nagoya University, Dept. of Nuclear Engineering, Furo-Cho, Chikusa-ku, Nagoya 464-01, Japan Michio Kiritani

150-152. National Institute for Fusion Science, Furo-cho, Chikusa-ku, Nagoya 464-01, Japan Osamu Motojima Chusei Namba Nobuaki Noda

153-155. National Research Institute for Metals, Tsukuba Branch, Sengen, Tsukuba-shi, Ibaraki-ken, 305, Japan

Fujio Abe Josei Nagakawa Haruki Shiraishi

156. Osaka University, Dept. of Nuclear Engineering, 2-1 Yamadaoka, Suita, Osaka 565, Japan Tetuo Tanabe

157. PNC Oarai, 4002 Narita, Oarai, Ibaraki 311-13, Japan Itaru Shibasaki

158. Science University of Tokyo, Dept. of Materials Science \& Technology, 2641 Yamazaki Noda City, Chiba Prefecture 278, Japan Naohira Igata

159. Teikyo University, Otsuka, Hachioji, Tokyo 192-03, Japan Akira Miyahara

160. Tohoku University, Institute for Materials Research, Katahira 2-2-1, Sendai 980, Japan Hideki Matsui

161-162. Tohoku University, Institute for Materials Research, Oarai Branch, Oarai, Ibaraki 311-13, Japan Tatsuo Shikama Hideo Kayono

163. Tohoku University, Dept. of Nuclear Engineering, Tohoku University, Aoba, Aramaki, Sendai 980, Japan Katsunori Abe

164-166. University of Tokyo, Dept. of Nuclear Engineering, 3-1, Hongo 7-Chome, Bunkyo-Ku, Tokyo 113, Japan Shiori Ishino (2) Naoto Sekimura

167-168. University of Tokyo, Dept. of Materials Science, 3-1, Hongo 7-Chome, Bunkyo-ku, Tokyo 113, Japan Akira Kohyama

Yutaka Kohno

169. Commission of European Communities, Directorate-General for Research Science and Education, Fusion Programme RUE De La Loi 200, B-1049 Brussels, Belgium J. Darvas

170-171. Chalk River Nuclear Laboratories, Atomic Energy of Canada, Ltd., Chalk River, Ontario KOJ 1J0, Canada
I. J. Hastings
D. P. Jackson 
172. Southwestern Institute of Physics, P.O. Box 432, Chenedu 610041, Sichuan, P.R. China J. P. Qian

173. Institute of Alomic Energy, Academia Sinica, P.O. Box 275-51, Beijing, P.R. China J. Yu

174 Riso National Laboratory, Materials Dept., P.O. Box 49, DK-4000, Roskilde, Denmark B. N. Singh

175. Centre d'Etudes Nucleaires, Saclay, DLPC/SMCM, Commissariat a l'Energie Atomique, 91191 Gif-Sur-Yvette, Cedex, France N. Roux

176. Commission for European Communities, Joint Research Centre, I.A.M. Ispra Establishment 21020 Ispra (Varese), Italy P. Schiller

177. EURATOM/CIEMAT Fusion Association, Avenida Complutense 22, 28040, Madrid, Spain E. R. Hodgson

178. Paul Scherrer Institute, CH-5232 Villigen, Wuerenlingen PSI, Switzerland M. Victoria

179. Harwell Laboratory, B393, Radiation Damage Dept., Oxfordshire, OX11 ORA, United Kingdom C. A. English

180. Metallurgical and Nuclear Consultant, 9A Cumnor Rise Road, Cumnor Hill, Oxford OX2 9HD, United Kingdom

D. R. Harries

181. Culham Laboratory, U.K. Atomic Energy Authority, D5/117, Abingdon, Oxon OX14 3DB, United Kingdom G. J. Butterworth

182. Hahn-Mietner-Institut fur Kernforschung Berlin, Postfach 390128, Glienicker Str. 100, D-14109, Germany H. Wollenberger

183. Institut fur Festkorperforschung Forschungszentrum Jülich, Postfach 1913, D-52425 Jülich, Germany H. Ullmaier

184-185. Kernforschungszentrum Karlsruhe, Postfach 3640, 75 Karlsruhe 1, Germany
M. Dalle-Donne (INR)
K. Ehrlich (IMF-II)

186. A. A. Baikov Institute of Metallurgy, USSR Academy of Sciences, Leninsky Prospect 49, Moscow, Russia

L. I. Ivanov

187. CRISM "Prometey," Naberezhnava r. Monastyrick 1, 193167, St. Petersburg, Russia V. V. Rybin

188. D. V. Efremov Institute of Electro-Physical Apparatus, 189631, St. Petersburg, Russia Yu. G. Prokofiev

189. Institute of Power Engineering, 218 M. Krasnosel's Kaji St., 107113 Moscow, Russia G. M. Kalinin 
190. Kharkov Institute of Physics \& Technology, Radiation Damage and Materials Dept.,

Akademicheskaya 1, 310108 Kharkov, Ukraine I. M. Neckludov

191. V. I. Lenin Research Institute of Atomic Reactors, 433510 Dimitrovgrad-10, Ulyanovsk Region, Russia V. K. Shamardin

192. Department of Energy, DOE Oak Ridge Field Office, P.O. Box 2008, Oak Ridge, TN 37831-6269

Assistant Manager for Energy Research and Development

193. Department of Energy, DOE Oak Ridge Field Office, P.O. Box 2008, Oak Ridge, TN 37831-6269

S. D. Frey

194. Department of Energy, Office of Basic Energy Sciences, Washington, D.C. 20585

R. J. Gottschall

195-202. Department of Energy, Office of Fusion Energy, Washington, D.C. 20585
S. E. Berk
N. A. Davies
R. E. Price
M. M. Cohen
W. F. Dove
F. W. Wiffen
D. H. Crandall
T. R. James

203. Department of Energy, Richland Operations Office, Federal Bldg., MS-A590,

Richland, WA 99352

D. Segna

204-253. Department of Energy, Office of Scientific and Technical Information, Office of Information Services, P.O. Box 62, Oak Ridge, TN 37831

For distribution as shown in DOE/TIC-4500, Distribution Categories UC-423 (Magnetic Fusion Reactor Materials) and UC-424 (Magnetic Fusion Energy Systems) 


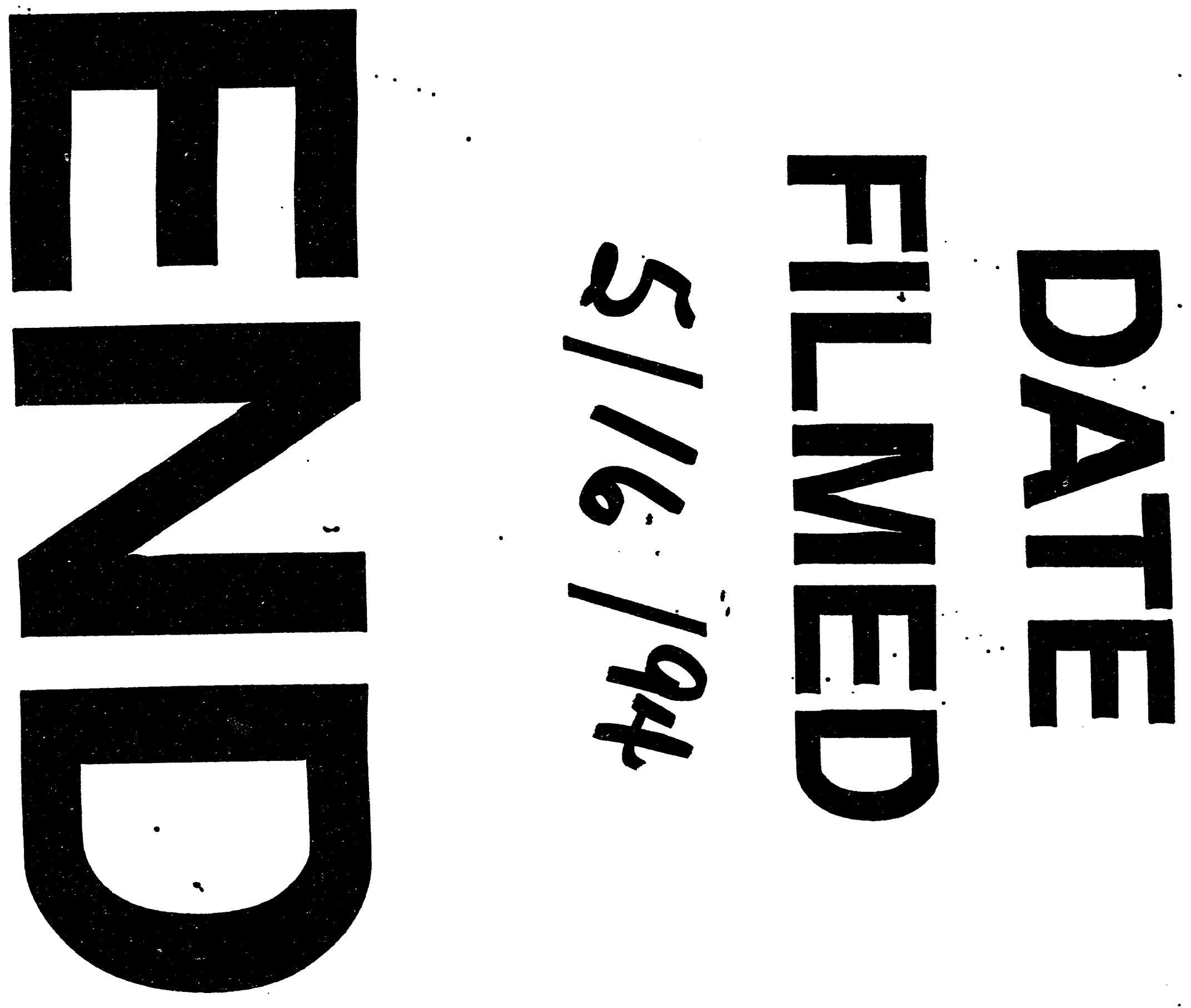


